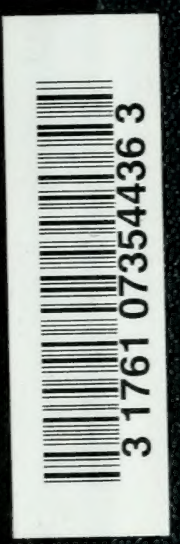




$$
\mu^{l}
$$




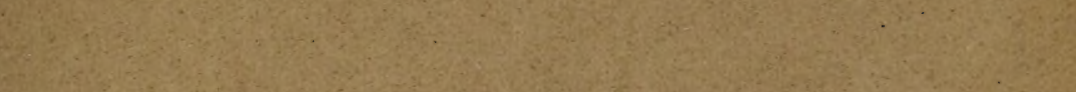

\section{s}

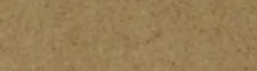

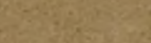




Digitized by the Internet Archive in 2011 with funding from University of Toronto 


\section{DER BEOBACHTER.}


Alle Rechte vorbehalten.

Druck von Bächinger \& Kübler in Trogen. 


\title{
DER BEOBACHTER.
}

ALLGEMEINE ANLEITUNG

ZU

\section{BE0BACHTUNGEN ÜBER LAND UND LEUTE}

FÜR

TOURISTEN, BXKURSIONISTEN UND PORSCHUNGSREISENDE.

\author{
NACH DEM \\ „MANUEL DU VOYAGEUR“ \\ VON
}

D. KALTBRUNNER

MITGLIED DER GEOGRAPHISCHEN GESELLSCHAFTEN VON GENF, BERN UND ST. GALLEN

UNTER MITWIRKUNG DES VERFASSERS

BEARBEITET VON

F. KOLLBRUNNER

MITGLIRD DER SCHWEIZ. NATURFORSCHENDEN UND DER OSTSCHWEIZERISCHEN GEOGRAPHISCH-KOMMERZIELLEN GESELLSCHAFT.

IIT 270 FIGIREN IND 26 BILDERTAFELT.

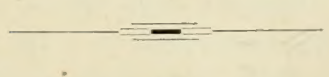

ZÜ RICH.

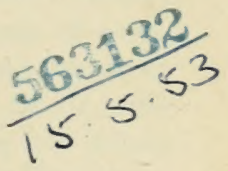

J. WURSTER \& C $\mathrm{C}^{\mathrm{IE}}$, GEOGR. VERLAG.

1882. 


$$
\begin{aligned}
& G \\
& 150 \\
& K 315
\end{aligned}
$$




\section{VORWORT $/ 2{ }^{\circ} M$...TLANLEL IU TOYAGELR".}

Bei Bearheitung des rorliegenden Werkes hatte der Vertasser die Absicht, aus den rerschiedenen Tissenschaften in Einem Bande Dasjenige zusammenzustellen, was als allgemeine Anleitung für Jedermann, der sich mit Beobachtungen über irgend eine Gegend und deren Einwohner befassen will, geeignet schien.

Obwohl bereits einige Werke mit ähnlichem Zweck ${ }^{1}$ ) existirten, war die Aufgabe, welche ich mir gestellt, keine leichte: Das Gubiet der Wahmehmungen, welche man auf Reisen machen kann, der Beobachtungen, die gemacht werden sollten, ist so weit und manigfaltig, das Wissen, dessen es hiezu bedarf, so rielseitig und rerschiedenartig, dass es schwer hailt, all das in einen Ueherhlick zusammenzufassen und ohne störende Weglassung wesentlicher Partien gemeinverständlich darzustellen. Ich schmeichle mir denn auch nicht, die Aufgahe in rollkommener Weise gelöst zu

1) Col. Jaclison. What to Observe or the Traveller's Rememlirancer. London 1861. - Sir Fohn Herschet. A Mameal of Srientific Enquiry. Lomlon 1871. - Instructions générales anx coyagenes, pulliées par la société de séengraphie. Paris 1855. - Dr. G. Yeumayer. Anleitung zu irissenschaftliden Beoluchtungen auf Reisen. Berlin 1875. - A. Issel. Istruzioni scientifiche pei Viaggiatori. Roma 1875. - F. Galton. Hints to Travellers. London 1878. 
haben, wie es möglich gewesen wäre, wenn kompetentere Personen deren Durehführung unternommen hätten; aber ich hoffe, in diesen Blättern dem Leser des Erspriesslichen soviel zu bieten, dass ich eine nachsichtige Beurtheilung ihrer Unvollkommenheiten erwarten darf. Um übrigens diese letzteren auf ein Minimum zu reduziren, wurde das Manuskript des Buches vom Verleger der Beurtheilung durch höchst kompetente Mäuner unterbreitet, welche die Güte hatten, eine Durchsicht der je ihr Spezialfach betreffenden Abschnitte vorzunehmen.

Allgemein wird hente dem Reisen hoher Bildungswerth zuerkannt. Dieser Werth aber besteht in dem Gewiun, welchen wir uns verschaffen durch richtiges Benbachten; er ist daber nicht gebunden an die Reisen in ferne Länder, welche immer ein Privilegium verhältnissmässig Weniger sein werden; er kann vielmehr den Touren und Exkursionen, die fast Jedermann in seiner nïheren und entfernteren Umgebung zu unternehmen Gelegenheit hat, ebenfalls zukommen, - sofern nämlich die Voraussetzung hiefür zutrifft: dass der Tourist und Exkursionist wie der Reisende zu beobachten weiss. Nanchem entgeht solcher Gewinn nur desshalb, weil er jene Vorbedingung nicht erfüllt. Die wesentliche Schwierigkeit ist keineswegs die, dass er nicht über das nothwendige Maass an Geld und Mussezeit verfügt oder dass es ihm an Interesse und gutem Willen gebräche, wohl aber die, dass er nicht methodisch zu beobachten versteht, nicht weiss, .wie er hiebei zu Werke gehen soll und daher - in Ermanglung eines Leitfadens, an welchen er sich hiebei halten könnte - nach unbefriedigendem Ausfall der ersten, mit Eifer unternommenen Versuche davon ablässt, die Sache weiter zu verfolgen. Die wünschenswerthe Vervielfältigung der Beobachtungen verschiedener Art und die Mehrung des Gewinnes, welcher hierans dem einzelnen Betheiligten wie der Wissenschaft erwachsen würde, kann nur 
erreicht werden durch Beseitigung oder wesentliche Verminderung jener besprochenen Schwierigkeit. Ein Versuch dazu ist das vorliegende Buch, welches - wenn auch nur unvollkommen - eine Lücke in der Literatur unserer Sprache ansfüllt.

Es ergibt sich aus dem Gesagten, dass ich nicht sowohl Gelehrte und Reisende von Fach im Auge habe, als vielmehr Dilettanten, Touristen und Exkursionisten, mit Einem Wort alle Diejenigen, welchen das Reisen nicht Beruf ist, sonder'n eine Erholung von den Berufsgeschäften, Ausfüllung der Mussezeit und einiger grösserer Pausen inmitten der alläglichen Obliegenheiten. Dabei glaube ich immerhin annehmen zu dürfen, dass auch die Männer jener ersten Kiategorie, die Entdeckungs- und Forschungsreisenden selbst, doch einigen Nutzen aus der Durchsicht dieses Werkes ziehen könnten.

Den verschiedenen Kategorien der Reisenden, von welchen soeben die Rede war, denke ich ferner einen Dienst zu erweisen durch Bearbeitung eines demuächst erscheinenden Buches, worin sich in Einem Bande das Wissenswertheste aus Geographie, Geologie etc. zusammengestellt findet, das sonst in einer Menge verschiedenartiger Spezialwerke aufgesucht werden muss, welche dem Reisenden nicht allenthalben zur Verfügung stehen. Dasselbe wird namentlich Denjenigen zu Gute kommen, welche vor der Reise nicht Gelegenheit zu gehöriger Vorbereitung auf dieselbe hatten, aber auch in vielen andern Füllen als Nachschlagebuch elwünscht sein.

Mögen sich die beiden Werke als Rathgeber und Hülfsmittel für Reisende bewähren!

Zürich, 20. September 1878.

\section{Kaltbrunner.}




\section{VORWORT ZTM „BEOBACHTER“.}

Das ,Mannel du Voyageur" von D. Kaltbrunner ist al, Seite hervorragender dentscher Fachmänner sehr günstig beurtheilt und ron mehreren derselben - so den Herren Dr. Charanne, v. Hellwald, Dr. Kersten, Dr. Schweinfurth ist hiebei der Wunsch nach einer dentschen Ausgabe des Werkes geäussert worden. Diese Uebertragung liegt in dem „Beobachter" vor.

Wemn ich, ron Verfasser und Verleger des , Mannel* mit Besorgung der deutschen Ausgabe betraut, dieselbe hiemit dem Publikum übergebe, nehme ich zunächst auf Dasjenige Bezug, was hinsichtlich der Schwierigkeiten, welche die Bearbeitung eines solchen Werkes bietet, im Vorwort zum "Manuel" gesagt ist. Die wenigen Worte, die ich beifüge, betreffen theils einzelne Bemerkungen des französischen Autors, wobei ich namentlich diejenigen über Zwech und Charakter seines Werkes etwelchermaassen zn ergänzen habe, theils speziell die dentsche Bearbeitung.

In ersterer Hinsicht darf ich wohl einige Gesichtspunkte, welche die Eigenart des Werkes - orler mit anderen Worten nichts Geringeres als Werth und Berechtigung desselben betreffen, zur Sprache bringen. Der Autor des „Manuel* legt allen Nachdruck darauf, dass sein Werk ein Leitfaten zu Beobachtungen üher Land und Lente sein soll; demgemäss hat er dasselbe näher bezeichnet als "Recueil d'instructions indiquant la maniere de recucillir des obsercations sur une contréc quelconque et sur ses habitants, soit-qu'on réside ou qu'on séjourme dans le payss, soit quion le parcoure en touriste, en excursionniste on en exploraten." 
mo entsprechend ist auch nie deutsche Ausgabe als Anleitung an Beobachtungen äber Laml und Lente betitelt. Damit wird zwar auf das Wesentliche des Werkes hingewiesen; um indess seine Absicht genügend zu bezeichnen, dürfte ferner herrorgehohen werden, dass es besonders auch ein Rathgeber sein will in Bezug auf das Anlegen ron Sammlungen verschiedener Art, sowie für die Darstellang der Beolsachtungen in Bilul und Trort. Namentlich die letztere Seite des Gegenstandes berücksichtigt es in höherem Grade und in gleichmässigerer Weise als anlere Trerke ähulichen Inhalts; sie ist Sell stzwech einiger Abschnitte und mitbestimmendes Jument in anderen Partien, welche nicht sowohl eine materielle Belehrung, als vielmehr den Rahmen und die Gesichtspunkte der Beobachtung wie Schema und Art der Darstellung im Auge haben.

Ein anderer bemerkenswerther Torzug des Buches, welcher mit der umfassenden Anlage desselhen in Zusammenhang steht, ist bei Besprechmo des, Mamul* in den ,Geographischen Nachrichten von Dr. 0. Kersten gewürdigt worden. Ich darf mir wohl erlauben. mit seinen Worten hier dieser Seite des Werkes zu gedenken. Der betreffende Passus in den -Geogr. Nachrichten" rom Jahre 1879 lautet: Kaltbrumer's .Handbuch", welches in anregender. allgemein verständlicher Weise Anleitungen zum Beobachten und Sammeln gibt, ist in noch höherem Maasse wie sein leutscher Vorgänger: Anleitung zu wissenschaftlichen Be11) athtungen auf Reisen- ron Interesse für unser'n handelsgeographischen Verein ( $Z$ entralverein für Handelsgeographie), denn es berüchsichtigt zugleich auch pratifische Interessen, während letzteres sich fast ausschliesslich auf wissenschaftlichem Gebiete bewegt. . Wir müssen, rom Standpunkte un serer Bestrebungen aus, einzelnen Kapiteln, lie sich speziell mit den nutsbaren P'voluliten beschäftigen, unsere besondere Anerkenumng zollen, weil sie mit wirklich 
kaufmännischem Geiste geschrieben und frei von allen Phantastereien sind, denen junge Reisende in ihrem Streben, etwas Verwerthbares zu finden, nur allzuleicht sich hingeben... Wir würden uns freuen, wenn diese Besprechung dazu diente, das in wissenschaftlichen Kreisen so sehr anerkannte Buch auch bei den Freunden un serer Bestrebungen einzubürgern.

Andererseits ist das, Manuel — weil sein Ziel vornehmlich darin besteht, zum Beobachten und Sammeln anzuleiten und es dieser praktischen Tendenz wegen eine Ergïnzuny zu den georraplischen und naturhistorischen. Lehrbiachern bildet, welche die fertigen Resultate der Wissenschaft mittheilen, ohne dem Modus des Zustandekommens derselben viel Aufmerksamkeit zu schenken - insbesondere auch für Lehrerkveise empfohlen und ist dabei nur bedauert worden, dass einer allgemeinen Benutzung desselben durch Lehrer deutscher Zunge der fremdsprachige Text Schwierigkeiten entgegenstelle. Möge nun das Buch auch in diesen Kreisen freundliche Anfnahme und fruchtbare Verwendung finden, nachdem es jetzt in deutschem Texte vorliegt.

Wenn ein Buch von der Anlage und dem Charakter des "Manuel" in zwei nach ihrer Bedentung einander so nahe kommenden, nach ihrer Natur so verschiedenen Sprachen wie Deutsch und Französisch erscheinen soll, so kann die eine Ausgabe unmöglich durchwegs eine blosse Uebersetzung der andern sein. Es existiren daher anch zwischen dem „Manuel" und dem "Beobachter" im Einzelnen gewisse Verschiedenheiten; im Ganzen aber ist letzterer eine möglichst treue Wiedergabe des ersteren Werkes. Die Bearbeitung in diesem Sinne zu halten, schien vor Allem geboten mit Rücksicht auf das dem "Manuel " so günstige Gesammturtheil der Kritik, welches nicht am wenigsten der Selbstbeschränkung galt, die darin waltet. Hinwieder war ich auch bestrebt, einerseits den Anregungen, welche die 
Rezensionen in verschiedenen deutschen Zeitschriften enthielten, andrerseits neuen Thatsachen und Anffassungen. welche seit Erscheinen des „Manuel“ veröffentlicht wurden, Rechnung zu tragen. Es erforderte dies eine Anzahl Zusütze, und um hiedurch das Volumen des Werkes nicht ungebührlich zu vermehren, mussten gegenüber dem „Manuel" auch einige Reduktionen eintreten. Hiebei wurden namentlich der besondere Abschnitt des Hannel (S. 181-221) betr. die topographische Terminologie und sodann der logarithmischgoniometrische Theil der Tafel IV im Anhang desselben weggelassen. Von den Zusätzen und Erweiterungen, welche schon mit Rücksicht anf Raumersparniss oft als Fussnoten angebracht sind, mögen folgende erwähnt werden: Neu sind im Kontest die Abschnitte über Hypsothermometrie, S. 50-52, und über Bestimmung der temporären Härte (Alkalität) des Wassers, S. 458-460, von grösseren Anmerkungen diejenigen auf $S .79$ und 85, 99, 104 und 106,231 und 285,510 und 568 ; im Texte vermehrt die Abschnitte über: Höhenmessung, S. 47-50 und 431, geographische Ortsbestimmung, S. 79-92, Terrainzeichnung, S. 132-139. Andere Modifikationen finden sich da und dort, so im Abschnitt über Photometeore (S. 439-445), Flusssysteme (S. 453-456), Abbalgen der Sängethiere und Vögel (S. 528-535); Volkszählıugen (541-543), Sprachen und Dialekte (586-589), Wohnungen (685-687), Anstalten $(728-730)$, Gewerbe $(731-743)$ und in Anhang (S. $860-863,878-888$ ). - Für gefällige Mitwirkung hiebei bin ich meinen Freunden, den Herren Prof. J. Rebstein in Zürich und Gymnasialdirektor Dr. F. Haag in Schaffhausen (Ersterem in Betreff mathematischer, Letzterem hinsichtlich der linguistischen Partien) zu Dank verpflichtet. Die Verlagshandlung ihrerseits hat nicht unterlassen, auch die Ausstattung des Buches noch mehr zu bedenken: Die zwei Bildertafeln (obere Luftspiegelung S. 440, Brocken- 
gespenst S. 445) und die fünf Figuren im Kapitel über lip atmosphärischen Lichterscheinungen sind eine neue Beigabe, die nicht nur dem Buche zur Zierde gereicht, sondern auch wesentlich zum Verständniss des betreffenden speziellen Kapitels dient. In 'Taf. VI (S. 136) wurde ein T'errainbild aus einer reinen Kurvenkarte statt der weniger zweckentsprechenden Darstellung des Diablerets-Gebietes anfgenommen u. S. W.

Das Werk, dessen am Schlusse des Vorrorts zum, „Manuel " gedacht wird, ist seither erschienen. Es führt den Titel Aide-Mémoive du Voyurgenr, contenant des Notions générales de Géographie mathématique, de Géographie plysique, de Géographie politique, le Géologie, de Biologie et d’Anthropologie à l'usagedes royageur, desétudiants et desgens dn monde, par D. Kultbrune' (Zürich, Wurster \& Cie., 1881 ) und bildet, unbeschadet der selbständigen Aufgabe eines jeden der beiden Werke, ein Supplement zum vorliegenden Buche, worauf bei Bemtheilung desselben Rücksicht zu nehmen ist. ITeun z. B. im „Beobachter"6 beim Kapitel über den Synchronismus der Gesteine (S. 356--363) keine Aufzählung und Charakteristik der geologischen Formationen und in den ethnographischen Partien (z. B. S. 568) keine solche der verschiedenen Menschenrassen gegeben ist, so findet sich Beides im ,Aide-mémoire (S. 413-431 und 234-244), ron welchem ebenfalls eine deutsche Ausgabe - unter dem Titel "Vademecum des Reisenden * - veranstaltet wird.

Frauenfeld (Schweiz), 14. Januar 1882.

Emil Kollbrunner. 


\section{INHALTSVERZEICIINISS.}

Vorreden .

$\mathrm{V}-\mathrm{XII}$

\section{VORBEREITUNG.}

Unfang ler Vorbereitung 3. - Eigenschaften des Reisenten 3. Wissenschaftliche Torkenntnisse $\bar{\tau}$. - Praktische Kemutniss': Instrumente 13, Jethoden 21, Lelungen 120. - Photographie uni Hanlzeichnen 121. - Topographisches\%cichnen 126. - Sprachkenntnisse 145. - Erkundigungen über das zu hereisende Land 147. - Klepilung unl Ausrüstung 149.

\section{BEOBACHTUNGEN UND STUDIEX.}

Beobachtungen im Allgemeinen . . . . . . 159

\section{DAS LAND.}

Lage-171. - Grenzen und Grösse 173. - Eintheilung 175.

Konfiguration des Landes (Topographie). Definition 17i. - Rekognno:zirungen 176. - Prüfung uml Berichtigung rorhandener Karten 17. - Topographische Aufnahmen 181. - Aufnahme der erforschten liegend 187. - Fliegente Aufnahmen 211. - Photographische Aufnahmen 213. - Entlehnte Karten 213. - Profile 214. - Ansichten 215. - Panoramen 220. - Beschreibung 222.

Geologie. Definitionen 222. - Geologie der Erdoherfläche. NiwanAenderungen (Hebungen unil Senkungen) 223. - Emgestaltung der Kü̈sten 231. - Ersprung und Billung der Elyenen 239. - Entstehung der Becken und anlerer Botemlepressionen 243. - Enebenheiten des Bodens 246. - Ablachungen uml rehänge 248. - Terrassen und Plateaux 250. - Gehirge 251. - Jetzige Gletscher 255. - Spuren alter Cletscher 261. - Tulkane und valkanische Erscheinungen 267. -Erdbeben 273. - Thäler 278. - Höhlen und Grotten 282. - Tiefen- 
temperaturen 284. - Quellen 285. - Fliessende Gewïsser 289. Seen und Lagunen 294. - Résumé 297.

Geologie des Erdinnern. Vorbemerkungen 298. — Aufschlüsse 299. Reiseroute und Vorgehen im Allgemeinen 300. - Data, die zu erleben sind 302. - Stratigraphische Erhebungen 303. - Sammeln von Gesteinsmustern 326. - Sammeln von Versteinerungen 328. Relatives Alter der Gesteine 335 (Schichtgesteine 335, ungeschiclitete Gesteine 347). - Geologischer Srnchronismus 356. - Aeltere geologrische Aenderungen 363. - Résumé 373.

Der Boden nach seinen Schätzen und Erzeugnissen.

Der Boden in industrieller Beziehung. Bodenschätze 3r3. -. Zwei (truppen dersellen 375. - Absatz uml Kosten 376. - Artikel füir weite Transporte 378. - Steinkohle 37s. - Erze und ILetalle 384. - Edtelsteine 393. - Guano 393. - Holz 394. - Verschiedene Produkte 395. - Accessorische Angaben 395.

Der Boien in lamdwirthschaftlicher Hinsicht. Definitionen 397. Aqrikoler Wertlı des Bodens 398. - Areal des urbaren Bodens 399. - Topographische Klassifikation desselben 400 . - Agronomische Karte 401. - Mineralogische Klassifikation des Bollens 401. - Absatzverhältnisse 403, - Urbarmachung 403. - Nelioration 404.

Klima. Wichtigste Filitoren und Gesichtspunkte 405. - Temperatur 406. - Reinheit und Durchsichtigkeit rler Luft +16. - Feuchtigkeitsgehalt iler Luft 417. - Verlunstung 421. - Fondensation des Wasserdampfes und Niederschläge 422. - Luftilruck 430. Winde 432. - Ozon 436. - Elektrizität 437. - Gewitter 438. Verschiedene meteorologische Beobachtungen (Photometeore) 439. Tabellen, Karten und Diagramme 450. - Fresammtbild des Klimas 451 .

Hydrologie. Vorbemerkungen 451. - Fluss- oder Stromgebiete 452. - Flusssysteme 453. - Fliessende Gewässer 461. - Unterirdische Gewässer 471. - Stagnirende Gewässer 471. - Seen 472. -Flussmündungen 477. - Strömungen und Gezeiten 478.

Pflanzenwelt. Aufgabe 481. - Pflanzenformationen 482. - Charakteristische Pflanzenformen 483. - Zonen unil Regionen 484. - Nutzpflanzen 485. - Schälliche Pflanzen 486. - Verïnderungen der Flora 4b7. - Darstellung der Flora 488. - Abdrücke lebender Pflanzen 488. - Sammlungen 489. - Lebende Pflanzen 490. Samen 493. - Herbarien, Sammlungen von Blüthen und Früchten 495.Sammlungen von Hölzern 502.

Thierwelt. Anfgabe 595. - Allgemeiner Charaliter 505. - Besondere Verhälnisse 506. - Distrikte und Stationen 507. - Nützliche 
Thiere 507. - Schädliche Thiere 508. - Aenderungen der Fauma 509.Ansichten und Beschreibung der Thierwelt 511. - Zoologische Sammlungen 512. - Sendungen lebender Thiere 535.

\section{DAS VOLK.}

Bevölkerungsstatistik. (iesammtzahl 538. - Elemente der Bevölkerung 541. - Rïumliche Gruppirung 542. - Dichtigkeit der Bevölkerung 542. - Statistik der Stänle und Berufsarten 543. - Altersstatistik 543. - Zivilstandsstatistik 54t. - Eheschliessungen, Geburten und Todesfälle 544. - Bevölkerungsbewegung 545.

Rassen und Typen. Die ethnischen Charaktere im Allgemeinen 547.Anatomische Merkmale 551. - Physische Merkmale 552. - Physiologische Merkmale 563. - Physiognomische Merkmale 566. liassen und Mischlinge 568. - Typen 569. - Geistige Eigenschaften und Mängel 571. - Pathologisehe Eigenthümlichkeiten 575.

Sprachen und Dialekte. Allgemeine Bemerkungen 576. - Einzusammelnde Mraterialien 579. - Vokabulare und Phraseologie 579. Grammatik 587. - Sprachverwandtschaft 599. - Sprachgehirte 601. Koexistenz verschiedener Idiome 602. - Dialekte 604. - Schrift 605. Schriftproben, Schreibweise und Schreibmaterial 608. - Zahlensystem610.

Sitten und Gebräuche. Allgemeine Bemerkungen 614. - Begrüssungen 616. - Freunischaftsbezeusungen 618. - Verträge und Eidschwüre 618. - Gastfreundschaft 619. - Anaya 619. - Tabu 620. Blutrache 620. - Zweikampf 620. - Diebstahl und Raub 621. Razzias 621. - Entführung 622. - Epigamie 622. - Exogamie 623. Endogamie 624. - Polygamie 624. - Polyandrie 626. - Monogamie 626. - Ehelosigkeit 627. - Brautkauf 627. - Mitgift 628. Verlobung 628. - Hochzeit 630. -- Keuschheit und eheliche Treue 630. Schwangerschaft und Niederkunft 631. - Mïmerkindbett 632. - Abortus und Kindermord 632. -- Stillen und Eutwöhnen 633. - Taufe und Beschneilung 633. - Festgeschenke 634. - Fhescheidung 634. Gebräuche betreffend den Landbau 635. - Kriegsgebräuche 635. Kannibalismus 636. - Achtung vor dem Alter 636. - Achtung vor Geisteskranken 636. - Behandlung von Kranken 636. - Muru 637. Tod und Leichengebräuche 638. - Bestattung 638. - Traner und Torttenkult 641.

Ideenwelt, Glaube und Religion. Allgremeine Bemerkungen 642. Vorstellungen über Anmuth und Reịhthun 643. - Vorstellungen über Gegenstände und Beschäftigungen 644. - Vorstellungen üher fremde Lünder und Völker 645. - Kosmogonische Vorstellungen und Systeme 64t. - Erklärung der Naturerscheinungen 6it5. - Glaube an Geister 
und Götter 647. - Glaube an die Seele 649. - Glaube an ein künftiges Leben 651. - Naturalismus 652. - Totemismus 652. Fetischdienst 653, - Bilderdienst und Reliquienlultus 653. - Schamanismus 654. - Spiritualismus 655. - Atheismus 655. - Polytheismus 655. - Dualismus 656. - Monotheismus 656. - Ursprung der Religion und Dogmen derselben 656. - Konfessionen und Sekten 657. - Tempel und kirchliche Anstalten 657. - Geistlichkeit 658. Kultus, Ritus, Zeremonien 659. - Religiöse Werke 660. - Charakter der Religion 661. - Alserglaube und abergläubische Gebräuche 662.

Kleidung und Schmuck. Allgemeine Bemerkungen 663. - Volkstracht 664. - Besondere Trachten 665. - Accessorische Bestandtheile der Toilette 666. - Abzeichen 667. - Waffen 66s. - Bemalung 670. - Tätowirung 672. - Narben, Ringe ete. 672. Künstliche Missbildungen 673. - Haar- und Barttracht 674.

Nahrung. Nahrungsmittel 675. - Zubereitume der Speisen 678. Das Feuer und dessin Enterhaltung 679. - Küchengcrïhe 680. IIahlzeiten 681. - Gutrïnke und Erregungsmittel 682. - Preise der Lebensmittel 683 .

Wohnungen. Haupttypen 684. - Koexisteuz der Tỵun 687. Beschreilumg 68s. - Besonulere Wohnungen 689. - tiemeinsame Wohnumgen 690. - Bienenstockintige Wolmmenen 690. - Zerstreute Wohuhäuser 690. - (iebüulegruppen orler Agrolomerationen 691. Lage der Ortschaften 691. - Ansichten und Pläne 692. - Baustyl 693. - Physionomie der Stadtyutrtiere 694. - Strassenbeleuchtung, Wasserversoryung und Reinigung der Städte 694.

Lebensweise. Allgemeine Bemerkungen 695. - Häusliches Leben 696. - Geselliges Laban 697. - Politisches Lethen 697. - Geistiges Leben 698.

Organisation der Familie. der Gesellschaft und des Staates. Familie 698. Verwandtschaft 702. - Familien- uml Tomamen 704. - Autoritït in der Familie 7o6. - Stellung rles Weibes 707. - Stellung der Kinder 708. - Gesellschaft 709. - Kasten und Klassen 712. Politische Organisation 71 .

Recht und Eigenthum. Torbemerliung 719. - Hecht 720. - Strafen 722. - Eigenthum 723. - Erbfolge 726.

Verschiedene Einrichtungen. Statatsverwaltung 727 . - Gerichte 727.Bililungsanstalten 725. - Krippen, Finle1- unil Waisenhäuser 729. Armenhänser und Asyle, Herberwen und Hospize 729. - Spitäler 729. Besserungs- und Strafaustalten 729. - Finanzinstitute 730. - Handels- 
institute 730. - Versicherungsanstalten 730. - Vereinswesen 731. Innungen und Bruderschaften 731.

Gewerbe. Definition 731. - Sammelgewerbe 732. - UrproIluktion 733. - Handwerk und Fabrikation 735. - Handel 737. Miethgewerbe 738. - Hülfsgewerbe 739. - Sanitätsgewerbe 740. Vergnüguigsgewerbe 740. - Erziehungsgewerbe 741. - Résumé 741. Rïumliche Vertheilung 743. - Gewerbliche Charakterbilder 744. Influirende Verhältnisse 745 . - Werkzeuge und Methoden 748 . Lohnverhältnisse 749 .

Handel. Allgemeine Bemerkungen 749. - Tausch 751. - Eigentlicher Handel 751. - Binnenhandel 752. - Aussenhandel 752. Transit 753. - Handelsrégime 753. - Verkehrsmittel 755. - Geld 757.

- Maasse und Gewichte 759. - Handelsbrïuche 760. - Spesen 760. - Conti finti 760. - Mustersammlungen 761.

Literatur. Vorbemerkungen 761. - Regionale Literatur 762.Lokale Literatur 763. - Unedirte Literatur 763.

Kunst und Wissenschaft. Vorbemerkung 765 . - Zeichnen unil IIalerei 765. - Skulptur 766. - Architektur 767. - Musik 767. Wissenschaften 767 .

Ursprung und Geschichte. Allgemeine Bemerkungen 768. - Erkundigungen und Indizien 774. - Höhlen mit Spuren des Menschen 776. - Alte Lagerplätze 792. - Pfahlbauten 797. - Kjökkenmöłdinger 803. - Fanggruben und Verstecke 804. - Prähistorische Werkstätten 805. Megalithische Monumente 806. - Tumuli 814. - Verschiedene Grabformen 820. - Alte Zufluchtsorte und Befestigungen 821. - Alte Städte 824. - Tempel und Altäre 826. - Skulpturen und Insrhriften 827. - Münzen und Medaillen 830. - Sagen 837. - Verschiedene Dokumente 833,

Allgemeine Betrachtungen. Einfluss der geographischen Verhältnisse auf den Menschen, abweichende Ansichten 836. - Konnex zwischen Bodengestalt, Klima, Pflanzen- und Thierwelt 838. - Einwirkung dieser Faktoren auf den Irenschen und Selbstbestimmung desselben 841. 


\section{ANHANG.}

Seite.

I. Erste Meridiane . . . . . . . . . 852

II. Länge der Meridian- und Parallelkreisgrale . . . $\$ 53$

III. Merkatorprojektion . . . . . . . . . . 854

IV. a) Zentrische Reduktion eines Winkels . . . . . 856

b) Koordinaten von Dreieckspunkten . . . . . 857

c) Trigonometrische Höhenmessung . . . . . . 859

Y. Barometrische Höhenmessung (graphische Methode) . . 864

VI. Vergleichung der verschiedenen Thermometer-Skalen - 869

VII. Psychrometrische Tabellen . . . . . . . . 870

VIII. a) Gold- und Silbermünzen der wichtigsten Länder • 878

b) Uebersicht der gebräuchlichsten Münzen . . . . $\$ 82$

IX. a) Metrisches Maass- und Gewichtssystem . . . . 885

b) Englische Maasse und Gewichte . . . . . 886

c) Aeltere Maasse . . . . . . . . . . 887

d) Maasse geographischer Karten . . . . . . 888

ALPHABETISCHES REGISTER . . . . . 889-904. 


\section{BILDERTAFELN.}

Sicite.

I. Planaufnahme . . . . . . . . . 64

II. Messen und Berechnen von Flächen . . . . . 73

III. Menschlicher Schädel . . . . . . . . . 111

IV. Menschliches Skelett . . . . . . . . . 114

V. Abhängigkeit des Kartenbildes von rer Relluktion . . 12!

VI. Terrainzeichnung in Kurven . . . . . . . 137

VII. - in Schraffen . . . . . . . . . 137

VIII. - in Kurven und Schraffen . . . . . . 137

IX. Konventionelle Bezeichnungen für Karten und Pläne . 139

X. Kartographische Symbole für die Detailzeichnung . . 139

XI. Kartenschrift . . . . . . . . . . . 140

XI1. Croquis einer Marschroute . . . . . . . . 187

X11J. Eintheilung einer Karte in Sektionen . . . . . 209

XIV. Topographische Profile . . . . . . . . 215

XV. Ansicht (Matterhorn) . . . . . . . . . 215

XV1. Vogelperspektive (Ladâk) . . . . . . . . 220

XVII. Panorama-Zeichnung . . . . . . . . . 221

XVIII. Geologische Karte . . . . . . . . . 367

XIX. Geologische Profile . . . . . . . . . 325

$\mathrm{XIX}^{\mathrm{a}}$ - Obere Luftspiegelung (Seegesicht) . . . . . 440

$\mathrm{XIX}^{\mathrm{b}}$ Brockengespenst * . . . . . . . . . 445

XX. Tabelle für meteorologische Beobachtungen . . . 450

XXI. Meteorologische Zeichen . . . . . . . . 450

XXII. Vertheilung der Bevölkerung nach Sprache, Konfession ete. 542

XXIII. Bevölkerungsdichtigkeit . . . . . . . . 542

XXIV. Volkstypen, Tracht und Haltung . . . . . . 664 

VORBEREITUNG. 



\section{UMFANG DER VORBEREITUNG.}

Je nach der zur Verfügung stehenden Zeit wird die Vorbereitung eine mehr oder minder umfassende sein. Je weiter sie aber gediehen ist, um so mehr Reiz wird das Reisen darbieten.

In Nachstehenden werden wir die gesammen Eigenschaften, Fähigkeiten und Kenntnisse ins Auge fassen, die dem Reisenden zu vollständiger Ausbildung nüthig sind. Ein Jeder mag dann diejenigen Punkte bei Seite lassen, hinsichtlich deren ihm die Zeit zur Yorbereitung fehlt orler woron er glaubt Lmgang nehmen zu sollen, um seine Kéräfte auf die andern konzentriren zu können.

\section{EIGENSCHAFTEN UND FÄHIGKEITEN.}

Es gnibt grewisse geistige Eigenschaften, welche für den Reisenden durchaus nothwendig sind, die zu erlangen er sich daher in erster Linie bemühen nuss, und daneben andere Fähigkeiten, die ihm, wenn auch nicht gerarde unenthehrlich, doch sehr förderlich sein werden. Wir besprechen sie kurz in Nachstehendem.

$1^{\circ}$ Beobachtumysyabe. Die gebräuchlichen Unterrichtsmethoden pflegen das Gedächtniss auf Kosten des Terstandes und der Lebung unserer simne auszubilden und selten zum Beobachten anzuleiten. Das Beohachtungsvermögen ist durch vielfache Uebung zu erwerben. Hier gilt, wie in jedem Zweige des Wissens und Könnens, das Sprichwort: Es fällt kein Meister rom Himmel. Was man wissen will, muss gelernt, was man künnen soll, muss geëibt worden sein. Will man sich solche Cebung und Befähigung verschaffen, so beansprucht dies anfänglich die ganze Aufmerksamkeit und Willenskraft, aher durch oftere Wiederholung eines und desselben Aktes wird 
uns dieser allmählig so mechanisch geläufig, dass wir ihn schliesslich mühelos und fast unbewusst vollbringen.

$2^{\circ}$ Forschungstrieb. Das Beobachten besteht lediglich darin, dass wir Dem unsere Aufmerksamkeit schenken, was unserer sinnlichen Wahrnehmungsich darbietet; der Forschungstrieb aber lässt uns nicht abwarten, bis der Zufall uns mit der Aussenwelt in Berührung bringt; er veranlasst uns, den Dingen nachzuspüren, unsere Untersuchungen in einem bestimmten Sinne, gregen ein festes Ziel hin zu betreiben, um Thatsachen aufzufinden, die sonst unentdeckt bleiben würden. Das ist es, was man in der Wissenschaft unter Experimentiren versteht. Sein Erfolg hängt ab von dem erfinderischen Geiste, von Scharfsim und Begabung des Einzelnen.

Handelt es sich um Erkundigungen, so begnügt sich der Erforschungsgeist nicht damit, zu hören; er frägt, um zu erfahren, was er wissen will. Diese Eigenschaft besitzen vorzugsweise die englischen Touristen; sie wird aber leicht zur Gewohnheit bei Jedem, der sie öfters anwendet.

$3^{\circ}$ Kritischer Sim. Der Reisende muss die Thatsachen objektiv zur Darstellung bringen. Unbefangener Blick, ruhiges und gesundes Lrtheil sind also von Wichtigkeit für ihn. In Bezug auf naturvissenschaftliche Thatsachen muss er sich hüten vor Fehlern der sinnlichen Beobachtung, vorgefassten Meinungen und Systemsgeist; handelt es sich aber um soziale Facta, so muss er gänzlich vorurtheilsfrei an dieselben herantreten; dann ist er vielleicht zu einem Lrtheil eher befähigt als die Bewohner des Landes selber; nicht interessirt in der Sache, wird er sie besser $\mathrm{zu}$ beurtheilen vermögen. Endlich hat der Reisende hauptsäichlich nöthig, in Dem, was er zufüllig oder absichtlich erfährt, Wahres und Falsches wohl zu unterscheiden und auseinanderzuhalten; welches Vertrauen eine Aussage verdient, welche Bewegräunde Denjenigen, der zu ihm spricht, bestimmen können, sich mehr in diesem als im andern Sinne zu äussern, muss er wohl zu beurtheilen wissen, um die erlangten Aufschlüsse nach ihrem wahren Werthe zu taxiren. Er soll namentlich nicht unterlassen, die Aussagen der Einen, wenn immer sich dazu Gelegenheit bietet, zu kontroliren durch Angaben Anderer.

$4^{\circ}$ Accessorische Eigenschaften und Fïhigheiten, die dem Reisenden sehr nützlich sein werden, sind folgende. 
Er muss Comfort entbehren können, um nicht rom Besuch abgelectener Oertlichkeiten ahgehalten zu werden durch die Furcht, dort nicht alle die Bequemlichkeiten zu geniessen, deren er sich zu Hause in der Stadt erfreut. Wrer Veues sehen will, hat dip auscretretenen Wegre zu meiden: wer aber das thut, kam nicht erwarten, überall den Comfort grosser Hôtels zu treffen. Er muss also nothwendig mehr odter minder auf Bequemlichkeit rerzichten und sich begnügen kömen mit magerer Kost und ärmlichem Lager. Auf solche kleine Enthehrungen aher muss man sich vorbereiten: wer gegehenenfalls darunter nicht zu sehr leiden soll, muss hereits daran gewöhnt sein. Haben wir es dazu gehracht, so sind wir nicht mehr gebunden an eine durch Städte markirte Reiseroute: dann kümnen wir überall hin, wohin uns zu gehen gelüstet und können dort weilen, so lang es uns gefällt, ohne ängstlich darauf bedacht sein zu miissen, dass wir zur Esspnszeit im Gasthof eintreffen. Tnd glaube man es nur: kein Gericht kommt an Schmackhaftiggkeit der Brodkruste gleich, die wir geniessen, gelagert an sprudelndem Quell. Solche improvisirte Touren mögen zeitweise Lnannehmlichkeiten mit sich hringen: aber diese sind hald rorbei und rergessen, während uns ron der Fahrt Erinnerungen der angenehmsten Art bleiben.

Der Reisende muss sich überall rasch und so bequem, als rle Limstände es zulassen, einzurichten wissen. Ein solches Talent wird für ihn ron grossem Vortheil sein. Demn erstens erspart er dabei Zeit, ein auf Reisen besonders kosthares Gut, und zweitens sichert er sich dadurch ein gewisses Behagen, das ihn vergessen lässt, was ihm allenfalls abgehen mag. Es handelt sich dabei wirklich um ein Talent: Alles kommt auf die Art an, wie man sich hiebei benimmt.

Strapazen aller Art, Kälte, Hitze, Entbehrumgen muss man in gewissem Grade ertragen kömen. In dieser Hinsicht haben die englischen Touristen eine ausgezeichnete Methode, sich durch stufenweise [ebungen (traiming) aufs Reisen vorzubereiten. Ohne in ihre Tebertreibungen zu verfallen, muss man in dieser Richtung Etwas thun. Kann man Nichts ertragen, so ist der gute Wille und die beste Absicht umsonst. Bei dieser physischen Torbereitung hat man aber weniger die Muskelkraft und die Stärke ihrer Leistung als 
vielmehr die Dauer der letzteren ins Auge $z u$ fassen. Wesentlich ist, dass man sich befähige, den Strapazen, den Lnbilden der Witterung einen gewissen Grad ron Widerstand entgegenzusetzen. Dabei ist aber vor jeder Tebertreibung zu warnen - man kann, in Allem leicht über das rechte Mass hinausgehen. Nicht indem man sich durch Gewaltmärsche oder allzu ungewohntes Fasten erschöpft, erwirbt man die Fähigkeit, Anstrengungen und Entbehrungen zu ertragen; vielmehr muss der hörper, soll er gesteigerten Anforderungen gewarhsen sein, jederzeit eine gewisse Reserve an Kraft und Elastizitü besitzen; bringt man doch die elastische Feder auch nicht damit zum spielen, dass man sie bricht. Die Tebungen, woron wir sprechen, sollen also antänglich mässig scin, dann stufenweise gesteigert, nie aber zum Exzess getrieben werden. Liommt der Noment praktischer Verwerthung, so werden zur Jeberwindung der Schwierigkeiten drei Dinge erheblich heitragen: erstens die Lebensweise vor und während der Exkursionen, sodamn die Stimmung, welche man dazu nithringt, und endlich der feste Wille, alle Hindernisse zu überwinden.

Einige medizinische Kenntnisse sind immer sehr nützlich. Ein L'nwohlsein kann ̈̈usserst störend wirken und sogar, wemn jede Hülfe ferm ist, ernstliche Schwierickeiten verursachen, wïhrend zu dessen Beseitigung manchmal nur Weniges erforderlich ist. Erkrankt ein Begleiter, ein Führer oder irgend Jemand ron der Reisegesellschaft, so muss man denselben, wenn nicht zu heilen, doch soweit herzustellen wissen, dass er einen bewohnten Ort erreichen kann. Der Reisende in fremden Erdtheilen wird auch oft von den Eingebornen zu Rathe gezogen, die jeden Europäer für einen Gelehrten und Arzt halten. Diesen Irrthum berichtigen zu wollen, wäre vergeblich und würde nur als Terstellung und Nangel an dienstbereiter Gesinnung betrachtet. Besser zieht man sich aus der Sache, wenn man darauf eingeht; dabei bietet sich Gelegenheit, Dienste zu erweisen und sich beliebt zu machen.

Umgangsformen, welche dem Reisenden die Achtung und die Sympathie der Personen erwerben, mit welchen er zu verkehren hat; der nöthige Takt, um diese Leute in keiner Weise - in ihrer Würde, ihren Sitten, Bräuchen und ihrem Glauben -- zu verletzen: diese Eigenschaften werden in 
vielen Fällen wesentlich dazu beitragen, die Schwierigkeiten zu beseitigen, welche entstehen aus dem Misstrauen der Bewohner des Landes, dem Mangel guten Willens bei den Führern, feindlicher Gesinnung der Bevölkerung. Es ist das un so notlıwendiger, als eine unwissende Berölkerung immer misstrauisch ist mit Bezugr auf den Zweck von Reisen und Intersuchungen, und die Lente, was man auch immer sagen may, kaum zu überzeugen sind, dass der Reisende einzig die Absicht habe, sich zu belehren.

\section{WISSENSCHAFTLICHE TORKENNTXISSE.}

Gewisse Vorkemntnisse aus den Wissenschaften, welche auf Geographie und Reisen Bezug haben, sind dem Reisenden unenthehrlich. Treffend sagt hierüber Richard Strachey in *inem Vortrag, den er am 26. August 1876 in der Sitzung der britischen geographischen Gesellschaft hielt: „Der Reisende ist der Pionier der Wissenschatt. In allen Theilen der Erde sammelt er Beobachtungen, Facta, welche der Gelehrte in seinem Kabinet oder Laboratorium analysirt, verGeicht, klassifizirt: er liefert dem Gelehrten die Yittel, um induktive Folgerungen und Hypothesen auf ihre Richtigkeit zu prüfen. Der Reisende, welcher der Pflicht genügen will, die ihm durch die wissenschaftliche Arbeitstheilung auferlegt wird, bedarf einer Bildung. die hinreicht, um beurtheilen zu kömen, für welche Kategorien ron Thatsachen weitere Beobachtungen erforderlich sind. Jugend, Gesundheit und Kraft sind kosthare Eigenschaften : aber ein hestimmtes Mass wissenschaftlicher Ausbildung ist nöthig dazu, um ein nützlicher Forschungsreisender zu werden."

Dem Reisenden unserer Tage ist eine doppelte Aufgabe gestellt:

$1^{\circ}$ Er hat die Thatsachen zu beohachten und zu verzeichnen, welche dem ron ihm hesuchten Lande eigen sind, die charakteristischen Züge der (iegend und ihrer Bewohner: 2 Er hat aber auch in diesem Lande diejenigen Beobachtungen fortzuführen, die anderwärts gemacht wurden, um zu erfahren, ob sie überall die nämlichen Resultate liefern oder ob und worin diese Ergebnisse nach den Oertlichkeiten 
differiren. Er muss also einerseits Entrleckungreisender, andererseits fachgelehter Forscher sein.

Der Reisende hat das Ganze ins Auge zu fassen und keinen seiner Theile zu veruachlässigen: der gelehrte Forscher mag sich auf sein Fach beschräken und lediglich hierin sein Ziel verfolgen.

Selhstrerständlich, sind die heiden Rollen nicht scharf getrennt und nicht immer auseinanderzuhalten. Es hielte oft schwer zu bestimmen, wo für den blossen Reisenden das forschende Beobachten aufhöre und in welcher Weise es zu geschehen hahe. In der That: soll er sich begnügen mit hloss allgemeinen Wahrnehmungen und Angaben, soll er nicht vielmehr genaue und vollständige Daten zu liefern suchen? Letzteres wäre wohl das Beste; aber man reist unter so rerschiedenen Bedingungen: so oft mangeln zur Anstellung eingehender Beobachtungen Kemmtnisse, Zeit und Gelegenheit, dass man nicht ron vonherein eine allgemeine positive Regel aufstellen kamn. Wir stimmen daher Hrm. Tr. Güssfeldt bei, wemn dieser saut: "Nach unserel Ansicht muss es jedem Reisenden ïberlassen bleihen, für sich selbst diese Grenz zu ziehen, denn sie ist für jertes Individuum eine andere, je nach der Anlage und der Himmeigung zur I'niversalität" oder Spezialitat, fügen wir hinzu; ferner: "Wir sind der Leberzengung, dass der Reisende nur wenige Disziplinen kultiviren kann, dass ihm aber die oberflichliche Kenntniss der übrigen Wissenswebiete nöthig ist, damit er jederzeit stärker bleibe als die äussern Eindrïcke und keine der Thatsachen ühersehe, ans denen sich die grossen Züge der geographischen Charakteristik zusammensetzen."

Was die Form der Beohachtungsiesultate betrifft, so gibt es Dinge, auf die man nur einen Blick zu werfen braucht, um sie zu konstatiren, so der allgemeine Charakter des Landes, Kostüm und l'hysiognomie der Bewohner; andere muss man messen, da keine Beschreibung sie genau wiedergeben kömnte; so Temperatur- und Höhenverhältnisse $u$. dgl. In solchen Fällen nimm die Beobachtung einen wissenschaftlichen Charakter an. Endlich gibt es gewisse Punkte, hinsichtlich deren auf beide Arten verfahren werden kann; man kann sie nach Schätzung oder nach Messung, approximativ oder ganz genau angeben, so die ethnischen Charaktere. 
Soll man nur sagen, die Eingebornen haben dunkle Hautfarbe, Langschädel, scharf rortretende Xasen - was eigentlich nicht viel hejssen will, da die donkle Haut vom Aschgrau bis zur Schwärze des Ebenholzes variiren kann und die andern rorerwähnten Kennzeichen ähnliche Abstufungen aufweisen: ist es nicht vorzuziehen, da doch die Wissenschaft uns die Vittel dazu gibt, in wenig Worten, mitunter durch eine einzige Ziffer weit genauere Angahen zu liefern? Diese Frage stellen, heisst sie lösen.

Begnïgte man sich einfach, als Reisender zu beohachten, d. h. heschränkte man sich darauf, Thatsachen zu konstatiren und zu registriren, so hiesse das, sich leichthin zu einer bloss passiven und medhinischen fiolle bequemen. Jeder muss aber Verlangen tragen, das Gesehene rerstehen, sich und Andern erklären zu können. Hiezu aber ist eben nüthig, dass man wenigstens einigermassen bewandert sei in den Wissenschaften, welche auf Geographie und Reisen Bezug haben.

Alles bietet dem Reisenden Stoff zu Beobachtungen und Forschungen: Gestaltung des Borlens: geologische, hydrologische, klimatische Verluälnisse: Ptlanzen- und Thierwelt des Landes, die Flüsse, seen und Ieere: ethnoyraphische Verhältnisse, Syrachen. Sitten und Gebräuche, Verwaltung, Regierungsform und andere Eimrichtungen: Politik, Religion, Tradition und (ieschiclite, Archäologie und Tumismatik, Literatur, Industrie und Handel u. dọl. mehr. Es ist ein weites Feld, das Alles umfasst: die Erde und den Menschen. Besitzt man nun in diesem oder jenem Punkte nur ungenügende Kenntnisse, so wird sich dieser Mangel bei Beohachtungen immer fühlbar machen. Jede der grenamnten Wissenschaften ist ein verschlossenes Buch für den Reisenden, der nicht rertraut ist mit gewissen Grundhegriffen über die Materie. Damit ist nicht gesagt, dass man, um mit Nutzen zu reisen, ein lniversalgenie sein oder die Zeit, die man aufs Reisen verwenden sollte, damit zubringen müsse, sich hierauf vorzubereiten. Ile Kenntnisse, deren der Reisende bedarf, sind nicht diejenigen, welche man von einem Gelehrten verlangt: für iln ist keineswegs nüthig̨, dass er die Wissenschaften, die wir rorhin nannten, ron Grund aus beherrsche. 
Nehmen wir beispielsweise die Geographie. Wenn irgend eine Wissenschaft in enger Bezichung zum Reisen steht, so ist sie es. Folgt nun daraus, dass man, um mit Erfolg zu reisen, die Geographie kennen soll wie ein Geograph von Fach? Nit nichten. Was man davon wissen muss, sind die Grundprinzipien, die grossen Züge; keineswegs aber soll man sich auf Einzelheiten verlegen, wofern diese nicht gerade dasjenige Land betreffen, das man zu bereisen sich vorgenommen hat.

Fassen wir num die Meteorologie, die Botanik, Zoologie, Geologie u. s. w. ins Auge, Wissenschaften, welche alle auf Reisen häufig zur Anwendung kommen. Was uns von ersterer wesentlich ron Nutzen sein wird, ist der Theil, welcher vom Klina handelt: die Klimatologie. Was die einzelnen athmosphärischen Erscheinungron betrifft, genügt es, davon so viel zu wissen als nöthig ist, um sie unterscheiden, rerstehen und beschreiben zu können.

Was Botanik und Zoologie anbelangt, muss sich der Reisende namentlich in den Stand setzen, eine Pflanze oder ein Thier rasch, auf den ersten Blick, zu erkennen. Es ist nicht seine Sache, seltene Pflanzen und Thiere aufzusuchen, wohl aber, die Charakterzüge der Flora und Fauna des bereisten Landes, die vorherrschenden Pflanzen und Thiere anzugeben. Daneben kann er immer seine Zuflucht zum Sammeln der Objekte nehmen, um später deren Ḱlassifikation und wissenschaftliche Namen kennen zu lernen.

dehnliches gilt von allen andern Zweigen der Naturwissenschaften. Was der Reisende nach dieser Richtung bedarf, ist mit einem Wort Scharfblick, Beobachtungsgabe und eine gewisse allgemeine Bildung zum Verständniss des Gesehenen. Der Scharfblick aber, von dem wir sprechen, ist - von organischen Fehlern selbstrerständlich abgesehen — Sache der Uebung, der Gewöhnung. Wir werden uns später darüber äussern, wie man denselben ausbilden kann. Was die allgemeine Bildung betrifft, die wir meinen, so besitzt diese ein jeder unserer Leser; es handelt sich also nur darum, in Betreff ron Punkten, welche in Vergessenheit gerathen konnten, das Gedächtniss aufzufrischen, die Kenntnisse systematisch $\mathrm{zu}$ ordnen und in gewissen Richtungen zu ergänzen. 
Indem wir so unsere Kenntnisse Rerue passiren lassen, haben wir in jeder einzelnen Wissenschaft rornehmlich auf das zu achten, was man den gegenerirtigen Stand der Frecte nennt. Ich will mich hierüber genauer aussprechen.

Eine bestimmte Angabe, eine Theorie wird vorgebracht, aufgestellt und verfochten von den Einen, bestritten und angegriffen von Andern; eine gewisse Erscheinung wird vou einer Schule dieser, von einer andern jener Ursache zugeschrieben $u$. s. f. Es ist nun wesentlich, dass man diese Meinungsverschiedenheiten kenue. Sie lenken unseren Blick auf die bestätigten, wie auf die bestrittenen, verschiedener Auslegung fähigen Punkte und bewirken so, dass wir anch unsrerseits Beweise suchen und finden für ihr Sein oder Nichtsein, ihre Richtigkeit oder Lnrichtigkeit, für die Art, wie sie zu Tage treten, und für ihre wahrscheinliche $\mathrm{Ur}_{r}$ sache. Bekannt mit dem Stand einer Frage, sind wir befähigt, uns darüber in wissenschaftlicher Weise auszusprechen, und können wir vielleicht Beweismaterial beibringen zur Diskussion für oder gegen allgemein angenommene Theorien und Hypothesen. Solche Beiträge werden, wenn sie aus Gegenden herrühren, in Bezug auf welche man allenfalls noch nicht Gelegenheit hatte, sich dieselben zu verschaffen, fast immer von grossem Werth sein.

Was man endlich dem Reisenden nicht genug anempfehlen kann, ist: dass er vor der Abreise die ihm bekannten Gelehrten hesuche, um ihnen seine Pläne rorzulegen und darüber ihre Ansichten und Räthe $\mathrm{zu}$ vernehmen. Der Reisende, welcher zum Voraus weiss, was in dem Lande, das er bereisen will, beobachtet zu werden rerdient, wird sich viel unsicheres Imhertasten und manche unnütze Mühe ersparen; er wird mit weit mehr Gewissheit darauf rechnen können, werthvolle Aufschlüsse zu erlangen.

Da vor der Reise oft die Zeit fehlt zu der besprochenen Vorbereitung und deren Ergänzung, und da man gewisse Daten oft dann nicht mehr im Gedächtniss hat, wenn der Noment zu deren Gebrauch, Erprobung oder Diskussion gekommen ist, so hielt ich. es für nützlich, in dem Vademecum des Reisenden ${ }^{1}$ ) ein Hülfsmittel zu bieten, zu welchem

1) Unter diesem Titel erscheint, im Anschluss an den "Beobachter ${ }^{u}$, eine deutsche Ausgabe des unlängst veröffentlichten Aidc-mémice du Voygtyeur par D. Kaltbrunner. 
man bei Bedürfniss seine Zuflucht nehmen kann. Jedes Fach ist darin, um den Lmfang des Buches nicht übermässig auszudehnen, in sehr knapper Form behandelt; aber die bibliographischen Verzeichnisse, welche an die Spitze der einzelnen Abschnitte gestellt sind, werden Denjenigen, welche eine weitere Ausführung wünschen, ihre Aufgabe erleichtern, wie sie auch dem Reisenden, welcher irgendwo einen längern Aufenthalt macht, ermöglichen, die Schriften, deren er bedarf, sich da zu rerschaffen oder sich diesclben dorthin kommen zu lassen, ohne dass er sich hiemit schon bei der Abreise bemühen muss. Die heste Art der Vorbereitung besteht indess immerhin darin, ror der Abreise einige Spezialwerke zu durchgehen. Hiebei mache man sich Notizen über all Das, was zu wissen ron wesentlicher Bedeutung ist, und stelle diese Totizen zusammen in einem Heft, das man mit sich tragen kamn. Tm aber diese Sammlnng nicht zu voluminös werden zu lassen und das Gedächtniss nicht übermässig zu belasten, behalte man auch hiebei seinen bestimmten Zweck wohl im Auge; man mache sich damit recht rertraut und rergegenwärtige sich beständig, was zum Zwecke unsrer Beobachtungen nothwendig und wichtig ist. Dem Tebrigen schenke man zwar diejenige Aufmerksamkeit, welche alles das rerdient, was an und für sich ron Interesse und dessen Lektüre von Nutzen ist; aber da es im gegebenen Fall für uns kein Objekt praktischer Verwerthung hildet, so lasse man es vorläufig bei Seite und mache es nicht zum Gegenstand eines Auszuges, eines Eintrags in das Notizhuch. Hienach bleibt damn nur nöthig, sich auf dem Laufenden zu halten. Es gibt keine Wissenschaft, die nicht ron Jahr zu Jahr fortschreitet. Zuweilen lässt eine cinzige Thatsache alte Hypothesen als irrig erscheinen; dieselbe zu erklären, stellt man Theorien auf, die ihrerseits wieder umgestürt und durch neue ersetzt werden. Die Diskussion darüber fördert neue Gesichtspunkte zu Tage, und so wird nach und nach die Wissenschaft umgestaltet, ohne dass man je behaupten könnte, dass nun das letzte Wort gesprochen sei. Mit diesen Aenderungen muss man sich auf dem Laufenden erhalten, will man nicht riskiren, einen überwundenen Standpunkt zu vertreten oder aber Ansichten als neu rorzutragen, die schon ron andern ausgesprochen wurden. 
Soll eine Reise oder ein Aufenthalt ziemlich lange dauern, so thut man gut, sich periodische Publikationen zusenden zur lassen, welche wöchentliche oder monatliche Uebersichten der Fortschritte in den verschiedenen Zweigen menschlicher Erkenntniss geben - eine jener Revüen, wie deren die Finglander besitzen in the Atheneme und the Academy ${ }^{\mathrm{T}}$ ). Das ist ein einfaches Mittel, um, ohne grosse Bände durchgehen zu müssen, sich au courant zu halten.

\section{PRAKTISCHE KENNTNISSE.}

Wir haben gesehen, dass beim Reisen die Kunst des Beobachtens hauptsächlich von Wichtigkeit ist.

Ian kann, ohne gerade in den Wissenschaften sehr hewandert zu sein, recht nützliche Daten sammeln, wenn man genau weiss, was und wie man beobachten muss. Es wird das in dem Abschnitte, Beobachtungen und Untersurdunurn" des Xähem besprochen werden. Hier bemerken wir zunächst, dass blosses Wissen nicht genügt, sondern dass damit die Praxis verbunden werden muss: letztere abrer erfordert die Kenntniss der gehrüuchlichen Instrumente und Methoden sowie Lehung im Beobachten auf dem Terrain.

\section{INSTRUMENTE.}

Es liegt ganz und gar nicht in meiner Absicht, ein rollständiges Verzeichniss der Instrumente zu geben, deren man sich zum Zwecke der Beobachtungen bedienen kamn. Dieselben sind zahllos; es handelt sich, will man sich nicht mit Lmüitzem and Leberflüssigem befassen, un eine sorgrfültige Auswahl. Ist ein Instrument zu verschiedenartigen Beobachtungen verwendbar, so wird man sich seiner vorzugsweise bedienen, lieber als dass man deren zwei oder drei $\mathrm{zu}$ Spezialzwecken bestimmte mit sich führt.

1) E's gibt mehrere deutsche Zeitsehriften dieser Art, so: J/er Nuturforscher, herausgegeben von Dr. Wilh. Sklarek in Berlin; - Dus Ausland, redigirt von Friedr. von Hellwald in Stuttgart; - lie Natur, Organ des deutschen IIumboldt-Vareins, herausgegeben von Dr. Karl Müller in Halle; - Kosmos, herausgegeben von Dr. Firnst Kirause; - Giäa, herausgegeben ron Dr. H. Klein; - Revue der Fortschritte der Naturwissenschaften, herausgegeben von der Redaktion der Gäa. - Als gleichartige fransosische Zeitsehriften nennen wir folgende: Rovue scientifique de la France ct de l'Etranger, publiée à Paris sous la direction de MI. Yung et Alglave: La Wature. Hevue des Sciences, par R. Gaston Tissandier; - Archives des Sciences plyysiques ct nuturelles, Genève; - Revue Suisse des Beuux-Arts, d'Archóologic, de Litterature ctle Biographie, publice a Geneve sous la direetion de M.JohnGrand-Carteret. 
An dieser Stelle werde ich nur die wichtigsten Instrumente erwähnen; von den andern wird bei Besprechung der Operationen noch die Rede sein. Vollständigere Verzeichnisse der gebräuchlichen Instrumente sind übrigens von Fabrikanten mathematischer und physikalischer Apparate zu beziehen. Für die Anschaffung ron Instrumenten ist nur zu empfehlen, dass man, wenn immer möglich, die genauesten und bequemsten wähle. Beim Anlauf lasse man sich, nachdem die Ausuahl getroffen, gleich.anch Zusammensetzuny, Gebrauch und Zerlegung aler Instrumente zeigen. Mit diesen Details können wir uns hier nicht beschäftigen; sie würden uns zu einlässlichen Erörterungen führen, die unnütz wären für Den, der weiss, wie er die Apparate zu handhahen hat, und ungenügend für Denjenigen, der darin keine Erfahrung besitzt ${ }^{1}$ ).

Theodolit und Visirkompass. Vor Allem bedarf der Reisende eines Instrumentes zum Winkelmessen. Erwird dasselbe in sehr vielen Fällen anwenden müssen.

Das beste Winkelmessinstrument ist unstreitig der Theodolit (A Fig. 1), denn er macht es möglich, direkt die auf die Ebene des Horizontes bezogenen. Winkel (Azimuthe) und zugleich die Zenithdistanzen, bezw. die Höhen zu messen (daher die englische Bezeichnung Altazimuth für den Theodolit). Zudem ist er ein Präzisionsinstrument, dessen man sich

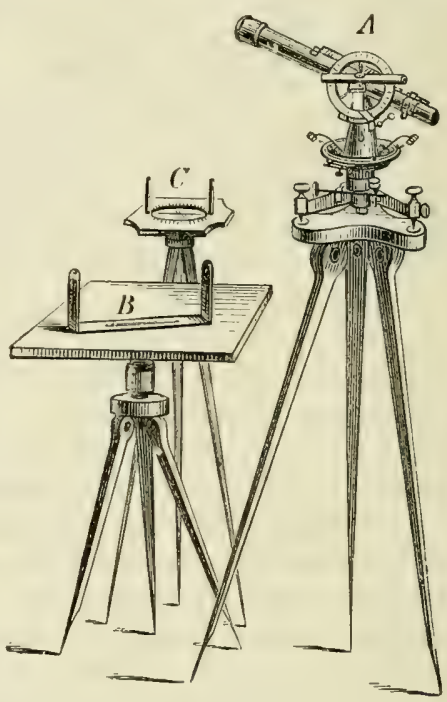

Fig. 1 .

1) In Bezug auf die geodätischen Messinstrumente verweisen wir auf: Antoine $d$ 'Abbadic, Instruments à cmployer en voyage et manière de s'en servir ; Paris 1878 ; Dr. R. Wolf, Taschenbuch für Mathematik etc. Zürich 1869 (Ausführlicheres in dessen Handbuch); - J.Rebstein, praktische Geometrie; Frauenfeld 1868 ; - M. Buuernfcind, Elemente der Vermessungskunde; München 1868; - Dr. W. Jordan, Handbuch der Vermessungskunde, I. Band; Stuttgart 1877. - Hinsichtlich der physikalisehen Apparate findet man das Nöthige in jedem guten Lehrbuch derPhysik, so bei Housson (Ziirich), Reis (Leipzig), Pouillet-Millers Lehrbuch und Mïllers Grundriss (Braunsehweig). 
mit Vortheil bedient für topographische Aufnahmen, für ausgedehnte Nivellements, für Längen- und Breitenbestimmungen, zu Aufnahmen für geologische Karten und Profile etc.

Es gibt Miniatur-Theodolite, die speziell zum Gebrauch für Reisende bestimmt und leicht in einem kleinen Kästchen zu transportiren sind.

Zwar ist das Stativ oder Fussgestell für den Transport etwas unbequem; aber diese Unbequemlichkeit haben auch die beiden andern Instrumente, der Wesstisch (B Fïg. 1) und der Visirlompass oder die grusse Boussole (C Fig. 1), die man gewöhnlich anstatt des Theodolits anwendet, die aber denselben nur in sehr unvollkommener Weise ersetzen, indem sie einerseits für grosse Distanzen keine so genauen Resultate liefern und andrerseits nur die Richtungswinkel, nicht auch die Höhenunterschiede geben, daher neben ihnen zum Zwecke von Nivellements und astronomischen Beobachtungen - noch andre Instrumente erforderlich werden ${ }^{1}$ ).

Die allerdings hohen Kosten des Theodolits lohnen sich reichlich durch die Dienste, welche das Instrument im Laufe einer längern Reise leistet; handelt es sich aber um blosse Exkursionen und beansprucht man für die Messungen nicht grosse Genauigkeit, so kann man sich begnügen mit dem Visinlompass, boussole de recomaissaner von Gravet in I'aris oder mit einer gewöhnlichen Boussole nebst einem Klinometer ${ }^{2}$ ).

Wir. werden später sehen, dass man bei Operationen auf Reisen Umgang nehmen kamn von Messfahnen, Signalen und Nivellirlatten, welche - abgesphen von Zeitverlust bei deren Aufstellung - Trüger und Gehülfen erheischen würden.

Eins der beiden vorerwähnten Instrumente (Theodolit oder Boussole mit Klinometer) und eine einfache IISsstictte oder ein Messbrand (Rollmass ${ }^{3}$ ) sind für geodätische und trigonometrische Operationen ausreichend.

1) Ein leicht transportables Instrument ist der Spiegelsextant; die Beobachtungen mit demselben erfordern aber viel Calcül, da sie alle auf den Horizont reduzirt werden miissen. D'Abbadie spricht sich entschieden gegen die Anwendung der Reflexionsinstrumente (Sextant und Prismenkreis) auf Landreisen aus.

2) Eine gute, zu verychiedenen $Z$ wecken verwendbare Boussole wird einfach nach Graden abgetheilt; sie wird noch versehen mit einem Klinometer (Gefällmesscr) zum Messen der Feigung (des Fallens) von Felsschichten und mit Dioptern zum Messen der Winkel.

3) Das Messband (Rollmass) aus Hanf oder Seide mit Firnissüberzug ist weit weniger als metallene Ketten den Dimensionsänderungen durch Temperaturdifferenzen unterworfen. Die Messkette wird zudem durch häufigen Gebrauch verlängert und liefert dann falsche Resultate. Das Messband ist auch transportabler. 
Taschenkompass oder kleine Boussole. Ein Taschenkompass ist oft von Nutzen, weniger als Messinstrument denn vielmehr zum Zwecke der Orientirung in öden Gegenden und im Nebel. Es gibt phosphoreszirende Boussolen, welche auch Nachts, in der Dunkelheit, das Orientiren ermöglichen. Der Taschenkompass kann auch zu raschen Rekognoszirungen und verschiedenen andern Zwecken angewendet werden.

Chronometer. Will man Länder bereisen, wo die geographische Lage wichtiger Punkte noch nicht genau bestimmt ist, so hat man sich mit einem Chronometer zu versehen, das gerichtet ist nach der Zeit der Sternwarte, von welcher aus man die Meridiane zählen will.

Für meteorologische Beobachtungen brauchen wir folgende Instrumente :

Thermometer, ein oder mehrere, zur Bestimmung der Temperatur der Luft, des Wassers etc.

Im Allgemeinen wird man sich der Quecksilberthermometer bedienen. Für Beobachtungen in kalten Ländern hat man sich mit einem oder zwei Weingeist-Thermometern auszurüsten. Handelt es sich dagegen um heisse Gegenden, so muss man darauf achten, dass die Skala auch auf die Messung hoher Temperaturen berechnet sei.

Die besten Thermometer und die, welche zugleich am wenigsten Raum in Anspruch nehmen, bestehen aus einer feinen Glasröhre, welche die Quecksilbersäule enthält, und einer auf der Glasröhre eingravirten oder auf Porzellan angebrachten Skala, die noch $1 / 5\left({ }^{2} / 10\right)$ Grad abzulesen gestattet. Man kann sie verwenden zur Messung der Lufttemperatur im Schatten und an der Sonne wie der Temperatur ron Wasser, welches Thermometer mit Netallgestell durch chemische Wirkung beschädigen könnte.

Damit man nicht in der Nacht aufstehen oder am Tage sich derangiren muss, um die Temperaturextreme von 24 Stunden zu beobachten, kann man sich ein Hinimum- und Maximum-Thermometer (Fig. 2) anschaffen. Zur Messung der strahlenden Sonnenwärme aber gebraucht man ein Maximum-

Wenn man Stahlbänder anwendet, so muss man bei wichtigen Messungen die Ausdehnung des Metalles durch die Wärme in Rechnung ziehen. Diese Ausdehnung beträgt $0,12 \mathrm{~mm}$. auf 1 Grad C. Man muss vorerst experimentell die Temperatur bestimmen, bei welcher die auf dem anzuwendenden Instrument bezeichnete Strecke von $10 \mathrm{~m}$ wirklich genau $10 \mathrm{~m}$ Iänge hat; sodann hat man die Ausdehnung zu berücksichtigen, welche der Erhöhung der Temperatur über jenen Grad hinaus entspricht - was, wie man sieht, ziemlich umständlich ist. 
thermometer, dessen Kugel üherzogen ist mit einer Mischung von Firniss und Russ und dessen Skala auf der Glasröhre selbst angebracht ist. Dasselbe kann bis zu einem gewissen Grad das Aktinometer - ein für unsern Zweck zu komplizirtes Instrument - ersetzen.

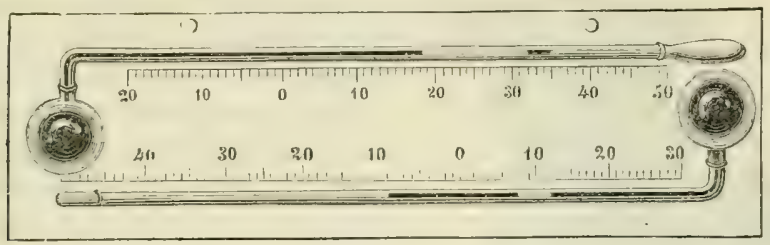

Fig. 2.

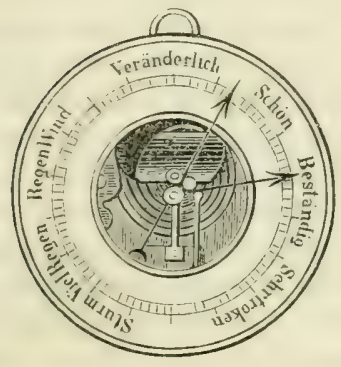

Fig. 3. Gews̈lnliches Aneroid.

Federbarometer oder Aneroid. Dieses Instrument leistet uns denselben Dienst wie ein gewöhnliches Barometer, ohne an dessen Zerbrechlichkeit und andern Inkonvenienzen zu leiden. ${ }^{1}$ )

Will man sich mit einem gewöhnlichen Aneroid (Fig. 3) behelfen, so wähle man eines vom grössten Taschenformat, das zu finden ist; alsdann vergreiche man dessen Angaben mit denjenigen eines gewöhnlichen Barometers. Nan muss aber nicht auf allzulangen Gehrauch desselben rechnen; sein Mechanismus nutzt sich mit ler Zeit ab.

Das Aneroid kann auch zu Höhenmessungen dienen; zu diesem Zwecke muss man sich aber mit dem Instrument an die Stellen begehen, deren Höhe über Neer man messen will, während man mit Hülfe des Thendolits die Höhe entfernter und unzugänglicher Punkte bestimmen kann.

Aneroide nach neuen Systemen. welche den gewöhnlichen weitaus vorzuzichen sind, indem sie viel grnauere Messungen ergehen, konstruirt Mechaniker. foldschmid in Zürich. Solche

3) Vgl. bei Jorlan, a. a. O., den Abschnitt (\$s 146-150) über die Aneroidbarometer. Mit Recht wird daselbst S. 465 getadelt, dass die Instrumente oft durch sinnlose Inschriftcn wie z. B., ,Schön Wetter", ,Sturm" etc. vcrunstaltet werden. 
sind in den Figuren $f$ und j) dargestellt. Das eine (Fig. j) ist sein Taschen-Aneroid, das andere (Fig. 4) das MikroskopAneroid nach Weilenmann. Dieses neue Instrument ist rom

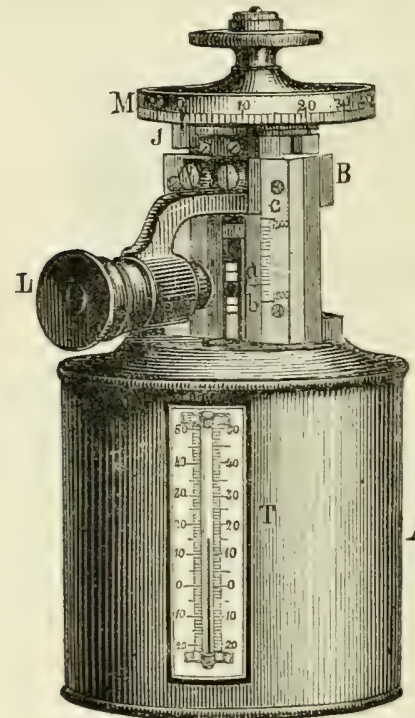

Fig. t. Mikroskop-lnernid.

Erfinder selbst beschrieben in einem besonderen Heft, welches seitens des Verfertigers jedem Instrument beigegeben wird. (Vgl. Jordan, a. a. O., S. 465).

Cyanometer zur Messung der Himmelsbläue. Die Cyanometer ron Saussure, Humboldt, Arago etc. sind nichts anders als Cartonblätter, eingetheilt in 40 Abschnitte mit blauer Farbe in Abstufungen ron Weiss, Nr. 1, bis Nr. 40, welches sich dem Schwarz nähert. Die Beob-

A achtung besteht einfach darin, dass man bestinmt, welcher dieser Nüancen die Farbe des Himmels im Zenith entspricht und diese Nummer der Skala notirt. Da aber die Farbe der Eimwirkung ron Luft und Licht ausgesetzt ist, so schiene es mir zweckmässig, als Cyanometer quadratische Glastäfelchen von blass bläulicher Farbe an-

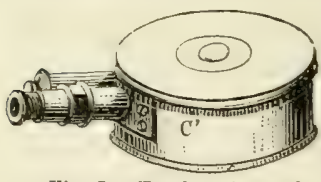

Fig. 5. Tuschen-Aneroid. zuwenden und $\mathrm{zu}$ bestimmen, wie viel dieser Täfelchen man über einem weissenPapier aufeinanderlegen muss, um die betreffende Nüance zu erhalten. Andernfalls sollte man wenigstens einen zweiten graduirten Farbenstreifen haben, welcher verschlossen zu halten wäre und als Probemass zu dienen hätte. Man würde dann nicht die Nummer der durch langen Gebrauch gebleichten Skala notiren, sondern die entsprechende Nummer desjenigen Cyanometers, dessen Farben unverändert erhalten geblieben sind.

Feuchtigkeitsmesser. Zur Ermittlung der Luftfeuchtigkeit gebraucht man das Hygrometer und das Psychrometer. 
Als Hygrometer kann man das aus einer einfachen Glasröhre konstruirte Thermometer verwenden, von welchem oben die Rede war. Es genügt, die Kugel desselben mit Musselin zu umhüllen und darüber einen Ring aus Gold oder Silher anzuhringen (Fig. $(j a)$. Mittelst eines kleinen Pinsels tränkt man die Musseline mit Aether ; hierauf beobachtet man die Temperatur, die vorhanden ist in dem Momente, in welchem der glänzende Ring die erste Trübung durch Wasserbeschlag zeigt. Dies gibt den Thaupunlit.

Zieht man aber ein Spezialinstrument vor, so ist als das Beste und Bequemste für den Reisezweck das neue Hygrometer des Dr. C. Koppe (Fig. (6b) zu empfehlen. Es ist ein Haarhygrometer in einem Metallgehäuse, welches dasselbe vor Stössen sichert und worin das Haar so angebracht ist, dass es sich durch kontinuirliche Ausdehnung verlängern kann. In diesem Gehäuse sind zwei Thermometer aufgehängt, wovon eines als Reserve zu dienen hat, falls das andere zerbräche.

Das transportabelste Psychrometer besteht

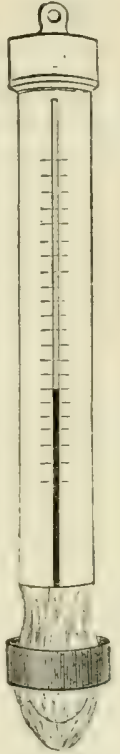

Fin. $6 u$. ans zwei Thermometern der schon beschriebenen Art, die oben ( $\mathrm{egl}$. Fig. $6 \mathrm{c}$ ) durch Charniere verbunden und 1 bis höchstens $2 \mathrm{~cm}$ von einander entfernt sind. Sie werden aufbewahrt in einem Etui ron $3 \mathrm{~cm}$ Breite und einer Länge gleich derjenigen des Instrumentes. Man umhüllt die Kugel eines dieser. Thermometer mit Nusseline und hefestigt darunter mit Hülfe von Metallfäden ein kleines Metallgefüss $V$, das ein wenig weiter als die Kugel des Thermometers und be-

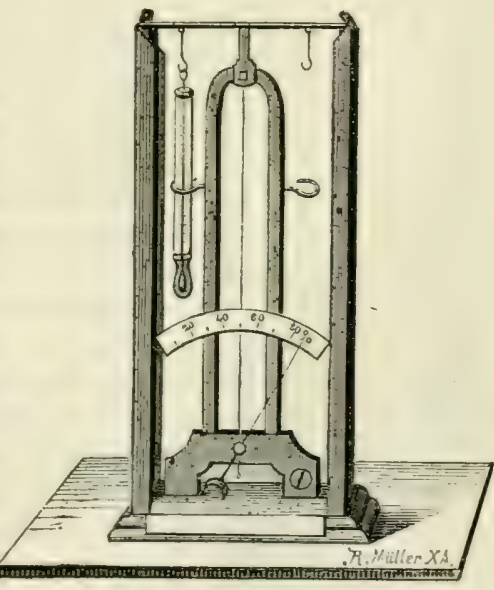

Hij. Gi. Heurliygrometer. 
stimmt ist zur Aufnahme ron Wasser, welches damn durch die Musseline emporsteigt. Man notirt die Temperaturdifferenz zwischen dem trockenen und feuchten Thermometer und bestimmt. mit Hülfe ron Tafeln (s. Anhang Taf. TII) den Grad der reluticen Fenchtiplerit oder den hy!mometrischen Zustund der Luft.

Das Koppe sche Hygrometer kann auch als Psychrometer rerwendet werden. Zu diesem Zwecke braucht man nur den zur Anbringung des einen Thermometers bestimmten Ring aus dem Rahmen herauszunehmen und mit dem letzteren so zu verfahren wie eben beschriehen wurde, d. h. dessen Kungel mit Musseline zu umwickehn und ein kleines Wassergefäss anzubringen.

Thaumesser odre Drosometer. Dieses Instrument, dazu dienend, die Quantitit Than zu messen, welche in der

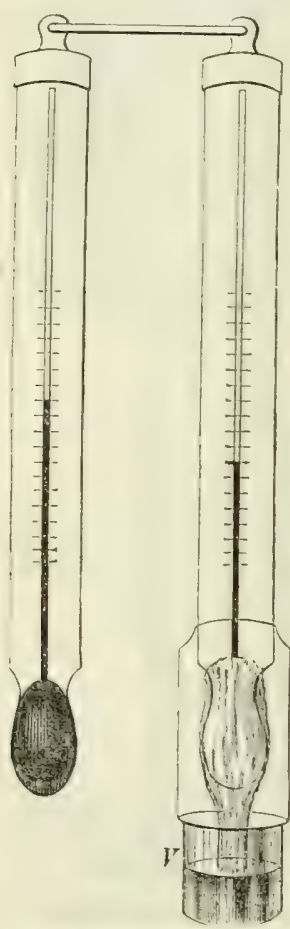

Fig. 6 c. Psychrometer.
Nacht füllt, ist nicht absolut unentbehrlich. Für den gewöhnlichen Reisenden handelt es sich nicht darum, auf $1 / 1000$ oder auch nur 1/100 genau die Menge des gefallenen Thaues zu kennen, vielmehr darum, ausserordentlichen Thaufall zu konstatiren, wie man solchen auf den Hochebenen Mexikos, in der Sahara u. s. w. beobachten kamn. Das grosse Quantum dieses Thaues ermöglicht es, ihn auf gleiche Weise wie die Regenmenge zu messen.

Aus denselben Gründen kann man den Regenmesser (Pluviometer oder Ombrometcr), welcher zur Messung der wässrigen Niederschläge (Regen, Schnee etc.) bestimmt ist, und das Atmometer, welches zur Messung der Wasserverdunstung dient, ersetzen durch einen im Innern mit graduirter Skala rersehenen Rezipienten mit flachem quadratischem oder oblongem Boden von bekannten Dimensionen, z. B. ron $3 \mathrm{dm}$ Seite oder ron $25 \mathrm{~cm}$ Breite auf $4 \mathrm{dm}$ Länge. Dieser Rezipient wird, trotz des ron ihm in Anspruch genommenen Raumes, für den 
Transport nicht gerarde lästigr fallen, demn er kann zur Lonterbringung kleiner Gegenstände verwendet werden.

Ozonometer. Zur Messung des Ozongehaltes der Luft wendet man Jodpapier an, wie unter dem Abschnitt ron den meteorologischen Beohachtungen auseinandergesetzt wird, oder man benutzt hiezu den sirhönbein schen Ozonometer.

Elektrometer. Ieines Wissens gilut es lieine Elektrometer /d. h. Tnstrumente zum Nachweis und zur Messung der Luftelektrizität, die genau und zugleich für den Reisenden bequem wären. MIan wird sich also darauf beschränken, elektrische Erscheinungen $\mathrm{zu}$ notiren; will man mehr thun, so verschaffe man sich den Elektrometer von Peltien (heschrieben im Ammaire métrorologique de Frances, Band II, p. 161).

Was die Instrumente zur Messung des Erdmagnetismus hetrifft. so erfordern sie so frime Beohachtumgen und so komplizirte Pechumenen, dass man deren Gebrauch dem einfachen Reisenden nicht empfehlen kann. ${ }^{1}$ )

Instrumente zur Beobachtung von Erdbeben. Ist die fierent, wolkhe man hereisen will, in besonderem Giarle Frellyehen ausurestzt, so wird man sirh zum Zwecke regentmiissiger Beohachtungen mit einem Srismometry \& Bewegungsmesser-) versehen. [nten, bei Besprechung der geologischen Beolachtungen, werden wir zeigen, wir man mit wenig hosten einen vorzüglichen Seismographen herstellt.

\section{METHODEN.}

Im Allgemeinen werden die Methoden, die Arten des Terfahrens, bei Besprehumg der anzustellenden Beobachtungen beschrieben. Hier werle ich nur solche erwähnen, welche rorgängige Lebung erfordern, daher zur Vorthereitumg gehören.

Lesen der Karten und Pläne. Irh setze voraus, der Leser verstehe eine Karte zu lesen, d. h. er wisse, wenn er die hildliche Darstellung rines Landes ror sich hat, alle die (1)jplite zu erkemnen, welche da hezeichnet sind, und sei also im stande, sich eine klare Vorstellung zu rerschaffen

1) Ygl. übrigens D. Kaltbrunner, Lide-mémoire du Voyaycur, Zürich 1881, pag. $138-140$. 
von der geographischen Situation einer Ortschaft, von ihrer Lage in Bezug auf Gewässer und Gebirge etc. ${ }^{1}$ )

Aber man muss weiter gehen. Man muss sich üben, sofort - welches auch der Massstab oder die Verjüngung der Karte sei - die Entfernung zwischen zwei Punkten zu schätzen und die Bedeutung der Terrainschwierigkeiten zu beurtheilen. Hiefür gibt es kein andres Mittel, als wiederholte Vergleichung von Karten verschiedenen Massstabes mit dem dargestellten Terrain.

Die Zeit, welche man braucht, um von einem Punkt zum andern zu gelangen, ist das beste Mass für die wirklichen Distanzen ${ }^{2}$ ), und hat man mühsam einen steilen Abhang erklettert, so weiss man - besser als nach der besten Erklärung — was dichtgedrängte kurze Schraffen, nahe aneinanderliegende Niveaukurven oder benachbarte, aber verschieden grosse Höhenzahlen bedeuten.

Uebt man sich ausserdem darin, aus dem Gedächtniss immer grössere Theile Landes zu zeichnen, und diese Skizzen entweder mit dem Terrain selbst oder mit vorhandenen Karten zu vergleichen, so wird man den Formensinn für Auffassung von Bodengestalt ausbilden, wie auch grosse Gewandtheit in Terrainaufnahmen à ve erlangen.

Orientirung. Die eben besprochenen Uebungen lehren uns, wie wir mittelst der Karte uns orientiren können. Es genügt, zu diesem Zweck die Gegend um sich wohl anzusehen, während man zugleich die Karte zu Rathe zieht.

Kennt man auf der Karte den Ort, wo man sich befindet, so hat man nur in der Ferne irgend einen charakteristischen Punkt (Thurm, Berg etc.) zu suchen und die Karte zu drehen, bis dieses Objekt und dessen Bild' in dieselbe Richtung kommen, so ist damit die respektive Lage auch aller andern Punkte gegeben. Da, sofern nicht aus-

1) Hülfsmittel: Terrainlchre und Kürtenlesen, herausgegeben vom eidüenössischen topographischen Bureau, Bern 1875, - V. v. Streffleur, allgemeine Terrainlehre (nach Streffleurs Nachlass bearbeitet von Aug. Neuber, k. k. Generalmajor) Wien 1876. - M. Bnuernfeind, Elemente der Vermessungskunde. München 1868. III. Abtheilung. - Heinrich Buch (Ingenieur-Topograph beim $k$. würtembergischen topographischen Bureau), Theorie der Bergzeichnung inVerbindung mit Geognosie, Stuttgart 1852 u. a. m.

2) Es wird angenommen, dass ein Fussgänger im Gebirge durchschnittlich 1 Stunde brauche, um 1000 Fuss $(300 \mathrm{~m}$ ) höher zu steigen, ob dabei die Abdachung - immerhin innert gewissen Grenzen — stärker oder schwächer sei. 
drücklich das Gegentheil bemerkt ist, der obere Rand einer Karte Norden bezeichnet, der untere Rand aber Süden, der heim Betrachten links liegende Westen, der rechte Osten, so hat man damit die richtige Lagre zu den 4 Himmelsgegenden.

Handelt es sich aber darum, auf der Karte den Ort zu finden, wo man ist, so muss man in der Lmgebung einige auffallende Gegenstände suchen und darauf achten, in wel(her Richtung man sie beobachtet und in welcher Entfernung von uns sie sich befinden. Sucht man sodann diese nämlichen Punkte auf der Karte, so wird man zunächst annähernd die eigene Position in Bezug auf jene Punkte bestimmen, sodamn mit Hülfe der Terrainverhältnisse und ihrer Darstellung nach und nach dazu gelangen, genau den Punkt der Karte zu bezeichnen, wo man sich befindet. Als Mittel zur Verifikation lassen sich einige in der eben beschriebenen Weise vorzunehmende Alignements anwenden.

Zur Orimtirmy olue Karte, wie auch zur Bestimmung der Richtung, in welcher sich ein Gegenstand befindet, gibt es verschiedene Mittel.

$1^{\circ}$ Merkzeichen auf der Erde. Kennt man die Richtung einer Bergkette oder eines Wasserlaufes, die Lage einer stadt, eines Dorfes, eines isolirten Bergkegels ete., so hat man damit Fixpunkte, wonach die Lage des Ortes, an dem man sich befindet, oder diejenige anderer Stellen erkannt werden kann. In der That kemnen wir die eigene Position so ziemlich, wenn wir in einiger Entfernung ein Gebirge, eine Stadt oder ein Dorf bemerken, die uns bekannt sind, oder wenn wir einen Fluss treffen, dessen allgemeine Richtung gegeben ist.

$2^{\circ}$ Die Gestirne. Sonne, Mond und Sterne gehen alle im Osten auf, im Westen unter. Wir haben also bei hellem Himmel Morgens und Abends ein bequemes Mittel zur Bestimmung der 4 Haupthimmelsgegenden und folglich auch der Richtung, in welcher von uns aus irgend ein Gescenstand erscheint. Haben wir rechts Osten (Aufgang, Morgen), links Westen (Lntergang, Abend), so ist ror uns Norden und hinter uns Süden. Die Zwischenrichtungen sind Nordost und Südost, Südwest und Nordwest (Fig. 7).

Steht die Sonne schon hoch über dem Horizonte, so kann man sich orientiren nach dem Schatten, welchen ein 
senkrecht in den Boden gesteckter Stab wirft. Man weiss ja, dass in der nördlichen Hemisphäre der Schatten Mittags gen Norden fällt, auf der südlichen Erdhälfte gen Süden

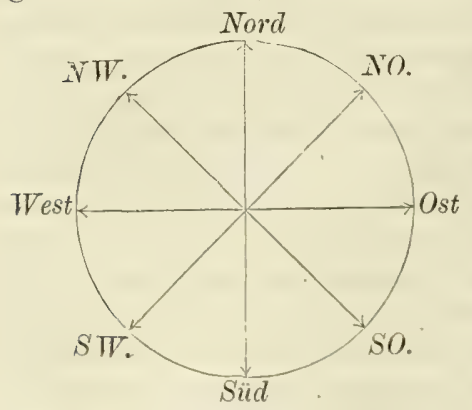

Fig. 7 .

(so wenigstens mit Ausnahme derZone zwischen den Wendekreisen, innerhalb welcher die Schattenrichtung im Laufe des Jahres wechselt). Man hat also nur die Richtung des Schattens zu bestimmen, welchen zur Mittagszeit unser Stab wirft (a Fig. 8). $\mathrm{Zu}$ diesem Zweck zieht man um den Stab als Mittelpunkteinen

Kreis, welchen man in 6 gleiche Abschnitte theilt. Der Mbschnitt, worin sich der Schatten befindet, wird seinerseits in 4 gleiche Partien getheilt ${ }^{1}$ ); der Schatten durchläuft dam in jeder Stunde eine dieser letzteren

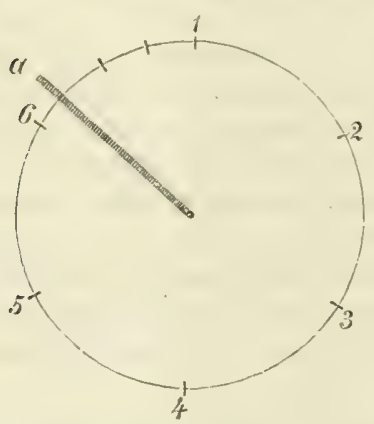

Fig. 8.

Abtheilungen. Man hat also nur die Zeit zu berechnen, die noch verstreichen muss bis Mittag, und das eqtsprechende Bogenstück nach der Seite, nach welcher der Schatten schreitet, abzutragen, um in der nördlichen Erdhälfte den Mitternachtspunkt (Norden), in der südlichen Halbkugel aber den Mittagspunkt zu erhalten.

Setzen wir z. B. voraus, es sei 9 Thr Morgens und der Schatten des Stabes gehe durch ", so wird man drei der Bogenstrecken hinzufügen,

1) Cm auf dem Felde einen Kreis zu ziehen, nimmt man eine Schnur ron ca. $1 \mathrm{~m}$ Länge. Am einen Ende macht man e ne Schleife, welche sich rings um einen Stab bewegen lässt; am andern Ende bringt man ein zugespitztes Stück Holz an. Mit diesem zieht man dann um den aufreptianzten Stab, indem man die schnur gestreckt bïlt, den Kreis. Die Eintbeilung des Kreisumfangs in 6 gleiche Logenstücke geschieht nun durch einfaches Abtragen der Scbnur (des Radius) auf demstiben, von irgend einem Punkt aus; dann theilt man jedes dieser Stücke in 4 solche durch zweimalige Halbirung, wozu man sich auch wieder der Schnur bedienen kann, die man zu diesem Zweck erst einmal, dann noch einmal zusammenlegt. 
welche den rom Schatten binnen, einer Stunde zu durchlaufenden Weg rorstellen und so den Punkt erhalten, den der schatten Jittags einnehmen wird. Hat man erst eimmal diesen Punkt, so kennt man damit auch die andern. Allerdings ist das, wir man leicht einsirht, nicht ein streng exaktes Verfahren; aher es yenügt zu einer approximativen Bestimmung. Sicher ist, dass Mittages 12 Thr der Schatten genau nach Torden gerichtet ist auf der nördlichen Halbkugel, genau nach sürlen auf der sürlichen Hemisphäre immer mit der Ansnahme, dass dies zwischen den Wendekreisen je nur in der einen Hälte des Jahres stattfindet). Ist nun Mittag rorüber, so wird man verfahren, wie oben beschrieben, nur dass man den Bogen, welcher der seit Mittan rerflossenen Zeit entspricht, in dem der Bewermu des Schattens entgegengesetzten Sime abträgt.

Nachts kann man, wenigstens auf der nördlichen Erdhialfte, sich nach den Polarstene orientirn. Lim densulben aufyutinden, sucht man am Hinnmel zunächst das unter dem Namen grosser Bür oder grosser Wayen (Fig. 9) bekannte Sternbild auf, welches mehr in die Augen fällt als der klcine Bär oder Fleine Wayen, dem der Polarstern angehört. Indem man in Gedanken durch die zwei Sterne $\beta$ (beta) und $\boldsymbol{\alpha}$ (alpha) des grossen Bären („Hinterräder des grossen Wagens")eine geradeLinie zieht, trifft man unfehlbar auf den Polarstern, welcher der nächste helle Stern in der Richtung $\beta \alpha$ ist und sich ganz nahe am wahren Nordpunkte befindet.

Polarstern

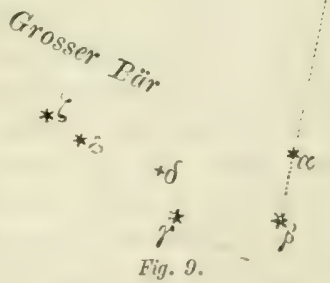

$3^{\circ}$ Die Bousscle oder der Kompuss. Da die Orientirung mit Hülfe der Gestime nur bei nicht bestecktem Himmel möglich ist, so crehietet die Vorsicht. falls man ohne Führer in öden Gegenden reist, wo die einförmige Gestaltung des Bodens zuweilen dem duge keinen natürlichen Inhaltspunkt gewihlt, sich mit einem Kompass zu versehen. Bekanntlich besitzt die freischwebende Iagnetnadel die Eigenschaft, 
sich - abgesehen von Störungen aus natürlichen oder andern Ursachen — beständig in eine nordsüdliche Richtung zu begeben, d. h. ihr magnetisches (stahlfarbiges) Ende

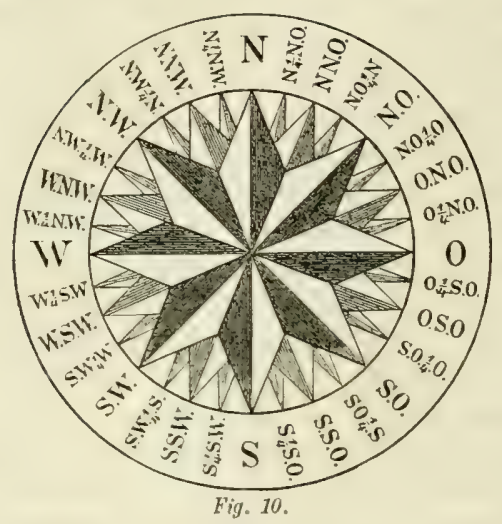
richtet sich gen Nord, das nicht magnetische (silberfarbige) nach Süd. Beim Kompass der Seefithrer ist die Nadel über einer sogenannten Windrose (Fig. 10) angebracht, d. h. über einer Art Stern, dessen 32 Spitzen oder Strahlen ebensoviel Richtungen entsprechen und zwar von Nord nach Ost oder von links nach rechts: Nord, Nord $1 / 4$ Nordost(Nordnordost gen Nord), Nordnordost, Nordost 1/4 Nord (Nordnordost gen Ost), Nordost, Nordost ${ }^{1}$ Ost, Ostnordost, Ostnordost gen Ost (Ost $1 / 4$ Nordost), Ost ete. Die Magnetnadel zeigt indess nur annähernd (nur an wenigen Orten genau) nach dem wahren Nordpunkt; überall, mit Ausnahme jener wenigen Stellen, weicht sie von der nördlichen (mexidionalen) Richtung mehr oder weniger nach links oder mach rechts ab. Diese Abvcichung, Missueisung oder Delilination der Magnetnadel (auf englischen Seekarten als Truviation bezeichnet), welche für einen und denselben Punkt der Erde jährlich eine andere ist, wird vorausberechnet, so dass man wissen kann, welche Korrektion anzubringen ist, um den wahren Nordpunkt zu erhalten. Da man indess nicht immer die auf jene Korrektion bezüglichen Angaben besitzt und da es natürliche und künstliche Störungen der Nadel gibt - namentlich in Gebirgsländern so muss man zur Erzielung grosser Genauigkeit den Fehler in der Deklination beseitigen durch Visiren nach dem Polarstern oder nach einem andern bekannten Fixpunkt. Wir werden übrigens später, wenn wir von der Bestimmung des Meridians sprechen, sehen, wie man die nordsüdliche Richtung für irgend einen Ort genau auffindet. Handelt es sich weder um einen zu langen Zeitraum, noch um eine 
schr ausgedehnte Gegend, so darf man die durch den Kompass gegehene Richtungslinie als hinlänglich beständig ansehen zum Zwecke der (Orientirung und flüchtigen Aufnahme (flyin!! surrey). Es genügt bei Benutzung des Instrumentes auf Vermeidung abnormer störungsursachen (nahe Gegenstände aus Eisen: Waffen, Instrumente, Handwerkszeug u. dgl.) Bedacht zu nehmen; sodann lasse man der Nadel genug Zeit, dass sie den Ruhezustand annehmen kann und notire nun die Richtung orler den Winkel, unter welchem die Gegenstïnde erscheinen. Nach beendigter Operation muss man die Sadel mit Hülfe des Knopfes in ihrer Richtung fixiren (arretiren), damit sie nicht beständig in's Schwanken gerathe und dadurch sich abnütze.

Das Abstecken von Linien. Hat man auf dem Felde die Richtung einer greraden Linie in ihrer Fortsetzung zu bestimmen, die Gerade also zu ver]ängern, so benutat man liezu gerade Stäbe oder Pflöcke, die unten zugespitzt, oben leicht gespalten sind, so dass man dort eine Karte orler ein stück weisses Papier anbringen und so den Stab leicht kenntlich machen kann (Fil. 11). Diese Stäbe müssen gut in den Boden gesteckt werden, so dass der Wind sie weder umzuwerfen noch in schiefe Lage zu bringen vermag. Ist der Boden zu hart dazu, so lïsst man die Stäbe halten und stellt inzwischen am Fusse derselben aus Erdschollen oder Steinen einen kleinen Hügel her. Die Stäbe müssen aber genau vertikal gestellt werden. $\mathrm{Zu}$ dem Ende placiren wir uns in einiger Lntfernung mit einem Senkblei, dessen Faden in Stimhöhe so zu halten ist, dass die Kugel fast bis zum Boden reicht; dann vergewissert man sich, dass die Stäbe nach keiner Seite hin geneigt sind.

Es können folgande Aufgaben zu lösen sein.

$1^{\circ}$ Zuei Stäbe in cine bestimmte Richtung $z u$ bringen. Nachdem der eine Stab in solider Weise aufgepflanzt, lässt man einen andern ungefähr. in der gewünschten Richtung anbringen, stellt sich hinter Fig. 13 . den ersten und gibt dem Gehülfen, welcher den zweiten Stock zu placiren hat, mit der Hand Zeichen, den Stock je nach seiner Stellung mehr nach rechts oder links zu versetzen, bis er in die gesuchte Richtung kommt, d. h. 
bis er beim Visiren nach der zu hestimmenden Richtung durch den ersten Stock gedeckt erscheint.

$2^{\circ}$ Punkte in einer Geraden zuischen zwei Stiben zu bestimmen. Kann man sich hinter einen der beiden Stäbe begeben und dabei den andern doch im Ange behalten, so ist es leicht, andere in der gleichen Geraden aufzustellen. Van hat nur zu rerfahren, wie vorhin angegeben wurde, indem man darauf achtet, dass die Stäbe sich alle decken. Kann man sich aber nicht hinter einen der äussersten Stäbe begeben um zu visiren, so muss man die Aufgabe durch Verstiche lösen. Nan pflanzt einen zwischenliegenden Sitab auf, begibt sich hinter denselben und lässt einen andern zwischen diesen ersten und einen der ïussersten einstellen. Dam tritt man hinter den zweiten Stock, visirt nach dem andern Endfunlit und lässt den mittlem Stab anders placiren, wenn er nicht in der Geraden erscheint. So fährt man fort, indrom man abwerhselnd rom einen und andern der mittlem stäbe aus visirt, bis die gerade Linie hergestellt ist. - Ist einer der beiden Endstäbe rom andern aus nicht sichthar, so begiht man sich nach einem zwischenliegenden Punkte, von wo ans man heide sehen kann; mit Hülfe einer ebene'n Flïrhe (Tafel, Brettchen) bestimnt man die vertikale lihene, in welcher sich die beiden äussern Stähe hefinden und lïsst hierauf demgemäss die mittleren Stöcke aufstellen.

$3^{\circ}$ Eine abgesteckte Gerade zu verlüngern. Man tritt hinter die schon aufgestellten Stäbe nud lässt andere in der sleichen Richtung aufpflanzen. In stark geneigtem Terrain muss man hiehei die Stäbe in liurzen Entfernungen von cinander anbringen. - Soll die Verlängerung ïber eine Anhöhe hinüber bewerkstelligt werten, so wendet man ein ähnliches Terfahren an, wie wenn ein Stab von einem andern aus nicht sichtbar ist. - Ist das Hinderniss umpassirbar, so umgeht man dasselbe. In der Nähe desselben angelangt, entfernt man sich nämlich davon um eine gewisse Strecke, unter einem rechten Winkel; dam folgt man einer Parallelen zur ersten Linie, his man über das Hinderniss hinaus ist und kehrt hierauf wieder unter einem Winkel ron $90^{\circ}$ und mittelst Einhaltung derselben Distanz, um welche man 
seitwärts ausgewichen ist (Fig. 1:2, $a, b$, $c, d, c, f)$, in die erste Richtung zurück $\left.{ }^{1}\right)$.

Der Theodolit erleichtert all das ungemein; da sein Fernrohr sich in vollkommen vertikaler Ebene bewegt, so bezeichnet es genau die Richtung, in welche Stäbe zu stellen sind, auch auf grosse Distanzen und bei grossen Niveaudifferenzen, wie für Linien, welche über Anhöhen himüber fortzusetzen sind.

Bei Benutzung des Theodolits oder eines anderen, mit weittragendem Fernrohr versehenen Instrumentes, verwendet man

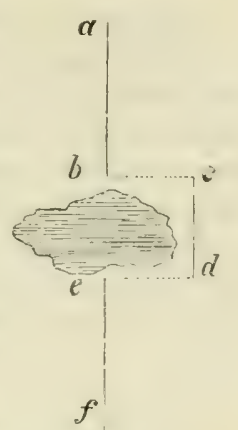

Fig. 12. statt der Stäbe Zeichen, die von Weitem sichtbar sind (Stangen mit Fähnchen, Strohwische u. dgl.), und die Gehülfen, welche dieselhen tragen und aufstellen müssen, werden dirigrit durch signale mit Taschentïchern, durch Hörnerruf oder Pistolensehü̈sse, deren Bedeutung vorher rerabredet worden ist.

Das Schätzen und Messen von Distanzen. Beim licisen hat man so oft Entfermungen abzuschützen. dass es gut ist, wenn man sich darin übt.

Es gehört viel Uebung dazu, um von freiem Auge

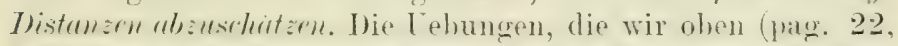
Kartenleseni empfohlen, bereiten indess darauf ror. Tiei aller Fertigkeit, die man in dieser Beziehung erworben, muss man immer wohl auf der Hut sein gegen mögliche Fehler, Irrungen und deren Quellen. So z. B. sehen wir bei verschiedengradiger Intrehsichtigkeit der Luft die Gegenstände hald deutlicher und scheinhar näher, bald unbestimmter, mehelhaft, und dem Anscheine nach in grösserer Entfernung. Sodamn täuscht uns auch oft die Art der Beleuchfung eines Objektes: ein hell helenchtetor oder leuchtender (iegenstand erscheint uns näher als er wirklich ist. Darum täuscht man sich Nachts fast immer ïher die Entfernung, in weleher ein Licht ist order eine Fenershrunst stattfindet. Alle solche Fehlerguellen, oft lokaler und zufälliger Yatur, muss man zu würdigen wissen.

1) In Ermanglung riner Boussole oder eines andern Instrumentes konstruirt ran diese rechten Winkel, indem man längs der Ränder einer Tafel, eines Ileft:s oder Buches hinvisirt. 
Man schätzt Distanzen auch nach der Zeit, die man braucht, um sie zu Fuss oder zu Pferd zurückzulegen. Um hiebei eine gewisse Genauigkeit zu erlangen, muss man vorher seinen Schritt oder den des Reitthiers reguliren und zu diesem Zwecke öfters eine gegebene Strecke durchlaufen, um die hiefür benöthigte Zeit kennen zu lernen. Durch wiederholte Uebungen unter verschiedenen Verhältnissen (bergan und bergab, in sandigen oder sumpfigen Gegenden, bei Hitze, Müdigkeit etc.) wird man eine mittlere Strecke kennen lernen, die man in einer gegebenen Zeit zurückzulegen rermag. Selbstverständlich muss man Haltepausen wie rerschiedene Gangarten der Reitthiere berücksichtigen.')

Nur cn passont erwähne ich das Distanzenschätzen mittelst des Schalles. - Sieht man, was den Schall erzeugte (z. B. die Axt oder den Hammer, womit gegen einen Baum oder auf einen Stein geschlagen wird, den Blitz beim Ahfeuern eines Gewehrs u. s. w.), so kann man die Entfernung berechmen, indem wir wissen, dass der Schall in der atmosphärischen Luft (bei einer Temp. von $+10^{\circ}$ ) sich mit einer Geschwindigkeit ron $337,2 \mathrm{~m}$ in der Sekunde fortpflanzt, und dass diese Geschwindigkeit mit jedem Grad des Steigens oder Sinkens der Temperatur um $0,626 \mathrm{~m}$ zu-oder abnimmt, während das Licht augenblicklich zu uns gelangt ${ }^{2}$ ). Man darf indess nicht vergessen, dass die Schnelligkeit der Fortpflanzung des Schalles durch den Wind beeinflusst wird.

Zur Dessung liurzer Distanzen kann man Stangen (Messlatten) anwenden ron bestimmter Länge, die horizontal und mit den Enden an einander gelegt werden. Die zu messende Linie muss, wenn deren Endpunkte ziemlich weit von einander entfernt sind, vorher abgesteckt werden, damit man nicht

1) Das Mittel der menschlichen Gehgeschwindigkeit ist etwa $5 \mathrm{~km}$ pro Stunde, das Minimum $4 \mathrm{Km}$, das Maximum $6 \mathrm{Km}$; mehr als $5,5 \mathrm{Km}$ pro Stunde lässt sich auf die Dauer nicht leisten; ein Schritt ist im Mittel $0,8 \mathrm{~m}$, etwa mit Grenzwerthen von 0,7 und $0,9 \mathrm{~m}$. Wer seinen Schritt wiederholt unter verschiedenen Umständen, auf verschiedenem Boden und bei verschiedenem Zustand der Ermüdung bestimmt und die Aenderungen verfolgt, kann sehr wobl aus seinen Schrittmaassen Resultate ziehen, welche auf $1-20 \%$ genau sind. Nach Erfahrungen von Cailliaud, Rohlfs und Güssfeldt hat der Geograph das Recht, die Itinerare von Kameelkaravanen in Nordafrika und Arabien nach dem Massstab 1 Stunde $=4 \mathrm{Km}$ zu rerwerthen und wird hiemit bei längeren Strecken kaum um $50 / 0$ fehlen. Jordan, a. a. 0 . \$\$ 58 und 208

2) Die Geschwindigkeit des Lichtes in der Sekunde beträgt:

$\begin{array}{cccc}\text { nach } & \text { Fizeau } & \mathbf{3 1 5 , 0 0 0} & \text { Kilometer, } \\ , \text { Foucault } & 298,000 & , \\ \text { " } & \text { Cornu } & 300,400 & , "\end{array}$


von derselben nach rechts oder links abweicht. Ferner muss man sich über die wagrechte Lage der Messlatten rergewissern mittelst einer Libelle, die eine Luftblase enthält (Fi\%. 1.3) und die man in der Tasche bei sich führen kann. Bei abschüssigem Terrain wird man sich anch eines Senkbleis bedienen, um sicher zu sein, dass die Enden der Messstangen einFig. 13. ander genau entsprechen (Fig.14).

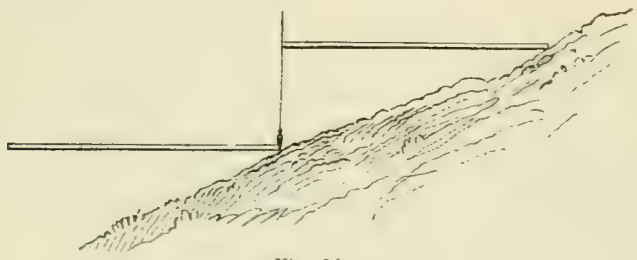

Fig. It.

Sind die zwei Punkte, deren Entfermung man hestimmen will, durch cin Hinderniss (Teich, Wäldchen, Fels, Gehäude etc.) getrennt, so stellt man zwischen ihnen die Verbindung her, wovon S. 28 die Rede war, misst ab, $c$ d, ef (Fig. 15) und erhält durch Addition dieser 3 Strecken die Gesammtlänge $a f$, da ja die Linie $c d$ genau gleich sein muss $b e$, wenn man sorgfältig zu Werke gregangen ist, d. h. wenn die Winkel bei $b, c$, $d$ und $"$ wirklich rechte Winkel sind.

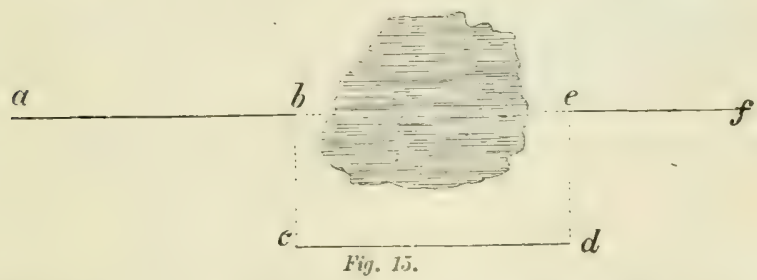

Das Hinderniss kam aher so hesthaffen sein, dass eine Lmgehung desselben unmöglich ist, so z. B. wenn zwischen den Endpunkten $a$ und $b$ der zu messenden Linie ein breiter Fluss sich hinzieht (Fi\% 16). 


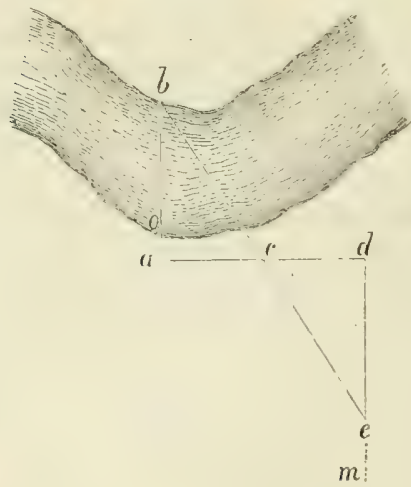

Fig. 16 .

In diesem Falle steckt man eine beliebig lange Gerade ab, welche auf $a b$ in $a$ senkrecht steht. Die Mitte von ad wird durch einen stark in die Augen fallenden Stab bezeichnet. Dann errichtet man in $d$ eine Senkrechte auf $a d$ und geht in der Richtung soweit rückwärts, bis der Stab in $c$ das Objekt $b$ deckt. Diesen Punkt $(e)$ bezeichnet man wieder durch einen Stab. So

$m$ hat man zwei kongruente rechtwinklige Dreiecke hergestellt, worin $c d=c a$ und $d c=u b$, der gesuchten Distanz.

Wie man sieht, kann dies Verfahren auch angewendet werden, um die Breite eines Flusses zu messen, olne dass man auf's andere Tfer hinïhersetzt. Man braucht nur für den Punkt b (Fin. J6) einen Baumstamm, einen grossen Stein oder irgend einen andern angenfälligen Gegenstand am andern Ufer zu wähleñ und von der Strecke $a b$ die Jistanz " (his zum diesseitigen [fer) zu subtrahiren, so gibt der Rest die gesuchte Breite.

Häufig trifft es sich aber, dass das Terrain nicht hinlänglich geeigneten Raum gewïhrt zur Tornahme des beschriebenen Verfahrens. I)am wendet man ähnliche Dreiecke an, statt kongruenter $\left.{ }^{1}\right)$.

Es soi $a b$ (Fin. 1y) die zu messende Breite eines Stromes mit waldigen oder felsigen Ufern, wo dem Fluss entlang nur ein schmaler Streif sandigen Bodens eben ist. Man steckt. a d ah, wie rorhin gesagt wurde; dam bringt man einen besonder's bemerkbaren Stab in r'so an, dass $c$ d der vierte Theil ron ad ist; errichtet in $d$ wieder ein Perpendikel auf

1) Kongruente (identische) Dreiecke nennt man solche, in welchen jedes Stïck des einen bezichungsweise gleich ist je einem entsprechenden Stück des andern, s) dass die Dreiecke zur genauen Deckung gebracht werden können, wenn man sie auf einander legt. Achuliche Dreiecke hingegen sind solche, die nur in den Winkeln übereinstimmen (was der Fall ist, wenn von zwei Winkeln des einen jeder gleich ist je einem Winkel des andern), während die Seiten ungleich gross sind, so dass das eine dieser Dreiecke vom andern nur zum Theil gedeckt würde. Das Charakteristische der ähnlichen Dreiecke ist, dass ihre korrespondirenden (homologen) Seiten proportional sind. 
" d und geht abermals in der Richtung $d m$ bis zu dem Punkte $e$, wo der Stab das Objekt $b$ am andern Uffer deckt. Die Dreiecke rab und cale sind nun ithnlich, d. h. sie haben yleiche Winkel und proportionale Seiten. Da nun ac das Dreifache von $c d$, so ist auch die gesuchte

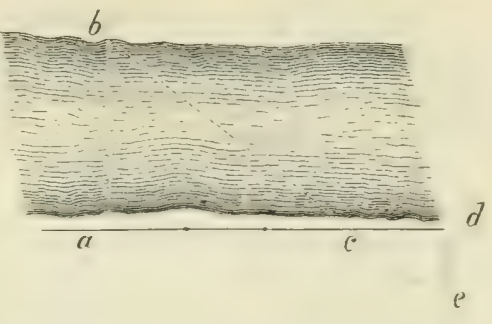

Fiig. 17 .

Ibistanz ab drei mal so gross als de. Es ist klar. dass man cel irgend einem Bruchtheil ron "d gleich machen kann: die Regel ist immer die: so oft mal $c d$ in $a c$ enthalten, so riel mal urüsser ist die gesuchtio läinge $\| l$ als dies streche de. Ist also $c d=1 / 10$ von $a d$, $a c$ mithin $=9 / 10$ ron ad und folglich $c d$ in $a c$ neummal enthalten, so muss man $d e$ nermmal nehmen. um die gesuchte I)istan\% al) zu behommen.

Ist die zu messende Linie an ihren beiden Enden znoünglich wie al, in Fing. 1s, so begiht man sich zu einem Punkt $o$, von wo aus $a$ und $b$ sichtbar sind. Nachdem man die Linien $"$ o und bo bezeichnet hat, steckt man ron "inem Punkte c den man in der Linie a"so wählt, dass "r. ein berquemer Theil, $\frac{1}{n}$, ron " $(l)$ aus eine Parallele zu al, ah, indem man " gleich demselben aliquoten Theil $\left(\frac{1}{n}\right)$ ron ob macht, und erhält so wieder zwei ähnliche Dreiecke. Man misst $o c, c d$ und $o a$; so oft nun $o c$ in oa enthalten ist, so viel mal grösser ist die gesuchte Strecke a $b$ als die Länge $c d$.

Es gibt noch andere geometrische Methoden für Konstruktion and Berechnung von Dreiecken; die oben erwähnten sind aber die einfachsten und vollständig genügend $\mathrm{zu}$ annähernd genauer Messung kleinerer Distanzen.

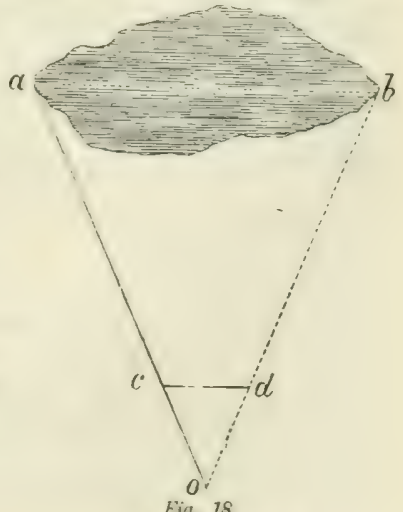

Fig. 15. 
Was num die yrossen Strecken betrifft, so kann man solche auf Reisen unmöglich so messen, wie es soeben für kleinere gezeigt worden ist. Man muss zu andern Nitteln greifen. Solche Mittel sind:

Das Odometer (Hudometer), Pedometer, der Teqmesser. Schrittmesser oder Schrittzühler, ein Instrument, das bei Beginn der Reise am Knie eines Menschen oder Pferdes angebracht oder in der Tasche mitgetragen wird und welches die Länge des zurïckgelegten Weges durch die Zahl der Schritte oder Radumdrehungen angibt. Das Instrument ist Störungen unterworfen und nicht immer bequem anzuwenden.

Der Distanzmesser, ein Fernrohr mit parallelen Fäden, welche ermöglichen, eine Entfernung zu messen, indem man ein Objekt ron hekamnten Dimensionen oder eine Nivellirlatte (Nivellirmassstah) anvisirt. Sie hat für den Reisenden das Unbequeme, dass man fast immer an den Punkt, dessen Entfernuny man kemnen lernen will, einen Mann hinsenden muss, damit er sich daselhst a ufstelle oder die Nesslatte anbringe ${ }^{1}$ ).

Trifomometrische Messungen. Dieses Mittel ist das zuverlässigste und bequemste, wemn es auch auf den ersten Blick etwas komplizirt erscheint. In letzter Linie läuft es auf die Messum! eimer yroden Linie (Basis) hinaus, welche die Seite eines Dreieckes bildet, und auf die Messung eines oder mehrerer Winkel. Die andern Stücke, Seiten und Winkel, die min nicht gemessen hat, und die manchmal unmöglich direkt gemessen werden könnten, bestimmt man dam durch Techumu! oder durch Fonstrutition anf dem Papice.

Wir haben gesehen, wie man eine gerade Linie, d. h. die Entfernung zwischen zwei Punkten misst.

Die Winkel, unter welchen man Gegenstände erblickt, z. B. A und $B$ (Fï. 19) hestimmt man mit Hülfe eines Instrumentes (Theodolit oder Boussole), welches einen graduirten Kreis hat.

Ist das Instrument in $C$, so visirt man nach dem Punkt $A$. damn nach $B^{2}$ ); die Differenz der beiden auf dem eingetheilten Kreise abgelesenen Zahlen ist das Mass für den Winkel.

1) Man kann auch den Gunmet'schen Taschentelemeter mit Doppelreflexion (Telemètre de poche, à double réflexion, du capit. Gaumet) anwenden, welcher beschrieben ist in No. 10 der Comptes rendus de l'Académie des Sciences de Paris, 1876, page 152.

2) Der eingetheilte Kreis (Limbus), muss in genau horizontaler Lage sein; ebenso die Kippaxe des Fernrohrs. Sind die anvisirten Gegenstände in verschicdener 


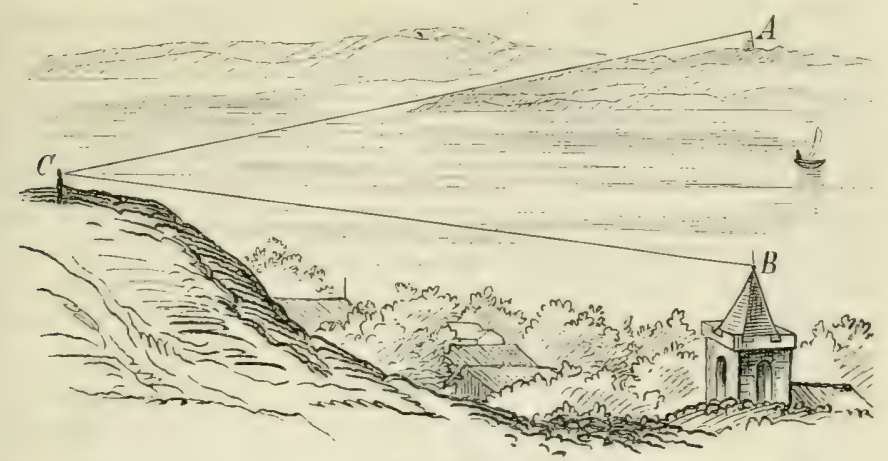

Fig. 19.

I) Visirrichtung ('. 1 grehe durch $25^{n} 10^{\prime}$ der Kreiseintheilung (des Limbus), die Linie ('B) durch 46" 25 ', so findet man durch die einfache Subtraktion:

$$
46^{\circ} 25^{\prime}-25^{\circ} 10^{\prime}
$$

die Grösse $21^{\circ} 15^{\prime}$ für den Winkel $A B C$. Nan kann aber sogar diese subtraktion ersparen, indem man das Instrument so aufstellt, dass die Visirrichtung (Ad über den Nullpunkt der Kreistheilung geht. Die Ahlesung für die Visirlinie $C B$ gibt dann sofort den Winkel an.

Soweit hat also die Sache keine Schwierigkeiten.

Höhe, so darf man nicht etwa den Kreis in eine schiefe Lage bringen, sondern man muss sie durch die Oefinungen des Diopters oder durch das Fernrohr visiren, ohne eine stürung der horizontalen Lage des Kreises zu bewirken.

Auch muss das Centrum des Instrumentes genau senkrecht über dem Punkt $C$ liegen. Ist das Instrument auf einem Stocke befestigt (Stockboussole), so genügt es, mit Iülfe eines Senkbleies sich ron der genau vertikalen Stellung des Stockes zu überzeugen. Ruht aber der Apparat auf einem dreibeinigen Statir, so ist dieser Dreifuss unter der Mitte seiner Platte gewöhlich mit einem kleinen Ring rexsehen, an welchen man ein Senkloth aufhängen kann.

Es ist nun nicht immer möglich, das Instrument genau im Punkte $C$ aufzustellen; es kann sich an diesem Iunkte ein Gebäude (ein Thurm u. dgl.) befinden, oder ein anderer Gegenstand, wie ein Baum, ein Fels, ein Signal. Dann begibt man sich etwas seitwäts, nach links oder rechts, z. B. nach $C^{\prime \prime}$ (Fig. 20) und visirt um soriel nach links oder rechts ron $A$ und $B$ hinwcg, indem man berücksichtigt, dass eine Distanz wie $C^{\prime} C^{\prime}$ in der Ferne auf einen sehr geringen Betrag reduzirt wird. - Im Anhang ( $T a f . I V B)$ werden wir genauere Methoden dieses unter dem Namen zentrischer Reduktion cines Winkels bekannten Verfahrens besprechen.

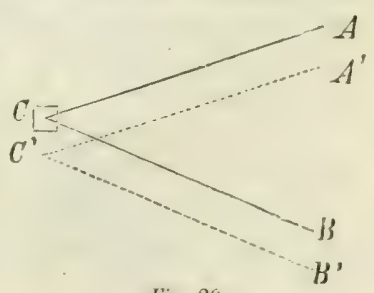

Fiiy. 9 (1). 
Wir wollen jetzt einige Grundsätze betrachten, welche uns die Methode klar machen werden.

Ein Dreieck ist bekanntlich eine von 3 Seiten begrenzte Figur. Die eine dieser Seiten heisst die Gmudlinie oder Basis des Dreiecks, Spitze der Scheitel des gegenüberliegenden Winkels, Höhe der senkrechte Abstand der Spitze von der Grundlinie, gemessen auf dem Perpendikel, welches man von der Spitze aus auf die Basis oder deren Verlängerung fällen kann. (Fig. 21).

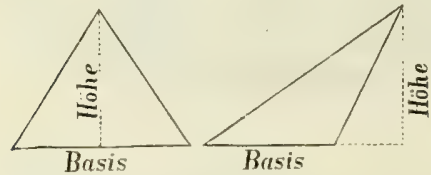

Fig. 21.

Jedes Dreieck hat 6 Stücke: 3 Seiten und 3 Winkel.

Ein Dreieck ist mu bestimmt, d. h. man kann alle seine Stücle berectuen oder konstruiven, wem man drei

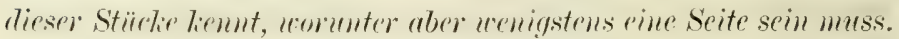

Nehmen wir z. B. das Dreieck abc (Fig. 22). Die drei Stücke, die bekannt sein müssen, können sein:

$1^{\circ}$ Die drei Seiten $a b, b c$ und $a c$.

$2^{\circ}$ Zwei Seiten, z. B. $a b$ und $a c$, und der von ihnen eingeschlossene Winkel (a).

$3^{\circ}$ Zwei Seiten, $a b$ und $b c$, und der Gegenwinkel $c$ der grössern Seite.

$4^{\circ}$ Eine Seite, z. B. $a c$, und die zwei anliegenden Winkel ( $a$ und $c$ ).

$5^{\circ}$ Eine Seite, z. B. a c, ein anliegender und der Gegenwinkel ( $a$ und $b$ ).

Da es beim Reisen zu zeitraubend wäre, grosse Linien auf dem Terrain direkt zu messen, so werden wir uns auf die Fälle 4 und 5 beschränken, welche

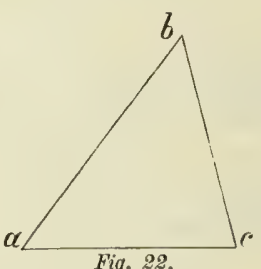
nur eine einzige Seitenmessung exfordern.

Was die Berechnung der Winkel anbetrifft, so muss man sich erinnern:

a) Dass die Summe der 3 Winkel eines Dreiecks immer gleich ist zwei Rechten oder $180^{\circ}$.

b) Dais man folglich, wenn man zwei Winkel des Dreiecks oder auch nur deren Summe kennt, den dritten erhält, indem man einfach jene Summe von $180^{\circ}$ subtrahirt. 
(c) Beim rechtwinkligen Dreieck ist, da einer seiner Winkel $90^{\circ}$ hat, die Summe der beiden andern auch $90^{\circ}$; man braucht also nur einen dieser zwei spitzen Winkel zu kennen, so findet man sofort den andern.

Nehmen wir nun an, es handle sich um Bestimmung der Distanz $A B$ (Fig. 23).

Eine Linie $A C$ als Basis stecken wir ab und messen wir mit all' der Sorgfalt, wovon Seite 31 die Rede war. Dann stellen wir unser Instrument der Reihe nach in $A$ und in $C$ auf und messen die Winkel $C A B$ und $A C B$ (s. Seite 35). Statt den Winkel bei $C$ zu messen, können wir aber auch, wenn dies für uns bequemer ist, denjenigen bei $B$ messen. Wir brauchen dann nur die Summe der Winkel $A$ und $B$

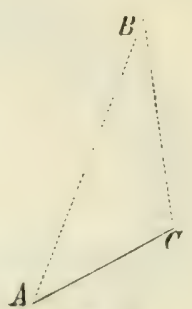

Fig. 23. von $180^{\circ}$ zu subtrahiren, um den Winkel bei $C$ zu erhalten.

Im einen wie im andern Fall haben wir 3 bekannte stücke, worunter eine Seite. Lm nun die 3 andern, inshesondere die gesuchte Länge $A B$ zu erhalten, bedient man sich gewöhnlich trigonometrischer Formeln und der Logarithmentafeln. S. Anhang Taf. $I V$. Da aber nicht Jedermann mit deren Gebrauch vertraut ist, wollen wir hier ein weit einfacheres und doch hinlänglich genaues Verfahren angeben. Es besteht in Folgendem:

Auf ein Blatt Papier zeichnet man die gemessene Basis $A C$ in verkleinertem Massstabe, wozu man sich eines eingetheilten Lineals oder doppelten Dezimeters (Fig. ‥f) bedient,

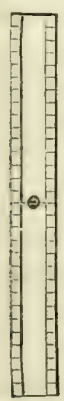
wobei ein Millimeter z. B. eine wirkliche Länge von $1 \mathrm{~m}$ darstellt, so dass die gemessene Basis auf dem Papier $90 \mathrm{~mm}$ lang wird, wenn sie in Wirklichkeit $90 \mathrm{~m}$ hat. An den Endpunkten $a$ und $c$ dieser Linie, welche uns die Basis in verjüngtem Massstabe gibt (Fig. 25), tragen wir die Winkel $a^{-c}$ ab. $\mathrm{Zu}$ diesem Zwecke bringt man das Centrum des Transporteurs (Fig. 26) zuerst auf den Punkt $a$ und zugleich die Linie $00^{\circ}\left(180-180^{\circ}\right)$ des InstruFig. 2\%. mentes genau auf die Linie $a c$. Dann

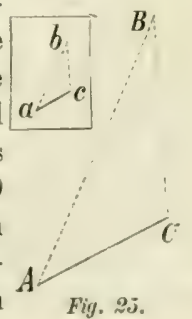

Fig. 25. 
bezeichnet man auf dem Papier am Bogenrande des Instrumentes, den Punkt der Kreistheilung, welcher der auf dem Felde gemessenen Winkelgrösse entspricht. Nachdem man in Bezug auf den Punkt $C$ dasselbe Verfahren angewendet, zieht man die Linien $a b$ und $a c$, welche sich in einem

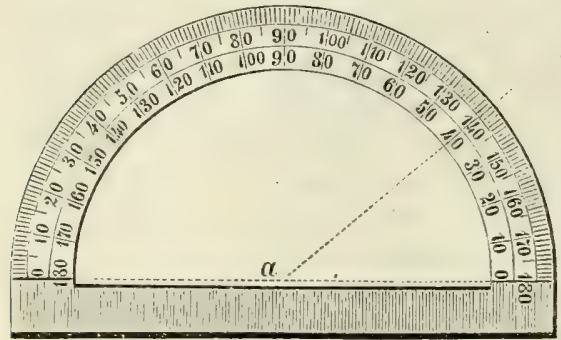

Fig. 26. Punkte $b$ schneiden. b Um nun die Distanz $A B$ in ihrer wirklichen Grösse kennen zu lernen, hat man nur deren Abbild a b mit dem Doppeldezimeter (verjüngten Massstab) zu messen und die abgelesene Grösse mit der Zahl zи multipliziren, welche die bei der Zeichnung angewendete Reduktion angibt. Haben wir also auf dem Papier $1 \mathrm{~mm}$ angewendet statt eines Meters auf dem Felde und hat die Linie $a b 145 \mathrm{~mm}$, so ist die gesuchte Strecke $A B$ im Terrain $145 \mathrm{~m}$ lang.

Bei Anwendung dieses Verfahrens ist die Basis auf dem Felde so zu wählen, dass die Visirstrahlen von deren Enden A und $C$ nach dem. Punkte B nicht einen allzuspitzen Winkel bilden; denn sonst würde der Schnitt der Linien (1) und $b c$ auf dem Papier und damit das Endresultat ungenau.

B. Um einen solchen Fehler zu vermeiden, setzt man die Basis $A C$ in solcher Weise fest, dass der Winkel bei $C$ nur selten grösser ist als ein rechter und verlängert sie so weit, dass der Winkel bei $A$ nicht mehr als $60^{\circ}$ hat; ja man soll so viel als möglich darnach trachten, dass jeder der beiden Winkel $A$ und $C$ unA gefähr $60^{\circ}$ habe; es ist dies das beste Ver$A^{\prime}$ hältniss zu einer genauen Dreiecksmessung. Fig. 27.

Nicht immer ist es möglich, das Instrument im Punkte $A$ aufzustellen und noch weniger, von diesem Punkte $A$ aus passendes Terrain für eine Basis zu finden. In diesem Fall verfährt man folgendermassen.

Es sei $A B$ (Fig. 2\%) die zu bestimmende Distanz. Man stellt einen Stab auf in einem Punkte $A^{\prime}$ ihrer Fortsetzung 
und steckt nun eine Linie $A^{\prime} C$ annähernd senkrecht zu $A B$ ab. Nit dieser Geraden $A^{\prime} C$ als Basis bestimmen wir das Ireieck $B A^{\prime} C^{\prime}$ in der vorhin beschriebenen Weise, d. h. durch Messung von $A^{\prime} C^{+}$und der beiden Winkel in $A^{\prime}$ und $C^{\prime}$. Von der Zahl, die man so für $A^{\prime} B$ erhält, zieht man nun die direkt gemessene Strecke $A^{\prime} A$ ab und erhält so die gesuchte Distanz $A B$. Ein zweites Beispiel: Gesucht sei die Distanz E $F$ (Fig. 28). Senkrecht zu $E F$ steckt man von $F$ aus eine Gerade $F H$ ab. Mit einem Theil $G H$ derselben als Basis bestimmt man das Dreieck $E G H$,

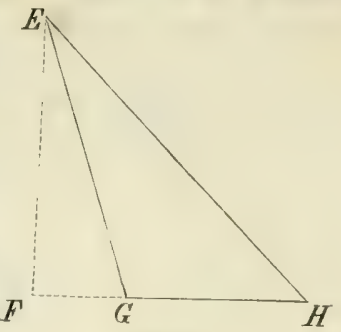

Fig. 28. dessen Höhe die gesuchte Distanz $E F^{\prime}$ ist.

Müsste man für jede Distanz, die man bestimmen will, jeweilen zuerst eine Basis messen, so wäre die trigonometrische Methode kaum zu empfehlen. Glücklicherweise ist das aber nicht nöthig. Die Basis $A C$ (Fig. 29) dient uns zunächst nicht nur zur Bestimmung der Entfernung des Punktes $B$, sondern aller Punkte, die man von $A$ und $C$ aus unter geeigneten Winkehn zu sehen vermag, wie $D, E, F$, $G, H, I$ etc. - Dann können wir, nachdem uns einmal $A D$ bekannt geworden, dasselbe als Basis benutzen, um die Distanz $A K$ zu finden, welche uns von $A C$ aus mit diesem unter einem zu spitzen Winkel erschien. Zu diesem Zwecke brauchen wir uns bloss nach $I$ ) zu begeben (ohne dass wir etwa $A D$ auf dem Felde zu messen haben, indem wir dasselbe durch Rechnung bereits kennen) und den Winkel A D I zu messen, welcher mit dem in $A$ zu messenden Winkel I) $A K$ (oder, wenn man das vorzieht, mit dem Winkel $D K A$, gemessen in $K$ ) die drei stücke liefert, deren wir zur Konstruktion oder Berechnung des neuen Dreiecks bedürfen. Da ferner die gegenseitige Lage der Spitzen aller Dreiecke durch die Zeichnung auf dem Papier bekannt ist, so sind damit auch die Distanzen gegeben zwischen $G_{x}$ und $H, I I$ und $I$ etc. Diese Strecken sind also neue Grundlinien, von wo aus wir die Entfernung oder die gegenseitige Lage wieder andrex P'unkte $L, M, N, O$ u. s. w. bestimmen können, welche man von $A$ und $B$ aus nicht oder aber unter zu spitzen Winkeln sah. 


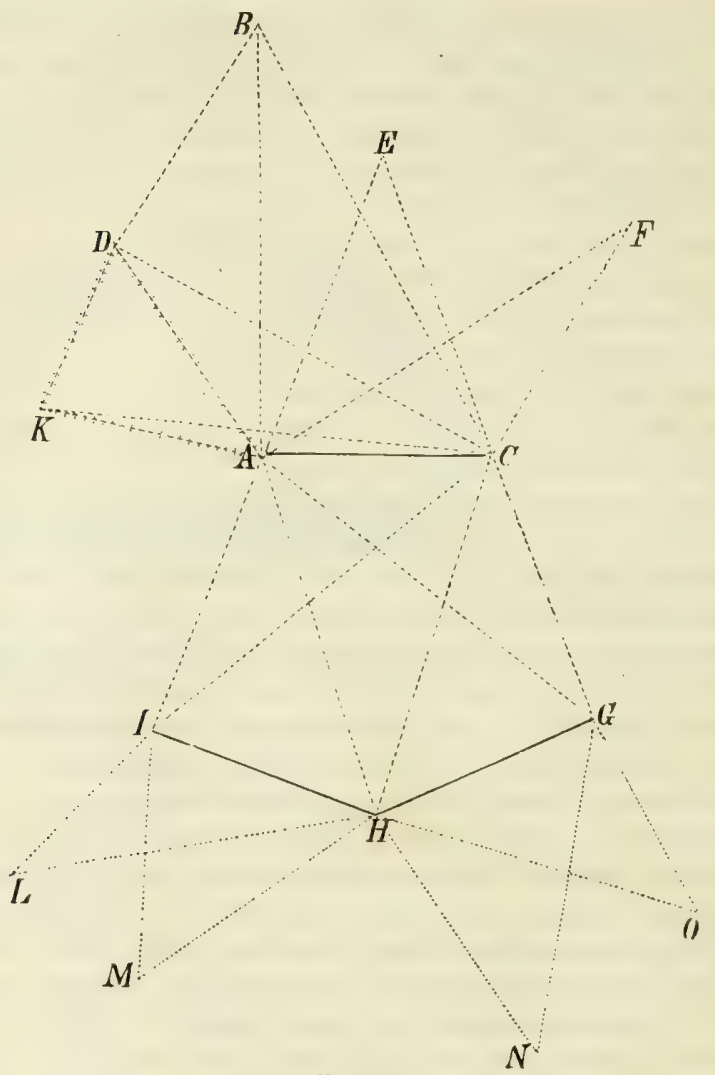

F'ig. 29.

Dieses Verfahren, welches, wie man sieht, darin besteht, die Lage der wesentlichsten Punkte einer Gegend durch ein Netz von Dreiecken zu bestimmen, heisst Triangulation.

Dass man dabei von einer Basis auf eine andere übergehen kann, ist sehr werthvoll aus folgendem Grunde:

Die Nachtheile zu spitzer Winkel würden uns nöthigen, behufs Bestimmung grosser Distanzen eine sehr lange Linie als erste Basis zu wählen und $\mathrm{zu}$ messen. Um so in direkter Weise Distanzen zu erhalten wie $A B$ (Fig. 30), welches vielleicht über $10 \mathrm{Km}$ betragen mag, würde es nicht 


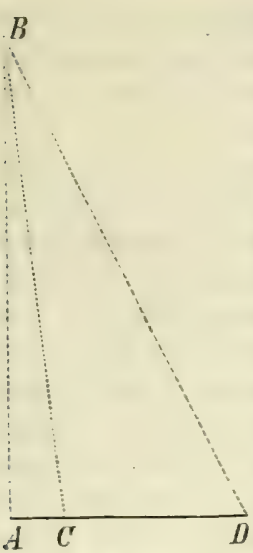

Fig. 30.

genügen, dass wir uns nach $C$ begäben; vielmehr müssten wir wenigstens bis $D$, etwa $5 \mathrm{Km}$ von $A$ weg, gehen. Nun ist es nicht nur sehr schwierig, ein Terrain zu finden, das günstig ist zur Absteckung einer so ausgedehnten Basis, sondern es kommt noch dazu, dass, selbst wenn man dasselbe fände, die genaue Messung solch einer langen Grundlinie viel Zeit in Anspruch nähme. Um also nicht gezwungen zu sein, eine solche Basis zu messen, wird man wenn es sich um trigonometrische Bestimmung grosser Distanzen handelt — darnach trachten. eine ausgedehnte Basis zu erlangen, ohne dass man genöthigt wäre, sie auf dem Felde zu messen.

Zu dem Ende verfährt man folgendermassen :

Auf gleichmässig ebenem Terrain steckt und misst man eine Basis $B b$ (Fiy. 31) von etwa $1 \mathrm{Km}$ ab. Von dieser kurzen Grundlinie geht man mit Hülfe einer Reihe von Dreiecken zu einer 5 bis $10 \mathrm{mal}$ grössern Basis $Q T$ über. Dazu genügt es, zunächst das Dreieck $B b A$ zu konstruiren oder zu berechnen, dann mit $A B$ als Basis das Dreieck $B A C^{\prime}$ n. s. w. Achtet man hiebei darauf, dass man immer die grösste Seite eines bereits bestimmten Dreiecks als kleine Seite des folgenden Dreiecks nimmt, so nehmen die neuen durch Rechnung oder Zeichnung erhaltenen Grundlinien an Länge sehr rasch zu, bis wir endlich solche bekommen,

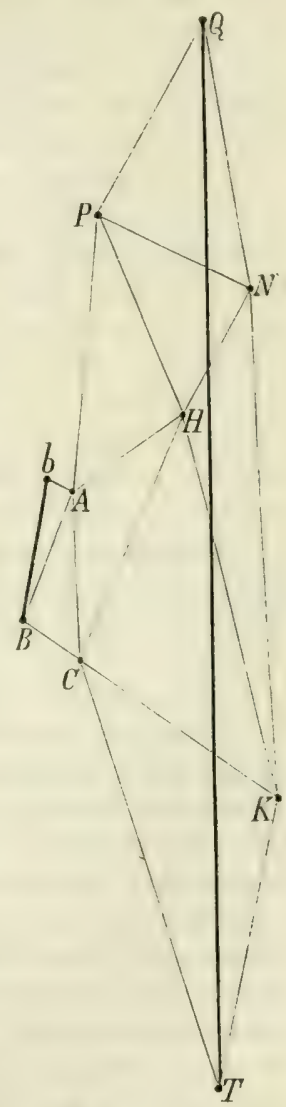

Fig. 31. 
die zur Messung auch der grössten Entfernungen genügen. Das ist was man , ton einer yemessenen Basis zn ciner yrösseren. "ubergehen" heisst. Ein solches System ron Dreiecken wird als Basisnetz bezeichnet.

Lm ganz sicher zu sein, dass man die so erlangte Basis yenau bestimmt habe, geht man durch eine entgegengesetzte Operation (d. h. durch eine Anzahl immer kleinerer Dreiecke) auf eine Basis ron mässiger Länge zurück und misst dieselbe auf dem Felde. Das Ergebniss dieser Messung muss der durch Rechnung oder Konstruktion erhaltenen Länge gleich sein. Andernfalls wären die Operationen mit Fehlern hehaftet und müssten unter Anwendung grösserer Sorgfalt ron Yenem rorgenommen werden. Auf diese Anwendung

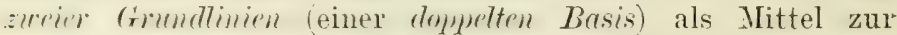
Verifikation sollte man nie rerzichten, trotz der hieraus 'ntspringenden Iehrarbeit: denn ein geringfügiger anfänglicher Fehler kann, indem er sich von Dreieck zu Dreieck fortpflanzt und vergrössert, das schliessliche Resultat ganz intstellen. Mindestens ist man, hei Tnterlassung jener Vorsichtsmassregel, im Zweifel über den Werth der Arbeit, während man andernfalls darïber Gewissheit erhält — und das Bewusstsein, genau gearheitet zu haben, ist für uns eine uPwisse Genugthumg und erfüllt uns mit mehr Sicherheit.

Schätzung und Messung von Höhen. Was die IIöhen anbetrifft, so kann man kaum rom Abschätzen derselben sprechen: dem üher keine Naasse täuscht man sich so leicht wie üher Höhen, wenn man sie nach dem Augenschein beurtheilt, selbst wenn man hierin geübt ist.

Tebrigens handelt es sich hei Reisen und inshesondere hei Berghesteigungen meistens darum, zu wissen, ob irgend ein hestimmter Punkt tiefer oder höher liegt als der, an welchem nir uns befinden. Dazu gibt es, wenn nicht sehr grosse Crenauigkeit gefordert wird, ein ganz einfaches Mittel. Bekamntlich ist die Oberfläche des Wassers in einem Gefässe horizontal. Man füllt daher ein Glas oder eine Flasche mit Wasser, bringt den Wasserspiegel in Augenhöhe und hlickt darüber hin. Jenachdem der Visirstrahl, welcher die Wasseroberfläche streift, unter den beobachteten Punkt oder aber über ihn zu liegen kommt, ist derselbe höher oder niedriger als der, worin wir uns befinden. Nan kann auch 
längs der Randlinie einer Libelle visiren, deren man, ihrer häufigen Anwendung wegen, immer eine bei sich haben sollte. Bei wagrechter Lage des Instrumentes - wobei die Luftblase die Mitte einnehmen muss - wird man, je nach dem Punkt, nach welchem der Visirstrahl ausläuft, unmittelbar beurtheilen kömen, ob man sich höher oder niedriger befindet als der Ort, der in Frage kommt. Man kann auch die Libelle, resp. ihre Achse, nach diesem ()rte richten, wie beim Zielen mit einer Schusswaffe. Bewegt sich dabei die Luftblase, die immer den höchsten Punkt aufsucht, nach dem Beobachter hin, so liegt die anrisirte Stelle tiefer: rntfernt sich die Blase rom Auge des Beobachters, so liegt hingegen der fragliche l'unkt höher als der Ort, an dem man sich befindet und ron wo aus man beobachtet.

Es gribt wenige Methoden, un Hïhen ohue Instromente $z u$ messen. Setzen wir aber den Fall, man habe keine Apparate zur Hand und wolle sich dennoch eine wenigstens annähernd richtige Vorstellung von der Höhe eines Baumes odler Gebäudes verschaffen. Man schätz.t oder misst nun die Entfernung bis zum

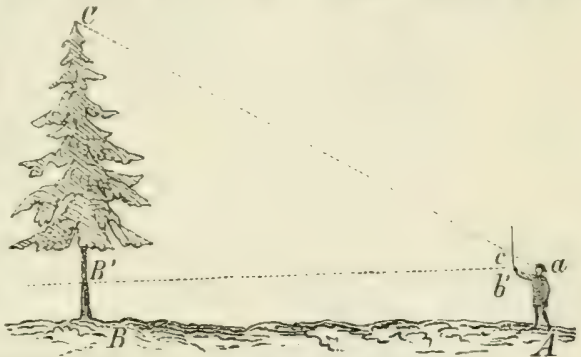

Fig. 3?.

Fusse B (Fiy. 32) des Gegenstandes, dessen Höhe man kennen zu lernen wïnscht. Dann bestimmt man mit ausgestrecktem Arm und mittelst eines Stockes die Punkte $l^{\prime}$ und c, worin die Visirstrahlen rom Augre des Beohachters " nach $B^{\prime}$ und nach der Spitze (' des Gegenstandes den Stab treffen. Die Länge $l '{ }^{\prime}$ ' auf dem Stahe multiplizirt mit der Zahl, welche angiht, wie oft mal länger $A B$ sei als der ausqgestreckte Arm, gibt die IIöhe $I^{\prime}$ ('; zu welcher man noch $B B^{\prime}$ addiren muss, d. h. dip Höhe des Beol-achtungspunktes (Auges) über dem Boden. So erhält man die gesuchte Höhe $B C^{1}$ ).

1) Auf diesem P'rinzip beruhen die Höhenmesser ron Faustmann, Weise u. A., lie so eingerichtet sind, dass man nach Einstellung des Instrumentes die zu messende Höhe am Index ablesen kann. 
Ein andres Verfahren, das aber kaum erheblich genauer ist, beruht darauf, dass man die Höhe aus Schattenlängen ableitet (Fig. 33). Man steckt einen Stab in a auf, misst

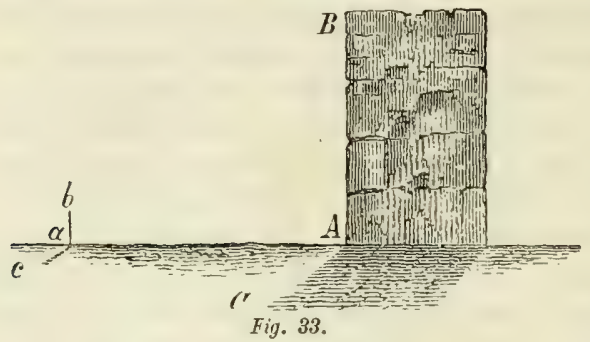
$A C$, $a b$ und $a c$. Die gesuchte Höhe $A B$ ist nun gleich $a b \ngtr \frac{A C}{a c}$, weil die Schatten denHöhen proportional sind $(A B: a b=A C: a c)$. Hiebei muss der Boden, auf welchen die Schatten geworfen werden, vollkommen eben sein.

Nur kurz erwähne ich das Höhenmessen mit Hülfe einer Wasserfläche $B^{\prime}$ (Fig. 3i), worin das zu messende Objekt sein Spiegelbild hat. Nach einem bekannten optischen Gesetze

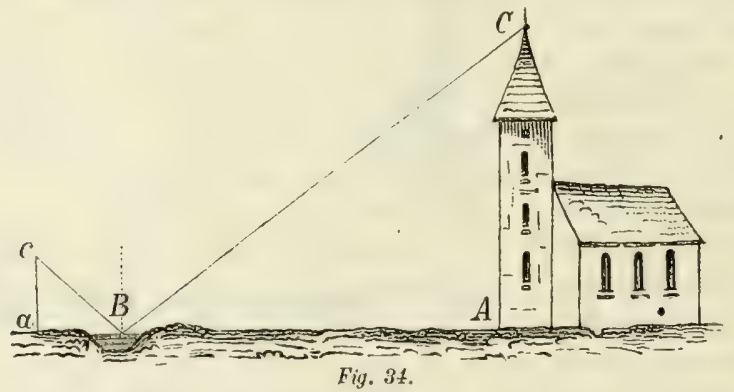

ist der Einfallswinkel eines Lichtstrahls gleich dem Reflexionswinkel, also auch der Winkel $A B C$ gleich dem Winkel " $B c$, so dass die beiden Dreiecke $A B C$ und $a b c$ (da sie rechtwinklig sind, also noch in einem zweiten Winkel übereinstimmen) ähnlich, folglich ihre Seiten proportional sind. Wenn man nun a $B, a r$ und $B A$ misst, so findet man die gesuchte Höhe $A C=a c \times \frac{B A}{a b}$.

Das sind indess, wie leicht ersichtlich, eher Schätzungsals Messungsmethoden. Wollte man sie auf ferne Gegenstände anwenden, so würde man bei dem Missverhältniss, welches dam zwischen den Dreiecksseiten bestünde, gan\% unzuverlässige Resultate erhalten. 
Will man die Höhe entfernter Punkte bestimmen, so muss man sie durchaus mit Instrumenten messen.

Beim Höhenmessen unterscheidet man nun die relutir. Hühe, d. i. die Nicenutiffornz zwischen zwei Punkten, die man aufeinander bezieht: und die absolute Höhe oder ILrew'shioile (altitude), d. h. den senkrechten Ibstand eines Ortes rom Niveau des Meeres, das man sich fortgesetzt denkt bis unter oder über diesen Ort.

Die relative wie die Meereshöhe werden beide rertikal yemessen, in der Richtung des senklothes, wie die Entfernung zweier verschieden hoch gelegener Punkte durch den wagrechten Abstand der Vertikalen dieser Punkte bestimmt wird (Fiy. 35). Dor relatire Höhr (Niveaudifferenz) heisst prsitir

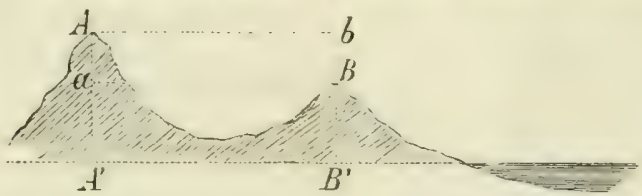

$A b$ Horizontale Entfernung der Punkte $A$ a Höhenunterschied der Punkte

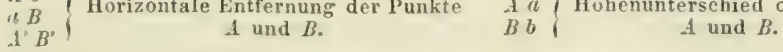

$\left.A^{\prime} \frac{A}{B}\right\}$ Absolute Höhen der Punkte $A$ und $B$.

Fig. 3.5.

1-i. wemn der Punkt, dessen Höhe man sucht, höher liegct als der ron welchem aus man misst: andernfalls heisst sie negatic (-). Die absolute Höhe ist positiv $(+)$ für alle über dem Meeresspiegel gelegenen Orte, neryatic - - aber für diejenigen, die wie z. B. das Jordanthal tiefer liegen als das Nireau des Meeres. Die Höhenzahlen oder Coten auf den Karten geben, wenn nicht ausdrücklich das Gegentheil bemerkt ist, positive, d. h. Höhen über dem Meere an. Zur Messung der Niveaudifferenzen bedient man sich grewöhnlich der Wasser- orler Kanalwaage ${ }^{1}$ ), welche aus einer an beiden Enden umgebogenen Glasröhre besteht. Der Wasserspiegel in den beiden Röhrenenden bestimmt eine durchaus horizontale Visirlinie. Eingetheilte Nivellir-

1) Es gibt eine Wassercaage mit Mainometer, erfunden von Ingenieur Gallaud, französischem Strassen- und Brïckeninspektor in türkischen Diensten, beschrieben in den ,Annales des Ponts et Chaussées, Paris Sept. 1876, pag. 312-314, welches Instrument sebrzweckmässig scheint für kleinere Nirellements; aber man braucht hiefür einen Gehülfen und es ist auch eher greeignet für die Detailoperationen beim Traciren von Fisenbahnen als für Aufnahme ron Nivellements einer grössern Landschaft. 
latten, die man an den heiden Punkten aufstellt, deren Höhendifferenz man ermitteln will, machen es möglich, leicht zu berechnen, um wie viel der eine dieser Punkte höher oder tiefer liegt als der andere. Aber abgesehen daron, dass man diess Verfahren nur auf kleine Distanzen anwenden kann, ist die Kanalwaage ein so wenig zum Transport geeignetes und so zerbrechliches Instrument, dass man es Reisenden nicht empfehlen kann. Auch kam es andere Instrumente, wie Theodolit und Boussole mit Klinometer nicht ersetzen, wird dagegen durch dieselben entbehrlich gemacht, wesshalb wir nur zeigen wollen, wie man sich jener beiden Instrumente bedient. Es sei A (Fiy. Bi

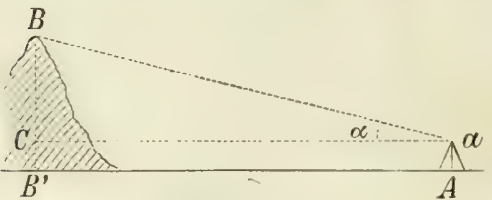

Fig. 36 . des Beobachter's, $B$ derjenige, dessen relative Höhe man bestimmen will. Man stellt in $A$ das Instrument so auf, dass der Nullpunkt des graduirten Vertikalkreises in die mittelst der Libelle bestimmte horizontale Gerade a $C^{\prime} z u$ liegen kommt. J)ann visirt man nach $B$ und liest den durch die beiden Visirstrahlen gebildeten Winkel $c$ ah. Die Linie $A B^{\prime}$ hestimmt man auf die rorhin (Abschnitt „Distanzemmessung") angegebene Weise. So haben wir nun ein rechtwinkliges Ireieck " $C B$, worin wir eine Seite $a=A B^{\prime}$ und den Winkel a kennen. Da (" ein rechter Winkel ist $\left(90^{\circ}\right)$, so kennen wir im Dreieck " $($ $B$ drei Stücke, worunter eine Seite " C', können also das Dreieck auf dem Papier konstruiren und $B$ C' messen oder berechmen; noch einfacher ist es, hielsei Tafeln anzuwenden, die speziell diesem Zwecke dienen ${ }^{1}$ ). Zu berücksichtigen ist dabei noch, dass die Niveaudifferenz zwischen $A$ und $B$ nicht $B C^{\prime}$, sondern $B B^{\prime}$ ist, d. h. $B C+C B^{\prime}$; man muss also zu $B C$ noch $B^{\prime} C$ addiren, welches gleich ist a $A$ oder der Höhe des Instru-

1) $\mathrm{Zu}$ empfehlen sind namentlich die hypsometrischen Tubellen von Kaupert, Vermessungsinspektor im Grossen Generalstabe, Berlin 1872. Dieselben geben einleitend eine Gebrauchsanweisung, sodann Cotentafeln zur Ermittlung des nscheinbaren Höhenunterschieds" zweier Objckte (Tab. I), die wegen Erdkrümmung und Strablenbrechung anzubringenden Korrektionen (Tab. II), endlich die Werthe (auf 4 Dezimalen) der Sinus, Cosinus und Tangenten für die Winkel von 0 bis $45^{\circ}$ (Tab. III) und sind ron bequemem Taschenformat. - Zur Verwendung bei der logarithmischen Berechnung eignet sich für unsern Zweck die vievstellige logurithmischtrigonometrische Handtafel von F. G. Gauss (Berlin). 
mentes (genatuer: des Mittelpunkts seines Vertikalkreises) über dem Boden. Lïge Punkt $B$ tiefer als $A$ (Fin. ži), so wäre das Verfahren dasselbe, mit dem einzigen Interschied, dass man die Instrumentenhöhe (Bodenabstand des Höhenkreismittelpunktes) zu subtrahiren hätte. Diese Korrekturen (Addition und Subtraktion) vermeidet man, indem man ron $a$

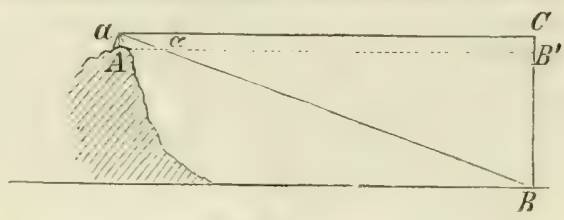

Fig. 37.

aus in Augen- oder Instrumentenhöhe eines in $B$ angenommenen Beobachters visirt. Bei Berechnung des Höhenunterschieds weit entfernter Objekte hat man zwei kleinr liorrektionen anzubringen: eine wegen der Differmz zwischeru

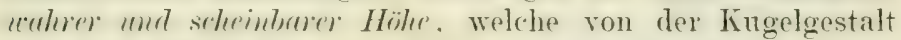
der Erde herrührt, - und eine zweite zur Ausgleichumg des Refirationsfohle's, welcher verursacht wird durch die Brechung der Lichtstrahlen bei ihrem Durchgang durch Iuftschichten von ungleicher Dichtigkeit. Diese Kon'rektionen fallen ansser Betracht für Distanzen bis zu 250 Meter unr sind auch für etwas grössere Strecken (bis zu $1500 \mathrm{~m}$ ) so unbedeutend, dass sie vernachlissigt werden können: für Distanzen ron 1500 Neter an hat man sie aher zu berüchsichtigen, indem sie ron da an $1 / 10000$ des Betrages. und mehr ausmachen.

Handelt es sich weder um grosse Distanzen, noch um grosse Genauigkeit und kemnt man wenigstens annähernd den horizontalen Abstand zwischen dem Standort und dem Fusse der durch den anvisirten Punkt gehenden Vertikalen, so kam man zur Berechumg der Höhenunterschiede dir mustehende Tabelle benutzen. in Bezng auf deren Vèrwendung wir Folgendes hemerken. Zieht man zwischen den Schenkehn a $B$ und $a C$ eines Winkels $B$ a $C$ eine gerade Linie $B C$ senkrecht zu einem Schenkel a (', so ist der Quotient (Bruch) aus jener Senkrechten und diesen (nummehr begrenzten) Sichenkel die trigmometrische Tandente des Winkels. In dem Dreieck a $B C$ (Fi\%. 36 und 3i) ist also die Grösse $\frac{B C}{B C}$ dir Tangente des Winkels a (tany.c. tgcs). Die Ausdrïcke $\frac{b C}{a c}$ 
und tyce sind demmach gleichbedeutend. Der erstere (gohrochene) Ausdruck aber $\left(\frac{B C}{a C^{\prime}}\right)$ gibt, mit a $C$ (seinem Nemer) multiplizirt, $B$ (' (seinen Zähler); folglich muss auch der zmeite jenel gleichwerthigen Ausdrücke (tgcs) durch Nultiplikation mit $a C$ die Grösse $B C$ ergeben, d. h. es ist $B C^{\prime}=a C^{\prime}$. trics. Die Tafel gibt nun diese Tangenten für Winkel bis zu $45^{\circ}$ (ganze und halbe Grade). Es sind diese Zahlen, wie man sieht, einfach als Falitwen mit den jeweiligen Horizontaldistanzen zu multipliziren. Haben \%. B. zwei l'unkte 1 (Standort) und $B$ einen Horizontalabstand von $100 \mathrm{~m}$ bei einem Höhenwinkel ron $+10^{\circ}$, so ist ihr Höhenunterschied $=0,1 \overline{7} 63 \times 100=1 \overline{7}, 63 \mathrm{~m}$. Hahen sie $500 \mathrm{~m}$ Distanz bei dem Winkel $-1^{0}$, so ist ihr Höhenunterschied $=-0,0174 \times 500=-8,7 \mathrm{~m}$. Im ersteren Falle liegt alson $l$ ' um $17.63 \mathrm{~m}$ höher, im letztern $11 \mathrm{~m} 8.7 \mathrm{~m}$ tiefer als A. - Für den Winkel $45^{\circ}$ ist der Höhenunterschied gleich der Horizontaldistan\%.

\begin{tabular}{|c|c|c|c|c|c|c|c|}
\hline inkel & $\begin{array}{c}\text { Fahitor } \\
\text { ty }\end{array}$ & $"$ & $\begin{array}{c}\text { Fakitor } \\
\text { lyul }\end{array}$ & ${ }_{t}$ & $\begin{array}{c}\text { Fakitor } \\
t_{y, t}\end{array}$ & in & $\begin{array}{l}\text { anto } \\
\text { ty } u\end{array}$ \\
\hline $30^{\circ}$ & & & & $5^{\prime \prime} 30^{\prime}$ & & "i & \\
\hline 1 - & & $30^{\prime}$ & & & & $30^{\prime}$ & \\
\hline $30^{\prime}$ & & ${ }^{0}-$ & 3 & $30^{\circ}$ & & 10 & \\
\hline & & $30^{\prime}$ & & $27^{0}-$ & & $30^{\prime}$ & \\
\hline 30 & & $0-$ & 9 & $30^{\circ}$ & & $40^{\circ}-$ & 391 \\
\hline - & & $30^{\circ}$ & 3 & $28^{\circ}-$ & & $30^{\prime}$ & \\
\hline $30^{\prime}$ & & $16^{\circ}$ & & $30^{\circ}$ & & $41^{0}$ & \\
\hline & & $30^{\prime}$ & & - & & $30^{\prime}$ & \\
\hline $30^{\prime}$ & & - & & $30^{\circ}$ & & $42^{\circ}-$ & \\
\hline - & & $30^{\prime}$ & & $30^{\prime \prime}-$ & & $30^{\circ}$ & \\
\hline $30^{\circ}$ & & - & & $30^{\circ}$ & & - & \\
\hline & & $30^{\prime}$ & & $31^{0}-$ & & $30^{\circ}$ & \\
\hline $30^{\prime}$ & & $0-$ & & $30^{\prime}$ & & - & \\
\hline & & $30^{\prime}$ & & $32^{\circ}-$ & & $30^{\circ}$ & \\
\hline $30^{\circ}$ & & 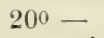 & & $30^{\circ}$ & & 0 - & \\
\hline & & $30^{\prime}$ & & - & & $30^{\prime}$ & \\
\hline $30^{\prime}$ & & - & & $30^{\prime}$ & & te & \\
\hline - & & $30^{\prime}$ & & - & & $30^{\prime}$ & \\
\hline $30^{\prime}$ & & $22^{0}-$ & & $30^{\prime}$ & & $47^{0}-$ & \\
\hline & & $30^{\prime}$ & & $5^{n}-$ & & $30^{\prime}$ & \\
\hline $30^{\prime}$ & & $23^{0}-$ & & $30^{\circ}$ & & $48^{\circ}-$ & \\
\hline & & & & 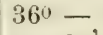 & & $20^{\prime}$ & \\
\hline $30^{\circ}$ & & 2 & & $30^{\circ}$ & & $49^{\circ}$ & 04 \\
\hline - & & $30^{\prime}$ & & $37^{\circ}-$ & & & \\
\hline & & & & & & & 1,191 \\
\hline
\end{tabular}


Zur Frlangung genauerer Resultate sind Formelı zu benutzen, die wir nebst Rechnumgsbeispielen im Anhange ('Taf. IV D und E) geben ${ }^{1}$ ).

Kennt der Beobachter die wagrechte Entfernung seines Standpunktes von dem anvisirten Punkte nicht, so ist folgendermassen $z u$ verfahren: In 1 (Fin. 3is) aufgestellt, misst man den Winkel $\alpha$; dann begibt man sich nach $B$ mol misst den Winkel $\beta$; endlich bestimnt man die Jänge A B. Nun ist der Winkel $\gamma=180-\beta$, und man kennt also in demDreieck $A B D$ wieder drei Stiicke: eine Seite $A$ sowie die zwei anliegenden Winkel a und $\gamma$, was genügt, um das Dreieck aufs Papier zeichnen \%1 kömmen. Ver-

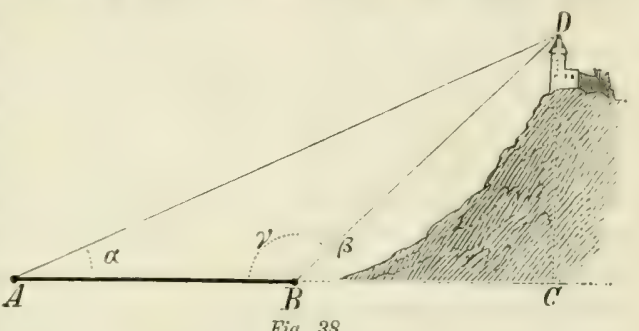
Fig. 38 .

längert man $A B$ und fällt man von $D$ aus einen Perpendikel $I C$, so ist dieses letztere die gesuchte $H_{0 ̈ h}^{2}$ ).

Die absolute Höhe oder Meereshöhe findet man

$1^{\circ}$ Durch eine Reihe von Nivellements, die rom Meeresufer ansgehen, wobei man das mittlere Meeresniveau, d. h. den Vittelwasserstand zwischen Fluth und Ebhe, zur Grundlage wählen muss.

Die relativen und absoluten Höhen können auch durch das Barometer und das Ifypsothermometer hestimmt werden.

Die barometrische Hölen-MEssum! beruht darauf, dass der Luftdruck nach oben abnimmt. Wir werden hierauf später, bei Behandlung des Luftdruckes noch zu sprechen kommen und beschünken uns hier darauf, eine für Reisende hequeme Formel zur barometrischen Höhenbestimmung mitzutheilen. Von zwei Stationen habe die untere den Barometerstand $I S$ u. die Temperatur (C'entigr.) $T$, die obere den

1) Im Weiteren kann auf die Abschnitte über trigonometrische Hōhenmessung n den S. 14 zitirten geodätischen Werken verwiesen werden.

2) Hinsichtlich der Berechung vgl. Anhang, Taf. $I V$, sowie Lübsen, Lehrbuch der cbenen und sphürischen Trigonometrie zum Selbstunterricht mit Rücksicht auf die Zwecke des praktischen Lebens (Leipzig). 
so ist nach der Fischer'schen (oft nach Babinet benamnten') Formel ihr vertikaler Abstand in Meter

$$
h=15976 \cdot \frac{B-b}{B+b}\left(1+\frac{T+t}{500}\right) .
$$

Es seien z. B. für zwei Stationen durch gleichzeitige Beobachtungen folgende Werthe erhalten worden:

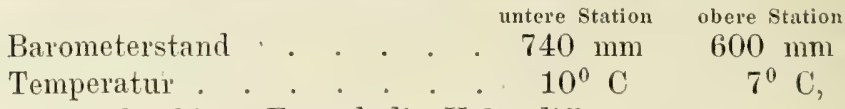

so ist nach obiger Formel die Höhendifferenz

$$
\begin{aligned}
h & =15976 \cdot \frac{740-600}{740+600}\left(1+\frac{17}{500}\right) \\
& =15976 \cdot \frac{140}{1340}(1+17 \cdot 0,02) \\
& \left.=15976 \cdot \frac{140}{1340} \cdot 1,034=1725 \text { Meter }^{2}\right) .
\end{aligned}
$$

Wie schon früher bemerkt, ist dem Quecksilberbarometer wegen der I'nbequemlichkeit, welche der Transport desselben verursacht, das Aneroid (Barometer ohne Flüssigkeit") vorzuriehen, und wir bedienen uns seiner wie zu meteorologischen Beobachtungen, so auch zu harometrischen Höhenbestimmungen.

Zur Termeidung konplizirter Rechnungen geben wir im Anhang eine graphische Tabelle mit Gebrauchsanleitung.

Ein gutes Aneroid gibt sehr genaue Resultate. Man kann sich aber nicht schlechterdings auf die Konstanz eines einzelnen Instrumentes verlassen; bei längeren Reisen genügt es auch nicht, dasselbe zu Anfang und Ende mit einem Quecksilberbarometer zu vergleichen, sondern man muss unbedingt Hülfsmittel für die Kontrole während der Reise selbst zur Hand haben. Hiezu eignet sich das Siede- oder Lorhjumlit-Thermometer, Hypsometer (Hypsothermometer ${ }^{3}$ ), welches darauf hasirt, dass in grösserer Höhe wegen des verminderten

1) Vgl. Dr. R. Wolf, IIandbuch der Mathematik, I. Id., Zürich 1870, S. 373.

2) Beispiel aus Bernoulli's Vademecum des Mechanikers, bearbeitet von Fr. Autenheimer. XIV. Aufl., Stuttgart 1872. Man wird gut thun, die Anwendung der Formel auf kleinere Vertikalabstände (bis ea. $1000 \mathrm{~m}$ ) zu beschränken; dann aber mag der Koeffizient 15976 durch die runde Zahl 16000 ersetzt werden, wodureh der Ausdruck die für eine rasche approximative Berechnung möglichst bequeme Form annimmt. Beispie]:

$$
B=730, b=635 \mathrm{~mm} ; T=20, t=150 \mathrm{C} . ; k=1191,5 \mathrm{~m} \text {. }
$$

A. Guyot, Meteorological and physical tables, 3. ed., Washington 1859, D. VI. Dr. Bohn, Ergebnisse physikalischer Forsehung, Leipzig 1878, S. 139.

3) Dr. A. Mousson, Physik auf Grundlage der Erfahrung II. Band, 3. Auf., Zürich 1880, S. 169. A. d'Abbadie, Instructions pour les Voyages d'explorations; Bulletin de la Société de Géographie de Paris, mars 1867, p. 268. 
Luftdruckes das Wasser hei niedrigerer Temperatur zum Sieden kommt. Durch direkte Beobachtung ergaben sich z. B. folgende Zahlen :

\begin{tabular}{|c|c|c|}
\hline \multirow[b]{2}{*}{ Montblanc } & \multicolumn{2}{|c|}{ Höhe_(m) Siedepunkt (C) } \\
\hline & 4775 & \\
\hline Pic von Teneriffa & 3710 & $88^{\circ}$ \\
\hline St. Bernhard . & 2491 & $92^{0}$ \\
\hline St. Gotthard & 2075 & 92,9 \\
\hline Paris (Observatorium) & 65 & 99,7 \\
\hline Berlin . . . . & 40 & 99,8 \\
\hline
\end{tabular}

Auf Grund zahlreicher Beobachtungen sind von Regnault. Moritz und (iuyot Tafeln erstellt ${ }^{1}$ ) worden, welche die Barometerstände angehen, die verschiedenen Temperaturen des siedenden Wassers (in ganzen und Zelntelsgraden ausgedrückt) entsprechen. Eine solche Tabelle lassen wir unstehend folgen. Thr Gehrauch ergibt sich leicht; hat man z. B. aus einer Reilhe von Versuchen für den Siedepunkt den Werth $88^{\circ}$ C $^{\prime}$ gefunden, so entspricht diesem ein Barometerstand (Luftdruck) ron $486,64 \mathrm{~mm}$. Finer Siedetemperatur ron $92,9^{1)}$ entspricht ein Barometerstand ron $586,14 \mathrm{~mm}$; für den Siedepmnkt 98,50 gibt die Tabelle $720,08 \mathrm{~mm}$ Luftriruck ete. Hiemit rergleicht man den aus gleichzeitigen mehrfachen $\mathrm{Ab}$ lesungen des Aneroids gefundenen Mittelwerth und ersieht so, ob dieses den Luftdruck in anderer Weise messende Instrument erhebliche Veründerungen erlitten halee. Man kann leicht zwei oder drei Hywsothermometer mitführen, daher stets den Siedepunkt des reinen Wassers bestimmen, daraus und mit Hülfe der Tabelle den Luftrinck ableiten und durch Vergleichung desselben mit den Angaben des Aneroids sich vor gröberent Irrthümern beim Gehrauche dieses Instruments schützen ${ }^{2}$.

Die mittelst des Aneroidharometers direkt bestimmte Höhendifferenz zweier Punkte kamı zur Verifikation ihres Horizontalabstandes benutzt werden. Kennt man nämlich den Höhenunterschied $B B^{\prime}$ (Fï. 39) zwischen $A$ und $B$, so braucht man nur noch den Winkel a zu messen. Der

1) Annales de chimie et de physique, t. XIV, p. 206; t. XXVIII, p. 123 (Regnault); Journal de l'Institut, Paris, Oct. 1956 (Moritz); Meteorological and physical tables, 8. D XXIY - XXVI (Guyot).

2) Neumayer. Anleitung pag. 678. - F von Richthofen empfiehlt (ebendas. S. 237) statt dessen die Verwendung dreier Aneroide, woron zwei zur Kontrole. 13ei Beobachtungen in dem heissfeuclsten Kima der Landenge von Panama fand Bourdiol die Ablesungen zweier Quecksilberbarometer ron Gay-Iussac unter sich stärker differirend als mit denen eines Aneroids. D'Abbadie, Instructions, P. 268. 
Siedetemperaturen und Barometerstände.

\begin{tabular}{|c|c|c|c|c|c|c|c|}
\hline \multirow{3}{*}{ 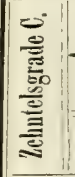 } & \multicolumn{7}{|c|}{ Celsius-Grade } \\
\hline & 87 & 88 & 89 & 90 & 91 & 92 & 93 \\
\hline & \multicolumn{7}{|c|}{ Millimeter } \\
\hline 0,0 & 468,17 & 486,64 & 505,70 & 525,39 & 545,71 & $|566,69|$ & 588,33 \\
\hline 0,1 & 469,99 & 488,52 & 507,65 & 527,40 & $5+7,78$ & 568,82 & 590,53 \\
\hline 0,2 & 471,82 & 490,40 & 509,59 & 529,41 & 549,86 & 570,96 & 592,74 \\
\hline 0,3 & 473,65 & 492,29 & $511,5+$ & 531,42 & 551,94 & 573,11 & 594,96 \\
\hline 0,4 & 475,49 & 494,19 & $513, \tilde{50}$ & 533,44 & 554,03 & 575,27 & 597,18 \\
\hline 0,5 & 477,33 & 496,09 & 515,47 & 535,47 & 556,12 & 577,43 & 599,41 \\
\hline 0,6 & 479,18 & 498,00 & 517,44 & 537,51 & 558,22 & 579,59 & 601,65 \\
\hline 0,7 & 481,04 & 499,92 & 519,42 & 539,55 & 560,33 & 581,77 & 603,89 \\
\hline 0,8 & 482,90 & 501,84 & 521,40 & 541,60 & 562,44 & 583,95 & 606,14 \\
\hline 0,9 & 484,76 & 503,77 & 523,39 & 543,65 & 564,56 & 586,14 & 608,40 \\
\hline \multirow{3}{*}{ 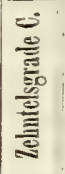 } & \multicolumn{7}{|c|}{ Celsius-Grade } \\
\hline & 94 & 95 & 96 & 97 & 98 & 99 & 100 \\
\hline & \multicolumn{7}{|c|}{ Nillimeter } \\
\hline 0,0 & 610,66 & 633,69 & 657,44 & 681,93 & 707,17 & $|733,19|$ & 760,00 \\
\hline 0,1 . & 612,93 & 636,03 & 659,86 & 684,42 & 709,74 & 735,84 & 762,73 \\
\hline 0,2 , & 615,21 & 638,38 & 662,28 & 686,92 & 712,31 & 738,49 & 765,46 \\
\hline 0,3 & 617,50 & 640,74 & 664,71 & 689,42 & 714,90 & 741,15 & 768,20 \\
\hline 0,4 & 619,79 & 643,10 & 667,15 & 691,94 & 717,49 & 743,82 & 770,95 \\
\hline 0,5 & 622,09 & 645,48 & 669,59 & 694,46 & 720,08 & 746,50 & 773,71 \\
\hline 0,6 & 624,39 & 647,86 & 672,05 & 696,98 & 722,69 & 749,18 & 776,47 \\
\hline $0,7$. & 626,71 & 650,24 & 674,51 & 699,52 & 725,30 & 751,87 & 779,25 \\
\hline $0,8^{\|}$ & 629,03 & 652,63 & 676,97 & 702,06 & 727,93 & 754,57 & 782,03 \\
\hline 0,9 & 631,36 & 6555,04 & 679,45 & 704,62 & 730,55 & 757,28 & 784,82 \\
\hline
\end{tabular}


Winkel $\beta$ ist dann, weil es sich um ein rechtwinkliges J) reieck handelt, gleich $90^{\circ}-$ u. Man kennt also in dem Dreieck num eine Seite $B B^{\prime}$ und die zwei anliegenden

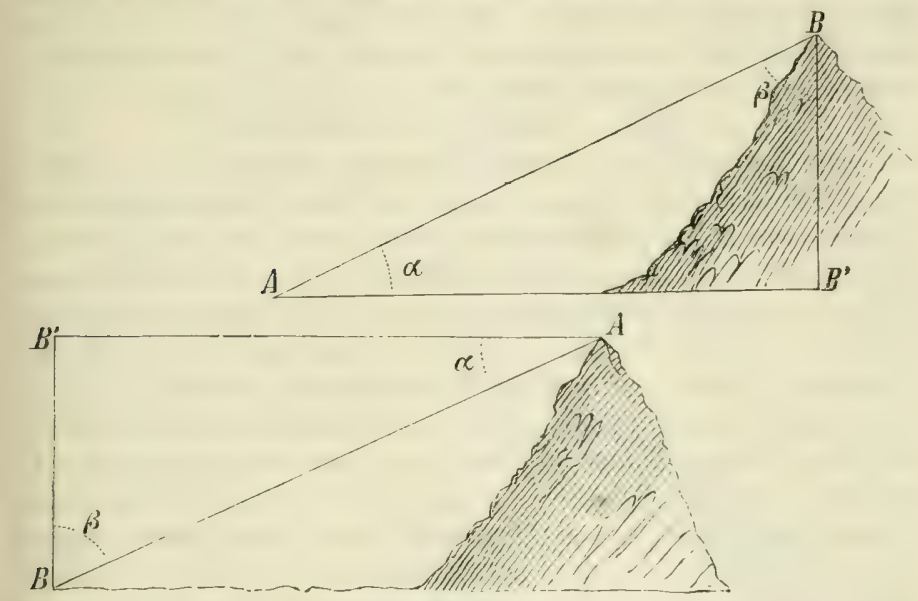

Fig. 39.

Winkel ( $\beta$ und den rechten Winkel $B^{\prime}$ ), wonach man leicht die Länge $A B^{\prime}$ hestimmen kann, d. h. die Entfernung des Punktes $A$ von der Horizontalprojektion $B^{\prime}$ des Punktes $B$.

Zur Berechnung derselben kann man sich einer Tangententafel (S. 48) bedienen. Es ist nämlich $\frac{A B^{\prime}}{B B^{\prime}}=\operatorname{tg} \beta$, folgclich $A L^{\prime}$ $=B B^{\prime} \cdot \operatorname{tg} \beta$.

Schätzung und Messung von Tiefen. Lm die Tiefe einer Schlucht, eines Abgrundes zu messen, lässt man eineu Stein hinunterfallen, indem man ihn aber wirklich einfach aus der sich öfnenden Hand frei fallen lässt, ohne ihn zu werfen. Die Dauer des Fallens gibt annähernd die-gesuchte Tiefe, ๙. h. den Höhenunterschied zwischen dem Punkte, ron welchem aus der schwere Körper fiel, und der Stelle, wo er auffiel, nach folgender kleinen Tabelle:

Zeitdauer des Fallens

1 Sekunde

2 Sekunden

3

4
Tiefe in runder Zahl

5 Meter

20 .

45

.80

125 Meter u. s. f. 
Zur Berechnung der Tiefe hat man nur die Dauer des Fallens in Sekunden mit sich selbst zu vervielfachen (zu (quadriren) und dieses Produkt (Quadrat) noch mit $5 \mathrm{zu}$ inultipliziren. Braucht z. B. der Stein 10 Sekunden, um den Boden zu erreichen, so beträgt die Tiefe (Fallhöhe) annähernd unter allen Breitegraden

$$
10 \times 10 \times 5=500 \mathrm{~m} \text {. }
$$

Zur Messung der Tiefe von Bächen, Flüssen und seichten Seen bedient man sich mehrerer mit den Enden aneinandergrefügter und zum voraus gemessener Stangen oder Latten. Den Nullpunkt bringt man unten an, damit der Punkt an der Wasseroherfläche ummittelbar die gesuchte Masszahl angebe. Ist aber die Tiefe zu gross, als dass man dieses Mittel anwenden kömnte, so bedient man sich eines Senkbleis, d. h. riner durch Knoten in je $10 \mathrm{~m}$ Distanz eingetheilten Schnur, an deren Ende ein stück Blei oder ein Steín befestigt ist, womit man die Schanur bis auf den Grund des Wassers hinahriehen lässt. Der Nullpunkt der Schnur ist wieder an untern Ende, wo das Gewicht angebracht ist; die Anzahl der untergetauchten Knoten gibt ebensoviel mal $10 \mathrm{~m}$ an; der Ueberschuss (zwischen zwei Knoten) wird mit einem gewöhnlichen Taschenmassstab ausgemessen. Bei fliessendem Wasser wird das Senkblei mitgerissen, aus der vertikalen lage abgelenkt (Fiy. (4)), und man muss dann das abge-

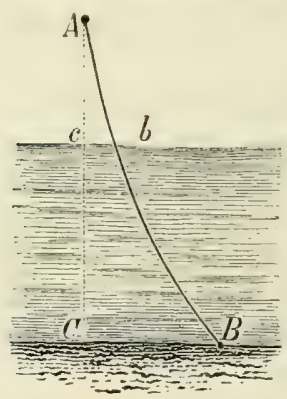

Fig. 40. lesene Resultat korrigiren. Um nun die durch Ablesen gefundene Länge $A B$ auf den wahren Werth oder den direkten Abstand $A C$ zu reduziren, misst man mittelst eines Stockes oder Taschenmassstabes die Linie $A c$ und bildet die Proportion

$$
A B: A C=A b: A c
$$

woraus folgt $A C=\frac{A B \cdot A c}{A C}$, welcher Ausdruck, um $A$ i verkleinert, die gesuchte Tiefe gibt.

Schätzung und Messung des Gefälles. Ueber das Gefälle oder den Neigungswinkel des Terrains täuscht man sich oft in fast unglaublicher Weise, wenn man darüber nur nach dem Eindruck des Gesichtssinnes urtheilt, ohne dass man Ver- 
gleichsobjekte benutzen kann; die Neigung erscheint uns immer viel grösser als sie in Wirklichkeit ist. L'm wenigstens gan\% grobe Schätzungsfehler zu vermeiden, muss man das Profil der Abdachung oder des Abhangs, wofür man die Neigung schätzen will, mit benachharten loth- oder wagpechten Linien vergleichen, es also z. B. heziehen auf Bäume, Manern, Thürme oder auf Spiegel ron Teichen, Seen etc. Auch kann man zu diesem Zweck ein Senkloth (einen Faden mit einem Stein) anwenden, das man von der Höhe der stirn bis gegen den Boden heruntergehen lässt, und zugleich rine libelle, wo dam die beiden Richtungslinien einen rechten Winkel bilden (i'i\%. 41) mit dessen Hülfe man das Gefälle des Bodens oder den Neigungswinkel (Böschungswinkel) c ziemlich genau abschätzen kann. Hat man eine mit Klinometer versehene Boussole zur Hand, so legt man einen Stab (eine Latte) auf den Boden, in der Richtung seiner Abdachung, und stellt die Boussole aufrecht darauf; damn

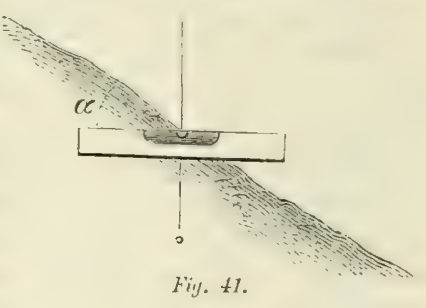
kann man den Neigungswinkel ummittelbar $a b$ $\left.\operatorname{lesen}^{1}\right)\left(F_{i g}\right.$. 42).

Man verwendet auch rine Art Klinometer (Fig. 13), bestehend aus einer Libelle, die auf einer Messingplatte ruht und

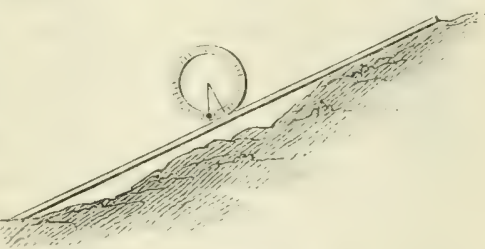

Fig. 42, am einen Ende mit einem Chamiere versehen ist, welches "möglicht, dass man das andre Ende längs eines einge-

1) Die Boussole muss an den Stab oder an die Latte mit dem Nullpunkt ilver Theilung angelegt werden. Das Gefalle wird dann angegeben durch den Winkel, welchen der Radius des Nullpunktes mit der Vortikalen (der Lothrichtung) bildet. Es beruht diess auf dem planimetrischen Satze, dass zwei Winkel a (Gefallswinkel des Terrains) und $b$ (Winkel, weleher an der Boussole abgelesen wird) gleich sind, wenn ihre Sehenkel aufeinander senkrecht stehen. Diess ist aber ter Fall, indem der horizontale Schenkel uc des Neigungswinkels senkrecht steht auf der Lothrichtung $b e$ und der Radius $b f$ senkrecht auf dem schiefen Schenkel a $d$ des Neigungswinkels, weil lieser eine Tangente (Berührungslinie) an den Boussolenkreis im Punkte $f$ (Nullpunkt) bildet.

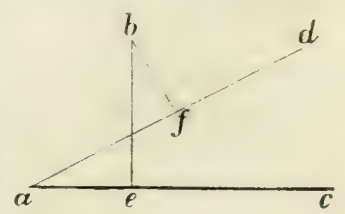


theilten Kreisbogens bewegt. Indem man die flache Messingplatte des Instrumentes auf den Boden legt, dessen Gefälle zu bestimmen ist, oder auf den am Boden angebrachten Stal, von dem oben die Rede war, bewegt man die Libelle um ihr Charnier aufwärts, bis deren Luftblase ihre Mittelstellung einnimmt („einspielt") und liest die Anzahl der Grade an dem entsprechenden Punkte des getheilten Kreisbogens ab. Diese Ablesung gibt den gesuchten Neigungswinkel.

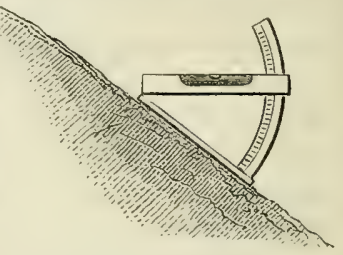

Fig. 43.

Am leichtesten gestaltet sich die Messung des Gefälsoder Neigungswinkels vermittelst des Theodolits. Man braucht nur einen Punkt oben an der geneigten Fläche anzuvisiren, welcher sich ebensohoch über dem Boden hefindet wie das Auge des Beobachters.

Aufnahme eines Planes. Wer unsere bisherigen Ausführungen aufmerksam rerfolgt hat, der wird unschwer einen Plan aufzunehmen vermögen. Denn diese Operation beschränkt sich in der That darauf, dass die verschiedenen Punkte, deren Lage man kennen will, durch Stäbe bezeichnet, unter sich durch Linien - gedachte oder abgesteckte - verbunden und dass diese Linien gremessen werden oder dass man die Winkel misst, welche sie mit schon bekannten Linien bilden. Dadurch erhalten wir alle Elemente (Bestimmungsstücke), die nöthig sind, um die Punkte, welche fïr uns in Betracht kommen, auf dem Papier zu fixiren, so dass ihre Lage auf dem Papier derjenigen auf dem Terrain entspricht und wir nur noch die Linien zu ziehen haben, welche dieselben miteinander verbinden und die Grenzen oder Lmrisse der zu bestimmenden Objekte bilden.

Wir haben daher nur noch die gebräuchlichsten Methoden anzugehen, unter welchen diejenige ausgewählt werden muss, welche einem gegebenen Fall an besten angepasst ist.

$1^{\circ}$ Methode der Koordinaten. Man steckt eine Axe $H E$ (Fig. 4f) ab, auf welche man ron jedem der zu bestimmenden Punkte aus eine Senkrechte (Normale, Perpendikel) fällt. Damn misst man die Perpendikel sowie die Distanzen zwischen ihren Fusspunkten ${ }^{1}$ ). Das Fällen der Senkrechten auf dem

1) Die Distanzen auf der Axe $H E$ heissen Abszissen; Die Axe $H E$ selbst hat daher den Namen Abszissenaxe, die Perpendikel heissen Ordinaten. - Dass für die 


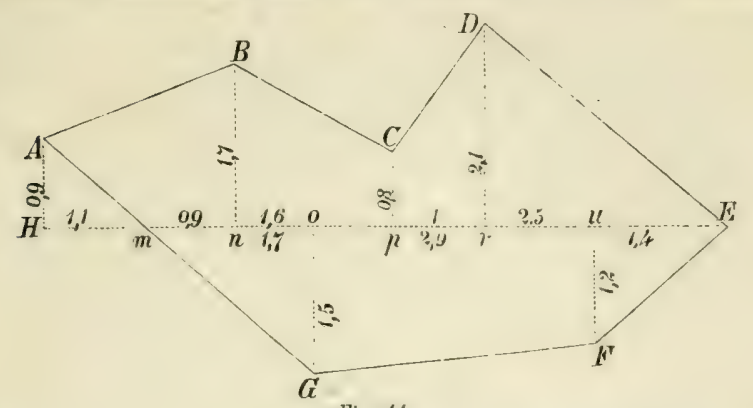

Fig. 4 .

Felde geschieht am leichtesten mittelst der Krör.:scheibe (Fig. 45). Den gleichen Dienst wie die Krenzscheibe leistet der Winkelspiegcl, ein sehr einfaches Instrument, das wenig Raum beansprucht ${ }^{1}$ ). In ganz gleicher Weise verfährt man, um Punkte im Innern der Figur zú bestimmen. Jede Normale kann dabei ihrerseits als Axe benutzt werden.

Sind die Grenzen, statt durch gerade, ganz oder theilweise durch krumme Linien (Kurven) gebildet, wie in Fig. 46, so benutzt man zunächst einen Linienzug aus geraden Strecken, auf welchen sich das vorige Verfahren anwenden lässt; dann behandelt man der Reihe nach $A B, B C, C D$, $D E$ als Axen, mit Bezug auf welche man die wichtigsten Punkte der gebogenen Linie $A B C D E$ festlegt. Dieselbe Methode kam angewendet werden zur Bestimmung eines Flusslaufes, Fig. $4 \%$.

Im Vorigen wurde angenommen, das Terrain zwischen den Punkten ABCD etc. (Fig. 44) sei zugänglich und man könne leicht über den Fluss $A C B$ (Fig. $(\hat{y})$ hinübergelangen. Nehmen wir num andre Verhältnisse: Es sei ein Situationsplan zu erstellen über einen See, sumpfiges T'errain, Wald oder über ein fliessendes Gewässer,

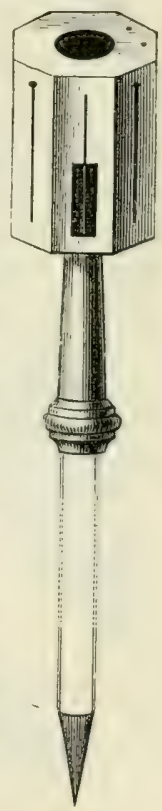

Fig. 4.j. das wegen grosser Tiefe oder zu starker Strömung nicht passirt werden könne. In einem solchen Falle umschliessen

Messungsoperation dem Messband der Vorzug zu geben sei, wurle bereits bemerkt, mag aber hier noch hervorgehuben werden.

1) Gebrauch des Winkelspiegels und Goldschmieds Doppelwinkelspiegel s. J. Hrbstein, praktische Geometrie, S. 47-49. 


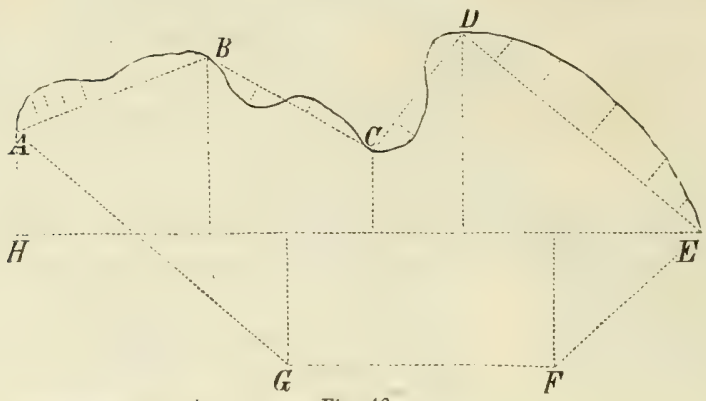

Fiig. $t 6$.

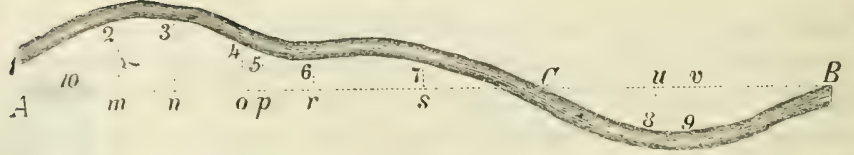

Fig. 47.

wir die Fläche, deren Grundriss anfyenommen werden soll, mit einem Rechteck $A B C D$ Fig. 48 und 49. Auf die vier Seiten dieses Rechtecks errichten wir Perpendikel in der Weise, dass diese durch alle diejenigen peripherischen Punkte

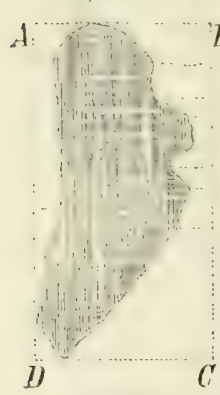

Fig. ts.
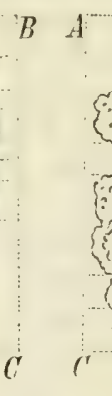

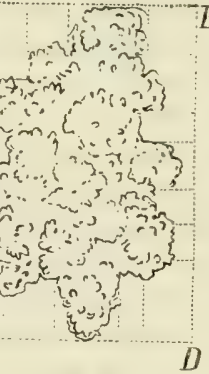

Fig. 49. der Fläche gehen, welche uns wesentlich scheinen; bei dem Flussabschnitte aber bringen wir die Abszissenaxe so an, dass sie für die ganze Strecke, welche in Frage kommt, auf einer und derselben Seite des Gewässers liegt, und errichten nun die er$D$ forderlichenNormallinien. (Fiy. 50).

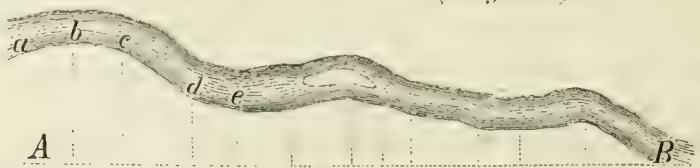

Fig. 50.

$2^{\circ}$ L'mfangsmethode. Nan geht von einem Punkte A (Fiy. 51) aus und indem man der Grenze $A B C^{\prime} D$ entlang vorrückt, bestimmt man jeweilen Richtung und Iänge der einzelnen 


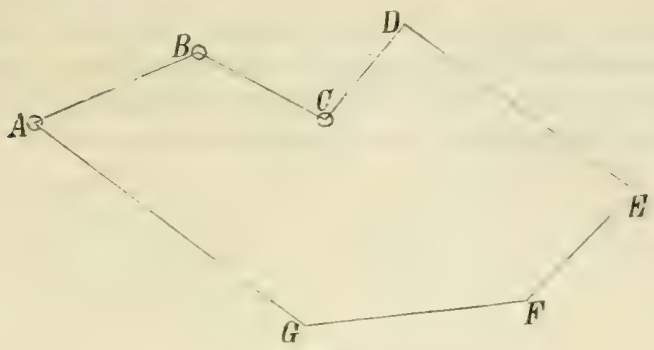

Fig. 51 .

Linien. Zu diesem Zwecke stellt man die Boussole der Reihe nach in $A, B, C$ u. s. w. auf und misst die Strecken $A B, B C, C D$ u. s. f. Dieses Verfahren ist namentlich passend bei Aufnahmen ron Terrains mit Gebüsch. Felsen oder Gebäuden. Statt dass man diese. wie hei der vorigen Methorle. durch ein Piecheck umgrenzen miisste - das auf dem Felde nicht immer leicht zu erhalten ist oder $z$ gross Dimensionen annehmen kïnnte - hat man dipselben, hei dem zweiten Verfahren. einfach in sin Vieleck oder Polygon einzuschliessen, ron dessen seiten aus man nöthigenfalls immer Perpendikel nach den Punkten führen kann, die man bestimmen will.

Im einen stark gebogenen Flusslauf aufzunehmen ohne allzulange Perpendikel messen zn müssen, stellt man ehen-

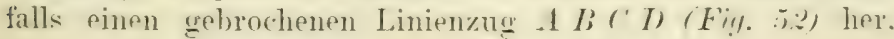

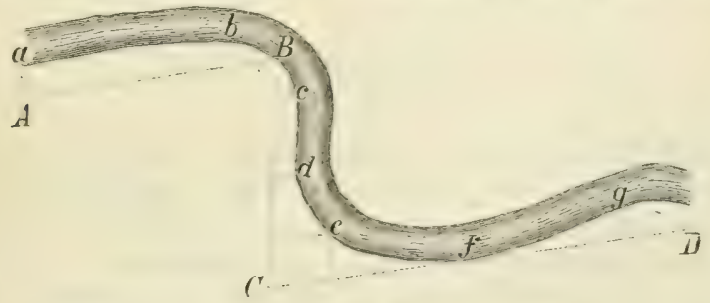

Fig. 5:.

welcher sich dem Laufe des Gewässers anschmiegt, und ron welchem aus nur kur\%. Perpendikel zu errichten sind, um die Punkte $a b c d$ u. s. f. zu bestimmen.

Sehr zwerkmässig ist diese Methode ferner bei Aufnahme

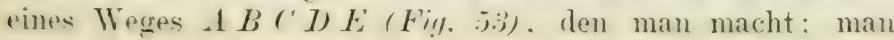


braucht sich dabei nicht rom Weg zu entfernen, um eine Axe abzustecken und muss auch nicht umkehren. Namentlich ron Wegen, welche durch ausgedehnte Waldparzellen führen, macht man am Besten eine Boussolenaufnahme.

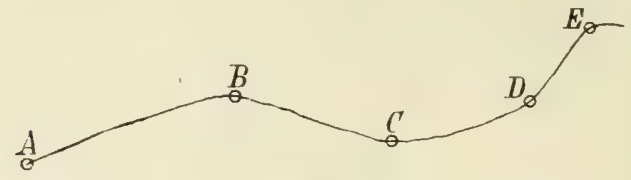

Fig. 53.

$3^{\circ}$ Methode der Eckistrahlen. Man stellt sich in einem zentralen Punkte $O$ (Fig. ju) auf und visirt nach $A, B$, C etc. Das nemnt man: Strahlen nach diesen Eckpunkten ziehen. Bestimmt man (z. B. mit der Boussole) die- Richtung dieser Strahlen und misst man deren Länge, so ist die Lage der

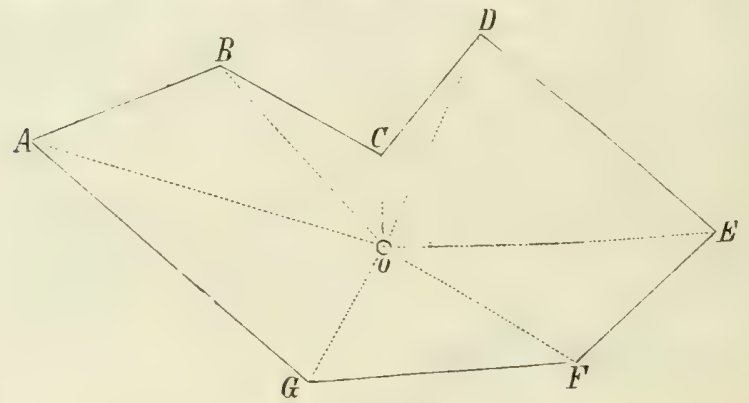

Fig. 57.

Punkte $A B C I$ u. s. w. unzweideutig fixirt. Auf dieselbe Art kann jeder im Immen der Figur befindliche Punkt bestimmt werden.

Dieses Verfahren ist indess nur anwendbar bei offenem Terrain, das überall gangbar ist und so gestattet, einen Zentralpunkt auszuwählen, von welchem aus man freie Aussicht hat und nach allen Richtungen operiren kann.

$4^{0}$ Method" rer Diagonalen. Die vorerwähnten Methoden haben alle das Lnbequeme, dass sie lange und zahlreiche Aufnahmen auf dem Felde erfordern. Tiel einfacher ist die Diagonalmethode, die eigentlich dasselbe Verfahren ist, das 
wir oben heim Distanzenmessen beschrieben haben. Man wird ilm demn anch den Vorzuy vor den andern geben überall wo es irgend anwendhar ist, $d$. h. wenn man mit offenem Terrain zu thun hat, sei es zugänglich oder nicht.

Es sei $A B C D E F G$ (Fig. 55) das aufzunehmende Terrain. Ob es sumpfig sei, einen See enthalte, von einem Fluss durchschnitten werde: dies alles ist unerhehlich, wenn

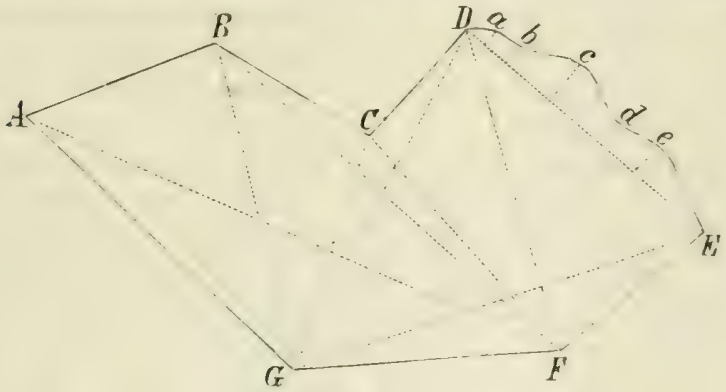

Fig. 5.5.

nur zwei Punkte da sind, $F$ und $G$ zum Beispiel, von welchen aus man die andern sehen kann. Jan misst ganz crenan die Linie ( $F$ F ab und benutzt sie nun als Basis zur Bestimmung der Punkte $A B C$ etc., indem man dabei in der früher besprochenen Weise zu Werke geht. Da einige

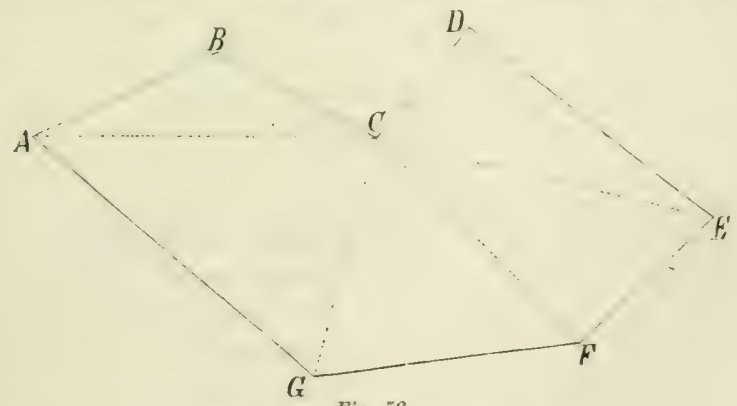

Fig. 56.

Linien sich unter zu spitzen Winkeh schneiden, so geht man, nach rorgenommener Bestimmung der Position C', ron der gemessenen Basis (' $F^{\prime}$ (Fiy. j(i) zu der konstruirten oder berechneten Basis (; ' 'über, um die Lage des Punktes 
$A$ zu fixiren: damn zur Basis $A C$, um den Punkt $B$ zu finden. Ebenso sucht man von der konstruirten oder berechneten Basis $F^{\prime} C^{\prime}$ aus den Punkt $\boldsymbol{E}$, weiter ron diesem und $C$ aus dem Punkt $D$.

Die Vortheile dieses Verfahrens gegenüher der Methode der Eckstrahlen sind hiebei angenscheinlich. Nan hätte sich nach letzterer', in (' aufstellen und nach allen andern Punkten visiren kömen. Damn hätten wir aber alle Linien, $C^{\prime} I, C^{\prime} A, C^{\prime}\left(', C^{\prime} H, C^{\prime} E\right.$ und $(' I)$ messen müssen, während wir jetzt eine einzige Länge $G$ F durch direkte Messung zu ermitteln hatten.

Sellostverständlich kömmen diese verschiedenen Methoden mit einander liombinirt werden, wo diess rortheilhaft scheint und der ansschliessliche Gebranch einer derselben nicht genügt. Hat man $\%$. B. durch die Diagonalmethode die Hauptpunkte I I; C I) (Fiy. ja und (j) bestimmt, so hindert uns nichts daran, die Lage der sekundären Punkte a $b \quad c$ d $e$ nun mittelst Koordinaten zu fixiren.

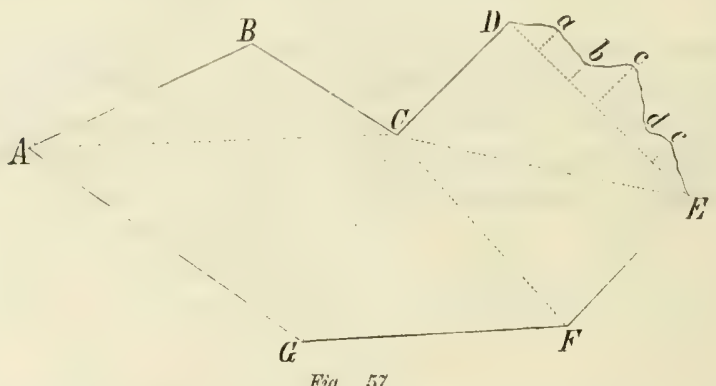

Um den Grumbliss eines Gebüudes aufzunehmen, misst man dessen Seiten mit der Messschnur oder mit Messlatten.

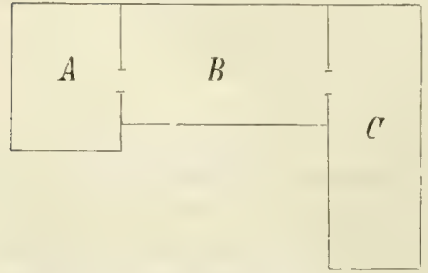

Fig. ขร.
Stehen die Mauem und Wände rechtwinklig zu einander, z. B. $A B C$ (Fig. 58 ), so braucht man nur ihre Länge zu kennen; ist dies aber, wie bei $E F^{\prime} G\left(F^{\prime} i g .5 .9\right)$ nicht der Fall, so theilt man den Raum durch die Diagonalen $F K, H K, H I$ in 
Dreiecke und misst auch die Längen dieser Diagonalen, um auf dem Papier ähnliche Dreiecke konstruiren zu können mit Hülfe ihrer drei Seiten.

Ein Gundriss ron sehr xumegelmässiger Form (Fig. (jo) kann auch mach der Koordinatenmethode aufgenommen werden rermittelst einer beliebig gewählten Axe.

Diese Methoden sind auch anwendbar, um Grundrisse anfzunehmen von unterirdischen Riummen, Souterrains, Erdhöhlen u. s. f., nur dase man, um im Dunkeln zu visiren, Kerzen oder Laternen statt Stähen verwenden muss.

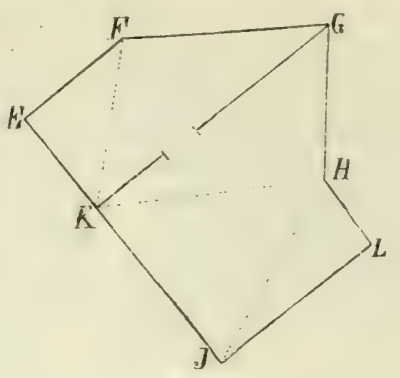

Fii. .5.

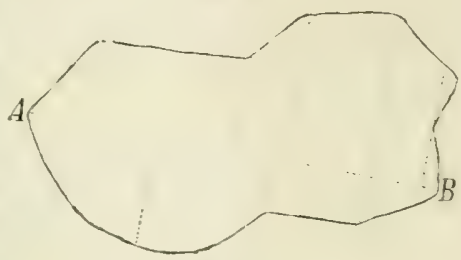

Fig. 60 .

Um aber den Grundriss unterirdischer Räume (Tumnel, IHöhlen, stollen und sichachte) in Beziehumy zu setzen mit der allgemeinen Aufuahme an der änsemen Erdfläche. verfaihrt nan folgendermassen. Die Lenchtzeichen tLaternen oder Kerzenl, welche zur Bestimmung einer wesentlichen unterirdischen Linie gerlient haben. lässt nan an ihrer Stelle nund begilut sich num hinter dasjenige diespr Zeichen, welches unter all denen, von wo aus man die Gegenstände aussen noch wahrnehmen kann, am weitesten rom Eingang ahsteht. Eines dieser Ohjelite in der Richtung jener Zeichen oder ein hesonderes signal, das man aussen in dieser Richtung anhringen lässt, wird anvisint und man begiht sich mit dem Instrument zu demselben. Nun richtet man von hier aus die Visirlinir des.s Instrumentes wieder anf die Ieuchtzeichen, so dass diese sich decken; ist man dieser Richtung (der Deckung) sicher geworden, so visirt man nun - olne die stellung des Instrumentes in horizontalem sinne iryendwie zu ändern - in der gleichen Vertikalebene einen andern Gegenstand an, welcher an der brdoberfläche sich befindet und erhält so die äuscere coleriddisches spur jener unterirdischen Linie. 
Einfacher als dieses Verfahren ist die Anwendung des Kompasses (der Bonssole), womit man zunächst die Richtung der unterirdischen Linie bestimmt, um dann, vom Eingange des unterirdischen Raumes aus, eine entsprechende Richtung auf der Erdoberfläche aufzusuchen.

Um zu erfahren, welcher Stelle der Erdoberfläche oder des Terainmantels ein unterirdischer Raum entspricht, genügt. es übrigens mitunter, wenn man innen mit einem Hammer an die Decke (Wölbung) der Höhle schlägt. Kennt man urgefähr die Richtnug, in welcher die Höhle sich hinzieht und horcht man nun aussen am Boden, so vernimmt man unschwer das Geräusch der Hammerschläge; man beobachtet dasselbe num an verschiedenen Stellen; der Punkt, wo man os am deutlichsten hört, mutspricht dex Axe des Hohlraumes ${ }^{1}$ ).

Wie man, nachdem die nöthigen geometrischen Daten rrlangt sind, zu Werke geht, um den Plan zu zeichnen und zu koloriren, werden wir später sehen. Inzwischen geben wir an dieser Stelle ein Beispiel einer Planaufnahme in Tuf. I, wo die punktirten Linien den bei der Aufnahme eingeschlagenen Gang bezeichnen.

Flächenmessung. "Eine Flärche messen " heisst ermitteln, wie viel mal grösser dieselbe ist als ein Quadrat, das die Längeneinheit zur Seite hat. Dieses Quadrat ist also die Flächeneinheit, und der Inhalt einer Fläche ist nichts Anderes als eine Zahl, welche angibt, wie oft mal eine gegebene Fläche jene Einheit enthält. Nun wissen wir aus dem eben resagten, dass jede gradlinig begrenzte Figur zerlegt werden kann in Dreiecke, Rechtecke und Trapeze; der Inhalt dieser Figuren aber ist nach wenigen geometrischen Regeln leicht zu berechmen, wenn man nur die Längen gewisser Linien kennt. Diese Sätze, die man häufig anzuwenden hat, sind folgende :

$1^{\circ}$ Der Flächeninhalt eines Parallelogramms ist gleich dem Produkte von Grundlinie und Höhe (ihrer Masszahlen).

$2^{\circ}$ Der Flächeninhalt eines Dreieckes ist gleich dem halben Produkte aus Grundlinie und Höhe (d. h. dem halben Produkte der Masszahlen von Basis und Höhe).

1) Breton, Traité du levé des plans et de l'arpentage, Paris 1865, p. 521. 
Taf.I.

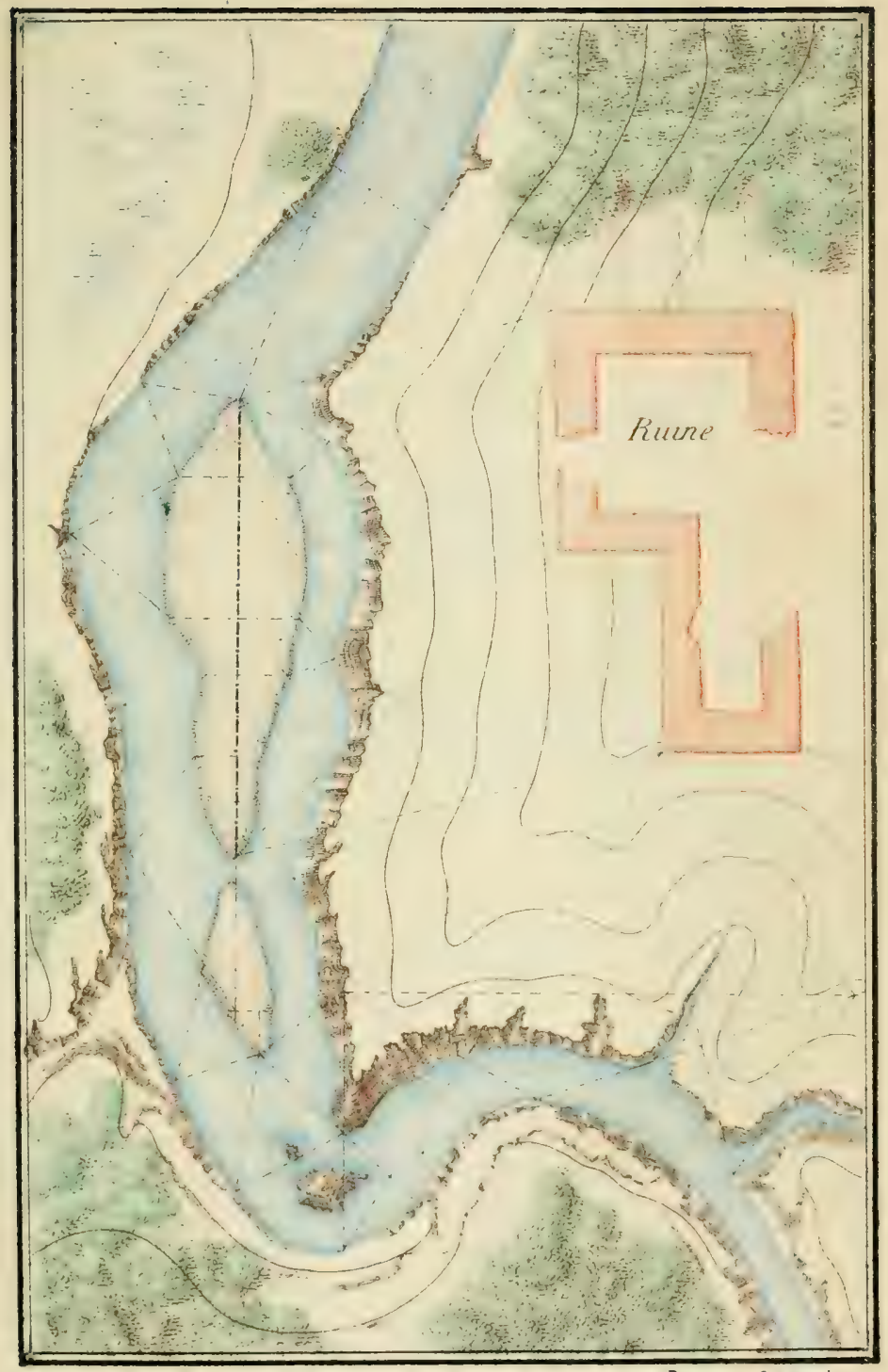

Murster Ránaesger \& C " Wenterthur. 

$3^{-}$Der Flächeninhalt eines Trapezes ist gleich dem halben Produkte aus der Summe der Parallelseiten (Grundlinien) und der Höhe.

Höhe ist bekanntlich der senkrechte Abstand von der Grundlinie oder deren Verlängerung zur gegenüberliegenden Spitze (beim Dreieck) oder Parallelseite (beim Parallelogramm und Trapez).

Diese Sätze sind so bekannt, dass wir uns darüber nicht weiter rerhreiten müssen; dagegen scheint es uns zweckmässig, dieselben durch nachstehende Figuren zu veranschaulichen, indem wir nur einige ganz kurze Bemerkungen beifügen.

An dem Rreleter, welches eine besondere Art des Parallelogramms hildet ${ }^{1}$ ), sieht man unmittelbar (Fi\%. bi), dass es so viele der quadratischen Flächeneinheiten enthält, als das Produkt der Grundlinie $C D$ mit der Höhe $A C$ angibt. Hat die Basis oder Länge, wie in der Fig. 61, 9 Meter, die Höhe oder

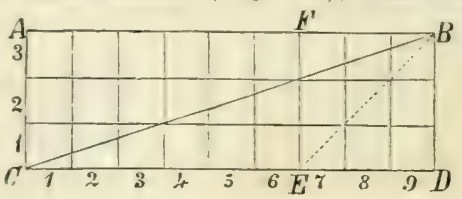

Fig. 61 . Breite 3 Meter, so ist der Inhalt 27 Quadratmeter $\left(\mathrm{m}^{2}\right)$, d. h. das Rechteck enthält die Flächeneinheit 27 mal. Fiy. fi:" zeigt, dass ein schiefwinkliges Parallelogramm $A B C D$ gleich gross ist wie ein rechtwinkliges $C D E F$, wenn es mit demselben gleiche Grundlinie (Länge $C D$ ) und gleiche Höhe (Breite, $E D$ oder $C F$ ) hat.

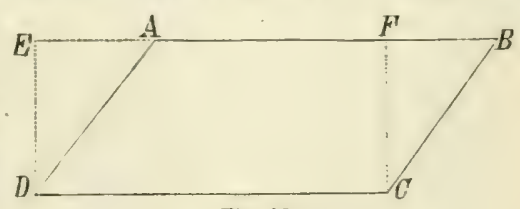

Fig. 62a.

Diese zwei Figuren sind offenbar grleich gross, weil sie übereinstimmen in dem gemeinsamen grrösseru Bestandtheil $A L C F$ und in den kleinern Theilen, welche eine jede ron ihnen besonders hat; den Dreiecken $A D E$ (Bestandtheil des Rechtecks) und $B C F$ (Bestandtheil des schief-

1) Parallelogrumm heisst jedes Viereck, dessen Seiten parreise einander parallel und gleich sind. Hat es lauter rechte Winkel, so heisst es Rechteck; hat es zudem lauter gleich grosse Seiten, so ist es ein Quadrat. Der Rhombus ist ein schiefwinkliges Parallelogramm mit gleich langen Seiten, 
winkligen Parallelogramms). Also ist auch der Inhalt des schiefwinkligen Parallelogramms gleich Grundlinie mal Höhe. Aus Fig. $62^{b}$ ersieht man leicht, dass ein Dreieck $C D B$ oder $A B C$ genau halb so gross ist wie ein Parallelogramm,

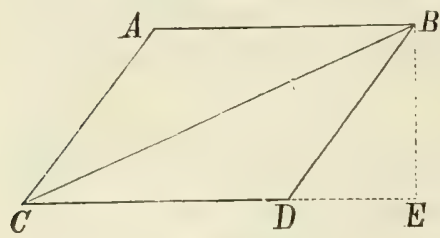

Fig. $62 b$. das mit ihm gleiche Grundlinie $(C D)$ und gleiche Höhe $(B E)$ hat. Sein Inhalt, die Fläche des Dreiecks, ist also gleich der Hälfte desProduktes von Grundlinie und Höhe.

Am augenscheinlichsten ist dies übrigens bei der Theilung des Quadrates (Fi\%. (j3) durch eine Diagonale. Wenn die Seiten des Quadrates $A B C D$ je $5 \mathrm{~m}$ lang sind, so enthält das Quadrat 25, also $5 \times 5$; Quadratmeter; eines der Dreiecke $A B C$ oder $B C^{\prime} D$ hat aber $12^{1 / 2}$ Quadratmeter: 10 ganze und 5 halhe Quadratmeter, also $\frac{5 \times 5}{2}$. Die Fig. 61 zeigt uns dasselbe. Das Dreieck $B C D$ ist die Hälfte des Rechtecks $A B C D$, hat also $\frac{27}{2}=13,5$ Quadratmeter. Das Dreieck $B D E$ hat $4^{1 / 2}$ Quadrat-

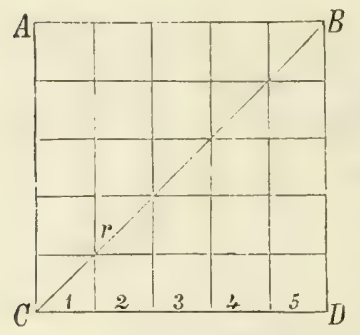

Fig. 63. meter. Nehmen wir das Letztere rom ersteren weg, so bleibt uns das Dreieck $B C \boldsymbol{E}$, dessen Inhalt also $13,5-4,5 \mathrm{~m}^{2}=9$ Quadratmeter ist; das aber ist wieder die Hälfte des Rechtecks $A C E F$, dessen Inhalt $6 \times 3=18 \mathrm{~m}^{2}$ beträgt. Da auch das Dreieck $C E F$ den gleichen Inhalt von $9 \mathrm{~m}^{2}$ hat, so sehen wir hiedurch den Satz wiederum bestätigt.

Die dritte Formel für den Inhalt des Trapezes — welches Viereck zum Unterschied rom Parallelogramm nur ein Paar parallele Seiten hat und welche Seiten einander nicht gleich sind - ergibt sich auf einfache Weise aus der Fig. 64 . Der Inhalt des Dreiecks $A B D$ ist gleich $\frac{A B \cdot A D}{2}$, derjenige des Dreiecks $D B C=\frac{C D \cdot B E}{2}$ oder $\frac{C D \cdot A D}{2}$; der Inhalt beider Dreiecke oder also der des Trapezes folglich gleich 
der Summe ron $\frac{A B \cdot A D}{2}$ und $\frac{C I \cdot A I}{2}$. Hier hat man also zuerst $A B$, damn (' $I$ ) je mit $A I$ ) zu multipliziren und durch 2 zu dividiren, schliesslich beides zu addiren. Kürzer addirt man zuerst $A B$ und $C D$, vervielfacht dann die Summe mit $A D$ und halbirt dieses Prodult. Es entspricht dies dem Ausdruck $\frac{(A B+C D) \cdot A D}{2}$ oder: $\frac{1}{2}(A B+C D)$. A $D$.

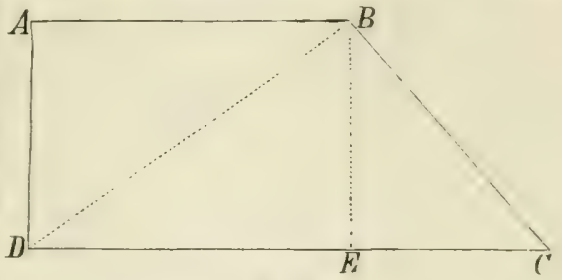

Fig. 6t.

Ist z. B. $A B=11 \mathrm{~m}, D C=18 \mathrm{~m}, A D=8 \mathrm{~m}$, so ist

$$
\begin{aligned}
& \text { Dreieck } A B D=\frac{11 . \mathrm{s}}{2}=44 \mathrm{~m}^{2} \\
& \times \quad B C D=\frac{18^{2} \cdot \mathrm{s}}{2}=72 \mathrm{~m}^{2} \\
& \text { Zusammen } 116 \mathrm{~m}^{2}
\end{aligned}
$$

Obige Formel gibt $\frac{1}{2}(11+18) \cdot 8=29 \times \frac{8}{2}=$

$$
29.4=116 \mathrm{~m}^{2} \text {. }
$$

Beispiele für Berechnung verschiedener Flächen. Dem Cours complet d'Arpentary ron D. Puille entnehmen wir folgende praktische Beispiele.

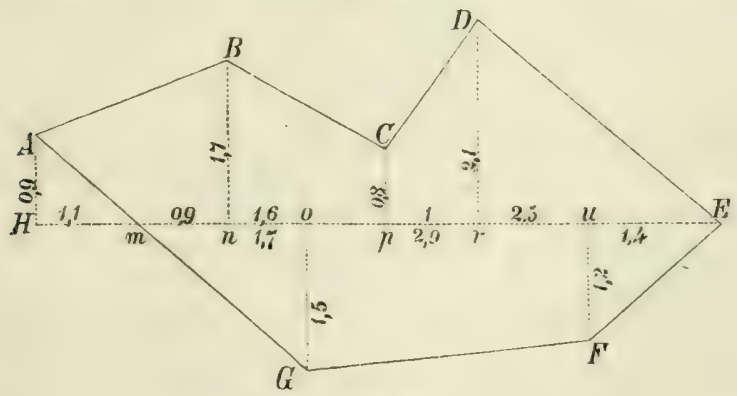

Fig. 65.

Zunächst kehren wir zu dem in Fig. 44, S. 57 betrachteten Falle zurïck. (Fig. 65.)

Diese Fläche zerfällt in 4 Dreiecke und 4 Trapeze, nämlich : 


$$
\begin{aligned}
& D r E=\frac{2,5 \cdot 2,1}{2}=2,625 \mathrm{~m}^{2} \\
& D r p C=\frac{1}{2}(2,1+0,8) \cdot 1=1,450 \% \\
& \text { Cp } n B=\frac{1}{2}(0,8+1,7) \cdot 1,6=2,000 \text { n } \\
& B n H A=\frac{1}{2}(1,7+0,9) \cdot 2=2,600 \text {, } \\
& m \circ G=\frac{1,7 \cdot 1,5}{2}=1,275 \% \\
& \text { Gou } F=\frac{1}{2}(1,5+1,2) \cdot 2,9=3,915 \text { \% } \\
& F \| E=\frac{1,2 \cdot 1,4}{2}=\frac{0,840 \%}{14,705 \mathrm{~m}^{2}}
\end{aligned}
$$

wovon abzuziehen ist:

$$
A H m=\frac{1,1 \cdot 0,9^{\circ}}{2}=0,495 \%
$$

Einen andern Fall bietet Fig. 66. Es sei die Fläche $C D E F G H I$ zu berechnen aus den Abschnitten einer Axe $A B$ und den ron allen Eckpunkten auf sie gefällten Perpendikel (Ordinaten).

Man berechnet zunächst den Inhalt der drei Trapeze $C m \circ D, o D E s$ und $s E F^{\prime} u$. Es ist

$C m \circ d=\frac{1}{2}(13,3+23,2) \cdot(5,2+4,1)=169,725 \mathrm{~m}^{2}$ o $D E S=\frac{1}{2}(23,2+21,4) \cdot(6,9+8,3+5,4)=459,380$. $s E F u=\frac{1}{2}(21,4+14,5) \cdot 9,5 \quad=170,525 n$

$$
\text { Zusammen }=\overline{799,630 \mathrm{~m}^{2}}
$$

Hievon hat man die Fläche der kleinen ausserhalb der Figur liegenden Trapeze abzuziehen, nämlich :

$$
\begin{aligned}
& m C I n=\frac{1}{2}(13,3+7,4) \cdot 5,2=53,820 \mathrm{~m}^{2} \\
& n I H p=\frac{1}{2}(7,4+11,3) \cdot(4,1+6,9)=102,850 \% \\
& p H G r=\frac{1}{2}(11,3+7,2) \cdot 8,3=76,775 \% \\
& \jmath G F u=\frac{1}{2}(7,2+14,5) \cdot(5,4+9,5)=161,665 \%
\end{aligned}
$$

Rest $\frac{395,110 \%}{404,520 \dot{\mathrm{m}}^{2}}$ 
Ist die zu messende Fläche unwegsam oder ungangbar, so umschliesst man sie mit einer möglichst einfach auszumessenden und

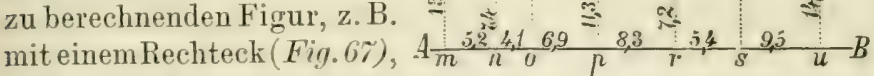
und zieht dann hievon die Flächenstücke $\mathrm{ab}$, welche

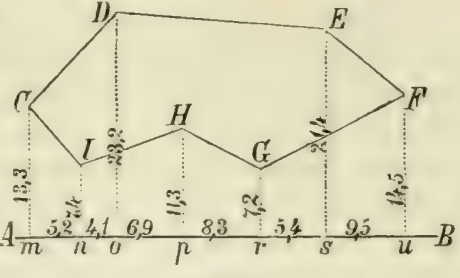

Fig. 66. dem zu bestimmenden Gebiete nicht angehören. In Fig. Gr wird man also rom Inhalte des Rechtecks $I K L$ II die Dreiecke $E I H, E I G, G K A, B L C$ und das Trapez

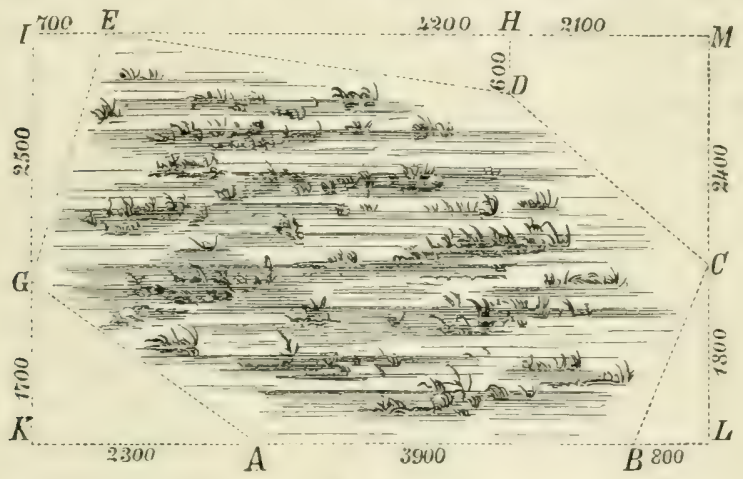

Fig. 67.

$C M H I$ subtrahiren. Der Rest ist die Fläche des Sumpfes $A B C D E G$.

Ist aber eine Fläche, statt durch Gerade, durch krumme(gebogene) Linien begrenzt, so wendet man d verschiedene $\mathrm{Me}$ thoden an:

$1^{\circ}$ Die Kompensations- oder Ausgleichnugsmethode.

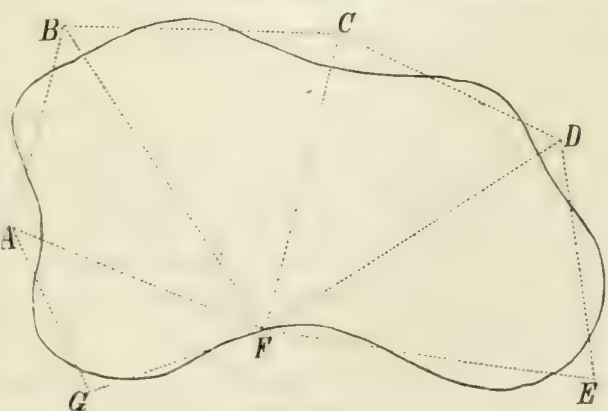

Fig. 68. 
In $A B C D E$ E $\quad$ G (Fig. 68) steckt man Stäbe auf, um ein.Vieleck zu bilden, dessen Fläche der des fraglichen Terrainstückes ziemlich gleichkommt, indem man die Vieleckspunkte so anordnet, dass jeder der durch seine Seiten von der Figur abgeschnittenen Theile ersetzt und ausgeglichen (kompensirt) wird durch ein hinzugefügtes Stück. Mit einiger Uebung bringt man es bald dazu, das Vieleck in einer für Kompensationen passenden Weise abzustecken. Das weitere Verfahren, die Ausrechnungsmethode, erfolgt dann nach Massgabe der oben ertheilten Anleitung.

$2^{\circ}$ Tëherungsmethode. Nachdem man in den Hauptpunkten $A B C D E F^{\prime}$ (Fï. 6.9) des krummlinigen Umrisses Stäbe gesteckt hat, verbindet man diese Punkte durch gerade Linien $A B, B C$ u. s. w., auf welche man ron allen charakteristischen Punkten der Kurve (da wo dieselbe aus-

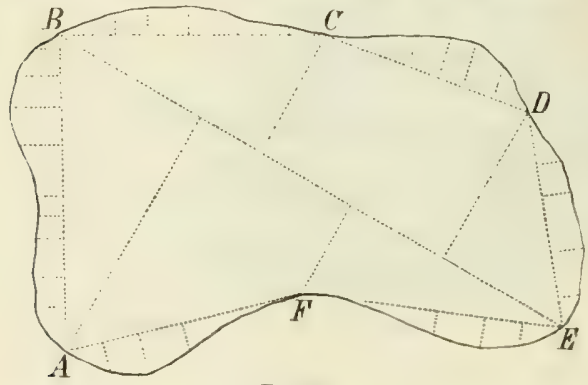

Fig. 69. gesprochene Richtungsänderungen erleidet) Senkreckte fällt, zwischen welchen nun lauter solche Abschnitte der unregelmässig gestalteten Umrisslinie liegen, die man ohne wesentlichen Fehler als Gerade betrachten und behandeln

kann. So erhält man eine Anzahl Dreiecke und Trapeze, deren Inhalt demjenigen des eingeschriebenen Vielecks $A B C D E F$ hinzugefügt werden muss.

Das nämliche Verfahren wendet man auch auf ungangbare Terraintheile oder solche mit Visirhindernissen wie Seen, Wälder etc. an, nur dass man hier die Polygonseiten ausserhalb der krummlinig begrenzten Figur anbringt, so dass die Fläche der kleinen Dreiecke und Trapeze vom Inhalt des der Figur umschriebenen Vielecks zu subtrahiren sind.

Bei all diesen Operationen muss man ein Hauptaugenmerk auf die Summe der positiven (additiven) Flachen einer- 
seits, der negaticen (subtraliticen) Flähen andererseits, d. h. darauf richten, was hinzuzufïgen, was aber hinwegzunehmen sei.

$3^{\circ}$ Analytische Inthode. Selten wird der Reisende eine Fläche mit einer noch grössern Genauigkeit bestimmen müssen, als die beiden eben besprochenen Methoden gestatten. Tritt aber dieser Fall ein, so kann man folgendermassen zu Werke gehen:

Die Axe oder Leitlinie $A B$ (Fig. $r(1)$ wird in eine gerade (paarige) Anzahl gleicher Stücke abgetheilt; in jedem Theilungs-

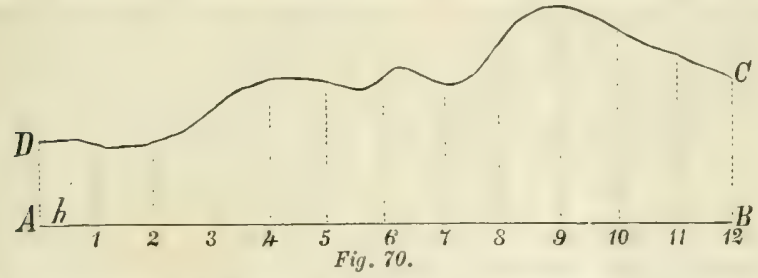

punkt errichtet man auf $A B$ eine Senkrechte, die sich bis zu der gekrümmten Linie erstreckt, welche die Figur begrenzt. Dann ist der Inhalt der Fläche $A B C^{\prime} I$ gleich dem arithmetischen Mittel (der halben Summe) der Endordinaten $A D$ und $B C$, mehr der Summe aller andern geraden Ordinaten $\left(N_{r} .2, \&\right.$ u. s. w.), mehr der doppelten Summe der ungeraden Ordinaten ( $\mathrm{N} r .1$, 3 etc.) all diess zusammen multiplizirt mit $2 / 3$ des Abatandes $/$ der Perpendikel. Bezeichnen wir also die Ordinaten mit gerader Nummer durch $\mathrm{O}_{2}, \mathrm{O}_{4}, \mathrm{O}_{6} \mathrm{u}$. s. f. die, ungerader $, \quad \mathrm{O}_{1}, \mathrm{O}_{3}, \mathrm{O}_{5} \mathrm{u}$. s.f. die Summe der erstern mit $\stackrel{S}{p}_{p}$, der letztern mit $S_{i}$, so ist die fragliche Fläche

$f=\left[\frac{A D+B C}{2}+\left(O_{2}+O_{4}+O_{6}+\ldots\right)+2\left(O_{1}+O_{3}+O_{5}+\ldots\right)\right]^{2 h} \frac{h}{3}$ oder $f=\left(\frac{A D+B C}{2}+\mathrm{S}_{\mathrm{p}}+2 \mathrm{~S}_{\mathrm{i}}\right) \frac{2 \mathrm{~h}}{3}$.

Das Resultat ist um so genauer, je kleiner der Abstand oder das Intervall $h$ zwischen den Ordinaten ist.

Wir sind nunmehr in den Stand gesetzt, beliebige Flächen messen und berechnen zu kömmen ${ }^{r}$ ). Es mag aber am Platze sein, den Leser, hevor wir diesen Alsschnitt schliessen, noch auf einige ziemlich verbreitete Irrthümer aufmerksam zu machen, damit er vor denselben auf der Hut sei.

1) Ueber die Verwendung der Planimeter vgl, Rebstein, a. a. O., S. 84 ff. 
Zunächst ist zu bemerken, dass die Fläche eines geneigten Terrainstückes nicht nach der schiefen Fläche auf der Abdachung selber $z u$ bemessen ist, sondern nach seiner Horizontalprojektion, $d$. h. nach der lothrecht unter ihm in horizontaler Lage befindlichen Fläche, sodass der Inhalt von $A B C D$ (Fig. r1) gleich dem von $A^{\prime} B^{\prime} C D$ ist, wie denn bereits oben (S. 45) gesagt wurde, dass die geneigte

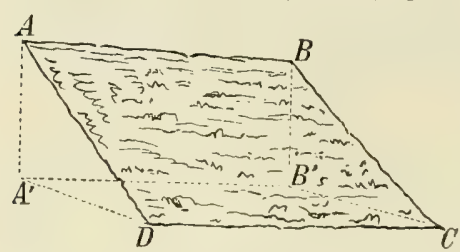

Linie $A D$ nicht in dieser ihrer schiefen Richtung, sondern in der Horizontalen $A^{\prime} D$ gemessen wird.

Sodann bedeutet die Anzahl Quadratmeter des In-

Fig. 71 .

haltes so viele Quadrate von je einem Meter Seitenlänge. "Vier Quadratmeter" heisst also nicht etwa, wie unserer Erfahrung mach Manche meinen, "ein Quadrat von 4 Meter Seitenlänge", sondern vier Quadrate von ein Meter Seite."

4 Quadratmeter. Quadrat von 4 Meter.

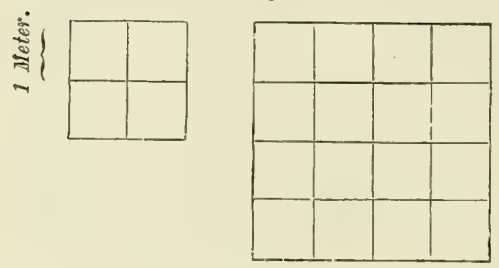

Fig. 72.
Die Fig. 72 zeigt deutlich den Unterschied zwischen "4 Quadratmeter" und einem Quadrat von 4 Meter Seitenlänge ${ }^{1}$ ).

Endlich ist ein Quadratdezimeter nicht etwa der zehnte Theil des Quadratmeters, sondern $1 / 100$ des-

1) Man mag vielleicht finden, dass wir hier doch all zu elementare Dinge behandeln, die oben erwähnten Erfahrungen nicht massgebender Art sein dürten und wir bei unsern Isesern doch allzuwenig voraussetzen. Wir erlauben uns daher, auf Erfahrungen hinzuweisen, welche in eben so einfachen, wenn nicht noch elementarern Dingen von Andern gemacht und in einer Sammlung ausgezeichneter Abhandlungen, worin weitgehende Anforderungen an die Leser gemacht werden, zur Verwerthung gelangten. In Dr. G. Neumayers berïhmter "mit besunderer Rücksicht auf die Bedürfnisse der kaiserlichen Marine" verfasster "Anleitung zu wissensehaftlichen Beobachtungen auf Reisen" S. 41 sagt ein Praktiker wie H. Kiepert über topographisehe Beobachtung und Zeichnung unter Anderm Folgendes: "Wenigstens in Beziehung auf die betreffende Seite des Weges, $o b$ rechts oder links, sollte man zuverlässige Angaben von einem nur halbwegs auf: merksamen Reisenden um so mehr erwarten, je unentbebrlicher solche für die Kartenkonstruktion sind und je grössere, mitunter unheilbare Verwirrung in dieser Beziehung irige Angaben verschulden. Gleichwohl zeigt die Erfahrung, duss selbst sonst geübte Beobachter gerade jene einfachsten Beziehungen, so wie die der entsprechenden Himmelsgegenden (am leichtesten Ost und IVest) hüufig genug verwechseln: ein Wink, die Aufmerksumkeit auf diesen Punkt su verdoppeln und womöglich durch eine wenn noch so roh gezeichnete Skizze, welche gerade solchen Umkehvungen der Richtung nicht unterworfen ist, der Wegebeschrcibung zu Hülfe zu 
Beispiete tur das Messen und Berechnen vun Flärhhen.
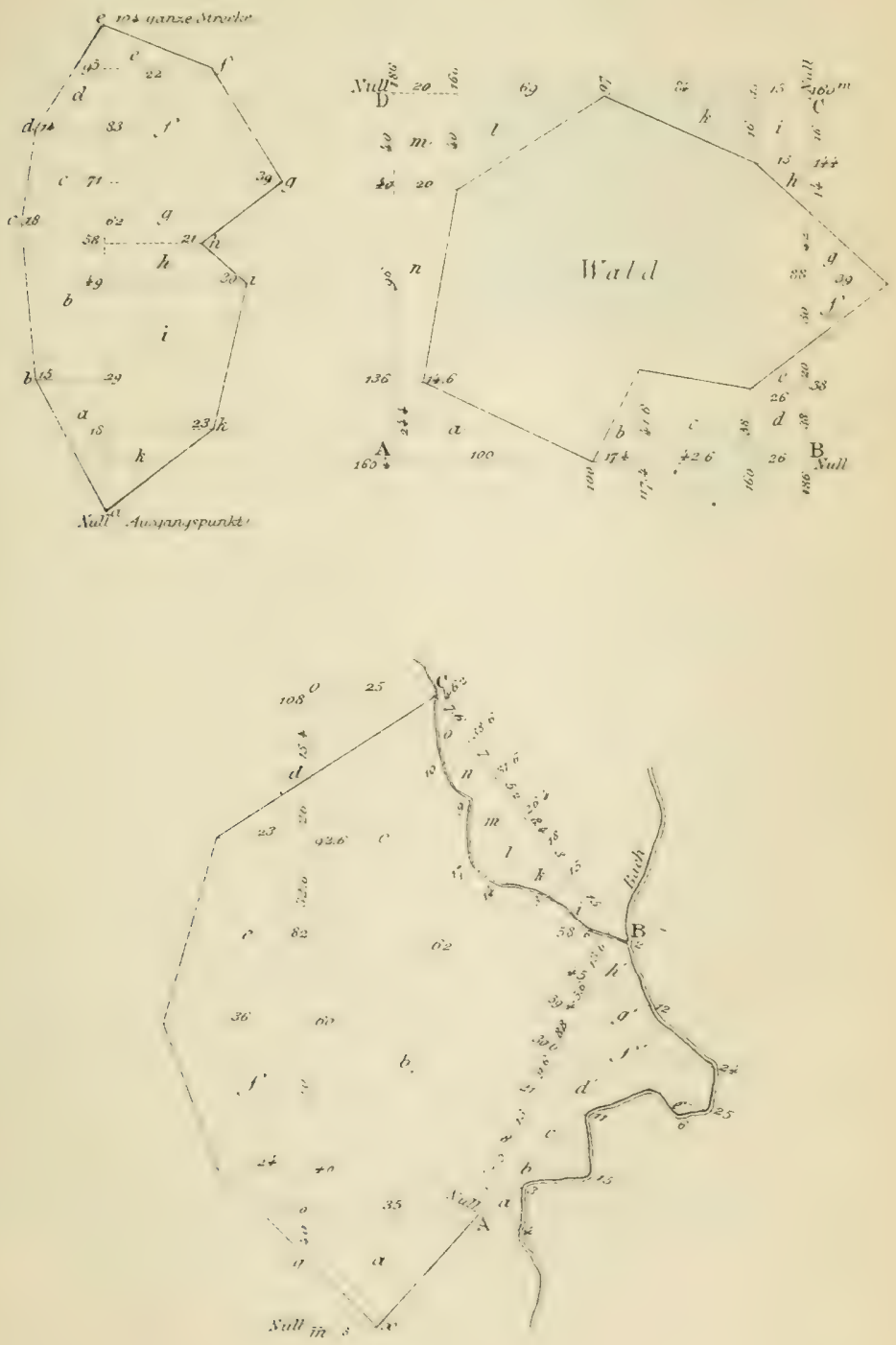

selben; der Quadratcentimeter ist nicht $1 / 100$, sondern $1 / 10000$ Quadratmeter.

In der That, wenn $A B C D$ (Fig. 73) einen Quadratmeter vorstellt, so sieht man leicht, dass es hundert kleinere Quadrate enthält, deren jedes ein Dezimeter Seitenlïnge hat, und ebenso enthält der Quardratcentimeter, welchen fïg. r.t in richtiger Grösse gibt, 100 kleinere Quadrate - Quadratmillimeter.

Multiplizirt man also zwei Nasszahlen, welche Dezimeter und Centimeter enthalten, mit einander, so hat man, um den Inhalt in Quadratmetern anzugehen, nicht zwei, sondern 4 Stellen als Dezimalen abzuschneiden. Sind 7. B. die in Neter bestimmten $D$ Masszahlen 20,15 und 5,50 miteinander

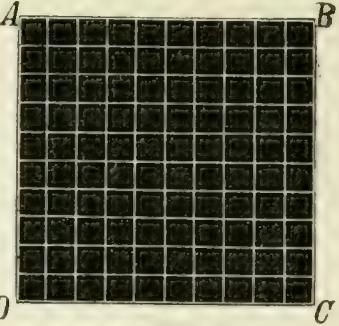

Fig. 73. zu multipliziren, so bedeutet das Produkt 1108250 Quadratcentimeter oder 110,8250 Quadratmeter. Ind hat man in zwei miteinander $\mathrm{zu}$ multiplizirenden metrischen Angaben je eine Dezimalstelle (Dezimeter), z. B. 4,5 . 3,2, so muss man vom Produkte

Fig. 74. zwei Stellen rechts abschneiden, um Quadratmeter zu haben. Das Produkt im gegebenen Falle ist 1440 Quarlratdezimeter $=14,40$ Quadratmeter.

Die nebenstehende Tafol II gibt Figuren, die als L'ebungsbeispiele zur Flächenberechnung verwendet werden mögen.

Am Schlusse dieses Abschnitts bemerken wir noch, dass wenn man von einem Gebiete, einem See z. B., dessen Fläche berechnet werden soll, schon einen Plan oder eine Karte in grossem Massstah hat, es oft genürt, die zur Zerlegung in Dreiecke, Rechtecke u. s. w. nöthigren Hülfslinien auf dem Papier zu ziehen und zu messen, ohne dass es nöthig ist, diese Operationen auf dem Felde vorzunehmen.

Bestimmung der Mittagslinie. Mittagslinie eines Ortes nennt man den Schnitt seiner Horizontalebene mit der Ebene seines Meridians oder Längenkreises; es ist eine

kommen". Wer je sich längere Zeit mit irgend einer Art instruirender Thätigkeit zu befassen hatte, weiss, wie oft der Instruirende in den Fall kommt, in einfachsten Dingen falsche Ansichten und Auffassungen zu berichtigen - und auf welchen Irrungen man sich mitunter selbst ertappt? 
Linie in der genauen Richtung Nord-Süd. Zu deren Bestimmung gibt es verschiedene Mittel.

Erste Wcthode. Der Polarstern beschreibt scheinbar um den Nordpol einen Kreis ron sehr geringer Dimension. $\mathrm{Er}^{\mathbf{r}}$ ist in der Ebene des Meridians, wenn er sich in der Vertikalen befindet, welche durch den Stern $\boldsymbol{\varepsilon}$ (epsilon) des grossen Bären oder $\gamma$ (gamina) der Kassiopeja (Fig. rj) geht'1). Wir

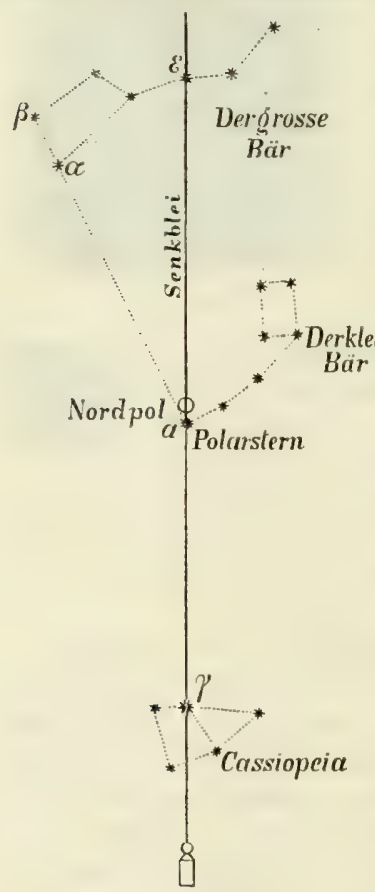

Fig. $7 \overline{5}$.

haben aber schon gesehen, dass man den Polarstern leicht auffindet durch Verlängerung der Linie, welche die Sterne $\beta$ (beta) und $\alpha$ (alpha) des grossen Bären verbindet. Das Bureru des longitudes liefert in seinem Amuaire alljährlich eine Tabelle (s. nebenstehende Seite 75) welche es mögBär lich macht, den Zeitpunkt zu berechnen, in welchem der Polarstern den Meridian eines Ortes passirt $^{2}$ ), dessen Länge man annähernd kennt. Man hängt num z. B. an einem Baumast ein Senkblei auf, welches bis fast auf den Boden reicht. Im Momente, wo die oben genannten Sterne genau in derselben Linie mit dem Senkloth sich befinden, lässt man in der durch das Senkloth und den Polarstern bestimmten Richtung in einiger Entfernung einen mit einem Licht versehenen Stab aufstecken. Am folgenden Morgen bezeichnet man die durch diesen Stab und das Senkel gehende Linie auf dem Terrain in genügender Weise: das ist der gesuchte Meridian.

Auf der südlichen Hemisphäre rerfährt man ähnlich, bedient sich aber, da dort ein Polaistern wie auf der nörd-

1) Vgl. Sternkarte in D. Kaltbrunner, Aide-mémoire du Voyagcun,, Tuf. V (pag. 18).

2) Befindet sich ein Gestirn im Meridian eines Ortes, so nennt man dies die (obere oder untere) Kulmination des Sternes für jenen Ort. 


\section{Kulmination des Polarsterns für Paris pro 1881}

(Mittlere Zeit).

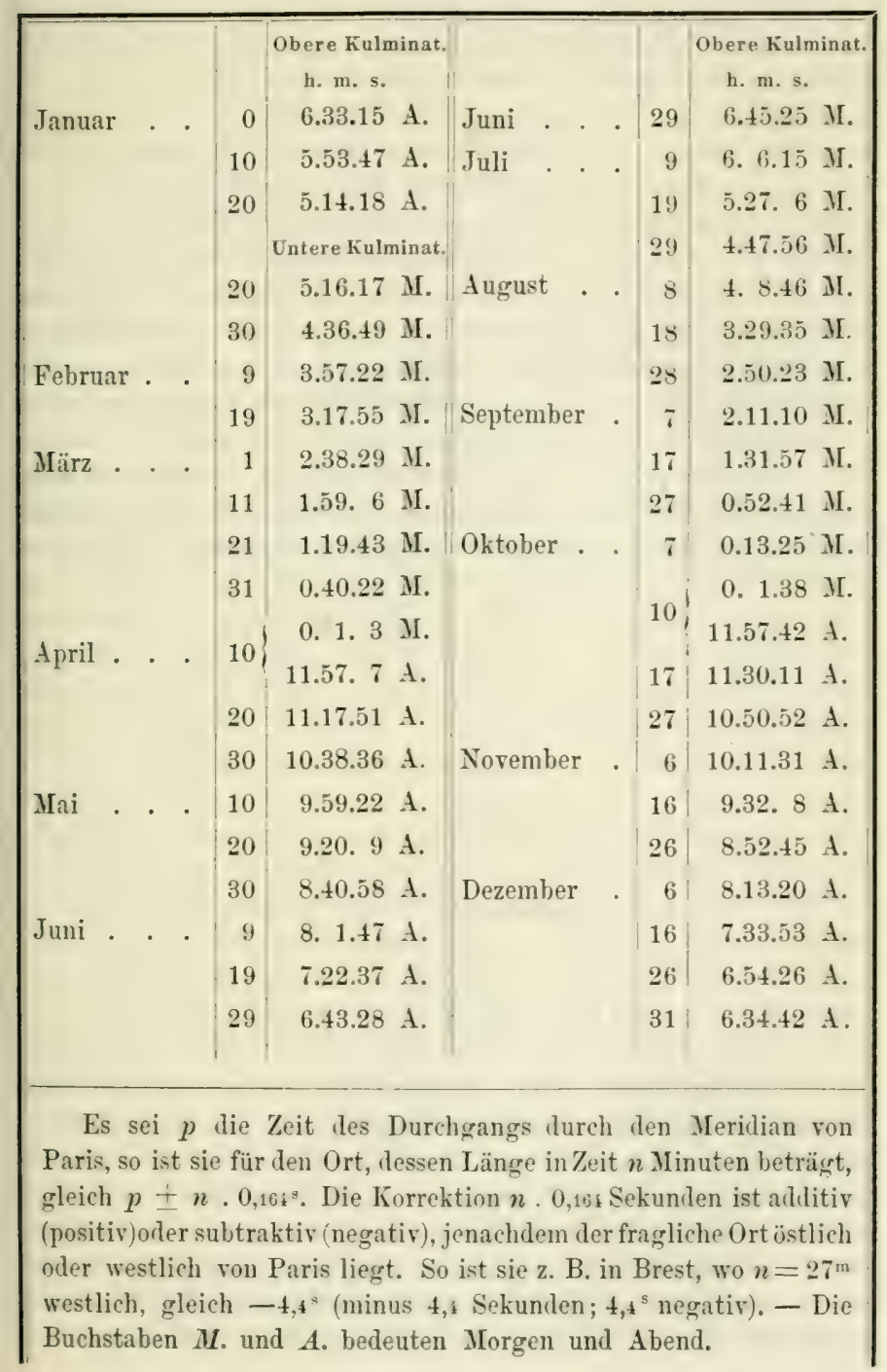


lichen Halbkugel nicht existirt, eines andern der dem Südpol des Himmels nächsten Sterne, indem man diesen zur Zeit seiner beiden Meridiandurchgänge (des obern und untern) beobachtet. (Als Südpolarstern kann am ehesten $\sigma$ Octantis Sigma im Oktanten — betrachtet werden.)

Die Zeit des Durchgangs oder Kulminirens - des obern wie des untern - ändert von einem Tag zum andern. Nan beobachtet nun bei Anbruch der Nacht, sobald Sterne sichtbar werden, die Bewegung sogenamnter Circumpolarsterne, welche nicht auf-oder untergehen, sondern sich beständig über dem Horizonte befinden. Da diese in $2 t$ Stunden einen vollen Kreis über dem Horizonte beschreiben, so kann man bis auf einige Minuten genau die Zeit abschätzen, zu welcher ihr Durchgang durch den Meridian (die Kulmination) stattfinden wird.

Zueite Methode. Es sei B (Fig. rG) der Ort, dessen Mittagslinie man bestimmen will; $L$ der Punkt des Aufgangs and $C$ derjenige des Untergangs der Somme am Horizont, endlich $L^{\prime}$ der Punkt des Sonnenaufgangs für den nächstfolgenden Tag.

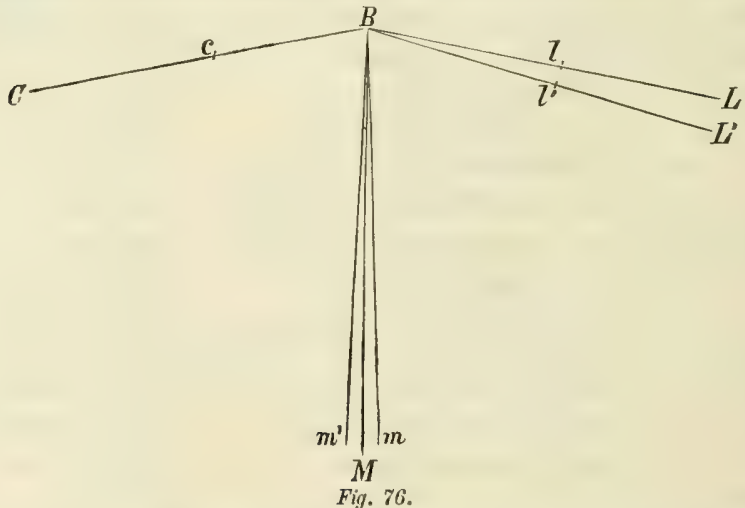

Die Richtungen nach diesen Punkten werden auf dem Terrain bezeichnet durch die Stäbe $l$ c $l^{\prime}$. Man halbirt nun die Winkel $L B C$ and $L^{\prime} B C$, erhält so die Richtungen $B m$ und $B m^{\prime}$ und halbirt endlich auch den neuen Winkel $m B m^{\prime}$ durch die Linie $B M$. Dies ist die Mittagslinie. Dieses Verfahren gibt indess nur dann gute Resultate, wenn der Horizont sowohl beim Aufgang als beim Untergang der Sonne ganz frei, ohne Wolken und Dünste ist. 
Dritte Methode. Dieselbe erfordert ein ganz flaches und ebenes Terrain oder eine horizontale Tafel mit einer vertikalen Stange, an welcher oben eine mit kleiner Oeffnung $m$ (Fi\%, ; r) versehene schwarze Eisenplatte so angebracht ist, dass sie Mittags die Lichtstrahlen möglichst genau in senkrechter Richtung empfängt. (Gnomon, Somnenzeiger). Mittelst eines Senkels projizirt man das Zentrum $m$ in $m^{\prime}$. Von $m^{\prime}$ als Mittelpunkt aus beschreibt man mehrere Kreise $p p^{\prime}, n n^{\prime}$ u. s. w. Indem man sodann den Lauf der Sonne vor und nach Mittag verfolgt, markirt man die Kurve $p n o n^{\prime} p^{\prime}$, welche beschrieben wird von dem beleuchteten Punkt, oder blos die Punkte $p n n^{\prime}$ u. s. w., worin diese Kurve die Kreisbogen — einen jeden zweimal schneidet. Durch die Mittelpunkte dieser Bogen zieht man die Gerade $m^{\prime}$ o $\sigma^{\prime} \sigma^{\prime \prime}$, welche die Mittagslinie angibt. Bei richtigem Verfahren müssen die Punkte m' o o' "o" genau in einer Geraden liegen; ist dieses nicht der Fall, so muss man diejenige Gerade nehmen, welche so genau als möglich jenen Punkten entspricht. Zur Bezeichnung der Mittagslinie auf dem Terrain wird man in der Richtung $m^{\prime} o^{\prime \prime}$ zwei Stäbe anbringen lassen. - Die genauesten Resultate erhält man durch diese Methode beim hüchsten Sonnenstand, zur Zeit der Sommersonnenwende; am ungenauesten fallen sie aus in der Zeit des tiefsten Sonnenstandes, im Wintersolstitium. (Vgl. die sachbezürgliche Note Seite 80, unten.)

Vierte Methrole. Sehr genau erhält man die Mittagslinie durch den Theodolit nach der sogerannten IIstlude der liorrespondirenden Sternhishen (vgl. Note S. 80), indem man folgendermassen $\mathrm{zu}$ Werke greht. Man visirt nach einem Fixstern ror seiner Kulmination, d. h. wenn er sich noch ostwärts rom Meridian hefindet - was man approximativ nach dem Polarstern oder nach dem Kompass beurtheilt und liest auf dem Horizontalkreis des Instrumentes (Limbus) ab. Dann richtet man das Fernrohr, ohne seine Neigung gegen den Horizont zu ändern, auf einen Punkt, der vom approximativ angenommenen Meridian in westlicher Pichtung an- 
nähernd denselben Abstand hat wie der Stern in seiner vorherigen Position, und man beobachtet nun den Stern, bis man ihn - ohne dass inzwischen der Neigungswinkel des Fernrohrs geändert, also dasselbe auf- oder abwärts bewegt worden wäre - wieder in der Mitte des Gesichtsfeldes (des Fadenkreuzes) in der Axe des Fernrohrs erblickt, und liest auf dem Limbus wieder die Fermrohrstellung ab. Das arithmetische Mittel beider Ablesungen (korrespondirenden Azimuthe, rgl. Note S. 80) gibt den Punkt der Theilung des Horizontalkreises, welcher genau der Meridianrichtung entspricht, und es bleibt nur übrig, diese Richtung durch Pflöcke zu markiren, beziehungsweise sich geeignete Gegenstände in derselben (Meridianzeichen) zu merken.

Diese Beobachtungen sind keineswegs auf die Nachtzeit beschränkt, denn mit einem guten Fernrohr sieht man die helleren Sterne auch bei Tage (vgl. Dr. G. Schröder, Sichtbarkeit der Sterne am Tage im Jahre 1881, Natur 1881, Nr. 6). Um aber bei Beobachtungen in der Nacht nicht blos die Uhrzeit, sondern auch die feine Theilung des Kreises ablesen zu können, muss der Reisende einen angemessenen Vorrath von Kerzen oder leuchtender Bleistifte (nach Bouquet de la Grye, vgl. D'Abbadie, Instruments, pag. 6) bei sich haben. Ferner ist für eine Vorrichtung zu sorgen, wonach das Fernrohrfadenkreuz in geeigneter Weise beleuchtet werden kann (vgl. Dr. Joh. Müller, Lehrbuch der kosmischen Physik IV. Aufl., Braunschweig 1875, Seite 25).

Die der beschriebenen Operation entsprechende Einstellung des Fernrohrs auf korrespondirende Somnentiölen resp. Korrespondirende Somen-Azimuthe — wobei vor das Okular des Fernrohrs ein dunkles Glas, das Sonnenglas, angebracht und auf den obern Sonnenrand visirt wird - ergibt die genauesten Resultate zur Zeit der Solstitien, die ungenauesten um die Zeit der Tag- und Nachtgleiche.

Geographische Ortsbestimmung. Als geographische Ortsbestimmung bezeichnet man die Ermittlung der geographischen Breite und Länge irgend eines Punktes der Erdoberfläche ${ }^{1}$ ).

1) Aus der Literatur über Ortsbestimmungen empfehlen wir namentlich: Albrecht und Vierow, Lehrbuch der Navigation, V. Aufl., Berlin 1877, wozu Ta- 
Die geographische Breite eines Ortes, d. i. dessen in Winkelmass ausgedrückter Abstand vom Erdäquator, ist yleich seiner Polliöhe, d. h. der Höhe des Himmelspols über dem Horizont dieses Ortes. Eine jede dieser beiden Grössen (geogr. Breite und Polhöhe) ist nämlich das Kromplement des Abstandes, in welchem sich das Zenith dieses Ortes rom Himmelspol befindet und welcher als Poldistanz de's Zenithis oder Zonithdistanz (Apromith) des Pols zu bezeichnen ist ${ }^{1}$ ).

feln von Domke, 7. Aut. (1879). (Aelteres, aber treffliches, mebr elementares Werk: v. Freeden, Handbuch der Nautik, Oldenburg 1861); - Ant. $d^{\prime}$ Abbadie, Instruments vgl. Note S. 14, Instructions pour les voyages d'exploration und Géodésie d'Ethiopie ;Dr. W. Jordan, physikalische Geographie und Meteorologie der libyschen Wüste, Kassel 1876.

1) Komplement eines Winkels oder Bogens beisst bekanntlich dessen Ergänzung zu 900. Zenith (Scheitelpunkt Z. Fig. 78 r) ist der Punkt des Himmelsgew genau über dem Haupte (Scheitel) des Beobachters o, in der nach dem Himmelsgewölbe verlängerten Loth-

linie $0 Z$ des Ortes. Dieser Punkt entspricht in seiner Lage auf der Himmelskugel dem Orte des Beobachters $o$ auf der Erde: Der Winkelabstand $A Z$ des Zeniths vom astronomischen oder Himmelsäquator (Deklination des Zcniths) ist gleich dem (ebenfalls in Winkel- oder Bogenmass ausgedrückten) Abstand jenes Ortes rom Erdäquator (geogr. Breite). Durch das Zenith gehen senkrecht zum Horizont $H H^{\prime}$ die Tertikalk'eise, $Z S R, Z S^{6} R^{6}$ u. s. w., deren gegemeinschaftlicher Durchmesser die Lothlinie $Z Z^{6}$ des Ortes ist. Der Ort eines Punktes (Sternes) $S$ in einem Vertikalkreise kann nun auf zwei Arten bezeichnet werden: entweder gibt man dessen Abstand $l i S$ rom Horizont oder den Abstand Z $S$ rom Zenitb an; der erstere Bogen $\left(I S, R^{6} S^{6}\right)$ ist die $H_{\bar{o}} h e$, der andere $\left(Z S, Z S^{6}\right)$ die Zenithdialunz des Punktes.

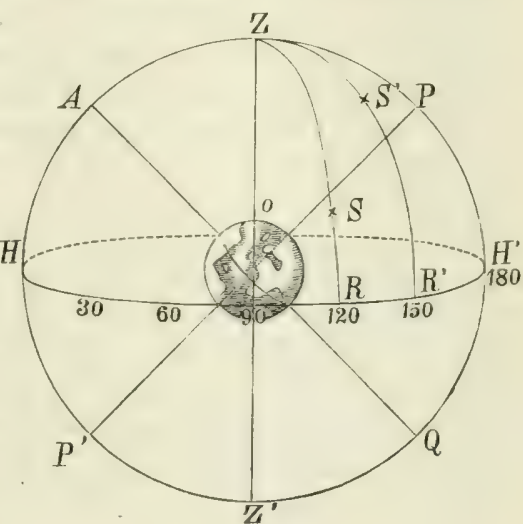

Fig. 78 a.

Höhe und Zenithdistanz eines und desselben Objektes machen also zusammen immer $90^{\circ}$ (einen rechten Winkel oder Kreisquadranten) aus. - Einer der Verticalkreise ist der astronomische Meridian $H A Z P H^{6} Q Z^{6} P^{6}$ des Ortes; auf ihm werden Höhe und Zenithdistanz der Himmelspole $P$ und $P^{\prime}$ sowie des Himmelsäquators $A Q$ gemessen, und $z$ wischen diesen Grössen besteht also die Beziehung, dass Aequatorhöbe $A H+Z$ Znithdistanz des A equators $A Z=90^{\circ}$ Polhöhe $H^{*} P \quad$ Zenithdistanz des Poles $P Z \quad 90^{\circ}$

Die Summe der vier aufeinanderfolgenden Grössen $H A, A Z, Z P$ und $P H^{6}$ ist 1800 , diejenige der beiden Apozenithe $A Z$ und. $Z P$ (Bogen zwischen Aequator und Pol) allein $90^{\circ}$, somit machen A equatorhühe $A H$ und Polhöhe $Y H^{\circ}$ zusammen ebenfalls noch $90^{\circ}$ aus, d. h. sie sind zu einander ebenfalls Komplementarwinkel. Wir fügen bei, dass die Iage eines einzelnen Vertikalkreises $Z S R$ bestimmt wird dureh Angabe des Winkels, welchen er mit dem Meridian $H A Z$ macht; diese Winkel, vom Sïdpunkte $H$ aus gezählt, sind die Azimathe.

Der Stern $S$ hat ein östliches Azimuth von $120^{\circ}, S^{\prime}$ ein solches von $150^{\circ}$ Tritt der Stern $S$ bei der scheinbaren täglichen Drehung der Himmelskugel von Ost nach West in den auf der westlichen Halbkugel liegenden Theil des Fertikal- 
Wenn z. B. (Fig. $\% 8$ ) die Höhe des Pols über dem Horizont $(\boldsymbol{\alpha})=35^{\circ}$, so ist der Zenithabstand des Pols $(\boldsymbol{\beta})$ $=55^{\circ}$; diese beiden Winkel oder Bogen sind komplementär,

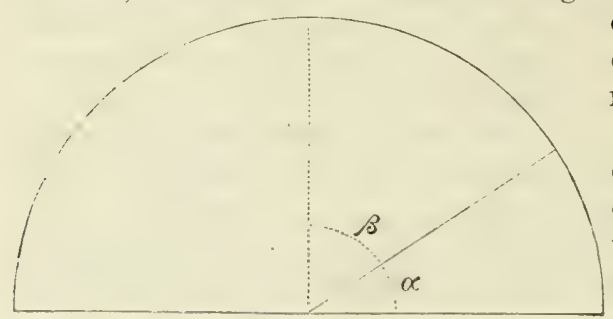

Fig. 78. da sie zusammen $90^{\circ}$ oder einen Quadranten ausmachen. Zur Bestimmung der geogr. Breite eines Ortes wendet man namentlich folgende Methoden an. Erste Methode. Man misst die Höhe pines dem Pole benachbarten Sternes (Circumpolarsternes) bei dessen beiden Durchgängen durch den Meridian (obere und untere Kulmination) und nimmt das Mittel aus diesen zwei Messungren. Lm das Resultat ron zufälligen Fehlern zu befreien, nimmt man diese Messungen bei mehr als einem Circumpolarsterne ror und leitet daraus einen Durchschnittswerth ab.

kreises $R S Z$ (dessen Fortsetzung man sich hinter der Zeichnungsebene zu denken hat, in velcher der Meridian $H Z H^{*} Z$ und vor welcher die Bogen $Z S R$ und $Z S^{*} R^{\prime \prime}$ liegen), so exreicht er daselbst mit dem westlichen Azimuth von $120^{\circ}$ wieder cine Höbe $=R S$ und ebenso wird sich $S^{*}$ wieder in einer Höhe $=S^{\star} R$ befinden, sowie er auf seiner scheinbaren tüglichen Bewegung das westliche Azimuth $150^{\circ}$ annimmt. Solche einander entsprechende Stellungen eines Punktes $S$ auf der östlichen und westlichen Ilalbkugel werden als korespondirende Höhen und korrespondirende Azimuthe tiezeichnet. Ueber die Verwertbung derselben für Ortsbestimmungen vgl. D'dbuadie, Instruments und Instructions p. 264. - Meist werden übrigens die Azimuthe vom Südpunkte aus nicht nach zweiSeiten, sondern nur nach einer lichtung und zwar im Sinne der Uhrzeigerbewegung (von Süd über West, Nord, $H^{\prime}$ etc.) von 0 bis $360^{\circ}$ gezäblt. Hienach wäre das Azimuth von $S=240^{\circ}$, das Azimuth von $S^{\circ}$ $=210^{\circ}$. In beiden Fällen ist das Azimuth von $A, H$ und $P^{\kappa}=0^{0}$, das von $P, H^{3}$ und $Q=180^{\circ}$.

Auf Grund vorstehender Erklärungen bemerken wir noch, dass der Gnomon Fig. 77 auch zu० annühernden Bestimmung ron Hohe (Zonithdistanz) und Asimuth dev Sonne in einem gegebenen IIoment benutzt werden kann. Ist einmal die Hittagslinie $00^{6} 0^{6}$ festgestellt, so ist der Winkel $p m^{6} 0^{e r}$ das Azimuth der Sonne für den Moment, wo ihre Strahlen die Oeffnung $m$ auf $p$ projiziren. Der Winkel $m^{\circ} l m$ (Einfallswintel der Sonnenstrahlen) gibt die Höhe der Sonne für den gleichen Moment, und $p m m^{6}$ ist der Winkelwerth des zugehörigen Zenithabstandes, denn $p m m^{\prime}$ ist in dem bei $m^{*}$ rechtwinkligen Dreieck $p m^{*} m$ das Komplement zum Winke! $m^{\circ} p$ und der "Scheitelwinkel* der Zenithdistanz (Scheitel $m$ ). Bezeichnen wir für diese Stellung der Sonne den Höhenwinkel $m^{\circ} p m$ mit $h$, so ist $\frac{m m^{*}}{m^{*} p}=t a n y$ h. Wäre z. B. das Verhältniss (der Bruch) $\frac{m m^{*}}{m^{*} p}=1: 3$, so betrüge nach $T \iota f$. S. 48 die Sonnenhöhe annähernd $181 / 20$; mittels vollständigerer Tafeln (z. B. Kaupert) findet man für diesen Fall die Höhe genauer $=18^{\circ} 26^{6}$.

Von diesem Verfahren unterscheidet sich die Bestimnung der Sonnenhöhe mit einem Sextanten einfachster Art (Müller, a. a. O., S. 93) im Prinzip wesentlich nur dadurch, dass der Fusspunkt $p$ der Linie $p m$ fest bleibt, hingegen dem Punkto $m$ eine nach der Sonnenböhe wechselnde Lage gegeben wird. 
Zureitr Mrthude. L'm dieses Verfahren Methode der cinfurden Mrevidiuhlïhen) anwenden zu künnen, muss man gewisse astronomische Tafeh zur Hand haben, welche, mit den zu ihrem Gebranche nothwendigen Erläuterungen versehen, jührlich reröffentlicht werden. Solche Puhlikationen sind: das nutische Jathlunh oder Ephemeriden und Tafeh, herausgregeben rom deutschen Reichskanzlerant (früher von Dl. Bremiker), redigirt von P'rof. Tietjen: das Berliner astrmomischer Jahllurh, redigirt ton den Professoren Förster und Tietjen: die Commaissuner des Trmps. herausgegeben ron dem franzïsischen Burran des Lmugitudes. dessen schon erwïhntes Ammuir Auszüge aus jenem voluminöseren Werke gibt:

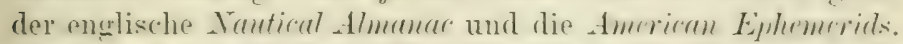

Man misst dip Zenithdistanz z pines Gestimes hei dessen Meridiandurchgang (hulnination) und sucht in den Tafeln die Deklination $\delta$ (delta) desselhen, d. h. seinen Abstand rom Himmelsäyuator. Handelt es sich um die olser hulmination eines Fixsterns (wobei derselhe seine grösste Höhe erreicht) und findet sie zwischen Zenith und leyuator statt, so ist die gesuchte Breite $\mathscr{T}$ (phi) gleich I)eklination plus Apozenith (of $=\delta-z$ ): liegt die Stelle des obern Durchgangs zwischen Zenith und Y'ol, so ist die Breite gleich Deklination minus Zenithdistanz ( $f=\delta-Z$ ). Handelt es sich aber - bei einem Cirkumpolarstern - um den untern Inurchgange (wobei der stern den tiefsten Punkt in dem Kreise annimmt, welchen er bei der scheinharen täglichen Drehung des Himmels beschreibt), so ist die Breite das Supplement zu der summe ron Deklination und Apozenith, d. h. gleich $180^{\circ}$ weniger jene Summe: $\varphi=180-(\delta+z)$.

Es sei beispielsweise $a$ (Fig. $\% 9$ ) ein Gestirn in seiner obren Kulmination arischen Zenith und ferpuetror: seine-Zenithdistanz $z=a Z$ sei $15^{\circ}$; seine Deklination $\delta=E a$ betrage nach den astronomischen Tafeln für die Zeit der Beobachtung $20^{\circ}$, so giht die summe $20-15=35^{\circ}$ die Polhöhe oder geographische Breite $(\varphi=H P$ ) des Beohachtungsortes: dem die Bogen $E Z$ (Summe ron a $Z$ und a $E$ ) und $H P$ gehören zu Winkeln, deren Schenkel auf einander senkrecht stehen (S. 55 ) und ein jeder ron ihnen macht mit $P Z$ zusammen die gleiche Grösse $\left(90^{\circ}\right)$ aus. Steht hingegen ein Stern b in oberer Kulminution zucischen 
Zenith and $P o l$, ist seine Zenithdistanz $Z b=50^{\circ}$, seine Deklination $E b$ nach den Tafeln $=85^{0}$, so gibt die Differenz $85^{0}-50^{\circ}=35^{0}$ die Polhöhe oder geographische Breite - aus demselben Grunde, nur dass vorhin der Bogen

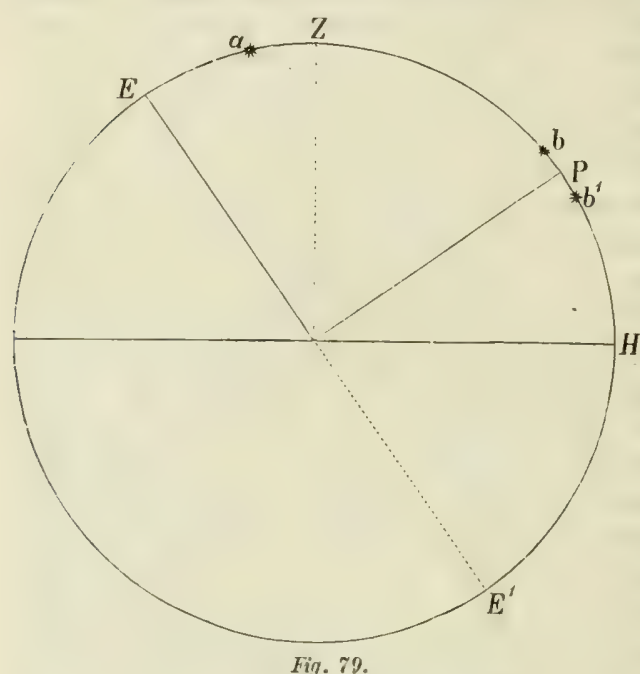
$E Z$ als Summe $(E a+a Z)$, jetzt aber als Differenz ( $E$ b $b-$ $Z$ b) erscheint. Wird endlich der letztere Stern in unterer Kulmination $b^{\prime}$ beobachtet, $H_{\text {so }}$ ist die Zenithdistanz nun $Z b^{\prime}$ $=60^{\circ} ;$ die aus den Tafeln zu entnehmende Deklination ist aber gleich gross wie vorhin, indem sie sich 'auf den diametral der Stelle $E$ gegenüberliegenden Punkt $E^{\prime}$ bezieht $t^{1}$ ), und es ist nun die geographische Breite oder Polhöhe $35^{\circ}=180^{\circ}-$ $\left(85^{0}+60^{\circ}\right)$. Es ist nämlich immer der Bogen $H P=Z E$; dieser Bogen $Z E$ aber erscheint jetzt als Halbkreis $E Z H E^{\prime}$ $-Z E^{\prime}$, and $Z E^{\prime}$ ist gleich $Z Z^{\prime}$ (Zenithdistanz) $+b^{\prime} E^{\prime}$ (Deklination), also

$$
H P=E Z=180^{\circ}-\left(Z b^{\prime}+b^{\prime} E^{\prime}\right)
$$

Die Deklination eines Gestirnes muss immer korrigirt werden um den Betrag der Prïzession (Verschiebung der Nachtgleichenpunkte nach Westen), der Nutution (des Schwankens der Erdaxe in Bezug auf den Kreis, welchen ihr Pol zufolge jener Verschiebung am Himmel beschreibt) und der Aberration des Lichtes $\left.{ }^{2}\right)$. Die erwähnten Tafeln geben aber

1) In der scheinbaren täglichen Bewegung des Ifimmels beschreibt jeder Stern einen Kreis parallel zum Aequator, behält also seine Distanz von Aequator und Pol unverändert bei.

2) Betreffend Präzession und Nutation vgl, die trefflichen Grundzüge der matbematischen Geographie" ron Anton Steinharser, 2. Auf, (Wien 1880), S. 64, V. Adam, 2. Aufl. (Karlsruhe 1881), S. 28, sowie J. J.v. Littrow, die Wunder des 
jedes Jahr die scheinbaren Oerter der hauptsächlichsten Sterne für so viele Zeitpunkte (für jeden 10. Tag), dass dadurch jene Rechnungen erspart werden. Vgl. z. B. das Berliner astronomische Jahrbuch für 1881, S. 181 ff. Betreffend die Kulminationszeit vgl. S. 92.

Soll diese Methode zn möglichst genauen Resultaten führen, so ist nöthig, dass der Reisende rechtzeitig in Besitz der erwähnten Jahrbücher gelange, beziehungsweise an einem Orte stationire, wo er die zum bezeichneten Zwecke erforderlichen Terbindungen unterhalten kann, und wir haben die Methode zunächst im Hinblick auf solche Fälle besprochen. Da indess die Aenderungen der Deklination bei den Fixstemen im Laufe eines Jahres minim sind im Verhältniss zu dem durch einen Theodolit von geringen Dimensionen erreichbaren Grade von Genauigkeit - ein kleines Instrument gibt die Winkel kaum genauer als auf Minuten so kann man sich auch nur mit einer Tabelle versehen, welche die mittleren Oerter der Henptsterne für das ganze Jahr enthält. Das nautische Jahrbuch gibt die mittleren Oerter ron 75 Hauptsternen, das Berliner astronomische Jahrbuch die von 47 Hauptsternen und 25 anderen hellen Sternen, das "Annuaire" von 26 Hauptsternen und über 200 reränderlichen Sternen. Vgl. Anhang und Dr. Wolfs Tof. XIX.

Statt der Höhe eines kulminirenden Fixsternes bestimmit man behufs Ermittlung der geographischen Breite auch die Theridiunhighe der somme und zwar ihres obern Randes. Man risirt im wahren Mittag. des Ortes, d. h. wenn die Sonne durch dessen Neridian geht, nach dem obern Rande (Gipfel) derselben, indem man, wie schon bemerkt, rorher am Theodolitfernrohr ein Sonnenglas anbringt. Die Ephemeriden der astronomischen Jahrbücher geben für jeden Tag die Deklination der Sonne an, d. h. den Abstand ihres Mittelpunktes rom dequator ${ }^{1}$ ). $\mathrm{Cm}$ aus der direkt gemessenen Meridianhöhe des obern Sonmenrandes diejenige des Sonnenmittelpunktes zu finden, hat man von ersterer den halben Durchmesser der Sonne zu subtrahiren, welcher ca. 16 Bogrenminuten $\left(16^{\prime}\right)$ beträgrt und dessen Werth für die

Himmels, 6. Aufl. (von Karl Littrow, Berlin 1878) §§ 183 ff; betreffend Aberration Kap. VI des letzteren Werkes.

1) Je nach 4 Jahren wiederholen sich nahe dieselben Deklinationen. Wolf, Taf. XYI. 
Zeit der Beobachtung nebst der Korrektion wegen Refraktion wiederum den astronomischen Tafeln zu entnehmen ist. (Vgl. auch Wolf, Taf. 1i u. 13.) Subtrahirt man nun von dieser Sonnenhöhe die gleichzeitige Deklination des Sonnenmittelpunktes, so erhält man die Höhe des Aequator's, zu welcher die Polhöhe Komplement ist. Ygl. S. 79. - Aus der Anmerkung auf S. 80 ergibt sich, dass die Somenhöhe approximativ auch ohne ein winkelmessendes Instrument bestimmt werden kann. Die Höhe eines Gnomons dividirt durch die Länge seines Schattens in der Mittagslinie (bezw. die Höhe eines vertikal aufgestellten Stabes, dividirt durch die Länge des Schattens, welchen er im wahren \littag auf eine horizontale Ebene wirft) gibt die Tangente der gesuchten Sonnenhöhe, womit die letztere bestimmt ist. (S. 48.)

Die geographische Länge eines Ortes ist der Winkel, den sein Mexidian mit einem andern bildet, welchen man als Nullmeridian $\left(0^{\circ}\right)$ annimmt, oder also der in Winkelmass ausgedrüclite Bogen auf der Erdoberfläche zwischen diesen beiden Meridianen (senkrecht zu denselben genommen). Da die Meridiane der Erdkugel den Stundenliveisen der Himmelskugel entsprechen, so ist die Lüngendifforenz zweier Orte gleich dem Lnterschich der Stundemuinkel, welche ein beliebiger Himmelskörper in einem und demselben Zeitpunkte an den beiden Orten hat, oder gleich dem Luterschied der Ortszeiten (Mittaysunterschichl), wobei es gleichgültig ist, ob man diesenZeitunterschied als Differenz der Sternzeiten, Differenz der mittleren oder Differenz der wahren Sonnenzeiten auffasse. Endlich kann dieser Unterschied definirt werden als die Differenz', welcher zuschen den Relitaszensionen der Scheitelumbite zueien Beobachtun!sorte in einem und demselben Zeitpunlite stattindet. Dieser Zeitunterschied ist mit $15 \mathrm{zu}$ multipliziren, um denselben in Winkelmass auszudrücken ${ }^{1}$ ).

Die geogr. Länge wird nach folgenden Methoden bestimmt:

$1^{\circ}$ Als Mittagsunterschied durch Benbachtung der Somnenhulminationszeit eines Ortes mittelst des Chronometers, das regulirt ist nach dem mittleren Nittag derjenigen Sternwarte, von welcher aus man die Längengrade zählt.

1) Stundenkreise heissen die grössten Kreise, welche man an der scheinbaren IIimmelskugel durch die beiden Ruhe. oder Angelpunkte ihrer Drehung, die Pole, gezogen denkt. Solche Kreise durch die Pole $P$ und $P^{*}$ senkrecht zum Aequator 
Die Zeitangahen im -Nautischen Jahrbuch" beziehen sich auf den Meridian der Sternwarte zu Greenwich, diejenigen des -Amuaire", bezw. der "Commaissance des Temps", auf Paris, diejenigen im _Berliner astronomischen Jahrbuch" auf Berlin. Das . Nautische Jahrbuch" und .Berliner astro-

A $Q$ sind $P S P^{\prime}$ und $P S^{\circ} P^{\prime}$ Fig. 79 a. Auf ihnen werden die Deklinationen oder Abrcichungen $D S, D^{\prime} S^{\prime}$ und die Poldistunzen $P^{\prime} S$, $P S^{\prime}$ gemessen, welche letzteren die Komplemente der ersteren sind. Aurh der astronomische Meridian $Z P Y P^{\prime} A$ ist ein solcher Stundenkreis; er gehört eben den beiden Kreissystemen des Horizonts (Fig. $78(t)$ und des Aequators (Big. 79 a) zugleich an: er ist der Vertikalkreis durch den Pol und der Stundenkreis durch das Zenith; $A Z$ ist Zenithabstand des dequators und Deklination des Zeniths, $P Z$ ist Zenithabstand des Pols und Poldistanz des Zeniths.

Stundentinkel heisst der Winkel, welchen der astronomische Meridian eines Ortes (Stundenkreis 0 ) mit einem andern, durch irgend ein Beobachtungsobjekt am Himmelsgewölbe (z. B. durch den Sonnenmittelpunkt)gelegtenStundenkreise bildet. Diese Winkel werden in derltichtung der scheinbaren täglichen Bewegung des Himmelsgew ülbes, also rom Meridian aus nach Westen - im gleichen Sinne wie dieAzimuthe -

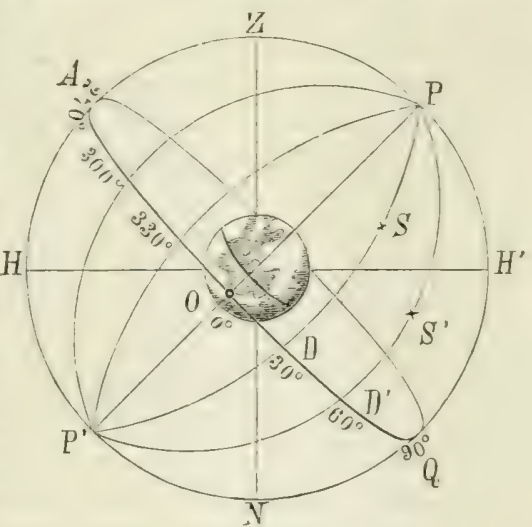

Fig. $79 a$. gezählt, in der Regel aber nicht nach Graden (Winkelmass) ron 0 bis 360 , sondern nach Stunden (, in Zeit") von 0 bis 24 ; es ist also $1 \mathbf{h}=150$, und dieselbe Beziehung besteht zwischen Zeitminuten und Bocrenminuten, Zeitsekunden und Bogensekunden: $1 \mathrm{~m}=15 ;, 1 \mathrm{~s}=15 \%$. Es haben also die verschiedenen Punkte in unserer Figur folgende Stundenwinkel: $Z, A$ und $H$ immer $0 \mathrm{~h}=00 ; H^{\prime}, Q$ und $Y$ immer $12 \mathrm{~h}=180^{\circ} ; S^{\prime}: 14 \mathrm{~h}=2100 ; S: 16 \mathrm{~h}=2400 \mathrm{u}$. s. $\mathrm{K}$. Die Stundenwinkel auf der östlichen Halbkugel, links rom Meridian (in der Zeichnung diesscits der Bildebene oder Papierfläche) können (gleich wie die Azimuthe auf dieser Halbkugel) vom Meridinn aus nach Osten gezählt werden; sie sind dann aber auch ausdrücklich als östliche Stundenwinkel zu bezeichnen. Für $S$ wäre der östliche Stundenwinkel $\mathrm{Sh}=1200$, für $S^{\circ}: 10 \mathrm{~h}=150^{\circ}$; für $Z, A, H$, wie für $H^{\prime}, Q$ und $N$ bleiben die ohbemerkten Werthe.

A uf eine ztceite Art werden die Winkel der Stundenkreise angegeben mit Bezug auf den Punkt $O$ des dequators, in welchem sich am 21. März (Frühlingsuachtgleiche) der Mittelpunkt der Sonne befindet, wenn diese aus dem tiefern Theil der Bahn, welche sie auf ihrer scheinbaren jährlichen Bewegung von West nach Ost beschreibt, in den höhern Theil derselben übergeht. Dieser Punkt ist der Frühlingsoder Widder-Punkt $\left(0^{0}\right)$, der Stundenkreis durch denselben das holur der Wachtgleichen. (Dass letzteres, $P O P$, in der Figur senkrecht zum Meridian steht, in gleichen Abständen ron den Punkten $\mathcal{A}$ und $Q$, ist eine beliebige Annahme; Punkt 0 könnte auf dem Aequator ebensogut irgendwo anders, in irgend welchem A bstande von $A$ oder $Q$, angenommen werden). Der Winkel, welchen der Stundenkreis eines Gestirnes $S$ mit dem Aequinoktialkolur bildet, beziehungsweise der entsprechende bogen $\left(O D=30^{\circ}\right)$ auf dem Aequator - vom Frühlingspunkt an ostecirts gezäblt - heisst die Rektaszension oder gerude Aufsteigung jenes Sternes. Sie kann in Graden etc. oder (als . Kektaszension in Zeit ${ }^{\text {") }}$ in Stunden ete. angegeben werden. Die Rektaszension des Sternes $S^{\prime}$ ist also der Bogen $0 D^{\prime}=60^{\circ}$ 
nomische Jahrbuch" zählen die Stunden nach astronomischem Gebrauche von 0 bis 24 ab Mittag, sodass der astronomische Tag 12 Stunden später beginnt als der bürgerliche Tag desselben Datums; das "Annuaire" hingegen wendet die bürgerliche Zeitrechnung an, sofern nicht ausdrücklich etwas Anderes bemerkt ist.

$=4 \mathrm{~h}$; diejenige des Punktes $H^{\prime}$ ist $O Q=$ (nach der erwähnten Annahme) $90^{\circ}=6 \mathrm{~h}$, und diejenige von $Z$ ist (wieder in jenem Sinne) $0 Q A=270^{\circ}=18 \mathrm{~h}$.

Der Ort eines Himmelskörpers in Bezug auf den Aequator (in AequatorialKoordinaten) ist also bestimmt einerseits dureh Deklination und Stundenwinkel, andrerseits Deklination (Abweichung) und Rektaszension (Gradaufsteigung, Ascensio recta $=A l i)$. Diese Begriffe entsprechen beziehungsweise den geographischen Ausdrücken Breite und Länge, wäbrend die ustionomischcn Begriffe "Länge und Breite ${ }^{\alpha}$ sich auf die scheinbare Sonnenbahn (Ekliptikal-Koordinaten) beziehen.

Wuhve Sonnenzeit oder kurz wahe Zeit für einen bestimmten Ort und Moment ist der Stundenwinkel der Sonne (ihres Mittelpunktes) für jenen Ort und Zeitpunkt; wuher Hittag eines Ortes ist die Zeit der. Sonnenkulmination, wo jener Winkel 0 ist. Die Veränderung des Stundenwinkels der Sonne ist eine ungleichfürmige Bewegung; neben der wirklichen oder wahren Sonne nimmt man daher eine ideelle sogenannte mittlere Some an, welche mit gleichfürmiger Geschwindigkeit den L"mlauf im Himnelsäquator in derselben Zeit vollendet wie die wahre Sonne mit ungleichfürmiger Geschwindigkeit ihren jährlichen Umlauf in der Ekliptik. Diese mittlere Sonne ist in Bezug auf die wahre bald voraus, bald zurück; ihr Stundenwinkel ist die mittlcre Somnchzcit oder kurz mittlerc Zcit; muss sie im Meridian des Ortes befindlich gedacht werden, so hat dieser seinen mittleren Mittur. Die Zeit zwiscben zwei Í́uminationen der mittleren Sonne ist der mittlere Sonnentug. Die jeweilige Differenz zwischen wahrer und mittlerer Zeit, oder der Winkel zwischen den Stundenkreisen der wahren und mittleren Sonne in jenem Moment, heisst die Zrityleichung; es ist der Stundenwinkel der mittleren Sonne im wahren Mittag oder der Stundenwinkel der wahren Sonne im mittleren Mittag. (Wolf Taf. 17.)

Während die bürgerliche Zeitrechnung unter einem Tug den Zeitraum von Mitternacht zu Mitternacht versteht und in dieser Periode zweimal zwölf Stunden zählt, versteht die ustronomische Zeitrcchnung unter einem Tug den Zeitraum von einem Mittag zum andern und zählt hiebei von 0 bis 24 h. Die zucite Hälfte dieser Stunden (13 bis 24), um 12 rermindert, sind also Formittugsstunden des nïchstjolgenden Tuges nach bürgerlicher Zeitrechnung; $z$. B. bedeutet die astronomische Bezeichnung, 8 . Februar $16 \mathrm{~h}$ in bürgerlieher Zeitrechnung: 9. Februar 4 Uhr Morgens. Denken wir uns in Fig. 79 " unter $S$ die Sonne, so stellt die Figur die 16. Stunde dar, $S^{4}$ aber die 14. Stunde (2 Uhr Morgens).

Sternङcit heisst der Stundenwinkel des Frühlingspunktes für einen gegebenen Ort und Moment; nach Analogie des Ausdruckes Sonnenzeit wäre derselbe als Frithlingspunktzeit zu bezeichnen. In unserer Figur ist es der Bogen $A Q 0=18 \mathrm{~h}$ $=270^{\circ}$. Die Sternzeit ist glcich $A R$ dcs Zcuiths (Gradaufsteigung des Scheitelpunktes) $O Q A$ der Figur; es wird nur der Winkel oder Bogen nicht beide mal in gleicher, sondern in entgegengesetzter Richtung gemessen. Es ist $0 \mathrm{~h}$ Sternzeit und $0^{0} A h$ des Zeniths, wenn der Frïhlingspunkt sich im Meridian befindet; die Zeit zwischen $\mathrm{zwei}$ solchen Kulminationen des Widderpunktes ist ein Sterntag. Derselbe ist um $3 \mathrm{~m}$ 55,9s mittlerer Zeit kürzer als der mittlere Sonnentag, oder dieser ist um $3 \mathrm{~m}$ 56,5s Sternzeit länger als der Sterntag. ( $\mathrm{V}$ gl. die Tabelle sternzeit in Paris im mittleren Mittag ${ }^{4}$ Annuaire 1881 pag. 69 und 70, ferner die Tafeln von Domke S. 91/92). - Nimmt man einen beliebigen Himmelskörper $S$, $s_{n}$ ist der Stundenwinkel $A O D$ gleich der Sternzeit des Ortes ( $A R$ des Zeniths) $A Q O$ weniger die $A R$ des Sterns, $O D$. Ist $S$ die Sonne, so folgt hieraus, das die sternzeit $(A Q O=18 \mathrm{~h})$ gleich der wahren Zeit $(A Q D=16 \mathrm{~h})$ plus $A R$ der wahren Sonne $\left(O D=30^{\circ}=2 \mathrm{~h}\right.$ Rektaszension in Zeit) oder also die wahre Zeit gleich Sternzeit minus $A R$ der wahren Sonne, folglich die mittlere Zeit gleich Sternzeit minus $A R$ der mittleren Sonne. - Es ist zu empfehlen, dass man sich mit all diesen Begriffen mittelst eines Himmelsglobus gründlichst vertraut mache. Vgl. Littrow, a. a. O. I. Bd. Kap. XIII und für die Verwandlung der verschiedenen Zeitarten in einander die "Geographische Ortsbestimmung " von Bohnenberger-Jahn $\$ 70$. 
Aus der Angabe über die Zeitgleichung ersieht man, wann an einem gegebenen Tage nach mittlerer Zeit die Somne im angenommenen Nullmeridian kulminirt; dieser Zeitpunkt sei $t$. Man hat nun lediglich unter Benutzung des Chronometers den Zeitpunkt zu bestimmen, in welchem am Beohachtungsorte die Kulmination stattfindet. Diese Mittargszeit des Ortes, dessen Länge gesucht wird, lässt sich nun ausser in direkter Weise ermitteln durch Beobachtung der Zeitpunlite korrespondirender Somnenhijhen. Nan visirt am Vormittag nach dem obern Sonnenrande und notirt nach dem Chronometer die Zeit, da derselbe eine bestimmte Höhe erreichte. Am Nachmittag stellt man, unter Beibehaltung jenes Höhenwinkels für das Fernrohr, dieselbe Beobachtung an. Das arithmetische Mittel der beiden Chronometerablesungen gibt die mittlere Greenwicher (Pariser, Berliner) Zeit für den wahren Mittag des Beobachtungsortes; wir wollen sie mit $t_{1}$ bezeichnen. Jie Differenz zwischen den beiden Zeiten $t$ und $t_{1}$ gibt die geographische Länge des Ortes mit Bezug auf den angenommenen Ausgangspunkt (Greenwich etc.), ausgedrückt in Zeit; multiplizirt man mit 15, so hat man die Angabe in gewöhnlicher Kreistheilung.

Der Ort, um den es sich handelt, hat östliche Länge, wenn seine Zeit derjenigen des Chronometers voraus ist; westliche Länge im entgegengesetzten Fall.

Zum Beispiel zeige das Chronometer in dem Momente, da die Sonne im Orte $A$ kulminirt, $11^{\mathrm{h}} 19^{\mathrm{m}} 55^{\mathrm{s}}$ wahre Greenwicher Zeit (incl. Zeitgleichung), so ist der Längenunterschied $40^{\mathrm{m}} 5^{8}$ oder (nach Multiplikation mit 15) $10^{\circ} 1^{\prime} 15^{\prime \prime}$. Dies ist die westliche Länge von $A$ mit Bezug auf den Nullmeridian.

Zeigte aber das Chronometer für den Moment der Sommenkulmination im Orte $B \quad 2^{\mathrm{h}} 45^{\mathrm{m}} 20^{\mathrm{s}}$ wahre Zeit Gr., so wäre diese Zahl die Längendifferenz in Zeit; mit 15 vervielfacht, gibt sie $41^{\circ} 20^{\prime}$ östliche Länge von Greenwich.

$2^{\circ} \mathrm{Als}$ Zeitunterschied in einem beliehigen Nomente durch Bestimmung der Ortszeit roraus berechneter Erscheinungen (am Himmer, welche für eine ganze Erdhälfte gleichzeitig sichtbar sind oder bei denen man, wenn sie nicht überall im selben absoluten Noment gleich gesehen werden, den Einfluss der Länge in Rechnung ziehen kann. Solcher Be- 
obachtungen muss man sich immer bedienen, wenn die Reise längere Zeit - mehrere Monate - dauert, ohne dass man Gelegenheit hat, an einem Orte von bekannter Länge die Uhr zu verifiziren. Zu Ermittlungen dieser Art eignen sich für den Reisenden die Verfinsterungen der Jupiters-Trabanten, ferner die sogenannten Bedeckungen von Fixsternen und Planeten, endlich gewisse Mondbeobachtungen.

In den erwähnten Jahrbüchern findet man Angaben über die Zeit der Jupiters-Trabanten-Vertinstermugu nach Anfang und Ende (Eintritt des betreffenden Jupitermondes in den Schatten des Planeten und Austritt aus demselben, so für die beiden inner'n Satelliten) oder für die Mitte der Verfinsterung und ihre Dauer (so hinsichtlich der beiden äusseren Trabanten). Vgl. Annuaire 1881 pag. 60 und 61, Berliner astronomisches Jahrbuch 1881 und 1882, S. 168 ff., Nautisches Jahrbuch je auf Seite VI der Ephemeriden jedes Monats. - Diese Zeitangaben beziehen sich auf den Nullmeridian. Man beobachtet num jene Erscheinungen am Aufenthaltsorte durch ein Fernrohr ron genügender Stärke (welches den Polarstern deutlich als Doppelstern zeigt ${ }^{1}$ ) und bestimmt die Ortszeit ihres Eintrittes, die man vorher durch Beobachtung der Sonnenkulmination verifizirte. Der Unterschied zwischen der so beobachteten Ortszeit und der für den nämlichen absoluten Moment geltenden Zeitangabe im astronomischen Kalender (Jahrbuch) gibt die Längendifferenz. Man beobachtete z. B. in Calcutta am 27. Februar 1823 den Austritt des ersten Jupitermondes aus dem Schatten des Planeten um $8^{\mathrm{h}} 44^{\mathrm{m}} 49^{\mathrm{s}}$ mittlerer Ortszeit; nach den Vorausberechnungen erfolgte in Paris das Ende der Verfinsterung $\mathrm{um} 3^{\mathrm{h}} 0^{\mathrm{m}} 47^{\mathrm{s}}$; es betrug also der Zeitunterschied $5^{\mathrm{h}} 44^{\mathrm{m}} 2^{\mathrm{s}}$, woraus sich für Calcutta eine östliche Länge von $86^{\circ} 0^{\prime} 3^{\prime \prime}$ von Paris ergibt. (Hann und Hochstetter, Allgemeine Erdkunde, 3. Aufl. 1880 S. 14.) Die Beobachtung eines solchen Phänomens ist zugleich ein Nittel, um den Gang des Chronometers zu kontroliren und zu korrigiren.

In die zweite der vorhin erwähnten Kategorien zu den Erscheinungen, welche für weit entfernte Orte nicht genau gleichzeitig sichtbar sind, gehören die Sterubedeckungen.

1) Vgl. Dr. H. Klein, Anleitung zur Durchmusterung des Himmels, Braunschweig 1880, pag. 581. 
In ca. $27^{3} / 4$ Tagen vollbringt der Mond am Himmel in der Richtung von West nach Ost einen vollen L'mlauf; im Durchschnitt legt er täglich einen Weg ron über $13^{\circ}$, stündlich also von über 32' (ungefährer Durchmesser der Mond-, sowie der Somnenscheibe) zurück; dabei geht er nun ofters vor Fixsternen und Planeten (in der geraden Linie zwischen diesen und der Erde) vorüber, sorlass dieselben dem Beobachter durch den IIond für eine Zeit lang entzogen werden. Dieses Verschwinden eines Gestims hinter der Mondscheibe heisst eine sternbedectum (Occultation). Wir geben im Anhang ein Verzeichniss ron Sterubedectungen für das Jahr 1882; hinsichtlich derjenigen im Jahr 1881 verweisen wir auf das Annuaire pag. 62 und das Berliner astronomische Jahrbuch S. $248^{1}$ ). Nan ermittelt wierler die Ortszeit des Beginnes (Eintritts) sowie des Endes der Erscheinung und vergleicht die Resultate mit jenen Daten der astronomischen Kalender. Eine Stembedeckung wird aber nicht an allen Orten, wo sie überhaupt sichthar ist, im gleichen Moment gesehen; da der Mond einen verhältnissmässig geringen Abstand von der Erde hat, so erblickt man ihn von zwei weit auseinanderliegenden Orten $A$ und $B$ der Erde auf dem fernen Hintergrunde des Fixsternhimmels an zwei verschiedenen Stellen $a$ und $b$. Befindet sich der Beobachtungsort $A$ ostwärts von $B$, so ist die Stelle a des Firmanentes, an welcher der Mond von $A$ aus erscheint, westlich von $b$, wo ihn der Beobachter in $B$ sieht; liegt $A$ nördlich von $B$, so ist $a$ südlich von $b$. Ueber diese Verschiebung oder Parallaxe (Höhenparallaxe) des Mondes, welche bei diesen und ähnlichen Beobachtungen berücksichtigt werden muss, findet man Angaben in den Nautischen Jahrbüchern. Durch Anbringung der Parallaxe wird die Beobachtung auf den Erdmittelpunkt reduzirt oder der ferocentrische Ort des Mondes (der Punkt des Himmels, in welchem die Erscheinung vom Erdcentrum aus gesehen würde ${ }^{2}$ ), bestimmt. Wenn

1) Das Nautische Jahrbuch enthält diese Daten nicht. Mit den obgenannten Verzeichnissen vgl. man die Sternkarten in 1 . Kaltbrumer, dide-mémoire du Yoyugeur.

2) Treffend erläutert J. Herschel dieses Verhältniss durch den Vergleich mit einer Uhr. "Der sichtbare gestirnte Himmel ist das Zifferblatt unserer Uhr; die Sterne sind die auf demselben vertheilten festen Zeichen; der Mond ist der bewegliche Zeiger, welcher einen monatlichen Umlauf unter denselben vollbringt, indem er augenscheinlich theils vor manchen vorübergeht und sie verbirgt oder sie bedeckt, theils neben und zwischen andern sich fortbewegt. Es fehlt nur ein einziger Umstand, um unsern Vergleich vollständig zu machen. Statt dass 
man diesen geocentrischen Ort für einen und denselben Augenblick in Ortszeit des Punktes $A$ und Ortszeit des Punktes $B$ (Nullmeridian) berechnet, so gibt die Differenz dieser Zeiten den Längenunterschied ron $A$ und $B$. Wegen der anzubringenden Korrektionen gestaltet sich die Berechnung dieser Beohachtungen etwas umständlich; die Beobachtung selbst aber ist leicht zu machen, namentlich, wenn sie sich auf den dumkeln Rand des Mondes bezieht. Die Fehlergrenze bei einer solchen Längen-, resp. Zeitbestimmung lässt sich bedeutend reduziren, wenn bei der Bedeckung eines hellen Sternes nicht nur der Zeitpunkt seines Vèrshwindens am einen, sondern auch der Moment seines Wiedererscheinens an andern Mondrand bestimmt wird. Auch gewimnt die Beobachtung sehr an Werth, wenn man durch ein mit Mikrometer versehenes Fernrohr zu verschiedenen Zeitpunkten vor und nach der Bedeckung die jeweilige Distanz des Sterns rom benachbarten Mondrande bestimmt. (Vgl. A. d Abbadie, Instructions pour les Voyages, a. a. 0., pag. 266/67.)

Was im Weitern den $M$ Lond hetrifft, so findet man in der . Connaissance des Temps " für Paris den Zeitunterschied ${ }^{1}$ ) angegeben zwischen der Kulmination des Mondes und derjenigen irgend eines Fixsterns; ferner ist angegeben, um wieviel dieser Zeitunterschied stündlich kleiner wird, wenn der Stern östlich rom Monde ist, wieriel er hingegen grösser wird, wenn der Stern sich westwärts rom Monde befindet. Nun beobachtet man an dem Orte, dessen Position zu bestimmen ist, die Zeitdifferenz zuischen Irond- und Stern-

sich die Zeiger ganz dicht am Zifferblatte bewegen, wollen wir annehmen, dass sie beträchtlich von demselben abstehen. Wenn wir nun bei dem Betrachten derselben unser Auge nicht gerade in der Richtung ibrer Achse halten, so können wir dieselben nicht richtig auf die ihnen zugetörigen Orte auf dem Zifferblatte projizirt erblicken. Und wenn uns diese Parallace (Verschiebung) unbekannt wäre, so würden wir bei Ablesung der Zeit grosse Fehler begehen, indem wir den Zeiger auf das falsche Zeichen bezögen oder seinen Abstand von dem richtigen unrichtig schätzten. So verhält es sich genau in Bezug auf die Bewegung des Mondes vor den Sternen, welche unermesslich weit von ihm entfernt sind; wenn wir auf der Oberfläche der Erde unsern Ort verändern, so entsteht eine Parallaxe, welche den Mond scheinbar unter den Sternen verschiebt und die in Rechnung gebracht werden muss, ehe wir den wahren Ort bestimmen können, den er einnebmen wïrde, wenn wir ihn aus dem Mittelpunkt der Erde sähen." Ueber die bezüglichen Berechnumgen vgl. Bohnenberger-Jahn, a. a. O. $\$ \S 169-174$.

1) Hinsichtlich der Angaben von Monddistanzen im "Nautiscben Jahrbuch", die für Greenwich gelten und vorziglich zur See angewendet werden, verweisen wir auf die bezüglichen Ephemeriden (S. IX-XIV jedes Monats) und die einschlägigen Erläuterungen des Jahrbuchs selbst. 
liulmination. Diesen Lnterschied subtrahirt man ron der Differenz, welche sich in der "Commaissance des Temps" angegeben findet, dividirt das Resultat durch die angegebene stïndliche Aenderung und multiplizirt mit 15 . So erhält man die Länge: zugleich kann man nun das Chronometer nach Pariser Zeit korrigiren und dann wieder während einiger Wochen die erste Methode der Längenbestimmung anwenden.

Die Monddistanz in Bezug auf einen Stern kamm auch

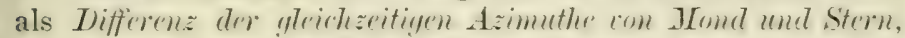
verbunden mit der Messung ihrer Zenithdistanzen, bestimmt werden. Diese Beobachtungen sind zahlreich und zur Kontrole wie bei den korrespondirenden Azimuthen je auf beiden Seiten des Meridians, unter genauester Notirung der Zeit jeder einzehnen Beobachtung, vorzunehmen. Nach den Erfahrungen ron $A$. d'Abbadie gil,t eine Reihe ron Zenithdistanzen (Apozenithen) des Mondes die gesuchte Länge auf 5 bis $6 \mathrm{Km}$, beziehungsweise (a. 3 Bogenminuten, genau, und es bezeichnet derselbe ${ }^{1}$ ) dieses Terfahren als die beste gebräuchliche Ilethode, um auf der Reise durch ron einander unabhängige Einzelbeobachtungen die geographische Länge eines Ortes zu bestimmen.

$3^{\circ}$ Durch Triungulatim. Man verbindet den Punkt, dessen Länge gesucht wird, mit einem solchen (Observatorium, Kirchthurm, Leuchtthurm etc.) ron bekannter Länge. Zu diesem Zrrecke macht man sich vor der Abreise aus einem Werke, das solche Daten enthält ${ }^{2}$ ), einen Auszug mit Angabe der Lüngen etc. für die Orte der Gegend, die man besuchen will oder der nüchsten Punkte ron bekamnter Länge. Die Tahelle S. 93 ist hiezu bestimmt. In dieselbe soll die Länge, die Breite und womöglich auch die Höhe von Lokalitäten eingetragen werden, welche den Reisenden interessiren, indem sie ihm als Anhalts- oder Ausgangspunkte dienen kömnen. Nachstehend bringen wir diese Angaben für einige Sternwarten nach $A$. Auwers (in Behms geour. Jahrbuch 1878, und Dr. Wolfs Ortstafel.

1) A. d'Abbadie, Instructions pour les Voyages, a. a. O., pag. $265-267$.

2) Vgl. namentlich Domke, a. a. O., S. $296-379$ (Taf. XIII: Breite und Länge der wichtigsten Küstenpunkte, Seestädte etc.); - Annuaire du Bureau des Inngi-

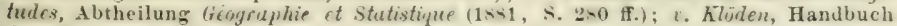
der Erdkunde, 3. Auf., 1. Bd., S. $1293-1332$ („Tabelle der Länge, Breite, Höhe und mittleren Jahrestemperatur einiger Orte, mit Einschluss meteorologischer Stationen"; Sternwarten ${ }^{4}$ ) und S. 61/62. 


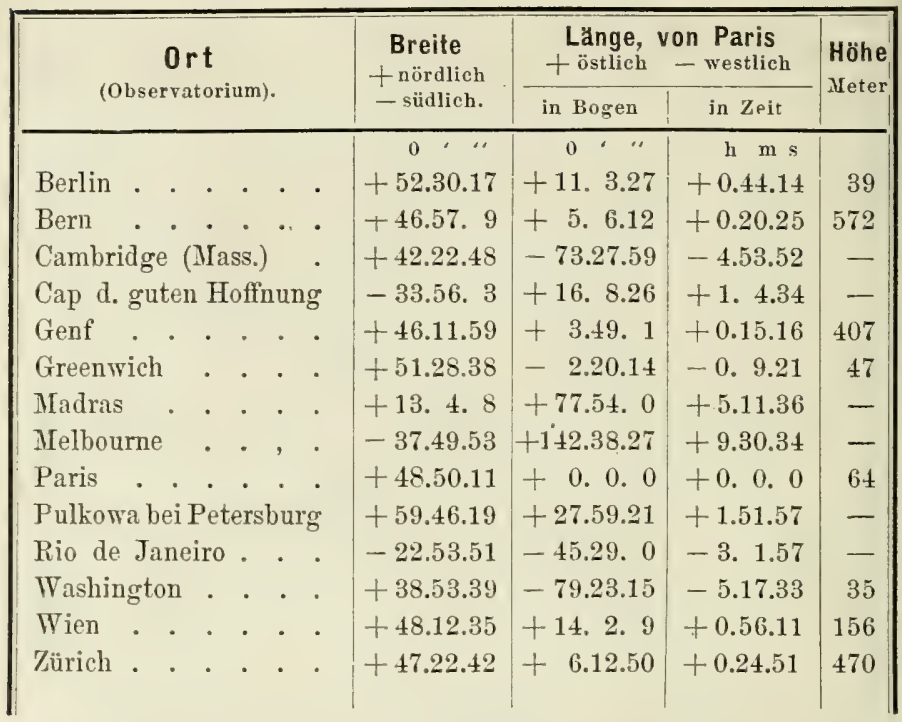

Die Längendifferenz wird berechnet nach der Entfernung zwischen dem Orte, dessen Länge beliannt und demjenigen, dessen Länge gesucht ist. Diese Entfernung muss immer senkrecht (normal) zum Meridian gemessen und nach der Taf: II im Anhang berechnet werden, in welcher die Längen der Parallelkreisgrade verschiedener Breiten angegeben sind. -

Kennt man einmal die Länge eines Ortes, so kann man mit Hülfe der astronomischen Tafeln ermitteln, wamn an diesem Punkte die Kulmination irgend eines Fixsterns stattfindet, die man behufs einer Breitebestimmung beobachten will, S. 83. Die Rektaszension in Zeit gibt, wie wir S. 86 (Note) sahen, für den Nullmeridian zugleich die Sternzeit der Kulmination eines Sternes; man hat diese nur in Sonnenzeit umzurechnen (S. 86) und auf den Meridian des Beobachtungsortes zu reduziren, um zu erfahren, wann an diesem Orte die fragliche Kulmination stattfindet. Zu einer ungefähren Ermittlung dieser Zeit genügt eine blos annähernde Kenntniss der Länge des Aufenthaltsortes.

Hinwieder kann die durch astronomische Mittel vorgenommene geographische Ortsbestimmung dazu dienen, die 


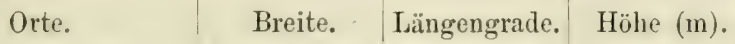


für eine Triangulation erforderliche grosse Basis zu erhalten, welche dann als astronomische Basis bezeichnet wird. Hiezu eignen sich namentlich Breitenbestimmungen, da bei einer solchen der wahrscheinliche Fehler viel geringer ist als derjenige einer Längenbestimmung.

Zeitmessung. Manchmal muss man genau wissen, wie viele Sekunden eine Beobachtung dauert. Hat man nun keine zuverlässige Sekundenuhr, so hängt man einen schweren Gegenstand (Stein, Bleikugel etc.) ans Ende eines Fadens, den man irgendwo, z. B. an einem Baumast, befestigt hat.

Die Länge, welche man diesem Faden geben muss, richtet sich nach der geographischen Breite. Sie beträgt - gemessen rom Aufhängepunkt bis zum Centrum (Schwerpunkt) des Gewichtes dieses improvisirten Pendels -

$$
\begin{aligned}
& \text { unter dem Aequator . . 0,991 m } \\
& \begin{array}{c}
45^{0} \text { Breite * * } 0,994 \mathrm{~m} \\
\text { in der Polargegend } \\
0,996 \mathrm{~m} \text {. }
\end{array}
\end{aligned}
$$

Angaben für die zwischenliegenden Breiten sind überflüssig, da man die Länge des Fadens doch nur bis auf 2 oder $3 \mathrm{~mm}$ genau reguliren kann.

Wenn man nun das Gewicht aus der vertikalen Richtung hinausbewegt und es dahin zurückkehren lässt, ohne dass man einen zu starken Ausschlag verursacht, so hat man ein Sekundenpendel.

Noch einfacher macht man solche Zeitmessungen durch Beobachtung des Pulses, indem man für einen gesunden Menschen ca. 7,5 Pulsschlüge in der Minute anmehmen darf. Immerhin ist dieses Nittel weniger genau als das andere, da die Zahl der Pulsschläge bei den einzelnen Individuen rerschieden ist und beim gleichen Individuum nach Alter, Gesundheitszustand und zufälligen Verumständungen sich ändert. Durch Uebung kann man sich aber auch daran gewöhnen, isochrone Sckundenzählungen vorzunehmen, $\mathrm{d} . \mathrm{h}$. Zählungen ron Sekunden in gleich langen Zeiten.

Bestimmen von Felsarten und Mineralien. Gestein oder Fels nennt man in der Geologie jede erhebliche Masse, welche einen Bestandtheil der Erdrinde bildet, ohne Rücksicht auf Härte oder Ursprung. Sand, Lehm, Torf, Braunkohle, Guano etc. sind dem Geologen ebensogut Gesteine oder Felsarten, wie der härteste Granit. 
Wenn wir uns in der Natur umschauen, so gewahren rir, dass der Boden ziemlich allgemein in folgender Weise zusammengesetzt ist:

$1^{\circ}$ Aus der Krume, die wir gewöhnlich Boden oder Erde nennen.

$2^{\circ}$ Aus unzusammenhängenden, beweglichen (losen) Theilen, Gesteinstrümmern.

$3^{\circ}$ Aus anstehendem, gewachsenem Fels.

Gewachsenen Fols oder anstehendes Gestein nennt man eden integrirenden Bestandtheil der Erdrinde, welcher sich on dieser nicht abgelöst hat, also z. B. Felsmassen, welche an der Erdoberfläche sichtbar werden (zu Tage treten) und an ihrer Basis in Zusammenhang mit der Erdrinde stehen, solirte Felsen, Berge, unterirdische Bänke, Schichten, Lager, stöcke etc. Diese Felsen kommen in grossen Massen oder Masiven, üher die ganze Erde verbreitet, in zahlreichen Varieäten ror, welche sich aber nach einigen Haupttypen ordnen assen, so zwar, dass die Felsarten eines jeden Typus auch n sehr weit von einander entfernten Gegenden dasselbe allremeine Bild darbieten. Mit diesen Grundtypen muss man ich wohl rertraut machen um die verschiedenen Felsarten, relche man beobachtet, darauf bezichen zu können. So verden die Namen, welche wir zur Bezeichnung der Gesteine inwenden, wenn nicht ganz genau, doch im Allgemeinen utreffend sein.

Das beste Mittel aher, sich mit den wichtigsten Gesteinsypen gehörig vertraut zu machen, besteht darin, dass man elher eine kleine Sammlung solcher anlegt, die man immer ur Hand und vor Augen hat. Nur müssen hiezu charakeristische Handstücke genommen werden, in welchen die Iaupttypen gewissermassen personifizirt sind, also nicht twa Stücke, welche die Charaktere zweier verwandter Arten ugleich enthalten. Kennt man einmal diese Typen gut, o kann man dann die Varietäten und Uebergänge studiren. es gibt nämlich keine scharfen Grenzen, z. B. zwischen Granit und Gneiss; viele Zwischenglieder vermitteln den Cebergang rom einen zum andern. Es gibt intermediäre Typen wie Gneissgranit und Granitgneiss, Thonschiefer und Srchieferthon, deren Name schon andeutet, welchen der eiden verwandten Grundtypen ein Gestein näher steht. 
Teben diesen Lebergängen bestehen die Varietäten im engern Sinne, die erhebliche Unterschiede in der Gesteinszusammensetzung oder in den accessorischen Bestandtheilen, die sie enthalten, aufweisen. Hat man ror Antritt der Reise genug Zeit um diese Varietuiten kennen zu lernen, so können als Führer empfohlen werden: Prof. Dr. Th. Simmler, Peträa und Orykta; - Prof. Dr. Senft, Analytische Tabellen zur Bestimmung der Mineralien und Gebirgsarten, Hamnover 1874; Joh. Lemmis, Schul-Naturgeschichte, III. Theil, und Synopsis der drei Naturreiche, III. Theil (letzteres Werk als "Symopsis der Mineralagic und Grologie" ebenfalls von Dr. Senft bearloeitet; von demselben Autor "Fels und Erdboden ", Nünchen 1876). Als Nittel zum Studium der mineralogischen $\mathrm{Zu}$ sammensetzung der Gesteine kommt übrigens immer mehr das Mikroskop zur Anwendung. So bizarr noch einem de Siaussure die Idee rorgekommen wäre, Berge wie den Monthlanc unter dem Miliroskop zu studiren, so scheint doch diese Forschungsmethode bestimmt, arosse Dienste zu leisten ${ }^{3}$ ).

I)as Bestimmen der Mineralien erfordert ziemlich viele chemische und krystallographische Kenntnisse, die kaum anders als unter der Leitung eines erfahrenen Mineralogen erworhen werden können. Allein der Reisende hat nicht die Aufgabe, seltene Mineralien aufzusuchen und zu entdecken, sondern vielmehr die, zu konstatiren, welche der gewöhnlichen Mineralien in der von ihm besuchten Gegend vorherrschen orler zu den regelmässigen Vorkommmissen gehören. I)ie Zahl dieser Mineralien aber ist eine beschränkte. Will man weiter gehen, so wird man gut thun, die mineralogischen Sammlungen kennen zu lernen, die unserer Bemutzung zugänglich sind, oder sich selbst eine Sammlung zu verschaffen, die man stets zur Verfügung hat. Solche Handsammlungen zum mineralogischen Studium - aus 100, 200, 300 oder 500 Mustern bestehend, je nach der Geldsumme, die man darauf verwenden will - sind vielerorts und mit verhältnissmässig geringen Auslagen käuflich zu

1) Vgl. Dr. F. Zirkel, die mikroskupische Beschaffenheit der Mineralien und Gesteine, Leipzig 1873. - Dr. C. Doelter, die Bestimmung der petrographisch wichtigeren Mineralien durch das Mikroskop. Wien 1876. - H. Rosenbusch, Mikroskopische Physiographie der petrographisch wichtigen (gesteinsbildenden) Mineralien; Stuttgart 1873. - H. Rosenbusch, Mikroskopische Physiographie der massigen Gesteine. Stuttgart 1877. - J. H. Whyte, The Mikroscopist, London 1877. 
erwerben. Ton deutschen Firmen, an die man sich hiefür wenden kann, ist z. B. das Heidelleryer Aneralien-Comptoir sehr zu empfehlen ${ }^{1}$.

Man wird sorlann selher Mineralien sammeln, die man zu bestimmen sucht, indem man sie mit Musterstücken eines Museums oder der eigenen Sammlung vergleicht oder sich hiezu eines gepigneten literarischen Hülfsmittels bedient, wie der oben erwähnten Petrïa und Orylita ron Dr. Th. Simmler, der analytischen Tabellen ron $F$. r. Koblut, des dritten Imineralogrischeni Theiles rerschiedener Ausgaben naturgeschichtlicher Werke ron Lemis und Anderer. Die Anwendung dieser schriften setzt voraus, dass man einige rhemische und yhysikalische Hülfsmittel zur Hand hat. Diesp könuen entweder mit den Mineraliensanmlungen oder mit den einschlägigen schriften zugleich gekauft werden. So wird beisplelsweise zu simmler: ' P'eträa zumleich ein minerologfisch-ypulongischers Besteck abgegehen, das ausser den Instrumenten und chemikalien zum Bestimmen anch Hämmer zum sammeln (s.chlagen) und Formiren von Gesteinsproben enthäl.

Bestimmung der Fossilien oder Petrefakten. Fossil nder Petrefakt nemint man jeden Körper oder jede Spur rorweltlicher Organismen (Thiere oder Pflanzen! und Vorgänge Saturerscheinumgen, welche man in der Erde, in Gesteinen findet.

Man nennt sie:

crllstindige Petrefaliten, wenn alle Theile erhalten sind;

cumbllstiondige Irtrefuliten, wenn gewisse Theile fehlen:

Abchüclie (moules extérieursi, wenn der hörper des organischen Wesens verschwunden ist, aber im einschliessenden Gestein Spuren zurückgelassen hat;

Stecinleme (moules intérieurs). wenn der imere Raum, die Form des organischen Körpers, z. B. einer Muschel, ron Mineralsubstanz erfüllt und in dieser Weise als Abguss erhalten worden ist;

Thierspuren (empreintes ou restiges), wie Fährtenahdrücke (Fuss-Spuren ron schreitenden Thieren, Furchen ron Kriechthieren), Bohrlöcher von IIscheln und Würmern u. dgl., endlich

1) Die gleiche Bemerkung gilt für Sammlungen ron Gesteinsarten, Petreakten, Conchylien u. a. m. 
Spuren ron Thturerscheimunfen, wie z. B. ron Regentropfen, Hagel, Wirkung des Wassers, des Windes u. s. w.

Versteinerte Exkremente rorweltlicher Thiere heissen Koprolithen.

Man sagt ron den Fossilien wie ron Mineralien, sie seien $1^{\circ}$ an primürer Lagerstäte (en place), wenn man sie da findet, wo die Thiere oder Pflanzen, von denen sie herrühren, gelebt haben und gewachsen sind;

$2^{\circ}$ an sckundirer. Stelle (remaniés), transportirt, wenn sie an Orten gefunden werden, wohin sie zufällig, z. B. durch fliessendes Wasser, gelangten.

Das Bestimmen der Fossilien erfordert gründliche Kenntniss der lebenden (jetzigen) und vorweltlichen Pflanzen- und Thierwelt und liann also nicht jedermanns Sache sein. Die wesentliche Aufgabe des Reisenden besteht indessen nicht darin, dass er an Ort und Stelle angeben könne, zu welcher Art oder Abart ein Petrefakt gehört, sondern nur darin, dass er unter den gesammelten Fossilien diejenigen erkennt, welche eine Formation charakterisiren. Diese, die sogenannten Litfussilion, bilden aber eine kleine Anzahl. Man muss sich also nur mit verhältnissmässig wenigen Formen vertraut machen, die mit einander nicht $\mathrm{zu}$ verwechseln sind. Diese Leitfossilien oder Leitmuscheln freilich muss man so genau kemnen lernen, dass man dieselben — wie ein Meister der Geologie, Prof. Marcou, sagt - gleich Münzen auf den ersten Blick erkennt. Hiezu gibt es zwei Wege:

$1^{\circ}$ Man studirt die Petrefakten in den grossen paläontologischen Museen oder in kleinen sorgfältig ausgewählten Sammlungen, die man wie andere, wovon wir sprachen, kaufen kann. Auch in dieser Beziehung kamn das Heidelberger Mineraliencomptoir bestens empfohlen werden. Oder

$2^{\circ}$ man sammelt selber Petrefakten und sucht sie zu bestimmen.

Deren Formen sind dem Gedächtniss einzuprägen. Sammlungen kamn der Reisende nicht überall hin mit sich nehmen; es ist daher sehr gut, wenn man sich im Besitze von Abbildungen, eines Atlas der wichtigsten Petrefakten befindet. Ein solcher ist der Atlas ron Dr. G. Laube, be- 
titelt: "Tafeln zur Benutzung beim Studium der Geologie und Paläontologie $\left.{ }^{1}\right)$."

Bodenanalysen. Die Kenntniss und Beurtheilung der Ackerkrume erheischt einige Tehung in chemischen Analysen, welche übrigens ziemlich einfacher Art sind. Ich werde hier nur kurz angeben, wie man hiebei zu Werke geht, und behalte mir vor, die Frage des Studiums der Erdkrume später noch zu besprechen.

Es gibt ein sehr cinfaches, rasch zum Ziele führendes Mittel, un die Zusammensetzung des Bodens kenuen zu lernen. Man hringt eine Ilandroll Erde in ein cylindrisches Glas (ein Bierglas z. B.), schüttet in crenügender Nenge Wasser hinzu, rührt das Ganze türchtig um und lässt es dann stehen, damit die schwebenden (susprendirten) Stoffe sich zu Boden setzen. Es bilden sich hiebei mehrere Lagen oder Schichten, welche von oben nach unten folgende Stoffe enthalten :

Humus
Thon
Kalk
Sand
Kies (Gerölle).

Das Höhe- oder Dickeverhältniss dieser Iagen gestattet. einen Schluss auf die Zusammensetzung des Bodens.

Ein genaueres Verfahren ist folgendes. Man sondert zunächst die Kieselsteine, sowie andere grobe und fremde Bestandtheile aus, trocknet die Erde gut, bis zur Ver-

1) Ferner wird man sich zum Studium folgender einschlägiger und treftich illustrirter Werke bedienen: von Hochstetter, die feste Erdrinde (aus: Hann, Hochstetter und Pokorny, Allgemeine Erdkunde) 3. Autl., Prag 1880; - H. Credner, Elemente der Geologie, 4. Aufl, Leipzig 1878; - U. W. Gümbel, Kurze Anleitung zu geologischen Beobachtungen in den Alpen, 1878; - v. Saportu, die Pflanzenwelt vor dem Erscheinen des Menschen, übersetzt ron C. Vogt, Braunschweig 1881; - C. Fogt, Lehrbuch der Geologie und Petrefaktenkunde, 4. Autl., Braunschweig 1879; - Zittel, Handbuch der Paläontologie, München $1876 \mathrm{ff} . ;-$ Ostecld Heer, Urwelt der Schweiz, 2. Aufl, Zürich 1879, Fossile Flora der Polarländer, Band I - VI, Zürich 1868 - 1880; Fossile Flora der Schweiz, Zürich 1876 ff.; F. Sandberger, die Land- und Süsswasserconchylien der Vorzeit; - Aeltere Werke sind die von Qucustedt (Jura), Nuumam (Geognosie), Dr. Schmid (Petrefaktenbuch) etc. - Nachdem man sich mit den nöthigen allgemeinen Vorkenntnissen ausgerüstet, versuche man, mit den einschlägigen Verhältnissen eines bestimmten Gebietes von geringem Umfange an der Hand eines Spezialwerkes (einer geologischen Monographie) über dieselbe sich grünlich vertraut zu machen, indem man die bezüglichen Torkommnisse in der Natur und deren Darstellung in dem Snezialwerke einem sorgfäligen vergleichenden Studium unterzieht, bis man durch die wiederholten Beobachtungen auf dem Terrain schliesslich in den Stand gesetzt wird, sich über die geschilderten Verhältnisse und die Adäquatheit der Dar- 
dunstung alles (nicht chemisch gebundenen) Wassers, wägt hievon 1 Kilogramm ab und bringt diese Substanz in reines Wasser, worin man sie umrührt.

Der Humus schwimmt obenauf. Man nimmt ihn weg, lässt das Wasser klar werden, trocknet den Rückstand und wägt ihn. Die Differenz gegen die vorige Wägung (was also zu 1000 Gramm fehlt) gibt das Gewicht des Humus.

Auf den getrockneten Rückstand giesst man nun langsam Salpeter- oder Salzsäure, so lange bis beim Zugiessen kein Brausen (keine Kohlensäure-Entwicklung) mehr stattfindet. Man trocknet und wägt auch diesen neven Rückstand. Die neue Differenz gibt das Gewicht des kohlensauren Kalks, welcher durch die Säure zersetzt wurde.

Hierauf bringt man die Masse neuerdings durch Umrühren in Wasser zu feiner Zertheilung (Suspension) und schlämmt sie, d. h. man lässt das trübe Wasser oben ruhig abfliessen.

Wenn bei mehrmaliger Wiederholung dieser Operation das Wasser sich nicht mehr trübt, so sammelt man den Sand, welcher auf dem Grunde des Gefässes zurück blieb, trocknet und wägt ihn. Die jetzige Gewichtsdifferenz (gegenüber der vorigen Wägung) gibt das Quantum des T'hons; der Rest ist Sand oder Kieselerde.

Will man noch genauer verfahren, so muss man nach Entfernung des Humus die Masse mit dem dreifachen Volum Regenwasser versetzen, umrühren, abgiessen, trocknen und wägen. Der Gewichtsverlust gibt die Menge der löstichen Salze, welche in der Probe enthalten waren.

Wenn man das bei der Scheidung von Thon und Sand (beim Schlämmen) abgegossene Wasser filtrirt und den Filter-

stellung ein eigenes Urtheil zu bilden, letztere zu ergänzen oder zu berichtigen. Als Gebiet für ein solches Selbststudium wird man womöglich vorab die nächste Umgebung wählen; dieselbe ist aber dazu vielleicht ungeeignet, sei es wegen Dürtigkeit oder wegen Komplizirtheit der fraglichen Verhältnisse. In diesem Falle wählt man sich ein anderes, möglichst nahe gelegenes Beobachtungsgebiet das für unsern Zweck besser geeigenschaftet ist. Man wird gut thun, - und es wird dies nicht schwer halten - hierüber kompetenten Rath einzuholen; denn eine glückliche Wahl des Arbeitsfeldes bedingt zu einem wesentlichen Theile den guten Erfolg solch' eines autodidaktischen Verfahrens. - Zu einer Verwerthung in diesem Sinne eignen sich beispielsweise manche Bände der „Beiträge zu eine $0^{\circ}$ geologischen havte der Schweiz", welche je das Gebiet eines Blattes des topographischen Atlas der Sehweiz (in 1/100000) behandeln. Uebrigens gelten obige Bemerkungen mutritis mutandis wie für geologische, so auch für botanische, zoologische u. dgl. Beobachtungen. 
Rückstand trocknet, so erhält man eine zweite Angabe für das Gewicht des Thons, welche zur Verifikation dienen kann.

Das Verhältniss zwischen den drei Bestandtheilen

Kall:

Thon

Sand oder Kiesclerde

kennzeichnet die Bodenart.

Noch strengere Untersuchungen als die erwähnten, eigentliche chemische Bodenanalysen, sind Arbeiten für das Laboratorium, womit ein Reisender sich kaum befassen kann ${ }^{1}$ ).

Bestimmen von Pflanzen. Jeder Reisende, sei er Botaniker oder nicht, sollte lernen, die Pflanzen, welche er trifft, auf den ersten Blick zu erkennen und von einander zu unterscheiden. Es liegt in dem Bilde, das ein Gewächs dem Auge darbietet, in Tracht und Färbung, ein gewisses Etwas, welches eine solche Art des Erkennens möglich macht; welches die Trsache dafür ist, dass z. B. ein Landschaftsmaler, ohne in der Botanik stark bewandert zu sein, weiss, zu welcher Art Bäume gehören, deren Umriss er in der Ferne gewahrt and worauf auch die Richtigkeit der Beurtheilung, der Erkenntniss beruht, womit Laien, Kinder selbst, eben so rasch als sicher über Arten und Sorten sich aussprechen, die sie häufig zu beobachten Gelegenheit haben, ohne dass sie mit deren wissenschaftlichen Unterscheidungsmerkmalen bekannt wären oder sich davon Rechenschaft gäben.

Dieses Talent, dieser coup d'oeil ist um so nützlicher für den Reisenden, als er bei raschem Durcheilen einer Gegend deren Vegetation nicht anders denn nach grossen Zügen der äussern Form, nach dem Aussehen oder Habitus beurtheilen kann. Seine Sache kann es nicht sein, sozusagen jeden Augenblick vom Wege abzugehen oder vom Pferde zu steigen, um eine Pflanze analytisch zu studiren; abgesehen hievon wäre ihm dieses wissenschaftliche Bestimmen auch desshalb nicht immer möglich, weil er die Pflanze nicht gerade mit Blüthen und Früchten, kurz mit allen den Theilen, wovon die spezifischen Merkmale hergenommen werden, finden könnte. Das Bestimmen nach dem

1) Für den Zweck, den wir im Auge haben, kann die Benutzung von Stöckhardls Schule dev Chemie (Braunschweig) oder Schiblers Agrikulturchemie (Aarau) empfohlen werden. 
blossen Anblick, wenn es auch unter Lmständen nicht ganz genau ist, genüigt für den Zweck des Reisenden. Für ihn ist auch das Pflanzenkleid einer Gegend nur ein Theil eines grössern Ganzen, eines umfassenderen Bildes. Er muss dasselbe besprechen, mit in Betracht ziehen, weil die Flora einer Gegrend wesentlich wie zum Schnucke so zur Physiognomie der Landschaft beiträgt. Mber wenn er nicht jede Pthanze mit ihrem lateinischen speciesnamen bezeichnen kam, wird ilm hieraus Niemand einen Vorwurf machen. Besser ist es jedenfalls, sich mit allogemeiuern Benennungen zu begnügen, als zu riskiren, dass man sich auf Details eimlasse, wenn man nicht sicher ist ror der Gefahr, mrichtige Einzelheiten rorzubringen. Besser man berichte nur, Nadelwälder ggetroffen zu liaben, als dass man z. B. sage, es seien Seyuoien gewesen und es sich nachher herausstellt, dass es Cypressen waren! Für die Mehrzahl der Leser erweckt zudem die allgemeine Benemung eine bestimmtere Vorstellung; einem Jeden schwebt das Bild eines Nadelwaldes ror; nicht Jeder aber hat eine richtige Idee ron Sequoiaoder Cypressenwäldern.

Die Fähigkeit, einen Gegenstand, wie eine Pflanze, nach ihrem Aussehen auf einen flüchtigen Blick hin zu erkennen, wird dadurch erworben, dass man das Objekt, um welches es sich handelt, öfters zu sehen bekommt. Auch besitzt ein Jeder diese Befühigrung, nur in rerschiedenem Grade und Umfange. Niemand rerwechselt eine Pappel mit einer Tanne oder eine Eiche mit einem Weidenbaume; aber verhältnissmässig Wenige sind im Stande anzugeben, wodurch diese Pflanzen sich von einander unterscheiden. Die natürliche Gabe, die rerschiedenen Formen zu unterscheiden, muss durch Uebung entwickelt werden. Die besten Definitionen sind nicht soriel werth wie das einfachste Bild des Objektes. Bei diesen Uebungen beginnt man mit einigen von einander bedeutend verschiedenen Pflanzenformen, wie Eiche, Pappel, Nussbaum, Weide, Linde, Hollunder, Sauerdorn, Salbei, und gewöhne man sich daran, diese überall herauszufinden, wo immer sie zu treffen sind, wie man einen Bekannten mitten aus einer grossen Volksmenge herausfindet. Hat man viele Eichen gesehen, kleine und grosse, so besitzt man, als $\mathrm{Ab}$ straktum der vielen Bilder, eine Idee von dem, was man mit 
rem Ausdruck Eiche bezeichnet, eine Torstellung ron dem Gattungshegriffe Eiche. Dieses typicche Bild ist jetzt geistiges Eigenthum. Sun achte man auf dis Eigenthümlichkeiten der verschiedenen Arten ron Eichen, auf die Unterschiede zwischen der sommer- oder steineiche (Quercus perlunculata) und der Winter-oder Traubeneiche (quercus sessiliflora) etc. Man dehne diese studien aus auf andere Gattungen, Arten und Varietiiten, erweitere durch solch fortgesetzte Lehungen den Lmfang des hekannten Formenkreises, und man wird es dazu bringen, nicht zwar alle Pflanzen - aber doch jede I'flanze ron charaliteristischem Anssehen kemen zu lernen.

Sehr selten sind es niedrige Pflanzen, welche der Flora einer Gegend ihren hesonderen Charaliter rerleihen. Die Typen, welche an meisten dazu heitragen, den Landschaftscharakter zu bestimmen, sind die Flechten (Lichmen) in kalten Torden, in den Polargegrenden: damn in den gemässigcten Breiten Tamen. Eichen und Buchen, Wallnusshäume und Kastanien: weiter gregen sürlen Oliven und l'inien, und in den heissen Klimaten Palmen, Aloen und Fettpflanzen.

Im die Vryotutionsformen verschierlener Zonen und Regionen kemen zu lernen, hesuche man öfters hotanische Gärten ${ }^{1}$ ) und Gewächshäuser, durchgehe Herharien, und achte aufmerksam auf die Pflanzen und ihre Namen. Xöthigenfalls behelfe man sich mit naturgetreuen Abhildungen in illustrirten Werken: immer trachte man darnach, zu sehen, zu beobachten!

Lm aber die Aufmerksamkeit, das Anschaumngsvermögen und Gedächtniss nicht nach allzurielen Richtungen in Anspruch zu nehmen, wende man sie namentlich den Gewächsen der Zone zu, welcher das zu hereisende Land angehört, und lese man die schriften, welche auf diese suezialflora Bezug hahen, - immerhin ohne zu übersehen, dass die Vegretation eben auch nach den Höhen (Regionen) rerschieden ist und man daher selbst in der Aequatorialzone Pflanzen finden kann, welche einem gemüssigten oder sogar kalten Kilima

1) Dieselben lassen, von dem hier in Frage kommenden Gesichtspunkte aus betrachtet, allerdings oft viel zu wünschen. Vgl. Ernst Hallier, Ausfuge in die Natur, Berlin 1876 (Kapitel: botanische Gärten und bot. Sammlungen). 
angehören. Details hierüber findet man in den Partien der botanischen Lehrbücher, welche die geographische Vertheilung der Pflanzen behandeln, namentlich aber in den pflanzengeographischen Werken von Dr. Karl Mü̈ler und Prof. $A$. Grisebach ${ }^{1}$ ). Ueber die Flora bestimmter Gegenden existiren auch Spezialwerke, ron blossen Katalogen der daselbst wildwachsenden Pflanzen bis zu ganz eingehender Behandlung derselben.

Wiederholt hat man den Versuch gemacht, eine physiognomische Klassifikátion der Pflanzen aufzustellen, eine Eintheilung der Gewächse nach ihrer Tracht oder ihrem Habitus. Bekannt ist eine Abhandlung Alex. von Humboldt's in seinen "Ansichten der Natur", wo siebzehn physiognomische Pflanzentypen unterschieden werden. Die beste, eingehendste und vollständigste Klassifikation dieser Art ist aber die von $A$. Grisebach, Vegetation der Erde I. Band, S. 11, vgl. Neumayer, Anleitung S. 336. Wohl ist hiegegen eingewendet worden, solche physiognomischen Systeme vereinigen oft in einer Gruppe Arten, welche nach dem Gesichtspunkt

1) Dr. Karl Müller von Halle, das Buch der Pfunzenwelt, eine botanische Reise um die Welt, 2. Auf. Leipzig 1879; - A. Grisebach, die Vegetation der Erde nach ihrer klimatischen Anordmung, ein Abriss der vergleichenden Geographie der Pflanzen, 2 Bände, Leipzig 1872; Gesummelte Abhundlungen und kleinere Schriften su Pflanzengeographie von A. Grisebach, herausgegeben von Dr. Ed. Grisebach, Leipzig 1880. ${ }_{n}$ Die Vegetation der Erde ${ }^{\alpha}$ ist das wichtigste phanzengeogr. Werk; die Gesammelten Abhandlungen" enthalten namentlich die Berichte über die Fortschitte der Pfanzengcographie, welche $\Lambda$. Grisebach für Behm's geogr. Jahrbueh schrieb und von welchen E. Behm (Petermann's Mittheilungen 1880 Nr. 11) mit Recht bemerkt, dass sie allgemein als Muster wissenschaftlicher Jahresberichte anerkannt wurden.

Indem wir gerne dem Studium der Schriften A. Grisebach's das Wort reden, empfehlen wir indess unsern Lesern, sich vorher mit dem erwähnten Werke von Dr. Karl Jiuller vertraut zu machen. Der Schwerpunkt von Grisebach's Werk liegt, wie schon sein Titel andeutet, in den wissenschaftlichen Untersuchungen über die Beziehungen zwischen Klima und Flora eines Gebietes; dieselben sind ganz ausgezeichnet und man wird aus ihnen mehr klimatologisches Wissen und Verständniss schöpfen als aus manchem Werke, das sich "Meteorologie" betitelt; nicht geringere Anerkennung verdienen die Schilderungen der Florengebiete nach Vegetationsformationen und Regionen. Dagegen werden andere Seiten des Gegenstandes, entsprechend dem zielbewussten Streben des Werkes, nur beiläufig berührt oder ganz unberücksichtigt gelassen. Ersteres gilt von den Vegctationsformen in physiognomischer Hinsicht (während ibre klimatischen Beziehungen bezw. Anpassungen eingehende Würdigung finden), letzteres von den sachbezüglichen geognostischen und geologischen Verhältnissen. Dr. Mïller's Werk ist gleichmässiger und allseitiger, indem es in besonderen Abschnitten auch diesen Gesichtspunkten die geeignete Würdigung zu Theil werden lässt (vgl. 1. Abthlg., 2. Buch: Geschichte der Pflanzenwelt, 3. Buch: Physiognomik der Gewächse) und die Erreichung seines Zweckes durch seine illustrative Ausstattung wirksam fördert. - Nach der historischgeologischen Seite hin wird die Darstellung Grisebach's (ausser durch die S. 99 genannten Werke) ergänzt durch den Versuch einer Entwicklungsgeschichte der Pflanzenwelt von Dr. A. Engler, 1. Theil, Leipzig 1879; für einzelne engere Gebiete sind Schriften wie die von H. Christ (Pflanzenleben der Schweiz, Zürich 1879), A. r. Kerner, Nägeli u. A. zu empfehlen. 
der ,natürlichen Verwandtschaft" als sehr rerschieden bezeichnet werden müssen, vertheilen hinwieder genealogisch zusammengehörige Arten in physiognomisch ganz verschiedene Gruppen und erfordern den Gebrauch ron Benennungen, die sich nicht von selber verstehen, sondern welche die Kenntniss von Definitionen als eines Schlüssels zu ihrem Verständniss erfordern. Aber trotz dieser nicht zu beseitigenden Inkonvenienzen ist eine Klassifikation wie diejenige Grisebachs und ist das Studium derselben von unbestreitbarem Nutzen.

Der Reisende muss aber nicht nur diese Kenntniss der Gewächse nach dem (wesentlich durch die vegetativen Organe bestimmten) Gesammtbilde ihrer äussern Erscheinung, - er muss nicht minder auch eine gewisse Vertrautheit mit dem sogenannten natïrlichen System derselben besitzen, d. h. mit der auf die Beschaffenheit der Fortpflanzungsorgane gegründeten Eintheilung, welche Kemntniss der wissenschaftlichen Charaktere wenigstens soweit gehen muss, dass man die Familie oder Unterfamilie (Tribus) bestimmen kamn, zu welcher eine aufgefundene Pflanze gehört, dass man also weiss, was Ausdrücke wie Coniferen, Gramineen, Orchideen u. dgl. bedeuten, welche Pflanzen jenen Kategorien zugehören und dieselben bilden. Der Reisende wird ja mitunter Pflanzenformen antreffen, die ihm nach Art und Gattung völlig unbekannt sind, die er noch nie gesehen hat, die vielleicht noch unbeschriebene und unbenannte neue species sind. Wie soll er dam diese bezeichnen und beschreiben, wenn er es nicht thun kann durch Beziehung derselhen auf eine hekannte Familic oder dadurch, dass er die morphologischen Nerkmale angibt, welche zu deren Einreihung in's System nöthig sind?

Etwas praktische Botanik, d. h. Lebung im Bestimmen und Beschreiben von Pflanzen ist also unerlässlich. Als geeignete Werke hiefür können namentlich empfohlen werden:

Dr. A. B. Frank, Pllanzentabellen zur leirhten, sctunellen und sichern Bestimmung der höheren Gentïlese Tord- und Mitteldeutschlands, 2. Aufl., Leipzig 1874; - Dr. R. Th. Simmler, butanischer Taschenbegleiter des Alyenklubisten, Zürich 1871; - Dr. J. A. Schmidt, Anleitung zur Kenntniss der natürlichen Familien der Phanerogamen (Stuttgart 1865); 
ferner die illustrirten ${ }^{1}$ ) naturgeschichtlichen Werke ron Leunis (Leitfaden, Schulnaturgeschichte, Synopsis) II. Theil. Der letztere Autor nimmt zugleich überall Rücksicht auf die Eigenschaften und Verwendung, auf Nutzen und Schaden der Pflanzen füx den Menschen, wie auch deren Beziehungen zur Thierwelt in diesem Simne, — während hinsichtlich anderer, erst in neuester Zeit zu rechter Würdigung gelangter Verhältnisse zwischen Pflanzen- und Thierwelt (gegenseitige Anpassungen derselben) namentlich auf die Schriften ron Dr. Hermann Müller, John Lubbock und Dr. Arnold Dodel zu verweisen ist $^{2}$.

Bestimmen der Thiere. Nach dem, was soeben über das Bestimmen der Pflanzen gesagt wurde, können wir uns in Bezug auf das Bestimmen der Thiere kurz fassen; wir müssten schon Gesagtes wiederholen, wenn wir hier in Details eintreten wollten.

Hinsichtlich der Thiere kann sich der Reisende noch weniger als in Betreff der Pflanzen mit genauem, anato-

1) Den erstgenannten Werken feblen Abbildungen. Den Leser, welcher auf die Erleichterung, welche gute Illustrationen beim Bestimmen gewähren, nicht verzichten will, verweisen wir auf Hermann Wagner's Illustrirte deutsche klora, Stuttgart 1871 (Vorbild: Bentham's Illustrated Handbook of the British flora) und als Ergänzung zur letzten Tabelle Frank's (S. 169 ff.) auf Ioritz Willkomm, Deutschlands Laubhölzer im Winter, 3. Aufl., Dresden 1880. Moritz̈ Willkomm's Waldbüchlein, ein Vademecum für Waldspaziergänger (2. Aufl., Leipzig 1880), enthält in bequemem Taschenformat die Illustrationen aus dem grösseren Werke: der Wald, von $E$. $A$. Rossmüssler, dem Autor der bekannten Schriften: die + Jahreszeiten, Flora im Winterkleide etc. - Hermann Wagner hat auch verschiedenc, durch den Buchhandel zu mässigem Preise erhältliche Herburicn zusammengestellt (Phanerogamen-, Kryptogamen-Herbar; Gräserherbarium u. s. w.). Da es sich hiebei nicht nur um ein Pflanzenstudium handelt, sondern zugleich um Muster der Anlage solcher Sammlungen, so machen wir aufmerksam auf das Herbar: "Schweizerische Kryptogramen" von Dr. Wartmann in St. Gallen und B. Schenk in Stein a. Rh. (Ktn. Schaffhausen), welch letzterer auch anderweitige naturhistorische Sammlungen liefert. In von Touristen stark besuchten Gebirgsgegenden sind öfters auch Herbarien käuflich zu haben, worüber die gebräuchlichen Reisehandbücher Auskunft geben; dicse Sammlungen kommen aber begreiflicherweise oft so hoch zu stehen, dass in solchen Fällen die Beschaffung sachbezüglicher kolorirter Bilderwerke (wie die Alpenpflanzen, gemalt von Jos. Seboth, mit Text von F. Graf, Prag) fast eher zu empfehlen wäre. - Wir wollen an dieser Stelle nicht unerwähnt lassen, dass ausser dem Sammeln der Objekte selbst auch den Volksnamen derselben Beachtung zu schenken ist; es hat dies nicht bloss sprachlich-geschichtlichen, sondern oft auch naturkundlichen Werth. Diese Bemerkung gilt selbstverständlich eben* so g'ut für zoologische als für botanische objekte; beispielsweise nennen wir von solchen Sammlungen: Jos, Rhyner, volksthümliche Pflanzennamen der Waldstätten, Schwyz 1866 ; Dr. B. Wartmann, Beiträge zur St. Gallischen Volksbotanik, St. Gallen 1874; Prof. Mühlberg, Flora des Aargau, A arau 1880; v. Siebold, die Süsswasserfische Mittel-Europas, Leipzig 1863 (S. $396-402$, S. 181, Note 2 etc.)

2) Dr. Hermann Hüller von Lippstadt, die Wechselbeziehungen zwischen den Blumen und den ihre Kreuzung vermittelnden Insekten; Fncyklopädie der Naturwissenschaften, 1. Abthlg., 1. Lfg., Breslau 1879; - Alpenblumen, ihre Befruchtung durch Insekten und ihre Anpassung an dieselben, Leipzig 1881; - Dr. Arnold DodelPort, illustrirtes Pflanzenleben, Zürich 1880/81. 
mischen Studium befassen. Er muss den Voygel im Fluge, das vierfüssige Landthier im Sprung zu heobachten wissen. Ein geübter Blick täuscht sich hierin selten; Flug und Gefieder, oft auch der Gesang oder das Geschrei charakterisiren den Vogel; nach Grösse, Gestalt, Ging, Farbe und Stimme können die meisten Süugethiere unterschieden werden; ja Grösse, Gestalt und Farbe reichen meist hei Fischen und Reptilien, oft noch bei Insekten hin zur Erkennung der Thiere. Niemand, der in den Lüften einen Raubrogel kreisen sieht, wird ihn für einen Paben halten; eben so wenig wird man letzteren mit einer Taube verwerhseln, selhst wenn man von ihm zu weit entfernt wäre, um Form und Farbe genügend deutlich zu erkennen. Wer einen Löwen, Jaguar oder eine Iyäne auch nur eine Sekunde lang sieht, wird wissen, woran er ist, ohne dass er weitere Belehrung braucht oder unnïtz Pulver rerschwendet. Indessen wird man Thiere, die man zu sehen nicht alle Tage Gelegenheit hat, in zoologischen Museen ${ }^{1}$ ), Thiergärten und Menagerien kemen zu lernen suchen und nicht blos in illustrirten Werken. In Lehriegen muss man, wie hinsichtlich der Pflanzen, ron der Kenntniss einiger weniger wesentlich verschiedener Formen ausgehen und durch Ausdehnung dieser Studien es dazu bringen, selbst nächstverwandte Thierspecies unterscheiden zu kömen. Auch wird man, wie die Flora, so die Thierwelt der zu besuchenden Länder oder von Gegenden mit ähnlichen Verhältnissen besonders studiren. Hiebei leistet das berühmte Werk von Alfred Russel Wrallace (die gendraphische Terhatung der Thieve, deutsche Ausgabe von A. B. Meyer, Dresden 1876) die besten Dienste.

Da der Reisende ihm unbekannte Thiere, wenn er solche gefangen oder erlegt hat, nicht so leicht mit sich nehmen und einem kompetenten Beurtheiler rorlegen kam, wie dies mit Pflanzen möglich ist, hat er um so mehr eine gewisse Kenntniss der Verkmale nöthig, worauf die zoologischen Klassifikationen beruhen, und eine gewisse Vertrautheit mit deren Gebrauch zum Bestimmen und Beschreiben, sodass man eine wissenschaftliche Beschreibung liefern oder wenig-

2) Wichtig ist hiebei hinsichtlich der höheren Thiere fast weniger die Reichhaltigkeit einer solchen sammlung als der L'mstand, dass die Thiere in Stellung, Gruppirung ete. möglichst lebenswahr dargestellt seien. 
stens Orduung und Familie angeben kann, zu welcher ein Thier gehört. Hiefür sind die Grundzüge der Zoologie von Prof. Claus, das Lehrbuch der Zoologie von Dr. Schmarda, sowie die mehrerwähnten naturgeschichtlichen Bücher von Lemis (Leitfaden, Schulnaturgeschichte, Synopsis) I. Theil, treffliche Führer. Selbstverständlich ist daneben wieder das Studium von Spezialfannen (wie z. B. des S. 106 erwähnten Werkes ron Prof. Siebold über die Süsswasserfische ron Mitteleuropa) zu befürworten.

Was den Gesichtspunkt des Nutzens und Schadens anhetrifft, die materiellen Beziehungen der Thiere zum Menschen und zu andern Organismen, so ist diese Seite des Gegenstandes auch in den zoologischen Büchern von Leumis berücksichtigt. Lebrigens kommt die Frage des Nutzens bei der Thierwelt weniger in Betracht als bei der Pflanzenwelt, anderntheils ist bei ihr im Gegentheil dies Verhältniss auffallender. Es ist z. B. ein Säugethier gesucht wegen seines Pelzes, ein Togel wegen seiner Federn, ein Fisch wegen seines Fleisches u. s. f. ${ }^{1}$ ) Unter allen Umständen sollte man von Thieren zum Voraus mehr wissen als ihren blossen Namen; insbesondere kommt ihre Lebensweise in Betracht; ob sie z. B. paarweise oder in Heerden leben; ob sie in bestimmten Jahreszeiten wandern; wie sie gejagt, ob und in welchem Grade sie gezähmt, zum Hausthier gemacht werden können u. s. w. Hierüber findet man reiche Belehrung in dem grossen Werke von Dr. Alfred Brehm: Illustrirtes Thierloben, dessen vortreffliche Illustrationen separat unter dem Titel „Bilder aus Brehms Thierleben" systematisch geordnet in 55 Tafeln erscheinen. Von weniger umfangreichen Werken gleicher Richtung nemmen wir: Brehm und Rossmilssler, die Thiere des Waldes (Seitenstück zu Rossmässlers Buch: Der Wald); F. $\bullet$. Tschudi, das Thierleben der Alpenwelt; $M r . G$. Jïger, Deutschlands Thierwelt nach ihren Standorten; Adolf und Karl Mïller, Wohnungen, Leben Eigenthümlichkeiten der Säugethiere und Vögel; $L$. Glaser und $C$. Klotz, Leben und Eigenthümlichkeiten der mittleren und niederen Thierwelt. — Hinsichtlich der verschiedenartigen Anpassungen im Gebiete der Thierwelt (Mimicry u.s. w.)

1) Vgl. hierüber nöthigenfalls Animal Products, their Preparation, Comnercial Uses and Value, by P. L. Simmonds, London 1877 . 
existirt eine überreiche Literatur; wir kommen in unserm - Vademecum " auf diesen Gegenstand zu sprechen ${ }^{1}$ ) und verweisen hier nur beinebens auf (harles Inaruiris berühmte Werke, die ,Darwinsche Theorie" ron Dr. G. Seydlitz und die "Allgemeine Erdkunde" ron Hann, Hochstetter und Pokorny, III. Theil.

Anthropometrische Bestimmungen. Lnter den zahlreichen Eigenschaften, durch welche sich die Menschenrassen ron einander unterscheiden, gehören die messbaren, welche Dimensionsrerhältnisse des Kopfes, die Kürpergestalt etc. hetreffen, zu den wichtigsten. Wir bringen sie an dieser Stelle zur Sprache, weil viel darauf ankommt, dass man sich rechtzeitig mit diesen Verhältnissen und deren Bestimmung bekannt macht. Der schwierige Lmstand, dass die Individuen, welche man messen will, liamm längere Zeit unbereglich in einer angewiesenen Stellung bleiben künnen oder wollen, macht es nöthig, dass man bei diesen Messungen rasch und leicht, wie spielend, zu operiren wisse.

Da die Messungen am lebenden Kürper ron denen abgeleitet sind, welche man gewöhnlich am slielett vornimmt, beginnen wir mit diesen letzteren.

A. Die Mrswungen am Shelett werden in craniometrische, d. h. Schädelmessungen, und in osteometrische, d. h. Messungen an den übrigen Theilen des Slielettes, unterschieden.

a) Die Meinungen über die zweckmässigste Art der Schüdchmsuny gehen weit auseinander. Es gibt in dieser Frage verschiedene Schulen und nicht einmal die Gelehrten einer und derselben Schule sind hierïber vollkommen einig ${ }^{2}$ ).

Nachstehend gehen wir ein Résumé der von Dr. Topinard nach dem System des Prof. Paul Broca rorgeschlagenen Methode ${ }^{\text {) }}$. Wir beschränken uns darauf, da unmüglich alle Methoden erwaihnt werden können, sind auch überzeugt, dass, wenn man nicht das grosse angesammelte Material rerlieren will, man genöthigt sein wird, ein Mittel ausfindig zu machen, um die nach den verschiedenen Methoden ge-

1) D. Kaltbrunner, dide-mémoire, S. $450 \mathrm{ff}$.

2) Tgl. über diese Verschiedenheiten $O$. Peschcl, Vülkerkunde, Leipzig 1874, S. $55 \mathrm{ff}$.

3) Vgl. L'Anthropologie, par Mr. le Dr. Paul Topinard. 2ème ed, Paris 1877. 
lieferten Angaben unter sich zu vergleichen und auf ein und dasselbe Mass zurüickzuführen ${ }^{1}$ ).

Die craniolorgischen IIcrlmale, welche genaue Messungen erheischen, sind folgende:

$1^{\circ}$ Die Schädelkapazität oder Schädelgeräumigkeit;

$2^{\circ}$ Der Schädelindex, d. h. das Verhältniss zwischen Breite $B$ und Länge ' $L$ des Schädels;

$3^{\circ}$ Die Höhe $H$ des Schädels;

$4^{\circ}$ Der Umfang desselben uach verschiedenen Richtungen;

$5^{\circ}$ Die Breite des Gesichtstheils;

$6^{\circ}$ Die Länge oder Höhe des Gesichtstheils;

$7^{\circ}$ Der kleinste Stirndurchmesser.

Dem Reisenden wird es selten möglich werden, diese rerschiedenen Abmessungen mit der wïnschenswerthen Genauigkeit vorzunehmen. Um eine Angabe von wirklich wissenschaftlichem Werth zu erhalten, muss die Messung, welche der Reisende macht und die nur als eine provisorische zu betrachten ist, wiederholt und kontrolirt werden durch Fachmänmer, welchen man die gesammelten Proben einsendet. Bei dem grossen Interesse, welches die Forschungen über vorgeschichtliche Rassen erwecken, muss aber der Reisende lebhaft wünschen, dass er selber seine Funde wenigstens in einer vorläufigen Zusammenstellung verwerthen könne. Zu dem Ende ist folgendermassen zu verfahren ${ }^{2}$ ).

$1^{0}$ Messen der Schäddyeriummigliceit. Man füllt die Schädelhöhle mit feinem Schrot sorgfältig und vollständig, schüttet dann das Schrot in ein graduirtes Gefäss, ebnet es oben gut und misst nun so $\mathrm{ab}^{3}$ ).

$2^{\circ}$ Bestimmung des Schïdelindex. Unter dem Index versteht man, wie schon bemerkt, das Verhältniss $\frac{B}{I_{s}}$ zwischen Breite und Länge des Schädels. Diese Dimensionen werden mit dem Tasterzirkel (Compas d'épaisseur, Fig. 80) und mit dem Gleit- oder Schiebezirkel (Craniometer, Fig. 81) gemessen.

1) Wer sich für diese Frage speziell interessirt, findet sachbezügliche Artikel im Avchiv für Anthropologie, Braunschweig, und in der Zeitschrift für Ethologie, Berlin.

2) Zur Erlangung möglichst genauer Angaben sind die Schädel an warmer Luft zu trocknen, da sie in feuchtem Zustande ihre Dimensionen etwas ändern.

3) Man kann hiezu dasselbe graduirte Gefäss verwenden, womit man die Regenmenge misst. Die Grundfläche desselben multiplizirt mit der Iöhe vibt das Volumen. Kennt man das Gewicht eines Liters, d. h. eines Kubikdezimeters vom angewendeten Schrot, so kann man aus dem Gewicht der Schrotmenge, welche zur Ausfüllung des Schädelraums diente, das Volum der Schädclhöhle in $\mathrm{cm}^{3}$ ableiten. 



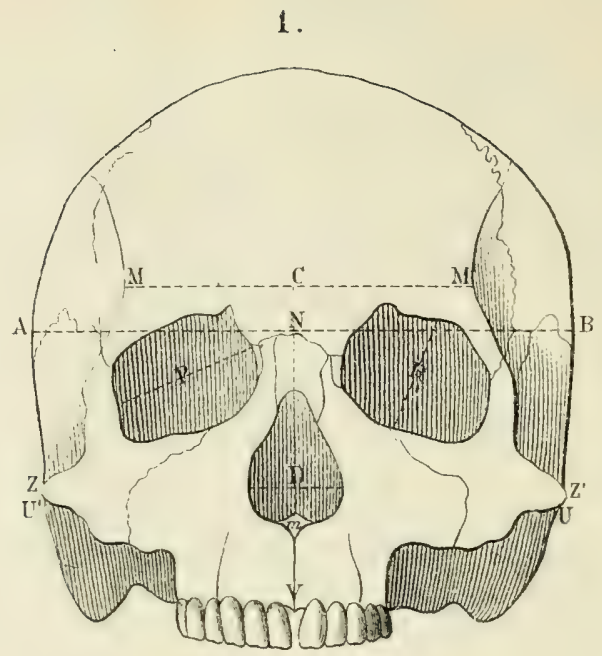

1. Menschlicher Schädel, Vorderansicht.

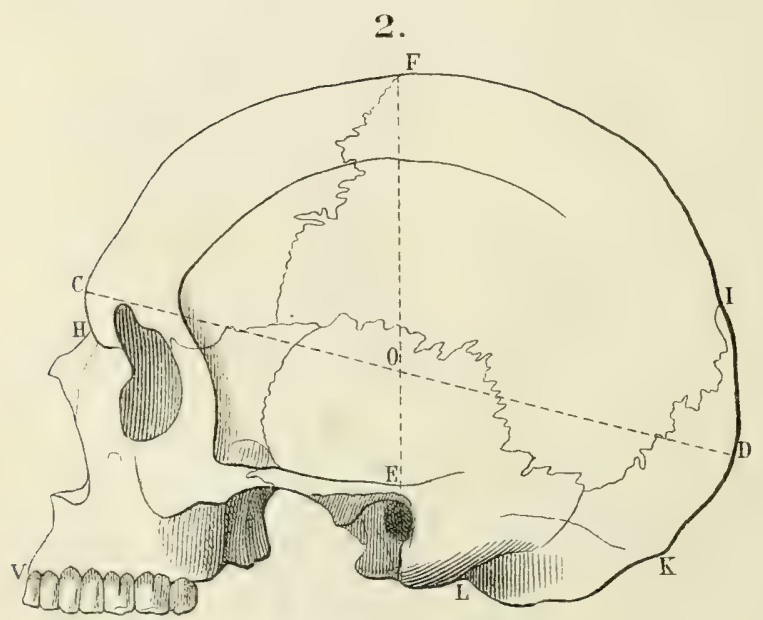

2. Menschlicher Schädel, Seitenansicht. 
Dis Brwite I' oder der grösste Transversaldurchmesser wird über den Ohren zwiwchen $A$ und $I$ ' $T$ af: $I I I, 1$ ) abgemessen, d. h. zwischen den Punkten des Schärdels, die an weitesten seitlich vortreten und genau symmetrisch liegen.

Die Linge $L$ oder der grösste Schädeldurchmesser in der Richtung rom Vorderzum Hinterschädel (in der Medianebene, welche den symmetrischen Körper halbirt) wird abgegriffen zwischen $C$ und $D$ (Taf: III, 2) 7. h. zwischen der Stirnglatze (Glabella, oder dem Uunkte mitten zwischen den Augenbrauenknochen) und dem äussersten Vorsprunge les Hinterhauptes.

Bezeichnen wir die Breite mit $B$, die Länge mit $L$, so

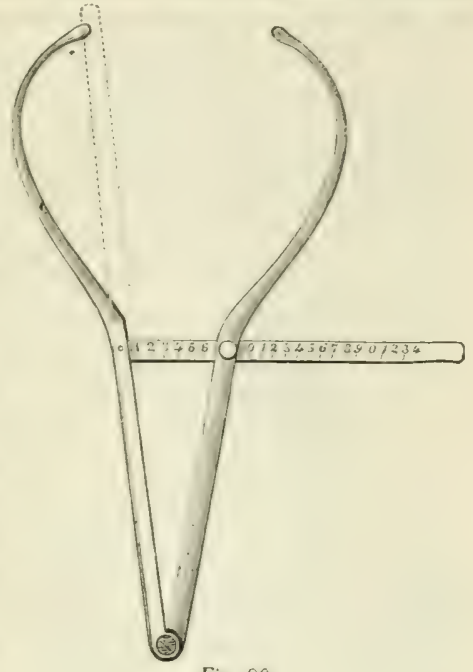

Fig. So.

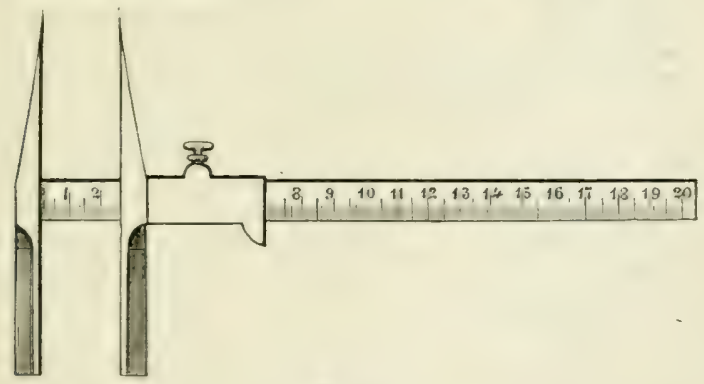

Fig. 81.

st der Schädelindex in Prozenten $\frac{100 B}{L}$. Ist z. B. die Breite oder der kürzere Inurchmesser $0,11.52 \mathrm{~m}$, die Länge oder der rrössere Durchmesser $0,182-\mathrm{m}$, so ist der Index $14,52: 0,18: 7$ $=79,17$.

Die Schärlel mit kleinem Index (unter 74) nennt man Dolichorpluche, Lang- orler Schmalschädel, die mit grossem 
Index (über 80) Brachycephale, Kurz-, oder Breitschädel, die Mittelformen Meso- oder Mesaticephale (Mittelschädel, Broca; Orthocephale = Rechtschädel nach Welcker). Hinsichtlich der genauen Grenzen zwischen diesen Formen herrschen indess wieder Meinungsverschiedenheiten. Der Eine nennt einen Schädel noch dolichocephal, welchen ein Anderer schon als brachycephal bezeichnet, und die Finen stellen Unterabtheilungen zwischen Formen auf, die ron Andern nicht anerkannt werden ${ }^{1}$ ). 'H. Welker nimmt die Zahlen 74 und 78, Calori, Virchow und Andere nehmen 74 und 80 als Grenzwerthe für die Mittelgruppe. Prof. Broca unterscheidet folgende Formen: Index

Dolichocephale . . . .75 und darunter

Subdolichocephale . . . 75,01 - 77,77

Mesaticephale . . . 77,78-80

Subbrachycephale . . . $80,01-83,33$

Brachycephale . . . 83,34 und darüber.

$3^{n}$. Itessum! der Schädclhöhe. Bis hierin zwischen den verschiedenen Methoden Einigung erzielt ist, gibt man am Besten die absolute schädelhöhe $H$ an, welche man findet zwischen den Punkten $E$ und $F$ (Taf. $I I I, 2)$, d. h. zwischen dem Vorderrand des Occipital- oder Hinterhauptloches und dem Bregma, dem höchsten Punkt des Schädels, wo die Nähte der Schädelknochen zusammentreffen.

$4^{\circ}$ Messuny des Schüdchumfanys. Der Umfang des Schädels wird in drei rerschiedenen Richtungen gemessen, nämlich: in der Medianebene $H C f J K L E H$ ('Taf. III, 2); in der Transversalen $U^{\prime}$ Af $B U U^{\prime}$ (Taf. $I I I, 1$ );

in der Horizontalen $C^{r} O D$ und zurück, doch nicht sowohl in horizontaler Linie, als vielmehr in der Richtung der grössten Schädelbreite.

1) Vgl. hierüber die interessante Zusammenstellung von Dr. H. von Ihering in der Zeitschrift für Ethnologie V, 1873, Heft 3 und 4, pag. 143. - Nach dem (indess wenig zuverlässigen) Höhenindex $\frac{H}{L}$ unterscheidet man hohe und niedrige Schädel (Hypsicephale und Chamae- oder Platycephale). Wichtiger ist die auf das Gesichtsprofil, wie die Stellung der Kiefer, Zähne und Lippen bezügliche Eintheilung in geradzälmige oder ovthognuthe Schädel, bei welchen die Scbneidezähne senkrecht in den Kiefern stehen, und schiefzïhrige oder prognathe mit schiefer Zahns stellung und vortretenden Kiefern (Lippen). Durch Kombination dieser beiden Typen mit den drei oberwähnten Abtheilungen erhält man die sechs Schädelformen der schief- und geradzähnigen Lang-, Mittel- und Kurzköpfe. Vgl. den Abschnitt über die Charaktere der Menschenrassen. 
beiden Jochbogen, wesshalb sie auch Jochbreite oder bizygomatischer Diameter heisst.

$6^{\circ}$ Die Lünge oder Höhe des Gesichts wird gemessen vom schon erwähnten Punkte $C$ bis zum obern Alveolenpunkte $Y$ (Tuf. III, 1 und 2) am Hals der mittleren Schneidezähne; diess heisst die einfache Gesichtslänge (Höhe). Unter totaler Höhe oder Länge des Gesichtes rersteht man die Distanz von $C$ bis zum Unterrande des Kinns.

$7^{\circ}$ Die Linie $\lambda I^{\prime} M I^{\prime}$ über den schmalsten Theil der Stirn heisst Fleinster Stirndurchmesser.

Wir beschränken uns auf Hervorhebung dieser wesentlichsten Messungen: detaillirtere Nessungen gehören ins Gebiet der verifizirenden und ergänzenden Operationen, wovon oben die Rede war $^{1}$ ), ausgenommen noch die Ermittlung der Indices für Nasen- und Augenhöhlen.

Unter dem Nasalindex rersteht man das Verhältniss der Linie $D$ (Taf. III, 1) oder der Breite der vordern Nasenhöhle zu ilhrem Längenmaximum, von der Nasenwurzel $I I N$ bis $m$, der herzförmigen Basis der schraffirten Nasenhöhle. Bezeichnen wir das letztere mit 7 , so ist dieser Index $=\frac{1000}{b}$.

Der Orbitalindex (für die Augenhöhlung) ist das Verhältniss zwischen den Linien $R$ und $P$ (Taf. $I I I, 1$ ) oder der grossen und kleinen Axe der Augenhöhle. Diese Axen haben ihre Ausgangspunkte je bei einer Knochemnaht und schneiden sich rechtwinklig. Der Index ist $\frac{100 R}{P}$.

Die Projektionsmethode, welche jetzt bei der Schädelmessung immer mehr Anwendung findet, eignet sich nur für die Laboratorien der Gelehrten. Der Reisende ist selten in der Lage, mit der hiezu nothwendigen Genauigkeit operiren zu können und er wird besser thun, diese schwierigen Messungen berufeneren Händen zu überlassen ${ }^{2}$ ).

b) Die astermetrischen MIerkimale der übrigen Skelettpartien (Taf. IV) sind:

$1^{\circ}$ Die Grösse oder Statur - falls man ein Skelett ror sich hat, das in seiner natürlichen Lage, in allen Theilen unverändert, ungestört geblieben ist.

1) Näheres findet der Leser, der Solches wünschen sollte, in den Instructions craninlogiques et craniometriques von Paul Broca, Paris 1875; in der Anthropoloyif von Dr. Topinard (II. Auf. Paris 1875) und in dem Részmé des Instructions craniologiques et craniométriques von Dr. Collineare (Paris 1877).

2) Vgl, das ausgezeichnete Kapitel hierüber in Dr. Topinard, Anthropologie 2 ed. Paris 1877 , S. $269-305$. 
Taf. IV.

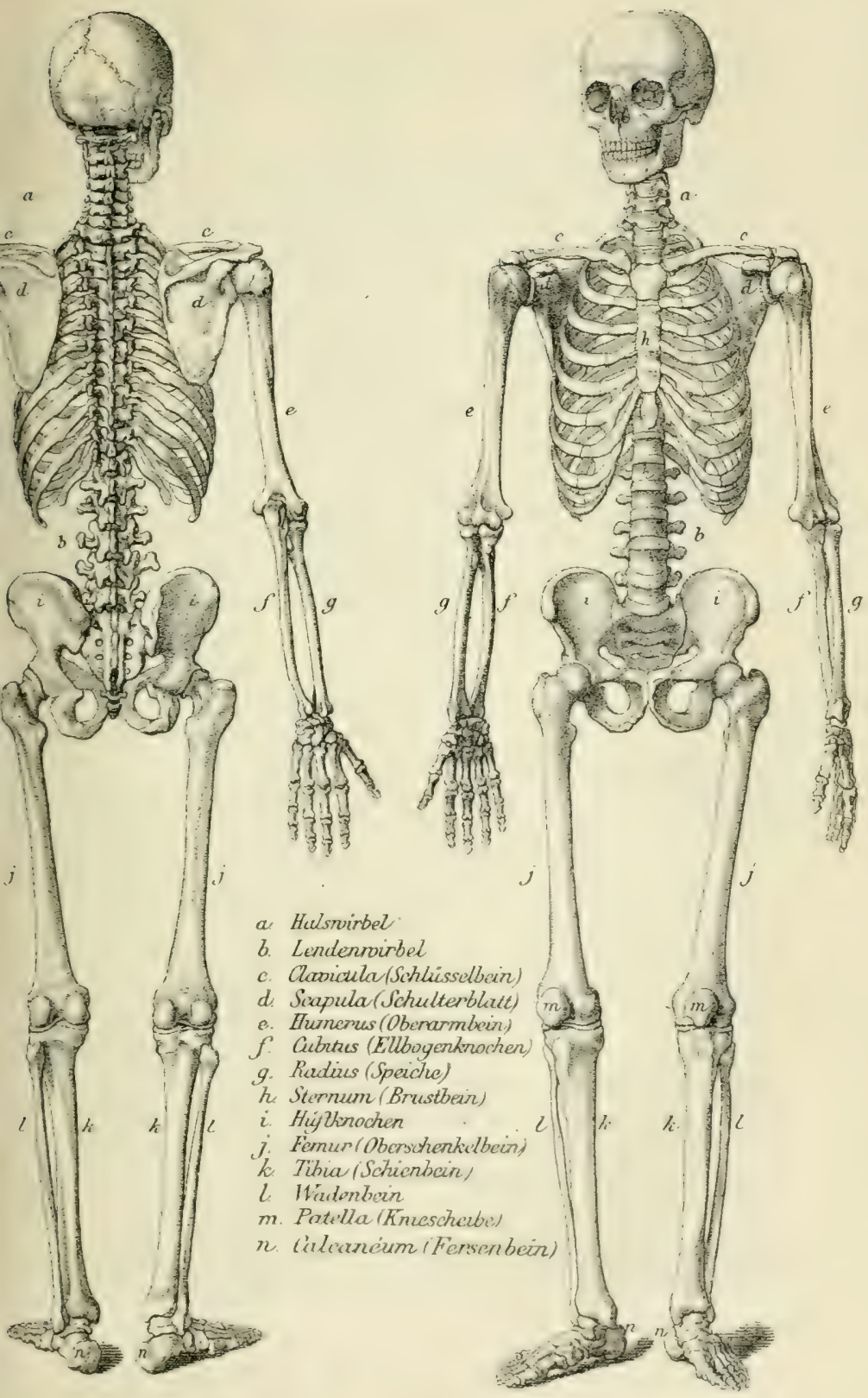



$2^{\circ}$ Die Längen der wichtigsten Knochen, wie des Schlüsselbeins, Oberarmbeins (Humerus), des Radius und Cubitus (Speiche und Ellbogenknochen), Oberschenkelknochens, Schienund Wadenbeins.

Zu diesem Zwecke legt man diese Knochen auf ein eingetheiltes Brett und bestimmt mit Hülfe zweier Winkelhacken die Projektionen der beiden Endpunkte auf dem Brette ${ }^{1}$ ).

B) Die IIessungen am lebenden Körper sind, wie wir schon bemerkten, mit erheblichen Schwierigkeiten rerbunden, und um sie mit Erfolg ausführen zu können, muss sich der Reisende darauf vorbereitet haben. Dr. R. Virchow in Berlin äussert sich hierüber (Neumayer, Anleitung pag. 588) wie folgt: „Autodidakten sind nirgends unzurerlässiger als in den messenden Zweigen der Wissenschaft. Jeder Reisende sollte sich bei einem Anatomen oder sonst sachrerständigen Anthropologen einüben lassen, selbst die gewöhnlichen Kenntnisse des Arztes reichen nicht aus, um in jedem Augenblicke diese Art der Nessungen richtig anzustellen oder gar zu lehren." - Die am Lebenden vorzunehmenden Messungen sind folgende:

c) Am Kopfe

$1^{\circ}$ Die Breite oder der grösste Querdurchmesser, über den Ohren, wie am Skelett.

$2^{\circ}$ Die Lïnge oder der grösste Mediandurchmesser, von der Glabella (dem Punkt in der Mitte der Linie zwischen den obern Theilen der Augenbrauen) bis zum entferntesten gegenüberliegenden Punkte, wie beim Skelett.

$3^{\circ}$ Diese beiden Maasse bestimmen den Schüdelindex für Larmde. Lm hieraus den Index für das Kopftheil des Skelettes abzuleiten, muss man die Dicke der Tegumente (Haut und Muskeln) in Rechnung ziehen; zu dem Ende müssen die am lebenden Körper erhaltenen Zahlen etwa um 2 Maasseinheiten reduzirt werden.

$4^{\circ}$ Die Shardrlhijhe wird bestimmt als Differenz zwischen der ganzen Körperhöhe bis zum Scheitel, woron wir nachher sprechen, und der Höhe oder Länge des Körpers von unten his zu einer Horizontalen durch die Mündung des

1) Da über die beste Methode zum Messen ron Skelettpartien Meinungsverschiedenheiten bestehen, so wird man gut thun - welche Methode man auch befolgt - ganz bestimmt zu sagen, wie die betr. Messung zu rerstehen sei. 
Gehörgangs (welchen man hier als Ersatz für das Hinterhauptloch nimmt) und die Nasenbasis.

$\tilde{5}^{\circ}$ Die verschiedenen Arten des Schüdelumfangs oder wenigstens deren wichtigste Abschnitte werden gemessen wie am Skelett, mittelst eines Messbandes, vorbehalten die Reduktionen, welche mit Rücksicht auf die Dicke der Tegumente and des Haarwuchses nöthig sind.

Die Breite und die (einfache wie totale) Höhe oder Länge des Gesichts werden auf dieselbe Weise gemessen wie am Skelett, ebenso auch :

$6^{\circ}$ der hileinste Stirndurchmesser.

$7^{\circ}$ Wenn man von der gesammten Höhe des Körpers diejenige von unten bis zum Kinn abzieht, so erhält man die Höhe des Kopfes. Ihr fügt man, behufs späterer Bestimmung des Gesichtswinkels, noch

$8^{\circ}$ die Höhe des zuischen den Augenbrauen gelegenen Superorbitalpunlites $C$, d. h. dessen Abstand vom Boden, bei.

Hiebei muss man das $\mathrm{zu}$ messende Individuum in gut aufrechter Haltung an eine Wand oder Nauer stellen, an welche man das Messband oder den Massstab anlegt (sodass der Nullpunkt am Boden ist) oder eine metrische Theilung anbringt. Längs der Mauer oder des Massstabes fährt man mit einem Winkelhacken hin, dessen oberer Rand den gesuchten Punkt auf der Skala bezeichnet. Der Kopf ist so zu halten, dass die Nündung des Gehörganges und die Basis der Nase in eine Horizontale zu liegen kommen.

Sind die Punkte, deren Höhenlage man bestimmen will, etwas entfernt von dem Winkelhacken, den man anwendet, so bedient man sich eines zweiten solchen Instrumentes (Winkel, Equerre), legt dasselbe an das erstere so an, dass es mit ihm einen rechten Winkel bildet und bestimmt damit die Lage derjenigen Punkte, welche mit dem erstern sich nicht erreichen lassen. Dieses, das Hauptinstrument, wird oben mit einer Metertheilung versehen und so angelegt, dass der 0 Punkt an die Wand (Mauer) zu liegen kommt. So kann man zugleich den Abstand wesentlicher Punte ron der Rückenebene (Wand) bestimmen, wie den Abstand des Gehörganges, des Superorbitalpunktes (der Glabella, Stirnglatze) und des obern Alveolarpunktes. 
Berührt der Kopf die Wandfläche nicht, ohne dass die Linie durch Gehörgang und Nasenbasis (Nasenlöcher) aus der horizontalen Lage kommt, so bringt man zwischen Wand and Kopf einen Gegenstand an, wie ein Buch oder Brett, und zieht nachher dessen Dicke ab.

B) Am ganzen Körper (Taf. IV).

Das Individuum wird in der eben beschriebenen Weise an eine Wand oder Mauer gestellt und muss die sogenannte Grundstellung der Soldaten annehmen, Fersen aneinander, Arme seitlich am Körper gestreckt, die Finger ausgestreckt an die Schenkel angelegt. Dann nimmt man mit Hülfe zweier Winkel - die Anwendung des Meterbandes allein gäbe zu ungenaue Resultate - folgende Maasse ab:

$1^{\circ}$ Grösse oder Statur, d. h. Abstand des Scheitels vom Boden, wie oben bemerkt.

$2^{\circ}$ Rump $f$, d. i. Distanz vom Halswirbelvorsprung zwischen den Schultern (cc, Tuf. $I V$ ) bis zum Ende der Wirbelsäule, d. h. bis zum Heiligenbein oder Steissbein (sacrum oder coccyx); auch die Distanz zwischen der Vereinigungsstelle beider Schlüsselbeine (oberer Rand des Brustbeins) und dem Schooss- oder Schambein (oberer Rand).

$3^{\circ}$ Oberarm (c) - Höhe des Vorsprungs (Akromion) am Schulterblatt (d) oder der Schulter selber, vom Boden aus gemessen, weniger die Höhe des Ellbogens (Aussenende des Oberarmbeins) vom Boden aus.

$4^{\circ}$ Vorderarm. Die letzterwähnte Zahl weniger den Abstand des Endes der Speiche of (Vorsprung an der Handwurzel, auf der Seite des kleinen Fingers) vom Boden.

$5^{\circ}$ Hand ; das letztere Maass weniger den Abstand zwischen dem Boden und dem (untern) Ende des Mittelfingers.

$6^{\circ}$ Schenkel i (Oberschenkel). Abstand zwischèn dem Boden und dem Oberende des Schenkelknochens (dem Oberrand des grossen Trochanter oder Rollhügels) weniger Kniehöhe (Mitte des Kiniees auf der gewölbten Aussenseite $m$ ). $7^{\circ}$ Unterschenliel. Die letztere Zahl weniger die Höhe des Oberrandes der Fusswurzel $n$ (des Malleolus internus) über dem Boden.

$8^{\circ}$ F'uss. Höhe: das eben genannte Maass. Länge: vom hintersten Vorsprung der Ferse bis zur Spitze der grossen Zehe. 
$9^{\circ}$ Klafterweite der Arme: Die Distanz der Mittelfingerenden bei wagrecht vom Körper abstehenden (zu ihm in Kreuzform gebrachten) Armen.

$10^{\circ}$ Schulterbreite: Abstand von einem Akromion (Schulterhöhe, Grätenecke) zum andern.

$11^{\circ}$ Beclienbreite. Abstand von einem Hüftrand (crista ilei) zum andern.

Diese 3 Maasse sind mittelst zweier Winkel (Equerres) abzunehmen, während das Individuum mit dem Rücken an die Wand lehnt, an welcher nachher die Entfernung der Equerren durch das Messband ausgemittelt wird.

$12^{\circ}$ Endlich die Distanz zichishen Kniescheibe (m) und Mittelfinger: die unter Ziffer 5 erwähnte Zahl weniger den Abstand des obern Kniescheibenrandes vom Boden.

Um die Proportionen der Glieder zu erhalten, braucht man nur alle jene Maasse in Prozenten der ganzen Körperhöhe anzugeben, diese also gleich $100 \mathrm{zu}$ setzen und die Messungsresultate hienach umzurechnen.

Ebenso verfährt man, um die Verhältnisse der Gliederlängen $z u$ einander abzuleiten, z. B. das Verhältniss der oberen Gliedmassen (Ober- und Vorderarm) zu den unteren (Ober- und Unterschenkel), wie dasjenige des Oberarms zum Vorderarm und des Oberschenkels zum Unterschenkel. Nan setzt immer die Länge des Gliedes, womit man ein anderes vergleichen will, $=100$ und leitet durch eine Proportion die Verhältnisszahl für das andere in Prozenten ab. Diese Verhältnisszahl gibt Hundertel, wenn man das Vergleichsmaass zu 1 statt 100 annimmt.

Diesen Messungen kann man endlich noch folgende beifügen, welche leicht mit dem Messband abzunehmen sind: Umfang des Halses, um die Schultern,

" unter den Armen,

" um die Mitte des Oberarms,

"ums Handgelenk,

" um die Lenden (Taille),

" um die Hüften,

" oben am Schenkel,

"am Knie,

" um die Wade,

» ob den Fussknöcheln. 
Wir schliessen diesen Abschnitt mit der Bemerkung, dass dem Reisenden mit Rücksicht auf die verschiedenen Messungen, die von ihm gewünscht werden, zu empfehlen ist, rechtzeitig einige Dimensionen seines eigenen Körpers zu bestimmen, beziehungsweise bestimmen zu lassen, so namentlich seine Höhe, die Höhe (den Bodenabstand) von Auge, Ellbogen und Knie. (Vgl. A. d'Abbadie, Instructions pag. 281.)

Statistische Erhebungen. Wenn auch ein Reisender nicht daran denken kann, direkt eine vollständige und detaillirte Statistik der Bevölkerung oder des Handels oder über andere interessante Gegenstände zu erstellen, so wird ihm dagegen der Aufenthalt in fremden Ländern oft Gelegenheit bieten, amtliche statistische Dokumente zu verwerthen, die noch nicht veröffentlicht oder doch wenig bekannt sind. Es handelt sich also für ihn weniger darum, zu wissen wie man bei genauen statistischen Aufnahmen verfahren muss, als viehmehr darum, dass er sich in schon rorhandenen Dokumenten über Gegenstände der Statistik zurechtzufinden und so die Naterialien zu benutzen wisse, welche durch Personen, die hiefür besser situirt sind als ein Reisender, bereits gesammelt wurden.

In dieser Beziehung gibt $A$. Meitz'n in den "Anleitungen zu wissenschaftlichen Beobachtungen auf Reisen", pag. 153, sehr gute Räthe; wir glauben dem Leser nicht besser dienen zu kömnen als durch wörtliche Wiedergabe derselben:

"Der Reisende wird gewiss gut thun, vorher zu Hause, wo er mit Leichtigkeit volle Belehrung finden kann, auch wenn dort die statistischen Arbeiten der Staaten, die sein Reiseziel sind, nicht $\mathrm{zu}$ erlangen sein sollten, doch die ähnlichen Werke seiner Heimat auf Inhalt und Gebrauch näher anzusehen.

„Er findet da bei jeder höhern Behörde zahlreiche Tabellen, Staatshandbücher, Jahrbücher und periodische Schriften über die verschiedenen statistischen Gegenstände. Alle diese Veröffentlichungen werden durch die übereinstimmende Natur der Dinge in den verschiedenen Staaten ziemlich ähnlich gestaltet.

"Je mehr er sich mit Zweek und Anordnung solcher Aufstellungen bekannt gemacht hat, desto leichter wird es ihm werden, ähnliche Arbeiten im fremden Lande aus- 
zunützen, und er wird um so rascher Einsicht in dieselben gewinnen und durch persönliche Rücksprache Grundlagen für die richtige Würdigung erreichen."

Ich füge bei, dass es dem Reisenden sehr nützlich sein wird, wenn er zum Voraus ein Tableau erstellt über die statistischen Aufnahmen, die er an seinem Bestimmungsorte machen will, d. h: wenn er das Schema mit Kolonnen und Ueberschriften sorgfältig zum Voraus erstellt. Jede gesammelte Angabe kommt dann gleich an ihren richtigen Ort; mit einem Blick übersieht man dann, welche Lücken noch bleiben und nach welchen Richtungen man also noch Erhebungen machen muss, um vollständige tabellarische Uebersichten zu erhalten. Diese rorgängige Arbeit wird die Verwerthung umfangreicher Werke, die man zu benutzen Gelegenheit hat, ungemein befördern, und man wird weniger in die Lage kommen, ganze Seiten mit ungeordneten Zahlen zu füllen, unter welchen man sich vielleicht später schwer zurecht finden würde.

\section{UEBUNGEN.}

Welches auch der Grad der Vorbereitung sei, bis zu dem man es gebracht hat, so benutze man Mussestunden zu Exkursionen in der nächsten Umgegend, um dabei die Lehren und praktischen Winke, die wir in Vorstehendem behandelten und in dem Abschnitt "Beobachtungen und Untersuchungen" weiter geben werden, zu verwerthen. Denn wer sich praktische Geschicklichkeit aneignen will, muss sich vorher in den Operationen üben, deren Vornahme am Reiseziel erforderlich ist.

Ein solches Verfahren bringt entschiedene und grosse Vortheile.

Zunächst eignen wir uns dabei die Fähigkeit an, zu sehen, was um uns ist. Diese Fähigkeit ist leider keineswegs eine so allgemeine, wie man erwarten möchte; in sehr vielen Fällen treffen die Worte J. J. Rousseau's zu: man beobachtet am wenigsten was man beständig vor Augen hat. Lernen wir aber auf die Dinge um uns achten, dann werden wir oft mit freudiger Ueberraschung Erscheinungen sehen, die uns noch unbekannt sind; dann werden wir auch 
in einer Gegend, die wir gut zu kennen glaubten, immer wieder Neues wahmehmen, das dem ungeschulten Blicke entging, und überall werden wir Vergleichungspunkte finden.

Ein zweiter Vortheil des erwähnten Verfahrens ist der, dass man sein Wissen anurnden, gebrauchen lernt, dass man zum Wissen das Können, zur Kenntniss die Fertigkeit fügt. So kommt man denn auch zur Erkenntniss der Lücken und Fehler, die man noch zu beseitigen hat. Tur so erlangt man auch die Fähigkeit, dass man sich üherall einzurichten und zu behelfen weiss, die Fertigkeit des Operirens auf jedem Terrain - unenthehrliche Eigenschaften für einen Jeden, der wirklich in der Natur, im Felde beobachten will.

Ebenso lernen wir hiedurch die Eigenschaften und etwaige Fehler unserer Instrumente kennen; wir kommen darauf, ihnen die passendste Form zu geben, sie auf das unumgänglich Nothwendige zu reduziren, ohne Wesentliches wegzulassen. Sonst passirt es Einem nur zu leicht, dass man sich mit überflüssigem Gepäck belastet und dass, wenn der Noment kommt, wo das reiche Arsenal benutzt werden sollte, man auf einmal zu seinem grossen Verdrusse die leidige Wahrnehmung macht, dass man unter einer Menge umö̈thiger Dinge gerade die nützlichsten nicht hat. Nur Lebung, Praxis, lehrt uns mit Sicherheit, was man gegehenen Falls. wirklich braucht, was aber nicht.

Durch diese Uebungen und nur durch sie rerschaffen wir uns auch die Kenntniss der Mittel und Wege - gewisser "Kunstgriffe", einfacher Dinge, auf die man aber nur in der Praxis verfällt - um die Genauigheit der verwendeten Instrumente und der erhaltenen Resultate $\mathrm{zu}$ kontroliren und sich von der Richtigkeit der Operationen zu vergewissern. Diese Gewissheit wird später von grossem Werth, wenn die Beobachtungen, aus Mangel an Mitteln zur Verifikation, keine andere Garantie bieten als die Genauigkeit der Instrumente und das praktische Geschick des Beobachter's.

\section{PHOTOGRAPHIE UND KUNSTZEICHNEN.}

Abgesehen davon, dass gut ausgeführte Zeichnungen den Reiseberichten eiren eigenartigen Reiz verleihen, ist es in vielen Fällen von hohem Werth, wenn die Objekte bildlich 
dargestellt, statt blos in Worten beschrieben werden können. Es ist das recht oft das beste, ja das einzige Mittel, um davon eine richtige und getreue Vorstellung $\mathrm{zu}$ erwecken; auch kann man hiebei das Schwierige und Schwerfällige, das den Beschreibungen oft anhaftet, vermeiden.

Jeder Reisende "sollte daher im Stande sein, die Dinge bildlich darzustellen, die seine Aufmerksamkeit erregten. Nicht nur werden er und seine Freunde es angenehmer finden, solche Albums zu durchblättern als Notizen zu durchmustern; auch für die Wissenschaft hat das Bild eines Gegenstandes oft mehr Werth als die Beschreibung aus der Feder eines Laien.

Die Mittel, welcher sich der Reisende zur Anfertigung solcher Bilder bedienen kann, sind

$1^{\circ}$ die Photographie;

$2^{\circ}$ das Kunst- oder Freihandzeichnen.

Unter letzterem verstehe ich das Kreidezeichnen, das Tuschen und die Aquarellmalerei. Von der Oelmalerei spreche ich hier nicht, weil sie ein für den Reisenden $\mathrm{zu}$ beschwerliches Material erfordert.

Diese beiden Darstellungsmethoden des Photographirens und des Zeichnens scheinen sich gegenseitig auszuschliessen; allein ihre kombinirte Anwendung bringt grossen Vortheil. In der That erwecken Photographien nicht dasselbe Interesse, wie eine gut ausgeführte Zeichnung oder gar ein Aquarell. Anderseits haben Photographien den Vortheil grösserer Genauigkeit für sich und bieten sie eine Fülle naturgetreuen Details bis ins Kleinste, so dass Zeichnen und Malen hierin mit ihnen unmöglich konkurriren können. Nun besteht das Verdienstliche bildlicher Darstellungen, welche ein Reisender zurückbringt, weit mehr in ihrer Zuverlässigkeit als in ihrem künstlichen Werth. Naturtreue ist dabei die Hauptsache; allein Eleganz der Zeichnung und schönes Colorit sind zum Mindesten angenehme Beigaben. Es handelt sich also darum, das Verlässliche, Naturgetreue der Photographie zu vereinigen mit den Eigenschaften, welche Vorzüge des Zeichnens als Darstellungsmittel sind.

Jedem, der schon nach der Natur gezeichnet oder gemalt hat, ist zur Genüge bekannt, wie schwierig es ist, eine nach Treue und Vollständigkeit befriedigende Ansicht fertig zu 
bringen, wemn man nicht ziemlich riel Zeit hierauf verwendet und wiederholt auf den Punkt zurückkommit. Bei einem Aquarell ist die Sache noch schlimmer. Während des Skizzirens verändert sich die Phy̧siognomie der Landschaft: es rerschwinden Lichteffekte, welche dem Bilde einen Hauptreiz verliehen: es ändern sich die Töne und Schattirungen, hevor noch unsere ersten Farben zum Trocknen kommen, und es bleibt keine andre Wahl als entweder das Gemälde nach dem Gedächtniss zu vollenden oder die erst begonnene Arbeit rerdriesslich auf die Seite zu legen.

In der ungünstigsten Lage mit Bezug auf alle diese Momente befindet sich nun der Reisende. Gebunden durch Rücksichten auf seine Route und seine Zeit, darf er oft nicht verweilen und nicht an die Stelle zurückkehren. Ebensowenig kann er sein Gepäch mit Feldsessel und Malerparasol belasten; will er zeichnen, so muss er das thun ohne Schutz ror den Sonnenstrahlen, auf einem Baumstamme oder Stein als Sitz, unter Bedingungen also, welche ein längeres und genaues Arbeiten erschweren. Führer und Begleiter drängen zum Aufbruch, und wohl oder übel nuss man ihnen nachgeben, wenn man in der Eile auch nur eine halbfertige Skizze entwerfen konnte. Man muss auch zugehen, dass der Reisende, wollte er seinen Willen durchsetzen und darauf bestehen, Bilder aufzunehmen und zu vollenden, in einem Tag weder eine grosse Wegstrecke zurücklegen noch riel Aquarelle zu Stande bringen würde.

Mit denselben Schwierigkeiten und obendrein mit noch andern hat man zu kämpfen, wenn man das Glück hat, typische Tolksgestalten zu treffen, Charakterköpfe ron Fischern, Hirten, Aelplem, die man gerne für seine Mappe verwerthen mörhte. Wie soll man das thun, wie zu einem guten Bilde kommen, wenn man nicht gewandter Porträtmaler ist? Selbst ein solcher hat noch Schwierigkeiten zu bewältigen, rorab die, dass ihm das Individuum kaum lange genug ruhig in einer Stellung bleibt.

Angesichts dieser Schwierigkeiten habe ich mir in solchen Fällen immer damit geholfen und mich dabei am Besten befunden, die Landschaft oder das Individuum ror meinen Augen zu photographiren und dabei rasch auf einem Blatt Papier (Carton) die Färbung, den Teint der verschiedenen 
Theile meines Bildes anzugeben. Ist dies gethan und bleibt mir Zeit zu Weiterem, so arbeite ich sofort die kolorirte Skizze aus; andernfalls packe ich meine Sachen zusammen, sehe mir aber meinen Gegenstand noch einmal gut an, um mir sein Bild wohl einzuprägen.

So bin ich im Besitz der Elemente zu einer naturgetreuen Darstellung: einer photographischen Aufnahme, welche alle wünschbaren Details zu einer genauen 'Zeichnung der Formen erhält, und von Notizen für die Farbengebung, welche namentlich dann ausreichen, wenn ihnen noch die frische Vorstellung des Gesehenen zu Hülfe kommt.

Neines Erachtens empfängt man ein besseres Bild des Ganzen, des Charakters einer Landschaft, ihres eigenthümlichen Gepräges, wie auch der Physiognomie von Individuen, wenn man nicht durch materielle Arbeit und viele Details in Anspruch genommen ist.

Wenn man, was in der beschriebenen Weise fixirt wurde, später mit Musse zur Erstellung einer sorgfältigen Zeichnung verwerthet, so kann man das photographische Bild hinter eine vergrössernde Linse (Lupe) bringen und hienach eine bis ins Kleinste getreue Zeichnung anfertigen, welche man nach Nassgabe der Notizen und der Erinnerung kolorirt; oder man vergrössert das aufgenommene Bild (die Platte wird aufbewahrt) wieder auf photographischem Wege, bezw. man lässt es durch einen Photographen in gewünschter Weise vergrössern und retouchirt es mit Hülfe des Pinsels.

Das Material, welches man zu diesem ganzen Verfahren nöthig hat, ist folgendes:

$1^{\circ}$ Ein Scenograph von Dr. Candèze ${ }^{1}$ ), ein photographischer Apparat, dessen sämmtliche Theile enthalten sind in einer Cassette von $28 \mathrm{~cm}$ Länge, $17 \mathrm{~cm}$ Breite und $9^{1 / 2} \mathrm{~cm}$ Höhe und welcher Aufnahmen liefert im Format von $16 / 11 \mathrm{~cm}$.

$2^{\circ}$ Ein Stock, welcher sich als Fussgestell für den Scenographen verwenden lässt, wozu man auch das Stativ des Theodolits oder der Orientirboussole verwenden kann.

$3^{\circ}$ Eine Schachtel mit feuchten Farben von J. M. Paillard in Paris, Winsor und Newton in London oder Schönfeld \& Cie.

1) Dieser Apparat ist zu beziehen durch C. Deyrolle fils in Paris, rue du Quatre Septembre 35. 
in Düsseldorf, Schachtel ron $11 \mathrm{~cm}$ auf $4 \frac{1}{2}$; ein WasserHäschchen und einige Stücke Bristol- oder Harding-Carton, die man in der Tasche trägt. Den Stock ausgenommen, kamn man Alles das in der Cassette placiren, die für den Handtransport mit Messinggriff oder Lederriemen versehen ist.

Die Glastafeln (Platten) kauft man vollständig präparirt; bei Anwendung gewisser Vorsichtsmassregeln erhalten sie sich grut während mehrerer Monate vor und nach der Operation. Was dann die Entwicklung des Bildes anbetrifft, die Lebertragung anf Papier etc., so kann man das einem Photographen von Fach übergeben, sodass man selber jedweder langen und heikeln Manipulation enthoben ist. Weitere Auseinandersetzungen können wir unterlassen: man findet das Nöthige in den Broschüren, welche mit den Apparaten zugleich verkauft werden ${ }^{1}$ ).

Was von Landschaftsbildern und Porträts gesagt wurde, gilt auch ron Denkmälern, Inschriften, Trachten, Waffen und Werkzeugen, Jagd- und Fischereigeräthen, Münzen und Schmucksachen, Pflanzen, Insekten u. s. w., von denen man sich ohne allzugrossen Aufwand ron Zeit und Yühe eine gute Abbildung verschaffen will.

Was Gruppen von Nenschen und Thieren, Szenen aus dem Leben anbetrifft, so ist man vielleicht im Stande, durch eine rasche Aufnahme ein Bild zu fixiren, das, wenn es auch an sich ungenügend ausfillt, doch später zur Unterstïtzung des Gedarchtnisses dient und in dieser Eigenschaft von Nutzen ist. Oft aber sind derartige Szenen zu rasch vorübergehend; man wird darum gut thun, ihnen für die kurze Zeit, da man sie vor Augen hat, volle Aufmerksamkeit zuzuwenden und nachher aus der Erinnerung ihr Bild zu entwerfen.

Ehenso verhält es sich mit der Darstellung typischer Figcuren. Wollte man einen wilden Eingebornen photographiren, so würde dieser nicht die hiezu nöthige Puhe und Unbeweglichkeit der Gesichtsmuskeln annehmen; der Versuch

1) Die Broschüre zum Fritz'schen Apparat (VI. Auflage mit 6 Holzsihnitten) à $50 \mathrm{Pfg}$. (70 Cts.). Bei dem Optiker Deyrolle ist auch ein photographischer Apparat zu haben unter dem Namen Polygraph, zu welchem man als Negativ Kollodiumpapier verwendet. Damit wird ein wesentlicher Zuwachs zum Gepäck vermieden: 300 Blätter dieses Papiers erfordern nicht mehr Raum als ein Dutzend Glasplatten. 
würde hiedurch schon missglücken. Zudem ist der wahre Typus ein Ideal, das man selten oder nie in einem Individuum verkörpert trifft; folglich ist hier die Photographie unzureichend. $Z u$ solch einem Typenbilde muss man die Elemente aus der Beobachtung vieler Individuen sammeln und man muss es verstehen, die verschiedenen Züge, die man da und dort bemerkt hat, in ein Gesammtbild $\mathrm{zu}$ vereinigen. Dazu aber gehört sowohl eine tüchtige Beobachtungsgabe als auch eine geübte Hand, welche die feinsten Nüancen wiedergeben kann.

Zum Schlusse dieses Abschnittes können wir das Gesagte dahin resumiren :

Ist der Reisende nicht Zeichner, so kann er doch mit Hülfe der Photographie Bilder zurückbringen, die nicht nur erwünschte Andenken für ihn sein werden, sondern ihm auch möglich machen, seinen Reisebericht mit werthvollen Illustrationen zu versehen, wenn er sich zu diesem Zweck mit einem Künstler in Verbindung setzt, der die Photographien und zugehörigen Notizen wohl zu benutzen weiss.

Ist aber der Reisende im Zeichnen und noch einigermassen im Malen geübt, so wird er sich leicht und ohne viel Zeitverlust das nöthige MIaterial an Skizzen verschaffen, um mit Musse ein kostbares Album von Zeichnungen und Aquarellen herzustellen - ein Resultat, welches die Mühe reichlich lohnt, die man auf das Zeichnen von Nasen und Mundformen verwenden musste, um die Elemente der Kunst sich anzueignen! Nichts bildet Auge und Hand so wie das Zeichnen nach der Natur, wenn man nur einmal über die ersten Anfänge hinaus ist. Diess verdiente beherzigt zu werden. Wer bei Antritt seiner Reise noch ein mittelmässiger Künstler ist, wird sich im Verlauf derselben bei nur einiger Beharrlichkeit zu einem guten Zeichner ausbilden.

\section{TOPOGRAPHISCHES ZEICHNEN.}

Das topographische oder Plan- und Kartenzeichnen bezweckt die bildliche Darstellung der Gestalt und Beschaffenheit des Bodens mit dessen natürlichen oder künstlichen Einzelheiten. 
anzugeben ausser eben durch Zeichen und Farben besonderer Bedeutung. Ausser diesen konventionellen Symbolen bringt man auf den Karten soviel als möglich auch die Namen der dargestellten Objekte an oder wenigstens an deren Stelle - wenn die Karte durch Anbringen der vollen Namen überfüllt und die Zeichnung dadurch beeinträchtigt würde Abliürzmgen, deren Bedeutung auch bekannt ist oder in der Karte noch besonders erklärt wird; z. B. Fl. = Fluss; C. = Cap.

Das Kartenzeichnen beruht also einerseits auf geometrischen Prinzipien, andrerseits auf der Verwendung konventioneller Symbole. Um eine lesbare Karte zu erstellen, ג. h. eine Karte, die andern verständlich sein soll, muss man jene geometrischen Grundlagen und vereinbarten Zeichen kennen.

Wir haben nun schon gezeigt, wie man auf dem Terrain die Distanzen, Winkel und Höhen misst und wie man sie zu Papier bringt, um eine erste Skizze und Fixpunkte zu erhalten, welche der vollendeten Karten- oder Planzeichnung zur Grundlage dienen müssen. Es bleibt uns nur ïbrig, das eigentliche Kartenzeichmen zu besprechen. Hier glauben wir indessen zunächst einige Worte über die Wahl des Massstabes, der Redulition oder Verjüngung anbringen zu sollen.

Unter der Redultion einer Karte oder eines Planes versteht man das Verhältniss zwischen den wirklichen (horizontalen) Distanzen auf dem Felde und den entsprechenden Längen auf dem Papier. Die letzteren sind selbstverständlich immer kleine Bruchtheile der wahren Distanzen; aber eben diesen Bruch muss man kennen, um genau zu wissen, welche Länge auf dem Terrain einer solchen auf dem Papier entspricht. Ist dieser Bruch oder diese Verhältnisszahl (Reduktion) 1/100, so folgt daraus, dass $1 \mathrm{~cm}$ auf dem Papier in Wirklichkeit $100 \mathrm{~cm}$ oder also $1 \mathrm{~m}$ vorstellt; ist jene Zahl $1 / 10000$, so bedeutet $1 \mathrm{~cm}$ der Zeichnung $100 \mathrm{~m}$ auf dem Terrain u. s. w. Man sagt in diesen Fällen, der Plan sei in 1/100, 1/10000 (in Einhundertel, ein Zehntausendtel) konstruirt, und wie man sieht, hat man die in der Zeichnung enthaltenen Längen einfach mit dem Nenner des betreffenden Bruches zu multipliziren, um die Strecken auf dem Felde zu erhalten, welche durch jene Längen repräsentirt werden. 
.

(1) 


\begin{tabular}{|c|c|}
\hline 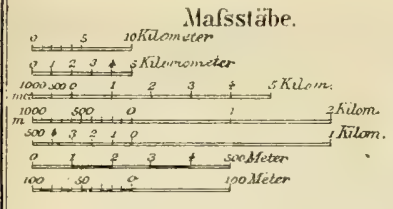 & $\begin{array}{l}\frac{1}{1,000,000} \\
\frac{1}{500,000} \\
\frac{1}{250,000} \\
\frac{1}{300,000} \\
\frac{1}{50,000} \\
\frac{1}{25,000} \\
\frac{1}{10,000}\end{array}$ \\
\hline
\end{tabular}

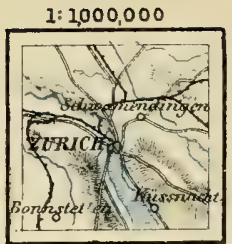

1: 500,000
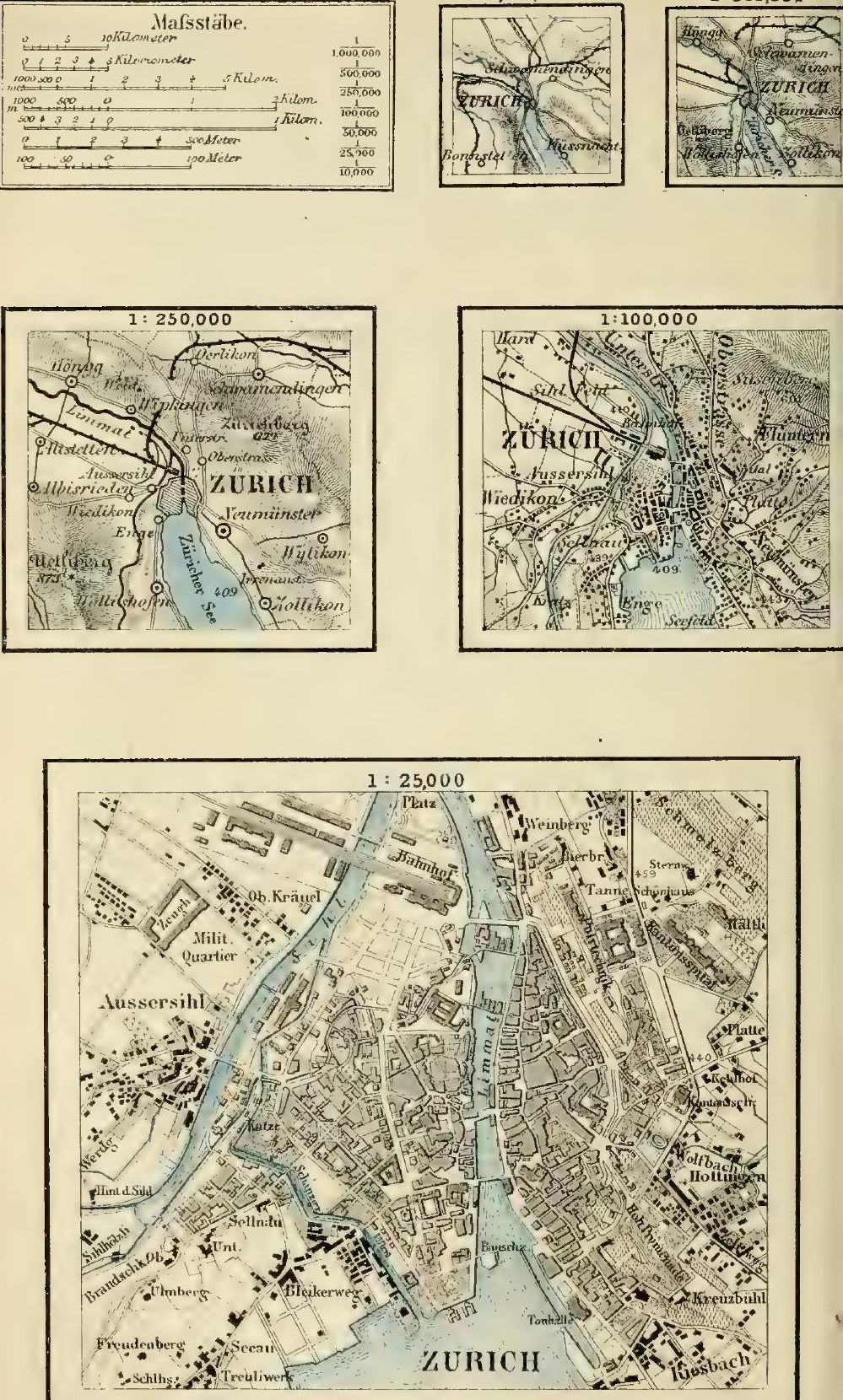
Die Wahl dieser Reduktion nun wird innerhalb gewisser Grenzen durch Zweck und Aufgabe der Zeichnung bestimmt; es kommt zunächst darauf an, ob man ein ganzes Land, eine ziemlich grosse Gegend desselben oder aber die Details eines kleinen Theiles der Erdoberfläche darstellen will.

Die gebräuchlichsten Reduktionen sind folgende:

$1^{\circ}$ Für geographische (Generul-) Karten: $1 / 1000000$ oder $1: 1000000$, wobei $1 \mathrm{~cm}=10000 \mathrm{~m}=10 \mathrm{Km}$ $1 / 500000 \gg 1: 500000, \quad, 1 \mathrm{~cm}=5000 \mathrm{~m}=5 \mathrm{Km}$ $1 / 250000,1: 250000, \quad, 1 \mathrm{~cm}=2500 \mathrm{~m}=2,5 \mathrm{Km}$.

$2^{\circ}$ Fiir topographische (Spezial-) Karten: $1 / 100000$ oder $1: 100000$, wobei $1 \mathrm{~cm}=1000 \mathrm{~m}=1 \mathrm{Km}$ $1 / 50000,1: 50000, \quad, 1 \mathrm{~cm}=500 \mathrm{~m}=1 / 2 \mathrm{Km}$ $1 / 25000$ $\gg 1: 25000, \Rightarrow 1 \mathrm{~cm}=250 \mathrm{~m}=1 / 4 \mathrm{Km}$.

$3^{\circ}$ Für topographische Pläne:

$1 / 10000=1: 10000$, wobei $1 \mathrm{~cm}=100 \mathrm{~m}$
$1 / 5000=1: 5000, \quad \Rightarrow 1 \mathrm{~cm}=50 \mathrm{~m}$
$1 / 2500=1: 2500, \quad \Rightarrow 1 \mathrm{~cm}=25 \mathrm{~m}$
$1 / 1000=1: 1000, \quad \Rightarrow 1 \mathrm{~cm}=10 \mathrm{~m}$.

Die nebenstehende Taf. $Y$ lässt erkennen, von welchem Einfluss der Massstab auf die Zeichnung ist.

Mitunter hat sich die Wahl des Massstabes nach den Dimensionen des Papiers zu richten. Kennt man ungefähr die Ausdehnung des Terrains, so dividirt man sie durch die antsprechende Dimension des Papierblattes. Handelt es sich 2. B. um eine Partie Land von $10 \mathrm{Km}$ Länge und $5 \mathrm{Km}$ Breite und hat man Papier von $80 \mathrm{~cm}$ Länge auf $50 \mathrm{~cm}$ Breite, so ergeben sich die Verhältnisse

$$
\begin{aligned}
10000: 0,8 & =12500 \\
\text { und } 5000: 0,5 & =10000,
\end{aligned}
$$

voraus folgt, dass auf dem Papier nicht genug Platz ist. ür eine Karte in $1 / 10000$. Hat man in dieser Gegend die iekognoszirungen von der Mitte (der Route) aus auf $5 \mathrm{Km}$ ach jeder Seite ausgedehnt, so muss man die Zeichnung nindestens auf $1 / 20000$ reduziren, um auf dem Blatte Raum ür sie zu finden. Die Rücksicht hierauf soll indess nicht. resentlich und nicht in erster Linie bestimmend einwirken; nan kam ja die Karte auf mehreren Blättern zeichnen, die nan nachher zusammenfügt. 
Was nun das Entwerfen der Karte anbetrifft, so muss man vor Allem das Blatt Papier, welches man benutzen will, auf einem Reissbriett oder sehr starken Carton aufspannen. Dann setzt man auf demselben die Richtung Nord-Süd, die Mittagslinie eines zentralen Punktes der abzubildenden Gegend, fost; hierauf die Richtung 0st-West, welche zu jener rechtwinklig ist. Genügt für die Zeichnung Ein Blatt, so halbiren diese Linien dasselbe nach Länge und Breite, und ihr Schnitt ist der Mittelpunkt des Blattes. Braucht man zu der Karte vier Blätter, so werden diese Richtungen durch Randlinien des Papiers bezeichnet und die Mitte der Karte ist da, wo die vier einander zugekehrten Ecken der Blätter zusammentreffen. - (Damit man die Blätter leicht zusammenfügen kann, wird man indess nur bei einem die Zeichnung überall bis zum Rande ausdehnen; auf jedem der andern lässt man je auf einer Seite einen schmalen Streifen frei, auf welchen man dann das benachbarte Blatt aufkleben kann).

Man beginnt nun mit der Zeichnung des mittleren Theils des Gebiets.

Vom Mittelpunkt aus trägt man die auf dem Terrain gemessenen Entfernungen ab und rückt mit der Arbeit gegen die Ränder hin vor. Zum Abtragen der Linien auf dem Papier hat man Massstab und Transporteur anzuwenden. Letzterer wurde auf S. 38 besprochen. Der Massstab ist einfach eine gerade Linie auf dem Papier, an welcher man die durch die Reduktion bestimmten Bruchtheile der im Terrain angewendeten Längeneinheiten unter dem Namen der letzteren aufträgt. (Vgl. Taf. V). Da es aber unzweckmässig wäre, immer auf diesem Massstab mit dem Zirkel die gemessenen Längen abzugreifen, so bedient man sich lieber eines Doppeldezimeters, d. i. eines flach-abgedachten Lineales, auf welchem die $\mathrm{cm}$ - und mm-Theilung angebracht ist. Zeichnet man in $1 / 10000$, so ist nach dem oben Gesagten jeder mm des Lineals gleich $10 \mathrm{~m}$ auf dem Felde. Man hat also, um eine gewisse Länge richtig auf das Papier überzutragen, für dieselbe auf dem Lineal mit dem Zirkel soviel $\mathrm{mm}$ abzugreifen, so viel mal sie $10 \mathrm{~m}$ enthält (soviel Dekameter sie hat). Die einzelnen Meter wird man, so gut es geht, noch berücksichtigen durch verhältnissmässige Theilung eines Millimeters nach dem Augenmass. Genauer ist es, wenn man 
sich zu letzterem Zwecke eines Transcersalmassstabes bedient. Einen solchen stellt Fiy. s: dar und zwar für die Reduktion 1: 5000 . Hiebei repräsentiren also $2 \mathrm{~cm}$ eine wirkliche Distanz von $100 \mathrm{~m}$. Sind nun auf diesem verjüngten Massstab $207 \mathrm{~m}$ abzugreifen, so nimmt man die Distanz $m u$ auf der 7. Parallelen in den Zirkel, für $344 \mathrm{~m}$ die Länge es auf der vierten Parallel-Linie; man fasst hiebei im ersten Falle zunächst die Strecke von 20() bis () in's Auge, rückt nun mit dem Zirkel bis zur 7. Linie hinunter, indem man den einen Fuss desselben auf der durch 200 bezeichneten Senkrechten in $m$, den andern Fuss auf der durch 0 gehenden schiefen Linie in $u$ einsetzt; im andern Fall merkt man sich zuerst die Distanzen 300 bis 0 und 0 bis 40 und verfolgt wieder die Senkrechte auf der einen Seite $(300)$ und die schiefe Linie auf der andern (links, 40 ). Man hat immer his zu der Parallelen hinuiter zu rücken, deren Nummer durch die Einerstelle angegeben wird.

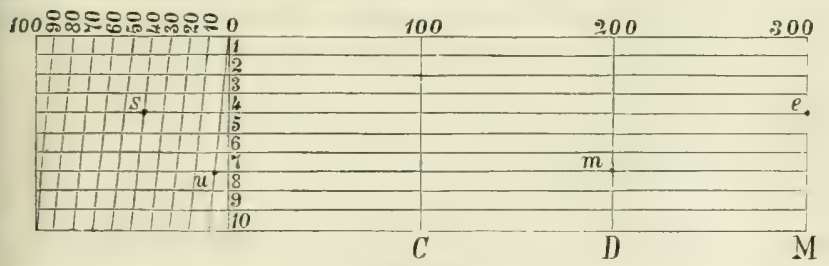

Fig. 82.

Nummehr haben wir das eigentliche Kartenzeichnen zu besprechen; dasselbe umfasst:

$1^{\circ}$ Die Situation;

$2^{\circ}$ Die Terraindarstellung;

$3^{\circ}$ Das Zeichnen des Details;

$4^{\circ}$ Die Schrift.

$\mathrm{Zu}$ alle diesem kann man entweder blos Feder und Tusch oder auch Pinsel und rerschiedene Farben anwenden. Je nachdem heisst die Karte schwarz oder farbig.

situntimsididmun!. Nachdem man auf dem Papier alle Fixpunkte aufgetragen, die man auf dem Terrain hatte, zeichnet man mit Bleistift in feinen Linien die Lmrisse der rerschiedenen Objekte. Sind dieselben in Richtigkeit gehracht, so fixirt man die gültige Kontour durch Federzeichnung, entweder schwarz (mit Tusch) oder farbig (blau für Gewässer, 
roth für Steinkonstruktionen etc.); gerade Linien zieht ma mit der Reissfeder aus statt mit der Zeichnen- (ArchitektenFeder. ${ }^{1}$ ) Ist die Situationszeichnung in dieser Weise be endigt, so beseitigt man noch die nun überflüssigen Blei stiftlinien mit Krume von altbackenem Brod, weichem Glaçé handschuhleder oder Gummi elasticum.

Terrainzcichunng. Die blosse Angabe von Höhenzahle reicht nicht hin, um eine Vorstellung von der plastischer Beschaffenheit des Bodens zu erwecken, und sobald man viel solcher Höhenzahlen oder Coten anbringt, so wird das Karten bild dadurch überladen. Man nimmt daher zu andern Mittel Zuflucht, die ebenso genau sind und dem Zweck besse dienen. Diese Mittel wollen wir in Kürze besprechen.

$1^{\circ}$ Die Isohypsen, Niveaukurven oder Horizontalkurver sind Linien, welche Terrainpunkte von gleicher absolute Höhe verbinden. Gibt man für eine solche Linie eine einzig Zahl (Cote) an, so kennt man damit die Höhe aller ihre Punkte. Zudem wählt man in der Regel aequidistante Hori zontalen, d. h. Niveaukurven, deren Ebenen gleich weit vor einander abstehen, so dass dieser senkrechte Abstand (di Aequidistanz) $10 \mathrm{~m}, 20 \mathrm{~m}$ oder (je nach dem Massstab) ein andere, unzweideutig bezeichnete Höhe hat; dann brauch man nicht einmal für jede einzelne Kurve die Höhe anzugeben; es genügt, wenn dies bei einigen der Fall ist. Wirc z. B. die Isohypse von $100 \mathrm{~m}$ bezeichnet und kennt mar noch (nach anderen Zahlen oder nach dem Lauf der fliessenden Gewässer) die Richtung des Gefälles und der Steigung so weiss man, dass die nächsthöhere Kurve lauter Punkte von 110 oder $120 \mathrm{~m}$ Höhe enthält, je nach der zu Grunde gelegten Aequidistanz, welche in der Karte angegeben sein muss

Eine Karte mit Isohypsen ermöglicht, nach jeder Richtung Profile anzufertigen, d. h. Zeichnungen derjenigen Linien. nach welchen der Terrainmantel von vertikalen Ebenen (odes auch von andern Flächen) geschnitten wird, Profile, diє natürlich um so genauer ausfallen, in je grösserer Zahl sicl auf bestimmtem Raume die Horizontalkurven finden. Dis Karte ermöglicht so auch, für jede Stelle des Terrains di

1) Umrisse, welche der Natur der Sache nach keine scharfen Linien sei können, wie Grenzen von Sandbänken, Sümpfen u. dgl, werden nicht durch vol ausgezogene Linien, sondern durch Reihen von Strichen und Punkten bezeichnel 
Neigung in Graden oder Prozenten anzugeben. Der Neigungsoder Böschungswinkel $\boldsymbol{\alpha}$ ist nämlich enthalten an der untern Spitze eines rechtwinkligen Dreiecks, dessen beide Katheten sich aus der Karte entnehmen lassen: die eine, und zwar die Basis b ist die kürzeste wagrechte Entfernung der beiden Horizontalen an der betreffenden Stelle, d. h. deren Abstand, gemessen in der Ebene des Papiers und auf einer Linie, die zu beiden Kurven normal steht; die andere, nämlich die Höhe $h$, ist der senkrechte Abstand der Horizontalen, die Aequidistanz. Durch den rechten Winkel und diese beiden ihn einschliessenden Seiten ist das Dreieck bestimmt, und indem man dasselbe zeichnet, erhält man unmittelbar den Neigungswinkel mittels des Transporteurs in Graden ablesbar. Will man die Neigung in Prozrnten kennen, so braucht man nur nach dem Massstab der Karte die Längen der zwei Seiten $b$ und $h$ zu bestimmen und zu berechnen, welche Höhe $h$ nun das Dreieck haben müsste, wenn die Basis $b=100$ wäre. Setzt man aber die Grundlinie $b$ $=1$ (statt 100), so gibt die Höhe die trigonometrische Tangente des Büschungswinkels, welche somit nichts anderes ist als der hunderte Theil der in Prozenten angegebenen Neigung $\left(\operatorname{tg} a=\frac{h}{b}=\frac{h}{1}\right)$. Hienach kann das Gefülle mittels der Tangententafel s'. 48 und einer einfachen Rechnung ohne Zeichnung und Transporteur bestimmt werden. Die dritte Seite (Hypothenuse) des erwähnten Dreiecks gibt. zugleich an, wie weit die beiden Endpunkte, zwischen welchen das Gefälle gemessen wurde, auf dem Terrain selber in schiefer Fichtung auseinander liegen. Diese Seite (die Hypothenuse) stellt eine Linie dar, welche sich auf dem Terrainmantel selher befindet, während die Katheten des Dreiecks als innerhalb des Bodens befindlich oder unter diesem liegend aufzufassen sind ${ }^{1}$ ). Da die Höhen im Verhältniss zu den andern

1) Diese dritte Seite des Böschungsdreiecks als Länge zu kennen, hat aus früher bezeichneten Gründen wenig praktischen Werth. Indess mag hier bemerkt werden, dass auch sie leicht berechnet werden kann: 1) nach dem pythagoräischen Lehrsatze als Quadratwurzel aus der Summe der (Quadrate beider Katheten, 2) nachdem der Bösehungswinkel bestimmt ist, mittels einer Sekanten-, wie auch einer Sinus- oder Cosinustafel. Bezeichnen wir diese dritte Seite (Hypothenuse) mit $c$, so ist nämlich $\frac{c}{b}=\sec a$, also $c=b . \sec a$, ferner $\frac{h}{c}=\sin a, \frac{b}{c}=\cos a$, folglich $c=\frac{\sin a}{h}=\frac{\cos a}{b}$. 
Distanzen nur kleine Beträge ausmachen, so zeichnet man sie oft in einem grösseren Massstab als diese. Es muss das, zum richtigen Verständniss des Profils, ausdrücklich bemerkt, d. h. es muss angegeben werden, ob Höhen und Längen im natürlichen (wahren) Verhältnisse aufgetragen oder in welchem Verhältniss die ersteren vergrössert worden seien. Das letztere Verhältniss nennt man die Ueberhöhung des Profiles.

Wie man für gegebene Richtungen mit der Kurvenkarte die Neigungswinkel ermitteln kann, so ist man durch eine solche Karte auch in den Stand gesetzt, die umgekehrte Aufgabe zu lösen: ein Tracé auszuwählen und einzuzeichnen, das ein bestimmtes Gefäll hat, beziehungsweise ein vorgeschriebenes (in Graden oder Prozenten angegebenes) Steigungsmaximum nicht überschreitet. Diese Aufgabe kommt indess für unsern Zweck weniger in Betracht; wir halten uns daher hiebei nicht auf, empfehlen hingegen dem Leser, der sich mit Kurvenkarten vertraut machen will, zu diesem Zweck ausser Profilen auch Modelle nach Kurvenkarten anzufertigen, worauf wir unten noch zu sprechen kommen (S. 139).

$2^{\circ}$ Wenn die Niveaukurven eine leichte und exakte Bezeichnungsweise der Terrainformen liefern, so sind sie nicht in gleichem Masse auch ein plastisch wirkendes Darstellungsmittel. Es bedarf schon ziemlicher Uebung, um aus einem Plane oder einer Karte rasch die Gestaltung des Bodens heraus zu finden, wenn dieselbe nur mittels Horizontalkurven angegeben ist und diese nicht sehr nahe an einander liegen. In wirksamer, augenfälliger Weise werden aber die Terrainformen hervorgehoben durch Schraffen, das sind dunkle (meist schwarze) Striche in der Richtung des grössten Gefälles (des Wasserlaufes) oder also senkrecht zu den Horizontalen, welch' letztere - auch wenn sie in der fertigen Karte nicht ausgezogen sind - die Grundlage, das Gerippe für die Schraffirung liefern müssen, so zwar, dass die zwei Linien, innerhalb deren eine Schraffenreibe liegt, Horizontalen sein sollen. Hieraus folgt, dass die Schraffirstriche um so kürzer sein müssen, je steiler das Terrain ist, weil in solchem Falle der wagrechte Abstand der horizontalen Schnittlinien ein geringer ist. In gleichem Masse, wie die Schraffen sich verkürzen, werden sie aber auch stärker und dichter (enger) gezeichnet. Dabei fallen nun allerdings Terrain- 
partien mit grossen Neigungswinkeln selır dunkel aus. Man behilft sich dann damit, dass man für die Schraffen einen bräunlichen Ton (statt schwarz) anwendet, welcher die Terraingestaltung ebensogut reliefartig hervortreten lässt, ohne dass dabei die Niveaukurven, die Schrift und die Details der Karte gestört und unkenntlich werden.

Die Art der Schraffenzeichnung hängt indess nicht blos ron der Form des Bodens, sondern auch davon ah, wie man sich densolben beleuchtet denlit, d. h. welche Richtung man annimmt für das Einfallen der Lichtstrahlen. Man unterscheidet zwischen schiefer und senkiverhter (zemithaler) Beleuchtung. Im ersten Falle nimmt man an, die Sonnenstrahlen treffen auf flaches Terrain unter einem Winkel von $45^{\circ}$ von links nach rechts, so dass an den Abhängen Licht- und Schattenseiten vorkommen, wobei die letzteren in der Zeichnung stärkere, die ersteren schwächere Schraffen erhalten. Diese Darstellungsart liefert sehr schöne reliefartige Bilder, namentlich für Gegenden mit ausgesprochenen Kamm- und Kettengebirgen. Diese Art Terrainzeichnung ist sicherlich die am allgemeinsten ansprechende und verständliche. Wir sind uns eben grewohnt, die Landschaft einseitig beleuchtet zu erblicken. Auch weiss ein Jeder, dass im Hochsommer um die Mittagszeit, wo der Einfallswinkel der Somnenstrahlen sich dem Rechten bis auf $1 / 3$ und mehr nähert, eine Landschaft weniger plastisch erscheint, dass ihre Höhen, deren Vorsprünge und Einschnitte weniger scharf von einander sich ahheben, als wenn man dieselben im Frühjahr oder Spätherbst oder in Morgen- und Abendstunden betrachtet, wo das Licht der Sonne schiefer auffällt. Von dem Bilde, das uns so die Landschaft selber bietet, unterscheidet sich aber eine nach dem System schiefer Beleuchtung schraffirte Karte kaum wesentlich als durch den Mangel der Schlagschatten. - Im andern Falle, nach dem Systeme der senlirechten Beleuchtung, denkt man sich die Sonne im Zenith, die Strahlen also in vertikaler Richtung auf das Terrain fallend, so dass keine im Schatten befindlichen Flächen vorkommen, sondern nur beleuchtete, und die Stärke der Beleuchtung lediglich vom Gefälle des Bodens abhängt, wagrechte oder nur sehr wenig geneigte Flächen ganz hell, die stärksten Abdachungen aber sehr dunkel (wenig beleuchtet) erscheinen. Bei dieser 
Zeichnungsweise richtet sich also die Stärke der Schraffirung (Dicke und Dichte der Schraffen) einzig nach der Grösse des Neigungswinkels, dessen Schenkel auch die Richtung der Schraffen bestimmt. Der Unterschied zwischen dieser Schraffenzeichnung and der Darstellung durch Horizontalkurven hat also seine Entstehung darin, dass die letztere von der Höhenlage der Punkte des Terrains ausgeht und diese Höhen angibt, während bei der zuletzt besprochenen Schraffirmethode vom Gefälle, vom gemessenen Neigungswinkel ausgegangen und dies darzustellen versucht wird. Diese Darstellung kann indess nicht so genau sein wie diejenige durch Kurven; sie kann nicht jeden beliebigen Winkel andeuten, sondern nur Neigungen in gewissen Abstufungen und zwar höchstens von 5 zu 5 Grad. Es geschieht das nach verschiedenen Schraffenskalen oder sogen. Böschnngmasstüben, von welchen sich die Müfling'sche oder hessische und preussische Generalstabsmethode durch Verwendung konventioneller Schraffenformen und Kombinationen derselben (punktirte und geschlängelte Schraffen; in der gleichen Schraffenreihe geradlinige und ganze Schraffen von verschiedener Stärke in bestimmter Zahl) ausgezeichnet. Auf eine nähere Besprechung dieser Skalen können wir hier nicht eintreten; wir dürfen davon auch um so eher absehen, als die Darstellung durch Kurven sich immer mehr einbürgert. Die ältere Methode der skalamässig schraffirten Karten entsprang und diente wesentlich militärischen Rücksichten, für welche die Bezeichnung der Neigungswinkel einerseits sehr wichtig, andrerseits genügend war, auch wenn sie blosin Stufen von $5 \mathrm{zu} 5^{\circ}$ erfolgte und alles Terrain, dessen Steigung eine gewisse Grenze (45 oder höchstens $60^{\circ}$ ) überschritt, gleichmässig behandelte. Mit der Veränderung oder Erweiterung der Aufgabe von Karten sind auch die Methoden und der Werth derselben geändert worden. Genaue Vertrautheit mit den Schraffenskalen und Uebung in deren Gebrauch hat jetzt grossen Werth fast nur noch für den Kartenzeichner von Beruf. Die Leser, welche sich hierüber noch näher informiren wollen, verweisen wir auf den früher erwähnten III. Theil der "Elemente der Vermessungskunde" von Prof. Dr. Bauernfeind, wie auf die einleitenden Partien der Geographiebücher von Dr. Schacht und E. Sydow. Vgl. auch "Deutsche Rundschau für Geo-

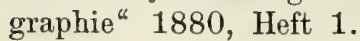




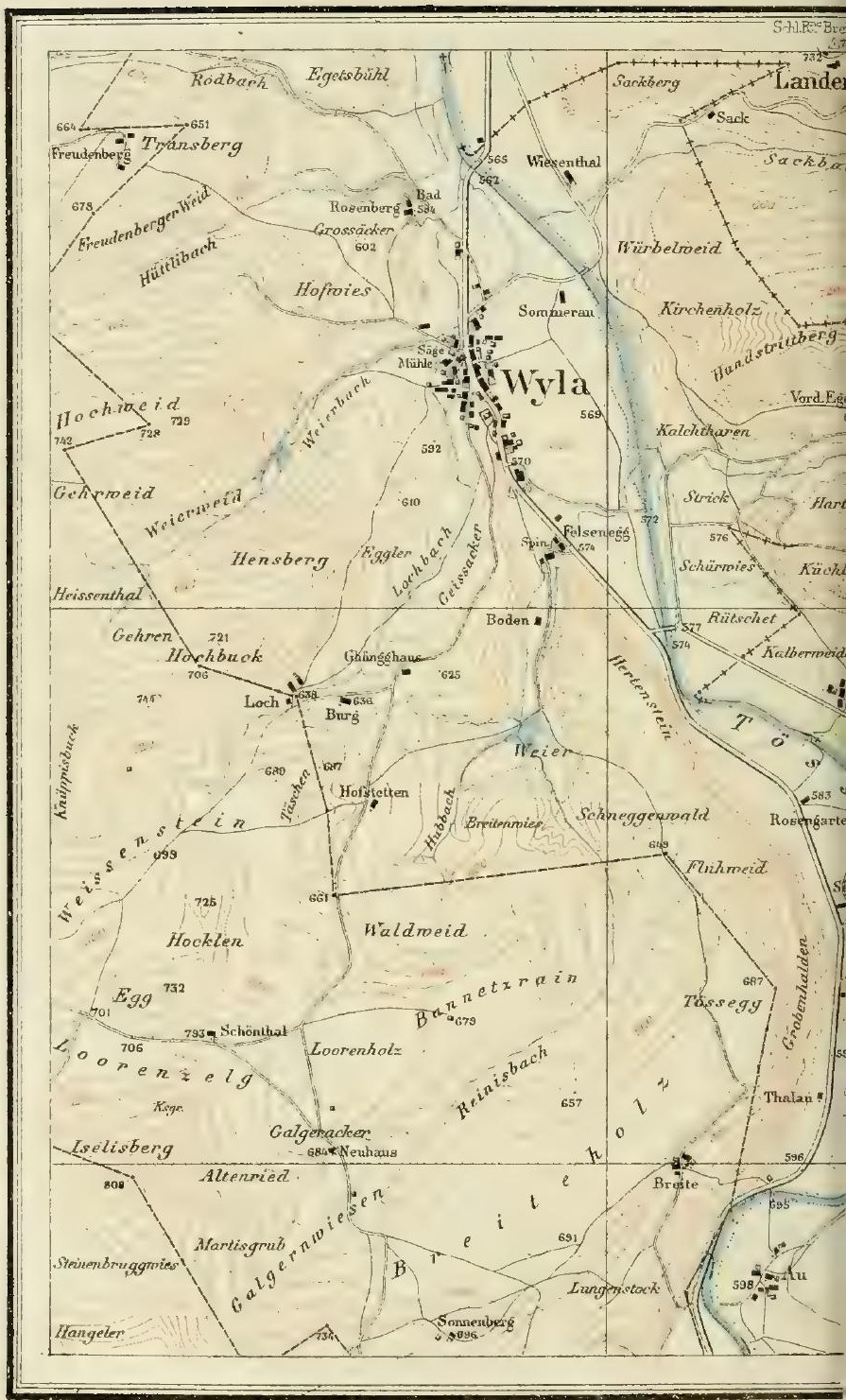




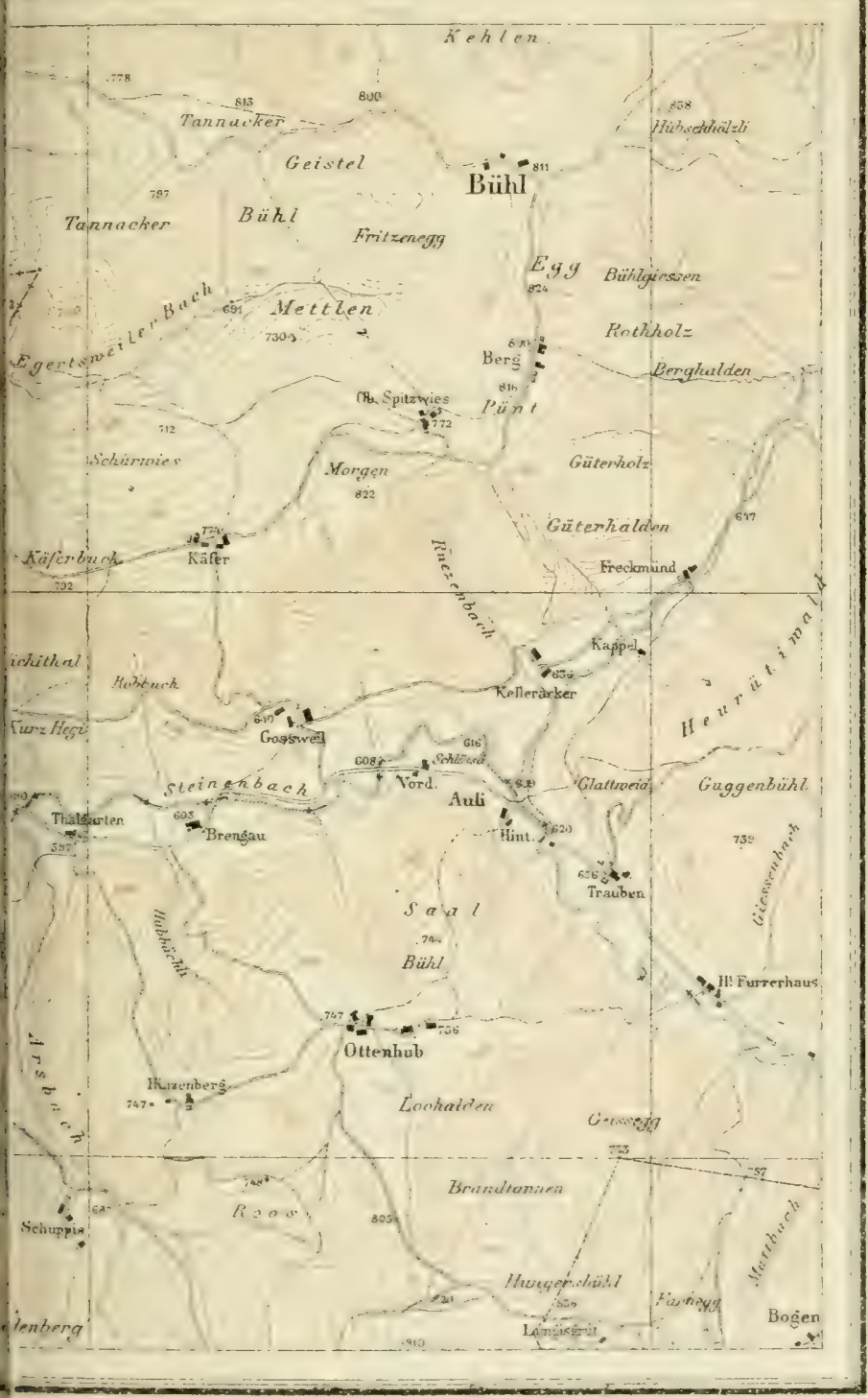

Wurster Ranileyorer \&: C: Winterthu. 



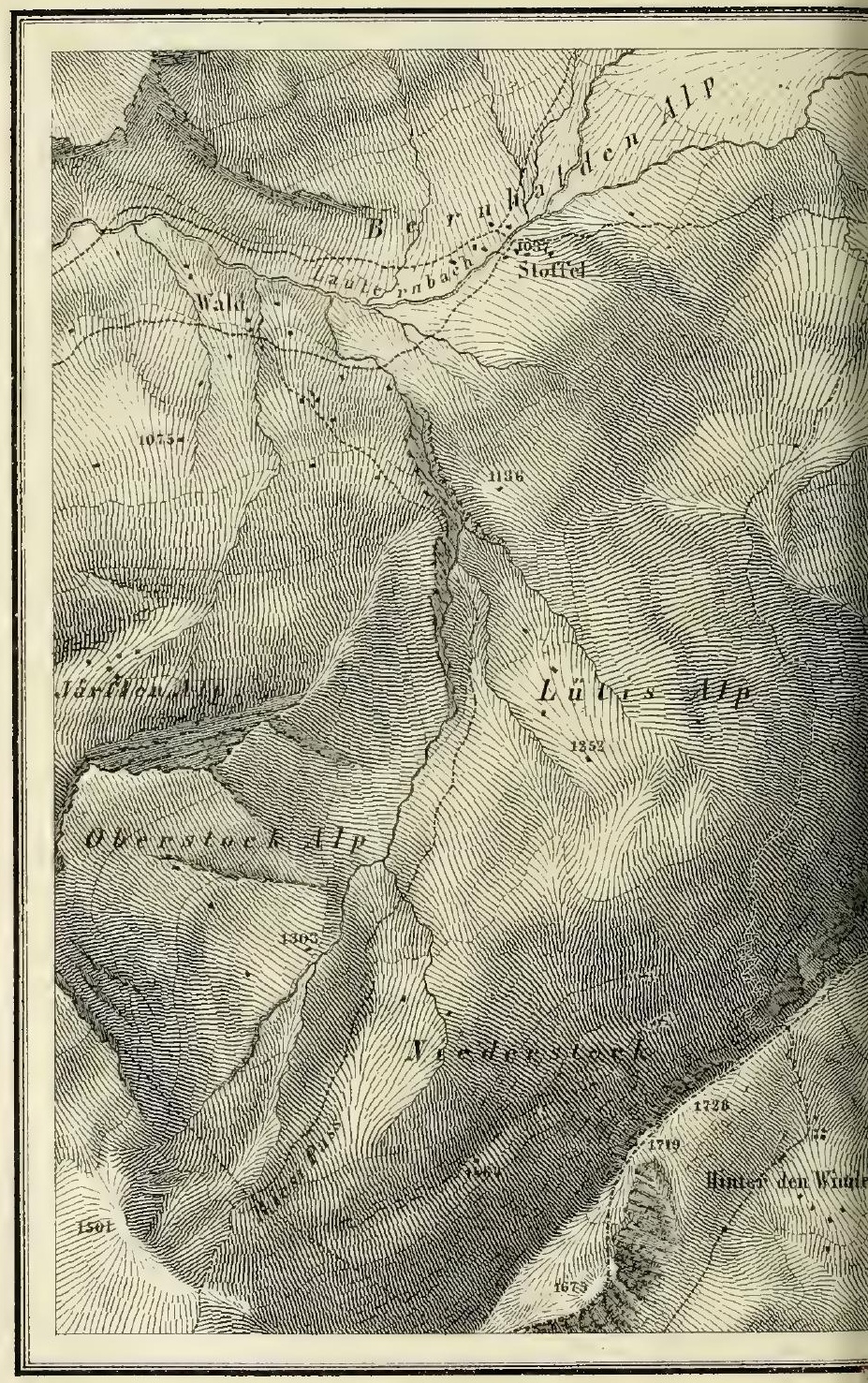




\section{Taf. V11}

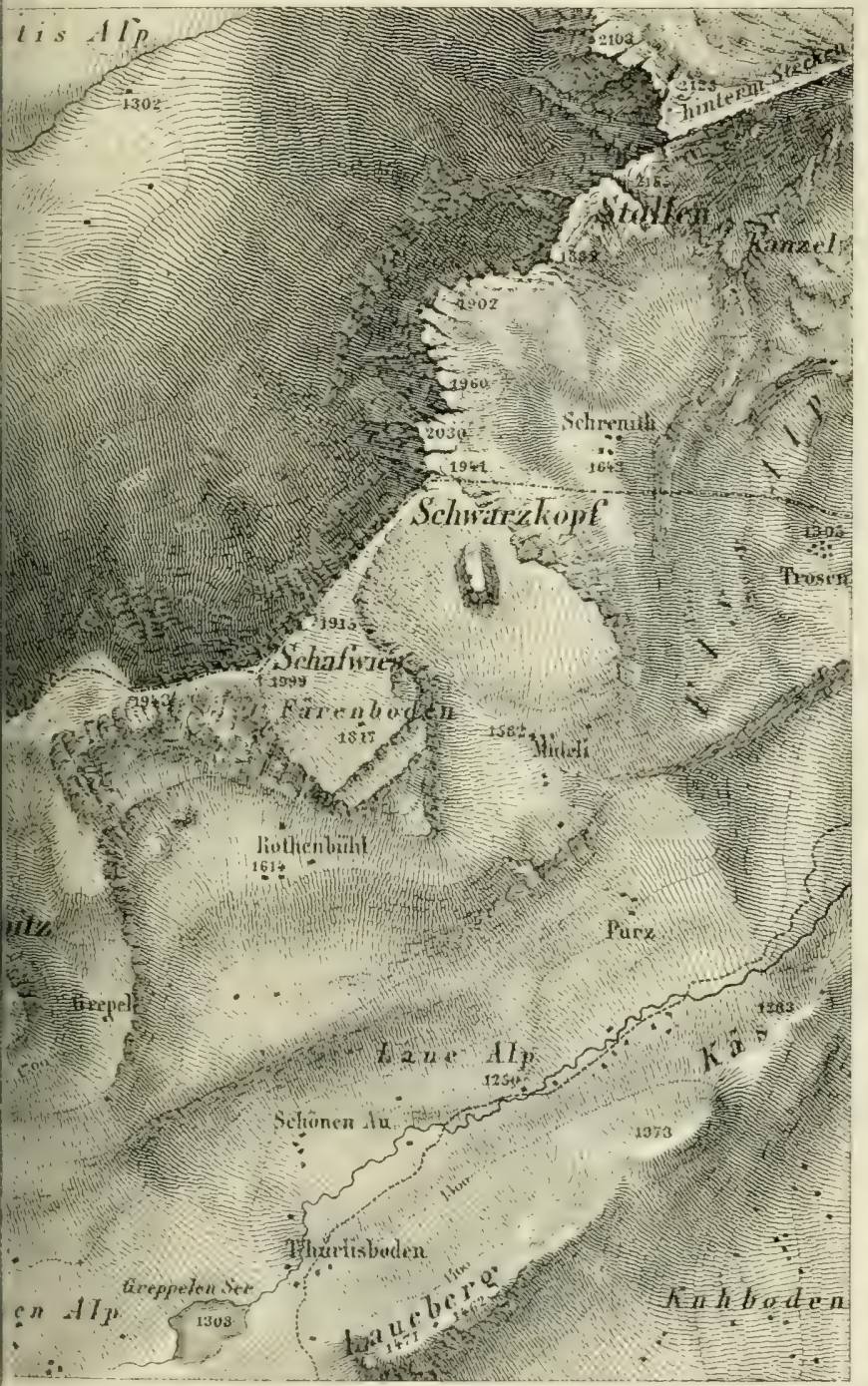





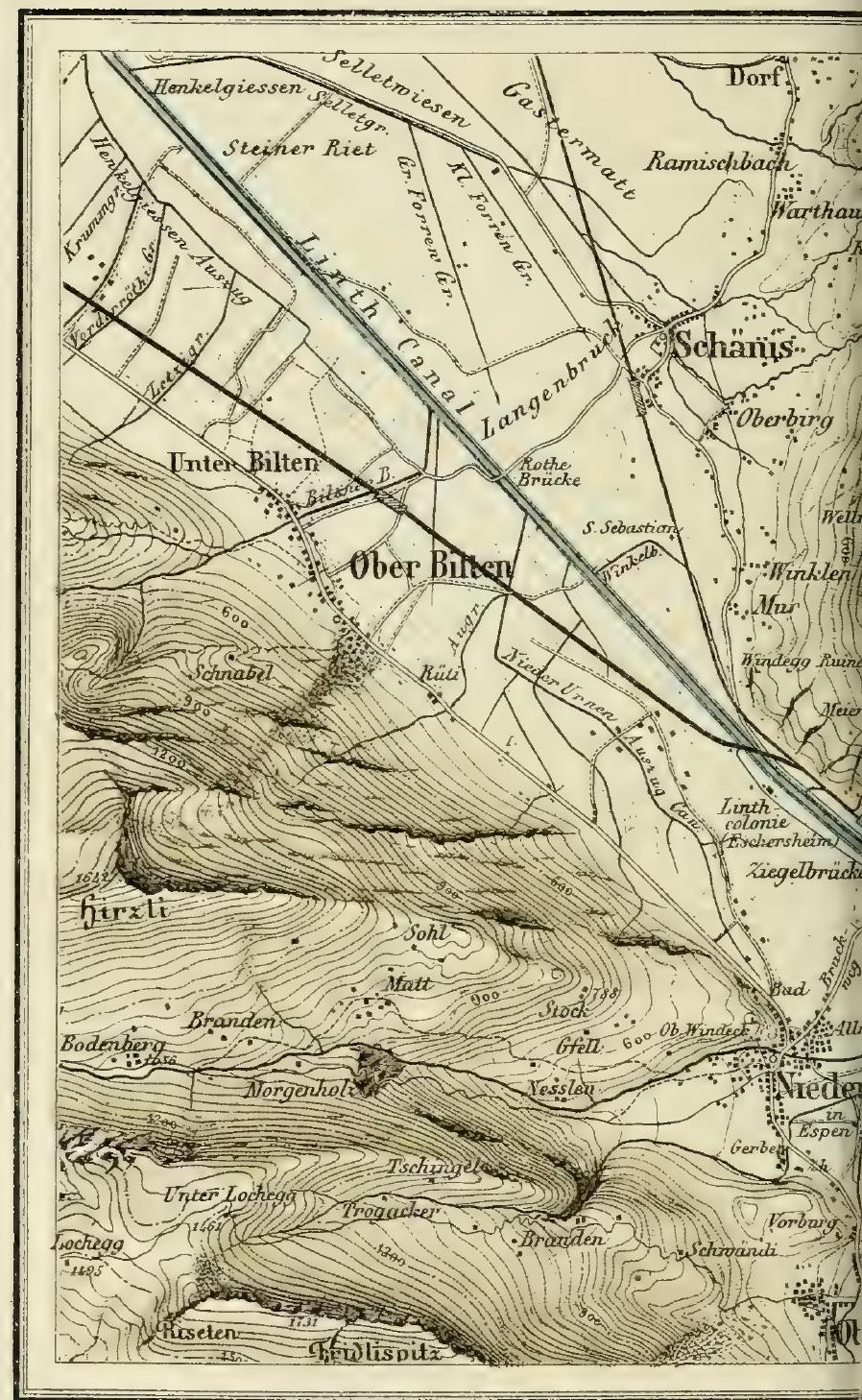



$3^{\circ}$ Das Schraffiren ist unter allen Umständen, namentlich aber nach der letztbesprochenen Nethode eine mühsame, zeitraubende und kostspielige Arbeit. Man ersetzt es daher öfters durch eine ähnlich wirkende aber weit bequemer herzustellende Tuschirung oder Kreideschummerum, wobei man mit Pinsel oder Wischer die mehr oder minder geneigten Flächen in so verschiedenen Graden schattirt, dass die Zeichnung einen ähnlichen Effekt hervorbringt wie eine schraffirte Karte. Sofern die Bodenformen einzig durch dieses Mittel bezeichnet werden sollen, ist dasselbe nur zulässig für auf dem Terrain selbst erstellte Skizzen. Dagegen ist es allgemein anwendbar auf Karten und Pläne, welche schon Horizontalkurven enthalten, ja selhst auf schon schraffirte Karten. Das Terrainbild erhält dadurch mehr Relief; schon durch eine leichte Retouche gewinnt es wesentlich an Plastik.

$4^{\circ}$ Oefters wendet man auch für die Darstellung der Höhenverhältnisse auf Karten, um dieselben übersichtlicher zu gestalten, rerschiedene Farbenschichten an, so zwar, dass eine hestimmte Farbe oder Nüance eine gewisse Höhenregion oder Schicht - oben und unten je durch eine Horizontalkurve begrenzt - bezeichnet, nach einer Skala, die $\mathrm{Abstufungen}$ von 200,500 und mehr Meter enthält. Solche Farbenschichten können ebensowohl zur Darstellung ron Tiefenverhältnissen grosser Wasserbecken wie der Höhenregionen des Festlandes dienen. Man nennt solche Darstellungen Schichten-, hypsometrische und Tiefenkarten.

$5^{\circ}$ Grmischte oder lombinirte Methoden der Terrainzeichnung sind solche, wobei mehrere der obgenannten Darstellungsmittel zugleich angewendet werden. Diese Kombinationen sind oft von glücklicher Wirkung; solche zu erzielen, ist aber wesentlich Sache des guten Geschmackes; positive Regeln lassen sich hierüber nicht geben.

Die nebenstehenden Tafrln VI, VII und VIII (zürcherisches Oberland um Wyla im Tössthal, Sentispartie und westliche Umgegend des Wallensees) geben Muster von drei der gebräuchlichsten Arten der Terraindarstellung. Mit Bezug auf dieselben bemerken wir zur Ergänzung des Vorstehenden und des S. 21 über das Kartenlesen Gesagten Folgendes: Felspartien sind schwarz gehalten und auf beiden Blättern, wo sich solche finden (Taf. VII und VIII), in ähnlicher 
künstlerischer Weise behandelt. Auf Taf. VI sind sämmtliche Gewässer, auf Taf. VIII nur die grössern in blauer Farbe dargestellt; das der Vegetation zugängliche Terrain ist verschieden gezeichnet: in Taf. VI durch bräunlich-rothe Horizontalkurven von $10 \mathrm{zu} 10 \mathrm{~m}$, nebst einem Farbenton für Wald, in Blatt VII und VIII durch schwarze Kurven und durch Schraffen, für welche auf Taf. VII Schwarz, auf Taf. VIII brauner Ton gewählt ist. Dort (Taf. VII, 1:25000) ist das Terrain wesentlich durch Schraffen dargestellt; es finden sich nur fein gestrichelte Horizontalkurven von $100 \mathrm{zu} 100 \mathrm{~m}$; zwischen je zweien derselben sind 10 Reihen Schraffirstriche; eine solche entspricht also der Aequidistanz von $10 \mathrm{~m}$. Im andern Fall (Taf. VIII, 1:50000) haben wir ein dichtes, vollständiges Kurvensystem vor uns, mit einer Aequidistanz ron $30 \mathrm{~m}$; je die 10 . Horizontale ist als Hauptkurve ausgezeichnet durch Strichelung und Beifügung der Höhenzahl (von $300 \mathrm{zu} 300 \mathrm{~m}$ ). Höhenangaben (Coten) für einzelne Punlite finden sich überdiess auf allen drei Kartenausschnitten.

Bei näherer Betrachtung dieser Tafeln wird der Leser sich unschwer mit diesen Darstellungsmethoden vertraut machen. Er wird z. B. bald wahnehmen, dass abwärts gehende (d. h. nach der Richtung des Wasserabfiusses sich erstreckende) Vorsprünge oder Ausbiegungen der Kurven komexes Terrain (Bergrücken, gewölbte Gletschertheile etc.) bedeuten, solche nach auficirts aber (der Richtung des Wasserlaufes entgegen) lionkaves Terrain oder Hohlformen: Thalfurchen, muldenförmige Gletscherpartien u. dgl.; dass ebenso ein Abhang, an welchem sich die Kurven nach oben dichter zusammendrängen, eine konkave, ein Abhang hingegen mit nach unten näher gelagerten Kurven eine konvexe Form hat, während gleichweit auseinanderliegende Kurven an einer Abdachung ein gleichmässiges, konstantes Gefälle bezeichnen. Er wird unschwer ein Profil zeichnen, z. B. über den Lauf (Thalweg) der Töss oder eines der Bäche (Längenprofil) oder einer Schnittlinie wie Thalgarten-Käferbuck-Tannacker (Querprofil) — sei es, dass man, um nicht genirt $z u$ sein durch die in der Reduktion von $1 / 25000$ nur noch $2 / 5 \mathrm{~mm}$ betragende Aequidistanz, die Höhen etwa in fünffachem Massstab der Längen (also in 1/500n) auftrage, wodurch die Aequidistanz im Profi $=2 \mathrm{~mm}$ wird, oder dass man, um das richtige Verhältniss 


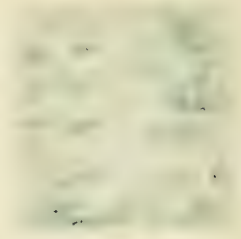




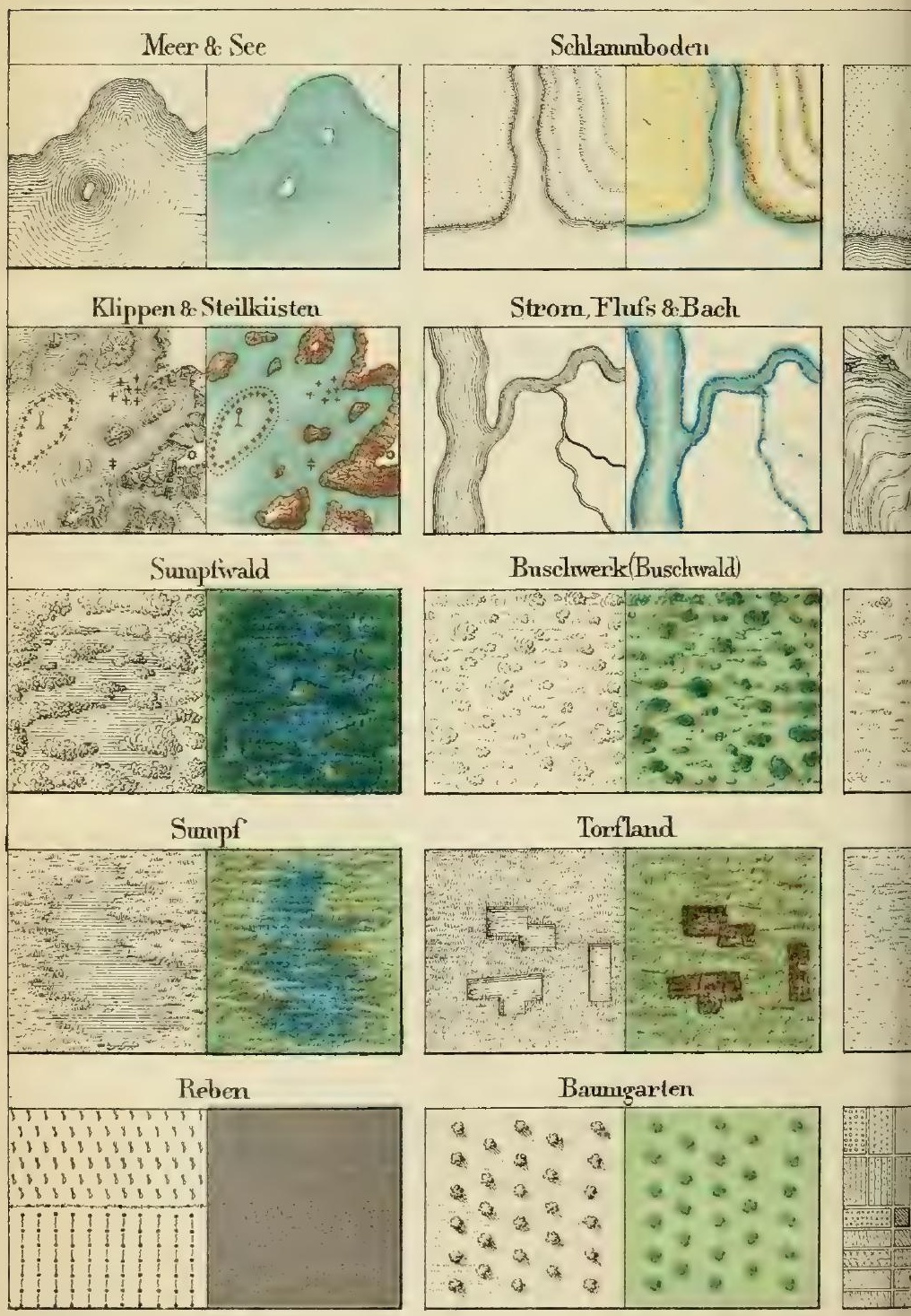




\section{Taf. IX .}

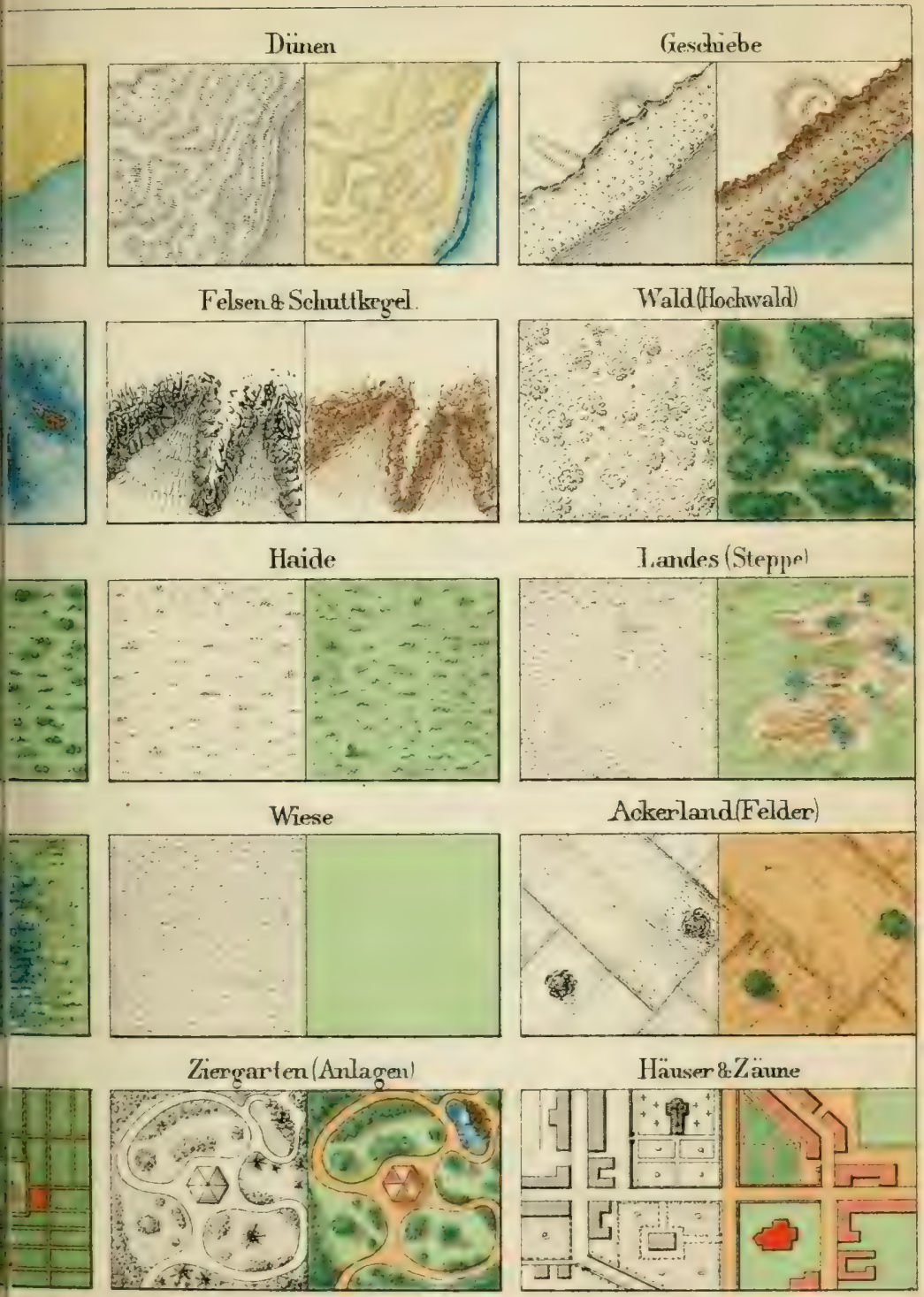



ron Höhen und Längen beizubehalten, beide fünfmal grösser zeichne als die Karte sie cribt, also das ganze Profil in ${ }_{15}^{1} 5000$ zeichne. - Ebenso wird man mit Leichtigkeit ein grutes Modell, z. B. der Gegend westwärts der Töss, herstellen, wenn man Carton oder Laubsägeholz von ${ }^{2} / 5$ mm Dicke nimmt, davon Stücke abschneidet, die begrenzt sind je durch ein Stück der Kurven, welche in dem hezeichneten Gebiet liegen und der Reihe nach auf einander folsen, sodann noch nach einer oder mehreren Seiten durch Gerade oder aber nur durch eine geschlossene (in sich selbst zurücklaufende) Kurve. Indem man mit der untersten, weitesten hurve heginnt und zu den höheren und engeren fortschreitet, zeichnet man dieselben nebst den zugrehörigen geraden Grenzen oder andern die Lage markirenden Punkteu auf Pauspapier durch, klebt dieses auf den Carton oder das Laubsägeholz, schneidet nun den durchgepausten Linien nach die stücke zurecht und fügt sie (beziehungsweise klebt sie) in ihrer richtigen Reihenfolge aufeinander, so zwar, dass die entsprechenden geraden Grenzlinien genau zusammenfallen und, wenn nur noch eine Seite gerade Begrenzung hat, beim Zusammenfügen (Auflegen) die massgebenden Abstände der betr. Kurven auf jener geraden Grenzlinie beachtet werden, wie auch bei ganz geschlossenen Kurren die Merkpunkte für deren richtige Lagre. - Solche Uebungen tragen wesentlich bei zur Erlangung von Gewandtheit im Kartenlesen und entschädigen so reichlich für die hierauf verwendete Zeit und geringe Nühe.

Detailzeichmung. Hat man die horizontalen Lmrisse und die rertikale Gestaltung des Terrains zur Darstellung gebracht, so sind noch die kleineren Objekte zu berücksichtigen: man hat jetzt im Bilde anzugeben, ob gewisse Flächen von Wasser, Sümpfen, Wäldern eingenommen; ob sie Fiulturland seien und im letztern Falle - bei hinlänglich grossem Massstab - welche Arten Bodenkultur (Wein-, Ackerbau etc.) hier vorkommen; auch, was für Bauten sich da rorfinden u. s. w. $\mathrm{Zu}$ diesem Zweck wendet man lionerntimulle Bezeichmugen an, die wir in Taf. IX zusammenstellen, indem wir je für einen Gegenstand zwei Muster geben: die einen für schwarze, und die andern für farbige Karten.

Auf einer folgenden Tafel ( $\mathrm{X}$ ) finden sich die gebräuchlichsten derjenigen Zeichen, welche dazu dienen, Details wie 
das Vorhandensein von Furten und Fähren, von Mühlen, Sägen, Gasthäusern etc. anzugeben. Selbstverständlich müssen diese Symbole in einer dem Massstab der Karte entsprechenden Grösse angewendet werden; auch kann man sich — immer im Einklang mit dem Reduktionsverhältniss der ganzen Karte - noch anderer Bezeichnungen bedienen, deren Bedeutung dann in der Legende (Zeichenerklärung, explication des signes) zur Karte erläutert werden soll.

Kartenschrift. Die Wahl der Schriftarten für Karten und Pläne und ebenso diejenige der Schriftgrössen ist Sache des Geschmacks, der ästhetischen Beurtheilung. Vor Allem soll die Karte klar, nicht mit Namen überfüllt sein. „Nur leer scheinende Karten prägen sich dem Gedächtnisse ein " lautet ein Ausspruch Alex. von Humboldts. Gegen die Wahrheit, welche in diesen Worten einer grossen Autorität liegt, wird nur zu oft noch arg gesündigt; Jeder wird uns hierin beistimmen, der schon Karten benutzen musste, in welchen es so recht ron Namen wimmelte, und der daneben einmal eine sogen. stumme Karte (ohne Schrift oder nur mit wenigen und abgekürzten Namen) betrachtete, wie wir deren eine Anzahl besitzen. In der Nomenklatur der Karten ist also Mass zu halten und ist dieselbe auf das Nothwendige zu beschränken. Im Uebrigen kann man nur empfehlen, der Schrift eine Grösse zu geben, welche im richtigen Verhältniss steht einerseits zum Massstab der Karte und andrerseits zur Bedeutung der Objekte, deren Namen man mit ihr schreibt.

Die in Karten und Plänen gebräuchlichen Schriftarten sind auf Taf. XI zusammengestellt. Andere, namentlich sogen. Zierschriften, wendet man fast nur für Ueberschriften (Titel) an.

Die Namen werden soviel möglich parallel zum obern und untern Blattrand geschrieben, nicht in beliebigen Richtungen, um zu vermeiden, dass man zum Zwecke des Namenlesens beständig die Lage des Blattes ändern muss. Indessen schreibt man die Namen von Bergketten, Strömen, Kanälen, Eisenbahnen, Strassen u. dgl. in der Längsrichtung dieser Objekte: ebenso muss man bei Namen von Meeren und Seen die Gestalt dieser Wasserfächen berücksichtigen und danach die Lage oder Stellung der Namen wählen.

Wo mehrere Objekte derselben Art und welche durch ganz oder nahezu gleiche Schriftarten bezeichnet werden, 
Q Thum + Kreuz

i...: Ruine

[F Hof od Meierei

B... Bahnhof

aos Posthalterei

¿ Briefpost

Telegraph

1 Gasthaus

Schenkininthschaft

E Einzelnes Itaws

口8 Glashütte

* Windmizle, Steinkon."

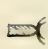

$$
\text { Hotrkonstr. }- \text { Therme }
$$

* Aussichtspunkt

$\triangle$ Trigonometr. Signal

(F) Ermbisthum

If Bisthum

Mannerabtei

i Frauenabtei

fo Mainerkloster

if Frauenkloster

t) Kurche

IU Noschee

${ }_{+}^{+}+ \pm$Friedhof

t) Kapelle
C Grotte oderHöhle

Heerstrasse

[n 'Trumphboyen

$\square \quad$ Pyramide

回 Obetisk

Heidnischer Tempel

- S. Sáule

- Götrenbila

$\Omega$ Steinbrich

$\times$ Bergroerk

\%) Huttennoerk

Q) Mühte

- Sägemuitle

Bahn

Bahnibel Ueberbrickung

Bahnuibergar

* Altes Schlachtyeld

D Neweres Schlachtfeld

x Gefécht

Grenzen.

Klainerer

Curosser Schi

Eisenb.

sersid

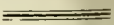

Sch

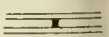

Fabrik- od 


\section{ZEICHEN}

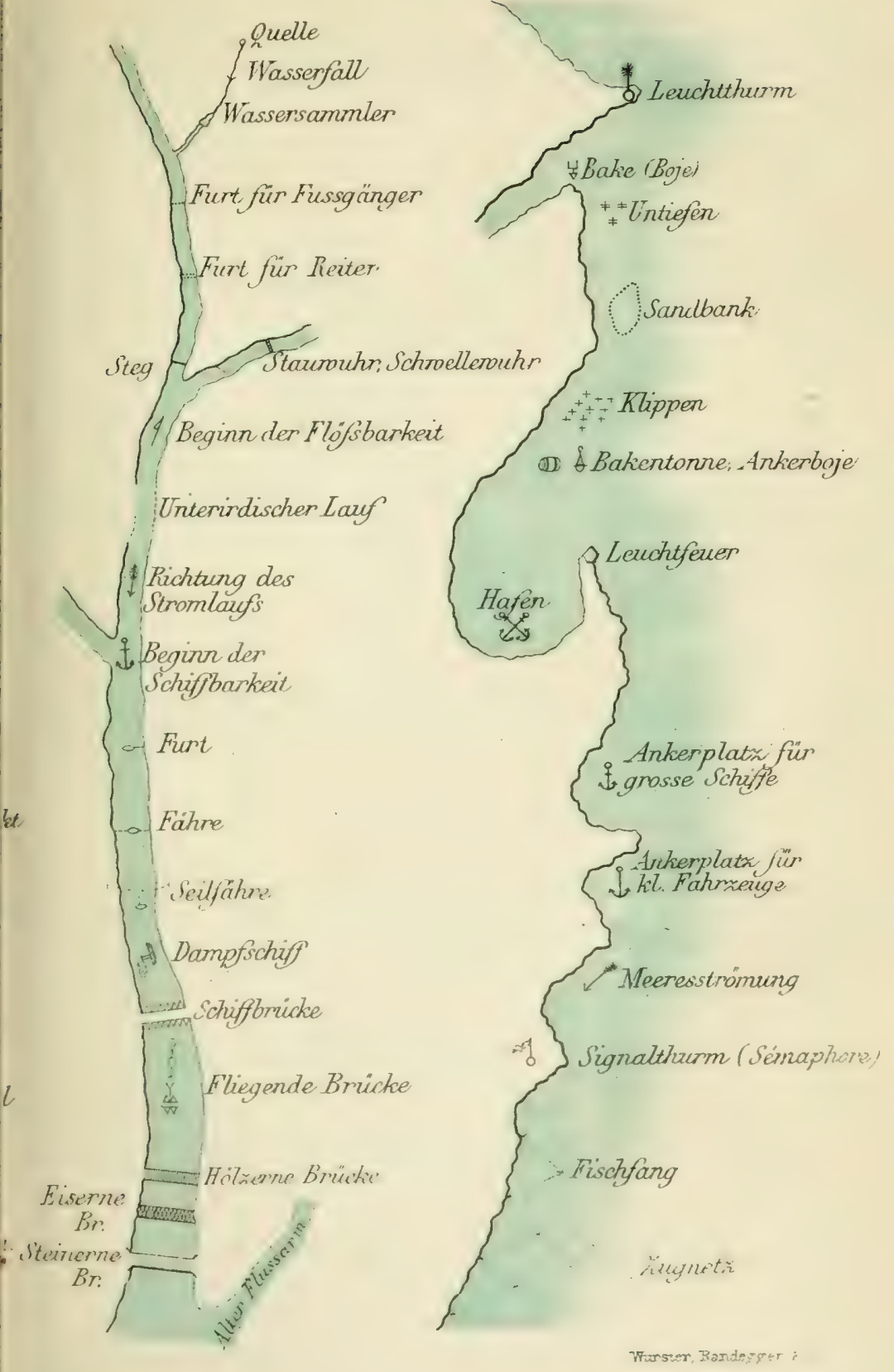





\section{abcdefghijkl}

III.LIE

\section{ABCWEIGUIJKU.}

IV. $L i$

abcactshilk

abadelghilal Arabische Zahlen.

$$
\begin{aligned}
& 1.2 .3 .4 .5 \cdot 6.7 .8 .9 \cdot 10.50 .100 .500 .11 \\
& 1.2 .34 .5 .6 \% .9 .910 .50 .100 .500 .16
\end{aligned}
$$



z. B. Ortschaften von annähernd gleicher Grösse, ziemlich nahe bei einander sind, ist grosse Aufmerksamkeit auf richtige Placirung der Namen zu verwenden, damit nicht bei Benutzung der Karte die Namen auf andere Objekte bezogen werden als diejenigen, $\mathrm{zu}$ welchen sie gehören und damit man auch nicht über den richtigen Sarhverhalt im Zweifel bleibt. Solche Fehler finden sich mitunter: sie sind aber sehr störend, so sehr, dass man besser thut, den einen oder andern Namen lieber aus der Karte wegzulassen, als durch dessen Aufnahme in jenen Fehler zu verfallen.

Lm die Karte nicht durch schrift zu überladen und da es oft an Raum fehlt, um gewisse Worte in ihrem vollen Umfang zu schreiben, gebraucht man Ablïrzungen. Die häufigsten derselben finden sich in folgendem Terzeichniss.
A. Alp, Amt
hs. ... haus
a/ am
a/d. an der
hsn. ...h hausen
Arch. Archipel
I. Insel
In. Inseln

B. Ballon, Belchen, Bach K. Kuppe, Koppe

B. Bai, Bucht, Busen Kan. Kanal

Bez. Bezirk

Kant. Kanton

bg. ... berg

Kgr. Königreich

bg. ... burg

Kl. Klus

C. Cap, Col

Kr. Kreis

Can. Canal

Cant. Canton

L. Lac, lago, lacus (See)

Lag. Lagune

Cl. Clus

Ld. Land

Dep. Departement

II. Neer

df. ... dorf

Dt. Dent.

Fab. Fabrik

Fl. Fluss, fleuve

Ft Fort.

G. Golf

MB. Meerbusen

Mdg. Mündung

Mt. Mont, Mount (Bèrg)

Mits. Montagnes, Mountains

Nd. Nieder...

(Gebirge)

Gbg. Gebirge

Gl. Gletscher

OA. Oberamt

Ob. Ober...

Gmde Gemeinde

Gr. Gruppe, Gross...

P. Pass, Pic, Pizzo

Pl. Plateau

Prof. Profil

H. Hoch ...

Prov. Provinz 


\section{Q. Quelle Schl.' Schloss}

R. Rivière,River,Rio(Strom, Sp. Spitze

Reg. Region

Rep. Republik

S. - San ...

St. Saint, Sankt

st. ...stock, ... stein

S. See

Sal. Saline

\section{Fluss)}

s/

Str. Strom, Strasse(Meerenge) Th. Thal

th. ...thum (Herzogth.,Gr.Unt. unter...

V. Vulkan, Val, Vallée v. von.

Nach Bedürfniss können noch andere Abkürzungen angewendet werden, wenn sie nur verständlich oder in der Karte erklärt sind. Es hat auch nichts zu sagen, wenn die eine oder andere Abkürzung zwei oder mehr verschiedene Bedeutungen haben kann, sobald nur die auf diese Weise bezeichneten Objekte so verschieden sind, dass keine Verwechslungen entstehen können, also z. B. B (Bach, Bai), C (Cap, Col), P (Pass, Pic). Vermeidet man aber den Gebrauch solcher melirdeutigen Abbreriaturen, so ist das um so besser.

Behufs gänzlicher Vollendung der Karte bringt man um dieselbe noch einen Rand an, meist eine doppelte Umrahmung, in welche man nach Bedarf die Grade und Minuten für die Meridiane und Parallellireise einschreibt; ferner am obern Rande oder in einer freien Ecke den Titel und die Reduktionszahl oder den .1Lassstab; in einer andern die Leyende oder Erklärung der Zeichen und Abkürzungen, sowie allenfalls nothwendige Spezialbemerkungen. Endlich hat man für den Fall, dass die Karte nicht genau nach den Randlinien orientirt ist, noch die Orientimung anzugeben durch Beifügung eines Pfeiles, dessen Spitze nach Norden zeigt.

Am Besten übt man sich im Kartenzeichnen, indem man zunächst gute Muster reproduzirt; freilich darf diese Reproduktion kein sklavisches Nachahmen, kein mechanisches Kopiren sein, sondern man muss die Vorlage studiren, um ihrer Vorzüge bewusst zu werden und sie mit kritischem Sinne zu verwerthen.

Kopiren von Karten und Plänen. Die Kopie kann identisch reproduzirt oder in einem andern Massstabe als dem des Originals ausgeführt werden. 
Die inlrutisthe Konpe oder die genaue Wiedergabe im Massstab der Vorlage kann angefertigt werden mittels Durchzeichnens, Durchstechens, sowie mit Hülfe eines Netzes von Quadraten etc. Beim Durchreirhurn leg̣t man das Zeichnungspapier auf die Torlage und befestigt heide an einander an ihren vier Edken, hält sie gegen ein Fenster und fährt mit dem Bleistift allen wesentlichen Linien der Originalzeichnung nach. Diesps Verfahren ist indess nicht hequem; man zielit es daher vor, durchsichtiges Iapier (Pauspapier, Oelpapier) zu verwenden, welches man auf die Vorlage legt und welches das Nachzeichnen aller ihrer Details ermöglicht. Das Durchzeichnen nach dem einen und andern Verfahren ist indess nur zwechmässig, wem man rasch eine Reproduktion in grossen Zügen haben will, nicht aber, wenn es sich um eine sorgfïltig anszuführende Arbeit handelt.

Beim Inurhsterh'n legt man die Vorlage auf das weisse Papier und sticht mit einer feinen gaestielten Varlel (wie sie, häufig die Griffe der Reissfedern enthalten) die Endpunkte aller geraden Linien und überhaupt alle wesentlichen P'unkte durch. Dann zeichnet man den Plan oder die Kiarte, indem man sich einerseits durch die durchgestochenen Punkte auf dem weissen Papier, andrerseits durch das Original, welches man vor Augen hat, leiten lässt. Dieses Verfithren ist, da dabei die Vorlage verdorhen wird, natïrlich nur anzuwenden, wenn man blos einen Entwurf order eine schlecht ausgefallene Zeichnung übertragen will. - Beim Kopiren mit. Hülfe eines Qundraturtapy theilt man durch sehr fuin gezogene Linien die Vorlage und das Papier in gleiche Quadrate ein (Fil. s:3) und bestimmt mit Hülfe des Zirkels die Punkte, wo die Linien $A$ des Planes die Seiten der entsprechenden (homologen) Quadrate schneiden müssen, sowie - als Schnitt- $B$ punkte - die Lage

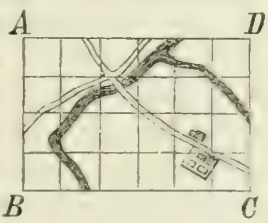

Fig. 83.

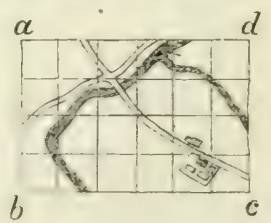

c

von Punkten im Innern der Quadrate. Im das Origrinal nicht zu heschädigen, kann man es mit Pauspapier überziehen und die Quarhate auf diesem anbringen. Enthält ein Quadrat viele Einzelleeiten, so theilt man dasselbe in kleinere. 
Uebrigens istes, wenn man einmal ziemliche Gewandtheit erlangt hat, fast ebenso vortheilhaft, die Lage der Hauptpunkte auch blos mit dem Zirkel als Schnittpunkte zu bestimmen, indem

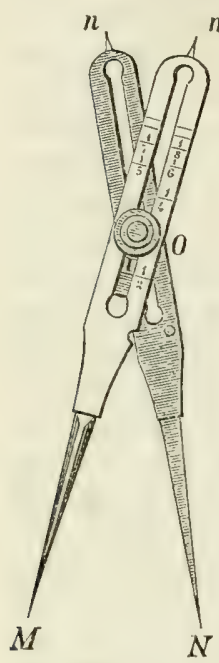

Fig. 84.

$m$ man die Entfernungen eines neu zu bestimmenden Punktes von zwei schon eingetragenen abmisst. - Ueber verschiedene andere $\mathrm{Me}$ thoden, die zwar sehr förderlich, auf Reisen aber nicht anwendbar sind, gehe ich hinweg.

Die reduzirte Kopie oder die Nachbildung in kleinerem Massstabe wird angefertigt, indem man auf Vorlage und Zeichnungsblatt Quadrate anbringt, so dass die Seiten der letzteren blos Bruchtheile der ersteren sind oder einfacher durch Bestimmung von Schnittpunkten mit Hülfe eines Redultionszirlicls (Fig. 84), den man so einstellt, dass die Entfernung $M N$ dem Massstab des Originals, $m n$ aber dem der Kopie entspricht. Hat man aber keinen Reduktionszirkel, so kann man sich auch mit dem gewöhnlichen $N$ Zirkel behelfen, wenn man zuerst einen $R e$ dultionsurinkel konstruirt (Fig. 85). Zu diesem Zwecke zieht man eine Linie $x o$, nimmt eine gewisse Länge (z. B. 500) nach dem Massstab des Originals in den Zirkel, beschreibt hiemit von $x$ aus einen Kreisbogen $z 0$, greift nun dieselbe Länge (500) auf dem Massstab der Kopie ab, beschreibt

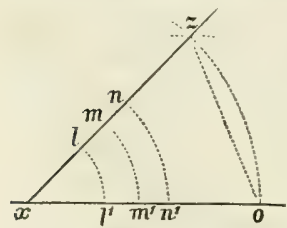

Fig. 85. hiemit einen Kreisbogen von $o$ aus und verbindet den Schnittpunkt $z$ mit $x$. Die Distanzen des Originals werden nun auf $x z$ und $x o$ abgetragen, wodurch man die Punkte $l$ und $l^{\prime}, m$ und $m^{\prime}$ etc. erhält; dann sind $l l^{\prime}, m m^{\prime}$ u. s. w. die reduzirten Längen.

Die verqrösserte Kopie wird in analuger Weise erstellt mit Hülfe entweder von Quadraten auf dem Zeichnungsblatt, welche grösser sind, als die im Original, oder eines Reduktionswinkels, wo die Entfernung zwischen zwei Punkten beider Schenkel, welche Punkte man durch Abtragen einer Länge $x z, x o(500)$ nach dem Massstab des Originals erhielt, grösser ist als die abgetragene Länge (Fig. 86). Es sind das 
rinfache Anwendungen der Sütze über die Proportionalität der Linien in ähnlichen Dreiecken. Vgl. S. 32, 33 und 37.

Es mag noch beigefügt werden, dass man bei Anwendung eimes halb oder doppelt so grossen Massstabes als der in Original ist, Karten erhält, die viermal kleiner oder grösser sind als die Vorlage, weil eben jede der beiden Dimensionen, Breite und Höhe, zweimal kleiner oder grösser gemacht wurde. Vgl. S. 72.

Der Reisende liommt, wie wir sehen werden, oft in den Fall, vergrösserte und rerkleinerte Kartenkopien anzufertigen; die ersteren, um Croquis in grossem Massstabe zu zeichnen von den Gegenden, die er bereist und erforscht; die letzteren, um diese Croquis, nachdem er sie an Ort und Stelle berichtigt, wieder zu reduziren und zu

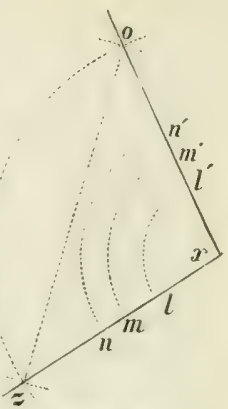

Fig. 86 . Einer Gesammtkarte zu vereinigen. Im num die kostbare Zeit auf der Reise möglichst zu sparen, muss man diese Uebung im Zeichnen vorher erwerben.

\section{SPRACHKENNTNISSE.}

Es braucht kaum hervorgehoben zu werden, wie nützlich lem Reisenden die Kenntniss wenigstens der verbreitetsten lebenden Sprachen ist. Man sagt wohl, mit dem Französischen könne man durch die ganze Welt kommen. Es mag das buchstäblich richtig sein; aber wenn man reist, um zu studiren, sich zu unterrichten, so genügt es nicht, dass man einigermassen sicher ist, in den grossen Hôtels sich verständlich machen und überall Ciceroni finden zu können, welche einige Brocken Französisch rerstehen; wer mit Genuss und Erfolg reisen und nicht ron Andern abhangen will, muss selhst verstehen, was um ihn herum gesprochen wird und soll hiefür nicht auf die Hülfe eines Dritten, eines Dolmetschers, angewiesen sein.

Wenn, wie in manchen Iändern, die sprache der höheren stände ("Hochsprache") eine andere ist, als diejenige der untern Klassen (..Mundart "), so muss man die letztere ver- 
stehen, um Sitten und Gebräuche, um den Volksgeist kennen zu lernen. Zwar trifft man fast überall in den oberen Schichten der Gesellschaft Offiziere, Kaufleute, Pflanzer etc., mit denen zu verkehren ron grossem Werth ist wegen ihrer Kenntnis von Land und Leuten; aber im Umgang mit diesen Personen wird der Reisende schon eher seine eigene Sprache anwender können, und zudem hat er nicht desshalb eine lange Reise unternommen, um Alles nur mit den Augen jener Drittpersonen anzusehen. Es darf nicht vergessen werden, dass man in der "guten Gesellschaft" selbst bei den Antipoden einen Ton, Ansichten und Vorurtheile findet wie in Paris Berlin und London, vorgefasste Meinungen, welche nothwendig. wenn auch in verschiedenem Grade, das Urtheil über die Eingeborenen beeinflussen. Es wäre aber nicht der Mühe werth wenig bekannte Völkerschaften aufzusuchen und kennen zu lernen, wenn man über sie oberflächliche, mangelhafte oder gar falsche Berichte zurückbrächte.

Um ein Volk wirklich kennen zu lernen, muss man mit und unter ihm in seiner Weise leben, wenigstens mit Denjenigen verkehren, welche das Volk ausmachen, mit ihner vertraulich sprechen über ihre eigenen Angelegenheiten und kleinen Interessen, theilnehmen an ihren Freuden und Leiden eingehen auf ihre Ideen und Anschaungen. Dazu aber is nothwendig, dass man mit ihnen direkt verkehren könne, ohne die Umständlichkeiten und oft gar Fehler der Verdolmetschung

Die ersten theoretischen Studien in der Sprache oder Mundart, um welche es sich handelt, wird man vor des Abreise betreiben. Man findet zu diesem Zwecke in den Katalogen der Buchhandlungen F. A. Brockhaus in Leipzig: Maisonneuve \& Cie. oder Ernest Leroux in Paris eine Auswahl von Vokabularien und Grammatikbüchern aller bekannter Idiome.

An die praktische Erlernung der Sprache kann man sicl oft erst machen, wenn man in dem betreffenden Lande selbst angelangt ist, es sei denn, man treffe vorher schon Personer an, welche das fragliche Idiom sprechen. Wie dem abes auch sei, in jedem Falle soll man bei der ersten sich dar. bietenden Gelegenheit sich keck auf die Konversation ein. lassen; unbekümmert und ja nicht ängstlich wegen mögliche: Fehler, die eben für jeden Anfänger unvermeidlich sind 
Diese Konversation wird anfünglich langsam, in gebrochener Fede, in unzusammenhängenden Sätzen erfolgen und mit fehlerhafter Aussprache; aber in Kurzem wird man - indem man gewisse Worte wiederholen hört, gewisse Laute nachzuahmen, Sätze und Satzglieder verbinden lernt — sich geläufig und verständlich ausdrücken. Denn eine Sprache mag noch so reich sein, so hat sie doch stets nur eine sehr beschränkte Zahl von Ausdrïcken, welche in der gewöhnlichen Konversation zur Anwendung kommen ${ }^{1}$ ) und diese Ausdrücke, die Kurantmünzen der Lmgangssprache, eignet man sich baid an, um so rascher, je mehr man mit und unter dem Volke lebt und je mehr man vermeidet, ein anderes Idiom als das, welches man lernen will, zu sprechen oder zu hören. So dringt man ein in's Verständniss, in den Geist der Sprache, und für die aufgewendete Nühe wird man reichlich entschärligt durch die vielfuche Erleichterung und Förderung, welche die erlangte Kenntniss gewährt, durch die Herzlichkeit in ITmgang und Verkehr, welche sie ermöglicht.

\section{INFORMATIONEN ÜBER DAS LAND.}

Ein Philosoph sagt: „Jeder sieht im Verhältniss zu seinem Wissen und Kennen", und er hat Recht; denn, beim Reisen wenigstens, beobachtet man zuverlässig das am besten, woron man schon las oder sprechen hörte, und man übersieht nur zu leicht Dinge,. woron man noch keine Kunde hat. Es ist daher nichts weniger als unnützer Zeitverlust, sondern es bringt grossen Vortheil, wenn man liest, was über das zu bereisende Land schon geschriehen wurde. Eine solche Darstellung und Kenntnissnahme dessen, was man seherr wird, vermehrt in hohem Grade den Reiz des Reisens, indem sie für die kleinsten Details ein Interesse erweckt, das ihnen sonst nicht in gleichem Masse zu Theil würde; sie ermöglicht oder erleichtert überdiess die Orientirung in dem Labyrinth der

1) Cinq cents mots appris par cour, et accompagnés de quelques notions sur la manière de les lier ensemble, suffiront au voyageur pour dire tout ce qu'il veut, au bésoin par des périphrases. Si en outre il s'arrange pour avoir des réponses par oui ou par non, il pourra, sans autre bagage linguistique, faire une Jarge récolte de renseignements. D'Abbadie, Bulletin de la Soc. de géogr. 187̃, pag. 173. 
erforderlichen Beobachtungen und verschafft uns einen Stock von Einzelheiten, welche zu studiren oder zu verifiziren sind; auch bewahrt dies Vorgehen vor der Gefahr, dass man als neu Dinge veröffentlicht, welche bereits bekannt sind.

Verzeichnisse der neuesten Publikationen über jedes Land findet man in den geographischen Mittheilungen von Justus Perthes in Gotha, der Zeitschrift der Gesellschaft für Erdkunde in Berlin und in dem zu Paris erscheinenden Année géographique. Diese Verzeichnisse enthalten öfters kurze Notizen oder Auszüge aus den betreffenden Werken, wonach man den Inhalt der letzteren beurtheilen kann.

Man wird nicht Alles lesen, was über die Gegend, welche uns interessirt, geschrieben worden ist, wohl aber einige der besten Darstellungen.

Wenn man dazu Gelegenheit hat, so versäume man ja nicht, sich in Sachen zu erkundigen bei Personen, welche das fragliche Land besucht oder in demselben gelebt haben. Von besonderer Wichtigkeit ist es, die Förmlichkeiten bei Vertragsabschlüssen kennen zu lernen. (D’Abbadie Instr. 284.)

Ferner verschafft man sich die besten, d. h. genauesten und detaillirtesten Karten der Gegend.

Neben den allgemeinen Informationen, von denen wir eben sprachen, sind gewisse Erkundigungen praktischer Art einzuziehen, z. B. solche - und zwar genaue Angaben - über Transportmittel, Fahrtenpläne der Eisenbahnen, Schifffahrtskurse, Kosten und Bedingungen der Ueberfahrt u. dgl. Man findet das in den allgemeinen Kursbüchern von Hendschel („Telegraph“), Chaix, Bradshaw u. s. w. und in den speziellen Reisebegleitern für einzelne Länder, wie bei den verschiedenen Gesellschaftsagenturen. Eine genaue Kenntniss der Verkehrsgelegenheiten zwischen zwei Punkten erspart viel Zeit und Geld.

Die genannten Hülfsmittel reichen indess mit ihren Angaben gewöhnlich nicht weiter als bis zum Landungshafen für die zu besuchende Gegend und lassen uns in Unkenntniss über die Verkehrsanstalten im Innern jenes Landes. Nun muss man an die Gefälligkeit von Personen, welche dort zu Lande gelebt haben, appelliren, um zu erfahren, welches die empfehlenswerthen Gasthöfe und Pensionen seien, welches die üblichen Preise, die Tarife für Führer, für Pferde u. dgl., 
sowie viele andere Details, deren Kemntniss theuer zu stehen kommt, wenn man sie durch eigene Erfahrungen erlangen muss.

Hat man diese Aufschlüsse nicht ror der Abreise erhalten können und auch nicht unterwegs von Personen, mit welchen uns der Zufall bei der Leberfahrt zusammen brachte, so muss man auf gut Glück ein Hôtel wählen: hat man abex das gethan mol sich eingerichtet, so suche man hei erster Musse, ohne indes: Eile zu verrathen, sich üher die Verkehrsgelegenheiten an Ort und Stelle zu nrientiren. Ist man dann üher Tegre, Transportanstalten und Preise genügend instruirt, so kann man seine Exkursionen so eimrichten, dass man in kurzer Zeit Vieles sieht.

Noch mag bemerkt werden, dass die raschesten Transportgelegenheiten nicht immer auch die günstigsten sind. Man heobachtet mehr und besser von einer lintsche aus oder vom Bankett eines Fostwagens herunter, als durch das Fenster eines Eisenhahnwagens. Zu Pferd oder Esel kamn man Halt machen, wo es belieht. Fusstouren endlich sind in vielen Fällen das Vorzüglichste: dem dabei kamm man alle Einzelheiten der Gegend studiren, an jeder stelle verweilen, die uns interessirt, die gewöhnlichen Touristenwege zur Seite lassen, kurz, die Gegend zwar langsamer, aber mit weit mehr Gewinn durchreisen.

\section{KLEIDUNG UND AUSRÜSTUNG.}

Dieselhe hängt sehr ab von Art und Dauer der Reise, die man unternimmt.

Ak allyemeine Regel kann man die aufstellen: dass man ja rermeide, Dinge mit sich zu nehmen, welche mañ sich ebensogrut am Bestimmungsorte oder Landungsplatze verschaffen kann. Thue man das Letztere: selhst wemn man dann diese Gegenstände doppelt so theuer hezahlen müsste als dahein, so wird man dabei immer noch im Vortheil sein, mit Rücksicht einerseits auf die hosten ron Fracht und Zoll, andrerseits auf die Belästigung und die Widerwärtigkeiten, die man sich so ersparte.

Iuss man viel Gepäck mitnehmen, so vertheile man es auf rerschiedene lilrine Fellrisen oder Handküfferchen, lieber 
als dass man Alles in einen grossen Koffer zusammenpacke, in welchem man mit Mühe findet, was man sucht, und welcher bei Reisen im Lande gewöhnlich sehr lästig fällt. Solide Lederköfferchen mit starken Riemen leiden weniger durch den Transport, und sie machen eine Unterbringung der Effekten möglich in der Art, dass in einem derselben Alles beisammen ist, was man immer zur Hand haben will oder was man auf kleinen Exkursionen nöthig hat; endlich kaun man sie leichter Reit- und Saumthieren aufladen, da man sie hiezu nur, mit Rücksicht auf Gleichgewicht, paarweise rerwenden muss. Braucht man mehrere Köfferchen, so wird man sie numeriren, und für jedes ein Verzeichniss seines Inhaltes anfertigen.

Gerrisse Taxen werden freilich nach der Stückzahl des Gepäcks berechnet, ob dies grösser oder kleiner sei; auch riskirt Jemand, der nur Einen Koffer mitnimmt, weniger, dass ihm Gepäck abhanden komme durch Nichtabgabe am rechten Orte. Diese beiden Gründe können dazu führen, dass man bis zum ersten Reiseziel nur einen Koffer mitnimmt; dann aber verschaffe man sich ein oder zwei Köfferchen für die Exkursionen, die man abseits ron den grossen Verkehrswegen unternehmen will.

Besondere Aufmerksamkeit rerdient die Rleidung. Man wähle weite bequeme Kleider, die riele Taschen enthalten und aus Wolle oder Flanell bestehen, welche Stoffe gegen rasche Temperaturänderungen Schutz gewähren. Ausser den Kleidern im engern Sinne sind wesentlich: wollene Strümpfe, zwei Jacken (Unterwesten) aus feinem geschmeidigem Flanell, ferner gute Schuhe, die nach Nass angefertigt wurden und in welchen man sich wohl findet. Was die Wäsche anbetrifft, so kann man diese überall erneuern; es ist also unnöthig, sie in Dutzenden ron Stücken mitzuschleppen. Die Wahl der Kopfbedeckun! ist mehr oder minder Geschmackssache; aber ein weicher hoher und hellfarbiger Filzhut mit breiten Rändern ist immer bequem. In heissen Ländern wird man daran noch einen Nacken- oder Halsschirm anbringen, welchen man übrigens ersetzen kamn durch ein weisses Taschentuch oder Foulard, das mit zwei Stecknadeln an den Hut befestigt wird. Auch muss der Hut ein Sturmband haben, womit man ihn unter dem Kinn, oder eine 
Elastique-Schure, womit man ihn an einem Knopfe befestigt, wemn man reitet oder bei windigem Wetter marschirt.

Als Mantel oder Plaid ist am besten eine gute Wollderlir: sie muss fein und zugleich dick sein, nicht leicht wasserdurchlassend und muss eine Oeffumb haben, um sie üher den Kopf anzuziehen, nach Art des Pourho der Südamerikaner: statt einer einzigen Decke kam man auch deren zwei verwenden, die an einer Seite so zusammengenäht sind, dass daselbst noch Raum genug bleibt zum Durchschlüpfen des Kopfes. Ein Mantel dieser Art lässt die Arme frei und schüłzt Körper und Beine beim Reiten; er hält den Regen genugsam ab, und hei sonnenschein legrt man ihn vierfach zusammen, um ihn auf dem Sattel anzuhringen oder auf ein Felleisen zu schnallen. Bei Nacht wickelt man sich in denselben ein oder man rollt ihn zusammen und benutzt ihn als Kopfkissen — in Ermanglung von Besserem.

Die Kleidung wird rervollständigt durch solide Lederhundsthuhe, die bis zum Handgelenk reichen müssen, um Schutz zu bieten gegen stechende Insekten und Dornen.

Alle diese Kileidungsstücke sollen so einfach als hequem sein, von falber, nicht auffallender Farbe, nicht schauspielermässig nach Form und Schnitt, aber gut nach Stoff und Arbeit.

Als arcesserische Ausrïstungsstüclie sind zu empfehlen : ein Fermolur oder gnter Foldsterher (wie man deren zum Gebrauch der Stabsoffiziere anfertigt) mit Leder-Etui uid Ripmen zum Tragen an der Seite; ein Taschentompusss mit phosphoreszirendem Grunde, um sich auch im Dunkeln orientiren zu können, und ein gutes Taschommesser mit mehreren Klingen.

Für Gletschertouren braucht man ferner einen Alpenstork, ein Eistreil, Beryschule, srile aus Manila-Hanf, Tomister, Frldflarke, Schleier etc. Diese Objekte werden fast ron Jahr zu Jahr verbessert; um nun das Vollkommenste zu crhalten, wird man gut thun, in Sachen sich mit einem Mitglied eines Alpenklubs zu berathen.

Was Wraftem anbetrifft, die man in manchen Ländern nüthig hat, so ist ein Revolver sicher die beste Schutz- 
waffe $^{1}$ ). Als Jagdflinten wird man öfters noch die alten Perkussionsgewehre vorziehen, wegen der Schwierigkeit, für andere, nach Spezialsystemen, die erforderliche Munition zu bekommen.

Zur weiteren materiellen Ausrïstung wird man voral das nöthige Schreibzeug beschaffen. Es gibt Schreib-Etui.s (Portable writingstand), welche Papier, Tinte, Federn, Bleistifte etc. enthalten und in einem Koffer wenig Platz einnehmen. Soll die Reise lange dauern, so wird man dies Naterial von Zeit zu Zeit durch neues rervollständigen und ersetzen müssen, oder man muss einen lileinen Torrath an Papier, Tintenpulver, Federn $u$. dgl. mitnehmen.

Die während des Reisens zu machenden Notizen können ganz wohl mit Bleistift aufgezeichnet werden, wenn man sie nur später mit Tinte zu Papier bringt; desswegen genügt dann auch ein halbes Ries Papier und eine Porte-Crayon mit einem Dutzend Graphitstifte zum Einfügen in denselben.

Zum Zwecke des Photorfophirens versieht man sich mit einem Apparat und präparirten Platten oder mit den Stoffen, welche nöthig sind, um sie herzurichten für die Aufnahme, Entwicklung und Fixirung des Bildes, wenn man diese $\mathrm{Zu}$ richtung selber vornehmen will.

Als ILaterial zum Zeichnen und Aquarelliren nimmt man ein Album oder einen Vorrath von Whatmann-Papier oder Harding-Carton, weiche Bleistifte von verschiedenen Nummern, ein Sortiment Pinsel und eine Schachtel Farben von Schönfeld \& Cie. in Düsseldorf, J. M. Paillard in Paris oder Winsor \& Newton in London, mit zugehörigen plattirten Flacons (japanned water bottles).

Ein Faber'scher Porte-Crayon mit zwei oder drei Sortimenten sibirischer Graphitstifte thut denselben Dienst wie fünf Dutzend gewöhnliche Bleistifte und beansprucht viel weniger Platz. Das Mitnehmen von Reissbrettern erspart man sich durch sogen. Albums-blocs, in welchen die Blätter aufgespannt sind.

Es gibt Albums dieser Art von jeder beliebigen Grösse und Papiersorte. Farbenschachteln gibt es sogar welche,

1) D'Abbadie meint nach Erfahrungen aus Afrika, dass in vielen Fällen ein blosser Stock das Beste sei! Instructions pag. 283. 
die kaum mehr Lmfang haben als eine grosse Taschenuhr: sie sind aber nur zu empfehlen, wemn es sich blos darum handelt, rasch die wesentlichen Farben einer kleinen Skizze zu notiren. Will man nach der Yatur Aquarelle zeichnen, so darf weder die Farbenschaale noch die Wasserflasche zu klein sein, weil es sonst schwierig wäre, genug Farbe zu präpariren und die Pinsel reinlich genug zu halten, um reine Töne herzustellen. Die Anzahl der Farben kann beschränkt werden auf die häufig anzuwendenden: diejenigen, welche man nur ausnahmsweise braucht, kann man besonders, z. B. in einer Tasche, aufbewahren.

Zum Zwecke toportaphiseder Aufuahmen wird man sich mit den Instrumenten versehen, wovon wir schon gesprochen haben: Theodolit oder Orientirboussole, Messschnur, Libelle und Senkblei; ferner mit einem besondern Notizenheft hiefür und mit aufgespanntem Papier (album-l)loc) für die Croquis. Inter dem Gepäck, das man an seinem Hauptyuartier oder Stationsort hat, soll eine Partie Rollempapier (sogen. endloses Papier) sowie Panspapier sein, ferner ein Reisszeug mit gewöhnlichem und Reduktionszirkel, Reissfeder, Transporteur u. s. w., ein langes flaches Lineal (Reissschiene) mit Ecrpuerre und DoppeIdezimeter, sowie ein stück chinesische Tusche. Dabei setzen wir voraus, es werde überall ein Tisch zu finden sein zum Aufspannen und Befestigen des Papiers, eine Lntertasse oder Tellerscherbe zum Farbenanreiber, und dass die nöthigen Bleistifte, Pinsel und Farben in der Aquarellschachtel sich vorfinden.

Von Instrumenten für verschicdene Beobachtungen war schon oben (S. 16 ff.) die Rede, nämlich von Chronometer, Thermometer, Barometer, Hygrometer u. s. w. Wir erinnern hier nur daran ${ }^{1}$ ) und machen darauf aufmerksam, 1) dass deren Richtigkeit (in Bezu@ auf Funktion) vor der Abreise kontrolirt werden muss, indem man ihre Angaben vergleicht mit denen von Normalinstrumenten: 2) dass sie sehr sorgfältig verpackt werden müssen, namentlich für den Fall eines weiten Transportes. Bei einer Reise über Meer

1) Bei der Verschiedenheit der Ansichten in solchen Dingen mag hier auch auf die sachbezügliche Zusammenstellung ron D'Abbadie, Instructions pag. 274 und 275 , aufmerksam gemacht werden. 
thut man gut, alle Netalltheile, die rosten könnten, mit befetteter Leinwand zu umhüllen.

Man wird ferner mit sich nehmen alle die Objelite, welche man auf vorgängigen übungsweisen Exkursionen als unentbehrlich kennen lernte für ycologische, botanische und zooloyische Forschungen und Sammlungen, ausgenommen, es seien diese Gegenstände auch am Bestimmungsorte zu haben.

Handelt es sich nur nm kleine Exkursionen, wovon man jeden Abend nach Hause zurückkehren kann oder um Reisen, wobei man sicher ist, überall ein Nachtlager zu finden, so genügt es, eine Reisctasche oder Korbtasche mitzunehmen mit einigen L'tensilien und dem Tagesbedarf an Mundrorrath.

Wenn hingegen in der Gegend, die man durchreisen oder erforschen will, nicht sicher auf die nöthigen Hülfsquellen gezählt werden kann, so muss man sich mit Reisczelt und zugehörigem DLobiliar, mit Küchen-Gerithen und Vorräthen versehen. Alles das findet man aber gewöhnlich eben so gut in den überseeischen Kolonien und Landungsplätzen wie in Europa. Will man sie gleichwohl ror der Abreise in den grossen Magazinen zu Berlin, Paris und London und in andern grossen Städten einkaufen, so wird man gut thun, diese Gegenstände nach getroffener Auswahl sich direkt an den Bestimmungsort zusenden zu lassen und sich nicht für die Ueberfahrt mit Gepäck' zu belästigen, das man noch nicht braucht.

Was Zelte, Gurtbetten, zusmmmenlegbare Tische and Sessel. betrifft, so kann es auch genügen, wenn man nur Muster mitnimmt und darnach diese Möbel anfertigen lässt in den paar Tagen, welche zwischen dem Landen und den Expeditionen in's Innere verstreichen.

Für alle Fälle aber verschaffe man sich eine Hüngematte aus Aloebast, welche wenig Platz einnimmt und in Ermanglung eines Bettes überall aufgehängt werden und so Schutz bieten kann vor Reptilien und Bodenfeuchtigkeit.

An Küchengerëthen wird man selbstverständlich nur die allernöthigsten mitnehmen und nur solche, die man in dem zu besuchenden Lande nicht erhalten könnte. Diese transportabeln Geräthe werden Jahr für Jahr vervollkommnet und bereichert und man hat es dazu gebracht, dass Jemand in 
ceinen Taschen eine demontirte Küchenbatterie mit sich führen kann, die zur Bereitung der unentbehrlichsten Speisen genügt.

Lnter Mundirmithen verstehen wir hier komprimirte Gemüse (Konserven), kondensirte Milch, Chocolade, Kaffee, Thee u. dg̣l., welche eine Ergänzung bilden sollen zur landesiiblichen Küche und Yahrung (die — wie Wildpret, Eier, Geflügel u. s. w. - an Ort und Stelle beschafft werden mïssen oder welche auch bei eintretendem Mangel an andern Lebensmitteln hiefür Ersatz bieten sollen.

Nicht rercressen darf man eine kleine Tushom-oder Foldapotheke und einen Vorrath an Insektenpulrer.

Je nach dem Lande, das man aufsuchen will, muss man

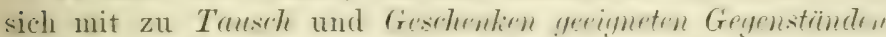
versehen. Es kam nämlich rorkommen, dass man $u m$ Geld nicht odler kaum erhält, was man leicht und vielleicht zehnmal billiger erwirht durch Tausch gegen ein Sïuck farbigen Zeuges, ein Halsband aus Glasperlen, eine Axt, ein Messer etc. Auch kamn man sich hiedurch erkenntlich beweisen für genossene Gastfreundschaft und empfangene I)ienste, wofür man nicht, ohne zu verletzen. Geld anbieten dürfte. Kurz man wird auf diese Art überall wohl ankommen. Nur muss man nichts sehen lassen als das, was man geben will, auch sich hüten, allzuleicht und viel Geschenke auszutheilen, um nicht Enttäuschungen zu rerursachen oder die Habgier der Eingebornen zu reizen.

Bevor man solche Artikel einkauft, muss man sich darüber unterrichten, was in dem hetreffenden Lande ron den Eingebornen im Allgemeinen am meisten geschätzt wird; denn hier gilt vor Allem das sprüchwort: üher Geschmackssachen lässt sich nicht streiten: - es ist sehr wohl möglich, dass man mit einem Paar rergoldeter Epauletten, die bei uns ausser Kurs gekommen, viel mehr Freude macht als mit einem sehr werthrollen Gegrenstand.

Für grosse Expeditionen muss man sich mitunter ungrwölunliche Oljelite beschaffen, wie: demontirte und transportable Schiffe für Flüsse und Seen: Schlitten zu Polarreisen; im Innern gefirnisste Eisenkisten für das Mitführen von Wasservorräthen in Wüsten etc.: aber solche Expeditionen erfordern auch ein eingehendes und spezielles Studium in 
Bezug auf deren ganze Organisation; sie sind auch gewöhnlich von langer Hand vorbereitet, und man kann darüber Nänner zu Rathe ziehen, welche in solchen Unternehmungen erfahren sind.

Da es schwer ist, an Alles zu denken und Nichts zu vergessen, da ferner Vorräthe ausgehen, nothwendige Objekte abhanden kommen können, so wird man die Adressen, vielleicht auch die Preiskourante der Lieferanten aufbewahren, damit man im Stande ist, nachkommen zu lassen, was fehlt und sich als nothwendig erweist. 
BEOBACHTUNGEN UND STUDIEN. 



\section{BEOBACHTLNGEN IM ALLGEMEINEN.}

Anfuabe des Reisenden ist die Termehrung der Kenntnisse über das Land, welches er bereist.

Dieses Ziel erreicht er theils durch eigene Beobachtungen, theils dadurch, dass er mnverüfentlicht gebliebene Beobachtungen Anderer sammelt oder Untersuchungen reranlasst durch Männer, deren persönliche Eigenschaften orler Lebensstellung sie hiezu besonders geeignet erscheinen lässt.

Hierüber einige Worte.

Man trifft in jedem Lande Personen, welche aus Interesse oder Beruf sich mit Forschungen über gewisse Fragen und Thatsachen beschätigen. Manchmal sind es wahre, aber in ihrer Bescheidenheit unbekannt gebliebene Gelehrte, meist aber einfach Leute ron reicher Erfahrung, die zwar nicht viel gelesen, aber dafür um so mehr gesehen und beobachtet haben. Man kann oft eine erstaunliche Summe positiver Kenntnisse über eine Gegend, deren Bewohner, Klima, Pflanzen- und Thierwelt u. s. w. erlangen an einem Abend, welchen man im Pfarrhaus eines kleineu Dorfes, bei einem Pflanzer oder Kolonisten, auf einem Waldhofe, in einer Sennhütte, im Gespräche mit den Personen verlebt, mit welchen uns der Zufall zusammenführte. Es kann zwar auch im Gegentheil rorkommen, dass man hiebei grober Inwissenheit begregnet oder schlechtem Willen und Misstrauen und dass die Aufschlüsse, welche Einem zu Theil werden, ron Absurdititen und Lebertreibungen strotzen, so dass sie äusserst wenig Werth haben. Man lasse sich aber dadurch nicht abschrecken: trifft man selbst auf zehn Personen nur eine, ron der man etwas Nützliches rernimmt, so hat man seine Zeit nicht verloren, hat man gegrentheils allen Grund, bei erstem Anlass denselben Versuch wieder zu machen. Wenn man dabei unter einer 
unkultivirten Berölkerung einen gebildeten Mann findet, so wird sich Dieser freuen, Jemanden zu treffen, mit dem er sich unterhalten kann und man wird in seiner Gesellschaft angenehme Stunden verleben. Er wird gerne auf Wuusch seine Beobachtungen mittheilen, seine Sammlungen vorzeigen und uns zu interessanten Punkten hinführen. Vielleicht dass er seit Jahren mit geduldiger Hingebung statistische Angaben, seltene Manuskripte $u$. dgl. gesammelt hat und uns die Benutzung dieser Materialien gestattet. Hat er sich aber mit dem Sehen begnügt, so wird doch die Unterhaltung mit ihm interessant und lehrreich sein und unsere Aufmerksamkeit auf Dinge hinlenken, die wir sonst leicht unbeachtet gelassen hätten. Lm aus einem solchen Verkehre Nutzen zu ziehen, ist es nicht unerlässlich, dass unser Gesellschafter ein gebildeter Mann sei; nur hüte man sich in solchem Falle wohl davor, ihn ron oben herab zu behandeln, seine Unkenntniss zu belächeln, seiner irrigen oder abergläubischen Meinungen zu spotten oder ihn nach Art eines Verhöres ausfragen zu wollen. Auf diese Weise würde man nur ausweichende Antworten erhalten. Lasse man ihn also nach seiner Art sprechen über Das, was er am besten kennt und leite man ihn erst hernach und unrermerkt auf das Thema, das uns beschäftigt, um zu hören, was er darüber denkt. Dass diese Nittheilungen nur mit Vorbehalt weiterer Information aufzunehmen sind, ist selbstrerständlich.

Diese Art Studien - die Erkundigungen - sind namentlich ron Nutzen mit Rücksicht auf Gegenden, in die man nicht leicht eindringen kann. Ton Resultaten, welche auf diese Art erlangt wurden, will ich beispielsweise nur zwei anführen.

Zu einer Zeit, wo der Stamm der Kabylen noch nicht unterworfen und wo es sehr gefährlich war, ihr Land zu betreten, unternahm es General Daumas, damals noch Hauptmann, Erkundigungen einzuziehen ron den Eingeborenen, welche Zufall und Geschäfte nach Algier führten. Als man später das Land eroberte, erwiesen sich die Berichte und Beschreibungen des Generals Daumas als erstaunlich genau; so gut hatte er sich seiner Aufgabe entledigt.

Das zweite Beispiel betrifft den rerstorbenen Freiherrn Heinr. v. Maltzan. Wir lassen ihn selber sprechen, da seine 
Vorte Fingerzeige über das einzuschlagende Verfahren entalten. Es handelte sich um Nachrichten über eine Gegend m südlichsten, Aden benachbarten Theile Arabiens, wohin och kein Europäer gekommen war. "Ich eröffnete," sagt Maltzan, „ein Informationsbüreau und arbeitete da drei Ionate lang Tag und Nacht; denn viele Araber hatten erst spät. $\mathrm{m}$ Abend frei. Zuerst war erforderlich, eine Karte in grossem Iassstab zu zeichnen, damit ich mich in dem massenhaften eographischen Material, welches mir die Aufschlüsse der ingebormen lieferten, orientiren kounte. Die Aussagen ridersprachen einander oft; aber indem ich sie unter einnder verglich, wegliess, was als Lebertreibung erschien, und ur auf die rertrauenswürdigsten Berichte, welche mit einnder übereinstimmten, mich verliess: gelangte ich zu einer errollständigung der Karte, welche zum einzigen, aber sichern ührer durch dies Labyrinth und Chaos wurde. Was mir och zu thun hlieb, war verhä]tnissmässig leicht. Nach den ussagen der Araber wurden Beschreibungen der in der Farte angegebenen Ortschaften zusammengestellt, welche den opographischen und politischen Angaben zur Erklärung ienen sollten. So konnte ich ungefähr 1000 topographische unkte notiren: Berge, Thäler, Flüsse, Ehenen, Schluchten, Iuellen, Brunnen, dazu eine grrosse Zahl von Städten, Dörfern, olksstämmen - und jedem kurze Angaben über seine Beeutung und Natur, über Gebräuche, Religion und Politik er Eingebornen beifügen."

Wenn man in Folge gründlicher Vertrautheit mit Sprache nd Sitten eines Landes im Stande ist, als Eingeborner verkleidet u reisen, wie z. B. Vambery und Gerhard Rohlfs es thaten, ) kann man Alles selher beobachten, und dies ist allerdings as Beste; reist man aber als Europäer, so kommt es, wie laltzan bemerkt, sehr oft ror, dass die Eingebornen aus lisstrauen die Ortschaften links und rechts der Route nicht ?nnen und der Reisende nur kennen lernt, was unmittelbar I seinem Wege liegt, und dies ist $\mathrm{zu}$ wenig. In solchen ällen wendet man besser die Methode der Erkundigungen 1, womit man, wie wir sahen, ganz überraschende Resulte erreichen kann.

Es gribt Länder, deren Herrscher die Zustände und Veriltnisse ihres Gebietes nach Aussen geheim halten wollen. 
Da wäre es natürlich unnütz, sich an Beamte zu wenden oder an Offiziere des Gefolges, welche oft weniger die Aufgabe haben, den Reisenden zu dessen Schutze zu begleiten, als rielmehr die: zu verhindern, dass er zu viel beobachtet. Aber auch in solchen Fällen gibt es Mittel, um doch den Zweck zu erreichen. Zum Beweise hiefür berufe ich mich auf das prächtige Werk ron Aimé Humbert über Japan und auf die Fülle ron Einzelheiten desselben über Sitten, Gebräuche, Szenen im Innern u. s. f. Wie ihm das möglich wurde in einem Lande, wo den Augen der Europäer Alles so sorgfältig entzogen ist, sagt er uns selber: "Die rielen Zeichnungen, Skizzen etc., welche man überall findet, ersetzen zum Theil die Aufschlüsse, welche man umsonst erfragen würde."

Das sind indessen extreme und zum Glück seltene Fälle, und wenn wir ron einzuholenden Erkundigungen sprechen, denken wir mehr an allgemeine oder spezielle Aufschlüsse, die nicht wohl anders als auf diesem Wege erlangt werden können, wie Resultate von Zählungen in rerschiedenen Zeitpunkten, Ein- und Ausfuhrtabellen, meteorologische und andere Beobachtungen, welche sich über einen längern Zeitraum erstrecken - alles Dinge, zu deren selbständiger Ermittlung der Reisende nicht Zeit und Gelegenheit hat. Wenn solche Dokumente theilweise und ziemlich allgemein schon bekannt wären, so kann es immer noch gut sein, sich $\mathrm{zu}$ unterrichten über Werth und Vertrauen, welche sie rerdienen, sowie darüber, wozu, durch wen und wie sie gewöhnlich erstellt werden.

Bei amtlichen Dokumenten werden Zweck und Geist derselben oft als Kriterium dienen können. Es ist offenbar ein Unterschied zwischen unparteiischen Erhebungen über die Hülfsquellen eines Staates und andrerseits solchen Zusammenstellungen, welche der betr. Staat selbst am Yorabend der Aufnahme eines Anleihens in aller Eile veranstaltete. Auck können politische Rücksichten und Selbstüberschätzung dazv führen, dass gewisse Zahlen (wie die für Land- und Seemacht zu hoch, andere (so diejenigen über die schwebende Staatsschuld) zu niedrig angesetzt werden. Man muss also di waltende Tendenz kennen, um die Angaben richtig würdiges zu können. Es ist ferner von Werth, die Personen zu kemmen 
relchen die Arbeit anvertraut worden ist, um beurtheilen u künnen, ob sie durchaus genau und gewissenhaft vorgerangen sind orler sich mit ungefähren Angaben begnügten, b sie ein Interesse hatten oder nicht, gewisse Zahlen grösser der kleiner zu sehen. Endlich wirken die Yerhältnisse, unter relchen die Aufnahme erfolgte, auf das Resultat ein. Man tann ron einer unsichern, ungenügenden und fehlerhaften Basis ausgegangen sein, oder gewisse Lmstände können das Ergebniss zu einem unrichtigen gemacht haben. Wenn z. B. ine Bevölkerung üherzeugt ist, die Zählung werde vorge10mmen zum Zweck eines Massenaufgebotes, einer Ausheung oder einer Steuererhöhung, so wird sie den Personaland Termögenshestand zu verheimlichen suchen. Als die Engländer im Jahre 1872 eine Volkszählung in Indien verunstalteten, verstieg sich das Misstrauen soweit, dass die ceute glaubten, man wolle einen Teberschuss der Bevölkerung nassakiriren oder wenigstens in unbewohnte Berggegenden leportiren. Begreiflich waren sie unter solchen Lmständen iicht gerade bemüht, sich zahlreich einzustellen. Wo die iteuern nach der Stärke des Viehstandes bemessen werden, larf man sicher anmehmen, es werde ror einer Yiehzählung in Theil der Heerden entfernt; in Lündern mit hohen Zöllen und larlurch reranlasstem starkem Schmuggel werden die amtlichen Tehersichten der Ein- und Ausfuhr nicht den vollen Waarenerkehr an den Grenzen angeben kömen; wo die AuswanLerung verhindert oder mit dem Tode bestraft werden will, rie in China, findet sie heimlich statt; wo sie aber frei und inkontrolirt ist, kann man sie auch nicht in vollem Imfang rmitteln. Selbst an sich exakte Aufnahmen ergeben falsche iesultate, wenn sie nicht im ganzen Gebiet, worauf sie sich ieziehen, gleichzeitig erfolgen; denn die Verschiehungen, Wohnind standortswechsel, welche inzwischen rorkommen, führen ntweder Lücken oder Doppelzählungen herbei.

Gegen Angaben, welche von Privaten gesammelt wurden, nuss man noch mehr auf der Hut sein. Es ist persönliche Bekanntschaft mit dem Autor der Aufnahmen nothwendig, In darüber ein Urtheil zu hahen, wieweit es ihm möglich ar, genaue Piesultate zu erlangen. Sein Wissen, seine Geauickeit, sein Charakter, die Mittel, worüber er rerfügte, ie Methorlen und die Instrumente, welche er anwandte, 
alles dies muss in Betracht gezogen werden, um zu ermessen welchen Grad von Vertrauen sein Werk verdient.

Was die nicht veröffentlichten Dokumente betrifft, so muss man, um solche zu entdecken, oft andauernde Nachforschungen in allen Richtungen anstellen, ohne sich durch Miss. erfolge entmuthigen zu lassen. Diejenigen, deren Eigenthum sie sind, wissen oft selbst nicht, dass sie solche besitzen und Diejenigen, welche sie in Verwahrung haben, bemühen sich nicht immer darum, dieselben aufzusuchen. Man muss viele Leute fragen, um $\mathrm{zu}$ erfahren, wer in einem Lande sich mi bestimmten Untersuchungen beschäftigt oder beschäftigt hat man muss Archive und ihre Aktenfaszikel durchsuchen, um — mit Hülfe günstigen Zufalls — werthvolle Entdeckunger zu machen.

Unabhängig von diesen Erkundigungen über schon gemachte Beobachtungen ist es möglich, andere $\mathrm{zu}$ veranlassen, Punkte betreffend, worüber man sich informiren möchte, die man aber aus Mangel an Zeit oder aus andern Gründer. nicht selbst studiren kann.

Hat man mehrere Reisegefährten, so kann eine Arbeitstheilung eingeführt werden, so dass ein Jeder eine bestimmte Aufgabe erhält, die speziell er zu lösen hat: der Eine die Topographie, der Andere die Geologie u. s. f. - Ist man allein, so kann man sich in gewissem Grade durch die Eingebornen helfen lassen, z. B. was Anlage von Sammlungen betrifft, indem man ihnen genaue aber einfache Anweisungen gibt. So ist wenigstens Hermann v. Schlagintweit-Sakünlünski dazu gelangt, Pflanzen der verschiedenen Regioner. von Hochasien zu sammeln. Gewisse Gegenden von Tibet welche für Europäer unzugänglich waren, wurden bereist vor Eingebornen, die durch den Major Montgomerie eigens zu Lösung dieser Forschungsaufgabe unterrichtet wurden. Dir französische Regierung lässt die Theile von Marocco, wohi Christen nicht dringen können, durch einen Israeliten, der Rabbiner Mardochée, studiren. Es fehlt also nicht an Bei spielen hiefür, wie man sieht; die Erfolge werden zwar zi wünschen lassen aus Mangel an hinreichender Bildung be den mit solchen Missionen betrauten Eingebornen; um is dieser Beziehung soviel als möglich zu leisten, muss ma die intelligentesten Leute auswählen und sie mit durchau 
Haren Instruktionen versehen. Das Sicherste wäre, zwei oder Irei derselben gleichzeitig oder successive zu senden und die Aussage des Einen zu kontroliren durch die des Andern.

Abgesehen von Gegenden, welche für Europäer unzugängich sind und wohin man besondere Forschungsreisende :enden muss, gibt es eine Menge ron Beobachtungen, die nan sammeln liann, indem man einfach Männer, deren Stelung und Beruf sie zu solchen Arbeiten besonders befähigt, nierauf aufmerksam macht. Mancher ist nur noch nicht auf ine bestimmte Idee gekommen, aber einmal darauf gebracht, ridmet er sich gerne der Sache. Handelt es sich z. B. um ine den schneeregionen eigene Erscheinung, so spreche man larüber mit einem Gemsjäger orler sonst Jemanden, den sein Letier nach jenen Höhen führt. Will man die Schwankungen les Wasserstands eines Sees oder Flusses kemnen lernen. so asse man eine Sliala (ein Pegel) anbringen und reranlasse inen in der Nähe wohnenden Schiffer, dass er jeden Tag inen Blick auf die Zahl werfe, welche der Wasserspiegel rreicht. Bearbeitete Feuersteine und andere prähistorische "unde werden auf Rechnung des Reisenden von Erdarbeitern resammelt werden, wenn man sie hierauf aufmerksam macht: ler Bauinspektor wird lionstatiren, unter welchen Verhältiissen diese Oljjekte gefunden wurden; der Lehrer wird sich nit meteorologischen Beobachtumgen hefassen und so wird nan, Jank der Vielzahl ron Nitarbeitern und wemn auch er Beitrag eines einzelnen derselhen gering sein mag, zu iner beträchtlichen Masse Beobachtungsmaterial gelangen. Alles das entbindet freilich nicht von der Pflicht, selber u beohachten. I)ie direkte, eigene Beobachtung wird überall, o sie üherhaupt möglich ist, das Sicherste und Beste sein; ie ist und bleilst die Hauptaufgabe des Reiseuden. "Wir ahen davon schon gesprochen im ersten Theile dieses Werkes Iorhereitung): es muss aber Einiges speziell anempfohlen erden. Ich lasse hierïber Männer surechen, die kompetenter ind als ich.

.Die Natur nach jeder Seite und gut sehen, mit einem Vort: immer und jederzeit beobachten — sagrt uns Prof. [arcou ${ }^{1}$ ) — das ist die Rolle des Reisenden."

1) Instructions générales aux royageurs, publiées par la Société de geéographie Paris 1875, pag. 58. 
„Wer um den Preis von Strapazen ein Land zu studiren geht - sagt Baron Nau de Champlouis ${ }^{1}$ ) - muss nicht. blos für sich selbst und in Dingen, welche ihn direkt interessiren, Beobachtungen machen, sondern auch für Diejenigen, welche in den ruhigeren, mehr abwägenden Forschungen der Studirstube den Gewinn an Thatsachen zusammenstellen und vergleichen. Hiedurch kann jede einzelne Beobachtung werthvoll werden; nie soll sich daher ein Reisender von Aufzeichnungen abhalten lassen durch die Befürchtung, nur etwas Unvollständiges zu liefern; nur muss er dabei immer genau bemerken, unter was für Verhältnissen seine Beobachtungen mit Rücksicht auf die Exaktheit derselben angestellt wurden."

Es sei mir gestattet, noch folgende Punkte zu betonen:

$1^{\circ}$ Man beobachte den Thatbestand ebenso aufmerksam als gewissenhaft und notire die Wahrnehmungen unverzüglich in ein Heft, nach dem Eindruck, den man davon empfing und solange dieser noch frisch ist. Später, bei ruhigerer Ueberlegung, wird man schon erkennen und ausscheiden, was in diesen ersten Eindrücken und Notizen Uebertriebenes enthalten sein mag.

$2^{\circ}$ Ist das Objekt der Beobachtung ein komplizirtes, so zerlege man es in Gedanken, man studire es in seinen verschiedenen Theilen, in allen seinen Formen, und achte dabei stets auf seine Beziehungen zum Ganzen; dann füge man wieder zusammen, was man vorher auf dem Wege der Abstraktion zerlegte und schaffe sich so ein Gesammtbild.

$3^{\circ}$ Man forsche immer nach der tieferen Bedeutung, nach einer wahren und wirklichen Erklärung selbst der scheinbar einfachsten und gewöhnlichsten Thatsachen; mit andern Worten, man suche die Ursachen und Wirkungen zu ergründen.

$4^{\circ}$ Die Thatsachen ihrerseits konstatire man unter sorgfältiger Vermeidung gewagter Theorien und Erklärungen. Ist uns Etwas unbekannt oder zweifelhaft, so sage man es rund heraus. Man vermeide ja, etwas als sicher und gewiss hinzustellen, was nur eine Annahme, eine persönliche Meinung ist.

$5^{\circ}$ Man versäume und vernachlässige keine Beobachtung; bei der Rückkehr, wenn man die Resultate sammeln, resumiren

1) Instructions générales, pag. 87. 
und generalisiren will, werden rorhandene Lücken fühlbar und man bedauert dann zu spät, eine Beobachtung unterlassen zu haben, die man leicht hätte machen können.

Es ist kaum möglich, zum Voraus in allgemein-gültiger Weise Gang und Reihenfolge der Beobachtungen zu fixiren. Ganz zufüllig können sich vorzügliche Arlässe zu Beohachtungen darbieten. Wollte man sie unbenützt lassen, weil sie nicht in das Programm passen und daher ungelegen kommen, so wäre das ein grosser Fehler. Andrerseits soll man auch nicht auf's Gerathewohl auf Beobachtungen ausgehen. Man muss einen Plan aufstellen, der es möglich macht, viel zu sehen: man muss aber auch gelegentlich daron abzugehen wissen, muss Aug und Ohr immer offen halten für Alles, was sich zufällig und ausnahmsweise darbieten könnte.

-Unterwegs denke ich, mich zu unterhalten - sagt uns Baron ron Hübner in der Vorrede zu seinem schünen Werke -Spaziergang um die Welt" — d. h. die merkwürdigen und für mich neuen Dinge zu sehen, und jeden Abend schreibe ich in mein Notizheft, was ich am Tage gesehen habe und was man mir sagte."

Wie oben bemerkt wurde, ist es zu empfehlen, dass man nicht eimmal den Ahend abwarte, um seine Notizen und Erinnerungen aufzuzeichnen. Inzwischen könnten sich ja Hindernisse einstellen, und häufig wird man nach einem anstrengenden Reisetag nicht dazu aufgelegt sein, das Tagebuch nachzuführen; man würde es dann neuerdings rerschiehen, diesmal auf den folgenden Tag. Besser man mache nur kurze Notizen, aber diese möglichst bald.

Mit rollem Recht sagt Dr. P. Güssfeldt ${ }^{1}$ ): „Drei Reggeln, dünkt uns, sollten mit goldenen Lettern jedem Tagebuch rorgedruckt sein :

Ein Reisender hat liein Geclächtniss ${ }^{2}$ ).

Nichts ist so gering, dass es nicht werth wäre, notirt zu werden.

1) Verhandlungen der Gesellschaft für Erdkunde zu Berlin 1878, Nr. 10, S. 9.

2) "Trust no memory", ruft Ch. Darwin. Yor der Unverlässlichkeit des Gedāchtnisses kann in der That kaum zu sehr gewarnt werden. Viele sind, welche mit (C. 5. Sonklar (Kettler, Zeitschrift für wissenschaftliche Geographie 1850, S. 215) sprechen: Ich selbst habe die Wahrheit dieser Bemerkung oft erprobt. 
Alle Notizen, die im Laufe des Tages genommen sind, müssen am Abend durchgelesen und evweitert werden."

So riskirt man nicht, dass man, wenn man tagüber Vieles hörte und sah, die Dinge mit einander verwechselt oder sie zum Theil vergisst; zudem wird man auf diese Art den Geist frei und frisch erhalten für Alles, was neu auftaucht und man wird Abends, wo man Schlaf und Ruhe nöthig hat, nicht durch Gedanken an eine noch unerledigte Arbeit belästigt werden.

$\mathrm{Zu}$ empfehlen ist es aber, dass man Abends die am Tage gemachten Notizen überlese, um bei noch frischer Erinnerung allfällige Lücken auszufüllen und unleserliche oder ungenaue Angaben zu korrigiren. Später, in Zeiten unfreiwilliger Unthätigkeit, kann man in Musse diese kurzen Notizen weiter ausführen und zu einem Reisetagebuch entwickeln.

Wir unterscheiden also zwischen

$1^{\circ}$ den laufenden Notizen einerseits,

$2^{\circ}$ dem eigentlichen Reisejournal andrerseits.

Für jene Notizen genügt ein kleines Taschenbuch mit einem Bleistift, das man im Knopfloch hängen hat, damit es immer zur Hand ist. Bei etwelcher Lebung kann man sogar im Reiten oder Fahren Notizen machen. Nur muss man nicht zu enge ineinander schreiben, sondern Zwischenraum oder einen freien Rand lassen, um ein Wort oder einelı Satz, den man vergessen hat, in leserlicher Weise nachträglich anbringen $\mathrm{zu}$ können.

Für das Reisejournal oder die vervollständigte und detaillirte Reinschrift der Notizen soll man soviel als möglich die Feder anwenden. In Ermanglung von Tinte oder eines Surrogates derselben bedient man sich hiebei eines harten Bleistiftes, damit die Schriftzüge nicht verwischt und ausgelöscht werden. Einige Reisende empfehlen den Gebrauch loser numerirter Blätter, statt eines Heftes oder gebundenen Buches. Diese Blätter, sagen sie, bieten den Vortheil, dass man dabei weniger riskirt, sein ganzes Tagebuch zu rerlieren, und den Verlust einzelner fliegender Blätter kann man eher wieder gut machen, indem man die betreffenden Partien neu redigirt an der Hand des Heftes mit den laufenden 
Yotizen, welches man für alle Fälle aufhewahrt. ${ }^{1}$ ) Wenn man an die grosse Widerwärtigkeit denkt, das Reisetagebuch, die Frucht langer und mühsamer Arbeit, zu verlieren, so wird man die Vorsichtsmassregel nicht überflüssig finden, dass man immer einen Theil des Journals oder einen Doppel desselben an einen sichern Ort in Verwahrung gibt.

Nan wird daher bei sich darbietender Gelegenlreit die schon redigirten Blätter einem Konsulat übergeben. Am Besten wäre es, das Journal mit Kopirtinte zu schreiben (die gewöhnliche Tinte bedarf nur eines Zusatzes ron gejulvertem ('ummi arabicum oder gestampftem Zucker) und Blatt für Blatt auf befeuchtetem L'apier zu reproduziren, auf welches man die beschriebene Seite legt, während man mit der Hand über die Rückseite fährt. Man erhielte so ein Duplikat, welches nach Europa gesandt werden könnte, wïhrend das Original bis zum Zeitpunkt der Rückreise an einem sichereren Orte deponirt würde.

Welches Verfahren man aber auch in dieser Beziehung einschlage, jedenfalls soll das Reisejournal in sorgfältiger Ordnung, in klarer und übersichtlicher Weise greführt werden, sowohl damit man sich selhst darin leicht zurecht finde, als auch danit die Angaben desselloen von Andern verwerthet werden kömen, wenn man selber nicht dazu gelangen würde, sie zu publiziren. - Ein alphabetisches Inlaaltsverzeichniss, das stets auf dem Laufenden zu erhalten ist, erleichtert das Nachsuchen und erspart Wiederholungen, die sonst selten aushleiben; ebenso erleichtert es die Gruppirung des Stoffes, welche später nöthig wird, wenn man einen allgemeinen Bericht oder Alriss der Reiseergebnisse verfassen will. Wir bemerken hier, dass ein Reisejournal, d. h. ein Bericht über die täglichen Erlebnisse, üher das, was man sah und hörte, zwar von grossem Xutzen für den Reisenden sellsst ist, dass aber die interessantesten Beschreibungen und Erzählungen, in dieser Form dargeboten, ungeniesshar würden und die Leserwelt daran wenigg Geschmack findet. Daher hat man nach der Rückkehr die gresammelten Materialien neu zu ordnen,

1) Bedient man sich aber eines Heftes oder Buches, so ist für manche Fäle die kaufmänische Methode zu empfehlen, wonach man in der Buchhaltung dem einzelnen bestimmten Gegenstande je eine ganze Seite widmet und auf jeder colehen Seite Hinweisungsziffern anbringt in Betreff der andern Pagina, welehe rür den gleichen Zweck bestimmt sind. 
um daraus ein Ganzes zu gestalten. (Vergl. Anmerkung S. 169). Aber vor der Rückreise darf man nicht unterlassen, die Notizen zu durchgehen und sie bis in die kleinsten Einzelheiten zu vervollständigen. Diese Arbeit darf nicht auf eine spätere Zeit verschoben werden; denn ist man wieder zurückgekehrt in die Heimat und ihr Medium, in das zivilisirte Leben, so erblassen die Eindrücke dessen, was man erlebt, bald erscheint Alles, was man gesehen und erfahren hat, nur wie ein Traum; die Einzelheiten des Bildes verflüchtigen sich, wenn man sie auch festhalten will. 


\section{DAS LAND.}

\section{A G E.}

Zum Ersten, womit sich im Allgemeinen ein Reisender befassen muss, gehört es, dass er die geornaphische Lage des Ortes, der Gegend oder des Landes, welches er besucht und das er beschreiben will, kennen lernt und angibt. Ich sage, „im Allgemeinen"; denn es gibt Lokalitäten und Gegenden, deren geographische Lage als Jedermann bekannt anzusehen ist, so dass es naïv erscheinen würde, wenn man dieselbe angeben wollte. Solche Fälle ausgenommen, ist es aber immer gut, die geographische Lage, um die es sich handelt, zu bezeichnen.

Diese Bezeichnung kann relativ oder absolut sein.

Relatir ist sie, wenn sie sich auf andere Orte bezieht, z. B.: Villafranca, am Golf ron Genua, $2 \mathrm{Km}$ östlich von Nizza; Retimo, auf der Insel Kreta, $70 \mathrm{Km}$ südwestlich ron Kandia; der Canigou, ein Hauptoipfel der Ostpyrenäen, in der Landschaft Roussillon; die Insel Oesel in der Ostsee, am Eingang des rigaischen Meerbusens; Copiapo, in nördlichen Chile, am gleichnamigen Flusse, $8 \mathrm{Km}$ ostwärts von dessen Mündung. Diese Bezeichnungsweise ist, wie man sieht, höchst einfach; sie besteht lediglich darin, dass man angibt, bei welcher Stadt, bei welchem Berg, Fluss, Golf etc. der in Rede stehende Ort sich befindet oder in welchem Erdtheil und in welcher Gegend das fragliche geographische Objekt liegt.

Die absolute oder mathematische Position eines Ortes ist dessen Lage auf der Oberfäche der Erdkugel in Bezug auf das Gradnetz (Parallelkreise und Meridiane, bezw. Aequator und 
Nullmeridian), bezeichnet durch die Angabe der geographichen Bieite und Iü̈nge; man kann noch die absolute Höhe hinzufügen; diese drei Angaben zusammen (oder auch nur die erstern zwei) heissen die geographischen Koordinaten des Ortes. Z. B. Quito, die Hauptstadt der südamerikanischen Republik Ecuador, liegt unter $0^{\circ} 14^{\prime} 0^{\prime \prime}$ südl. Br., $81^{\circ} 5^{\prime} 30^{\prime \prime}$ westl. Lg. von Paris und $2908 \mathrm{~m}$ ü. M.; Teheran, die Hauptstadt von Persien, unter $35^{\circ} 40^{\prime} 44^{\prime \prime}$ n. Br., $49^{\circ} 7^{\prime} 15^{\prime \prime}$ ö. Lg. von Paris und $1229 \mathrm{~m}$ ü. M.

Handelt es sich um einen wichtigen Ort, dessen geographische Lage noch ungenügend bekannt ist, so muss diese ermittelt werden durch astronomische Beobachtung and genaue Messung, wie das im ersten Abschnitt (Vorbereitung) auseinandergesetzt wurde hinsichtlich der Breiten und Längen (pag. 79 ff.) wie in Bezug auf die Höhenbestimmung (pag. 49 ff.).

$\mathrm{Zu}$ diesem Zwecke wählt man einen jederzeit leicht aufzufindenden fixen Punkt, wie einen Kirchthurm, Leuchtthurm u. dgl. Der Angabe füge man bei, ob es sich um nördliche oder südliche Breite (n. Br. oder s. Br.) handelt, d. h. ob die Zahl der Grade $\left({ }^{\circ}\right)$, Bogenminuten (') und Bogensekunden (") vom Aequator aus gegen den nördlichen oder südlichen Pol hin zu zählen sei; auf welchen Anfangsmeridian sich die Länge beziehe, ob auf den von Paris, von Greenwich oder einen andern, und ob die Länge östlich oder westlich (ö. Lg., w. Lg.) sei. Was die Höhe betrifft, so muss gesagt werden, ob sie für den Boden oder für den höchsten Punkt des Gebäudes gilt und im letzteren Fall, wie hoch dieser Punkt über dem Boden sich befindet.

Für weniger wichtige Oertlichkeiten genügt eine relative Bezeichnung der Lage, so zwar, dass man sich hiebei auf Punkte bezieht, deren Position festgestellt ist. Man hat dann die Richtung der geraden Linie vom Ausgangspunkt nach der fraglichen Lokalität anzugeben.

Die geographische Lage einer Gegend wird bestimmt

$1^{\circ}$ relativ, durch Angabe der Position von Bergen, Flüssen, Meeren und Grenzgebieten im Norden und Süden, Osten und Westen derselben;

$2^{\circ}$ absolut, durch Angabe der Parallel- oder Breitenkreise und der Meridiane oder Längenkreise, zwischen welchen sie liegt. 


\section{GRENZEN UND GRÖSSE.}

Von der Gegend, die man als Beobachtungsugebiet erwählt hat, wird man nach der geographischen Lage zunächst Grenzen und Grösse angeben.

Die Grenzen sind theils natürliche, theils kiünstliche. Natürliche oder physische Grenzen sind diejenigen, welche gebildet werden durch Berge und Gewässer, künstliche Grenzen solche, welche durch blos gedachte Linien zwischen zwei Punkten bezeichnet resp. vereinbart werden. Die politischen Grenzen können auf kürzern oder längern Strecken natürliche sein; sehr selten sind sie es in ihrem ganzen Verlauf, es sei denn, dass eine einzelne Insel einen Staat für sich bilde. Zumeist sind die Grenzen grossentheils künstliche. Die nordamerikanischen Unionsstaaten haben als solche häufig Meridiane und Parallelkreise benutzt, wie ein Blick auf die Karte derselben sofort zeigt.

Der Reisende wird, je nach seinem Zweck, die eine oder andere Grenzbezeichnung anwenden, um das Gebiet zu umschreiben, anf welches sich seine Beobachtungen erstrecken. schildert er eine Insel, ein Delta, Thal u. s. f., so machen sich von selhst die natürlichen Grenzen geltend; beschreibt el aber ein Land, eine Provinz oder einen Kanton, so muss er die künstlichen politischen oder administrativen Grenzen berücksichtigen. Meistens genügt die Betrachtung der Karte, - wenn diese gut ist - um die natürlichen wie die künstlichen Grenzen zu erkemmen, und man braucht sie blos aufzuführen. Wenn aber eine Karte fehlt oder zu Zweifeln an ihrer Richtigkeit Anlass gibt, so muss man anders verfahren.

Die natürlichen Grenzen kann man, da sie augenfällige Dinge sind, bei der Besichtigung des Terrains kennen lernen und topographisch aufnehmen; die künstlichen Grenzen aber fallen - abgesehen ron den Punkten, wo Marksteine angebracht sind - nicht so in's Auge und man muss sie desshalb durch Erkundigungen kennen lernen. In der Regel beruhen solche Grenzen auf einem Vertrage zwischen zwei Staaten. In diesen Fällen wird man die genaue Grenzbestimmung aus den amtlichen Alten entnehmen kömnen. Eine solche Grenze zieht sich manchmal zwischen bestimmten Punkten in gerader Richtung hin, manchmal aber verläuft sie zwischen diesen Punkten 
krummlinig, hin- und hergebogen. So war vor dem Kriege von 1879-81 die Grenze zwischen Chile und Bolivia eine gerade Linie, welche mit dem Parallelkreis ron $24^{\circ} \mathrm{s}$. Br. zusammenfiel; die südöstliche Grenze der zentralamerikanischen Republik Costarica ist eine gerade Linie, welche rom Cap Burica am Grossen Ozean (Golfo Dulce) aus quer durch das Land in der Richtung nach der Insel Escudo de Veragua im Antillenmeer sich hinzieht; im Gegensatz hiezu sind z. B. die Grenzen der Schweiz sehr wunderlich gestaltet. Man muss also nicht allein in Erfahrung bringen, welches die Hauptgrenzpunkte seien, sondern auch, welchen Verlauf die Grenzlinie zwischen denselben nehme. Die politischen Grenzen können zudem wechseln. Man muss sich also auch darüber informiren, ob etwa seit dem Abschluss des Hauptvertrages Zusatzartikel oder eine partiale Revision des Vertrages rereinbart worden seien.

Nicht selten, namentlich in noch unzivilisirten Ländern, kommt es vor, dass die Grenzen lediglich auf mündlichem oder stillschweigendem Uebereinkommen beruhen und dass keine Aktenstücke vorhanden sind, die man hierüber zu Rathe ziehen könnte. Auch sind die Grenzen dann oft unbestimmte und willkürlich angenommene, folglich zweifelhaft und streitig, wie z. B. die Grenzen zwischen China und Japan, die zwischen Egspten einerseits, Tripolis und Abyssinien andererseits, die Südgrenze von Algerien u. s. w.

In solchen Fällen werden natürlich die Angaben verschieden ausfallen, je nachdem man sie von der einen oder andern interessirten Partei erhält. Will man sich also nicht der Gefahr aussetzen, zu Irrthümern und ungenauen Angaben verleitet zu werden, so muss man Erkundigungen an verschiedenen Quellen einholen und die divergirenden Meinungen erwähnen, welche über die Grenzen der uns beschäftigenden Territorien bestehen.

Ist einmal das Beobachtungsgebict genau umschrieben, so erübrigt zunächst die Kenntnissnahme und Angabe seiner Ausdehnung oder Grösse, wenigstens in annähernder Weise.

Die Grösse eines Thales, einer Insel, eines Landes wird bezeichnet durch Angabe entweder seiner maximalen und mittlern Dimensionen nach Länge und Breite oder seines Flächeninhalts (Areals). 
Hat man eine Karte der Gegend oder ein Croquis, welches nach den Aufschlïssen über die Grenzen erstellt wurde, so sind damit die Lmrisse, die Form des Ganzen gegeben, und es sind daraus die Dimensionen und der Flächeninhalt zu entnehmen.

Wenn man sich hierüher Angaben verschaffen kanm, die auf neuern geodätischen Arbeiten und Katastervermessungen beruhen, so wird man es nicht unterlassen, dabei indess sorgfältig die Quelle bezeichnen, ans der man schöpfte. Sind aber solche Angaben nicht erhältlich, so wird man das Areal des Territoriums aus der Karte oder dem Croquis in der Weise ableiten, wie dies in Betreff der Flächenberechnung oben (pag. 64 bis 71) gezeigt wurde. Sehr bequem erweisen sich hiehei die Planimeter, ron welchen Instrumenten namentlich der Polarplanimeter des Professor Amsler in Schaffhausen zu empfehlen ist. (Vgl. S. 71, Anmerkung.)

Da man immer bestrebt sein muss, vollständigere und genauere Angaben als die schon vorhandenen zu liefern, so darf man nie unterlassen, die Berichte der Vorgänger zu verifiziren und nöthigenfalls zu korrigiren.

\section{EINTHEILUNG DES LANDES.}

Es gibt, wie natürliche und künstliche Grenzen, so auch natürliche (physische) und künstliche (politische oder administrative) Eintheilungen eines Lardes.

Man kann unterscheiden:

orographisch und hypsometrisch - ebene, Hügel- und Bergregionen;

hydrographisch - Flussgebiete;

geographisch - nördliche und südliche, östliche, westliche und zentrale Gebiete;

nach Beschaffenheit und Kultur des Bordens - Sandebenen, Haiden, Sümpfe und Torfmoore, Steppen, Wiesen-, Ackerund Rebgelände, Wälder, Gebirce, Gletscher u. s. w.

Und das Land kann eingetheilt sein:

politisch - in Staaten, Provinzen, Herzogthümer, Grafschaften, Departemente, Kantone und Gemeinden; administratiy - in Bezirke und Kreise, Diözesen und Kirchspiele etc. 
Die Art der Eintheilung, welche man wählt, richtet sich nach den Gesichtspunkten und der Auffassung des Ganzen. Jenachdem wird man das Gebiet gliedern und ordnen, Lage und Naturcharakter oder aber politische und administrative Eintheilung hervorheben, welche sehr oft ausserhalb des betreffenden Landes, ziemlich unbekannt sind.

\section{KONFIGURATION DES LANDES.}

\section{TOPOGRAPHIE.}

Unter der Konfiguration eines Landes verstehen wir dessen Gestaltung in Bezug sowohl auf seine Grenzen (Kontouren) als auch auf sein Bodenrelief. Man bezeichnet das Eine als horizontale, das Andere als vertikale Konfiguration. Es handelt sich dabei also sowohl um Linien (Küsten und Grenzen, Richtung von Bergketten und Flüssen etc.), als auch um plastische Formen (Ebenen, Bassins, Gebirge, Tafelländer, Thäler etc.)

Das Bild, das hiemit in grossen Zügen gegeben ist, wird dann vervollständigt durch kleinere, aber immerhin charakteristische Elemente wie Schluchten, Hügel, Bäche u. s. w., endlich durch die Linien, welche die Hand des Menschen in der Landschaft zog (Strassen, Eisenbahnen, Kanäle) und durch die Bauwerke, welche er in sie hineinstellt.

Das Studium der Konfiguration oder Gliederung eines Landes ist unbedingt nothwendig als Basis für alle andern Beobachtungen; es ist auch unerlässlich, wenn man eine richtige Vorstellung von dem bereisten Lande gewinnen und geben will.

Rekognoszirungen. Um sich ein Bild von der Konfiguration eines Landes zu verschaffen, muss man dasselbe in allen Richtungen bereisen und möglichst viele Höhenpunkte aufsuchen (Kirchthürme, Leuchtthürme, Hügel, Berge), von wo das Auge einen grossen Theil des Gebietes übersieht.

Aus dem Chaos von Linien und Formen, welches da vor unseren Augen liegt und welches beim ersten Anblick unentwirrbar scheinen kann, werden wir bald gewisse Hauptzüge herausfinden. Eine Uferlinie oder eine Bergkette begrenzen 
das Beobachtungsfeld. Wasseradern und grosse Faltungen des Bodens zerlegen es in Unterabtheilungen. Man geht von den grossen Massen zu den Einzelheiten über und erhält so ein Netz, dessen Maschen immer dichter werden und in welches auch isolirte und geringfügige Objekte sich einbeziehen lassen. So gelangt man dazu, das Ganze zu umfassen und sich zurechtzufinden in dem, was anfänglich ein Labyrinth schien.

Man muss durchaus auf Berggipfel steigen, wenn man die grossen Züge der Bodengestalt eines Landes, gewissermassen das Gerippe oder Gebälke desselben, richtig erkennen will. Von Punkten der Ebene aus überblickt man immer nur zu beschränkte Gebiete; man sieht wohl die Kontouren einer Bergkette, aber man gewinnt keine Vorstellung ron ihrem Streichen und ihrer Verzweigung. Befinden wir uns aber auf dem Gipfel eines Berges, so liegt die weite Gegend ausgebreitet vor unsern Augen; die Details verschwinden, und die grossen Züge treten hervor. Je mehr man sich erheht, um so mehr gleicht das Land zu unsern Füssen einer topographischen Karte; auf diese Weise also, durch Berghesteigungen, erhält man eine Vorstellung von einem Lande, welche als getreues Bild desselben gelten kann.

\section{Prüfung und Berichtigung vorhandener Karten.} Wir nehmen an, der Reisende habe sich ron der Gegend, die er besucht, die besten Karten verschafft, namentlich die detaillirtesten. Man findet fast für jedes Land General- oder Spezialkarten, welche mehr oder minder dem Zwecke des Reisenden entsprechen. Das Erste, was man nun zu thun hat, ist, dass man die Karte an Ort und Stelle auf ihre renauigkeit prüft und sie nöthigenfalls ${ }^{1}$ ) berichtigt oder

1) Wir stimmen vollständig überein mit C. v. Sonklar,! wenn dieser (a. a. O. ag. 215) sagt, dass die "Rektifikation bestehender Karten ${ }^{*}$ nur jene Kartenwerke :um Gegenstande hat, welehe nicht auf dem Wege regclmässiger Landesaufnahmen, ondern nur durch die Compilation dürftiger graphischer Materialien, schwankender tinerarien, von Reiseberichten und dgl. zu Stande gekommen sind, wie es z. B. elbst in Furopa mit den Karten von grossen Theilen der türkisch-griechischen Ialbinsel noch heutzutage der Fall ist; dass jedoch, was die Karten von Gebieten rie derjenigen Europas (ausser dem genannten Theil) anbetrifft, die Reisenden zu iniger Behutsamkeit aufgefordert werden dürften vor der Lust, die bestehenden, on erfahrenen Fachmännern in Jahre langer Arbeit aufgenommenen und gezeicheten Karten ${ }_{n} z u$ schulmeistern. ${ }^{\mu}$ Indessen weist auch Sonklar an anderer Stelle Anleitung $2 u$ wissenschaftlichen Beobachtungen in den Alpen S. 3) darauf hin, ass z. B. mitunter in einer Karte die Verbindung zweier Gebirgsketten unrichtig argestellt sei. „Dies wird $z$. B. dann der Fall sein, wenn die Karte als den notempunkt zweier Ketten nicht den wahren, sondern einen andern nahestehenden ipfel angibt; hier wird die entsprechende Bemerkung am Platze sein." Dass die 
ergänzt. Während der Reise ziehe man die Karte häufig zu Rathe und mache man keine Exkursionen ohne sie. Vor jeder Exkursion fertige man nach den rorhandenen Karten ein Croquis in grossem Massstabe an über die Gegend, die man dabei erforschen will. Je grösser man den Massstab wählt, desto mehr treten die Ungenauigkeiten der Karte hervor und desto grössern Werth haben die Berichtigungen, welche man - wenn auch nur de visu - anbringt, für eine Korrektur der Originalkarte. Man kann in dem Croquis die Linien nur schwach bezeichnen und sie dann stärker ausziehen, nachdem man sie als richtig erkannt hat, indem man diejenigen auswischt, welche korrigirt resp. durch andere ersetzt werden müssen; auf diese Weise bringt man ron jeder Exkursion eine klare und getreue Skizze der durchwanderten Gegend zurück.

An Aussichtspunkten angelangt, ron wo man einen weiten Landstrich überblickt, wird man, falls das nicht bereits geschah, den Massstab der Karte wohl in's Auge fassen, um sich eine richtige Vorstellung zu verschaffen von dem Grössenverhältniss zwischen der Gegend, die vor unsern Augen liegt, und ihrer Darstellung in der Karte. Wenn der Massstab nicht Kilometer, sondern Stunden, Meilen, Werste etc. angibt, so verwandle man diese in Kilometer, wozu die Reduktionstafeln $(I X$, d) im Anhang dieses Buches dienen. Ist die Verjüngung (Reduktion) in Bruchform angegeben, so muss man nur den Nenner dieses Bruches durch 1000 dividiren, um eine Zahl zu erhalten, welche die Länge auf dem Terrain bezeichnet, die auf dem Papier durch $1 \mathrm{~mm}$ dargestellt ist. Die englischen Karten des Survey Office z. B. sind in 1/63360 gezeichnet, so dass ein englischer Zoll eine englische Meile repräsentirt (one-inch-map, Einzoll-Karte); hier ist nun $1 \mathrm{~mm}$ auf dem Papier gleich $63360: 1000=63,360 \mathrm{~m}$ auf dem Terrain. Ist gar kein Massstab angegeben, so misst man die wirkliche. Distanz zwischen zwei in der Karte bezeichneten Punkten. Die Entfernung dieser Punlite auf dem Papier sei $20 \mathrm{~mm}$,

Prüfung der Karte auf ihre Follständigkeit zu sehr wünschenswerthen Ergänzungen namentlich hinsichtlich der Höhenverhältnisse (Sattelhöhen) führen kann, wird ebendaselbst bemerkt (S. 3); aber auch im ebenen Lande bietet sich nicht selten Gelegenheit zu Ergänzungen von Karten, die oft viele Jahrzehnte nicht fortgeführt wurden und so manches Neue (Verkehrswege, Aenderungen in Wasserläufen u. dgl.) noch nicht enthalten. Fgl. Jordan, a. a. O. I. S. 696. 
die wirkliche Distanz derselben auf dem Terrain $815 \mathrm{~m}$, so stellen also $20 \mathrm{~mm}$ der Zeichnung eine wirkliche Grösse ron $815 \mathrm{~m}$ vor, $1 \mathrm{~mm}$ also $40,75 \mathrm{~m}$. Ist die Aequidistanz der Niveaukurven nicht bekamnt, so zählt man die Kurven oder Schraffenreihen zwischen zwei Punkten mit beigefügten Coten (Höhenzahlen); man rundet die Coten ab, hestimmt hierauf die Differenz dieser beiden Höhenzahlen und theilt dieselhe durch die Anzahl jener Kurven oder Schraffenlagen. Es seien z. B. zwei Punkte bezeichnet durch die Coten $758 \mathrm{~m}$ wind $1218 \mathrm{~m}$ und dazwischen finde man 9 Horizontalkurven oder Schraffenreihen. Da man weiss, dass den Niveaulinien immer eine runde Höhenzahl zukommt, so ersetzt man 758 durch 760, 1218 durch 1210 ; die Differenz $1210-760=450$, getheilt durch 9, gibt eine Aequidistanz von $50 \mathrm{~m}$. Auf diese Weise findet man z. B. für die Schweizerkarte in $1 / 100000$ (Dufour-Karte), dass eine Schraffenlage im Hochgebirge $40 \mathrm{~m}$, eine solche im Hügellande $25 \mathrm{~m}$ Aequidistanz bezeichnet. Ian beachte auch die Legende der Karte wohl, damit man weiss, was gewisse Zeichen, Ziffern und Abkürzungen bedeuten, inshesondere aber, ob die Höhenangaben auf den Neeresspiegel bezogen sind order auf einen andern See und ob sie in Metern ausgedrückt sind oder in andern Einheiten, die man nöthigenfalls umrechnet. Dasselbe gilt ron den Zahlen für die Tiefen der Seen u. s. w. - Alles das erfordert weniger Zeit in Wirklichkeit, als für diese Auseinandersetzung nöthig war.

Nach diesen Vorbereitungen orientirt man sich, wie das oben S. 22 auseinandergesetzt wurde; dann visirt man nach allen markauten Punkten, um sich zu überzeugen, dass sie sich in der Richtung befinden, welche die Karte für sie angibt. Zu diesem Zwecke bedient man sich eines Kompasses mit Dioptern zur Aufnahme der verschiedenen Winkel, unter welchen man die Objekte gegeneinander oder in Bezug auf den Meridian erblickt. Diese Winkelbestimmung bezeichnet man als das Peil'n der betreffenden Punkte. Nit dem Transporteur prïft man nachher, ob man auf der Karte oder den Crorfuis für dieselben Gegenstände die nämlichen Winkel erhält. In Ermanglung eines Kompasses breitet man die Karte oder das Crorfuis flach aus, bezeichnet mit einer Nadel den Punkt auf dem Papier, welcher dem Orte der Beohachtung entspricht, und mit einer zweiten Nadel einen zweiten Punkt, woselbst 
sich das Bild eines Objektes befindet, welches man in der Ferne gewahrt, eines Berggipfels, Thurmes u. dgl. Dann dreht man die Karte so, dass dieser Gegenstand in die Richtung der beiden Nadeln kommt und fixirt sie nun in dieser Lage derart, dass keine Verschiebung stattfinden kann. Hierauf bringt man in den rerschiedenen Punkten, deren Lage man verifiziren will, Nadeln an und visirt über sie nach den entsprechenden Punkten. Auf diese Art bemerkt man, ob sie sich in der durch die Nadeln bezeichneten Visirlinie befinden oder nicht. Wenn die Karte genau ist, so muss man jede im Bilde enthaltene Lokalität auf dem Terrain in der Richtung erblicken, welche angegeben wird durch die Tadel, welche den Stationsort und diejenige, welche die dargestellte Lokalität bezeichnet. Trifft dies nun nicht $\mathrm{zu}$, so korrigirt man die Karte, indem man die zweite Nadel so

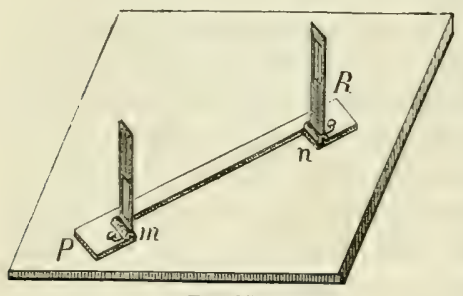

Fig. 87 . weit nach links oder rechts verschiebt, bis sie beim Visiren mit dem fraglichen Objekte koïnzidirt. Diese korrigirte Richtung ist sodann in der Karte vorzumerken. Man wendet auch ein mit Dioptern oder Fernrohr versehenes Lineal (Fig. $87)$ an. Dasselbe wird so placirt, dass seine innere Kante $n m$ durch die beiden Punkte der Karte geht, deren Lage zu einander man prüfen will. Diese Operation wiederholt man nun von andern Stationspunkten aus und man erhält so für einen und denselben Punkt 3-4 Alignements; wo diese Linien sich schneiden, ist die richtige Position des Kartenzeichens für den betreffenden Terrainpunkt, rolausgesetzt, dass man die Stationsorte in der Karte exakt bestimmt habe. Wären diese Stationspunkte falsch angegeben, so würde man dies bald daran wahrnehmen, dass die Visirlinien nach Objekten, deren Lage schon von andern Punkten aus rerifizirt wurde, nicht durch die Schnittpunkte gehen, in welchen die von jenen Punkten aus nach den fraglichen Objekten gezogenen Linien zusammentreffen. In einem solchen Fall müsste man vorerst die Position des neuen Stationspunktes richtig bestimmen, entweder durch 
Abschätzen seiner Entfernung ron einigen der früheren Stationen oder durch Messung der Winkel, welche er mit solchen bildet. Mit Bezug auf die so in ziemlicher Anzahl festgestellten Fixpunkte untersucht man nun auch Lage und Richtung ron Flüssen, Strassen etc., dabei wird man sich entweder von der Korrektheit der Karte überzeugen, deren Werth bei dieser Kontrole nur gewinnen kann, oder man wird sie in wesentlichen Punkten korrigiren und eine bessere Bearbeitung derselben liefern können.

Topographische Aufnahmen. Wenn über eine Gegend keine detaillirten Karten vorhanden sind oder wenn Zweifel bestehen an der Verlässlichkeit der von früheren Reisenden grelieferten Karten, so schreitet man selber zu topographischen Aufnahmen.

Es bieten sich hiebei zwei Fälle dar:

$1^{\circ}$ Entweder beschränkt man sich darauf, das Land in gewissen Richtungen zu durchwandern, ohne sich hievon weit nach links oder rechts zu entfernen; mit anderen Worten man nimmt einfach die Narschroute, das Itinerar auf;

$2^{\circ}$ oder man stationirt in einigen Punkten, von wo aus man Exkursionen nach allen Richtungen macht und nimmt die so erforschten Gegenden auf.

Aufnahme der Marschroute (Wegekarten, Itinerare ${ }^{\mathbf{1}}$ ). Als Ausgangspunkt wählt man einen Ort, dessen geographische Lage man genau kennt, sei es aus schon rorhandenen Karten oder auf Grund eigener Bestimmung seiner Breite, Länge und, soweit möglich, auch seiner Höhe. Die Wahl eines solchen Ausgangspunktes ist unerlässlich, wenn das Itinerar, welches zu publiziren ist, sich an schon bestehende Karten anschliessen und dieselben ergänzen oder berichtigen soll.

Bei der Aufnahme selber wendet man die auf S. 58, Ziff. 2, besprochene Methode an. Die Richtung des Weges, heziehungsweise der Begehungslinie eines Cmfangspolygons, hestimmt man mit dem Kompass ${ }^{2}$ ), die Entfernungen durch

1) Ueher die Rolle und die Bedeutung der Itinerare für die (ieschichte der Kartographie rgl. die \$. 136 erwähnte ,Iundschau für Geographie und Statistikvon Jr. C. Irendts, München 18so, Heft I die kartographische Darstellung der Erdoberfliche von Ior. Wolkenhauer).

2) Giht man zu Fusse, so kann man die Stockboussole (S. 35) anwenden. Die Boussole selbst trïgt man in der Tasche, den als statir dienenden stock fübrt 
Angabe der Zeit, die man brauchte, um sie zurückzulegen, wobei je die Zeitpunkte der Abreise und der Ankunft, nicht blos die dazwischen liegende Zeit vorzumerken ist, da sich sonst leicht Irrthümer einschleichen könnten, namentlich in Bezug auf den Moment der Abreise an einem Orte. Diese Zeitnotirung soll nicht nur an den beiden Fndpunkten eines Marsches vorgenommen werden, sondern bei jedem einigermassen bedeutenden Punkte des zurückgelegten Weges, insbesondere bei Ortschaften, an Gewässern und bei Richtungsänderungen der Route.

Bei jedem solchen Richtungswechsel ist der Winkel aufzunehmen, welche die eben zurückgelegte Wegstrecke mit der ror uns liegenden, beziehungsweise mit dem (magnetischen) Meridian bildet; ebenso misst man (vgl. pag. 54) oder schätzt man wenigstens das Gefälle des Weges und des Terrains zu beiden Seiten und entwirft nach dem Augenmasse eine bildliche Darstellung dieser Bodenverhältnisse.

Ausser dem auf die einzelnen Strecken verwendeten Zeitbedarfe muss man auch die Verumständungen vormerken, welche auf die Geschwindigkeit der Reise einwirken, die beschleunigenden oder verzögernden Faktoren, welche bei der Distanzberechnung in Würdigung zu ziehen sind.

Die Richtung fliessender Gewässer, längs welcher oder über welche der Weg hinführt, ist durch einen Pfeil anzugeben, dessen Spitze mit der Richtung des Wasserlaufes ïbereinstimmend gezeichnet wird.

Jedes bemerkenswerthe Objekt, welches man vom Wege aus nach links oder rechts gewahrt, soll aufgenommen werden und zwar soviel möglich immer von zwei oder drei verschiedenen Punkten aus. Namentlich gilt das von den Ortschaften durch die hindurch oder an welchen vorbei der Weg führt. Durch eine solche von verschiedenen Punkten aus wiederholte Aufnahme erhält man genaue Positionen und kann man die einfache Wegaufnahme kontroliren. Hat man ferne Objekte von verschiedenen Stellen des Weges aus gepeilt, so zieht man nach erfolgter Zeichnung der Marschroute die Peilstrahlen

man als Gehstab mit. Sohald man eine Richtung peilen will, stösst man den Stock in die Erde fest, setzt die Boussole auf und kann dann mit Leichtigkeit jede Ricbtung auf etwa $1^{0}$ genau peilen. - Jordan, a. a. O. I. Bd. S., 597. - Ueber die Verwendung von Höhenwinkeln zur Distanzbestimmung vgl. daselbst S. 706. 
für jenes Objekt und erhält nun die Situation desselben aus den mehr oder minder zusammenschliessenden Schnitten der Peilstrahlen. Entfernungen scharf begrenzter Objekte kamn man durch Triangulirung auf kleiner Basis rasch bestimmen.

Kennt man die Namen der Objekte (Dörfer, Berge etc.) nicht, welche man sieht, so bezeichnet man sie inzwischen durch Buchstaben, wobei selbstverständlich darauf zu achten ist, dass ein und derselbe, ron rerschiedenen Punkten aus gesehene Gegenstand immer denselben Buchstaben erhalte, z. B. Thurm ", Berggipfel b, Vorgehirge ". Später, nach erhaltenem Aufschluss wird man diese Buchstabenhezeichnung durch die Namen ersetzen. In Bezug auf die Namenangaben einheimischer Führer muss man freilich rorsichtig sein; oft wissen sie die Namen nicht, wollen aber das nicht merken lassen und machen dann irgend eine unrichtige Angabe. Zudem ist es nicht selten, dass rerschiedene Namen rorkommen für dasselbe Gewässer oder Gebirge bei den Bewohnem der beiden Lfer oder Abdachungen, für einen Fluss auf ein und derselhen Strecke oder auf verschiedenen Theilen seines Laufes und dass eine Lokalität hezeichnet wird mit einer Kollektivhenemung, welche der ganzen Gegend gilt. Demnach muss man sich über die geographischen Namen sorgfältig und an rerschiedenen Quellen erkundigen. Was die Art und Weise der Orthographie oder Transskription dieser Namen anbelangt, so kann man nicht genug empfehlen, dass man sich soriel als immer möglich an die Orthographie oder - wenn eine Schriftsprache mangelt — an die Aussprache der Eingebornen halte. Im ersteren Fall wird man sich den Namen, wenn er irgend welche Schwierigkeiten darbietet, mit einigen Buchstahen notiren lassen. Ist das Alphabet, welches hiebei zur Anwendung gelangt, nicht das deutsche oder englische (lateinische), so bleibt noch die Aufgahe, den fraglichen Namen mit den uns geläufigen Buchstaben auszudrücken. Man muss dann für die Laute und Zeichen, welche unserem Alphabete fehlen, Aequivalente suchen und hiefür ein Verzeichniss sorgfältig ausgewählter Beispiele grehen. Im andern Fall — wenn die fremde Sprache kein Schriftsystem hat muss man sich den Namen wiederholt und von mehr als einem Individum rorsprechen lassen und ihn hierauf in einer Weise niederschreiben, welche die Aussprache möglichst gut 


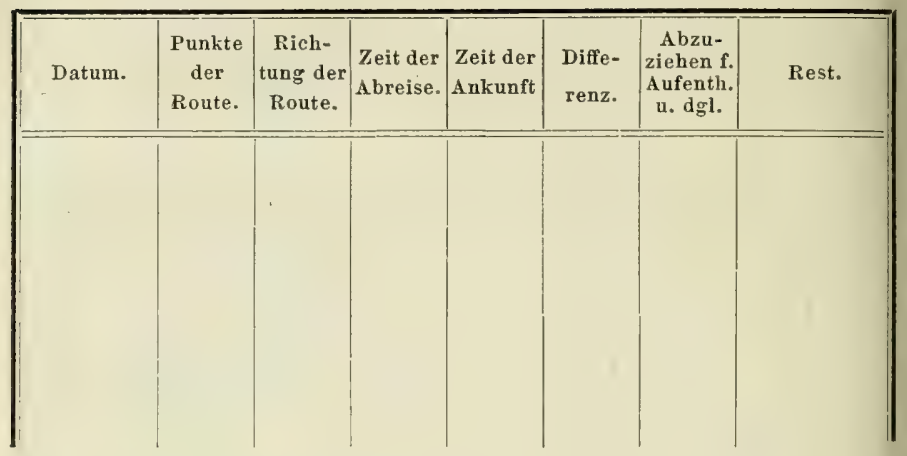

\begin{tabular}{|c|c|c|c|}
\hline $\begin{array}{c}\text { Art des } \\
\text { Reisens. }\end{array}$ & $\begin{array}{c}\text { Faktoren, } \\
\text { welche auf die } \\
\text { Geschwindigkeit } \\
\text { influirten. }\end{array}$ & $\begin{array}{c}\text { Schätzungswerth } \\
\text { des zurückgelegten } \\
\text { Weges. }\end{array}$ & Richtung. \\
\hline & & & \\
\hline & & & \\
\hline
\end{tabular}

Besondere Details betreffend

Anvisirte Punkte.

Gefälle und Niveauverhältnisse.

die Marschroute. 
(riedergibt $\left.{ }^{1}\right)$. Die einheimischen Namen haben oft eine beachtenswerthe Etymologie oder Bedeutung, die man passend in Parenthese beifügen wird.

Die unterwegs gemachten Notizen werden zweckmässigerweise tabellarisch zusammengestellt. Schemata für solche Tabellen finden sich nebenstehend S. 184.

Wo möglich entwirft man gleich während des Marsches ein Croquis über den zurückgelegten Weg und trägt unmittelbar die Notizen, ron denen wir sprachen, wie auch die Terrainbezeichnung ein. Dabei muss man sich aber wohl hüten, in das Croquis Anderes oder mehr einzutragen, als was man wirklich gesehen hat (also nicht z. B. den muthmasstichin Lauf eines Flusses), oder dann muss man wenigstens in unzweideutiger Weise bezeichnen, was blos hypothetisch ist. Besser ist es, man lasse eine Stelle leer oder rersehe sie nur mit einer Bemerkung (z. B. Hügelregion, nach Angabe der Eingebornen), als dass man die Karte mit Phantasiebildern ausstatte. Die Karte ist, auch wenn sie Lücken hat, doch ron Werth; sie beweist so, dass der Reisende es mit den Angaben, die er lieferte, genau nahm.

Bei jedem Aussichtspunkte nehme man Alles auf, was zu sehen ist, und zeichne es grleich ein. Eine solche Aufalme des ganzen Tmkreises, beziehungsweise der Winkel n demselben, heisst Horizontabschluss (tour d'horizon, Ringsufnahme). Man widmet ihr je ein besonderes Blatt im Sotizhuch oder Album, wobei man die Station so deutlich sezeichnet, dass man sie auf der allgemeinen Skizze über lie Marschroute leicht wieder findet; ferner sind auf dem Blatte die für dessen Orientirung nöthigen Notizen anzuringen. Ist ein einziges Blatt nicht ;ross genug für die Zeichnung, so immt man hiezu deren zwei bis vier. m ersteren Falle zeichnet man die itation in der Mitte einer der Langeiten des Blattes (Fig. 88); im anlern Falle kommt die Station in den

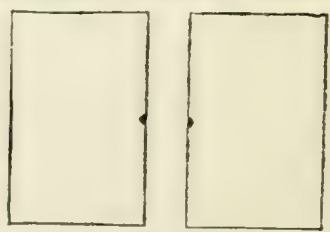

Fig. 88.

1) Vgl. hierüber den Artikel von L. Ewald in Darmstadt: Veber die Rechthrcibuny der geogriphischen Sumen in Petermann's geographischen Mittheilungen 376, XIII. pag. 297. 


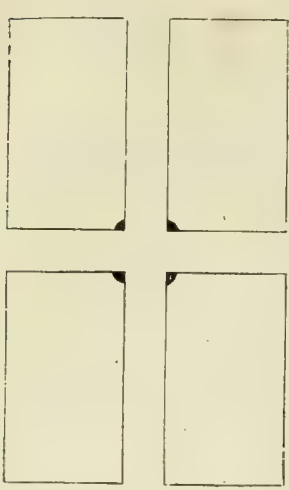

Fig. 89.

Winkel der vier Blätter (Fig. 89). Wen die Bilder der anvisirten Objekte trot Verwendung mehrerer Blätter doch übe den Raum der Zeichnung hinausfaller so trägt man die Richtung der Visil linie ein, fügt einen Pfeil bei und ein Notiz längs der Linie oder am Ran des Blattes.

Behufs Einzeichnung dieser Horj zontabschlüsse (Ringsaufnahmen) richte man das Papier so, dass die gezogene Linien in ihrem Verlaufe denjenigen at dem Terrain entsprechen (Fig. 90).

Bei der Schwierigkeit, Objekte, dere wahre Form und Dimension im perspektivischen Bilde sic nicht richtig beurtheilen lässt, in Horizontalprojektion dar zustellen, zieht man es mitunter vor, die Gegenstände s

Fig. 90. - Form des darzustellenden Terrains.
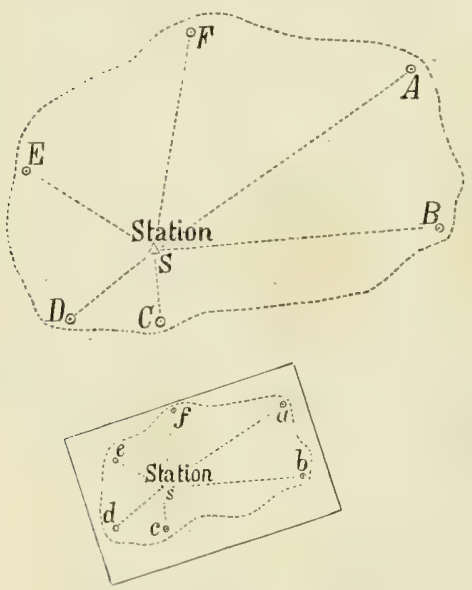

Haltung des Kartenblattes beim Zeichnen. abzubilden, wie sie demBlick erscheinen.

Mindestens einmal im Ver lauf der Reise muss man di Mittagslinic ermitteln (pas 65), um die wahre Nord Süd-Richtung zu erhalter wozu der Kompass allei nicht genügt.

Endlich hat man überal wo man sich aufhält - un wenn der Halt nur 24 Stur den dauern sollte - dieBreir und Länge zu bestimmen (pą̧ 69 ), weniger, um so die gec graphische Lage des betre: feiden Punktes anzugebel die vielleicht nicht von $B t$ deutung ist, als vielmehr uu die nöthigen Fixpunkte zu erhalten zur definitiven Feststellun des Tracés unseres Weges.

Jeden Tag ist eine Reinschrift und Reinzeichnung de Notizen anzufertigen, entweder während einer längern Ras 
NB. Die römischen Ziffern bexpichnen Stunäers des Vormittays (Morgens, von Mitternxcht bis Mittag); die arabischen solche des Nachanitirgs (Abends, , on Mittay bis Mitternacht). - Die wa are Nordrichtung ist vor dem Aufbruch am 21 Juni bestimunt roorder.

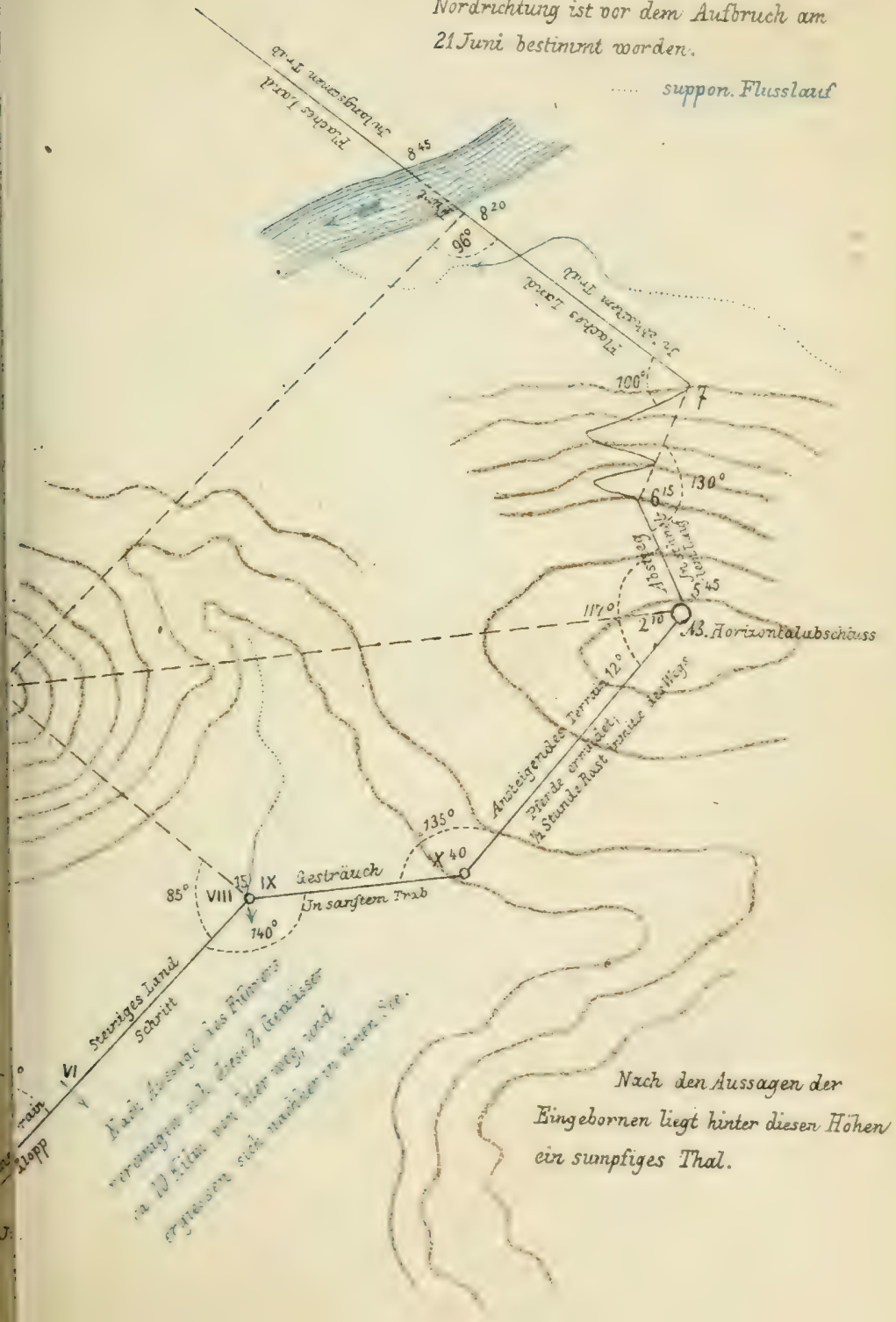



m Mittag oder Abends, im Gasthof oder Bivouak. Zu diesem wecke ïberträgt man die Notizen auf ein grosses Blatt apier (rorzüglich eignet sich sogen. endloses oder Rollenapier auf Leinwand aufgezogen) und konstruirt man die inien und Winkel mit Doppeldezimeter und Transporteur. liese alltägliche Reinschrift und Reinzeichnung der unterwegs emachten Totizen ist unerlässlich; denn wenn über eine ahl, eine Messung u.s.w. Zweifel entstehen, so kann man icht - wie bei gewöhnlichen Aufnahmen bestimmt umrenzter Terrainpartien - zu dem betreffenden Punkte zuückkehren, um an Ort und Stelle eine Kontrole vorzunehmen. Ian muss somit über'die Sache in's Reine kommen, so lange ran Alles noch frisch im Gedächtniss hat. Wemn es an Zeit ebricht, um auch die Horizontahschlïsse zu ühertragen, so fird man hei jerler Station, wo man solche aufgenommen, auf ie Blätter des Albums orler des Yotizhuches verweisen, auf ielchen sich diese Abschlüsse befinden, und man wird diese 3lätter bei Seite legren, um die Arbeit mit Musse zu vollenden.

Wem man mit dem Tracé der Narschronte an den Rand es Blattes lommt, bevor dasselbe (beziehungsweise das auf ieses Blatt grehörende Stïck derselben) ganz eingetragen st, so bringt man einen quergehenden :heilstrich an und zeichnet von dessen nderm Endpunkt aus die Fortsetzung ler Route unter Beigabe einer deutichen Hinweisung (Fig. 91). Der Ueberang von einem Blatt zum andern bietet ieine Schwierigkeiten dar; es genügt, lie beiden Ränder aneinander zu legen, :o dass sie sich berühren, ohne einInder zu bedecken. Die Blätter sind

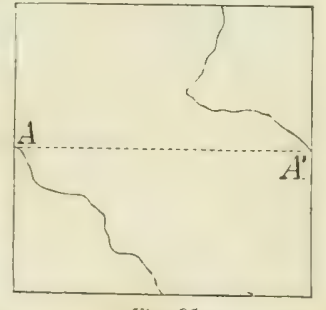

Fig. 91. : u numeriren oder sonstwie so zu bezeichnen, dass man reiss, in welcher Ordnung sie aufeinanderfolgen.

Als Beispiel für ein Croquis über eine Marschroute geben vir die nebenstehende Taf. XII.

Aufnahme der erforschten Gegend. Wenn statt einer Iarschroute der topographische Plan oder die Karte eines rewissen Gebietes aufzunehmen ist, so veranstaltet man cunächst eine iorlanfige Rekorguszirun!, wie das oben gesagt vurde (pag. 176). 
Nachdem man sich ein Bild von den Hauptlinien und -Formen verschafft hat, zerlegt man die Gesammtfläche des Terrains in wohl umschriebene Theile, die begrenzt sind durch Wasseradern, Strassen und andere scharf ausgesprochene Linien. Dann legt man sich ein Itinerarium so an, dass man denselben Weg nicht mehrmals zu machen hat.

Will man eine Triangulation vornehmen, so benutzt man die Rekognoszirung zur Auswahl eines Terrains, welches geeignet ist zur Messung einer Basis und zur Bestimmung von Dreiecks-Punkten.

Oben in dem Abschnitt "Vorbereitung" (pag. 37 und 41) haben wir schon gesehen, wie man die Messung eincr Basic auf dem Felde vornimmt und wie man verfährt beim Uebergang ion einer gemessenen Grundlinie zu einer grösseren Basis. Es sind das sehr delikate Arbeiten; von der Sorgfalt, die man dabei anwendet, hängt die Genauigkeit der ganzen übrigen Aufnahme ab.

Tor dem Beginn dex Operationen hat man sehr sorgfältig die Länge der Messlatten zu verifiziren, die man anwenden will, sowie die Genauigkeit der Libelle. Wenn man sich statt der Messlatten oder Messstangen - die aus ganz. trockenem Holze bestehen müssen und deren Länge mittels einer Hanfschnur jeweilen geprüft wird - eines stählerner Messbandes bedient, so muss man, wie oben bemerkt (pag.16. Note), die Ausdehnung des Metalls durch entsprechendt Korrektion berücksichtigen. Die Libelle prüft man, inden man sie so auf einen Gegenstand stellt, dass die Luftblase durch den Theilstrich in der Mitte der Röhre genau halbirt wird; dann dreht man sie um $180^{\circ}$, so dass je ein Endt derselben nun an die Stelle kommt, wo vorher das andert Ende war. Hat nun die Luftblase dieselbe Lage wie vorher so ist das Instrument fehlerfrei. Mit dem Senkblei regelt man, wie auf S. 31 gesagt wurde, die Lage der Messlatten wenn der Boden nicht horizontal liegt. In letzterem Falle also bei geneigtem Terrain, kann man auch direkt auf der Boden messen, wenn man zugleich den Neigungswinkel ermittelt; die Basis wird dann berechnet nach den im Anhane mitgetheilten Formeln für geneigte und gebrochene Grundlinien

Nicht nur ist jede einzelne Messung mit der grössten Sorgfalt $\mathrm{zu}$ behandeln, sondern sie ist auch wiederholt (3-4 Mal, 
vorzunehmen, bald in der einen bald in der andern Richtung; die Resultate dürfen von einander nicht namhaft abweichen; schliesslich ist aus ihnen das arithmetische Mittel zu nehmen.

Ist die Basis festgestellt, so schreitet man zur Orientirung, d. h. man steckt, wie S. 74 gezeigt, den Meridian durch einen Endpunkt der Basis ab. Endlich bestimmt man womöglich die Breite, Länge und Höhe desselben Punktes, der für alle andern Messungen als Ausgangspunkt dient. Schon mit einem sehr einfachen Theodolit, Sextant oder Prismenkreis kam man eine geographische Breite in 5 his 10 Minuten mindestens auf $1^{0}$ genau messen $\left.{ }^{1}\right)$. Bei Ausmittlung der geographischen Länge darf man sich nicht allein auf das Chronometer verlassen; denn dieses Instrument, das sich auf Seereisen ganz gut bewährt, ist auf Landreisen (zu Fuss und zu Pferd) über unebenes Terrain oft Störungen unterworfen. Sein Gang leidet durch rasche Temperaturwechsel, Erschütterung, Staub und Feuchtigkeit. Wenn man auch das Instrument bei jeder Gelegenheit kontrolirt, sei es durch Vergleichung mit andern Chronometern, sei es dadurch, dass man nach demselben Längen berechnet für Orte, deren geosraphische Lage schon bekannt ist: so ist es doch immer athsam, dass man bei Feststellung einer Triangulationsbasis lie mit dem Chronometer gefundene geographische Länge lerselben verifizirt, indem man diese Basis nach der S. 91 seschriebenen Methode in Verbindung bringt mit einem 'unkte (einem Hafenorte z. B.), dessen Länge bereits genau restimmt ist.

Findet man kein passendes Terrain zur Absteckung einer iasis ron genügender Länge, so muss man die Busis am limmel messen. (Vgl. S. 94.) A. d'Abbadie hat bei seinen rodätischen Arbeiten in Abessynien folgende Methode anewendet. Man bestimmt die geographische Breite zweier unkte, die unter demselben Meridian so gelegen sind, dass an von einem jeden aus den andern erblicken kann. Die reitendifferenz zwischen diesen Punkten gibt nun ihre Entrnung an, wie man im Anhang findet auf der Tafel (II) r die Längen der Meridiane und Parallelkreise. So hat

1) Jordan, I. 696 . 
man, statt auf dem Boden, am Himmel eine Basis gemessen, was übrigens für die folgenden Operationen keinen Unterschied ausmacht.

Zunächst nämlich handelt es sich nun um Kionstrulition des topoyrajhisch'n Netzes der Karte: das Terrain, welches man aufnehmen will, ist mit einem Dreiecksnetz zu überziehen. Zu diesem Zwecke wählt man gewisse charakteristische Punkte aus (Bergspitzen, Thürme etc.), die man unter sich durch gedachte Linien verbindet, so dass man grosse Dreiecke Dreicclie erster Ordmuny - erhält. Von diesen Punkten aus wählt man andere von geringerer Bedeutung und Entfernung (Thürme, Felsen, isolirte Bäume), durch deren Verbindung man kleinere Dreiecke — zweiter Ordmung - erhält. Nöthigenfalls erstellt man noch ein Netz ron Dreiecken dritter Ordmur. Dieses Verfahren, rom Grossen ins Kleine zu arbeiten, ist besser, als wenn man gleich Anfangs eine Nenge kleiner Dreiecke aufstellen würde. Vermittels der grossen Dreiecke erhält man sicher festgestellte Fixpunkte, die sich zur Verifikation und Kontrole eignen. Zu grösserer Sicherheit misst man ührigens noch eine Grundlinie, sogenannte Verifilationsbasis. (Vgl. S. 41 ff.)

Da der Reisende nicht auf den Punkten, deren Lage er hestimmen will, trigonometrische Signale anbringen kam, so muss er sich behelfen mit natirlirlen Signalen ${ }^{1}$ ), wie Berggipfeln, Baumwipfeln, Dächern, Ecken von Felsen, Küstenpunkten ron Inseln und Seen, Kniepunkten von Flusskrümmungen u. dgl. Diese Anhaltspunkte genügen, wenn man Rücksicht nimmt auf den nach dem Standpunkt veränderten Anblick der Objekte.

Nachstehend geben wir den Gang der Operationen im. Allgemeinen an, um sodann - auch auf die Gefahr hin, zu wiederholen - eine jede davon einzeln $\mathrm{zu}$ besprechen.

Indem man, den vorstehenden Erörterungen gemäss, eine Basis bestimmt, hat man zwei Punkte, deren genaue Position gegeben ist. Diese Basis wird in reduzirtem Massstabe auf

1) Ebenfalls nach A. d'Abbadie. Vgl, Vivien de St. Martin. Année géographique. Paris 1868 , pag. $90 \mathrm{ff}$. 
das Papier übertragen. Hierauf stellt man das Messinstrument erst im einen, dann im andern Endpunlit der Basis auf, visirt nach den Objekten, deren Position man bestimmen will und liest die Richtungswinkel (Peilungen, Azimuthe) ab. Man ïberträgt nun auch diese auf's Papier, mit dem Transporteur, der an die Basis in der Zeichmung angelegt wird, so zwar, dass sein Centrum auf den betreffenden Endpunkt der Basis zu liegen kommt. Der Schnitt je zweier Schenkel, welche die Visirlinien (Peilstrahlen) ron den beiden Enden dex Grundlinie aus nach demselben Objekt darstellen, liefert den gesuchten Bildpunkt.

Gleichzeitig mit dem Direktions- oder Richtungswinkel misst man den Elevations- oder Höhenwinkel. Dabei ist nach einem Punkte des Objektes zu visiren, welcher der Angenoder Instrumentenhöhe eines dort aufgestellten Beobachters entsprechen würde, womit man sich eine Korrektion des Resultates ersparen kam. Die Entfernung zwischen jenem Objekt und dem Standpunkt ist nach den vorangegangenen Messungen nicht mehr unbekannt; man braucht sie nur auf dem Papier abzugreifen und mit der Reduktionszahl zu vervielfachen; dann entnimmt man aus den hiefür bestimmten Tafeln (pag. 48) die Niveaudifferenz, welche jener Entfernung und dem beobachteten Höhenwinkel entspricht. Diese Differenz ist positiv, wenn das fragliche Objekt über, negativ aber, wenn es unter unserem Horizonte ist. Im erstern Fall ist sie also zur Höhe (Cote) des Standpunktes zu addiren, im zweiten davon zu subtrahiren. Dieses Verfahren enthebt uns jeder komplizirten Berechnung; man braucht dabei keine Sinus, Cosinus, Tangenten etc. etc, noch auch Logarithmentafeln. Wenn man nicht Visirpunkte von zu grosser Entfernung wählt, so ist es auch nicht nöthig, in die Rechnung Korrektionen einzuführen mit Rücksicht auf Strahlenbrechung und Erdkrümmung. Bei sorgfältigem Verfahren werdèn die Resultate hinlänglich genau. Es giht zudem ein leichtes Mittel der Verifikation: man muss das Objekt nur noch von einem dritten Punkte aus anvisiren. Die neue Richtungslinie muss auf dem Papier durch den Schnittpunkt der früher erwähnten zwei Schenkel gehen und die neue Cote muss der früheren gleich werden, wenn beim Messen genau zu Werke gegangen wurde. 
Nach dieser Darlegung des einzuschlagenden Ganges wollen wir die verschiedenen Operationen einzeln betrachten.

Die Bestimmung der Dreieckspunkte erster Ordnung muss mit der grössten Sorgfalt geschehen; von der Genauigkeit dieser ersten Messungen hängt die Zuverlässigkeit alles Uebrigen ab. Wer immer mit Logarithmen umzugehen weiss, thut besser, diese grossen Dreiecke trigonometrisch zu berechnen als sie durch Konstruktion auf dem Papier zu bestimmen. Diese Berechnungen können nach den auf dem Terrain gemachten Notizen bei Musse vorgenommen werden, unter Benutzung der im Anhang (Taf. IV) hiefür gegebenen Formeln.

Beim Messen der Winkel ist zu beachten, was S. 35 (Note) über die Aufstellung des Instrumentes gesagt wurde. Wenn das Instrument nicht an dem als Signal dienenden Punkte selbst (zentrisch) aufgestellt werden kann, so halte man sich für Dreieckspunkte erster Ordnung, bei der Reduktion auf das Stationszentrum, nicht an die S. 35 angegebene elementare Methode, sondern berechne die Differenz mit Hülfe der Formeln im Anhang. (Taf. IV).

Es kommt mitunter bei starker Erwärmung der Luft, am Morgen und Mittag, vor, dass die anrisirten Punkte zu zittern scheinen, wie Gegenstände, die man durch die Luftschicht hindurch betrachtet, welche sich unmittelbar über einem flackernden Feuer befindet. Bei solchem Zustand der Luft kann man nicht genau visiren. Eine feine Messungsoperation muss also auf eine andere Tageszeit verschoben werden. Oft auch veranlassen weisse Mauern und Wasserspiegel eine so starke Reflexion des Lichtes, dass man an jeder Operation gehindert wird, solange die Sonne hoch steht. Wenn die Schwierigkeit aber nux darin besteht, dass die Lichtstrahlen auf das Objektivglas des Fernrohrs geworfen werden, so hilft man sich einfach durch Anbringung einer cylindrischen Röhre (aus Metall oder Carton) vorn am Fernrohr, als eine Art Verlängerung desselben (Abblenden des Lichtes). Bei einiger Uebung wird man bald wissen, welches in einem gegebenen Lande und bei gegebenem Klima die geeignetste Tageszeit ist zur deutlichen Wahrnehmung mehr oder minder entfernter Gegenstände, d. h. der Zeitpunkt, wo Dünste und Nebel sich auflösen und der Boden noch nicht 
so erhitzt ist, dass dadurch die Luft in jenes scheinbare Vibriren geriethe, von dem wir oben sprachen. - Sind die Glïser des Fernrohrs trübe oder mit Staub bedeckt, so muss man sie mit feinem Stoffe, am besten mit weichem Handschuhleder (Hirschleder) reinigen. Genügt das nicht, so reibt man sie leicht mit Schwefelblumen und wäscht sie nachher mit etwas Alkohol. Beim Auseinandernehmen oder Zerleger des Fernrohrs muss man aber wohl auf die Reihenfolge der Theile achten, damit beim Wiederzusammenfügen der Stücke ein jedes wieder an seine richtige Stelle komme.

Die Winkelmessungen auf jeder Hauptstation können auf zweierlei Weise erfolgen:

$1^{\circ}$ Richtungsbeubahtungen. Man visirt bei irgend einer Lage des Kreises nach den Dreieckspunkten $A, B, C$ u. s. w. und liest am Theilkreise ab. Nan habe z. B. (Fig. 9:2):
OA..... $12^{0}$
$O B \ldots 47^{\circ}$
$O C \ldots 102^{0}$
$O D \ldots 182^{0}$
$O E \ldots 227^{\circ}$
$0 F \ldots 312^{\circ}$,

so erhält man daraus die $F$ Winkel :

$$
\begin{array}{r}
A O B=47-12=35^{\circ} \\
B O C=102-47=55^{\circ} \\
\text { COD }=182-102=60^{\circ} \\
D O E=227-182=45^{\circ} \\
\text { EOF }=312-227=85^{\circ} \\
\text { FOA }=372-312=80^{\circ} \\
\text { Total }=360^{\circ}
\end{array}
$$

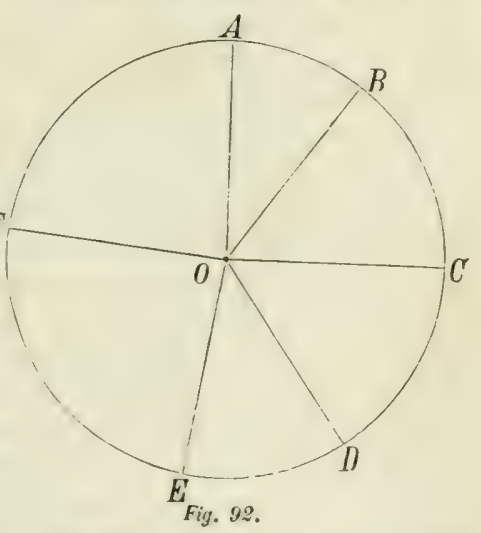

$2^{\circ}$ Winliclbebachetungen. Man misst successive die Winkel $A O B, B O C, C O D$ u. s. f., z. B. (Fig. 92):

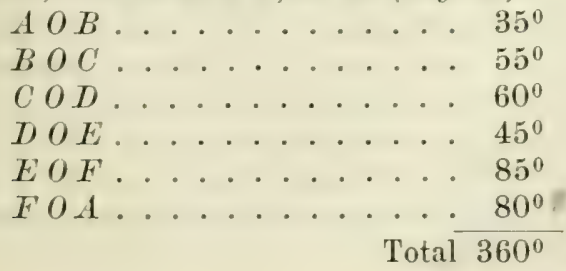


Wenn man in Folge unbedeutender Beobachtungsfehler etwas mehr oder weniger als $360^{\circ}$ erhält, so muss man den Fehler gleichmässig auf die einzelnen Winkel vertheilen. $\mathrm{Zu}$ diesem Zweck ist die positive oder negative Differenz durch die Anzahl der Winkel zu dividiren. Wenn aber das Gesammtresultat erheblich ron $360^{\circ}$ abweicht, so darf die Differenz nicht vernachlässigt oder proportional vertheilt, sondern es muss die ganze Messung wiederholt werden.

Jedesmal, wenn man den dritten Winkel eines Dreiecks bestimmt, dessen beide erste Winkel schon gemessen sind, hat man nachzusehen, ob die Summe der drei Winkel auch wirklich $180^{\circ}$ ausmache.

Während man die Vermessung der Dreiecke erster Ordnung vornimmt, misst man zugleich auf jeder Station die sämmtlichen Winkel, welche hier ihren Scheitelpunkt haben, d. h. also die Direktionswinkel für die Geraden nach Funkten, welche später benutzt werden zur Bildung ron Dreiecken zweiter. und dritter Ordnung, oder welche sogar eine noch mehr untergeordnete Rolle spielen. Hat man für einen solchen Punkt von drei Stationen aus die Richtungswinkel gemessen, so ist seine Position ganz genau bestimmt, da schon die dritte Messung zur Kontrole der beiden ersten dient.

Ist die Lage der Punkte erster Ordnung genau festgestellt; so konstruirt man im Innern dieser Hauptdreiecke kleinere - Dreiecke zweiten Ranges u. s. f., bis nur noch die Detail des Terrains aufzunehmen sind.

Für diese letzte Operation wendet man die auf S. 56-64 angegebenen Methoden der Planaufnahme an; d. h. man bestimmt die Position der einzelnen Punkte durch auf dis Dreiecksseiten gefällte Perpendikel, oder durch Eckstrahlen Diagonalen etc. Die Wasseradern, Strassen, Eisenbahnen Gebäude etc. sind immer bestimmt durch eine gewisse Anzah von Punkten; die Einzelaufnahme derselben besteht also nu in einer mehr oder minder häufigen Wiederholung der Ope rationen, durch welche man die Lage eines Punktes zu eine Linie oder zu andern gegebenen Punkten fixirt. Sind di Objekte, deren Lage bestimmt werden soll, von den Dreiecks seiten $\mathrm{zu}$ weit entfernt, so zieht man im Innern dieser Dreieck, Hülfstinien, welche von einer Seite bis zu einer zweiten reiche und als Abszissenaxen dienen können (Fig. 93). 
Hand in Hand mit den Triangulationsarbeiten soll das Virell'ment vorgenommen werden, insbesondere für die Dreieckspunkte erster und zweiter Ordnung, damit man nicht auf mitunter schwer zugängliche Stationen zurïckkehren muss.

Unter dem Nivellement rersteht man die Gesammtheit der Operationen, durch welche man den senkrechten Abstand (die Höhe) der P'unkte von einer idealen Horizontal- oder Niveaufläche bestimmt. Diese Fläche kann willkürlich gewählt werden, indessen nimmt man dazu gewöhnlich die Meeresoberfläche an.

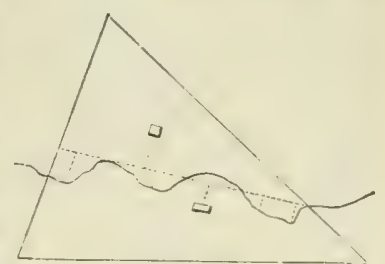

Fig. 93.

Da es aber nicht immer möglich ist, rom Meeresufer auszugehen orler von einem P'unkt mit schon bekannter Höhe, so muss man oft eine andere Ebene zum Ausgangshorizont wählen. In solchen Fällen nimmt man an, der Punkt, von dem aus man die Operationen beginnt, sei 10, 100 oder $1000 \mathrm{~m}$ ï. II. Zu diesen runden Ziffern sind die Niveaudifferenzen zu addiren, welche sich ergehen für höher gelegene P'unkte, und es sind diejenigen zu subtrahiren für Punkte in tieferen Lagen.

Da man nie sicher ist, dass man nicht beim Vordringen in eine noch ziemlich unbekannte Gegend Punkte finde, die 10, 100 oder $1000 \mathrm{~m}$ unter dem Ausgangspunkte liegen, so ist es besser, man nehme die Grundfäche in solcher Höhe an, dass man dabei sicher über dem muthmasslichen Meeresniveau bleibt. Hätte man z. B. eine Grundebene bei $100 \mathrm{~m}$ ii. M. angenommen und man fünde Depressionen, deren Meereshöhe weniger als $100 \mathrm{~m}$ betrüge, so erhielte man Punkte üher und unter der Grundfäche und folglich theils positive theils negative Coten. Wenn man aher das Vergleichsniveau zu hoch annimmt, z. B. auf $4000 \mathrm{~m}$, wïhrend es sich nachher nur zu 2812 ergibt, so hätte man ron allen berechneten Coten $1188 \mathrm{~m}$ abzuziehen. Indem man etwas üher dem muthmasslichen Meeresspiegel bleibt, rerhütet man die Verwendung ron zweierlei Coten - positiven und negativen - und wenn man nachher die genaue Meereshöhe des Ausgangspunktes kennen lernt, so muss man nur zu allen Coten, um sie richtig zu stellen, eine gewisse Zahl hinzufügen. Dies ist aber 
einfacher und verursacht weniger Fehler, als wenu man bald addiren bald subtrahiren muss.

Wie man den Höhenunterschied zweier Punkte bestimmt, haben wir auf S. 45 gesehen. In dem Falle, den wir hier im Auge haben, handelt es sich nur um eine ausgedehnte und vielfache Anwendung jenes Verfahrens, indem man die Höhenunterschiede aufsuchen muss zwischen dem Stationsorte und allen andern namhaften Punkten ringsum, insbesondere denen, welche für das Dreiecksnetz verwendet wurden. Da hiebei das auf S. 47 erwähnte Verfahren keine genauen Resultate mehr liefert, sobald es sich um Entfernungen von über $1500 \mathrm{~m}$ handelt, so muss man in diesem Falle die Formeln und Rechnungsmethoden anwenden, welche im Anhang (Taf. IV) angegeben sind.

Das geodätische oder trigonometrische Nivellement ist das einzige Mittel zur Bestimmung der Höhen einer grossen Anzahl von Punkten, ohne dass man sich auf diese selbst hinbegeben muss. Will man das barometrische Nivellement anwenden, so ist es gut, wenn man zwei Aneroide zur. Verfügung hat, mit denen man gleichzeitig zwei Beobachtungen anstellt, die eine am Fusse der Anhöhe, die andere in dem Punkte, dessen Höhe zu bestimmen ist. Bei der folgenden Operation muss das vorhin im Thale gebrauchte Instrument nun in der Höhe angewendet werden und umgekehrt. (Vgl. auch S. 51, Note 2.) Es soll auch soviel als möglich die obere Station auf einem freien Plateau oder isolirten Gipfel, die untere auf einer offenen Ebene, nicht etwa in einem engen geschlossenen Thale, angenommen werden.

Wenn das geodätische Nivellement nicht vom Meere aus oder wenigstens von einem Punkte mit genau bekannter Höhe ${ }^{1}$ ) aus begonnen werden konnte, so muss man es fortzusetzen suchen bis zu einem Orte, von wo aus man das Meer am Horizonte erblickt; die Niveaudifferenz berechnet man sodann mit Hülfe der Formel im Anhang; oder man muss das topographische Nivellement successive erweitern bis zu einem Punkt am Meere. Hat man das Nivellement

1) Zum Zweeke dieser Verbindung mit einem bekannten Niveau ist in der Tabelle auf S. 93 eine Kolonne nicht nur für Längen und Breiten, sondern auch für Höhen aufgenommen worden. 
mittels des Aneroids ausgeführt, so müssen dessen Angaben auf $0^{0}$ Höhe zurückgeführt werden:

Nachdem man ein sorgfältiges Nivellement der Dreiecksjunkte erstellt und womöglich nicht nur deren relative, sondern auch die absoluten Höhen ermittelt hat, schreitet man zum Detail-Xirellement. Dieses erfordert keine so grosse Genauigkeit wie das für die Dreieckspunkte erster und zweiter Ordnung, und man kann dabei den Lnterschied zwischen wahrem und scheinbarem Niveau wie den Einfluss der Strahlenbrechung unbeachtet lassen. Der Zweck des Detailnivellements ist, Fixpunkte zu erhalten für die Darstellung des Bodenreliefs. Man muss daher vor Allem die Formen des aufzunehmenden Terrains wohl studiren. Dieselben sind bestimmt durch die Richtungen der Bergliamme oder Firsten, der Thalsohlen oder Thahregp und des yrössten Grfälles. Kammlinien nennt man die (gedachten) Verbindungslinien der höchsten Punkte, Thalwege die Verbindungslinien der tiefsten Punkte, und Linien grösster Neigung diejenigen, welche die kürzeste Terbindung zwischen den höchsten und tiefsten Punkten herstellen. Die Bedeutung dieser Linien tritt am besten herror in der Polle, welche sie spielen mit Bezug auf wässerige Niederschläge. Fällt Regen, so funktionirt der Kamm oder First als "Wasserscheide" : ron ihm aus fliessen die Meteorwasser nach verschiedenen Seiten ab) : die Richtung des grössten Gefälles ist zugleich diejenige, in welcher das Wasser am Ahhang herunterfliesst; der Thalweg endlich ist die Axe der Pinne, in welcher die Wasser zusammenfliessen. Hiebei wurde rornusgesetzt, das Terrain sei an Form dem Dache eines Gebäudes zu vergleichen. Wie aber das Gebäude auch ein Thurm sein könnte mit spitz zulaufendem Dache, so kann die Kammlinie oder die Wasserscheide sich auf einen Punkt reduziren, so bei einem isolirten spitzen Berghegel (Pic). Hinwieder kann jene Linie nur schwach ausgesprochen und kaum erkennbar sein, wenn nämlich zu ihren beiden Seiten nicht sofort stark geneigte Abdachungen, sondern fast ehene Flächen liegen: breite Rücken, zu vergleichen mit der Plattform auf einem Dache. So wie endlich ein Dach stark abschüssig oder nach allen Seiten nur sanft geneigt, fast ganz flach sein kann, so auch das Terrain. Fïlle dieser Art bieten die Tafelländer, Hochebenen oder Plateaux, die oft vollkommen 
horizontal scheinen und wo nur ein genaues Nivellement eine Abdachung nach einer Seite oder in mehreren Richtungen herausfindet.

Hat man diese verschiedenen Linien, natürliche Kanten oder Verschneidunglinien des Terrains wohl erkannt, so bezeichnet man durch Signale (Stäbe etc.) ihre wesentlichsten Punkte, d. h. die Stellen an ihrem Anfang und Ende und diejenigen, wo die Richtung ihres Streichens oder wo das Gefälle sich ändert. Dann bestimmt man die Position und die Höhe eines jeden dieser Punkte.

Wo Theile des Terrains von Wasser bedeckt sind, an Seeufern und Meeresküsten, müssen Tiefenmessungen, Lothungen oder Sondirungen vorgenommen werden. In dem ersten Abschnitte (Vorbereitung, S. 53) haben wir schon gesehen, wie man die Tiefen misst. Es handelt sich aber weiter darum, wie man die Lage des Punktes bestimmt, an welchem man sondirt hat, wenn derselbe auf einer weiten Wasserfläche ziemlich entfernt vom Ufer sich befindet.

Es gibt hiefür zwei Mittel:

$1^{\circ}$ Ein Beobachter auf dem festen Lande bestimmt von dort aus die Position des Fahrzeuges, von welchem aus man lothet.

$2^{\circ}$ Der Beobachter ist selbst auf dem Schiffe und bestimmt von hier aus diePosition durch zwei Alignements nach Fixpunkten auf dem Lande, z. B. $A B C$ und $A D E$ (Fig. 94). $A$ sei die Stelle, an welcher sondirtwird; $B$ und $C, D$ und $E$ fixe Punkte (Thürme, Bäume, charakteristische Felspartien), so ist nachher $A$ auf dem Plan leicht $\mathrm{zu}$ bestimmen: man braucht nur die Linien $C B$

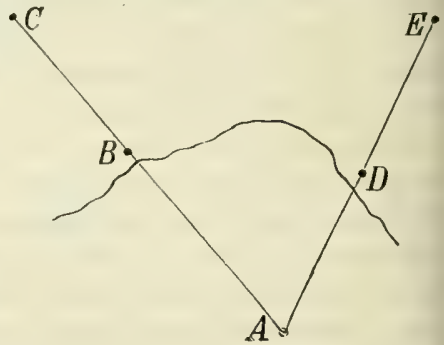

Fig. 94. und $D E$ in der Karte zu ziehen und zu verlängern, bis sie sich schneiden. Der Schnittpunkt gibt die Position $A$. Indessen wird man nicht immer von der Stelle auf dem Wasser aus so bemerkenswerthe Punkte erblicken, die sich paarweise je in einer geraden Linie befinden; dann misst man auf der 
Sondirstelle die Winkel, welche die von ihr ausgehenden Strahlen nach drei hervortretenden (schon durch die Triangulation bestimmten) Punkten, z. B. B ('D) (Fiy. 9:j) mit dem Punkte auf dem Wasser bilden (pothenotische Bestimmung der Punkte). Diese B Winkel(Peilungen) zeichnet man nun auf ein Stück Pauspapier, legrt dieses auf die Karte oder den Plan und bringt es in eine solche Lage, dass die Schenkel genau durch die drei Fixpunkte gehen. Dann gibt der gemeinsame Scheitelpunkt in der Karte die

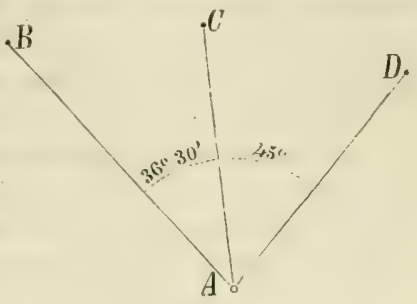

Fig. 95. Position $A$ an, welehe man nummehr durchsticht. - Nebst den Peilungen nimmt man auch Höhenwinkel und bestimmt die Entfernung vom Lande durch Abfeuern ron Schüssen (Beohachtung der Zeit zwischen Schuss und Echo ${ }^{1}$ ).

Wo immer man Gelegenheit dazu hat, bestimme man die wirkliche Tiefe von Seen an Punkten, wovon die Uferanwohner behaupten, "hier habe man noch nie den Grund erreichen kömnen" (der See sei "bodenlos"). Man wird dabei oft statt eines unermesslichen Abgrundes einen Seeboden finden, der weit weniger tief liegt und viel flacher ist, als man erwartete.

Bei diesen Sondirungen muss man die Tiefenzahlen mit Rücksicht auf die Abweichung, welche die Sonde durch Strömungen erleidet, festsetzen und überdies dieselben in Beziehung bringen mit einem bekannten Niveau, resp. mit den Coten auf dem Lande. Dieses Niveau wird entweder das des betreffenden Sees selber sein oder dann das mittlere Meeresniveau.

Mit Hülfe der beschriehenen Nivellements erhält man einen cotirten Plan, d. h. eine Karte, in welcher jedem charakteristischen Punkte seine Höhenzahl (Cote) in Bezug auf den als Norm angenommenen Horizont beigesetzt ist. Die Tiefenzahlen für Seen, welche sich auf den Seespiegel heziehen, können in positive oder negative Coten umgerechnet werden, so dass sie für die gleiche Basis verstanden sind wie die anderen.

1) Hinsichtlich soleher Beobachtungen vom Sehiffe aus verweisen wir z. B. auf Petermann's Geogr. Mittheilungen 1875 S. 228 (norweg. Exped. nach Jan Mayen). 
Diese cotirten Pläne geben nun schon eine Vorstellung der wichtigsten Niveaudifferenzen der Gegend und sie können benutzt werden zur Erstellung von Profilen für auszuführende Arbeiten (Strassen, Kanäle, Eisenbahnen). Aber, wie schon bemerkt wurde, bieten sie dem Auge nicht in rascher und genügender Weise ein plastisches Bild der Bodenformen; ja sie sind um so schwerer zu lesen, zu erfassen, je mehr Coten sie enthalten, je vollständiger also sie sind. Desshalb kommt man mehr und mehr dazu, die arithmetische, ziffernmässige Bezeichnung der Coten zu ersetzen durch eine geometrische, graphische Darstellung: statt durch viele Höhenzahlen bezeichnet man die Niveaurerhältnisse durch Isohypsen, Horizontal- oder Nireauliuren (für Seetiefen Isobathen, Linien gleicher Sonden), welche Punkte von derselben absoluten Höhe mit einander verbinden. Je nach der Genauigkeit, welche man der Darstellung geben kann und will, ist der vertikale Abstand der Kurven, respektive ihrer Ebenen ${ }^{1}$ ) von einander grösser oder kleiner anzunehmen. Dieser Abstand soll aber in derselben Karte immer der gleiche sein (Aequidistanz).

Man versteht die Bedeutung dieser Isohypsen am leichtesten und zeichnet sie am besten, wenn man sie in dem Sinne auffasst, welchen der Name Nireaulinien gibt. Die Horizontalkurven einer Terraindarstellung geben in der That an, welches in der Gegend die Grenzlinien zwischen Land und Wasser wären, wenn der Meeresspiegel ansteigen oder sinken würde bis auf die Höhe oder Tiefe, welche durch irgend eine dieser äquidistanten Kurven bezeichnet ist. Ein Thal z. B. würde hiebei zunächst in einen Golf oder eine Bucht verwandelt, in eine Meerenge oder Meeresstrasse aber, wenn das Wasser anstiege bis über die Höhe des Passes, der dieses Thal mit einem benachbarten verbindet. Die Berge würden dabei in Inseln verwandelt, deren Grösse abnähme mit dem Wachsen der Höhe des Wasserspiegels, so dass schliesslich nur die höchsten Gipfel als kleine Eilande in der Neeresfluth erschienen. Jeder Wasserstand ergäbe neue Kontouren, immer aber würde ein und derselbe Wasserstand bezeichnet durch Punkte von gleicher Höhe : die Niveau-

1) Dieser vertikale Abstand der Kurvenebenen von einander (Aequidistanz) ist nicht zu verwechseln mit dem Abstand der Kurven auf dem Papier. 
inien sind die Isohypsen oder Horizontalkurven, durch welche las Land in vertikaler Richtung nach Höhenstufen und Tiefenchichten gegliedert erscheint. Alle Punkte ron derselben löhe gehören einem und demselben Horizonte an, nicht aber uch ein und derselben Horizontalkurve. Es ist klar, dass n der nämlichen horizontalen Ébue im grleichen Niveau eine rosse Anzahl geschlossener Linicn - Niveaukurven nöglich sind und dass jede einzelne Niveau-Ehene aus der Iantelfläche eines wechselreichen und mannigfaltigen Terrains iele Isohypsen (Horizontalkurven) herausschneiden muss, die ber alle eine und dieselbe Cote besitzen. Die Vorstellung, lass alles Land unterhalb einer bestimmten IIöhe mit Wasser redeckt sei, gibt uns auch in dieser Beziehung das beste Bild rom Einzel-Verlauf der Horizontalkurve. Hat man eine Inzahl benachbarter Punkte von gleicher Höhe, ron denen nan sicher ist, dass sie ron ein und derselben Lferlinie Wassergrenze) berührt würden, so weiss man damit auch, lass sie der nämlichen Horizontalkurve angehören; ist die lequidistanz, welche zur Anwendung gelangt, z. B. $10 \mathrm{~m}$, o weiss man ferner, dass jeder $10 \mathrm{~m}$ höher oder tiefer geegene Punkt in die nächstfolgende Kurve nach oben oder - beziehungsweise - nach unten fallen muss. Was die 'unkte anbetrifft, deren Höhe nicht ein Vielfaches der Aequilistanz ist, so kann man - vorausgesetzt dass an jener Stelle die Abdachung gleichmässig sei - den Verlauf der senachbarten Kurven in Bezug auf solche Punkte durch

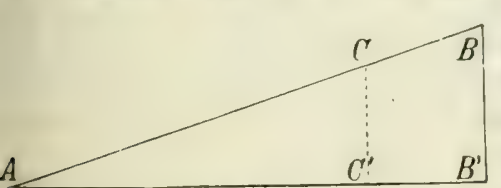

Fig. 96 . Rechnung bestimmen. Es habe z. B. (Fig. 96) der Punkt $A$ die Höhe $74 \mathrm{~m}$ und $B 82 \mathrm{~m}$, sei also die Höhendifferenz $B B^{\prime}=$ $8 \mathrm{~m}$; die wagrechte Entfernung der Punkte (beiehungsweise Kurven) $A B^{\prime}$ sei $25 \mathrm{~m}$. Nun muss die Kurve on $80 \mathrm{~m} 6 \mathrm{~m}$ über $A$ und $2 \mathrm{~m}$ unter $B$ sich hinziehen, lurch den Punkt $C$. Der Horizontalabstand desselben ron 1, nämlich $A C^{\prime}$, ist aber $=\frac{6}{8} \cdot A B^{\prime}=\frac{6}{3} .25=18,75 \mathrm{~m}$ and von $B=\frac{2}{8} A B^{\prime}=\frac{2}{8} \cdot 25=6,25 \mathrm{~m}$. Man erhält lso den Punkt $C$ in der Karte zwischen $A$ und $B$, indem 
man auf der Graden $A B$ von $A$ aus $18,75 \mathrm{~m}$ oder von $B$ aus $6,25 \mathrm{~m}$ abträgt. In gleicher Weise kann man noch mehr Punkte bestimmen, durch welche die Kurve zu ziehen ist.

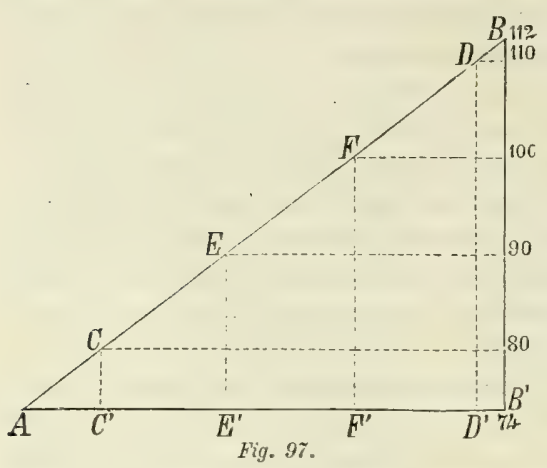

Und ähnlich verfährt man, wenn ein oder mehr Kurven zwischen solchen Punkten gezogen werden sollen. Es sei (Fig. 9\%) die Höhenzahl von $A=74 \mathrm{~m}$, die von $B=112 \mathrm{~m}$, die Niveaudifferenz also $38 \mathrm{~m}$, so kommen zwischen $A$ und $B$ hinein 4 Kurven, nämlich die von $80,90,100$ und $110 \mathrm{~m}$. Die erste davon muss $6 \mathrm{~m}$ oberhalb von $A$ durch $C$ gehen, die letzte $2 \mathrm{~m}$ unter $B$ durch $D$. $A B^{\prime}$, der wagrechte Abstand des Punktes $B$ ron $A$, sei $50 \mathrm{~m}$, so ist

$$
\begin{aligned}
& A C^{\prime}=\frac{6}{38} \cdot 50=7,89 \mathrm{~m}, \\
& B^{\prime} D^{\prime}=\frac{2}{38} .50=2,63 \mathrm{~m} .
\end{aligned}
$$

Die Isohypse von $80 \mathrm{~m}$ muss also die gerade Verbindungslinie der Punkte $A$ und $B$ in $7,89 \mathrm{~m}$ Entfernung ron $A$ schneiden, und im gleichem Sinne muss die Isohypse ron $110 \mathrm{~m}$ durch einen Punkt $D$ gehen, welcher von $B$ aus gegen $A$ in 2,63 $\mathrm{m}$ Horizontalabstand liegt. Der Zwischenraum $C^{\prime \prime} D^{\prime}$ aber ist nun einfach in drei gleiche Theile zu zerlegen; durch die beiden Theilpunkte müssen die Kurven von 90 und $100 \mathrm{~m}$ gehen.

Diese Rechnungen kann man auch durch Konstruktionen ersetzen: Man zeichnet nach Analogie obiger Figuren ein rechtwinkliges Dreieck, dessen Grundlinie die wagrechte Entfernung der zwei Punkte $A$ und $B$ und dessen Höhe ihr vertikaler Abstand ist. Auf der Kathete $B^{\prime} B$ trägt man die Höhen ab, welche Nultiple der Aequidistanz sind, und zieht durch diese erhaltenen Punkte die horizontalen Geraden, welche $A B$ in $C, E, F$ und $D$ schneiden. Von diesen vier Punkten fällt man Perpendikel auf $A B^{\prime}$; deren Fusspunkte 
$C^{\prime} . E^{\prime}, F^{\prime}, I^{\prime}$ gehen damn die Entfernungen für das Einzeichnen der Kurven zwischen $A$ und $B$.

Die Anwendung des ehen besprochenen arithmetischen and graphischen Verfahrens setzt roraus, dass die Abdachung in dem hetreffenden Terraintheile gleichmissig sei. Allgemein anwendhar ist aber folgende einfuche Methode zur Bestimmung des Verlaufes der Kurven auf dem Terrain. is sei z. B. die Isohyjse von $80 \mathrm{~m}$ übre der angrnommenen Grundfläche zu ermitteln, so benützt man ein Nivellirinstrument, dessen Fernrohraxe horizontal gestellt wird. Sodanu stellt man eine Nivellirlatte in einem solchen Terrainpunlite auf, dass die Ablesung der Höhe $80 \mathrm{~m}$ entepricht. Ohne das Femrohr aus seiner wagrechten Lage zu hringen, stellt man sich mit der Latte in rerschiedenen Terrainpunkten auf; dam gehören alle diejenigen Funkte der Kurve 80 m an, für welche die Lattenablesung dieselbe ist. Man lïst sie durch Pflöcke hezeichnen und nimmt sie dann direkt auf ${ }^{1}$ \%. Hierauf rerändert man den Standpunkt des Instrumentes und sucht die Terrainpunkte auf, welche eine um $10 \mathrm{~m}$ kleinere Lattenablesung ergeben und wiederholt dasselhe Verfahren; so bestimmt man den Verlauf der Nireankurve ron $90 \mathrm{~m}$ etc. Diese Methode darf indess nicht auf sehr entfernte Punkte, heziehungsweise auf grosse Distanzen angewendet werden. Die horizontale Fläche ist nämlich, genau genommen, nicht.

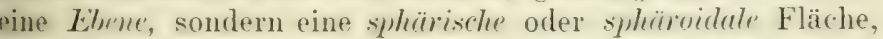
das Fernrohr aber, mit dem man die hurvenpunkte anvisirt, heschreibt bei seiner Drehung eine Ehene, welche die splhäroidale Niveaufläche in einem Punkte berïlut (tangrirt); für kleinere Entfermungen darf angenommen werden, es falle die Ebene mit der erwähnten Fläche zusammen.

Bei der Terraindarstellung mittelst Isohyjsen setzt man wenigrstens den Hauptliuren ihre Höhenzahl bei, z. B.

1) Dieses Verfahren hat in gewissem Sinne ein Gegenstück an der Art und Weise, wie man die Höhe der Schneelinie (untere Grenze des ewigen Schnees) in einem frebirge bestimmt. (Vgl. Sonklar, Anleitung zu Beobaehtungen in den Alpen, S. 13.) Hier handelt es sich um eine physisch gegebene Linic; es ist mit dem Instrumente deren Höhe aufzunehmen. Da die Schneelinie einer Berglehne sich am besten aus einiger Entfernung erkennen lässt, so begibt man sich mit dem Winkelinstrument (Theodolit) womöglich an eine regenüberliegende Thalwand und sucht an dieser Berghalde auf der andern Seite des Thales - dessen Fistenz hiebei vorauszusetzen ist - solche Punkte auf, von welchen aus man hei horizontaler stellung des Fernrohrs durch dieses die gegenüberliegende schneelinie sieht. 
den ganzen Verlauf der Niveaulinie; bei längerer Erstreckung der Kurven wiederholt man indessen mitunter die Höhenangaben. Auch bringt man hie und da bei den wichtigsten Punkten die Coten an.

Diese Niveaukurven lassen nun nicht blos auf bequeme Weise die Höhenverhältnisse erkennen, sondern sie geben überdies auf den ersten Blick ein plastisches Bild der Bodengestaltung, und zwar um so mehr, je kleiner im Verhältniss die Aequidistanz angenommen ist, je näher oder dichter die Kurven zu liegen kommen. Wie wir bei der Besprechung des topographischen Zeichnens S. 134 erwähnt haben, vereinigt man mit der Kurvenzeichnung die Schraffirung, um das Terrainbild noch plastisch wirksamer, noch mehr reliefartig zu gestalten.

Selbstverständlich werden die Karten nicht auf dem Terrain vollendet; aber man trägt an Ort und Stelle in ein Notizenbuch alle Angaben ein, die nöthig sind, um später mit Musse die aufgenommene Gegend kartographisch darzustellen. Es ist nicht gleichgültig, wie diese Notizensammlung angelegt wird; die spätere Arbeit wird erleichtert oder schwierig, jenachdem man hierin ein gutes und klares System befolgt oder nicht. Nachstehend geben wir hiefür ein Schema und einige sachbezügliche Rathschläge; ein Jeder mag beides nach Massgabe seiner Erfahrungen modifiziren.

Auf dem Terrain füllt man nur die Kolonnen 1, 2, 3, 5 und 8 aus. Hiebei müssen die Stationen und anvisirten Punkte leserlich und unzweideutig bezeichnet und ebenso die Ziffern gut geschrieben sein.

Auf jeder Station ist der Visirpunkt Nr. 1 immer eine der früheren Stationen, auf welche man gewöhnlich den Nullpunkt der Kreistheilung einstellt; der Direktionswinkel für $B 1 \mathrm{z} . \mathrm{B}$. wird daher $0^{0}$ sein. Es folgt der Winkel, unter welchem von der Station aus die Entfernung der Visirpunkte Nr. 1 und 2 erscheint; dieser Winkel (der Schwinkel für jene Distanz oder das was man in der Astronomie die Parallaxe nennen würde, vgl. S. 89) wäre $0^{0}$, wenn die beiden Punkte 1 und 2 mit der Station in derselben Geraden liegen. So fährt man fort, bis man die Winkel ringsum abgemessen („den Horizont abgeschlossen ") hat, d. h. zum Ausgangs- 
punkte zurückgekehrt ist, wobei die Ablesung nun $360^{\circ}$ ergeben muss.

Die Höhen- oder Nireaudifferenz wird bestimmt aus dem Höhen- oder Elevationswinkel, unter welchem man den einzelnen Punkt (1, 2, 3 etc.) erblickt. Weun der anvisirte Punkt höher liegrt als der Horizont des Instrumentes, so ist. der Winkel positiv $(+)$, sonst aber negativ (-). Im ersten Falle hat man die Nireaudifferenz zur Cote der Station zu addiren, im andern Falle ist sie zu subtrahiren.

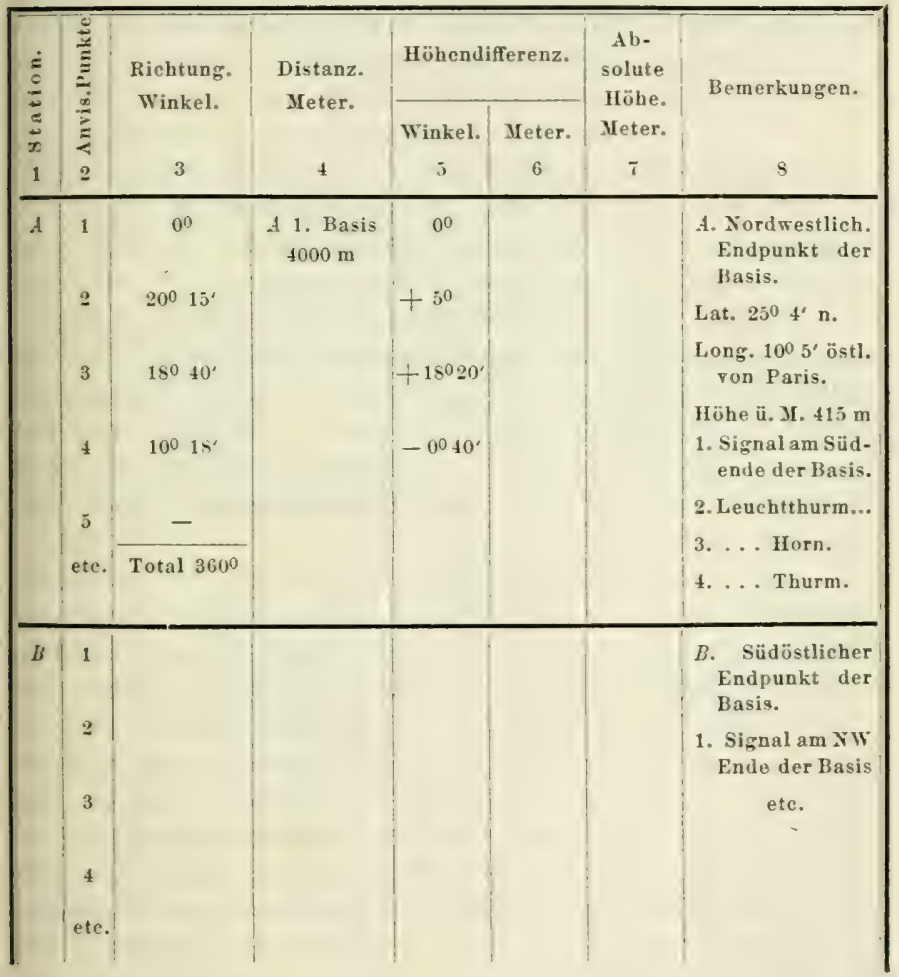

Die Rubriken 4, 6 und 7 werden später ausgefüllt, wenn man Zeit hat, die Dreiecksseiten zu konstruiren oder zu berechnen. 
Um nicht durch Raummangel genirt zu sein, kann man die Rubriken 1 bis 7 auf eine Seite bringen und die nebenstehende Seite für "Bemerkungen" reserviren. In Bezug auf die Bezcichnung der Lokalitüten beachte man was auf S. 183 gesagt ist über die provisorische Notirung, die Bestimmung, Orthographie und Transskription geographischer Namen.

Man wird gut thun, neben dieser Notizensammlung auf leeren Seiten des Heftes oder eines Albums nach dem Augenmasse ein Croquis anzufertigen über die vorgenommenen Operationen, die Basis, Winkel und Dreiecke. Die Stationen und anvisirten Punkte sollen in diesem Croquis dieselben

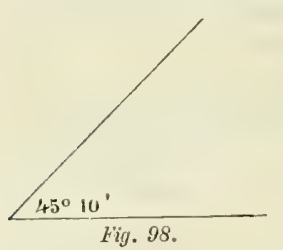

Bezeichnungen erhalten wie im Notizenbuch. Auch soll die Länge der Basis und die Grösse der einzelnen Winkel notirt werden. Letztere Massangabe kann man in den Winkel selbst hineinschreiben, wenn das Croquis gross genug ist (Fig. 98); sobald aberUndeutlichkeit befürchtet werden muss, so ist es besser man bringe ein Zeichen an, das nur als Hinweiszeichen dient, und notire das Winkelmass am

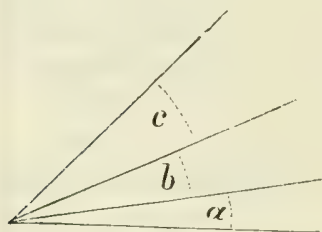

Fig. 99.

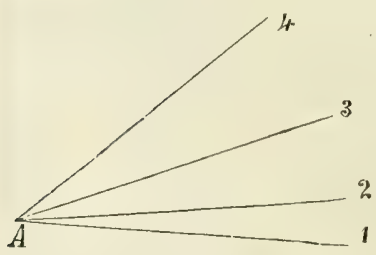

Fig. 100. Rande (Fig. 99) oder bezeichne den Winkel durch $a=8^{0} 10^{\prime}$ Buchstaben und Ziffern (Fig. $\left.b=1505^{\prime}, 100\right)$.

$c=11045^{\prime}$

Diese doppelte Notirung, im Heft und im Croquis, hat den Vortheil, dass dadurch den Unannehmlichkeiten vorgebeugt wird, welche entstünden, wenn in einem dieserDokumente - wenn $1 A 2=8010^{\prime}$ nur das eine existirt $2 A 3^{\prime}=15^{0} 5^{\prime}$ eine Ziffer vergessen, ver$3 \dot{A} 4=21045^{\prime}$ wischt oder sonst unleserlich wäre, wodurch der Abschluss der Arbeit verhindert werden könnte.

Bei der Detailaufnahme genügt die Notirung im Croquis, wenn man dieses in ziemlich grossem Massstabe zeichnet und 
sowohl die Winkel als die Distanzen mit etwas hartem Bleistift einträgt, sodass kein Ausirischen zu riskiren ist.

Cnter allen Lmständen ist es durchaus nothwendig, dass man im Notizenbuch wis auch im Cropuis klare und vollständige Angaben eintrage und sich ja nicht auf́ das Gedächtniss verlasse, dem man wird im Birouak und überhaupt an Haltestellen sich nicht immer damit hefassen können. in grossem Massstab das trigonometrische Netz oder gar in sorgfältiger Ausführung die Kontouren und die vertikale Gestaltung des Terrains abzubilden. Die Reinzeichnung wird viehnohr rerschohen werten müssen his zum Aufenthalt an einer Ifauptstation oder gar bis zur Rückkehr ron der Reise: dann aher dürfen die gesammelten Notizen zu keinen Zweifeln Aulass geben.

relbstrerständlich ist es immer gut, diese Reinzeichnung so schnell als möglich rorzunehuen unrl an besten, wenn dies so rechtzeitig greschieht, dass man, falls Zweifel auftauchen, noch an die betreffendle Stelle zurückkehren kann, um sich über Form- oder Massverhältnisse zu vergewissern.

Sobald als nur immer möglich unternimmt man also an Hand des Totizenbuches und des Cropuis die Rerinzcirhumu!! der topographischen Anfuahme auf starkem Zeichmugspapier ron grossem Format. Dahei werden die Dreiecke konstruirt mit Hülfe des Doppeldezimeters und des Transporteurs oder herechnet nach den im Anhang enthaltenen Formein und Tahellen.

Auf ein erstes Blatt trägrt man nur das Dreiecksnetz und die hierauf bezüglichen Jasszahlen ein. Dieses Blatt legt man nun auf ein zweites, welches für die Terraindarstellung bestimmt ist, sticht die Dreieckspunkte durch und bringt nun an Hand des Notizenheftes und der Spezialcroquis dif minder wesentlichen Punkte an: die Verbindungslinien derselben deutet man mur nit sanften Bleistiftstrichen an. Sind auf diese Weise alle Punkte in ihre richtige Position gebracht, so hat man schliesslich noch die Lmrisse und Terrainformen darzustellen, wie es im ersten Theile dieses Buches (Alschnitt Topographisches Zeichnen) auseinandergesetzt worden ist.

Da man auf eine Rrise nicht Papier ron sehr grossem Format mitnehmen wird und auch Tische oder sonstige ebene 
Flächen und Unterlagen zum Zeichnen auf solchem Papier fehlen würden, so muss man oft mehrere Blätter anwenden, um eine Karte in etwas grossem Massstabe zu zeichnen. In einem solchen Falle vorab ist es nöthig, das Dreiecksnetz auf einem besondern Blatte darzustellen. Dann aber kann man nicht die Dreieckspunkte durchstechen, sondern man muss die Dreiecke in grösserem Massstabe auf neue Blätter übertragen, z. B. auf jedes Blatt ein Dreieck, sodass man eben so viele Blätter verwendet als Dreiecke erster Ordnung vorhanden sind. Nur muss man alle Dreiecke in derselben Vergrösserung übertragen, z. B. alle Seiten in doppeltem oder alle im fünf- oder im zehnfachen Massstabe. Auf jedem Spezialblatt zeichnet man alle Positionen in dem vom betreffenden Dreieck umschlossenen Raume und führt in diesen Grenzen auch die Terrainzeichnung aus. Dann kann man entweder die Dreiecke genau herausschneiden, um sie später aneinander zu fügen oder man kann die Blätter intakt aufbewahren, um die Zusammenstellung derselben zu einer einzigen Karte nach der Rückkehr von der Reise vorzunehmen.

Man kann auch das Blatt mit dem Dreiecksnetz in Quadrate eintheilen durch rechtwinklig sich schneidende Linien, die parallel sind zum untern Rande und zu den Seitenrändern des Blattes. Jedes Quadrat stellt dann ein Spezialblatt vor; auf diese einzelnen Blätter überträgt man in vergrössertem Massstabe die Dreiecke oder Dreiecksstücke, welche enthalten sind in den Abtheilungen des Triangulationsblattes. Dieses Verfahren ist namentlich am Platze, wenn man - wie dies im Anhang gezeigt ist - die Koordinaten der Dreieckspunkte bestimmt hat.

Die Bedingungen, welche die Karte erfüllen soll, sind in erster Linie die, dass sie genau, vollständig und doch klar sei. Vollkommenheit der Ausführung bis in die kleinsten Details kann man von ihr nicht verlangen, wenn sie nur leserlich ist und angenehm in die Augen fällt. Die Genauigkeit aber hängt wesentlich $a b$ von der Sorgfalt, die man auf die vorhin behandelten Operationen verwondet. Vollständig ist sie in Bezug auf den Reisebericht, wenn sie alle in demselben erwähnten Orte, Flüsse, Berge etc. enthält. Klar oder übersichtlich ist sie endlich, wenn der Massstab gross genug ist, um alle Details und deren Namen mitzutragen, ohne dass 



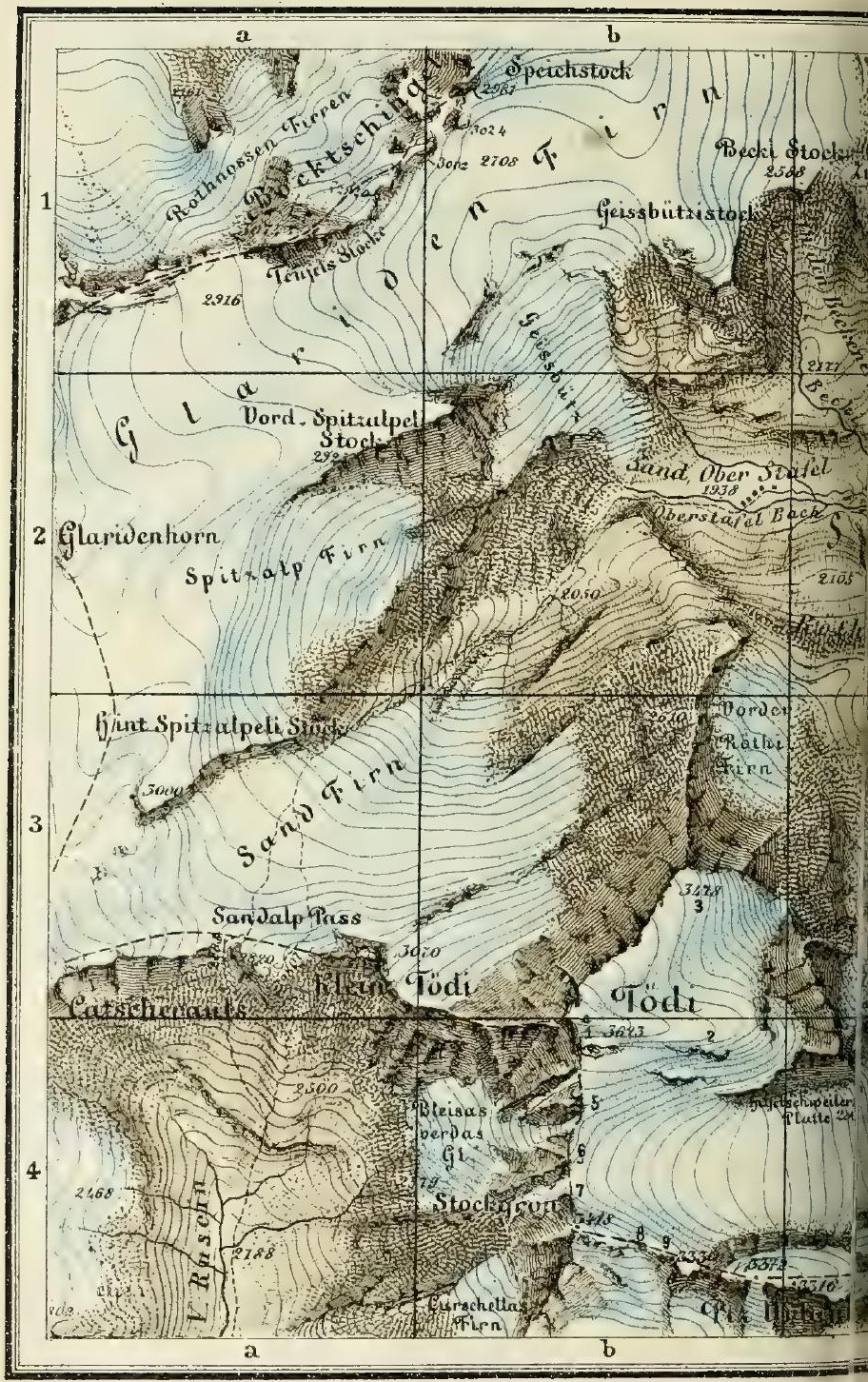




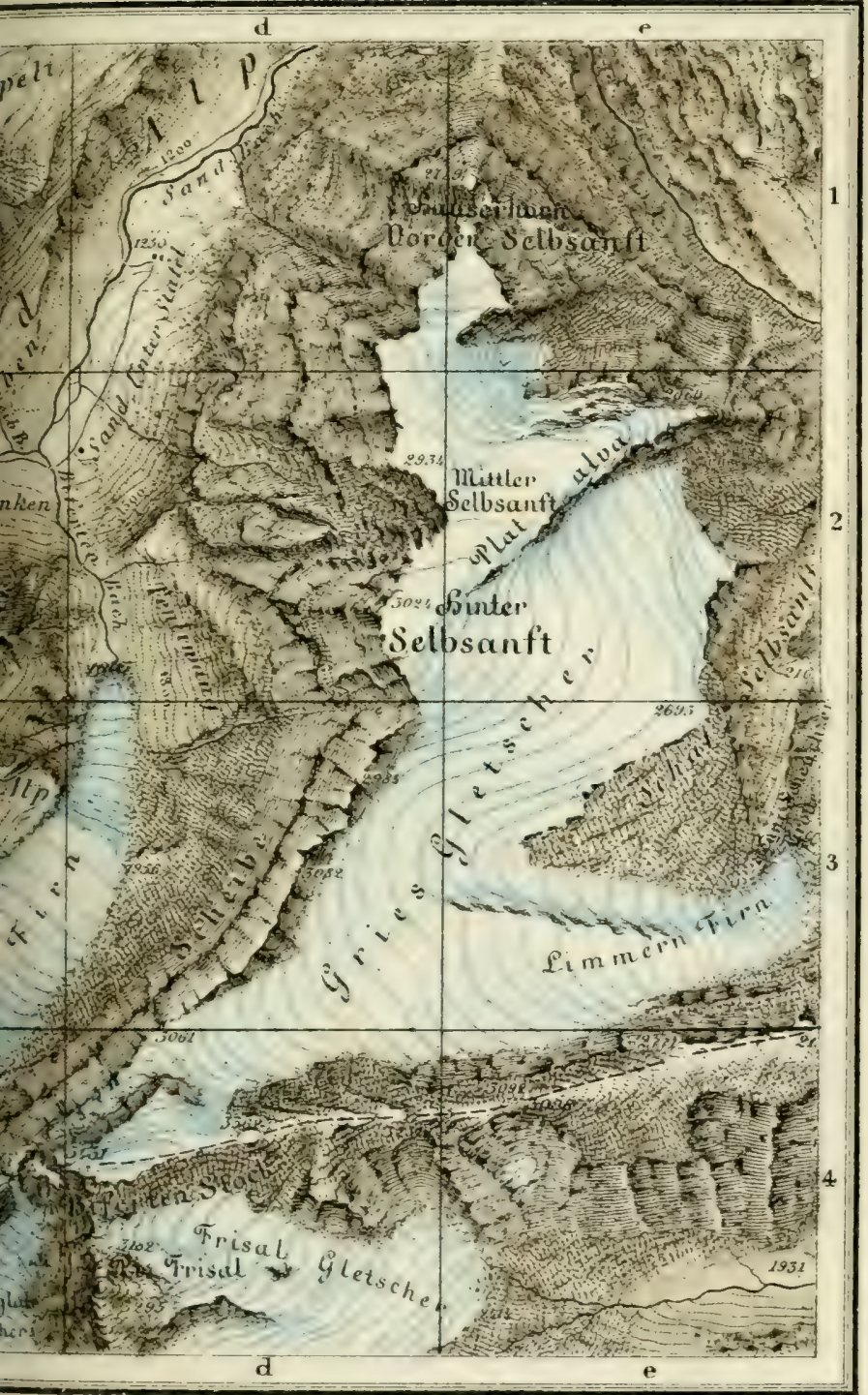



daraus Leberladung und Verwechslumgen entstehen und wenn man zudem die Marschroute des Reisenden leicht rerfolgen kann. Die Benutzung der Karte wird wesentlich erleichtert durch Beigahe eines alphabetischen Namensverzeichnisses, wo neben jedem Namen die Sektion der Karte angegeben ist, in welcher sich der betreffende Ort, Fluss oder Berg lefindet. Zu dem Ende wird die Karte in Vierecke eingetheilt entweder durch die Meridiane und Parallelkreise oder durch beliebige andere sich rechtwinklig schneidende Linien, und diese Sektionen werden bezeichnet durch Buchstaben ron links nach rechts und Ziffern ron oben nach unten, wie dies Taf. XIII darstellt ${ }^{1}$ ).

Das alphahetische Verzeichniss bekommt dann nachstehende Form

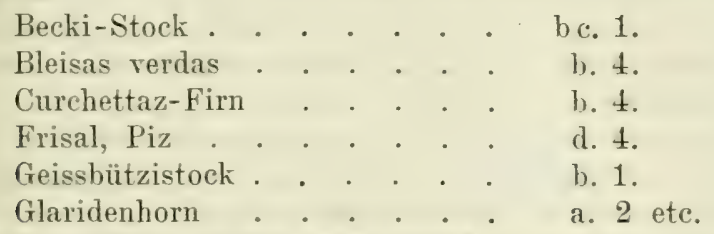

Auf diese Weise findet man leicht auch die weniger wichtigen Punkte auf.

Lm diese Kreuz- und Querlinien auf der Karte zu rermeiden, kann man auch die Eintheilung nur am Rande der Karte andeuten. Mit Hülfe des Buchstabens und der Ziffer, welche die Stelle des betreffenden Objektes bezeichnen, findet man dieses unschwer auf, indem man mit dem Finger oder blos mit dem Augre die Richtung verfolgt, um welche es sich handelt.

Nicht selten ist eine Vereinigung von Karten über verrhiedene Gegenden. die nirde umittellor aneinanderstossen, rorzunehmen, so zwar, dass die in ein Blatt verschmolzenen Karten zu einander ihre richtige natïrliche Lage haben. Auf Exkursionen wurde etwa da ein Thal, dort ein Gewässer, anderorts ein Gebirge, eine Meeresbucht etc. aufgecommen. Nun möchte man einen Leberblick haben über las, was erforscht und das, was noch zu erforschen ist. I, diesem Zwecke müssen zunächst die rerschiedenen Partial-

1) Ygl. auch J. M. Ziegler, hypsometrische, geologische und Reisekarte der jehweiz 1 : 300000 . Zürich, Wurster \& Cie. 
karten auf einen und denselben Massstab gebracht werden, wenn dies nicht schon der Fall war; dann muss man zwischen ihnen eine Verbindung herstellen, entweder durch eine rasche Triangulation des zwischenliegenden Gebietes oder mit Hülfe der Meridiane, Längen und Breiten, welche man für je einen Punkt dieser Karten bestimmt hat. Auf ein Blatt Pauspapier zeichnet man dann das Dreiecksnetz oder — mit Hülfe der Taf. II im Anhang über die Länge der Parallelkreise - jene Kartenpunkte, deren geographische Koordinaten bestimmt wurden, sowie den Neridian (die Nord-Südlinie) dieser Punlite; hierauf bringt man die fraglichen Karten unter dieses Blatt, so zwar, dass die entsprechenden Dreieckspunkte oder Meridiane einander decken, und befestigt nun Karte und Pauspapier aneinander mit Nadeln oder Mundleim. Mittels Durchzeichnens erhält man schliesslich eine allgemeine und einheitlich gestaltete Karte der erforschten Gebietstheile.

Selten wird der Reisende geornayhische Karten zu zeichnen haben; die wenigsten werden ihre Forschungen so weit ausdehnen, um bei der Darstellung des Gebietes die Kugelgestalt der Erde in Betracht ziehen zu müssen. Wenn dies aber geschieht, so ist folgendermassen zu verfahren.

$1^{\circ}$ Für die Zone zu beiden Seiten des Aequators bis $20^{\circ}$ Breite wendet man die sogenannte cylindrische Kartenprojelition und zwar Plattlarten an, d. h. Karten, worin dif sphärischen. Trapeze des Gradnetzes auf der Kugeloberflächє ersetzt sind durch Quadrate, sodass also die Grade der Parallelkreise gleich gross erscheinen wie diejenigen der Meridiane.

$2^{\circ}$ Für die Zonen von $20-60^{\circ}$ Breite kann man entwedel die Merkiator'sche Projektion anwenden - wobei man sick der im Anhang beigefügten Taf. III bedienen muss - odel die Flamsteed'sche Projektion. Bei ersterer sind Meridian und Parallelkreise gerade Linien, auf einander senkrecht; all Parallelkreisgrade sind gleich gross gezeichnet, die Meridian grade aber - um sie überall mit den anstossenden Paralleles im richtigen Verhältniss zu haben und so die Konformitï der Karte, d. h. die Aehnlichkeit in den kleinsten Theiles $\mathrm{zu}$ erhalten - in höheren Breiten entsprechend rergrössert Bei letzterer (Flamsteed'scher Projektion) sind die Parallel 
nahmen (flying surveys, levés expédiés et levés à vuc). Dieselben können entweder rasch mit den einfachsten Instrumenten oder nur nach dem Augenmass bewerkstelligt werden.

Im ersteren Falle bestimmt man rasch einige Hauptlinien und beschränkt sich für den Rest auf Schätzungen. Im zweiten Falle gibt man so genau wie möglich die Wasseradern, Strassen etc. an, welche gewisse Gebiete begrenzen; die Objekte, welche innerhalb dieser Demarkationslinien liegen, placirt man nach Schätzung der Verhältnisse.

Bei gehöriger Uebung im Schätzen und schnellen Messen von Distanzen, Winkeln, Höhen etc. kann man auch in solchen Aufnahmen Gutes leisten. Zum Beweise dessen zitiren wir hier unter Bezugnahme auf S. 181, was Prof. Jordan (a. a. O. S. 697) über die flüchtige Aufnahme eines Itinerars während des Marsches sagt. "Die Stockboussole lässt sich nur anwenden, wenn der Beobachter auf dem Boden stille steht. Nun will man aber auch oft Richtungen peilen, auf einem Reitthier sitzend, oder wenn man zu Fuss geht, ohne stille zu stehen. Hiezu dient die Taschenboussole von der Grösse einer Taschenuhr mit Theilung von $10 \mathrm{zu} 10^{\circ}$. Man hält dieselbe in freier Hand, lässt die Nadel auf $0^{\circ}$ und $180^{\circ}$ einspielen und visirt mit freiem Auge über die Theilung hinweg nach dem Zielpunkt, dessen Richtung man haben will. Diese Methode erscheint auf den ersten Blick ungeheuer roh; man wird sich aber nach einigen Versuchen überzeugen, dass man damit auf etwa $10^{\circ}$ genau peilen kann, und das reicht für flüchtige Aufnahmen meist aus. Bedenkt man, dass man diese Methode zu Pferd oder Kameel, zu Wagen, zu Schiff, während des Gehens, kurz überall anwenden kann, wo alle andern Mittel den Dienst versagen, so wird man diese einfache Peilmethode bei fortgesetzter Beschäftigung mit flüchtigen Aufnahmen hauptsächlich anwenden, und durch Uebung auszubilden suchen." Der genannte Autor hat verschiedene "Peilungen nach Augenmass mittelst des kleinen Taschenkompasses" direkt mit genauern Theodolitpeilungen verglichen und sich dabei überzeugt, „dass man durch die erstere Methode sehr wohl Richtungen auf $10^{\circ}$ genau abschätzen kann und dass, wenn man dabei ruhig stehen kann, der mittlere Peilungsfehler nur etwa 5 bis $10^{\circ}$ ist." Itinerare aber, deren Einzelstrecken auf etwa 
$10^{\circ}$ genau gepeilt sind, ergeben sehr befriedigende Resulate, sofern nur die Zahl der Peilungen genügend gross ist a. a. O. S. 699).

Dass sellsst geographische Breiten- und trigonometrische Oistanzhestimmungen approximativ in sehr kurzer Zeit bererkstelligt werden künnen, wurde bereits (\$. 189) bemerkt. Jiese Methoden rerdienen sehr beachtet zu werden: dem ft kommen Reisende - wegen Nangel an Zeit und in Instrumenten oder wegen Feindseligkeiten der Eingeornen - in eine Lage, die es ihnen unmöglich macht, n augenfälliger genauerer Weise zu operiren. Wenn immer nöglich wird man zwar eine regelrechte Triangulation ornelımen. Wird aber eine genaue Detailaufnahme absolut mmöglich, so ist eine beschleunigte oder aplroximative Aufnahme erwünscht, welche sich an die trigonometrisch estimmten Fixpunkte anschliesst. Dabei können dann die Cehler nicht mehr sehr gross werden; die Formen sind renigstens annähernd gegeben, und nachfolgende Reisende rönnen immer die angefangene Arbeit in ihrem Detail reiter führen.

Photographische Aufnahmen. Da ein räumliches rebilde durch zwei mathematisch orientirte perspektivische Ceichnungen geometrisch bestimmt ist, so kann man auch hotomraphische Aufuahmon zur Kartenhomstrulition benützen. )ieses Verfahren ist in der Militärwissenschaft, beziehungsreise in der Topographie, unter dem Namen Photormammetrir ekannt. Wir müssen davon Lmgang nehmen, hier auf lasselbe einzutreten, und verweisen den Leser, welcher sich larüber zu unterrichten wünscht, auf bezügliche Spezialbhandlungen, wie diejenige Jordans in der "Zeitschrift für Cermessungswesen " 1876 S. $1-17$.

Entlehnte Karten. Wenn es dem Reisenden ganz unnöglich geworden wäre, irgend eine Karte aufzunehmen, so äre dies kein Grund, um der Reisebeschreibung gar keine iarten beizugeben; denn es ist für den Leser sehr unanrenehm und störend, wenn er Namen von Orten, Flüssen etc. or sich hat, ohne dass er sich ihre Lage rergegenwärtigen ann. Es wird auf diese Weise unmöglich, sich die Reise, eren Verlauf und die Erlebnisse dabei klar vorzustellen: 
ein Reisebericht ist für uns nur dann von Interesse und von Nutzen, wenn man die Erzählung leicht verfolgen und sich im Detail zurechtfinden kann. Zu dem Zweck muss man der Reisebeschreibung eine Karte beigeben; nur darf man dazu nicht die erste beste Karte des betreffenden Gebietes, wie sie ist, nehmen; die Karte würde sonst in den meisten Fällen mit dem Text nicht übereinstimmen, sei es in den Positionen oder, in der Schreibart der Namen. Die Karte muss also als Beilage zum Reisewerke besonders bearbeitet und mit diesem letzteren in Uebereinstimmung gebracht werden. Man muss darin alle Oertlichkeiten, Flüsse, Berge u.s.f., welche die Beschreibung anführt, leicht und unter denselben Namen auffinden können. Freie Hand hat der Reisende aber in Bezug auf die nicht beschriebenen Partien des Gebietes. Es geziemt sich, ausdrücklich zu bemerken, dass die Karte nicht durch den Reisenden aufgenommen und wo sie entlehnt wurde, einerseits, damit nicht die Uebereinstimmung zwischen Text und Karte irrthümlich als ein Beweis aufgefasst werde von der Genauigkeit der beiden Karten, andrerseits, damit man nicht sich selber das Verdienst zuschreibe, welches dem Autor der ersten dieser beiden Karten gebührt.

Profile. Die Karte allein, wenn sie noch so vollkommen ist, genügt nicht immer, um eine genaue Vorstellung der Bodenkonfiguration $\mathrm{zu}$ geben. In gewissen Fällen muss man Längen- und Querprofile beifügen, so z. B. um eine richtige Idee zu erwecken vom Gefälle eines Thales, von seinem Querschnitt, von den Kontouren einer Bergkette, einer Meeresküste u. dgl.

Die Erstellung dieser Profile an der Hand der Angaben. welche das Nivellement, und von Anhaltspunkten, welcht die Geometrie uns liefert, bietet keine Schwierigkeiten Man zieht eine wagrechte Linie als Grundhorizontale; dieses Horizont kann derselbe sein wie derjenige für die Kart oder ein ganz beliebiger, z. B. ein höherer. Auf dieser Geraden trägt man im verjüngten Massstab die Distanzer ab zwischen den einzelnen Punkten der Linie, nach welche: das Profil gezeichnet werden soll. In jedem dieser Punkt errichtet man auf jene Gerade ein Perpendikel, dessen Läng gleich gemacht wird der Höhe des betreffenden Punktes ir Bezug auf den angenommenen Horizont und Massstab. Di 


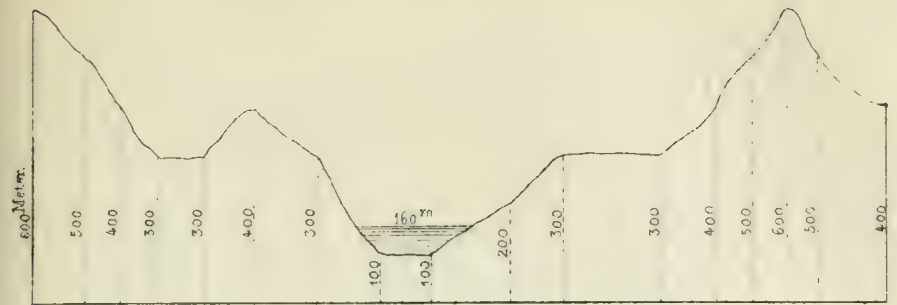

\section{Meter}
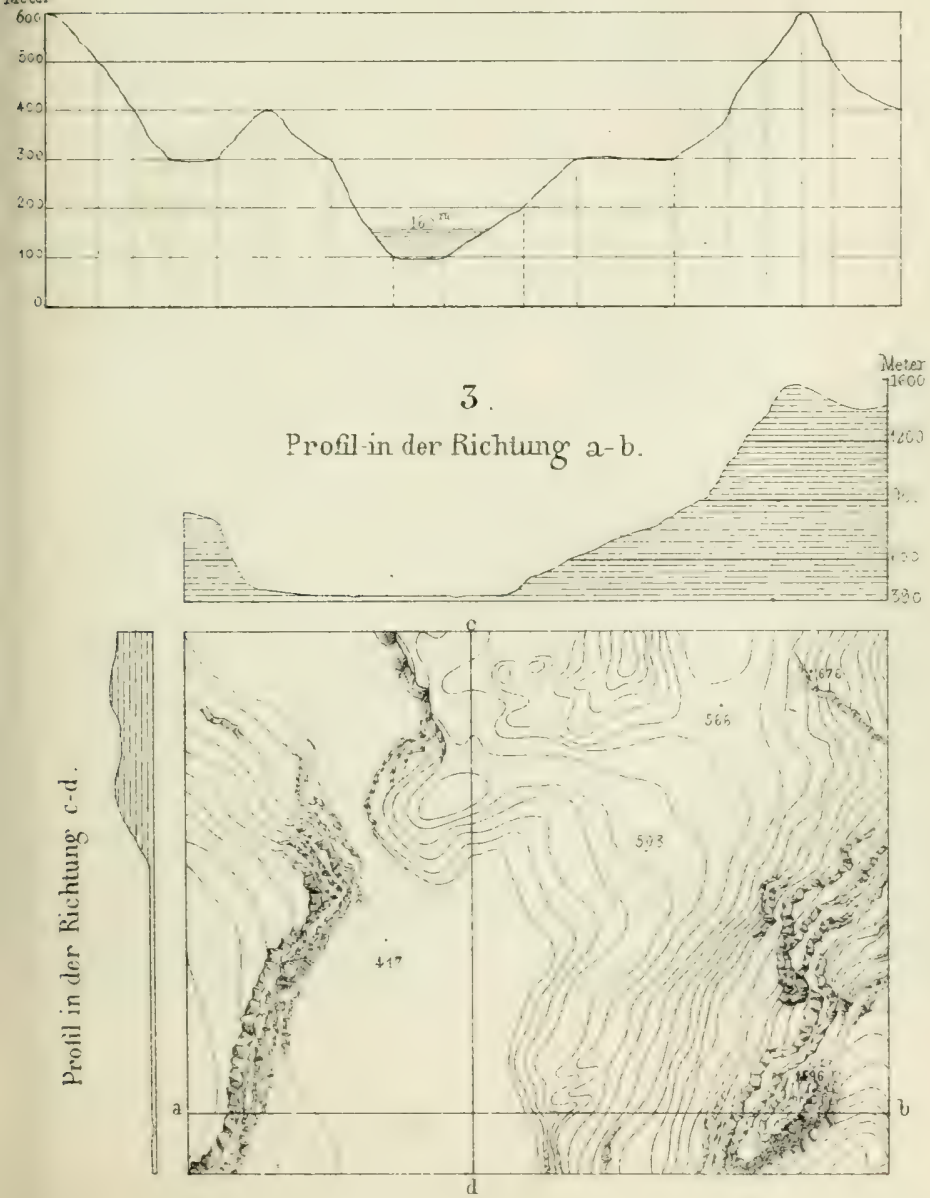


Taf. XV.

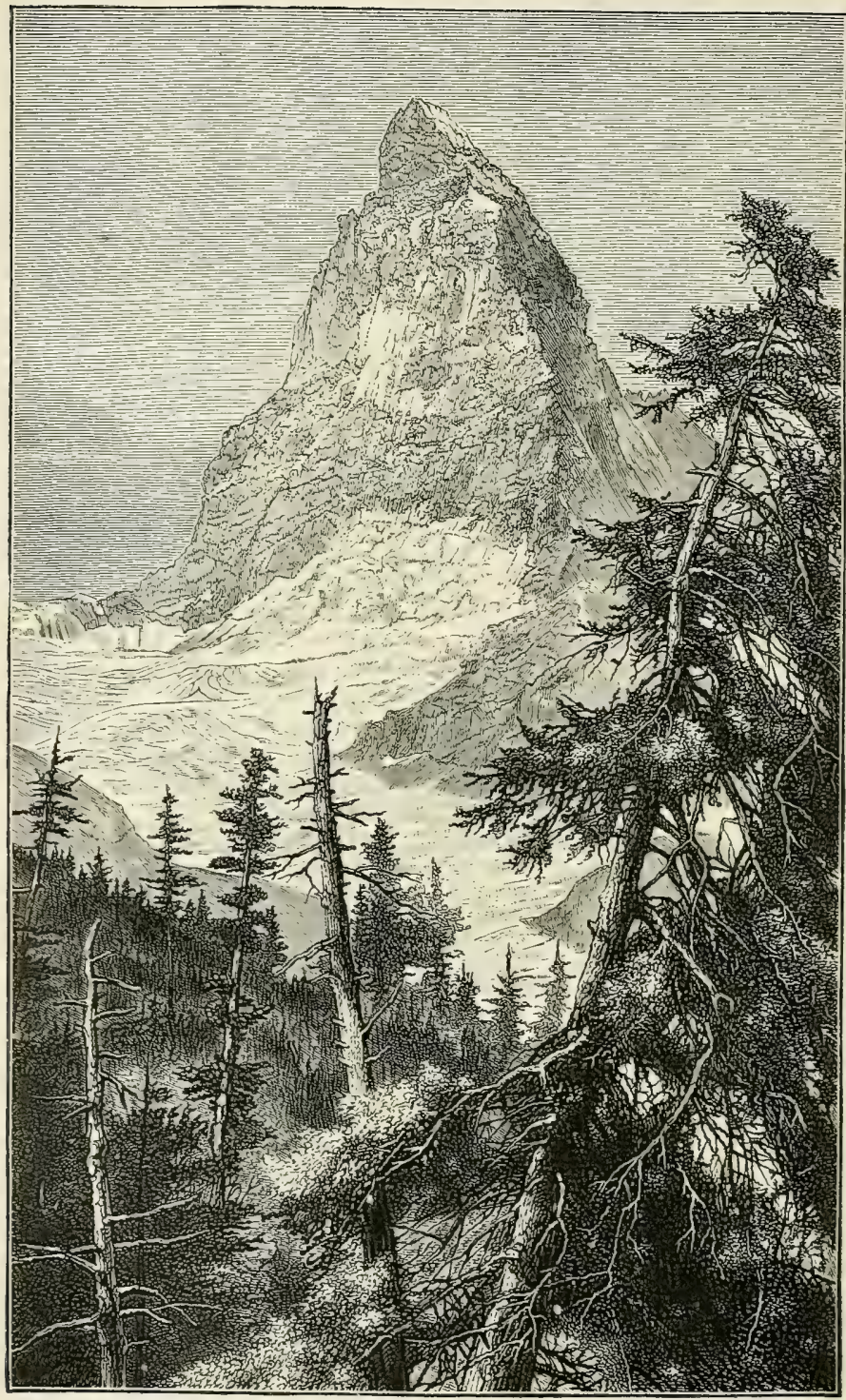

pas Matterhorn. 
Endpunkte dieser Senkrechten werden mit einander verbunden; so erhält man die Profillinie. L'm zu verhüten, dass die Profile allzu lang werden und um andrerseits die vertikale Gliederung des Bodens mehr hervorzuheben, nimmt man zumeist einen kleinern Massstab für die Längren an und einen (10-, 20-, $100 \mathrm{mal}$ ) grössem für die Hühen, z. B. für die Längen $1 / 10000$, für die Höhen aber $1 / 1000$, $1 / 500,1 / 100$. (Vgl. Taf. XIV, 1.) Hat man äquidistante horizontale Kurven angewendet, so brancht man nicht die Läncre jedes Perpendikels besonders abzutragen, sondern man zieht dann in gleichen Abständen Gerade parallel zur angenommenen Horizontalen oder man wendet hiezu linirtes Papier an. Die Distanzen für die einzelnen Punkte werden aufgetragen wie rorhin, und die Perpendikel werden dam gezogen bis zu derjenigen wagrechten Linie, welche der Isohypse des betreffenden Punktes entspricht (Tat. $\mathrm{X} I Y, 2)$.

Will man endlich (siehe oben S. 138) Profile erstellen auf Grund einer Karte oder eines Planes, so zieht man die Linien (Profilrichtungen), nach welchen man sich das Terrain durchschnitten denkt und zieht ron jedem Schnittpunkte rieser Linien mit den Kurven Gerade senkrecht zum Kartenrande über diesen hinaus in der erforderlichen Länge. (Vgl. Taf. $\mathrm{XIV}, 3$. )

Will man ein Bild geben ron der Form eines Berges, ron dem Anblick, den er bietet, ohne dass man Zeit hat zur Erstellung eines genauen Profils, so zeichnet man eine Skizze oder eine Ansicht desselben, wie solche in Fi\%. 10:5 und Taf. XV gegeben sind für das Matterhorn.

Ansichten. Das Vorige führt uns naturgemäss zur Besprechung der Ansichten als eines der besten Mittel zur Darstellung der Physiognomie einer Gegend oder eines Landes.

.Sehr selten, " sagt ein Maler $\left.{ }^{1}\right)$, , bieten Ansichten, die ron einem sehr erhabenen Punkte aus aufrenommen werden, ron wo das Auge mit Entzücken nach allen Richtungen zahlreiche und wechselvolle Einzelbilder erblickt, in der Zeichnung so viel Reiz dar, wie man von rornherein anzunehmen geneigt

1) A. D. Vergnaud, Manuel de Perspective, du Dessinateur et du Peintre. Paris 1835. 
ist; die Kunst, so vollendet sie sein mag, reicht eben nicht hinan an die unerschöpflichen Hülfsmittel der Natur."

In der That treten gewisse Details, welche das Auge in der Landschaft deutlich und mit Wohlgefallen wahrnimmt, in einer kleinen Zeichnung so zurück und werden sie so undeutlich, dass die Darstellung bei aller Treue bei Weitem kein der Wirklichkeit entsprechendes Bild gibt. Und doch haben auch solche Ansichten ihr Gutes: sie geben einen Ueberblick im Grossen, den man nicht ersetzen kann durch

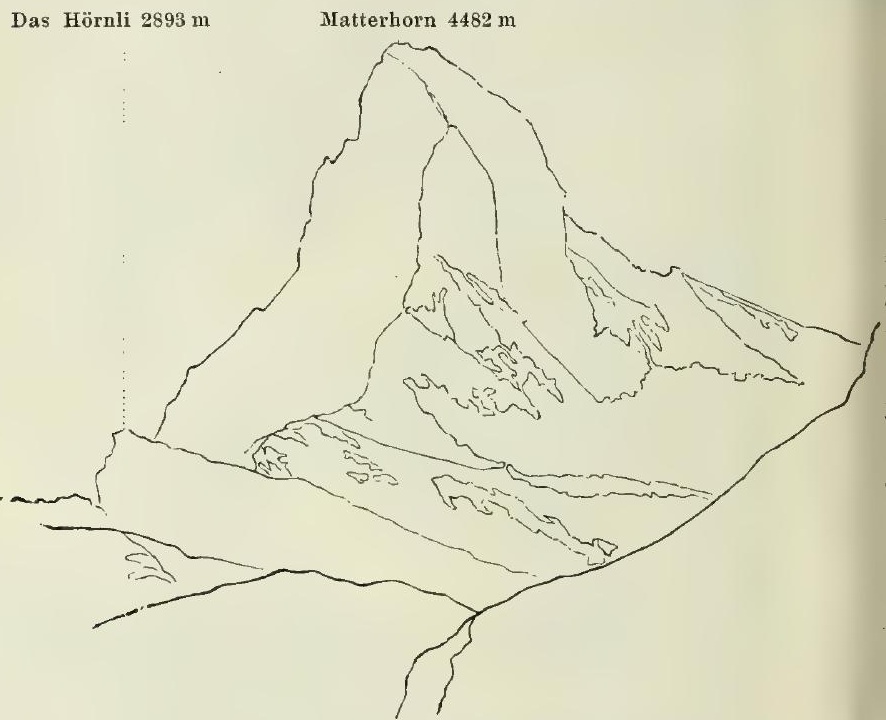

Fig. 105. - Das Matterhorn von NO aus gesehen.

die Betrachtung spezieller Darstellungen einzelner Landschaften. Solche Ansichten werden aber am besten als Panoramen behandelt, wovon sogleich die Rede sein soll.

Was die Wahl der darzustellenden Objekte betrifft, so muss man wohl unterscheiden zwischen der Aufgabe des Reisenden und derjenigen des Malers. Der Letztere sucht für seine Darstellungen nur das Schöne auf; der Reisende ist an seine Marschroute gebunden und hat uns die Gegenden vorzuführen, welche er besuchte. 
Im ersten Theile dieses Buches (Vorbereitung, pag. 122 ${ }^{1}$ ) haben wir schon gesehen, welche Bedingungen zu erfüllen sind durch die Zeichnungen, die ein Reisender sammelt, und wie man in kurzer Zeit ein Bild herstellen kann, welches zur Treue der Kontouren und zur Genauigkeit des Details die Vorzüge des Kolorites hinzufügt. Aber bei aller Raschheit des Verfahrens kann der Reisende nicht Alles zeichnen, was sich ihm auf seinem Wege darbietet. Er muss sich auf das Bemerkenswertheste, auf Charakteristisches beschränken. Jede Gegend hat ihr eigenes Geprägre; man suche nun die Ansichten bildlich darzustellen, worin solch Eigenthümliches besonders ausgeprägt ist; ferner wird man sich womöglich Ansichten verschaffen von bedeutenden Orten und durch ihre Lage wichtigen Landschaften.

Ehe man die Zeichnung beginnt, hat man zu prüfen, welcher Standpunkt die günstigste Ansicht gewähre. Da ferner Tageszeit und Beleuchtung hiebei von wesentlichem Einfluss sind, so nehme man wo immer möglich auch hierauf Rücksicht. Ferner hat man sich zum Voraus recht klar zu machen, was man in den Rahmen des Bildes aufnehmen will und ob dieser Theil, vom Ganzen abgelöst, wirklichen Werth habe. Falls man hiefür nicht schon ein geübtes Auge besitzt, so thut man gut, wenn man mit vier Papierstreifen oder Holzstücken einen Rahmen bildet von der Grösse des Zeichnungsblattes und dann die Landschaft durch diesen Rahmen betrachtet, so zwar, dass man demselben verschiedene Entfernungen vom Auge giht, his man für das projektirte Bild eine Umgrenzung gefunden hat, die geeignet scheint. Es ist diese letztere Aufgabe weniger leicht als man gemeinhin annimmt. Man darf ferner nicht vergessen, dass die Ansichten, die Zeichnungen üherhaupt, welche man zurückbringt, als Beilagen für das Reisewerk bestimmt sind und dabei folglich auch das Format berücksichtigt werden muss. Dieser Umstand influirt aber wieder auf die Grösse, in welcher einzelne Objekte - wenn eine gewisse Harmonie herrschen soll - dargestellt werden. Die Illustrationen des ${ }_{n}$ Tour du Monde" können in mehrfacher

1) Zur Ergänzung des dort Gesagten empfehlen wir die nGundsätze der Perspektive in Dienste des Zeichnens nach der Natur" von Prof. U. Schoop (Frauenfeld 1868). 
Beziehung als Muster angeführt werden, so auch in Bezug auf das Format, dessen Dimensionen sind: 24 und $16 \mathrm{~cm}$ bei grossen und 16 und $8 \mathrm{~cm}$ bei kleinen Bildern ${ }^{1}$ ).

Nachdem man den Standpunkt gewählt hat, von wo aus das Sujet sich am günstigsten darstellt; nachdem man hiebei vor- und rückwärts, auf- und abwärts gegangen ist, um zu sehen, welche Modifikationen das Bild erleidet durch die Wahl - in der Sprache des Malers verstanden — von Distanz und Horizont, bleibt noch die Ausführung des Bildes.

Ich nehme an, man habe sich den Charakter der Landschaft und der Darstellungsmittel reiflich vergegenwärtigt mit Rücksicht darauf, dass ein Bild auf den Beschauer annähernd denselben Eindruck mache, den die Naturszenerie hervorbrachte. Diess ist nicht leicht. Die Eindrücke, die wir von den Objekten der Aussenwelt empfangen, sind bestimmt durch die Ideen, welche diese hervorrufen. Manchmal ist das Objekt selber und direkt Ursprung und Quelle des Eindruckes, unter dem wir stehen, und dann ist dieser qualitativ derselbe für alle Individuen; oft aber beruht der Eindruck auf einer ganz zufälligen Ideenassociation, auf persönlichen Stimmungen und Erinnerungen; dann ist er individuell sehr verschieden. Zwischen diesen Arten der Wirkung - derjenigen der Sache und dem Antheil der Ideen, die wir mit ihr verbinden - muss wohl unterschieden werden, wenn dasselbe Objekt auf Andere den gleichen Effekt hervorbringen soll wie auf uns.

Auch über die Art der Behandlung des Sujet muss man mit sich zu Rathe gegangen sein, z. B. bei einem Aquarell darüber, welche Töne man verbinden will, wie Luftperspektive und Halbdunkel wirken. Wohl muss man lediglich die Natur nachahmen und ihren Charakter wiedergeben; aber die Wahl der Mittel hiebei ist nicht unwesentlich. Es gibt zudem Fälle genug, wo diese Nachahmung keine ängstliche, sklavische sein darf. Nicht Alles ist schön, was man erblickt, und Niemand wird den Zeichner tadeln, der im Bilde eine Telegraphenstange weglässt, welche in der Landschaft sich unschön ausnimmt, oder Bäume, die

1) Le Tour du Monde. Journal de Voyages, publié sous la direction de M. Edouard Charton, Paris 1960 à 81 . 
keine gute Figur machen, etwas besser darstellt. Ebenso darf man, ohne der Treue des Bildes nahe zu treten, grosse gleichfömige Flächen durch eine Einzelheit unterbrechen; solche Details sind z. B.: ein Kahn mit Fischern auf einem See, Rinder auf einer Weide, ein Wagen oder Fussgänger auf einer ebenen Strasse. Soll die Gegend als unbelebt oder verödet dargestellt werden, so darf man als Mittel der genannten Art wenigstens Wolkenschatten rerwenden. Meist aber ist es passend, die Landschaft belebt erscheinen zu lassen: einsame Wälder durch Raubvögel und Rothwild, Sümpfe durch Wasservögel, den Meeresstrand durch eine Barke und eine Fischergruple, eine Stadt - einen Hafenplatz vor Allem - durch eine grosse greschäftige Menge mit Mamnigfaltigkeit der Stellungen und Haltung. Die Oede einer Lokalität, welche selten ein Mensch betritt, wird dadurch noch mehr herrorgehohen, dass man in ihr Bild den Reisenden hineinstellt, der sie aufsucht. Zudem liefert eine Figur ein Mass zur Schätzung und Beurtheilung der Dimensionen anderer Objekte. Es rersteht sich aber ron selber, dass man bei dieser Belebung und Berölkerung eines Landschaftsbildes mit kritischem Urtheil nur Dasjenige wählen darf, was der Gegend, die man darstellt, wirklich zukömmt und angehört, resp. mit ihr rereinbar ist, dass ferner diese Finzelbilder gut angeordnet und - handle es sich um Menschen oder Thiere - in naturgemässer, lebendiger und wechselvoller Stellung gehalten sein müssen. Der Beschauer soll aus dem Bilde herauslesen können, was jedes der dargestellten Wesen thut und will. Nichts rerleiht einer Landschaftszeichnung mehr Lokalcharakter als diese Einführung von Figuren, die allerdings vielleicht im gegebenen Moment nicht da sind, die aber in einem andern Zeitpunkt da zusammentreffen können. Von dieser Freiheit abgesehen, soll die Darstellung durchaus genau naturgetreu sein, so dass F'ersonen, welche jene Orte besucht haben oder später besuchen, sich nach der Zeichnung selbst im Einzelnen zurechtfinden können.

Was Ansichten von Städten und andern merkwürdigen Orten betrifft, so wird man sie rorzugsweise ron der Seite aufnehmen, von welcher der Ankömmling sie gewöhnlich erblickt und ron einem Punkte aus, der ein Gesammtbild 
bietet; dieser Ansicht können dann immerhin solche beigefügt werden von andern Punkten aus, die vielleicht Bilder von grösserer malerischer Wirkung liefern. Zeichnungen in Vogelperspektive haben den Vortheil, dass sie zugleich als Ansicht und Plan dienen können, wie die nebenstehende Taf. XVI zeigt, die dem Berichte von Rob. Shaw über seine Reise in der hohen Tartarei ${ }^{1}$ ) entnommen ist.

Panoramen. Die Panoramen haben, wie schon bemerkt, den Vorzug, dass sie ein allgemeines Uebersichtsbild einer ausgedehnten Gegend bieten. Sie erleichtern die Orientirung in gewisser Hinsicht mehr als die Karte, weil sie die Objekte so darstellen, wie man dieselben in Wirklichkeit erblickt. Man kann zudem in die Panoramen wie in Karten die Namen der Orte, Flüsse, Berge (und namentlich die der Hauptgipfel) eintragen. - Die wesentlichste, man darf fast sagen, die einzige Anforderung an ein Panorama ist die: dass es exakt sei; schöne Ausführung ist nicht absolutes Erforderniss; man kann sich auf eine Zeichnung in blossen Linien beschränken; es wird dabei manchmal eher möglich, die Umrisse genau anzugeben und Details hervorzuheben.

Es wäre eine sehr zeitraubende und schwierige Arbeit, wollte man ein inhaltreiches, viel umfassendes Panorama nach dem blossen Anblick und doch genau erstellen; man wendet daher hiezu verschiedene Instrumente an, wie die camera obscura, die camera lucida, eine Glastafel etc., komplizirterer Instrumente $^{2}$ ) nicht zu gedenken. Der Reisende wird sich indess nicht — blos in der Voraussicht, dass er allfällige Panoramen zu zeichnen habe - mit solchen Instrumenten beladen; er muss trachten, auch hiezu diejenigen Instrumente zu verwenden, womit er ohnehin versehen sein soll: den photographischen Apparat und den Theodolit.

Mit dem ersten kann man ein vollständiges Panorama erstellen, wenn man denselben absatzweise auf seinem Gestelle als um eine vertikale Axe dreht, so dass man einen Cyclus aufeinanderfolgender Bilder erhält, Abschnitte des Gesammtpanoramas, welche den ganzen Horizont umfassen. Mit dem Theodolit nimmt man von einem zentralen Standpunkte aus

1) Rob. Shaw, Reise nach der hohen Tartarei, Yarkand \& Kaschgar, Jena 1876.

2) Vgl. z. B. den Teleiconograph von Révoil und Violet-le-Duc, beschrieben in des letzteren Werke: Le Massif du Mont Blanc, Paris 1876. Introduction pag. XI. 
Taf. XVI.

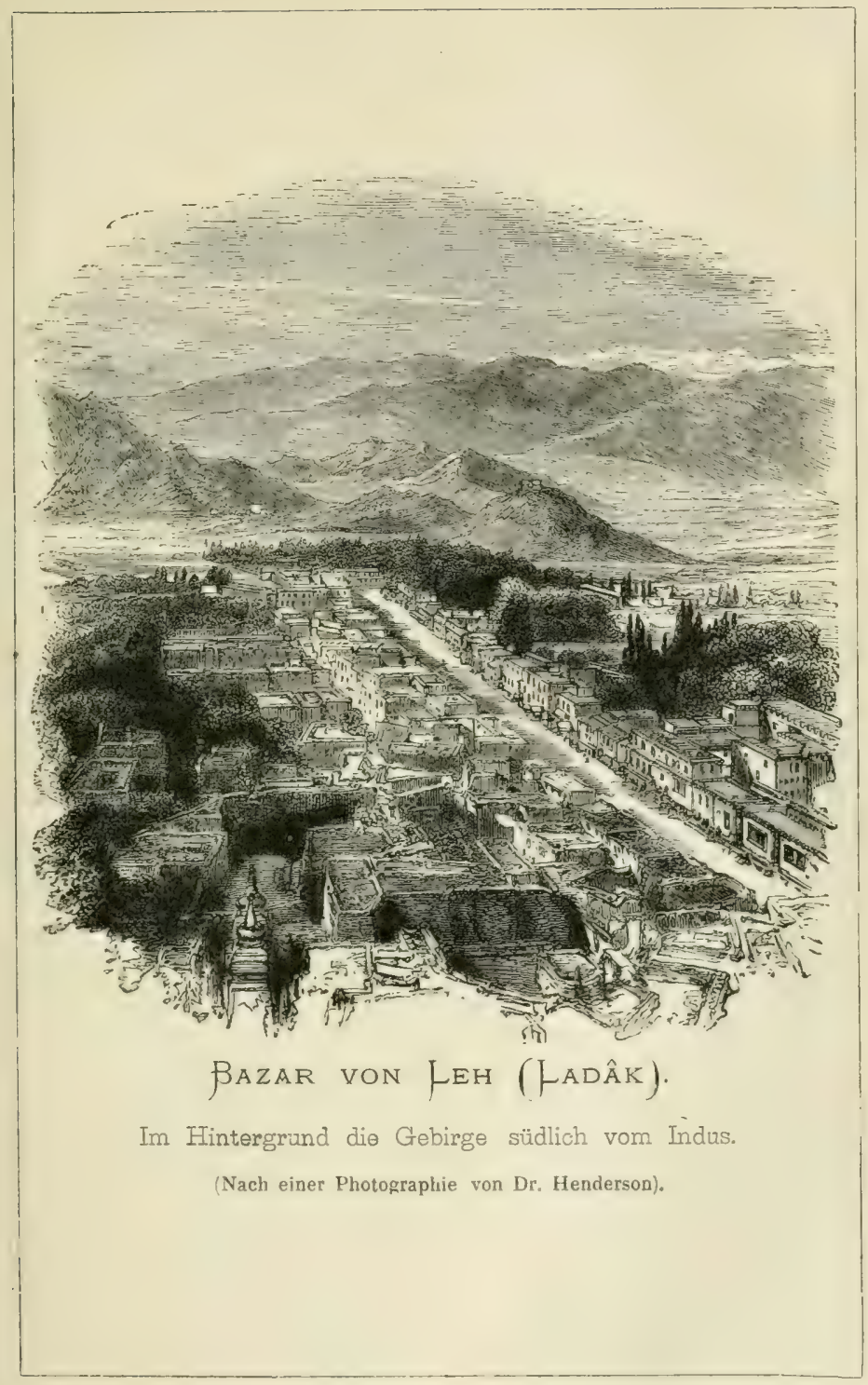





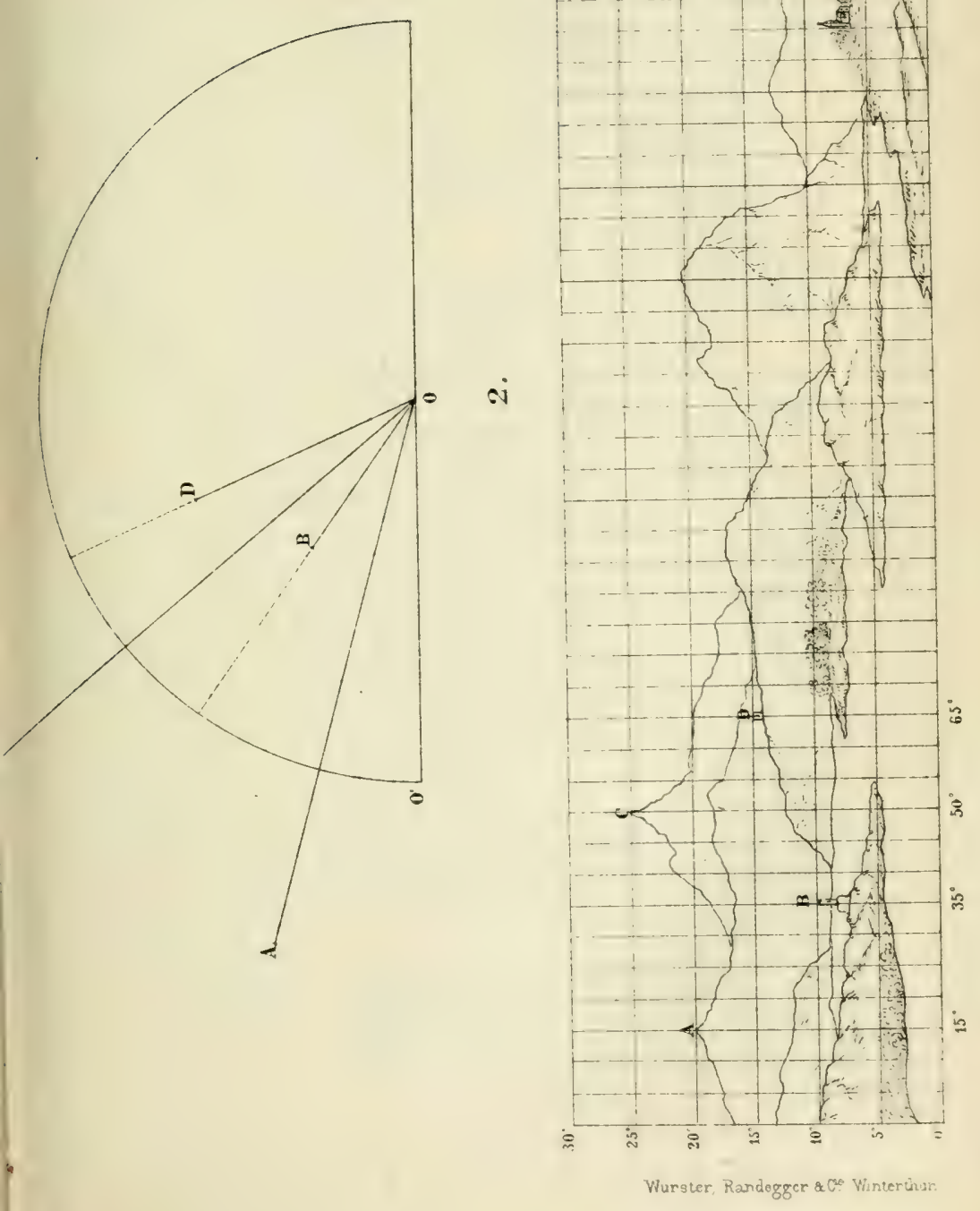



die Winkel auf, unter welchen man die Objekte zu einander erblickt, um ihre gegenseitige Lage festzustellen und die nöthigen Anhaltspunkte für eine grute Skizze zu gewinnen. Für einen jeden Punkt bestimmt man den Direhtions- und den Höhenwinkel. Es ist zu herücksichtigen, dass bei einem Panorama alle Gegenstände, ob nah oder fern, in Einer Ehene dargestellt werden, so dass deren Entfernung als konstanter Radius hetrachtet wird und die Höhenunterschiede in der Zeichnung nur von dem grössern oder kleinern Betrag des Winkels abhängen, unter welchem man die anvisirten Ohjekte prblickt. Lm die wirkliche Höhe des Punktes laandelt es sich nicht: ein naher Thurm kann einen fernen Berg ron einigen tausend Meter Höhe verdecken. Das Verfahren bei der Aufnahme und Zeichnung ist folgendes. Es sei $O$. Tut. XIII, Fï. 1, der Standort, $O^{\prime}$ der Ausgangs- oder Anfangspunkt.

$O A$ Visirstrahl nach einer Bergspitze $A$, Direktionswinkel $15^{\circ}$, Elevationswinkel $20^{\circ}$,

$O B$ Visirstrahl nach einem Leuchthurm $B$,

Direktionswinkel $35^{\circ}$, Elevationswinkel $10^{\circ}$,

$O C$ Visirstrahl nach einem Gipfel $C$,

Direktionswinkel $50^{\circ}$, Elevationswinkel $25^{0}$,

$O D$ Visirstrahl nach einem Kirchthurm $D$,

Direktionswinkel $65^{\circ}$, Elevationswinkel $15^{0}$

u. s. f. Nun nimmt man linirtes Papier, z. B. sogen. Commercial (Tut. XVII, Fi!. 2), wohei die Höhen der Rechtecke doppelt so gross sind als die Längen, damit das Panorama nicht zu flach erscheine; jedes Feld stelle etwa $5^{0}$ ror, so ist es sehr einfach auf diesem Papier die Punkte $A, B, C, D$ etc. zu hezeichnen, welche als Fixpunkte für das Entwerfen der Skizze dienen.

Fixirmittel. Um in Kreide oder weichem Bleistift ausgreführte Zeichnungen vor dem Verwischen und Abreiben zu schützen, bedient man sich rerschiedener Mittel, den Graphit oder die Kreide auf dem Papier zu fixiren. Das beste ist folgende Mischung:

4 Theile fettes Oel,

6 , Terpentinessenz,

1 , Firniss. 
In Ermanglung dieser Stoffe kann man auch schwarzen Kaffee, Milchkaffee oder Milch, Gummi- und Zuckerwasser und selbst gewöhnliches reines Wasser anwenden. Das Papierblatt wird mit diesen Flüssigkeiten befeuchtet (z. B. unter einer Brunnenröhre) oder in dieselben eingetaucht — beides rasch — und dann lässt man es trocknen, am besten aufgespannt, damit es nicht Blasen wirft.

Beschreibung. Der Karte und den Ansichten, die aufgenommen wurden, hat man endlich die topographische Beschreibung der Gegend beizufügen. Positive Vorschriften hierüber lassen sich nicht geben. Der Werth der Beschreibung hängt zunächst ab von der Vollkommenheit in der erlangten Kenntniss des Landes; sodann von dem Anschauungs- oder Auffassungsvermögen in Bezug auf die räumlichen Formen; endlich vom Geschick, in wirksamer, anschaulicher und ansprechender Weise wiederzugeben, was wir zu unserm geistigen Eigenthum gemacht haben. Vor allen Dingen trachte man nach Klarheit der Darstellung, damit dem aufmerksamen Leser nicht Zweifel aufsteigen über das, was thatsächlich dargelegt werden wollte — Zweifel, welche ein Gefühl der Unsicherheit, Misstrauen und Unmuth wecken. Man gebe einen genauen und vollständigen allgemeinen Ueberblick über die zu beschreibende Gegend, und vergegenwärtige sich dabei neuerdings lebhaft alle Verhältnisse der Form und Lage, die man durch Rekognoszirungen und topographische Aufnahmen kennen lernte. Aber man hüte sich, diese Vertrautheit mit der Gegend - trotz Karten und Ansichten, die man beifügt - auch schon beim Leser vorauszusetzen. Vielmehr halte man möglichst darauf, dem Text, bei aller Bezugnahme auf die graphischen Beilagen, Verständlichkeit, Anschaulichkeit und so zu sagen plastische Wirksamkeit zu geben, als ob er selbständig, für sich allein, da wäre. Daneben wird es Aufgabe des Verfassers sein, aus der Darstellung Trockenheit fern zu halten, um auch in dieser Hinsicht den Leser zu fesseln.

\section{GEOLOGIE.}

Es gibt ein Gebiet der Geologie - und nicht das unwesentlichste - welches ein Jeder, ohne dass er Geolog von Fach ist, in der Gegend, welche er besucht, studiren 
kann; es ist dasjenige, was wir die Cremtumie der Erdutureflüch nennen werden und worunter wir die Erscheinungen und Veränderungen an der Erdoberfläche verstehen, welche in relativ neuer Zeit stattgefunden haben und fortwïhrend noch stattfinden. Ihr stellen wir gegenüber die Creotonge des Erdimern, welche sich mit der Struktur des Bodens, mit den rerschiedenen geologischen Formationen und deren Alter befasst und welche zu ihrer Anwendung und ihrem Verständniss viele Spezialkenntnisse und viel Tebung erfordert.

\section{GEOLOGIE DER ERDOBERFLÄCHE.}

Niveau-Aenderungen. Bekamntlich findet man an den Abhängen und auf Gipfeln sehr hoher Berge versteinerte Inschehn des Meeres; am Himalaya z. B. his z.u $4600 \mathrm{~m}$ absoluter Höhe. Daraus folgt, dass entwedter eimmal das Meer bis zu diesen Höhen hinaureichte und sich nachher um diesen ungeheuer grossen Betrag zurückzog und rerkleinerte, oder aber dass die Felsen, welche jene Muscheh einschliessen, früher in der Tiefe sich befanden und später emporgehoben wurden auf die Höhe, wo wir sie jetzt finden. Auf die eine oder andere Weise müssen jene Felsen einmal unter dem Meeresspiegel gewesen sein, so dass marine Muscheln sich auf und in denselben einfinden konnten. Num ist aber der erste Theil der Alternative zum Tornherein unwahrscheinlich: wenn die Berge früher schon die Höhe gehabt hätten wie jetzt, wemn der Ozean diese Hühen erreicht und bedeckit, dann aber durch Verdunstung und Rückzug sich auf seinen jetzigen Stand reduzirt hätte - wohin sollten so ungeheure Wassermassen gekommen, welches sollten die Lrsachen einer so unbegreiflichen Verdunstung gewesen sein? I)ie Hypothese, ron der die Rede ist, könnte auch offenbar nur angenommen werden, wenn die Gesteinsschichten mit eingeschlossenen Meermuschehn nur aus wagrechten regehmässigen Bänken bestünden, nach Art der Ablagerungen, die sich jetzt auf dem Meerescrunde und an den Küsten hilden. Allein dies ist nicht der Fall; rielmehr sind jene Schichten und Bänke in schiefe, oft sehr stark geneigte, oft senkrechte Stelhung gebracht, gehoben, dislozirt. Diese Thatsache allein schon spricht ent- 
scheidend für die zweite Erklärungsart: das Material der Kontinente und Berge, die Gesteine mit Ueberresten von Meeresthieren, sind aus dem Schoose des Ozeans, auf dessen Grunde sie entstunden, sammt den organischen Einschlüssen emporgestiegen, emporgehoben worden. Bei dieser Bewegung, die mehr oder minder schnell oder langsam, ruckweise oder stetig erfolgen mochte, wurden viele Schichten aus ihrer ursprünglichen annähernd horizontalen Lage herausgebracht und traten grosse Störungen ein. Welches immer die Ursache (die causa efficiens) dieser Bewegung sei: wir sind durch die erwähnten Thatsachen gezwungen anzunehmen, dass in Laufe dex geologischen Perioden eine Gegend bedeutende Aenderungen ihres Niveaus erleiden konnte und musste.

Solche Veränderungen - Hebungen und Senkungen des Bodens - gehen noch vor sich; die Erdkruste ist keineswegs so stabil, wie man gewöhnlich glaubt. Zahlreiche Traditionen sprechen von Landgebieten, welche dem Schoosse des Meeres entstiegen und von früherem Festland, das jetzt Meeresboden sei. Ausserdem gibt es positive Beweise, zuverlässige Beobachtungen, welche konstatiren, dass solche Bewegungen in geologisch neuer Zeit vorkamen und noch vorkommen in der Gegenwart. Um bei dem bekanntesten Beispiel stehen zu bleiben, erwähnen wir nur die Beobachtungen von Celsius, Linné und andern Gelehrten über die Küsten von Schweden und Norwegen. Celsius und Linné brachten 1731 an Felsen der Ostseeinsel Loëffgrund Merkzeichen an, womit sie konstatiren konnten, dass diese Insel in 13 Jahren um $18 \mathrm{~cm}$ gehoben worden war. Im Jahre 1849 betrug die Differenz $91 \mathrm{~cm}$. Andrerseits bewies Nilson 1837, dass der Boden von Schoonen, des südlichsten Theiles von Schweden, sich gesenkt habe, dass ein Felsblock, dessen genaue Entfernung vom Meere Linné 1749 gemessen hatte, nunmehr $30,5 \mathrm{~m}$ näher am Meeresufer sei. Es beweist dies wiederum, dass diese Veränderungen nicht in Schwankungen (Steigen oder Sinken) des Meerespiegels bestehen; sonst wäre die Aenderung überall, jedenfalls wenigstens an derselben Küste, die nämliche nach Art und Betrag, während in Wirklichkeit nachgewiesen ist, dass in hundert Jahren der Hintergrund des bottnischen Golfes (bei $66^{0}$ n. Br.) um 1,6 m, die Küste bei den Aalandsinseln $\left(61^{\circ}\right)$ um $1 \mathrm{~m}$ gestiegen, die Südspitze Schoonens aber 
(bei Malmö, $56^{\circ}$ ) seit den Beohachtungen Linnés um 1,5 m gesunken ist. Es ist das also nicht ein allgemeines Sinken des Landes, sondern eine Schunlalberergung desselben um eine gewisse Axe.

Seit man auf diese Schwankungen aufmerksam gemacht hat, sind die Beispiele von solchen sehr zahlreich geworden; man hat sich überzeugt, dass sie sozusagen in keiner Gegend fehlen. Der nachgewiesene Betrag dieser Niveauändorungen ist ein geringer; allein man mass wohl bedenken, dass die Geologie eine noch junge Wissenschaft ist und die ersten Beobachtungen üher diese Oszillationen des "festen " Bodens aus dem Jahre 1749 datiren; mit Rücksicht auf die rerlältnissmässig kurze Zeit, die seit jenen ersten Messungen dieser Art verflossen ist, sind die Zahlenwerthe der in Rede stehenden Bodenbewegungen erheblich genug. Wenn es eines mehrere Generationen umfassenden Zeitraums bedarf, um jene langsamen sogenannten säcularen Aenderungen recht bemerkbar werden $\mathrm{zu}$ lassen, so sind andrerseits die jetzt schon erlangten Resultate hierüber derart, dass die Erscheinung, der Vorgang an sich, als eine unzweifelhaft nachsewiesene Thatsache bezeichnet werden muss. Wir sprechen nicht von den plützlich eingetretenen Niveauveränderungun, deren einige unter den Augen der Bewohner des betreffenden Gehiets sich preigneten, wie rlie Bildung des Monte Nuovo bei Teapel im Jahr 1538, die des Vulkans Jorullo in Mexico 1759, das Erscheinen und Verschwinden vulkanischer Inseln etc., sondern von den langsamen oder sürular'n Srhurankungen de's Budcns, deren Effekt erst nach längerer Zeit bemerkbar wird.

Es gehört zu den Aufgaben des Reisenden, zu erforschen ol) die Gegend, welche er besucht, solche Niveauschwankungen aufweist oder nicht.

Jies zu konstatiren, ist im Binnenlande sehr schwierig; denn gesetzt, man hätte für gewisse Punkte, deren Höhe cchon bestimmt war, durch neue Messungen andre Resultate erhalten, so wüsste man nicht, soll man diese einer Niveaureränderung oder aber Fehlern in der (alten) Messung zu- (hreihen. Erst auf Grund sehr genauer Nivellements (Präzisionsnivellements) wird man später solche Veränderungen nachweisen kömnen; zudem muss dahei vorausgesetzt werden 
dürfen, dass der Anfangs- oder Ausgangspunkt des Nivellements selber unveränderlich, unbeweglich sei. Inzwischen kann man Bodenschwankungen in Binnenländern nur nachweisen, wofern sie Veränderungen im Laufe fliessender Gewässer hervorgebracht haben. Wenn eine Wasserader allmälig immer mehr nach einer und derselben Seite hin verlegt wird, so beweist dies, dass auf dieser Seite eine Senkung oder auf der andern eine Hebung des Bodens stattfand. Wenn ein Gewässer seinen Lauf so ändert, dass er rom frühern, unter Durchbruch des alten Ufergeländes, senkrecht abbiegt, so muss unzweifelhaft der Boden nach dieser Seite hin gesunken sein. Wenn ein Fluss in seinem Unterlauf ein trockenes, verlassenes Bett aufweist, das Wasser sich im Boden verliert oder Seen, Lagunen und Moräste bildet, so kann man daraus auf eine stattgefundene Hebung der Küstengegend schliessen. Uebrigens können Niveauveränderungen, ausser durch Bodenschwankungen, auch durch Ablagerungen und Abtragungen (Erosion) des Wasser's und andrer Agentien verursacht sein. Die egyptischen Tempel sind halb begraben im Wüstensand; der alte Boden, worauf sie erbaut sind, liegt also in einer gewissen Tiefe unter dem jetzigen. Dir Seitenterrassen der Thäler andrerseits zeigen uns, wie wir später sehen werden, dass früher der Thalboden höher war als jetzt.

Leichter sind die in Rede stehenden Nachweise in Küstenlandschaften, wo der Meeresspiegel eine Basis für Vergleichungen bildet. Allein die Methode, deren sich Linné bediente, wäre kaum anwendbar für einen Reisenden, der selter so lange in einem Lande bleiben wird, dass allfällige Bodenschwankungen inzwischen messbare Beträge liefern würden Alles was er in dieser Richtung thun könnte, bestünds darin: dass er Fixpunkte anbrächte, deren Entfernung von Meere oder deren Höhe über dem mittleren Meeresspiegel genar bestimmt würde; den Bewohnern des Landes oder künftiger Reisenden läge es ob, nach Verfluss einer mehr oder mindes langen Zeit zu konstatiren, ob sich Veränderungen in der Lage dieser Merkzeichen nachweisen lassen oder nicht.

Es gibt aber glücklicherweise andere Mittel, um diest Niveauänderungen $\mathrm{zu}$ erkennen und oft auch zu messen Hieher gehört vorab die Kenntniss des früheren Zustand: 
der Dinge nach mündlichen Teberlieferungen, alten Karten und Schriften. Auf diese Weise konnte der berühmte Geologe Leopold ron Buch die Hebung der Nordküste des hottnischen Golfes konstatiren; er brachte nämlich in Erfahrung, dass an der Stelle, wo jetzt die Strasse dem Meeresufer entlang lüuft, ehemals die Fischerbarken sich tummelten. Felsen, die jetzt im gleichen Niveau mit dem Meeresspiegel liegen, während sie früher, etwa nach Beobachtungen alter Lootsen, über die Wasserfläche emporragten; seichte Meeresluchten, an deren Stelle früher, wie Greise sich erimnern, Fulturland war, oder Torkommnisse entgegengesetzter Art sind Anzeichen ron Schwankungen des Bodens in der einen oder andern Richtung, Schwankungen, deren Betrag (Amplitïde) man wenigstens annähernd hestimmen kann, wemn man den Zeitraum kennt, in welchem sie vor sich gingen. Stärlte. welche alte Geographen als Hafenplaitze nemen, die aber jetzt in einiger Entfernung rom Neere und über dessen Niveau liegren, sind gewichtige Beweise einer Hebung der Kü̈sten. So befindet sich der alte rümische Hafen Alaterra (Cramond), dessen Quais man noch sieht, heute 7,5 m über dem Neere in ziemlich grosser Entfernung von der Küste. Andrerseits ist die Abtei Saint-Nicolas-de-Grave, ron der die Chroniken des 13. Jahrhunderts samen, sie sei auf einem Vorgebirge erbaut, rerschwunden - untergetaucht; nur ein Theil des Vorgebirges ist sichthar gehlieben: es ist der rorker de Cordoum, welcher $7 \mathrm{Km}$ von der Kü̈ste entfernt ist, mit welcher er nach der Tradition noch gegen das Jahr 1500 durch eine Landzunge verbunden war. Man wird ferner die alten Hafenbücher und hydrographischen Karten zu Rathe ziehen, um zu sehen ob ihre Angaben, Tiefenzahlen u. s. w. dem jetzigen Zustand entsprechen. Beim Nachmessen der Tiefen muss man namentlich sondiren über Klippen und Felsgrund üherhaupt, d. h. an Stellen, wo eine Tiefendifferenz nicht von Versandung oder von Auswaschung durch fliessendes Wasser herrühren kann. In manchen Fällen künnen die Schwankungen direkt nachgewiesen werden ohne Zuhülfenahme ron Zeugenaussagen und historischen Anhaltspunkten. Hat z. B. das Meer untere Quartiere einer Stadt oder eines Dorfes am Gestade rerschlungen orler bedeckt es zum Theil eine Strasse, welche 
der Küste entlang geht, so muss an diesen Stellen eine Senkung vorgekommen sein; wenn ein Hafen die nöthige Tiefe nur beibehält in Folge von Baggerungen und ähnlichen Wegräumungsarbeiten, so ist es wahrscheinlich, wenn nicht gewiss, dass der Boden sich hebt. Ebenso zeigen Fluthmarken über dem jetzigen Wasserstand, frühere Hafenplätze, die nun im Lande liegen, Ringe, die zum Anbinden der Schiffe dienten und jetzt rom Wasser weit abstehen, sowie ähnlich gelegene alte Anker und andere Schiffsüberreste eine stattgefundene Hebung an; während andrerseits vom Wasser verschlungene Gebäude, römische Gräber, Strassen, Mosaikboden u. dgl., die jetzt vom Meere bedeckt sind, offenbar eine Senkung des Bodens verrathen, der sie trug. Endlich gibt es natürliche Merkzeichen stattgefundener Oszillationen des Bodens. Solche sind einerseits die Spuren des früheren Meeresspiegels, welche an den gehobenen Strandfelsen durch Bohrmuscheln (Lithophagen) sowie durch die Wirkung des Wassers entstanden und die alten Küstenumrisse, welche bezeichnet sind durch Dünenwälle und landeinwärts liegende alte Uferlinien; andrerseits Spuren von unter Wasser versenkten Wäldern, bestehend in Ueberresten von Landpflanzen.

Gewisse Schalthiere des Meeres wie die Stein- und Messermuscheln (Pholaden und Balanen) bohren in die Felsen Löcher, worin sie wohnen, und sie thun das namentlich an der Wassergrenze. Solche Löcher findet man ausser an dem gewachsenen Fels der Küste auch an Gebäuden, deren Fuss lange vom Meere bespült wurde. Beobachtet man nun diese Bohrmuschelspuren in einem Niveau, welches vom Meeresspiegel nicht mehr erreicht wird - an Felsen des Strandes, am Fuss eines Leuchtthurmes, an einem Damme, Quai oder einem Gebäude: so weis man, dass hier der Boden gehoben worden ist. Ja wenn das Gebäude, um welches es sich handelt, seiner Bestimmung gemäss ursprünglich ausser dem Bereich des Meeres gewesen sein musste, so kann man aus solchen Bohrlöchern auf eine zweimalige Niveauveränderung schliessen: es musste eine Senkung eintreten, damit die Fluthen das Gebäude bespülen konnten, und dann eine Hebung, welche es wieder ausser den Bereich des Wassers brachte. Ein klassisches Beispiel hiefür bietet der Serapistempel bei Neapel. 
Diese langsamen Bodenschwankungen bewirken keineswegs den Einstur'z der Gebäude; und aus dem guten Zustand, in welchem solche sich befinden, darf man nicht ohne Weiteres den Schluss ziehen, dass seit deren Bau der Boden, ihre Unterlage, stabil geblieben sei.

Sind die Bohrlücherreihen am Ufer, an Gebäuden u. s. w. nahe an einander, so muss die Hebung eine langsame, allmälige gewesen sein; stehen sie aber von einander ziemlich weit $a b$, so beweist dies, dass die Hebung rascher vor sich ging, es wäre denn, dass Hebungen mit Senkungen gewechselt hätten.

Lnter der steten Einwirkung der Wellen bilden sich an Steilküsten Höhlen oder Grotten, deren Niveau gegeben ist, indem es da liegt, wo die Wogen brandend an die Küsten schlagen: zwischen dem Wasserspiegel und derjenigen Höhe, in welcher die Kraft der Wellen sich rerliert, indem diese in Schaum zerstieben. Wenn man also in einer Höhe, wohin jetzt die Wellen nicht mehr gelangen, solche Höhlungen bemerkt, so kann man daraus auf eine Hebung der Küste schliessen. Würde man im Gegentheil dergleichen Grotten wahrnehmen, welche sich unter Wasser befinden, so wäre damit eine Senkung nachgewiesen.

Indem die Meereswogen beständig die Felsen des Strandes benagen, bilden sie ferner in der Ebene des Wasserspiegrels oder etwas höher oben eine Art Gesimse oder Plattformen, mehr oder minder ausgedehnte Terrassen: „horizontale Einschnitte an den Felsabhängen der Küste, welche sich, wemn grut erhalten, wie Wege ausnehmen, die man durch Einsprengung in die Felswand eingelegt hat ${ }^{\text {"1 }}$ ). Die Felsen unter dem Wasser sind geschützt; die obern werden erodirt; zwischen beiden bildet sich in wagrechter Richtung, im Niveau des Meeres, eine gesimsartige Fläche. Wo die Gezeiten sich greltend machen, entstehen gewöhnlich zwei solcher Terràssen : wovon eine der Fluth und die zweite der Ebbe entspricht. Beobachtet man nun solche Formationen über oder unter

1) Ueber ehemalige Strandlinien in anstehendem Fels in Norwegen von Dr. R. I.ehmann, Halle 1879. Vgl. Naturforscher 1879, Nr.39. Zur Strandlinienfrage von Dr. R. Lehmann; Giebel's Zeitschrift für die Gesammten Yaturwissensehaften 1880, S. 280. Ebendaselbst (S. 246-279): C. Petersen, Scheurungserscheinungen in der gegenwärtigen Littoralzone. - Gäa 18s0, XII. Heft, S. 701: Graf F. Berg, die strandlinien Surwegens. - Studer, physikalische Geographie I. Bd. S, 177 ff. und $365 \mathrm{fr}$. 
dem jetzigen Wasserspiegel, so sind das werthvolle Anzeichen stattgehabter Schwankungen des Bodens.

An Flachküsten führen die Wogen bei ihrem Rückzug Kies und Sand mit sich und bilden so zusammenhängende Wälle oder einzelne Hügel von Sand und Geröll, Strand- oder Uferwälle und Dünen ${ }^{3}$ ). Findet man nun an einer und derselben Küste. mehrere solcher Wälle oder mehrere Reihen von Dünen, so muss die Küste gehoben worden sein; denn jede Düne bezeichnet eine Meeresgrenze für eine bestimmte Periode. Sind die Strandwälle und Dünenketten weit von einander entfernt, so muss die Hebung rasch, ruckweise vor sich gegangen sein; langsam aber, wenn die Hügel nah aneinander, nicht. scharf getrennt und hervortretend sind.

Neeres- oder Küstenterrassen finden sich oft tief im Binnenlande. Man muss aber sehr aufmerksam beobachten, um sie zu erkennen, denn oft sind sie verdeckt durch Wald und Buschwerk, oft durch Schutthalden, die an ihrem Fusse in Folge Verwitterung der obern Partien sich gebildet haben; oft auch sind sie tief durchfurcht von Wasserrinnsalen, so dass der Zusammenhang unterbrochen, die Wand zerstückt ist. In. allen solchen Fällen wird man genau prüfen, ob man es mit einer alten Steilküste zu thun hat oder nicht. Die Kennzeichen, welche eine solche nackte Felsmauer als früheren Strand charakterisiren, sind: Spuren von Erosion durch Wellenschlag; Löcher von Bohrmuscheln; Grotten am Fuss steiler Wände; fest verkittete Konglomerate aus Sand und Strandgeröllen (platte und glatte Steine), mitunter gemischt mit Meermuscheln — welche Konglomerate sich in den erwähnten Grotten und am Fusse der Steilwände vorfinden.

Enge, nach dem Meere zu ausmündende Thäler können alte Fjorde ${ }^{2}$ ) einer gehobenen Küste sein; es sind daher deren Seitenwände aufmerksam zu beobachten; die Spuren einstiger Bespülung durch das Meer sind hier sehr oft besser erhalten als anderwärts.

An Küsten mit Korallenriffen sind Bewegungen des Bodens leicht zu konstatiren; da die Polypen nicht ausserhalb des

1) Vgl. unten S. 238, ferner Peschel-Leipoldt, Physische Erdkunde, I. Band, Leipzig 1879, S. 447 ff. B. Studer, physikalische Geographie und Geologie, 1. Bd. S. $186 \mathrm{ff}$.

2) Vgl. Peschel-Leipoldt, a. a. O. S. 352 ff. und $461 \mathrm{ff}$. Desor, der Gebirgsbau der Alpen. 
Wassers und nicht in grosser Tiefe leben können, so beweisen Korallemiffe, die sich über dem Meeresspiegel befinden, da sie nur unter Wasser entstanden sein können dass eine Hebuny stattgefunden hat; grosse Tiefen aber in der Nähe ron Korallenriffen sind ein Beweis für ein allmüliges Sinken des Meeresurundes: denn die P'olypen komnten ihren Bau nur beginnen auf einem nicht tief unter Wasser gelegenen Fundamente.

Für den Reisenden handelt es sich in all diesen Fätlen um genaue Beohachtung der Thatsachen. Was die Lrsachen dieser langsamen, säkularen Oszillationen der Erdrinde anbetrifft, so ist man dafür immer noch auf Hypothesen angewiesen. Der Beobachtung entgehen sie, ausgenommen, wemn es sich um lokale und mehr zufällige Niveauänderungen handelt ${ }^{1}$ ).

Umgestaltung der Küsten. Hebungen und Senkungen rerändern selbstrerständlich die Küstenumrisse; es gribt aber Tmgestaltungen der Grenzlinien zwischen Land und Wasser, die ron andern [rsachen herrïhren. Eine Meereshucht, ein Hafen künnen versanden; die Küste zieht sich dann zurück, olme dass eine Niveauänderungr stattgefunden hätte. Vielleicht hat man aber, gestützt auf einzelne solche Vorkommuisse, zu sehr generalisirt und ist es wahrscheinlich, dass unter den Fällen, die man als hiehergehörig aufgezählt findet, mehrere sind, wobei langsame Hebungen des Bodens mit-

1) Wir geben diesen Abschnitt unverändert nach der Fassung des französischen Origicals. Es kann dies um so eher gescheben, als darin nachdrücklich betont wird, dass die Beobachtung der Thatsachen das Wesentlichste sei. Immerhin wollen wir in Betreff der einschlägiten greologischen Theorien beifügen, dass sich in denselben ein wichtiger Umschwung bemerkbar macht. Schmick, Trautschold und Petersen haben in neuerer Zeit die Ansicht verfochten, nicht das Land ändere sein Nireau, sondern das Meer; ihnen schliesst sich nun der berühmte österreichische Geologe Ed. Süess an. Derselbe erregte grosses Aufsehen durch einen in den Sitzungen der geologischen Reichsanstait zu Wien mitgetheilten Vortrag -über die rermeintlichen säkularen Schwankungen einzelner Theile der-Erdobertäche , worin er die Ueberzeugung aussprach, dass es keinerlei vertikale Bewegungen des Festlandes gebe. Die Erscheinungen, welche als Belege für die säkularen Hebungen und Senkungen angesehen werden, erklärt Süess (wie Schmick) durch fortdauernde Veränderungen in der Gestalt der flüssigen Hülle des Erdkürpers. Eine grüssere Arbeit des geistvollen Wiener Geologen über diesen Gegenstand - die eigentliche Vertheidigung seiner Lehre und Diskussion der gegen dieselbe unrerzüglich entstehenden Einwendungen - soll nachfolgen. Vgl. Verhandlungen der k. k. geologischen Reichsanstalt 1880 Xr. 11. Petermann's geographische Mitheilungen $1880 \mathrm{Nr}$. 4. - Die bis anhin herrschende Anschaung über diesen Gegenstand findet man kurz dargelegt in einem Vortrag vor Dr. Toula üher säkular. Hebungen und Senkungen. Vigl. auch Heer's "Crweltw und Darwin's -Korallenriffe, $"$ 
wirkten. Die Stadt Adria in Venetien, von welcher das adriatische Meer seinen Namen hat, liegt jetzt $18 \mathrm{Km}$ von der Küste entfernt; Ostia am Tiber wurde, wie sein Name andeutet (Ostium, Mündung) an der Mündung des Flusses erbaut; die Stadt wurde auch wiederholt näher ans Meer verlegt, und doch ist sie jetzt davon ziemlich weit entfernt; in diesen Fällen darf man annehmen, die Landstriche zwischen Meer und Stadt seien durch Ablagerungen der Flüsse gebildet worden: Der Detritus, den Po und Tiber mit sich führen, kann hiezu genügen. Wenn aber der alte Hafenplatz Utica in Tunis rom Meere jetzt durch eine weite Ebene getrennt ist, so scheint es kaum statthaft, dass dies ohne mitwirkende Küstenhebung blos durch Alluvionen, eines so unbedeutenden Flüsschens wie der Medjerda geschehen sei. Ebenso scheint es unwahrscheinlich, dass Einbrüche des Meeres wie die Bildung der Zuydersee ohne Bodensenkung, bloss durch Wasserwirkung, verursacht worden seien.

Wie dem auch sei: Vorgänge, deren Wirkung weniger in einer Aenderung des Niveaus als vielmehr in einer Umgestaltung der Küstenumrisse besteht, besprechen wir unter letzterem Titel und rechnen also hieher die Versandungen und Auffüllungen (Colmatirungen) einerseits wie Meereseinbrüche andrerseits. Dem Reisenden bleibt es überlassen, in jedem Spezialfall die verwickelten Ursachen der Erscheinung zu erforschen.

Streng genommen gibt es keine Küste, die bei der bald zerstörenden bald aufbauenden Wirkung des Wassers unverändert bleibt. Eine jede wird im Laufe der Zeit mehr oder weniger umgestaltet. Für den Reisenden ist es von Interesse, diese Veränderungen zu studiren, sei es vom rein geologischen Standpunkt aus, sei es mehr mit Rücksicht auf die historische Seite der Sache: die Frage nach der früheren Konfiguration des Landes.

Den Aenderungen, wovon wir sprechen, ist eine Küste in um so höherem Grade unterworfen, je mehr Vorsprünge und Einschnitte sie hat. Die Wellen üben ihre zerstörende Thätigkeit namentlich an den zungenartigen Vorsprüngen des Landes, und das Gerölle und den Sand, welche sie mitführen, setzen sie namentlich in den Buchten mit ruhigen Wasser ab. Die Küstengestalt, welche am meisten Wider- 
standsfähigkeit besitzt, ist indessen nicht die gradlinige, sondern eine regelmässig hin- und hergebogene.

Die hohen Steilküsten sind den Angriffen des Wassers mehr ausgesetzt als die niedrigen Flachlï̈sten: die ersteren bieten den anprallenden Wogen eine grössere Angriffsfläche dar. Dabei wirkt das Wasser nicht blos durch seine eigene Kraft, sondern auch durch die Gesteinstrümmer, welche die heramrolleuden Wogen mit sich führen und gegen die Felsen schleudern. Diese unaufhörliche Thätigkeit der Wellen unterhöhlt die Felsen am Strande, sodass obere Theile dersellen herunterstürzen: schmale Spalten werden rerbreitert und ganze Blücke des anstehenden Gesteines lösen sich ab: die Trümmer werden von den brandenden Wogen gewissemassen als Widder gegen die Felswände geworfen und helfen so mit an dem Werke der Zerstörung. Die Grundwellen erreichen die Küste mit ausserordentlicher Höhe und Gewalt, die oft noch vermehrt wird durch Stürme, sorlass ihr Anprall den Fels in seiner ganzen Masse fort und fort erschüttert. $\mathrm{Zu}$ dieser grossen mechanischen Wirkung (Erosion) hommt hinzu, dass das Meerwasser hei seinem salzquhalt auch eine grössere lösende Kraft hat als süsses Wasser, dass mithin ein starkes chemisches Erosionsvermören dem mechanischen noch Hülfe leistet. Der Widerstand der Küsten ist rerschieden nach Härte, Kompahtheit und Schichtung des Gesteins. Alle Steilküsten aber werden erodirt und rückwärts gedrängt.

Kleinere und grössere Inseln und Klippen in der Nähe der Küsten sind gewöhnlich abgelöste Theile des Kontinents, mit welchem sie früher fest verbunden waren und zu welchem von ihnen aus oft noch untermeerische Felsrücken hinüberleiten. Bei aufmerhsamer Prüfung der Formen und des Reliefs dieser sogenamnten kontinentalen Inseln, der Richtung ihrer Berokitmme und Felsschichten, kann man öfters die früheren Landumrisse in grossen Zügen rekonstruiren. Indessen künnen solche Lostrennungen auch verursacht werden durch rasche, gewaltsame Dislokationen; einen solchen Vorgang wird man annehmen müssen, wenn die Schichtung der beiden Theile (der Insel und des gegenüberliegenden Landes) eine ungleichartige (diskordante) ist. Endlich ist nicht zu übersehen, dass durch Senkung und Hebung Halbinseln zu Inseln werden können und umgekehrt. 
Von allen Seiten der Wirkung des Wassers ausgesetzt, nehmen die Inseln mit steilen Küsten fortwährend an Grösse ab; umgekehrt werden aus gleichen Ursachen Meerengen mit steilen Ufern durch Wogen und Strömungen beständig verbreitert.

Das Material, welches die Wellen von Steilküsten ablösen, wird entweder in der Tiefe des Meeres abgelagert oder zu neuen Uferbildungen verwendet. In weiten Buchten, wo auf wenig geneigtem Strande die Wellen sich verflachen und besänftigen, wird der Sand und das Geröll abgelagert, welches das stark bewegte Wasser mit sich brachte. Die Tiefe nimmt ab; der Boden erhöht sich, wird fester und bedeckt sich schliesslich mit Vegetation. Dieser Landzuwachs kompensirt den anderwärts eingetretenen Landverlust. Zuweilen lagern Wellen und Meeresströmungen die Stoffe, welche sie mitführen, nicht unmittelbar an der Küste, sondern in einiger Entfernung von derselben ab. Auf diese Weise entstehen die Nehrungen oder lidi, welche sich der Küste entlang hinziehen, manchmal den Eingang zu einer Bucht absperren und so Lagunen oder Strandseen (étangs) bilden, deren stagnirendes Wasser sich mit Pflanzen bedeckt, verdunstet und bald ersetzt wird durch mehr oder minder sumpfiges Terrain.

Die Ströme führen namentlich in Zeiten des Anschwellens viele suspendirte Theile, Sand und Schlamm, bei ihrer Mündung ins Meer. Wenn der Fluss eine starke Strömung hat, so trägt diese die schwebenden festen Theile weit hinaus; aber bei geringer Wassermasse und Geschwindigkeit des Flusses gewinnt die stauende Wirkung des Meeres die Oberhand, sie verhindert den Weitertransport der Sinkstoffe und bewirkt, dass diese nahe der Mündung abgelagert werden. Es bilden sich dann Barren quer zur Richtung des Flusses, Sandbänke an der Strommündung. Es kann hinzukommen, dass in Folge von Meeresströmungen die Mündung und der unterste Theil des Flusslaufes allmälig verlegt wird. Die vom Strome mitgeführten Sinkstoffe müssen nothwendig auch zur Ausfüllung (Colmatirung) der Lagunen und Aestuarien (Mündungstrichter) mitwirken, und die Flussdeltas müssen sich ins Meer hinaus und seitwärts vergrössern, je mehr erdige Theile der Strom herbeibringt. 
Diejenigen sandigen und erdigen Theile, welche sich nicht hier absetzen, sondern noch schwebend (suspendirt) bleiben und von Wellen und Strömungen weitergetragen werden, bilden dann ihrerseits Inseln, Sandbänke und Verlandungen längs der Küste, und sie tragen viel bei zur Colmatirung der Golfe, zur Verstopfung der Meer-Engen.

Lingekehrt kann die See durch fortgesetzte Erosion Hindernisse beseitigen, welche sie von tiefer gelegenem Terrain tremnen, und kann so weit ins Festland eindringen, indem sie Flächen, die vordem von Wäldern oder Ortschaften bedeckt und der Kultur dienstbar waren, in Meeresbuchten verwandelt.

Die Kï̈sten sind also in beständiger Lmgestaltung begriffen; ewig wechseln ihre Kontouren, und nie ist ihnen Dauer beschieden. Der Topograph, der sie zeichnet, stellt uns dar, was momentan ist, nicht aber, was war und sein wird. Es ist aber geologisch und historisch sehr interessant, wenigstens die namhaftesten dieser Aenderungen zu kennen, welche die Gegend erfubr, die man besuchte. Wer mit den Ursachen dieser Vorgänge vertraut ist, kann nach Untersuchungen an Ort und Stelle durch Rückschlüsse zum Theil die Modifikationen ermitteln, welche in der Küstemmodellirung rorgekommen sein müssen; aber es ist gut, dass man auch hierüber die Erinnerungen der Einwohner, Ueberlieferungen und Dokumente zu Rathe ziehe. Das Andenken an solche Vorgänge kann sich erhalten, sich verewigen, wenn es sich um grosse Ereignisse handelt wie Einbrüche des Meeres, Durihbrüche von Landengen, Ueberfluthungen von Städten und Dörfern, Zerstörung von Inseln und Felsküsten. Was die Verlandung von Lagrunen (Haffen), Meeresbuchten und Flussmündungen, sowie das Anwachsen der Deltas betrifft, so sind das Erscheinungen, die viel langsamer vor sich gehen und daher weniger bemerkt werden. Man müss $\mathrm{Zu}$ stände aus verschiedenen Perioden vergleichen, um hierüber Grewissheit und genauen Aufschluss zu erlangen. Alte Karten genügen selten; denn ihre Exaktheit kann zweifelhaft sein; aber man wird mitunter Anhaltspunkte finden bei alten geographischen und geschichtlichen Schriftstellern. Ihre Worte muss man indess oft mit vieler Vorsicht aufnehmen. Hiefür nur zwei Beispiele. Man liest, das Delta der Rhone 
und dasjenige des Nils haben sich meerwärts verlängert, da der hl. Ludwig in Aigues-Mortes und in Damiette sich einund ausschiffte, während jetzt diese Stätte beide in einiger Entfernung vom Meere liegen. Nun ist aber bewiesen worden, dass zur Zeit des hl. Ludwig auch keineswegs die grossen Seeschiffe bis Aigues-Mortes kamen, sondern dass man in diesem Orte Fahrzeuge von geringerem Tiefgange bestieg, um sich so an Bord der Schiffe zu begeben. Und was Damiette anbetrifft, so mussten die Kreuzfahrer einen alten Kanal öffnen, um dorthin zu gelangen. Auch ist das heutige Damiette nicht das aus der Zeit Ludwigs des Heiligen; das letztere wurde geschleift und, nach dem arabischen Historiker Abu'l-Feda, weiter oben wieder auferbaut. Wir erinnern hier zudem an das, was wir oben über die Versandung von Häfen sagten: dass zu prüfen sei, ob dabei nicht auch Hebung mitgewirkt. Zu diesem Zwecke wird man sich vergewissern, ob die Höhenlage eines früheren Hafenplatzes noch so sei, dass die Meerwasser in denselben eindringen könnten und müssten, wenn die trennende Barriere nicht existirte, dass z. B. seine Quais nicht mehr als 1 bis $1^{1 / 2}$ Meter über dem mittleren Spiegel der See liegen. Ist der Höhenunterschied grösser, so ist das Verlanden sicherlich einer Hebung zuzuschreiben ${ }^{1}$ ).

Die Küsten bieten, vom geologischen Gesichtspunkt aus betrachtet, öfters noch andre interessante Eigenthümlichkeiten dar. Wir erwähnen zuerst die Fjorde, enge spaltenartige Thäler mit senkrechten, ja überhängenden Wänden, oft vielverzweigt und weit ins Land hinein sich erstreckend. Die Ansichten über ihre Entstehung sind noch sehr getheilt. Einige Geologen schreiben ihre Bildung, das Aushöhlen oder Ausgraben der Fjorde, der Thätigkeit alter Gletscher zu. Andere hingegen bestreiten die Möglichkeit eines solchen Auspflügens der Fjorde durch Gletscher und sind der Ansicht, die Gletscher haben vielmehr in der Weise gewirkt, dass sie diese Küsteneinschnitte vor Zerstörung bewahrten; ihre Thätigkeit sei also eine konservirende gewesen; die Fjorde selbst aber seien entstanden durch Spaltenbildung, durch Dislokation bei der Hebung der Kontinente oder durch die erodirende Thätigkeit fliessender Gewässer. Die Fjord- oder

1) Credner, Die Deltas; Geographische Mittheilungen 1878 (Ergänzungsheft). 
Splitterküsten kommen namentlich in den hohen Breiten beider Hemisphären vor, zwischen den Polen und $50^{\circ}$ Breite; sie sind zahlreicher und mehr entwickelt an westlichen Küsten. Selten finden sie sich in der gemässigten Zone, und zwischen den Wendekreisen kommen sie nicht ror. Desshalb vermuthet man eine Beziehung zwischen den Fjorden und den Gletschern, welche einstens grosse Theile der Erde bedeckten. Die Fjorde hätten sich besser erhalten, wo die alten Gletscher längrer bestanden, während in Gegrenden, wo Gletscher nie oder nicht lange existirten, jene Spalten und Einschnitte in die Küsten wieder verwischt und zerstört wurden durch lang andauernde chemische und mechanische Erosionswirkung der Luft und des Wassers.

Der Reisende unterlasse nicht, wenn er dazu Gelegenheit hat, in erster Linie zu konstatiren, ob nicht Ausnahmen rorkommen in Bezug auf das oberwähnte "Gesetz " der geographischen Tertheilung der Fjorde. Dann aber forsche er nach den Lrsachen, welche Fjorde bilden lionnten; er untersuche zu diesem Zweck die Wände jener Thäler, um romöglich zu ermitteln, welchen Agrentien die Ausfurchung und Ausweitung dieser Küstenspalten zuzuschreiben sei, ob der Erosion und welcher Art derselben. Geglättete und gestreifte Felsflächen, wovon unten noch die Rede sein wird, zeigen Gletscherwirkung an ${ }^{1}$ ), und eine sorgfältige Untersuchung weist oft nach, dass die Tiefe des Fjords an seiner Ausmündung ins Neer geringer ist als binnenwärts; dass der Boden des Fjords am Ausgange erhöht ist durch alte submarine Gletscherwälle (Frontmoränen).

Flachküsten ihrerseits haben oft errutische Blüclie. Das Vorliommen solcher „Findlinge“ muss man zu erklären suchen, wobei dieselben ja nicht verwechselt werden dürfen mit Trümmern von Felsstürzen, vulkanischen Erup, tirgesteinen u. dgl.

Die erratischen, Findlings-, Irr- oder Wanderblöcke können hergetragen und abgesetzt worden sein durch Gletscher frühere oder jetzige - aus dem Innern des Landes. In diesem Fall muss ihre Gesteinsart den Bergmassiren des Landes angehören. Sie kümnen aher auch über das Meer, durch Eisberge, an den Strand getragen worden sein. Dann

1) S. indessen die S. 129 erwähnte Abhandlung des Dr. C. Petersen. VgI. auch Kollbrunner, Morphologie der Thalbildungen S. 20. 
ist $\mathrm{zu}$ untersuchen, woher das Eis stammen konnte, welches Blöcke brachte von Gesteinen, die von den Felsarten des Landes verschieden sind. Einen ersten Fingerzeig über die Richtung, in welcher man nachforschen muss, gibt die Lage der Küste. Unterrichtet man sich dann über die geologische Beschaffenheit der Gegenden, aus welcher möglicherweise die Blöcke stammen können, so wird man ihren Ursprungsort oft ganz genau zu ermitteln im Stande sein. Die Blöcke können auch von den Eisbergen nach langem Umhertreiben beim Abschmelzen des Eises auf Meeresgrund gefallen sein, der später durch Hebung zur Küste wurde. Die Frage nach der Herkunft der Findlinge wird desshalb eine komplizirte, um so mehr als der Weg des Treibeises bestimmt sein konnte durch Meeresströmungen, die vielleicht andere Richtungen hatten als jetzt.

Auf sandigen Flachküsten finden sich ziemlich allgemein Düncn, das sind Sandhügel, welche gewöhnlich da entstelien, wo ein sanft geneigter Strand, zusammengesetzt aus kleinkörnigen losen Gesteinstrümmern, welche durch Wind und Wellen leicht in Bewegung gebracht werden, sich weit ins Meer hinaus erstreckt. Diese Sande, welche der Wechsel von Fluth und Ebbe bald unter Wasser, bald an die Luft bringt, werden im letzteren Falle sehr rasch trocken, und an einer offenen Küste werden sie, ein Spiel der Winde und der Wellen, landeinwärts getrieben. Tritt dieser Bewegung irgend ein Hinderniss entgegen, so entsteht an dieser Stelle sofort eine Anhäufung von Sand. Durch beständigen Nachschub neuen Materials wächst der Haufen, die Erhöhung, zum Hügel oder Walle an. Die Sandmassen oben am Scheitel oder Kamm der Düne, welche ausserhalb des Bereichs der Wogen liegen, sind die trockensten, daher die leichtesten und beweglichsten, und vorzugsweise eine Beute des Windes, dessen Angriffen sie infolge ihrer Lage ohnehin mehr ausgesetzt sind. Der Wind weht sie von der Stossseite weg; entweder gleiten und fallen sie nun an der andern, vom Winde abgekehrten Seite (Leeseite) hinunter oder sie werden in dieser Richtung weit forttransportirt. Weht der Wind lange Zeit und stark in derselben Richtung, so wird in dieser immer wieder dieselbe Bewegung der Theilchen wiederholt, die Düne selbst verändert ihre Stelle, sie wandert. Es ist 
mit Rücksicht auf die Veränderungen, welchen eine Küste im Laufe der Zeit unterworfen sein komte, ron Interesse, an Ort und Stelle selber die Art der Bildung und des Wanderns der Dünen zu studiren und sich zu erkundigen ïher das Maass des Fortschreitens derselhen in geschichtlicher Zeit. - Kieine Dünen finden sich auf Flachküsten, die bestehen aus thonigem Boden, aus liompalitem schlamm, aus Sanden, die reich mit organischen (pflanzlichen oder thierischen) Stoffen gemischit oder die verkittet sind durch $\mathrm{Ab}$ saitze aus Kalk- und eisenhaltigem Wasser. Der Sand kann auch nicht die zur Dünenbildung erforderliche Beweglichkeit erlangen, wenn er zu grobkürnigr ist oder zu viel grobe Gerölle enthält. An solchen Küisten bilden sich Geschirbehiüml und Wïlle, welche den Dünen ähnlich, aber niedriger sind und - weil ihr Material zu schwer ist für die Stossliraft des Windes und nur starker Wellenbewegung folgt sich nicht weiter hinaus erstrecken als bis zu den Stellen, wo die stärksten Wellen sich verlaufen.

Ursprung und Bildung der Ebenen etc. Jeder flache Boden, welches auch seine Ausdehnung und seine Höhe sein mag, verräth Wasserwirkung. Die Tiefebenen sind entweder langsam emporgehobener Meeresborlen oder Seeboden, der trocken gelegt wurde durch Vertiefung des Austlusskanales oder Alluvialbildungen, welche allmälig die früher vorhandenen Depressionen des Bodens ausfüllten.

In jeder Ehene, scheine sie noch so gleichmässig und sei sie noch so reichlich bewachsen, wird man natürliche oder künstliche Einschnitte finden - Gräben, Fluss- und Bachbetten und kleine Wasserrinnsale, Wegeinschnitte, Sandund Kiesgruben etc. - welche die Struktur des Bodens blosslegen (geologische "Aufschlüsse"). Ist das Material feinkörnig und regelmässigg geschichtet, so muss es sich in ruhigem Wasser abgesetzt haben, und zwar auf Meeresursund, wenn die eingeschlossenen organischen Reste marinen Pflanzen oder Thieren angehören, hingegen auf dem Boden eines Süsswasserbeckens, wenn die organischen Einschlüsse von Land- oder Süsswasser-Pflanzen und -Thieren herrühren; beobachtet man eine Mischung der beiderlei Fossilien, so hat man ein ausgrefülltes Aestuarium vor sich. Gröberes Material, unregelmässigere, nicht ganz wagrechte Schichten sind Zeugen der 
Thätigkeit fliessenden Wassers; aus der Grösse des Geschiebes kann man. auf Geschwindigkeit und Stärke der Strömung schliessen. Es sind sogar bis zu gewissem Grade Schlüsse möglich in Bezug auf Herkunft und Richtung der Strömungen; zu diesem Zweck sammelt man Geschiebsmaterial an rerschiedenen Punkten und vergleicht dasselbe in Bezug auf die Grössenverhältnisse. Da fliessendes Wasser zuerst die grössten Gesteinstrümmer, die Blöcke, absetzt, dann die Fragmente ron mittlerer Grösse, das Geröll oder Geschiebe, zuletzt Sand und Schlamm, so werden jene Proben und deren umsichtige Vergleichung werthvolle Fingerzeige geben.

Ist die Ebene gehobener Meeresgrund, so ist es wahrscheinlich, dass sich an ihrem Rande Spuren alter Uferbildungen vorfinden. Ist sie durch Kolmatirung aus einem Lestuarium entstanden oder durch Vergrösserung eines Deltas, so zeigt der Boden in rertikalen Durchschnitten (Profilen) eine Reihe geneigter Schichten, die nach unten dicker (mächtiger), nach oben dünner und zudem von einer fast wagrechten Bank groben Gerölles überlagert sind (Fig. 102).

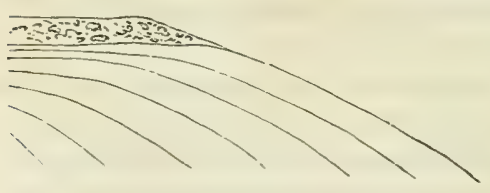

Fig. 102.

Ist aber die Ebene alter Seeboden, trocken gelegt durch Abfluss oder Verdunstung des Süsswassers, so hat sie beckenartige Form, d. h. sie ist in der Mitte etwas tiefer, und an ihren Rändern gewahrt man noch Spuren jener Uferabstürze, die man Seehalden nennt. Wenn ein Meeresarm, ein Golf, ein Haff (Strandsee, Lagune) zufällig geschlossen, vom offenen Meere abgetrennt wird und durch Verdunstung austrocknet, so zeigt das Terrain die vorhin erwähnten Merkmale, ist aber mit Salz-Efflorescenzen bedeckt und durch Einschlüsse mariner Pflanzen- und Thierreste ausgezeichnet. Wenn endlich die Ebene zu Stande kam durch Ausfüllung (Kolmatirung) früherer Bodendepressionen, durch Absatzbildungen aus Gewässern, die chne Abfluss waren, so fehlen marine Reste und der Boden besteht aus horizontalen Schichten, die nach oben sehr feinkörnig sind, indem das Naterial der obersten Lagen entweder feiner Sand oder hart gewordener Schlamm ist. Ein Durchschnitt, z. B. ein tiefer 
Wegeinschnitt, wird öfters unter den hier besprochenen schichten den alten Boden erkennen lassen, auf welchem jene Sedimente sich bildeten.

Auf welche Art immer eine Ebene sich gebildet haben mag, so wird sie selten intakt geblieben sein. Fliessende (rewässer schmeiden in sie Furchen ein, die verschieden weit und tief sind je nach der Menge und Geschwindigkeit des Wassers, der Dauer seiner Thätigkeit und der Beschaffenheit des Bodens. Bald sind es einfache Bach- und Flusshetten und -Thäler, bald tiefe und enge Schluchten wie die Cañons des nördlichen Amerika, die "Klammen" der Ostalpen, bald breite Erosionsthäler, durch deren Sohle heute vielleicht nur noch eine unbedeutende Wasserader sich durchschlängelt. Es kommt vor, dass der alte Thalboden durch die erodirende Thätigkeit der Gewässer bis auf wenige isolirte Fragmente abgetragen und fortgeführt wird; jene Reste, die noch Zeugniss ablegen für den alten Zustand der Dinge, bestehen aus den festesten Gesteinen oder tragen wenigstens eine Decke aus resistenterem Material, wodurch sie geschützt wurden und erhalten bleiben konnten.

In diesen verschiedenen Fällen wird man eine gewisse Lebereinstimmung finden für das Niveau der beiden Seiten eines und desselben Querprofils durch das Thal oder die Schlucht, sowie für die Höhenverhältnisse der Reste eines früheren Thalbodens im Längenprofil desselben ${ }^{1}$ ). Ein senkrechter Querschnitt (Fig. 103-105) wird im Allgemeinen oben eine annähernd wagrechte Linie aufweisen, die unterbrochen ist durch Einschnitte ron grösserer oder geringerer Breite und Tiefe; man kann im Geiste die alte Ebene rekonstruiren, so wie sie war vor ihrer Umgestaltung durch erodirende Gewässer: das alte Niveau der Ebene wird angegeben durch die wagrechte Oberfläche; die Lücken muss

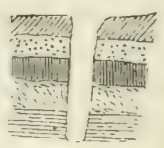

Fig. 103. man sich ausgefüllt denken. Bei genauerer Betrachtung der

1) Die im Querprofil einander entsprechenden Thalbodenreste gehören zu einer und derselben Terrasse; die im Längenprofil zusammengehörenden Theile iilien eine Thulstufic. A. Heim, Intersuchungen über den Merhanismus der Gebirgsvildung, Basel 1878, I. Bd. S. 282. A. Bodmer, Terrassen und Thalstufen der Schweiz, Zürich 1850 . 
Struktur des Bodens wird man bemerken, dass die Seitenwände von Schluchten und Thälern und isolirten Felsresten übereinstimmende Schichten aufweisen. Wenn derart horizontale Bänke in entsprechender Lage und gleicher Anordnung auf einander folgen, so ist es augenfällig, dass die Bodenformen nur durch Erosion entstanden sein können,

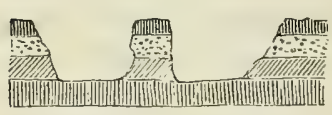

Fig. 105. welche sie aus dem Vollen herausarbeitete wie der Meissel des Bildhauers aus dem rohen Block eine Figur schuf.

Das oben Gesagte bezieht sich auf Ebenen jeder Art: Steppen, Prairien, Pampas, landes etc. Die Unterschiede, welche die Art ihrer Vegetation bewirkt, hängen weniger zusammen mit der Art ihrer Entstehung als vielmehr mit der Bodenbeschaffenheit, wie mit Mangel oder Reichthum an Feuchtigkeit. So beruht die traurige Oede der südwestfranzösischen Heiden (landes) darauf, dass ihr Lntergrund aus einer kompakten Sandschicht besteht, welche das Regenwasser zurückhält in stagnirenden Lachen und so den Boden kulturunfähig macht.

Die Wüsten unterscheiden sich von andern Ebenen nur durch ihre Unfruchtbarkeit, welche aus vollständigem Mangel an Feuchtigkeit und Regen entspringt und sie unbewohnbar macht. ${ }^{1}$ ) Was aber die Bildung, den Ursprung derselben betrifft, so ist dem oben Gesagten nur beizufügen, dass die Wüsten sich manchmal bilden, beziehungsweise sich ausdehnen, auf Kosten fruchtbarer Landstriche, indem Sande, welche aus der Zertrümmerung (Verwitterung) von Sandsteingebirgen sich bilden, in der Richtung der vorherrschenden Winde verbreitet werden. Wenn solche fortschreitende Wüstenbildungen neueren Datums sind, wird man sie zu konstatiren vermögen mittels Spuren menschlicher Ansiedlungen, Dörfer und Städte, oder von Wäldern, die nun durch Sandmassen verschüttet sind; oder man. wird sie konstatiren auf Grund von Ueberlieferungen und von Aussagen der Eingebornen. Auch der umgekehrte Fall ist zu beachten: dass die Wüste

1) Vol. Alfred R. Wallace, Tropical Nature and other Essays. London 1878 "Wherever the soil is sandy and there are no lofty mountain chains to supply ample irrigation, the result is a more or less perfect desert, "welchen Satz ein Rezensent (E. D) in der Allgemeinen Augsburger Zeitung (April 1879) für einen "Humboldt's ehen Irrthum" erklärt. 
an Terrain verliert, z. B. durch Vordringen der Vegetation auf natürlichem Wege, auch ohne Zuthun des Menschen ${ }^{1}$ ).

Besondere Aufmerksamkeit verdienen die Oasen, welche als grüne Inselı im Sandmeere überall auftreten, wo der Boden genug Feuchtigkeit hat. Es ist werthwoll, zu konstatiren, welchen speziellen Ursachen sie ihre Existenz verdanken, welche Veränderungen sie im Laufe der Jahrhunderte erlitten, welche früheren Oasen verschwanden, welche andere und wie dieselben geschützt werden mussten gegen das Vordringen des Flugsandes, welche dritte endlich durch Erstellung artesischer Brunnen neu entstanden sind.

Es ist ferner interessant in den Wüsten, an Ort und Stelle, Bimuruluddiunen zu studiren. Die einen derselben wandern unter dem Einfluss vorherrschender Winde und bedecken allmälig Alles, was sich auf ihrem Wege rorfindet. Andere sind stationär: sie scheinen einen Kern festen Gesteins zu enthalten, $u$ und über welchen die Sandmassen aufgehäuft werden.

Es gibt endlich Stcinü̈sten, d. h. Flächen, die übersäet sind mit scharfkantigen Felstrümmern, von welch' letzteren man annimmt, sie entstehen in Folge einer Zertrümmerung des Gesteins durch raschen Wechsel zwischen grosser Wärme am Tage und kalten Nächten, in welchen das Thermometer öfters unter Null sinkt.

Entstehung der Becken und anderer Bodendepressionen. Ein Becken unterscheidet sich ron einer Ebene nur dadurch, dass es konkav statt flach ist. Die typische Form des Beckens ist die einer Schale mit erhöhten Piändern. Die Entstehung der kontinentalen Becken ist eines der schwersten Probleme der Geologie.

Gewisse Becken sind entstandendurchSenkung des zentralen Theiles oder durch Hebung der Randzonen. Das Nähere hierüber wird im Abschnitt

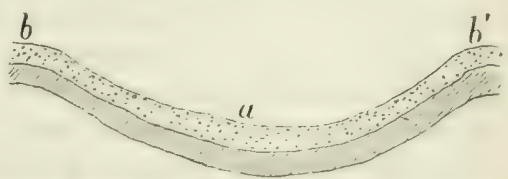

Fig. 106. über die Stratigraphie zur Sprache kommen. Hier bemerken wir nur, dass in beiden Fällen die Felsschichten des Beckens im senkrechten Durchschnitt (Profil, F̈̈\% 106) konkar erscheinen, ohne dass man sagen kömnte, ob der tiefste P'unkt a - durch

1) Vgl. E. Kollbrunner, Morphologie der Thalbildungen, Frauenfeld 1877 S. 15. 
Senkung - oder die höhern Punkte $b b^{\prime}$ - durch Hebung - ihre Höhenlage geändert haben. Zur Beurtheilung dieser Frage müssen Anhaltspunkte gewonnen werden durch geo-

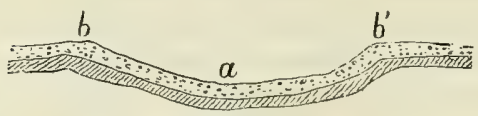

Fig. 107.
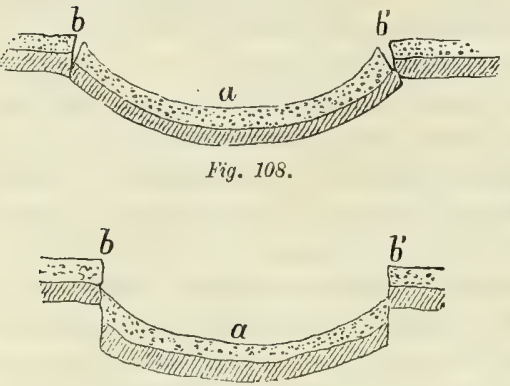

Fig. 109.

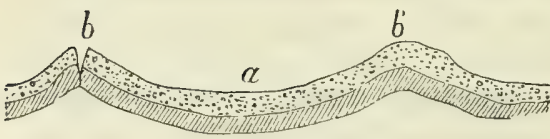

Fig. 110. logisches Studium der Umgegend. Wennz.B. (Fig. 10\%) die Schichten zu beiden Seiten der Hohlform wagrecht sind, so ist anzunehmen, dass eine Senkung der mittleren Beckenpartie stattgefunden habe, namentlich wenn man am Rand des Beckens deutliche Spuren von Brüchen der Felsbänke und von Verschiebung der Schichten längs dieser Spalten trifft. (Fig. 108 and 109).

Wenn man hingegen zu beiden Seiten des Beckens Terrainfalten bemerkt, wulstartig erhöhte Stellen (Fig. 110), so wird man, auch wenn Brüche oder Spalten vorhanden sind, auf eine stattgefundene Hebung der Ränder des Beckens Punkte $b$ und $b^{\prime}$ schliessen, sei es, dass diese Hebung verursacht wurde durch eine vertikale von unten nach oben wirkende Kraft oder durch seitlichen Druck, der Falten erzeugte.

Ein Becken kann auch entstanden sein durch ungleiche Senkung des Bodens. Wenn die Mittelpartien eines ursprünglich horizontalen Gebietes aus sandigen, leicht beweglichen Theilen bestehen, die Ränder aber aus hartem Fels, so wird ein solches Terrain Störungen seiner gleichmässigen Oberfläche erleiden schon durch blosse Wirkung der Regen, welche Jahrhunderte lang auf die Fläche fielen und allmälig den Boden im Zentrum abgetragen haben, während die Randpartien intakt blieben. 
Ist der Untergrund durchlassend, so kann die mineralische Substanz der mittleren Partien in unterirdischen Wasserläufen, chemisch gelöst, langsam fortgeführt und dadurch die Fläche, auch wenn sie von allen Seiten geschlossen scheint, durch Wasser unterspült, unterhöhlt worden sein.

Bei denjenigen Becken, welche nicht vollständig geschlossen sind, muss die Erosion eine grosse Rolle gespielt haben. Das kleinste fliessende Gewässer reicht hin, um die Erde nach und nach wegzuführen und eine Schlucht zu furchen. In diese rollt das Material von den begrenzenden Seitenwänden hinab: es bildet so ein Hinderniss, welches das Wasser staut; es entsteht ein kleiner See; eines Tages durchbricht dieser. die Barriere und strömt mit grosser Gewalt ab. Ist der See leer, so gibt die Erde, welche bisher durch den Druck des Wassers, zurückgehalten wurde, nach, kommt auf den Boden fles schmalen Thales und wird hier rom fliessenden Wasser fortgeführt. Dieser Vorgang wiederholt sich; der zentrale Theil des Beckens wird vertieft; seine Ränder werden zu Gehängen, die mehr oder minder sanft geneigt sind, je nach der Beweglichkeit oder Verwitterbarkeit des Bodens, woraus sie bestehen.

Aber wenn auch Becken durch das Wasser geformt wurden oder selbst früher Seegrund waren, so kann ihr Boden jetzt ganz trocken oder blos sumpfig sein. So nehmen die Torfmoore sehr häufig die Stelle alter Seen ein. Es ist das eine Umwandlung, deren Spuren und Ursachen der Reisende zu ermitteln suchen muss. Die früheren Quellen können versiegt sein; der Bach oder Fluss, welcher das Becken durchströmte, kann seinen Lauf geändert haben; es kann ein Damm oder Wall, welcher das Wasser zurückhielt, durchbrochen und so der hinterliegende See abgeflossen sein; es komute endlich das Wasser, welches ehemals den Hohlraum des Beckens einnahm, langsam verdunsten, etwa in Folge von Entwaldungen, welche den Feuchtigkeitsgehalt der Luft und damit das Mass der Wasserzufuhr' zum See verminderten.

Was die Aushöhlung von Becken durch alte Gletscher betrifft, so herrschen hierüber sehr widerstreitende Ansichten. Zur Beurtheilung dieser Frage muss vorerst die Art der Wirkung jetziger Gletscher studirt werden. Dann erst sind wir im Stande, zu entscheiden, ob ein Becken von einem 
früheren Gletscher, wenn nicht ausgefurcht, so doch mit Eis erfüllt war, mit Eis, welches das Becken vergrössern oder ausweiten oder geradewegs zu dessen Bildung beitragen konnte durch Abschluss des Ausganges mittels einer Stirnmoräne.

Kleiner und unbedeutender als die Becken sind die nur lokalen Hohlformen wie die Trichter (entonnoirs), auf deren Grund eine Quelle sprudelt, welche erdige Bestandtheile löst und auf unterirdischen Bahnen wegführt, so dass eine Aushöhlung entsteht in Trichter-, d. h. umgekehrter Kegelform.

In Kalkfelsen sieht man unregelmässig gestaltete Löcher und Furchen, Karren oder Schratten genannt, die entstanden sind durch chemische Erosion, welche die löslichen Theile des Gesteins wegführte.

Wasser, welches aus einiger Höhe hinunterstürzt, erzeugt bisweilen am Fusse alter Wasserfälle Vertiefungen oder Becken, deren Form ihnen den Namen Kessel verschafft hat. Man trifft solche auch in den Betten schnell fliesender Gewässer; in diesem Fall sind sie entstanden durch rotirende Bewegung fester Theile, Felsstücke, Kieselsteine, welche der Fluss mit sich führt.

Riesentöpfe heissen Löcher von runder, oft kreisrunder Form, welche in den Fels eingegraben wurden entweder durch Gletschermühlen oder durch Giessbäche, die viel Sand führen und hiedurch an den Wänden dieser Höhlen eine beständige Abreibung verursachen oder welche Steinblöcke in anhaltende drehende Bewegung versetzen. Die Blöcke, welche man sehr oft auf dem Grunde dieser Höhlen findet, sind glatt und gerundet wie Kugeln.

Unebenheiten des Bodens. Wir besprechen hier kurz diejenigen Unebenheiten des Terrains, welche nicht so grosse Dimensionen haben, dass sie als Berge und Gebirge bezeichnet werden müssen.

Der Boden, namentlich der nackte, erscheint oft wie zerrissen und zeigt klaffende Spalten oder Schlünde von verschiedener Tiefe. Man wird die Ursache dieser Erscheinung zu erforschen sich bemühen. In vulkanischen oder Erdbeben ausgesetzten Ländern rühren diese Spalten von den unterirdischen Bewegungen her. Anderswo entstehen sie durch übermässige Hitze und Trockenheit, welche in thonigem Boden Risse bildet, oder durch ungleiche Hebung und Senkung, welche die 
Schichten in ihrer Lage störten. Diese Spalten unterscheiden sich ron den Schluchten durch den Mangel eines Ausgangs, welcher es unmöglich erscheinen lässt, dass die Risse durch fliessendes Wasser entstanden seien, obwohl letzteres zu ihrer Erweiterung beigetragen haben kann.

Die Schluchten, Flussbetten und Flusstheiler sind bekanntlich ein Ergebniss der Wasserwirkung ("Auskolkung"). Indem das Wasser immer nach dem tiefsten Punkte strebt, durchfurcht es beständig selbst scheinbar ganz flachen Boden, und die Furchen, die es einschneidet, werden fort und fort erweitert.

Die verschiedenen Terainfalten haben, wenn sie nicht durch Erosion und die so veranlasste Senkung der angrenzenden Schichten entstanden sind, ihre Entstehungsursache tief im Frdinnern; sie wurden gebildet durch lokale Hebung oder Faltung der Schichten, welche die Erdkruste zusammensetzen.

Schon erwähnt haben wir (S. 243) die Stmallügel oder I)ïnen, welche ähnlich wie die Küstendünen (S. 238), aber im Innern des Landes infolge des Einflusses herrschender Winde sich bilden, da, wo staubiger, pulveriger Boden aufvewirbelt wird durch Winde und wo heftige Stürme die feinkörnigen Theile weithin tragen.

Die Hügel und Anhïlen sind gewöhnlich andern Ursprungs. Sie können ihre Existenz einem vorragenden Fels verdanken, der mit der Zeit an seiner Aussenfläche verwittert und zerfallen ist. Nanchmal sind es auch Reste eines im Tehrigen durch Erosion beseitigten Bodens. In andern Fällen sind sie von umliegenden Höhen heruntergestürzt. Seltener sind es alte Gletscherwälle (Moränen) oder Haufen von Gesteinstrümmern, welche an einer Küste oder auf dem Boden eines Neeres abgelagert wurden durch schwimmende Eisberge, die, beladen mit Steinen und Erde, hier strandeten.

Die isolirten Felsen stehen, sofern sie nicht von Bergstiirzen oder sonstigen Dislokationen in einzelnen Gebirgen herrühren, an ihrer Basis im Zusammenhang mit dem geologischen Gebälke des Gebietes; sie sind, wie die Berge, die vorragenden, sichtbaren Punkte seines Skelettes.

Den Gegensatz zu ihnen bilden die Blökl', indem diese losgretrennte, abgelöste Massen sind, dem Boden aufgelagert nder bis zu einer gewissen Tiefe in denselben eingesenkt, 
nicht aber in Zusammenhang mit den Schichten in der Tiefe. Der Ursprung dieser Blöcke ist sehr verschieden; die einen sind heruntergestürzt von den benachbarten Felswänden, andere sind hergetragen worden durch festes oder flüssiges Wasser. Im ersteren Fall haben sie, abgesehen von der oberflächlichen Verwitterungsrinde, scharfe Ecken und Kanten. Die Untersuchung an Ort and Stelle, in Bezug auf äussere Form und mineralogische Zusammensetzung, lässt meist die Herkunft dieser Felstrümmer erkennen. Die von fliessendem Wasser hertransportirten Steine haben abgestumpfte Kanten und Ecken, gerundete Formen. Die von Gletschern hergetragenen Blöcke endlich haben mit den abgelösten, heruntergestürzten Felsen die scharfen Kanten gemeinsam: sie sind aber mineralogisch verschieden von dem in der Gegend anstehenden Gestein.

Nur kurz erinnern wir hier an die vulkanischen Blöcke, welche Auswurfsprodukte sind.

Hie und da findet man verworrene Anhäufungen von Felsblöcken, theils aufrecht, theils umgestürzt, in phantastischen Formen, wahre Felslabyrinthe, welchen man die malerischen Namen Blockuiisten, Blockmeere, Teufelsmïhten u. s. w. gegeben hat. Es sind meistens Ueberreste weit umfangreicherer Felsmassen, die dislozirt und zertrümmert wurden und wovon ein Theil verschwunden ist. Nackte Felsflächen, die durch Einwirkung von Luft und Wasser so zerfressen sind, dass sie nur eine verworrene Masse von stehenden und liegenden Pyramiden, Säulen, Obelisken u. s. f. darstellen, heissen Lapiaz.

Lavavïsten sind Flächen, bedeckt von Lavaströmen, vulkanischen Schlacken etc., welche scharf geformte Erhebungen des Bodens bilden.

Abdachungen und Gehänge. Die Abhänge oder Thalwände sind fortwährend in Umbildung begriffen, deren Effekt eine Herabminderung des Gefälles ist. Die steilsten Wände und Böschungen verwandeln sich schliesslich in sanfte Abhänge durch den Wechsel der Witterung, worunter namentlich die obern Randlinien oder Kanten leiden, durch die erodirenden Gewässer, durch die Schutt- und Alluvialbildungen, welche sich in den tiefsten Punkten ansammeln. Das Regenwasser reisst Erde aus höheren Lagen mit sich, durchfurcht die Abhänge und gibt Anlass zu Rutschungen und Felsstürzen. 
Auf diese Weise kommt eine Ausebnung oder Nivellirung zu Stande: die Höhen werden abgetragen; an ihrem Fusse aber findet Auftragung statt.

Sehr steile Böschungen, senkrechte Wände findet man in Gegenden mit kompaktem, hartem Fels und an Stellen, wo fliessende Gewässer den Fuss der Gehänge abspü̈len oder Schuttmassen, in dem Verhältniss, wie sie angehäuft werden, wieder forttragen. Leberall sonst bilden sich am Fuss steiler Wände Shuttlegel oder Schutfwismen; erstere sind Massen von konischer Form, deren Spitze dem Ausgang, der Mündung einer Schlucht oder eines Bachtohels entspricht: die letzteren erreichen eine hedeutende Länge und sind einem Walle oder liegrenden dreiseitigen Prisma vergleichbar, dessen obere Kante längs der Felswand sich hinzieht. Es ist zu unterscheiden zwischen Schuttlegeln und -Prismen, gebildet aus heruntergestürzten Massen, und solchen aus Alluvionen, d. h. aus Iaterialien, die im Wasser transportirt und hernach ahgesetzt wurden. Diese letztern sind kenntlich an sanfterem Gefälle und daran, dass die gröbsten Materialien (Blöcke etc.) sich uben befinden, weil das Wasser dieselben zuerst ablagern musste; bei den andern (eigentlichen) Schuttkegehn und -Prismen ist das Gefälle grösser und die gröbsten Theile (Blöcke) finden sich am Fusse vor.

Diese Kegel und Prismen erreichen mitunter bedeutende Dimensionen, überziehen sich schliesslich mit einer Pflanzendecke und werden als Baugrund für menschliche Wohnungen benutzt, so dass man sich nur schwer vergegenwärtigen kamn, dass an tiefen Stellen einmal nur eine steile Wand existirte.

Eine besondere Form der Anschwemmungskegel sind diejenigen der Willbäche: Geschiebeablagerungen, welche weithin vordringen und auf welchen zur Zeit der Schneeschmelze oder bei starken Regengüssen die Wildwasser in einem höheren Niveau fliessen als dasjenige der anstossenden Gelände ist.

Die Abhänge können auch nmgestaltet werden durch Dislokationen und Spaltenbildung mit Bergstürzen oder Rutschungen, die verursacht sein können durch Erdbehen, durch unregelmässige Lagerung, durch lokale Erschütterung oder durch Sturz in Folge des Eigengewichts der Felsen.

Selten gibt es Gehänge, die, auch wem sie noch so gleichmässig scheinen, nicht von Wasserrimen durchfurcht sind. 
Denn das Regenwasser, welches auf einen Abhang fällt, spült nicht gleichmässig dessen ganze Oberfläche ab, vielmehr gräbt es Furchen ein. In diese Hohlräume fällt von deren Seitenwänden Erde hinein; neue Regengüsse schwemmen diese fort; andere Massen nehmen aber sogleich ihre Stelle ein; so verschwindet allgemach der Kamm zwischen zwei solchen Furchen und an dessen Stelle tritt eine grössere Schlucht, deren Wände sehr steil sind, falls der Boden aus festem Fels gebildet ist, sanfter abgedacht aber in beweglicherem Boden.

Wechseln an einem Abhang Bänke festeren Gesteins mit weicheren Schichten, so wirken auf diese ungleich resistenten Theile die umformenden Agentien in verschiedenem Masse ein, und es bilden sich mehr oder minder hohe Stufen, so dass nicht mehr eine gleichmässige Profillinie, sondern eine solche mit vorspringenden Stellen vorhanden ist.

Demselben Umstande, d. h. ungleichem Effekte der zerstörenden Agentien, sind gewisse bizarre Felsbildungen zuzuschreiben, wie die hängenden Blöcke, Felstische u. dgl., die man mitunter auf den Kämmen zwischen zwei Abdachungen trifft. Es sind Ueberreste von Felsen, die auf Erdpyramiden, auf unsicherer Unterlage ruhen, nachdem das umliegende Gestein fortgeführt worden ist durch Regen oder nachdem der Fels, worauf die Blöcke ruhen und welcher von geringerer Resistenz war als diese, durch den Einfluss der Atmosphärilien langsam verwitterte und verkleinert wurde.

Terrassen und Plateaux. Die Küstenterrassen sind im Allgemeinen frühere Ufer oder Reste von Tiefebenen, die langsam auf ihr jetziges Niveau gehoben wurden. Die Terrassen, welche sich im Binnenlande an den Berghalden vorfinden, können gleichen Ursprungs sein; noch öfter aber sind dieselben Reste alter, durch Wasser abgetragener Thalböden oder Felsbänke, welche durch die Thätigkeit der Atmosphärilien blossgelegt wurden. Terrassen in den Thälern und überhaupt solche von entsprechendem Niveau sind zumeist alte Alluvialbildungen, in welche die Gewässer sich ein tieferes Bett von mehr oder minder bedeutender Breite eingegraben haben.

Was die Plateaux, Hochebenen oder Tafelländer betrifft, so haben sie in der Regel denselben Ursprung wie die Tiefebenen (vgl. S. 239), von welchen sie sich nur durch ihre höhere Lage unterscheiden. Mitunter indess verdanken sie 
ihre Existenz Lava-Ergüssen, wobei vulkanische Gesteine üher weite Flächen eine solide Decke bildeten und dieselben auf diese Weise vor zerstörenden Einflüssen schützten.

Die Terrassen und Plateaux sind um so weniger tief durchfurcht, je mehr ihr Borlen wasserdurchlassend ist.

Gebirge. Die wichtigsten Ursachen der Gebirgsbildung sind :

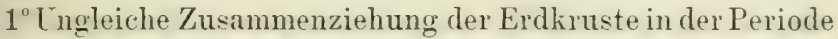
ihrer allmäligen Erkaltung;

$2^{\circ}$ Hebungen, welche durch unterirdische Kräfte bewirlit wurden;

3' Seitendruck, welcher Faltungen und Anfrichtung von Felsschichten veranlasste;

4" Lngleiches Aufquellen der verschiedenen mineralischen Bestandtheile der Erdrinde;

$5^{\circ}$ Grossartige Erosion (Denudation) alter Hochebenen, ron welchen die heutigen Berge nur Reste darstellen;

$6^{\circ}$ endlich, mit Bezug auf Vulliane, eine eruptive Thätigkeit, deren Auswurfstoffe zurüickfallen und sich um den Krater ansammeln.

Welcher dieser Lrsachen die Bildung eines bestimmten Gebirges zuzuschreiben sei, kann meist nur entschieden werden auf Grund stratigraphischer Studien, die wir unten besprechen. Die nächste Aufgabe des Reisenden ist aber eine einfachere: sie betrifft nicht die innere Struktur, sondern die äusseren Eigenthümlichkeiten des Gebirges und die Ursachen, welche diese äusseren Formen beständig verändern. Die Wirkung dieser umgestaltenden Agentien ist nirgends augenfälliger als auf hohen Berggipfeln; dort muss man sie studiren, um eine richtige Vorstellung zu erlangen von den ewigen Lmänderungs-, Lmlagerungsprozessen, welchen die feste Erdrinde unterworfen ist.

Stetsfort allen Einflüssen der Atmosphäre ausgesetzt, verändern sich auch die festesten Gesteine; es entstehen in denselben feine Risse und Spalten, und sie zerbröckeln so an ihrer Oherfläche. In die Risse dringt Wasser; es rergrössert sie, und beim Gefrieren zersprengt es den Stein. Aehnlich wirken Pflanzen-, namentlich Baumwurzeln, welche sich in die Spalten hineinzwängen und durch Wachsthum an Dicke wie an Länge zunehmen. Lnter diesen zerstörenden 
Kräften spielt auch der Blitz eine Rolle, namentlich auf hohen Gipfeln, wo die Gewitter sehr häufig sind; wenn er einschlägt, trennt er Felsstücke ab. Das Rollen des Donners, vertausendfältigt durch den Wiederhall, erschüttert die Berge und löst Gesteinsfragmente ab. Dasselbe geschieht in grösserem Massstabe durch Erdbebenstösse, partielle Hebungen und Senkungen, Wildwasser und Lawinen, welche Felsen unterspülen, enorme Blöcke mitführen und auf ihrem Wege Alles niederreissen. Daneben kommen Bergstürze und Rutschungen vor, sei es als Folge von Stössen und Erschütterungen, sei es, dass die Felsen, die an ihrem Fusse vom Wasser angegriffen wurden oder auf Schichten ruhten, welche vom Wasser durchweicht und ausgelaugt worden sind, durch ihr Eigengewicht in Bewegung gerathen. Alles, was auf diese Weise an den Höhen oben abgetragen wird - von den Staubpartikelchen der Verwitterungsschicht, welche der Wind von den Gipfeln wegfegt, bis zu den gewaltigen Blöcken, welche durch Lawinen und Erdbeben herabgestürzt, durch Wildwasser mitgerissen werden - Alles wird in's Thal, in die Ebenen hinunter befördert, um dort die Vertiefungen auszufüllen und folglich auch dort die Bodenformen umzugestalten.

Beachtung verdient der Zusammenhang zwischen Beryformen und Gesteinsarten. Jedermann weiss, dass ein Granitgebirge anders aussieht als vulkanische oder Kalkgebirge; diese wie jene haben ihre besonderen Gestalten und charakteristischen Verwitterungsformen. Indessen handelt es sich hiebei oft um Nüancen, die man mehr instinktiv herausfinden muss, als dass man sie definiren könnte, die aber werth sind, dass man sie beachtet und studirt, um sich vielleicht zu vergewissern, dass die Abhängigkeit der Form von der Gesteinsart, die Uebereinstimmung zwischen beiden, allgemeinen Gesetzen unterliegt ${ }^{1}$ ).

Der Reisende hat im Weitern Beobachtungen anzustellen und Thatsachen zu erheben nach folgenden Gesichtspunkten.

Erstens in Bezug auf das Streichen oder die Richtung der Gebirgsketten, d. h. auf die Richtung, welche die Axe

1) Vgl. hierüber das schöne Werk von J. M. Ziegler: Ueber das Verbältniss der Topographie zur Geologie, ferner das S. 22 erwähnte Werk von H. Bach Dr. Baltzer, der Glärnisch, ein Problem alpinen Gebirgsbaus, Zürich 1873 ; A. Heim, Gebirgsbildung (I. Bd.) und dessen kleine Schrift ủber Verwitterung. 
les Gebirges - eine ideale Linie von einem Ende derselben zum andern - in Bezug auf die Himmelsgegenden hat.

Zweitens in Bezug auf den Lutershied der beiden $A b$ larhungen eines Gebirges. Oft ist der Abhang auf einer Geite steil, während auf der andern Seite das Gebirge sich anft abdacht. Man hat - wie uns scheint, etwas vorchnell - allgemeine Regeln aufgestellt darüber, wo bei einer' sestimmten Richtung des Gebirgs der Steilabhang sich beinden muss, sowie darüber, welche Ursachen diese Verchiedenheiten bewirken. Um so mehr ist Werth darauf zu egen, dass aus allen Welttheilen hiefür Thatsachen beigeoracht werden, welche entweder die Regel wirklich als allremein gültig bestätigen und zum Gesetz erheben orler welche sie widerlegen und lediglich als rorgefasste Meinung rscheinen lassen.

Eine Regel ist ferner aufgestellt worden über das Zu:ammentreffen oder vielmehr Geyenüberliegen de'r tiefsten Pässe. and der hö̈hsten Gipfel. Sie lautet dahin: die niedrigsten üsse, d. h. die Einschnitte, welche am weitesten unter die Cammlinie des Gebirgs hinabreichen, entsprechen in ihrer Lage im Allgemeinen den höchsten Gipfeln des gegenüberiegenden Massirs, und umgekehrt. - Der Reisende wird darauf chten, ob seine Beobachtungen dieses angebliche Gesetz betritigen oder ob die Ausnahmen häufiger sind als die Regel.

In Gebirgen, auf welchen das ganze Jahr Schnee liegt, vestimme man die Schneclinie, d. h. die untere Grenze dieses wigen Schnees. Sie liegt gewöhnlich an den zwei Bergeiten nicht in gleicher Höhe und variirt von Jahr zu Jahr; n einiger Entfernung erscheint sie als ziemlich scharf ausresprochene horizontale Linie; je mehr man aber sich ihr hähert, desto unregelmässiger stellt sich ihr Verlauf dar; ie steigt oder fällt, jenachdem die Lokalitäten den Sonnentrahlen, herrschenden Winden $u$. dgl. mehr oder minder usgesetzt $\left.\operatorname{sind}^{\mathrm{l}}\right)$.

1) Ygl. oben S. 203. Für Weiteres über diesen Gegenstand verweisen wir auf 3. Studer, Lehrbuch der physikalischen Geographie und Geologie II. S. 336 („Die ichneelinien") und I. S. 226. Sonklar, allgemeine Orographie S. 107 und 108 und lüller, Kosmische Physik, 4. Aufl. S. 522 ff. Die bei Studer ausgesprochene Verauthung, dass man in den höchsten Breiten der Polargegenden vielleicht auch im iiveau des Meeres eine niemals wegschmelzende Schneedecke finde, hat sich für lie nördliche Halbkugel nicht erwahrt. Vgl. Grisebach, Yegetation der Erde I. Bd. iollbrunner, über die Urwelt des Nordens, St. Gallen und Zürich 1881. 
An dieser Stelle wollen wir auch den Lauinen ${ }^{1}$ ) einige Worte widmen; sie sind eines der wirksamsten Agentien für den Transport. Man unterscheidet drei Arten: Stein-, Eisund Schnee-Lawinen.

Die Steinlauinen sind herunterstürzende Massen von Felstrümmern, welche namentlich von Mitternacht bis zur Morgendämmerung sich von den höchsten Berggipfeln ablösen, ohne Zweifel in Folge Gefrierens des Wassers in den Felsspalten: wie Wildwasser stürzen diese Steinregen von den schroffen Felswänden herab und durch die Runsen derselben herunter. Sie liefern das Material zu den Gletscherwällen (Moränen).

Die Eislawinen sind herabstürzende Eismassen, welche sich im Frühling ablösen ron steilen Wänden, wo sie während des Winters Gesimse, Stallaktiten und überhängende Wölbungen aller Art gebildet haben. Mitunter ist es auch ein Theil des Gletschers, welcher sich rom andern abtrennt und am Abhang niedergleitet oder der, wenn der Gletscher bei seinem Vorrücken auf einen Abgrund trifft, in diesen, übeı den Rand desselben herunterstürzt.

Die Schneelawinen sind oft nur Schneemassen, welch vom Winde in die Höhe gejagt wurden oder, durch ihrt eigene Schwere in Bewegung gesetzt, von den Höhen herak sich bewegen. Aber die eigentlichen Lawinen sind Schneemassen, welche unter furchtbarem Tosen und Krachen längs der Gehänge in die Thäler hinunterstürzen, auf ihrem Wegt Alles mitreissen und in Folge des gewaltigen Luftdrucks welchen sie verursachen, sogar Bäume und Hütten niederwerfen, welche nicht unmittelbar im Bereiche ihrer Bahr. liegen.

Die Staub-oder Winterlawinen entstehen aus frisch gefallenem Schnee, der auf eine Eiskruste zu liegen kam, wc er keinen Halt findet; der geringste Anstoss setzt grosst Massen dieses staubigen Schnees in Bewegung; sie wirker. sehr zerstörend durch ihren eigenen Fall wie auch durck die Luftbewegungen, die hiedurch verursacht werden. Dif Grund- oder Sommerlawinen bilden sich aus Schneemassen an den Berglehnen, deren Adhäsion an den Boden im Frühling

1) Vgl. F. v. Tschudi, Thierleben der Alpenwelt (Abschnitt Alpenregion); Heim a. a. O.S. 331 ("Steinschläge und Lauinenzüge"); J. Coaz, die Lauinen der Schweizer alpen, Bern 1881, und B. Studer, a. a. O. S. 229 und 230 , woselbst weitere Angaber über einschlägige (ältere) Literatur. 
und Sommer aufgehoben wird durch unter der Masse durchsickerndes Schmelzwasser. Sie hestehen aus kompaktem, halb gefrornem, halb nassem Schmee, Felsblöcken, entwurzelten Baumstämmen u. dgl., welche sie in ihrem Laufe mit fortreissen.

Die Lawinen sind periodische Erscheinungen, d. h. sie treten jedes Jahr an gewissen Stellen auf, welche den Bergbewohnern bekannt sind; die Wege, welche sie einschlagen und welche zum Theil Wasserrinnsale und Runsen sind, lieissen Lawinengänge: in den Thälern werden durch si Massen von Schnee und Eis aufgehäuft, welche die Sommerwärme kaum wegzuschmelzen rermag. Ihr Volum und ihre Wirkung sind verschieden; ihre spur haben manche tief eingegraben in den Boden, und dauernd erhält sich im Gedächtniss der Bergbewohner das Andenken an Lawinenverheerungen. So wird es dem Reisenden, auch wenn er nicht selber das grossartige Schauspiel des Lawinensturzes mitansehen kömnte, nicht schwer fallen, deren zerstörende Aktion nachzuweisen, sei es aus den Spuren ihrer Bahn, sei es durch Aussagen der Bewohner des Landes.

Von Interesse ist es auch, festzustellen, welche Vorsichtsund Schutzmasspegeln gegen diese Plage ergriffen wurden. Als solche dienen bald Bannwälder, Bestände hundertjähriger Bäume, die Niemand anzugreifen wagt und die eine schützende Sauer bilden zwischen den Höhen, von welchen Lawinen herabstürzen, und den menschlichen Wohnungen; hald Mauern aus Stein oder rereistem Schnee, an welchen die Lawinen sich brechen; bald Pfahlreihen und Stufen, welche die Lawinen in ihrem Laufe aufhalten oder doch deren Anprall abschwächen. Bei manchen Bergpässen wird der Weg an den gefährlichsten Stellen geschützt durch Galerien und Tumnels. Die hesten Torkehrungen gegen die Lawinenbildung sind Reihen alternirend (quincuncial, ,im Verbande ${ }^{\prime}$ ) in den Boden geschlagener Eisenstäbe am obern Ende eines Ganges und steinerne Sperren an den Berglehnen, ron wo die Lawinen kommen. Diese Vorkehrungen können die Lawinen festhalten am Orte ihrer Bildung, bevor sie Dimensionen angenommen haben, welchen Nichts mehr widersteht.

Jetzige Gletscher. Gletscher nennt man die Eisfelder oder Eisströme, welche sich in gewissen Hochthälern vorfinden 
und oft in die tieferen Thäler hinabreichen. Der eigentliche Gletscher (die "Eiszunge") liegt unterhalb der Firnlinie oder der Grenze, an welcher das im Sommer schneefreie Eis aufhört: oberhalb dieser Linie befinden sich die Schneefelder, welche die Gletscher alimentiren und welche Fim heissen. Der Firn besteht aus harten und körnigen Schichten alten Schnees, welcher über die Plateaux und obere Seitenflächen der Hochgebirge eine weisse oder schmutziggraue Decke bildet oder die Thalmulden und Vertiefungen erfüllt. Diese Schneemassen werden mit Wasser durchtränkt, wenn die Sonne deren oberste Lage zum Schmelzen bringt; in der Nacht gefrieren sie wieder und rerwandeln sich so in Eis; durch ihr Eigengewicht wie durch den Druck höher liegender, ihnen aufgelagerter Massen werden sie in den rerschiedenen Thalformen abrärts bewegt und bilden hier die Gletscher, welche weit thalabwärts vorrücken ${ }^{1}$ ).

Nicht alle Gebirge, welche über die Schneegrenze emporragen, enthalten Gletscher. Die Gletscherbildung ist an gewisse meteorologische und orographische Bedingungen geknüpft. Die Schneeregion des Gebirgs muss Raum genug bieten zur Entstehung grosser Schneefelder; die Luft muss feucht und. die Temperatur tief genug sein zu reichlichem Schneefall; die Thalgründe müssen schwaches Gefälle haben, damit die Schneemassen sich nur langsam abwärts bewegen; es müssen mehrere Thäler in ein gemeinsames Sammelbassin einmünden; die Temperatur in den rerschiedenen Jahreszeiten muss erhebliche Differenzen aufweisen, so dass in den obern Schneefeldern Aufthauen und Wiedergefrieren mit einander wechseln. Ist die Luft trocken, das Klima zu gleichmässig und fehlt es an sanftem Gefälle der Thalböden, so entstehen keine Gletscher, selbst wenn die Berggipfel mit ewigem Schnee bedeckt sind.

Es ist ron Wichtigkeit, dass Reisende unter allen Klimaten und in den verschiedensten Ländern die Ursachen studiren, melche Gletscherbildung veranlassen und begünstigen; es ist das ron hoher Bedeutung für die Geologie, weniger noch der jetzigen Gletscher wegen als mit Rücksicht auf die Frage nach den Faktoren, welche die sogenannte Gletscherperiode

1) Tgl. Kaltbrunner, Aide-mémoire p. 54; ferner machen wir aufmerksam auf die Abschnitte betreffend Gletscher in folgenden Werken. B. Studer, a. a. 0. S. $121 \mathrm{ff}$. F. v. Tschudi, a. a. O. Müller, kosmische Physik S. 526 ff. PeschelLeipoldt, Bd. II, S. 336 ff. v. Sonklar, Allgemeine Orographie, Wien 1873, S. 109. 
nder Fiszeit und später den Rüclizuz jener Gletscher bewirkt laben.

Wer sich mit dieser Materie genauer rertraut machen will, muss nothwendig einige der zahlreichen Syezialwerke iibser die Gletscherfrage studiren. Hier sprechen wir nur rnn solchen Beobachtungen, welche liein Reisender unterlassen darf, namentlich wenn es sich um ferne, noch ziemlicht unbekamnte Gegrenden handelt, wo die Gletscher vielleicht eigenthiümliche Erscheinungen darbieten, die anderwärts nicht in gleicher Weise heobachtet wurden oder werden komten. Schon die hlosse Feststellung der Thatsache, dass Gletscher rorhanden seien oder nicht, ist von Bedeutung mit Bezug auf die gengraphische Vertheilung der Gletscher auf der Erdnberfläche.

Situationspläne, Durchschnitte (Profile), Ansichten von (Gletschern gehören zu den auf die Konfiguration des Bodens (s. daselbst) bezüglichen Materialien.

Gewisse Eigenthümlichkeiten der Gletscher, wie Gletschertische, Mittagslöcher, Gletschermüllen u. dgl. sind sich überall gleich $\left.{ }^{1}\right)$.

Wesentlich ist rorab die Messung der Höhe des untem (iletscherendes und der Firnlinie; sodann die Bestimmung der Geschwindigkeit für die Forthewegung (das Fliessen) der Fïsmasse; endlich die Beantwortung der Frage, ob sie im Vorrücken oder im Rückzug begriffen seien, d. h. ob ihr vorderes (Stirn-) Ende sich thalabwärts weiter vorschiebt oder ob es im Gegentheil thalaufwärts zurückrerlegt wird, ob also der Gletseher an Terrain gewinnt oder verliert.

Die unterr Grense der Glitscher ist sehr variabel und wird wesentlich durch lokale Einflüsse bestimmt. Ausser dem Klima wirken auf sie ein die Bodengestalt und die Mächtigkeit (Dicke) dles Gletschers. Falls kein Hinderniss der Vorwäitshewegung des Gletschereises im Wege steht, muss die untere Grenze des Gletschers da liegen, wo die Bewegung und das Abschmelzen des Eises sich das Gleichgewicht halten. Ausser der Meereshïhe der Gletscherbasis wird man womöglich die Mitteltemperatur des Thales ermitteln, in welches er hinabsteigt. - Die Lage der Firnlinie ist weit konstanter und sicherer zu

1) Vgl. unten S. 264, sowie Sonklar, Anleitung zu Beobachtungen in den Alpen S.16. 
ermitteln als der übrige Theil der Schneegrenze, daher ihre Bestimmung von Wichtigkeit.

Die Bewegung der Gletscher, das Fliessen des Eisstroms ist eine so wohl konstatirte Thatsache, dass nur die Aufgabe übrig bleibt, für jeden einzelnen Gletscher die Schnelligkeit dieser Bewegung zu ermitteln und die Ursachen des Vorgangs zu studiren.

Diese Bewegung, das Vorschieben der Eismassen nach tieferen Lagen, wird von den Einen aufgefasst als ein blosses Herabgleiten, welches bewirkt werde durch die eigene Schwere des Eises und durch den Druck der aufgelagerten Massen; Andere nehmen als fernere Ursache eine Volumvergrösserung an, bewirkt durch Wasser, welches in die Spalten des Eises eindringt, hier gefriert, nun eine Ausdehnung zur Folge hat, der nichts widerstehen kann und die sich eben nach der Seite geltend macht, wo am wenigsten Widerstand entgegenwirkt, d. h. nach dem untern Ende des Gletschers hin, in welcher Richtung das Eis sich bewegen muss. Namhafte Gelehrte endlich schreiben die Bewegung der Gletscher einer Plastizität der Masse zu, welche sich längs des Abhangs hinunterbewege in Folge des Druckes ihrer Theilchen, wie dies bei einem zähflüssigen Körper, einer geronnenen Masse der Fall wäre, wobei die durch Sonnenwärme bewirkte Ausdehnung die Bewegung noch vergrössert.

Die Gletscherbewegung findet auch statt auf Abdachungen, deren Gefälle ganz schwach, ja fast null ist. Sie scheint weniger vom Neigungswinkel abzuhangen als von der Mächtigkeit (Dicke) des Gletschers und der ihn alimentirenden Schneefelder, so dass ein mächtiger Gletscher bei schwachem Gefälle sich schneller bewegt als ein schwacher Gletscher auf stark geneigtem Abhang.

Die Geschwindigkeit dieser Bewegung ist aber nicht blos verschieden von Gletscher zu Gletscher, sondern auch bei einem und demselben Gletscher, je nach Jahres- und Tageszeit und den Theilen des Gletschers. Im Winter ist die Bewegung nur ungefähr halb so gross wie im Sommer. Die Verschiedenheiten nach der Tageszeit sind minder wichtig das Mass der Bewegung wird gewöhnlich für einen Zeitraum von 24 Stunden angegeben, so dass jene Differenzen sich hiebei ausgleichen. Was die verschiedenen Punkte auf dem Gletscher betrifft, an welchen die Geschwindigkeit gemesser 
werden soll, so ist zu bemerken, dass der Gletscher sich rascher bewegt in seiner mittleren Parthie als in den obern und untern Theilen, rascher an verengten Stellen als da, wo ihn die Wände seines Felsenbettes nicht auf schmäleren Raum einzwängen; rascher in der Längsmittelzone als an den Rändern, rascher an Stellen, wo er konvex als da, wo er konkav ist.

Um diese Messungen anzustellen, wählt man sich einen Standpunkt auf einem der hohen Uferfelsen des Gletscherbettes und einen Fixpunkt am andern Ufer; zwischen beiden lässt man quer über den Gletscher eine Reihe von Stäben oder Pfählen solid aufpflanzen, wie dies beim gewöhnlichen Linienabstecken S. 27 geschieht. Man notirt den Zeitpunkt, in welchem ein Pfahl eingeschlagen worden ist, und Tags darauf misst man, wie weit die Pfähle oder Stäbe von der geraden Linie zwischen den zwei Fixpunkten sich entfernt haben. Diese Zahl wird dividirt durch die inzwischen verstrichene Zeit, und man erhält so die Bewegungsgeschwindigkeit für die betreffende Zeiteinheit.

Wenn die Oberfläche des Gletschers unzugänglich ist, so sucht man die Geschwindigkeit gewisser charakteristischer Punkte desselben (Gletschertische u. s. w.) zu bestimmen durch Messung von Winkeln, deren Scheitel jene Punkte sind, während die Grundlinien der betreffenden Dreiecke auf den Felsen angenommen werden, welche den Gletscher seitlich begrenzen ${ }^{1}$ ). Um aber auch die Geschwindigkeit an den Rändern zu ermitteln, bringt man auf das Eis spitze Steine, die einem Felsvorsprung oder einer Blockkante entsprechen, und misst Tags darauf die Distanz, um welche sie sich mittlerweile von diesen Stellen entfernt haben.

Es ist gut, wenn man diese Operation während mehrerer Tage wiederholt vornehmen kann; man erlangt so einen Mittelwerth, der nicht oder wenig mehr durch züfällige Fehler beeinträchtigt ist. In jedem Falle aber muss man das eingeschlagene Verfahren genau beschreiben und sorgfältig angeben, zu welcher Zeit, an welchen Punkten und unter welchen Umständen man die Messungen vornahm.

Das Vorrïcken oder Zurückucichen eines Gletschers lässt sich konstatiren auf Grund von Ueberlieferungen und Aus-

1) Vgl. v. Sonklars Anleitung pag. 17. 
sagen der Bewohner des Gebietes, von Terrainbesichtigungen und endlich von genauen Messungen.

Die Chroniken erzählen z. B. von gewissen Alpenpässen, die heute unpassirbar sind, dass sie früher mit Saumthieren begangen und von Prozessionen benutzt wurden. Aehnliche Berichte kommen anderorts als Traditionen statt in Form schriftlicher Dokumente vor. Im Allgemeinen wird man von Bewohnern hoher. Thäler, von Greisen besonders, werthvolle Angaben über alte Gletschergrenzen erhalten; immerhin sind dabei Uebertreibungen zu riskiren und thut man daher gut, so viel als möglich durch eigene Beobachtung von der Sachlage sich zu überzeugen.

Hiebei ist hervorzuheben, dass die End-oder Strmmoräne eines Gletschers - entstanden aus Gesteinstrümmern, die auf die Gletscheroberfläche gelangten und am vordern Ende des Gletschers auf den Boden hinunterfielen - immer dessen grösste Ausdehnung bezeichnet. Wenn der Gletscher vorrückt, so stösst er diesen Steinwall vor sich her, zerstört ihn theilweise und wirkt dabei auf den Boden ein wie eine Pflugschaar; ist aber die Moräne zu mächtig, als dass der Gletscher sie bewältigen könnte, so staut er sich an diesem Hinderniss und übersteigt es endlich. Im einen wie im andern Falle besitzt der Gletscher, wenn der Vorgang neueren Datums ist, keine regelmässige Endmoräne, die im Verhältniss wäre zur Masse der Felstrümmer auf der Gletscheroberfläche. Zieht hingegen der Gletscher sich zurück, so entsteht zwischen der alten Frontalmoräne und dem neuen Stirnende des Gletschers ein Raum, der durch augenfällige Eigenschaften frïheren Gletscherbodens ${ }^{1}$ ) sich als solcher charakterisirt. In der That ist das freigewordene Bett eines durch $\mathrm{Ab}$ schmelzen zurückgegangenen Gletschers leicht an folgenden Merkmalen zu erkennen: Mangel an aller Vegetation, der Boden bedeckt mit feinem Sand oder Gletscherlehm und besäet mit eckigen scharfkantigen Gesteinstrümmern von allen Dimensionen und in allen Lagen; Felsflächen mit Rundhöckern (roches moutonnées), durch die Reibung des Eises

1) Den besten Ersatz für die Anschauung der NaturverhäItnisse - das beste künstliche Mittel, sich mit denselben vertraut zu machen - bieten in diesem wie in einigen anderen Fällen (Küsten- und Thalbildungen, Vulkane) die geologischen Reliefs von Prof. Albert Hezm in Zürich, unter, den bildlichen Darstellungen diejenigen von Prof. Simony in Wien. 
gegliittet (polirt), und gekritzt (gestreift) durch ins Eis eingefrorne harte Steine, welche in den anstehenden Fels Kritze eimrissen wie Diamant in Glas; kleine Teiche in den Vertiefungen des Bodens; grauliche Färbung des Ganzen, — ein Aussehen gleich einer Wüstenei.

Wenn einerseits, wie dargethan wurde, die oben angesebenen Merkmale hinreichen, $\mathrm{um} \mathrm{zu}$ konstatiren, ob Vorrücken oder Rückzug des Gletschers stattfand, so liefern dieselben andrerseits nur ein unvollkommenes Mass für den Betrug diese' Benegunu. Ein solches kann nur erlangt werden mittels fixer Punkte und Marken verbunden mit Beobachtungen, welche sich über einen langen Zeitraum erstrecken. Wemn auch der Aufenthalt eines Reisenden in einer Geggend nicht so lange dauert, dass er selber solche Beobachtungen anstellen kamn, so darf er doch nicht unterlassen, genau den Punkt zu markiren, bis zu welchem in der Zeit seiner Anwesenheit der Gletscher reichte. Spätere Beohachter sind dam in der Lage, die inzwischen stattgefundene Veränderung gil konstatiren.

Wemn ein Gletscher vorschreitet oder zurückgeht, so darf man hieraus nicht den Schluss ziehen, dass alle benachharten Gletscher sich nun gleich rerhalten und. dass dir Rewegung dieses einen in regelmässiger Weise und andauernd sich vollziehe. In Gegentheil kamn von zwei benachbarten Gletschern der eine Tendenz zum Vorschreiten, der andere zum Rückzug haben; und was die Dauer der Bewegung im einen oder andern simne betrifft, so scheinen variable Perioden von Vergrösserung und Abnahme dieser Eisströme mit einander zu wechseln.

Spuren alter Gletscher. Es ist bekannt, dass die Gletscher früher weit ausgedehnter waren als jetzt. Sie bedeckten nicht nur den grössten Theil Europas, sie erstreckten sich ïberdies auf heiden Hemisphären bis in Gegenden, deren heutiges Klima jede Möglichkeit der Gletscherbildung auszuschliessen scheint. Es ist denn auch das Studium früherer Eisverbreitung vom höchsten Interesse.

Ohen wurde gesagt, woran das von einem ahgeschmolzenen neueren Gletscher occupirt gewesene Terrain als Gletscherboden erkannt werden könne. Im Laufe der Jahrhunderte werden aber die charakteristischen Gesteinstrümmer fort- 
transportirt und anders gelagert (remanié) und der Boden überzieht sich mit einer Pflanzendecke; es werden also die Gletscherspuren theils verwischt, theils maskirt. Aber einige Merkmale, welche auf diese Spuren leiten, wird der kundige Beobachter selbst in einer solchen Gletschergegend entdecken, die jetzt einer reichen und vielseitigen Kultur unterworfen ist. Es hat die Moränenlandschaft ihre eigenthümliche Physiognomie, die Niemandem entgehen kann, der mit den Alpenregionen einigermassen vertraut ist ${ }^{1}$ ). Da zeigen sich dem Blicke zahlreiche rundliche Hügel, die keine bestimmte orographische Anordnung erkennen lassen; mehr oder minder regelmässig gestaltete Vertiefungen mit kleinen Seen und Teichen oder mit Torf und Schlammgrund, Felsblöcke der verschiedensten Form und Grösse, welche die Hand des Zufalls über die Gegend ausgesäet zu haben scheint, in welcher diese Felsarten sich nicht anstehend (als "gewachsenes" Gestein) finden.

An entblössten Stellen, in Strassen- und Bacheinschnitten etc., beobachtet man, dass der Boden aus ungeschichteten Massen von Sand, Lehm und Steinen („Kies") besteht, in welchen sich hie und da grosse Blöcke mit scharfen Kanten und Ecken vorfinden. Bei genauerem $\mathrm{Zu}$ sehen gewahrt man, dass die einzelnen Steine glattgeschliffene glänzende Flächen und auf diesen eingekritzte Streifen aufweisen. Findet man solche Steine in einem Fluss- oder Bachbette, so kann man hieraus auf die Nähe von Gletscherablagerungen schliessen: vom Wasser fortgerollt, verlieren sie diese Streifen bald und erhalten ein mattes Aussehen. Geschiebe, die noch deutliche Kritze zeigen, können also nicht weit her transportirt worden sein.

Ein anderer Beweis für stattgehabte Gletscherwirkung sind die erratischen Blöcke, von denen wir schon S. 248 sprachen. Diese Findlinge sind oft auf enorme Distanzen transportirt worden. Das Merkmal, welches sie am meisten charakterisirt, besteht darin, dass sie mineralogisch verschieden sind von dem in der Gegend anstehenden Gestein.

1) Sehr gut charakterisirt dies Desor in seiner Schrift "Le Paysage morainique" Paris und Neuchâtel 1875. Vgl. auch Rütimeyer, Pliocen und Eisperiode zu beiden Seiten der Alpen. Mühlberg, die erratischen Bildungen im Aargau. Gutzwiller, die löcherige Nagelfluh und ihre Beziehungen zu den tertiären und quartären Ablagerungen; Basel 1880 . 
Die Hügel, wovon oben die Rede war, sind die Reste alter End- oder Stirnmoränen. Sie sind oft überzogen mit Pflanzenwuchs, bedeckt mit Wohnungen und ganzen Dörfern. Sie sind nicht $\mathrm{zu}$ verwechseln mit den Ablagerungen angeschwollener Wildbäche, noch mit den Gletscherschutt-Massen, welche sich gewöhnlich weiter unten als die Erdmoränen finden. Aechte Noränen haben gewöhnlich Lücken, leere Zwischenräume, in ihrer Masse; die scharfkantigen Blöcke, welche einen wesentlichen Theil ihres Materials bilden, stossen oft nur mit ihren Eckpunkten oder Kanten zusammen und lassen so Hohlräume, welche durch Sand und kleinere Steine nur unvollkommen ausgefüllt werden. In den hügeligen oder haufenweisen Ablagerungen hingegen, welche durch angeschwollene Wildwasser erzeugt werden, sind die Blöcke und kleineren Geschiebe, durch Reibung abgerundet, eingebettet in Massen von Schlamm, der, weil das Wasser daran sehr reich war, alle Zwischenräume ausfüllte. Endlich gibt es Gletscherbildungen, die einem festen Cement gleichen, wo eckige Fragmente wie eingegossen sind in den kompakten kalkigen Sand, welcher sie als Grundmasse umhüllt und zusammenkittet. Dieselben sind zudem oft ausgezeichnet durch konische Hohlräume, die man in den Wildbachablagerungen nicht trifft - Höhlen, welche dadurch entstunden, dass im Moränenmaterial auch Eisblöcke mitgeführt wurden, die dann langsam schmolzen, während die Masse um sie herum trocknete und fest wurde, sodass der Raum leer blieb, den die Eisblöcke einnahmen.

Oft haben Gewässer wie Gletscherbäche die alten Moränen theilweise zerstört und umgelagert (remanirt), aber Reste davon finden sich gewöhnlich noch an den Thalseiten und diese Reste können ausreichen, um in Gedanken die alte Moräne und ihren früheren Verlauf zu rekonstruiren.

Hat man diese Linie erkannt und betrachtet man aufmerksam den Boden oberhalb ihres konkaven Theiles, so wird man beobachten, dass die Felsen, welche zumeist von Rasen überzogen, stellenweise aber durch fliessendes Wasser blossgelegt sind, gerundete Formen aufweisen, die herrühren von der Wirkung des vorrückenden Gletschers; es sind dies die sogenannten Rundhöcker (roches moutonnées); die nakten Felsflächen sind zudem oft noch gestreift, d. h. durchzogen 
von gradlinigen Furchen oder Kritzen, die eingeschnitten wurden durch harte Steine, welche das Gletschereis mit sich führte. Hie und da trifft man auch "Riesentöpfe oder Gletschermühlen", rundliche oder trichterförmige Höhlungen im Fels auf dem Boden eines alten Gletscherbettes, die eingegraben wurden durch Steine, welche in fortwährende rotirende Bewegung versetzt wurden durch die unter dem Eis hervorströmenden Gletscherbäche oder die Wasser, welche in Kaskaden über Eiswände herabstürzten. Endlich, aber seltener findet man "Gletscherstrassen", d. h. lange und enge Vertiefungen, die gleich Römerstrassen bedeckt sind mit zusammengepressten und nivellirten kleinen Blöcken.

Ist das alte Gletscherbett von steilen Felswänden eingeschlossen oder steigt man in das Thal hinauf, aus welchem der Gletscher liommt, so wird man bemerken, dass die Wände his auf eine gewisse Höhe bearbeitet sind durch die Reibung, welche der Gletscher ausübte. Ausser den Streifen, wovon oben die Rede war, beobachtet man "Schliffe", d. h. polirte, glatte, oft hell glänzende Flächen. Die scharfen Ecken und Kanten sind wie abgefeilt, namentlich wo ein Felsvorsprung dem Gletscherstrom entgegentrat und seinen Lauf änderte.

Die Existenz mehrerer Endmoränen, die von einander ziemlich weit abstehen und deutlich zu unterscheiden sind, beweist, dass der Gletscher sich ruckweise verkleinert hat. Andernfalls, d. h. wenn der Gletscher gleichmässig langsam zurückgegangen ist, erscheint der ganze Raum zwischen der äussersten Stirnmoräne und dem jetzigen Gletscherende übersäet mit Materialien, welche während der Zeit des allmäligen Rückzugs hier überall abgelagert wurden.

Um sich gehörig Rechenschaft zu geben über Ursprung und Bedeutung der Felstrümmer, die man im alten Gletscherbette trifft, muss man in Betracht ziehen, dass auf den seitlichen Rändern des Gletschers, längs der angrenzenden Felswände, sich Gesteinshaufen und Wälle bilden, welche Seitenoder Randmorïnen (Seitengandecken) heissen und dass solche Seitenmoränen da, wo zwei Gletscher zusammenstossen, auf dem vereinigten Eismeere sich als Mittelmoräne (Mittelgandecke, Guferlinie) fortsetzen. Eine Nittelmoräne entsteht also dadurch, dass die linke Seitenmoräne eines Gletscherarmes sich vereinigt mit der rechten Seitenmoräne des (links) anstossenden 
Armes; ein Hauptgletscher hat demnach eben so viele Mittelmorïnen als ihm seitliche Eisströme zukommen. Man unterscheidet ausserdem Moränen der Gletscheroherftäche unr Grundmoränen; erstere sind die ausschliesslich auf der Oberfläche des Eismeeres befindlichen; letztere sind grebildet durch Materialien, die sich zwischen Eis und Fels, auf dem Grunde und an den Seiten des Gletschers, vorfinden.

Aus der Anordnung, aus der lokalen Vertheilung der Materialien im alten Gletscherbett wird man hienach schliessen kïmnen, ob dieselben zu Seiten- oder Mittehmorïnen gehören und aus der Entfernung der letzteren von einander kamn man annähernd die Mächtigkeit der Affluenten des Gletschers heurtheilen. Die Bestandtheile der Grundmoräne werden heim Abschmelzen der Gletscher mit denjenigen der Moränen auf der Gletscheroherflaiche vermischt; die beiderlei Gesteinstrümmer sind aber insofern noch zu unterscheiden als diejenigen, welche den Oberflächenmoränen angehörten, nicht durch Reibung abgenutzt und nicht gestreift sind und, abgesehen vom Einfluss der Verwitterung, ihre scharfen Kanten und Ecken beibehalten haben, während die andern - infolge des enormen Druckes und der Reibung, welchen sie ausgesetzt waren - abgekantet, abgestumpft, geglättet und gekritzt erscheinen. Diese Materialien zeigen zudem his und da Spuren von Schichtung oder wenigstens Sichtung oder Sortirung, herrührend von der Wirkung der unter dem Gletscher fliessenden Wasser.

Mitunter, wenn man eine Moränenlandschaft oder eine Gegrend, die offenbar ehemals ron Gletschern berleckt war, trifft, kann man im Zweifel sein über die Herkunft des Gletschers. In solchen Fällen hat man sich zu vergegenwärtigen, dass die Endmoräne im Allgemeinen aus bogenfürmig grupprirten Hügeln besteht und der Gletscher in der Richtung der Axe dieses Bogens von dessen konkaver Seite herkommen musste. Die Linie, in welcher der Gletscher sich bewegte, wird auch angedeutet durch die Streifen oder Kritze im anstehenden Fels; es handelt sich also nur noch um die Richtung der Bewegung in dieser Linie. Diese lässt sich erkennen an den Rundhöckern, welche glatte Flächen haben nach aufwärts, nach der S'tross-šcite des Gletschers, während sie an der thalabwärts liegenden oder Lec-Séitr 
oft von splittriger und unregelmässiger Beschaffenheit sind. Zur Erklärung fügen wir die Fig. 111 bei. Es sei $A$ ein Fels, dessen Fläche abgerieben, gerundet worden ist durch die Reibung des sich bewegenden Eises. Ist das Eis in $a$ angekommen, so kann es auf die Wand $b$ des Hohlraums keine Wirkung ausüben, da diese nicht in der Richtung der Stoss-

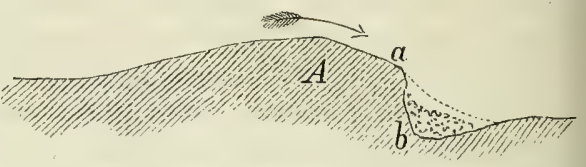

Fig. 111 .

kraft liegt; die Felsfläche $a b$ bleibt also intakt, die Höhlung wird lediglich mit Gletscherablagerungen erfüllt. Hätte sich aber der Gletscher in entgegengesetzter Richtung bewegt, so wäre der Vorsprung bei $A$ der Stosskraft des Eises ausgesetzt gewesen und abgerieben worden. Ist die Richtung der Gletscherbewegung ermittelt, so prüfe man das Terrain $\mathrm{zu}$ beiden Seiten der Quermoräne, die man vorgefunden hat, da diese Moräne leicht nur eine sein dürfte unter mehreren, welche die Etappen des Gletscherrückzuges bezeichnen, da demnach die äusserste Endmoräne viel weiter unten liegen könnte.

Die Mächtigkeit eines vorzeitlichen Gletschers erkennt man an der Höhe, in welcher man über dem Thalweg an den Felsen zu beiden Seiten noch Gletscherspuren trifft. Aus denselben kann man auch ermitteln, welches das Gefälle (die Abdachung) der Gletscheroberfläche war. Die grösste Ausdehnung des Gletscher's wird, wie schon bemerkt, bezeichnet durch die am weitesten vorgeschobene Endmoräne. Diese äussersten Grenzen sind indess nicht immer leicht zu bestimmen; oft entdeckt man sie nur durch Zufall oder durch beharrlich fortgesetzte Nachforschungen. Die grossen Gletscher jener vorhistorischen Zeit bedeckten eben, wie die Eismeere der Polarregion, das ganze Land mit einem ungeheuren Eismantel, aus welchem nur die höchsten Berge hervorragten; die Blöcke, welche von diesen Gipfeln sich ablösten, waren nun im Ganzen spärlich an Zahl und Masse, die Moränen also verhältnissmässig viel schwächer als diejenigen der heutigen Gletscher; nur die Grundmoräne war bedeutender. Auch konnte der Gletscher in jener Periode in einen heute nicht mehr bestehenden Meeresarm ausmünden; in einem solchen Fall lösten sich von ihm ungeheure Eis- 
massen ab, auf welchen das hergeführte Gesteinsmaterial weithin verfrachtet und zerstreut wurde. War das Gestade sanft abgedacht, so rückte der Gletscher in das Meer hinaus vor, bis zu einer Stelle, wo das Wasser so tief war, dass die Eismasse von ihm getragen, zum Schwimmen gebracht wurde. Hier nun bildeten sich Eisberge gleich denen, welche in unsern Tagen die Meeresströmungen aus den Polargegenden weithin transportiren und welche die mitgeführten Felstrümmer erst ablagern unter Breitegraden, wo die Eisberge schmelzen.

Vulkane und vulkanische Erscheinungen. Das Studium der Vulkane ist nicht minder interessant als das der Gletscher ${ }^{1}$ ). Der Reisende versäume nicht, bei Gelegenheit auch hierüber Beobachtungen anzustellen und Aufschlüsse zu erlangen.

Jeder Vulkan hat seine Geschichte. Man wird sie zu rekonstruiren versuchen aus Traditionen, alten Chroniken und aus Erinnerungen der Landesbewohner, wobei man sich indess zu hüten hat vor Uebertreibungen, welche aus Furcht und Aberglauben entsprangen. Die Angaben müssen sorgfältig geprüft, die einen durch die andern kontrolirt werden. So wird man so genau als möglich bestimmen, wann der Vulkan, falls er aus historischer Zeit datirt, in Thätigkeit trat; welches seine wichtigsten Ausbrüche waren; welche besondern Erscheinungen ihnen rorangingen oder auf sie folgten; seit wann der Vulkan ruht, welche Veränderungen er erlitt und seit wann er die jetzige Form hat.

Hierauf schreitet man zu eigenen direkten Beobachtungen; man rekognoszirt zunächt die Umgegend, nimmt dann den Berg topographisch auf und gibt davon einen Situationsplan, Profile (Durchschnitte) und wo möglich auch Ansichten von verschiedenen Punkten aus. Man notirt auch die Dimensionen des Kraters, seine Form und Lage, sowie Länge und Gefälle der wichtigsten Lavaströme.

Die Vulkane haben im Allgemeinen die Form steiler abgestumpfter Kegel. Oben auf dem abgestumpften Gipfel

1) Hinsichtlich der Frage im Algemeinen verweisen wir auch auf die einschlägigen Darstellungen in den S. 99 genannten geologischen Werken, ferner bei $F . v$. Hauer, die Geologie und ihre Anwendung auf die Kenntniss der Bodenbeschaffenheit der österreichisch-ungarischen Monarchie, Wien 1875; C. von Cotta, Geologische Bilder (Leipzig 1871), Peschel-Leipoldt a. a. O. I. Bd., S. 201, sowie auf die S. 260 erwähnten (je von einem kurzen Kommentar begleiteten) geologischen Reliefs von Prof. A. Heim. 
zeigt sich eine trichterartige Tertiefung oder ein Cirkus mit steilen Wänden: der Krater. Der Krater befindet sich indess nicht immer auf der Scheitelfäche; er kann auch an den Seiten des Berges rorkommen. Oft existiren mehrere Krater; dann heisst der oberste Haupt- oder Gipfelkrater, die andern sekundäre oder Nebenkrater.

Ein Vulkan muss aber nicht nothwendig ein Berg, er kann ein blosser. Hügel oder gar einfach ein Krater mitten im ebenen Lande sein, denn der Krater ist es, der den Vulkan ausmacht.

Der Eruptionskanal oder das Kamin des Tulkans, welches für die feuerflüssigen unterirdischen Stoffe einen Weg nach der Erdoberfläche bildet, öffnet sich im Innern des Kraters, aber nicht immer im Centrum, sondern manchmal an den Rändern und manchmal mit vielfachen MIündungen an rerschiedenen Stellen. Tm dieselben bilden die ausgerrorfenen Stoffe kleine Kegel, die oft durch nachfolgende Eruptionen wieder zerstört werden. Wenn die Gänge oder Schlote rerstopft sind oder die feuerflüssigen Massen auf deren Wände einen zu starken Druck ausüben, so kann bei einer Eruption der Vulkan theilweise zerstört werden oder es kann die Lava sich Bahn brechen durch eine Spalte an den Flanken des Berges. Berücksichtigt man ferner, welch grosse Wirkung auf das bewegliche Material eines Vulkans die Regenwasser ${ }^{1}$ ) und die stossweisen Erschütterungen haben müssen, so begreift man leicht, dass die Form eines Tulkans sehr randelbar ist. Ist der Feuerberg ron erheblichem Umfang, so findet man an ihm fast immer Spuren einer Verlegung seiner Thätigkeit: erloschene Krater und Spalten oder mehrere konzentrische Zirkusse. Geleitet durch das Aussehen dieser Spuren - ob alt oder frisch - und die Angaben der Anwohner kann man unter Lmständen in Gedanken den Vulkan in seiner frühern Form rekonstruiren.

Ist man am Kraterrande angekommen, so wird es nicht immer leicht, zu beohachten, was hier ror sich geht. Wenn Gasentwicklung stattfindet, so darf man sich nur auf der Seite aufhalten, vou welcher der Wind herweht und die Gase nach der andern Seite treibt. In den Zeiten relatirer

1) Die vom Wasser gegrabenen Thäler an dem Fulkan werden als Barançs bezeichnet. 
Ruhe, zwischen den einzelnen Ausbrüchen, wird man ein Sieden orler Kochen der Lava bemerken, gewissermassen das Athmen des Tulkans, untermischt durch das Pfeifen ausströmender Gase.

Nur wenn der Vulkan lange Zeit in Ruhe verharrte, darf man wagen, in den hrater hinabzusteigen, um hier grenauer zu beobachten. Um die Exhalationen, die sich entwickelnden Gase und die Sublimationsprodukte zu studiren, muss man freilich Chemiker sein; einem Jerlen aber ist es möglich, die verschiedenen Arten vulkanischer Thätigkeit zu konstatiren: die Bildung von Schwefelmassen der Solfataren, das Auswerfen ron Wasser und Gas bei den Fumarolen etc., Dinge, die man nicht nur im Innern der Krater, sondern anch an Spalten der Bergseiten heohachten kann. Leicht zu konstatiren ist ferner, mit welcher Langsamkeit. die Lava sich abkühlt; man notirt einfach die Temperatur ron Lavaströmen, deren Alter bekannt ist. Zu dem Ende braucht man nur einen Platinfarlen, welchen man in die noch zühflüssige Lava für einen Moment eintaucht. Die Farbennüance, welche das Platin beim Herausnehmen zeigt, gibt die Temperatur an und zwar:

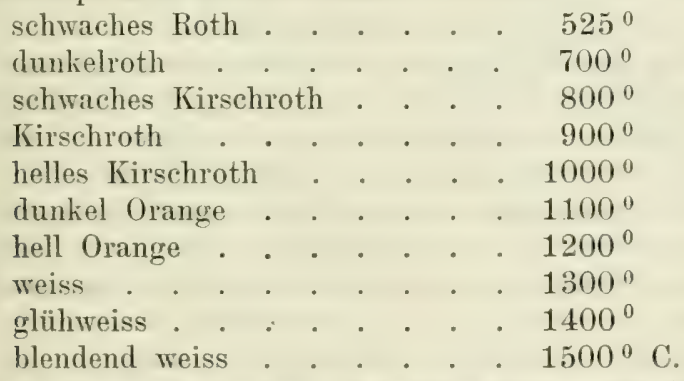

Die ausgeflossenen Lavamassen nehmen die verschiedensten Formen an; bald gleichen sie einem im Fliessen erstarrten Strom; bald bilden sie weit ausgedehnte Flachen, welche eine mächtige Decke über die Gegend bilden. Erkaltung und Zersetzung modifiziren zudem die Aussenfläche dieser Ströme und Felder ron Laven. Man trifft zuweilen grosse Stellen, an welchen die Lavamasse verschwunden ist, sodass Höhlen und Gänge entstanden sind, oder Lavaflächen mit zahlreichen und ansehnlichen Höckern und Hügeln, welche clas Bild eines rhaotischen Trümmerhaufens darbieten. - 
Unter den übrigen vulkanischen Auswurfsprodukten unterscheidet man die Schlacken (Scories), das sind unregelmässig gestaltete, gewundene und löcherige Fragmente, und die vulkanischen Bomben, das sind länglich-eiförmige, zuweilen im Fallen abgeplattete Massen. Kleinere Stücke heissen Lapilli oder Rapilli, wenn sie ungefähr Nussgrösse haben, vulkanische Asche aber, wenn sie feinem Sand oder Staub gleichen. Wenn diese Aschenmassen in Wasser kommen, so entsteht ein Schlamm, welcher beim Austrocknen sehr hart wird und den vulkanischen Tuff oder - indem er Gesteinsschutt aus Bestandtheilen der verschiedensten Dimensionen rerkittet - vulkanische Konglomerate bildet. Unter Bimsstein rersteht man poröse Schlacken aus feinkörnigem Material, die so leicht sind, dass sie auf dem Wasser schwimmen. Vulkanische Blöcke sind grosse Felstrümmer, welche aus dem Erdinnern, ron den Kraterwänden herrühren und bei der Eruption ausgeworfen werden. Die Entfernung von der Auswurfsstelle, in welcher man diese Blöcke und die Bomben findet, womit der Boden übersäet ist, sowie Volum und Gewicht derselben geben einen Massstab zur Beurtheilung der Stärke des Ausbruches.

Hat man Gelegenheit, eine Eruption zu beobachten, so versäume man nicht, sorgfältig Notizen zu machen über alle ihre Phasen; das Zeugniss eines kundigen and objektiven Beobachters wird immer von grossem Werth sein.

Uebertreibungen walten gewöhnlich und namentlich in Bezug auf die Vorboten eines Ausbruches; Jeder will irgend etwas Ausserordentliches bemerkt haben, Jeder pflegt die Aussagen Anderer zu überbieten. Die wirklichen Vorkommnisse dieser Phase sind zumeist am wenigsten konstatirt; gewöhnlich denkt man erst nach dem Ereigniss an die Anzeichen desselben und man kann dann die Thatsachen nur noch nach vagen Erinnerungen rekonstruiren. Wer in einer vulkanischen Gegend reist, thut daher gut, sich vorzusehen und, wif wenn er sicher auf eine bevorstehende Eruption rechnen würde, tagtäglich Alles zu notiren, was er Auffallendes und Ungewohntes bemerkt, das Bezug haben könnte auf wiedererwachende vulkanische Thätigkeit. $\mathrm{Zu}$ den Erscheinungen die Vorboten eines Ausbruchs sein können, gehören das plötzliche Versiegen von Quellen, ungewöhnlich reichliches 
Fliessen von Thermen, ein abnormer Zustand der Atmosphäre, Erschütterungen des Bodens, unterirdisches Getöse, auffallende Lnutue von Vögeln und andern Thieren, endlich reichliche Entwicklung von Dampf und Rauch aus Fumarolen und Vulkangipfeln.

Die Stösse und das unterirdische donnerartige Rollen nehmen gewöhnlich an Stärke zu bis zum Momente, wo mit schrecklichem Getöse die Eruption eintritt. Dann steigt eine ungeheure Rauchsäule in die Lüfte; sie breitet sich oben langsam aus zu einer Wolke, sodass sie die Form einer Pinienkrone annimmt. Der Himmel wird verfinstert: die Luft nimmt einen eigenthümlichen Geruch an, und ein feiner Aschenregen fällt auf die Erde nieder. Durch den schwarzen Rauch gewahrt man blitzartig aufleuchtende Streifen, herrührend von weissglühenden Lavamassen, welche in die Luft geschleudert wurden. Findet die Eruption Nachts statt, so wird die Rauchsäule erhellt durch den Wiederschein der im Krater kochenden Lava; sie bietet dann das Bild einer ungeheuren Feuersbrunst. Oft auch häufen sich die Wolken an, sie ballen sich zusammen, ein Gewitter bricht los, Blitze zucken durch die Wolken, in das Getöse der rulkanischen Detonationen mischt sich das Rollen des Donners, und immense Regenmassen ergiessen sich sündfluthartig auf den Tulkan hernieder; sie durchfurchen die Abhänge, und indem sie das bewegliche Material auf ihrem Wege mitreissen, rerwandeln sich diese Wassermassen - denen sich häufig noch solche beigesellen, welche der um den vulkanischen Gipfel gelagerte, durch den Ausbruch geschmolzene Schnee lieferte - in Schlammströme.

Sobald die Lava den Kraterrand erreicht oder sich durch Spalten im Berge Bahn bricht, so ergiesst sie sich am Abhang hinunter wie ein Strom geschmolzenen Metalles aus dem Hochofen; aber in Kurzem bedeckt sie sich mit einer starren Hautkruste und mit Schlacken; sie fliesst langsamer und nach einiger Zeit nur noch stossweise, wenn die noch feuerflüssige Lava stellenweise die Kruste durchbricht und die Hemmnisse beseitigt, welche sie selber ror sich her anhäufte. Gewisse Vulkane haben das Eigenthümliche, dass sie Massen von Schlamm auswerfen, welche Lavaergüssen ähnlich sind; man nimmt an, dass hiebei Sickerwasser tief 
ins Innere des Vulkans gelangten und dann mit grosser Energie ausgeworfen wurden, vermischt mit Gesteinstrümmern, vulkanischen Aschen und mitunter, wie angegeben wird, auch mit Resten von Organismen. Uebrigens bietet jede Eruption bemerkenswerthe Eigenthümlichkeiten dar, wenn auch das vorstehend in grossen Zügen entworfene Bild den gewöhnlichen Gang des Phänomens zeichnet.

Hat man einen Vulkan an und für sich, als isolirtes Objekt, studirt, so ist weiter die Beziehung zu prüfen, in welcher er zur Umgebung steht, ob er einer Gruppe oder Reihe von Vulkanen angehört und, wenn ja, ob die Perioden seiner Thätigkeit zusammenfallen oder abwechseln mit denjenigen der benachbarten Vulkane; ob der Vulkan in der Nähe des Meeres oder sonstiger grosser Wasserbecken ist und so durch ihn die Ansicht bestätigt würde, wonach die rulkanischen Ausbrüche hauptsächlich Sickerwassern zuzuschreiben wären, welche sich beim Kontakt mit heissem Gestein in Dampfmassen verwandeln von unwiderstehlicher Expansionskraft, oder ob eine wesentlich kontinentale Lage in einer trockenen Gegend diese Hypothese ausschliesst.

Ueberdies wird man nachforschen, ob in einem gewissen Umkreis andere Spuren vulkanischer Thätigkeit, Erscheinungen, die hierauf bezogen werden könnten, sich finden. Dazu gehören z. B. die heissen vutkanischen Quellen, welche sich von normalen Thermen durch höhere und veränderliche Temperatur unterscheiden; die Geysir, heisse intermittirende Springquellen, die Soffioni, welche aus Erdspalten unter Getöse heisse Dämpfe ausstossen; die Mofetten, aus welchen Gase ausströmen wie z. B. in der bekannten Hundsgrotte bei Neapel. Was die Salsen oder Schlammoullane betrifft, so kann man ihre Produkte, falls sie eine hohe Temperatur besitzen, als Erzeugnisse von Fumarolen betrachten, deren Entweichen gehemmt war durch Thon, Tuff und vulkanische Asche, durch welche die Gase und Dämpfe sich gewaltsam Bahn brechen mussten. Andernfalls, d. h. wenn ihre Temperatur nicht höher ist als die Lufttemperatur, so sirud diese Miniaturvulkane und deren Eruptionen lediglich zu betrachten als Produkt der Expansion von Gasen, erzeugt durch Zersetzung organischer Stoffe oder durch chemische Reaktion gewisser Mineralsubstanzen. 
Erdbeben. Wenn wir die Erdbeben im unmittelbaren Anschluss an die Besprechung der vulkanischen Erscheinungen hehandeln, so wollen wir damit der Frage, ob die beiden (iruppen von Erscheinungen im ursächlichen Zusammenhang stehen - worüber die Meinungen sehr getheilt sind - in keiner Weise präjudiziren.

Die Erdbeben sind, wie ihr Name andentet und welches auch ihre Ursache sei, Erschütterungen der festen Erdkruste oder wenigstens des (unsern Beobachtungen allein zugängichen) äussersten Theiles derselben, den man die Epidermis ler Erde nennen könnte. Die Stärke dieser Erschütterungen st sehr ungleich; die Erscheinung äussert sich manchmal n plötzlichen heftigen Stössen, manchmal nur in einem eisen, kaum wahrnehmbaren Erzittern.

Bei den stossweise auftretenden Exdbeben unterscheidet man: ertikale Bewegungen, in welchen der Boden sich zu heben and zu senken scheint, als würde er das eine Mal von einem anterirdischen Stosse emporgetrieben, das andere Mal durch lötzliche Belastung herabgedrückt; wellenförmige Bewegingen, in welchen der Boden zu oszilliren scheint wie wogendes Wasser; ferner, wie versichert wird, auch rotirende Bewegungen, welche als horizontal erfolgende Drehungen fühlbar werden; endlich gemischte Bewegungen, worin alle die rorrenaniten auftreten.

Die Fortpflanzung des Bebens heisst: konzentrisch, wenn lie Erschütterung von einem Punkte auszugehen und von nier aus nach allen Seiten, kreisförmig sich ausdehnend, ortzuschreiten scheint, wie Wellen in einem Teiche, in dessen uhiges Wasser ein Stein geworfen wird; transversal, wenn lie Bewegung von einem Zentrum aus in parallelen Wellen ich rerbreitet; linear, wenn sie von einem Punkte aus in iner geraden Linie nach den zwei entgegengesetzten Richungen sich ausdehnt.

Der Reisende wird sich bemühen, die Leberlieferungen zu ammeln, welche in einer Gegend mit Bezug auf die in ihr orgekommenen Erdbeben existiren. In Ländern mit häufigen irdbehen wird man sich auf die Traditioneu beschränken, relche sich auf die wichtigsten und jüngsten dieser Phä10mene beziehen, die sich am besten im Gedächtniss der 3ewohner des Landes erhalten hahen. Hinsichtlich der Erd- 
beben aus älterer Zeit darf man sich nur auf die glaubwürdigsten Zeugnisse verlassen; in allen Fällen sind die Spuren, welche von den Erdbeben blieben, durch den Beobachter selbst zu prüfen.

Es handelt sich nun noch um Beobachtungen solcher Erdbeben, welche allenfalls in der Gegend vorkommen, während der Reisende darin verweilt.

Hier wie bei den vulkanischen Erscheinungen muss man stets auf Alles achten, was in der Folge sich als Anzeichen oder Vorläufer eines Erdbebens herausstellen könnte. Es ist ron wesentlichem Interesse zu wissen, ob ein Erdbeben gewissermassen angekündigt wurde durch unterirdisches, überhaupt ungewöhnliches Getöse; ob die Atmosphäre durch irgend etwas Ausserordentliches sich auszeichnete; durch hohen Barometerstand, drückende Luft, Gewitter ; ob grosse elektrische Spannung rorhanden und die Magnetnadel Störungen unterworfen war; ob das Ereigniss eintrat nach einer langer Regenzeit ${ }^{1}$ ) oder zusammenfiel mit einer Periode besonderer Thätigkeit naher Vulkane; ob gewisse Thiere, wie gewarnt durcl ihren Instinkt, sichtliche Unruhe an den Tag legten u. s. f

Ob man nun auf den Eintritt des Erdbebens gefasst uni vorbereitet sei oder nicht, so ist es von Wichtigkeit, das man nicht unterlasse, genau Ort und Zeit zu notiren, wo der erste Stoss bemerkt wurde. Diese Angabe ist ron grossem Werth für die statistischen Ermittlungen über die Häufigkei der Erdbeben, ihreVertheilung nach Monaten, Jahreszeiten u. s.f Es ist ferner anzugeben, ob man sich hiebei an einem hoch. gelegenen Orte oder im Flachlande befunden habe unc ob im obern oder untern Theil eines Gebäudes. Was deı Zeitpunkt anbetrifft, so suche man, wenn der erste Eindrucl der Ueberraschung und Verwirrung vorüber ist, möglichs

1) Eine Einwirkung oder doch wenigstens ein Zusammenhang der Erdbebe mit dem Zustand der Atmosphäre gehört zu den weitverbreiteten und tief einge wurzelten Annahmen, hat sich aber bis jetzt wissenschaftlich noch nicht nach weisen oder begründen lassen. Erdbeben sind bei allen Barometerständen un ebensowohl beim Steigen wie beim Fallen derselben beobachtet worden. Die noc immer auf manchen gewöhnlichen Barometern gagenüber von 27 Zoll angebracht Angabe "Erdbeben ${ }^{*}$ ist daher eine absolut falsche und unsinnige ... Merkwürdi hartnäckig haftet im tropischen Amerika und auch andernorts noch der Glaubc dass Regen und besonders der Eintritt der Regenzeit in einigem Zusammenhan mit dem Erscheinen von Erdbeben stehe und man wird die gewöhnliche Annahme dass kurz nach Eintritt der Regenzeit auch Erdbeben folgen, wenigstens in vul kanischen Gegenden wohl nicht so ohne Weiteres als eine ungereimte a prio verurtheilen dürfen. $K$. $v$. Secbach, Erdbebenkunde (Neumayer, Anleitung, S. 312 
\&enau das Zeitintervall zu schätzen, welches man verstreichen liess, ohne dass man daran dachte, nach der Thr zu sehen. Ilie ron der [hr angegebene Zeit ist später, da sie öfters nicht die Zeit des betreffenden Ortes oder Meridianes sein wird, auf einen bestimmten Meridian zu reduziren.

Die Richtung der Bewegung wird im Allgemeinen angegeben durch das Schwingen frei hängender Gegenstände, wemm man nämlich den Beginn dieses Schwingens beobachten kann, d. h. wenn man die Gegenstände vor Augen hat im Momente, da man den ersten Stoss wahrnimmt. Ist dies nicht der Fall, so notirt man, nach welcher Himmelsgegend, nach welcher stelle des Horizontes Gegenstände hingefallen sind, die an einer Wand oder sonstwo in der Höhe angebracht waren. Bei sehr starken Erdbeben soll man auch beobachtet haben, dlass die Bäume sich successive neigten; diese Bewegung künnte die Richtung bezeichnen, um welche es sich handelt. Ist die Gegend reich an Erdbeben, so dass man darauf zählen kann, während des Verweilens in derselben Erdbeben beobachten zu können, so rerschaffe man sich eines der unter dem Namen Seismuraphen bekannten Instrumente. Es gibt deren sehr verschiedene. Die einfachsten bestehen in einem trogartigen Gefäss, das halb angefüllt ist mit Wasser, auf welches man Kohlenstaub oder Aschentheile streut, oder in einem Senkloth, an dessen Ende ein Gewicht sich befindet, das in feine Spitzen ausläuft und damit bei seiner Bewegung eine Schicht Asche berührt. Dieses Gewicht kan ersetzt sein durch einen Bleistift, an welchen man zur Beschwerung noch einen Stein befestigt und dessen Spitze sich frei bewegen kann über ein Blatt Papier, das man an den Rändern erhöht, damit der Stift sicherlich das Papier berühren müsse. cobald nun eine Erschïtterung eintritt, so greäth bei dem erst erwähnten Instrumente das Wasser in's Schwanken: dit' feinkörnigen Partikelchen auf demselben kommen an die- Wand des Gefässes in der Höhe, welche das Wasser dort erreicht, und sie bleiben dort haften. Hieraus erkennt man dam, in welcher Richtung das Schwanken des Wassers, also auch dasjenige des Bodens erfolgte. Die andern Instrumente aber riehen Furchen in die $\mathrm{Asche}$ oder striche auf dem Papjer, woraus man wieler ersehen kamn, nach welcher Richtung die Bewegung sich fortpflanzte. 
Die Stärke des Stosses ist nach seinen Wirkungen zu beurtheilen; oft erzeugt er nur ein schwaches Zittern ähnlich demjenigen, welches verursacht wird durch das Vorüberfahren eines Bahnzuges oder schwer beladenen Wagens; manchmal eine Erschütterung gleich der, welche entsteht durch den Fall eines sehr schweren Körpers; in noch andern Fällen sieht und hört man Alles um sich her schwanken, stürzen, krachen. In Ermanglung von Instrumenten, welche ein genaues Mass dei Intensität des Stosses liefern könnten, wird die Beschreibung der Vorgänge eine Idee geben von dem Grade der Heftigkeit des Erdbebens und seiner einzelnen Stösse.

Die Geschwindigkeit der Fortpflanzung könnte nur dadurch genau ermittelt werden, dass an verschiedenen, ziemlich weit von einander entfernten Orten gleichzeitig Beobachtungen erfolgen, woraus sich die Unterschiede ergäben in der Zeit, in welcher man an den verschiedenen Stellen der Stoss wahrnahm. Der Reisende kann aber dieses Mittel nich anwenden, noch kann er sich verlassen auf die Aussager von Leuten, die an genaue Beobachtungen nicht gewöhn sind und deren Uhren hiezu nicht taugen, weil sie mit einander nicht übereinstimmen. Er muss sich daher in diesen Punkte mit blosser Schätzung begnügen.

Die Dauer eines Erdbebens ist schwer anzugeben, wenr es in einem einzigen Stoss besteht. Wenn mehrere Stösse eintreten, so kann man die Zeit berechnen zwischen den ersten und letzten; dabei darf man sich aber nie auf blosse Schätzungen verlassen, denn hiebei wird gemeiniglich die Dauer des Ereignisses übertrieben gross angenommen. Wenr es sich endlich um Erdbeben handelt, die Wochen und Monat lang andauern, so hat man zu notiren, welche Anzahl vor Stössen auf eine gegebene Zeit fiel.

Die Ausdehnung oder der Erschütterungskreis eines Erd. bebens ist sehr verschieden. Die Grenzen können ermittel werden nach Aussagen von Personen, welche an verschiedener Orten das Erdbeben wahrnahmen oder auf Grund der sichtbaren Spuren desselben. Von grosser Wichtigkeit ist es zu erfahren, ob ein in gewisser Tiefe (in einem Bergwerk zum Beispiel) beobachteter Stoss auch an der Erdoberfläch wahrgenommen wurde, und umgekehrt; ferner ob zwischer zwei Ortschaften, wo das Erdbeben bemerkt wurde, solche 
liegen, an denen man davon nichts spürte. Die Ursachen einer solchen Anomalie sind zu suchen in der Lage dieser Oertlichkeiten, in der Natur des Bodens etc.

Selbstrerständlich sind auch die Erscheinungen zu notiren, welche das Erdbeben begleiten oder demselben nachfolgen. Sie bestehen gewöhnlich in unterirdischem Getöse, Spaltenbildung des Bodens, Rutschungen, Bergstürzen u. dgl. Quellen versiegen an den einen Orten; an andern kommen solche neu zum Vorschein oder die schon vorhandenen fangen an reichlicher zu fliessen. Die Temperatur der Thermen steigt oder fällt momentan. Aus Bodenspalten dringt Schlamm und Sand heraus, Haufen bildend, oder es entströmen jenen Spalten Gase. Neere und Seen überfluthen ihre Ufer, oder sie ziehen sich zurück und kehren dann wieder in einer ungeheuren Woge, die auf ihrer Bahn Alles wegspült. Alles dies zu sehen und aufzuzeichnen, ist freilich in jenem Moment selber nicht müglich; aber manche dieser Vorgänge hinterlassen dauernde Spuren, sodass man darüber später Erhebungen machen kann, indem man die Gegend bereist und auf diese Punkte achtet. So wird man z. B. untersuchen, ob die Spalten des Bodens strahlenförmig angeordnet sind, in welchem Falle es wahrscheinlich ist, dass sie entstanden durch Einsinken der obersten Erdschichten in Folge Bildung eines unterirdischen Hohlraums, der durch vulkanische Eruptionen, aber auch auf dem Wege der Auslaugung durch Wasser entstanden sein kann. Sind die Spalten linear (parallel) geordnet, so untersuche man, ob deren Ränder gegen einander verschoben seien und wie (in horizontalem oder vertikalem Sinne). Yan notire auch die Art des Bodens, in welchem die Risse entstanden, ob er lose oder kompakt, harter Fels sei etc. Die Gewässer der Gegend können Aenderungen erlitten haben in ihrem Wasserquantum oder in ihrem Laufe. Endlich zeigen namentlich die Gebäude sehr häufig deuttliche Spuren der stattgefundenen Erschütterung: Mauern sind gespalten, zum Theil eingefallen, Thürme umgestürzt u. s. w. Wenn diese Indizien der Heftigkeit des Erdbebens Charakteristisches an sich tragen, so zeichne man eine Skizze derselhen; ebenso in Bezug auf Säulen, Statuen und andere Ionumente, deren Theile Veränderungen der gegenseitigen Lage erlitten haben können, ohne dass sie zu Falle kamen; 
man wird solche Vorkommnisse zu erklären versuchen, indem man auf Alles achtet, was eine Erklärung möglich macht. Die Meinungen über die Ursache oder besser die vielerlei Ursachen der Erdbeben sind sehr verschieden; genau beobachtete Thatsachen sind werthvolle Beiträge zur Aufklärung der streitigen Punkte ${ }^{1}$ ).

Thäler. Die Thäler sind von Anhöhen eingeschlossene Landstriche mit beträchtlichem Niveauunterschied zwischen ihren beiden Enden. Man findet sie in sehr verschiedenen Höhenlagen und theilt sie hienach ein in Hochthäler und Thäler des Flachlandes.

Die Frage über Ursprung und Entstehung der Thäles wird in der Geologie sehr verschieden beantwortet. Die Autoren schreiben sie bald mehr bald weniger der Faltung des Erdbodens, seinen Dislokationen und Spaltenbildungen, der Erosion durch Gletscher und flüssiges Wasser zu. Die Einen nehmen eine einzelne dieser Ursachen als mehr oder mindel ausschliesslich wirkende an; Andere lassen deren zwei und mehr mitwirken.

Ueber die Entstehung eines bestimmten Thales, das el erforschte, wird sich der Reisende ein Urtheil erst bilden können nach stratigraphischen Studien, von welchen wi später sprechen. Fürs Erste wird er sich aber mit einel Prüfung der Oberflächenverhältnisse begnügen, deren Zweck ist, zu konstatiren, welche relativ neue Veränderungen eir Thal erlitten hat.

Wir haben schon gesehen, an welchen Merkmalen mar erkennt, ob ein Thal einen Gletscher beherbergt hat, welch Spuren eine solche Gletscherbedeckung hinterliess auf der Felsen des Thalbodens und der Thalwände.

Wir wissen auch, wie die fliessenden Gewässer wirken wie sie Furchen graben und die Thalwände modifiziren. Dies wird in vielen Fällen hinreichen zum Verständniss der Former des Thalbodens und der Gestaltung seiner Seitenwände.

Die Form eines Thales hängt wesentlich ab von der Be. schaffenheit des Terrains und von seiner Lage. Thäler zwischer

1) Hinsichtlich der Beobachtung ron Erdbeben ist die von Prof. A. Heim it Zürich im Auftrage der schueizerischen Erdbebenkommission verfasste, gemeinver ständliche Anleitung (die Erdbeben und deren Beobachtung, 1879) sebr zu empfehlen - Eine mathematische Behandlung des Gegenstandes findet man in Dr. Neumayer Anleitung zu wissenschaftl. Beobachtungen aufReisen"(Erdbebenkunde, v. Seebach) 
Hügeln und niedrigen Bergen haben gewöhnlich gleichmässige, grerundete Formen, solche in höheren Bergen haben schärfer ausgesprochene Formen, malerischen Charakter. Die Thäler des eigentlichen Hochgebirges endlich haben zerrissene Gehänge von wildem Charakter.

Der Thalgrund reduzirt sich manchmal fast auf eine Linie, in welcher die beiden Seitenwände zusammentreffen; oft aber ist es ein breiter flacher Boden, in welchen das Wasser ein Bett gegraben hat.

Dieses Flussbett reprüisentirt oft die ganze Geschichte des Thales.

Untersuchen wir seine Verhältnisse in Bezuc auf seine Längenausdehnung, so bemerken wir, dass sein Gefälle im Allgemeinen stark ist an seinem Ursprung; das Wasser fällt dort in Kaskaden herah, oder fliesst wenigstens auf stark geneigtem Terrain. Im weiteren Lauf rermindert sich aber das Gefälle und im Lnterlauf des Flusses wirl es ganz unbedeutend. Dies ist dis allgemeine Regel. Es gribt aber Ausnahmen. Mitunter hemmen resistentere Felsschichten an gewissen Punkten die erodirende Thätigkeit des Wassers, welche erst weiter unten in einem leichter angreifharen Boden wieder mit Erfolg wirkt. Das Thal zeigt in einem solchen Falle mehrere treppenartig angeordnete Stufen, d. h. mehrere ziemlich ebene Flächen, die verschieden hoch liegen und gretrennt sind durch Querwände mit starkem Neigungswinkel. Solche Hindernisse (Riffe oder Querriegel) rerursachen nicht selten die Bildung von Seen, indem sich hinter ihnen das Wasser ansammelt, bis es üher die Barriere abfliessen, dieselbe durchbrechen oder durchnagen kann. Auch die Breite des Thales ist in unverkemmbarer Beziehung zum Gefälle des Thalwegs. Seine Seitenwände stehen nahe zusammen und das Flussbett ist enge an Stellen mit grossem Gefälle; die Thalwände sind weiter ron einander entfernt, das Thal wird hreiter, wo das Gefälle abnimmt. Immer aber arbeitet das fliessende Wasser auf eine Beseitigung schroffer (diskontinuirlicher) Gefällsungleichheiten hin, so zwar, dass schliesslich der Thalweg in seinem Längenprofil eine regelmässig gestaltete Kurve bildet, die steil ist am L'rsprung oder im Hintergrunde des Thales und nur noch sanft geneigt an seiner Mündung. 
Betrachten wir die Thalfurche in ihrer Breitenausdehnung oder im Querprofil, so bemerken wir zunächst, dass hier die Form eines $V$ vorhanden ist, das eine mehr oder minder weite Oeffnung zeigt je nach der Resistenz des Bodens. In losem Terrain, das kein starkes Gefälle haben kann, weil seine Theile hiebei durch ihr eigenes Gewicht in Bewegung gerathen würden, ist der Einschnitt breit, weit offen stehend, von sanft geneigten Thalwänden eingerahmt; in kompaktem Boden aber, welcher der Erosion grossen Widerstand entgegensetzt und der nicht nachgleitet, auch wenn er vom Wasser an seinem Fusse angegriffen ist, wird man einen von steilen Wänden begrenzten engen Thaleinschnitt finden; in hartem Fels endlich trifft man enge Schluchten mit senkrechten Wänden. Es kommt aber im Weitern vor, dass der Boden und die Wände des Thales nicht durchwegs denselben Grad von Widerstandsfähigkeit aufweisen, dass losere Schichten abwechseln mit harten Felsbänken. Dann wird der Querschnitt des Thales unregelmässig; an den beiden Seiten erscheinen Terrassen oder Absätze ${ }^{1}$. Ist das Gestein der beiden Thalwände von einander verschieden, so wird die eine Seite, mit dem härteren Gestein, stärker abschüssig sein, die andere, mit dem loseren Material, sanfter geneigt. Man achte darauf, ob solche Unterschiede sich insbesondere bei meridional gerichteten Thälern zeigen, ob sie hier am rechten und linken Ufer vorkommen und sich erklären lassen aus der Bodenbeschaffenheit oder ob regelmässig das eine (rechte) Ufer das steilere ist, was nach der Ansicht einiger Autoren ${ }^{2}$ ) auf Rechnung der Erdrotation zu setzen wäre, indem das Wasser zufolge des Beharrungsvermögens, wenn es in meridionaler Richtung fliesst, stets mehr dem rechten Ufer zugetrieben würde, d. h. (für die nördliche Halbkugel) dem westlichen

1) C. v. Sonklar (Allgemeine Orographie S. 129) bezeichnet als "Thalabsätze oder Thalstufen" den Steilabfall von einem Thalboden zum andern. Es ist dies kaum eine glückliche Bezeichnung. Wir wenden die Ausdrücke Stufen und Terrassen in dem S. 241 erwähnten Sinne an. Dabei kann immerhin, wie es auch Sonklar thut, zwischen Fluss-oder Uferterrassen einerseits und Bergterrassen andererseits unterschieden werden. Gehören letztere auch genetisch je einer gewissen Thalstufe an, so hindert dies nicht, sie als Terrassen am Berge zu bezeichnen, so wenig als manwegen einer geologischen Theorie die malcrische Darstellung F. v. Tschudis bemängeln wird, der von den Bergterrassen spricht als nweidenreichen Stufen, in denen die Höhenlust, der Höhentrieb des Gebirges auszuruhen scheint." Aber das Wort Thalstufe eignet sich nicht zu einer wissenschaftlichen Bezeichnung in der Bedeutung, welche ihm Sonklar geben will.

2) K. F. v. Bär über Flüsse und deren Wirkungen. (Studien aus dem Gebiete der Naturwissenschaften II. Theil, I. Hälfte, Petersburg 1873). 
Ufer, falls das Gewässer südwärts strömt, dem östlichen aber, wenn der Lauf nordwärts gerichtet ist.

Die Grenze zwischen Thalwänden und Thalgrund ist oft schwer $\mathrm{zu}$ bestimmen, da durch Rutschungen an den Gehängen und Schuttbildung an deren Fusse Uebergänge gebildet werden ${ }^{1}$ ). Wenn die Grenze scharf ausgesprochen ist, so spricht dies dafür, dass einst das Thal in seiner ganzen Breite Flussbett war. Diese Annahme hat um so mehr für sich, $r$ inn der Thalboden relativ flach, gleichförmig ist. Wenn unterhalb dieser Parthie Spuren von Barrieren oder Querriegeln getroffen werden, Terrainanschwellungen, Thalverengungen $u$. dgl., welche einst den Wasserabfluss gehemmt haben müssen, so ist jene weiter thalaufwärts gelegene Partie höchst wahrscheinlich alter Seegrund. Finden sich aber keine Anzeichen solcher Hemmnisse und ist das Terrain auch in dieser Gegend thalauswärts deutlich geneigt, so muss man annehmen, es sei dasselbe ehemals in seiner ganzen Breite das Bett eines fliessenden Gewässers gewesen. In diesen Thalböden findet man oft mehr oder minder tiefe Furchen, durch welche jetzt nur noch unbedeutende Wasseradern sich hinziehen; auch trifft man zu beiden Seiten des fliessenden Gewässers je einige Terrassen, welche fast immer die verschiedenen Niveaux oder Thalböden bezeichnen, in welchen früher das Wasser strömte. Wo die Terrassen beider Thalseiten in entsprechenden Höhen liegen und nicht verursacht wurden durch einen Wechsel losen Bodens mit festem Gestein welcher die Entstehung grleichmässiger Ufer verhindert hätte - da müssen sie einer ruckweisen Abnahme des Gewässers zugeschrieben werden, welches ehemals das Thal durchfloss. Eine langsame, unmerkliche Abnahme in einem Boden von gleichmässiger Zusammensetzung hätte eine regelmässige Uferbildung, mit einerlei Lfer und Gefälle, bewirkt, ausgenommen, es seien periodisch starke Hochwasser eingetreten, deren Niveaux successive immer geringere Höhenlagen einnahmen und jeweilen die Böschung bis zu einer gewissen Höhe abtrugen oder auf den Ufern Bänke von Alluvium bildeten, welche nachher üher dem Wasserspiegel lagen. Die Grösse

1) Hinsichtlich der orometrischen Wichtigkeit einer richtigen Ausmittlung des Thalanfangs (Ursprungs) vgl. Sonklar, Anleitung zu Alpenreisen S. 5, sowie dessen Allgemeine Orographie S. 126 und 185. 
der Geschiebe dieser Flussterrassen gibt ein Maass der Geschwindigkeit oder Intensität, mit welcher ehemals das Wasser die verschiedenen Thalstufen durchströmte.

Die Thäler erleiden im Allgemeinen eine fortwährende Verbreiterung in Folge des Verwitterns, der Zersetzung und Erosion ihrer Flanken, der Rutschungen und Bergstürze an denselben. Infolge dieser Vorgänge müsste ein nicht von Wasser durchflossenes Thal offenbar allmälig erhöht und ausgefüllt werden, ebenso ein Thal, das in seiner Längsrichtung nur ganz schwach geneigt ist; denn im letzteren Falle hätte das fliessende Wasser nicht die Kraft, welche nöthig ist zur Fortschaffung des Schuttes, der sich im Thalboden anhäuft. Ist aber das Thal von einem rasch strömenden Gewässer, wie einem Wildbache, durchflossen, so wird es nicht nur nicht ausgefüllt, sondern immer tiefer gelegt. Wenn die von den Höhen ins Thal gelangten Gesteinstrümmer den Strom in seinem Marsche aufhalten, so wird diese Schranke bald durchbrochen von dem aufgestauten Wasser, welches, indem es mit grosser Gewalt sich Bahn bricht und abfliesst, das Bett tiefer als vorher einschneidet. Selbstverständlich kann die Vertiefung und die Ausweitung in einem and demselben Thale sehr verschieden sein, je nach den Strecken und ihrer Gesteinsbeschaffenheit ${ }^{3}$ ).

Nur kurz erwälnen wir hier der vulkanischen Thäler. Es sind das Vertiefungen, umgeben von Lava- und BasaltMauern, manchmal dadurch entstanden, dass zwei divergirende Lavaströme zwischen sich einen freien Raum gelassen haben.

Höhlen und Grotten. So nennt man im Allgemeinen jeden Hohlraum an und in einem Berge. Wird derselbe nur gebildet durch eine überhängende Felswand, so heisst er Balm; Höhle oder Grotte im engern Sinn aber, wenn er sich tief ins Innere des Berges erstreckt ${ }^{2}$ ).

Diese Höhlen können sehr verschiedene Entstehungsursachen haben. Sie können herrühren von der Wirkung des

1) Vgl. C. Pestalozzi, die Geschiebsbewegung und das natürliche Gefäll der Gebirgsflïsse, welche Schrift am Schlusse einen Ueberblick gibt über die "Beobachtungen, welche noch nothwendig sind, um die Art und das Maass der Geschiebsbewegung und Gefällsbildung in Gebirgsfïssen kennen zu lernen."

2) Vgl. Desor, Die Grundformen der Höhlen des Jura. Verhandlungen der schweizerischen naturforschenden Gesellschaft in Frauenfeld 1871. 
Wellenschlages, der Brandung an früheren oder jetzigen Steilküsten; von der Lnterspülung alter Lfer an ihrer Basis (rgl. ohen S. 229); von Dislokation der Felsschichten, von Einsturz solcher, wodurch Hohlräume, leere Zwischenräume entstanden; ron der Ausweitung, die vorhandene Spalten durch fliessendes Wasser erlitten; von Auslaugung durch unterirdisch verlaufende Wasseradern, wie ron Entleerung durch rulkanische Ausbrüche; ron Aufblähung durch feurigflüssige Gesteine oder durch ungleichmässigen Rückzug derselben; ron der Entleerung der innern Masse in Lavaströmen, deren Aussenschichten, mit der Luft in Berührung, erstarrten, während die noch heissen Massen im Innern ausflossen etc. etc.

Gründliche Lntersuchung wird ergeben, welcher dieser vielerlei Lrsachen eine gegebene Höhle oder Grotte zuzuschreiben ist. Wenn eine solche in durchwegs unterirdisch zu heissenden Tiefen entstand, so muss noch untersucht werden, auf welche Weise sie mit der Aussenwelt in Verbindung trat und zugänglich wurde.

So verschieden die Entstehungsweise, so verschieden sind auch Form und Vertheilung der Höhlen. Oft spotten diese Verhältnisse aller Beschreibung.

Viele Höhlen sind mit Krystullen austapezirt, noch mehr aher mit Konliretionen, Absatzbildungen aus Sickerwasser, das erdigge Theile enthält, welche beim Abtropfen und Verdunsten des Wassers sich an Decke, Wände und Boden der Höhle ansetzen. Diese Konkretionen sind hesonder's reich und vielgestaltig in Kalkgebirgen. Fliesst das Wasser den Wäuden entlang, so setzt es dort den gelösten Kalk in hörlerigen Komliretionen ab; tropft es aber von der Decke herab, so bilden sich von dort aus Absätze ähnlich den Eiszapfen: ihre breite Anheftungsstelle ist an der Decke, ihre Spitze ist dem Boden zugekehrt, nach welchem hin sie sich immer mehr verlängern; das sind die Stalalititen oder Tropfsteine im engern Sinne. Das herniedertropfende Wasser ist aber noch nicht frei ron Kalk; aus ihm entstehen noch Absatzbildungen auf dem Boden, unter den Stalaktiten, so dass sie den letztern in Form ron Pyramiden oder Kegeln aufwärts entgregenwachsen; das sind die Stalammiten. Beim Fortgrang des Prozesses treffen die entsprechenden Stalaktiten und Stalagmiten aufeinander und wachsen zusammen; 
so entstehen Säulen, welche die Decke zu tragen scheinen. Mitunter endlich ist der Boden der Höhle bedeckt mit einer verschieden dicken Kruste, die entweder ähnlich entstanden ist wie die vorhin besprochenen Tropfsteinbildungen oder die aus Quellwasser abgesetzt wurde. Wie wir später sehen werden, spielt diese Kruste eine sehr wichtige Rolle bei prähistorischen Forschungen, indem sie häufig die Deckschicht bildet für Spuren und Ueberreste des Urmenschen und ausgestorbener Thiere und diese schützt vor Vermischung mit ähnlichen Ablagerungen neuerer Perioden. Man darf nicht unterlassen, auch die andern Materialien (Thon, Sand, Gerölle etc.) zu studiren, welche einen Theil der Höhle erfüllen, und gleichzeitig zu untersuchen, wie sie hieher gelangen konnten.

Manche Höhlen haben das Eigenthümliche, dass aus ihrem von Spalten durchsetzten Boden Gase aufsteigen, seien es vulkanische Gasausströmungen (Mofetten), seien es Produkte einer durch die Bodenfeuchtigkeit begünstigten chemischen Reaktion.

Tiefentemperaturen. Das Vorstehende führt uns naturgemäss zur Besprechung der Wärmeverhältnisse, welche in gewisser Tiefe unter der Erdoberfläche bestehen und auf die man zu achten hat in Höhlen, die ausnahmsweise tief ins Erdinnere sich erstrecken, sowie in Schachten von Bergwerken, zu welchen man Zutritt erhält.

Bekanntlich nimmt im Allgemeinen die Temperatur zu mit der wachsenden Tiefe, d. h. sie steigt, je weiter man in die Erde eindringt. Wir kommen auf diese Thatsache zurück. An dieser Stelle beschränken wir uns auf die Bemerkung, dass jene Wärmezunahme nicht überall in selbem Maasse stattfindet; da aber sachbezügliche Angaben aus weit von einander entfernten Gegenden verhältnissmässig selten sind, so ist es von Werth, dass hierüber allenthalben, wo sich dazu Gelegenheit bietet, genaue Beobachtungen gemacht werden.

Hiebei handelt es sich nicht um die Temperatur der Luft am Grunde einer Höhle oder eines Schachtes, sondern um die Temperatur des Gesteins. Diese muss so gemessen werden, dass die Thermometerkugel nicht influenzirt wird durch Luftströmungen, durchsickerndes und tropfendes Wasser, 
Wärme-Strahlung von Lampen u. s. f. Man muss daher zum Zwecke solcher Messungen Stellen wählen, wo das Gestein nicht zerklüftet ist und kein Wasser durchdringen lässt. Hier bringt man nun im Fels eine cylindrische Höhlung an, in welche man das Thermometer einsenkt; die Hündung der Höhle wird dann verstopft, so dass nur die Röhre des Instrumentes noch vorragt. Man lässt das Thermometer so lange in dem Raume, bis es die Temperatur desselben angenommen hat und notirt dann die Ablesung. Dieses Verfahren wiederholt man mehrmals und nimmt das arithmetische Mittel der verschiedenen Ablesungen. Auf diese Weise werden zufällige Fehler ausgeglichen.

Quellen. Wenn Infiltrationswasser nach mehr oder minder langem unterirdischem Lauf zu Tage tritt, so entsteht eine Quelle. Die Gesammtheit der unterirdischen Wasseradern, durch welche eine Quelle alimentirt wird, heisst das Quellensystem.

Regen- und Schneeschmelzwasser dringen in den Boden, in die Poren und feinen Spalten der Felsen ein ${ }^{1}$ ); wenn sie

1) In jüngster Zeit hat Dr. G. H. Otto Volger ( der Wasserfrage; Vortrag einer neuen Quellenlehre"; Zeitschrift des deutschen Ingenieurvereins XXI. 11) die Ansicht entwickelt, dass keinerlei Wasser, welches wir in den Schichten des Erdbodens finden, vom Regenwasser oder meteorischen Niederschlägen herrührt, dass noch nie eine Quelle ihr Wasser rom Regen bezogen habe und desshalb die bisherige Quellenlebre als unhaltbar und unzulässig aufgegeben werden müsse. Auch der stärkste Regenguss dringe nur unbedeutend tief in den Boden ein, nie bis zu jenen Tiefen, in welchen wir das Grundwasser fiaden; ebenso vermögen stehende und flessende Gewässer ihre Uferwandungen nur auf ganz kurze Strecken in horizontaler Richtung zu infiltriren; der Boden sei für Wasser undurchlässig, wie Grundbauten neben Flüssen, trockene Tunnelbauten, das Aufführen ron Dämmen in Holland und Anderes mehr beweisen; der wahre Ursprung jeglichen Bodenwassers liege in dem Durchstreichen der warmfeuchten Luft durch die Poren und $\mathrm{Z}$ wischenräume des Bodens. Das Luftmeer erstrecke sich in den Erdboden hinein bis in unbekannte Tiefen, vielleicht bis zum Mittelpunkt, und die mit Wassergas beladenen Luftmassen strömen durch den Erdboden frei hindurch, setzen in dem Untergrund ihr Wasser ab und erfüllen alle Schichten des Bodens mit demselben. Daher müsse man das Hygrometer und nicht den Regenmesser zu Rathe ziehen, um Steigen und Fallen des Grundwassers zu verfolgen und zu erklären. - Diese Theorie wird indess von Prof. Dr. J. Hann als physikalisch unzulänglich angefochten. Vgl. Gäa 1880 , S. 703-714, 1881 S. 83 f. Es sprechen gegen dieselbe, beziehungsweise gegen die Behauptungen betreffend Cndurchlässigkeit des Erdbodens für Wasser, auch Beobachtungen wie diejenigen des Gotthardgeologen Stapff über Bakterien im Gotthardtunnel. Ygl. Zeitschrift für die gesammten Naturwissenschaften 1880, S. 848. Ernest Favre, Rerue géologique Suisse pour l'année 1880, Genève 1881, pag. 140. Andrerseits würde die Volger'sche Theorie Erscheinungen erklären von der Art derjenigen, die Ingenieur Lauterburg in seiner Darstellung der schweizerischen Stromubtlussmengen (Verhandlungen der schweizerischen naturforschenden Gesellschaft zu Frauenfeld 1871, S. 152 ; vgl. dessen 1876 erschienene einschlägige Broschüre) zur Sprache bringt. - Wir geben auch diesen Abschnitt unverändert nach der Fassung des französischen Originals dieses Werkes. Von anderweitigen Darstellungen derselben Theorie mögen hier erwähnt werden diejenigen bei Leipoldt-Peschel a. a. O., Bd. II., S. 287 ff. und bei Dr. O. Ule, die Erde und die Erscheinungen. ihrer Oberfäche (nach Reclus), I. Bd., Leipzig 1874, S. 196 ff. 
auf ihrem Wege nach der Tiefe auf ein Hinderniss stossen, suchen sie seitlich einen Ausweg und kommen an die Oberfläche, sie treten zu Tage. In festem nacktem Fels erfolgt dieses Austreten am untern Ende der Spalten oder Klüfte; in losen Schichten sickert das Wasser hinab bis zu einer undurchlassenden Schicht, welcher es dann folgt (Fig. 112 und 113). Wenn diese Schicht, bevor sie selbst zu Tage

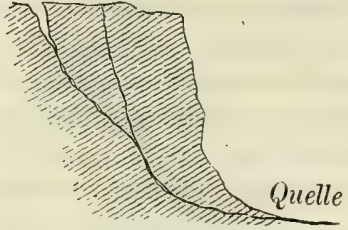

Fig. 112.

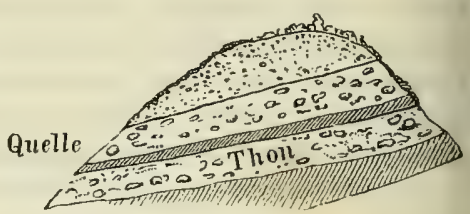

Fig. 113.

tritt, ansteigt, so folgt das Wasser auch dieser Gegensteigung und quillt dann vielleicht auf der Scheitelfäche einer Anhöhe empor (Fig. 114). Es geschieht dies nach dem Gesetz der

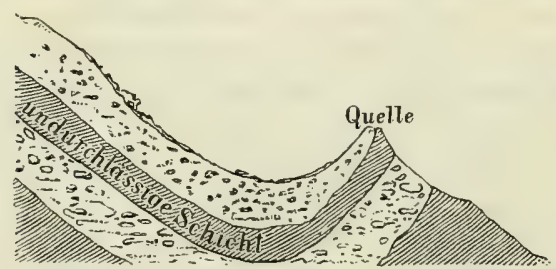

Fig. 114.

kommunizirenden

Röhren oder Kanäle, wonach das Wasser im einen Schenkel einer gebogenen Röhre eben so hoch steigt als im andern und in einem aufsteigenden Strahle

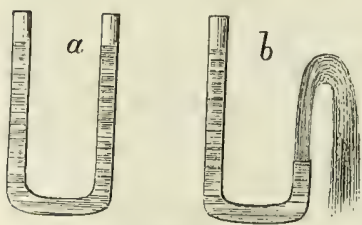

Fig. 115 . ausfliesst, wenn der eine Schenkel kürzer ist als der andere (Fig. 115 $a$ und $b)$.

Wenn ein Quellensystem zu jeder Jahreszeit durch reichliche Mengen von in die Erde sickerndem Wasser gespeist wird, so fliesst die Quelle beständig und mit ziemlich konstantem Wasserschatz: es ist eine permanente oder Dauerquelle. Wenn aber zu gewissen Zeiten wenig oder kein Infiltrationswasser vorhanden ist, so ist das Wasserquantum der Quelle veränderlich und dieselbe hört zeitweise $\mathrm{zu}$ fliessen auf; es ist eine temporäre Quelle. Die Periode, in welcher solche Quellen versiegen, ist be- 
stimmt durch die Entwicklung des Adernetzes derselben, d. h. durch die Länge des unterirdischen Laufes desjenigen Wassers, welches solche Quellen bildet. Ist dieser Lauf sehr kurz, so fliesst die Quelle nur in Zeiten mit öfterem Regenfall und unmittelbar nach der Schneeschmelze; ist er sehr lang, so kann es im Gegentheil rorkommen, dass die Quelle in regenreicher Jahreszeit rersiegt und am reichlichsten fliesst in Perioden der grössten Trockenheit.

Unter den temporären Quellen sind hervorzuheben die seitlichen Ausflüsse eines unterirdischen Wasserlaufes, welcher greschwellt durch überreichen Zufluss — sich Bahn bricht, um seinen Teherschuss an Wasser vor der Ankunft an der Hauptquelle zu entleeren. (Estacelles Fig. 116). Es gibt ferner temporäre Quellen oder Brunnen, die nur in ganz ausserordentlich regenreichen Jahren Wasser liefern, so dass ihr Fliessen zusammenfällt mit schlechten Erntejahren; sie heissen desshalb Hungerbrumen (Bramafan).

Mit den vorgenannten sind nicht

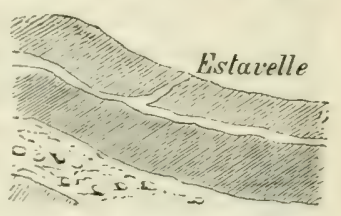

Fig. 116.

zu verwechseln die intermittivenden quellen, welche nur in grewissen bestimmten Intervallen fliessen, welche Erscheinung auf wesentlich andern Ursachen beruht als die obgenannten. Der Wechsel zwischen Fliessen und Versiegen, um den es sich hier handelt, rührt, wie man amnimmt, daron her, dass die Infiltrationswasser bei ihrem Laufe nach der Quelle auf eine Höhle treffen und sich hier sammeln, welche Höhle mit der Erdoberfläche durch einen heberartigen Kanal (Siphon) in Verbindung ist (Fiy. 11\%). Indem das Wasser zunächst auf diese Höhle trifft, füllt es dieselbe allmälig. Sobald der Wasserspiegel bei $a$, in der Höhe

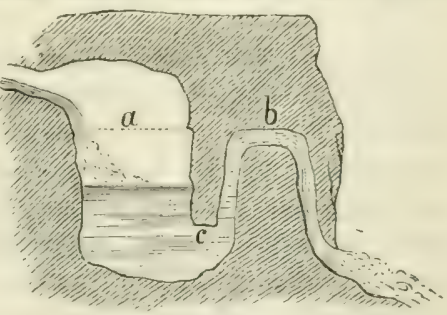

Fig. 117 . des Heberscheitels $b$, angehommen ist, füngt das Wasser an, durch den heberartigen Kanal auszuffiessen und dieses Fliessen dauert so lange, bis der sinkende Wasserspiegel den imnern Endpunkt $c$ des Hebers erreicht. Dam aber entleert sich 
dieser plötzlich und die Quelle beginnt nicht eher wieder zu fliessen, bevor in der Höhle sich ein so grosses neues Wasserquantum angesammelt hat, dass es abermals bis zum Niveau bei $a$ reicht.

Quellen, deren Temperatur höher ist als diejenige des Bodens oder die Mitteltemperatur des Ortes, heissen warme Quellen oder Thermen. Diese höhere Wärme rührt, wie man annimmt, davon her, dass die Wasser, bevor sie an der Erdoberfläche ausfliessen, in grosse Tiefen gelangten und die Temperatur eben in der Erde mit der wachsenden Tiefe zunimmt. Man muss sich in einem solchen Falle den unterirdischen Lauf des eingesickerten Wassers vorstellen als eine Art umgekehrten Hebers (Fig. 118), dessen Bogen

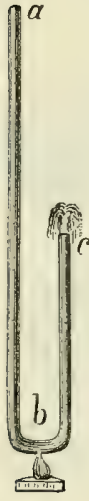

Fig. 118. sich in einer tiefen Gesteinsschicht von hoher Temperatur befände. Es käme dies im Effekt gleich heraus, wie wenn der Heber an jener Stelle durch eine Flamme erwärmt, das im Schenkel $a$ herabsteigende Wasser bei $b$ geheizt würde und dasselbe einen Theil seiner Wärme bis zum Austritt bei $c$ behielte.

Ob nun das Quellwasser kalt oder warm sei, immer hat es die Tendenz, sein früheres Niveau zu erreichen, es wird also im Schenkel $b c$ steigen und bei $c$ mit um so grösserer Kraft in einem Strahle emporgeschleudert, je grösser die Niveaudifferenz zwischen $a$ und $b$. So entstehen die Springquellen.

Die Geysir sind solche Springquellen und zwar gewöhnlich Thermen, deren heisses Wasser intermittirend in starkem Strahle hoch über die Erdoberfläche emporsteigt. Man findet sie in vulkanischen Gegenden und nimmt an, sie entstehen dadurch, dass Wasser welches tief in vulkanische Schlote (Krater) hineindringt, unter dem Einfluss hoher Temperatur sich massenhaft in Dampf verwandelt, welcher die auf ihm lastende Säule flüssigen Wassers als kochenden Strahl emporschleudert. Nach diesem Ausbruche fällt das nunmehr in der Luft etwas abgekühlte Wasser in sein Sammelbecken zurück, gelangt wieder in die unterirdischen Gänge, presst durch seinen Druck die sich fortentwickelnden Dämpfe zusammen, bis deren Spannung so 
stark geworden ist, dass die Wassersäule neuerdings emporrreschleudert wird. Dass die Geysir den Charakter vulkanischer Quellen haben, ergibt sich aus den verschiedenen ìntwicklungsstadien, in welchen sie in der nämlichen Gegend in verschiedenen Perioden sich vorfinden, namentlich daraus, dass einige derselben, die kein Wasser mehr haben, Wolken heissen Rauches und Dampfes, sowie Asche auswerfen.

Das Wasser aller Quellen, der kalten wie der warmen, ist mehr oder minder mineralhaltig, indem es auf seinem unterirdischen Laufe erdige Stoffe auflöst orter als suspendirte Theilchen mit sich führt ${ }^{1}$ ). Den Namen einer Mincralyuelle gibt man indessen nur solchem Wasser, welches so reich an diesen Stoffen ist, dass es hiedurch einen besondern Geruch oder Geschmack oder andere charakteristische Eigenschaften erhält. Nach dem rorwiegenden Stoffe heissen die Quellen dann Stahlwasser (eisenhaltig), Schwefelquellen, Säuerlinge oder Sauerbrunnen etc.

Führt das Wasser reichliche Mengen mineralischer Stoffe mit sich, so setzen sich diese im Umfang der Quelle ab als Konkretionen, gewöhnlich kalkige oder kieselige, welche fremde Körper im Bereiche dieses Wassers mit einer Kruste überziehen. Dies sind die sogenamnten inlivestrenden Quellen.

Endlich gibt es Erdpech-, Naphta-, Erelöl-Quellen u. dgl., welche zu betrachten sind als Entleerung ron mehr oder nninder (zäh- oder leicht-) flüssigen Mineralsubstanzen, die ich im Innern der Erde bilden und sich dort oft über grosse Flächen erstrecken.

Fliessende Gewässer. Wir betrachten hier die fliescenden Gewässer wesentlich. mit Rücksicht auf ihre geologische Thätigkeit.

Wir haben bereits gesprochen von der Wirkung des Regrenwassers, welches über den Erdboden hinfliesst und von dessen Aktion seine oft dunkeln, schlammigen Fluthen, wie z. B. hochangeschwollene Wildbäche, Zeugniss geben.

Nicht geringer ist die erodirende Thätigkeit desjenigen Wassers, welches in die Erde einsickert. Man braucht nur ammähernd zu berechnen, welche Massen mineralischer Stoffe eine einzige durchsichtig klare Quelle zu Tage fördert, um

1) Vgl. hierüber unten, Abschnitt Hydrologie. 
eine Vorstellung davon zu erhalten, welche Auslaugung und Aushöhlung im Erdinnern stattfindet bei der unsichtbaren ewigen Zirkulation dieser Gewässer.

Der stillste Bach greift seine Ufer an; er thut es allerdings nicht mit der zerstörenden Kraft eines Wildwassers; seine Wellen fliessen ruhig ihre Bahn dahin und wälzen nicht, wie jene, Felsblöcke daher, welche gegen die Ufer anstürmen wie. Widder gegen Festungsmauern; dafür abeı wirkt der Bach konstanter, indem er ununterbrochen fliesst. Am Rande einer Schlucht oder einer Felswand angekommen. stürzt der Bach in Kaskaden abwärts; er nagt an dem Felser oben, und das wirbelnde Wasser unten greift die Basis de1 Wand an und verursacht Einstürze höherer Partien. Sc wird mit der Zeit der Wasserfall umgewandelt in eine blosse Stromschnelle (einen „Laufen“) oder er wird rückwärts verlegt, der Quelle zu. Dieselbe Erscheinung zeigen in grösseren Massstab die Katarakte der Flüsse und Ströme.

Trifft ein Gewässer in seinem Lauf auf ein Hinderniss so arbeitet es an dessen Beseitigung. Der Erfolg diese Aktion ist eine Frage der Zeit. Die kleinste Lücke odes Spalte, welche dem Wasser Zutritt und Durchgang gewährt wird in Kurzem erweitert zu einer Bresche, oder der Damr wird an der Basis durchgenagt, sodass er nur noch eine Ar Brücke bildet, unter welcher das Wasser dahinrauscht. Wir die hemmende Schranke, der Querriegel, nicht in der eines oder andern Weise durchbrochen, so bildet sich dahinte ein See; das Wasser steigt so lange, bis entweder sein erodirende Thätigkeit vereint mit dem mechanischen Druc] die Barriere beseitigt oder bis es über diese hinweg ab fliesst. Im letzteren Falle beginnt sofort ein mächtiger Ero sionsprozess: das strömende Wasser durchsägt den Wall schneidet sich tief in und durch denselben ein Bett, i welchem der frühere Damm nur noch eine Art Schwell bildet.

Wenn zwei fliessende Gewässer sich vereinigen, vo: welchen das eine einen rascheren Lauf oder eine grösser Wassermasse hat als das andere, übt jenes auf das letzter einen Druck aus, sodass dieses ans entgegengesetzte Ufe hingedrängt wird. Besteht nun das Ufer aus losem Boder so wird es abgetragen und rückwärts verlegt. Auch wen 
die beiden Konfluenten ziemlich gleichbedeutend sind, so werden doch in ihrem Régime Unterschiede bestehen; die Hochwasser des einen werden nicht gleichzeitig sein mit denen des andern; demzufolge werden die Wassermassen abwechselnd bald gegen das eine, bald gegen das andere Ufer hingedrängt; die Linie der stärksten Strömung, der Stromstrich, wird hin und her verlegt; die Landzunge zwischen den beiden Konfluenten, bald rechts, bald links angegriffen, wird rerschmälert und durch diese Abtragung zum Zurückweichen gebracht.

Selten ist der Lauf eines Flusses oder Stromes gradlinig; Zufälligkeiten der Bodenbeschaffenheit veranlassen Richtungsänderungen und mehr oder minder bedeutende. Ausbiegungen. In diesen mäandrischen Krümmungen (Serpentinen) kommt der Stromstrich bald auf die eine bald auf die andere Seite zu liegen, immer nämlich in die Nähe der (rom Strom aus betrachtet) konvexen Theile seiner Randoder [ferlinien; diese Uferstrecken benagt er; am andern, mit Bezulg auf den Strom konkaven Ufer ist ruhiges Wasser, und dort wird Sand und Geröll abgelagert. Die beiden Enden eines solchen Querschnitts verhalten sich also sehr verschieden: am einen findet Abtragung, am andem Auftragung statt.

Hiebei ist es von Interesse, zu verifiziren, ob ein meridional - nordsüdlich oder südnördlich - fliessendes Gewässer eines seiner Ufer mehr erodire als das andere. Nach einer schon ofters ausgesprochenen Ansicht ${ }^{1}$ ), die aber heute noch sowohl Gegner als Anhänger hat, würde nämlich die Erdrotation auf meridionale Wasserläufe so einwirken, dass der Stromstrich auf der nördlichen Halbkugel ans rechte, auf der südlichen Halbkugel ans linke Ufer gedrängt würde, rlass somit auf unserer Hemisphäre bei Flüssen der bezeichneten Richtung rechts das steile oder Bergufer, links das niedrige oder Flach-Ufer läge.

Wo die Geschwindigkeit des fliessenden Wassers und damit dessen lebendige Kraft abnimmt, werden die mitgeführten Gesteinstrümmer und suspendirten Mineralstoffe abgesetzt. Zuerst bleiben - am Fuss von Strecken mit starkem Gefälle - die grossen Blöcke liegen, dann grobe

1) Vgl. oben, S. 280. 
Geröllsteine, hierauf kleineres Geschiebe (Kies), Sand und zuletzt der feinste Schlamm. Wirbel im Wasser befördern das Entstehen solcher Ablagerungen, die man als Bänke oder Flussinseln überall da trifft, wo durch ein Hinderniss die Kraft der Strömung gebrochen oder die letztere von ihrer Bahn abgelenkt wird. Die letzten festen Theile, die es führt, setzt ein fliessendes Gewässer ab bei seiner Einmündung in stehendes Wasser, Seen oder Meere.

Die fliessenden Gewässer sind also in doppelter Richtung thätig: sie tragen an den einen Orten $a b$ und an andern auf; was sie an ersteren zerstören, führen sie weg und verwenden es anderorts zu neuem Aufbau; das Volum der Ablagerungen muss genau dem Gesammtbetrag der Erosionswirkungen gleichkommen; wenn diese letzteren uns mehr auffallen, so erklärt sich dies dadurch, dass ein Theil der Absatzbildungen, die Alluvionen auf dem Grunde der Seen und Meere, sich unsern Blicken entziehen. Da die Materialien, welche durch fliessendes Wasser transportirt werden, den höheren Gegenden der Erdoberfläche entstammen und die daraus entstehenden Sedimente in tieferen Lagen abgesetzt werden, so kann man sagen, es gehe die zweiseitige Thätigkeit des fliessenden Wassers dahin, die Niveauunterschiede auf der Erdoberfläche zu vermindern und auszugleichen, indem sie Höhen abträgt und Tiefen ausfüllt.

Mit den allgemeinen Verhältnissen, die wir im Vorstehenden besprochen haben, vertraut, wird der Reisende den geologischen Veränderungen nachforschen, welche in der von ihm besuchten Gegend hervorgebracht wurden durch die Aktion fliessender Gewässer.

Er wird untersuchen, ob sich Spuren finden von ehematigen Flussbetten.

Es kann ein fliessendes Gewässer früher eine grössere Breite besessen haben; in diesem Falle bleiben Spuren übrig von alten Ufern, zwischen welchen man jetzt nur noch unbedeutendes Gewässer in schmalem Bette fliessen sieht. Mit solchen ehemaligen oder erloschenen Flussbetten darf man aber nicht die Hochwasserbetten oder Inundationsgebiete jetziger Gewässer verwechseln: Gebiete, welche von einem Fluss gegenwärtig noch regelmässig bei Hochwassern erreicht und bedeckt werden. 
Hat das Gewässer im Gegentheil die Tendenz, sein Bett zu verbreitern, so zeigen sich den Ufern entlang Felsinselchen, Leberreste früherer Landzungen, die jetzt abgeschnitten sind; Flussterrassen, die nur wenig unter der Wasseroberfläche liegen und einen tiefen Kanal begrenzen; Reste endlich ron alten Ufern, die jetzt zerstört oder rom Wasser bedeckt sind.

Das Bett kann tiefer gelegt wie auch erhöht (aufgelandet) worden sein. Im erstern Fall, wenn das Wasser an der Vertiefung seines Bettes arbeitet, erscheint der Bach oder Fluss eingeschlossen von hohen und steilen Lfern, deren Seiten- und Oberflächen Spuren des alten Wasserstandes zeigen. Im andern Fall, d. h., wenn das Bett in Erhöhung begriffen ist, indem sich auf seinem Boden die Materialien ablagern, welche das Wasser herführt, kommt es ror, dass der Fluss oder Bach höher liegt als das Gelände $\mathrm{zu}$ beiden Seiten und dass er seitlich eingeschlossen ist durch natürliche oder künstliche Erdaufwürfe, beziehungsweise Dämme.

$\mathrm{Zu}$ konstatiren und zu notiren sind ferner Aenderungen des Wasserlaufes und deren wahrscheinliche Ursachen.

Steigt man in einem alten, nun trocken gelegten (. erloschenen ") Flussbette oder demselben entlang aufwärts und beohachtet man sorgfältig, was dem Gewässer eine andere Richtung gegeben haben kann, so wird man mitunter bemerken, dass die Verlegung des Laufes bewirkt wurde durch einen Felssturz, welcher das Flussbett absperrte, in andern Fällen einfach dadurch, dass beständig wiederholte Ablagerungen und Aufschüttungen einen Arm des Gewässers verstopften. Wieder in andern Fällen kamn das Wasser in fortgesetzter Erosionsthätigkeit eine Halbinsel, um welche der Fluss früher herumlief, an ihrer schmalen Verbindungsstelle mit dem Hinterlande abgeschnitten und nun den geraden kürzern Lauf eingeschlagen haben; bei diesem Durchbruch kam die Bresche so erweitert worden sein, dass das eine der frühern Flussufer an dieser Stelle gänzlich verschwand. Solche Torkommnisse hleiben gewöhnlich lange erhalten im Gedächtniss, in den Erzählungen der Bewohner einer hievon betroffenen Gegend, und indem man diese lokalen Traditionen zu Nutzen zieht, wird man öfters auch noch im 
Stande sein, wenigstens annähernd die Zeit zu ermitteln, in welcher solche Aenderungen stattgefunden haben.

Seen und Lagunen. Die Seen sind geologisch interessant durch Natur und Ursprung, durch die ganze Bildungsweise der Becken, in welchen sie sich befinden. Indessen handelt es sich hiebei um sehr schwierige, komplizirte Probleme; über die Art und die Ursache der Entstehung gewisser Seen sind die Geologen ganz verschiedener Ansicht, und ein Reisender, der nicht selbst Geologe ron Fach ist, kann schwerlich zur Klärung dieser Differenzen beitragen.

Leicht begreiflich ist es, dass in vorhandenen Depressionen, mochten diese durch Faltung oder Einsenkung u. dgl. gebildet sein, durch Ansammlung von Wasser Seen entstunden, sowie dass zur Bildung andrer Seen Anlass gegeben wurde durch ein zufällig entstandenes Hinderniss des Wasserabflusses, einen Erdrutsch oder Bergsturz, der ein Thal absperrte. Wie aber gewisse schalen- und kahnförmige Becken ausgehöhlt wurden, ist eine schwer zu lösende Frage. Die erodirenden Agentien, welche wir kennen, bringen wohl vor unsern Augen Wirkungen gleicher Art hervor, nicht aber solche von nur annähernd gleichem Grade oder Betrage; wenn man nun auch annimmt, dass in früheren Perioden, als die Gewässer und die Gletscher Dimensionen hatten, die weit über die jetzigen hinausgingen, auch die Wirkungen grössere gewesen seien als in der Jetztzeit, so reicht das noch nicht hin zur Erklärung, wie Seebecken entstanden, deren Umfang oft über $100 \mathrm{Km}$ beträgt und deren Tiefe ganz bedeutend ist. Was die mechanische Wirkung des fliessenden Wassers betrifft, so sehen wir wohl, dass es tiefe und breite Furchen, Kanäle gräbt, nicht aber dass es schalen- oder kahnförmige Vertiefungen bildet, die es im Gegentheil, wo sie schon vorhanden, durch Alluvionen ausfüllt. Die Art aber, wie Gletscher auf felsigen Grund einwirken, hat mehr Aehnlichkeit mit der Arbeitsleistung eines Hobels als eines Hohlmeissels, und wenn es auch richtig ist, dass ein Eisstrom an einem $A b-$ hange hinaufsteigen und eine Schwellc, welche ihn von einem andern Bassin trennt, zu überschreiten vermag, so ist noch nicht bewiesen, dass er auch selber diese kahnförmige Höhlung bilden kann. Der Reisende wird daher gut thun, Alles zu sammeln, was Anhaltspunkte liefern kann in Bezug auf die 
Frage der primären Entstehungsursache von Seehecken, ohne darauf Anspruch zu erheben, selber eine Theorie aufzustellen.

Tebrigens gibt es, wie bereits angedeutet wurde, Fälle, wo del Irsprung eines Seebeckens nicht zweifelhaft sein kamn; so z. B. wem die umgebenden Felsschichten deutliche Biegungen zeigen, derart, dass man unschwer erkennt, sie haben durch Faltung, durch Dislokation ein Becken, einen Hohlraum gebildet, worin dann das Wasser sich ansammelte; ferner, wenn von steilen Felsen aus grosser Höhe herabstürzendes Wasser ein Reservoir ausgrub, oder wem irgend eine Querriegel- oder Barrierenbildung - ein Erdschlipf, eine Moräne - das Wasser rückwärts staute. Auch muss sich rlas Regenwasser vorzugweise ansammeln in bereits vorhandenen Depressionen, wir alten Kratern, Einsturzbecken, Spalten u. dgl.

Der Reisende wird vor Allem auf vorgekommene Veränderungen achten. Hatte der See früher grösseren Lomfang oder höheres Niveau, so wird man dies erkennen an Resten alter I'fer oder spuren früherer Wasserstände $\left.{ }^{1}\right)$. Weit schwieriger wäre der gegentheilige Fall zu konstatiren, weil damn die alten Ufer sich unter Wasser befinden müssten. Oft hemerlit man längs der Ufer eines Sees, unter dem Wasserspiegrel desselben, zwischen dem Lande und den tieferen Theile des Seebeckens, eine Art Terrassenbildung; diese Terrassen dürfen aber nicht ohne Weiteres als untercretanchte alte [fer betrachtet werden. Es scheinen das vichmehn säkulare Auffüllungen oder Alluvionen zu sein, herrührend ron Erosion der Lfer, der Welleubewegung des Sees; Auffüllungen, deren Material durch den Seitendruck des Wassers an Herabgleiten in das innere Seebecken gehindert wird.

Bekamntlich unterliegen alle Seen einer langsamen Ausfüllung. In den Seen der Gehirge und Thäler, welche in der Reggel nur von einer Seite Zufluss haben, findet die fortwährende Verkleinerung rom obern knde her statt, wo sich aus den gelösten und suspendirten Stoffen der zufliessenden Gewässer stetsfort Ablagerungen bilden. In den seen der Ehene kamn dieser Kolmatirungsprozess von rer-

1) Vgl. z. B. Steudel: Welche wahrscheinliche Ausdebnung hatte der Bodensee in der vorgeschichtlichen Zeit?" E. Farre, Revue géologique Suisse pour l'année 1876, pag. 166 . 
schiedenen Punkten des Seeufers ausgehen, indem er überall da stattfindet, wo ein Zufluss einmündet; seine Wirkung wird sich um so rascher fühlbar machen, je mehr erdige Theile, Felstrümmer, Geröll, Sand und Schlamm die fliessenden Gewässer mitführen. Ergiesst sich ein Fluss in einen See nahe an dessen unterm Ende, so wird er diesen untern Theil des Sees ausfüllen und nun nicht mehr in das so verkleinerte Seebecken, sondern in dessen Abfluss einmünden. Es darf denn auch fast in allen Fällen, wo der Abfluss eines Sees bald nachdem er diesen verlassen hat, einen Zufluss erhält, angenommen werden, dass der See früher weiter abwärts reichte und hier allmälig ausgefüllt worden sei. Empfängt der See einen seitlichen Zufluss in ziemlich grosser Entfernung ron beiden entgegengesetzten Endpunkten seines Beckens, so bilden sich leicht zwei verschiedene, durch eine Ebene aus angeschwemmtem Land getrennte Seen, wofür zahlreiche Beispiele zu finden sind ${ }^{1}$ ). Dieselbe Ursache kann Anlass geben zur Bildung der sogenannten rosenkranzförmigen Seen, d. h. von Seen, welche in einem und demselben Bassin auf einander folgen wie Perlen an einer Schnur. Hievon ist wohl zu unterscheiden die stufenweise Aufeinanderfolge ron Gebirgsseen. Diese Bergseen, welche ihre Existenz gewöhnlich einem vorliegenden Querriegel verdanken, verkleinern ihr Areal und verschwinden allmälig entweder durch Ausfüllung von oben her oder durch Entleerung in Folge Durchbrechens der Felsbarriere am untern Ende. Das so ausströmende Wasser ergiesst sich so weit thalabwärts bis es auf ein neues Hinderniss trifft. So entsteht eine Reihe von Seen, die gleichzeitig oder nacheinander existiren können, die aber in verschiedenen Höhenstufen liegen und damit die Annahme ausschliessen, dass sie ursprünglich Theile eines und desselben Sees gewesen seien.

Seen, welche in grosser Zahl auf verhältnissmässig kleiner Fläche vorkommen - man könnte sie gesellige Seen nennen, wie man von geselligen Pflanzen spricht — sind entweder einfache Ansammlungen von Regenwasser, welches die einzelnen Vertiefungen des Bodens ausfüllt, oder sie können

1) Vgl, Heer "Urwelt der Sehweiz", II. Aufl., S. 230, Kollbrunner, Morphologie der Thalbildungen und Flusssysteme, pag. 24. 
dadurch entstanden sein, dass der Boden eines früheren Neeres zum Theil über das Niveau des Wassers emporgehoben wurde. Fingerzeige für die Beurtheilung ihrer Bildungsweise gibt die Natur ihres Wassers und ihrer Fauna. Massgebend ist namentlich die letztere. Was das Wasser selber anbetrifft, so kann aus dem Lmstande, dass ein See salziges Wasser hat, noch nicht mit genügender Sicherheit geschlossen werden, er sei Leberrest eines früheren Meeres. Der Salzgrehalt des Wassers kann ron andern Lrsachen herrühren. Andrerseits gibt es Seen mit süssem oder doch höchstens als brackisch zu bezeichnendem Wasser, deren mariner Lrsprung bewiesen wird durch das Vorhandensein ron Meeresthieren, mariner Crustaceen oder selbst - wie beim Baikalsee - von Meeresthieren höherer Klassen wie Fische, Robben etc.

Die Teiche unterscheiden sich von den Seen wesentlich nur durch greringere Tiefe. Diejenigen im Binnenlande, sofern sie nicht die letzten Reste allmälig ausgefüllter Seen sind, werden gebildet durch Ansammlung von Tagewasser ohne Abfluss, oder in Folge seitlichen Durchsickerns ron Wasser aus einem See oder Fluss. Die Strandseen aber rühren, wie wir gesehen haben, davon her, dass die Landbildungen an der Küste einzelne Theile des Meeres isoliren oder aber dem Einmünden des zufliessenden süssen Wassers ins Meer hindernd entgegentreten und auf diese Weise jenes zwingen, sich hinter dem Querwalle auszubreiten.

Diese Binnen- und Strandteiche unterliegen alle einer fortschreitenden Verlandung. Die Veteorwasser, welche dieselben speisen, führen feste Theile hinein, welche langsam die Tertiefungen des Bodens ausfüllen; Sumpfpflanzen reranlassen Torfbildung; endlich verschwinden solche Wasserbecken in Folge ungenügenden Wasserzuflusses durch Verdunstung.

Résumé. Die verschiedenen Beobachtungen, welche wir sammelten, werden uns lehren, dass die Gegend in verhältnissmässig neuer Zeit mehr oder minder berleutende geologisehe Veräderungen erlitten hat, deren Crsachen theils äusserliche wie atmosphärische Einflüsse, Erosion v. dggl., theils innere (unterirdische Kräfte, Vulkane, Errbeben etc.) sind.

Wo immer man diese Veränderungen genugsam nachzuweisen vermag, trachte man darnach, die frühere Konfigu- 
ration des Landes im Vergleich zur jetzigen kartographisch darzustellen. Solche Karten über frühere Verhältnisse sind sehr werthvoll für prähistorische Forschungen; sie dienen hiebei als Wegweiser und helfen zur Erklärung von Thatsachen, welche ohne sie unverständlich blieben.

\section{GEOLOGIE DES ERDINNERN.}

Vorbemerkungen. Die Kenntnisse, die wir uns von einem Lande in Bezug auf seine Bodengestalt, die Geologie seiner Oberfläche, erworben, werden uns vielfach Gelegenheit dargeboten haben, uns in grossen Zügen ein Bild zu entwerfen von der geognostischen Zusammensetzung des Bodens, und einzelne interessante Thatsachen bezüglich geologischer Aenderungen älteren Datums vorzumerken. Wo immer wir dabei auf nacktes Gestein treffen, beachten wir dessen Vorkommen und besondere Art; wenn es auch nicht den Gegenstand unsers speziellen Studiums bildete, so werden wir doch verschiedene Beobachtungen gemacht haben über Lagerung, Schichtung und petrographische Natur desselben. Nunmehr handelt es sich darum, näher auf die Sache einzugehen.

Wie für unsere topographischen Studien, so werden wir auch zu diesem Zwecke vor der Abreise ein in grossem Nassstab ausgeführtes Croquis der zu bereisenden Gegend entwerfen, worin die Konfiguration des Bodens nur schwach angedeutet und in leichter Kolorirung die Art und Verbreitung der von unsern Vorgängern konstatirten Gesteinen bezeichnet sind. Die Genauigkeit dieser Angaben haben wir zu verifiziren, unrichtige Daten zu korrigiren. Was wir als richtig erkennen, wird sodann in stärkeren Farben in die Karte eingetragen.

Wenn zwischen Angaben schon vorhandener Karten und der Wirklichkeit sich wesentliche Widersprüche zeigen, so thut man am besten, die früheren Arbeiten bei Seite zu. legen und mit Ignorirung derselben durchaus selbständig vorzugehen, um sich so seine eigene Meinung zu bilden, nicht beeinflusst durch diejenige früherer Forscher. Ins Standquartier zurückgekehrt vergleicht man dann die selbst 
gezeichnete Karte mit den andern und konstatirt das Lebereinstimmende wie die Unterschiede derselben.

Besitzt man bereits cin Croquis der Gegrend in grossem IIassstab für die topographischen Aufnuhmen, so fertigt man für die geologischen Zwecke einfach eine Pause desselben an. Dabei rermeide man, dies Croquis resp. die Pause mit zu vielen Namen und umnützen Details zu überladen; wohl aber merke man darin alle Objekte ror, die bei geologischen dufnahmen als Fixplunkte dienen kömnen: Flüsse, Bäche, selhst ganz kleine Wasseradern; sodann Thürme, Windmühlen $u$. dgl.

Lm diese Karte möglichst beчuem zum Mitführen zu machen, zerlegt man sie in Blïter von Oktavformat; besser noch wird sie tale quale aufgezogen auf Leinwand oder grobe Mousseline; sie ist dam eher gegen Zerreissen gesichert und kann in dieser Form als Rolle an einer Schnur mitgetragen werden.

Beobachtungen, Aufschlüsse. Lm die geognostische Zusammensetzung einer Gegend kenmen zu lernen, muss man ron allen Aufschlüssen Gebrauch machen, von denen dies nur immer möglich ist; jede Terrainfalte, jede spalte des Bodens, Felswände und Felskïmme, Schluchten und Tohel, Trancheen, Gräben, Grubenschachte, Trümmer, die rom anstehenden Gestein heruntergefallen und solche, die rom Wasser forttransportirt worden sind - all das hat man zu untersuchen. Alle Punkte, wo nackter Fels zu Tage tritt, sind geologische "Aufschlüsse".

Achten wir darauf, welche Steine in dem Lande für die gewöhnlichen Bauten verwendet werden ${ }^{1}$ ); sammeln wir, wenn wir auf ein Tobel oder einen Wildbach treffen, Proben der Gesteine, welche die Wasser hinwegführen rom Fusse der Thalwände, und studiren wir in Musse diese Sticke: so werden wir schon orientirt üher einen Theil der FeIsarten des Landes, und wir werden dieselben leicht wieder erkennen, wemn wir sie anstehend treffen. Das Studium von Gesteinsfragmenten aus den Betten der fliessenden Gewässer gibt mitunter Kunde ïber das Vorkommen von Gängen, Lagern

1) Ich sage: die geröhnlichen Bauten; denn für Paläste, Villen etc. lässt man oft die Bausteine weit her kommen. In $Z$ weifelfällen wird es übrigens nicht schwer halten, zuverlässigen Aufschluss über die Herkunft dieser Materialien zu erlangen. 
und Stöcken, die sonst vielleicht unbekannt geblieben wären, und die genaue Besichtigung der Materialien in den verschiedenen Moränen liefert oft Aufschlüsse über die Felsarten, woraus die höchsten, zuweilen unzugänglichen Gipfel bestehen.

Reiseroute und Vorgehen im Allgemeinen. Selbstverständlich kann man, um zu Aufschlüssen zu gelangen, sich nicht dem Zufall überlassen; vielmehr muss man dieselben nach einem vorbedachten Plane aufsuchen. Man stellt also eine Reiseroute fest, welche über Punkte geht, woron mit der grössten Wahrscheinlichkeit angenommen werden darf, dass daselbst interessante Beobachtungen zu machen seien. So wird man beispielsweise nicht im Thale und in der Ebene bleiben, sondern einen Weg einschlagen, welcher über die Terrainfalten hin nach den Höhen führt; man marschirt Flüssen und Schluchten entlang nach Berggipfeln und Kämmen.

Es ist bereits oben bemerkt worden, dass die Küsten, insbesondere Steilküsten, häufig einen Ueberblick der geognostischen Struktur einer Gegend ermöglichen; sie bieten zahlreiche natürliche Profile, in welchen Felsen sichtbar werden, die anderorts durch aufgelagerte Schichten verdeckt sind und die den Schlüssel geben zur Beurtheilung der Lagerungsweisen, der Schichtenfolge. In Küstenlandschaften wird man daher die Felsbildungen, die Aufrisse am Strande, mit besonderer Sorgfalt studiren.

In ausgedehnten Ebenen ist weit seltener Gelegenheit zu geognostischen Beobachtungen geboten ; um so grösser ist die Wichtigkeit eines jeden Aufschlusses. Ein Erdeinschnitt, ein Tobel, Bachufer lassen öfters die unterirdischen Felsschichten erkennen, und bei der Gleichförmigkeit, welche gewöhnlich in ebenen Ländern auf grossen Flächen herrscht, ist es wahrscheinlich, dass dieselbe Schichtenfolge sich weithin erstrecke.

Gelangt man $\mathrm{zu}$ wechselvoller gestaltetem Terrain, so muss man schon die ersten Anhöhen und Böschungen, den Fuss der gebirgigeren Landschaft, aufmerksam untersuchen. Diese vorgelagerten Höhen und Utbergangspartien haben häufig Aufrisse, in welchen bis zu grossen Tiefen anstehendes Gestein beobachtet werden kann.

Wenn werthrolle Aufschlüsse eher an den Gehängen als im Thalboden zu finden sind, so kann immerhin der letztere 
durch fliessendes Wasser tief eingefurcht sein; dann ist es von Werth, dass man die abschüssigen Lfer des Fluss- oder Bachbettes untersuche, besonders an Punkten, wo das Gewïsser von einer Thalstufe zu einer tieferen abfällt und durch eingeengte Stellen sich Bahn bricht.

Sanfte, gleichmässige Abdachungen sind in der Regel arm an Aufschlüssen; um so weniger darf man diejenigen rernachlässigen, welche rorhanden sind; vielmehr muss man hier die kleinsten Anrisse, Steinbrüche, Gräben, Brummenschachte etc. wohl beachten.

Viel leichter ist die Aufgabe an wechselvoll gestalteten Berglehnen, welche in Felsrorsprüngen, Terrassen, Wänden und meist tief eingerissenen Schluchten ein reiches Beol)achtungsmaterial darbieten.

Bergyässe, Schluchten und Thalengen erschliessen in der Regel ein Bild der Felsen, welche sie umgeben.

Nähert man sich den Gipfelpunkten, so ist die Aufmerkcamkeit zu verdoppehn; die Felsschichten haben hier oft die stärksten Störungen erlitten und es ist deren Aufeinanderfolge desshalb schwerer zu erkenuen. Man kam mit einer gewissen Wahrscheinlichkeit erwarten, hier älteres Gestein anzutreffen als in den Thälern und Pässen.

IIan rersäume nie, die höchsten Gipfel zu erklimmen, um das Ganze der Gebirgslandschaft zu überblicken und mit einem guten Fernrohr das Streichen, den charakteristischen Zue der Bergketten, zu beohachten. Von hier aus wird man das Gerippe und Gebälke der Gegend, die Grundzüge ihres Baues erkennen, hier namentlich üben, was Prof. Marcou ren ,geologischen Blick" nemnt, den er definirt als ,eine Art Intuition, welche bewirkt, dass ein zum ersten Mal nuf dies Terrain gekommener Beobachter sofort dessen stratigraphische, orographische und lithologische Schwierigkeiten herausfindet, auf den ersten Blick die Massive nach ihrer Zusammengehörigkeit klassifizirt, mit einem Wort, sogleich das terrestrische Manuscript entziffert, welches ror ihm ausrebreitet liegt, ähnlich wie der Architekt ein Monument, der. Maler ein Bild, der Musiker eine Srmphonie beurtheilt $\left.{ }^{* 1}\right)$.

1) Texte explicatif d'une seconde édition de la Carte géologique de la terre; par M. Jules Marcou. Zürich, Londres, Paris etc. 1575, pag. 7. 
Die geologische Erforschung einer neuen Gegend ist natürlich in ihrem Gelingen bedingt durch die individuelle Befähigung des Beobachters; aber immer wird sie reich sein an fruchtbaren Resultaten, wenn man nur aufmerksam und gewissenhaft die Thatsachen konstatirt.

Wir schliessen diese Andeutungen mit dem Hinweis auf zwei von kompetenten Geologen herrührende Bemerkungen. Die erste derselben empfiehlt, dass man beim Abstieg mit derselben Aufmerksamkeit wie beim Hinansteigen Aufschlüsse suche und geognostische Aufnahmen mache, obschon dies beim Heruntersteigen mehr Schwierigkeiten hat, man auch gewöhnlich ermüdet ist und sich beeilen muss, den Bestimmungsort zu erreichen. Zweitens wird empfohlen, man solle, wenn man genöthigt war, den Marsch während der Nacht fortzusetzen, diesen Uebelstand soweit möglich dadurch wieder gut machen, dass man bei Tagesanbruch mit einem Fernrohr den in der Dunkelheit zurückgelegten Weg beobachte und zu diesem Zweck in der Nachbarschaft der Haltstelle den günstigsten Standpunkt aufsuche. Die Notizen über das Bild, welches die Gegend bietet, und über deren wahrscheinlichen geognostischen Bau macht man sodann auf Grund der Beobachtungen vom vorigen Tage und derjenigen, die man jetzt über die Umgebung anstellt. Selbstverständlich ist es noch besser, wenn man den zurückgelegten Weg noch einmal machen kann.

Data, die zu erheben sind. Die geologischen Angaben, welche beizubringen sind, zerfallen in $1^{\circ}$ stratigraphische, $2^{\circ}$ petrographische oder lithologische und $3^{\circ}$ paläontologische.

Die stratigraphischen Angaben beziehen sich auf Verbreitung und Lagerung der Felsen, die petrographischen (lithologischen) auf deren mineralogische Zusammensetzung, die paläontologischen endlich auf die organischen Einschlüsse, die Reste und Spuren vorweltlicher Pflanzen und Thiere, die gelebt haben in den verschiedenen Erdperioden, während welcher diese Felsen gebildet wurden.

In unserer Darstellung müssen wir diese inhaltlich verschiedenen Aufnahmen getrennt behandeln; auf dem Terrain sind sie aber selbstverständlich nicht auseinander zu halten, sondern hat man sie alle gleichzeitig zu berücksichtigen 
und vorzunehmen, da man selten im Falle sein wird, zum Zwecke systematisch verschiedener Aufnahmen an einem und demselben Orte diesen wiederholt zu besuchen.

Dabei kann nicht genug empfohlen und kam diese Bemerkung nicht genugg wiederholt werden: dass der Reisende sich zunächst darauf beschränke, genau die Thatsachen zu erheben, dass er konstatire was ist, ohne Voreingenommenheit und ohne verfrühte schlussfolgerungen. Andernfalls, d. h. wenn er an diese Studien herantritt mit rorgefassten Neinungen und sich durch Hypothesen leiten lässt, so lüuft er Gefahr, unvollkommen, weil befangen, zu beobachten, und auf Kosten gewisser Thatsachen, welche der Theorie zuwider sind, den Werth anderer Fakta zu übertreibeu. Sehr triftig sagt A. Favre, der gelehrte Genfer Professor: Für die Geologie ist die Zeit gekommen, wo es besser ist, gar keine Erklärung zu geben und lieber eine Frage pendent zu lassen als Hypothesen zu konstruiren die auf schlechter Grundlage ruhen.

Stratigraphische Erhebungen. Diese haben zum Zweck:

$1^{\circ}$ In der erforschten Gegend die Verbreitung der verschiedenen Felsarten an der Erdoberfliche zu bestimmen und deren Grenze in die Karte einzutragen.

$2^{\circ}$ Die Reihenfolge in der Lagerung dieser Felsen aufzufinden und in einer Anzahl Profile (Durchschnitte) darzustellen.

Um die Grenzen für die Verbreitung der Gesteine zu bestimmen, kann man auf zwei Arten verfahren.

Die erste Art besteht darin, dass man das Terrain in verschiedenen Richtungen durchreist nach einer Marschroute, die man zum Voraus festgesetzt hat, um ein öfteres Begehen derselben Lokalität zu rermeiden. Jedes Mal, wemn man einen Wechsel in der Felsart wahnimmt, z. B. zwischen Allurium und Thon oder diesem und Kalk, Sandstein, Granit etc., so macht man hierüber eine Notiz, entweder in der Karte selbst durch Abkürzungen, Farben und besondere Zeichen oder im Taschenbuche durch Ziffern und Buchstaben, womit auf die Karte rerwiesen wird. Diese Totiz muss die Felsarten zu beiden Seiten der Grenzlinie genau bezeichnen. Nan erhält so eine gewisse Anzahl von Punkten, worin die Grenzen der Felsarten den zurückgelegten 
Weg schneiden (Fig. 119). Die zu einer und derselben Gesteinsgrenze gehörenden Punkte verbindet man nun mit einander, wobei man sich aus dem Gesammtbilde klar zu
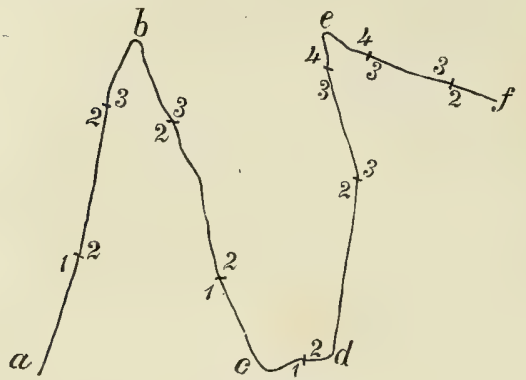

«b $c$ d ef Zurückgelegter Weg.

1 Gneiss.

2 Sandstein.

3 Thon.

4 Alluvium.

Fig. 119.

machen hat, welchen Verlauf die Linie zwischen zwei aufeinander folgenden Punkten nehmen muss (Fig. 120).

Die zweite Art, welche besonders anwendbar ist in unkultivirten Gegenden, besteht darin, dass man eine und

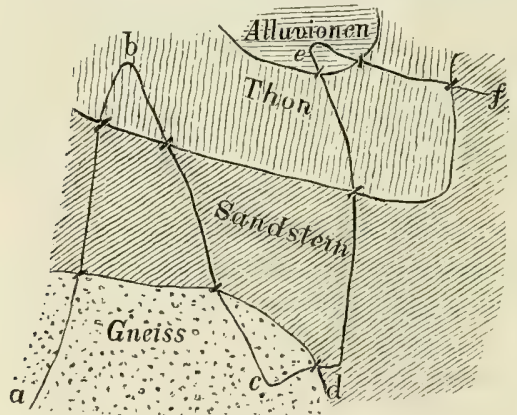

Fig. 120. dieselbe Felsart in allen Richtungen verfolgt, um genau die Grenzen ihrer Verbreitung zu bestimmen. Wenn sie aufhört, so sucht man nach, ob nicht weiterhin wieder Spuren von ihr sich finden. Indem man auf diese Weise einer $\mathrm{Ge}$ steinsart nachgeht, gelangt man zu Punkten, wo sie plötzlich verschwindet oder auch zu Stellen, wo sie allmälig und fast unmerklich in eine andere Felsart übergeht. Im einen dieser Fälle hat man also eine scharf ausgesprochene Grenze vor sich, im andern eine unbestimmte, eine Uebergangszone, die man auf der Karte durch punktirte Linien bezeichnet. Wenn ein Gestein an einer Stelle dem Auge des Beobachters entrückt wird und an andern Punkten wieder zu Tage tritt, so muss untersucht werden, ob es auf der Zwischenstrecke 
nur durch Dammerde (Verwitterungsprodukt und Boden mit Vegetation) oder durch eine andere Gesteinsart bedeckt ist. Ist letzteres der Fall, handelt es sich also um das Auftreten eines zweiten Gesteins, so bestimmt man nöthigenfalls auch die Verbreitung desselben durch Aufsuchen und Angabe seiner allseitigen Grenzen. Hernach geht man zu einer andern Felsart über und verfährt in Bezug auf diese in gleicher Weise, bis die ganze Serie durchgenommen ist. Es muss wohl kaum besonders bemerkt werden, dass dieses Verfahren nur empfehlenswerth ist für Detailaufnahmen in einem beschränliten Gebiete, in welchem die verschiedenen Fel-Schichten in sehr unregelmässiger Weise auftreten. Ist das Torkommen ein regelmässigeres, erstreckt sich vielleicht ein und dasselbe Gestein ununteibrochen äber hunderte von Kilometern, sind seine Grenzen gerade Linien oder nur schwach gehogene Kurven, so ist es weit besser, wenn man nicht diesen Grenzen nachgeht, sondern sie, wie diejenigen der höhern und tiefern Schichten, kreuzt und dann ihr Verbreitungsgebiet auf oben angegebene IVeise aus den erhaltenen Schnittpunkten bestimmt.

Welchen Gang man auch einschlage, so ist die unmittelhare Eintragung in die Karte von grossem Vortheil; sie nöthigt uns zu methodischerem Vorgehen und macht oft jede andere Notiz entbehrlich, indem einige Bleistiftstriche in der Karte Nanches schneller und besser bezeichnen als eine lange Beschreibung. Damit aber diese Mappirung (Kartirung) genau sei, muss der Beobachter jederzeit rasch und sicher die eingeschlagene Pichtung und den Standort zu bestimmen wissen. Dies erfordert eine gewisse Uebung, un so mehr, als der Geologe häufig von der vorgesteckten lioute abgehen muss, um gewisse Torkommuisse, welche Fingerzeige über die Natur des Bodens geben können, - wie Steinbrüche, Gräben, Teiche, Trancheen, Brumenschachte etc. — in nächster Nähe zu besichtigen.

Das erste, auf dem Terrain selbst entworfene geologische Croçuis entluält gewöhnlich nur unzusammenluängende AnGaben, d. h. nur eine Anzahl zerstreuter Punkte, welche die entblüssten Stellen, Einschnitte u. dgl. bezeichnen, wo anstehendes Gestein sichtbar war. Diese sporadischen Flecken hat man nun mit einander zu verbinden, rorab diejenigen, 
welche die Grenzen einer Gesteinsart, einer Felsschicht bezeichnen. Hier nun ist die Jebung, der corp d'oeil von unschätzbarem Werthe. Zwar kann man in gewissen Intervallen mit dem geologischen Hammer (Fig. 121) sich darüber

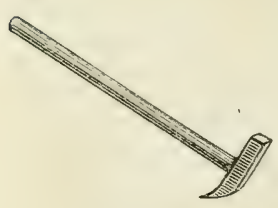

Fig. 121. vergewissern, was für ein Gestein unter der Dammerde liege, welche die oberste Schicht des Bodens bildet; aber zumeist ist man doch auf Konjekturen angewiesen, die man ableitet aus den mehr oder minder engen Beziehungen zwischen der Gestalt des Bodens und dem Gestein, woraus derselbe besteht. Um nur ein Beispiel anzuführen, sei bemerkt, dass rasche Aenderungen im Gefälle (Gefällsbrüche) gewöhnlich einen Wechsel der Gesteinsart anzeigen. Die Detailkarten, die wir besitzen und die topographischen Aufnahmen, die wir selbst machten, werden uns hier sehr zu Statten kommen, indem sie uns ein Gesammtbild geben über das allgemeine System der Bodenerhebungen und über deren Formen in der zu untersuchenden Gegend; es ist dies in um so höherm Grade der Fall, je mehr wir Uebung erlangt haben in Beurtheilung des Zusammenhangs zwischen äusserer Gestalt und innerer Konstitution des Bodens. Hiebei ist auch die Analogie ein ziemlich sicherer Führer; in einer und derselben Gegend manifestirt sich der Wechsel zwischen angrenzenden Schichten in der Regel nicht in wesentlich verschiedenen Formen; haben wir daher die Stellen, wo eine Felsschicht bloss liegt, und ihre sichtbaren Grenzen kennen gelernt, so werden wir dieselbe in Gedanken auch da verfolgen können, wo sie verborgen liegt unter Dammerde und Vegetation.

Die Zeichen und Ablürzungen, womit im Croquis die Gesteinsarten angedeutet werden, sind beliebige; Jeder nimmt diejenigen, welche ihm am besten konveniren; wesentlich ist nur, dass deren Bedeutung genau angegeben sei und nicht zu Missverständnissen Anlass gebe. Ist man über eine Felsart im Zweifel, so bezeichne man sie nur provisorisch durch eine Ziffer oder einen Buchstaben und bringe diese auch auf den gesammelten Proben (Musterstücken) des Gesteins an, um letzteres später mit Musse $\mathrm{zu}$ bestimmen. 
Geologische Karte.

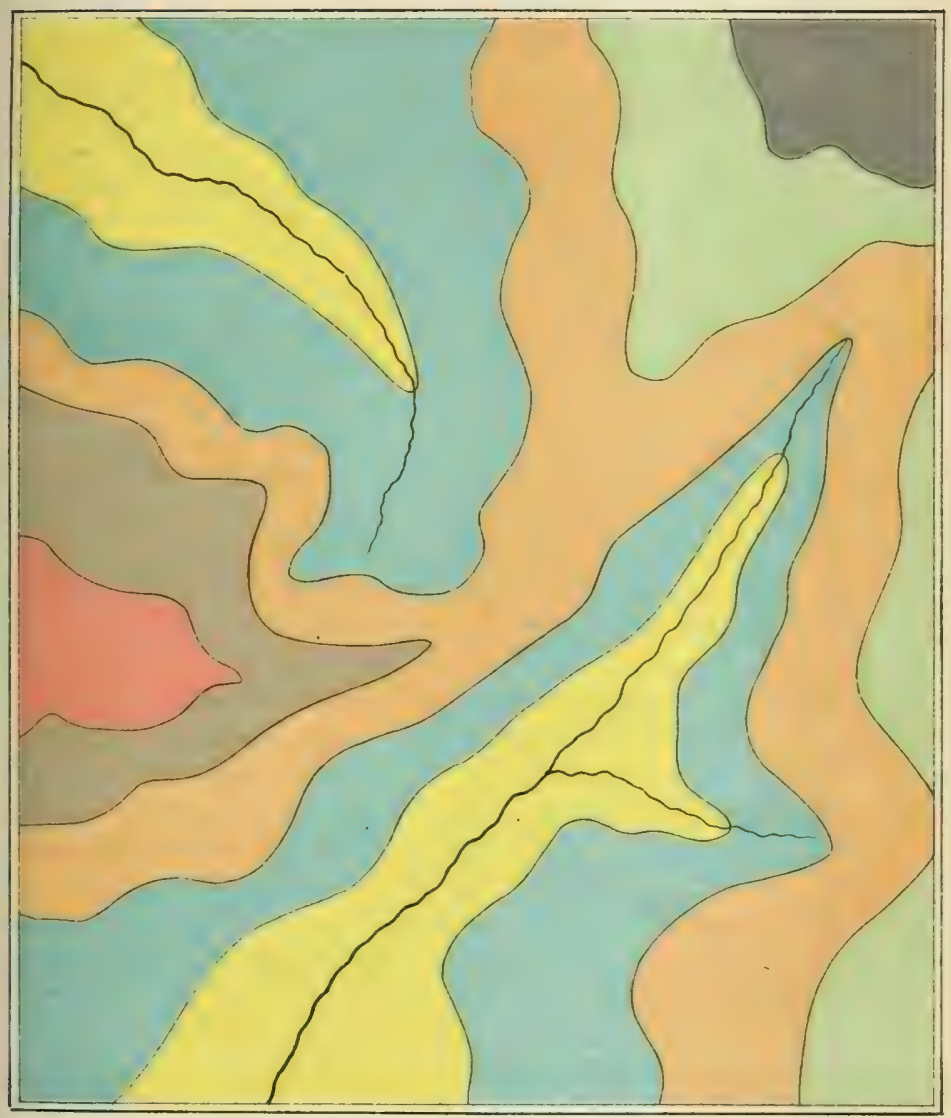

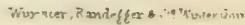

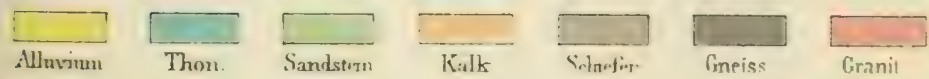



Wenn man statt der Zeichen und Buchstaben zur Angabe der Felsart Farben benutzt, so thut man gut, jeweils am Rande der Skizze mit dem Pinsel- oder Farbstift, den man brauchte, einen Strich und unmittelbar daneben den Namen des auf diese Weise bezeichneten Gesteins anzubringen. Statt auf dem Croquis kann das auch auf dem Papier geschehen, mit welchem man das entsprechende Gesteinsstück einwickelt.

Hat man für die Zeichnung der Grenzen aller aufgefundenen Felsarten eine genügende Zahl von Anhaltspunkten, so bemalt man die ganze von der nämlichen Gesteinsart erfüllte Fläche mit der entsprechenden Farbe. Jede Felsart wird dabei durch eine eigene Farbe oder einen besondern Farhenton bezeichnet. So erhält man eine Karte wie die nebenstehende Taf. XVIII, auf welcher man in einer Erklärung (Legende) die Bedeutung jeder Farbe und Nüance angibt.

Wenn man die Gegend durchreist, ohne dass man dabei viele Abstecher ron der Marschroute nach links und rechts machen kamn, so markirt man auf der Karte lediglich die Stelien des Weges, wo das Gestein einen andern Charaktex annimmt. Diese Notirung ist durchaus auf dasjenige Gebiet zu beschränken, in welchem man sichere Beobachtungen hat machen können.

Die geognostische Karte bezeichnet zunächt nur die horizontale oder geographische Verbreitung der Felsarten, ihr Vorkommen - nach Reihenfolge und Areal - an der Oberfäche; sie stellt die Gegend dar in einem Bilde, wie es etwa erschiene für einen Beobachiter hoch über derselben in der Luft, wenn dessen Auge durch die Decke von Felsschutt und Vegetation das drunter liegende Gestein erblicken oder wenn diese bergende Hülle, der Mantel von Pflanzen und Dammcrde, plötzlich entfernt werden könnte. Es ist nun eine weitere Aufgabe, die Aufeinanderfolge oder Lagerungsweise der Gesteine unter der Erdoberfläche, deren Verbreitung in vertikaler Richtung zu bestimmen und darzustellen. Diese Darstellung betrifft also die Reihenfolge und Mächtigkeit der einzelnen Felsarten, die Art und Weise, wie sie an einzelnen Punkten zu Tage treten, anderorts unterteuft, von andern Gesteinen überlagert werden. Behufs Lösung dieser Aufgabe 
wenden wir unsere Aufmerksamkeit den Stellen zu, wo des Boden eingeschnitten, gespalten oder durch Abrutschunger entblösst ist ; alle Steinbrüche, Erdeinschnitte, Felswände läng: Wasserläufen und Steilabfälle der Gebirge sind genau zr untersuchen.

Wir werden bald bemerken, dass diese vertikalen Auf risse oder natürlichen Profile nicht auf ihrer ganzen Fläch aus einer einzigen Felsart bestehen, dass vielmehr das Gesteir mehr oder minder ausgesprochene Unterschiede in Farbe unc Zusammensetzung erkennen lässt, woraus hervorgeht, das: die in der geologischen Karte bezeichnete oberflächlich Schicht Gesteinslagen anderer'Art bedeckt. Wir konstatirer num die Lagerungsweise dieser Gesteine und stellen sie da in einem geognostischen Profil (Durchschnitt), dessen Position in der Karte wir durch einen Strich und Buchstaben ode Hinweisziffern angeben. Bei der Aufnahme dieser Profil müssen die Grenzen der verschiedenen Felsarten möglichs genau bestimmt und zu diesem Zweck muss untersucht werden welches in Erdeinschnitten, Gräben etc. die Gesteinsart is unter der Decke von Schutt, der sich an Fusse solcher ent blösster Stellen anhäuft. Dieser Detritus stammt gewöhnlicl von höher gelegenen Felspartien her, von denen er durc] Verwitterung abgelöst wurde, um Schuttkegel und sonstig: Trümmeranhäufungen $\mathrm{zu}$ bilden, welche dann die tieferes Gesteinslagen überdecken.

Durch zahlreiche derartige Untersuchungen gelangen wi dazu, uns ein Bild der gesammten architektonischen Glie derung des Bodens machen und allgemeine Profile erstelle zu können.

Eine besondere Wichtigkeit für diese Studien komm den geschichteten Felsarten oder Sedimenten zu, d. h. den jenigen Gesteinen, welche mehr oder minder scharf von ein ander unterschiedene Schichten (Strata), Bänke oder Lage: bilden. Nicht nur sind diese geschichteten (stratifizirten Gesteine am häufigsten, sondern sie liefern auch durch ihr Lagerungsverhältnisse, wie wir später sehen werden, die wich tigsten Anhaltspunkte zur Beurtheilung des Alters der nicht geschichteten Felsarten oder Massengestcine (plutonische un vulkanische oder Eruptivgebilde), sowie über die in der Gegen vorgekommenen geologischen Veränderungen älterer Ordnung 
Es mag hier daran erinnert werden, dass diese Schichten der Bänke von Ablagerungen herrühren, die sich in verchiedenen geologischen Perioden im Wasser und durch II irkung des Wassers gebildet haben. Lrsprünglich müssen ie daher in Ganzen wagrechte Lagerung grehaht haben wie lie heutigen Wasserabsatzbildungen in Depressioneu des Bodens, unf dem Grunde der Seen und Meere. Ihre normale Lagerung rar also in amnähernd horizontalen übereinanderliegenden Echichten, nach Art des Durchschnitts in Fin. 1:... In rielen Gällen ist aber diese wrsprüngliche sagerung nicht geblieben, sondern sie st gestört, die Schichten sind dislozirt rorden. In Folge der Bewegungen, altungen, Hebungen, Senkungen, allgemeiner oder lokaler Dislokationen ind die mannigfachsten Störungen der

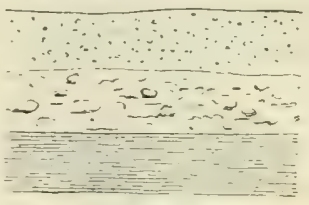

Fig. 122. anfünglichen Schichtenlage eingetreten und haben sich die erschiedensten Lagerungsformen gebildet, deren wichtigste n nachstehender Uebersicht enthalten sind.
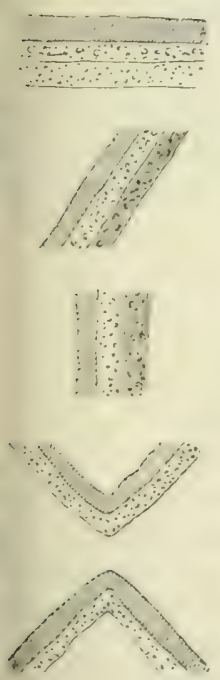

Wagrechte
(horizontale
oder söblige)
Schichten.
Geneigte
(schiefge-
stellte)
Schichten.

Senkrochte.
(Fertihale
oder saigere)
Schichten.
Muldenför-
mige(synkli-
nale)
Schichten.
Dachförmige
(antiklinale)
Schichten.

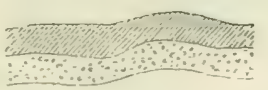

Wellenförmige (wellige) Schichten.

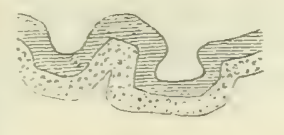

Gebogene Schichten.

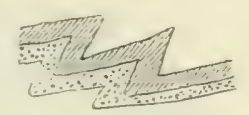

Zickzackförmige (paarweise isotlinale) Schichten.
Aufgerich- tete
Schichten.

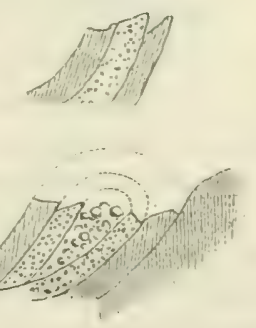

Ueberkippte Schichten (links). 
Die Art dieser räumlichen Anordnung der Gesteinsbänk€ an und für sich wie in Beziehung auf einander, nennt mar die Schichtung, Lagerung oder Stratifilation und man charakterisirt sie durch technische Ausdrücke, deren Bedeutung di Figuren erklären.

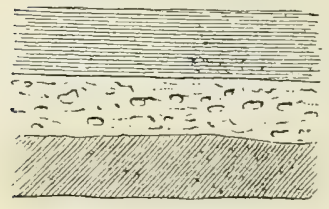

Fig. 123.

Horizontale Lagerung.

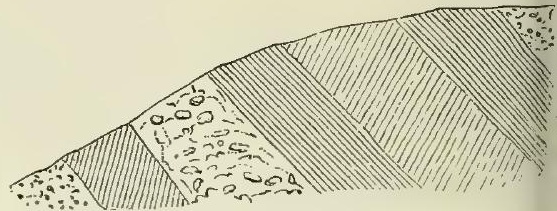

Fig: 124 .

Schiefe oder geneigte Lagerung.

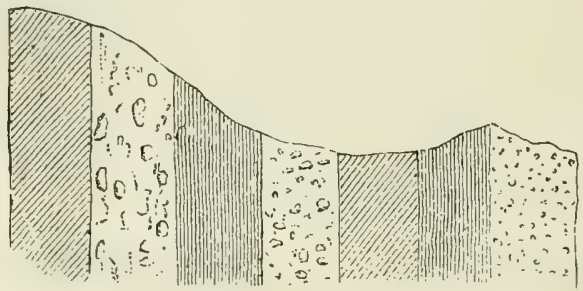

Fig. 125. Vertikale Lagerung.

Eine Linie, welche man sich über die Scheitelpunkte gewölbter (konvexer) Schichten gezogen denkt und von wo aus die Schichten nach beiden Seiten hin abfallen, nennt man ein€

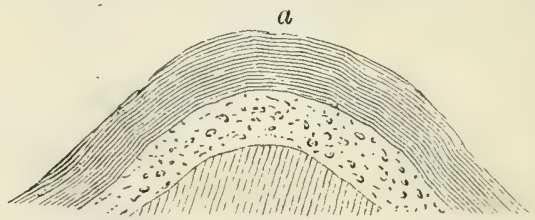

Fig. 126. Gewölbte oder sattelförmige Schichten.

Antiklinale. Sie ist also mit der Kammlinie oder dem Firste eines Daches zu vergleichen. In Fig. 126 bezeichnet $a$ den Schnittpunkt (die Spur) dieser Linie in der Zeichnungsebene. Die davon nach beiden Seiten abfallenden Schichten heissen die Schenkel oder Flügel des Gewölbes.

Analog wird als Synklinale eine Linie bezeichnet, die man sich durch die tiefsten Punkte konkaver (kahn- oder mulden- 


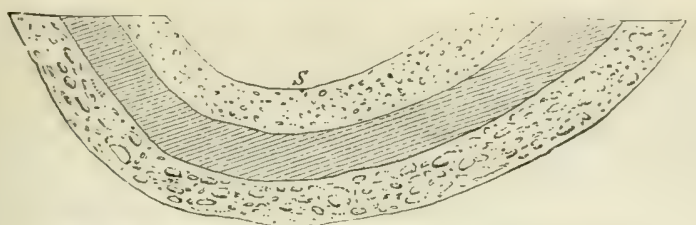

Fig. 127. Mulden-, kahn- oder schalenförmige Schichtung.

förmiger) Schichten gelegt denkt und ron welcher aus die Schichten nach beiden Seiten ansteigen, sodass die Linie wie die Antiklinale als eine Axe erscheint, welche die Punkte in sich fasst, wo die Richtung der Schichten in eine andere übergeht. Punkt s in Fiy. 1:r ist wieder der Schnitt oder die Spur dieser Axe mit der Bildebene, auf welcher sie senkrecht steht.

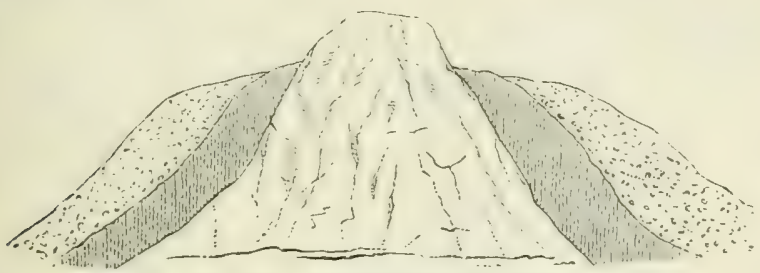

Fig. 12S. Mantelförmige Lagerung.

Bei der durch Fiy. 12S dargestellten Stratifikation ist das eruptive Massengestein von den Schichten, welche es emporgehoben hat, wie von einem Mantel umhüllt.

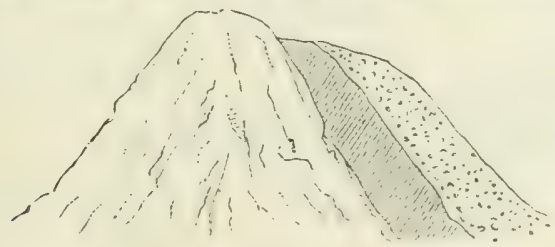

Fig. 129. Schildförmige Lagerung.

Bei der schildförmigen Lagerung Fig. 1:? ist das emporgedrungene Massengestein nur auf einer Seite durch von ihm gehobene Sedimente bedeckt.

Bei der fächer- oder garbenförmigen Schichtenstellung (Fil. 1,30) sind Sedimente durch eine zentrale Masse (beziehungsweise mit derselben) so gehoben worden, dass sie 


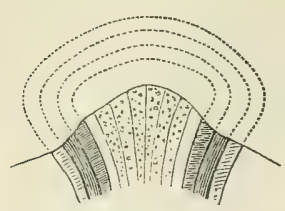

Fig. 130, Fächerförmigre Schichtenstellung.
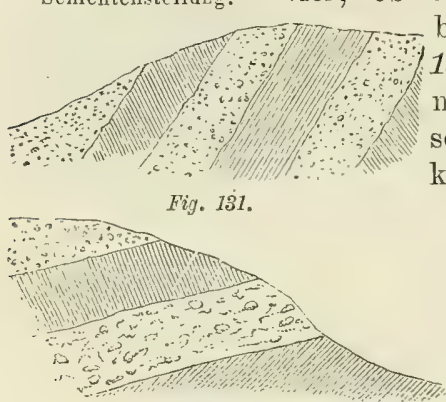

Fig. 132.

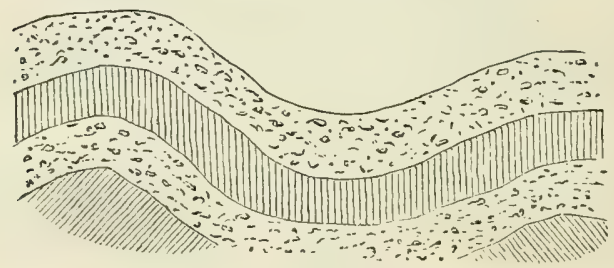

Fig. 133.

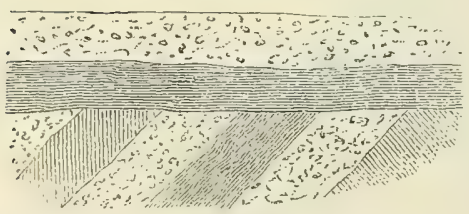

Fig. 131.

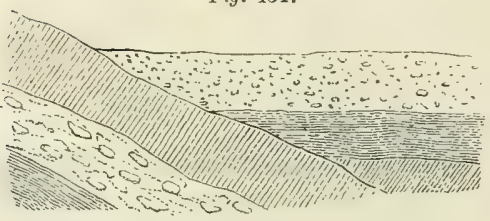

Fig. 135. förmige oder disliordante Schichtung (Fig. 134 und 135).

In der Natur erscheinen nun freilich die einzelnen Schichten oder Gesteinslagen nicht so scharf ausgesprochen und so bestimmt von einander unterschieden wie in den vorstehenden schematischen Zeichnungen. Wenn die Grenzen der Schichten 
leicht und sicher zu erkennen sind, wird die Schichtung als eine deutliche bezeichnet, als undeutlide oder unbestimmt, wenn die Grenzen schwer kenntlich und nicht mit Sicherheit zu verfolgen sind.

Toch haben wir grewisser Lnregelmässigkeiten der Schichten Frwähnung zu thun. Eine der wesentlirhsten dieser Un-

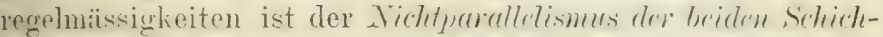
tum!stlïrlu'n einer und derselben Gesteinshank oder der Flächen, welche eine ganze Gruppe (Stufe, Storkwerk, étage) von Schichten heiderseits hegrenzen. In solchen Fällen ist entweder der Parallelismus von Ursprung an nicht rorhanden gewesen orler der anfänglich bestehende Parallelismus ist später zerstört worden. Hierüber ist Folgendes zu bemerken.

Dis Materialien, welche auf einem unebenen Boden abgelagert wurden, mussten sich diesen Lnebenheiten anpassen, welche letztere hinwieder - gerade in Folge der Tendenz sich ablagernder Sinkstoffe zur Ausfüllung von Hohlformen und in Folge der Bewegung des sie transportirenden Wassers - von weniger Einfluss waren auf die Bildung nachfolgender Schichten. Manche Felslagen mussten auf diese Art an

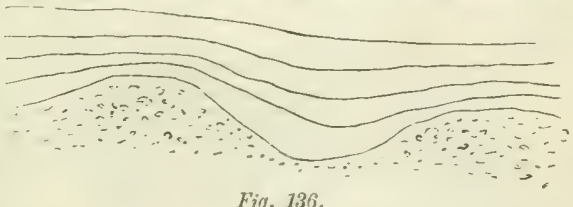

Fig. 136.

gewissen stellen dicker werden als an andern (Fi\%, 1:3i).

Absatzlildungen an Flussmünrlungen erstrecken sich nur auf bestimmte, mehr oder minder liurze Distanzen und werden

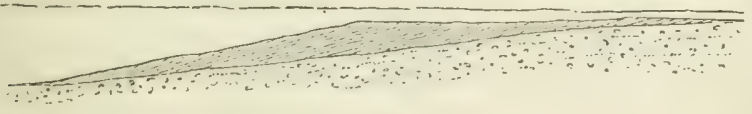

Fig. $13 \%$.

gregen ihre Grenzen hin nothwendig immer dünner. Eine so gebildete Ablagerung (Fi\%. 13\%) hann also nicht von parallelen Flächen begrenzt sein.

Ehenso müssen Ablagerungen von Gesteinstrümmern an steilen Halden Schichten bilden, deren Dicke oder Mächtigkeit nicht im granzen Verlauf gleich, sondern sehr verschieden ist (Fig. 138). 


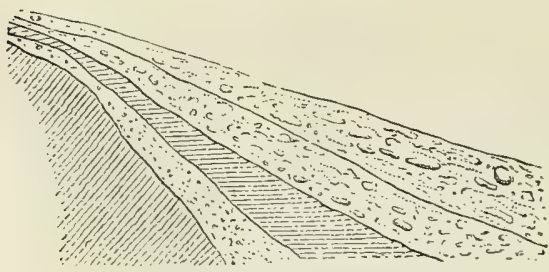

Fig. 138.

Wirbel und Strömungen, welche bald nach dieser, bald nach jener Richtung sich bewegen, stören normale Absatzbildungen und geben Anlass zu vielen Unregelmässigkeiten in den Abla-

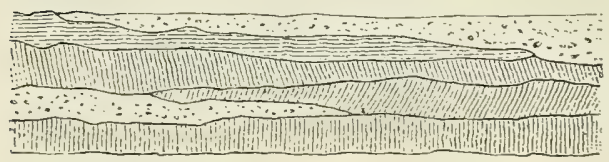
gerungen (Fig. 139).KeineAblagerung erstreckt sich über die ganze ErdoberFig. 139. fläche; diese ist also von den Sedimenten nicht etwa in der regelmässigen Weise umhüllt, wie z. B. Zwiebelschalen angeordnet sind. Jede Schicht ist lokal, d. h. sie ist begrenzt durch die

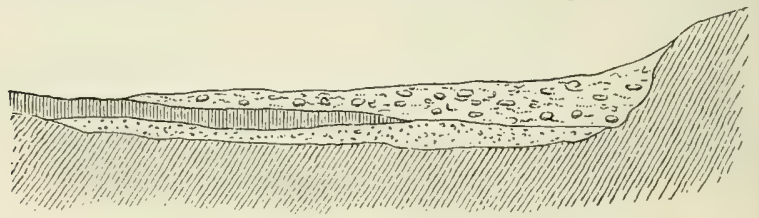

Fig. 140 .

Ränder des Bassins, worin sie abgelagert wurde. Alle Schichten müssen also entweder durch allmäliges Dünnerwerden langsam ausgehen (sich auskeilen, Fig. 140 linke Seite, auch 137 und 138) oder plötzlich abbrechen (Fig. 140 rechts), je nachdem die Grenzen gebildet sind durch solche für den Bereich der Wirkung sedimentbildender Kräfte oder durch Ränder des Bassins, worin die Ablagerung erfolgte.

Terrains, welche unter Wasser entstanden, dann gehoben wurden und während kürzerer oder längerer Perioden über Wasser geblieben, endlich aber in Folge von Senkungen wieder untergetaucht worden sind, mussten zur Zeit, da sie neuerdings vom Wasser bedeckt wurden, eine vielfach erodirte Oberfläche haben, da auf sie mittlerweile dieselben Kräfte eingewirkt hatten, die wir heute an der Modellirung des festen Landes thätig sehen. Die Schichten, welche damals 
- vor der abermaligen Bedeckung durch Wasser und der Bildung neuer Sedimente in diesem - die obersten waren, können also nicht mehr parallele Grenzfächen besitzen; vielmehr muss die äussere Fläche Unebenheiten haben, welche nun von der nächstfolgenden Schicht ausgefüllt und ausgeglichen wurden (Fig. 141).

Durch chemische Wirkungen können Partien aneinandergrenzender Schichten sich mit einander verkitten, sodass aus Theilen zweier verschiedener Gesteinsbänke sich eine dritte Masse (ein Lager, Gang oder Stock) bildet und nun der anfänglich

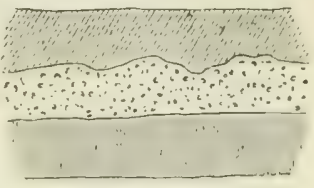

Fig. 141 . vorhandene Parallelismus der Grenzflächen zerstört ist (Fig. 142).

Manchmal sind die Schichten unterbrochen durch Spalten, welche ausgefüllt wurden von Trümmern der verschiedenen aneinanderstossenden Gesteine (Fig. 143). Manchmal auch ist eine grössere Partie der Schichten gegen die andern, zu beiden Seiten anstos-

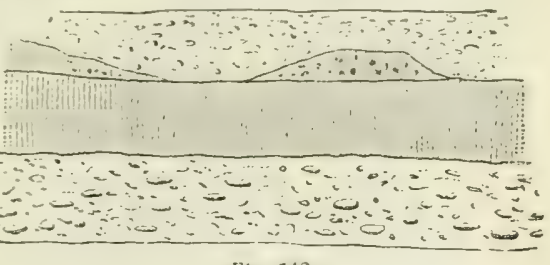

Fig. $1 \pm 2$.

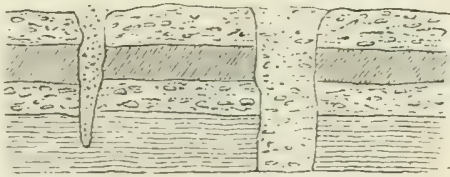

Fig. 143. senden, nach oben oder unten verschoben worden, sodass die Gesteinsbänke plötzlich endigen (abbrechen) und ihre Fortsetzung in einem andern Niveau zu treffen ist. Eine solche Stürung des ursprünglichen Schichtenbaus nennt man eine Veruerfung (glissement, faille); die ron der Dislokation betroffene Partie oder deren Grenze gegen die anstossenden Schichtenkomplexe wird als Veruerfumlsspalte hezeichnet (Fi\% 11t). Der Parallelismus der Schichten bleibt dahei zuweilen erhalten, manchmal aber auch wird er zerstiort und beobachtet man ein rerschiedenartiges Fallen der Schichten zu beiden Seiten der Spalte, welche 


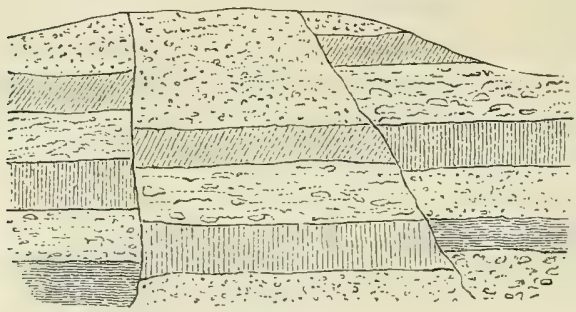

Fig. 114.

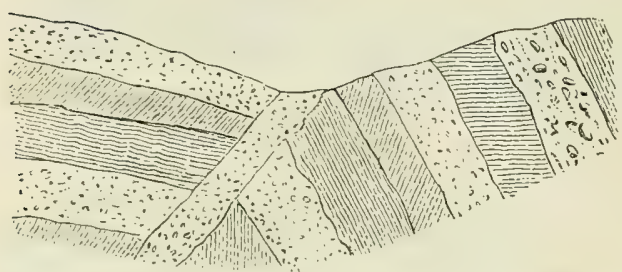

Iig. 145 .

oft mit dem Schutt der dislozirten Gesteine ausgefüllt ist (Fig. 145).

Diese Verwerfungen sind oft von Einfluss auf die äussere Bodengestalt, indem die eineSeite oder Lippe der Spalte über die andere hinausragt (Fig. 146).

Der obere Endpunkt dieser Erhebung ( $a$, Fig. 146) heisst

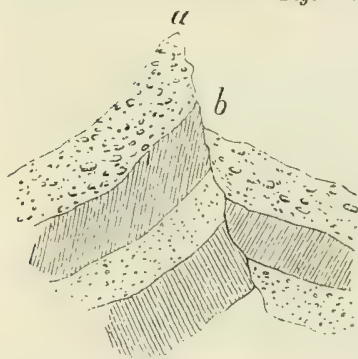
dann der Kopf, der untere (b, Fig.146) der Fuss dieser Verwerfung; die abgebrochenen Flächen. $(a b)$ der Felsbänke werden als Schichtenköpfe bezeichnet. Nicht selten werden indess solche Bildungen ausgeglichen und verwischt durch Erosion.

Unter der oder dem Streichen einerVerwerfungsspalte versteht man

Fig. $1 \neq 6$. deren Winkel mit dem Meridian, unter der Neigung oder dem Fallen derselben aber den Winkel, welchen sie mit der vertikalen Richtung bildet. Die Wände einer Verwerfungsspalte sind mitunter von der Reibung, welche sie erlitten, geglättet; solche Stellen werden als Spiegelflächen (miroirs de faille) bezeichnet.

Wenn ein Schichtenkomplex, ohne dass eine Verwerfung eintritt, einfach gehoben wird, die obern Lagen aber zu starr sind, als dass sie der Bewegung unter Beibehaltung ihres Zusammenhangs zu folgen vermöchten, so wird durch die Dislokation ein Bruch, eine Zerreissung bewirkt; es entsteht ein aufgerissenes Gewölbe (Fig. 147). 
Durch Wasserwirkungkönnen Partien einer oder mehrerer Schichten wegtransportirt werden (Fig. 148). Dieser

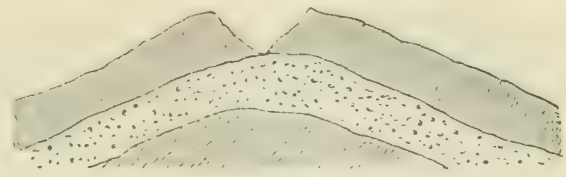

Fig. 147.

Vorgang wird als Ausuaschung (Erosion im engern Sinne) bezeichnet.

Unter Demudation versteht man den Prozess,

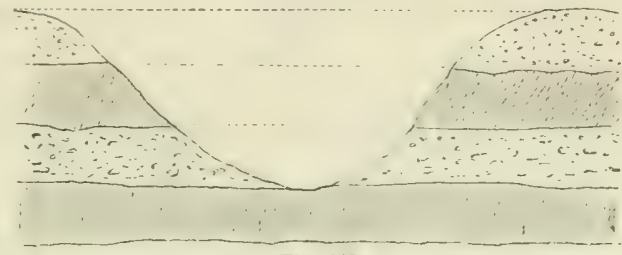

Fij. 115.

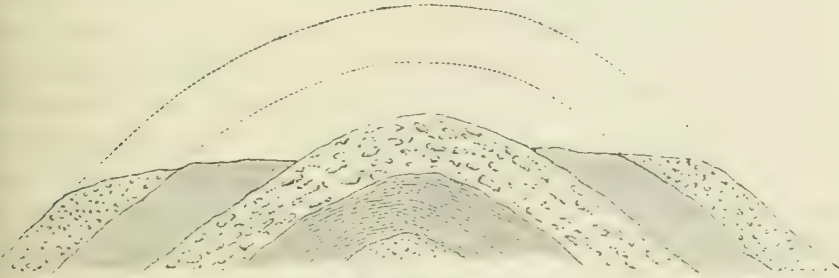

Fii. 149 .

wobei Schichten, die ehemals ron andern bedeckt waren, durch Wegfühlrung des Materials der letztern hlossgelegt wurden (Fig. 149).

I) Allation endlich ist eine Abtragung in grösstem Massstabe, welche sich horizontal nach allen Richtungen ïher ein weites Gehiet erstreckt, so dass hiedurch gewaltige Massen ron Gestein rerschwunden sind (Fig. 150).

An dieser Stelle mag noch die Bedeutung einiger geologischer Ausdrücke erwähnt werden.

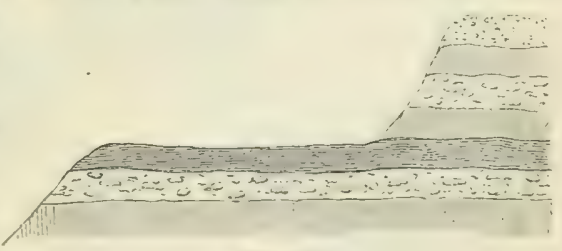

Fig. 150.

Als shichtungsflïchen bezeichnet man die Flächen, durch welche eine schicht unten und oben begrenzt und ron andern Schichten getrennt wird. In den Fiy. 151 und 15:2 


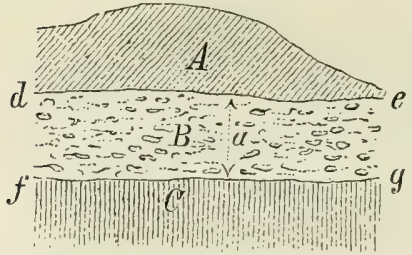

Fig. 151.

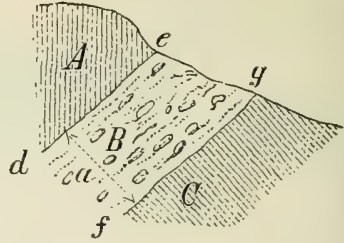

Fig. 152.

stellen die Linien de und $f g$ die Schichtungsflächen für die Gesteinsbank $B$ dar. Die Schicht unmittelbar über einer andern heisst in Bezug auf letztere das Hangende, die unter derselben das lieyende. So ist in den Fig. 150 und 151 die Schicht $A$ das Hangende oder Dach und $C$ das Liegende oder die Basis von $B$.

Die Mächtigkeit oder Dicke einer Schicht an einer gegebenen Stelle ist der kürzeste Abstand der Schichtungsflächen oder also die Entfernung zwischen Liegendem und Hangendem an jener Stelle. In den Fig. 151 und 152 ist diese Distanz für die Bank $B$ mit $a$ bezeichnet. Dieser Abstand muss immer in senkrechter Richtung zu den beiden Schichtflächen gemessen werden; wo dieselben nicht vollkommen parallel sind, wird ein Mittelwerth angenommen.

Wenn eine Schicht an entblössten Stellen des Bodens und

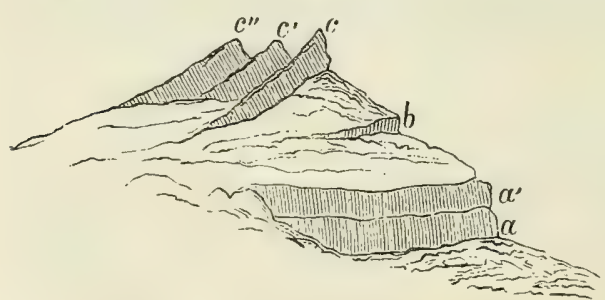

Fig. 153.

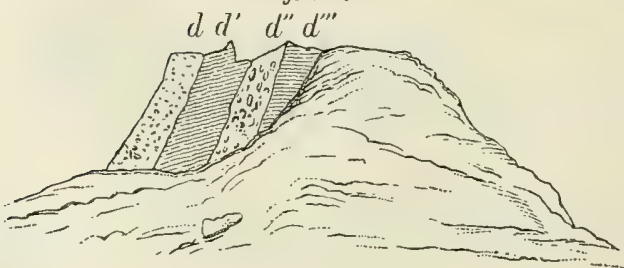

nicht nur mit ihrer Oberfläche sichtbar wird, so nennt man dies ihr $z \imath$ Tage treten. Die als Bruchstellen und Querschnitte erscheinenden Enden der Gesteinsbänke heissen die Schichtenköpfe (Fig. 153, $a, a^{\prime}, b, c, c^{\prime}$, $c^{\prime \prime}$; Fig. $154 d$, $\left.d^{\prime}, d^{\prime \prime}, d^{\prime \prime \prime}\right)$.

Fig. 154. 
Fallen und Streichen. Wenn eine Schicht nicht ganz wagrecht liegt, sondern mit der horizontalen Ebene einen Winkel bildet, so wird dieser das Fallen der Schicht genannt. Die Richtung der Fall-Linie ist diejenige, in welcher das Wasser abfliessen würde, das auf die Oberfäche der Schicht käme.

Unter dem Streichen einer Schicht versteht man die Richtung, nach welcher sie sich erstreckt, hezogen auf die Eintheilung des Horizontes, beziehungsweise des Kompasses. Die Streichungslinie ist senkrecht zu der Richtung des Fallens.

Bei einer vollkommen wagrechten Schicht kann also weder rom Fallen noch rom Streichen gesprochen werden. Bei einer geneigten Schicht (Fily. 15.5) findet das Fallen statt in der Richtung, welche der schiefe Schenkel (ab) des Neigungswinkels angibt, der ja inmer die Linie des stärksten Gefälls (diejenige des Wasserabflusses)bezeichnet. Diehierauf senkrecht stehende Horizontale cd gibt die Richtung des Streichens an.

Wenn nur eine Fläche der Schichten gesehen werdenkann,

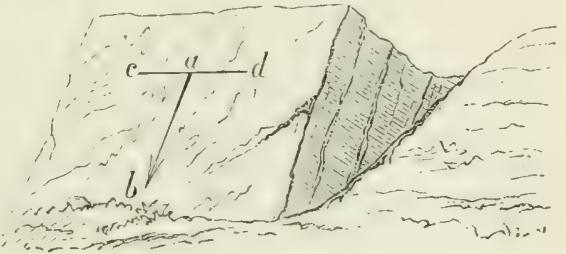

Fig. 155. so ist es nicht immer leicht, das Fallen und Streichen derselben zu bestimmen. Man muss sich dann bemühen, eine Spalte oder Bruchstelle aufzufinden, die erkennen lässt, in
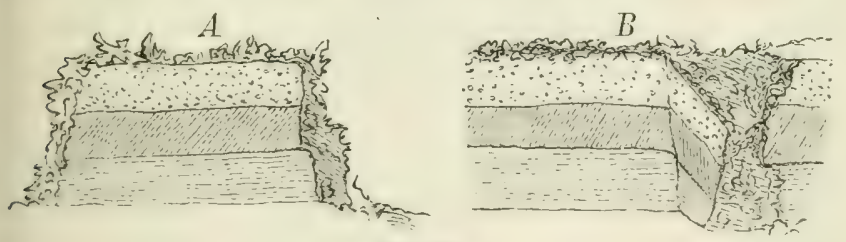

Fig. 156 .

welcher Richtung das Fallen stattfindet. Die Felswand $A$ in Fi\% 15\% z. B. erscheint als aus horizontalen Lagen zusammengesetzt; der Anschnitt bei $B$ aber zeigt, dass sie durch schiefe Schichten gebildet wird. 
Manchmal kann man das Fallen einer Sedimentschicht bestimmen, von der man nur einen kleinen Theil zu sehen bekommt, wenn man nämlich die Lage der eingeschlossenen Geschiebe und Fossilien beobachtet. Die Geschiebe nämlich müssen bei Bildung der Sedimente auf ihre breite Fläche und nicht etwa auf ihre schmälere Seite zu liegen gekommen sein, und in entsprechender Weise müssen sich auf dem Boden des Wasserbeckens die organischen Theile gelagert haben, Stellen ausgenommen, wo Wellenschlag und Strömungen dieselben aufrichten und die Geschiebe zusammenhäufen konnten. In der Regel wird also die Art der Lagerung von Geschieben, Blattabdrücken u. dgl. anzeigen, um welchen Betrag, in Winkelmass ausgedrückt, die Schicht von der ursprünglichen horizontalen Lage abgekommen ist; $d$. h. es wird hiedurch das jetzige Fallen angegeben.

Der Punkt des Horizonts, nach welchem hin eine Schicht fällt, wird unter Berücksichtigung der magnetischen Deklination mit dem Kompass bestimmt. Man gibt seine Lage an entweder mittels der Benennungen der. Windrose oder in Graden. Die letztern werden vom Nordpunkte aus gezählt, sei es nach Osten und Westen hin oder fortlaufend in einer Richtung von 0 bis $360^{\circ}$. Welcher Methode der Reisende sich bedienen wolle, hängt von dessen Belieben ab, nur muss während der ganzen Dauer einer Aufnahme durchwegs die gleiche Methode angewendet und es muss dieselbe zu Handen derer, welche später diese Beobachtungen benutzen, ausdrücklich angegeben werden.

Das Fallen oder der Neigungswinkel einer Schicht wird bestimmt, indem man in der bereits auf S. 56 für Messung von Gefällen angegebenen Weise die Klinometerboussole anlegt und abliest, um wie viel Grade

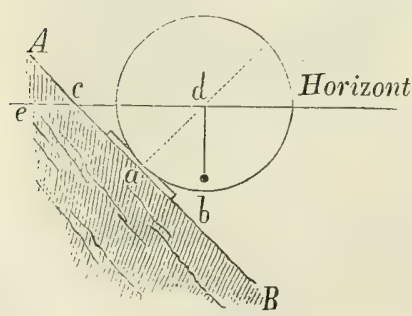

Fig. $15 \%$. die Senkrechte zur Schichtfläche vom Senkloth abweicht. Wie bereits oben S. 55 bemerkt wurde, ist dieser Winkel ( $a d b$ Fig. 157) gleich dem Neigungswinkel $d c a$ (oder $A c e$ ).

Ist eine Schicht nicht gleichmässig geneigt, so bestimmt $m$ an 
das Gefälle im Allgemeinen nach einem Mittelwerth. Das Strei(hen wird sodann gemäss dem bereits oben Gesagten bestimmt.

Die Schichten könmen in Form ron Calotten (Kugelhauben) ïber einander gelagert sein und so eine dom- oder kuppelförmige Erhebung bilden. In diesem Fall würde ein horizontaler Schnitt eine Reihe von Kreisen oder Ellipsen zeigen, welche ein gemeinsames Centrum, eine als Kern in der Mitte befindliche Masse umgeben. Diese Kurven wïren die Streichungslinien, und da der Schenkel des Neigungswinkels für irgend einen I'unkt der Streichungslinie auf dieser senkrecht stehen muss, so findet von den Kreisen und Ellipsen aus ein Fallen statt nach allen Punkten des Horizonts.

Dabei können die Schichten nicht blos nach aussen, sondern auch (Fig. 158) nach dem Innern der Kurven oder also der Erhebung hin fallen.

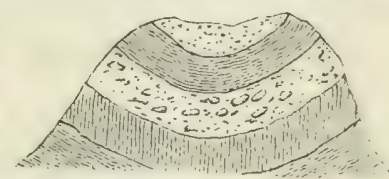

Fig. 1.5s.

Wenn ein Boden flach und eben ist, so darf aus diesem Umstande nicht ohne Weiteres geschlossen werden, dass er aus regelmässig und horizontal gelagerten Schichten bestehe. Früher vorhandene Unregelmässigkeiten oder Höhenungleichheiten

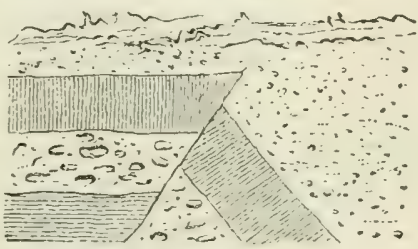

Fì. 159 . können durch Denudation abgetragen worden sein, und es ist möglich, dass unter der ()berfläche eine Spalte liegt, deren Ränder ausgeebnet worden sind

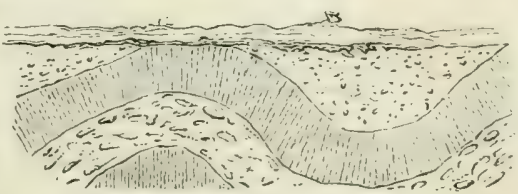

Fig. 160 。 Fig. 1;.9) oder dass man die Schichten im Innern stark und verschiedenartig gebogen findet (Fig. 160 ${ }^{1}$ ).

Um die Eigenthümlichkeiten der Stratifikation in einem zewissen Gebiete auf der geologischen Karte oder im Notizenuch kurz anzugeben, bedient man sich verschiedener Zeichen

1) Ueber Biegungen von Schichtenenden und andere Unregelmässigkeiten als Glacialerscheinungen rgl. Giebel, Gesammte Naturwissenschaften 1880, S. 660. 
und Abkürzungen. Dieselben können mehr oder minder beliebig gewählt werden. Nachstehend folgen einige Beispiele

$\equiv \quad$ Horizontale Schichten.

Geneigte Schichten.

Vertikale Schichten.

Diskordante Lagerung.

Gebogene Schichten, deren allgemeines Streichen durch die gerade Iinie bezeichnet wird.

Schichten, die solche Störungen erlitten haben, dass wederihrStreichen noch ihr Fallen bestimmt werden kaun.

Pfeile bezeichnen die Richtung des Fallens. Eine beigesetzte Ziffer gibt dieGrade desselben $15^{\circ}$ (d.Neigungswinkels)an.
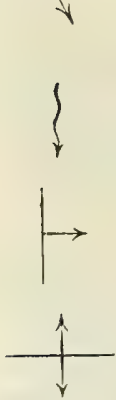

Antiklinale Linie (Axe).

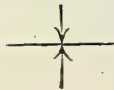

Synklinale Linie (Axe). solcher Bezeichnungen.

Was die Art der Uebereinanderlagerung (Superposition) von Schichten betrifft, so zeichnet man dieselbe, wie man sie in natürlichen (lokalen) Profilen sieht, in das Taschenbuch oder auf lose Blätter, wobei durch eine Hinweisziffer oder eine andere Bezeichnung mit gleichem Zwecke anzugeben ist, für welchen Punkt der Karte das Profil gilt.

Diese Profilskizzen können mit wenigen Bleistiftstrichen angefertigt werden; denn es handelt sich dabei nur um die Darstellung natürlicher Terraindurchschnitte $\mathrm{zu}$ geologischen Zwecken und nicht um eine vollendete Zeichnung wie bei einer Ansicht oder Landschaft. Dieverschiedenen Felsarten können mitFarbstiften oder mit konventionellen Aquarellfarben wi in der geologischen Karte der Gegend angegeben werden. Ausgedehnte und komplizirte Profile nimmt man am besten photographisch auf; dieses Verfahren empfiehlt sich sowohl in Bezug auf Raschheit als Genauigkeit der Aufnahme; das so erhaltene Bild ist eine treue Darstellung, welche auch die kleinsten Einzelheiten, auch die geringsten Bruchlinien des Gesteins wiedergibt. 
Die Daten, welche in Betreff der geschichteten Felsen aufdem Terrain zu erheben sind, sollen also — um das hierüber Grsagte kurz zu resümiren - womöglich umfassen:

$1^{\circ}$ das Streichen,

$2^{\circ}$ das Fallen,

$3^{\circ}$ die Mächtigkeit,

$4^{\circ}$ die Lagerungsweise der Schichten.

Was die murshichtoten oder mussigrn Gesteine anbetrifft, so soll deren Lagerung zu den andern bestimmt werden und muss man zu diesem Zwecke Skizzen aufnehmen über alle natürlichen Profile, wo die Grenzen und Kontaktstellen der beiderlei Felsarten zu sehen sind, wie dies Fig. 161 darstellt.

Sehen wir nun, wie man diese Daten benutzen kann, um den unterirdischen Verlauf der Schichten in einer Gegend festzustellen.

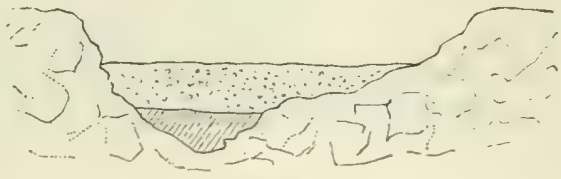

Fig. 161 .

Vorab darf als Regel angenommen werden, dass die Mächtigkeit und das Fallen einer Schicht rom Beobachtungspunkte aus eine Strecke weit nahezu gleich bleiben und rlass Veränderungen rerselben eher allmälig oder stufenweise als plötzlich und ohne Uebergang eintreten.

Wenn wir also die Grenzen und die Neigung gewisser nur an der Erdoberfläche sichtharer Schichten liennen, so werden wir, ohne grosse Fehler zu riskiren, den unterirdischen Verlauf derselben

anzugeben im Stande sein. Es sei $A B(F i g .162)$ das Terrain, welches wir begangen haben; abcd seien die verschiedenen Felsarten, die wir

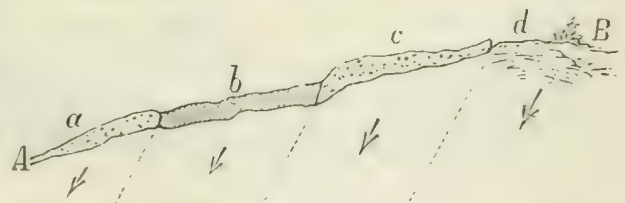

Fig. 162. rorfanden und deren Fallen wir kennen: so sind die beobachteten Grenzen in der Weise, wie die Abbildung zeight, nach dem Erdinnern hin zu verlängern. 
Oder es sei in Fig. 163 das Croquis eines natürlichen Profils gegeben, so werden wir die Fortsetzung der Schichten

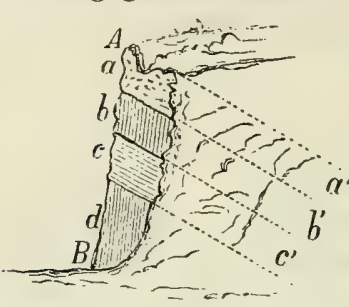

Fig. 163 . a b c d in der durch Vegetation bedeckten Partie in der Richtung nach $a^{\prime} b^{\prime} c^{\prime}$ angeben können, immerhin mit der Bedingung, dass diese Konjekturalkonstruktion nicht auf zu grosse Entfernung hin ausgedehnt werde.

Hiebei kommt nun aber weiter in Betracht, dass die verschiedenen Aufnahmspartien (Sektionen) einander gegenseitig ergänzen, wodurch es oft möglich wird, den Verlauf von Schichten auch auf grössere Distanz, und wenn er selbst ziemlich unregelmässig ist, zu bestimmen.

Vorausgesetzt, wir haben die drei Sektionen $A B, C D$ und $E F$ (Fig. 164) aufgenommen und in allen dreien das Vorkommen

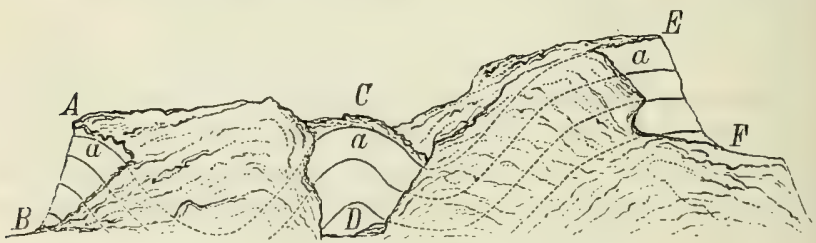

Fig. 164.

einer und derselben Schicht $a$ konstatirt, so werden wir die wahrscheinliche Lagerungsweise der sämmtlichen Schichten in einem Durchschnitte $A E$ darstellen können, wenn wir die entsprechenden Theile der drei Sektionen mittels naturgemässer Kurven (in der Figur durch punktirte Linien angedeutet) verbinden.

So wird es möglich, mit Hülfe der Daten über das Streichen, das Fallen und die Mächtigkeit der Schichten, sowie mit Hülfe der Skizzen über natürliche und künstliche An- und Einschnitte des Terrains, sehr ausgedehnte geologische Profile zu zeichnen, welche die unterirdische Lagerungsweise der Gesteine darstellen, so wie sie auf Grund der Beobachtungen als wahrscheinlich angenommen werden muss (theoretische oder Konjektural-Profile). 


\section{Geologische Profile.}
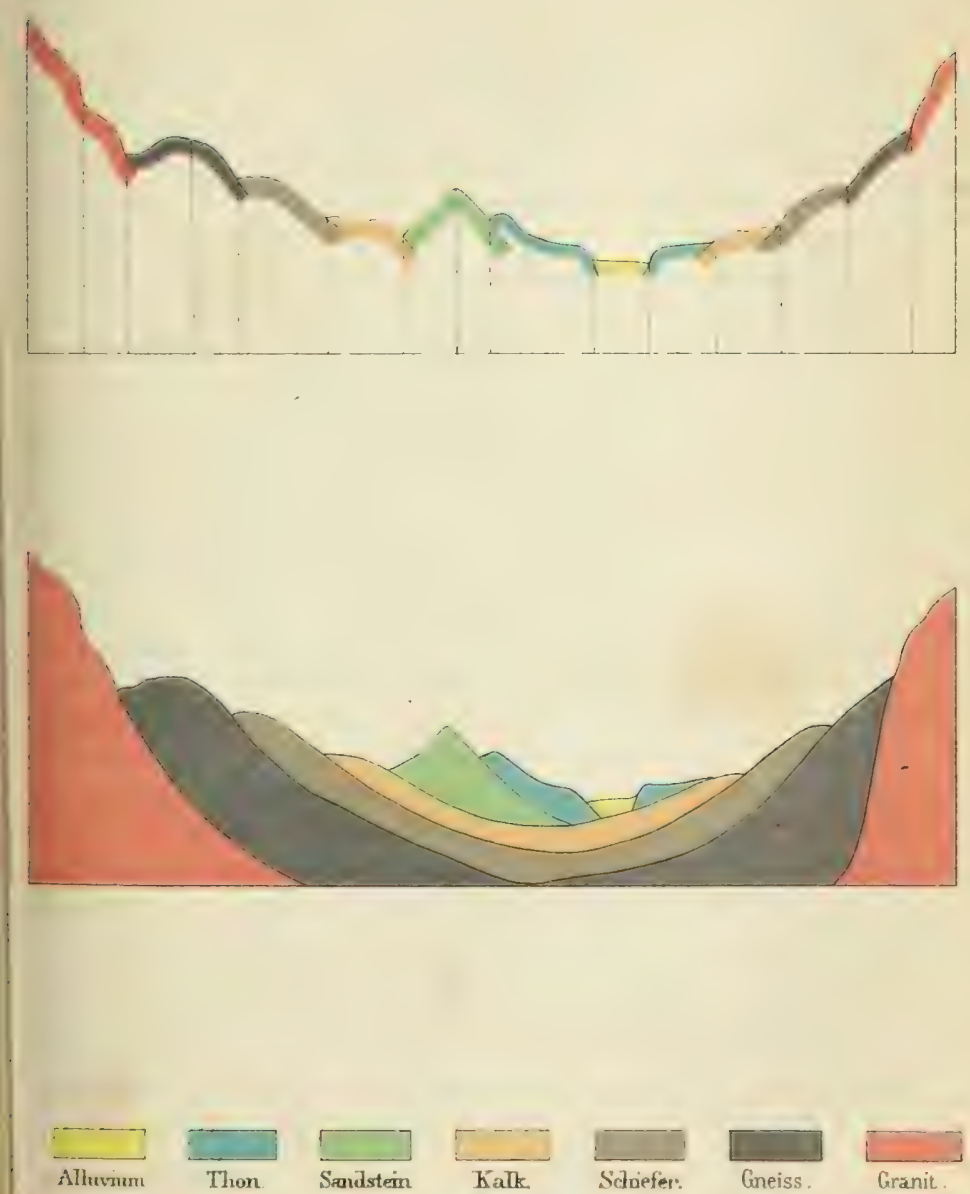

Es kann nicht genug empfohlen werden, dass man solche Konstruktionen - Verallgemeinerungen der erhobenen Thatsachen und Verbindungen verschiedener wirklich beobachteter Profile - auf dem Terrain selbst rornehme; die Schwierigkeiten und Zweifel, die sich hiebei erheben und die kaum ausbleiben werden, kann man am besten oder einzig an Or't and Stelle lösen; zu Hause in seinem Arbeitszimmer wird man auf Hypothesen angewiesen sein. Uebrigens muss schon beim Aufnehmen der einzelnen Daten und beim Zeichnen der isolirten Profile darnach gestrebt werden, einen Leberblick über das Ganze, ein Gesammtbild zu erhalten, und zu diesem Zwecke in Gedanken die einzelnen Schichten, wo sie sich dem Blick wieder entziehen, auf ihrem muthmasslichen Verlaufe zu verfolgen und zu errathen, wo sie wieder zu Tage treten werden. Treffen wir sie später wirklich da, wo wir sie rermutheten, so ist dies eine werthrolle Bestätigung unserer Amnahmen; andernfalls erkennen wir diese als unzureichend und werden uns zu einer Revision derselben veranlasst finden.

Es ist nicht leicht, die Lagerungsweise der Felsarten, welche sich unterhalb der äussersten Kruste befinden, auf dem Papier darzustellen. Zur Erreichung dieses Zweckes hat man nur ein Mittel; man erstellt theoretische Profile nach verschiedenen Richtungen, welche auf der Karte durch gerarle Linien angegeben sind, deren Enden je mit einem Buchstahen bezeichnet werden. Diese Durchschnitte werden dann selber durch die Ausdrücke „Profil oder Durchschnitt $\| b, \cdot d l^{*}$ etc. bezeichnet, und zur Angabe der Gesteine in denselben rerwendet man dieselben Farben und Symbole, die man brauchte, um in der geologischen Karte der Gegend die Verbreitung derselhen Felsarten an der Frdoberfläche anzugeben. Beispiele solcher Profile enthält Taf. XIX.

Bei der Konstruktion dieser Durchschnitte verfähr't man wie bei derjenigen topographischer Profile (pag. 138 und 214); den Verlauf der Felsschichten zeichnet man, wie oben auseinandergesetzt wurde, nach den Beobachtungen auf dem Terrain. Dabei ist zu empfehlen, dass der Massstah für die Höhen nicht allzu verschieden von dem für die Längen angenommen werde, weil man sonst ein verzerrtes Bild erhält, das der Wirklichkeit allzuwenig entspricht. 
Das Sammeln von Gesteinsmustern. Während man sich mit dem Studium der stratigraphischen Verhältnisse beschäftigt, sind auch diejenigen Erhebungen zu machen, welche nothwendig sind, um die Art und Zusammensetzung der Gesteine, d. h. ihren lithologischen oder petrographischen Charakter, zu bestimmen.

Es wäre sehr zu wünschen, dass man eine Kenntniss der Felsarten besässe, welche in den Stand setzte, auf den blossen Anblick derselben zu erkennen, welcher Kategorie sie angehören. Man würde dadurch viel Zeit ersparen und wäre der Beschwerlichkeit überhoben, zahlreiche Muster mitzunehmen, die später untersucht und bestimmt werden müssen. Da es aber dem Reisenden - ausgenommen, er sei perfekter Geolog und habe sein Auge für diesen Zweck in hohem Grade geübt - nicht möglich ist, an Ort und Stelle in exakter Weise die mineralogische Zusammensetzung eines jeden Gesteines zu bestimmen, so ist derselbe in den meisten Fällen darauf angewiesen, Proben oder Musterstücke der vorgefundenen Felsarten mitzunehmen, und hiefür glauben wir in Nachstehendem einige Fingerzeige geben zu sollen.

Die Gesteinsproben müssen dem anstehenden Fels entnommen werden und nicht abgelösten Blöcken und Trümmern, es sei denn, dass man genau wahrnehmen kann, woher ein solches Fragment gekommen, welcher Stelle es entstammt.

Die Proben müssen ferner aus noch unverwittertem Gestein herausgeschlagen werden. An der Oberfläche, die lange den atmosphärischen Einflüssen ausgesetzt war, erleidet jede Felsart Veränderungen in Farbe und Zusammensetzung. Man entnimmt demnach dem Fels, um welchen es sich handelt, ein grosses Bruchstück und schlägt nun aus diesem, unter Entfernung aller Partien, wo die Zersetzung schon stattgefunden oder doch begonnen hat, ein kleineres Stück frischen Gesteines heraus, welches als charakteristisches Muster und typischer Repräsentant der fraglichen Felsart gelten kann.

Gesteine, die weit verbreitet und in mächtigen Lagen vorhanden sind, zeigen mitunter in ihrer Zusammensetzung Verschiedenheiten, sei es in der horizontalen oder in der vertikalen Richtung ihres Vorkommens. In solchen Fällen muss man mehrere Proben mitnehmen und diese an Stellen herausschlagen, welche unter sich die schärfsten Differenzen aufweisen. 
Den Musterstücken gibt man eine möglichst bequeme und regelmässige Form. Wenn man immer kann, haut man sie auf eine rechtwinklige Grundfäche von $8-10 \mathrm{~cm}$ Länge und $6+8 \mathrm{~cm}$ Breite und eine nicht zu grosse Dicke zu, so zwar, dass die grössern Flächen den Schichtungsebenen mintrechen. Indess muss man mit diesem Formen an Ort und Stelle nicht so viel Zeit verlieren, es sei denn, dass man es zu dem Zwecke vornehme, un das Gestein durch allseitige Betrachtung kemnen zu lernen und sich zu vergrewissern, dass man nur gute, wirklich typische Prohen mitnehme.

Kann man unterwegs nicht längere Zeit verweilen, so heschränkt man sich darauf, nur kleine Stücke abzuschlagen, die wenigstens auf einer Seite frischen Bruch zeigen.

Ausser den Gesteinsproben, welche die im geognostischen Crounis angegebenen Felsarten zu repräsentiren haben, sammle man auch Mineralien, Geoden, Krystalle etc., die man unterwegs findet und die von Interesse zu sein scheinen.

Die gesammelten Stücke sind in Papier einzuwickeln und zwar so, dass diejenigen von geringer Festigkeit nicht beschädigt werden. Zu diesem Zweck umhüllt man sie auch mit Watte (in Ermanglung von solcher mit Moos oder Gras) und stopft damit ferner die Zwischenräume der einzelnen Stïcke aus, so dass diese sich nicht rerschieben und sich nicht an einander reiben können. Die weniger widerstandsfähigen Stücke (zerbrechliche, zerreibliche und leicht abhröckelnde, auch pulverige Substanzen) werden übrigens zweckmässig besonders verpackt in kleinen Kistchen oder Schachteln, die so vollständig als möglich auszufüllen sind.

Bevor man die Stücke einwickelt und einpackt, muss man sie etiquettiren und ihnen eine Ordnungsnummer geben, welch letztere übereinstimmen soll mit den Notizen im Tagehuch, hetreffend die Herkunft des Gesteins und sachbezügliche Details. Ein Stück, dessen Ursprung suäter ungewiss wäre, hätte fast keinen Werth. Die Verweisungsziffern dürfen also nicht rerwischt und rerwechselt worden. Um dies zu "rreichen, versieht man die Stücke, wenn sie weit und namentlich wenn sie über Meer zu transportiren sind, mit unauslïschlichen Nummern ans Oelfarbe, die auf dem Gestein sellst angebracht werden; wenn man aber Etiquetten an- 
wendet, so muss man die Sammlung von Zeit zu Zeit durchgehen, um sich zu vergewissern, dass die Aufschriften nicht durch Feuchtigkeit unleserlich geworden sind. Verwechslungen könnten entstehen durch doppelte Anwendung der nämlichen Nummer. Man kann dem, ausser durch Aufmerksamkeit, dadurch vorbeugen, dass man auf der Etiquette nicht nur die Ordnungsnummer, sondern auch nach Tag und Stunde den Zeitpunkt notirt, in welchem man das Stück getroffen und für die Sammlung bestimmt hat. Dabei kanı man Vormittags- und Nachmittagsstunden dadurch unterscheiden, dass man erstere mit römischen, letztere mit arabischen Ziffern bezeichnet. Diese Zeitangaben haben auch noch das Gute, dass sie später oft die besondern Umstände in Erinnerung rufen, unter welchen das Sammeln der betreffenden Stücke erfolgte.

Das Sammeln von Versteinerungen. Zur Vervollständigung unserer Daten müssen wir auch Nachforschungen darüber anstellen, welches die Pflanzen- und Thierwelt der zu erforschenden Gegend in den verschiedenen Epochen war, da die Gesteine, deren Vorkommen wir konstatirten, sich gebildet haben. Zu diesem Zweck suchen wir auch die Versteinerungen (Petrefakten, Fossilien) der Gegend auf und legen uns eine Sammlung derselben an, um später bei Musse die einzelnen Arten derselben zu bestimmen.

Die Säugethierreste finden sich gewöhnlich in Höhlen, Alluvialbildungen, Torfmooren, Schiefer- und Braunkohlenund anderen relativ jungen Formationen ${ }^{1}$ ).

Ueberreste von Vögeln sind ziemlich selten. Höhlen, Guano- und Torflager enthalten mitunter Rudimente von solchen, und in Felsen, welche aus einem feinen Schlamm entstanden sind, entdeckt man etwa Zehen-Abdrücke (Fussspuren). In Sandformationen hat man auch schon fossile Eier gefunden.

Weit häufiger kommen Versteinerungen von Reptilien vor und zwar nicht nur einzelne Knochen, sondern ganze Skelette. Reptilien werden auch die Koprolithen (fossile Exkremente) zugeschrieben.

1) In sehr kalten Gegenden kommen auch ausgestorbene Säugethiere vor, die eingefroren im Eise oder Boden, vollkummen erhalten geblieben sind. 
Yon fossilen Fischen finden sich meist nur Abdrücke, Schuppen, Zähne etc.

Die Insekten sind meist von so zarter Beschaffenheit, dass sie selten versteinert erhalten bleiben. Gewöhnlich hinterlassen sie als Spuren ihrer Existenz nur Abdrücke, Bruchstücke von Flügeldecken u. dgl. Eine Ausnahme bilden namentlich die in Bernstein, d. i. fossilem Harz, eingeschlossenen Insekten, welche prächtig erhalten bleiben.

Repräsentanten der andern Klassen des Thierreichs (Kruster, Mollusken etc.), namentlich solche, die durch eine Art Panzer, Schale oder sonstige harte Körperdecke geschützt sind orler deren Körper widerstandsfähige feste Theile enthält, finden sich in den Schichtgesteinen häufig, so dass diese dem Sammler reiche Ausbeute gewähren.

Von Pflanzen trifft man, trotzdem deren Erhaltung schwierig scheint, nicht nur Abdrücke, sondern selbst ganze Bäume (Stämme und Wurzeln) in der Kohlenformation. In Sandmassen finden sich auch rerkieste Baumstämme, d. h. solche, deren pflanzliche Masse (Cellulose) durch Kieselsäure ersetzt worden ist.

Immer aber finden sich Versteinerungen nur in geschichteten Felsen; sie in Massengesteinen wie Granit, Basalt u. s. w. zu suchen, wäre verlorene Mühe.

Die Schichtgesteine ihrerseits sind in Bezug auf ihren Gehalt an Petrefakten ungemein verschieden. In den einen finden sich nur spärliche Exemplare von Fossilien, andere sind erfüllt nit solchen, ja bestehen oft wesentlich aus Schalen und aus Resten mikroskopischer Thiere. Es kaun auch ein und dieselhe Schicht an einem Orte ganze Haufen ron Versteinerungen enthalten, anderorts aber an solchen arm sein. Jurch Misserfolg beim Sammeln muss man sich daher nicht zu rasch entmuthigen lassen, und dass eine Schicht petrefaktenleer sei, darf man erst erklären, nachdem man sich hievon durch heharliche Intersuchungen üherzeugt hat.

Auch um Fossilien zu entrlecken und in reichlicher Menge einzusammeln, bedarf es des Finderblicks, einer gewissen Kunst. Oft lässt das Gestein keine Spur des Vorhandenseins von P'etrefakten erkennen; man magr sich alle Mühe geben, es in tausend stücke zerschlagen, - man findet nichts. In derartigen Fällen untersuche man aufmerksam solche Theile des 
Gesteins, welche lange dem Wetter ausgesetzt waren; man wird dann oft wahrnehmen, dass auf unebenen Flächen die vorragenden Höcker von ebenso vielen Versteinerungen herrühren, die man auf dem frischen Bruche nicht bemerkte, die aber nun hervortreten, weil sie der Witterung besser widerstanden als das Muttergestein.

Aus demselben Grunde findet man Petrefakten am ehesten in den Schutt- und Trümmermassen am Fuss steiler Felswände, auf dem Thalboden von Schluchten, längs der Wasseradern wie in Steinbrüchen unter den als mangelhaft auf die Seite gelegten Stücken (Ausschuss). Beim Einsammeln solcher Fossilien muss man sich indessen sorgfältig Gewissheit verschaffen über deren eigentliche Herkunftsstelle; andernfalls ist es besser, die Petrefakten nur aus anstehendem Gestein zu gewinnen.

Um die Versteinerungen aufzufinden und herauszuschlagen, bedient man sich eines Hammers und, wenn der einschliessende Fels sehr fest ist, eines Meissels. Besteht das Muttergestein aus Kalk, so löst man ein geeignetes Stück desselben in Salz- oder Salpetersäure oder auch in starkem Essig auf. Von mürbem Gestein zerreibt man ein Stück zwischen den Fingern und untersucht mit der Loupe, ob es nicht mikroskopische Fossilien enthalte.

Wie zum Auffinden der Versteinerungen eine gewisse Kunst gehört, so gibt es eine solche, die darin besteht, dieselben mit richtigem Urtheil und in genügender Zahl auszuwählen und einzusammeln. Nicht leicht zwar kann man zu viel Petrefakten sammeln, namentlich in einer geologisch noch unerforschten Gegend; aber man hat schon mit Rücksicht auf die Transportschwierigkeiten doch gewisse Grenzen einzuhalten. Hierüber lassen wir am besten Herrn Professor Marcou sprechen $\left.{ }^{1}\right)$ :

"Trifft der Reisende auf ein reiches Lager von Knochen grosser Säugethiere und stehen ihm nur beschränkte Transportmittel zur Verfügung, so kann man ihm lediglich rathen, die Knochen bei Seite zu lassen und nichts einzusammelr als Zähne und Kieferstücke; sind diese Theile gut erhalten, so genügen sie fast immer zur Bestimmung der Thiere,

1) Instructions générales aux voyageurs, Paris 1875 , pag. 60. 
welchen sie angehörten. Wenn aber der Reisende sich daror hüten muss, zu grosse Knochen mitzunehmen, so ist ihm andrerseits dringend anzuempfehlen, von ganz kleinen Petrefakten recht viele zu sammeln, solche $\mathrm{z}$. B. von der Grösse einer Haselnuss, eines Fünffranken-, eines Halbfrankenstückes oder auch solche blos von der Grösse der Erbsen und Bohnen ... Hat man das Glück, auf eine versteinerungsreiche Lokalität zu treffen, so benutze man unverzüglich die günstige (ielecrenheit und verlasse die stelle nicht, bevor man sich eine schöne Samm!ung angelegt hat. Wenn man sich sagrt, dass dieselbe Formation ein wenig weiter wieder zu finden sei und wenn man aus diesem Grunde das Einsammeln der I'etrefakten, die man jetzt zur Hand hötte, auf einen andern Zeitpunkt des Reisetages oder gar auf einen andern Tag der Rieise hinausschiebt, so ist das eine lnklugheit begleitet von der hohen Wahrscheinlichkeit, dass eine Gelecrenheit unbenutzt bleibe, die oft während der ganzen Reise nicht wiederkehrt, wodurch man denn auch der Früchte einer grossen Zahl anderer Beobachtungen verlustig wird. Die anzulegende Sammlung soll aber eine gute Auswahl enthalten und nicht belastet sein mit zu voluminösen oder beschädigten Objekten: auch soll sie nicht zu riel gleichartige Stücke enthalten; ein oder zwei gute Exemplare derselben Art genügen vollständigg."

Kurz gesagt, wird man also - wenn man nicht über ausnahmsweise günstige Transportgelegenheiten rerfügt, wie dies der Fall ist, wenn man zu Schiffe den Lauf eines Flusses oder die Ufer eines Sees erforscht - sich damit hegnügen, von grossen fossilen Säugethieren Zähne zu sammeln, von grossen Platten, welche Abdrüclie von Thieren und Pflanzen, Fuss- und Regenspuren etc. enthalten, Photographien anzufertigen oder Aufnahmen durch eines derjenigen Mittel, ron welchen weiter unten in Bezug auf alte Inschriften die Rede ist; von petrifizirten Baumstämmen ein Querstück zu nehmen, gleichzeitig aber von denselben Zeichnungen anzufertigen, die Dimensionen, Zahl und Stellung der Bäume zu notiren u. s. w. Was die kleineren Petrefakten betrifft, so wird man, wemn sie selten sind, auch defekte Stücke nicht verschmähen; sobald sie aber in grösserer Zahl rorhanden sind, so wählt man die besten Exemplare aus und nimmt von jeder Art deren zwei bis drei mit. 
Soviel als möglich ist auf gut erhaltene, wirklich charakteristische Exemplare $\mathrm{zu}$ sehen, die nicht leicht $\mathrm{zu}$ Verwechslungen mit ähnlichen Formen aus andern Gegenden oder zu sonstigen Zweifeln Anlass geben. Desshalb wählt man in erster Linie Exemplare solcher Arten aus, welche in der Felsschicht, die man studirt, am häufigsten vorkommen; denn Formen, die massenhaft (gesellig) auftreten, sind bezeichnend für gut charakterisirte geologische Horizonte, während ein Fossil, das in einer Schicht vereinzelt gefunden wird, zu derselben in mehr oder minder zufälliger Beziehung stehen kann, sei es nun Vorläufer oder Nachzügler einer Form oder sei es, durch Wasser z. B., an eine sekundäre Lagerstätte gebracht worden.

Je mehr Petrefakten man aus einer Felsschicht sammmelt, desto sicherer wird man in der Bestimmung oder Einreihung dieser Schicht; das gemeinsame Auftreten gewisser Arten in einer Gesteinsbank garantirt uns, dass es sich nicht um ein ausnahmsweises Vorkommniss handle.

Um nicht auf der Reise unnütz Zeit zu verlieren, lässt man die Fossilien vorerst noch in ihrem Muttergestein and löst sie aus diesem erst später heraus, um auf diese Operation all die Sorgfalt und Vorsicht verwenden zu können, die sie braucht. Petrefakten in kompaktem Kalkgestein bringt man zweckmässig heraus, indem man das Gesteinsstück leicht erhitzt und es dann in eine heissgesättigte Lösung von borsaurem Natron taucht.

Versteinerungen, die man aus feuchtem Boden genommen hat, dürfen nicht sogleich an einen trockenen Ort gebracht werden; sie erhalten sonst viele kleine Risse oder zerspringen gar in Folge zu rascher Austrocknung.

Gewisse Fossilien werden an der Luft mürbe oder bekommen viele kleine Risse. Hiegegen kann man dieselben oft schützen, wenn man sie sofort in eine schwache Lösung von Gummi oder Fischleim oder auch in eine solche von Natronsilicat taucht, wonach sie beim Trocknen mit einer Art von durchsichtigem Firniss überzogen werden, der sie gegen die Atmosphärilien schützt. Versteinerungen aus porösen Felsen marinen Ursprungs legt man zweckmässig während mehrerer Wochen zu wiederholten Malen in süsses 
Wasser, um die Bildung von Rissen und salzigen Effloreszenzen zu verhüten. So geringfügig diese Vorsichtsmassregreln scheinen mögen, so wird man sicherlich deren Anwendung nicht bereuen, wenn man damit den Zweck erreicht, seltene oder weither transportirte Exemplare, die sonst durch irgend einen Lnfall werthlos werden könnten, zu konserviren.

Jedes Stück der Sammlung wird numerirt und etiquettirt oder mit einer Bemerkung versehen, betrefferid seine Herkunft, d. h. die Stelle und die Felsart, der es entnommen wurde, unter Bezugnahme auf die geologische Karte und die zugehörigen Profile.

Selbstverständlich müssen die Petrefakten noch sorgfältiger eingepackt werden als die Gesteinsmuster. Jedes Exemplar wird in Watte oder Moos gewickelt, sodann werden sie in besonderen Kisten untergebracht und nicht etwa mit den Felsstücken in die gleiche Kiste zusammengepackt, es sei denn, dass diese verschiedene Abtheilungen enthalte, in welchen Gesteine und Petrefakten getreunt placirt werden können; sonst würde man riskiren, dass Petrefakten durch den Druck der Felsstücke leiden müssten. Zartere Fossilien hewahrt man wohl auch in Glasröhren auf, die man mit Fliedermark verkorkt.

Da man unterwegs, auf dem Felde, nicht immer Zeit hat $\mathrm{zu}$ einer so sorgfältigen Verpackung, wie sie Petrefakten rfordern, so kann man dieselbe - wie wieder $\mathrm{Hr}$. Prof. IIarcou ${ }^{3}$ ) anräth - auf den Abend verschieben und bis dahin alle während des Tages gesammelten Fossilien in einem -inzigen gut zugebundenen oder zugenähten Paket mit einer inzigen Etiquette unterbringen; immerhin muss dann jedes itiick numerirt und gut mit Papier umwickelt werden, sonst würden dieselben durch Reibung so leiden, dass sie nachher blos noch zum Wegwerfen gut wären.

Auf langen Reisen tief im Innern von Kontinenten und .n Gegenden, wo die gewohnten Verkehrsmittel fehlen, kann nan sich genöthigt sehen, einen Theil des Gepäckes zurücksulassen und aufzugeben, um die Lastthiere oder Träger, leren Zahl sich reduzirt haben kann, zu entlasten. Da man un in der Regel blos die nothwendigsten Effekten und Yor-

1) A. a. O, pag. 62. 
räthe mit sich führt, so kann die Last nur durch Aufgabe eines Theils der Sammlungen reduzirt werden. So schwer dieses Opfer wird, muss es doch gebracht werden, da es sich hiebei oft um das Leben des Reisenden und der Leute in seinem Gefolge handelt. „In solchen Fällen höherer Gewalt, sagt der schon erwähnte Autor, opfere man zunächst die minder wichtigen Partien der Gesteinssammlung, dann die Mineralien, aber: man behalte so lange als möglich die Petrefakten. Muss man sich auch dieser zum Theil entledigen, so werfe man in erster Linie alle Doubletten und die nicht ganz gut erhaltenen Exemplare weg. Oft hat man zwar, ich weiss es wohl, auch nicht mehr die Musse oder sonstige Möglichkeit, eine solche Auswahl vorzunehmen; abgemattet und durchnässt ist man um ein Feuer gelagert, das unsere einzige Lichtquelle ist. Unter solchen Umständen hält es sehr schwer, Kisten zu öffnen, um zu untersuchen und auszuscheiden was man behalten und was man aufgeben will."

Wir fügen hinzu, dass es gut sein wird, in Voraussicht solcher Fälle schon beim Einpacken Alles das gesöndert unterzubringen, was man so lange als möglich behalten und erst in der äussersten Noth preisgeben möchte. Vielleicht erweist sich diese Vorsicht später überflüssig; wenn man aber in die Nothlage versetzt werden sollte, einen Theil des Gepäcks wegzuwerfen ohne im Momente seiner Preisgabe noch Zeit zu einer Auswahl zu haben, so wäre man dannzumal sehr froh, wenn man sich daraufhin vorgesehen und sich so ermöglicht hätte, wenigstens den kostbarsten Theil der Sammlungen zu retten.

Kommen die Objelite wohlbehalten am Bestimmungsorte an, so erübrigt uns, sie möglichst gut zu verwerthen für die geologische Erforschung der durchwanderten Gegend. Von der Reise zurückgekehrt, wird man nun zunächst ein Verzeichniss der mitgebrachten Arten von Gesteinen und Fossilien anfertigen und dabei nöthigenfalls die provisorischen Ueberschriften durch definitive und detaillirtere Etiquetten ersetzen. Man thut gut, wenn man bei dieser Arbeit die Stücke der Sammlung in derjenigen Reihenfolge vor sich hinlegt, in welcher sie gesammelt wurden; man erimnert sich dabei eher an die besondern Beobachtungen, die an Ort und Stelle gemacht wurden. 
Die genaue Bestimmung der Felsarten und Petrefaliten ist eine schwierige Aufgabe, an welche sich der Reisende nur wagen kann, wenn er über Musse und üher eine Anzahl Sirezialwerke zu verfügen im Falle ist. In Ermanglung soleher Werke oder ausreichender eigener Kemntnisse, sowie in allen zweifelhaften Fällen muss man sich an kompetente Personen wenden, diesen die zu hestimmenden Stücke zusenden und sie bitten, die wissenschaftliche Bestimmung romehmen zu wollen. Es ist überdies gut, wenn man auch das, was man selber bestimmt hat, noch Fachmännern zur Veritikation rorlegt.

Auch wenn wir nicht im Stande sind, die ron uns gesammelten Objekte selbst zu bestimmen oder wenn wir uns wenigstens hinsichtlich ihrer definitiven Bestimmung nicht einzig auf unsere eigenen kenntnisse verlassen künnen, so werden wir dennoch ans unsern geologischen Exkursionen Nutzen ziehen, wie wir gleich sehen werden.

Relatives Alter der Gesteine. Um die geologische Geschichte einer Gegend, d. i. die Geschichte der in und mit dieser Gegend rorgekommenen Veränderungen, zu ermitteln, muss man ror Allem das relative Alter der rerschiedenen daselbst rorfindlichen Felsarten kennen lernen; d. h. man muss die geologische Reihenfolge der in dieser Gegend auftretenden Gesteinsschichten ermitteln, ohne dass man desswegen sofort feststellt, dass dieselben eocen, jurassisch, triasisch etc. seien. Zur Lösungr dieser Aufgabe dienen uns wesentlich die stratigraphischen Beolachtungen, die wir machten, und die geologischen P'rofile, die wir aufuahmen. Es erübrigt uns nur, zur Wegleitung einige allgemeine Regeln aufzustellen.

\section{SCHICHTGESTEINE.}

Zuförderst erinnern wir daran, dass die geschichteten Felsen ron Ablagerungen herrühren, die unter Einwirkung des Wassers successive in Bodendepressionen oder auf dem Grund der Seen und Neere gehildet wurden. Sie sind charakterisirt durch ihre Anordnung in Sifhichtrn (Lager, Bänke), welche ursprünglich horizontal ausirebreitet waren und einander überdeckten, während dann süuter die Pegelmässigkeit dieser Lagerungsweise vielfach grestört und zerstört wurde. 
Hieraus ergibt sich durch ein einfaches Raisonnement Folgendes :

Die geschichteten Felsen, welche ihre urspringliche Lagerung yanz oder fast ungestört beibehalten, welche also horizontale oder mur schucach geneigte Schichten haben, sind immer älter als der Boden, auf dem sie ruhen und der sie uingibt (ihr Liegendes); die auf ihnen lagernden Schichten (ihr Hangendes) sind jünger und zwar um so mehr, je höher in der Reihe iltre Stelle ist.

So hat nothwendig das Becken $A$ (Fig. 165) oder dessen felsiger Boden existiren müssen, bevor die Ablagerungen $(a-d)$

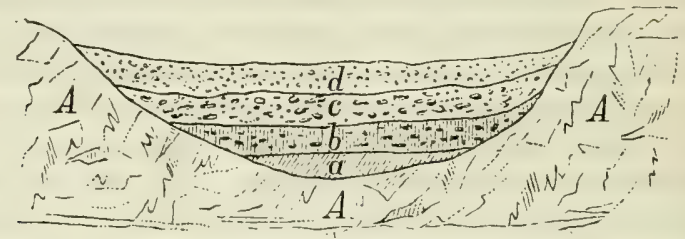

Fig. 165.

sich darin bilden konnten; von jeder der Lagen $a, b$ und $c$ musste die untere da sein, bevor die nächst höhere auf ihr sich absetzen konnte. Das Vorhandensein der Schichten a, $b, c$ und $d$ setzt die Prc̈existenz desjenigen Gesteins voraus, auf dem sie ruhen (ihres Liegenden).

Es kommt aber selten oder fast nie vor, dass man in natürlichen Ein- und Anschnitten des Terrains die ganze Reihe der Gesteinsschichten antrifft, welche in der zu erforschenden Gegend vorkommen; man muss desshalb die Reihenfolge der Lagerung herauskonstruiren aus den unzusammenhängenden Daten, die man da und dort sich verschaffen konnte.

$\mathrm{Zu}$ dem Ende bestimmt man in jedem Spezialfall das relative Alter, d. h. die zeitliche Aufeinanderfolge der Schichten nach folgendem Kriterium:

Von zwei oder mehr horizontalen oder schwach geneigten Schichten, die aufeinander liegen, ist die obere jünger als die untere. 
Die Schicht $c$ in Fig. 16if und 16ir ist also jünger als $b$, diese hinwieder jünger als $a$.

Ein anderes Profil (Fig. 168) bietet uns eine andere Reihe verschiedener Schichten, $e, f$ und $g$. Wir bestimmen wieder deren relatives Alter und wissen, dass die Schicht $g$ jünger sein muss als $f$, diese jünger als $e$. Das sagt uns nun freilich noch Nichts über

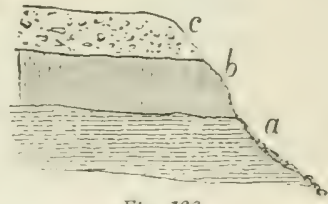

Fig. $16 \%$. das zeitliche oder Altersverhältniss, in welchem die beiden Schichtenserien $z u$ cinanderstehen. Dieses hönnen wir aber bestimmen und so unsere Profile durch einander ergänzen, wenn wir in einem natürlichen TerrainAnschnitt ein oder mehrere

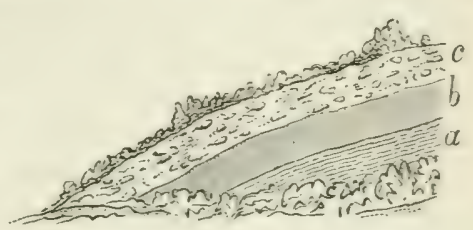

Fij. 15i. Glieder auffinden, die zwei oder mehr Profilen gemeinsam angehören.

Es sei Fig. 169 ein solches natürliches Profil, bei welchem wir im untern Theil die Felsschicht $c$ erkennen, welche in den obigen Durchschnitten (Fig. 166 und 16\%) das Hangende bildet, und eine Gesteinsschicht $e$, die auch dem Durchschnitt Fig. 168 (als Liegendes) angehört, so schliessen wir daraus, dass die Serie e $f g$ jünger ist als die Schichtenreihe $a b c$ und dass noch ein Zwischenglied $d$ existirt, welches wir in keiner der beiden Schichtenserien vorgefun-

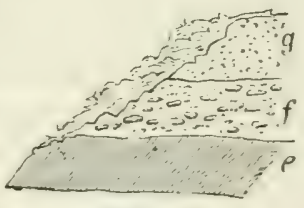

Fig. 16 s. den haben.

Die Reihenfolge derselben Schichtrn ist überall die nëmliche, wem nicht, was unschuer zu rrlirmush srin wird, Distrikationen und Umkiehung stattgefunden haben. 
Wenn man also an einer einzigen Stelle konstatiren konnte, dass die Schicht $d$ auf c liegt und selber wieder von $e$ überlagert wird - und zwar unter der eben genannten Voraussetzung - so ist man sicher, dass nirgends in der ganzen zu erforschenden Gegend die Schicht $c$ über $d$ und $e$ zu treffen sein wird (Stellen ausgenommen, wo durch eine starke Störung die normale Lagerung umgekehrt wurde). Andere Abweichungen können vorkommen, z. B. dass stellenweise die Schicht $d$ fehlt (sei es, dass sie an jenen Orten nie existirt hat, $d . h$. nie abgelagert worden ist, oder dass sie gebildet, aber wieder zerstört wurde) und dass nun e direkt auf $c$ folgt. Es kann sich ferner treffen, dass man an einem Orte zwischen zwei Schichten $c$ und $d$ eine Gesteinsbank (Thon, Lehm, Kalk etc.) eingeschoben findet, die man nirgends anderswo beobachtet hat. Im ersten Falle wird man die Bezeichnung der fehlenden Ablagerung (d) keineswegs aus der Liste der Zeichen für die Schichtenfolge ausmerzen; denn man hat das Fehlen dieses Gesteins lediglich als ein zufälliges lokales Vorkommniss zu betrachten, welches an dem relativen Alter oder dem Zeitverhältniss in der Aufeinanderfolge der Schichten $c$ und $e$ nichts ändert. Im zweiten Fall muss man für die neu beobachtete Ablagerung ein neues Zeichen ( $c^{\text {bis }}$ oder $c^{\prime}$ ) anbringen oder die ganze Bezeichnungsweise abändern, um in der Schichtenserie die neue Beobachtung zu berücksichtigen.

Indem wir so fortfahren, gelangen wir nach und nach zur Kenntniss der ganzen Serie geschichteter Felsen, welche in der zu erforschenden Gegend sich finden und der regelmässigen Reihenfolge ihrer Lagerung; d. h. wir erhalten die chronologische Stufenfolge der sämmtlichen Schichten, worin wir einer jeden derselben ihre wahre Stelle anweisen können und einen Massstab für ihr relatives Alter haben.

Die Regeln, die oben aufgestellt wurden, sind indessen, zunächst wenigstens, nur auf solche Schichten anwendbar, die unmittelbar auf einander folgen, nicht ohne Weiteres aber auch auf isolirte Schichten, die ohne Zusammenhang mit einander in verschiedenen Niveaux getroffen werden. So z. B. müssen in dem Erosionsthal (Fig. 170) die Ablagerungen $a$ und $a^{\prime}$, obschon höher gelegen als $b$ und $b^{\prime}$, offenbar älter sein als letztere, denn sie wurden schon ge- 


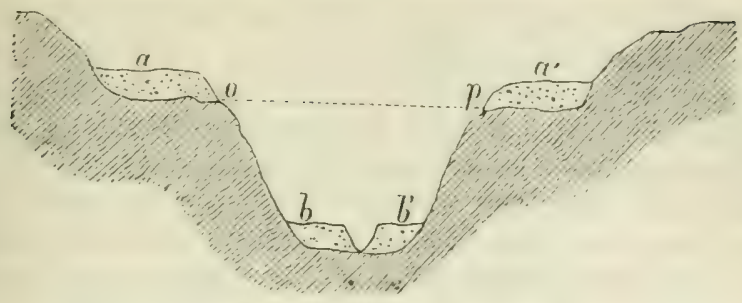

Fig. 1ro.

bildet, als die Thalsohle noch bei $o p$ lag, während $b$ und $l^{\prime}$ erst entstehen lionnten, nachdem das Wasser sein Bett tiefer eingegraben hatte.

Wenn aber der Höhenunterschied zwischen isolirten Schichten nicht immer Schlüsse auf die Differenz im relativen Alter der letztern erlaubt, so ist hinwieder die Lebereinstimmung im Niveau mancher Ablagerungen ein Indicium für die Gleichzeitigkeit derselben. In dem durch die obige Fï. 1\%0 dargestellten Falle z. B. vermuthen wir sofort, dass die Bildungen " und " gleich alt, dass sie Theile einer und derselben Ablagerung seien; ähnlich, wenn wir, wie in Fï. 1r1,

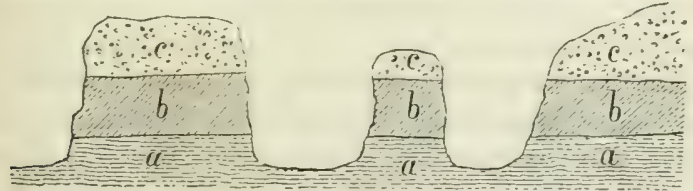

Fiig. 171 .

anstatt der beiden Seiten eines Thales, die Ueberreste grossentheils zerstörter Ablagerungen vor uns haben.

Selbstverständlich dürfen Schlüsse über einen solchen Zusammenhang, die Identität getrennter Ablagerungen sich nicht blos auf eine mehr oder minder grosse Lebereinstimmung in ihren Niveauverhältnissen stützen, sondem es ist dabei die Beschaffenheit, die Zusammensetzung der Schichten mit zu berücksichtigen.

Hiemit kommen wir auf die Merkmale zu sprechen, an welchen man erkennen kann, dass und ob zwei oder mehr verschiedene Durchschnitte dieselbe Schicht oder mehrere gemeinsame Glieder enthalten. 
Aus dem Gesagten ergibt sich, wie wichtig es ist, eine solche Identität konstatiren zu können; denn dies ist der Ausgangspunkt, um nach oben und unten die Reihenfolge der Gesteine in der Gegend festzustellen. Alles hängt von der Zuverlässigkeit dieser Identitätsbestimmung ab. Ist die angenommene Identität wirklich vorhanden, so haben wir in dieser Ermittlung eine sichere Grundlage für die Konstruktion der Schichtenfolge; ist aber die Annahme jener Uebereinstimmung und Zusammengehörigkeit ungenügend begründet oder gar falsch, so ist alles Uebrige zweifelhaft oder irrig. Nehmen wir an, wir haben vor uns zwei Serien $A$ und $B$ (Fig. 172 und 173) mit einer gemeinsamen Schicht $e$. Wenn

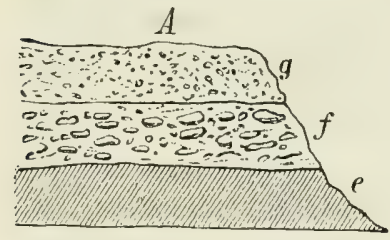

Fig. 172.

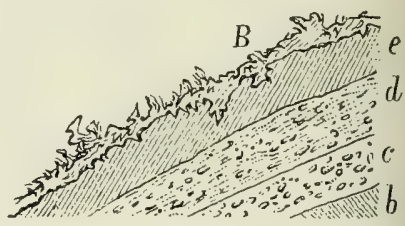

Fig. 178.

es uns nicht gelingt zu erkennen, dass in beiden Profilen das Element $e$ enthalten ist, so können wir dieselben nicht $\mathrm{zu}$ einander in Beziehung bringen; nur dadurch aber, dass wir eine solche Beziehung herausfinden, gelangen wir zur Ermittlung der ganzen Schichtenfolge $b$ bis $g$. Ohne das bleiben wir im Ungewissen. Wenn wir aber fälschlich $e$ und $\checkmark$ als einander entsprechende, beziehungsweise identische Glieder betrachten, so kommen wir damit zu dem unrichtigen Ergebniss, $c$ und $d$ seien jünger als $e$ (Fig. 172) und bringen so Alles in Verwirrung. Man kann also nicht genug darauf halten, einerseits die Aehnlichkeit räumlich getrennter Ablagerungen herauszufinden, andrerseits die Zusammengehörigkeit solcher genau nachzuweisen. Demgemäss stellen wir folgende Grundsätze auf:

Bei jedem neuen Durchschnitt, den man studirt, ist sorgfältig zu prïfen, ob in demselben nicht eine Gesteinsschicht vorkomme, welche man schon in einem früheren Profil antraf und mittels welcher die beiden Durchschnitte zu einander in Beziehung zu bringen sind. 
Die Identitüt einer Schicht an verschiedenen Stellen ihver Erstrectung, d. h. die Zusammengehöriglecit von Theilen derselben, die man an verschiedenen Orten getroffen hat, muss dargethan werden durch positive Tacheeise, welche so viel als möglich aus der Vebereinstimmung ron ILerkmalen verschiedener Art (stratignaphischen, petrographischen und palüontologischen) hergenommen sein sollen.

Der letztere Punkt, d. h. die Nothwendigkeit, sich nicht blos auf Charaktere von einerlei Art zu stützen, kann nicht genug betont werden. Wollte man sich einzig auf das stratigraphische Verhältniss, die Lagerung, verlassen, so könnte man leicht irre geführt werden durch das zufällige Fehlen eines Zwischengliedes oder durch das lokale Auftreten einer neuen Stufe. Blos die stratigraphische Anordnung berücksichtigend, müsste man in dem durch Fir. 1rt dargestellten

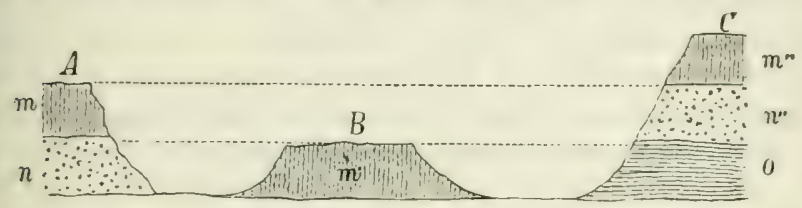

Fig. 174.

Falle zu der Ansicht kommen, die Gesteinspartien $n$, $m^{\prime}$ und o gehören einer und derselben Schicht an, während der durch die Zeichnung veranschaulichte Zustand dadurch herbeigeführt werden konnte, dass die aus mürbem Naterial bestehende Schicht $n$, die wir bei $A$ vorfinden, an der Stelle $B$ unter einer gewaltigen Gesteinsmasse $m^{\prime}$ in der Schicht $m$ erdrückt und die Trümmer durch Wasser forttransportirt wurden, sodass hier die Schicht $n$ vollständig verschwand. Eben so kann bei $C$ in einer Höhe, welche derjenigen entspricht, in welcher bei $A$ die Schicht $n$ und in $B$ die Schicht $m^{\prime}$ rorkommt, eine Thonschicht 0 auftreten, die an den andern Stellen nicht gebildet oder aber, wenn sie vorhanden war, durch Wasserwirkung wieder beseitigt wurde. Wenn man nun $n, m^{\prime}$ und $o$ identifiziren würde, so brächte dies in unsere Ergebnisse die grösste Konfusion.

Solche Fehler können wir verhüten, wenn wir ausser den Lagerungsverhältnissen auch die Gesteinsbeschaffenheit 
in Rechnung ziehen. Trotz des aus der Lagerung sich ergebenden Anscheins einer Zusammengehörigkeit von $n_{r}$ $m^{\prime}$ und $o$, werden wir eine solche nicht annehmen, wenn wir bemerken, dass $n$ Mergelfels, $m^{\prime}$ Kalkstein und $o$ eine thonige Schicht ist. Diese Ungleichheit der mineralogischen Komposition wird uns dazu führen, dass wir die rerschiedenen Stücke $m, m^{\prime}$ und $m^{\prime \prime}$ der diesen Profilen gemeinsamen Schicht in verschiedenen Niveaux aufsuchen. Konstatiren wir in denselben noch das Vorkommen gleicher Fossilien, so haben wir damit eine weitere Garantie für die Richtigkeit unserer Schlüsse. Die Uebereinstimmung oder Verschiedenheit der petrographischen und paläontologischen Merkmale lässt sich übrigens in den meisten Fällen ohne fachliche Detailkenntnisse nach dem blossen Anblick beurtheilen. Es ist zu diesem Zweck nicht nöthig, dass man das Gestein chemisch analysire oder die Petrefakten nach ihren einzelnen Arten bestimme; es kann genügen, wenn man den Fels und die Versteinerungen, die er enthält, einer aufmerksamen vergleichenden Beobachtung unterzieht.

Andrerseits sind auch die stratigraphischen Verhältnisse nicht zu unterschätzen und soll man die Identität, von der wir sprechen, auch nicht allein nach lithologischen und paläontologischen Charakteren beurtheilen. Damit würde man sich zuvörderst eines Hülfsmittels berauben; denn wenn auch die Stratigraphie allein nicht immer einen sichern Nachweis der Schichtenidentität liefert, so dient sie wenigstens als Wegweiser hiebei, indem sie zeigt, wo wahrscheinlich die Fortsetzung einer schon studirten Schicht zu finden sei. Sie kann demzufolge ein längeres unsicheres Umhersuchen ersparen. Sodann sind die petrographische und paläontologische Beschaffenheit einer Schicht nicht immer von der Art, dass sie für sich allein ausreichende Merkmale bieten, um die Identität leicht und sicher zu konstatiren. Eine Schicht behält nicht immer auf grosse Strecken eine solche Uebereinstimmung der Gesteinsbeschaffenheit, dass sie überall dasselbe Bild böte; vielmehr können Färbung, Textur und Zusammensetzung derselben sich ändern. Die Petrefakten ihrerseits sind am einen Ort häufig, fehlen aber oft gänzlich an einer andern Stelle; öfters auch gehören sie nicht ausschliesslich einer Schicht allein an, sondern 
finden sich sämmtliche in mehreren derselben. Wenn man sich also auf die petrographischen und paläontologischen Ierkmale beschränken wollte, so würde man sich damit die Aufgabe nicht rereinfachen und wäre weit daron entfernt, liedurch die Resultate zuverlässiger zu gestalten. Aus all' dem Gesagten ergibt sich vielmehr die Nothwendigkeit, dass man sich auf alle drei Arten von Merkmalen (stratigraphische, lithologische und paläontologische) stütze und sie gegenseitig durch einander kontrolire. Stimmen sie überein, so ist man damit der Sache gewiss; stimmen sie nicht zusammen, so sucht man nach den Ursachen dieser Erscheinung nnd wägt alle Umstände gegen einander ab, bevor man sich ein definitives Urtheil bildet.

Wenn wir länger bei den Grundsätzen verweilten, nach velchen das relative Alter von Schichten zu bestimmen ist, deren ursprüngliche Lagerung gar nicht oder nicht zu sehr cestört wurde, so geschah es, weil - wie wir sehen werden - die nämlichen Prinzipien auch auf diejenigen geschichteten Felsen anzuwenden sind, welche starke Lagerungsstörungen erlitten haben. In der That können wir Folgendes als Regel hiefür aufstellen:

Dic yeschirhteten Felsen, deren Schichten stark dislozirt (genrigt, cufgerichtet, umgelipmpt) erscheinen, müssen in Gedanken in ihre ursprïnglirhe La!genung zuriekersetzt werden. Hemach ist nach den oben aufyestellten Prinzipien in den einzeluen Dureleschitten das relative Altersurhuiltniss der Sdhichen und das Verhülniss der cinzelnen Selitionen zu sinander auszumitteln.

Die ursprüngliche Lagerung der Gesteinsbänke wird sich in den meisten Fällen unschwer rekonstruiren lassen. Wir werden die Lagerung selten überall in einem Grade gestört finden, dass wir bei genauer schrittweiser Verfolgung der Schichten nicht noch die eine oder andere Stelle antreffen, wo dieselben ziemlich horizontal geblieben sind. Mit dem Profil an einer solchen Stelle, die schwach geneigte Schichten zeigt, vergleichen wir nun unter den drei Gesichtspunkten der Lagerung, der Gesteinsbeschaffenheit und der Petrefakten die Durchschnitte von Orten mit starker Schichtenstörung und so werden wir zur Kenntniss der wahren Reihenfolge auch dieser Schichten gelangen. 
So bietet z. B. die Sektion $A$ in Fig. 175 ein schwieriges Problem; finden wir aber bei $B$ und $C$ dieselben Schichten in weniger gestörter Lagerung, so gestaltet sich die Lösung jenes Problems zu einer ziemlich einfachen.

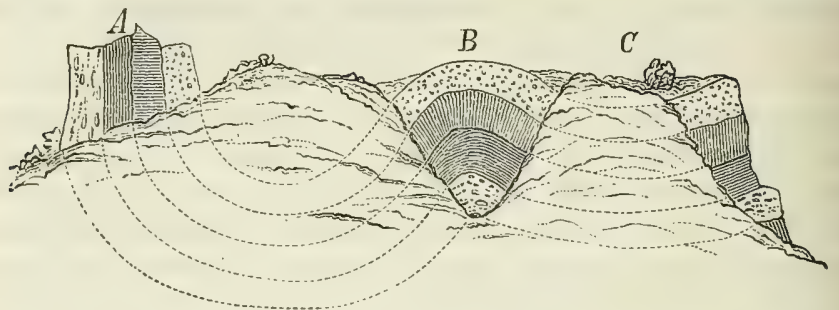

Fig. 175.

Indessen gibt es freilich Fälle, die verwirren können und schwer zu enträthseln sind. Wir wollen einige derselben behandeln.

Die urspmïngliche Lagernng vertikaler Schichten, die man nirgends anderswo in weniger abnormer Stellung findet, ist nach zufülligen Charatiteren (wie nach der Beschaffenheit eingeschlossener Bruchstïcke etc.) zu bestimmen.

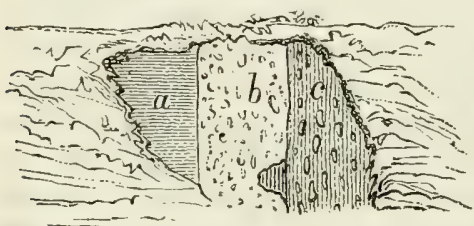

Fig. 176.

In Fig. 176 mögen $a$, $b$ und $c$ Schichten vorstellen, die sich in der bereisten Gegend weiter nicht vorfinden. Nichts zeigt uns, welches die jüngste derselben sei. Bei näherer Untersuchung finden wir aber in $c$ z. B. Gesteinspartien (Kiesel, Gerölle etc.), welche aus der Schicht $b$ stammen und früher ihr angehörten. Bedenken wir nun, dass jede Sedimentschicht sich auf Kosten schon vorhandener Gesteine, aus dem Material dieser schon früher bestandenen Massen bildet, so ist das Räthsel gelöst: wir dürfen als gewiss annehmen, dass ursprünglich die Schicht $b$ auf $a$ ruhte und dass sie den Boảen und die Wandung eines Beckens bildete, in welchem später die Schicht $c$ abgelagert wurde. Fig. 1ry veranschaulicht in idealer Darstellung diese Rekonstruktion der früheren Verhältnisse, aus welchen die späteren entstanden, indem die Schichtenpartie $A$ 
vertikal aufgerichtet und damit in die Lage gebracht wurde, in welcher sie nun die Fig. 176 zeigt.

Zueinemähnlichen Ergebniss gelangen wir, wenn wir beobachten, dass die Schicht $c$ stellenweise in das Niveau und die Masse derjenigen von

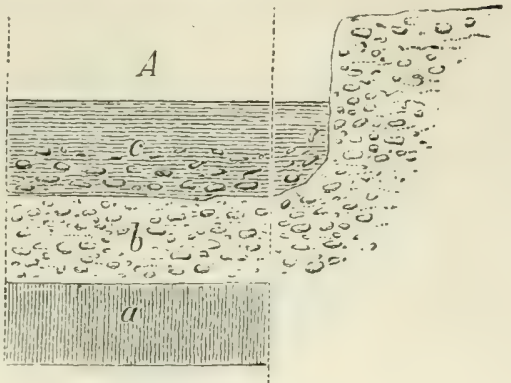

Fig. $17 \%$.

6 eindringt. In diesem Falle müssen wir ebenfalls annehmen, dass letztere Schicht vormals einen Boden gebildet habe, auf welchem sich $c$ absetzte, wobei das Naterial dieser neuen Schicht in Vertiefungen und Lücken der unregelmässigg gestalteten Oberfläche von $b$ eindrang und dieselben ausfüllte. Das theoretische Profil (Fig. 178) veranschaulicht diesen Fall, wobei indess die Unregelmässigkeiten der oberen Grenzfläche von $b$ übertrieben erscheinen, damit sie deutlicher hervortreten.

Jedes Mal, wem cine Aufrinanderfolye ïhnlicher Schichtengruppen zu beobachten

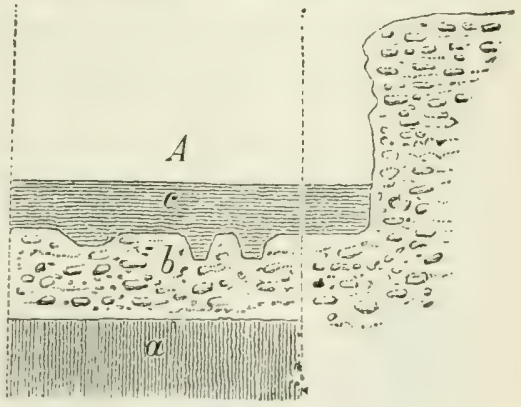

Fig. 178.

ist, muss die Ursache dieser Erscheinung gruau untersucht werden, damit man nicht die Wiedrotholung einer solchen Gruppr jeweilen als eine neue Schichtenreihe betrachte.

Fälle solcher Art können sich unter verschiedenen Formen darbieten. Wenn man z. B. das Terrain $A B$ Fig. 179 durchgeht,

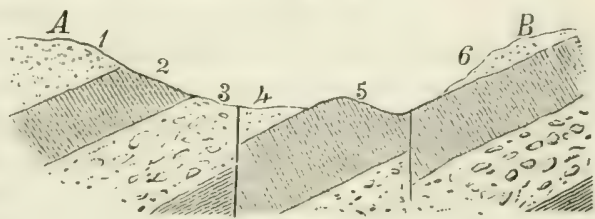

Fig. 179. 
so wird man leicht im ersten Moment zu der Meinung kommen, es seien da zahlreiche verschiedene Schichten vorhanden. Bei genauerem Nachsehen finden wir aber, dass die Schichten bei 1,4 und 6 identisch sind, eben so unter sich diejenigen an den Stellen 2 und 5 . Wir sehen mithin, dass hier einige wenige Schichten in einer Wiederholung auftreten, die durch Verwerfungsspalten und lokale Senkungen verursacht wurde.

Wenn wir ferner in dem Profil Fig. 180 beobachten, dass

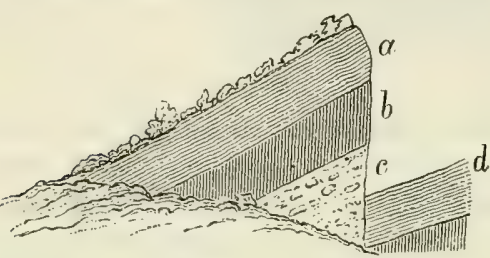

Fig. 180. die Schichten $a$ und $d$ mit einander übereinstimmen, so werden wir nicht - wie es sonst ge$d$ schehen würde - annehmen, dass $d$ sich unter die Schicht $c$ fortsetze (dieselbe "unterteufe ${ }^{\text {) }}$ und älter sei als $a, b$ und $c$, sondern wir liommen nun zu dem Schlusse, dass hier eine Verwerfung stattgefunden hat.

Mitunter ist eine Wiederholung derselben Schichten in der Weise zu beobachten, dass dieselben zu beiden Seiten

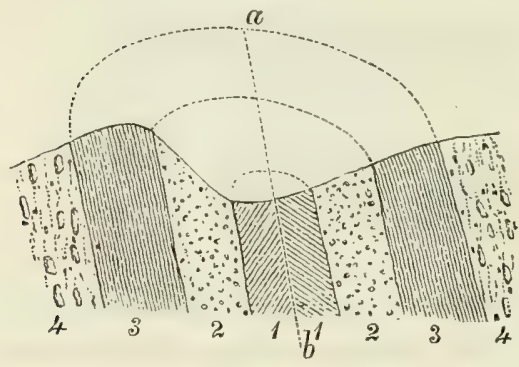

Fig. 181. einer Axe $a b$ (Fig. 181) symmetrisch angeordnet sind. In diesem Fall sind die beiden Serien als eine einzige ursprüngliche Schichtengruppe aufzufassen, deren Glieder früher in materiellem Zusammenhang standen, welcher später unterbrochen wurde durch Abtragung und Beseitigung des Materiais in den vormaligen Verbindungsstücken. Die Fü 181 deutet dies an durch die punktirten Linien des ursprünglichen Zusammenhangs der Schichten. Einen solchen Fall in andrer Form - nämlich verbunden mit Umkehrung oder Umkippung der Schichten - stellt die Fig. 18: dar. (Vgl. auch die fächerförmige Schichtenstellung, S. 312.) 


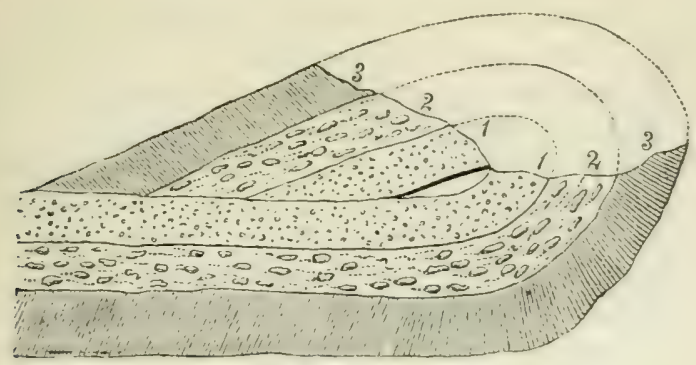

Fig. 182.

UXGESCHICHTETE (MCASSIGE) GESTEINE.

Die greschichteten Felsen sind, wie wir bemerkten, im Allgemeinen sedimente, aus Wasserabsatzbildungen entstandene Gesteine.

Die ungeschichteten oder massigen Gesteine sind andern Ursprungs oder wenigstens sind sie, wenn ihre Bildung dieselbe war wie die der Sedimente, seither durch andere Lrsachen so umgewandelt worden, dass sie jede Spur ron Schichtung verloren.

$\mathrm{Zu}$ den ungeschichteten Felsarten gehören die Erstarmun!sfrestcine, welche aus feurigflüssigen Massen durch Abkühlung entstanden. Sie treten auf in Massiren, welche rom anstossenden Gestein deutlich abgegrenzt sind; in Ketten, welche andere Felsmassen fast senkrecht durchbrechen; den letzteren eingeschlossen als Adern oder Gänge, welche vielfach verzweigt und als eine Art Injektionen in umgebenden Gesteinen erscheinen; endlich auch flächen- oder deckenförmig ausgebreitet zwischen oder über Sedimentschichten, nach Art ron ausgebreiteten Lavamassen.

Man theilt diese Erstarrungsgesteine, übrigens ziemlich willkürlich, in plutoniache und cullanisthe Massengesteine ein, jenachdem sie in grossen Tiefen oder an der Oberfläche (beziehungsweise nahe an dieser) gebildet wurden. Die einen wie die andern enthalten keine Petrefakten. Die plutonischen Massengesteine haben aber eine mehr krystallinische Textur als die rulkanischen und enthalten auch nicht Tuffe, Breccien und poröse Massen mit zelliggen Höhlungen wie letztere. 
Nach diesen Vorbemerkungen wenden wir uns wieder der Aufgabe zu, das relative Alter der verschiedenen Gesteine zu bestimmen, welche wir bei unsern geologischen Forschungen antreffen.

Hier stossen wir auf eine wesentliche Verschiedenheit der plutonischen Gesteine gegenüber den geschichteten. Die letzteren bilden sich aus successiven Ablagerungen, so dass die ältesten zu unterst und von den jüngeren bedeckt sind. Bei den plutonischen Gesteinen sind im Gegentheil die ältesten zu oberst und sie bedecken die neueren, insofern sie entstehen durch Abkühlung und Erstarrung feurig flüssiger Massen des Erdinnern, von welcher Abkühlung vorausgesetzt wird, sie gehe an der Aussenfläche des feurigen Zentralkerns oder gluthflüssiger Massen vor sich. Es würde hienach die Erdrinde an Dicke auf zweierlei Art zunehmen:

1) Nach Aussen, durch successive Ablagerung von Sediment- oder geschichteten Gesteinen (a, b, c, d, Fig. 183).

2) Nach Innen, indem sich unter einer ersten festen Kruste neue Massen bilden durch Erstarrung infolge allmäliger $\mathrm{Ab}$ kühlung der feuerflüssigen Stoffe im Erdinnern. Zwischen Lage-

Fig. 183. rungsweise und Alter besteht also bei den plutonischen Felsen ein Verhältniss, welches das Gegentheil desjenigen bei Sedimentgesteinen ist. Geschichtete Felsen, welche auf andern lagern, gelten für jünger als die letzteren; bei plutonischen Gesteinen hingegen wird aus einer solchen Ueberlagerung auf ein höheres Alter geschlossen. Denken wir uns einen Durchschnitt durch die ganze Erdkruste, wobei wir indess der Deutlichkeit halber absehen von den später zu besprechenden metamorphischen Gesteinen und bezeichnen wir (Fig. 184) durch Ziffern das Alter der Felsmassen, so erhalten wir für die geschichteten und plutonischen resteine zwei einander entgegengesetzte Reihen.

Die Darstellung in Fig. 184 zeigt auch, dass ein neueres plutonisches (IV) und ein neueres Sedimentgestein (4), wiewohl vielleicht einer und derselben geologischen Epoche 


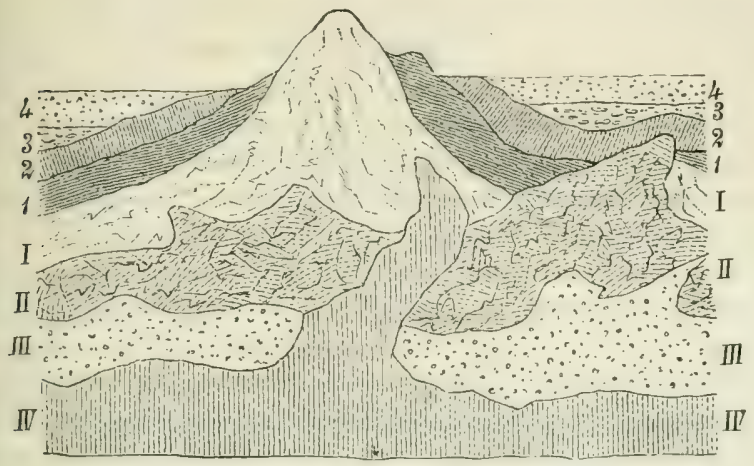

Fig. 181 .

angehörend, räumlich weiter von einander abstehen als die früheren Formationen und dass die Wahrscheinlichkeit gering ist, plutonische Gesteine $\mathrm{zu}$ finden, die nicht schon sehr alt sind.

Wir können also ohne grosse Gefährde für unsere Altersbestimmung folgende Regel aufstellen:

Die plutonischen Gesteine, welche der Geologe antrifft, sind (uilter als alle, selbst die untersten, Sedimente.

In der That muss nach der allgemein geltenden Anschaung die erste Kruste der Erde durch Erstarrung des äussersten Theils der feuerflüssigen Masse, die den Erdball bildete, entstanden sein. Offenbar viel später erst konnten sich aiie ersten Sedimente ablagern und zur Entstehung des ältesten aller Schichtgesteine Anlass geben. Es ist übrigens allgemein bekannt, dass Granit, Gneiss etc., d. h. die plutonischen Gesteine, die der Erforschung zugänglich sind, ein höheres Alter haben als die auf ihnen lagernden Sandsteine, Kalke u. s. w. Obwohl die plutonischen Gesteine sozusagen las Knochengerüst des Erdkörpers bilden, trifft man sie weniger bei tiefem Eindringen in die Erde als vielmehr in len Gegenden mit stark ausgeprägtem Bodenrelief, und auf len höchsten Berggipfeln. Ebenfalls daselbst beobachtet nan die ältesten Sedimentgesteine, und zwar in Schichten, velche an den Flanken des Gebirges aufgerichtet anstehen, xährend die jüngeren die Thäler und Ebenen bilden und 
auf dem Grunde von Seen und Meeren Schichten der jetzigen Periode in Entstehung begriffen sind.

Hat man zwei oder mehr plutonische Gesteine vor sich, so muss man zum Zuvecke der Bestimmuny ihres relativen Alters untersuchen, in welcher Weise sie einander durchsetzen, welches davon in das andere eindringt und welches von itnen Bruchstïcke eines andern derselben einschliesst.

Unter diesen, Gesteinen ist dasjenige das älteste, welches vom (beziehungsweise von den) andern durchsetzt ist, welches also das letztere oder die letztern injizirt enthält. Was eingeschlossene Fragmente betrifft, so ist klar, dass die Felsart, der sie entstammen, ülter sein muss als diejenige, welche sie einschliesst.

Eine zweite Kategorie der Erstarrungsgesteine bilden, wie schon bemerkt, die vulkanischen oder Eruptivgesteine. Sie treten auf in Form von horizontalen tafelförmigen Flächen oder Dechen, als Adern oder Gänge, dylies oder Mauern, als Säulen oder Massen, welche in regelmässige Prismen, zuweilen auch in kugelförmige Abschnitte getheilt sind, endlich als vulkanische Kegel und Lavaströme.

In stratigraphischer Beziehung unterscheiden sie sich von den plutonischen Gesteinen dadurch, dass sie die höheren Felslagen durchbrochen und sich einen Weg gebahnt haben bis zur Aussenfläche der Felsmasse, welche zur Zeit der Eruption die äusserste war und über welcher sie sich dann ausbreiteten, oder dass sie wenigstens nahe bis an diese Oberfläche emporgedrungen sind.

Wir können daher folgenden Satz aufstellen:

Ein vullanisches Gestein, welches auf Sedimentgestein lagert, ist jünger als letzteres.

Die Richtigkeit dieses Satzes ist evident. Damit die aus vulkanischem Gestein bestehende Decke o (Fig. 185) sich über der Sedimentschicht $c$ ausbreiten konnte, musste selbstverständlich diese letztere schon vorhanden sein.

Wenn hingegen das vulkanische Gestein ïberlagert wird von ge-

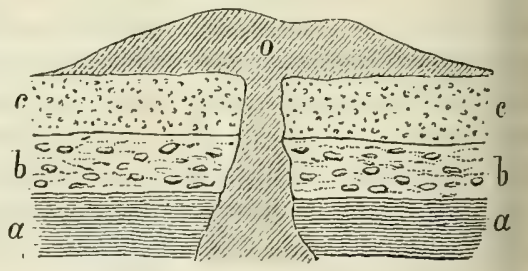

Fig. 185. 
schichtetem, so liann man hievans licinen Sihluss auf das relative Alter der beiden ziehen, sondern muss zu anderen Kennzeichen Zuflucht nehmen.

In der That kann eine von unten heraufkommende geschmolzene Masse in sedimentäres Gestein eindringen, olne die Oberfläche zu erreichen, oder es kann sich dieselbe einen Weg zwischen zwei Schichten hindurch bahnen, damn erkalten und erstarren, ohne dass eine Störung der Schichtenlagerung stattfindet. So z. B. kann sich die vulkanische. Gesteinsmasse o (Fig. 186) über der Schicht $b$ ebensowohl vor als nach der Ablagerung des Sedimentes $c$ ausgebreitet haben. Dass sie jünger als $b$ sein muss, ist sicher; ob sie aber älter oder jünger als $c$, kann nur beurtheilt werden, wenn sich

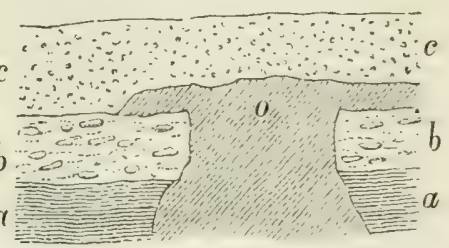

Fiig. 196 . nachweisen lässt, dass die Schicht $r$ durch das vulkanische Gestein Störungen (Hebungen etc. $F i ! .15 \%$ ) erlitt, in welchem Falle $c$ älter ist als $o$. Wenn die Schicht $c$ über $o$ eine regelmässige, vollkommen horizontale Oberfläche zeigt, so ist es allerdings wahrscheinlich, dass sie erst nach dem Austreten der Masse o abgesetzt wurde (Fig. 188).

Es gibt eine zweite Art von Indizien, welche die vorərwähnten stratigraphischen in ihrer Bedeutung verstärken der abschwächen können. Dieses Kriterium besteht in ler petrographischen Verän-

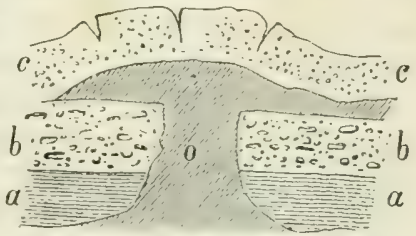

Fig. 187.

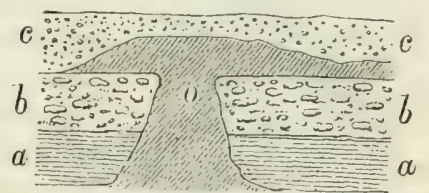

Fig. 188. lerung oder Nichtveränderung des Sedimentgesteins an den jtellen seiner Berührung mit der vulkanischen Masse. Wenn lie Schicht $c$ an den Kontaktstellen gegen o petrographisch nodifizirt erscheint, so ist es ziemlich gewiss, dass sie schon or dem Empordringen des vulkanischen Gesteins existirte. 
Zeigt sie sich aber an den Berührungsstellen unverändert, so muss angenommen werden, dass die Eruptivmasse $o$ schon da und schon abgekühlt war, bevor das Sediment darüber sich ablagerte.

Lässt sich das vulkanische Gestein auf weite Erstreckung verfolgen, so können vielleicht alle Zweifel gehoben werden. Es habe dasselbe z. B., nachdem es bei $A$ (Fig. 189) zwi-

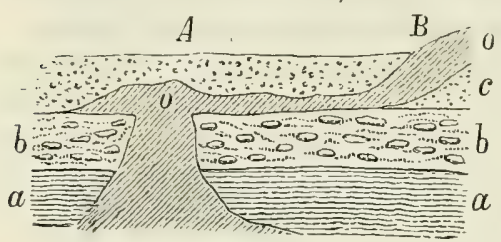

Fig. 189. schen die Schichten 6 und $c$ eingedrungen, bei $B$ die Schicht $c$ durchbrochen und sich über die Aussenfläche derselben hin ergossen, so ist dies ein augenscheinlicher $\mathrm{Be}-$ weis dafür, dass die Eruptivmasse $o$ nicht nur jünger als $b$, sondern auch jünger als $c$ ist.

Sind geschichtete und vulkanische Gesteine nicht überoinander, sondern blos an-, respelitive nebeneinander gelagert (in Juxtaposition), so besteht das beste Kriterium für die Ermittlung des relativen Alters in der Veränderung oder Nichtveränderung der Sedimente an den Stellen ihres Kontaktes mit dem Eruptivgestein.

Eine vulkanische Felsmasse o (Fi $\%$. 190) sei von verschie-

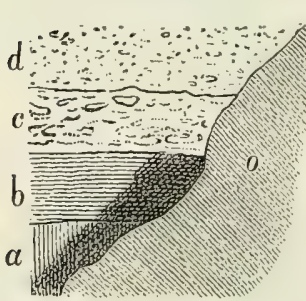
denen Sedimentschichten $a, b, c$ und $d$ flankirt. Wenn nicht diese Schichten, wenigstens ein Theil derselben, z. B. $a$ und $b$, an ihren Enden gegen $o$ hin Lagerungsstörungen (Hebungen) aufweisen, so haben wir keine stratigraphischen Anhaltspunkte zu Beurtheilung des Altersverhältnisses zwischen sedimentärem und eruptivem Gestein.

Fig. 190.

Das letztere konnte in geschmolzenem Zustande durch eine vorhandene Spalte aufsteigen, ohne die Schichten $a, b, c$ und $d$ in ihrer Laze zu stören; sie konnte aber auch schon vorhanden sein, ehe diese Sedimente abgesetzt wurden. Ueber den wirklichen Sachverhalt werden wir aber nicht länger im Zweifel sein, wenn wir beobachten, dass die Schichten $a$ und $b$ an den Kontaktstellen petro- 
graphisch rerändert sind, während $\Rightarrow$ und d bei ihrer Berührung mit o keine solche Gesteinsmetamorphose wahrnehmen lassen. In diesem Falle muss das eruptive Gestein o jünger sein als die Schichten $a$ und $b$, aber älter als $c$ und $d$, trotzdem es scheinbar auch diese durchbrochen hat.

Dieses Kennzeichen dient uns auch zur Bestimmung des Alters ron Gängen rulkanischen Gesteins in geschichteten Felsen. Diese Gänge oder Adern (Dykes) rühren davon her, dass geschmolzene Massen in Spalten und Risse anderer Felsen eindrangen und dieselben ausfüllten. Indem sich das rulkanische, gluthflüssige Material in solche Spalten und Risse ergiesst, nimmt es je nach der Gestalt derselben die verschiedensten Formen an. Die Fig. 191 zeigt solches Ausfïllungsgestein in Form eines Kamines, Fï. 19:2 anderes in astförmiger Verzweigung. Oft bildet es, wenn die Spalte in senkrechter Fläche sich weithin erstreckt, eine Art von

Wand; mitunter

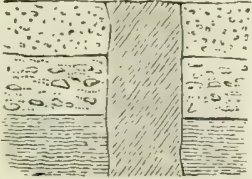

Fig. 191.

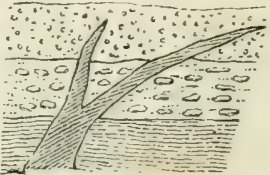

Fiy. 192. wird später das umgebende Gestein zersetzt und wegtransportirt und es bleibt allein die frühere Ausfüllungsmasse in Form einer Nauer übrig (Fii. 193). In andern Fällen findet umgekehrt die Zersetzung und Beseitigung des Ganggesteins rascher -tatt als diejenige der Felsen, von welchen es umgeben ist; es entstehen lann zunächst leereKamine undGänge 'Fig. 19.1), die sich später' zum Theil xieder mit verschiedenartigem Trümnergestein ausfüllen können(Fig.195).

Es ist wahrscheinlich, dass die jchichten, welche in dieser Weise on Eruptirgestein durchsetzt ercheinen, älter sind als letzteres, dass ie zur Zeit des Ausbruches der vulanischen Massen eben schon exitirten und diese in sie eindrangen.

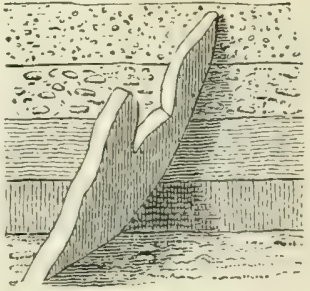

Fiv. 193.

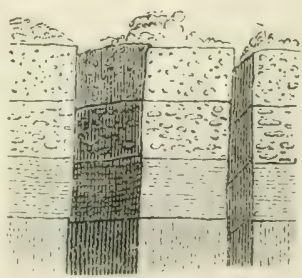

Fiig. 191. 


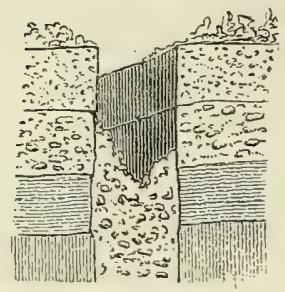

Fig: 195.

Indessen können seither Partien der Sedimentgesteine, namentlich der obern Schichten verschwunden und durch anderes Material ersetzt worden sein. Um nun seiner Sache sicher zu sein und namentlich $\mathrm{zu}$ wissen, bis $\mathrm{zu}$ welchem Niveau ein verschwundenes Ganggestein reichte, muss man genau nach den Spuren von Gesteinsumänderụngen, welche die Sedimente im Kontakt mit der vulkanischen Masse erlitten, forschen. Sedimentgesteine, die solche Modifikationen aufweisen, sind älter als das Ganggestein; die intakt gebliebenen Schichten aber sind wahrscheinlich jünger.

Wenn cin Sediment und ein vulkanisches Gestein cinandev gegenseitin durchsetzcn, so ist im Allgemeinen ein gleiches Alter derselben anzunehmen.

Diese Regel ist keine absolute und ausnahmslose; denn wenn sich z. B. eine Lavamasse ins Meer ergiesst, so wird sie sich durch den weichen Schlamm und Sand hindurch ein Bett oft bis zu ziemlich tief gelegenen Schichten eingraben.

Dic Gleirhscitiglicit (Gleichalteriglieit) sedimentärer und vulkanischer Gesteine ist mor sicher an crmitteh, wemn dieselben Merkmale haben, die beiden gemeinsam sind.

So können bei den Ausbrüchen eines Vulkanes Schlacken und rulkanische Asche ins Meer fallen und hier abwechseln mit Lagen von Sand, Thon etc., welche in den Intervallen zwischen den einzelnen Eruptionen abgesetzt wurden. Die Gleichzeitigkeit derselben ergibt sich nun aus den stratigraphischen Verhältnissen und wird evident, wenn die beiderlei Gesteine Reste der nämlichen Muscheln, Korallen, Kruster, Fische u. s. w. einschliessen, also in ihrem paläontologischen Charakter übereinstimmen.

Da die vulkanischen Gesteine in andere eingedrungene oder ausgeworfene Massen (Intrusions- oder Eruptionsprodukte) und ebensowohl von oben herab als von unten herauf gtkommen sein können, so ist ihr Niveau nicht entscheidend für die Beurtheilung ihres Alters.

Ebenso lässt sich das Alter nicht mit Sicherheit nach ihrem petrographischen Charakter bestimmen, welcher sich 
nicht so nach der Epoche des Ausbruchs oder des Empordringens (der Eruption oder Intrusion) richtet, dass hierïber feste Regreln aufgestellt werden könnten. Indessen ist zu bemerken, dass Laven ron gleicher mineralogischer Zusammensetzung, die man an verschiedenen P'unkten derselhen Gegend trifft, wahrscheinlich einer einzigen, früher zusammenhängenden Masse angehören und ron der nämlichen Eruption herrühren.

Was das Altersverhältniss der rulkanischen und plutonischen Gesteine zu einander anbetrifft, so simd rm तोu unser\%

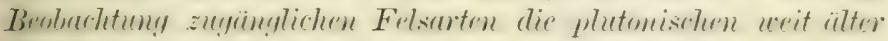
als die vulkanischen.

Wir haben ja auch bereits gesehen, dass plutonische Gesteine neueren Datums sich tief unter allen andern bilden mïisen; sie sind also unserer Wahrnehmung entzogen. Bei den rulkanischen Gesteinen findet, wie bei den Sedimenten, grerade das Gegentheil statt: die jüngsten erscheinen an der Erdoberfäche oder doch in deren Nähe.

Von den ungeschichteten oder Massengesteinen haben wir noch der metumoryhischen Fysarten zu gedenken. Es sind das Gesteine, welche ursprünglich wahrscheinlich Sedimente, d. h. aus denselben Materialien und auf gleiche Weise wie jene gebildet waren, später aber mehr oder weniger wesentliche Veränderungen durch Wärme, Thermen etc. erlitten, eine Umformung oder Metrmulusise (daher der Name metamorphische Gesteine), welche ihre chemische und mineralogische Zusammensetzung, Textur, Färlung, ihr ganzes Aussehen umgestaltete und sograr, bei weitgehendster Veränderung, jede Spur ron Schichtung und ron Versteinerungen beseitigte.

Wir haben schon ron Metamorphosen im Kleinen gesprochen, nümlich ron den petrographischen Veränderungen sedimentärer Gesteine an Stellen, wo sie mit plutonischen und rulkanischen Massen in Kontakt geriethen. Zum Verständniss der metamorphischen Massengesteine müssen wir uns nun vorstellen, dass solche und andere Lmänderungen in grösstem Massstabe stattfanden, sodass sie ganze Schichtengruppen betrafen.

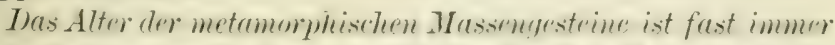

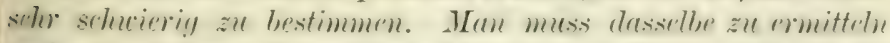

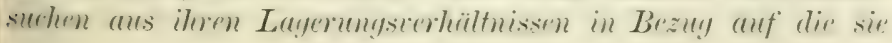


bedeckenden Sedimente oder das metamorphische Gestein bis zu einem Pinkte verfolgen, wo seine ursprïngliche Beschaffenheit noch besser zu erkennen, $d$. $h$. noch weniger veründert ist.

Wenn wir glaubten, die vorstehenden Erörterungen so einlässlich halten $\mathrm{zu}$ sollen, wie es geschehen ist, so war dies der Fall, weil es sich um Details handelt, die auf dem Terrain durch den Reisenden selbst beobachtet werden müssen. Diese Aufgabe kann nicht anderen Personen übertragen werden; der Reisende muss sich also in den Stand setzen, sie selbst $\mathrm{zu}$ lösen. Diese Chronologie der Gesteinsarten ist überdies die Grundlage für das so höchst interessante Studium der ältern geologischen Umgestaltungen, welche eine zu erforschende Gegend erlitten hat.

Synchronismus der Gesteine. Der Wunsch, das Alter von Gesteinen, die man in einer Gegend beobachtete, genauer anzugeben, führt dazu, diese Bildungen in Beziehung zu bringen und $\mathrm{zu}$ parallelisiren mit Gesteinsformationen von Ländern, die schon geologisch unter'sucht sind. So kommt es, dass man sagt, es seien selbst bei unsern Antipoden devonische, jurassische Schichten etc. aufgefunden worden. Damit soll gesagt werden, dass man sie für gleich alt hält wie die Schichten, deren Typus in der englischen Grafschaft Devon vorkommt, oder für ein Analogon derer, welche in charakteristischer Weise im Jura entwickelt sind ${ }^{1}$ ).

Es ist kaum nöthig, hier ausdrücklich zu bemerken, dass man bei diesem Bestreben, die Sache genauer bezeichnen zu wollen, leicht Gefahr läuft, ungenau zu werden. Wenn alle Schichten, die nacheinander an der Erdoberfläche abgesetzt wurden, sich um die ganze Erde erstrecken würden; wenn jede dieser Schichten in ihrer ganzen Ausdehnung dieselbe mineralogische Zusammensetzung aufwiese; wenn endlich während jeder geologischen Periode, in der sich solche Schichten bildeten, über die ganze Erde gleichmässig dieselbe Pflanzen- und Thierwelt verbreitet gewesen, diese Flora und Fauna aber verschieden wäre von derjenigen aller andern, frühern und spätern, Perioden: dann allerdings wäre es sehr leicht, die geognostischen Formationen einer Gegend mit denen einer andern zusammenzustellen; wie weit sie auch von einander entfernt wären, so müssen doch die

1) Vgl. D. Kaltbrunner, Aide-mémoire, pag. $416 \mathrm{sq}$. 
gleich alten Gesteine in ihren stratigraphischen, petographischen und paläontologischen Merkmalen übereinstimmen. Yon den drei obigen Voraussetzungen trifft aber nicht eine einzige zu. Nirgends findet sich die ganze Reihe aller Schichten vollständig und lückenlos vor. Gewisse Schichten, welche am einen Orte rorkommen, fehlen anderorts gänzlich. Es kann dies nicht anders sein, weil die Meere, in welchen die Ablagerung der wichtigsten Formationen vor sich ging, beständig deplacirt wurden und die verschiedenen Theile der Kontinente in wahrscheinlich sehr ungleichen Intervallen hald untergetaucht, bald wieder über den Wasserspiegel emporgehoben wurden. Die Sedimente, welche auf diese Art während derselben geologischen Periode in diesen verschiedenen Bassins abgesetzt wurden, konnten unter einander nicht gleich sein; denn das Material der einen stammte ron der Erosion alter Kontinente, das der andern ron der Auswaschung neuerer, erst vor Kurzem über Wasser gehobenen Formationen her. Man kann also nicht erwarten, dass Schichten ron gleichem Alter sich petrographisch, in ihrer mineralogischen Zusammensetzung, gleichen. Die Pflanzen- und Thierwelt einer Periode aber erscheint von derjenigen eines andern Zeitraums nur dann scharf geschieden, wenn man blos die Schichten einer einzigen Gegend betrachtet. Zwischen der Bildung einer dieser Schichten und der Bildung der folgenden Stufe rerfloss im Ganzen eine so lange Zeit, dass inzwischen die Flora und Fauma der Gegend einen andern Charakter annehmen komnte. Sobald man aber die für eine Gegend aufgestellte Eintheilung der Formationen verallgemeinern will, so gewahrt man bald, dass unmerkliche Lebergänge vorkommen und dass nur das örtliche Fehlen solcher rermittelnder Zwischenformen die Verschiedenheiten so scharf und deutlich erscheinen.liess, dass man glauben komnte, es haben sich die Verhältnisse von einer Formation zur andern plötzlich greändert. Ein einfaches Räsonnement sagt uns übrigens, dass die Pflanzenund Thierwelt zu jeder Zeit und ïberall variiren musste nach Massgabe der lokalen Verhältnisse und ihrer Medien ${ }^{1}$ ).

1) Derartige durch abweichende Lebensbedingungen herbeigeführte Ungleichbeiten werden (nach Amanz Gressly) als fucies-Unterschiede bezeichnet, als Verschiedenheiten der geologischen Provinzen aber, wenn sich in denselben die 
Nehmen wir auch an, dass irgend einmal vollständige und allgemeine Uniformität der Flora und Fauna bestanden hätte, so musste doch diese Pflanzen- und Thierwelt ihre Vorläufer und ihre Nachzügler haben. Denn ob man von der Hypothese einer langsamen stufenweisen Umformung der Arten ausgehe, nach welcher alle lebenden Wesen von einigen wenigen Typen oder sogar von einer einzigen Grundform abstammen, womit das organische Leben auf der Erde begonnen hätte, oder ob man zur Annahme successiver Schöpfungen und Schöpfungsakte hinneige, wonach jede Art als besondere Form eigens erschaffen worden wäre: immer muss man doch ein oder mehrere Zentren annehmen, an welchen eine bestimmte Art zuerst auftrat und von wo aus sie sich nach andern Gegenden hin ausbreitete. Und wie eine Species nicht an allen Orten ihres nachmaligen Verbreitungsgebietes gleichzeitig auftrat, so sind auch die ausgestorbenen Arten nicht an allen Punkten, wo sie früher vorkamen, zugleich verschwunden. Verschiedene Ursachen konnten bewirken, dass sie von einer Lokalität nach einer günstigeren übersiedelten und nun an letzterer noch lange existirten, nachdem sie an ersterer gänzlich verschwunden waren. Ihr Vorkommen und ihr Fehlen entsprechen also nicht überall dem nämlichen geologischen Horizont.

Nach dem Gesagten wird man leicht begreifen, dass wenn auf Grund ähnlicher Charaktere ein Synchronismus oder Parallelismus zwischen den geologischen Formationen der zu erforschenden Gegend und denjenigen einer geognostisch bereits gut bekannten festgestellt werden soll, dies nux mit grosser Umsicht geschehen kann und darf, wenn man nicht riskiren will, ganz zufällige und werthlose $\mathrm{Zu}$ sammenstellungen zu liefern.

Die Benennung und Charakteristik der geognostischen Stufen, Schichten etc. haben meist nur Gültigkeit für das Land, in welchem sie aufgestellt und in Gebrauch gekommen sind. Wenn man sich in engen Grenzen bewegt, d. h.

Differenzen der geographischen Lage, beziehungsweise vorweltlicher Klimate, aus sprechen. Vgl. v. Hauer, Geologie, S. 159. - Eine systematische Unterscheidung und Terminologie dieser chorologiscben Verhältnisse nach den Bildungsmedien, den Bildungsräumen und den Facies-Unterschieden der versteinerungsführenden Sedimente hat in neuerer Zeit Mojsisovics aufgestellt. Vgl. Hann, Hochstetter und Pokorny, Allgemeine Erdkunde, 3. Aufl., S. 399. 
wenn man eine noch weniger bekannte Partie solcher Länder oder an sie angrenzender Gebiete studirt, so darf man annehmen, dass die Aehnlichkeit in rerschiedenen Merkmalen ein genügender Beweis für die Gleichzeitigkeit der Formationen sei. Demn es ist wahrscheinlich, dass die Sedimente, welche in einem und demselben Bassin oder in zwar getremnten, aber einander benachbarten Becken abgelacert wurden, wemn nicht ganz, so doch annähernd gleich beschaffen seien. In solchen Fällen macr man sich um so eher durch diese Aehnlichkeiten oder Analogien leiten lassen, als man die so erlangten Resultate verifiziren kann durch die stratigraphischen Charaktere, die hier, wo man die wichtigsten Schichten ron einem Gebiet bis zum andern rerfolgen kamn, ron entscheidendster Bedeutung sind. Je weiter man sich aber von einer schon durchforschten Gegend entfernt, desto mehr schwindet der Werth jener Analogien. Woll herrscht unter den Formationen derselben Periode eine gewisse rage Aehnlichkeit der Zusammensetzung, die ein sehr geübtes Auge herausfinden mag, so dass die lithologrischen Nerkmale in ihrer Gesammtheit, in ihren grossen Zügen, für den bewanderten Fachmann ein Mittel zur Altershestimmung werden können; aher diese Anhaltspunlite in ilner Allgemeinheit haben doch nur soweit Werth, als sie nicht in Widerspruch treten mit Ergebnissen, die aus andern Falitoren abgeleitet wurden, als welche die Aufeinanderfolge der Schichten und der Reste ron Lehewesen, die sie enthalten, zu nennen sind, welche Reihenfolge überall dieselbe sein muss und nirgends umgekehrt sein kann. So z. B. wird man nie Schichten, welche Aehnlichkeit mit gewissen Stufen der Juraformation haben, als jurassisch ansehen, wenn sie in ursprünglicher Lagerung auf solchen Schichten ruhen, welche charakteristische Eigenschaften zeigen, die unzweifelhaft nur der Kreideformation zukommen; ebenso wenig wird man Gesteine, welche embryonäre Formen organischer Wesen einschliessen, für neuere Bildungen oder Schichten mit Resten höherer Thierformen (Knochen ron Säugrethieren u. dgl.) als ältere Formationen ansehen ${ }^{1}$ ).

Handelt es sich um eine Gegend in Europa, so mag man sich zunächst auf die Latgerungsverhältnisse - die

1) Vgl. D. Kaltbrunner, Aide-memoire, pag. 116 sq. 
Stratigraphie - stützen, sodann auf die petrographischen und paläontologischen Kennzeichen, wobei die von Herrn Professor Renevier veröffentlichte ausgezeichnete Tafel gute Dienste leisten wird ${ }^{1}$ ).

In Gebieten, welche an europäische Länder angrenzen oder in deren Nähe liegen, sind, soweit immer möglich, etappenweise die Modifikationen zu studiren, welche eine gegebene Schicht erleidet auf ihrem Verlaufe bis zu einem Punkte, der schon den bereits gut bestimmten Formationen des für die Geologie klassischen Europa angehört. Ist ein trennender Meeresarm da, so muss untersucht werden, ob die geologische Stufe, die man verfolgt, an beiden Gestaden mit übereinstimmendem petrographischem und paläontologischem Charakter vorkommt. Bei solchem sozusagen schrittweisem Vorgehen werden die Unterschiede in der mineralogischen Zusammensetzung und andere successive hervortreten; man wird die Uebergänge erkennen und zu verfolgen im Stande sein und so dazu gelangen, den Synchronismus oder Parallelismus zweier Formationen festzustellen, wenn sie auch durch weite Räume von einander getrennt sind und grosse Differenzen zwischen denselben sich geltend machen.

Wenn aber ein so streng exaktes Verfahren sich nicht anwenden lässt, wenn insbesondere die zu bereisende Gegend von Europa geschieden ist durch Meere oder ausgedehnte Länder, die geologisch noch nicht erforscht wurden, so muss man in seinem Urtheil sehr vorsichtig sein. Am besten ist es alsdann wohl, man unterscheide in der fraglichen Gegend zunächst nur eine Anzahl grosser, vielumfassender Formationen, von denen jede Gesteinsgruppen umschliesst, die gewisse charakteristische Eigenschaften gemeinsam haben. Nachher würde man diese Formationen oder Schichtensysteme nach Massgabe ihrer Lagerungsverhältnisse, ihres Gesteinscharakters und ihrer eigenthümlichen Petrefakten in Hauptund Unterabtheilungen (Glieder, Etagen oder Stockwerke, Stufen und "Zonen") zerlegen. Man erhält so eine vollständige mehr oder minder detaillirte Scala der Gesteinsmassen in der bereisten Gegend. Wenn man nun für die

1) Tableau desterrains etc. Lausanne 1874. Man vergleiche auch die Charakteristik der geologischen Formationen in D. Kaltbrunner, Aide-memoire, p. $416 \mathrm{sq.}$ 
einzelnen Stufen dieser Scala durchaus diejenigen Benemungen anwenden will, welche bei der geognostischen Klassifikation in Europa gebräuchlich sind, so hat man nach zuverlässigen Anhaltspunkten für eine solche Parallelisation zu suchen; diese wird man kaum in etwas Anderem erwarten dürfen als in einer gewissen Uebereinstimmung der Petrefakten. Das ist selbstverständlich nicht so zu verstehen, als ob es z. B. genügen würde, in einem tausend Meilen von Europa entfernten Terrain zwei oder drei entschiedene Kreidepetrefakten zu finden, um nun, gestiitzt hierauf, zu erklären, dlass man es hier mit der Kreideformation zu thun habe. Um ein solches neuerforschtes Terrain einer bestimmten Formation zuzutheilen, müssen in demselben die charakteristischen Fossilien der letztern vorherrschen und überdies mit solchen Petrefakten zusammen vorkommen, mit denen sie in jener Formation vergesellschaftet zu sein pflegen. Je zahlreicher und manigfacher die Petrefakten der Stufe, um die es sich handelt, sind, desto zuverlässiger wird die Bestimmung dieses ersten geologischen Horizontes. Immerhin ist damit das Ziel noch nicht erreicht. Da, wie oben bemerkt wurde, die Reihe der geologischen Formationen nirgends vollständig zu treffen ist, so sind wir nicht sicher, ob nicht ummittelbar unter der Schicht, deren Stelle im System der Formationen wir soeben bestimmten, eine Lücke sei oder im Gegentheil eine neue, in Europa noch unbekanute Stufe erscheine. Man muss also einen zweiten. und dritten Horizont bestimmen. Diese erste Arbeit erleichtert dann allerdings die weitere Aufgabe wesentlich. Denn sobald konstatirt ist, dass eine gewisse Anzahl untersuchter Schichten unzweifelhaft solchen Formationen angehören, die bereits chronologisch klassifizirt und allgemein bekaunt sind, so weiss man damit auch, dass alles Gestein über einem solchen Horizonte jüngeren und alles tiefer liegende älteren Formationen angehört. Dadurch aber ist die Zahl der Formationen, Etagen, Gruppen etc., womit man diese Partien noch zu vergleichen hat, in gewisse Grenzen eingeschränkt. Wenn man nun innerhalb der Grenzen zwischen zwei geologischen Horizonten weitere Analogien findet, so stellt man hienach Stufen fest, welche solchen in Europa aquivalent sind und wird dann bald bemerken, ob die 
Schichtenscala gegenüber der vollständigen Formationsreihe Lücken aufweist, und welche, oder ob umgekehrt zwischen zwei Stufen, die in Europa unmittelbar aufeinander folgen, in der erfor'schten Gegend eine neue vorhanden sei, welche die allgemeine Scala vervollständigen würde.

Man darf nicht erwarten, überali scharf unterschiedene Stufen zu finden, welche solchen der europäischen Geologie genau entsprechen. Die Gegend, welche man studirt, kann in einer gegebenen geologischen Periode länger unter Wasser geblieben sein als der Theil Europas, welchen man zur Vergleichung wählte; die obere Grenze der fraglichen Etage in jener Gegend bezeichnet dann einen höheren geologischen Horizont als die obere Grenze der entsprechenden europäischen Stufe. Die Zeiträume, während welcher zwei verschiedene, auf der Erdoberfläche weit auseinander liegende Partien jetzigen Festlandes vom Meere bedeckt waren, $d . h$. die Intervalle zwischen den Zeitpunkten, da jene Länder durch Senkung unter Wasser kamen und denjenigen, da sie wieder über den Meeresspiegel emporgehoben wurden - diese Zeiträume sind so sehr verschieden, dass es vielleicht nicht zwei räumlich entlegene Stellen gibt, wo solche korrespondirende Ablagerungen gleichzeitig begonnen und gleichzeitig beendigt worden wären. Wiewohl man sie "gleichzeitig" nennt, so sind sie es streng genommen nicht in ihrer ganzen vertikalen Ausdehnung, und es kann mitunter gut sein, wenn man soweit möglich von einer solchen neu erforschten Schichtengruppe angibt, welcher Theil derselben der als analog bezeichneten und zur Vergleichung benutzten Stufe genauer und insbesondere entspricht, welche andern Theile hingegen die Grenzen der letzteren zu überschreiten scheinen. Dieser Ueberschuss zu Gunsten der Ablagerung, die wir erforschen, der geologische Excess ihrer Mächtigkeit gegenüber der typischen Stufe, wird, wenn er sich auf die Basis derselben bezieht, Anhaltspunkte liefern zur Kenntniss der Thier- und Pflanzenwelt desjenigen Zeitraums, welcher dem Absatze des typischen Sedimentes unmittelbar vorherging; wenn aber dieser Excess die obere Grenze der Abtheilung betrifft, so wird man daraus ersehen, welche Flora und Fauna unmittelbar auf die Bildung der typischen Stufe folgte. Eine solche Unterscheidung wird oft sehr schwierig sein; 
sie ist aber von grosser Bedeutung namentlich in Fällen, wo zwei Stufen, die anderwärts und nach der üblichen Klassifikation als geren einander gut begrenzt gelten, in der bereisten Gegend mit einander eng verbunden erscheinen, sodass hier eine zusammenhängende Ablagerung sich bildete in einer Zeit, innerhalb deren anderwärts eine Unterbrechung der Sedimentbildung stattfand. Wir hätten also hier ein Verbindungsglied von einer Stufe zur andern vor uns. Ich kann diese Arbeit mit nichts besser vergleichen als mit dem Lnternehmen einer Anzahl Gelehrter, die von einem seltenen Werke, von welchem in den rerschiedenen Bibliotheken nur unrollstandige, halb zerrissene Exemplare mit einer Menge fehlender Blätter existiren, ein vollständiges Exemplar herstellen wollen. Jeder Einzelne dieser vereint arbeitenden Männer hätte zu untersuchen, welche Kapitel des defekten Exemplares, das er in Händen hat, in dem zu kompletirenden Exemplare schon vorkommen, und er müsste sorgfältig Alles aufzeichnen, was im ersteren Exemplare mehr vorhanden wäre, jeden kleinsten "Excess" desselben. Indem der Eine den Anfang oder das Ende eines Kapitels auffände, der Andere einige Blätter, ein Dritter die Seiten, die zur Ausfüllung einer gewissen Lücke fehlten, würde schliesslich das Werk vollständig rekonstruirt und ein Jeder könnte es nun als Ganzes im Zusammenhang lesen. Das Buch nun, um dessen Rekonstruktion es sich in unserm Falle handelt, ist kein geringeres als das Werk, welches die Geschichte der Erde enthält; zu demsellıen einige noch fehlende Blätter aufzufinden, ist ein nicht zu unterschätzendes Verdienst.

Die Bestimmung des geologischen Alters der Schichten - die Feststellung, welcher Formation und welcher Formationsstufe eine bestimmte Ablagerung angehört - hat zudem nicht blos wissenschaftlichen, theoretischen Werth, sie ist vielmehr ron ganz eminent praktischer Bedeutung: auf ihr heruht die rationelle Aufsuchung ron fossilen Kohlen, Erzen, und nützbaren Mineralien überhaupt, die als Flötze den Sedimentschichten eingelagert sind ${ }^{1}$ ).

Aeltere geologische Aenderungen. Nit Hülfe unserer geognostischen Beobachtungen und von Raisonnements,

1) v. Hauer, a. a. O., S. 159. 
die sich darauf stützen, vermögen wir bis zu einem gewissen Grade zu erkennen, welche physische Beschaffenheit die erforschte Gegend in den verschiedenen geologischen Perioden hatte.

Besonders werthvoll ist in dieser Hinsicht das Studium der Sedimentbildungen und ihrer Petrefakten.

Wir müssen uns dabei stets vergegenwärtigen, dass eine jede der übereinander lagernden und verschieden geneigten Schichten, die wir jetzt vor Augen haben, seiner Zeit die oberste war und dass sie eine annähernd horizontale Lage hatte, die erst später geändert wurde. Wenn nun eine dieser Schichten Eigenschaften besitzt, welche darauf hinweisen, dass sie auf dem Boden eines Meeres entstanden sein muss, so ist anzunehmen, dass zu jener Zeit an dieser Stelle kein Festland existirte, sondern diese einem Ozean, Meeresarm oder Golf angehörte. Aus der Beschaffenheit der Sedimente und der Versteinerungen ersehen wir, ob deren Ablagerung fern von der Küste und in grossen Tiefen oder ob sie am Strande, an einer Flussmündung etc., erfolgte (pelagische und litorale Bildungen). Ablagerungen, die auf festem Lande oder in Seen entstanden sind (subaërische, fluviatile und lacustrine Bildungen) bieten wieder besondere Merkmale dar, an welchen sich erkennen lässt, welche Gegenden Festland, welche andern aber von Seen eingenommen waren. Die Versteinerungen geben uns eine Vorstellung von Flora und Fauna und bis $\mathrm{zu}$ gewissem Grade auch von dem Klima der Periode, um welche es sich handelt. Die Eigenthümlichkeiten der Schichtenlagerung endlich ermöglichen Schlüsse auf die Zeit und die Ursache der Hebungen und andrer Vorgänge, welche die Physiognomie des Landes bestimmten. Die Neeresabsatzbildungen sind durch ihre Fossilien charakterisirt, welche wesentlich aus solchen Arten bestehen, die im Meere selber leben. Da einzig die feinsten Theilchen der im Wasser suspendirten Stoffe weit ins Meer hinaus getragen werden, so bestehen die Tiefseebildungen aus feinkörnigem und dichtem Material, einer Art verhärteten Schlamms, vermischt mit Resten von Schalthieren, Korallen u. s. w. Zuweilen sind sie chemische Niederschläge oder ganz aus Resten von Organismen gebildet. Sie bestehen gewöhnlich aus regelmässigen, mächtigen Schichten, 
deren petrographische Beschaffenheit auf weite Strecken die gleiche ist. Ausnahmsweise können sich darin grosse Felsfragmente finden, welche ron schwimmendem Eise hergetragen wurden und beim Schmelzen desselben in den Schlamm der Tiefe versanken.

Die am Strande gebildeten Ablagerungen sind ron um so gröberem Korn, je näher der Küste sie entstanden. Da die mittleren Wassertiefen dem organischen Leben sehr günstig sind, sodass in denselhen sehr viele Arten lehen, so erweisen sich diese Sedimente reich an Petrefakten, und es sind die letztern meist gut erhalten. Nicht selten berrecrnet man hier einem Wechsel oder einer Mischung ron Bildungen organischen Crsprungs, welche für tiefe Meere charakteristisch, und ron mechanisch entstandenen Ablagerungen, welche den Küstengegenden eigen sind.

Die Existenz vormaliger Korallenriffe verräth sich in Auftreten eines undeutlich geschichteten Kallgesteins, welches wesentlich aus an Ort und Stelle gewachsenen Korallen, sowie aus gerollten Bruchstücken solcher besteht (Korallenfacies).

Iie alten Ufer sind kenntlich durch Ablagerungen aus grohem Material: aus grossen Gerölsteinen, Blöcken, die rom Fels der Steilküsten herunterstürzten u. s. w. Diese Trümmergesteine, welche am Fuss der Strandfelsen und Böschungen Schuttwälle bildeten und dann durch Wellenschlag und Strömungen vielfach deplacirt und umgelagert wurden, erscheinen in unregelmässigen Schichten ron wechselnder Dicke, deren Material die starke Abnutzung durch Reibung heim Transport in bewegtem Wasser deutlich erkennen lässt. Versteinerungren sind hier selten und bestehen nur aus den widerstaurlsfühigsten Theilen ron Organismen, deren Erhaltung durch die Reibung an anderem Material in dem stark bewegten Wasser schwierig war (Strandfacies). Mitunter trifft man hier Leherreste von I'flanzen und Thieren des Festlandes, welche durch Flïsse und Strömungen hieher grelangten. Das Streichen dieser Ablagerungen giht die lichtung der Küste an; nach welcher strite das Meer lag, ergibt sich, wemn man in der Senkrechten zur Streichungslinie nachsieht, in welcher Richtung die Schichten allmäligg feineres Material aufweisen. 
Die alten Strandgegenden und morastigen Uferstriche, welche abwechselnd vom Wasser bedeckt und von demselben wieder verlassen wurden, machen sich kenntlich durch ihre sandige oder schlammige Beschaffenheit. Regelmässige Wellenlinien (ripplemarks) auf den obern Schichtenflächen, welche der Wogenschlag erzeugte, geben kund, dass hier einst seichtes Wasser war. Massenhaftes Vorkommen von Blättern, welche unzweifelhaft vom Winde zusammengehäuft wurden, ferner von Thierresten aus den Klassen der Insekten und Amphibien verrathen, dass Festland in unmittelbarer Nähe lag. Fussspuren von Landthieren, Abdrücke von Regentropfen, nach allen Richtungen sich erstreckende leichte Spalten und Risse der Oberfläche zeigen an, dass ein naher, weicher Boden öfters Perioden raschen Austrocknens durchzumachen hatte.

Wo früher ein Strom sich ins Meer ergoss, finden wir Reste von Thieren und Pflanzen des Festlandes, welche der Fluss mitführte, gemischt mit solchen mariner Arten, welche ron den Wellen hergetragen wurden. Zudem treten die Ablagerungen hier nicht in regelmässig geschichteten und wohl abgegrenzten Bänken auf, sondern es sind dieselben auf unregelmässige Weise in einander verkeilt und sie tragen die Spuren oftmaliger Umlagerung ihres Materials an sich, welches bei dem Kampfe zwischen bewegtem Meerund einströmendem Flusswasser nicht in normaler Weise abgesetzt werden konnte.

Sedimente ehemaliger Seebecken haben in ihrer Bildungsweise viel Analoges mit marinen Ablagerungen, nur dass hier, bei den Binnenseen, die Verhältnisse nicht so grossartige sind. Auch hier wird das Gesteinsmaterial feinkörniger in der Richtung vom Ufer hinweg nach dem Innern des Wasserbeckens; aber die einzelnen Bänke sind von geringerer Mächtigkeit; die Schichtung selbst ist sehr deutlich, da die Schichten wesentlich zur Ablagerung gelangten in der Zeit des Anschwellens der Flüsse, zwischen welchen Perioden hinein je eine solche relativer Ruhe, d. h. einer starken Verminderung, ja fast völligen Unterbrechung der Sedimentbildung fiel. Im Uebrigen ist die $\mathrm{Be}$ schaffenheit dieser lacustren Ablagerungen weniger regelmässig als die mariner Absätze: sie sind minder homogen, öfters mit fremdartigen Materialien untermischt. Die sumpfigen 
Iferstriche der Seen sind nicht wie die Flachliüsten der Meere dem Wechsel der Gezeiten ausgresetzt: aber sie zeigen analoge Erscheinungen, die hier ron den sonstigen Schwankungen des Wasserstandes herrühren. Als Petrefaliten treten Süsswasserorganismen oder marine Arten auf, je nach der Beschaffenheit des Wassers in dem Seebecken; in beiden Fällen finden sich auch Reste solcher Thiere und Pflanzen, welche? anderwärts im Wasser oder auf dem Lande lebten und ron Flüssen hertransportirt wurden. Die Fossilien der in Salzseen gebildeten $\mathrm{Ablagerungen} \mathrm{zeigen} \mathrm{öfters} \mathrm{gewisse} \mathrm{Verschiedenheiten}$ gregenüber den entsprechenden marinen Arten; namentlich simb sie im Allgemeinen kleiner, grewissermassen rerkümmert. Wenn solche charakteristische Petrefakten mangeln, so ist die Existenz, früherer Salzseen zu erkennen an den Ablagerungen von Kochsalz, Gyps und Dolomit, welche sie hinterlassen haben.

Die terrestrischen, $d . h$. auf festem Lande entstandenen Bildungen kommen den marinen und lacustren Ablagerungen an L'mfang und Mächtiglieit selten gleich. Sie sind im Allgemeinen Produkte der Zersetzung und Erosion von Gesteinen durch atmosphärische dgentien; mitunter aber sind sie auch erzeugt durch rulkanische Eruptionen, durch Absterben ron Pflanzen, welche den Boden bedeckten, durch Anhüufung von thierischen Exhrementen u. s. f. Demgemäss sind diese Bildungen mehr oder minder grobe Konglomerate oder Breccien aus scharfkantigen Gesteinstrümmern, Allurionen mit Fossilien, die nur terrestrischen und fluviatilen Arten - mit Ausschluss mariner und lacustrer Organismen - angehören; vom Winde angehäufte Sandmassen; verhärtete Gletscherablagerungen, sodamn vulkanische Tuffe, Lavafelder, Decken von Ackerkrume oder Humus, zuweilen auch dicke Lagen von Torf, Braun- und Steinkohle, in welchen man Baumstämme, die noch aufrecht stehen, sowie zahlreiche Abdrücke von Land- und Sumpfpflanzen trifft, die mit Reptilien u. dgl. untermischt sind; endlich gehören hieher die Guanolager. Es können indessen an Stellen, wo zu einer gewissen Zeit unzweifelhaft Festland war, terrestrische (subaërische) Bildungen fehlen; denn wenn die Oberfläche eines Kontinentes während einer langen Periode allen zerstörenden Einflüssen ausgesetzt war und dann plötzlich überfluthet wurde, so musste dies ihre Beschaffenheit stark alteriren. Die oberflächlichen Schichten 
können durch die denudirende Thätigkeit des Regens und anderer Agentien rerschwunden und es kann so zwischen zwei offenbar marinen Ablagerungen nichts geblieben sein als etwa hie und da eine Masse festen Materials, die zu kompakt war, um aufgelöst oder suspendirt und zu schwer, um sonst fortgeschafft zu werden. Eine solche Zwischenbildung kann der einzige Ueberrest eines verschwundenen Landes sein. Einen Beweis für einstiges Vorhandensein von Festland kann man zwar auch erblicken in dem gänzlichen Fehlen jeder Spur mariner oder lacustrer Bildungen auf grossen Strecken. I)ieses negative Kriterium ist besonders dann von Werth, wenn man zu beiden Seiten des fraglichen Areals marine oder lacustre Ablagerungen findet, die, obwohl gleichen Alters, zwei ganz verschiedene Faunen einschliessen; in diesem Falle muss man annelimen, dass die Wasserbecken, in welche jene Absätze sich bildeten, durch Land geschieden waren.

Auf Grund dieser Unterschiede in gleichzeitig, aber unter ungleichen Verhältnissen entstandenen Gesteine - Unterschiede, die man als Facies bezeichnet hat ${ }^{1}$ ) — können wir ermitteln, welches die Konfiguration und physische Beschaffenheit einer Gegend in verschiedenen geologischen Perioden war. Selbstverständlich handelt es sich dabei nur um ein in grossen Zügen zu entwerfendes Bild. Die Grenzen der alten Meere, im Laufe der Zeiten verwischt, können nur annähernd bestimmt werden, da die Ufer durch Erosion und Denudation vielfach modifizirt und zerstört worden sind.

Die organischen Einschlüsse der Gesteine geben uns auch Fingerzeige zur Beurtheilung des Klimas, welches in der Periode ihrer Entstehung herrschte. Gewisse Arten weisen auf ein nordisches Klima hin, andere auf ein südliches. Dabei ist freilich nicht zu übersehen, dass in einer und derselben Gegend zufolge der Höhenverschiedenheiten mehrere Klimate - klimatisch verschiedene Regionen - rertreten sein können, welche in vertikaler Richtung auf einander folgen, und dass diese Regionen in Flora und Fauna differiren. Die Pflanzen- und Thierwelt des Landes ändert. sich nach der absoluten Höhe, diejenige des Meeres nach der Tiefe. Ihr Charakter ist um so mehr ein nordischer,

1) Vgl. S. $35 \overline{7}$, Anmerkung. 
nicht nur je kälter das Klima der Gegend im Ganzen war, sonclern aus je grö̈sseren Bergeshöhen und Meerestiefen sie stammen. In den Meeren und Ozeanen konnten über- oder nebeneinander hinfliessende Strömungen bestehen, welche an stellen ron geringer Tiefendifferenz ganz verschiedene untermeerische Temperaturen rerursachen konnten. Wenn es sich endlich um sehr alte Schichten handelt, deren sämmtliche Petrefakten solchen drten angehören, die jetzt ausgestorben sind, so können wir nur nach Analogie schliessen, welche Terhältnisse für ihr Leben am günstigsten waren, für welches Ḱlima also ihr Vorkommen spricht.

Die Grösse des Zeitraums, welcher zur Bildung einer Schicht erforderlich war, ist keineswegs nach deren Mächtigkeit zu bestimmen; jenachdem die Zufuhr von Material für die Sedimentbildung stärker oder schwächer war, bedurfte es mehr oder weniger Zeit für die Erzeugung einer $\mathrm{Ab}$ lagerung ron bestimmter Mächtigkeit. Anhaltspunkte zur Würdigung dieser Frage liefert auch der Zustand, in welchem sich die organischen Einschlïsse der Schicht befinden. Sind zarte Schalthiere gut erhalten und finden sich noch Parasiten, welche auf schwimmendem Holz, auf oder in Thiergehäusen u. s. w. lebten und sich entwickelten, so muss die Absatzbildung sehr langsam erfolgt sein. In diesem Falle ist grosse Mächtigkeit einer Formation gleichbedeutend mit langer Bilcungszeit derselben. Anders, wenn das sediment starke Conchylienschalen zertrümmert enthält und Thiere einschliesst, welche in demselben lebendig begraben wurden; denn dies verräth, dass der Transport des zugeführten Materials in ungestümer Weise vor sich ging und der Absatz desselben rasch, plötzlich erfolgte.

Die Veränderungen sind oft nicht mit Schichtenstörungen verbunden. Die Schichten können eine Hebung oder Senkung erlitten und dabei doch ihre horizontale Lage beibehalten haben. Wenn aber zwei unmittelbar auf einander folgende Schichten erhebliche Verschiedenheiten erkennen lassen, so kann hieraus grefolgert werden, dass die eine unter anderen Verhältnissen als die zweite abgelagert wurde, dass also inzwischen Veränderungen eingetreten seien. Wenn z. B. auf eine terrestrische Bildung marine Sedimente folgen, so muss zwischen der Ablagerung beider eine Senkung des 
Gebiets eingetreten sein; wenn umgekehrt Meeresabsätze von terrestrischen (beziehungsweise lacustrinen) Bildungen überlagert werden, so zeigt dies an, dass in der Zwischenzeit der Meeresboden gehoben und Land, resp. ein Binnenwasserbecken, gebildet wurde. Die übereinstimmende (konkordante) Lagerung der Schichten sagt uns noch nicht, dass die neuere Formation unmittelbar auf die ältere, mit ihr gleichförmig lagernde, gefolgt sei. Die.Zwischenzeit kann Jahrhunderte umfassen; die Ablagerungen aber, welche in dieser Periode entstanden, können durch Strömungen und meteorisches Wasser beseitigt worden sein.

Wenn die Horizontalität von Schichten nicht ausschliesst, dass mit denselben seit ihrer Ablagerung Veränderungen vor sich gegangen seien, so beweist dagegen eine stattgefundene Störung der ursprünglich horizontalen Schichtenlage unbedingt, dass eine Bewegung der Erdrinde, also eine Veränderung erfolgt ist. Die Ursache eines solchen Vorgangs ist nicht immer leicht herauszufinden; denn die schiefe Stellung der Schichten kann ebensowohl von einer Hebung durch eine nach oben wirkende Kraft als durch eine Senkung an einer andern Stelle verursacht worden sein, und ebenso kann ihre Faltung sowohl herrühren von einem seitlichen Druck auf noch weiche Schichten als auch von der Hebung einer Masse, die nicht bis zur Oberfläche zu dringen vermochte, oder endlich davon, dass eine zu Tage liegende Partie einer Schicht gepresst und gefaltet wurde durch den Druck von Massen, welche die Schicht in ihrer Fortsetzung nach rechts oder links überlagern. Uebrigens liegt uns weniger daran, den Grund der Veränderung, als vielmehr den Zeitpunkt kennen zu lernen, in welchem dieselbe stattfand; diese Zeitbestimmung aber wird ermöglicht durch die Eigenthümlichkeiten, welche die Schichtung darbietet.

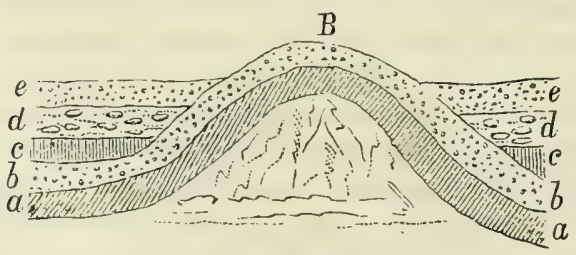

Fig. 196.
Eine Hebung oder Faltung habe in $B$ (Fig. 196) einen Theil der Schicht $b$ in die Höhe getrieben. Wir sehen sofort, dass diese Bewegung nach der 
Bildung der Schichten a und $b$, aber vor dem Absatz von $c, d$ und $e$ vor sich gegangen sein muss, da ja einzig die Lagerung der beiden ersten dadurch affizirt wurde, während die andern daran nicht theilnahmen und offenbar sich erst gebildet haben und modellirt worden sind auf und nach den Formen, welche durch jene Veränderung entstanden waren.

In gleicher Weise ist die Epoche zu bestimmen, in welcher eine Bergkette gehoben wurde. So existirte das Gebirge A (Fig. 19\%) noch nicht zur Zeit des Absatzes der Schichten

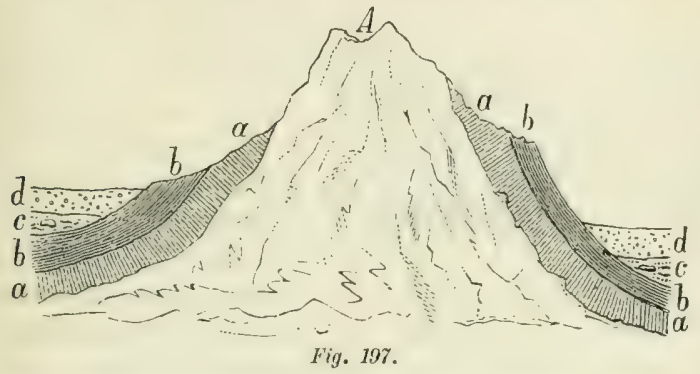

$a$ und $b$; denn als das Gebirge durch Hebung entstund, richtete es $a$ und $b$ mit auf, waren also diese Schichten schon gebildet. Andrerseits hat die Gebirgsbildung stattgefunden, bevor die Schichten $c$ und $d$ abgelagert waren; diese wären sonst von der Bewegung mit ergriffen worden.

Wenn der Aufrichtung eine Ueberschiebung oder Umkippung der Schichten folgte, so ist die Zeit eines jeden der beiden Vorgänge $\mathrm{zu}$ bestimmen. Das Profil Fig. 198 zeigt uns z. B., dass die Aufrichturig nach Ablagerung derSchicht $c$ und vol dem $\mathrm{Ab}$ -

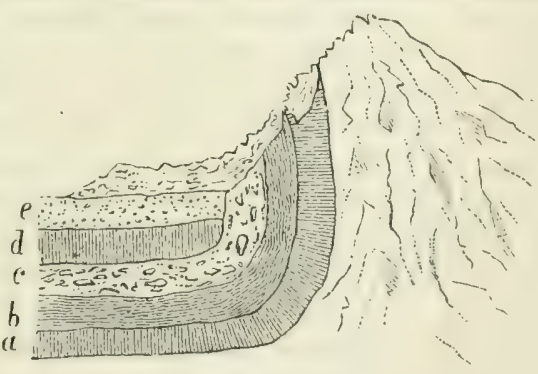

Fig. 198.

satze der Schicht d stattgefunden, dass aber die Umstürzung erst später stattfand, und zwar nachdem die Schicht $e$ bereits gebildet war. 
Im Allgemeinen ist jede Lngleichförmigkeit (Diskordanz) in der Lagerung ein Zeichen dafür, dass zwischen der Bildung der einen und der andern Schichtengruppe eine Aen-

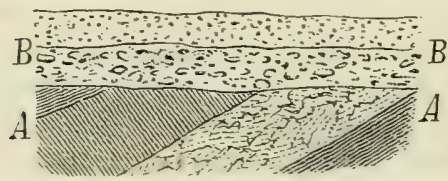

Fig. 199.

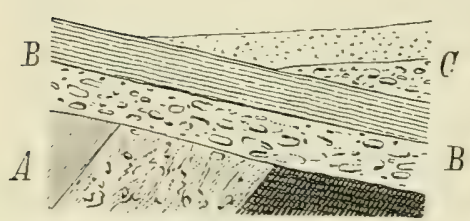

Fig. 200 . derung eintrat. Die beiden Schichtenreihen $A$ und $B$ (Fig. 199) sind discordant gelagert; nun ist es augenscheinlich, dass die untere Serie $A$ schon Störungen(Veränderungen der ursprünglichen Lage) erlitten hatte, ehe die obere Gruppe $B$ zur Ablagerung gelangte.

In dem Profil Fig. 200 $B$ hat auch die obere Schichtenreihe $B$ ihre Horizontalität eingebüsst und es besteht, mit Rücksicht auf eine dritte Schichtengruppe $C$, zwiefache Diskordanz. Daraus ist zu schliessen, dass eine partielle Hebung oder Senkung stattfand zu einer Zeit als die Gruppe $B$ schon, $C$ aber noch nicht gebildet war.

Der Zeitpunnt eines rulkanischen Ausbruchs lässt sich bestimmen nach der Stellung, welche die Laven und andere Eruptionsprodukte zu den Sedimentgesteinen einnehmen. Die Epoche des Ausbruchs muss jünger sein als die Zeit des Absatzes derjenigen Schicht, auf welcher das eruptive Material sich ausbreitete, aber älter als die Bildungszeit derjenigen Schicht, welche selber jene Materialien überlagert. Wir brauchen hier nur an Das zu erinnern, was wir oben über das relative Alter rulkanischer Gesteine sagten. Ein weiteres Kriterium liefern mitunter Organismen, welche ron vulkanischen Auswürfen bedeckt wurden. Es kommt nämlich vor, dass die Schlacken und Aschen, welche in der Nachbarschaft eines feuerspeienden Berges als vulkanischer Regen niederfallen, die Pflanzen, womit der Boden bewachsen war, und Thiere, welche ron dem Ereigniss überrascht wurden, begraben; wenn der Ausbruch am Ufer eines Meeres oder Sees stattfindet, so bedecken die Auswurfsstoffe den Grund des Wasserbeckens und schliessen Fische, Conchylien, Korallen u. s. w. in ihre Masse ein. 
Nach solchen Anhaltspunkten und Fingerzeigen können wir in grossen Zügen eine Geschichte der alten geologischen Veränderungen geben, welche eine Gegend erlitt, wie wir andrerseits eine Geschichte der neueren Vorkommnisse dieser Art herzustellen vermögen; da diese sich gegenseitig ergänzen, so gelangen wir so zur Kenntniss aller der verschiedenen Phasen, welche die in Rede stehende Gegend durchmachte, bevor sie ihre heutige Gestalt annahm.

\section{DER BODEN NACH SEINEN SCHÄTZEN UND ERZEUGNISSEN.}

Wir verstehen unter dem Boden die äussere, oberflächliche Partie der Erdrinde, auf welcher der Mensch sich bewegt, die ihm zugänglich ist und die er ausbeuten kann, sei es durch Gewinnung der Naturprodukte, welche in und auf demselben sich vorfinden, sei es durch Erzielung ron Erträgnissen der Pflanzenkultur und Viehzucht. Der Boden kann also unter zwiefachem Gesichtspunkt studirt werden, nämlich nicht nur, wie wir es bei unserer Beschäftigung mit der Konfiguration des Landes thaten, rein deskriptiv, topographisch, sondern auch rolliswirthschaftlich, d. h. mit Rücksicht auf die Hülfsquellen, die Schätze und Erzeugnisse, welche er bietet. In dieser Hinsicht ist zu unterscheiden zwischen dem industriellen und dem agrikolen Werth des Bodens, wonach wir denn auch das folgende Kapitel in zwei Abschnitte theilen.

\section{A. DER BODEN IN INDLSTRIELLER BEZIEHUNG.}

Der industrielle Werth eines Bodens, seine Bedeutung für ein Gewerbe, ist bedingt durch die Summe natürlicher Reichthümer, welche sich im Innern oder an der Oberfläche desselben vorfinden.

Unter diesen natürlichen Reichthümern oder Bodenschätzen und Bodenerzeugnissen versteht man die Baumaterialien wie Werk- und Bruchsteine, Pisé-Material, Lehmerde zu Platten, Back- und Ziegelsteinen, Dachsteine etc., gewöhnlicher und hydraulischer Kalk, Cement, Stoffe zur Mörtelbereitung wie Sand, Puzzolanerde und andere, Gyps, Asphalt und bituminöse 
Erdarten, Pfästerungs- und Beschotterungsmaterialien; Mineralien für Industriezweige wie die Rohstoffe für die Fabrikation von Porzellan, Fayence und gewöhnliche Töpferwaaren (Kaolin, Pfeifenerde, Thon u. s. w.); schmelzbare Stoffe zur Fabrikation von Glas und Krystall ; Walkererde, Okererde u. dgl.; Mühlund Schleifsteine; Lithographiesteine; Marmor, Alabaster und andere Stoffe für Skulpturen; Stoffe zu landwirthschaftlichen Bodenameliorationen: Mergel, Kalkphosphate, Guano u. s. w.; Rohstoffe für chemische Produkte; Brennmaterialien (Brenze) wie Torf, Braun- und Steinkohle, Anthracit, Erdpech (Bitumen), Erdöl, Naphta u.s.f.; Edelmetalle wie Gold, Silber und Platin; unedle Werkmetalle wie Eisen, Blei, Kupfer, Zinn u. s. f.; Edelsteine; Schwefel, Salz, Salpeter, Alaun u. s. w. In einer andern Kategorie hätten wir zuerst die Schätze des Waldes: Bau- und Werkholz, die harten Hölzer für feinere Tischlerarbeiten u. dgl., Farbhölzer, Brennholz u. s. w., endlich die Mineralwasser und selbst das Eis.

Es gehört nicht zur Aufgabe dieses Werkes, alle diese Bodenschätze und deren verschiedenartige Anwendung zu beschreiben. Wer sich hierüber näher unterrichten will, findet Aufschlüsse in Lehrbüchern der technischen Geologie wie: „Die technische Gcologie oder die Geologie in Anwendung auf Technik, Gewerbe und Landbau," von Dr. D. Brauns, Halle 1878; die Economic Geology von David Page, welche von Stanislas Meunier in seiner Géologie technologique frei in's Französische übersetzt wurde; ferner in The Explorers', Miners' and Metallurgists Companion und, was Waldprodukte anbetrifft, in dem Werke Les Bois indigènes et étrangers der Herren Dupont and Bouquet de la Grye.

Der gewöhnliche Reisende bedarf selten so umfassender und spezieller Kenntnisse.

In dicht bevölkerten Ländern, wo die Industrie schon stark entwickelt ist und jedes Naturprodukt unmittelbar nutzbringend gemacht werden kann, sind gewöhnlich schon Leute vorhanden, welche an solchen Nachforschungen und Untersuchungen direkt interessirt und dazu besser befähigt sind als der Reisende. Für den Lezteren wird es dann genügen, sich genauen Aufschluss geben zu lassen und sich von der Richtigkeit desselben durch eigene Beobachtung zu überzeugen, um sodamn ein hinlänglich vollständiges Verzeichniss 
der Naturprodukte dieser Gegend zu liefern. Was aber ferne Länder, entlegene Gegenden anbetrifft, worüber nicht leicht Aufschlüsse erhältlich sind, so wird dem Reisenden dasjenige Wissen zu Gebote stehen, das nöthig ist, $u m$ das Vorhandensein jener Produkte zu konstatiren; dabei wird er nach Erforderniss seine Zuflucht nehmen zum Sammeln von Iustern, die er bei Musse selber prüfen oder durch Andere mag analysiren lassen. Hiebei kommen solche Mineralien und Walderzeugnisse, welche nur vereinzelt zu finden sind, nicht in Betracht; für den Zweck, um welchen es sich hier handelt, verliert ein Objekt durch seine Seltenheit die Bedeutung. Nur insofern diese Dinge in grossen Quantitäten und Massen sich finden, soll dies Vorkommen konstatirt werden; dann aber machen sie sich eben auch durch ihr massenhaftes Vorhandensein jedem einigermassen aufmerksamen Reisenden bemerklich und ist kaum zu riskiren, dass sie übersehen werden. Wir bemerken im Weitern, dass wenn rom rein geographischen beschreibenden Standpunkt aus zwischen den verschiedenen Arten der Naturreichthümer, ron denen wir oben eine kurze Uebersicht gaben, nicht unterschieden werden müsste, dies ganz anders ist, wenn man sie rom praktischen, utilitarischen Gesichtspunkt aus behandelt. In einer Reisebeschreibung, namentlich wenn sie ferne und schwer zugängliche Gegenden betrifft, interessirt weniger ein vollständiges Verzeichniss der Bodenschätze des Landes als die Herrorhebung derjenigen unter ihnen, welche sich zu unmittelbarer Ausbeutung eignen. Wo sich eine dichte, aufgeklärte, reiche und gewerbfleissige Bevölkerung vorfindet, sind alle die Eingangs erwähnten Objekte wahre Reichthümer, weil an Ort und Stelle oder in nächster Nähe zahlreiche Konsumenten da sind, somit für sie sicherer und günstiger Absatz besteht; ganz anders aber verhält es sich mit den meisten dieser Gegenstände in entfernten, wenig bevölkerten Gegenden, weil dann der Mangel an Arbeitskräften, der höhere Preis für die Handarbeit, der Mangel an allen Hülfsmitteln und die Schwierigkeiten eines langen Transportes die Gewinnung oder Ausbeutung der Waare so vertheuern, dass dieselbe auf dem Markte nicht konkurriren kann mit dem gleichen Produkte aus andern Gegenden.

Der Reisende wird also, wenn er auch auf Vollständigkeit seines Verzeichnisses Bedacht nimmt, unterscheiden zwischen 
denjenigen Landesprodukten, welche sich $\mathrm{zu}$ unmittelbarer Ausbeutung oder Verwerthung eignen, und denen, welche gewissermassen eine Reserve für die Zukunft bilden, deren Ausbeutung nämlich erst unter veränderten Verhältnissen lohnend sein wird, z. B. wenn einmal die Gegend dichter bevölkert, der Verkehr in und mit ihr leichter geworden ist. Er wird sich also mit dem Studium der Baumaterialien, welche sich in der Gegend finden, nur befassen, wenn sie in unmittelbarer Nähe ihrer Fundstellen verwendet werden können oder sehr gesucht sind, wie dies der Fall ist mit schönem Marmor, Porphyr u. dgl. Steinen, deren hoher Preis den Transport auf grosse Distanzen ermöglicht. Ebenso wird man bei den Brennstoffen die Aufmerksamkeit wesentlich denjenigen von höherer Qualität zuwenden, wie der Steinkohle, mit Ausschluss von Torf, Schieferkohle u. dgl. Stoffen, welche keine grossen Transportkosten ertragen und daher nur zum lokalen Verbrauch geeignet sind.

Es ist also die Frage nach dem Absatzgebiet and dem Selbstkostenpreise, welche rorab in Betracht fällt bei Würdigung des Vortheils, welchen man aus den in einer Gegend rorhandenen Produkten ziehen kann. Das Absatzgebiet oder der Markt für ein Produkt besteht aus den Ländern und Orten, wo für dasselbe Konsumenten oder Käufer rorhanden sind. Der Selbstkostenpreis setzt sich zusammen aus den Kosten der Gewinnung und des Transportes mit Inbegriff aller Nebenkosten (accessorische Spesen). Es muss also zurörderst berechnet werden, wie hoch es komme, wenn ein Produkt gewonnen und nach auswärtigen Absatzorten geliefert werden soll; hierauf ist $z u$ untersuchen, ob diese Gesammtkosten es ermöglichen, dass man das Produkt zu niedrigerem Preise rerkaufe als ähnliche Produkte von anderer Herkunft, die auf jene Märkte gebracht werden. Wir sagen: „zu niedrigerem Preise"; denn die Gleichheit des Preises wird selten dazu führen, dass ein neues Produkt mit andern seiner Art konkurriren kann; einerseits nämlich drückt ein vermehrtes Angebot in der Regel die Preise herab, und andrerseits wird ein neues Produkt, wenn es nicht ron namhaft besserer Qualität ist, nur bei niedrigerem Preise rorgezogen. Die Berechnung der Gewinnungskosten ist nicht immer so einfach, wie man meinen könnte, denn die Normal- 
preise von andern Orten sind oft nicht anwendbar in einer Gegend, wo Alles anders ist als dort. Man muss den lokalen Verhältnissen gebührend Rechnung tragen und ziemlich viel für Lnvorhergesehenes ansetzen. Was die Transportiosten hetrifft, so hängen dieselben bekanntlich nicht blos von der Länge des Weges ab, sondern ebenso sehr von der Art der Waare, Verkehrsschwierigkeiten und verfügbaren Mitteln. Im Allgemeinen sind alle Produkte von geringem innern Werthe, alle schweren und viel Raum beanspruchenden Waaren nur für den Konsum an Ort und Stelle geeignet, es sei denn, dass günstige Verkehrswegre (Flüsse, Kanäle, Eisenbahnen) bestehen oder das Produkt in der Nähe des Meeres, beziehungsweise ron Hafenplätzen, grewonnen werde. Der geringste Landtransport durch Gegenden ohne gute Strassen erhöht die Selbstkosten in ungemessener Weise. Die Kosten des Transportes auf gewöhnlichen Strassen und Eisenbahnen sind im Allgemeinen proportional zum durchlaufenen Weg, mit der Ausnahme, dass gewisse Spesen (für Wägen, Auf- und Abladen etc.) gleich hoch kommen, ob nun der zurückzulegende Weg kürzer oder länger sei, wesshalb die Transporte auf kurze Distanzen verhältnissmässig die theuersten sind. Beim Transport zu Wasser und namentlich üher Yeer ist die Fracht selten proportional zur Distanz; z. B. zahlt man hei 2400 Seemeilen Weges nicht das Dreifache der Kosten für einen Transport auf 800 Meilen. Hier kommt weit mehr ein anderer Umstand in Betracht, ob nämlich die Schiffe, welche den Transport zu besorgen haben, den Weg hin und her befrachtet zurücklegen oder denselben in der einen Richtung leer machen müssen, sei es dass sie im letztern Falle eine Strönung nicht überwinden, sei es dass sie keine Rückfracht finden künnen. Es ist leicht einzusehen, dass dieser Lmstand auf die Fracht stark influirt, dieselbe sogar verdoppeln kann. Wenn die Schiffe, welche Landesprodukte als Ladung einnehmen, leer zurückkehren müssen und sich für den Rückweg nicht befrachten können mit Waaren, deren Absatz zu gutem Preise gesichert ist, so müssen sie offenbar für ihre Dienste weit mehr verlangen als sonst, denn im andern Fall wird ihnen das auf der einen Fahrt erzielte Benefiz billige Ansätze für die Rückfracht gestatten. Es ist sogar möglich, dass sie in Ermanglung anderer Ladung sich dazu verstehen, 
schwere und viel Raum beanspruchende Waaren zu sehr mässigen Frachtsätzen mitzunehmen. Es ist daher die richtige Veranschlagung der Transportkosten eine ziemlich komplizirte Sache; am einfachsten gestaltet sie sich für Naturprodukte, die bei geringem Volum oder Gewicht einen grossen Werth repräsentiren oder in beliebigem Grade theilbar sind. In diesem Falle kann man ziemlich genau schätzen, wie hoch die Last eines Träger's, eines Maulthiers etc. komme, die durch unebenes Terrain nach einem bestimmten Platze zu transportiren ist und wie hoch noch von hier bis zum definitiven Bestimmungsorte, nach den Tarifen der verschiedenen Transportunternehmungen. Mitunter sind die Kosten der Gewinnung und des Transportes eines Produktes im Verhältniss zu dessen Werth so gering, dass man auf jede Kalkulation derselben verzichten kann, so z. B. bei Diamant, Goldstaub u. dgl.

Unter den Bodenprodukten gibt es einige, welche die Kosten eines langen und schwierigen Transportes ertragen und lohnen können. Mit dieser kleinen Gruppe wollen wir uns speziell befassen, da sie die besondere Aufmerksamkeit des Reisenden verdient. Es ist in der That von Wichtigkeit, wenn es sich um eine ferne, selten besuchte Gegend handelt, dass man nicht nur konstatire, es seien sehr werthvolle, leicht auszubentende und zu transportirende Bodenschätze vorhanden, sondern dass man auch Angaben liefere, welche ein Urtheil darüber gestatten, ob es sich verlohne, dass man nach den erwähnten Oertlichkeiten hingehe und die Gewinnung jener Produkte unternehme.

Wir werden nun ein jedes der Produkte betrachten, welche die in Rede stehende Gruppe bilden, indem wir noch einmal bemerken, dass die Grenzen derselben um so enger zu ziehen sind, je entfernter und schwerer zugänglich die Gegend ist, deren Ausbeutung unternommen werden soll, d. h. dass in diesem Verhältniss die Zahl der Naturprodukte, die einer unmittelbaren und lohnenden Ausbeutung fähig sind, sich reduzirt.

Steinkohle. Die Entdeckung von Steinkohlenlagern in günstigen Verhältnissen für die Gewinnung der Kohle ist immer von grossem Werth. Wenn man bedenkt, dass heute jährlich beinahe 300 Millionen Tonnen Steinkohle verbraucht werden und dass man ernstlich befürchtet, die bisher bekannten 
Kohlenlager könnten dem wachsenden Bedürfniss nicht mehr genügen, so begreift man leicht, wie werthvoll in vielen Fällen die Steinkohle als Ausfuhrartikel ist.

Ihre Hauptbedeutung hat die Steinkohle in Gegenden, die bereits Grossindustrie besitzen. Sie macht oft erst die Einführung ron Fabrikation möglich und wird so für das Land, um welches es sich handelt, zu einer wahren Quelle des Reichthums. Da alsdann sozusagen ein Konsum an Ort und Stelle stattfindet, so braucht man sich nicht mehr um Schwierigkeiten und Kosten des Transportes zu bekümmern; denn dann handelt es sich nicht mehr um die Versendung dieser schweren und riel Platz erfordernden Waare, sondern um den Transport der Fabrikationsartikel, zu deren Herstellung sie diente.

Auch Kohle in entlegenen, öden oder doch dünn bevölkerten Gegenden ist von grossem Werthe, wenn sie sich an Schiffsrouten, an zugänglichen Küstenpunkten oder Inseln findet, wären letztere auch scheinbar verloren mitten im Meer; denn in solchen Fällen ermöglicht das Vorkommen der Kohle die Anlage von Depots zur Verproviantirung der Dampfer. Es ist bekannt, dass die Steinkohle entstanden ist aus Pflanzen und eigentlichen Wäldern, welche in fernen geologischen Epochen die Erde bekleideten und entweder an Ort und Stelle fielen oder durch fliessendes Wasser in Niederungen transportirt wurden, wo sie manchenorts ungeheure Lager bildeten.

Diese Lager findet man in alten Sedimentärgesteinen, besonders in Ablagerungen aus der Periode, die man als Steinkohlenzeit (carbonische Periode ${ }^{1}$ ) bezeichnet hat. Selten

1) Die Ablagerungen der produktiven Steinkohlenformation treten in zwei Typen auf, deren Versehiedenheit wichtig ist und die man als paralische und limnische Form der Ausbildung oder als paralische und limnische Facies bezeichnet hat. Die purulischen Ablagerungen, zu welchen die reichsten und ausgedehntesten Kohlenfelder gehören, ruhen auf einer Meeresbildung, welche die untere Gruppo der Formation ausmacht (Kohlenkalk) und haben auch zwischen ihren Schichten mitunter marine Sedimente; es sind Uferbildungen, entstanden an Flachküsten alter Kontinente und Inseln, bei wiederholten Niveauschwankungen und unter Verbältuissen, wie sie uns jetzt einerseits die Torfmoore an der Ost- und Nordsee, andrerseits die Sumpfwälder an den Mississippimündungen darbieten. Die limnischen Ablagerungen, von beschränkterem Umfang, haben keine marine untere $\Lambda$ btheilung und entstunden in kontinentalen Bimenbecken, jedoch nicht sowohl als Absätze in Landseen denn vielmehr als Bildungen in flachen, von Flüssen durchströmten, oftmaligen Ueberschwemmungen ausgesetzten Sumpflandschaften ähnlich denen am oberen Nil, bei dessen Zusammenfluss mit dem Sobat, wo mächtige Pflanzenbarren die Schiffahrt hindern. Vgl. Hann, Hochstetter u. Pokorny, S. 416. 
tritt die Kohle in horizontalen Lagen auf, sondern meist in konkaven, mulden- oder uhrglasförmigen Schichten, die von neueren Bildungen überlagert sind. Oefter's wiederholen sich die Kohlenschichten in verschiedenen Niveaux, d. h. es können mehrere über einander befindliche Lager vorkommen. Oft auch trifft man sie dislozirt und verdreht, mit Unterbrechungen der Schichten durch Verwerfungsspalten.

Eine blos aus (plutonischen und vulkanischen) Erstarrungsgesteinen bestehende Gegend enthält keine Kohle. Was aber die älteren Sedimente betrifft, so ist die Wahrscheinlichkeit, dass man in ihnen Steinkohlenlager finde, um so grösser, je näher sie der Gruppe stehen, die man als Steinkohlenformation (Carbongruppe) bezeichnet hat. Ist diese Grenze überschritten, so nehmen die Chancen mehr und mehr ab, in dem Masse als neuere Formationen auftreten; wenigstens ist in diesem Falle Steinkohle, wenn sie überhaupt in der Gegend vorhanden, nur in grosser Tiefe zu finden. Wenn indessen die Formationsreihe in dieser Gegend Lücken hat, so kann allerdings die Kohle auch unmittelbar unter verhältnissmässig jungen Bildungen sich finden.

Ist die Steinkohle von andern Gesteinsformationen überlagert, so wird sie nur durch günstigen Zufall zu entdecken sein; indess sind die Kohlenschichten oft so verbogen, dass sie mit einem Ende zu Tage treten.

Trotz der Veränderungen, welche die zu Tage tretenden Flächen der Kohle erleiden, ist dieselbe durch ihr ganzes Aussehen und namentlich ihre Farbe überall kenntlich, wo immer sie dem Reisenden bei seinen geologischen Streifereien entgegentritt, seien es nun Kopf- oder Schichtflächen, die zu Tage liegen. Aus der Mächtigkeit der Kohle an diesen entblössten Stellen wird man auf die Mächtigkeit der unterirdischen Lager schliessen, wobei $\mathrm{zu}$ berücksichtigen ist, dass bei mulden- oder kahnförmigen Schichten die sichtbaren Ränder im allgemeinen einen geringeren Dickedurchmesser haben als die mittleren Partien. Wenn man zudem den allgemeinen Verlauf der Schichten in der Gegend kennt, so kann man oft - indem man die verschiedenen Punkte, wo Kohle beobachtet wurde, durch hypothetische Linien verbindet - die Ausdehnung eines Lagers bestimmen und ideale Durchschnitte desselben anfertigen, ohne dass Son- 
dirungen nöthig würden, deren Vormahme für den Reisenden kaum möglich wäre. Dabei darf nicht übersehen werden, dass Störungen durch rulkanische Ausbrüche, Verwerfungen und Rutschungen grosse Partien einer scheinbar ununterhrochenen Schicht zerstört oder dislozirt und in letzterem Falle auch so angeordnet haben kömen, dass man eine Pieihe von Kohlenlagen zu erblicken glaubt, wo in Wirklichkeit nur eine Schicht vorhanden ist.

Der Verlauf der Schichten, welche die Kohlenlager einschliessen oder auch nur derjenigen, welche sich über ihnen befinden (des Hangenden) griht Anhaltspunkte zur Beurtheilung des Terlaufes der kohlenführenden Schichten selbst. Ist das Hangende regrelmässig geschichtet, so darf angenommen werden, es verhalte sich ebenso mit den Kohlenlagern, und umgekehrt. Dagegen sind die Kohlenschichten wahrscheinlich grestört, wo in ihrer Nähe Eruptirgesteine auftreten, welche jünger sind als die Kohlenlager. Es kann aber auch eine solche Störung stattgefunden haben, olne dass Eruptirgesteine an die Oherfläche gelangten, z. B. durch Erdbeben, Hebungen, Senkungen, unterirdische Dislokationen, die oft keine äusserlich wahrnehmbaren Spuren zurückgelassen haben.

Die günstigsten Bedingungen zur Ausbeutung eines Kohlenlagers sind rorhanden, wenn die Kohle nicht in zu grosser Tiefe liegt, in wagrechten, regelmässigen und mächtigen Bänken auftritt und überlagert ist ron festem, nicht nachstürzendem Gestein. Es ist leicht einzusehen, dass mächtige Schichten ron überlagerndem (hangendem) unproduktivem oder "todtem" Gestein, das durchbrochen werden muss, bevor man zur hohle gelangen kann, den Abhau des Lagers sehr rertheuern müssen und dass der gleiche Effekt ausgeübt wird, wenn das Hangende nicht aus festem, sondern aus mürbem Gestein besteht, welches man durch Schutzbauten ror dem Einstürzen und Nachrutschen sichern muss, oder wenn endlich dieses Gestein viel Wasser führt, sodass $\mathrm{Ab}$ leitung des letztern nöthig wird. In allen diesen Fällen ist die Ausbeutung des Lagrers mit Kosten und ebenso auch mit Gefahren verbunden.

Wenn die Kohle in grossen Massen auftritt, so ist dies anch ein weit grünstigeres Verhältniss als wenn sie in zahl- 
reichen, aber getrennten und unbedeutenden Lagen vorkommt, welche dazu nöthigen, den Abbau an vielen Stellen zugleich in Angriff zu nehmen und für jeden dieser Punkte eine vollständige Ausrüstung mit allem nöthigen Werkzeug zu beschaffen.

Endlich wird die Ausbeutung eines Kohlenlagers sehr erleichtert durch regelmässigen, ungestörten Verlauf der Bänke; wo hingegen die Kohlenschichten sich auskeilen, arbeitet man mit wenig lohnendem Erfolg oder gar mit Verlust; ebenso werden kostbare Arbeiten nöthig, wo infolge von Verwerfungen die Fortsetzung einer Schicht in einem andern Niveau gesucht werden muss.

Die Steinkohlen sind von sehr verschiedener Qualität und müssen wohl unterschieden werden von anderen fossilen Kohlen minderen Werthes wie Anthracit und Braunkohle (Lignit). Man wird sich desshalb vor Allem Musterstücke derselben verschaffen, die genau untersucht werden müssen. Solche findet man aber erst in einer gewissen Tiefe; denn an der Oberfläche trifft man meist nur eine erdige, zerfallene Masse. Bei muldenförmigen Schichten ist zudem das Material an den Rändern in der Regel geringer als dasjenige der zentralen Theile des Beckens. Zeigen sich mehrere über einander befindliche oder parallele Bänke, so muss jede Schicht einzeln untersucht werden, denn sie können qualitativ stark verschieden sein, wiewohl sie am gleichen Orte gebildet wurden.

Die Braunkohlen oder Lignite gleichen ausgetrocknetem oder verkohltem Holze; die Anthracite erscheinen als schwarze, glänzende und undurchsichtige Steine; ihr Glanz ist bald mehr der des Glases, bald halbmetallisch. Die Steinkohlen werden unterschieden in Hart-, Pech-, Fett- und Magerkohlen. Die Verbrennung dieser verschiedenen Kohlenarten im verschlossenen Tiegel gibt folgende durchschnittliche Resultate:

F'ester Rückstand

(Kohle und Asche)

Braunkohle ...... 45

Magere Steinkohlen ... 55

Fettkohlen ...... 65

Pechkohlen ..... 70

Hartkohlen ..... 80

Anthracit ...... 90
Flüchtige Bestandtheile (Wasser, Bitumen, Gase)

55
45
35
30
20
$10 \quad "$


Ihrem Aussehen nach sind diese rerschiedenen Kohlensorten auch daran zu unterscheiden, dass die Lignite gewöhnlich noch Holz-Struktur zeigen, die Mager-, Fett- und Pechkohlen erdig aussehen und an den Fingern abfärhen, die harten Steinkohlen und Anthrazite das Aussehen ron Steinen haben und an den Fingern nicht abfärben.

Der Werth der Kohlen richtet sich selhstverständlich in erster Linie nach ihrer Heizkraft, in zweiter Linie sodam nach dem Grade ihrer Festigkeit (Kohïsion) oder Zerreihlichkeit, wodurch sie sich mehr oder minder geeignet erweisen, transportirt $\mathrm{zu}$ werden, ohne dass sie zerschlagen werden. $\mathrm{Zu}$ berücksichtigen ist ferner der Prozentgehalt und die Zusammensetzung ihrer Asche, ferner ihre Agglomerationsfähigkeit, d. h. die Eigenschaft, vermöge welcher sie unter Einwirkung der Hitze zum Theil weich werden und selbst schmelzen.

Nicht jedem Reisenden werden die Spezialkenntnisse oder die Musse zu Gebote stehen, welche nöthig sind zur Bestimmung der Qualität von Kohlen die er entdechte; alsdann wird er sich eben damit begnügen, Muster mitzunehmen und diese zur Untersuchung Fachmännern zu übermitteln.

Womöglich wird der Reisende auch Sondirungen oder Bohrungen vornehmen, sei es um Proben zu erhalten, die ein wirklich zuverlässiges Urtheil über die Qualität der Kohlen des Lagers gestatten, sei es um Lage und Mächtigkeit der unterirdischen Schichten konstatiren zu können.

Hiebei ist zuerst nach Massgabe der äusserlichen Indizien ein geologisches Profil üher due muthmassliche Lage der Kohlenbänke anzufertigen. Dann wählt man auf Grund desselben(Fig. 201) für die Bohrung einen Punkt $a$ oder $b$ aus, unter wel-

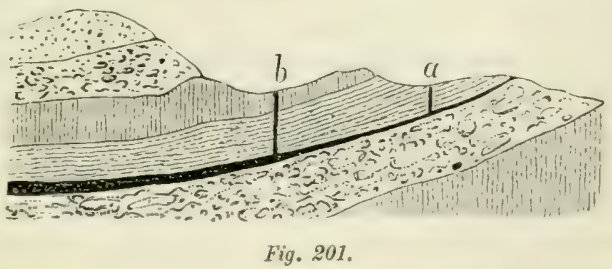
chen die Kohle wahrscheinlich in geringer Tiefe anzutreffen ist. Dabei darf nicht vergessen werden, dass eine einzige Bohrung nicht genügt, falls Verwerfungen der Kohlenlager 
stattgefunden haben. So würde eine Bohrung oder ein Probeschacht in $a$ ( $F i g .202)$ eine grössere als die wirkliche Mächtigkeit ergeben; eine solche in $b$ würde zu dem Ergebniss führen, dass hier keine Kohlen vorhanden seien, weil hier das Lager zufällig von einem todtenGang

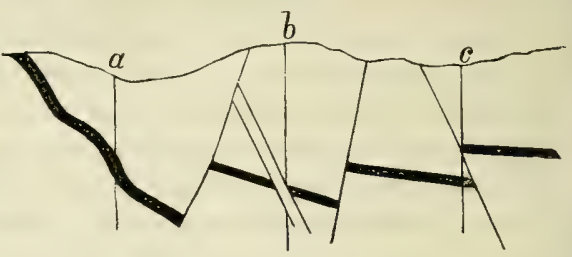

Fig. 202.

durchsetzt ist; nach einem Versuch in $c$ endlich hätte es den Anschein, es seien zwei Kohlenbänke vorhanden, während in Wirklichkeit nur eine Schicht existirt. Zur Vermeidung solcher Irrthümer muss man wenigstens drei Bohrungen oder Probeschachte vornehmen und zwar so, dass die drei Punkte je 50-100 Meter auseinander liegen und ein gleichseitiges Dreieck bilden. Stimmen die so erhaltenen Resultate mit einander überein, so ist die Lage und die mittlere Mächtigkeit der Kohlenschichten in genügender Weise bestimmt.

Erze. Unter Erz versteht man jede mineralische Sub$\operatorname{stan} z$, aus welcher man ein Metall oder mehrere in demselben vereinigte Metalle erhalten kann. Findet sich ein Metall in der Natur rein vor oder doch fast frei von jeder Beimischung, so wird es als gediegen bezeichnet (gediegenes Gold etc.)

Ueber den Ursprung der Metalle ist man nicht im Klaren. Die herrschende Meinung geht dahin, sie entstammen dem Erdinnern, aus welchem sie in verschiedenen geologischen Epochen flüssig oder dampfförmig in die Spalten der festen Erdrinde emporgedrungen seien and dieselben, zu festen Körpern kondensirt, ausgefüllt haben. Andrerseits sind in den Felsen injizirte und sporadisch enthaltene Metalltheilchen oft auf mechanischem und chemischem Wege ausgeschieden und an gewissen Stellen angehäuft worden. Uebrigens kommt für unsern Zweck weniger der Ursprung als das Vorkommen der Metalle in Betracht und hierüber ist Foigendes zu bemerken.

Die Metalle finden sich:

1" Imprägnirt in gewissen Erstarrungsgesteinen, in weche die Metallpartikelchen injizirt wurden als die Masse 
noch feuerflüssig war, so dass sie gleichzeitig mit dieser an die Erdoberfläche oder in deren Nähe gelangten.

$2^{\circ}$ In Gängen oder Adern, d. h. als Ausfüllungen von Spalten der Erdrinde. In diese können sie von untenauf gelangt sein als metallische Dämpfe oder als Lösungen in Thermen mit andern Mineralsubstanzen, welche dann das sogenannte Gang- oder Muttergestein bilden. Sie können aber auch aus dem angrenzenden Gesteine stammen und sich gebildet haben als Sublimationen an den Wänden der unterirdischen Spalten. Endlich rühren sie oft her aus zersetztem Gestein an der Erdoberfläche, aus welchem sie in Lösung zur Tiefe gelangten, um hier Spalten der Erdkruste auszufüllen.

$3^{\circ}$ In Stöcken oder unregelmässigen Massen, die erzeugt sind durch starke lokale Imprägnationen, durch Ausfüllung unterirdischer Hohlräume oder endlich durch örtliche Ansammlung von Rückständen der Zersetzung metallhaltiger Gesteine.

$4^{\circ}$ In Lagern oder Bänken, die eingebettet sind zwischen Sedimentschichten oder in Alluvialbildungen an der Erdoberfläche. Diese Ablagerungen sind im Allgemeinen entstanden durch Wassertransport oder durch einfachen Niederschlag aus stagnirendem Wasser, wobei die schweren Metalltheilchen von den andern Materialien mechanisch getrennt wurden.

Als gerdiegene Netalle finden sich Gold, Silber, Platin, luecksilber und Kupfer. Gold und Platin kommen selten inder's als gediegen vor und zwar meist als Blättchen, Körner Ind Klumpen von der Grösse eines Stecknadelknopfes bis zu ler einer Kokosnuss. Das gediegene Silber tritt in formlosen Iassen auf oder aber in baumförmigen Gestalten, welche an arrenwedel erinnern; öfter indess erscheint das Silber in iängen kombinirt mit andern Ietallen, namentlich mit Blei. las Quecksilber findet sich zuweilen gediegen in kleinen Kugeln der Tropfen, meist aher als Schwefelmetall (Zinnober) von chön rother Farbe oder in Verbindung mit Silber. Gediegenes upfer ist ziemlich verbreitet und findet sich namentlich in ushuchtungen und Höhlen der Günge, sowie da, wo diese u Tage treten; es kommt aber auch in vielfachen Verindungen mit andern Metallen vor. 
Eisen, Blei, Zinn und Zink erscheinen nur ausnahmsweise als gediegene Metalle. Vom ersteren kennt man eine Menge Erze, in welchen es als Oxyd, Oxhydrat (Hydroxyd), Ses. quioxyd, Sulfurat, Karbonat etc. enthalten ist. Das Blei tritt am häufigsten als Schwefelverbindung (Bleiglanz) auf und enthält gewöhnlich Silber. Das Zinn findet sich meist als krystallisirtes Oxyd (Zinnstein) und das Zink als Schwefelverbindung (Blende).

Oft sind in den Gängen und Adern diese verschiedenen Metalle mit einander kombinirt, aber immer in bestimmten Gruppirungen nach gewissen Gesetzen. So z. B. kommen Silber und Blei zusammen vor, Silber und Zinm aber nicht. Ebenso bestehen gewisse Beziehungen zwischen den Erzen und dem Ganggestein; das Gold z. B. findet sich gewöhnlich in Quarz.

Enthält ein Erz rerschiedene Netalle, so gibt man ihm den Namen des vorherrschenden oder werthvolleren, indem man von den sekundären Bestandtheilen absieht. In diesem Sinne spricht man von Silberadern, Kupferbergwerken u. s. w.

Die Gänge und deren Verästelungen (Adern) haben nicht, wie man glauben könnte, eine cylindrische Form. Es sind Ausfüllungen von mehr oder minder breiten Spalten, deren horizontale Ausdehnung aber immer weit grösser ist als der Abstand der Spaltenwände. Mit einem Baume kann man daher nur ihren Durchschnitt vergleichen. Die Mineralmasse, welche die Gänge und Adern erfüllt, erschiene für sich allein — befreit rom umschliessenden Gestein — in Form grosser Mauern oder Tafeln, die unter verschiedenen Winkeln zusammentreffen und zusammenhängen, nicht aber in Form eines Baumes mit seinen Aesten.

Bei Weitem nicht alle Gänge und Adern enthalten nutzbare oder werthvolle Metalle. Meistens sind dieselben von Mineralien ohne technischen Werth ausgefüllt, und unter den metallhaltigen Gängen gibt es arme, deren Erze nicht so riel Metall führen, dass dessen Gewinnung sich lohnen würde.

$\mathrm{Ob}$ ein Erz als reichhaltig zu bezeichnen sei oder nicht, hängt übrigens von der Art des Metalls ab. Ein Golderz z. B. ist reich, sobald es über $0,01 \%$ Gold enthält, ein Eisenerz arm, wenn es nicht mehr als $30 \%$ Eisen liefert. Beim jetzigen Stande der Montanindustrie müssen die ver- 
schiedenen Erze, wenn die Ausbeutung lohnend sein soll, folgenden Metallgehalt haben:

$$
\begin{aligned}
& 0,01 \% \text { Gold, } \quad 3,5 \% \text { Blei, } \\
& 0,10 \text { \# Silber, } 5,00 \text { ॠ Zink, } \\
& 2,00 \text {, Kupfer, } \quad 35,00 \text { ॠ Eisen. }
\end{aligned}
$$

Dabei ist selbstverständlich, dass der Gehalt noch grösser sein muss, wenn zu den Kosten der Metallgewinnung noch solche in grossem Betrage für lange und mühsame Transporte kommen.

Man unterscheidet zwischen Injektionsadern und Gängen mit Konkretionen. Die erstern sind diejenigen, welche mit feuerflüssigen Substanzen erfüllt wurden, die gewöhnlich eine homogene Masse bilden und selten Metalle enthalten. Die letzteru hingegen sind angefüllt mit Substanzen, die sich langsam an den Wänden abgesetzt haben und nun, da sie im Laufe der Zeit ungleich waren, eine Masse bilden, welche aus verschiedenen Lagen besteht, die parallel und mit Bezug auf eine Axe symmetrisch angeordnet sind. Die einen dieser Lagen kömmen Metalle oder Erze, die andern todtes oder taubes Gestein sein. Mitunter ist auch die Regelmässigkeit der Bildung gestört worden durch Bruch des einschliessenden Gesteins, dessen Trümmer sich mit dem ausfüllenden Ganggestein mischten, so dass ein Konglomerat oder eine Breccie entstund.

Selten sind die Metalladern auf ihrer ganzen Erstreckung gleich reichhaltig. Oft sind die zu Tage tretenden Kopfenden der Gänge reicher als die übrigen Partien, oft aber auch sind jene verhältnissmässig arm; namentlich ist letzteres der Fall bei den sogenannten rosenkranzförmigen Adern, in welchen Erweiterungen und Verengungen mit einander $a b$ wechseln, in denen man aber oft Stellen oder Nester ron grosser Reichhaltigkeit findet. Manche Günge nehmen in ihrem Verlaufe an Gehalt stufenweise oder auch plötzlich ab, namentlich an Stellen, wo sie in ein anderes Gestein übersetzen oder mit andern Gängen zusammenstossen.

Selten ist ein Gang genau vertikal, vielmehr ist er in der Regel mehr oder minder geneigt; dam neunt man die Felsfläche, auf welcher er ruht, "Mauer", diejenige aber, welche ihn überdeckt, „Dach."

Die Trigmy eines Ganges ist der Winkel, welchen dir Richtung seines grössten Gefälles mit der Vertikalen billet; 
das Streichen desselben wird bestimmt durch den Punkt des Horizontes, nach welchem er sich hinzieht.

Ein Gang heisst „gekreuzt", wenn er unter irgend einem „Winkel von einem andern Gang geschnitten wird, welch letzterer dann der durchkreuzende Gang heisst;" zurückgeworfen wird er genannt, wenn er durch einen andern Gang deplacirt und zurückgedrängt, aber nicht durchschnitten wurde. Endlich heisst er "unterbrochen " oder „abgeschnitten ", wenn er da aufhört, wo er auf einen andern Gang stösst. Die Kenntniss dieser Bezeichnungen erweist sich nützlich bei Beschreibung des Verlaufes von Gängen, die man allenfalls entdeckt.

Da die Bildung dieser Metall-Lager und Gänge keinem positiven Gesetz unterliegt, so ist deren Aufsuchung ausserordentlich schwierig; nur Zufall oder eine in's Einzelne gehende geologische Untersuchung führen ihre Entdeckung herbei. Umsomehr ist auf Alles zu achten, was irgend auf die Spur leiten könnte.

In erster Linie handelt es sich dabei um Erkundigungen bei den Bewohnern der Gegend. Vielleicht machen sie ein Geheimniss daraus, an welchem Orte sie ein Erz gefunden oder die Existenz eines Ganges bemerkt haben; aber schon die Thatsache, dass ein solcher Fund gemacht wurde, genügt, um das Vorkommen von Metall-Lagern in dem Lande zu verrathen und man wird dann erfahren können, in welcher Richtung ungefähr nachzusuchen ist. Ist man soweit gelangt, so begibt man sich an die angezeigten oder muthmasslichen Stellen, um hier das Terrain genau zu erforschen.

$\mathrm{Zu}$ gleichem Zwecke muss man die Gerölle der Schluchten, Flussthäler und Flussbetten untersuchen. Findet man unter diesen Geschieben Erzstücke, so wird man thalaufwärts nach deren Herkunft forschen.

Eine besondere Aufmerksamkeit ist dem Fluss-Sande zu widmen; denn hiebei hat man Chancen, Edelmetalle in Körnern und Blättchen zu finden. Das Gold im Alluvium stammt aus zersetzten Felsen her; die Körner insbesondere scheinen dadurch entstanden zu sein, dass sich um einen kleinen Quarzkern Metallpartikelchen niederschlugen, welche in Mineralwassern aufgelöst waren. In der Regel existiren in einer Gegend mehrere Niveaux von Alluvialbildungen, welche ihre Entstehung successiven Erosionen verdanken; in Bezug auf die 
Ausbeutung derselben hat man nun zu unterscheiden zwischen oberflächlichen Ablagerungen, die nur von einer dünnen Sandoder Kiesschicht bedeckt sind, und tiefgelegenen Ablagerungen, welche überdeckt sind von mächtigen Schichten im Laufe der Jahrhunderte gebildeten Alluviums. Diese Ablagerungen hat man sich nicht als regelmässige Schichten vorzustellen, welche grosse Becken einnehmen; vielmehr bestehen sie in einem Netz von Streifen und Bändern, welche - bald breit, bald schmal — allen Vertiefungen des Bodens und allen Krümmungen des Thalwegs folgen, in welchen die Gewässer flossen oder noch fliessen.

Sellstverständlich wird man zuerst die Ablagerungen an der Oberfläche untersuchen und hier zuerst wieder die am stärksten gekrümmten Partien des jetzigen Flussbettes oder rerlassener Arme desselben. Handelt es sich um ein tiefes Gewässer, so kann man kaum anderswo als in alten Flussarmen Untersuchungen anstellen. Es kommt hiebei viel auf richtige Erfassung des Bodenreliefs an, so dass man ohne langes Herumsuchen die tiefsten Stellen der Flussbetten auffindet. Hier gräbt man nun im Sand oder Gerölle, bis man auf den Felsgrund trifft, oder auf die Thonbänke, worauf rormals das Gewässer floss. Namentlich sind solche Punkte auszuwählen, an welchen — nach der Bodengestalt zu schliessen - die Strömung an Geschwindigkeit abnehmen musste, indem sie auf ein Hinderniss traf und wo sie folglich die mitgeführten schweren Theile zu Boden sinken liess. Es sind das besonders solche Punkte, wo die Gewässer, nachdem sie ein enges und tiefes Bett passirt, plötzlich zwischen weiter auseinandertretenden Ufern sich ausbreiten können; solche ferner, wo eine starke lokale Vertiefung im Stromstrich oder ein Hinderniss Wirbel erzeugte; weiter solche, wo ein Felsriegel die Strömung hemmte oder wenigstens die auf dem Flussbette sich hinbewegrenden Stoffe aufhielt; endlich solche, wo das Wasser am Fusse einer Kaskade ein Becken ausgrub.

L'm zu untersuchen, ob Alluvialbildungen Gold enthalten, braucht man nur ein eimer-oder kufenförmiges Gefäss. Man füllt dieses halb mit Sand und Wasser und gibt ihm bei etwas schiefer Lage eine drehende Bewegung, so dass das Wasser langsam ausfliesst. Dies bewirkt eine Scheidung der erdigen Stoffe von den schwereren: die ersten werden rom 
Wasser mitgerissen, die letzteren sinken zu Boden. Man schöpft nun von Neuem Wasser in das Gefäss und fährt fort wie vorher, indem man grobes Geschiebe mit der Hand entfernt, bis auf dem Boden des Gefässes ein Rückstand bleibt, der im Glücksfalle metallisches Aussehen zeigt.

Der Grad des Erfolges bei dieser Untersuchung der oberflächlichen Ablagerungen muss darüber entscheiden, ob man die Untersuchungen aufgeben oder aber auch auf die tiefer gelegenen Bildungen ausdehnen soll. So lange man nur auf Thon gestossen ist, muss man nicht glauben am Ziele zu sein; gegentheils soll man bis auf den Felsgrund zu gelangen suchen, denn hier finden sich zumeist die reichhaltigsten Ablagerungen. Wo die Alluvialbildungen, welche man als metallführend erkannt hat, aus verschiedenen superponirten Schichten bestehen, die durch Thonbänke geschieden sind, muss man die Geschiebe untersuchen, welche auf diesen Thonlagen ruhen, sowie die, welche direkt auf dem Felsgrunde lagern; denn oft sind die Metallpartikelchen durch dieThonschichten hindurch in dieTiefe gedrungen und haben sie sich in den Fugen des felsigen Bettes angehäuft.

Der Metallgehalt solcher Alluvialbildungen ist ungemein verschieden; die reichsten Partien finden sich gewöhnlich an vereinzelten Stellen, wo (wie oben bemerkt wurde) besondere Umstände die Strömung beeinflusst und den Absatz der schweren Theile bewirkt haben. Wenn der Felsgrund aus einem durch ein Bindemittel verkitteten Konglomerat besteht, so ist es wahrscheinlich, dass dieses Konglomerat sehr reichhaltige Partien habe.

Es kann vorkommen, dass die Gewässer nicht immer den jetzigen Lauf hatten und man die älteren Alluvionen an andern Stellen suchen muss. In solchen Fällen werden die Studien über Aenderungen in der Bodenkonfiguration von praktischem Werthe; denn sie geben uns die Antwort auf die Frage, ob die Gewässer sich immer tiefer eingeschnitten haben - in welchem Falle man die Reste des alten Alluviums auf den Plateaux suchen muss, welche die jetzigen Thäler beherrschen, oder auf den Seitenterrassen längs dieser Thäler und die Metallpartikelchen vielleicht einzig von der Abtragung dieses alten Alluviums und dessen Umlagerung (Remaniément) durch fliessendes Wasser herrühren. Wenn die Thäler verlegt wurden, so muss man sich im Geiste 
die frühere Gestalt der Gegend vergeçenwärtigen und die alten Wasserläufe, ron welchen sie nicht durchzogen war, Schritt für Schritt verfolgen, um womöglich deren Lrsprungs-Stelle zu rmitteln, von welcher her sie aus rerwitterndem Gestein mit Yetallpartikeln rersehen wurden.

Die Metalle befinden sich in diesen Bänlien oder plarers an sekundärer Lagerstätte; sie kommen aus Felsen, wo sie in Adem oder Blättchen enthalten waren. Diese Felsen kimnen in Veroleich mit der metallführenden Bank seln arm sein; eine Unze Goldstaub des Alluviums (Schwemmlandes) ist oft das Resultat der Zersetzung einer grossen Gesteinsmasse, in welcher das Metall in kaum wahrnehmbaren Partikelchen zerstreut enthalten war. Aber wie dem auch sei, so ist es immerhin der Mühe werth, dass man sich über den Sachrerhalt orientire und untersuche, ol) nicht jenes Gestein selbst die Ausbeutung lohne.

In den placers oder Seifen findet man, je nach den Ländern, folgende Erze: gediegrenes Gold und Platin als Staub, Blättchen und Körner; Magneteisen als feinen Staub: Zinnoxyd in kleinen Krystallen. Die andern Erze findet man mehr in Gängen und Lagern.

Erinnern wir uns, dass die Gänge nachträglich ausgefüllte Spalten der Erdkruste sind und ziehen wir ferner in Betracht, dass diese Spalten ron unten her entstanden; so kommen wir zu dem Schlusse, dass die ältesten Gesteine am meisten Gänge und Adern enthalten müssen: denn diejenigen Spalten, welche in den ältern Perioden entstanden, konnten sich nicht in die neueren Formationen hinein fortsetzen, die ja noch nicht existirten: und diejenigen, welche später entstanden sind, fanden ihr Ende in rerschiedenen Niveaux, so dass sie nicht alle in die jüngeren Bildungen hineinreichten.

Im Allgemeinen sind daher die Chancen, in einer Formation viele und reiche Erzqcänge zu finden, um so grrösser, je älter die Formation ist. Wir wissen aber, dass man keineswegs nöthig hat, in die Tiefen der Erde einzudringen, um diese alten Formationen anzutreffen, sondern dass man sie in den grossen Bodenerhebungen, in Gebirgsłändern, schon an der Oberfläche findet. Ensere Lntersuchungen werden daher vorab solchen Gegenden gelten; Eruptivgesteine, 
welche unter Hebung des Bodens an die Oberfläche gelangten, und deren Nachbarschaft werden wir zunächst ins Auge fassen, insbesondere wieder die Stellen, wo dieselben in Kontakt sind mit anderm, von ihnen durchsetztem oder dislozirtem Gestein; ferner die weichen Schichten, welche unter der Einwirkung feuerflüssiger Massen metamorphosirt, mit Metallpartikeln imprägnirt oder von Adern durchsetzt wurden. Ein günstiges Anzeichen ist das Vorkommen von Mineralquellen, namentlich von Thermen, in der Gegend, weil dies einen tiefgespaltenen Boden verräth, in welchem das Wasser Metalle in Lösung aufnehmen kann.

Beim Durchwandern solcher Gegenden hat man sorgfältig auf alle nackten Felspartien zu achten. Entdeckt man hiebei Mineralien, welche als Ganggesteine charakteristisch sind, so untersuche man, nach welcher Richtung sie aboder zunehmen und verfolge letztere Richtung, um womöglich die Erzlagerstätte zu entdecken. Oft auch ragt das Ausgehende derselben über die Umgebung empor und macht sich in dieser Weise bemerklich.

Mit Bezug auf das Eisen speziell ist zu bemerken, dass es in verschiedenen Formen und Formationen nicht nur in Gängen, Lagern und Stöcken vorkommt, sondern auch als oberflächliche Absatzbildung an Stellen, wo sich lange Zeit stagnirende eisenhaltige Wasser befanden.

Man kann rom Rieisenden nicht erwarten, dass er die gesammelten Erze analysire; um so mehr aber ist es nöthig, dass er in seinem Tagebuch Alles aufzeichne, was auf diese Funde Bezug hat, dass er die Fundstellen in der Karte notire und die nöthigen Angaben zu deren leichter Wiederauffindung beibringe.

In Ländern mit alten aufgegebenen Bergwerken darf der Reisende nicht unterlassen, Proben des Erzes mitzunehmen, welches daselbst ausgebeutet wurde, und ebenso Reste des ausgeschmolzenen Metalles und Schlacken. Bei der Unrollkommenheit des früheren Verfahrens kommt es nicht selten vor, dass diese Schlacken jetzt noch eine lohnende Ausbeutung gestatten. Dasselbe gilt von Bergwerken, deren Abbau durch Eingeborne des Landes betrieben wurde, die nur ein unvollkommenes Verfahren kannten oder nicht die nöthigen Geldmittel besassen. 
An Orten hinwieder, wo Bergwerke in vollem und rollkommenem Betriebe stehen, wird man durch die Gefälligkeit ihrer Direktoren interessante Angaben erhalten können.

Edelsteine. Hinsichtlich der Edelsteine wäre in vieler Beziehung zu wiederholen, was über die Erze gesagt wurde. Man schreibt ihnen die gleiche Bildungsweise zu wie letztern, und sie finden sich meistens auch in Gängen, Höhlen oder einfachen Spalten in Eruptivgesteinen oder deren Nähe, es sei denn, dass diese Gesteine bereits zersetzt wurden und nun die Edelsteine im Schwemmland rorkommen. Die Entdeckung der Edelsteine hängt aber noch in riel höherem Grade als diejenige der Erze rom Zufall und ron Aufschlüssen der Eingebornen ab.

Guano. Der Guano ist bekanntlich ein sehr wirksamer Düngstoff, bestehend aus einem Gemenge ron phosphorsaurem Kalk mit organischen Resten und entstanden aus der Ansammlung von Excrementen ungeheurer schaaren ron Neeresvögeln. Er findet sich in mehr oder minder ausgedehnten und mächtigen Bänken an den Küsten, wo die Neeresvögrel nisten und brüten: seine werthrollen Eigenschaften behält er aber nur in regenlosen Gegenden. Je nach seinem Alter erscheint er als braune oder graue erdige Masse: es wird daher unterschieden zwischen hraunem und weissem Guano. Der letztere bildet sich noch heutzutage, während der erstere aus ältern Zeiten stammt.

In Gegenden mit Regenfall verliert der Guano seine stickstoffhaltigen Bestandtheile and es bleiben ihm nur die Phosphate; diese genügen nun allerdings noch, um ihn zu einem guten Dünger zu machen; aber als Ausfuhrartikel hat dieser erdige Guano nur geringen Werth. Der Reisende wird also in regenreichen Gegenden nicht nach Guanolagern forschen, ausgenommen es sei in der Nähe Verwendung für denselben.

In den regenlosen oder doch regenarmen Gegenden, in welchen einzig guter Guano zu finden ist, wird der Reisende die ron Meervögelschwärmen besuchten Lfer fischreicher Gewässer untersuchen; ferner aber auch — da ja die Verhältnisse im Laufe der Zeit wechseln - himenwärts gelegrene alte [fer und Steilküsten, wo der braune Guano, erkenntlich an seinem üblen Geruche, unter einer üppigen Pflanzendecke 
liegen kann. In manchen Höhlen findet sich auch Guano von Fledermäusen; wiewohl diese Lager weniger mächtig sind als die des Vogelguanos, lohnen sie doch mitunter die Ausbeutung.

Holz. Da die Wälder sich ohne Weiteres bemerkbar machen, so hat der Reisende nur darauf zu achten, dass er Lage, Umfang, Ort und Dichtigkeit derselben angibt. Ihre Lage ist in die Karte einzuzeichnen, und die Aufnahme ihrer Grenzen ermöglicht zugleich die Berechnung ihres Areals.

Was die Art der Wälder ${ }^{1}$ ) anbetrifft, so bestehen dieselben selten aus einer einzigen Baumspecies; in der Regel sind mehrere Baumarten in wechselndem Verhältniss mit einander gemischt oder es finden sich isolirte Gruppen, welche von den übrigen Beständen verschieden sind. Der Reisende wird seine Aufmerksamkeit zuerst der vorherrschenden Baumart oder den mehreren wesentlichsten Species zuwenden, hierauf den seltenern, wenn diese immerhin in beachtenswerthem Maasse vorkommen. Nach der Verwendung, welcher das Holz fähig ist, unterscheidet man Bau- oder Werkholz, Farbholz, Holz für Parqueterie und eingelegte Arbeiten etc. Wenn man nun auch über die Art der Verwendbarkeit einer Holzspecies nicht im Zweifel ist, so wird man gleichwohl gut thun, davon Nuster zu nehmen, um sie Fachmännern zur Prüfung mitzutheilen; denn die Qualität und der technische Werth einer und derselben Baumart kann je nach dem Lande, dem Klima, Boden und Standort sehr verschieden sein. Die Proben, welche man entnimmt, sollen aus einem Querabschnitt (einer abgesägten Scheibe des Stammes) und einem oder mehreren Längsabschnitten (Tafeln oder Brettchen) bestehen.

Bei der Verschiedenheit in der Dichtigkeit der Waldungen genügt die Angabe ihres Umfangs nicht zur Bestimmung des Werthes oder Reichthums derselben; vielmehr müssen Angaben über deren Bestand beigebracht werden, d. h. über die durchschnittliche Anzahl Bäume, welche auf eine Hektare entfallen, über die Grösse derselben etc. $\mathrm{Zu}$ dem Ende durchwandert man den Wald nach verschiedenen Rich-

1) Vgl. hierüber das Kapitel "Regions et grands aspects" in $\mathrm{H}$. Kaltbrunner", Aidemémoire du voyageur, p. 150-232. 
tungen, wählt sich eine Partie aus, welche am ehesten die mittlere Bestandsdichtigheit repräsentirt und zählt hier die Bäume auf der Fläche einer Hektare; dann misst man bei einigren als typisch anzunehmenden Bäumen mit pinem Jessband den Stammumfang in einer Höhe ron etwa 1 Meter - ̈iller dem Boden oder bestimmt auf die s. 43 angegebene Weise die Höhe der Bäume. Wenn der Wald in seinem Bestande sehr rerschieden ist, wemn er z. B. stellenweise Lichtungen, anderwärts hlos Gebüsch oder vereinzelte Büume enthält, während manche Partien desselhen dichter Hochwald sind, so muss man denselben in Zonen oder lieviere eintheilen, jedes dieser Gebiete auf der Karte nach Lage und Lmfang besonders zeichnen und überhaupt so behandeh als ob es ein Wald für sich wäre.

Verschiedene Produkte. Die anderen Bodenschätze, wie mineralische Oele (Petroleum, Naphta u. s. w.), Schwefel, Borax, Salpeter: Alaun, Steinsalz, Kaolin, fossiles Elfenhein, Kalkphosphate und sonstige Düngstoffe rerdienen ein besonderes Sturlium ab Seite des Reisenden nur dann, wenn sie in der Gegrend ungewöhnlich reichlich vorhanden sind. Immerhin wird der Reisende von ihrem Vorkommen Yotiz nehmen und auch Muster derselben sammeln.

Accessorische Angaben. Der Reisende muss seinen Aufenthalt im Lande benutzen, um sich über Alles zu unterrichten, was von günstigem orler nachtheiligem Einfluss auf die Ausbeutung oder Verwerthung der natürlichen Reichthümer des Landes sein kann, und im Interesse Derer, welche sich hiemit befassen wollen, muss er Alles mittheilen, was er Sachbezügliches beobachtet oder erfahren hat.

Zunächst wird er sich darüber erkundigen, welche Schritte zu thun und welche Formalitäten zu erfüllen sind, um eine Konzession oder eine Erlaubniss für die fragliche Ausbeutung zu erhalten. In manchen Gegenden kann Jeder einfach und ohme Weiteres Hand ans Werk legen, und seine blosse Priorität bildet einen unanfechtharen Rechtstitel: hinwieder muss dieses Recht nöthicrenfalls mit eigener hraft und Gewalt geschützt werden, wenn Andere Lust zeigen, sich am gleichen Orte zu etabliren. Oft aber ist es nöthig, dass man sich einen Erlaubnissschein rerschaffe: dieser wird bald ohne Weiteres ertheilt, hald aber muss das Gesuch durch 
so viele Hände gehen und von so viel Personen geprüft und begutachtet werden, dass Jahre verstreichen können, bevor es erledigt ist.

Die schönste Konzession, welche in einem Lande ohne feste Regierung oder in einem despotischen Staate auf Gutdünken hin ertheilt wurde, hat in der Regel keinen Werth, weil keine bestimmte und gesicherte Dauer; der Unternehmex kann es erleben, dass sie ihm plötzlich entzogen wird, nachdem er grosse Installationskosten hatte. Sogar in Staaten von geordneter Regierungsform kommt es vor, dass die Verwaltungsorgane Schwierigkeiten machen und den Unternehmer in Allem zu hemmen suchen.

Der zweite, wohl zu prüfende Punkt ist die Frage nach Qualität und Preis der Handarbeit. Wenn das Land volkarm ist, wird es schwer halten, die nöthigen Arbeiter zu bekommen, und selbst wenn Leute im Ueberfluss vorhanden, so sind diese vielleicht ungeeignet für die Arbeit, welche man von ihnen verlangt. Wenn man nun ausser den Ingenieuren und Oberaufsehern auch noch die gewöhnlichen Arbeiter mit grossen Kosten kommen lassen und sie theuer bezahlen müsste, damit sie bleiben, so könnte das Unternehmen schwerlich lohnend sein.

Die Frage nach den Unkosten bei der Gewinnung und dem Transport der Produkte ist, wie bereits bemerkt, ein wesentlicher Faktor zur Beurtheilung der Rendite eines solchen Unternehmens. Sie hängt aber eng zusammen mit der Frage nach den Absatzgebieten oder Märkten für das Produkt, weil hiedurch, d. h. durch die Entfernung des Absatzortes, die Länge des Transportes bedingt ist. Ist der Reisende nicht in der Lage, diesen Gegenstand mit genügender Sachkenntniss $\mathrm{zu}$ behandeln, so suche er wenigstens Angaben zu liefern, welche annähernde Berechnungen gestatten. Solche Angaben haben sich zu beziehen auf die Lage des Platzes, die $\mathrm{Zu}-$ fahrten zu demselben, den Stand der Verkehrswege, die Distanzen, sowie auf Art und Zahl (ob viel oder wenig) der Transportmittel.

Man muss auch wissen, ob das Land die nöthigen Hülfsmittel bietet, damit ein Unternehmen in grossem Massstab betrieben werden kann; hievon hängt der Erfolg zu einem grossen Theile - mehr als man gewöhnlich glaubt - ab. 
Wenn man alles Nöthige, Geräthe, Nahrungsmittel u. s. w., ron weit her muss kommen lassen, dem Aufsichtspersonal und den Arbeitern Logis beschaffen und für die Hülfsindustrien, die jeweilen nöthig werden, selber sorgen muss, so wird das Internehmen in vielen Fällen zu kostspielig oder es erfordert doch sehr grosse Kapitalien. Selten zieht man den Nangel lokaler Hülfsquellen genugsam in Betracht; man ist zu sehr daran gewöhnt, alles Nöthige bei der Hand zu haben oder sich leicht verschaffen zu können und denkt so nicht an die einfachsten Erfordernisse, z. B. dass man, um Brod zu bekommen, einen Ofen haben muss und einen Arbeiter, der einigermassen das Backen versteht; dass man, um für frisches Fleisch und Gemüse zu sorgen, nothwendig Vieh halten, etwas Landbau treiben, einen Netzger und Gärtner haben muss; dass scheinbar unbedeutende Werkzeugreparaturen den Besitz einer Schmiede und eines Schmiedes erfordern, wenn man nicht einen Arbeitstag damit verlieren soll, die nächste Schmiedewerkstätte aufzusuchen. Diese Kleinigkeiten, die so unbedeutend scheinen, verursachen Auslagen, welche schliesslich insgesammt grosse Posten bilden.

\section{$B$. DER BODEN IN LANDWIRTHSCHAFTLICHER HINSICHT.}

In agricoler oder kultureller Beziehung versteht man unter Boden die lose Erdschicht zwischen der äusseren Erdfläche und dem anstehenden oder gewachsenen Fels in der Tiefe. Diese Schicht zerfällt in zwei verschiedene Partien. Die obere ist die Humusschicht oder der eigentliche Boden, die Dammoder Ackererde (sol végétal). Sie besteht aus einer Mischung loser Mineralsubstanzen mit zersetzten organischen Ueberresten. Die tiefere Lage heisst der Untergrund und besteht. zumeist aus Fragmenten aller an der Oberfläche vorkommenden Gesteinsarten des Landes. Diese beiden Bodenschichten unterscheiden sich gewöhnlich schon durch ihre Farbe von einander. Die Humus- oder Dammerdeschicht, die in Gegenden mit noch jungfräulichem Boden oft in reichlichem Naasse rorkommt, ist eine braune oder schwärzliche Substanz an der Oberfläche des Bodens, welche ihr Dasein der Zersetzung thierischer und pflanzlicher Stoffe verdankt. 
Der agrikole Werth des Bodens ist bedingt durch den Umfang und den Grad der Fruchtbarkeit des kulturfähigen Landes.

Die Fruchtbarkeit des Bodens kann zunächst beurtheilt werden durch die Beschaffenheit der stehenden Ernten auf kultivirtem Lande und durch das kümmerliche oder üppige Aussehen der auf noch unbebautem Lande wildwachsenden Pflanzen. Im letzteren Falle darf man jedoch nicht nach Sumpfpflanzen oder Dornen urtheilen, welche ein üppiges Dickicht bilden können, wiewohl der Boden für Kulturgewächse zu nass oder zu wenig tiefgründig ist.

Im Allgemeinen ist jeder Boden fruchtbar, der lose, nicht zu grobkörnig, tief, nicht übermässig feucht, hingegen den Sonnenstrahlen genugsam zugänglich ist; denn in einem solchen Boden können die Wurzeln der Pflanzen sich entwickeln und genügend Nahrung finden; Luft und Wasser können gehörig zirkuliren, Wärme und Feuchtigkeit in genügendem Maasse eindringen, um das Keimen und Reifen zu bewirken, ohne dass der Boden zu sehr dem Froste und der Trockenheit ausgesetzt ist.

Die Tiefe des Bodens ist die Dicke der Acker- oder Dammerdeschicht, von der Bodenoberfläche bis zum Untergrunde. Diese Tiefe steht gewöhnlich in naher Beziehung zur Fruchtbarkeit des Bodens; denn je grösser sie ist, desto eher finden die Pflanzen ihre Nahrung, selbst wenn der Boden an Nährstoffen nicht reich ist.

Die Dammerde darf weder zu grob sein, noch aus zu feinen Theilchen bestehen. Grobe Felstrümmer und Steine hemmen die Bearbeitung des Bodens und die Entwicklung der Pflanzen; andrerseits hat ein $\mathrm{zu}$ feinpulveriger, staubartiger Boden den Fehler, dass er schon nach schwachem Regen eine teigige Masse bildet, die beim Trocknen hart wird. Der Aggregatszustand des Bodens muss so sein, dass das Wasser in demselben langsam zirkulirt, ohne allzulange zurückgehalten zu werden.

Die Bodenfeuchtigkeit kann aus der Atmosphäre stammen, d. h. von Regen, Schneeschmelze, Dünsten und Nebeln herrühren. Dann dringt sie also von oben her in den Boden ein; wenn aber das Wasser den Untergrund erreicht, so muss es entweder von diesem absorbirt werden oder ab- 
fliessen können. Die Beschaffenheit des Lntergrunds ist daher nicht bedeutungslos. Ist el undurchlässig, so hält er das Wasser zurück und dieses, stagnirend, schadet den Pflanzen; ist er zu stark durchlassend, so wird der Boden kaum die nöthige Feuchtigkeit beibehalten.

Das Wasser des Bodens kann aber auch von seitlichen Infiltrationen der Flüsse und Seen oder aus unterirdischen Wasseransammlungen herstammen. In diesem Falle kam es rermöge der Kapillarität des Bodens bis an dessen Oberfläche gelangen; wenn aber dieses unterirdische Wasser in zu geringer Tiefe angesammelt ist, so wirkt es schädlich.

Das Wärmequantum, welches ein Borlen empfängt und absorbirt, hängt von mehreren Faktoren ab, deren wesentlichste das Klima, die Höhe über Neer und die Lage zu den Himmelsgegenden (die Exposition) sind. Die beiden letzteren können den Effekt des Klimas zum Theil paralysiren; bei geringer Höhe über Meer und einer mittäglichen (der "Sommenseite" oder südlichen Partie des Horizontes zugekehrten) Lage (auf der nördlichen Halbkugel) ist der Boden gegen strengen Frost geschützt, bei grosser Höhe und nördlicher Lage (auf der Schattenseite) gegen grosse Hitze $\left.^{1}\right)$.

Das Areal des urbaren Bodens einer Gegend kann auf folgende Arten bestimmt werden.

$1^{\circ}$ Von der Gesammtfläche zieht man das Areal desjenigen Bodens ab, welcher der Kultur entzogen ist, also das Areal der nackten Felsen, Gletscher, Sandwüsten und Dünen, stehenden und fliessenden Gewässer, Sümpfe, Torfmoore, überbauten Stellen (Städte; Dörfer etc.), Eisenbahnen, Strassen und Kanäle.

$2^{\circ}$ Man fasst im Gegentheil die einzelnen Komplexe kulturfïhigen Landes ins Auge und addirt deren Flächeninhalte.

1) Für die rasch vorübergehenden, aber nichts desto weniger gefährlichen Sffitfrüste des Frühjahrs und vorzeitigen Fröste im Ierbste (Reifbildungen) gelten besondere liegeln. Die Frühjahrsfröste sind sehr oft am gefährlichsten für die tiefer liegenden Gegenden. Es bängt dies zum Theil von ganz lokalen Verhältnissen $a b, z, B$, ob eine Oertlichkeit im Bereich der naichtlichen Thalnebel liegt oder nicht, gegen den Wind geschützt ist oder nicht; in manchen Gegenden gelten gewisse windgeschützte Stellen als ,Reiflöcher"; auch ist die Gefährlichkeit solcher Früste für die Lokalitäten mit Exposition gegen die Morgensonne geführlicher als für solche, welche nicht schon ron den ersten Sonnenstrahlen des Tages erreicht werden. Tgl. unten, Abschnitt "Klima". 
Da aber die verschiedenen Partien kulturfähigen Bodens von sehr ungleichem Werthe sind, so wird es nöthig, sie zu klassifiziren.

In Hochthälern und Hochebenen besteht meist nur eine dünne Schicht Ackerkrume unmittelbar über dem Felsgrunde. In diesem wenig mächtigen urbaren Boden macht sich der Wechsel von Frost und Hitze für die Pflanzen stark fühlbar und finden diese wenig Nahrung zu ihrem Wachsthum.

An ziemlich stark geneigten Halden wird die Dammerde oft von Regengüssen und austretenden Gewässern weggeschwemmt und bei starkem Gefälle wird das Pflügen des Bodens schwer, wo nicht unmöglich. Schwach geneigtes Terrain hingegen ist bei günstiger Exposition sehr vortheilhaft; das Regenwasser von den Höhen her unterhält hier eine genügende Feuchtigkeit und findet auch wieder hinreichenden Abfluss.

Boden unmittelbar am Fusse eines Berges lässt oft in Bezug auf seinen Aggregatszustand, d. h. die Grösse seiner Bestandtheile, zu wünschen übrig, indem die Dammerde hier oft mit groben Gesteinsbruchstücken untermischt ist. Zudem sind die Kulturen hier der Gefahr ausgesetzt, dass sie überschüttet und begraben werden durch Bergschlipfe oder durch Geröllmassen, welche Regengüsse und ausgetretene Wildwasser ins Thal herabschwemmen.

Die fruchtbarste Ackererde findet man gewöhnlich in den breiten Thalböden, Ebenen und Flussbecken. Sie besteht aus Alluvium, dessen auf langem Transporte zerriebenes Material den richtigen Grad der Zerkleinerung hat und meist reich ist an fruchtbaren Stoffen, welche die Gewässer in die Niederungen führten. Mitunter aber sind diese Gegenden wegen zu geringer Abdachung übermässig feucht oder von stehenden Gewässern bedeckt.

Eine erste und allgemeine Klassifikation des urbaren Bodens kann also erstellt werden nach Massgabe seiner Situation. Der Reisende wird sodann jede einzelne dieser Kategorien einer weitern vergleichenden Prüfung unterziehen, um ihre Vor- und Nachtheile kennen zu lernen und durch einen Mittelwerth bezeichnen zu können. 
Wiewohl die Ackerkirume von der Zersetzung der Gesteine herrührt, welche die feste Erdrinde bilden, so besteht nicht immer eine unmittelbare Uebereinstimmung zwischen der Dammerde einer Gegend und dem Gestein, auf welchem sie liegt. Die Ackerkrume kann allerdings an Ort und Stelle entstanden sein, durch langsame Zersetzung des gewachsenen Felsens; sie kann aber auch durch Wasser, Winde etc. hertransportirt sein und steht dann natürlich nicht in Beziehung zu dem Fels, der ihre Grundlage bildet.

Die geologische Karte gestattet daher keine sichern Schlüsse auf die mineralogische Zusammensetzung der Ackerkrume einer Gegend. Im diese Zusammensetzung kennen zu lernen, nimmt man Bodenproben, wobei man bis zu $15 \mathrm{~cm}$ Tiefe geht, und analysirt dieselben gemäss dem auf S. 99 angegebenen Verfahren; kann das aus Nangel an Zeit nicht unmittelbar an Ort und Stelle rorgenommen werden, so packt man diese Iruster, nachdem sie sorgfältig etiquettirt wurden, ein, um sie später zu untersuchen. Auf einer in grossem Massstab erstellten Karte der Gegend bezeichnet man die Grenzen des urbaren Bodens, sowie die Punkte, ron welchen man Nuster nahm. Zu diesem Zwecke kann man sich nur in grossen Zügen eine Pause des topographischen Croquis der Gegend anfertigen.

Sind die Bodenproben analysirt, so klassifizirt man die Bodenarten nach ihrer mineralogischen Zusammensetzung und stellt sie allenfalls auch in der Karte oder Pause mittels rerschiedener Farben dar.

Die Hauptbestandtheile der Ackerkrume sind Thon, Kalk, Sand und Humus. Das Verhältniss derselben ergibt folgende Klassifikation :

I. Thonboden . . . . .

II. Sand. Thonboden (Lehmboden)

III. Kalkthonboden (Mergelboden).

IV. Humöser Thonboden . . . .

V. Sandboden .

VI. Thoniger Sandboden . . .

VII. Kalkbaltiger Sandboden. . .

VIII. Humöser Sandboden . . . .

IX. Kalkboden.

x. Humusboden

\begin{tabular}{|c|c|c|c|}
\hline $\begin{array}{c}\text { Thon } \\
0,0\end{array}$ & $\begin{array}{c}\text { Kalk } \\
0 \%\end{array}$ & $\begin{array}{c}\text { Sand } \\
0 / 0\end{array}$ & $\begin{array}{l}\text { Humus } \\
-0 / 0\end{array}$ \\
\hline iber 40 & unter 5 & unter 50 & $5-10$ \\
\hline über 30 & unter 5 & $50-70$ & $5-10$ \\
\hline über 30 & $5-10$ & unter 50 & $5-10$ \\
\hline über 30 & unter 5 & unter 50 & über 10 \\
\hline inter 10 & unter 5 & über 80 & $5-10$ \\
\hline $10-20$ & unter 5 & über 70 & $5-10$ \\
\hline ter 10 & $5-10$ & über 70 & $5-10$ \\
\hline ter 10 & anter 5 & über 70 & über 10 \\
\hline ter 1 & über 10 & $50-70$ & $5-10$ \\
\hline & & ter 50 & ber $2 c$ \\
\hline
\end{tabular}


Man gibt auch die Dicke der Ackerkrume an und ebenso annähernd die Dicke des Untergrunds oder man bezeichnet diese letztere etwa folgendermassen:

flach - bei weniger als $0,3 \mathrm{~m}$ Dicke,
mittelmässig - bei 0,3 bis $0,5 \mathrm{~m}$ - bei über $0,5 \mathrm{~m}$
tief

Die Qualität des Untergrundes wird bezeichnet als:

$\begin{array}{ll}\text { sandig, } & \text { kalkig, } \\ \text { steinig, } & \text { mergelig, } \\ \text { felsig, } & \text { thonig (lehmig). }\end{array}$

Man bemerke auch, ob der Boden kompakt oder locker und namentlich, ob er durchlassend oder undurchlässig sei.

Hinsichtlich der Bodenfeuchtigkeit kann man etwa 5 Klassen aufstellen, die in folgender Weise durch Nummern bezeichnet werden :

1. sehr trockener Boden,

2.

3. mittlere Feuchtigkeitsgrade,

4.)

5. nasser oder sumpfiger Boden.

Dabei wäre mit Nummer 3 ein Boden von mittlerem oder normalem Feuchtigkeitsgehalt zu bezeichnen und die Nummern 2 und 4 hätten anzuzeigen, ob der in Rede stehende Boden dem einen oder andern Extrem näherstehe.

Mit Bezug auf die Nutzbarmachung disponiblen Bodens in der fraglichen Gegend müssen die vorerwälnten Angaben ergänzt werden durch solche über Absatzorte (Märkte) und Transportmittel; denn sie bedingen die Möglichkeit, den Boden zu Nutze zu ziehen, sowie die beste Art dieser Benutzung. Das fruchtbarste Land hat wenig Werth, wemn es für die gewonnenen Produkte an Absatz fehlt. Liegt es weitab von jeder grossen Ortschaft und sind die Verbindungen schlecht, so kann man den Betrieb nicht auf solche Produkte einrichten, deren Transport kostspielig ist; man wird sich dann wesentlich mit Viehzucht befassen, weil das Vieh selbst den Weg nach den Märkten, beziehungsweise nach den Schlachthäusern machen kann oder davon nur Theile wie Häute und Wolle zu transportiren sind. Die Nähe eines bedeutenden Absatzortes, einer grossen Stadt, der gute Zustand der Strassen und ungewöhnlich günstige Transportgelegenheiten (auf Flüssen, Kianälen, Eisen- 
bahnen etc.) können hingegen selbst mittelmässigen Ländereien grossen Werth rerleihen: denn indem sie den Betrieb) der rortheilhaftesten Kultur gestatten, ermöglichen sie eine sichere Tiendite. Die Nähe volkreicher Städte macht auch eine Gartenoder Gemüsekultur in grossem Massstabe möglich: und da liehei die Beschaffung von Dünger leicht ist, so kann die kleinste Landparzelle zu einer unerschöpflichen Goldgrube werden, indem sie weit mehr Produkte zu liefern vermag als ein ausgedehntes, aber ungünstig situirtes Landstïck.

Auch mit Bezug anf agrikole Unternehmungen muss man sich, wie hinsichtlich der industriellen, nach den Schritten und Formalitäten erkundigen, die erforderlich werden zum Erwerbe ron Rechten auf die Benutzung des Bodens, ferner nach den Garantien gegen die Gefahr des Depossedirtwerdens.

Wenn der Absatz der Bodenprodukte hinlänglich gesichert und als Folge der Bevölkerungsvermehrung eine wachsende Nachfrage zu erwarten ist, so richte man sein Augemmerk auch darauf, ob für die fragliche Kultur noch Ländereien gewonnen werden können, die jetzt dazu noch ungeeignet sind, oder ob die Produktivität von Ländereien, die zu wünschen lässt, gesteigert werden kann. Das Erstere kann erreicht werden durch Lrbarisirung ron Wäldern, Sümpfen, seichten Weihern und Seebuchten, ferner durch Errichtung von Teichen oder Dämmen, welche das Flachland gegen das Eindringen ron Wasser schützen. Zu diesen Vorkehrungen ist auch die Korrektion und Kanalisation der Flüsse zu rechnen, sowie die Anlage ron Pflanzungen, welche dem periodischen Austreten der Gewässer entegegenwirken sollen. Bevor man solche Anordnungen trifft, wird man sich aber darüber Gewissheit verschaffen, ob das zu gewinnende Land an sich diejenigen Eigenschaften und den. Werth hat, dass es als hompensationsobjekt für die Kosten gelten darf, und ob das Abholzen von Wäldern, sowie die Austrocknung grösserer Wasserbehälter nicht ron nachtheiliger Wirkung auf den Boden, resp. dessen Fenchtigkeitsgrad, sind. Eine Steigerung der Produktionsfähigkeit des Borlens wird bewirkt durch Beseitigung seiner wesentlichen Fehler. So z. B. haben die artesischen Brunnen, we]che man in der Sahara grub, wüste Sandtlächen in fruchtbare grüne Oasen 
umgewandelt. Von solchen extremen Fällen abgesehen, könnten noch viele Ländereien verbessert werden entweder durch eine rationelle Bewässerung, wenn sie an Trockenheit leiden, oder durch Entwässerung, wenn sie zu feucht und sumpfig sind. Mitunter kann man unfruchtbaren magern Boden verbessern durch Kolmatirung, durch Anschlämmen von Bestandtheilen, die ihm fehlen. Die Operation besteht bekanntlich darin, dass man über jenes Land Wasser hinleitet, welches mit feinem Schlamm und organischen Resten beladen ist, welche Bestandtheile sich dann ablagern und den Boden fruchtbarer machen müssen. Diese Kolmatirungen sind indess seltener anwendbar als andere Bodenameliorationen. Zur Vornahme der letztern findet man bei einiger Aufmerksamkeit meistens in der Nachbarschaft mittelmässigen Bodens die Elemente, welche derselbe nöthig hat, um eine fruchtbare Erde zu bilden. Oft sind diese Elemente schon im Untergrund enthalten; dann sind sie durch tiefes Umarbeiten desselben (Rigolen) in die Höhe zu bringen und mit der Ackerkrume zu mischen. Anderorts muss man sie aus einiger Entfernung herbeischaffen, auf dem Boden ausbreiten und sie mit demselben mischen durch Umplügen und kräftiges Eggen. Was man im Allgemeinen als Bodenmeliorationen, im Speziellen als Kalken, Mergeln u. dgl. bezeichnet, beruht Alles auf dem nämlichen Prinzip, nämlich darauf, dass man einen Boden verbessert durch Mischung mit den Bestandtheilen, welche ihm fehlen; dass man so, jenachdem, bewirkt, dass er weniger kompakt wird und leichter zu bearbeiten ist oder geeigneter, Feuchtigkeit zurückzuhalten und Pflanzennahrstoffe zu absorbiren, oder dass seine chemisch-mineralogische Zusammensetzung korrigirt wird durch Zusatz von Kalk, Thon u. s. f., je nachdem ihm dieser oder jener Bestandtheil fehlte.

Wenn endlich in der Gegend selbst Stoffe vorkommen, die als Düngmittel brauchbar sind, wie Seealgen oder Tange, marine Sande mit organischen Ueberresten, Muschellager, Guano (wenn auch von geringer Qualitäı), Phosphate, Karnalit u. s. w., so unterlasse der Reisende nicht, dies zu erwähnen, weil diese Stoffe, wiewohl als Ausfuhrartikel ohne Bedeutung, von grossem Werthe sind für die Steigerung der Produktivität des Landes. 


\section{KLIMA.}

Als Klima eines Ortes oder eines Landes bezeichnet man die Witterungsverhältnisse desselben, d. h. den Zustand der Atmosphäre und des Himmels daselbst.

Die sachbezüglichen Beobachtungen erstrecken sich also auf Temperatur, Luftfeuchtigkeit, Luftdruck, Richtung, Stärke and sonstige Beschaffenheit der vorherrschenden Winde, Bewölkung des Himmels, atmosphärische Niederschläge u. s. w.

Die Faktoren, welche das Klima bedingen, sind sehr verschieden: die geographische Lage, die Höhe über Meer, die Exposition, grössere oder geringere Nähe am Meer oder Entfernung von demselben, Richtung und Höhe der Bergketten, Reichthum oder Armuth an Vegetation sind ron solchem Einfluss auf das Klima, dass vielleicht nicht zwei Gegenden der Erde ganz dasselbe Klima haben und es ron Wichtigkeit ist, dass die Eigenthümlichkeiten des Klimas eines Ortes oder einer Gegend genau erforscht und dargestellt werden.

Wo meteorologische Observatorien oder Stationen vorhanden sind, welche mit guten Instrumenten wissenschaftlichen Beobachtungen obliegen, wird sich der Reisende selbstverständlich damit begnügen, die schon vorhandenen Angahen zu rekapituliren; wo wenigstens einzelne individuelle Beobachtungen gemacht wurden, wird er diese sammeln und angemessen verwerthen. Direkte eigene Beobachtungen werden also auf Lokalstudien in noch ziemlich unbekannten Ländern oder in entlegenen Ortschaften beschränkt sein.

Ist die Gegend, um welche es sich handelt, kolonisationsfïhig, so hat man ihr Klima, namentlich rom hygieinischen Standpunkte aus, zu studiren, weil ron dem gesunden oder ungesunden Klima Erfolg oder Misserfolg künftiger kolonisatorischer Unternehmungen abhängen kann.

Bleibenden Werth erlangen die meteorologischen Beobachtungen freilich erst, wem sie sehr lange Zeit fortgesetzt werden: denn nur so kommt man zur Kenntniss der normalen oder durchschnittlichen Witterungsverhältnisse, der Mittelwerthe für die verschiedenen klimatischen Faktoren. Gleichwohl vernachlässige der Reisende die isolirten Beohachtungren, die 
er en passant anstellen oder sammeln kann, nie; denn diese Angaben können einerseits als Ausgangspunkte, als erste Elemente, dienen und von andern Reisenden ergänzt werden, um daraus Mittelwerthe abzuleiten; andrerseits können sie beitragen zur Kenntniss der Abweichungen von schon ermittelten Durchschnittsverhältnissen, der sogenannten Anomalien, welchen in neuerer Zeit nicht weniger Beachtung zu Theil wird als den Mittelwerthen, während sie früher diesen gegenüber von der Meteorologie vernachlässigt wurden.

Temperatur. Die Temperatur, d. i. der Wärme- oder Kältegrad eines Punktes zu einer gegebenen Zeit wird, wie bekannt, mit dem Thermometer gemessen. Da hiefür drei verschiedene Gradeintheilungen oder Skalen bestehen, so muss man jeweilen angeben, welche derselben benutzt wurde. Ist man genöthigt, bei den Beobachtungen ein Thermometer zu verwenden mit einer anderen Eintheilung als derjenigen, die man zu gebrauchen wünschte, oder sind die indirekt erhaltenen Temperaturangaben nach einer solchen Skala gemacht - nach Réaumur oder Fahrenheit, während man Centigrade wünschte - so können mit Hülfe der Taf. VI im Anhang dieses Buches leicht die nöthigen Umrechnungen vorgenommen werden.

Vir setzen voraus, der Reisende habe sich vor der Abfahrt mit einem guten Instrument versehen und dessen Angaben bei jeder vorkommenden Gelegenheit mit denen andrer Thermometer verglichen. Eine solche Verifikation muss sich, damit sie zuverlässig sei, auf mindestens zwei Punkte der Skala beziehen. Zu dem Ende taucht man das zu prüfende Instrument und ein Normalthermometer in warmes Wasser von etwa $40^{\circ}$, sodann in Wasser von gewöhnlicher Temperatur oder noch besser in schmelzenden Schnee, und notirt die Differenzen, welche das zu untersuchende Thermometer gegenüber dem als Norm dienenden Instrument aufweist. Diese Korrektionen bleiben für mehrere Jahre unverändert.

Es kann indess vorkommen, dass man ein Instrument anwenden muss, hinsichtlich dessen Ziverlässigkeit wir keine Garantien haben und das man nicht durch Vergleichung mit einem Normalthermometer verifiziren kann. Es mag desshalb am Platze sein, hier anzugeben, wie man sich in solchen Fällen vergewissern kann, dass keine merklichen Fehler vor- 
kommen. Zu dem Ende taucht man die Kugel und den untern Theil der Röhre des Instrumentes in ein Gefäss, in welchem Eis oder Schnee mit Wasser zu einem dicken Brei vermischt sind. Ist das Instrument genau, so muss das (Uuecksilber bei jeder Wiederholung des Versuches bei dem Theilstrich stehen bleiben, welcher der Temperatur schmelzenden Eises entspricht, d. i. bei $0^{0}$ nach der Celsius'schen und Réaumur'schen Skala, bei $+32^{\circ}$ nach Fahrenheit. Andernfalls kennt man nun die Differenz, welche man den Angaben des Instrumentes hinzufügen oder von denselben abziehen muss, um die wahre Temperatur zu erhalten ${ }^{1}$ ). Noch besser bringt man zerstossenes Eis in ein durchlüchertes Gefäss, aus welchem das Schmelzwasser abfliessen kann, wolei in einem Lokal von über $0^{\circ}$ Temperatur zu operiren ist. - Ferner verifizirt man das Instrument, indem man dasselbe in den Dampf bringt, welcher bei einem Luftdruck ron $760 \mathrm{~mm}$ siedendes Wasser erzeugt. Ist das Instrument richtig, so muss es um 100 Centigrade, $80^{\circ}$ nach Réaumur und $212^{\circ}$ nach der Fahrenheit'schen Skala zeigen. - Während bei den Quecksilberthermometern die Verifikation für längere Zeit und erst nach ziemlich langen Intervallen wiederholt werden muss, sollten Weingeistthermometer, welche bei Reisen viel mehr Störungen unterworfen sind, vor jedesmaligem Gebrauche mit einem Quecksilberthermometer verglichen werden.

Wemn die Quecksilhersäule des Thermometers sich auf der Reise in zwei oder mehr Partieen trennt oder Quecksilhertropfen oben an der Glasröhre hängen bleiben, so muss man dem Instrument leichte Stösse ertheilen oder es vorsichtig erhitzen, bis die verschiedenen Quecksilberpartieen sich wieder rereinigt haben. Die Abkühlung des erhitzten Instrumentes darf, wie die Erwärmung, auch nur langsam erfolgen.

Vor jedem Gebrauche hat man Kugel und Röhre des Thermometers sorgfältig von Staub und Feuchtigkeit zu reinigen, wenn dies im geringsten nöthig scheint.

Da man auf der Reise nicht jeden Augenblick am Instrumente Ablesungen machen kamn, so merke man sich, dass

1) Bei den meisten neu angefertigten Thermometern rückt der Nullpunkt mit der Zeit - und zwar besonders stark im Anfang - hinauf, sodass alle abgelesenen Temperaturen zu hoch sind. Die Viellpunktskorrektion ist dann von den positiven Temperaturen zu subtrahiren, den negativen aber hinzuzufügen. 
in der Regel das Maximum der Tagestemperatur zwischen 2 und 3 Uhr Nachmittags eintritt, das Minimum aber etwa $1 / 2$ Stunde vor Sonnenaufgang, und dass die halbe Summe dieser beiden Zahlen von der Mitteltemperatur der 24 Stunden des Tages nur wenig abweicht. Folglich kann man sich auf 2 tägliche Temperaturbeobachtungen beschränken, wenn man diese in den genannten Zeitpunkten macht. Konvenirt es nicht, die eine Beobachtung so früh anzustellen oder ist man nicht sicher, dass man in dem Zeitpunkt, wo die andere gemacht werden sollte, wieder am Beobachtungsorte sei, so wendet man Maximum- und Minimumthermometer an.

Es ist indessen gut, dass man soviel möglich auch in der Zwischenzeit Beobachtungen mache, z. B. von 3 zu 3 Stunden, um so ein Bild zu erhalten von dem Gange oder den Schwankungen der Temperatur im Verlaufe eines Tages. Als Zeitpunkte für solche Beobachtungen wird man etwa die folgenden wählen: $3^{\text {h }}, 6^{\text {h }}, 9^{\text {h }}$ Vormittags; $12^{\text {h }}$ Mittags ; $3^{\text {h }}, 6^{\text {h }}, 9^{\text {h }}$ Nachmittags und $12^{\text {h }}$ Mitternacht, wobei man die Beobachtungen zur Nachtzeit einem Wächter überträgt, beziehungsweise Denen, welche nächtlicherweile die Runde um das Lager zu machen haben. Hat man sich einmal für bestimmte Zeitpunkte entschieden, so ändere man dieses System nicht ohne Noth und jedenfalls nicht ohne eine bezügliche Notiz im Reisejournal.

Die Mitteltemperatur eines Ortes zu bestimmen, ist schwieriger als man oft glaubt. Die Exposition desselben, Strahlung, Luftströmungen etc., wirken auf den Stand des Thermometers ein. Nan muss daher hierauf Rücksicht nehmen und alle störenden Einflüsse zu vermeiden suchen. Das Instrument bringt man in einer Höhe von etwa $1 \mathrm{~m}$ über dem Boden und wenigstens $1 / 2 \mathrm{~m}$ von jeder Mauer oder Felswand entfernt an. Es muss immer im Schatten, auf der nördlichen Halbkugel also gegen Norden, auf der südlichen gegen Süd, gerichtet sein. Wemn es aber geschützt werden soll vor Sonnenstrahlen und Regen wie auch vor kalten und warmen Winden, so muss es doch wieder genügend der Luft ausgesetzt sein. Diese verschiedenen Bedingungen sind nicht immer leicht zu erfüllen. Bei Aufstellung des Instrumentes im Freien möchte man etwa hiezu eine schattige Stelle in einem Walde am Saume desselben wählen; aber die Temperatur unter den 
Bäumen ist nicht dieselbe wie im offenen Lande: sie ist im Sommer niedriger und im Winter höher. Auch sind dort die Zeitpunkte für die Temperaturextreme andere und zwar spätere. Unter einem Zelte kann man das Instrument auch nicht anbringen, denn dabei würde man wieder nicht die Temperatur der Luft in Freien erhalten. In solchen Fällen bleibt nichts andres übrig, als an dem Instrument eine Schnur anzubringen (es zu einem Schleuder-Thermometer zu machen) und es nun so lange lebhaft in der Luft zu schwingen, bis dis Quecksilher einen festen Stand amnimmt. So erhailt man selbst in rollem Sonmenlichte ziemlich genau die richtige Luftemperatur.

Ist einmal das Thermometer an einer bestimmten Stelle angehracht, so muss man es ziemlich lange dort lassen, damit es die Temperatur seiner Lmgebung annimmt. Jas Ablesen muss schmell und ohne Berührung des Instrumentes greschehen, damit nicht der Athem und die ausstrahlende Körperwärme den Stand des Quecksilber's verändere. Bei nächtlichen Beobachtungen hüte man sich, ein Licht in die Nähe des Instrumentes zu bringen; zum Ablesen bediene man sich liebei einer kleinen Phiole, die ein Stück Phosphor in siedendem Olivenöl enthält, mit welch letzterem ${ }^{2 / 3}$ des Gefässes gefüllt sind. So oft man die Phiole entliorkt, leuchtet der Yhosphor auf und man kann damn die Ablesung machen. Bei dieser sind - ob sie am Tage oder in der Nacht vorgenommen werde - zuerst die Bruchtheile (Zehntel) der Grade abzulesen und erst dann die ganzen Grade; auf diese Weise ist man am ehesten gesichert gegen den störenden Einfluss der Anmäherung des Beobachters. Giht die Skala keine Zehntel an, so schätzt man diese ab nach dem Stande des Quecksilbers zu den nächsten Theilstrichen. Dabei wird es kaum der Bemerkung bedürfen, dass die Zehntel bei Wärmegraden (über $0^{\circ}$ ) nach oben, bei Kältegraden (unter $0^{n}$ ) nach unten zu nehmen sind.

Bei Placirung eines Minimumthermometers bringt man das Instrument in etwas geneigte Lage, so dass die Kugel sich höher befindet als das andere Ende der Glasröhre. Hiebei rückt der Schwimmer bis an's Ende der Weingeistsäule vor, wo ex Halt macht. Nummehr legt man das Instrument horizontal und liasst es in dieser Lage während des ganzen 7eitraums, für welchen man die Minimaltemperatur bestimmen 
will, also z. B. während der ganzen Nacht. Da, nach der Konstruktion dieses Thermometers, der Index (Schwimmer) gegen die Kugel gezogen wird, wenn die Weingeistsäule sich zurïckzieht, aber in Ruhe bleibt, wenn die Flüssigkeit sich ausdehnt und gegen das andere Ende der Glasröhre vorrückt, so bezeichnet das von der Kugel abgekehrte Ende des Schwimmers die niedrigste Temperatur der Beobachtungsperiode, welche Position auch im Momente der Ablesung die Alkoholsäule einnehme.

Das Maximumthermometer hingegen bringt man so an, dass die Kugel unten ist und gibt ihm leichte Stösse bis der Index (Stahlstift oder Bolzen) dicht auf die Quecksilbersäule zu liegen kommt. Dann legt man auch dieses Instrument wagrecht und lässt es in dieser Lage bis nach gemachter Ablesung. Das der Kugel abgewendete Ende des Index bezeichnet nun die höchste Temperatur der Beobachtungszeit; es ist das der Punkt der festen Skala, bis zu welchem der bewegliche Index (Stift) von der Quecksilbersäule vorgeschoben wurde und wo das Quecksilber denselben liegen liess, als es sich zurückzog.

Zweck der thermometrischen Beobachtungen ist die Kenntniss der Temperaturextreme, der täglichen Wärmeschwankungen, d. h. der Temperaturveränderungen innerhalb 24 Stunden, endlich der täglichen, monatlichen und jährlichen Temperaturmittel. Wir haben nun soeben angegeben, wie man die Temperaturextreme ermittelt. Was die täglichen Schuankungen der Temperatur betrifft, so sind zu deren Kenntniss Beobachtungen in kurzen Intervallen nöthig, z. B. allstündliche oder solche von 2 zu 2 Stunden, und zwar sollten diese Beobachtungen mindestens den Zeitraum eines ganzen Jahres umfassen. Solches kann man nun nicht von einem Reisenden erwarten, sondern nur von Personen, die während langer Zeit in einem Lande verweilen. Der Reisende soll aber doch soviel Beobachtungen dieser Art machen als ihm nur möglich ist; dabei wechsle er mit den Stationen ab, operire bald an der Meeresküste, bald im Innern, bald im Flachland und bald im Gebirge, das eine Mal bei hellem, ein andres Mal bei bedecktem Himmel etc. Kann man an ein und derselben Station zum zweiten Mal, in einer anderm Jahreszeit, Beobachtungen anstellen, um so besser. 
Behufs Veranschaulichung der Resultate überträgt man dieselben auf carrirtes Papier nach der in Fị. :20:3 dargestellten Art. Am linken Rande bringt man als Skala die Thermometergrade an, unten die Stunden. Die rom Beginn der Beobachtung an verflossenen Zeiten erscheinen somit als Abszissen; auf der Ordinate (Senkrechten) welche einem gegehenen Zeitpunkt zugehörte, trägt man die entsprechende

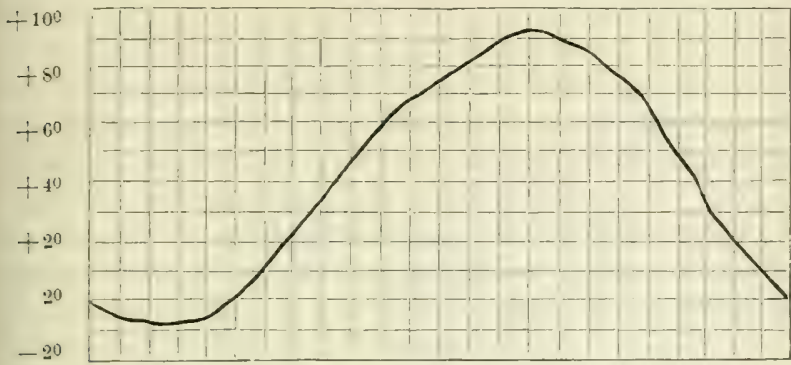

Mitternacht $2 \quad 4 \quad 6 \quad 8 \quad 10$ Mittags $2 \quad 4 \quad 6 \quad 8 \quad 10$ Mitternacht

Fig. 203.

Temperatur auf; die so erhaltenen Punkte verhindet man durch eine Kurve, welche nun die Schwankungen (Variationen) oder den Gung der Temperatur während des Beobachtungszeitraums vorstellt.

Die Hitteltemperaturen erhält man ganz einfach, indem man die (algebraische) Summe der sämmtlichen abgelesenen Temperaturen durch die Anzahl der Beobachtungen dividirt ${ }^{1}$ ).

Kennt man nur die Temperaturextreme eines Tages, d. h. eines Zeitraums ron 24 Stunden, so ist die halbe Summe derselben (das arithmetische Mittel) als Mitteltemperatur anzusehen, z. B.:

\begin{tabular}{lrrr} 
Maximum & $25^{0}$ & $+15^{0}$ & $+7^{0}$ \\
Minimum & $9^{0}$ & $-3^{0}$ & $-17^{0}$ \\
\cline { 2 - 4 } Summe & $34^{0}$ & $+12^{0}$ & $-10^{0}$ \\
Mittel & $17^{0}$ & $+6^{0}$ & $-5^{0}$
\end{tabular}

1) Ausser den S. 40 erwähnten 2 täglichen Beobachtungen und denjenigen ion $3 \mathrm{zu} 3$ Stunden können hiezu auch solche von 6 zu 6 Stunden benutzt werden, erner 3 malige Beobachtungen im Laufe eines Tages: $6 \mathrm{~h}, 2 \mathrm{~h}, 10 \mathrm{~h}$ oder $7 \mathrm{~h}, 1 \mathrm{~h}, 9 \mathrm{~h}$. 
In entsprechender Weise wird die Mitteltemperatur bestimmt, wenn man im Laufe der 24 Stunden 4 oder $6 \mathrm{Be}$ obachtungen machte, z. B.:

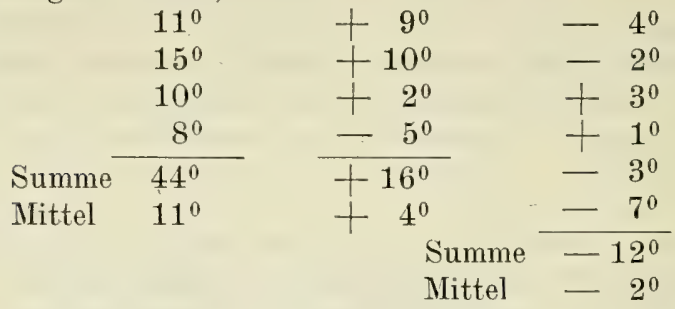

In ähnlicher Weise erhält man die Mitteltemperatur eines Monats oder eines Jahres, indem man die Summe der abgelesenen Temperaturen durch die Gesammtzahl der Ablesungen dividirt; einfacher addirt man die Tagesmittel und dividirt diese Summe durch die Zahl der Tage des betreffenden Monats oder des Jahres. Zu dem Ende wäre aber nöthig, dass der Reisende während langer Zeit täglich Beobachtungen machte, was in den meisten Fällen unmöglich ist. Da zudem die einzelnen Jahrgänge verschieden sind, so kann die wahre Mitteltemperatu cines Ortes nur erhalten werden aus mehrjährigen ununterbrochenen Beobachtungen ${ }^{1}$ ). Um nun die mittleren Temperaturen der besuchten Orte wenigstens annähernd kennen zu lernen, muss der Reisende Mittel anwenden, die rascher zum Ziele führen als die erwähnte genaue Methode. Ein solches Mittel bieten Beobachtungen der Bodentemperatu in einer Tiefe von $15-25 \mathrm{~m}$ oder, was dem Reisenden weit leichter fällt, Beobachtungen über die Temperaturen der Quellen in der Gegend (selbstverständlich mit Ausschluss der Thermen) oder nicht zu tiefer Brunnen und endlich unterirdischer Räumlichkeiten (Souterrains).

Die Temperatur des Erdbodens muss in um so grösserer Tiefe gemessen werden, je grösser für die betreffende Gegend der Unterschied zwischen Sommer- und Wintertemperatur ist. Unter den Tropen, wo die Jahreszeiten sich nicht sehr von

1) In den Aequatorialgegenden sind die Abweichungen der einzelnen Beobachtungen von den mittleren Werthen sehr geringfügig; dort stellen schon einjährige Beobachtungen fast genau die mittleren Wärmeverhältnisse eines Ortes dar; je weiter aber ein Ort vom Aequator entfernt liegt, einer um so längern Beobachtungsdauer bedarf es, um dessen durchschnittliche Temperaturverhältnisse festzustellen. Vgl. Hann, Hochstetter und Pokorny, Allgemeine Erdkunde S. 75. 
einander unterscheiden, hören die Schwankungen im jährlichen Gang der Wärme schon in greringer Tiefe auf. In der gemässigten Zone muss man schon tiefer in die Erde eindringen, um auf eine Schicht mit konstanter Temperatur zu treffen. Indem man eine solche aufsucht, hat man wie schon oben, S. 285 , bemerkt wurde - sich zu hüten vor Stellen, an welchen das Thermometer störenden Einflüssen ausgesetzt wäre, z. B. durch Sickerwasser, benachbarte heisse Quellen, Mofetten u. dgl. An der gewählten Stelle gräbt man ein Loch und versenkt das Thermometer, nachdem man dessen Kugel mit einem schlechten Wärmeieiter (Wolle, Werg, Wachs, Harz etc.) umgeben und das ganze Instrument zu dessen Schutze in eine Schachtel gehracht hat. Hierauf verstopft man das Loch wieder angemessen mit Erde, wohei vorzusorgen ist, dass nicht Tagwasser in dasselbe fliessen kann. Man lässt das Thermometer wenigstens 12 Stunden in der Erde, bevor man es zum Zwecke des Ablesens der Bodentemperatur herausnimmt.

Zur Bestimmung der (uellentemperetur sucht man Quellen anf, die sich in normalen Verhältnissen befinden; solche dürfen also nicht unmittelbar von schmelzendem Schnee oder Gletschermasser genährt werden, noch in der Nähe thätiger Vulkane sich befinden; ebenso sind von diesen Beobachtungen Quellen auszuschliessen, deren Wasser sehr tief in die Erde eingedrungen ist, bevor es wieder zu Tage trat. Die Temperatur der Quelle wird sodann bestimmt, indem man das ganze Thermometer in dieselbe eintaucht und zwar möglichst nahe an der Stelle, wo das Wasser hervorsprudelt und indem man das Instrument lange genug im Wasser lässt, damit es dessen Temperatur annimmt. Dann zieht man es soweit heraus, lass die Ablesung gemacht werden kann und wiederholt das Verfahren noch ein- oder zweimal; sind zwischen deu Bebachtungen Differenzen vorhanden, so nimmt man das Mittel lerselben. Die Ablesung muss selbstverständlich sehr rasch urfolgen, sodass inzwischen das Instrument nicht durch die suftemperatur beeinflusst werden kann. Die Quellentemperatur ind die mittlere Lufttemperatur eines Ortes stimmen indessen uur genau überein in den Zonen zwischen $30^{\circ}$ und $40^{\circ}$ Iördlicher oder südlicher Breite; näher am deruator ist die nittlere (Luft-) Temperatur eines Ortes etwas höher als die 
Quellentemperatur; zwischen 40 und $55^{\circ}$ ist die erstere etwas tiefer, und diese Differenz nimmt jenscits des 55. Breitegrades merklich zu. Auch gilt die Uebereinstimmung zwischen Luft- und Quellenwärme nur bis zu $1000 \mathrm{~m}$ absoluter Höhe; in grösseren Höhen sind die Quellen um mehrere Grade wärmer als die Luft.

Ausserhalb des Gebietes, in welchem die Mitteltemperatur eines Ortes mit seiner Quellentemperatur übereinstimmt, muss man womöglich in verschiedenen Jahreszeiten gewöhnliche Temperaturbeobachtungen vornehmen. Diese werden durch Angaben andrer Reisenden vervollständigt werden, und indem man die Daten aus gleich weit von einander abstehenden Monaten vergleicht, wird man einen approximativen Mittelwerth konstruiren können.

Eine Aufgabe des Reisenden wird es auch sein, Beobachtungen zu machen über die Abhüngigkeit der Lufttemperatur ron der Hühe $\left.{ }^{1}\right)$. Das beste Verfahren hiefür wäre das, dass man mit vorher verglichenen Thermometern an verschiedenen Punkten, welche in horizontaler Richtung nicht weit auseinander liegen, in vertikaler aber je zirka $300 \mathrm{~m}$ Abstand zeigen, gleichzeitige Beobachtungen vornähme. Da dies aber nicht immer möglich ist, so wird der Reisende wenigstens notiren, in welcher Höhe gewisse Kulturpflanzen, Baumarten, die Wälder aufhören und der ewige Schnee beginnt (vgl. S. 253).

In manchen Fällen wird der Reisende auch die Lufttemperatur auf hohen Bergspitzen bestimmen oder doch deren Extreme, letztere, indem er ein Maximum- und ein Minimumthermometer anbringt, das später von ihm oder seinen Nachfolgern beobachtet wird.

Die Messungen der Lufttemperatur, von welchen bisher die Rede war, müssen im Schatten und an Stellen, welche vor Wind geschützt sind, gemacht werden. Aber um alle Faktoren des Klimas einer Gegend, Alles, was auf ihre Pflanzenwelt und ihre ganze organische Natur einwirkt, kennen zu lernen, muss man auch die Temperatur in freier Luft bei

1) Das Maass dieser Abnahme in Gebirgen und Bergländern hat man ziemlich gleichförmig, in den Tropengegenden wie bei uns, zu $0,60 \mathrm{C}$. für je $100 \mathrm{~m}$ gefunden, so dass die Jahreswärme um $10 \mathrm{C}$. abnimmt für je zirka $170 \mathrm{~m}$ Zunahme der Höhe. Ueber die Verschiedenheiten dieser Abnabme nach Bodengestalt (PlateauErhebungen ete.), Exposition, Jahres- und Tageszeit vgl. Hann, a. a. O. S. 80 . 
woll'y Somnenstrahlung ermitteln, d. h. die Wärmegrade ablesen, an einem Thermometer, welches in keiner Weise geschützt ist, weder gegen die Sonnenstrahlen noch gegen Winde, seien diese kalt oder warm. Stellen zu solchen Beobachtungen wird man leicht finden; an denselben braucht man einfach das Thermometer in ungefähr $1 \mathrm{~m}$ Höhe über dem Boden frei aufzuhängen.

Als Ursachen, welche die Temperatur eines Ortes bedingen, lommen in Betracht die Zustrahlun! ion Somurnuciome (Radiation, Insolation, Somenstrahlung) und die terrestrische Wärmeansstrahlumy.

Die Präzisionsinstrumente, womit man die einem Orte durch die Somue zugestruhlte Wärmemenge (solare Wärme, Insolation ${ }^{1}$ ) misst, sind sehr kostbar und schwierig zu transportiren; der Reisende ist desshalb kaum in der Lage, diesfallsige genaue Beobachtungen zu machen: es ist aber sehr $\mathrm{zu}$ wünschen, dass er wenigstens approximative Angaben über die Intensitiit der durch die Sonnenstrahlen bewirkten Wärme und über den Wärmeverlust durch Ausstrahlung in der betreffenden Gegend liefere. Zu diesem Zwecke kam man Extremthermometer (Minimum- und Naximumthermometer) anwenden, deren Kugeln mit Kienruss geschwärzt wurden.

Setzt man ein Naximumthermometer mit geschwärzter Kugel auf einer Wolldecke oder einem andern schlechten Wärmeleiter, welcher dasselhe vor dem Einflusse der terrestrischen Wärmestrahlung schützt, der Somne aus, so gibt es ziemlich genau die solare Radiation, d. h. das ausschliesslich den direkten Sonnenstrahlen zuzuschreibende WärmeQuantum an. Damit das Resultat ganz exakt ausfiele, müsste man freilich das Instrument noch der Einwirkung der äussern Luft entziehen und es zu diesem Zwecke in einen Cylinder pinschliessen, aus dem nachher die Luft herauszupumpen wäre. Die Ausstrathlum! ron Erefucirme geht namentlich während der Nacht vor sich; um sie zu messen, bringt man ein Maximum- und ein Minimumthermometer in horizontaler Lage entweder direkt auf dem Boden an, wenn er nackt oder

1) Vo], hierüber Uann, a. a. O., Seite 69; ferner: Dr. Karl Remeis, die Strahlung und die Temperatur der Sonne; eine Darstellung und Erörterung der einschlägigen Messungen und erlangten Resultate. Gäa 1880, Heft $\mathbf{X}$ bis XII. 
mit Schnee bedeckt ist, oder placirt sie auf zwei kleinen Stützen 2-3 cm hoch über kurz geschnittenem Rasen, da wo es sich um bewachsenen Boden handelt. Gegen Morgen liann man dann ablesen, welches das Maximum der Wärme gewesen ist, die von der terrestrischen Ausstrahlung herrührte und welchen Grad nächtlicher Abkühlung der Boden erlitt. $\mathrm{Zu}$ solchen Beobachtungen muss man Tage und Nächte mit klarem Himmel und ruhiger Luft wählen, da die solare Radiation wie die Erdwärmeausstrahlung in hohem Grade durch den Zustand der Atmosphäre, namentlich durch Wolken und Nebel, beeinflusst werden.

Reinheit und Durchsichtigkeit der Luft. Da die normale Zusammensetzung der Luft überall die gleiche ist, so braucht man nur die Aenderungen zu notiren, welche dieselbe an einem gegebenen Orte zu gegebener Zeit erleidet; die Reinheit der Luft kann gestört werden durch fremcle Bestandthcile wie Gase, Miasmen, Rauch und Staub.

Die Gasausströmungen, die Miasmen und der Rauch sind rein örtliche Vorkommnisse und affiziren den Geruchsinn, sobald sie einen namhaften Theil der Luft ausmachen. Der Rauch wird zudem sichtbar, sobald er in bemerkenswerther Menge vorkommt. Die Staubtheilchen in der Luft - wenigstens die grösseren ${ }^{1}$ ) — werden ebenfalls sichtbar, wenn man durch eine kleine Oeffnung Somnenlicht in den Raum eindringen lässt; zuweilen trüben sie die Atmosphäre und setzen sich in reichlicher Menge auf allen festen Körpern ab; dies ist der Fall mit den rom Winde aufgewirbelten Staubwolken und vulkanischen Aschen.

Die Durchsichtiglicit der Luft hängt zum Theil von ihrer Reinheit ab, zum Theil auch von ihrem Gehalte an Wasserdampf. Man beurtheilt dieselbe nach dem Grade der Sichtbarkeit entfernter Objekte wie der Kontouren von Bergen, und die Durchsichtigkeit der höhern, zwischen dem Auge des Beobachters und dem Zenith befindlichen Luftschichten misst man mit dem Cyanometer (vgl. pag. 18), wobei man

1) Nach Untersuchungen von John Aitken in Edinburgh (Vortrag vor der Rojal Society daselbst, 20. Dezember 1880) ist zu unterscheiden zwischen diesen grösseren Staubtheilchen, welche uns sichtbar werden, indem sie das Sonnenlicht reflektiren, und unendlich kleinen unsichtbaren Theilehen, die eine wichtige Rolle spielen bei der Bildung von Nebel und Wolken und hinsichtlich der blauen Farbe des Himmels. Vgl. Naturforscher 18s1, Nr. 8; Gäa 1881, S. 208. 
von dem Grundsatze ausgeht, dass die Durchsichtigkeit der Luft um so grösser sei, je dunkler das Blau des Himmels erscheint.

Feuchtigkeitsgehalt der Luft. Die Luft enthält immer, auch wenn sie noch so trocken scheint, ein gewisses Quantum Wasserdampf, welcher sichtbar wird, sobald die Temperatur so tief sinkt, dass der Wasserdampf kondensirt wird ${ }^{\text {) }}$.

Die Wasserdampfmenge, welche die Luft enthalten kann, längt ron der Temperatur ab. Je wärmer die Luft ist, um *o mehr Wasser kann sie in Form unsichtharen Dampfes enthalten; je kälter sie aber ist, um so weniger Dampf hedarf sie zu ihrer Suittirmuly, d. h. um den Zustand anzunehmen, in welchem das dampförmige Wasser verdichtet und sichtbar wird. Die Temperatur, bei welcher dies geschieht, heisst der Thaupunkt.

Man weiss, wie viel Wasserdampf ein bestimmtes Quantum Luft bei jeder Temperatur enthalten muss, um gesättigt zu sein. Man drückt sie aus, indem man das Gewicht des in einem Kubikmeter enthaltenen Wasserdampfs angilut oder aher den Druck (die Tension oder Spannung), welchen dieser J)amp auf Alles, was ihn umgilot, ausübt und der gemessen werden kann durch die Höhe der Quecksilbersäule, welche ihm das Gleichgewicht hält. Zwischen jenem Gewicht, in Grammen ausgedrückt, und dem in Millimetern angegebenen Dunstdruck besteht ein Verhältniss, welches konstant ist, soweit es sich wenigstens um die in der Praxis vorkomnenden Fälle handelt. Bei 10 Gramm Gewicht ist die jpannung $=10 \mathrm{~mm} ; 15 \mathrm{~mm}$ Spannung entsprechen einem jerricht ron 15 Gramm u. s. w.

Als absoluten Frubtiglicitigledult der Luft bezeichnet man las in der Volumeneinleit Luft wirklich enthaltene Dampf-

1) John Aitken stellt auf Grund mehrfacher (ror der Royal Society in Edin, urgh wiederholter) Yersuche folgende Sätze auf: 1) Wenn überhaupt Wasserampf in der Atmosphäre kondensirt, so geschieht dies stets auf irgend einem rsten Kern; 2) Stazbtheilchen bilden in der Luft die Kerne, auf welchen der ampf kondensirt; 3) wenn kein Staub rorhanden wäre, würden auch keine Nebel, eine Wolken, keine Dünste und wahrscheinlich kein Regen existiren, und die bersättigte Luft würde jeden Gegenstand auf der Erdoberfläche in einen Kondenator verwandeln, auf dem sie sich abscheiden würden; 4) wenn in kalter Luft 'nser dthem sichtbar wird und jeder Dampfstrahl, sowie er in die Luft entweicht, 0 beweist dies den unreinen und staubigen Zustand unserer Atmosphäre. Vgl. ie in roriger Note (S. 416) angeführten Zeitschriften. 
quantum; unter der relaticen Fenchtinlicit aber, oder dem hygrometrischen Zustand der Luft, rersteht man das Verhältniss zwischen der absoluten Feuchtigkeit und derjenigen Menge Wasserdampf, welche die Luft bei der gegebenen Temperatur enthalten müsste, um gesättigt zu sein; sie wird ausgedrückt in Prozenten, d. i. in Hunderteln des zuletzt erwähnten Wasserdampfquantums.

Analog verrendet man die Ausdrücke absoluter Dunstdruck und relativer Dunstiruck. Da bei den in freier Luft rorkommenden Temperaturen die Dichte des Wasserdampfes stets nahzu ${ }^{5}$ 's ron jener der Luft gleicher Temperatur und Spannkraft ist, so drückt annähernd dieselbe Zahl die relative Feuchtigkeit und den relatiren Dunstdruck aus.

Unter den Instrumenten, welche, wie S. 19 bemerkt wurde, dazu dienen, die hygrometrische Beschaffenheit der Luft zu beobachten, befindet sich in erster Linie ein Thermometer, welches dazu bestimmt ist, die Temperatur anzugeben, bei welcher die umgebende Luft gesättigt wäre (den Thaupunkt); die Lufttemperatur wird durch das gewöhnliche Thermometer bestimmt. Aus diesen heiden Angaben berechnen wir nun die relative Feuchtigkeit in Prozenten. Es sei z. B. die Lufttemperatur $20^{\circ}$, so braucht der $\mathrm{m}^{3}$ Luft 18,77 gr. Wasserdampf zu seiner Sättigung. Das zmeite Thermometer sei auf $4^{0}$ gestanden, als der silberne Ring desselben mit Wasserdampf beschlagen wurde; hei dieser Temperatur enthält gesättigte Luft nur 7,82 gr. Wasserdampf; die relative Feuchtigkeit ist daher $\frac{\pi, 52}{18,77}=0,42$ oder $42^{\circ}{ }^{\prime} 0$. Ein andres Beispiel. Der Thaupunkt sei bei $12^{\circ}$ eingetreten, die Lufttemperatur aber sei $16^{\circ}$. Nun ist die Spannung des Wasserdampfs bei $12^{\circ}$ Wärme $=10,5 \mathrm{~mm}$ und bei $16^{0}=13,5 \mathrm{~mm}$. Die relative Feuchtigkeit ist daher $\frac{10,5}{13,5}=0,78$ oder $78 \%$. Tabellen, welche diese Berechnungen erleichtern, finden sich im Anhange (Taf. 7 ).

Das Haarhyrometer ron Dr. C. Koppe (S. 19) gibt die relative Feuchtigkeit in Prozenten, resp. Hunderteln, direkt an; man braucht blos die Zahl abzulesen, welche ein Zeiger auf einem Zifferblatte bezeichnet. Ein sorgfältig konstruirtes und kontrolirtes Haarhygrometer ist ein Instrument, das in manchen Fällen (bei Temperaturen unter 0 und Schwankungen 
derselben um 0 herum) den Vorzug vor dem Psychrometer verdient; es ist aber zu empfehlen, dass man sich rechtzeitig durch einen geübten Beobachter in dessen liorreliter Anwendung und Kontrole unterrichten lasse.

Das Psychrometer, welches wir auf S. 19 beschrieben, heruht auf dem I'rinzip, dass in einer mit Feuchtigkeit gesättigten Luft lieine Verdunstung erfolgen kann; das trockene und das hefeuchtete Thermometer müssten hier die gleiche Temperatur zeigen; die Verdunstung ist um so stärker, je trockener die Luft; um so grösser ist auch der Wärme-Entzug aus dem befeuchteten Thermometer, um so tiefer also sinkt dassellye. Dieses Sinken und die Differenz zwischen den beiden Thermometern (dem trockenen und benetzten) stehen also unter übricens gleichen Lmständen in geradem Verhältniss zur Trockenheit der Luft, ron welcher man auf die relative Feuchtigkeit, ihr Komplement, schliesst.

Bei der Anwendung des Psychrometers ist einige Vorsicht nöthig. Zunüchst muss man sich vergewissern, ob die Thermometer in ihren Angaben übereinstimmen. Zu diesem Zwerke taucht man beide bis zum gleichen Theilstrich in Wasser, das man successive auf verschiedene Temperaturen gebracht hat und das man gut umrührt, damit die ganze Menge möglichst denselben Wärmegrar habe. Wird dies mehrmals wierlerholt, so muss man dabei für jede einzelne Temperatur auf beiden Thermometern dieselben Angaben erhalten. Zeigen sich Lnterschiede, so notirt man dieselben, um sie bei den Beobachtungen zu berïcksichtigen. Solche Terifikationen werden namentlich dam nothwendig, wenn etwa ein Thermometer zerbricht und durch ein andres ersetzt werden muss, das ielleicht keines ron den besten ist. Die Mousseline, womit nan die Glaskugel des zu befeuchtenden Thermoneters ungibt, darf nicht zu dick und muss gut gewaschen sein. Ian befestigt sie am Thermometer, indem man sie über und inter der Glaskugel mit einem Faden bindet, so dass sie ich gut anschmiegrt, Falten und Doppellagren aber möglichst ermierlen werden. Diese Mousselinehülle muss erneuert werden, obald sie steif wird und das Wasser nicht mehr leicht absorbirt, uch, sobald sie zerrissen oder schmutzig ist und irgend einen "unkt der Glaskuggel unbedeckt lässt. Das Wasser, womit man as Gefiiss füllt, in welches der untere Theil der Mousseline 
wie ein Docht eintaucht, muss möglichst rein sein. In Ermanglung nicht zu kalkreichen Trinkwassers verwendet man Regen- oder destillirtesWasser oder solches, das durch Schmelzen aus Eis und Schnee gewonnen wurde. Die Füllung des Gefässes soll nicht zur Zeit der Beobachtung erfolgen, sondern das Wasser soll einige Zeit darin sein, bevor man sich dessen bedient. Auch hat man sich zu vergewissern, dass der Mousselinedocht das Wasser gut absorbirt und während der ganzen Dauer der Operation mit demselben in genügender Berührung bleibt. Ist die Temperatur sehr niedrig, so muss man die Thermometerkugel und ihre Umhüllung mehrmals in ein Glas Wasser tauchen, das man von unten heraufberegt, und muss warten, bis sich um die Kugel eine dünne Eisschicht gebildet hat.

Hinsichtlich der Aufstellung oder Exposition des Psychrometers ist Dasselbe zu sagen wie mit Bezug auf das gewöhnliche Thermometer (pag. 408). Es ist besonders nothwendig, dass die Luft frei um das Instrument herum zirkuliren könne, ohne dass letzteres einer Luftströmung oder einem Winde ausgesetzt ist, wodurch die Verdunstung übermässig beschleunigt würde. Die definitive Ablesung am Thermometer soll erst gemacht werden, wenn das benetzte Instrument den tiefsten Stand erreicht hat, wovon man sich überzeugt durch wiederholte Ablesungen, welche dasselbe Resultat ergeben müssen. Bei grosser Kälte und sehr feuchtem Wetter braucht es ungefähr eine halbe Stunde, bis das benetzte Thermometer das Minimum erreicht, weun man es nicht schon rorher sorgfältig befeuchtet. Wenn etwa die Kugel desjenigen Thermometers, das trocken bleiben soll, benetzt würde durch Regen oder Schnee, welchen der Wind zuwehte, so müsste man sie sorgfältig abtrocknen und mit der Beobachtung von Neuem beginnen.

Die Ablesung an den beiden Thermometern, woraus das Psychrometer besteht, muss mit derselben Torsicht stattfinden wie die des gewöhnlichen Thermometers (pag. 409). Bei starkem Nebel, wie bei kaltem ruhigem und hellem IVetter kommt es vor, dass das benetzte Thermometer weniger tief sinkt als das trockene, weil seine Umhüllung es gegen die Ausstrahlung schützt. In diesem Fall abstrahirt man von dieser kleinen inversen Differenz und nimmt an, die Luft habe den Sättigungszustand oder die relative Feuchtigkeit 100 erreicht. 
Sobald die Ablesung erfolgt ist, notirt man die an beiden Thermometern beobachtete Temperatur, ohne sich darauf zu verlassen, dass man sie im Gedächtniss behalten könne; die Ablesung am trockenen Thermometer bezeichnet man mit $t_{1}$, die am befeuchteten mit $t_{2}$. Die Berechnung der Differenz und der weiteren Werthe kann später, bei Musse, erfolgen; immerhin sollen diese Operationen nicht zu lange verschoben werden. War das Wasser auf der Kugel des benetzten Thermometers gefroren, so bezeichnet man die bezügliche Ablesung im Notizbuche mit dem beigefügten Buchstaben $g$, also z. B.: $t_{2}-4^{0} g$.

Im Anhang findet man die Tabellen, um mit Hülfe der Temperaturdifferenz die relative Feuchtigkeit zu berechnen.

Besitzt man zwei Hygrometer von verschiedener Konstrulition oder ein Hygrometer und ein Psychrometer, so verwende man beide gleichzeitig behufs gegenseitiger Kontrole der Resultate.

Da der hygrometrische Zustand der Luft und die Wasserdampfspannung nach Zeit und Höhe sich ändern, so muss empfohlen werden, dass man möglichst zahlreiche Beobachtungen und diese an verschiedenen Stationen anstelle. Insbesondere trachte man darnach, vollständige Serien von Beohachtungen für einen und denselben Tag zu erhalten und zwar zu verschiedenen Zeiten und bei verschiedenen Temperaturen, um so die Amplitüde der Temperaturschwankungen und auch die Zeitpunkte, wo Maxima und Minima eintreten, $\mathrm{zu}$ ermitteln.

Verdunstung. Die Feuchtigkeit oder der Wasserdampf in der Luft rührt ron der Verdunstung her. Das Wasser der Neeve und Seen, Regen, Schnee und andere Niederschläge werden durch die Sonnenstrahlen und die Atmosphäre überhaupt - um einen trivialen Ausdruck zu gebrauchen in die Höhe gepumpt. Die Verdunstung findet selbst bei kalter Witterung, sogar in den Polarregionen und auf den beeisten Gipfeln der Hochgebirge statt, lebhafter aber natürlich bei heissem und trockenem Wetter in der tropischen und gemässigten Zone. Gar keine Verdunstung findet nur dann statt, wenn die Luft mit Feuchtigkeit ganz gesättigt ist.

Es wäre sehr interessant, konstatiren zu können, ob eine Gegend ihre Feuchtigkeit unmittelbar der Verdunstung aus 
den Wasserbecken und anderen sie bildenden Flächen verdankt oder ob dieselbe vielmehr von den Winden hergetragen wird, welche anderwärts mit Wasserdampf beladen wurden. In der Pegel wirken beide Ursachen zusammen; die Luft ausgenommen diejenige über regenlosen Wüsten, deren Feuchtigkeit fremden Ursprungs ist — erhält ihren Wasserdampf zum Theil direkt durch die Verdunstung, zum Theil aus der Ferne durch Winde; das Verhältniss dieser beiden Theile aber ist ein sehr rerschiedenes. Da man zwischen diesen zwei Quellen der Luftfeuchtigkeit praktisch nicht scharf unterscheiden kann, trachtet man wenigstens nach Ermittlung der hauptsächlich wirksamen Ursachen besonders da, wo die hygrometrischen Verhältnisse abnorme Erscheinungen darbieten; namentlich wird man Beobachtungen über das Mass der direkten Verdunstung anstellen.

Bei Besprechung der Instrumente (Seite 20) wurde gesagt, dass man die Verdunstung genau genommen messen könnte mit einem kleinen Rezipienten, der im Innern eine graduirte Skala enthielte. Dieser Rezipient wird bis zu irgend einem Theilstrich der Skala mit Wasser gefüllt und dann in horizontaler Lage der freien Luft ausgesetzt, nöthigenfalls geschützt gegen Regen und Thiere. Die Verdunstung wird nun bezeichnet durch das in Millimetern ausgedrückte Sinken des Wasserspiegels.

Die Kondensation des Wasserdampfes und die wässerigen Niederschläge. Die Kondensation des Wasserdampfes und die Bildung wässeriger Niederschläge sind der Gegensatz zu dem Verdunstungsprozesse. Das vorher unsichtbar gewordene Wasser nimmt nun wieder sichtbare Gestalt an in Form von Nebeln und Wolken oder als Thau, Regen, Schnee u. s. w.

Wenn die Luftschichten sich abkühlen, so scheidet sich ein Theil des in ihnen enthaltenen Wasserdampfes als Dünste, Nebel und Wolken aus. Die Dünste steigen in Form leichter Schleier von der Erde auf oder schweben in der Luft; die Nebel sind kompakter und bilden sich unmittelbar über dem Erdboden. Die Wolken unterscheiden sich vom Nebel nicht wesentlich; der Unterschied besteht nur in der Höhenlage. Wenn man auf einem Berge oder im Luftballon eine Wolke passirt, so erscheint sie uns als Nebel, und wenn man von 
piner Bergspitze aus Nebel betrachtet, welcher über der Ebene in der Tiefe lagert, so kommen sie uns wie Wolken ror. Hier aber hört die Aehnlichkeit auf; ihre klimatischen Wirkungen sind nicht dieselben.

Die Bildung, Beschaffenheit, Stärke und Häufigkeit der Jïnste und Nebel sollen sorgfültig heohachtet und heschrieben werden. Man notire auch, in welcher Jahreszeit sie am hänfirsten sind; zu welcher Tageszeit sie gewöhnlich entstehen, wie lange nach Sonnenaufgang sie verschwinden und wie lange nach sonnenuntergang sie wieder erscheinen; ob sie in die Höhe steigen und hier hleiben oder ol, sie am Boden hinziehen: welcher Wind sie bringt und zerstreut etc. Mitunter sind noch spezielle Eigenthümlichkeiten zu beobachten, so Vebel mit besonderem Geruch, herrührend ron cigenthümlichen Dünsten, womit sie imprägnirt sind; leuchtende Nebel, das sind Abendnebel, welche eine gewisse Hellinkeit verbreiten: endlich trockene Nebel, sogenannter Höhenrauch, welche wesentlich aus Rauchmassen bestehen, die hoch in der Luft schwehen. Eine Wirkung des Nehels ist auch der Rauhfrost ("Duft", "Gischt", "Ghick" u. s. w.), (ler entsteht, wenn bei kalter Witterung Nebeltheilchen an Stengehn, Aesten und Zweigen der Pflanzen, an den Haaren der Ienschen, dem Stoff der Kleider u. s. w. krystallisiren.

Besondere Erwähnung rerdienen die Wollicn; denn ihre An- oder Ahwesenheit hedingt die Helligkeit oder Dunkelheit des Himmels und indirekt das Quantum an Licht, Somnenwärme und Regen, welche die betreffende Gegend erhält.

Die Bexölliung oder Nephetie (Grad der Bedeckung des Himmels mit Wolken oder das Verhältniss, in welchem letztere zu west einem bestimmten Zeitpunkte verbreitet sind) kann auf zwei Arten geschätzt werden. Die erste Art besteht darin, dass man das Himmelsgewölbe in 4 Quadranten eintheilt (Fiy. 201)

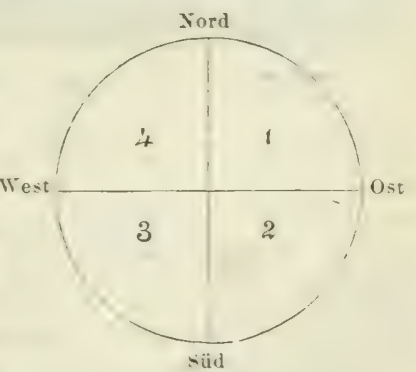

Fig. 201 . und nun der Reihe nach abschätzt, welcher Bruchtheil eines Quadranten mit Wolken bederkit sei. Indem man die Resultate 
addirt, bekommt man eine Verhältnisszahl für den ganzen sichtbaren Himmel; die zweite besteht darin, dass man den Umfang jeder Wolkengruppe in's Auge fasst und hienach abschätzt, den wievielten Theil des Firmamentes sie zusammen einnehmen.

In beiden Fällen wird die Bedeckung durch die Ziffern $0,1,2,3$ bis 10 ausgedrückt, wobei 0 ganz klaren wolkenfreien, 10 ganz bedeckten Himmel bezeichnet. Die Intensität der Bewölkung oder die Dicke der Wolken wird durch

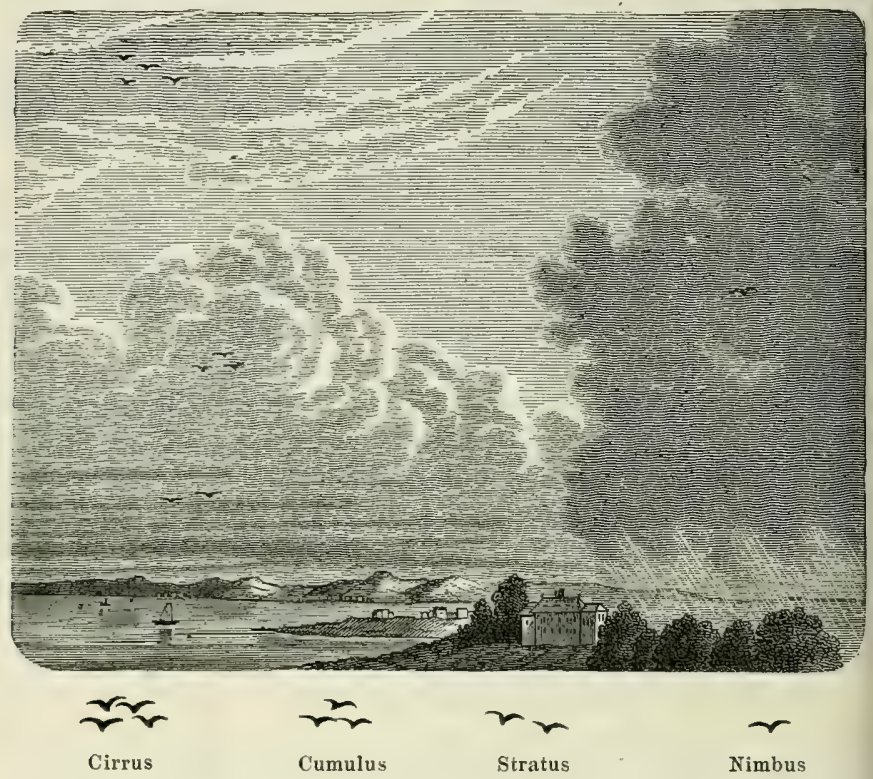

Fig. 205.

eine in Exponentenform beigesetzte Zahl angegeben; z. B. bedeutet $5^{0}$, dass der Himmel zur Hälfte von leichten Wolken überzogen, $10^{2}$ dass er ganz mit dichten Wolken bedeckt sei. Ist keine kleine Ziffer beigesetzt, so bedeutet dies, dass die Intensität der Bewölkung keine besonders bemerkenswerthe sei.

Die Wolken unterscheiden sich von einander in hohem Grade durch ihr Aussehen und man bezeichnet den allgemeinen Charakter einer jeden Art durch besondere Namen. (Vgl. Fig. 205). 
Die Cirrus- oder Federwolken sind weissliche Wölklein, welche gewissermassen wie aufgelöste Fasern aussehen. Die C'umulus- oder Haufenwolken sind rundliche Nassen, Baumwollballen ähnlich. Die Stratus- oder Schichtwolken erscheinen als Streifen oder Bänder parallel zum Horizont. Die Regenwolke (nimbus) hat keine charakteristische Form, wohl aber eine eigenthümliche graue Färbung und gefranste Ränder. Zwischen diesen vier Haupttypen kommen Lebergangsformen und rerschiedene Kombinationen ror, wodurch es oft sehr schwierig wird, den Charakter der Wolke zu bestimmen. Oft liommen auch gleichzeitig zwei oder mehr dieser Formen in verschiedenen Höhen ror, z. B. Federwolken (cirri) in den oheren Luftregionen, Haufen- und Schichtwolken in geringerer Höhe.

Durch häufige Beobachtungen soll namentlich der gewöhnliche Zustand des Himmels konstatirt werden: die oft vorhandene Regelmässigkeit in Bezug auf die Tagesstunden, da der Himmel sich bedeckt oder aufhellt; die Dauer und Persistenz der Bewölkung während ganzer Tage und Wochen: der Konnex zwischen dem Aussehen des Himmels und der nachfolgenden Witterung. Auf Grund solcher Beobachtungen wird es möglich, festzustellen, welches in einem Lande der tägliche und jährliche Gang der Bewölkung ist ${ }^{1}$ ).

Der Than ist bekanntlich ein Niederschlag, welcher in hellen Nächten bei ruhiger kalter Luft auf der Bodenoberfläche sich bildet. Wiewohl man gemeiniglich ron während der Nacht grefallenem" Thau spricht, so besteht doch keine Analogie zwischen der Bildung von Thau und Regen: der Thau fällt nicht aus der Luft herab, sondern entsteht an Ort und Stelle, wo er sich findet, in Folge der nächtlichen Ausstrahlung. Den Namen Thau (rosée) wendet man übrigens speziell für denjenigen Thau an, welcher sich gegen Norgen bildet, während man den bald nach Sonnenuntergang entstehenden als Abendfeuchtigkeit (serein) bezeichnet.

Fehlt ein Instrument zur Messung dieser Abendfeuchtigkeit und des Morgenthaus (Drosometer), so schätzt man die Quantität derselben. Ihr spärliches oder reichliches Vorkommen wird durch folgende konventionelle Bezeichnungen angegeben:

1) Vgl. Zeitschrift der österreichischen Gesellschaft für Meteorologie 1881, 3. 99, und Gäa 1881, S. 193: Untersuchungen von Renon über die durchschnittiche Bewölkung in Europa. (La Nature 1880, août 21.) 


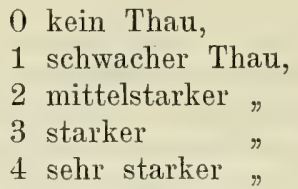

In Ländern mit ungewöhnlich starkem Abend- und Morgenthau kann man denselben mit Hülfe des oben besprochenen Rezipienten messen. Derselbe wird vollkommen trocken und leer an einem Punkte aufgestellt, der sich unter freiem Himmel befindet, d. h. nicht von Mauern umgeben, nur gegen Wind geschützt ist. Das Wasserquantum, welches sich nun in dem Gefässe sammelt während der Stunde unmittelbar nach Sonnenuntergang, gibt die Menge des Abendthaus; das Quantum, das man Morgens bei Sonnenaufgang vorfindet, ist die Menge des in der Nacht entstandenen Thaus. Diese Quantitäten können schätzungsweise in Millimetern angegeben werden nach dem Niveau, bis zu welchem das Wasser im Rezipienten reichte; genauer aber bestimmt man dieselben, indem man sie sorgfältig in einen graduirten Glascylinder (Messglas) giesst; die Quantitätsbestimmung geschieht dann durch eine sehr einfache Rechnung. Die Grundfläche des Rezipienten habe $0,4 \mathrm{~m}$ Länge und $0,25 \mathrm{~m}$ Breite, also 0,1 Quadratmeter Inhalt, und das Wasser im Messcylinder erreiche den mit "0,15 Liter" bezeichneten Theilstrich. Da nun 1 Liter $=1$ Kubikdezimeter, so handelt es sich um eine Wassersäule von $15 \mathrm{~mm}$ Höhe und 1 Quadratdezimeter Grundfläche; da aber die Fläche, auf welcher dieses Wasser in Wirklichkeit sich abgesetzt und von welcher man es gesammelt hat, nämlich die Grundfläche des Rezipienten, 10 Quadratdezimeter beträgt, so ist die Höhe der Thauschicht nur 1,5 mm.

Der Reif ist gefrorner Thau, indem bei intensiverer nächtlicher Ausstrahlung der Niederschlag feste Form annimmt.

Ausser den Notizen über die spärliche oder reichliche Menge des Abend- und Morgenthaus sollen auch solche gemacht werden über die Häufigkeit des Thaus, die Bedingungen, welche ihn veranlassen, begünstigen oder verhindern; die Zeit von Sonnenaufgang bis zum Verschwinden des Thaus oder Reifs; die Wirkung dieser Niederschläge auf die Vegetation und auf den Gesundheitszustand der Bewohner etc. 
Besondere Aufmerksamkeit verdient seiner klimatischen Wichtigkeit halber der Regen, und zwar nicht nur in Bezug auf die Quantität, sondern auch in Betreff seiner Vertheilung auf die einzelnen Stunden ron Tag und Nacht und über das ganze Jahr.

Das Pluviometer (Udometer, Ombrometer) oder, in dessen Ermanglung, unser Rezipient mit graduirter Skala, dient zur Messung des während eines Regengusses oder eines Tages refallenen Niederschlag-Quantums. Die ausgewählte Stelle darf nicht zu sehr lokalen Einflüssen ansgesetzt sein, also nicht in einem speziellen Regenstrich liegen, sondern muss normale (mittlere) Verhältnisse darbieten. Der Rezipient muss genau „ins Blei" gebracht werden, sodass seine Axe lothrecht, sein Boden horizontal ist, und es ist Alles zu entfernen, was dem Zutritt des Regens — selbst des rom Winde hergewehten - hinderlich sein könnte. Die Ablesung Hühe des gefallenen Regens in Millimetern) muss sofort corgenommen werden, sobald der Regen aufhört, damit nicht das Resultat durch Verdunstung alterirt werde.

Um die Temperatur des Regenwassers zu bestimmen, stellt man in der Nähe des Rezipienten ein zweites Gefäss uf, in welchem ein Thermometer angebracht ist, das über lie ganze Dauer des Regenfalls dort belassen wird. Vor und nach dem Regen wird auch die Luftemperatur notirt.

Endlich macht man Notizen über den Rückstand, welchen legen mitunter zurücklassen, sowie über besondere Erscheiungen, wie Regen bei heiterm Himmel, sogenannte Blut.nd Schwefelregen $u$. dgl.

$\mathrm{Zu}$ erwähnen ist auch das Vorkommen von Glatteis; tzteres ist nichts anderes als Regen, der in Berührung mit ehr kaltem Boden gefror.

Hayel, Gramene (Riesel) und Schnee sind drei besondere "ormen wässeriger Niederschläge. Das Quantum eines solchen iederschlags kann angegeben werden durch Messung des Jassers, welches man im Rezipient durch Schmelzen erhält. Idessen ist das Resultat hiebei nur annähernd richtig. Die itensität des Hagelfalles wechselt zumeist stark ron Stelle I Stelle, und es ist nicht leicht, bei der Abschätzung ücksicht zu nehmen auf die Hagelkürner, welche beim uffallen zurückschnellten und so ausser das Sammelgefäss 
geriethen. Der Schnee seinerseits wird unter dem Einflus bestimmter Winde in gewissen Strichen reichlicher angehäuft während derselbe Wind anderorts den schon zu Boden ge fallenen Schnee wegführt; je nach der Lokalität, in welche der Rezipient angebracht ist, kann der Schnee in letzterer aufgehäuft oder im Gegentheil aus demselben hinausgeweh werden. Uebrigens ist die Feuchtigkeitsmenge, welche Hage und Schnee der Erde zubringen, von geringerer Bedeutun als die sonstigen Wirkungen, welche starker Hagel ode reichlicher Schneefall verursachen.

Was speziell den Hagel anbetrifft, so suche man genaw. Angaben zu erhalten über seine Häufigkeit, ferner darüber in welchen Zeiten des Jahres namentlich Hagel fällt un welche Theile des Landes von demselben am meisten heim gesucht werden. Man mache auch Bemerkungen über di mittlere Grösse der Hagelkörner (Schlossen), ihre Form unc Struktur wie über die beigemengten fremden Stoffe und der Rückstand, welchen sie mitunter beim Schmelzen lassen üher ihre Wirkungen auf die Pflanzenwelt, die Ernteerträg. nisse u. A. m.

Mit Bezug auf den Schnee notirt man die Häufigkei oder Seltenheit des Schneefalls; die Winde, welche Schnef bringen (Schneewinde); die Mächtigkeit der Schneedecke des Bodens; Höhe und Exposition der Stellen, an welchen del Schnee bleibt und derjenigen, wo er sofort wegschmilzt; seine Wirkungen auf Boden und Vegetation; seinen hinderlichen oder förderlichen Einfluss auf den Kreislauf des Wassers u. s. w. Wo möglich - wenn man genaue und vertrauenswürdige Angaben hierüber erhalten kann - notirt man auch, zu welcher Zeit im Jahre der erste Schnee fällt und wann der Schnee wieder gänzlich verschwindet.

Im weitern achte man auf die verschiedenen Formen (Körner und Flocken) wie auch auf ausnahmsweise Färbung desselben. Die Form der Schneekrystalle untersucht man am besten, indem man solchen Schnee, welcher auf einen dunkelfarbigen Stoff, z. B. einen Rockärmel, gefallen, mit der Lupe betrachtet; der hygrometrische Zustand kann beurtheilt werden, indem man eine Hand voll Schnee zusammendrückt, um ihn zu ballen. Ist er trocken, so zerfällt er hiebei in Staub; ist er feucht, so lässt er sich ballen 
und behält die Form, die man ihm gab; ist er mit Feuchtigkeit gesättigt, so gibt er wie ein Schwamm heim $\mathrm{Zu}$ ammendrücken einen Theil des in ihm enthaltenen Wassers $\mathrm{ab}$, wird halbdurchsichtig (durchscheinend) und hart.

)ie Färbung des Schnees rührt, soweit sie nicht blosse Wiriung der Reflexion ist, von beigemengten fremden Stoffen rer, die unter Lupe oder Mikroskop zu prüfen sind; nöthigenalls schmilzt man eine Partie Schnee und untersucht den ich ergebenden Rückstand.

Zur Abkürzung der Notizen über die wässerigen Niederchläge kömen diese mit Buchstaben bezeichnet werden rie folgt:
$D=$ Dünste
$N=$ Nebel
$R f=$ Reif
$A T=$ Abendthau
$M T=$ Morgenthau
$R r=$ Rauhreif
$W=$ Wolken
$R=$ Regen
$G=$ Glatteis
$\mathrm{Gr}=$ Graupen
$H=$ Hagel
$S=$ Schnee.

Anfang und Ende einer Erseheinung, wie eines Regender Schneefalls, werden bezeichnet durch Beisetzung der tunde und der Buchstaben $m$. (Morgen) und $s$ (Abend). B. bedeutet $R 10 \mathrm{~m}-4 \mathrm{~s}$ einen von $10^{\mathrm{h}} \mathrm{Vm}$ bis Im andauernden Regen. Was oben vom Regen bemerkt urde: dass nicht nur seine Quantität, sondern auch die ertheilung derselben über das Jahr von grösster Bedeutung i, gilt von den wässerigen Niederschlägen im Allgemeinen. ach der Jahreszeit, in welche der meiste Regen fällt, unterheidet man Gebiete mit Sommer- oder Winter-, FrühlingsJer Herbstregen und spezieller mit Rücksicht auf die Veriltnisse der einzelnen Monate (wobei vorab diejenigen der egetationsperiode wichtig sind) vorherrschende Mai-, Juni-, ali-Regen etc. Zählt man jeden Tag, an welchem ein essbarer Niederschlag (Regen, Schnee, Hagel) stattfand, als gentag und dividirt man die mittlere Zahl der Regentage nes Monats (aus einer längeren Beobachtungsreihe) durch e Zahl der Tage dieses Monats, so gibt der Quotient die ittlere Refuemcahrsheinlirhkeit in diesem Monat an, während 'm als Regendichtiglieit für einen bestimmten Nonat den totienten bezeichnet, den man aus der Niederschlagsmenge 'egenhöhe) dieses Monats und der Zahl seiner Tage erhält. ir die Beurtheilung der Vegetationsverhältnisse sind diese 
Zahlen charakteristischer als diejenigen über die blossen Regenmengen ${ }^{1}$ ).

Luftdruck. Der Druck, welchen die atmosphärische Luft ausübt, wird bekanntlich mittels des Barometers gemessen.

Welche Art ron Barometer oder Luftdruckmesser man anwende (das Aneroid oder Holosterik, das Quecksilberbarometer oder ein anderes), immer muss man so oft als möglich die Ablesungen an demselben vergleichen mit den Angaben ron Normalinstrumenten, z. B. derjenigen Barometer, welche in den Observatorien und meteorologischen Stationen, die man besuchen hamn, gebraucht werden. Im Uebrigen wende man alle Vorsichtsmassregeln an, welche für das betreffende Instrument empfohlen werden; insbesondere hüte man sich davor, ein Barometer, womit man Beobachtungen anstellen will, den Sonnenstrahlen oder der Wärme eines Lagerfeuers im Birouak auszusetzen. War aber das Instrument während des Transportes einer abnormen Temperatur ausgesetzt, so lasse man dasselbe den Wärmegrad des neuen Mediums, in dem es sich befindet, amehmen, beror man damit Beobachtungen anstellt.

Diese Beobachtungen müssen möglichst zahlreich, in kleinen Zeitintervallen, gemacht werden, da der Luftdruck Schwankungen unterworfen ist, sowohl im Verlaufe eines Tages als im Laufe der Jahreszeiten und bei Gewittern grosse Störungen erleidet. Womöglich nimmt man stündliche Beobachtungen ror und lernt so die Amplitude dieser Schwankungen kennen, d. h. deren Grenzwerthe (Maxima und Minima), und die Zeitpunkte, in welchen sie bei Tag oder Nacht eintreten. Ebenso sollten die Beobachtungsstationen möglichst zahlreich und über die Gegend vertheilt sein; denn der Gang des Barometers, der Betrag seiner Schwankungen und die Zeit des Eintritts ron Maximum und Minimum differiren, je nachdem man am Neere oder im Binnenlande, in Ebenen oder auf Bergen beobachtet.

Die Abnahme des Luftdrucks mit der Höhe erfolgt in einer geometrischen Progression. Als durchschnittlichen Barometerstand am Neeresniveau nimmt man (für $0^{0}$ Temperatur)

1) Vgl. Hann, Hochstetter und Pokorny, S. 120. 
$760 \mathrm{~mm}$ an; dieser Normaldrurk würde ausgeülst durch eine Inftsäule von 7991 Neter, wenn die Luft überall dieselbe Dichte und dieselbe Temperatur $\left(0^{0}\right)$ hätte. Man hat diese (irïsse $(7991 \mathrm{~m})$ als die Höhe der homogenen Atmosphäre hezeichnet. Nit Hülfe derselben findet man die Höhendifferenz für $1 \mathrm{~mm}$ Aenderung des Luftdruclis (Barometerstandes), indem man jene Grösse (7991 m) durch den beobachteten Luftdruck (Barometerstand) dividirt. Man findet dabei, dass bei mittleren Luftrerhältnissen und geringer Erhebung über den Meereshorizont das Barometer um $1 \mathrm{~mm}$ faillt auf circa $11 \mathrm{~m}$ Höhendifferenz ${ }^{1}$ ). Es ermöglicht dies eine hergueme approximative Berechnung ron Höhenunterschieden. Fïr diesen Zweck haben wir auf S. 50 die Formel gegreben

$$
h=16000 \cdot \frac{B-b}{B+b}\left(1+\frac{T+t}{500}\right) .
$$

Hiebei ist rorausgesetzt, die Barometerstände heziehen sich auf eine Temperatur ron $0^{0}$. Ist bei $t^{0}$ ein Barometerstand b) abgelesen worden, so wird derselbe auf $0^{0}$ reduzirt durch IIultiplikation mit dem Bruche $\frac{5550}{5550+t}$. Bezeichnen wir diesen eduzirten Barometerstand mit bo, so ist also $b_{0}=b \cdot \frac{5550}{5550+t}$.

Lm auch die in rerschiedenen Neereshöhen beobachteten 3arometerstände in Bezug auf die Vertheilung des Luftiruckes auf einander beziehen und mit einander vergleichen u können, reduzirt man sie auf einerlei Niveau, dasjenige les Meeres (0 Meter Höhe). Bezeichnet man den bei einer Iöhe $h$ und einer Temperatur $t$ abgelesenen Barometerstand iit $b$, den auf $0^{0}$ und das Meeresniveau reduzirten Werth ieser Ablesung mit $B$, so ergibt sich der Logarithmus des stzteren aus demjenigen der $A$ blesung durch Addition der Grösse

$$
\mathrm{h}: 18382\left(1+\frac{4 t+0,01 h}{1000}\right) \text {. }
$$

1 sehr einfacher Art können übrigens auch diese Redukonen, wie die Höhenermittlungen, vorgenommen werden mit ülfe der Taf: $V$ im Anhang und rerweisen wir für Weiteres af dieselbe, wie auf die ihr beigegebenen Erläuterungen nd Beispiele ${ }^{2}$ ).

1) Vgl. Kaltbrunner, Aide-mímoire, pag. 96 ; Hann S. 88.

?) Eine Formel für die barometrische IIöhenmessung, deren Anwendbarkeit Bezug auf Höhen und geographische Breite) nicht den Beschrïnkungen der en mitgetheilten unterliegt, ist

$$
\mathrm{h}=18400 \log \frac{B}{b}\left(1+\frac{T+t}{500}\right) \times(1+0,0028 \cos 2 \varphi)
$$


Winde ${ }^{1}$ ). Wind ist eine durch eine Störung im Gleichgewichtszustande der Atmosphäre verursachte Luftbewegung. Die Winde sind nach drei Gesichtspunkten zu betrachten, nämlich nach Richtung, Art und Stärke.

Die Richtung des Windes wird beurtheilt mit Hülfe einer Windfahne oder eines Wimpels oder auch, in Ermanglung dieser Mittel, nach dem Rauche eines Kamines, einer Fackel oder eines Strohwisches, den man eigens zu diesem Zweck anzündet. Die Windfahnen haben den Nachtheil, dass sie eine bestimmte Richtung zeigen, auch wenn gar kein Wind weht; dass sie oft $\mathrm{zu}$ wenig empfindlich, d.h. zu schwer beweglich sind, und dass sie auf- und absteigende Luftströmungen nicht anzeigen.

Die Richtung des Windes wird bezeichnet durch Angabe der Himmelsgegend, von welcher her er kommt, nicht derjenigen, nach welcher er hinweht. $N$, Nordwind, bezeichnet also einen aus Norden, $N E$ einen aus Nordosten wehenden Wind. Eine andere Bezeichnungsweise ist die durch Pfeile, deren Spitze nach der Himmelsgegend gerichtet ist, nach welcher hin der Wind weht und deren Fahne je nach der Windstärke mehr oder minder Striche hat. Werden 6 Stärkegrade unterschieden, so würde

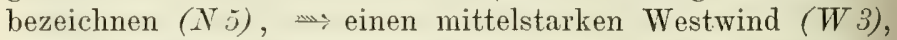
$\swarrow$ einen sanften Nordostwind (NE1) u. s. f. So in Bezug auf die Richtung zum Horizonte; was die Richtung in der vertikalen Ebene anbetrifft, d. h. den Winkel, welchen aufund absteigende Luftströmungen mit dem Horizonte bilden, so kann man dies abschätzen oder mit Hülfe eines getheilten Kreises abmessen nach der schiefen Richtung des Wimpels oder einer Rauchsäule, wobei man nur die Angabe von Winkelgraden durch einen Buchstaben oder einen Pfeil erläutern muss, durch welche die Richtung (ob auf- oder abwärts) bestimmt wird, z. B. $a$ (aufsteigend, ascendant), $d$ (descendant, absteigend) oder $*$ und $\varkappa^{*}$.

wo $\varphi$ die geographische Breite bezeichnet. Vgl. übrigens Bohn, Ergebnisse physikalischer Forschung, S. 139 ff. Jordan, a. a. O., S. 514.

Die Formel

bei Hann, S. 95 .

$$
\log B=\log b+\frac{h}{18382[1+(4 t+0,01 h) 0,001]}
$$

1) Auch in Betreff dieses Absehnittes ist auf Kaltbrunner, Aide-mémoire (p. $100 \mathrm{sq}$ ) als ein wesentliches Supplement zu verweisen. Ferner machen wir aufmerksam auf die einschlägige Darstellung in Dr. $H$. Wettstein's Werke: die Strömungen etc. (Zürich 1880). 
Oft her'schen in höheren Regionen der Atmosphäre Luftströmungen in andrer Richtung als in den tieferen Schichten. Jan erkennt sie meist am Zuge der Wolken. Diese oberen (remplrimmungen (contre-courants) sind sehr wichtig, denn sie bestimmen das Wetter; der Reisende muss auf dieselben um so mehr achten, als er Windfahnen und Wimpel kaum in grosser Höhe über dem Boden anbringen kann und daher durch dieselben nur die (oft abgelenkten) Winde kennen lernt, welche nahe am Boden hinziehen. Die Höhe dieser obern Luftströmungen bestimmt man annähernd nach der Form der Wolken und folgender Skala: Die Haufenwolke (Cumulus) entspricht einer mittlern Höhe ron $1000 \mathrm{~m}$; die federige Haufenwolke (Cirro-Cumulus, Schäfchen) und die streifige Haufenwolke (Cumulo-Stratus) entsprechen einer mittlern Höhe von $6000 \mathrm{~m}$, die Federwolke (Cirrus) und federige Schichtwolke (Cirro-Stratus) einer solchen von $10000 \mathrm{~m}$. Da man die leichten Wölklein, welche in der Luft schweben, ron freiem Auge oft kaum recht wahrzunehmen rermag, so hedient man sich eines doppelten gelbgefärbten Glases, durch welches man auch die leichtesten Wolken sehen kann. Richtung und Geschwindigkeit dieser Luftströmungen beurtheilt man nach dem scheinbaren Ausgangspunkte der wandernden Wolken am Horizont und nach der Schnelligkeit, mit welcher dieselben über dem Haupte des Beobachters dahinziehen. Mitunter sind in Bezug auf Richtung und Geschwindigkeit der Winde nicht blos zwei, sondern drei Regionen zu unterscheiden.

Die Stïrlie des Windes ist theoretisch verschieden von seiner Grschuindiglicit, indem erstere gemessen wird durch den auf eine gegebene Fläche durch die hewegte Luft ausgreübten Druck, die zweite aber durch den in gegebener Zeit zurückgelegten Weg. In der Praxis indessen braucht man oft den einen dieser Ausdrücke für den andern; man sollte aber lahei nicht ühersehen, dass die Stärke nicht der Geschwindigkeit :elbst, sondern dem Quadrate derselhen proportional ist.

Die Stärke des Windes wird auf zwei drten angegeben; sei der ersten, approximativen, wendet man Zahlen an, $\therefore$ B. von $0-4$, nach folgender Skala:

I = ruhige Luft: der Rauch steigt senkrecht in die Höhe, Wasserflächen und die Blätter der Bäume sind gänzlich bewegungslos. 
1 = schwacher Wind: der Rauch steigt nicht so direkt in die Höhe, die Wasserflächen erscheinen leicht gekräuselt und die Blätter der Bäume leicht bewegt.

$2=$ mittelstarker Wind: der Rauch erhebt sich in ganz schiefer Richtung; das Wasser ist ziemlich bewegt, ebenso das Zweigwerk der Bäume.

3 = starker Wind: Rauch und Staub werden in wagrechter Richtung hingetrieben; der Wind bildet auf dem Wasser Wellen und bewegt an den Bäumen starke Aeste.

$4=$ Sturm, Orkan: die ganze Natur erscheint in wildem Aufruhr; die Stämme der Bäume selbst biegen sich oder es werden diese entwurzelt.

Genauer wird die Windstärke bezeichnet, wenn man den Weg angibt, welchen der Wind in einer Sekunde durchläuft, also mittels Angabe der Geschwindigkeit des Windes. $\mathrm{Zu}$ dem Ende bedient man sich eines Instrumentes, welches Anemometer (Windmesser) genannt wird. Dasselbe kann bei Bedarf an Ort und Stelle selbst konstruirt werden, denn in seiner einfachsten Form ist es ein Windhaspel oder Drehkreuz mit 4 Flügeln, deren jeder an seinem Ende eine hohle Halbkugel trägt, so dass immer eine solche Höhlung dem Winde offen steht, während die andern ihm die seitliche oder die konvexe Fläche darbieten. Die Zahl der Umgänge, welche nun eine dieser Halbkugeln in gegebener Zeit macht, ist immer proportional zur Geschwindigkeit des Windes, d. h. zum Wege, welchen er in dieser Zeit zurücklegte. Das Verhältniss zwischen beiden ist ziemlich genau $1: 3$. Der Weg, welchen der Wind zurücklegt, ist $\mathrm{zu}$ berechnen nach der Formel

$$
\frac{2 R \pi \times 3 n T}{m}
$$

worin $R=$ Länge eines Flügels (Arms) des Kreuzes vom Zentrum an, $2 R$ also dessen Durchmesser,

$\boldsymbol{\pi}=\mathbf{3 , 1 4}$ oder genauer $3, \mathbf{1 4 1 5 9 2 6 5}$,

$3=$ die Zahl für das Verhältniss zwischen den Umıdrehungen des Apparats und der Geschwindigkeit des Windes,

$n T=$ Anzahl der Umdrehungen (Umgänge) des Apparats, $m=$ die Dauer der Beobachtung in Sekunden. 
Diese beiden Bezeichnungsarten für die Windstärke stehen zu einander in der Beziehung, dass:

die Ziffer 1 einer Geschwindigkeit von $0,5-2 \mathrm{~m}$ per Sekunde (1800-7200 $\mathrm{m}$ in der Stunde),

2 einer Geschwindigkeit von $5-10 \mathrm{~m}$ (18-36 Km per Stunde),

3 einer Geschwindigkeit von $15-25 \mathrm{~m}(54-90 \mathrm{Km})$,

4 endlich einer Geschwindigkeit von $30-50 \mathrm{~m}(108-180 \mathrm{Km})$ entspricht.

Weht der Wind stossweise, so ist dies zu bemerken und es ist dessen Stärke oder Geschwindigkeit in ihrem Maximum anzugeben.

H. Mohn gibt in seinen "Grundzügen der Meteorologie" folgende sechstheilige Skala:

\begin{tabular}{|c|c|c|c|c|}
\hline \multicolumn{2}{|c|}{ Windstärke } & $\begin{array}{c}\text { Geschwindigkeit } \\
\text { des Windes }\end{array}$ & Winddruck & \multirow{2}{*}{ Wirkungen des Windes } \\
\hline & $0-6$ & $\begin{array}{l}\text { Meter in der } \\
\text { Sekunde }\end{array}$ & $\begin{array}{l}\text { Kilogramm auf } \\
\text { den Quadratmeter }\end{array}$ & \\
\hline 0 & Stille & $0-0,5$ & $0-0,15$ & $\begin{array}{l}\text { Der Rauch steigt ge- } \\
\text { rade oder fast ge- } \\
\text { rade empor. }\end{array}$ \\
\hline 1 & Sehwach & $0,5-4$ & $0,15-1,87$ & $\begin{array}{l}\text { Für das Gefuhl be- } \\
\text { merkbar, bewegt } \\
\text { einen Wimpel. }\end{array}$ \\
\hline 2 & Mässig & $4-7$ & $1,87-5,96$ & $\begin{array}{l}\text { Streckt einen Wim- } \\
\text { pel, bewegt die } \\
\text { Blätter d. Bäume. }\end{array}$ \\
\hline 3 & Frisch & $7-11$ & $5,96-15,27$ & $\begin{array}{l}\text { Bewegt die Zweige } \\
\text { der Bäume. }\end{array}$ \\
\hline 4 & Stark & $11-17$ & $15,27-34,35$ & $\begin{array}{l}\text { Bewegt grosse Aeste } \\
\text { und schwächere } \\
\text { Stämme. - }\end{array}$ \\
\hline 5 & Sturm & $27-28$ & $34,35-94,4$ & $\begin{array}{l}\text { Die ganzen Bäume } \\
\text { werden bewegt. }\end{array}$ \\
\hline 6 & Orkan & über 28 & über 94,4 & $\begin{array}{c}\text { Zerstörende Wirk- } \\
\text { ungen. }\end{array}$ \\
\hline
\end{tabular}

Die Art, der Charater des Windes kam nicht eigentlich durch Messungen, sondern mehr nur nach Schätzung angegreben werden und zwar nach folgender zweifacher Skala: 
Warmer - lauer - kühler - kalter Wind,

Sehr trockener - trockener - feuchter - Regen-Wind.

Bei der Beurtheilung kann man Thermometer und Hygrometer zu Hülfe nehmen, um sich nicht blos auf das Gefühl $\mathrm{zu}$ verlassen.

Durch längere Zeit fortgesetzte Beobachtungen lernt man die in einer Gegend herrschenden Winde kennen. Man addirt hiebei die Zeiten, in welchen ein jeder Wind wehte und drückt die Summe in Bruchtheilen des ganzen Beobachtungszeitraumes aus.

Ist man durch eine Reihe von Beobachtungen dazu gelangt, zu erkennen, welche allgemeinen oder lokalen Winde in der Gegend eine gewisse Periodizität oder eine gewisse Regelmässigkeit in ihrem ganzen Charakter zeigen, so wird man diese Eigenthümlichkeiten möglichst genau angeben. Z. B. wird man Folgendes notiren:

$1^{\circ}$ Dauer des Windes; es gibt Winde, welche 3, 6, 9, 12 Tage und mehr ununterbrochen wehen;

$2^{\circ}$ den Zeitpunkt des Tages oder der Nacht, wo sie nach einer Pause zu wehen beginnen oder wo wieder eine Pause eintritt;

$3^{\circ}$ die Zeitpunkte, in welchen etwa eine Veränderung im Charakter des Windes fühlbar wird (in Richtung, Stärke, Temperatur, Trockenheit oder Feuchtigkeit, Abnahme oder Zunahme in dieser Hinsicht);

$4^{\circ}$ das Gesetz der Winddrehung, d. h. in welcher Weise die Winde verschiedener Richtung aufeinander folgen oder mit einander abwechseln;

$5^{\circ}$ welche Aenderungen des Wetters sie bewirken, und welchen Einfluss sie überhaupt ausüben, auf Klima, Vegetation, auf das Befinden der Bewohner u. s. w.

Aus den ermittelten Thatsachen wird man die Ursachen abzuleiten, die regelmässigen Erscheinungen wie die Anomalien zu erklären versuchen.

Ozon. Das Ozon ist Sauerstoff in einem Zustand gesteigerter chemischer Wirksamkeit. Reichlich vorhandenes Ozon befördert die Lebensprozesse. In waldigen Gegenden und in der Landluft kann das Ozon zuweilen schon durch den Geruch wahrgenommen werden, während es in Städten oft schwer hält, dessen Gegenwart nachzuweisen. Zu diesem Nachweis und 
um zu konstatiren, in welchem Verhältniss Ozon sich in der Luft vorfindet, wendet man besondere Instrumente (Ozonometer) oder ozonometrisches Papier an, welches folgendermassen angefertigt wird. Man stellt sich aus 11 Wasser, 50 gr Stärkemehl und 5 gr Jodnatrium eine Flüssigkeit her, tränkt in dieser Papierstreifen ron $7 \mathrm{~cm}$ Lünge und $15 \mathrm{~mm}$ Breite und lässt dieselben nun trocknen. Nach dieser $\mathrm{Zu}$ hereitung bewahrt man die Papierstreifen in einer Schachtel auf. Um damit Beobachtungen vorzunehmen, setzt man sie 12-24 Stunden der Luft aus; bei Anwesenheit von Ozon wird das Natriumjodür zersetzt, das freiwerdende Jod wirkt auf das Stärkemehl und firrbt dieses violett, - um so dunkler, je mehr Ozon vorhanden ist. Zur Vergleichung hat man als Skala zehn Proben farbigen Paniers, rom Weiss bis zum tiefsten Violett. Bei der Wahl des Beohachtungsortes sieht man auf eine stelle, an welche der Wind nicht von hewohnten Lokalitiiten herweht, weil an Stellen letzterer Art der Ozongrehalt im Allgemeinen geringer ist als anderwäts. Die Zeit, während welcher das ozonometrische Papier der Luftwirkung auscresetzt bleiben muss, ist rerschieden je nach Ort und Witterung. In der Nähe des Meeres, wo dies Papier sich rascher färbt, genügen einige Stunden für den bezeichneten Zweck; im Binnenlande aber braucht man hiezu mehr Zeit. Von der Witterung hängt dic Dauer des Experiments insofern ab, als das Jodprapier bei Sturm und nahendem Lngewitter sich rascher, bei ruhiger Luft sich langsamer färbt.

Elektrizität. Beobachtungen über die Luftelektrizität sind sehr interessant, aber kaum ausführbar für einen Reisenden, der seinen Aufenthalt in rascher Folge andert und nicht bei jedem Halt Apparate aufstellen kamn, wie sie zu Beobachtungen im Grossen und von der nöthigen Vollkommenheit erforderlich sind. Der Reisende wird sich daher den Fall ausgenommen, dass er im Besitze eines Elektrometers ist, womit wenigstens annähernd die flditrische Spanmung in den untern Luftschichten bestimmt werden kann - damit begnügen, das Torkommen oder Fehlen der Luftelektrizität nach gewissen Anzeichen zu beurtheilen. Man kann z. B., wenn die Luft viel Elektrizität enthält, beobachten, dass die Schweifhaare der Pferde sich mehr oder minder von ihrer normalen Stelle oder Lage entfernen und dass grob- 
wollige Kleidungsstücke beim Reiben oder Schütteln Funken geben. Es ist auch wohl, namentlich auf Berggipfeln, die Ausströmung von Elektrizität aus dem Boden in die Luft von einem summenden Geräusch begleitet und es scheint hiebei der Mensch als Konduktor zu wirken; wenigstens sträuben sich die Bart- und Kopfhaare. Mitunter nimmt man in der Luft eine Detonation wahr wie einen Donnerschlag aus wolkenlosem Himmel. Auffallender und bekannter sind aber andere elektrische Erscheinungen wie das St. Elmsfeuer (eine Art spitze Flamme auf Masten and Thürmen), das Wetterleuchten, der Blitz, das Nordlicht und die Störungen der Magnetnadel ${ }^{1}$ ).

Gewitter ${ }^{2}$ ). Die Gewitter verdienen eine aufmerksame Beobachtung, denn sie sind durch ihre Natur, Häufigkeit, Dauer und Stärke von ganz wesentlichem Einfluss auf das Klima einer Gegend.

Sie sind bald einfachere, bald komplizirte Erscheinungen; ersteres, wenn sie lediglich in einer grossen Bewegung der Luft bestehen, die auch bei ganz hellem Himmel vorkommen Kann; letzteres, wenn die Winde von Regen, Schnee, Hagel und elektrischen Entladungen begleitet sind.

Der Wind oder Sturm weht hiebei selten in kontinuirlicher Weise und gleichmässiger Stärke; es gibt vielmehr Ruhepausen, nach welchen der Wind von Neuem, oft mit etwas veränderter Richtung auftritt. Die Luftbewegung macht. sich in Stössen geltend (welche in der französischen Sprache je nach ihrer Stärke - ob Winde oder Stürme - als bouffées und rafales unterschieden werden).

Der Wind weht auch nicht immer in gerader Linie. Sei es, dass er abgelenkt werde durch das Bodenrelief oder durch Luftströmungen in andrer Richtung: es bilden sich Wirbeluinde, welche den Staub der Strassen und das dürre Laub der Hecken und Wälder aufwirbeln, d. h. in schraubenförmigen Linien bewegen. Diese Wirbel nehmen oft grosse Dimensionen an und treten dann im Hochgebirge als Schneestürme (Guxeten), in Wüsten als Sandstürme auf. Grosse kreis- oder spiralförmige Luftbewegungen sind auch die gefürchteten Phänomene der Wasserhosen oder Tromben, der

1) Vgl. unten S. 448 und Dr. Wettstein's Strömungen S. 95 ff.

2) Tgl. Anmerkung S. 432 (betreffend Aide-mémoire und Wettstein). 
Teifune (Typhoons), Tomados und C'ylitmen. Als Orlian (englisch hurricaur) bezeichnet man alle ausserordentlich heftigen Stürme, wobei die ganze Natur in wildem Aufruhr scheint, ohne dass es sich um wohl charakterisirte Wirbelwinde handelt. Der französische Sprachgebrauch unterscheidet wohl zwischen murcum und temprite, je nachdem der Schauplatz des Sturmes Land oder Meer ist. Im einen wie im andern Fall tritt der Orkan nicht immer mit Wolken, Regen oder Blitz als begleitenden Erscheinungen auf, sondern oft zeichnet er sich nur durch die Intensität der Lufthewegung aus, die auch bei heiterm Himmel eintreten kann.

Es hat übrigens sozusagen jede Gegend ihre besondere Art ron Gewitter, Winden und Stümen, welche in Gang und Entwicklung eine gewisse Regelmässigkeit erkennen lässt ${ }^{1}$ ). Diesen Erscheinungen ist daher in dem Lande, welches man bereist, eine besondere Aufmerksamkeit zu widmen und es sind deren einzelne Phasen genau zu beschreiben. Man notire auch deren Häufigkeit und Dauer, Jahres- und Tageszeit ihres Auftretens, heziehungsweise ihrer grössten Häufigkeit, ihre geographische Ausdehnung und ihre gewöhnlichen oder zufälligen Wirkungen.

Verschiedene meteorologische Beobachtungen. Es bleiben uns noch einige meteorologische Erscheinungen zu besprechen, welche, wenngleich nicht ron nachweisbarem Einfluss auf das Klima, doch ron grossem Interesse sind und zum Theil in gewissem Grade die Gegend charakterisiren, indem sie zur besondern Physiognomie derselben beitragen. Es sind das gewisse atmosphürische Lichtersohemungen oder Photometeore.

Wir gredenken hier in erster Linie der Iuftspiemplung. Bekanntlich handelt es sich dabei um optische Täuschungen, deren Ursache auf ungleicher Dichtigkeit der rerschiedenen Luftschichten infolge ungleicher Temperatux derselben beruht. Diese Phänomene sind nicht auf Wüsten und Stelpen der heissen Zone beschränkt, sondern kommen, wie es scheint, nicht selten auch auf Meeren und in den Polarregionen vor.

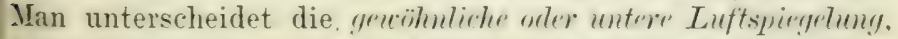
bei welcher man rerkehrte (abwärts gerichtete) Bilder gleich

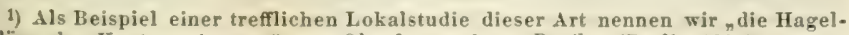
schläge des Kantons Aargau von Oberforstmeister Ryniker (Berlin 1881). 
denjenigen in einem Wasserspiegel oder aber ferne Objekte in phantastischen Formen erblickt, sowie auch Bilder ron Gegenständen, die sich unter dem Horizonte befinden ${ }^{1}$ ); die obere Luftspiegehung zeigt das umgekehrte (abwärts gerichtete) Bild eines Gegenstandes in der Höhe über dem Objekte, oft letzteres allein, oft mit einem zweiten und aufrechten Bilde; die scitliche Luftspiegelung ( $F i g .206$ ) lässt das Bild $\left(a_{1}, b_{1}, c_{1}\right)$ eines Gegenstandes $(a, b, c)$ links oder rechts von diesem erscheinen. Die Fata moryana ist eine Luftspiegelung, bei welcher die Bilder der Objekte nach jeder Richtung verzerrt, gebrochen oder in mehrfacher Wiederholung, in wechselnden Formen, Dimensionen und Abständen erscheinen ${ }^{2}$ ).

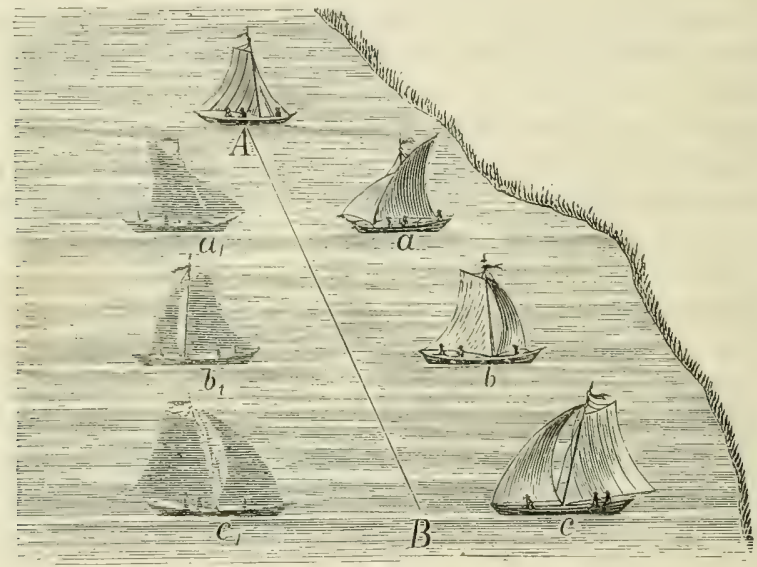

Fig. 206.

Unter den übrigen am Tage sichtbaren Phänomenen, die wir hier im Auge haben, befinden sich einige sehr bekannte, welche nur pro memoria genannt werden mögen, neben selteneren, die eine nähere Bezeichnung erfordern.

Der Regenboyen, in unsern Gegenden eines der häufigsten Phänomene, ist anderwärts seltener; denn er ist bedingt durch einen besondern Zustand des in der Atmosphäre ent-

1) Vgl. das Reich der Luft, frei nach C. Flammarion, von Wilhelm Schütte. Leipzig 1875, S, 144-147.

2) Vgl. Schütte, a. a. O., S. 151 ff. Hayes, das offene Polarmeer, Jena 1868 , S. 366 . 

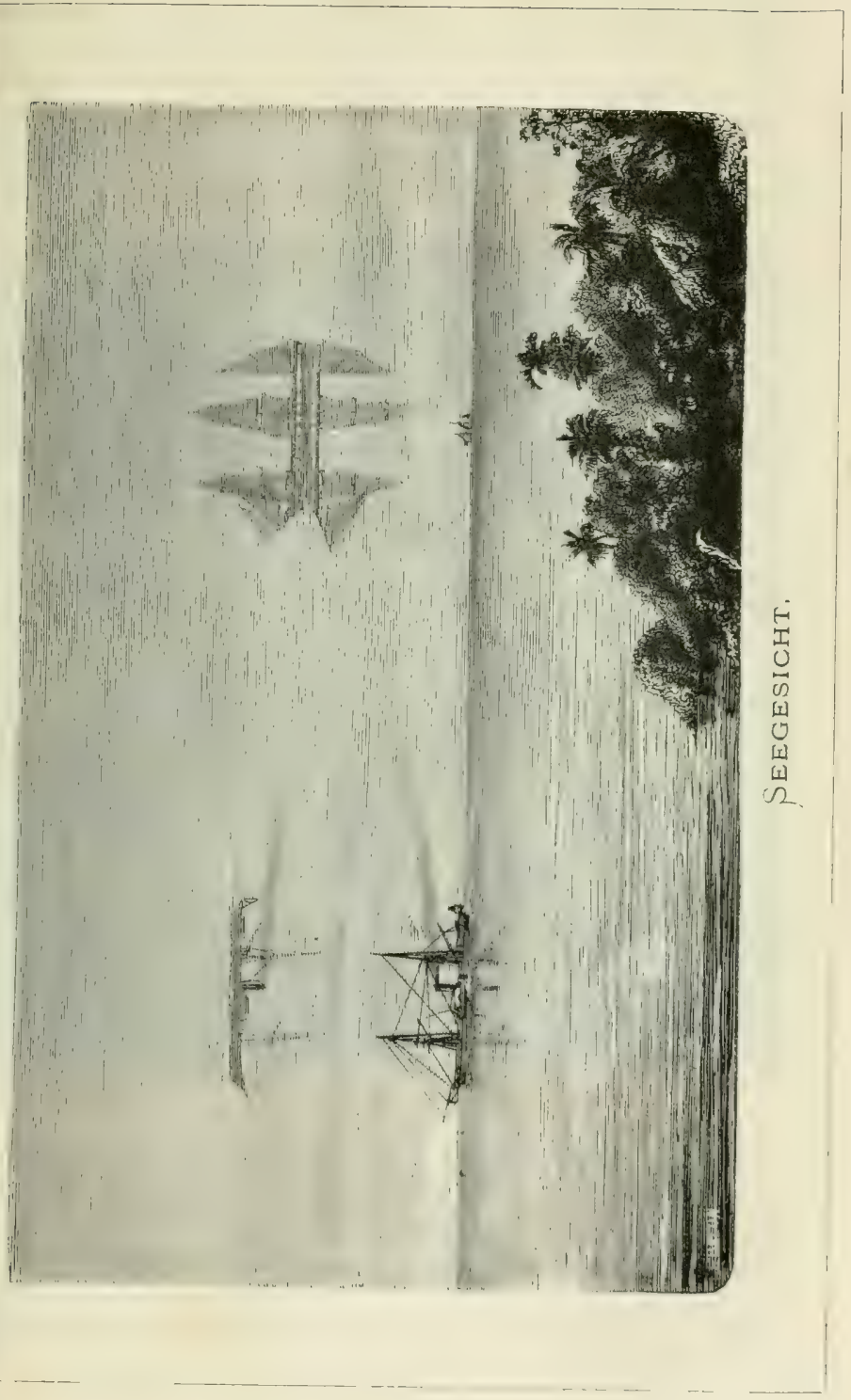

haltenen Wassers. Er wird immer an dem Theil des Horizontes oder Himmelsgewölhes sichthar, welcher dem Orte der Sonne gegenüber liegt. Mitunter ist er doppelt, seltener vielfach; d. h. der Hauptregenbogen (mit Roth nach Aussen) hat über sich einen zweiten (Nebenregenhogen) oder deren mehrere (Fin. $2\left(O_{i}\right)$. Die Reihenfolge der Farben (Roth, Orange, Gelb, Grün, Blau, Indigo, Violett ${ }^{1}$ ) in zwei

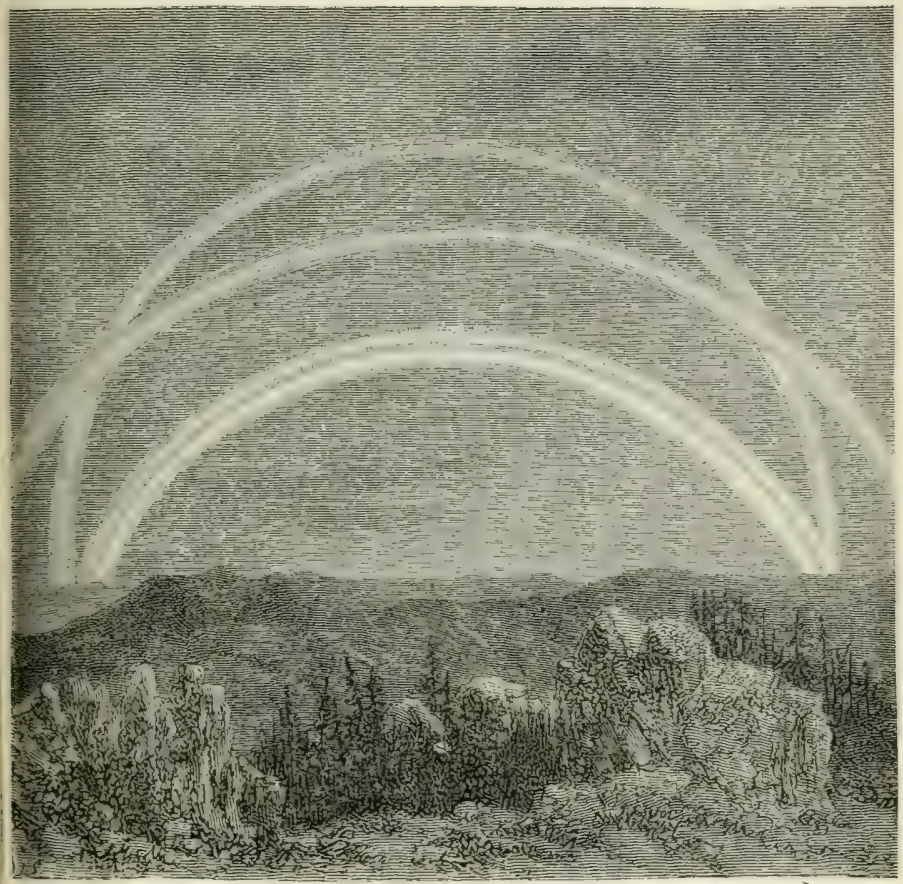

Fig. 207.

der benachbarten Regrenbogen ist entgegengesetzt, d. h. die Reihe im einen Bogen ist das Inverse ler Farbenserie des andern. Wemn dabei zwei Regenbogen sich theilweise decken, so entsteht durch das Aufeinandertreffen komplementärer

1) Betreffend weitere (meist grüne und rothe) Farbenstreifen über das Violett hinaus (sekundäre oder überzählige Bogen) vgl. Müller, kosmische Physik S. 423. 
Farben Weiss. Der Mondregenbogen entsteht in ganz analoger Weise wie der gewöhnliche Regenbogen, wird aber seltener beobachtet, schon weil er weniger intensiv ist.

Als Höfe oder Ringe ("grosse Höfe", Halones ${ }^{1}$ ) bezeichnet man leuchtende Kreise um Sonne oder Mond, welche unter gewissen atmosphärischen Verhältnissen diese Gestirne in bestimmten Abständen (gewöhnlich von 22, seltener von $46^{\circ}$, Fig. 208) umgeben. In Bezug auf die Häufigkeit verhalten sich die Höfe um Sonne und Mond umgekehrt wie die beiden Arten von Regenbogen: der Mondhof ist häufiger zu beobachten

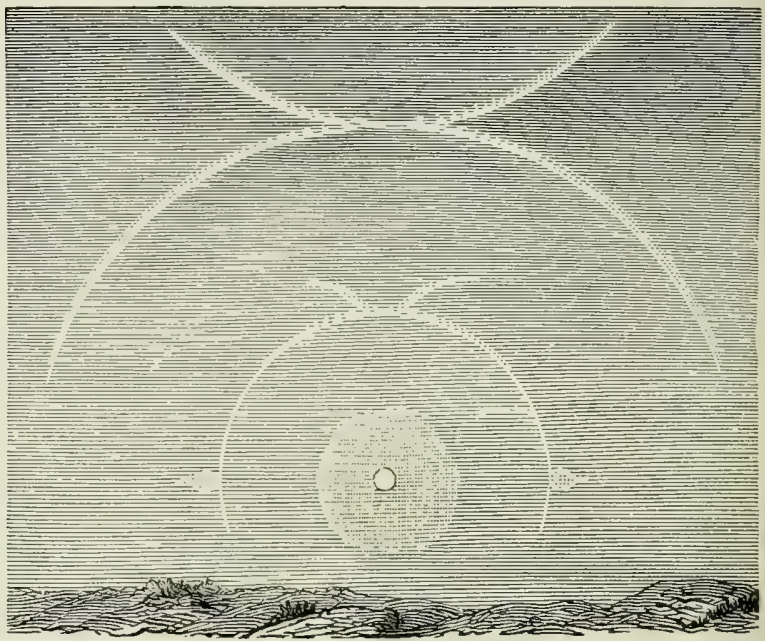

Fig. 20S.

als der Hof um dic Somne, denn jener ist auffallender, weil er durch das blasse Licht des Mondes nicht so überstrahlt wird, wie dieser durch das grelle Sonnenlicht. Die Höfe entstehen infolge einer durch Schnee- und Eiskrystalle in

1) Die Terminologie dieser und anderer Lichterscheinungen der Atmosphäre lässt viel $\mathrm{zu}$ wünschen. Der deutsche Sprachgebrauch bezeichnet als Höfe die Licht- und Farbenkreise umittelbur um Sonne oder Mond, und insofern ist ein entsprechender Vorschlag von Dr. Müller (kosmische Physik S. 425) gerechtiertigt; in der Wissenschaft dominirt aber die gegentheilige Bezeichnung, die wir mit Klöden, Bohn, Schiitte u. A. nachstehend acceptiren. 
der Luft bewirkten Brechung der Lichtstrahlen. Wenn die lireise farbig erscheinen (was nicht immer der Fall ist, beziehungsweise nicht immer deutlich genug hervortritt), so ist das Roth auf ihrer innern Seite, dem Gestirne zugekehrt, das Violett (Blau) aussen. Mitunter hat der Hof infolge optischer Täuschung eine elliptische Form, wobei er um so lileiner wird, je höher das Gestirn steigt. Das blendende Licht der Sonne macht es oft unmöglich, den Hof um dieselbe zu sehen; man nimmt ihn aber in solchen Fällen wahr, wenn man das im Wasser reflektirte Bild der Sonnenscheibe oder aber diese selbst durch ein geschwärztes Glas betrachtet. Zuweilen zeigen sich neben dem Hof Bogen, welche denselben berühren (Tangentialborgen, Fig. 208).

Purbrien oder Nebensomen, falsche Sommen, sind leuchtende und farbige - rothe, gelbe oder hellgrüne - Flecken, welche in bestimmten Entfernungen (denselben wie die Höfe) links oder rechts von der Some erscheinen und mit dieser selbst eine entfernte Aehnlichlieit haben (Fiy. ¿2()s). Die Ursachen dieser Erscheinung sind die gleichen wie die der Höfe; sie zeigt sich auch gleichzeitig mit letzteren. Mitunter sind die Nebensonnen ungemein glänzend, sodass sie hierin der Sonne nahe kommen. Zuweilen, freilich selten, erzeugt dann jede Vebensonne zwei neue, welche alsdann sckumdire Xebonsmmen genannt werden. Lnter dem parhelischen Kreis oder Horizontullireis versteht man einen leuchtenden Streifen, welcher durch den Sonnenmittelpunkt und rings um den Horizont geht, so zwar, dass auf diesem die Nehensonnen erster und zweiter Ordnung sich befinden müssen ${ }^{1}$ ).

Die Nebemmude, Paraselenen oder falschen Monde sind I'hänomene, welche ganz den Nebensonnen entsprechen, nur dass sie an Intensität diesen nachstehen, wie das Licht des Mondes demjenigen der Sonne.

Einige Aehnlichkeit mit den Höfen haben die Glorien nder Kränz" (Coronx, Kronen, „kleine Höfe") um S'mun and 7foud: ihre Entstehungsweise ist aber eine andere. Sie bilden sich nämlich, wenn leichte Wolken vor der Somme oder dem Monde hinziehen, durch Beugung des Lichtes; die Sonne sieht dann aus wie wenn man sie durch ein

1) Vgl. Mousson Physik (Optik, 1881, S. 433) und Bohn, Ergebnisse, S. 612. 
mittels Anhauchens getrübtes Glas betrachtet. Die rothe oder röthliche Farbe befindet sich hier auf dem äussern, ron dem Gestirne entfernteren Rande, dessen Abstand indess nicht über $5^{0}$ beträgt. Diese Erscheinung (Fig. 209) ist beim Monde nicht selten, wird vom Volke als "Mondhof" bezeichnet und gilt als Vorbote von Regen.

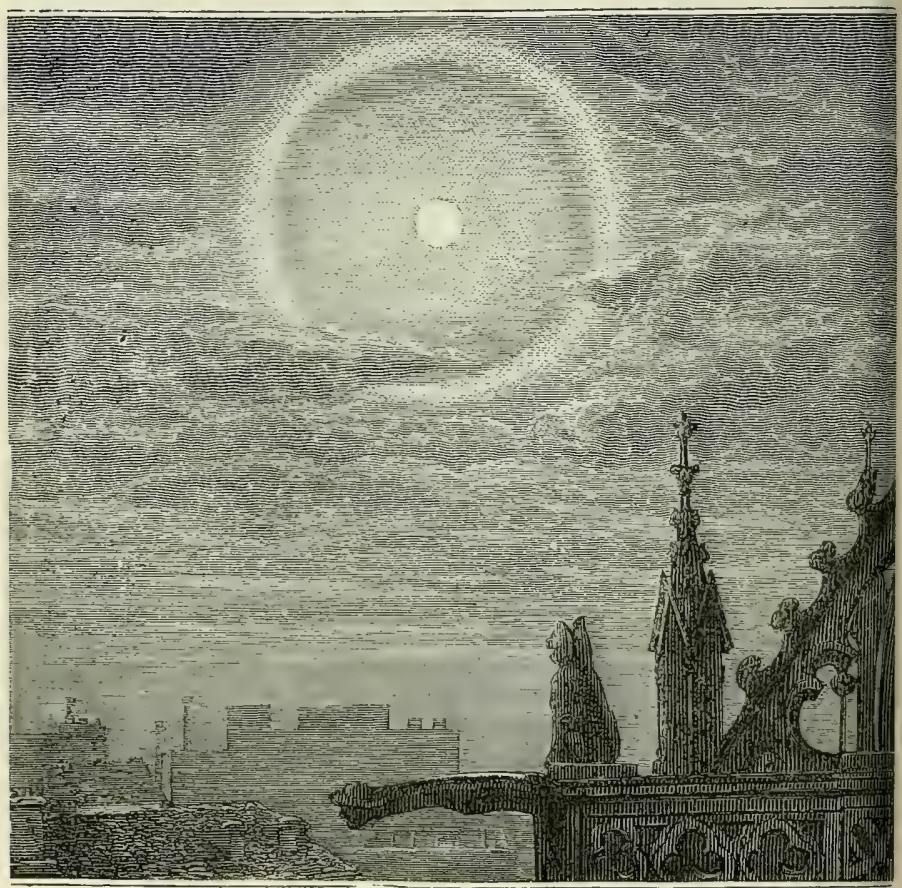

Fig. 209.

Pseudhetium heisst ein Doppelbild der Sonne, wovon das eine wirklich, das andere durch die Wolken reflektirt ist. Man beobachtet diese Erscheinung zureilen auf hohen Bergen, wenn man sich über den Wolken befindet.

Kurz vor dem Auf- oder Untergang der Sonne sieht man auch mitunter Bündel von Liclitstrahlen, welche dadurch erzeugt werden, dass dem Beobachter unsichtbare Wolken 


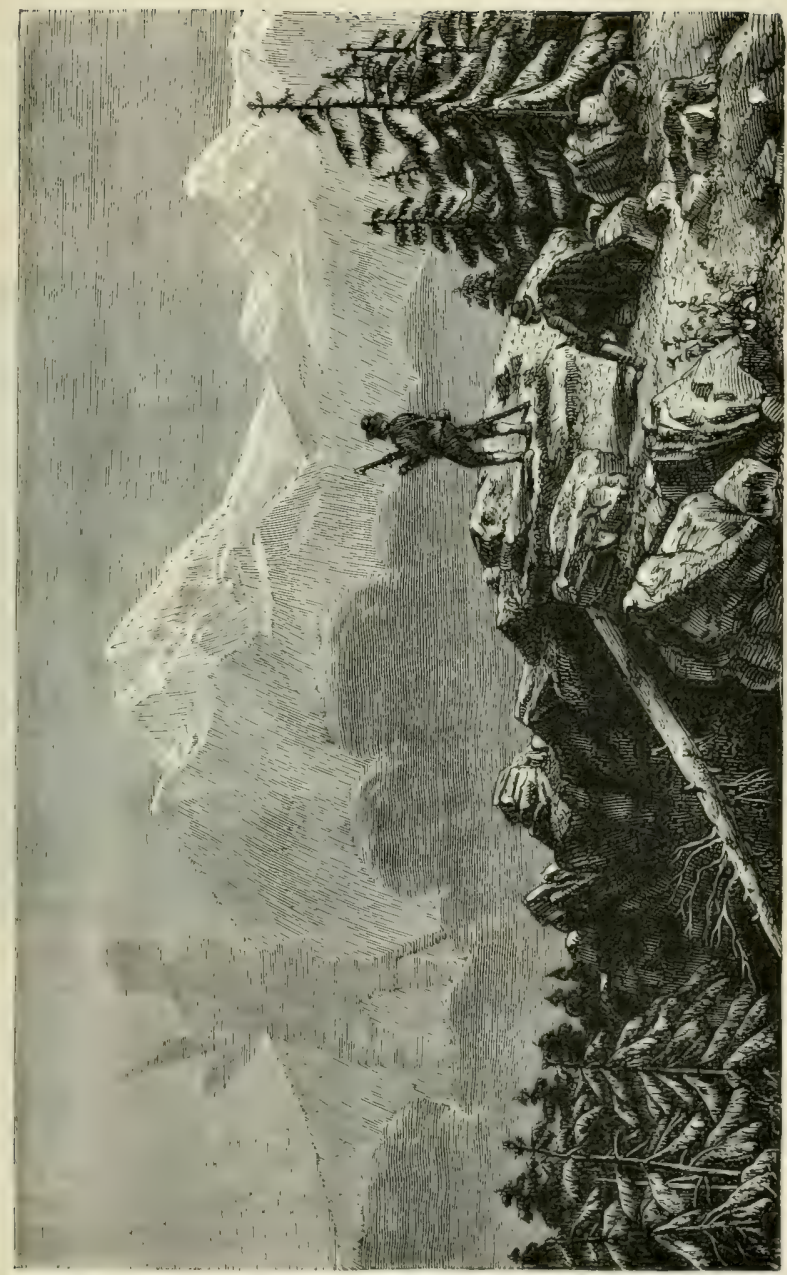

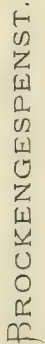



oder Berggilufel einem Theile der somenstrahlen in den Weg kommen und nun die Stellen mit freier Fortpflanzung des Lichts um so heller erscheinen. Zu andern Zeiten wieder gewahrt man Lirhtsäulen und irrstherdene bilder wie Sonnenkreuze (Fiy. :210), welche durch Reflexion der' Lichtstrahlen an Eiskrystallschichten in der Luft hervorgebracht werden.

Ein Paranthetium ist ein weissliches, mehr oder minder verschwommenes Bild der Some, welches ziemlich genau dieser gegenüber am Himmel sich befindet.

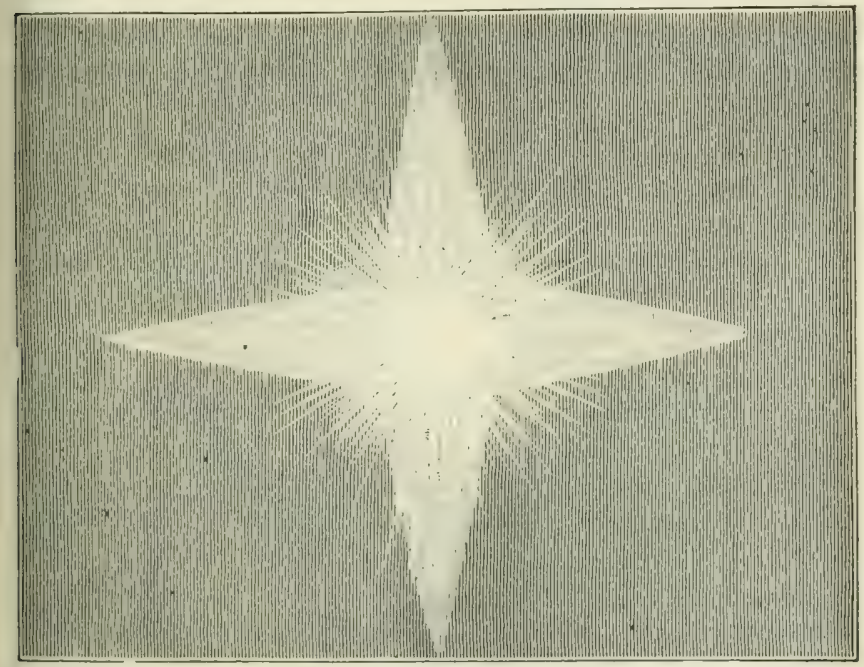

Fig. 210,

Als Anthelien oder Gegensomen bezeichnet man überhaupt die Lichterscheinungen, welche nach Art des Regenbogens am Himmel zur Sonne in Opposition sich befinden. Dahin gehüren z. B. die Schatten, welche die Berge bei Sonnenauf- und Untergang auf Wolken- und Nebelschichten werfen. Hieher gehört auch das unter dem Namen ,Broclin"psurust, Righigespenst" bekannte Phänomen, bei welchem ein uf einem erhöhten Punkte zwischen der Sonne und einer Nebelmasse befindlicher Beobachter auf dieser letztern sein 
Bild oder vielmehr seinen Schatten von hellen Kreisen wie von einem Heiligenschein umgeben sieht ${ }^{1}$ ). Sind mehrere Beobachter bei einander, so sieht jeder das Bild oder den Schatten des andern, aber den leuchtenden Ring, die Gloriole, sieht er nur um sein eigenes Abbild. Dieselbe Wahrnehmung kann man übrigens machen, wenn man, während man die Sonne im Rücken hat, vor sich auf einen Wasserspiegel blickt oder am frühen Morgen auf eine reichlich bethaute Ebene.

Bei Sonnenauf- und Untergang kann man nicht selten Deformationen der Somme am Horizonte beobachten, welche Gestaltverzerrungen durch ungleiche Dichte der untern Luftschichten und dadurch verursachte Strahlenbrechung entstehen $^{2}$ ).

Die Dämmerung ist bekanntlich die Helligkeit vor Sonnenauf- und nach Sonnenuntergang und unterscheidet man hienach Morgen- und Abenddämmerung. Die verschiedenen Gegenden der Erde haben verschieden lang andauernde und verschiedene Effekte mit sich bringende Dämmerung. Am Aequator und überhaupt in der Tropenzone folgen Tag und Nacht rasch und unvermittelt auf einander; hier gibt es keine Dämmerung. In der gemässigten Zone dauert die Dämmerung ungleich lange, je nach der Jahreszeit. In den Polarregionen endlich sind Tag und Nacht eigentlich nichts anderes als eine lange Dämmerung. Die Farbe des Himmels bei Auf- und Untergang der Sonne und die sie begleitenden Erscheinungen variiren nach dem Klima und dem Zustand der Atmosphäre. Wer je einen schönen Sonnenauf- oder Untergang sah, wird erfüllt gewesen sein von Bewunderung über dies immer grossartige und unendlich wechselreiche Bild. In der bunten Manigfaltigkeit, welche diese Erscheinung überall bietet, gibt es aber gewisse charakteristische Züge, die in jedem Lande andere und ihm eigen sind. Ein Sonnenuntergang in der Wüste ist weit verschieden vom Sonnenuntergang im hohen Norden; aber auch benachbarte

1) Brockengespenst heisst diese Luftspiegelung in Deutschland, weil sie daselbst zuerst vom Brocken, dem viel besuchten Höhepunkt des Harzgebirges, bekannt wurde. Dieselbe Erscheinung kennt man aber auch vom Schafberg im Salzkammergut, Piz Currer in Graubünden, vom Rigi, Pilatus etc.

2) Vgl. Schütte, a. a. 0. S. 137. 
Gegenden haben in dieser Hinsicht Eigenthümlichleiten aufzuweisen.

Eine der hauptsächlichsten Wirliungen des Somnenuntergangs ist in Gebirgsländern das sogenannte Alpenglïhen, ein Erglühen der Berggipfel in reflektirtem Lichte, welches etwa 20 Minuten nach Somnenuntergang stattfindet, d. h. 20 Minuten von dem Zeitpunkte an, da die Sonne unter den Horizont sank und die direkte Beleuchtung der Berge durch sie aufhörte. Nachdem sich so die Berge liurze Zeit im Schatten befunden, erglänzen sie in einem leuchtenden Roth, gleich demjenigen glühender Lava oder flüssigen Metalls, das aus den Hochöfen ausströmt. Allmälig erlöscht dann das prachtvolle Phänomen und weicht den Schatten der Nacht.

Das Zodialallicht ist eine helle Region des Himmels, die eine Ellipse bildet, in deren Zentrum sich die Sonne befindet. Die grosse Axe dieser Ellipse fällt ziemlich zusammen mit der Ekliptik; das Zodiakallicht erscheint daher unter dem Aequator und unter den Tropen in fast vertikaler Stellung. Ueberall zeigt sich dasselbe als eine langgezogene Ellipse; in der südlichen Halbkugel erscheint die grosse Axe nach Norden, auf der nördlichen Halbkugel nach Süden gerichtet. Die Frage nach der Natur des Zodiakallichtes ist noch nicht entschieden; es bestehen hierüber zahlreiche Theorien. Es zeigt sich am Himmel vor Sonnenauf- und nach Sonnenuntergang. Auf der nördlichen Halbkugel kann man es zur Zeit des Herbstäquinoctiums am besten vor Sonnenaufgang beobachten, um das Frühlingsäquinoctium am besten nach Sonnenuntergang. Auf der Südhemisphäre hingegen sieht man es im September Abends, im März Morgens. In den tropischen Gegenden zeigt es sich als eine glanzvolle Erscheinung bei hellem Wetter jeden Abend. Seine Grenzen sind aber nur dann deutlich wahrzunehmen, wenn der Himmel zwar unbewölkt, aber dunkel, d. h. weder durch Dämmerung noch durch Mondschein erhellt ist. Zur Beobachtung desselben bedient man sich wohl auch eines Cylinders ron $30 \mathrm{~cm}$ Durchmesser und Länge, dessen Inneres geschwärzt oder mit schwarzem Papier ausgekleidet wurde. Bei der Beschreibung des Zodiakallichtes hat man namentlich anzugeben, welche Sterne dessen Grenzen bezeichnen; hienach trägt man dann diese Grenzen in eine Sternkarte ein, wobei 
auch so gut als möglich die Lichtstärke der rerschiedenen Partien zur Darstellung gelangen soll ${ }^{1}$ ).

Die Polarlichter, welche man mit Unrecht blos .Nordlichter" genannt hat, - man beobachtet sie gegen den Südpol hin ebensowohl wie gegen den Tordpol — sind optische Phänomene, welche zuweilen, gleich dem Wiederschein einer ungeheuren Feuersbrunst, in der Nacht den Himmel erhellen und alle erdenklichen Formen annehmen. Nan schreibt sie einem Ausströmen ron Luftelektrizität $z u$, welche sich, statt plötzlich in Gewittern, langsam in den obern Schichten der Atmosphäre vollziehen soll. Die Erscheinung ist am häufigsten in den Polarregionen ${ }^{2}$ ) zu beobachten, indessen mitunter auch in niedrigeren Breiten. Hiebei sind folgende Momente zu lionstatiren: der Zeitpunkt des Eintritts der Erscheinung; die Dauer derselhen: die Himmelsgegend, in welcher sie sich zeigt. Im Weitern sind ihre verschiedenen Phasen zu beschreiben und soweit möglich nach Formen und Farben bildlich darzustellen. Dauert das Phänomen bis gegen Tagesanbruch, so beobachte und notire man, wie der Theil des Himmels aussieht, an welchem rorher das Polarlicht sich zeigte.

Das Funlieln der Sterne oder das Flimmern und scheinbare Zittern derselben ist eine durch einen eigenthümlichen

1) Vgl. Beobachtungen über das Zodiakallicht von Henry Corvill Lewis in Germantown; , Sirius, " Zeitschrift für populäre Astronomie 1851, S. 87. Auf Grund 5 jähriger Beobachtungen (bei $40^{\circ} \mathrm{n} . \mathrm{Br}$.) werden hier am Zodiakallicht 3 Theile unterschieden: der Zodiakalkegel, der Zodiakalstreifen und der Gegenschein. Der Zodiakalkegel ist das ,Zodiakallicht" der meisten Autoren. Seine Höhe über dem Horizont und seine Helligkeit stehen in direktem Zusammenhang mit der Dänmerung und der Schiefe der Ekliptik. Die günstigste Zeit, denselben zu sehen, ist stets unmittelbar nachdem die letzten Spuren der Dämmerung verschwanden. Der Unterschied von der Dämmerung, mit welcher er oft verwechselt wird, liegt darin, dass die letzten Spuren der Dämmerung eine seitliche Lichtausbreitung längs des westlichen Horizontes bilden, während der abendliche Zodiakalkegel, von etwa derselban Farbenabschattirung, sich schräger erhebt als der Kegel, der je nach der Jahreszeit mehr oder weniger zugespitzt ist. In jedem der 5 Jahre war der abendliche Zodiakalkegel am glänzendsten von Mitte Februar bis Mitte März. Anfangs Dezember wird er so hell wie die Milchstrasse, übertrifft diese dann bald an Helligkeit - kann sogar Schatten werfen - bis er im April das blassere der beiden Objekte zu werden beginnt. Der Zodiakalstreifen ist eine ungemein schwache Lichtzone längs des Thierkreises (Zodiacus) quer durch den Himmel ron Horizont zu Horizunt, der Genenschein ein rundlicher oder ovaler Lichtfleck, welcher nächtlich an der Stelle des Zodikalstreifens erscheint, die $180^{\circ}$ von der Sonne entfernt ist. - Ohne physischen Zusammenhang mit dem Zodiakallicht, aber wesentlich für die Beobachtung des letzteren sind: 1) "das Horizontlicht, ein blasses Band weissen Lichtes mit parallelen Seiten rings um den Horizont, am hellsten unten, wo der Rand etwa 50 über dem Horizont scharf begrenzt ist: 2) der Absorptionsstreifen, ein dunkler Raum unter dem Horizontlicht, auf dem Horizonte rubend.

2) Vgl. C. Weyprecht, praktische Anleitung zur Beobachtung der Polarliehter und der magnetischen Erscheinungen in hohen Ereiten. Wien $18 s 1$. 
Zustand der Atmosphäre bewirkte Interferenz-Erscheinung. Wenn die verschiedenen Luftschichten ron wesentlich ungleicher Dichte sind und von der Erde warme Dünste aufsteigen, so entsteht in der Luft eine zitternde oder wimmelnde Bewegung ähnlich derjenigen, die man am Tage über stark erhitzten Flächen beobachten kann; die Sterne glänzen dann in raschem Wechsel bald stärker bald schwächer; sie scheinen, einen vulgären Ausdruck zu gebrauchen, am Himmel zu tanzen. Letztere Erscheinung kann aber ihren Grund auch im Beobachter haben, dessen Auge durch längeres scharfes Beobachten des Himmels den nöthigen Grad ron Ruhe verliert.

Die Sternschmupren oder fallenden Sterne scheinen abgelöste Kometenpartikelchen zu sein. Ihre Häufigkeit richtet sich nach der Jahreszeit und ist übrigens in ein und derselben Nacht sehr rerschieden; bald treten sie nur selten und rereinzelt, bald als wahre Sprühregen von Sternen auf ${ }^{1}$ ). Es ist namentlich auf die Richtung ihrer Bewegung zu achten und dabei anzugeben, ron welchem Sternbild sie ausringen und nach welchem andern sie sich hinbewegten; erner mache man Notizen über deren Anzahl, Grüsse, Ge:chwindigkeit, besondern Glanz und Farbe.

Die Feuerkugeln sind feste Körper, welche, wie ihr Name jesagt, am Himmel in Gestalt feuriger Kugeln erscheinen; ie lassen eine leuchtende Spur hinter sich und zerspringen :uweilen mit einem Kinall gleich riesigen Raketen. Auch in 3ezug auf diese Vorkommnisse hat man die Region des timmels zu bezeichnen, in welcher sie erscheinen, sodann lie Richtung ihrer Bahn ${ }^{2}$ ) und die ungefähre IIöhe, in welcher ie explodirten, endlich die besondern begleitenden Erscheiıngen. Die auf den Boden gefallenen Trümmer einer Feuerugel nennt man Meteorsteine oder Aerolithen; da sie mit iner sehr grossen Fallgeschwindigkeit auf dem Erdboden nkommen, so dringen sie oft tief in denselben hinein. Bei ich darbietender Gelegenheit unterlasse man nicht, solche

1) Vgl. Schütte, a. a. O. S. $154 \mathrm{ff}$.

2) Sorgfältige Analysen der Schallieahrnehmungen bei Meteoritenfïllen machen 3 möglich, den beiläufigen Weg des Meteors abzuscbätzen, auch wenn dasselbe :hlecht oder gar nicht gesehen und beobachtet worden. Sirius 1881, S. 133 ntersuchungen über die Bahnverhältnisse des Meteoriten von Orgueil in Franksich, rom 14. Mai 1864). Vgl, auch Schütte, a. a. O. S. 159 ff. 
Aerolithen zu sammeln; können sie wegen grossen Umfangs und Gewichts nicht transportirt werden, so beschreibe man sie genau, mache eine photographische Aufnahme und nehme Handstücke von denselben mit.

Tabellen, Karten und Diagramme. Die meteorologischen Daten, welche der Reisende gesammelt hat, wird derselbe in übersichtlicher und anschaulicher Weise zur Darstellung bringen. Als Mittel zu diesem Zwecke sind Tabellen, Karten und Diagramme zu bezeichnen.

Die Tabellen geben eine summarische Rekapitulation der täglich beobachteten Elemente oder Faktoren. Jeder wird diese Tabellen nach seinem speziellen Zweck einrichten. Beispiele hiefür geben wir in Taf. $X X$. Man kann sich derselben bedienen, um darnach Spezialtabellen für kürzere oder längere Perioden anzufertigen. Die Rücksicht auf Raumersparniss macht es oft wünschbar, dass gewisse Angaben statt in Worten durch Zeichen gemacht werden. Eine Zusammenstellung solcher Zeichen ist in Taf. XXI enthalten. Man wird indessen auf alle Fälle gut thun, am Fuss oder Kopf der Tabellen, die man anfertigte, eine Erklärung der hiebei gebrauchten Zeichen und Abkürzungen beizufügen, sowie auch angegeben werden soll, welcher Instrumente man sich bei den Beobachtungen bediente. Hinsichtlich der Notizen, die in einer solchen Tabelle nicht aufgenommen werden können, verweist man auf die betreffenden Spezialblätter.

Die Karten sind namentlich geeignet zur Darstellung von Erscheinungen mit örtlichen Modifikationen, d. h. solcher Phänomene, die nur einzelne Partien der Gegend betreffen, um welche es sich handelt, oder deren Wirkungen wenigstens nach diesen einzelnen Partien verschieden sind. wird man z. B. in Karten durch konventionelle Farben Zonen von Hagelschaden bezeichen, ebenso durch abgestufte Töne die Vertheilung des Regens, wobei man dann mit einem Blicke sieht, welche Gegend wenig, welche andern hingegen reichlich Regen erhalten.

Diagramme eignen sich zur Darstellung aller Erscheinungen, deren Intensität gemessen werden kann. Eine solche graphische Darstellung gibt oft eine bessere Idee von der Sache als lange Zahlenreihen. Ein Beispiel hievon hatten wir schon bei Besprechung des täglichen Ganges der Temperatur 


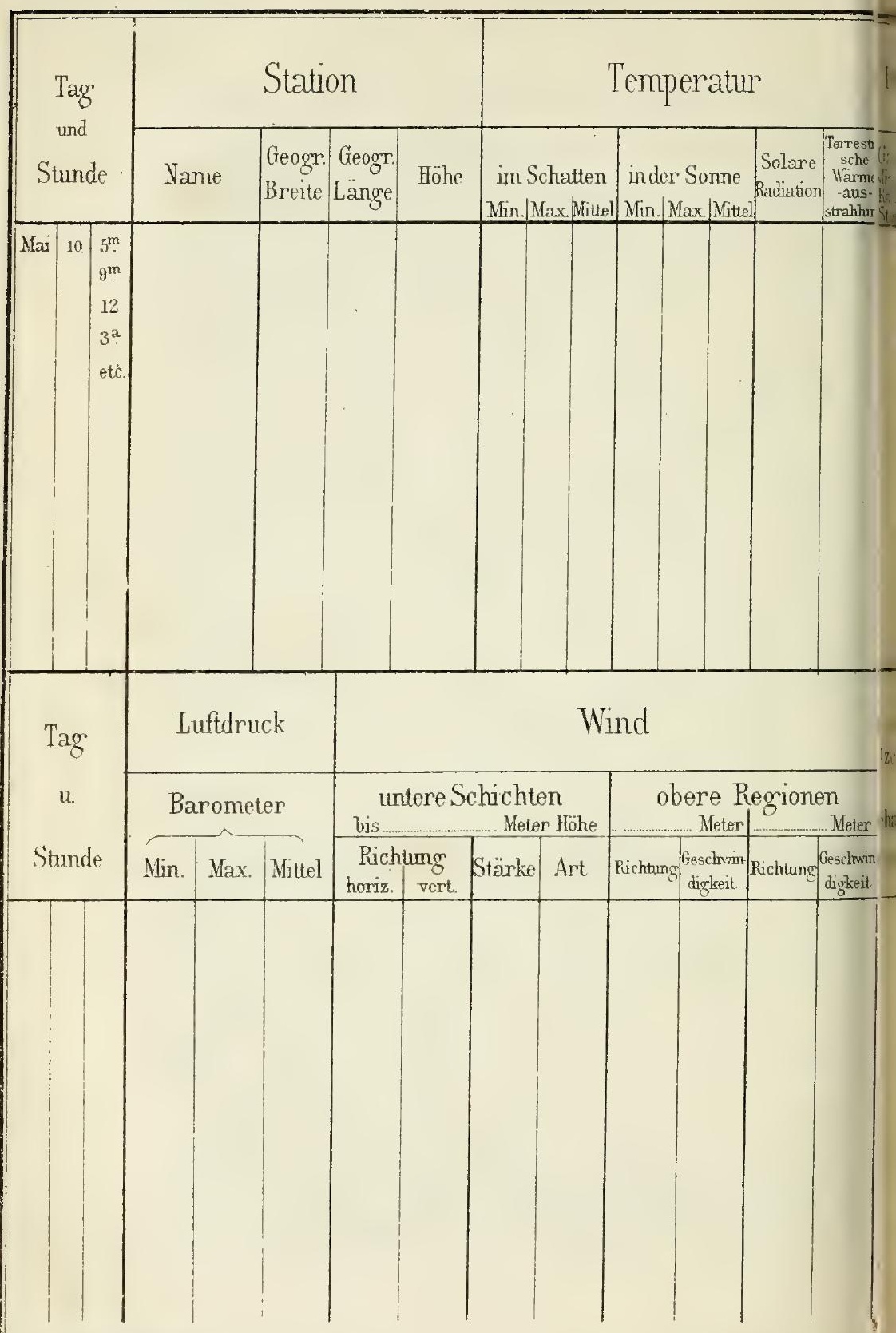

Accessorische Beobarhtungen: 



\section{METEOROLOGISCHE ZEICHEN .}

Abendthau

Morgenthau

raj

Ditiste

ieichter Vebel

itankes Nebel

Seuchtender Nebel

Wuftender Nebel

Rauchfrost

Töhenrauch

chroacher Regen

tarker Regen

'olkentruith.

latteis

ragel

raupein

isnadeln in der Luft

hree

dineesturm
- Elehtrisches Tosen _._._._. id

$s^{t}$ Elmsfeuer

$\downarrow$

Blitr

Blitrschlag

Polarlicht

Luftspiegelung

Regenbogen

Doppelter Regenbogen

Sonnenhof

(0) oder $\theta$

Mondhof

$\checkmark$ oder

Nebensonnen.

200

- Tébenmonde

Sonnenknone

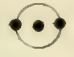

Thगका:

Mondkrone

Gervitter:

() oder. (1)

- oder i2

Iद

sturm

Wirbetroind

* Windhose, Wasserhose

Giyclone

3. Die Intensitait der Erscheinung wird durch eine hiffer rechts ber dem heichen angegeben, is, $B$.

- Schroacher Thau

$\approx \approx$ Leichte Dünste

$\equiv{ }^{2}$ Sehrstarker Nebel

- Strömender Regen 

(S. 411); nachfolgend geben wir ein zweites Beispiel, woraus zu ersehen ist, wie die Monatsmittel der Niederschläge eines Jahres angegeben werden.

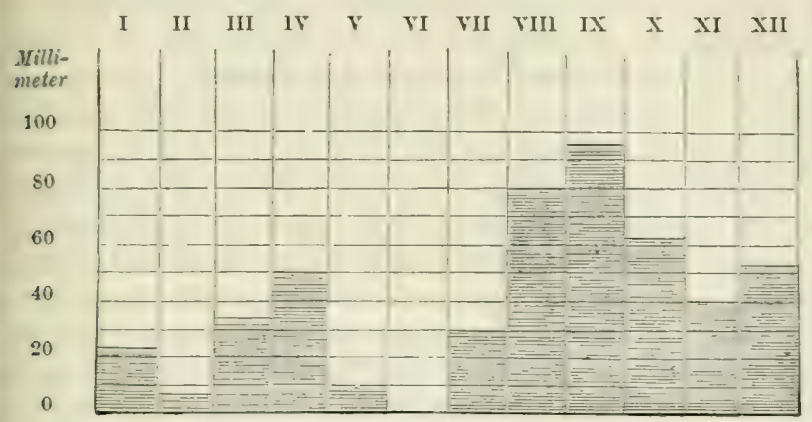

Fig. 211.

Diese beiden Beispiele mögen genügen, um zu zeigen, wie solche Diagramme zu erstellen sind. Es geschieht immer nach einem und demselben Prinzip: Nan hat eine gewisse Zahl ron Kólonnen für Stunden, Tage oder Monate (als Alsszissen), andrerseits eine Skala, wonach man die Intensität der Erscheinung bezeichnet (als Ordinaten): durch die so erhaltenen Punkte zieht man eine Kurce, welche den Gang der Erscheinung, die Schwankungen derselben, repräsentirt.

Gesammtbild des Klimas. Nachdem man in der beschriebenen analystischen Weise die einzelnen meteorologischen Faktoren des Klimas betrachtet hat, bleibt uns die synthetische Arbeit, das Klima in seiner Gesammtheit aufzufassen, wach seinen Ursachen wie nach seinen Wirkungen, insbesondere was seinen Einfluss auf die Lebenserscheinungen, auf Landwirthschaft und Gesundheitsverhältnisse betrifft.

\section{HYDROLOGIE.}

Unter diesem Titel fassen wir alles Dasjenige zusammen, was sich auf die Erforschung der Gewässerverhältnisse des besuchten Landes bezieht.

Wir sprachen bereits von den Niederschlägren, welche das Land in Form ron Thau, Regren, schnee und Hagrel erhält. 
Unter dem Einfluss der Luft und der wärmenden Sonnenstrahlen verdunstet ein Theil dieser Niederschläge; ein anderer Theil wird absorbirt durch Sandboden und Dammerde, welche er momentan befeuchtet, oder von Pflanzen, in deren Säftemasse er übergeht und deren Wachsthum er vermittelt; der Rest fliesst an der Erdoberfläche in kleinen Wasseradern, in Bächen, Flüssen und Strömen, um entweder dem Meere zugeleitet zu werden oder in tiefere Erdschichten einzusickern und im letzteren Falle bald wieder hervorzutreten als Quellen, die selber auch Wasserläufe alimentiren, bald jene unterirdischen fliessenden und stehenden Gewässer zu bilden, deren Kenntniss noch so mangelhaft ist.

Es wäre von hohem Interesse, für jede Gegend den Gesammtbetrag der atmosphärischen Niederschläge zu kennen, die sie im Laufe eines Jahres erhält und ebenso den Verlust an Wasser, welchen sie auf verschiedene Weise, namentlich durch Verdunstung und fliessende Gewässer erleidet; aber dies zu bestimmen, wäre eine schwierige und undankbare Aufgabe. Wir beschränken uns daher auf eine Betrachtung der Hauptwirkungen dieser Niederschläge; der Bewässerung und Entwässerung des Landes, welches wir zu diesem Zwecke in hydrographische Bassins - Flussgebiete oder Flussbecken - eintheilen.

Fluss- oder Stromgebiete. Das gesammte Areal, dessen aus Quellen, Regen, Schnee und Gletschern stammende Wasser sich in ein bestimmtes (stehendes oder fliessendes) Gewässer ergiesst, heisst bekanntlich das Gebiet, Becken oder Bassin jenes Gewässers. Wenn es sich um Flüsse und Ströme handelt, so kann ihr Becken oder Bassin als das Gebiet bezeichnet werden, dessen natürliche Entwässerung oder Drainimung durch jene Flüsse oder Ströme stattfindet, indem dieselben für dieses Gebiet ein grosses System des Wasserabflusses bilden.

Diese hydrographischen Bassins, Fluss- und Stromgebiete sind gegen einander abgegrenzt durch die Wasserscheiden, das sind Verbindungslinien von Punkten - oft unmerklichen Terrainanschwellungen - von denen aus die meteorischen Wasser nach (zwei oder mehr) verschiedenen Richtungen abfliessen. Diese Linien erscheinen als vielgestaltete und oft sehr unregelmässige Kurven; mitunter sind dieselben vollkommen geschlossen, in sich selbst zurücklaufend, wenn 
nämlich die Gewässer sich in Sand oder einem Sumpf verlaufen oder sich in ein abflussloses Wasserbecken - Binnensee, Binnenlagune - ergiessen; meist aber sind dieselben an einer Stelle offen, indem zwischen Anfangs- und Endpunkt eine Küstenstrecke liegt.

Die Wasserscheiden fallen durchaus nicht immer zusammen mit den Kamm- oder Firstlinien der Gebirge, d. h. jenen ebenfalls blos gedachten Linien, welche die aufeinanderfolgenden höchsten Punkte eines Gebirges verbinden. Nicht selten kommt es vor, dass ein Höhenzug, von dem man glauben sollte, er müsse den natürlichen Rand eines hydrographischen Beckens bilden, von den fliessenden Gewässern umgangen oder in einer engen Schlucht (Klus, Cañon), zuweilen selbst in unterirdischem Laufe, durchbrochen wird, so dass die Wasseradern ihren Anfang hinter jener Kette auf niedrigeren Höhen haben, oft auf Ebenen, wobei dann die Wasserscheide nur durch unbedeutende Bodenerhebungen gebildet werden kann.

Die Grenzen der verschiedenen hydrographischen Gebiete werden in der für topographische Aufnahmen im Allgemeinen beschriebenen Weise bestimmt; auf Grund einer solchen Darstellung erhält man sodann den Flächenimhalt derselben nach Methoden, die ebenfalls bereits dargelegt worden sind (rgl.S.175).

Fluss-Systeme. An die Bestimmung von Grenzen, Umfang und Inhalt eines hydrographischen Beckens schliesst sich die Untersuchung der Art seines Flussnetzes oder Stromsystems an. Man versteht hierunter das Gesammtbild der Wasseradern dieses Beckens, welches im Allgemeinen dem Bilde eines Baumes mit seinen Aesten und Zweigen oder mit seinem Wurzelsystem gleicht. Das Analogon zum Stamm des Baumes ist der Hauptstrom; den grössten Aesten oder Hauptwurzeln entsprechen die Tebenflïsse und den kleineren Aesten oder Wurzeln die Zuflüsse, welche ihrerseits wieder Zuflüsse zweiten, dritten und weiter untergeordneten Ranges haben, wie die Aeste sich in gröbere und feinere Zweige ausgliedern. 'So im Allgemeinen. Es gibt indessen Ausnahmen. Nit Berücksichtigung dieser haben wir vier Typen ron Flusssystemen zu unterscheiden :

Erster Typus. Nehr oder minder gleichlaufende Wasseradern ziehen sich durch eine Abdachung hinunter und er- 
giessen sich in ein stehendes Gewässer (Meer oder See) ohne Zuflüsse aufzunehmen: einfache Küstenflïsse oder Querströme (Fig. 212). Das Bild, das diese bieten, gleicht nicht einem Baume, sondern mehr den Zähnen eines Kammes (a), den divergirenden Speichen eines Rades (b) oder den konvergirenden
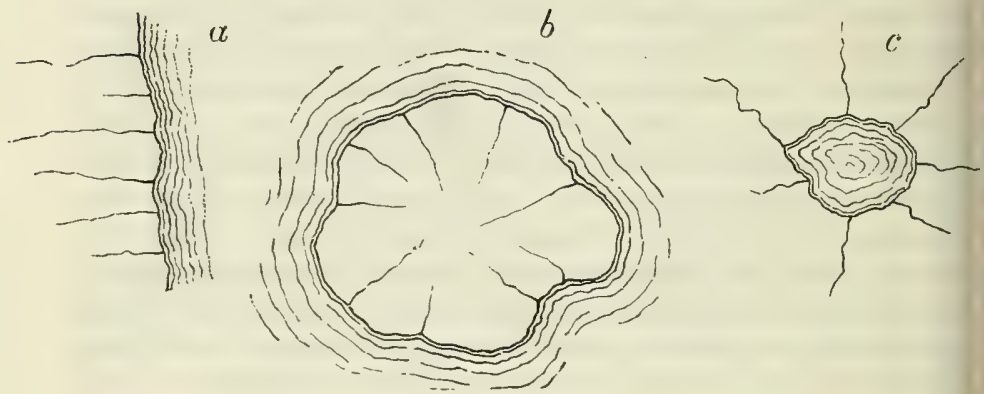

Fig. 212.

Furchen einer Schale mit kannelirten Rändern (c). Wir können diese Wasserläufe als parallele, radial-divergivende und radiallionvergirende Küstenflïsse bezeichnen, wofern wir nur bemerken, dass die Bezeichnung radial nicht nur auf eine kreisförmig begrenzte, sondern auch auf elliptische oder durch unregelmässige Kurven umschriebene Wasserbecken $\mathrm{zu}$ beziehen ist.

Zweiter Typus. Eine am

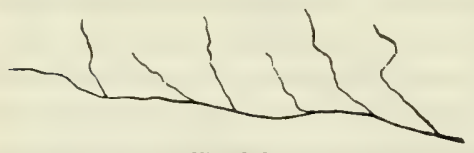
Fusse eines Abhangs sich hinziehende Wasserader erhält nur von einer Seite namhafte Zuflüsse (Fig. 213). Es Fig. 213. ist dies Oskar Peschel's ${ }^{1}$ ) „Längenstrom mit Nebenflüssen auf Einem Ufer", ein Typus, den wir auch als einfaches und einseitiges Fluss-System bezeichnen können.

Dritter Typus. Eine Wasserader, welche die Sohle eines Thales annähernd in der Nitte derselben durchzieht und von beiden Seiten des Thales her einfache (d. h. nicht weiter ver-

1) Neue Probleme der vergleichenden Erdkunde. 1870. S. 133. Sonklar. 
zweigte Zuflüsse empfängt (Fig.¿1í); - Peschel's ${ }_{n}$ Längenstrom mit Nebenflüssen an beiden Ufern" (a. a. O.S. 135), ein Typus, den wir als cinfaches zureiscitigesFlusssystem bezeichnen wollen.

Vierter Typus. Das Flusssystem, von welchem schon die Rede war: wo ein Haupt-

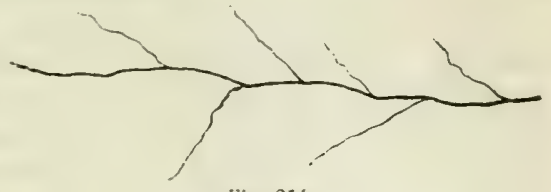

Fig. 214 . strom von beiden Seiten her Nebenflüsse erhält, die selbst wieder seitliche und sich weiter verzweigende Zuflüsse aufnimmt (Fig. 215), ein Typus, der als zusammengesetztes oder ausgebildetes Flusssystem bezeichnet werden mag. Erhielte die Hauptader eines solchen Flussnetzes nur von einer Seite $\mathrm{Zu}$ flüsse, so wäre dasselbe als zusammengesetztes, aber nur einseitig ausgebildetes System zu bezeichnen und diesem gegenüber das Netz, welches wir vorhin in's Auge fassten, als normal-zusammengesetztes oder beidseitig entwickeltes Stromsystem.

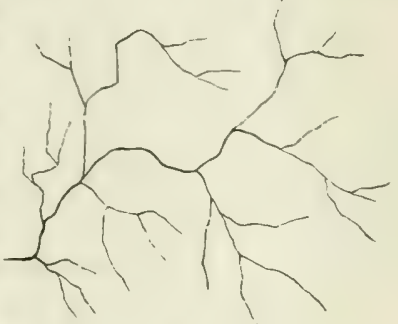

Fig. 215.

Die Seitengewässer können je nach der Stufe, welche sie in dem System einnehmen, als solche I. Ordnung (Nebenflüsse), II. Ordnung (Zuflüsse), III. Ordnung etc. betrachtet werden. Wichtiger als die Aufstellung solcher Rangstufen im hydrographischen Netz ist die Unterscheidung der Gewässer und einzelner Strecken derselben einerseits in Lüngcnströme und andererseits in Querströme, jenachdem sie mit dem Streichen des Gebirgs wesentlich parallel oder dazu annähernd senkrecht gerichtet sind und demmach ihre Thäler den Charakter von Längs- oder aber von Querfurchen im Gebirge haben. Ferner ist es von Bedeutung, verschiedene Wasseradern und Theile von solchen - beziehungsweise deren Thäler — nach den Bezichungen in ihver rïumlichon Anordum, zu betrachten. Es ist dies um so wichtiger, als die morphologischen Verhältnisse von heute, um deren Konstatirung es sich zunächst handelt, das derzeitige Resultat 
einer geschichtlichen Entwicklung sind, als solches auf frühere Zustände hindeuten und uns auch hier anregen sollen, das Seiende als ein Gewordenes, ein Entwicklungsstadium, zu betrachten.

Nicht alle parallelen Flussstrecken sind, wie dies Fig. $212 a$ darstellt, auch gleichgerichtete; vielmehr kommen Fälle vor, wo die Gewässer in den parallel nebeneinander liegenden Flusslinien nach entgegengesetzter Richtung sich bewegen; solche Flüsse oder Flussstrecken mögen antiparallel genannt werden, zum Unterschied von den eigentlich parallelen der ersten Art.

Zwei oder mehr Flüsse können eine Flussreithe bilden, indem die Gewässer in einer und derselben Linie nach einer Seite oder nach entgegengesetzten Richtungen - im letztern Falle von einander hinweg oder auf einander zuströmen.

Beispiele für diese Typen bietet fast jede Landkarte, wenigstens fast jede gute Karte eines Gebirgslandes, und man wird, indem man sie verfolgt, an Einsicht in das System der natürlichen Entwässerung des Gebietes gewinnen. Die Strecken einer Flussreihe werden sich meistens als Theile eines frühern Ganzen nachweisen lassen, als Stücke eines Thales, welches durch nachträgliche geologische Veränderungen - durch Terrainbewegungen oder Wasserwirkung in verschiedene Partien abgegliedert wurde ${ }^{\mathbf{1}}$ ).

Von Wichtigkeit für den Charakter eines fliessenden Gewässers ist ferner die sogenannte (räumliche) Entwicklung scines Laufes und dessen Gefälle. Unter dieser Entwicklung eines Flusslaufes versteht man das Verhältniss der Lauflänge zu dem direliten Abstand zwischen Quelle und Mündung. Auf Grund unserer topographischen Aufnahmen und Zeichnungen können wir die in Rede stehenden Werthe leicht ermitteln. Die Lauflänge erhalten wir, indem wir den Flusslauf auf der Karte in so viele Stücke eintheiler, dass jedes davon als eine gerade Linie betrachtet werden darf, diese Stücke einzeln messen und ihre Summe mit der Reduktionszahl der Karte multipliziren, beziehungsweise den wahren Werth der Stücke und ihrer Summe mittels des Massstabes der Karte bestimmen. Die Lauflänge ist demnach die rektificirte (zu einer geraden Linie ausgezogene) Horizontalprojektion des Flusses, wie letztere im Kartenbild erscheint. Es gibt besondere Instrumente zur

1) Vgl. E. H. Wichmann, die Elbmarseh und die Flüsse der deutschen Tiefebene. Gäa 1881. S. 193 ff. 
raschen und genauen Messung solcher unregelmässigen Linienzüge ; das angegebene Verfahren kann aber genügen. Der direkte Abstand zwischen Quelle und Mündung oder die Luftdistanz zwischen diesen beiden Punkten wird mittels eines Massstabs oder eines Zirkels abgemessen, wieder unter Berücksichtigung der Verjüngung, welche für die Karte angewendet wurde. Diese Reduktionszahl, beziehungsweise der Kartenmassstab, kommt freilich nur in Betracht für die Angabe des absoluten Betrages der Lauflänge und des erwähnten direkten Abstandes, ist dagegen selbstrerständlich unerheblich, wenn man nur das Terhiltniss dieser beiden Werthe, die relative Laufentwicklung bestimmen will. Das Grifulle des Flusses oder einer Strecke desselben ist das Verhältniss der Höhendifferenz zweier Punkte des Flusslaufes zur Lauflänge zwischen diesen beiden Punkten. Dieses Verhältniss wird gewöhnlich in Prozenten $\left({ }^{0} / 0\right)$ oder Promille $\left({ }^{0} 00\right)$ angegeben, d. h. auf eine Flusslänge von 100 oder 1000) berechnet. Es sei z. B. eine Flussstrecke gegeben mit den Endpunkten $a$ und $b$, woron ersterer $750 \mathrm{~m}$ und letzterer $678 \mathrm{~m}$ absolute Höhe (Cote) habe, so ist also die Höhendifferenz dieser Endpunkte $72 \mathrm{~m}$. Die Laufänge des Flusses zwischen denselben sei $3600 \mathrm{~m}$, so ist das Gefälle

$$
\begin{aligned}
& \text { auf } 100 \mathrm{~m} \text { Lauflänge } \frac{72}{36}=2^{0} \% \text {, } \\
& \text {. } 1000 \% \quad \frac{72 \cdot 1000}{3600}=20 \% \text {, } \\
& \text {, } 1 \text {, } \quad \frac{72}{3600}=0,02 \text {. }
\end{aligned}
$$

Letztere Zahl (die also auf eine Laufänge $=1$ Bezug hat) ist die trigonometrische Tangente des Neigungswinkels, welchen der Flusslauf mit der Horizontebene bildet. Da das Gefälle der verschiedenen Strecken eines Flusses meist wesentlich verschieden ist, so muss für die Ausmittlung dieser Werthe darauf gehalten werden, dass man den Fluss in solche Strecken eintheile, deren Gefälle ein ziemlich gleichmässiges ist.

Quellen. Bei den Quellen handelt es sich um Qualität and Quantität des Wassers, wohei wir unter Qualität die shysikalische und chemische Beschaffenheit desselben verstehen. 
Wir haben schon (S. 413) davon gesprochen, wie die Temperatur der Quellen bestimmt wird. Die genaue Angabe dieser Temperatur ist selbstverständlich von grösserem Werthe als die blosse Unterscheidung zwischen kalten oder gewöhnlichen and warmen Quellen oder Thermen.

Die Zusammensetzung des Quellwassers ist nicht immer leicht zu bestimmen. Das Wasser ist nie chemisch rein, sondern enthält immer ein gewisses Quantum mineralischer Stoffe in Lösung. Bei starkem Gehalt an solchen Stoffen heisst es ein Mineralwasser. Dieselben können ihrer Natur nach meist auf leichte Art unterschieden werden durch Untersuchung der Absatzbildungen an ihren Rändern oder durch Kosten derselben auf der Zunge; dabei wird sich oft, auch wenn sie völlig hell scheinen, ein besonderer Geschmack oder Geruch - nach Eisen, Schwefelwasserstoff, Kohlensäure, Salzen etc. - herausstellen. Will man die Zusammensetzung des Quells genau kennen lernen, so muss man eine vorher gut gereinigte Flasche mit diesem Wasser füllen und sorgfältig verschliessen, um später den Inhalt zu analysiren oder analysiren zu lassen. Hinsichtlich solcher Quellen, welche nur wenig mineralische Stoffe enthalten, genügt es, zu untersuchen, ob das Wasser trinkbar, d. h. für den häuslichen Gebrauch tauglich ist. Sie sind das nicht, oder doch nicht genügend, wenn Seife darin nicht löslich ist; es beweist dies, dass sie zu viel Gyps (Kalksulfat) enthalten; sie heissen dann Gypsquellen.

Von Professor Dr. V. Wartha in Budapest ist kürzlich auf die Wichtigkeit und Leichtigkeit einer Untersuchung der Alkalitït oder "Härte" von Quellen und anderen Gewässern aufmerksam gemacht worden. Es ist ihm gelungen, eine Methode $\mathrm{zu}$ finden, wonach der Gehalt eines Wasser's an alkalischen Erden bei Anwendung von nur $10 \mathrm{~cm}^{3}$ desselben mit Hülfe einer einzigen Reagenzflüssigkeit innerhalb weniger Minuten bei gewöhnlicher Temperatur fast ebenso genau bestimmt werden kann wie bisher durch umständlichere Methoden, welche ein Kochen und Titriren des Wassers in besonderen Schalen nöthig machten und sich daher mehr nur für das Laboratorium als für den Reisenden eigneten. Der Geologe Ludwig Loczy hat auf seiner letzten Reise in China und Tibet das von Dr. Wartha empfohlene Verfahren 
vielfach erprobt und dargethan, dass dessen Anwendung den Reisenden, für welche das Mitschleppen ron Wasserproben lästig und oft unmöglich wird, zu empfehlen ist. Wir wollen desshalb nicht unterlassen, diese Methode hier zu erwähnen.

Zur Ausführung bedient man sich einer etwa $30-40 \mathrm{~cm}$ langen, an einem Ende rund abgeschmolzenen Glasröhre, an welcher eine untere Marke den Rauminhalt von $10 \mathrm{~cm}^{3}$ bezeichnet. Von dieser Marke an gegren die Mündung soll die Röhre in Zehntelskubikcentimeter $\left(0,1 \mathrm{~cm}^{3}\right)$ eingetheilt sein.

Zur Bestimmung der temporären Härte füllt man nun die Röhre bis zur untern Marke mit dem zu untersuchenden Wasser und setzt ein kleines Stückchen vorher mit Campecheholzextrakt getränkten und dann wieder getrockneten Filtrirpapiers hinzu, wodurch das Wasser eine violette Färbung erhält. Hierauf fügt man aus einer Tropf-Flasche so lange Hundertelnormalsalzsäure bei, bis die Farbe der Flüssigkeit sich mehr dem Orange nähert. Nan schliesst sodann die Röhre mit dem Daumen zu und schüttelt tüchtig durch. Dieses Schütteln ersetzt das bisher angewendete Kochen vollständig. Der grösste Theil der Kohlensäure entweicht und die Flüssigkeit wird wieder roth. Man kann auch die Entfernung der Kohlensäure durch Hineinblasen in das Glasrohr nach dem Schütteln befördern. Hierauf setzt man wieder ron der Reagenzflüssigkeit (Hundertelnormalsalzsäure) zu, schüttelt abermals, und wird nun dieselbe Erscheinung wie früher wahrnehmen, aber jetzt in schwächerem Masse. Dieses Verfahren wird fortgesetzt, bis der nächste Tropfen der Säure lie Farbe der Flüssigkeit in ein helles Zitrongelb umwandelt. Dieser Punkt ist schon bei ganz geringer Uebung mit grosser schärfe zu treffen. Die Anzahl der verbrauchten Kubikventimeter $\left(\mathrm{cm}^{3}\right)$ ron Normalsäure wird an dem Schüttel:ohre abgelesen. Diese Zahl bezeichnet den Grad der Alkalität les Wassers ${ }^{1}$ ).

Wie man sieht, braucht man nur eine Messröhre, ein ?läschchen mit Hundertelnormalsalzsäure und ein Stück mit

1) Aus dem Verbrauch an Normalsalzsäure kann man auf bekannte Art (durch hemische Proportionen) die Menge der chemisch gebundenen Kohlensäure, beiehungsweise des kohlensauren Kalkes, berechnen, welche das Wasser enthält. 'rof. Wartha schlägt aber der Einfachheit wegen vor, die Alkalität des Wassers u bezeichnen durch die Anzahl $\mathrm{cm}^{3}$ von Hundertelnormalsalzsäure, welche man ur Neutralisation von $10 \mathrm{~cm}^{3}$ Wasser braucht. Man erhält dieselve Zabl, wenn lan nach der früheren Methode $100 \mathrm{~cm}^{3}$ Wasser mit Zehntelnormalsäure titrirt. 
Campecheholzextrakt getränkten Filtrirpapiers mit sich zu führen, um auf einer Exkursion den alkalischen Grad einer ganzen Reihe von Quellen oder Brunnen bestimmen zu können.

Die Alkalität eines Wassers ist nicht nur von Interesse in geologischer Beziehung, sondern auch vom hygieinischen Standpunkt aus, zur Beurtheilung der Güte eines Trinkwassers, und sie ist exakter und leichter zu ermitteln als das spezifische Gewicht, das man auch zur annähernden Beurtheilung ron Trinkwasser benutzt. Das Grundwasser löst um so mehr alkalische Erden, es schliesst auch die Alkali-Silikate des Bodens um so mehr auf, je reicher an Kohlensäure die mit dem Wasser in Berührung kommende Grundluft ist. Da nun diese Kohlensäure fast ausschliesslich ron zersetzten organischen Substanzen herrührt, so erlaubt die Bestimmung der Alkalität in den meisten Fällen (abgesehen von den Mineralquellen) einen Schluss auf den Ursprung, beziehungsweise die Güte des betreffenden Grundwassers. Professor Wartha hat gefunden, dass die Alkalität derjenigen Brunnenwasser, welche in Budapest als gut bezeichnet werden und die sich durch die Geringfügigkeit ihres Chlor- und Amoniakgehaltes auszeichnen, zwischen 3 und $6^{0}$ schwanke, während dieselbe bei amoniak- und chlorreichem Wasser, welches von der Bevölkerung als schlecht bezeichnet und nur im Nothfall getrunken wird, bis zu $15^{0}$ stieg $\left.^{1}\right)$.

Unter der Stärke einer Quelle versteht man die ron derselben in einer bestimmten Zeit gelieferte Wassermasse. Dieselbe ist gleichmässig oder veränderlich, regelmässig oder unregelmässig, je nachdem sie entweder das ganze Jahr

1) Vgl. W. Wartha, über eine einfache Methode zur Bestimmung der temporären Härte des Wassers. Zeitschrift für Untersuchung von Lebensmitteln und Verbrauchsgegenständen, herausgegeben von Dr. Max Biechele. Eichstätt und Stuttgart, III. Jahrgang (1850) Nr. 7 S. 98 ff. - Ueber die Wichtigkeit derselben Untersuchung hinsichtlich des Wassers ron Flüssen und Seen s, unten. - Wir fügen hier bei, dass nach Versuchen von $H$. Langfeldt im Trinkwasser befindliche Infusionsthiere getödtet und beseitigt werden können, indem man solchem Wasser 1/2000 Zitronsäure ( $1 / 2$ Gramm englische Zitronsäure für 1 Liter des von Infusorien belebten Wassers) zusetzt, es bierauf einige Minuten ruhig stehen und beim Trinken einen kleinen Rest im Gefässe lässt. Nit wenig Ausnahmen sterben die mikroskopischen Thiere auf den Zitronsäurezusatz biunen 2 Minuten, und in ca. einer Minute nach dem Absterben sinken sie zu Boden. - Der Säuregeschmack ist in dieser Verdünnung nicht unangenehm und auch der Preis dieses Mittels erlaubt dessen allgemeinen Gebrauch, Vgl. Pharmaceutische Zentralhalle, 1880, S. 280. Gäa 1881, S. 189 . 
hindurch ziemlich gleich bleibt oder grossen Aenderungen unterworfen ist, ja in gewissen Zeiten sogar zu fliessen aufhört. Man unterscheidet in dieser Hinsicht einerseits permanente oder perennirende, andrerseits variable und periodische (intermittirende) Quellen. Die Stärke einer Quelle in einem gegebenen Moment wird bestimmt, indem man alles Wasser, welches dieselbe zu dieser Zeit liefert, in einem Gefäss auffängt und dessen Masse (Anzahl Liter) durch die in Sekunden ausgedrückte Zeit der Operation des Wasserauffangens dividirt. Lieferte die Quelle in 5 Minuten 3 Liter, so ist also deren Stärke ${ }^{3} / 300=0,01$ Liter. Die Wassermassen sehr reichlich fliessender Quellen sind in gleicher Weise zu bestimmen wie die fliessender Gewässer.

Fliessende Gewässer. Bei jedem fliessenden Gewässer handelt es sich zunächst um die Art seiner Alimentation oder Speisung. Nicht alle haben eigentliche "Quellen"; manche entstehen durch blosses Zusammenfliessen des oberHächlich abströmenden Regen- oder Schmelzwassers; andere durch Vereinigung vieler kleiner Fäden von Sickerwasser, lie zusammen eine ansehnliche Ader bilden, deren eigentlicher Trsprung schwer zu bestimmen wäre; wieder andere brechen als wasserreiche Bäche oder Ströme aus Gletscherthoren und Felsenspalten hervor oder bilden den Abfluss von Mooren and Seen, ohne dass man diese Stellen als eigentliche QQuellen" jener Gewässer zu bezeichnen hätte.

Die Kenntniss des Alimentationsmodus eines Gewässers st von Nutzen; sie erklärt oft gewisse Eigenthümlichkeiten lerselben, die sonst räthselhaft erscheinen könnten.

Die Temperatur des Gewässers muss für verschiedene Ciefen desselben mit aller Sorgfalt ermittelt werden; dabei st auch die Temperatur der Luft in einiger Entfernung on dem Flusse zu bestimmen, nämlich an einem Punkte, ler nicht mehr unter dem Einfluss der durch die Wassererdunstung bewirkten Temperaturerniedrigung in nächster Tähe des Flusses steht.

Der Grad der Durchsichtigkeit wird wenigstens annähernd ezeichnet durch Angaben wie: klar, duichsichtig, trüb, chlammig etc.

Auch die Fïrbung des Wassers ist zu notiren; ebenso, renn sie besondere Eigenthümlichkeiten aufweist, die Ursache, 
welcher man sie zuschreibt, wie: Ursprung des Gewässers, Beschaffenheit des Flussbettes und seiner Umgebung, Beleuchtungsverhältnisse, Tiefe des Wassers, Gehalt an suspendirten Theilen etc.

Die Kenntniss der chemischen Zusammensetzung des Wassers hat meist praktisches, technisches Interesse. Es zeigt sich dabei, dass Wasser ron bläulicher Farbe, womit ein eigenthümlicher Glanz verbunden ist, sich am besten zur Speisung ron Brunnen, zur Verwendung für häusliche Zwecke, eignet, wogegen grünliche glanzlose (matte) Gewässer für industrielle Zwecke sich eignen und einigermassen trübes Wasser, das organische Reste und suspendirte Mineraltheilchen enthält, die sich als feiner und fetter Schlamm niederschlagen, für die Landwirthschaft nützlich ist.

Eine interessante Arbeit von Prof. Dr. Weith in Zürich ${ }^{1}$ ) weist nach, dass der Kalkgehalt des Fluss- und Seewassers in Beziehung steht zu dessen Tauglichkeit für das Fischleben, dass unter sonst gleichen Bedingungen der Kalkgehalt eines Gewässers als Massstab für dessen Fischgehalt gelten könne. Hieraus geht hervor, dass dem oben (S. 459) mitgetheilten einfachen Verfahren für die Bestimmung der temporären Härte als Beitrag zur Statistik des Wassers wesentliche Bedeutung zukommt. Es wäre in der That sehr erwünscht, auch in dieser Hinsicht möglichst viele Daten aus grossen Stromgebieten zu erhalten ${ }^{2}$ ).

Der Gehalt an suspendirten und rom Wasser mechanisch transportirten Massen (abgesehen von grobem Geschiebe) kann ermittelt werden, indem man eine Flasche von hellem farblosem Glase und von bestimmtem Inhalt, z. B. einem Liter, füllt und nachher so lange ruhig stehen lässt, bis die suspendirten Theile sich zu Boden gesetzt haben und das Wasser ganz klar erscheint. Dann misst man die Dicke des Absatzes, der sich auf dem Boden der Flasche gebildet hat und berechnet hieraus das Volum desselben (in Bruchtheilen des Liters). Statt dessen kann man auch das Gewichtsverhältniss angeben; man filtrirt das Wasser und wiegt

1) Chemische Untersuchung schweizerischer Gewässer, Zürich 1880.

2) Der schon (S. 458) erwähnte Geologe L. Loczy hat z. B. gefunden, dass der ca. 10000 Fuss hoch gelegene, den Bodensee an Oberfäche vielmals übertreffende und sehr fischreiche $\mathrm{Ku}-\mathrm{Ku}$-nor (-See) eine sehr hohe Alkalität besitzt. Vgl. Wartha, a. a. O. 
sowohl das Filtrat als den getrockneten Filtrirrückstand. Die Art des Absatzes nach seinen hauptsächlichsten Bestandtheilen wird sich unschwer beurtheilen lassen; dagegen ist eine genaue Prüfung (Analyse) desselben Sache eines Chemikers von Fach; ebenso auch die genaue Angabe der im Wasser chemisch yelösten Stoffe; wir bemerken in dieser Hinsicht nur, dass ein und dasselbe Gewässer in Bezug auf Menge und Zusammensetzung dieser letzteren (in demselben chemisch gelösten) Stoffe ziemlich konstant ist; während Nenge und Komposition der mechanisch mitgeführten (suspendirten) Theile starken Aenderungen unterliegt, je nach dem Quantum der atmosphärischen Niederschläge und deren Vertheilung über die verschiedenen Partien des Einzugs- oder Sammelgebiets eines Flusses. Führen die Gewässer grohes Geröll, Felsstïcke, Baumwurzeln, Stämme und ganze Bäume, Eisschollen u. dgl. m. mit sich, so ist das zu erwähnen mit Rücksicht auf die Gefahren, welche durch solche Vorliommnisse für die Uferanwolıner und ihr Grundeigenthum, für Brücken- und andere Bauten, sowie für die Schifffahrt entstehen.

Die Strömung oder die Art der Bewegung eines fliessenden Gewässers ist eine gleichförmige; der Stromstrich, d. h. die Linie scheinbar schnellster Bewegung der Wassertheilchen, befindet sich nicht immer in der Mitte des Flusses, in gleicher Entfernung von beiden Lfern, sondern liegt - - in grösserem oder geringerem Grade - näher an einem derselben, und zwar oft abwechselnd bald nach diesem, bald nach jenem Ufer hin. Er ist nämlich dem Ufer am nächsten, nach welchem hin der Fluss am tiefsten ist, in Windungen also näher am konkaven (ausbiegenden) Theil der Flussrinne. Dies gilt als Regel; man wird nun prüfen, ob sie überall zutreffen oder ob und inwiefern sie Ausnahmen erleide durch den Umstand, dass, wie behauptet werden will, in meridional fliessenden Gewässern der Stromstrich durch die Erdrotation nach ein und demselben Ufer (dem zur Rechten) hingedrängt werde.

Die Geschuindiglicit strömenden Wassers wird mit einem, den Seeleuten wohlbekannten Instrumente (Log) oder mit Kugreln und ziemlich schweren Holzstücken bestimmt, die etwas unter der Oberfläche schwimmen. Man beobachtet, wie viel Zeit ein solcher Gegrenstand bedarf, um eine gewisse Strecke schwimmend zurückzulegen und berechnet nun, wie 
viel Meter Weg auf eine Zeitsekunde fallen; diese Zahl gibt die Geschwindigkeit der Strömung. Solche Messungen müssen auf geraden Strecken des Flusses vorgenommen werden, um Kurven und Wirbel zu vermeiden, in welchen der Verlauf der Strömung ein anderer ist als derjenige der Uferlinien; das Instrument, beziehungsweise der zur Messung verwendete Gegenstand, ist in die stärkste Strömung zu bringen, also in den Stromstrich oder in das Wasser über dem tiefsten Theil des Flussbettes (welchen man dessen Thalweg nennt) und darf nicht über die Oberfläche hervorragen, weil sonst Wind und Luftwiderstand störend einwirken. Hat der fragliche Gegenstand in dieser Weise z. B. während einer Viertelstunde $270 \mathrm{~m}$ zurückgelegt, so ist die Geschwindigleit an der Oberfläche $0,3 \mathrm{~m}$ in der Sekunde.

Will man, ohne Vornahme genauer Messungen, nur einen allgemeinen Begriff von der Schnelligkeit einer Strömung geben, so kann dies geschehen durch die Bezeichnungen: Strömung unmerklich — schwach - lebhaft - stark sehr stark - reissend, welche annähernd folgende Geschwindigkeiten bedeuten:

schwache Strömung $0,5 \mathrm{~m}$

starke

sehr starke

reissende

(Beispiele: Rhone und Rhein)

Wie schon bemerkt ist die Geschwindigkeit eines fliessenden Gewässers nicht in allen Theilen eines und desselben Querprofils (Querschnitts) gleich gross; vielmehr ist die Geschwindigkeit an der Oberfläche, deren Kenntniss für Schifffahrtszwecke Bedeutung hat, grösser als diejenige der ganzen Masse, weil sie grösser ist als die Geschwindigkeit des Wassers am Rande und unten in der Tiefe, welches durch Ufer und Boden des Flussbettes, Reibung und Wirbel daselbst, in seiner Bewegung gehemmt wird. Die mittlere Geschwindigkeit der ganzen Wassermasse in einem bestimmten Theile (Querschnitt) des Flusses ist annähernd $4 / 5$ der Geschwindigkeit an der Oberfläche. Genauere Resultate erhält man durch Benutzung ziemlich komplizirter Formeln, welche man in Lehrbüchern der Hydraulik findet ${ }^{1}$ ).

1) Vgl. „Der Mississippi ${ }^{\kappa}$ von Humphry Abbot, deutsch von J. G. Kohl. 
Annähernd kann die Geschwindigkeit auch abgeschätzt werden nach den Ablagerungen des Flusses auf dem Grunde seines Bettes. Bei den nachfolgend angegebenen Geschwindigkeiten (pro Seliunde) setzt der Fluss das daneben bezeichnete Naterial ab:

$$
\begin{aligned}
& 0,06 \mathrm{~m} \text { - Dammerde (Ackerkrume), } \\
& 0,12 \text { - suspendirte Thontheile, } \\
& 0,24 \text { - feinen Sand, } \\
& 0,32 " \text { - groben Sand, } \\
& 0,18 \text { - haselnussgrosses Kies, } \\
& 0,96 \text { - Geschiebe von der Grösse eines Eies. }
\end{aligned}
$$

Um die Wassrmass', welche in einer gegebenen Zeit bei einem bestimmten Punkte des Flusses durchströmt, oder die Abflussmenye desselben zu finden, berechnet man zunächst einen Quershuitt des Gewässers: man misst die Breite des Wasserspiegels zwischen beiden Lfern und die verschiedenen Tiefen längs dieser Querlinie; mittels dieser Zahlen konstruirt man das Querprofil (Fii. :16i) und berechnet dessen Flächen-

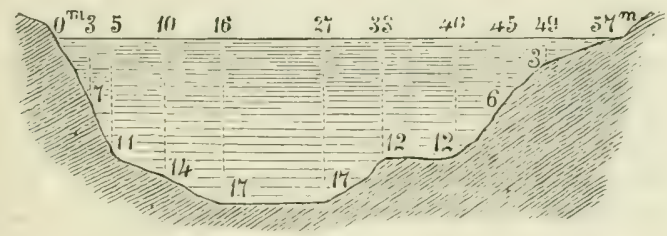

Fig. 216 .

nhalt. Indem man diesen nun mit der mittlern Geschwindigkeit nultiplizirt, erhält man die Wassermasse.

Der Reisende, welcher eine Gegend rasch durchzieht, fird sich auf die erwähnten Angaben beschränken müssen; ıält er sich aber einige Zeit in dem Lande auf, so wird er lieselben durch wiederholte Messungen vervollständigen; denn ie Höhe des Wasserstandes eines Flusses ist Schwankungen nterworfen; damit ändern sich die Geschwindigkeit und die ro Sekunde durchfliessende Wassermasse in hohem Grade; s bedarf daher einer ganzen Reihe von Beobachtungen in en rerschiedenen Jahreszeiten, um das Régime des Stromes ennen zu lernen, d. h. sowohl seinen gewöhnlichen Stand Is auch die Art und den Grad seiner Veränderungen: die 
Zeitpunkte und die Raschheit ihres Eintritts, die Dauer und die Extreme derselben.

Will man das Régime eines Gewässers erforschen, so hat man vor Allem einen hiezu geeigneten Punkt ausfindig zu machen. Man wird diesen im Allgemeinen unter der Einmündung des letzten Zuflusses zu suchen haben, indess nicht zu nahe an der Einmündung des Gewässers in ein anderes, fliessendes oder stehendes, da im letztern Falle der Wasserstand beeinflusst würde durch Rückstauung von dem Strome her, in welchen sich unser Gewässer ergiesst oder durch die Bervegungen (Gezeiten und "Seiches") des stehenden Wassers (Meeres oder Sees).

Nachdem die Wahl einer passenden Stelle getroffen ist, schreitet man zu einer sorgfältigen Aufnahme des Querprofils und zwar des vollständigen Querschnitts an dieser Stelle, der nicht auf die momentane Höhe des Wasserspiegels beschränkt werden, sondern die Ufer wenigstens bis zu den grössten bekannten Hochwasserständen enthalten soll. An einem geeigneten Punkte dieses Profils bringt man hierauf einen graduirten Pfahl (Fluviometer oder Pegel an), welchen man an der rechten Stelle und im richtigen Verhältniss in die Profilzeichnung einträgt.

Da man nicht zum Voraus das Niveau der Minimalniederwasserstände des Flusses kennt, so muss der Nullpunkt der Fluviometer- oder Pegel-Skala dem tiefsten Punkt des Flussbettes entsprechen; auch soll derselbe wo möglich, um dessen absolute Höhe $\mathrm{zu}$ erhalten, mit dem geodätischen Nivellement der Gegend in Verbindung gebracht werden.

Ist der Fluviometer in dieser Weise angebracht, so liegt uns noch ob, zu beobachten, bis zu welchen Punkten der Skala in verschiedenen Zeitpunkten das Wasser steigt und welche mittlere Geschwindigkeit diesem Wasserstande entspricht. Die Flächenberechnung für die verschiedenen Querprofile ist sehr einfach, da nur die obere Grenze derselben sich ändert. Die Multiplikation dieser Flächen mit den entsprechenden mittleren Geschwindigkeiten gibt die Abflussmengen des Gewässers für die Zeitpunkte der einzelnen Beobachtungen.

Fortgesetzte Beobachtungen dieser Art führen zur Kenntniss der Nieder-, Mittel- und Hochwasserstände, der Ab- und Zunahme oder des Fallens (Sinkens) und Steigens (Wachsens, 
Anschwellens) eines Flusses, wie seiner Geschwindigkeit und Abflussmenge beim mittleren Niveau und bei den extremen (minimalen und maximalen) Wasserständen. So lernt man alle erforderlichen Faktoren kennen: die einem gegebenen Wasserstande entsprechende $\Lambda \mathrm{b}$ - oder Durchflussmenge; die Dauer des Bestandes eines solchen Niveaus; die Zeitpunkte des Eintritts der Hoch- und Niederwasser; die Art der Wasserstandsänderungen: ob dieselben langsam oder rasch, ja plötzlich, regelmässig oder unregelmässig, periodisch oder zufällig erfolgen; die jährliche Gesammtabfhussmenge und die mittlere Alfflussmenuk, welche man aus jener erhält durch Division mit der Zahl der Sekunden eines Jahres $(31,55$ j,600): endlich den gewöhnlichen oder normalen Wasserstund des Flusses, als welchen man dasjenige Niveau zwischen Hochund Niederwasser erklärt, welches der Fluss die meiste Zeit des Jahres einnimmt (einhält).

Kennt man diese einzelnen Phasen des Flusses, sowie das Quantum der in seinem Wasser chemisch gelösten oder suspendirten Bestandtheile, so kann man weiter berechnen, welche Massen fester Stoffe er jührlich aus dem Lande herausführt, welches demnach der Betrag der Auslaummen und Abtrayun!y im höher gelegenen Theile des Flussgebietes ist.

Alle diese Angaben werden um so richtiger, je mehr unmittelbar aufeinanderfolgende Jahre die Beobachtungen umfassen, weil auf diese Weise die zufälligen Einflüsse eliminirt oder ausgeglichen werden.

Die Anordnung der Notirungen wird ein Jeder nach Gutfinden einrichten. Wir geben indess schematische Tahellen hiefür auf S. 468 und 469, sowie in den Fig. 217 und $: 18$ Iruster ron Diagrammen zur graphischen Darstellung der bemerkenswerthesten Erscheinungen.

Ein Gewässer hat den Charakter des Wildwassers, wenn Perioden ron Trockenheit seines Bettes rasch mit grossen Hochwassern wechseln.

Wenn Operationen im Grossen vorzunehmen sind, so aann man die Werke ron Rery und Allan Cunningham zu Rathe ziehen ${ }^{1}$ ); dieselben geben ausgrezeichnete Beispiele über

1) Hydraulics of Great livers. The Purana, the Urumuay and the La Plata Estuary, is J. J. Revy, London 1874; - Hydraulics Experiments at Boorkee, by Capt. Allan Junningham. 1876. 
Kubikmeter

pro

Sekunde.

6000

5000

4000

3000

2000

1000

0

Jan: Febr. März April Mai Juni Juli Aug. Sept. Okt. Nov. Dez.

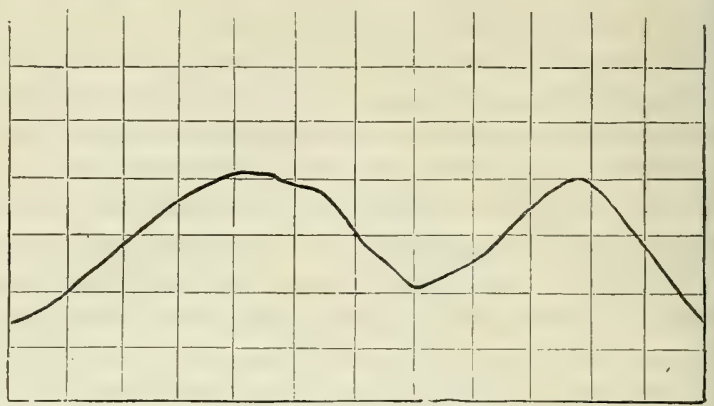

Fig. 217.

Wasserstundsänderungen des.... Flusscs.

Jan. Febr. März April Mai Juni Juli Aug. Sept. Okt. Nov. Dez.

Meter

60

50

40

30

20

10

0

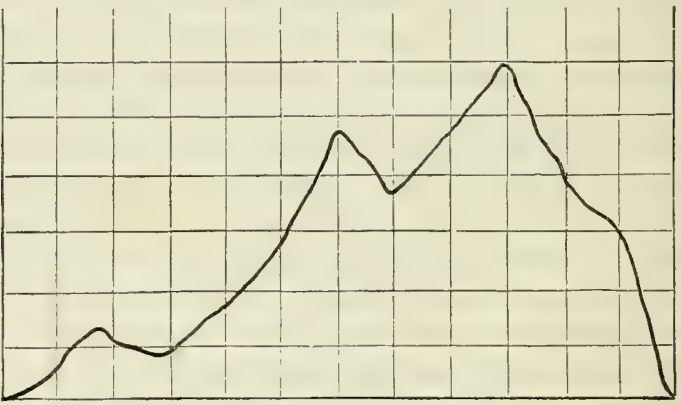

Fig. 218.

Beobachtungen über das Régime des ....Flusses.

\begin{tabular}{|c|c|c|c|c|c|}
\hline $\begin{array}{c}\text { TAG } \\
\text { und } \\
\text { STUNDE }\end{array}$ & $\begin{array}{c}\text { PEGEL- } \\
\text { STAND }\end{array}$ & $\begin{array}{c}\text { INHALT } \\
\text { des } \\
\text { Quer- } \\
\text { profils }\end{array}$ & $\begin{array}{c}\text { Mittlere } \\
\text { Gesehwin- } \\
\text { digkeit }\end{array}$ & $\begin{array}{c}\text { Abfluss- } \\
\text { menge } \\
\text { pro } \\
\text { Sekunde }\end{array}$ & BEMERKUNGEN \\
\hline & & & & &
\end{tabular}


Rekapitulation.

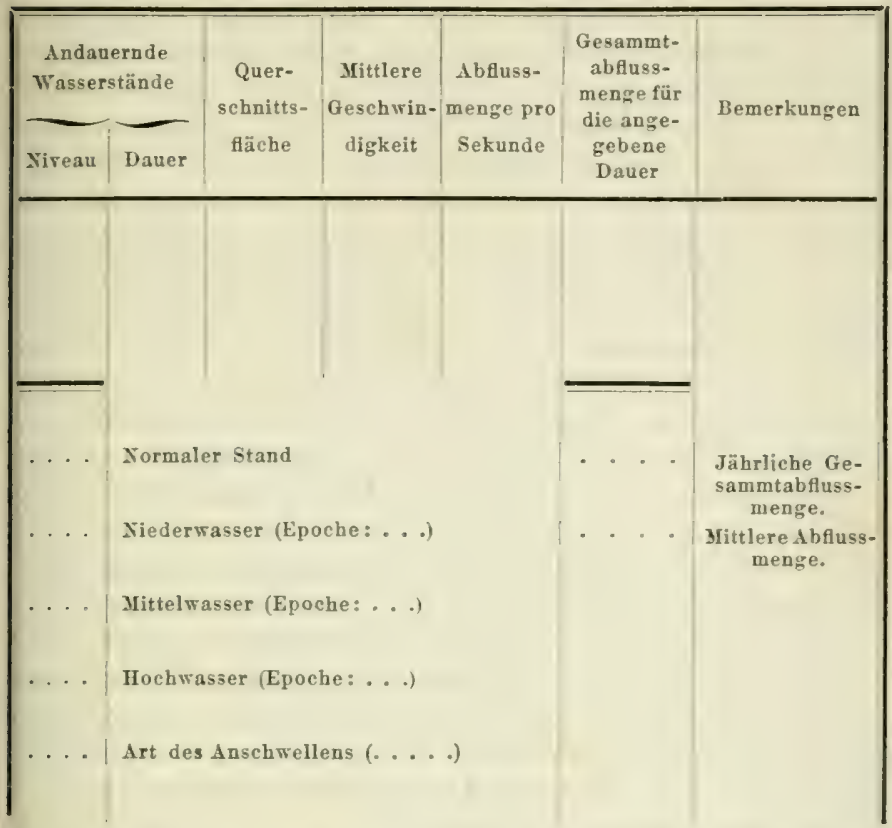

die Organisation des Materiellen und Personellen, sowie üher das Ganze der zu treffenden Anordnungen.

Die Lrsachen de's Anschucllens der Gewässer verdienen ein sorgfältiges Studium. Sie sind natürliche oder durch den Menschen (durch unvorsichtige Entwaldung einer Gegend) herbeigeführte. Eine und dieselbe Lrsache erzeugt nicht immer auch die gleiche Wirkung. Selbst ein bedeutendes Hochwasser macht sich bei manchen Flusssystemen in untern Theile derselben kaum bemerkbar, wenn sie auf ihrem Laufe grosse Wasserbecken durchfliessen, welche als Regrulatoren wirken; indem sie den plötzlichen Wasserüberfluss in sich aufnehmen und nur langsam wieder abgeben. In andern Fällen trifft das Anschwellen der einen Zuflüsse zusammen mit der Abnahme andrer, so dass die Veränderung des Wasserstandes in der Hauptader des Vetzes nur unbedeutend ist. Wenn aber alle Wasseradern eines und desselben Systems 
gleichzeitig anschwellen, so resultiren hieraus grosse Hochwasser: die Flüsse treten aus und über'schwemmen das Land.

Die Ucberschuemmungen sind in ihrer Wirkung ungleich; bei den einen werden durch rasches Anschwellen der Gewässer Dämme durchbrochen, Schutt und Trümmer abgelagert und die Gegenden aufs Schwerste verheert; bei anderen, die durch langsam eintretendes, aber andauerndes Hochwasser verursacht sind, wird im Gegentheil ein fruchtbarer Schlamm abgesetzt. Es genügt also bei Ueberschwemmungen nicht, deren Ursache, Zeit und Periodizität oder Unregelmässigkeit anzugeben; man muss auch genau die Stellen bezeichnen, an welchen sie eintreten, den Pevimeter, d. h. den Umfang des Gebietes, welches von ihnen betroffen wird, und endlich die schädlichen oder nützlichen Folgen derselben.

Verweilt der Reisende nicht so lange in dem Lande, dass er diese verschiedenartigen Beobachtungen selber vornehmen könnte, so hat er Indizien aufzusuchen oder Informationen einzuziehen.

Indizien dafür, dass eine Gegend Ueberschwemmungen ausgesetzt ist, sind z. B. auf Pfählen gebaute Hütten, auf Anhöhen erstellte Wohnungen. Spuren von Hochwassern wird man überdies längs der Flüsse und in einiger Entfernung ron denselben öfters an Felswänden und isolirten Felsstüchen (Säulen, Zeugen), ja selbst an Stämmen und in Kronen von Bäumen auffinden.

Die Erinnerung an grosse Hochwasser erhält sich bei den Einwohnern der betroffenen Gegenden meist sehr lange; durch Befragen älterer Leute wird man sachbezügliche Ueberlieferungen kennen lernen oder aufmerksam gemacht werden auf Thatsachen, die niedergelegt sind in den Annalen des Landes oder auf Steine und andere Zeichen, welche das Niveau angeben, das von Hochwassern in ausserordentlichen Jahrgängen erreicht wurde.

Aus Spuren früheren Wasserstandes oder durch Erkundigungen wird man auch zu erfahren suchen, ob das Gewässer, um welches es sich handelt, wesentliche Veränderungen in seinem Régime erlitten hat, ob eine merkliche $\mathrm{Ab}$ - oder Zunahme seines Wasserreichthums eingetreten ist und welches dessen Ursachen seien ${ }^{1}$ ).

1) Vgl. Schill, geologische Beschreibung der Umgebungen von Waldshut, Karisruhe 1866 ; Kollbrunner, thurgauische Fischfauna und bezügliche Gewässerverhältnisse, Frauenfeld 1879 , S. $84 \mathrm{ff}$. 
Ton grosser praktischer Bedeutung sind Beobachtungen über die Schiffluthleit der Gewässer. Man unterlasse daher nie, die hierauf bezüglichen Verhältnisse vorzumerken und namentlich die Punkte anzugeben, wo die Schiffbarkeit begrinnt für Flüsse (Flossharkeit), für kleine Fahrzenge, für Dampfhoote und endlich für Schiffe ron grossem Tiefgang. Wem das Gewässer sich in mehrere Arme theilt, ist anzuyeben, welcher derselben unter den bestehenden Verhältnissen am besten für die Schiffahrt geeignet sei.

Unterirdische Gewässer. Es kommt zuweilen ror, rass in den Boden einsickernde Regenwasser nicht wieder (als Quellen) an die Oberfläche gelangen und dass Flüsse an Stellen, wo der Grund ihres Bettes durchlässig ist, rerschwinden, wobei das Bett in seiner Fortsetzung trocken gelegt wird; das Wasser dringt, statt an der Oherfläche weiter zu fliessen, in den Boden ein, bis es auf eine undurchlassende Schicht trifft, fliesst nun auf dieser fort und bildet so untrivdisthr Wassmlinufe. Wem diese in geringer Tiefe liegen, so sind sie von wesentlicher Bedeutung; ror starker Verdunstung geschützt, liefern sie den Wurzeln der Pflanzen das erforderliche Wasser und ermöglichen sie dem Jenschen, durch Grahen ron Brunnen sich das Wasser für seinen hauswirthschaftlichen Bedarf und für Bewässerung ron Gegenden, die sonst unfruchtbar und unbewohnbar bleiben würden, zu verschaffen.

Es ist nicht immer leicht, diese unterirdischen Gewässer, ihre Vertheilung und ihren Umfang, zu verfolgen; ihr Vorlanriensein ist nicht immer an der Erdoberflïche wahrunehmen, und man ist daher oft auf Toraussetzungen angewiesen. Wo indessen Spalten, Gruben u. dgl. es ermöglichen, unterirdische Wasserläufe wahrzunehmen, rersäume der Reisentle nicht, aufmerksam zu beobachten, in welcher Tiefe sie sich befinden, welche Temperatur, Farbe, Zusammensetzung und andere Eigenthümlichlieiten sie haben.

Stagnirende Gewässer. Als stagnirende Gewässer sind solche zu bezeichnen, welche keinen oder doch nur mangelhaften Al,fluss haben. Sie sind rerschieden nach Entstehung, Charakter und Wirkung. Die einen sind Ansammlungen von Regenwasser in Vertiefungen eines wenig durchlassenden Bodens: andere ron Flussrasser, das sich über 
ein flaches Terrain ergoss und zurückblieb, nachdem die Hochwasser sich verlaufen; dritte endlich von Wasser, welches durch die Poren des Bodens zwischen einem See oder Fluss und dem anstossenden tieferen Terrain seitlich durchsickerte - nicht zu gedenken der stagnirenden Gewässer in zeitweise verlassenen Flussläufen oder Abzweigungen von solchen (wie der Bayous von Louisiana).

Je nach ihrem Umfang heissen diese Wasseransammlungen Pfützen, Lachen, Tümpel, Teiche, Weiher, Sümpfe, Moore und auch wohl Seen; zuweilen tragen sie eine Pflanzendecke wie die schwimmenden Inseln Mexikos.

Ihre Grenzen lassen sich oft nicht genau angeben, da sie oft nach den Jahreszeiten stark variiren. Es ist auch weniger wichtig, den Flächeninhalt dieser Gewässer fast bis auf den Quadratmeter genau, als vielmehr deren Wirkungen zu kennen. Die meisten entwickeln Fäulnissgase, Miasmen, welche die Gregend ungesund machen für Menschen und Thiere, was sich im kränklichen Aussehen derselben zeigt. Andere sind lediglich ein Hinderniss für die Ausdehnung der Landeskultur und den Verkehr. Es gibt auch solche von nur temporärem Bestande wie die Schotts oder Sebkhas im nördlichen Afrika, welche sich in der Regenzeit mit Wasser füllen, im Sommer aber austrocknen und dann entweder mit einer Salzschicht bedeckt oder auch mit grüner Pflanzendecke bekleidet werden.

Von Interesse ist es, anzugeben, auf welche (mitunter oft einfache) Weise die Trockenlegung (Drainirung) dieser Becken bewirkt und damit die Gegend gesund gemacht, der Kultur neues Areal gewonnen werden könnte.

Seen. Seen sind mehr oder minder umfangreiche Wasserbecken von grösserer Tiefe als die vorgenannten stagnirenden Gewässer; wiewohl sie als stehende Gewässer bezeiclinet werden, können sie einen mehr oder minder starken $\mathrm{Zu}-$ und Abfluss und auch im Innern des Beckens eine mehr oder minder rasche fliessende Bewegung haben; ihr Wasser kann süss, salzig oder brackisch sein.

Lage, Umfang, Meereshöhe und Tiefe derselben gehören der Topographie an; die Art ihrer Bildung ist mehr eine Frage der Geologie als der Hydrologie. Die einen dieser Wassermassen füllen — ganz oder theilweise - alte Krater 
aus, andere Längs- und Querthäler (Mulden, Comben, Klusen), Trichter oder beliebige Einsenkungen und Tertiefungen des Bodens. Die einen werden durch Gletscher gebildet, welche ihre Schmelzwasser zwischen sich und Felswänden einschliessen: andere durch Querriegel, z. B. Moränen, welche nur zeitweise die Wasser zurückzuhalten vermögen, allmälig aber ron diesen durchschnitten und durchbrochen werden. Seen der letzteren Art befinden sich oft auf Terrassen in verschiedener Höhe über einander. Viele endlich sind nur mehr oder minder bedeutende Erweiterungen ron Flussbetten.

Tach ihrer Lage und Höhe unterscheidet man Seen des Gebirgs, der Thäler und der Ehene (Berg-, Thal- und Flachlandseen). Von den letzteren unterscheiden sich die ringsum geschlossenen Yeere nur durch weit grössere Ausdehmung.

Ein jeder See hat sein hydrugraphisches Bassin, für welches er der Wassersammler ist, wohin alles Wasser fliesst, welches im Linkieise (Einzugsychict) des Beckens zur Erde fällt oder aus der Erde quillt. Hinsichtlich dieser Surisumu der Scen wären die gleichen Bemerkungen zu machen wie in Betreff der Speisung fliessender Gewässer. Zu berechnen, welche Thassemasse ein See empfängt und abgibt, ist eine schwierige Aufgabe; in beiden Beziehungen sind Faktoren rorhanden, die sich der Wahrnehmung oder Ermittlung entziehen kömnen. Hieher gehören in gewissem Grade die auf die Seefläch" selber entfallenden atmosphärischen Niederschläge und auf dem Grunde des Beckens entspringende Quellen, andrerseits der Wasserverlust durch Verdunstung und durch Versickerung im ganzen benetzten Umfang des Beckens.

Neben der Speisung dieser Wassersammler ist die dit itures Abflusses zu betrachten. Manche zeigen heinen sichtbaren Abfluss; oft ist auch wirklich kein Abfluss vorhanden, dann nämlich, wenn dem See nicht mehr oder nur,uubedeutend mehr Wasser zufliesst, als ihm die Verdunstung entzieht, so dass sein Niveau dabei ziemlich konstant bleibt. Wenn aher ein See reichliche Zuflüsse empfüngt, so muss er einen sichtbaren oder verborgenen (unterirdischen) Abfluss hesitzen; andernfalls müsste er nothwendig austreten. Hat man die Tour um den Sce gemacht, ohne dabei einen Ausfluss zu finden, so muss man den Verlauf der Strömungen im Seebecken untersuchen und namentlich auf Punkte achten, 
Wo das Wasser und auf demselben befindliche Gegenstände in Wirbeln sich bewegen und in die Tiefe gezogen werden; an solchen Stellen muss ein unterirdischer Abfluss vorhanden sein, dessen anderes Ende rielleicht bei einer Erforschung der Lmgegend entdeckt rerden kann.

Die Tireanceranderungen, die mit einem See stattfanden oder noch stattfinden und was damit zusammenhängt: seine allmälige Verlandung, seine alten Lfer, sein langsames Austrocknen oder plötzliches Verschwinden - all' das gehört der Geologie an und wir haben uns damit an dieser Stelle nur insoweit zu befassen, als es sich um solche Schwankungen des Wasserstandes handelt, welche die Folge langer Trockenheit oder ausserordentlicher Niederschläge sind.

Teben diesen Niveaureränderungen erheischen zuweilen noch solche ganz anderer Art sorgfältige Beobachtungen, nämlich die sogenamnten Intermittenzen und die "seiches" (Ruhssen) yewisser Seen, welch letztere Erscheinung namentlich rom Genfer See bekannt ist, Dank den Studien des Professors Forel ron Lausanne; hieher gehören ferner die Gezciten gewisser ringsum abgeschlossener Meere. Diese Niveauveränderungen lassen sich am Ufer mit blossem Auge wahrnehmen, wenigstens an den Enden des Sees, wo die Schwankungen eine grössere Amplitüde aufweisen und dadurch sichtbarer werden; auch können dieselben an einem vertikal aufgepflanzten graduirten Stabe gemessen werden. Aber um diese verschiedenen Phänomene wissenschaftlich zu rerfolgen, sind spezielle Instrumente nöthig, welche nicht zum gewöhnlichen Gepäck eines Reisenden gehören.

In gewissen Seen beobachtet man mitunter auch plötzliche Ticeanshumlingen oder Bewegungen, einen Aufruhr der Wasser, wobei die Ursachen meist unbekannt sind, in der Regel aber auf unterseeische, senkrecht wirkende Erdstösse oder auf partielle Einstürze zurückgeführt werden.

Die Tollenbercgung auf den Seen ist eine andere als auf dem Meere, insofern die Wellen der Seen kürzer, aber viel stärker als die des Neeres sind. Die Gründe dieser Erscheinung hestehen darin, dass einerseits die Wellen auf einem See sich nicht so entwickeln können wie auf der weitgedehnten Meeresfläche und dass andererseits das süsse Wasser ein geringeres 
Gewicht hat und sich daher durch den Wind leichter heben lässt als das Salzwasser.

Gewöhnlich haben auch die scheinhar stillsten Seen ihre Strömungen, die theils durch die in dieselben sich ergiessenden Zuttüsse und den Abfluss, theils aher durch Temperaturdifferenzen der rerschiedenen Wasserschichten verursacht werden. Lnter den übrigren Eigenthümlichlieiten mancher Seen erwähnen wir auch das Blühen derselben, eine Erscheinung, die namentlich den Gebirgsseen eigen ist und dadurch hervorgerufen wird, dass die tausend Wasserfiden im Einzugs:gehiete des Sees herunterrefallenen Blüthenstaub mitführen, welcher nun auf dem Seespiegel lange streifen gelb-, lila- oder rosafarbigen Schaumes bildet. Eine andere Erklärung schreiht dieses Blühen der seen mikroskopischen Thierchen zu, welche sich zu Zeiten fabelhaft rasch vermehren.

Oelquellen oder Oelflecken sind glatte Stellen auf der Oberfläche eines leicht rom Winde bewergten Sers. Sind diese Flecken stark in die Länge ausgedehnt, so heissen sie Trye. Thre Entstehungsweise ist noch nicht genügend bekannt; die Einen erblicken in ihnen eine Modifikation der leichten Wellen, welche durch die Brise oder das Fallen der Regentropfen entstehen; Aurlere schreiben sie einer dünnen Schicht einer öligen Substanz zu, welche ungleichmässig über die Oberfäche des Wassers ausgebreitet ist.

Die Farbe der Seen ist verschieden, fast hei jedem See eine andere Nüance, bald tiefdunkel, fast schwarz (so beim Titisee im Schwarzwald), bald schmutzigg gelb oder bräunlich (wie bei kleinen Schwarzwaldseen), bald - und zwar in der grossen Mehrzahl der Fälle - himmelblau oder grün. Diese verschiedenen Färbungen können bedingt sein durch die Beschaffenheit des Wassers, ron welchem der See gespeist wird, durch die mehr oder minder grosse Tiefe, die Farhe des Seegrundes und der Ufer, sowie durch den Lichtreflex ron den Höhen aus, welche den See eimrahmen. Zudem kann die Farbe wechseln nach dem Zustand des Himmels und der Wasseroberfläche: ob jener hell oder bewölkt, diese ruhig oder hewegt sei. Auch zeichnen mitunter die Strömungen eines Sees auf demselben ein Band, eine Zone mit einer ron der übrigen Wasserfäche verschiedenen Farbe. 
Die Durchsichtigkeit des Seewassers ist gemeiniglich grösser als die des Flusswassers, weil die in letzterem suspendirten Stoffe zu Boden sinken, wenn sie in ruhigeres Wasser gelangen. Je weniger solche Stoffe suspendirt bleiben, desto grösser ist die Durchsichtigkeit des Wassers. Schon aus diesem Grunde ist die Durchsichtigkeit auch nach den Jahreszeiten verschieden; denn nach starken Regengüssen und zur Zeit der Schneeschmelze müssen den Seen durch ihre Zuflüsse nothwendigerweise mehr solche Sinkstoffe zugeführt werden als sonst; auch ist die Dichtigkeit der einzelnen Wasserschichten im Winter eine andere als im Sommer und in dichterem (schwerem) Wasser können Theilchen noch schweben bleiben, welche in spezifisch leichterem Wasser zu Boden sinken würden. Die Durchsichtigkeit kann bis zu einem gewissen Grade gemessen werden mittels einer Blechscheibe von etwa $25 \mathrm{~cm}$ Durchmesser, die man mit weisser Oelfarbe bemalt und, an einer Senkschnur befestigt, in's Wasser hinab sinken lässt, bis sie sich dem Blicke entzieht. Man misst dann die Länge der abgewickelten Schnur für den Moment, da die Scheibe unsichtbar wurde. Hierauf zieht man diese langsam wieder empor und bestimmt wieder die Länge, welche die gespannte Schnur in dem Zeitpunkt hat, wo die Scheibe zuerst wieder sichtbar wird. Das Mittel dieser zwei Messungen gibt die Grenze der Durchsichtigkeit für den gegebenen Moment und Ort. Damit solche Messungen vergleichbar seien, muss immer eine und dieselbe Scheibenfläche (von konstantem Durchmesser) angewendet und müssen die äussern Umstände (wie die Beschaffenheit der Wasseroberfläche, Höhe der Sonne über dem Horizont etc.) berücksichtigt werden.

Die Temperatur des Seewassers ist verschieden je nach den Klimaten, Jahreszeiten, Tiefen und namentlich nach der Temperatur des Wassers der Zuflüsse: ein See, welcher im Sommer direkt Gletscherschmelzwasser erhält, hat selbstrerständlich niedrigere Temperaturen als ein anderer, dessen Zufüsse ihr Wasser auf einem langen Laufe durch Flachland erwärmten.

Zur Messung der Temperatur in verschiedenen Tiefen bedient man sich eines Metallcylinders, welcher an beiden Enden von unten nach oben sich öffnende Ventile hat. Dieser Cylinder wird an einer Schnur in die bestimmte Tiefe herunter- 
grelassen. Sowie man ihn heraufzieht, schliessen sich die Ventile, und wenn das Heraufziehen rasch geschieht, so hehält das eingeschlossene Wasser seine Temperatur, die man nun durch Eintauchen eines gewöhnlichen Thermometers misst.

Je nach seinem Geschmacke wird das Wasser süss, brackisch oder salzig genannt. Brackisch ist im Allgemeinen das Wasser ron Seen, welche eine geringe Tiefe und keinen $\Lambda$ bfluss haben; salzig ist es, wenn Gewässer, welche sich in den Seo ergiessen, über salzhaltigen Boden fliessen, wie das der Fall ist bei gewissen Steppenseen und anderen Binnengewässern, welche oft als Reste früherer Neere in Depressionen des Festlandes sich finden. Wenn ein solches Gewässer nur geringe Tiefe hat und starker Verdunstung ausgesetzt ist, so kann sein Salzgehalt wesentlich grösser sein als der des Meerwassers.

Um zu entscheiden, ob ein Wasser süss, brackisch oder salzig ist, braucht man es nur zu kosten; wenn es sich hiebei als stark salzig herausstellt, so hestimme man den Salzgehalt, indem man z. B. einen Liter dieses Wassers fasst, dieses Quantum verdunsten lässt und nun den salzigen Rückstand misst. Es gibt Seen, wo nur noch das Wasser der tiefsten Schichten salzig ist; man darf also nicht nur Proben von der Oberfläche kosten, sondern muss solche aus verschiedenen Tiefen untersuchen, um zu erfahren, ob diese verschiedenen Proben gleiche oder ungleiche Resultate liefern.

Flussmündungen. Hahen wir die stehenden Gewässer der Gegrend kennen gelernt, so begehen wir uns an die Küste, um unsere Aufmerksamkeit den Erscheinungen zuzuwenden, welche die fliessenden Gewässer an ihren Mündungen zeigen. Es handelt sich hier nicht um die Deltabildung u. dgl., was in's Gebiet der Geologie einschlägt, sondern um die Wasserverhältnisse an den Mündungen und insbesondere um diejenigen Verhältnisse, welche die Schiffbarkeit beeinflussen. Es ist also zu prüfen, ob das Einfliessen eines Stromes in ein Wasserbecken, das Einmünden desselben, in normaler Weise erfolge oder ob es gehemmt werde durch Winde, Strömungen an den Küsten und Gezeiten. Manche Flüsse werden durch die vom Meere herwehenden Winde gestaut; bei andern wird dieselbe Erscheinung bewirkt durch lebhafte Strömungen längs der Küsten, worlurch oft der Fluss gezwungen wird, einen andern Lauf zu nehmen; bei einer 
dritten Kategorie von Flüssen endlich wechseln zwei verschiedene Erscheinungen mit einander periodisch ab: bald strömen ihre Gewässer frei in das Meer hinaus, bald dringt im Gegentheil die Fluth ein und wälzt dieselben rückwärts, den Fluss hinauf, indem sie dergestalt das als Rastern, Barre oder Bore (mascuret, proroca) bekannte Phänomen verursacht. Es sind also Klippen und Sandbänke, die wir bei topographischen und Tiefenmessungen kennen lernten, nicht die einzigen Hemmnisse an Flussmündungen, sondern es gibt auch ähnlich wirkende Hemmnisse rein hydrologischer Art, welche in Bezug auf die Schiffbarkeit der Gewässer wesentlich in Betracht kommen.

Strömungen und Gezeiten. Es ist von Bedeutung, ob an den Küsten Neeresströmungen und Schwankungen des Meeresniveaus (Gezeiten) vorkommen oder nicht.

Die Existenz von Strömungen lässt sich erkennen an der Bewegung von Gegenständen, die auf oder besser — damit sie der Einwirkung des Windes entzogen werden - in dem Wasser hintreiben. Mit solchen Gegenständen sind Versuche in verschiedenen Tiefen zu machen, da oft verschiedene Strömungen - obere und untere - übereinander vorkommen und diese sogar in entgegengesetzter Richtung fliessen können. $\mathrm{Zu}$ diesen Experimenten wendet man sogenannte Schwimmer an, das sind Kugeln aus schwerem Hartholz, welche im Wasser untersinken und an einer Schnur befestigt sind, deren Länge der gewünschten Tiefe entsprechen muss und an deren oberem Ende ein Stück Kork angebracht ist, welches gerade die richtige Grösse haben soll, um der untergetauchten Kugel als Gegengewicht zu dienen und sie in der richtigen Tiefe zu erhalten. Noch besser versieht man die Kugel mit einer starren senkrechten Stange, deren oberes Ende ein Fähnchen trägt. Diese Schwimmer zeigen durch ihre Bewegung die Richtung wie auch die Geschwindigkeit der Strömung an, nur ist dabei der Einfluss der Wellenbewegung und der Gezeiten zu berücksichtigen, welche die Schwimmer nach einer bestimmten Richtung treiben können, wenn auch keine oder gar eine anders gerichtete Strömung vorhanden ist. Falls man einen Schwimmer anwendet, welcher aus Kork und Kugel besteht, so kann man aus dem Versuch nur dann sichere Schlüsse ziehen, wenn dabei die Schnur 
genau vertikal gerichtet, der Kork also senkrecht über der Holzkugel bleibt.

Die Existenz wie die Richtung und Geschwindigkeit ron Kï̈stenströmungen können auch ermittelt werden, indem man ein Schiff rerankert oder sonst an einer Stelle fixirt und nun das Log anwendet oder einen Schwimmer an einer sich leicht abwickelnden Schnur. Die Länge des in einer bestimmten Zeit abgewickelten Theiles dieser Schnur gibt den innerhalb dieser Zeit zurückgelegten Weg orler also die Geschwindigkeit an.

Es gibt veränderliche und temporäre Strömungen. Dazu gehören diejenigen, welche abhängen von der Windrichtung, von den Gezeiten; von der Wassermenge, welche die einmündenden Flüsse ins Neer ergiessen; ron Ungleichheit der Temperatur zwischen dem Wasser der hohen See und demjenigen einer mit ihr durch eine schmale Strasse rerbundenen Bucht; endlich ron stärkerer Verdunstung in einer solchen Bucht oder Lagune, welche Verdunstung ein Zuströmen des Wassers nach der Bucht, zur Ausgleichung der sich bildenden Niveaudifferenzen, bewirken muss. Nur zahlreiche, zu verschiedenen Tages- und Jahreszeiten vorgenommene Beohachtungen können zu einer genauen Kenntniss dieser Strömungen und ihrer Ursachen führen.

Gezriten (norddeutsch Tiden ${ }^{1}$ ) nennt man das wechselsweise Steigen und Sinken des Meeresniveaus, welches sich in einem Zeitraum von etwas mehr als 24 Stunden (im Nittel $24^{\text {th }}$ $50^{\mathrm{m}} 28^{\mathrm{s}}$ ) zweimal vollzieht. Während 6 Stunden steigt das Meer: es kommt die Fluth; während 6 andern Stunden wieder sinkt sein Niveau: es tritt Lbbre ein. Zwischen zwei solchen entgegengesetzten Bewegungen gibt es einen Moment, wo das Niveau des Wassers weder steigt noch fällt, sondern "steht", das eine Mal beim Hochuasser, das andere Mal beim Niedrigneasser, d. h. beim höchsten und tiefsten im Laufe eines Tages eintretenden Wasserstand.

In Bezug auf die Küste, welche man erforscht, ist zunächst zu konstatiren, ob sich an derselben die Gezeiten

1) Leser, welche sich eingehender mit diesem Gegenstande, insbesondere mit der mathematischen Theorie desselben, befassen wollen, verweisen wir auf Hann, 9. a. O., S. $179 \mathrm{ff}$, und die Abhandlung von Peters (über Fluth und Ebbe) in Neunayers mehrerwähnter Anleitung. 
bemerkbar machen. Wo sie stark ausgeprägt sind, wird man darüber bald ein Urtheil haben; denn das Bild, welches die Küste hier bietet, ändert sich in wenigen Stunden; wo sie aber nur in geringem Grade vorkommen, können sie durch die Wellenbewegung maskirt werden und es muss dann eine genauere Untersuchung stattfinden. Zu diesem Zwecke bezeichnet man einige Fixpunkte: man pflanzt Stäbe auf an den äussersten Stellen, bis zu welchen die Wellenschläge reichen und markirt an Felsen die Höhe, welche das Wasser erreicht. Nach einigen Stunden sieht man nach, ob die Grenzen des Wassers noch dieselben sind. Wenn sich nach einer. Reihe von Beobachtungen zeigt, dass keine Niveauänderungen zu konstatiren sind und wenn dies namentlich zur Zeit ron Voll- und Neumond (der Syzygien), sowie der Tag- und Nachtgleiche der Fall ist, so darf man annehmen, dass die fragliche Küste keine Gezeiten hat. Nimmt man aber im Gegentheil derartige Niveauschwankungen wahr, so ist die Amplitüde derselben festzustellen, indem man die wechselnde Höhe des Wasserstandes an solchen Punkten misst, hinsichtlich welcher die Ermittlung dieser Verhältnisse das meiste Interesse bietet. Nan bedient sich hiezu eingetheilter Stäbe, die man an Stellen, von welchen sich das Neer niemals - auch nicht bei tiefstem Niedrigwasser zurückzieht, senkrecht aufplanzt und mit einem Flechtwerk umgibt, damit die Oberfläche des Wassers um den Stab weniger durch den Wellenschlag gestört werde. Die Ablesungen müssen in um so kürzeren Zwischenräumen vorgenommen werden, je näher der Zeitpunkt eines extremen Wasserstandes (höchste Fluth oder tiefste Ebbe) heranrückt, damit man genau die Zeitpunkte ausfindig macht, in welchen die Maxima und Minima erreicht werden.

Ein und dasselbe Stadium der Gezeiten tritt nicht jeden Tag zur gleichen Stunde, sondern jeweilen mit zirka 50 Minuten Verspätung ron einem Tag zum andern ein. An einem bestimmten Orte treten die analogen Erscheinungen von Fluth und Ebbe (einander entsprechende Wasserstände beim Steigen oder beziehungsweise beim Sinken) nur an den Tagen des Voll- und Neumonds zur gleichen Stunde ein, d. h. in gleichen Intervallen ron der Kulmination des Mondes an. Dieses Intervall — die Zeit zwischen dem Meridiandurchgang des 
Mondes in den Syzygien und dem Eintritt des Hochwassers der Fluth - heisst die Hafrnzcit des Ortes. Der Verlauf der Gezeiten ist bedingt durch die Gestaltung der Kü̈sten und des Meeresbodens; die Gleichzeitigkeit der Erscheinungen, welche sonst rorhanden wäre, wird hiedurch gestört, und es treten an den Punkten einer Küste Fluth und Ebbe zu verschiedenen Zeiten auf. Linien, welche Punkte verbinden, die zu gleicher Zeit Fluth und zu gleicher Zeit Ehbe haben, heissen Isorachien (cotidal lines).

Die Höhe entsprechender Stadien der Gezeiten wechselt am gleichen Punkte im Laufe eines Tages; zwei ummittelbar aufeinanderfolgende Fluthstände ergeben nicht den nämlichen Wasserstand; das Gleiche gilt hinsichtlich der Ebbe. An zwei rerschiedenen Tagren sind diese Differenzen noch grösser. Der Niveaumuterschied zwischen Hoch- und Niederwasser ist bedingt durch die Mondphasen; er ist grösser zur Zeit der Syzygien, d. h. ron Voll- und Teumond (Sirimufluth), am kleinsten zur Zeit der Quadraturen, d. h. des ersten and letzten Viertels (Niplfhuth, taube F'uth). Die Syzygien oder Springfluthen sind wieder verschieden von einem Monat sum andern und werden am grössten zur Tag- und Nachtsleiche.

Die Amplitüde der Gezeiten für einen gegebenen Ort sestimmt man als die Differenz zwischen dem Durchschnitt ler Wasserstände zweier unmittelbar aufeinander folgender Iochwasser einerseits und dem Stand des dazwischen fallenden iiedrigwassers andrerseits. Um diese Daten mit solchen ür andere Punkte rergleichen zu künnen, gibt man die Iaxima der Amplitüde an, welche zur Zeit der Aerfuinoktien intreten.

\section{PELANZENWELT.}

Die Flora einer Gegend umfasst die Gesammtheit der aselbst wild wachsenden Pflanzen. Lm sie darzustellen, üsste man also alle Familien, Arten und Spielarten dieser flanzen aufzählen und nöthigenfalls beschreiben. Dies wäre ser meist eine riesige, jedenfalls eine schwierige und nur גrch Fachgelehrte zu bewältigende Aufgabe. Der gewöhnliche 
Reisende hann nicht so weit gehen; seine Sache ist es nur, das Charakteristische einer Flora hervorzuheben, dieselbe in ihren grossen Zügen zu schildern; die Erstellung eines Katalogs der in einem Lande wachsenden Pflanzen wird er dem Botaniker von Fach überlassen.

Eine der ersten Autoritäten ${ }^{1}$ ) sagt hierüber: „Ein statistisches Tableau, welches das räumliche Verhältniss zwischen Wald, Kulturland, Wiesen, Sumpf etc. angibt, liefert ein besseres Bild von der Vegetation des Landes im Allgemeinen als manche gelehrte Floren, von welchen die Botaniker viel Aufhebens machen." Ein solches statistisches Tableau kann leicht erstellt werden durch Verwerthung der Beobachtungen, welche der Reisende auf seinen verschiedenen Exkursionen gemacht haben wird.

Pflanzenformationen. Man betrachtet, dem Obigen gemäss, die Vegetation eines Landes zunächst nach der Vergesellschaftung ihrer Formen zu Pflanzenformationen ${ }^{2}$ ). $\mathrm{Als}$ solche kommen namentlich in Betracht: $1^{\circ}$ Die Wiilder - Hochwald, Niederwald und Buschwald (Maquis, Knieholz u. dgl.), Laub- und Nadelwald in reinen und gemischten, dichten oder lichten Beständen, einerseits als ausgedehnte Waldungen (in grossen kompalit-geschlossenen lückenlosen Komplexen oder unterbrochen und gegliedert durch Auen und Lichtungen), andrerseits als isolirte Gehölze; bald mit ziemlich gleichmässiger Wuchshöhe, bald mit einer Anzahl Baumgestalten, welche, die andern überragend, einen "Wald über dem Walde" bilden; $2^{\circ}$ Röhricht oder Dickicht aus hohen Gräsern (Dschungeln, Schilfrohr, Bambus); $3^{\circ}$ Steppen mit Zwiebelgewächsen, hohen Stauden, Kräutern und Gräsern; $4^{\circ}$ Wiesen; $5^{\circ}$ Sumpfebenen mit Rietgräsern und andern Wasserpflanzen; $6^{\circ}$ Haideland mit Ginster und Haidekraut; $7^{\circ}$ Tumlren

1) M. Alph. de Candolle. Des caractères qui distinguent la végétation d’une contrée (Archives des sciences physiques et naturelles. Genève 1854, p. 286).

2) Künstliche Pflanzenformationen bietet die Kubturlandschaft. Dr. Karl Müller (das Buch der Pflanzenwelt 1. Buch: der Pflanzenstaat) unterscheidet als Haupttypen der "Pflanzengemeinden " die Wälder, die Grasdecke, die Haide, die Moosdecke, die Meer- und Seeschaft, die Krautflur; - A. Meitzen (in Neumayers Anleitung S. 15̄5): Wald dicht oder licht, Gestrüpp, Schilf, Gras, Haide, Moos oder der dürre harte oder fliegende Boden (vgl. ebendaselbst S. 342 ff. Grisebachs Vegetationsformationen); - Max Haushofer: die Wüstenlandschaft, Haide und Steppenlandschaft Waldlandschaft, Sumpflandschaft, Kulturlandschaft („Pflanzenleben u. Landsehaftscharakter. Fin Beitrag zur Theorie der Landschaftsmalerei, Westermanns Monatshefte, Jan. 1880 , S. 498 ff. “). 
mit Moos und Flechten; $8^{\circ}$ Sand und Frlscë̈sten mit einzelnen Oasen.

Durch Zahlen oder besser noch durch konventionelle Farhen auf einem Cropuis in grossem Massstab gibt man das Areal dieser einzelnen Pflanzenformationen an.

Charakteristische Pflanzenformen. Nachdem man sich den Teberblick verschafft hat, von dem wir eben sprachen, untersucht man, aus welchen wesentlichen Bestandtheilen jene Formationen bestehen, welche Gewächse den Hochwald und das niedere Gehı̈lz, welche andern die I'flanzendecke der Ehenen bilden oder auf unkultivirtem Lande, an den Gestaden der Flüsse, in Teichen, Sümpfen etc. wachsen.

Dabei handelt es sich, wie bereits angerleutet, nicht um seltene und nur rereinzelt rorkommende, sondern um die nach Zahl und Masse vorherrschenden PHanzen, welche dazu beitragen, der Landschaft ihren eigenthümlichen Charakter zu verleihen ${ }^{1}$ ). Diese Pflanzenformen aber gehören meist allgemein bekannten oder leicht zu bestimmenden Arten an.

Man erleichtert sich diese Aufgabe, wenn man zunächst die pflanzenarmen, unfruchtharen Gegenden studirt, wie hohe Berggipfel und die Ründer von Wïsten, felsigen Hochebenen u. s. w. Hier wird man nur auf eine geringe Anzahl ron Pflanzenarten stossen, deren Bild man bei wiederholtem Anblick derselben sich leicht einprägt. Man geht sodamn zu solchen Landstrichen üher, deren Vegetation zwar reicher an Individuen, aber auch arm an Spezies, also ron monotonem Charakter ist, wie Haiden und Steppen; hier wird man die wenigen Pflanzenarten, welche die regetative Decke des Bodens ausmachen, wohl unterscheiden lernen. Nunmehr liann man sich Gegenden zuwenden, deren Pflanzenwelt eine reichere und manigfaltigere ist. Dabei beschäftignt man sich in erster Linie mit den rorherrschenden Arten; zuletzt studirt man die selteneren Pflanzen.

1) Solcher Pflanzenformen unterscheidet Max Haushofer (a. a. O., von dem dort bezeichneten Gesichtspunkt aus) nur folgende: Moose und Flechten, Gräser, Blumen und Kräuter, Strüucher, Palmen, Bäume. - Karl Müller (a. ฉ. O., 3. Buch: die Physiognomik der Gewächse) stellt 17 Formen auf: Palmen, Bananen, Orchideen, Lilien und Aroideen, Gräser, Farren, Moose, Flechten, Pilze, Nadelhölzer, Weiden, Form des getheilten Blattes, Haide, Cactus, Lippenblütler, Lianen, Form des Riesigen; also gleichviel, aber zum Theil nicht dieselben Typen, wie sie Alex. von Humboldt in seinen "Ansichten der Yatur" (Ideen zu einer Physiognomil der Gewächse) charakterisirte. - Die Grisebach'schen Vegetationsformen s. die Vegetation der Erde I. S. $11-14$ und Neumayers Anleitung S. $336-339$. 
Auch die Kulturgewächse sind zu erwähnen, namentlich wenn grosse Flächen mit ihnen bepflanzt sind, sodass sie dem Lande eine eigenthümliche Physiognomie verleihen. Falls dieselben Arten angehören, welche in dem Lande nicht wildwachsend vorkommen, so ist womöglich anzugeben, durch wen und wann sie eingeführt wurden.

Wenn in einer Gegend solche Arten, deren Vorkommen nach den klimatischen Verhältnissen vermuthet werden muss, sich nicht oder nur ausnahmsweise finden, so ist auch dieser Mangel vorzumerken. Desgleichen sind die wesentlichen Unterschiede in den Floren zweier benachbarter Länder oder Inseln anzugeben.

Zonen und Regionen ${ }^{1}$. Das Studium der Pflanzenwelt eines Landes lehrt uns, dass die Vegetation in dem Maasse, als wir an Gebirgen auf- und niedersteigen oder uns süd- oder nordwärts begeben, einen andern Charakter zeigt; es gibt, mit andern Worten, Gesetze für die Vertheilung der Pflanzen nach der geographischen Breite und der Meereshöhe. Darnach unterscheidet man Pflanzenzonen und Pflanzenregionen. Es ist von Wichtigkeit, dass man dieselben nach ihrer Eigenart gehörig unterscheide und deren Grenzen möglichst genau bestimme.

Innerhalb einer Zone oder einer Region sind die Pflanzen nach der Verschiedenheit der Standorte gruppirt, d. h. nach der physischen und chemischen Beschaffenheit des Terrains: nach seiner Gestaltung und Exposition, seinen Wärme- und Feuchtigkeitsverhältnissen; in letzterer Beziehung ist nicht nur ein Gegensatz zwischen dürren und bewässerten Gegenden vorhanden, sondern es kommt namentlich auch darauf an, ob eine Gegend von klarem Wasser getränkt, mit stagnirendem Wasser bedeckt, ob sie von einem See oder Meere bespült werde.

Bei solchem Studium wird man innerhalb der durch klimatische Faktoren bedingten Breitenzonen ${ }^{2}$ ) und Höhen-

1) Den Leser, der sich hierüber genauer unterrichten will, dürfen wir wohl auf die einlässliche Darstellung bei D. Kaltbrunner, Aide-mémoire pag. 150 sq. (Régions et grands aspects) aufmerksam machen.

2) Vgl. biefür z. B. Grisebachs Ueberblick über die Vertheilung der Baumformen: Es lassen sich vier Hauptformen von Büumen in der Richtung von der nördlichen Baumgrenze bis zum Aequator unterscheiden, von denen zwei dureh alle Breitegrade vertreten, die beiden andern auf die wärmeren Gegenden eingeschränkt sind. Die ersteren sind die Nadelhölzer und die periodisch belaubten Laubhölzer, die 
reggionen mehr oder minder zahlreiche kleinere Vegetationsgebiete und Unterabtheilungen von solchen bestimmen, von denen je zwei benachbarte durch besondere, vielleicht ganz lokale Verhältnisse sich ron einander unterscheiden.

Es ist freilich oft schwer, für solche Gebiete genaue Grenzen anzugeben; grewisse Pf̣lanzenarten werden in mehreren derselben vorkommen und diejenigen Spezies, welche nicht durch mehrere Gebiete hindurchgehen, haben oft ziemlich rerschiedene Verhreitungsgrenzen. Man wird daher beim Lnterscheiden solcher Abtheilungen immer den Gesammtcharakter einer Flora im Auge haben müssen und nicht ausser Acht lassen dürfen, was bei der Verbreitung einer Pflanze als Regel, was hingegen als Ausnahme erscheint. Jedenfalls sind Abtheilungrgrenzen da zu ziehen, wo mehrere der erwähnten Vegetationslinien nahe zusammenfallen.

Bei längerem Verweilen in einem Lande unterlasse der Reisende nicht, dieselben Lokalitäten zu verschiedenen Jahreszeiten in Augenschein zu nehmen; denn hiebei wird er sowoh] die Veränderungen, welche die Flora im Laufe des Jahres erleidet, kennen lernen als auch solche Pflanzen, die bei blos eimmaligem Besuch der Gegend seiner Wahrnehmung entgehen könnten; viele Spezies sind zur Zeit ihrer Blüthe, viele bei der Fruchtreife weit auffallender als sonst, und es sind dann ihre Verbreitungsgrenzen leichter zu bestimmen.

Nutzpflanzen. Nachdem man die Flora einer Gegend nach ihren allgemeinen Merkmalen studirt hat, wird man sie auch ron dem praktischen Gesichtspunkte ihres Nutzens aus betrachten.

Gewisse wildwachsende Pflanzen können zu einer lohnenden Verwerthung als Betrielss- oder Handelsartikel geeignet sein. Als Beispiel nenne ich nur die Alfa, eine Pflanze, welche grosse Flächen Nordafrikas bedeckt. Noch vor Kurzem wurde sie als ein ziemlich unnützes Gewächs betrachtet, das höchstens den Eingebornen zur Herstellung groben Flechtwerks diente.

letzteren tragen immergrüne Blätter und zerfallen in dikotyledonische und monoiotyledonische Formen... Um in einem grossen Ueberblick die Vertheilung der IVälder von Lappland bis zum Aequator aufzufassen, darf man sich vorstellen, dass lie Zone der wirdlichen Buzmformen im westlichen Europa bis zum 45 . Breitengrade der noch einige Grade weiter hinabreicht, dass die immergrunen Lutbhölzer die uldliche Hälfte der Hemisphäre einnehmen und dass in den Tiefebenen des Nordens ile Viudelholzer diesseits des Ural von der Baumgrenze bis zum f0. Parallelkreise, enseits bis zu den Steppen $\left(50^{0}\right)$ oder bis zum Amurgebiete (530) vorherrschen. Vegetation der Erde, I. S. 127.) 
Nun aber hat man in ihr ein treffliches Material zur Papierfabrikation erkannt und sie ist für das Land zu einer Quelle des Reichthums geworden; das Einernten derselben beschäftigt zahlreiche Hände, und Eisenbahnen sind eigens mit Rücksicht auf die Ausbeutung der Alfa-Felder gebaut worden. Die jährliche Ausfuhr Algiers an. diesem Artikel übersteigt den Werth ron 9 Millionen Franken. Eine kleine Stadt in Tripolis, die auf den Karten nicht eimmal angegeben ist - Omz, in der Nähe der Ruinen ron Leptis magna - exportirt jetzt jährlich über 100,000 Ballen Alfa, während sie früher gar lieine Industrie hatte. Einen solchen Umschwung hat die Entdeckung der nïtzlichen Eigenschaften einer Pflanze bewirkt.

Oft ist die Verwerthbarkeit eines Gewächses schon bekannt und es weiss der Reisende, dass die und die Pflanze als Nahrungsmittel, medizinischer oder technischer Artikel dienen kann; oft aber ist dies dem Reisenden oder überhaupt umbekannt, wie dies so lange Zeit bei der eben erwähnten Alfa und für zahlreiche andere jetzt als Nutzpflanzen verwendete Gewächse der Fall war. Dann kann nur systematische Beobachtung oder ein glücklicher Zufall die Entdeckung herbeiführen.

Kommt eine Pflanze so massenhaft ror, dass sie hiedurch zu einer Quelle des Reichthums für die Gegend würde, falls sie zu Nutzen gezogen werden könnte, so handelt es sich darum, in dieser Richtung Versuche, Studien zu machen. Hiezu bedarf es freilich eines erfinderischen Geistes; da gibt es keine positiven und allgemeinen Methoden; Alles hängt ron dem individuellen Scharfsinn ab. Indessen wird der Reisende in manchen Fällen eine Wegleitung erhalten können, wenn er beobachtet, wie die Eingebornen eine Pflanze verwenden oder wenn ex sich bei denselben nach den Eigenschaften solcher erkundigt. Auf diese Art sind verschiedene Textil- und Farbstoffe, ebenso die Harze, Guttapercha u. s. w. entdeckt worden.

Schädliche Pflanzen. Neben den nützlichen Eigenschaften sind dann auch die Nachtheile zu erwähnen, welche durch gewisse Pflanzen oder die Vegetation im Allgemeinen bewirkt werden.

Mitunter ist der Pflanzenwuchs so üppig, dass er zu einem schweren Hinderniss für die Kommunikation und die 
Bodenkultur wird. In tropischen Gegenden bilden die Gewächse oft liompalite Massen, wie Mauern, so dass man sich nur mit der Axt einen Weg bahnen kamn. Dicht verflochtene Lianen, sowie Bäume, welche vor Alter gefallen sind und deren Stänme nun jeden Augenblick den Wegr versperren, bilden ebensolche Hindernisse. Die stete Feuchtigkeit unter solchen dunkchi vegetabilischen Gewölben macht gut unterhaltene Strassen ummöglich, und wemm nicht ein sehr lebhafter Verkehr stattfindet, so sind die Wege bald überwuchert durch eine verschwenterisch reiche Vegetation, whlche in kurzer Frist jede spur einer Passage verschwinden lässt.

In Australien wächst ein Strauch von $4-5 \mathrm{~m}$ Höhe, die Maalyptlanze (Eucalyptus dumosa) auf ungeheuren Flächen in so dichten Massen, dass es überaus schwer hält, durch dipsen Buschwald zu dringen. Im Innern ron Westaustralien ist das grousste Hinderniss für Reisen ein hInsses liraut (Triodia irritans), welches die Beine der Lastthiere so sehr rerwundet, dass diese zum Weitermarsch untauglich werden.

Endlich giht es Pflanzen, wie in Algier die Zwergpalmen, welche sich des Bodens in einer Weise bemächtigen, dass man die grösste Nühe hat, sie auszurotten und das Land urbar zu machen, oder es haben solche, wie die Disteln, eine so enome Fähigkeit der Vermehrung, dass sie in einer für den Landmam trostlosen Weise üherhanduehmen und alle andern Pflanzen unterdrücken.

Veränderungen der Flora. Das P'flanzenkleir einer Gegend kamn in verhältnissmässig neuer Zeit Aenderungen erlitten haben. So wurde z. B. durch die Einführung der Merinoschafe in gewissen Distrikten Südafrikas das dortige Vegretationsbild wesentlich umgestaltet. Anderorts sind Bestandtheile der Flora verschwunden in Folge von Erschöpfung des Bodens oder Aenderungen des Klimas. Es bedarf hiezu keiner allgemeinen Temperaturerniedrigung; eine einzige sehr kalte Nacht kann die zartern, gegen Frost empfindlichsten Gewächse rernichten ${ }^{1}$ ). Wenn man sichere Zeugnisse über verschwundene oder dem Verschwinden entgegengehende Arten erhalten kann, so notire man dieselben sorgfültig und er-

1) Vgl. Ch. Martins, Sur l'origine paléontologique des arbres, arbustes et arbrisceaux indigènes du Midi de la France sensibles au froid dans les hivers rigoureux. Wontpellier 1877, pag. 93. 
mittle auch soviel als möglich die Ursachen dieser Erscheinung. Solche Zeugnisse bestehen nicht nur in Aussagen der Einwohner, in lokalen Traditionen; es gibt deren oft direktere und zuverlässigere. Man hört oft davon sprechen, dass früher Bäume in Höhen gewachsen seien, wo sie nun nicht mehr vorkommen, oder von Pflanzen, die man im Boden der Torfmoore finde, während jetzt in der Gegend nicht mehr dieselben Arten existiren. Der Reisende muss trachten, solche Daten zu verifiziren und deren Ursachen zu erforschen.

Darstellung der Flora. Die Mittel, welche der Reisende anwenden kann, um eine Vorstellung vom Aussehen des Pflanzenkleides einer Gegend zu geben, bestehen in charakteristischen Beschreibungen oder Schilderungen und bildlichen Darstellungen ("Landschaften", Gruppenbildern) für bestimmte Regionen.

Hinsichtlich der einzelnen Pflanzen genügt bei vielen die Angabe des Namens. Was die andern anbetrifft, so kam sich der Reisende nicht damit aufhalten, sie in minutiöser Weise zu zergliedern und zu zeichnen; oder jenachdem er nur eine Vorstellung von ihrem Aussehen (Habitus, Tracht) geben oder ihre botanischen Merkmale darstellen will, wird er sich Photographien (womöglich kolorirte) oder Abdrücke und sorgfältig behandelte Sammlungen beschaffen.

Abdrücke lebender Pflanzen. Für die Anfertigung von Pflanzenabdrücken gibt M. Bertot in den Comptes rendus de l'académie des Sciences (Paris 1876, pag. 998) folgendes Verfahren an:

Nan versieht sich mit Papier von grossem Format, Olivenoder anderem Oel, Bleiweiss, Asche und Harz oder Kolophonium.

Ein Bogen des Papiers wird auf einer Seite leicht geölt und dann vierfach zusammengelegt, die befettete Seite nach innen gekehrt.

Die Pflanze oder der Pflanzentheil, wovon man einen Abdruck anfertigen will, wird nun ?wischen die nicht befetteten Vorderseiten des zusammengefalteten Papiers gebracht, so dass sie nicht direkt mit dem aufgetragenen Oel in Berührung kommt, sondern nur mit solchem, das durch die Poren des Papiers gedrungen ist. 
Nun bringt man das zusammengelegte Papier mit der darin befindlichen Pflanzenpartie in eine gewöhnliche Enveloppe (Briefsack, Couvert) und streicht mit der Hand unter sanftem Druck wiederholt nach allen Richtungen darüber hin. Dabei wird die Pflanze mit Oel getüncht.

Nachdem dies geschehen, wird dieselhe aus dem greölten Papier herausgenommen und rorsichtig auf reines weisses Papier gelegt oder noch besser zwischen zwei Blätter (Bogren) ron solchem, da die Pflanze auf beiden Seiten befettet ist und also zwai Abdrücke liefern kann. Nan führt wie vorhin unter sanftem Drücken mit der Hand über das Papier hin, wohei aber darauf zu achten ist, dass die Lage der Pflanze durchaus unverändert bleibt.

Wenn man nun die Pflanze wegnimmt, so existirt auf dem Papier schon ihr Bild; nur ist es noch nicht sichtbar. Ian bestreut hierauf das Papier mit Bleiweiss, und zwar ausgriebig, nach allen Richtungen, ähnlich wie man beim Sanden eines frisch überschriebenen Blattes verfährt.

Mit Pastellfarben (in Pulverform) kann man, wenn man will, noch die Färbung der Pflanzentheile wiedergeben.

Zur Beseitigung des überflüssigen Bleiweiss, welches mitunter das Papier beschmutzt, wendet man Asche an, die ebenfalls auf das Papier gestreut wird.

Úm das so erstellte Bild zu fixiren, mischt man vorher dem Bleiweiss oder den anderen Farben Harz oder Kolophonium zu gleichen Gewichtstheilen bei. Schliesslich setzt man dann das Papier — entweder auf einem Ofen oder mittels eines heissen Eisens - einer Wärme aus, die zum Schmelzen des Harzes hinreicht; dani bilden das Oel, die Bleifarbe und das Harz ein dauerhaftes inniges Gemenge.

Diese Abdrücke liefern allerdings nicht immer ganz korrekte und sauber ausgeführte, aher doch getreue Bilder. Verbesserungen in Einzelheiten, die man daran noch wünschenswerth finden sollte, können leicht durch Handzeichnung angebracht werden. Indessen sind in vielen Fällen die blossen Ibdrücke, ohne jede Nachbesserung - wenn auch unvolliommener - einer vervollständigten Zeichliung vorzuziehen.

Sammlungen. Was lebende Pflanzen und Samen, Sammungen getrockneter Pflanzen (Herbarien), von Hölzern und ihnlichen Objekten betrifft, die man nach IIase senden oder 
selbst zurückbringen will, so theilen wir nachstehend die kurzen Instruktionen mit, welche Professor Milne Edwards in den "Archires des missions scientifiques et littéraires" (Band IV, Jahrgang 1877) für solche Reisende gab, welche, ohne dass sie Naturforscher wären, zum Fortschritt der Naturwissenschaften beitragen wollen.

Lebende Pflanzen. Unterirdische Theile - Zwiebeln und Knollen - von Liliaceen, Irideen, Erdorchideen, Aroideen $u$. s..w. werden am besten versandt, indem man sie in trockenes Moos oder noch besser in recht trockene Erde oder Sand rerpackt und zwar so, dass die Kiste, welche die Gegenstände enthält, vollkommen gefüllt ist. Die sogenannten parasitischen oder epiphytischen Orchideen mit grünen oberirdischen Knollen versendet man in hölzernen, durchlücherten und ganz trocken gehaltenen Kisten, nachdem man alle alten Blätter, welche durch Zersetzung Feuchtigkeit entwickeln könnten, entfernt und die Wurzeln mit dürrem Moose oder alten Leinwandstücken umgeben hat. Aehnlich verfähr't man mit Fettpflanzen wie Cactus; als Verpackungsmaterial wendet man dabei wohl auch Rosshaar, Wolle oder ähnliche Stoffe an, welche nicht durch Feuchtigkeit alterirt werden. Wenn diese Fettpflanzen voluminös sind, so muss man sie von andern, in die gleiche Kisten rerpackten Pflanzen gut isoliren, damit die letzteren nicht durch die Feuchtigkeit verdorben werden, welche bei allfälliger Zersetzung der ersteren entsteht. Auch muss auf die Umhüllung und Verpackung dieser Fettpflanzen besondere Sorgfalt verwendet werden, damit ihr Gewebe, das zarter und wasserreicher ist als dasjenige der Zwiebeln und Knollen, nicht durch ihr eigenes oft sehr bedeutendes Gewicht gequetscht und verletzt werde.

Für den Transport anderer lebender Pflanzen, der längere Zeit (einige Monate) dauern soll, muss man nothwendig die sogenannten $W^{\top}$ ard'schen Kisten verwenden, das sind Glaskästchen von besonderer Konstruktion, welche durch einen Hrn. Ward zuerst in England angewendet wurden. Diese Kästchen können nach Form and Grösse verschieden sein. Die im Allgemeinen übliche Form derselben, sowie die Anordnung der Pflanzen in denselben findet sich in nachstehender Fig. 219 dargestellt. Damit sie für den Transport, namentlich für die Aufbewahrung 
auf dem Verdeck des Schiffes, wo sie nothwendig bleiben müssen, nicht unbequem sind, dürfen folgende Dimensionen nicht überschritten werden :

9-11 Dezimeter Länge, $5 \mathrm{dm}$ Breite und 7-10 dm Höhe.
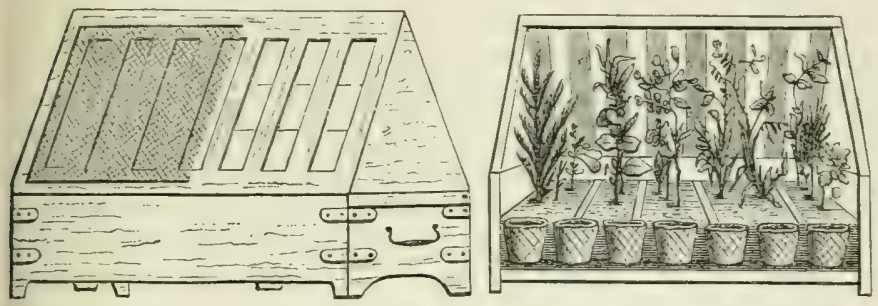

Fig. 219 .

Ihr Boden darf nicht unmittell)ar auf der Lnterlage aufliegen, sondern muss davon um einige Centimeter - die Höhe der Füsse in den vier Ecken - abstehen, damit er nicht durchnässt wird ron dem auf das Verdeck gespritzten Meerwasser. Die nach oben spitz zulaufenden Schmalseiten tragen zwei dachfïrmig angeordnete Glasfenster. Boden und Seitenwände bestehen aus gut trockenem Eichen- oder anderem Hartholz von 25-30 mm Dicke und müssen genau zusammengefügt sein.

Die Glasfenster sind durch von ohen nach unten laufende $4-5 \mathrm{~mm}$ breite Querstähe in Abtheilungen (Scheiben) ron $7-8 \mathrm{~mm}$ Breite eingetheilt. In die Fälze dieser Stähe sind dicke starke Glasscheiben eingefügt, die dachziegelartig aufeinanderliegen und gut verkittet sein müssen. Das Glasfenster der einen Seite ist festgenietet, also in einer nicht zum Wegnehmen bestimmten Weise angebracht: an dessen oherem Rande und den Seitenwänden wird das andere Fenster aufgeschraubt, nachdem die Schrauben grut geölt wurden, damit sie leicht herauszunehmen sind und nicht einrosten. Die Kisten müssen zudem in allen Fugen gut rerkittet und uussen mit Oelfarbe angestrichen sein.

In den beiden Schmalseiten sind in solider Weise starke siserne Handgriffe hefestigt, damit die Kästen leichter transgortirt und auf dem Verdeck des Schiffes festgebunden werden 
können. Endlich sind zum Schutze der Glasscheiben durch Eisenstäbe in einigem Abstand von denselben gehalten - starke engmaschige Eisengitter angebracht.

Um nun die Pflanzen in diese Kisten zu placiren, belegt man den Boden mit einer $4-5 \mathrm{~cm}$ dicken Schicht schwerer lehmiger Erde, die so befeuchtet wird, dass sie sich gut an das Holz anschmiegt; darauf bringt man eine $15-20 \mathrm{~cm}$ starke Lage guter.Ackererde, die weder zu schwer noch zu leicht und womöglich mit einem Quantum der bei den Gärtnern gebräuchlichen Dammerde (Modererde) vermischt sein soll. In diese Erde pflanzt man die zu transportirenden Gewächse sorgfältig ein, entweder direkt oder in Töpfen und Binsenoder Weidenkörben, welch letztere die einzelnen Stöcke isoliren und dabei den Vorzug haben, dass sie nicht zerbrechen.

Damit die Pflanzen bei den Stössen, welchen der Apparat auf See- und Landreisen ausgesetzt ist, nicht in Unordnung kommen und Beschädigungen erleiden, bedeckt man die Erde noch mit einer Schicht Stroh oder Binsen, welche man anpresst mittels Querhölzern, die man an den Wänden festnietet.

In einem Kästchen von den bezeichneten Dimensionen können 15-30 Stöcke - je nach der Grösse derselben untergebracht werden. Auch kann man zwischen denselben noch Pflanzensamen aussäen, was namentlich zu empfehlen ist hinsichtlich solcher Samenkörner, welche ihre Keimkraft nicht lange behalten, wie dies der Fall ist bei Palmen, Lorbeeren, Eichen, manchen Coniferen, Rosaceen u. s. f.

Die Pflanzen, welche auf die bezeichnete Weise in jenen Kisten transportirt werden, müssen gut angewurzelt sein; es ist daher zu empfehlen, dass man sie womöglich vorher eine Zeit lang in Töpfen kultivire. Sollten sie erst kürzlich rom freien Felde hereingebracht und verpflanzt worden sein, so ist es nöthig, dass man dieselben erstarken und sich erholen lasse, bevor man die Kiste definitiv schliesst.

Beim Schliessen — wobei das bewegliche Glasfenster nun auch solid befestigt wird - muss man darauf halten, dass die Erde gut, aber doch nicht zu reichlich getränkt sei. Ist dies der Fall, so soll für hermetischen Verschluss mittels Verkittens aller Fugen - gesorgt und die Kiste während der ganzen Reise nicht geöffnet werden. Wenn der 
Apparat einmal für den Seetransport verladen ist, so hat man nur dafür zu sorgen, dass er auf dem Verdeck, in rollem Tageslichte, bleibt, dass zerbrochene Scheiben sofort ersetzt und Spalten, welche im Holz entstehen, verkittet werden. Nur wenn die Kiste Pflanzen warmer Ländler entlält und man bei der Fahrt in Gegenden kommt, wo sie zur Zeit der Reise durch starken Frost gefährdet sein könnten, muss man dieselbe vom Verdeck weg in einen wärmeren Raum bringen. Gegen leichte Nachtfröste schützt ein über die Kiste geworfenes Tuch. Den Pflanzen soll so wenig als möglich das Tageslicht entzogen werden.

Bei dieser Behandlung bleiben die Gewächse in dem Apparat meist wohl erhalten; selten gehen ron zehn Exemplaren vielleicht eines oder zwei zu Grunde; oft liommen alle in gutem Zustande an und manche blühen selbst in den Kisten.

Freilich kann nicht genug empfohlen werden, die Sendungen so einzurichten, dass sie in Europa während der bessern Jahreszeit, zwischen dem 1. April und 1. Oktober, eintreffen; sonst können leicht noch Pflanzen durch Frost zu Grunde gehen, nachdem sie die Reise wohlbehalten zurückgelegt haben. Wenn es möglich gemacht werden kann, dass die Ankunft der Pflanzen in Europa im Mai oder Juni stattfindet, so ist dies das Beste.

Samen. Ueber den Sendungen lebender P'flanzen soll man nie diejenigen von Samen vernachlässigen; denn diese sind immer das einfachste und sicherste Mittel zur Verpflanzung und Kultur exotischer Gewächse.

Viele Samen bleiben ein Jahr und länger gut erhalten und keimkräftig, wenn man sie bei vollkommener Reife eingesammelt und trocken aufbewahrt hat. Wenn so viele Samen, welche Reisende nach Hause bringen, sich in schlechtem Zustand befinden, so liegt die Ursache darin, dass die Samenkörner boim Einsammeln nicht recht reif waren oder nicht recht trocknen konnten, bevor sie verpackt wurden. Man ist nur dann sicher, dass die Samen wirklich vollkommen reif seien, wenn sie sich ganz leicht ("von selbst") von der Pflanze lösen oder wenn die Früchte, in denen sie enthalten sind, sich ebenso leicht (selber) öfnen. Aber auch die anscheinlich reifen Samen, selbst solche ohne Fruchtfleisch, 
enthalten zur Zeit der Reife oft noch ein gewisses Quantum Wasser und werden schimmlig, wenn man sie in diesem Zustand verpackt. Sie müssen einige Tage lang getrocknet werden, entweder an der Somne oder doch jedenfalls an einem trocknen luftigen Ort, sei es offen der freien Luft ausgesetzt, sei es in Säcken ron dünnem hellfarbigem Stoffe oder grauem ungeleimtem Papier. Toch mehr hedürfen einer solchen Vorhereitung auf den Transport fleischige Früchte rie die Beeren. Man muss dieselben zerquetschen und sie dann an der Sonne oder - wie die Pflanzen eines Herbariums in Fliesspapier trocknen. Samen, welche derart in ihrem sorgfältig getrockneten Fruchtfleisch aufbewahrt und rersandt werden, bleiben im Allgemeinen sehr gut erhalten, so die Samen ron Cactus, Solanum, Bromeliaceen u. a. Erst wenn sie vollkommen lufttrocken geworden sind, soll man sie in Säcke ron geleimtem Papier bringen; sodann sind sie stets gegen Feuchtigkeit geschützt zu halten; zu diesem Zweck rerpackit man sie in gutrerschlossene Blech-, Glasoder Thongefässe oder aber in getheerte Säcke, die selbst wieder in rerschlossenen Kisten aufbewahrt werden. Wendet man aber eine solche Terpackung an, bevor die Samen rollständig lufttrocken sind, so gehen sie an Feuchtigkeit und Schimmelbildung zu Grunde.

Die meisten Samen bleiben, selbst bei sehr langem Transport, ganz gut erhalten, wemn man dieselben, nachdem sie so gut als möglich getrocknet wurden, in dickes ungeleimtes Papier und dieses sellst in grobe Leinwandsäcke rerpackt, welche man damn an einem trockenen und luftigen Orte aufhängt.

Samen mit öligen Stoffen, welche sich leicht zersetzen, und solche Samen, welche bald nach ihrer Reife keimen, müssen für den Transport in solcher Weise verpackt werden, dass während desselben die Keimung erfolgen kann. Dies ist der Fall bei Samen von Thee, Kaffee, Guayava, Lorbeer, vielen Palmen und Coniferen. Diese Samen werden am besten transportirt, indem man dieselben in die oben beschriebenen Glaskästen aussäet entweder in Kisten mit Pflanzen zwischen die letzteren, oder in besondere Kästchen, welche dann nicht so hoch sein müssen wie jene. In Ermanglung solcher Apparate wendet man gewöhnliche Kisten oder Fässer an, 
welche schichtenweise mit Erde und Samen gefüllt werden. Die Erde soll leicht und wenig feucht sein; statt derselben kann man sich zerriebenen morschen Holzes bedienen. Auf den Boden der Kiste oder des Fasses bringt man rine $\overline{5}-6 \mathrm{~cm}$ dicke Schicht Erde; auf diese werden die Samen gelegt, in Abständen, welche ihrem Durchmesser gleich sind. Hierauf folgt wieder eine Erdschicht ron $3 \mathrm{~cm}$ Dicke, eine nene Lage ron Samen u. s. f., bis das Ganze 3 oder 4 Dezimeter Höhe hat. Bei dieser Gesammtstärke aller Schichten soll die Kiste oder das Fass ganz angefüllt sein, damit die Samen nicht in Lnordnung gerathen können. Das Gefäss muss an einem trockenen Orte mit frischer Luft aufbewahrt werden und geschützt sein vor Meerwasser, dessen Zutritt die Samen und Pflanzen zu Grunde richtet.

\section{Herbarien, Sammlungen von Blüthen und Früchten.} Im Herbarium müssen die Pflanzenarten soviel als möglich einerseits durch Exemplare mit Knospen und Blüthen, andererseits durch solche mit Früchten vertreten sein. Kleine Pflanzen, und solche, welche sich in einem Bogen Papier durch geeignetes Zusammenlegen (Biegen und Einknicken) des betreffenden Exemplars noch zweckmässig unterbringen lassen, nimmt man ganz, mit allen ihren Theilen, selbst die Wurzel inbegriffen; von grösseren schneidet man Zweige ab bis zu 40 und $50 \mathrm{~cm}$ Länge. Da bei grossen krautigen Pflanzen oft die Blätter der verschiedenen Höhenabschnitte (Regionen) des Stengels rerschieden sind, so nimmt man ron ihmen sowohl einen untern oder basalen Theil mit den an ihm sitzenden Blättern, als auch Zweige mit Blättern und Blüthen. Die Sammlung ordnet man so an, dass je auf ein Heft, welches aus einigen in einandergelegten Bogen Löschpapier's besteht, eine Pflanze kommt oder eine Mehrzahl von solchen, wenn sie sehr klein sind und auf einem Bogen Papier nebeneinander Platz haben, ohne sich zu berühren; hierauf eine neue Lage Fliesspapier mit neuen Pflanzenexemplaren u. s. f. Ist auf diese Art ein Paket ron 2 bis hüchstens 3 Dezimeter Dicke gebildet worden, so presst man dasselle zwischen zwei Brettern oder starken Kartondeckeln durch Zuschnüren mit Stricken oder Lederriemen, welche Schnallen haben. Das Zusammenpressen muss mässig sein, d. h. stark genug, damit die Pflanzen nicht zusammenschrumpfen können, aber 
nicht so stark, dass durch den Druck ihre Form verunstaltet und ihr Gewebe zerquetscht wird. Die Pakete sollen, so lange die P'flanzen trocknen müssen, an einem trockenen Orte aufgestellt oder noch besser aufgehängt werden, und zwar so, dass die Papierflächen vertikal gerichtet sind, nicht wagrecht, indem erstere Anordnung das Verdunsten befördert. Die Papierlagen müssen von Zeit zu Zeit gewechselt werden; anfänglich (die ersten paar mal) sehr bald nach dem Einlegen und beginnenden Trocknen der Pflanzen. Bei diesem Wechseln des Papiers nimmt man jeweilen die schon ganz dürr gewordenen Exemplare heraus.

Das Trocknen der Pflanzen kann befördert werden, wenn man kleine Pakete von je nur 8-10 Exemplaren (beziehungsweise Lagen) und wenig dazwischengelegtem Papier bildet, und diese einzeln presst, indem man statt massiver Deckel Rahmen mit eingefügten Gittern von Eisendraht anwendet. Dabei muss unter jedes dieser Gitter zunächst eine $4-5$ Bogen starke Papierlage kommen, damit die Pressung gleichmässiger und das Zusammenschrumpfen der Pflanzen verhindert wird. Setzt man diese kleinen Pakete der. Sonne oder dem Luftzuge aus, so trocknen die Pflanzen sehr rasch; oft muss man nicht einmal das Papier wechseln, worin sie liegen. Wenn man aber nicht eine grössere Zahl der erwähnten Rahmen oder Gitter hat, so kann man nur eine geringe Zahl von Pflanzen gleichzeitig trocknen; das Verfahren empfiehlt sich daher am meisten für solche Personen, welchen die Anlegung von Herbarien ein Nebenzweck und nicht die Hauptaufgabe ist. Aber auch für den Botaniker von Fach, der ohne einen bedeutenden Papiervorrath eine grosse Zahl von Pflanzen trocknen will, kann dieses Verfahren sehr vortheilhaft gemacht werden, wenn man in der angegebenen Weise Pakete mit 15-20 Exemplaren (Lagen) bildet und diese in einen von erhitzter Luft durchströmten Tröckneraum bringt. Als solchen kann man einen Kasten benutzen, in welchem man die Luft bis zu $50^{\circ} \mathrm{C}$. erwärmt mittels einer Lampe, die unten angebracht und von den Pflanzenpaketen getrennt wird durch ein querlaufendes durchlöchertes Eisenblech. Nach 12 bis 24 Stunden sind die Herbariums-Exemplare vollkommen trocken. Diese Methode ist zuerst und mit bestem Erfolg von einem Assistenten des 
P'ariser Museums (MI. Doyère) angewendet worden und ist namentlich von Vortheil in feuchtwarmen Klimaten, sowie hei der Präparation schwer zu trocknender Pflanzen. Die pisernen Rahmen und Gitter können durch solche ron Bambusstäben ersetzt werden, welche man in den heissen Ländern ïberall leicht erhält.

Noch vortheilhafter in Bezug auf Papierersparniss und phenfalls sehr förderlich ist folgendes Verfahren, dessen Anwendung aber erfordert, dass man von Zeit zu Zeit ein grosses und trockenes Zimmer zur Verfügung habe. Man legt die Pflanzen je nur in einen Bogen Papier und presst. sie so; am Abend breitet man diese Bogen nebeneinander am Zimmerboden aus und lässt sie während der Nacht so liegen; am Morgen nimmt man sie auf und bringt sie wieder in die Presse. Es findet abwechselnd ein Zusammenpressen der Pflanzen in den Papierbogen und ein Trocknen derselben durch Verdunsten auf offen liegendem Papier statt. Dieses Verfahren liefert indess weniger schöne Exemplare als die oben beschriebenen Methoden, und soll daher nur angewendet werden, wenn man Mangel an Papier hat. Es muss eben dem Reisenden überlassen werden, jeweilen das Verfahren zu wählen, welches für ihn nach den Umständen das geeignetste ist.

Sehr saftige Pflanzen wie Zwiebelgewächse, Orchideen u. dgl. bleiben in den Herbarien oft noch Nonate lang lebend. Hat man daher diese Pflanzen in dem Zustand eingesammelt, in welchem man sie zu konserviren wïnscht, so thut man sut, sie eine Minute lang in siedendes Wasser zu halten oder für einige Stunden in Weingeist zu bringen. Auf diese Weise werden sie getödtet; beim Herausnehmen trocknet man sie zwischen Löschpapier und hat nun weiter mit denielben keine Schwierigkeiten.

Die Pflanzen einiger Familien erfordern besondere Kon:ervirungsmethoden. So können die Organe der Palmen oft hrer Grösse wegen nicht den gewöhnlichen Herbarien einrerleibt werden. Und doch ist sehr zu wünschen, dass die Cenntniss dieser interessanten Familie durch vermehrte Sammungen erweitert werde. Zu rliesem Zweck sind folgende Cheile derselben zu sammeln und zu konserviren:

10 Blätter; wenn sie nicht sehr gross sind, bringt man sie unter Beibehaltung der natürlichen Form und Lage 
ihrer Theile in Fliesspapier und trocknet sie so; sind dieselben aber zu gross, so legt man sie fächerförmig zusammen, trocknet sie an freier Luft und verpackt sie sodann in Löschpapier, das gut zusammengebunden wird.

$2^{\circ}$ Blüthenstände mit der umgebenden Scheide (spatha); bei getrenntgeschlechtigen Pflanzen sind sowohl die männlichen als die weiblichen Blüthen zu sammeln; man muss dieselben rasch an der Luft trocknen und sie dann in Papier oder Leinwand verpacken; auch die abgefallenen Theile derselben sollen aufbewahrt werden. Sind die Blüthenstände nicht zu gross, so konservirt man sie zweckmässig in schwachem Weingeist; jedenfalls soll man auf diese Art einige Zweige derselben aufbewahren, die man mit reifen Früchten der nämlichen Pflanze in das gleiche Gefäss bringt;

$3^{\circ}$ Fruchtstände, mit reifen Früchten, an der Luft getrocknet, und einige Früchte in Alkohol.

Die grossen unter dem Namen Tange bekannten Meerp fflanzen trocknet man einfach durch Aufhängen im Schatten an freier Luft, ohne dass man sie in Papier presst; hierauf bringt man sie in Papiersäcke mit Angabe der Fundstelle und der Färbung, welche sie in frischem Zustand hatten. Die Präparation derselben erfordert viel Sorgfalt und wird besser erst zu Hause (in Europa) vorgenommen, wenn der Reisende darin nicht Erfahrung besitzt. Für die anatomische Untersuchung derselben bewahrt man einige Stücke in Alkohol auf.

Die kleinen Algen werden ebenfalls an freier Luft getrocknet; rorher aber presst man sie leicht zwischen Löschpapier, um alles Meerwasser an denselben zu beseitigen.

Die meisten andern blüthen- oder samenlosen Pflanzen (Kryptogamen), wie Farne, Moose, Flechten und Pilze, seien sie von zarter oder derber Beschaffenheit, können ähnlich wie andere Gewächse für das Herbarium zubereitet werden. Die fleischigen Pilze aber sind nur im Weingeist zu konserviren, indem man sie durch Baumwolle oder Werg von einander isolirt; da sie aber auf diese Art nur ihre Form und Struktur, nicht auch die Farbe beibehalten, so muss man über diese einige schriftliche Notizen machen oder sie in 
einer Zeichnung angeben. Im Uebrigen ist hinsichtlich dieser Pflanzen zu empfehlen, dass man lieber junge als zu alte Exemplare nehme.

Bei all den besprochenen Sammlungen soll einem Exemplar jeder Art eine Aufschrift (Etiquette) mit Notizen über folgende Punkte beigegeben werden:

$1^{\circ}$ Die Fundstelle; wenn dieselbe wenig bekannt ist, so muss man ihre Lage mit Bezug auf einen allgemein bekannten Ort angeben;

$2^{\circ}$ die Zeit, in welcher die Objekte gesammelt wurden, unter besonderer Angabe für Pflanzen mit Blüthen und solche mit Früchten;

$3^{\circ}$ den einheimischen Namen der Pflanze; man lässt sich denselben wiederholt angeben und deutlich vorsprechen; womöglich ermittelt man auch seine Bedeutung und notirt diese ebenfalls ${ }^{1}$ );

$4^{\circ}$ die Anwendung der Pflanze zu häuslichen, industriellen oder medizinischen Zwecken, wenn man hierüber zuverlässige Daten haben kann;

$5^{0}$ die Farben der verschiedenen Theile, namentlich der Blüthe; Geruch derselhen; Konsistenz der Frucht, sowie Art und Weise des Oeffnens (Aufspringens) dersellen bei erlangter Reife; endlich andere nur an der frischen Pflanze bemerkbare Eigenschaften;

$6^{\circ}$ Grösse, Richtung oder Stellung (Lage) und Konsistenz der Pflanzen; bei Bäumen von bestimmtem Habitus fertige man womöglich eine Zeichnung an, aus der sich die Tracht erkennen lässt; es ist dies besonders wesentlich für Palmen und andere Monokotyledonen; hinsichtlich anderer Bäume kann man sich, in Ermanglung einer Skizze, darauf beschränken, sie mit einer der bekannteren Baumformen Europas zu vergleichen:

$7^{\circ}$ eine Ordnungsnummer; dieselbe ist bei allen Exemplaren und Theilen - Blüthen, Samen, Früchten, Holzmustern - einer Pflanze anzuwenden, welche einen Theil der Sendung ausmachen oder vom Reisenden aufhewahrt werden; ebenso im Katalog oder Reisejournal, so dass hienach später genaue Aufschlüsse über die

1) Vgl. oben, S. 106 . 
gesandten Pflanzen ertheilt werden können. Die während einer und derselben Reise angewandten Nummern sollen eine einzige Zahlenreihe bilden und nicht in Serien wieder früher schon gebrauchte Zahlen enthalten.

Wenn der Reisende die Höhen der Oertlichkeiten, durch welche ihn sein Weg führt, misst oder sonst kennt, so soll unter den über eine Pflanze gemachten Notizen auch die Höhe der Fundstelle angegeben werden.

Die trockenen Früchte werden in Kisten gesandt, versehen mit der Nummer und Aufschrift, welche im Herbarium der Zweig des Gewächses hat, von dem sie stammen. Alle trockenen Früchte, welche so gross sind, dass sie nicht wohl dem Herbarium einverleibt werden können, müssen in solcher Weise separat verpackt werden, man soll sie stets nur in gutreifem Zustande einsammeln, vollkommen trocknen lassen und sorgfältig in Papier einhüllen.

Die fleischigenFrüchte werden inBranntwein oder schwachem Weingeist (von $18^{\circ}$ ), Essigsäure oder Holzessig versandt; in Ermanglung dieser Flüssigkeiten wendet man Wasser an, in welchem reichlich — bis zur Sättigung - Meersalz aufgelöst wurde; diese Salzlake soll aber wirklich nur in Abgang der andern Mittel verwendet werden, denn sie eignet sich zur Konservirung der Objekte weniger als jene. Die Früchte jeder Art sollen in ein besonderes Gefäss kommen, umhüllt mit Leinwand, Werg oder Baumwolle; wenn man solche von mehr als einer Art in demselben Gefässe zusammen unterbringt, so müssen diejenigen einer jeden Species je in einen besondern Sack gethan und mit besonderer Aufschrift versehen werden.

Es ist sehr zu wünschen, dass in Flaschen mit schwachem Branntwein oder wasserfreier Essigsäure auch Blüthen gesandt werden, welche zu zart oder zu fleischig sind, als dass man sie in getrocknetem Zustande analysiren könnte. Auch hiebei soll ja nicht unterlassen werden, auf dem betreffenden Fläschchen eine Etiquette mit dem Namen der Pflanze oder wenigstens die Nummer anzubringen, welche im Herbarium die Pflanze hat, von der diese Blüthen stammen. Da auf die Flaschen geklebte Etiquetten sich oft ablösen, sind Nummern zu empfehlen, welche in Oelfarbe an jenen Gefässen selbst angebracht werden. Noch besser ist es, man lege in die Flasche ein kleines Holztäfelchen oder Pergamentblättchen mit der 
betreffenden Nummer oder Aufschrift; diese soll mit Bleistift (Graplit) geschrieben werden; Tinte kann man benutzen, wenn der Gegenstand in Alkohol kommt; fermer eignen sich zum gleichen Zwecke dünne Bleiblättchen, auf welche man mit einem Stichel schreibt. Wenn Theile mehrerer Pflanzenspecies in dasselhe Gefäss liommen, so muss wieder für jede Species eine besondere Etiquette der genannten Art beigegeben werden: sonst wäre die Sammlung nutzlos. Soviel als möglich vermeide man, Blüthen verschiedener Art in cin Fläschchen zu bringen; muss es doch geschelıen, so ist auf die erwähnte Weise dafür zu sorgen, dass keine Terwechslungen entstehen. Zu letzterem Zwecke kann man auch die Blüthen einzeln in Courerts aus geleimtem Papier rerpacken, diese mit Aufschriften versehen und sie nun in die Gefässe legen.

Hat man weder Flaschen noch Alkohol zur Verfügung, so trocknet man die Blüthensträusse ungepresst an der Luft, hringt sie in Briefsäcke mit Etiynette und rerpackt dieselben damn so, dass die getrockneten Blüthen gegen Druck geschützt sind.

Pflanzen, welche auf den Wurzeln anderer schmarotzen (Wurzelparasiten), honservirt man — mit der Wurzel selbst oder einem Stück derselben - in Branntwein oder Essig oder gesättigtem Salzwasser: soweit müglich nimmt man liebei die ganzen Pflanzen mit Blüthen und Früchten und zwar - wenn sie gretrennten Geschlechtes (_zweihäusig", diöcisch) sind, was oft der Fall ist - sowohl männliche als weibliche Exemplare. Diese Schmarotzerpflanzen zeichnen sich in der Regel aus durch Mangel an Blättern und grünen (chlorophyllhaltigen) Theilen, Heischige Konsistenz und geringe Wuchshöhe.

Die Herbarien und Fruchtsammlungen sollen, wenn die Objelite gut getrocknet sind, in Kisten verpackit werden, welche mit Eisenblech beschlagen oder mindestens gut getheert und gegen Mäuse wie gegen Insekten geschützt sein müssen.

Die Papierlagen mit Pflanzen formirt man, hevor man sie in Kisten verpackt, zu Paketen, die zwischen Brettern, Cartons oder Lagen leeren Papiers gut grepresst und zusammengebunden werden.

Beim Verpacken kann man in jeden Bogen Papier, wenn man an solchem Mangel hat, mehrere Stücke der Sammlung 
bringen und die Zahl der dazwischengelegten Bogen kann reduzirt werden; nur müssen die Pakete kompress und gut gebunden sein. Für diese Verpackung ist jede Sorte Papier tauglich; man kann dieses sogar durch Stücke von trockenen Bananen- oder anderen grossen Blättern ersetzen; unerlässlich ist nur, dass die Pflanzen sorgfältig geordnet werden und jedes einzelne Paliet durchwegs dieselbe Dicke hat.

Sammlungen von Hölzern u. dgl. In erster Linie nennen wir die Nutzhölzer, insbesondere diejenigen für Kunsttischlerei (Ebenisten) und Färberei; es ist sehr interessant, ron solchen rollständige Querstücke mit Splint und Rinde zu haben, sowie Zweige mit Blüthen oder Früchten, welche zur wissenschaftlichen Bestimmung dienen.

Fermer verdienen die unter dem Namen Liancu bekannten kletternden Holzgewächse die Aufmerksamkeit des Reisenden. Sie zeichnen sich meist durch bemerkenswerthe Eigenthümlichkeiten des Baues (der Struktur) aus, und ihr Studium kann ein bedeutsames Licht auf die Wachsthums- und Ernährungsweise der Pflanzen werfen. Schon haben Sammlungen dieser Art zur Aufhellung und Abklärung der erwähnten Fragen beigetragen; aber es bleibt in dieser Hinsicht noch viel zu thun, und Personen, welche warme Länder bewohnen, können ein kostbares Material liefern durch Sammeln nicht nur einzelner Stücke von allen derartigen Pflanzen, sondern auch grösserer Partien ziemlich grosser Stämme, Basistheilen mit Wurzeln von den ältesten Exemplaren; dann ron weniger alten Stengeln, von jungen (ein- und zweijährigen) Zweigen und endlich von blüthen- und fruchttragenden Zweigen, die getrocknet und im Herbarium aufbewahrt werden. Von grossem Werth ist eine Reihenfolge von Stücken, welche die verschiedenen Altersstufen repräsentiren: ron den einjährigen Zweigen mit Blättern, Blüthen und Früchten bis zu den ältesten Stamm- oder Stengelgebilden. Behufs Gewinnung dieses Materials haut man im Walde die grossen Bäume um, auf welche die Lianen hinaufklettern. Sowohl hinsichtlich dieser Bäume als in Betreff der Schlinggewächse notirt man sorgfältig die einheimischen Bezeichnungen (Volksnamen), sowie die Eigenschaften, welche die Eingebornen ihnen zuschreiben, und den Gebrauch, welche sie davon machen. Bei den meisten Lianen, auch denen, welche nicht 
sehr roluminös sind, namentlich aber bei den saftreichen, wie Cissus, thut man besser, Stengelabschnitte von nur einigen Centimetern Dicke zu nehmen als solche von grösserem Umfang; denn die ersteren behalten ihre Organisation eher unverändert bei.

Alle Stücke von derselben Pflanze müssen dieselbe Nummer tragen. - Als weitere interessante Objekte empfehlen wir der Aufmerksamkeit des Reisenden die pflanzlichen Faserstoffe, welche zu Geweben und Seilereiartikeln benutzt werden, ferner regetabilisches Wachs und Gummi, sowie Rinden, Wurzeln and Früchte, welche arzneilich oder technisch rerwendet werden.

Jedem Ohjelit soll eine Etiquette mit Nummer beigegeben werden, und womöglich sollen die Pflanzen, von welchen diese Produkte stammen, auch durch Herbariumexemplare rertreten sein. Es sollen die Volksnamen angegeben werden sowohl für diese Pflanzen als auch für die Produkte, welche von ihnen herrühren; ebenso ist mitzutheilen, welcher Gebrauch davon gemacht wird.

Hinsichtlich der Sammlungen von Stengelgebilden der vichtigsten' Gewächse ist verschieden zu verfahren, je nachdem es sich um Baumfarne und Monokotyledonen oder um Dikotyledonen handelt.

Was die ersteren anbetrifft: Baumfarne, Palmen, Drachenbäume u.s.w., so ist ihr Bau (die Struktur) ungleich je nach den Höhenabschnitten (Regionen) und dem Alter des Baumes, und es ist $\mathrm{zu}$ wünschen, dass davon vollständige Stämme erwachsener Exemplare — von der Wurzel bis zum Gipfel - geliefert werden, wenn das ohne zu grosse Kosten und Transportschwierigkeiten geschehen kann. Falls dies wegen der Grösse des Stammes und der erwähnten Schwierigkeiten nicht möglich ist, so sende man von einem Exemplar drei Partien, jede von etwa $50 \mathrm{~cm}$ Länge; den Basistheil mit Wurzeln, ein Nittelstück und die Gipfelpartie mit den Basaltheilen der Blätter. Sind die Stammstücke zu voluminös, feucht und schwer zu trocknen, so spalte man sie der Länge nach mitten entzwei, sende aber beide Hälften und nehme daron auch einige Querabschnitte (Scheiben) von $\check{5}-10 \mathrm{~cm}$ Dicke. 
Bei den Dikotyledonen genügt es, von einem Exemplar einen recht gesunden, weder durch Fäulniss noch von Insekten angegriffenen Stamm oder Hauptast auszuwählen und davon einen 40 bis $50 \mathrm{~cm}$ langen Abschnitt zu nehmen; hinsichtlich der Dicke dieser Stücke ist die passendste Dimension ein Durchmesser von 10 bis $20 \mathrm{~cm}$. Der Stamm oder Ast soll so alt sein, dass derselbe vollkommen ausgebildetes Holz (Kernholz) und Splint enthält, und bei Werkhölzern müssen Stammabschnitte genommen werden, die stark genug sind, um darnach die physikalischen Eigenschaften der Holzart gut beurtheilen zu können. Diese Stücke müssen mit vollständiger Rinde eingesandt werden. Steht zu befürchten, dass sie nicht gut austrocknen und desshalb verderben, so sägt man sie der Länge nach entzwei, aber nicht mitten üurch, sondern in einiger Entfernung rom Marke, damit dieses in einem der Längstheile (Scheiter) intakt ist; ausser den beiden Längshälften sende man dann ein vollständiges Querstück (Scheibe) von 5 bis $6 \mathrm{~cm}$ Dicke.

Alle diese Hölzer, seien es Farne, Monokotylen oder Dikotylen, sollen nicht in Kisten verpackt und versandt werden, bevor sie vollkommen lufttrocken geworden sind. Bis dahin müssen sie auch soviel als möglich gegen Insekten geschützt werden.

Damit die Holzstücke wissenschaftlich und praktisch nutzbar gemacht werden können, müssen sie durch Nummern bezeichnet sein, die solchen von getrockneten und dem Herbarium einverleibten Zweigen mit Blättern und Früchten entsprechen; sonst können sie nicht genau bestimmt werden. Diese Nummern bringt man auf einer glatten Schnittfläche des Holzes selbst an, mit Tinte, Bleistift oder (was besser ist) mit Oelfarbe. Sind der Stücke nur wenige, so kann man sie durch Kerben oder eingeschnittene römische Ziffern bezeichnen.

Sehr wichtig ist es, dass auf den Etiquetten im Herbarium oder in Katalogen angegeben wird, welche Volksnamen diese Hölzer in der Gegend tragen, von wo sie herstammen; diese Namen sind viel allgemeiner bekannt als diejenigen kleinerer Gewächse, und sie können zur Erlangung neuer Aufschlüsse dienen. 


\section{THIER TELT.}

Unter der Fauna einer Gegend versteht man die Gesammtheit der Thiere, welche daselhst im Naturzustande oder wenigstens in Freiheit leben. Eine vollständige Aufzählung und Beschreibung derselben zu geben, wäre ebenso schwer als dieselbe Aufgabe für die Flora, ja vielleicht noch schwieriger, demn das Thier entgeht der Beobachtung leichter als die Ptlanze. Aber der Reisende kann sich, wie schon bemerkt wurde, darauf heschränken, ron den wichtigsten Repräsentanten der lokalen Fauna Kienntniss zu erlangen und zu geben, ein allgemeines Bild derselben zu entwerfen und die wenig hekaunten Eigenthümlichkeiten hervorzuheben.

Allgemeiner Charakter. Der allgemeine Charakter der Thierwelt einer Gegend ist riel schwieriger zu erfassen und darzustellen als derjenige ihrer Flora. Die Indiriduen der Fauna stellen sich nicht so dem Blicke dar, wie diejenigen der Pflanzenwelt: man kamn bei jenen nicht wie bei diesen mit einem Blicke sich eine Gesammtansicht von den Massen verschaffen; viehmehr bedarf es hier langer und mit geduldiger Ausdauer fortgesetzter Studien, um die grossen Züge des Bildes zu erkennen.

Hinsichtlich der Hausthiere und derjenigen, welche den Menschen nicht fliehen, kann die direkte eigene Beobachtung genügen; aher in Betreff der wilden Thiere und solcher Arten, welche abgelegene Dertlichkeiten und Verstecke bewohnen, muss man Erkundigungen einziehen. Ebenso benutze man vorhandene naturhistorische Sammlungren, rorah die sueziell zoologischen Museen, sowie die Llärkte, auf welchen Jagdand Fischereiprodukte zum Verkauf gelangen. Eine Menge iützlicher Aufschlüsse kann man sich von Jägern und Fischern ierschaffen, in der Lnterhaltung mit denselben und durch Theilnahne an ihren Jagden und Zügen, wobei man nirht uur das Wild und die Wasserthiere beobachtet, welchen lieselben nachstellen, sondern auch diejenigen, welche sie erschmähen. Für die Beohachtung der niedern Thierwelt ienutze man jede Gelegenheit, auf Spaziergängen und Ausügen nach verschiedenen Punkten und Gegenden des Landes, m Meere wie im Innern, in der Ebene wie auf dem Gebirge, elbst in Höhlen, die man besucht. 
Erkundigungen hat man insbesondere auch einzuziehen hinsichtlich solcher Thierarten, die rur zu gewissen Jahreszeiten erscheinen, wie dies z. B. der Fall ist bei Wölfen und Bären, welche der Winter aus ihren Verstecken heraustreibt, bei Murmelthieren, welche nur im Sommer zum Vorschein kommen; bei Zugvögeln wie den Schwalben, Wanderfischen wie den Häringen, Insekten wie den Wanderschrecken, deren Invasionen mehr oder minder periodisch sind.

Die Vergleichung der Fauna einer Insel mit derjenigen des nahen Kontinentes oder der Faunen zweier durch eine Meerenge getrennter Gegenden wirft oft ein Licht auf frühere Verhältnisse, wie die vormalige Konfiguration des Landes. Die Aehnlichkeit derselben kann darthun, dass heute getrennte Erdtheile einst mit einander verbunden waren, und ihre Unterschiede können in manchen Fällen erkennen lassen, in welcher Epoche die Trennung stattfand.

In gleicher Weise kann durch sorgfältige Erforschung der Seen die Existenz früherer Meere oder Meeresverbindungen nachgewiesen werden. Ein paar Beispiele ${ }^{1}$ ): Wenn man im Baikalsee Robben trifft, so beweist dies, dass in der Vorzeit - und zwar in einer geologischen Periode, die nicht weit zurückliegen kann, sondern nahe an die geschichtliche Zeit heranreichen muss - an Stelle der heutigen Tundren und Steppen Sibiriens noch Meer war. Der Hauptfisch des Bodensees (der Felchen) lässt gewisse Rückschlüsse zu auf die Geschichte des Flusssystems, welchem der See angehört ${ }^{2}$ ). Marine Krustenthiere in der Tiefe des Gardasees, wie in schwedischen Süsswasserbecken, beweisen, dass diese Bassins früher Meerwasser enthielten ${ }^{3}$ ). Den überraschendsten Fall dieser Art haben die Untersuchungen von Louis Agassiz und Garman, sowie die neueren von Taxon ergeben, indem durch dieselben konstatirt wurde, dass die Krustenthiere des Titicacasees (3824 m über Meer!) einen ausgesprochenen marinen Charakter habe.

1) Lehrreiche Beispiele dieser Methode findet man vielfach in geologischen und thiergeographischen Werken, deren wir früber (S. 99) einige erwähnten: Heer, Wallace etc. Vgl. auch Rütimeyer, über die Herkunft unserer Thierwelt. Basel 1867.

2) Weismann, Thierleben des Bodensees 1876. Kollbrunner, thurgauische Fischfauna pag. 50 .

3) Solche Thiergesellschaften, welche als Ueberbleibsel und Zeugniss ver. gangener Zustände betrachtet werden müssen, sind (durch Leukart) als Reliktenfamen - und demgemäss dergleichen Seen als Reliktenseen - bezeichnet worden. 
Hinwieder sind in der Fauna einer Gegend solche Bestandtheile zu unterscheiden und anzugeben, welche derselben erst durch Einführung und Einschleppung (in neverer und neuester Zeit) zukamen, wie dies der Fall ist mit dem Dromedar in Nordafrika, den Ratten in der polynesischen Inselwelt u. s. w.

Distrikte und Stationen. Wie es botanische Zonen und Regrionen gillt, so zoolngische Distrikte und Stationen, d. h. Gebiete, welchen gewisse Thierarten nach ihren gewöhnlichen Aufenthaltsorten angehören und dadurch einen hestimmten zoologischen Charakter verleihen; nur besteht der Lnterschied, dass den freibewegrlichen Thieren nicht in der Weise wie den in ihrem Substrat wurzelnden Pflanzen ein so scharf bestimmter Standort eigen ist; immerhin haben auch die Thiere, da sie vorzugsweise die Orte aufsuchen müssen, wo sie am leichtesten und sichersten ihre Nahrung finden, ihre Aufenthalts-, Wohn- oder Standquartiere und sind sie insofern an gewisse Distrikte und Stationen gehunden: der Meeresstrand, die Kï̈stengegenden, sumpfige Niederungen, Höhlen, Hochthäler, die Schneeregionen der Gebirge, sie alle haben ihre Spezialfaunen, beherbergen je eine ihnen eigenthümliche Thierwelt.

Die Grenzen dieser zoologischen Bezirke und Stationen sind wesentlich durch die Bodenkonfiguration bestimmt und fallen zumeist mit physischen Linien zusammen. Man thut daher gut, zum Zwecke zoologischer Untersuchungen das Land in natürliche Gebiete einzutheilen und nun bei jedem einzelnen derselben zu erforschen, welches daselbst die Hauptrepräsentanten des Thierlebens seien: So hat man eine Fauna des Meeres, der Küste, des Littorals, eine Fauna der Ebenen, der Sümpfe und Moore, der Thäler, der Gebirge u. s. f., je wieder mit spezielleren Abtheilungen, in deren Unterscheidung man mehr oder minder weit gehen kann.

Nützliche Thiere. Unter den nützlichen Thieren sind in erster Linie die zähmbaren zu erwähmen, sodann diejenigen, welche durch Fleisch, Eier etc. den Eingebornen einen wesentlichen Theil ihrer Nahrung liefern; endlich solche, deren Häute, Felle, Bälge, Waffen (Hörner, Zähne), Haare, Federn u. s. w. Tausch- oder Ausfuhrartikel bilden oder zu solchen sich eignen. 
Mitunter wird zu prüfen sein, ob gewisse Thiere nicht dadurch nutzbar gemacht werden könnten, dass man dieselben in lebendem Zustande nach andern Ländern versendet oder dass man ihr Fleisch für die Ausfuhr präparirt. So sind z. B. ganze Heerden Strausse aus dem Innern Afrikas nach dem Kapland gebracht worden, wo man jetzt diese Thiere ihrer Federn und Eier wegen züchtet. Die Amerikaner ihrerseits haben reichen Gewinn zu ziehen gewusst aus den Fischen, welche in Menge nach dem Columbia- und Oregonfluss kommen; im Jahr 1875 haben sie 40 Millionen Pfund Lachs geliefert, wovon 16 Millionen bis nach England, Australien, Neuseeland und Südamerika versandt worden sind. Diese Ausfuhr repräsentirt einen Werth von 2,500,000 Dollars oder 121/2 Millionen Franken. In Südamerika wurden früher ungeheure Mengen von Hornvieh blos der Häute wegen geschlachtet, während das Fleisch den Geiern überlassen blieb, bis ein junger Hamburger Arzt, Dr. Giebert, auf die Idee kam, dieses Fleisch oder doch dessen Nährbestandtheile nutzbar zu machen. Nach Europa zurückgekehrt, sprach er hierüber mit dem berühmten Chemiker Liebig und begab sich dann wieder nach Uruguay, wo nun Fleischextraktfabriken die ehemaligen Saladeros oder Schlachtstätten ersetzen, welche früher die Luft verpesteten. Diese Erfindung ist seither allgemeiner angewendet worden in Ländern mit geringer Volkszahl und reichem Viehstand, und sie wird - weiter vervollkommnet, früher oder später dem zahlreichen Arbeiterstande Europas billiges Fleisch liefern, sodass die Verwirklichung der Idee des Dr. Giebert als eine wahre Wohlthat anzusehen ist.

Schädliche Thiere. Die Faunen vieler Länder enthalten Thiere, welche eine grosse Plage für Mensch und Vieh sind. So wurden anno 1876 in Englisch-Indien 21,391 Menschen und 48,234 Stück Vieh durch reissende Thiere und die Bisse von Schlangen getödtet. Im europäischen Russland erliegen den Wölfen Jahr für Jahr im Durchschnitt, nach offiziellen Erhebungen, 180,000 Stück Grossvieh, 560,000 Stück Kleinvieh und 125 Menschen. Aber nicht nur die reissenden Thiere und die Schlangen sind zu fürchten; eine Menge Thiere verursachen in anderer Weise grossen Schaden. Die Wildschweine durchwühlen das bebaute Land; Affen 
plündern die Getreidefelder; Termiten und Heuschrecken richten arge Verheerungen an. Die Tsetse-Fliege macht gewisse Gegenden des äıuatorialen Afrikas unbewohnbar für Nensch und Vieh. Die Kultivirung anderer tropischer Länder wird rerhindert oder erschwert durch die MIosquitos und Garrapatos (eine Art Motte oder Schabe), welche den Eingewanderten, die sich als Pionniere der Kultur dort ansiedeln wollen, keine Ruhe lassen. Die Ernten und selbst ganze Pflanzungen werden manchmal ruinirt durch Insekten ron unbedeutender Grüsse oder sogar mikroskopischer Kleinheit; es genügt, als Beispiele hiefür den Kolorado- oder Kartoffelkäfer (Doryphora decemlineata) und die Reblaus zu nennen.

Aenderungen der Fauna. $\mathrm{Zu}$ erforschen, welche Aenderungen eine Fauna erlitten haben kann, ist ron grossem Interesse.

Die Thierarten einer Insel, welche schon lange Zeit rom Kontinente getrennt sind, können sich wesentlich anders entwickelt haben als die analogen Arten des Festlandes. Thiere, welche bei Gründung von Kolonien oder Niederlassungen eingeführt und dam ganz oder theilweise sich selbst überlassen wurden, verwildern oft, $d$. h. sie kehren zu ihrem früheren Naturzustand zurück; es ist ron Werth, dass man sich Exemplare von solchen verschaffe oder doch wenigstens deren Skelette und Felle, damit hienach der Einfluss der veränderten Lebensweise studirt werden kann.

Die bisherigen Beobachtungen in den rerschiedensten Gegenden haben bekanntlich gezeigt, dass aus jedem Lande frühere Thierarten verschwunden sind, die man nun blos noch in fossilem Zustande findet. Weniger allgemein bekannt ist, dass man z. B. durch Erforschung der Tiefenfauna eines Sees öfters die letzten noch lebenden Ueberbleibsel-einer Fauna auffinden karm, welche früher in der Gegend unter anderen als deren jetzigen Naturverhältnissen lebte (marine Thiere - Fische, Mollusken etc. - in jetzigen Süsswasserbecken, vgl. S. 297 und 506).

Es gibt Thierarten, welche in einer Gegend erst verschwanden oder ausstarben, seitdem dieselbe von Menschen bewohnt und stets mehr kultivirt wurde, wovon Tradition oder Geschichte noch Kunde geben. Der Biber findet sich 
nicht mehr an den Ufern des Delaware, sowenig als der Löwe in Europa; aber am Delaware leben Leute, deren Ahnen - frühere Trapper und Squatters — dem Biber nachstellten, und Herodot erzählt uns, dass zu' Xerxes' Zeiten der Löwe in Macedonien vorkam.

Sehr viele Thiere ziehen sich zurück und verschwinden mehr und mehr in Folge zunehmender Entwaldung und Urbarisirung des Landes, welche ihr Wolngebiet stetsfort verkleinert. So ist jetzt der Löwe in Nordafrika sehr selten geworden; aus den Schweizeralpen ist der Steinbock fast ganz verschwunden, und der Gemse wird es mit der Zeit kaum besser ergehen. Gegen manche Thiere führt der Mensch einen unerbittlichen Vernichtungskampf. Den Büffel oder Bison Amerikas jagen die Rothhäute stetsfort; der Strauss wird überall verfolgt, wo er sich zeigt; alljährlich gehen den Gerbereien der Vereinigten Staaten 20,000 Alligatorhäute zu; fischreiche Seen und Flüsse werden entvölkert durch die Eingrebornen, welche die Gewässer vergiften. "Ueberall," sagt I'rofessor Rütimeyer ${ }^{1}$ ), „kann ein für Thiergeschichte aufmerksames Ohr den Ruf vernehmen: Ave Caesar, morituri te salutant!"

Der Reisende wird soweit immer möglich Indizien und Zeugnisse für das Vorhandensein einer ältern Fauna und positive Angaben über verschwundene oder im Verschwinden begriffene Arten sammeln $\left.{ }^{2}\right)$. Das allmälige Zurückgehen der

1) Ueber die Herkunft unserer Thierwelt. Eine zoogeographische Skizze. Basel und Genf 1867 , S. $46^{\circ}$.

2) Zu den Indizien für das einstige Vorkommen von Thier- und auch Pfianzenarten an Stellen, wo dieselben nun nicht mehr zu finden sind, gehören auch gewisse Lokalnamen: Bezeichnungen für Berge und Thäler, Wälder und Gewässer, sovie Flurnamen im engeren Sinne und auch Ortsnamen. So findet man die Namen Gemsberg und Thierberg oft in solehen Alpengegenden, wo jelzt keine Gemsen oder Thiere" mehr vorkommen; die Namen Wolfssehlucht, Hirschensprung u. dgl. in Gebieten, woraus die Wülfe und Hirsche verschwunden sind; Bibern, Biberach, Krebsbach für Gewiisser, an und in welchen keine Biber und Krebse mehr vorkommen. Aus alten $\mathbf{J}$ agd- und Fischereivorsehriften lässt sich in solchen Fällen oft beweisen, dass die fraglichen Thiere vor verhältnissmässig kurzer 7eit noeh in der Gegend lebten und um welehe Zcit sie verschwanden. Man achte desshalb auf dergleichen Namen. Mitunter sind dieselben nicht mehr leicht kenntlich; es ist ihre ursprüngliche Bedeutung dem Volksbewusstsein verloren gegangen und dessweger der Name - oft einer irrigen Auslegung wegen - verändert worden. So gibt es im deutschen Sprachgebiete Ortschafts- und Flurnamen, die jetzt geschrieben werden, als wären sie von "Wiese" abgeleitet, während sic auf das einstige Vorkommen des Wisent (Auerochsen) in jener Gegend zurückgeführt werden können und mïssen (Wiesendangen bei Winterthur, Wiesensteig bei Ulm, Wiesenthau bei Forchheim: Wisentwangen, Wisentsteig, Wisent-Au.) Vgl. W. Wackernagel, über den Ursprung und die Entwicklung der Sprache. Basel 1872. S. 50. Oft sini solche xamen zugleich von Thieren und Pflanzen hergenommen, ist aber ihr einer 
letzteren stellt man auf einer Karte der Gegend in anschanlicher Weise dar, indem man durch verschiedene Farbeu angibt, welches Areal eine bestimmte Species zu verschiedenen Zeiten einnahm.

Ansichten und Beschreibung der Thierwelt. Zur bildlichen Darstellung der Fauna eines Landes lässt sich die I'hotographie nicht so leicht anwenden wie hei der Pflanzenwelt: indessen ist es doch möglich, durch Augenhlicksaufnahmen Srenen des Thirlebens darzustellen, wie sich deren darbieten am Meeresstrande mit dessen Heerden ron Seevögeln, in Waldlichtungen mit weidenden (äsenden) und ruhenden Thieren, welche den Jäger noch nicht wahrgenommen haben oder noch nicht fürchten, fprner in der Nähe ron Städten und Dörfern mit den ab- und zugehenden Lastthieren für Personen- und Waarentransport, sowie mit dem Vieh, welches zur Feldarbeit, zur Tränke, auf die Weide geführt und getrieben wird oder nach den Ställen zurïckkehrt. Für die Darstellung von Jaydlizent'n muss man nothmendig zum Zeichnen nach dem Gedächtniss, der Erinnerung Zuflucht nehmen. Eine Nachhülfe ist es, wenn man dem erlegten Thier momentan eine gewolnte, an demsellien beobachtete Stellung gibt. Handelt es sich dabei um ein wenig bekanntes Thier, so nelme man, bevor man es enthäutet oder ausweidet, eine Photographie desselben auf, nachdem man ihm zuvor so gut als immer möglich eine natürliche Haltung gegeben, oder man zeichne dasselbe nach dem Gedächtniss in den verschiedenen Stellungen, die man an demselben in der Natur beobachtet hat. Solche Plotofrophien und Zeichnumen ermöglichen dem Präparator, welcher das Fell oder den Balg des Thieres für ein Nuseum ausstopft und herrichtet, demselben eine natürliche Haltung zu geben, statt daraus eine Karrikatur zu machen. Es gibt übrigens öfters Thiere, die so wenig scheu sind, dass man sich gute Photographien derselhen rerschaffen kam, sei es dass man sie in Grupuen oder aber in Einzcllildern aufnehme.

oder anderer Bestandtheil nicht sofort ohne Weiteres verständlich, z. B. „Bärentroos" für eine Alp, auf welcher früher Bären hausten und ein dichter Buschwald von "Troos" (Alpenerlen, Alnus viridis) bestand, wähend jetzt daselbst weder Bären noch Alpenerlen mehr vorkommen. Analoge Fälle finden sich in andern Sprachgebleten. 
Bei diesen Thierbildern ist auch auf eine angemessene Umgebung oder Gesctmmtszcnerie Rücksicht zu nehmen. Wenn es nicht möglich sein sollte, das Thier in seinem Medium oder einer seinen Lebensverhältnissen und Gewohnheiten entsprechenden Umgebung zu photographiren und zu zeichnen, so wird man diese erste Darstellung später nach der bezeichneten Seite ergänzen, d. h. nach derselben ein Bild anfertigen, auf welchem das Thier in einer seiner spezifischen Eigenthümlichkeiten angemessenen Umgebung erscheint.

Was die Darstellung in Worten anbetrifft, so beschränke man sie nicht auf eine blosse Beschreibung der körperlichen (somatologischen) Verhältnisse, die immer mehr oder minder trocken und dürftig bleiben wird, sondern gebe nach eigenen Beobachtungen oder glaubwürdigen Berichten auch Aufschluss über die Lebensweise des Thieres, Jagd und Fan!, Zähmung, sowie die Veruerthung der Produlite and Theile desselben. Solche Mittheilungen sind immer ron grossem Interesse; nur hüte man sich, in dieselben ohne Vorbehalt solche Angaben aufzunehmen, die sich bei genauerem Nachforschen als unrichtig herausstellen, d. h. man lasse sich bei der Darstellung nicht sowohl durch die „Merkwürdigkeit“ als durch die Zuverlässigkeit der berichteten Details leiten; andernfalls wird dieselbe zwar eine anziehende Lektüre, aber ohne wissenschaftlichen Werth sein.

Zoologische Sammlungen. Wir theilen auch hierüber mit gefälliger Erlaubniss des Autors die kurzen Instruktionen mit, welche Milne Edwards in den "Archives des missions scientifiques et littéraires" (T. IV, 1877) gegeben hat. Könnte doch dieser Gegenstand kaum von einer kompetenteren Feder als der seinigen behandelt werden.

$1^{\circ}$ Höchst wichtig ist bei allen naturhistorischen Sammlungen das Etiquettiren aler Exemplare: jedem derselben muss in einer vor Verschiebung oder Verwechslung gesicherten Weise eine genaue Angabe des Fundortes beigegeben sein; die von verschiedenen Lokalitäten stammenden Exemplare dürfen nicht vermengt werden, und es sollen Notizen vorhanden sein über den Hauptcharakter der Fundstelle, z. B. für Wasserthiere darüber, ob sie im Meere, in Brack- oder Süsswasser rorkommen, in welcher Tiefe, und von welcher Beschaffenheit der Grund des Gewässer's ist, worin sie leben; für 
Landthiere darüber, ob sie auf Wiesen, im Walde, an Felsen etc. laben, beziehungsweise gesammelt wurden, und in welcher Ilöhe.

Grosse Sorgfalt ist ferner dem Verpactien der Sammlun!cu zu widmen. In d’n Kisten düufen keine leeren Räume hleiben, wobei die naturhistorischen Objekte oder die Schachtoln und sonstigen Gefässe, in welchen dieselhen sich befinden, hin- und herbewegt, gerüttelt und gerollt werden künnten. Jeder Zwischemraum, den die Objekte und Gefäse lassen, muss mit Papier, Heu, Tangen u. dgl. Material ausgefüllt werden. Kleie, Sägmehl, Sand und ähnliche Stoffe, welche leicht eine Verschiebung ihrer Theile erleiden, eignen sich zu diesem Zwecke nicht; die Gegenstände in denselben grathen in Folge der Stösse und Frschütterungen, welchen die Kisten heim Transport ausgesetzt sind, nach und nach tiefer hinab, his auf den Boden derselben, sind nun ganz ungleichmässig angeordnet und beschädigen einander. Das Verpacken gewisser Sammlungen erheischt spezielle Vorsichtsmassregeln, die wir später besprechen.

2" Unter den zoologischen Sammlungen sind diejenigen ron Conchylien und Inseliten am leichtesten anzulegen und zu konserviren.

Was die Conchulien betrifft, so hat man, wenn die Schalen noch von den Thieren (Mollustien) besetzt sind, welchen sie angehören, zuvörderst diese aus dem Gehäuse zu entfernen; man zieht das Weichthier mit einer grossen Narkel, einem Seziroder Federmesser heraus, wascht die Schale und verpackt sie so, dass keine Reibung an andern Gegenständen stattfinden kann. Sehr zerbrechliche Schalen müssen sorgfältig mit Baumwolle (Watte) oder einem ähnlichen Stoff umhüllt und in einer Schachtel oder in I'apier gesöndert verpackt werden. Die Gehäuse von Landmollusken, selbst die scheinbar unbedeutendsten, wie diejenigen der gewöhnlichen Schneckenirten, sollen ebenso gut gesammelt werden als diejenigen ler Schalthiere des Süsswassers und des Meeres. Bei den 'weischaligen Weichthieren (Bivalven, Muscheln) soll das schloss oder Charnier intakt erhalten bleiben, und bei den inschaligen (Univalven, Schnecken) ist der Deckel des Gelïuses beizufügen, wenn dieses einer solchen Molluskenspecies 'ngehört, deren Fuss mit einer Scheibe rersehen ist, womit 
das Thier die Schalenöffnung, den Eingang seines Wohnhauses, verschliessen kann, wie dies bei vielen Gasteropoden des Meeres der Fall ist.

Hat der Reisende Weingeist zur Verfügung, so soll er darin einige Exemplare ron jeder gefundenen Molluskenart aufbewahren. Tor dem Einlegen derselben in den Weingeist sind deren Schalen zu zerbrechen, damit die Flüssigkeit zu dem Körper des Thieres von allen Seiten Zutritt hat und auf alle Theile desselben wirken kann. In Ermanglung von Weingeist oder anderer alkoholreicher Spirituosen kann man gewöhnlichen Branntwein mit einem Zusatz ron $6-7 \mathrm{Gramm}$ Borsäure auf den Liter benutzen oder eine Salzlösung ron folgender Zusammensetzung:

1 Liter Regenwasser,

115 Gramm Kochsalz,

$60 \rightarrow$ Alaun,

12 Centigramm Aetzsublimat.

$3^{\circ}$ Die Landmollusken (Landschnecken wie die Schnirkelschnecken, Wegschnecken etc.) kommen gewöhnlich an feuchten und schattigen Orten ror, in Moos, am Fuss der Bäume und Sträucher, unter dürrem Laub und Steinen, in Felsspalten und an altem Gemäuer. Es sind meistens Nachtund Dämmerungsthiere; die Testacellen (welche den nakten Weg- und Ackerschnecken gleichen, aber auf dem hintern Theil ihres Körpers eine kleine Schale haben) leben unterirdisch.

Die Süsswassermollusken finden sich zumeist in Quellen, Pfützen und Teichen; einige wie die Tellerschnecken (Planorbis, deren Schale scheibenförmig flach ist) lieben schlammige Gräben; andere kommen in Thermen, selbst in den heissesten, ror; endlich gibt es solche, welche ebensowohl in grossen Flüssen und Strömen als in Seen und Bächen leben, z. B. ron Zweischalern (Bivalven) die Unionen oder sogenamnten Flussmuscheln und Anodonten oder Entemmuscheln, deren Varietäten ungemein zahlreich und für die Zoologen sehr interessant sind. Die Land- und Flussmollusken hat mar nicht nur an und unter den Wasserpflanzen aufzusuchen, an und auf welchen sie herumzukriechen lieben, sondem auch am und im Boden des Gewässers, auf und unter den Steinen in demselben, wie an dessen Rande. 
Zum Fange dieser verschiedenen Weichthiere wendet man sogenannte Küscher oder Kötscher an (Fig. 220), Instru-

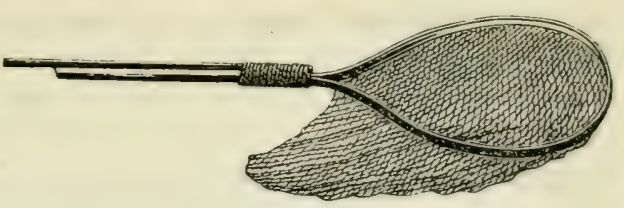

Fig. 220 . mente, die bestehen aus einer Art Sack, dessen Rand oder Saum an einem ovalen Gestell und mit diesem an einem langen Stock befestigt ist. Wenn der Reisende diese Fischereigeräthe nicht besitzt, so kann er sie selhst anfertigen; den Sack erstellt man aus Packleinwand oder irgend einem lockeren (maschigen) Gewebe, das Gestell aus einem ziemlich kräftigen Streifen oder Zweige grünen biegsamen Holzes, indem man dasselbe in die Form eines Reifes bringt und dessen beide Enden mit einer Schnur zusammenbindet.

Meeresconchylien, welche ron den Wellen an den Strand geworfen werden, findet man oft so gut erhalten, dass sie für den Sammler geeignet sind; im Allgemeinen ist es aber besser, wenn man die Schalen in ganz frischem Zustande hekommen kann, und zu diesem Zwecke muss man die Weichthiere, welchen sie angehören, lebend zu erlangen suchen. Nanche derselben, namentlich IIuscheln, halten sich im Sand und Schlamm auf; diese muss man zur Ebbezeit ausgraben, wozu Instrumente wie Spaten und Schaufel oder Schippe zu benutzen sind; andere kriechen auf den Felsen und Steinen herum, welche zur Ebbezeit ausser Wasser kommen; wenn man in den Lachen, welche sich bei dem Zurückziehen les Neeres bilden, grosse Steine trifft, deren Basis nicht in jand begraben ist, so thut man gut, dieselben umzuwenden: lenn fast immer findet man hiebei an ihrer untern Fläche Iollusken und andere für den Naturforscher interessante Thiere.

Gewisse Schalthiere leben in mehr oder minder tiefen üchern, welche sie in die Felsen graben (Bohrmuscheln, 'etricola, Saxicava, Lithodomus etc.): um sie zu bekommen, usss man das Gestein mit dem Hammer zerschlagen. Die fahlmuschel (Teredo, Schiffshohrwurm) greift in ähnlicher Teise das im Wasser befindliche $\mathrm{Holz}$ an, in welchem sie unge Kalkröhren von oft heträchtlicher Lä̈nge haut: wemn 
man solche Thiere ${ }^{1}$ ) entdeckt, so versäume man nicht, Exemplare derselben $\mathrm{zu}$ sammeln; dabei ist $\mathrm{zu}$ empfehlen, dass man sie in dem Holze lasse, welches sie bewohnen.

In den Meeren der heissen Zone kommen oft in geringem Abstand von der Küste Korallenriffe vor, die zeitweise in so geringer Tiefe unter der Wasseroberfläche sich befinden, dass man dieselben begehen kann und sich dabei nur etwa bis an die Knie im Wasser befindet. Diese Stellen sind namentlich reich an Mollusken, aber auch an anderen höchst interessanten und für Sammlungen erwünschten Thieren, wie Meerwürmern, Seeigeln, Seeanemonen (Aktinien) und Polypen, von welchen wir noch sprechen werden. Wenn man mit dem Hammer einzelne Theile dieser Korallenbänke zerschlägt, so findet man in deren Zwischenräumen eine Menge dieser verschiedenen Thierarten.

Um sich Mollusken zu rerschaffen, welche in grösseren Tiefen leben, muss man zumeist Fischereigeräthe anwenden wie das Scharrnetz (die Dredge), Quastenschlepper und Schwebnetze.

Das Scharv- oder Schleppnetz' (Dredge, Dredsche) besteht aus einem eisernen Rahmen in Form eines Kästchens, der als eine Art Krücke oder Rechen dient, und einem daran befindlichen sackförmigen Netz nebst einem langen Seil oder Tau, womit man den Apparat auf den Boden des Gewässers hinablässt und ihn sodann längs desselben hinzieht, damit das Scharrnetz den Boden aufkratzt, abräumt und die Objekte in sich aufnimmt, welche auf seinem Wege vorkommen. Das Instrument soll beim Hinunterlassen zufolge seiner Konstruktion eine solche Lage annehmen, dass der als Rechen dienende Rahmen mit einer Breit- resp. Langseite auf den Boden zu liegen kommt; um es nun in Funktion zu setzen, muss das Boot, woran es befestigt ist, sich langsam vorwärts bewegen. Mit solchen Schleppnetzen wird von den Fischern gewöhnlich der Austernfang betrieben.

Diese Apparate kommen in verschiedenen Konstruktionen vor; diejenige, welche unsere Zeichnung (Fig. 221) darstellt, wird namentlich von den amerikanischen Naturforschern

1) Die Pholaden oder Bohrmuscheln in engerem Sinn (Pholas L.) bewohnen in solcher Weise sowohl Steine als Holz. 
empfohlen, welche dieselbe bei ihren Seetiefenforschungen sehr häufig anwenden.

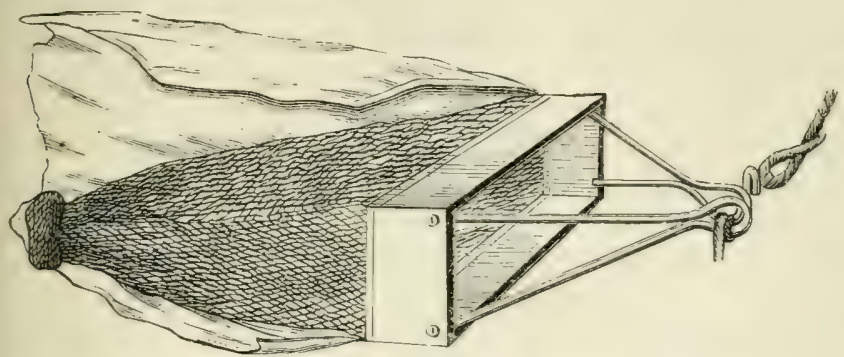

Iig. 221.

Diese Dredsche enthält $1^{\circ}$ einen Eisenrahmen, der an seinem hintern Rand mit einer Reihe kleiner Oeffnungen, am vordern Rand aber mit zwei Henkeln versehen ist, die einestheils nach dem Innern des Apparates hin zurückgelegt, anderntheils in der Weise, wie die Figur zeigt, rereinigt und an einem Seil (Zugtau) befestigt werden kömnen; $2^{\circ}$ ein engmaschiges Sacknetz, das mit seinem Vorderrand (Saum) an dem Eisenrahmen befestigt, am hintern Ende geschlossen ist, letzteres durch Zubinden mit einer starken Schnur in der Weise, dass es unschwer wieder geöffnet und dadurch entleert werden kann.

Wenn der Boden, auf welchem man dredscht, uneben ist, so placirt man das Netz in einen zweiten Sack aus grober Leinwand, der am Grunde offen (ohne Boden) sein muss, damit er das Wasser durchlässt (in der Figur ist ron diesem Sack nur die eine — hintere — Längshälfte dargestellt, damit das Netz in demselben sichtbar bleibt). Der eine Henkel wird an die Zugleine gut befestigt, an den andern aber nur mit einer dünnen Schnur, die unschwer zerrissen werden kamn; denn oft trifft der Rahmen des Scharmetzes so auf Steine, dass er nicht mehr losgemacht werden könnte, wenn beide Henkel unter sich und mit dem Seil in fester Verbindung wären; der Apparat ginge verloren; so aber kann in derartigen Fällen durch einen raschen Ruck an der Zugleine die schwache Schnur zerrissen und der Rahmen, welcher nun nur an einem Henkel gezogen wird, losgeschnellt werden. 
$\mathrm{Zu}$ bemerken ist noch, dass der Apparat um so grösser sein muss, je bedeutender die Tiefe ist, in welcher man dredschen will, und dass die Länge des Zugtaus doppelt so gross sein muss als diese Tiefe, wenn das Instrument eine passende Lage haben soll.

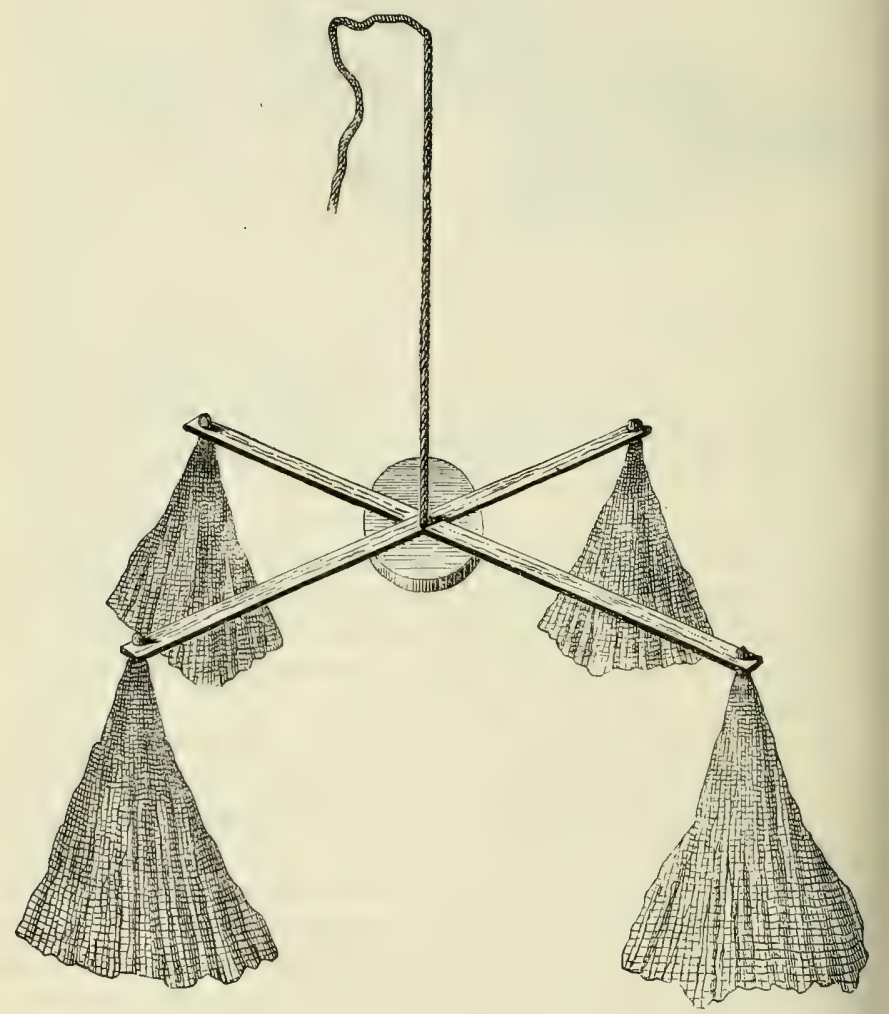

Fig. 222.

Auf felsigem Grund lässt sich kaum oder gar nicht dredschen; hier aber leistet der Quastenschlepper (salabre) gute Dienste, welches in vorstehender Zeichnung (Fig. 2:D) dargestellte Instrument seit undenklichen Zeiten von den Korallenfischern angewendet wird. Es besteht aus einem hölzernen oder eisernen Kreuz, das an einem langen Tau befestigt, mit 
einem Stein beschwert ist und an seinen Armen Quasten trägt aus Schnüren und Fäden, die nur unvollkommen zusammengedreht, daher zottig-gefranst sind, so dass in diesem faserigen Maschenwerk die Objekte, auf welche es trifft, leicht längen bleiben. Man lässt den Apparat auf den Grund des Wassers hinab, hebt iln dann ein wenig und lässt ihn wieder sinken; dies setzt man eine Zeit lang so fort; jedesmal nun, wenn das Instrument hinuntergesenkt wird, gehen die Fäden und Zasern auseinander und breiten sie sich am Boden aus; sowie man aber den Apparat emporheht, streichen sie über den betreffenden Theil des Meereshodens hin wie ein Besen oder Wischer und bringen num in ihrem Faserwerk eine Menge ron Thieren, wie Mollusken, Seeigrel, Polypen und Schwämme herauf ${ }^{1}$ ). Man wendet diese Vorrichtung auch an, um sich Objekte zu verschaffen, welche an den Seiten untermeerischer Felsen sitzen; um aber hiebei den Apparat gut zu handhaben, muss man darin schon geüht sein, während die Anwendung desselben unter gewöhnlichen Verhältnissen auf den ersten Versuch gelingt.

Um die ganz kleinen schwimmenden Weiclithiere zu fangen, welche sich bei ruhigem Meer nahe an der Oberfäche des Wassers herumtreiben, wendet man ein lilrines srfurelmetz an, das a us einem Reif und groher Musseline oder einem andern ähnlichen Gewehe besteht, welches wie ein Sieb das Wasser durchlässt, aher die darin befindlichen Thierchen zurückhält. Dieses Instrument eignet sich auch zum Fange der kleinen pelagischen Crustaceen, welche in Weingeist aufbewahrt werden müssen.

Cebrigens können alle in der zu erforschenden Gegend ron den Fischern angewendeter Fangmethoden gute Dienste leisten. Auch ist dem Reisenden zu empfehlen, dass er mitunter die Fischer begleite, un die Ohjekte einzuheimsen, welche dieselben in ihren Netzen finden, aber vernachlässigen, weil es keine Verbrauchsartikel sind.

Die grossen Cephalopoden (Kopffüssler - Weichthiere, deren liopf Fangarme orler Tentakeln trägt, die als Be-

1) Die Seeigel tragen Kalkstäbchen oder Stacheln, die oft sehr lang sind; die Verpackung derselben, wie auch diejenige anderer Strahlthiere (der Seesterne) muss mit grosser Sorgfalt erfolgen. Jedes Exemplar ist zunächst mit Watte zu umbiillen und dann erst in Leinwand oler I'apier einzuwickeln; denn diese Objekte sind ungemein zerbrechlich. Die baumartigen Gorgonen oder biegsamen Hornkorallen und die Schwïmme werden getrocknet oder in Weingeist aufbewahrt. 
wegungsorgane dienen) wie z. B. die achtfüssigen Seepolypen, die zehnfüssigen Tintenfische und Kalmars, sind entweder in Spiritus oder in der erwähnten Salzlösung aufzubewahren.

$4^{\circ}$ Die Krabben, Hummer, Langusten und andere Thiere, welche von den Zoologen als Crustaceen bezeichnet werden, finden sich an denselben Lokalitäten wie die Mollusken, von denen wir eben gesprochen haben, und sie können nach den gleichen Nethoden gefangen, aber in anderer Weise konservirt werden. Ist die harte Schale oder Kruste, welche bei diesen Thieren die Haut vertritt, dick, so braucht man nur die äusserı harten Theile langsam trocknen zu lassen, nachdem man die innern weichen Theile (Fleisch und Eingeweide) herausgenommen hat; letzteres aber geschieht in der Weise, dass man die Rückenplatte, welche dem Thiere als Schild oder Panzer dient, an ihrem Vorderrande aufhebt und nun mit einem Messer die darunter befindlichen Weichtheile entfernt. Die Kruster können auch in Kochsalz oder Weingeist aufbewahrt werden, nicht aber in der oben erwähnten Salzlösung; denn drese würde den Hartgeweben einen Theil ihrer lialkigen Stoffe entriehen und dieselben zu weich machen. Die Füsse und sonstigen Glieder oder Anhängsel der Krustenthiere sind sehr zerbrechlich; daher muss man sie vor dem Trocknen durch Anlegen an den Rumpf des Thieres in eine geschützte Lage bringen ; zudem ist jedes getrocknete Exemplar einzeln in Leinwand oder Papier zu verpacken.

Wo Süsswasserkrebse, Landkrabben und dergleichen Thiere vorkommen, sind dieselben nicht minder sorgfältig zu sammeln und aufzubewahren.

$5^{\circ}$ Die Zooplyyten oder Pflanzenthiere (Echinodermen und Colenteraten; Thiere, welche durch ihre Bildungsweise Pflanzen gleichen; auch als Strahlthiere oder Radiaten bezeichnet) müssen getrocknet werden, wenn sie ron steiniger Konsistenz sind wie die meisten Stachelhäuter (Seeigel, Seesterne) und Steinkorallen (Madreporen); wenn sie aber weich sind wie die Seewalzen oder Holothurien (zu denen die Thierart gehört, welche die Chinesen Trepang nennen), so hat man dieselben in Alkohol oder der öfter's genannten Salzlösung zu konserviren; für kleine Arten von sehr zarter Substanz verwendet man mit Vortheil Glycerin. 
Allverbreitet, selbst im Sand und in den schlammigen Ablagerungen am Strande und auf dem Boden des Meeres, sind kleine Organismen, die rom unbewaffneten Auge nicht mehr unterschieden werden können, deren Studium durch das Mikroskop aber unerlässlich ist zur Lösung verschiedener wissenschaftlicher Fragen von holrem Interesse. Es sollen desshalb I'roben dieser Ablagerungen, welche ein wesentlicher Bestandtheil submarinen Bodens sind, genommen und den zoologischen Sammlungen beigefügt werden.

$6^{\circ}$ Die Inseliten oder Kerbthiere (Kerfe, Sechsfüssler) sind in allen Ländern reichlich vertreten. Ihr Fang ist leicht und macht nur wenige Instrumente nothwendig. Das beste Verfahren, um diese Thiere in Menge zu fangen, besteht darin, dass man mit einem Käscher - Fang- oder Streifsack, der an einem eisernen Ring und durch diesen an einen langen Stock befestigt ist - rasch über die Pflanzen der Fluren, Wiesen und Waldlichtungen hin- und herfährt. Indem man das Instrument ähnlich wie der Mäher seine Sense, jedoch abwechselnd nach links und rechts bewegt, gelangen die Insekten, welche der so gehandhabte Sack trifft, auf den Grund desselben und wird auch den schnellsten das Entkommen aus demselben unmöglich gemacht. Nach beendigtem Fange nimmt man die Thiere Stück für Stück — von Hand oder mit einer Pincette - aus dem Sack heraus und spiesst sie an Nadeln, welche der Grösse des Thieres angepasst sein müssen, auf. Bei Käfern oder Coleopteren, deren Vorderflüigel oder Decken (elytra) hart und fest sind, wird die Nadel durch die rechte Flügeldecke orler Flügelscheide durchgestossen, bei den Zweiflüglern (Dipteren, Fliegen), Haut- oder Aderflüglern (Hymenopteren, Immen) und den Schmetterlingen oder Faltern (Lepidopteren) durch die Nitte des Bruststücks, bei den Gradflüglern oder Helmkerfen (Orthopteren: Heuschrecken, Grillen u. dgl.) und den Netz- oder Gitterflïglern (Neuropteren: Libellen und ähnlichen Insekten mit zartem Kïrper und durchsichtigen Flügeln, deren "Nerven" ein Gitternetz gleich feinem Spitzenwerk bilden) etwas hinter dem Brusttheil, mitten zwischen den Ansatzstellen der Flügel hindurch.

Hinsichtlich der kleineren Insekten ist das Aufspiessen weniger geeignet; sofern dieselben, wie die Kï̈fer und die 
meisten Halbflügler oder Schnabelkerfe (Hemipteren: Wanzen, Zirpen u. dgl.), von genügend starker Konsistenz sind, bewahrt man sie einfach in kleinen mit Papierspänen oder Watte gefüllten Schachteln und Fläschchen auf. Diese Methode ist auch auf grosse Exemplare anwendbar und namentlich für den Fall zu empfehlen, dass man zum sorgfältigen Aufspiessen der erbeuteten Thiere nicht Zeit hat. Auch zum Aufbewahren der Schmetterlinge braucht man sich nicht nothwendig der Tadeln zu bedienen: eine der besten Methoden, welche dem Reisenden für das Konserviren solcher Thiere empfohlen werden kann, besteht darin, einfach jedes Exemplar derselben mit ausgespannten Flügeln in ein Stück Papier einzuschliessen, welches einmal zusammengelegt und an den Rändern umgeschlagen wird, wie man dies in den Samenhandlungen und Apotheken beim Verpacken kleiner Portionen mancher Früchte, Samen und Pulver macht. Kleine Insekten aber, deren Tegument weich ist, legt man in Spiritus; denn durch das Austrocknen werden sie oft bis zur Unkenntlichkeit relunstaltet. In Weingeist sind ferner aufzubewahren die Raupen und andere Larven, sowie - behufs anatomischer Untersuchungen - eine Anzahl solcher Insekten, von denen man bereits getrocknete Exemplare besitzt.

Die Schmetterlinge fängt man mit dem Hamen, einem ähnlichen Instrument wie der Käscher, nur dass der Sack durch ein Netz aus feinerem Stoffe (Gaze) ersetzt ist. Diese Insekten finden sich namentlich auf blumenreichen Fluren und an Waldrändern; man muss sie aber auch an dunkeln Orten aufsuchen, da die Nacht- und Dämmerungsfalter sich am Tage an solchen Stellen (an Mauern, Baumstämmen u.s.f.) rersteckt halten. Bei einiger Gewand theit kann man die Thiere da spiessen, ohne sie rorher zu ergreifen; fürchtet man aber, dass dies nicht gelinge, so deckt man sie zuerst mit dem Schmetterlingsnetz und sticht dann die Nadel durch dessen Jaschen hindurch. Bei ruhiger Luft und dunkler Nacht bedient man sich mit Vortheil der Fackeln; eine einzige Flamme an einer tiefen und freigelegenen Stelle zieht eine Nenge Phalänen und andere nächtliche Kerbthiere an. Sehr zu empfehlen ist es auch, dass man Raupen sammle, diese mit Blättern der Pflanze, auf welcher man sie fand, füttere, bis der Schmetterling ausschlüpft, und den letzteren nun 
- also unmittelbar nach vollendeter Metamorphose spipsse. Es ist das die beste Art, sich recht schöne Exemplare ron Faltern zu rerschaffen; denn die Exemplare, welche man im Freien (im Fluge) fängt, sind selten mehr ganz frisch.

Hinsichtlich der Käfer genügt es nicht, in der oben beschriebenen Weise Krautpflanzen und Büsche abzusuchen, über die ersteren mit dem Netz hinzustreifen und die letzteren zu schütteln; man muss diese Kerfe auch unter Baumrinden und Steinen, in Pilzen und selbst im Boden suchen. Zu diesem Zweck benutzt man ein Instrument, welches dem Stemmeisen der Schreiner gleicht, aber etwas gehogen ist und in einem zugespitzten Spatel endigt.

Die Wasserinsekten füngt man mit einem ähnlichen Apluarat wie die übrigen; nur dass der Sack oder die Tasche desselben aus grobmaschigen Gewebe (Stramin) statt dichteren Stoffes bestehen muss. Zum Fange der Wespen, Bienen und anderer Hymenopteren, deren Stich oft zu fürchten ist, bedient man sich eines Schlagnetzes aus Tüll oder Drahtgeflecht.

Die Konservirung der aufgespiessten Insekten erfordert einige Sorgfalt. Um zu verhindern, dass die Schmetterlinge durch Zappeln sich beschädigen, kamm man ihnen gleich nach dem Fange den Thorax unten zusammendrücken; im Allgemeinen muss man aber alle gefangenen Insekten gleich nach Beendigung der Jagd und Rückkehr von derselben rasch tödten; das beste Verfahren ist das, dass man die Thiere in ein ron siedendem Wasser ungebenes truclemes Gefäss bringt; eine hohe Temperatur tödtet dieselhen in einigen Minuten. Wenn man sie in eine Flasche tringt, die etwas Aether enthält, sterben sie ebenfalls hald. Die Schachteln zur Aufnahme der entomologischen Sammlungen müssen aus weichem, leichtem Holz verfertigt und mindestens $7 \mathrm{~cm}$ tief sein; auf dem Boden derselben bringt man Korktafeln oder Platten aus einer ähnlichen weichen P'flanzensul,stanz an, in welche man die Insektennarleln möglichst tief hineinsteckt. Bei grossen Kerbthieren muss man rings um dieselben Nadeln anbringen, damit sie in ihrer Stellung fest bleiben: denn wem ein Exemplar abfällt, so verdirbt es sich und die andern, welche mit ihm zusammen eingepackt sind. Sohald eine Schachtel roll ist und die Insekten trocken genug sind, so rerschliesst man 
dieselbe und rerklebt alle Fugen mit Papierstreifen. In heissen Ländern, wo zerstörende Insekten in Menge vorkommen, genügt dies nicht einmal; viehmehr wird es mitunter nöthig, diese Schachteln noch in Blechkistchen einzuschliessen, welche man nachher ringsum verlöthet. Hiezu können alte Sardinen- oder Appert'sche Konservenbüchsen verwendet werden.

Die Srmmen und andern Thiere derselben Klasse (Arachniden) sind weniger zahlreich als die Insekten, verdienen aber ebenfalls Beachtung und Aufmerksamkeit ab Seite der Reisenden. Gewisse Arten leben im Wasser; die meisten aber sind Landthiere und halten sich an Gebüschen oder in Löchern alter Mauern sowie auch des Bodens auf. Der Kunsttrieb, welchen manche Spinnen in der Konstruktion ihrer Wohnungen oder ihrer Netze zum Fang anderer Thiere zeigen, erregt die Bewunderung des Beobachters; sehr merkwürdige Nester haben z. B. die Mauer- oder Minirspinnen; es sind cylindrische in die Erde oder in Rinden gegrabene Höhlen, an deren Eingang sich eine Art Fallthür befindet: ein mit Charnier versehener Deckel ähnlich einem Bierkannendeckel, der beim Oeffnen zurückgeschlagen wird. $\mathrm{Zu}$ erwähmen sind die giftigen Spinnen und die parasitischen Arten dieser Klasse.

Das Konserviren der Spinnenthiere ist etwas schwierig: heim Trocknen rerlieren sie ihre Form und im Alkohol die Farbe; man muss daher so viel als möglich Exemplare derselben Species auf beide Arten aufbewahren, wobei dieselben so zu numeriren sind, dass sie mit Sicherheit identifizirt werden können.

$7^{\circ}$ Die Fische des süssen Wassers sind nicht nur verschieden nach den einzelnen Ländern, sondern selbst nach den einzelnen Flüssen und Seen, worin sie leben. Daher ist es sehr wichtig, deren möglichst viele $\mathrm{zu}$ sammeln.

Unter den Meerfischen gibt es weitverbreitete Arten, welche aus verschiedenen ron einander: entfernten Gewässern in den nämlichen Formen bekannt sind; aber die meisten sind doch gewissen Gegenden, Buchten und Küstengewässern eigenthümlich. Man sammle daher Exemplare der Fische ron Gegenden, die naturhistorisch noch nicht genügend 
erforscht sind, selbst von den Arten, welche auf den Märkten feil geboten werden.

Die Fische sind in Spiritus oder in Branntwein mit Borsäurelösung aufzuhewahren; danit diese Flüssiggeiten leicht ins Innere der Thiere dringen, macht man auf ihrer Bauchseite, an der Mittellinie, einen kleinen Schnitt. Sehr zu empfehlen ist auch, dass man jedes Expmplar mit Leinwand, Heu oder einem andern passenden Stoff umlülle, damit dieselben sich nicht an einander reihen. Wenn die Exemplare zu gross sind als dass man sie in dieser Weise auflewahren könnte, so heschränkt man sich darauf, ihre Haut abzuziehen und zu trocknen, wohei immerhin dafür Sorge zu tragen ist, dass Kolf, Zälne und Flossen gat erhalten bleilen. Die Flossen müssen heim Trocknen ausgespannt sein: zu diesem Zwecke kleht man sie auf Iapier oder man hält ihre Strahlen dadurch auseinander, dass man die letzteren einzeln an Fäden befestigt.

Die Rrytilien werden ebenfalls in Branntwein gelegt, soweit ihre Grösse das ermöglicht: wenn sie aber hiefür zu gross sind, so nimmt man die Haut derselhen und leyt diese in Branntwein, was besser ist als das Trocknen dersellen.

Die Schildkrüten werden für das Konserviren zucerichtet durch rorheriges Wegschneiden des Bauchschildes oder Brustbeines: mittels einer Säge lüst man dieses (das sternum) ab im Nireau der seitlichen Fortsetzungen, welche dasselbe mit dem Rückenschild verbinden. Von den Gliedern bewahrt man nicht nur die Haut, sondern auch die Knochen auf: aber das Fleisch (die Muskeln) derselben beseitigt man. Ehenso ist zu rerfahren hinsichtlich des Halses, der mit dem Kopfe aufbewahrt werden soll: zu konserviren ist ferner die Haut der übrigen Körperpartien, welche nicht rom Knochenpanzer bedeckt sind.

Beim Abhäuten oder Ausbälgen der Schlangen muss man sich ror Beschädigung ihrer Schuppen hüten: der Kopf ist an der Haut zu lassen und mit dieser zu honserviren. Bei den Eirlechsen ist eine sorøfältigge Behandlung nöthig, damit nicht der Schwanz abbricht.

Es wäre zu wünschen, dass ron denjenigren Fischen und Reptilien, die wegen ihrer Grösse nicht in Spiritusgrefässen 
aufbewahrt werden können, die Skelette genommen und den Sammlungen einverleibt würden.

Um diese Skelette zu präpariren, braucht man nicht in minutiöser Weise alle, auch die kleinsten Fleischtheile zu entfernen; es genügt, dass man die massigeren Partien derselben beseitigt und dann das Knochengerüst als solches - ohne dass seine einzelnen Theile von einander getrennt werden - gut trocknet. Das so präparirte Skelett wird in eine Kiste mit Watte oder Papierschnitzeln verpackt. Ist es hiefür zu lang, so zertheilt man es in zwei oder drei Partien.

Sowohl in Alkohol als beim Trocknen entfärben sich die Fische und Reptilien schnell und in hohem Grade. Es ist daher sehr wünschenswerth und wichtig, dass der Reisende liolorirte Abbildungen dieser Thiere anfertigt, sollten sie auch als zoologische Zeichnungen sehr unvollkommen sein. Ist ihm aber die Anfertigung solcher Skizzen unmöglich, so nehme er wenigstens darauf Bedacht, dieselben so gut als möglich zu ersetzen durch Notizen über die bemerkenswerthesten Eigenthümlichkeiten der Färbung dieser Thiere.

$8^{\circ}$ Sammlungen von Vögch und Sängethieren (Vierfüssern) sind schwierig zu erstellen. Kleine Thiere dieser Klassen können in Spiritus aufbewahrt werden, wobei dieselben Vorkehrungen zu treffen sind, wie bei den Fischen; meist aber muss man die Thiere sorgfältig abhäuten (ausbälgen) und das Fell oder den Balg zum Schutze gegen Fäulniss und Insektenfrass eigens präpariren. Diese Operationen können aber nicht wohl in genügender Weise von Personen vorgenommen werden, welche darin keine Erfahrung haben; es ist desshalb jedem Reisenden, welcher ein fernes Land erforschen will, anzurathen, dass er vorher einigen Unterricht in der Taxidermie nehme bei dem Präparator, beziehungsweise in dem Laboratorium eines naturhistorischen Museums, wo er freundliche Aufnahme finden wird ${ }^{1}$ ).

Im Allgemeinen kann man sich Vögel leicht durch Jäger des betreffenden Landes beschaffen. Damit die Vögeỉ nicht

1) Als umfassendes literarisches Hülfsmittel kann empfohlen werden: $\mathrm{Ph} . \mathrm{L}$. Martin, Dic Praxis der Naturgeschichte, Weimar 1876, 3 Theile mit Atlas (I. Tu.cidermie, II. Termoplastik und Museologie, III. Naturstudien); einen trefflichen Artikel über Tuxidermie enthält ferner der "Dictionnaire unj versel d' histoire naturelle" von Ch. d'Orbigny. 
schadhaft werden, ist es nothwendig: $1^{\circ}$ Schrot oder Kugeh zu nehmen von einer Grösse, welche zu derjenigen des Thieres, das man jagt, im Verhältniss steht; $2^{\circ}$ das aus der Wunde fliessende Blut mit Baumwolle aufzutrocknen und auf die Stelle ein absorbirendes Pulver zu strenen, wie Gypsmehl oder feine Asche; $3^{\circ}$ die natürlichen Oeffnungen des Körpers mit Watte oder Werg zu verstopfen, um Entleerungen zu verhindern; $4^{\circ}$ die Federn, wenn sie nass sind, ebenfalls zu trocknen, was auch mit pulverigen Substanzen geschehen kann; $5^{\circ}$ die Federn in ihre natürliche Lage zu bringen und sie vor Druck oder Quetschung zu schützen; $6^{\circ}$ den Vogel - mit dem Kopf voraus - in einen Papiersack (Düte) zu bringen.

In den heissen Ländern müssen die Vügel sobald als nur immer möglich ausgebälgt werden; denn sowie die Fäulniss beginnt, fallen die Federn ab.

Die Säugethiere verursachen weniger Schwierigkeiten. Grosse Exemplare, die schwer zu transportiren wären, enthäutet man an Ort und Stelle; es wird das Fell längs der Mittellinie der Bauchseite aufgeschnitten und müssen die Knochen der Füsse und des Kopfes darin belassen werden (letztere narh Beseitigung des Gehirnes, beziehungsweise Leerung des Gehirnschädels, vgl. unten).

Da die Vögel einer Species nach Geschlecht und Alter sehr variiren, ist es erwünscht, dass man sich ron derselben Art männliche und weibliche, sowie jüngere und ältere Exemplare verschaffe. Hat man mehrere gleiche Exemplare, so lionservire man eines derselben in Alkohol. Ist aber das Exemplar für diesen Zweck zu gross, so skelettire man dasselbe, um den Sammlungen das Skelett beizufügen. Wenn ein Vogel einen fleischigen Kamm besitzt, so ist dessen Kopf in Weingeist aufzubewahren.

Sehr zu empfehlen ist auch das Sammeln von Eiern und Nestern. Die Eier entleert man durch kleine Oeffnungen an beiden Enden und verpackt sie in Gefässe, die mit Kileie oder Sand u. dgl. gut angefiillt sind. Welcher Art ein Ei mgehört, bezeichnet man dadurch, dass man auf ihm dipselbe Nummer anbringt, wie auf dem Balge oder dem Siriitusexemplare des Vogels, von dem das Ei stammt. Nur uf diese Art werden die Eier zu nützlichen Bestandtheilen 
einer ornithologischen Sammlung; sonst haben sie keinen Werth. Dasselbe gilt von den Nestern, welche immer in einer besondern Kiste, nicht mit den Eiern zusammen, verpackt werden sollen.

Die Bälge der Vögel sowie die Felle der Säugethiere würden bald der Zerstörung durch Insekten anheimfallen, wemn man nicht hiegegen besondere Vorkehrungen träfe. Das gewöhnlichste dieser Mittel besteht darin, dass die Häute auf ihrer Innenseite mit Arsenikseife (Sacon de Becocur) eingerieben werden. Dieselbe ist ron Museumsverwaltungen oder Präparatoren zu bekommen; auch kann man sie leicht nach folgendem Rezept selbst herstellen:

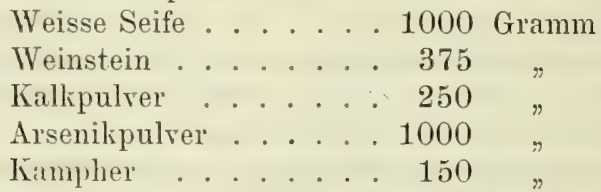

Man zerschneidet die weisse Seife in kleine Stücke, legt dieselben in eine steinerne Schale (Terrine), giesst ein wenig Wasser darauf und erhitzt nun langsam während man mit einem Holzspatel umrührt und successive so viel Wasser zusetzt, als zum Auflösen der Seife nöthig ist. Dann entfernt man das Gefäss ebenso allmälig vom Feuer, setzt unter stetem Umrühren - sodass eine rollkommene Mischung der Theile stattfindet -- den Weinstein hinzu, dann den Kalk und endlich das Arsenik. Die Zugabe des Kamphers, den man zu diesem. Zweck rorher in Weingeist auflösen kann, geschieht erst, nachdem die übrige Masse vollständig erkaltet ist ${ }^{1}$ ).

Ganz kleine Vierfüsser können in Weingeist konservirt werden; dabei ist die Haut- und Muskeldecke des Bauches aufzuschneiden, damit die Flüssigkeit ins Innere dringe.

1) Ph. L. Martin (Die Praxis der Naturgeschichte, I, Weimar 1876, S. 25) gibt ein etwas anderes Mengenverhältniss für die Ingredienzien der Becoeur'schen Arsenikseife: Weisse Seife $1 / 2 \mathrm{Kgr}$. wird mit $1 \mathrm{Kgr}$. Wasser (und wenn die Seife sehr aufquillt, noch mehr Wasser) zu einem Brei gekocht, alsdann $250 \mathrm{Gr}$, frischgelöschter Kalk dazu gerihht und wenn dieses geschehen $\mathbf{1}_{2} \mathbf{K g r}$. gepulverter weisser Arsenik nebst $250 \mathrm{Gr}$. Kampher mit der Masse innig vermengt." Uebrigens empfiehlt Martin an Stelle dieser Seife das arseniksaure Natron, arseniksauren Thon und Arseniksand; von ersterem (Natron arsenicosum, zu beziehen aus chemischen Fabriken und ron W. Schlïter, Naturalienbändler in Halle a/S). sagt er: "Reisenden ist sehr anzurathen, mit diesem Salze sich zu versehen, indem $11 / 2$ Kgr. davon so viel betragen als etwa 5 Kgr. Arsenikseife und viel leichter aufzuheben geht als letztere." A. a. O., S. 27 fr. 
Ist aber ein Thier zu gross als dass es auf diese Art aufbewahrt und mitgenommen oder rersandt werden könnte, so skelettirt man dasselbe und fügt den Bälgen das gut getrocknete Skelett (mit den Zähnen) hei. I)ie Skelette und Theile derselben (Schädel) müssen aber besonders verpackt werden, da sie Insekten anlocken können, von denen die Felle zu leiden hätten.

Das Aldulycn der Säugethiere und Vägel betreffend, geben wir nachstehend die einschlägige Anleitung in Nartins Taxidermie (a. a. 0., S. 73 ff.). "Diese noch ziemlich umfangreiche Beschäftigung des Sammlers lässt man entweder gleich nach dem Tode des Thieres, wenn solches noch warm, oder nach überschrittener Todtenstarre eintreten.

Grosse Süurethirye legt man auf den Rücken, schneidet unter Schonung der Bauchmuskeln rom After aufwärts über Bauch und Brust zur Brustspitze und ron dieser den Hals cntlang bis an's Kinn, so dass dieser Schnitt die Haut cränzlich breit legen lässt. Hierauf werden die Beine an ihrer hinteren Seite, von den Sohlen oder Hufen in der scheitelung der Haare aufwärts, ehenfalls aufgeschnitten. An den Vorderbeinen lasse man diesen Schnitt über die Ellenbogen hinweg nach der Armhöhle und von dieser nach dem grossen Längsschnitt auf der Brust einfach rerlaufen. Bei den Hinterbeinen wird der Schnitt über die Achillessehnen (Hessen) hinweg entweder nach dem After zu oder zwischen diesem und dem Bauch in den Hauptschnitt eingeführt. Ich mache darauf aufmerksam, dass diese Aufschnitte, wenn sie mehr nach der inneren Seite der Beine geführt wurden, sehr schwierig zuzunähen sind und stets vielmehr in das Auge fallen als an der hinteren Kante, wo die Scheitelung der Haare sie leichter verdeckt. Hodensäcke umgehe man mit dem Srhnitt, indem solche beim Ausstopfen immer einige Schwierigkeiten verursachen und schlecht aussehen, wenn sie getheilt wurden. Ausserdem ist auch der Schwanz rom After aus bis zu seiner Spitze aufzuschneiden.

Ist solchergestalt die ganze Thierhaut aufgeschnitten, : kann das Abstreifen beginnen, indem man an den Füssen infangend die Haut löst und rorn an den Hufen, Sohlen oder Händen die Gelenksbänder durchschneidet, wodurch die Iaut von den Beinen frei wird. Sind alle vier Beine durch 
Abbalgen entblösst, so liommt der Rumpf an die Reihe unrl wird der Kopf rom Halse getrennt, worauf die Haut rom Kadaver entfernt werden kann.

Ist dieses geschehen, so wird der Kopf abgebalgt, was namentlich an den Augen mit grosser Torsicht geschehen muss, da ohne dieselbe die Augenlider leicht sehr ärgerliche und entstellende Schnitte erhalten können. Ebenso sei man vorsichtig beim Ablüsen des Schädels von der Nase, da auch hier leicht unangenehme Einschnitte rorliommen können.

Hatte das Thier Hörner, so muss man rom Nacken an einen Schnitt bis zwischen die Hörner und ron da aus um jedes Hor'n herum schneiden, durch welchen Gabelschnitt hindurch der Schädel herauszunehmen ist. Wenn dieses greschehen, balge man die Ohren ab, was bei der Verdoppelung der Haut an ihnen durchaus nothwendig wird, wem anders sie nicht faul werden sollen. Man hilft dabei sehr rortheilhaft mit einem stumpfen Meisel oder dgl. und erhält so eine hohle Tasche, die später gut gesalzen wird. Ausserdem müssen die Lippen und die Nasenknorpel dünner geschnitten werden, da es sonst sehr riskant ist, dass diese Theile gehörig rom Salze durchdrungen werden kömnen.

Elephanten, Nashörner, Flusspferde und noch manche andere Thiere sind wegen ihrer Grüsse und ihres kolossalen Gewichtes für viele Reisende wahre ,noli me tangere". Nach dem hisher üblichen Sammelsystem war es auch in der That unmöglich, rex Häute solcher Lngeheuer in auch nur einigermassen genügender Weise hahhaft zu werden. Nach der von mir rorgeschlagenen Weise wird die Haut solcher Geschöpfe noch auf dem frisch erlegten Thiere in passend grosse Stücke geschnitten. Fast jedes grosse Thier besitzt natürliche Hautfalten, welche benutzt rerden können, um die Haut nach ihnen zerlegren zu kömmen. Das indische Rhinoceros z. B. ist für solchen Zreck wie geschaffen und braucht nur nach seinen Schildern aufgeschnitten zu werden.

Ist die Haut nicht allzu dick und ist sie fettlos, so kann sie nach kurzem Auswässern eingesalzen werden. Hat man es mit fetten Häuten zu thun, so müssen sie vor dem Einsalzen ron ihrem Fette durch Abkratzen desselhen mit geeigneten Instrumenten müglichst vollständig befreit werden. Ist die Haut aber ausserdem noch sehr dick, so wird es 
zur Nothwendigkeit, sie mit einem Gerbemesser dïmner zu schneiden, wozu aber Eile und grosse Vorsicht grehören.

Filviue Süugethirer werden insofern abweichend von den grossen abgebalgt, als man bei ihnen in der Regel die Beine und den Schwanz nicht aufschneidet, sondern dieselben herauszieht. Thut man dieses, so mïssen die sohlen dennoch aufgeschnitten werden, um die Ḧ̈nde, Tatzen u. s. w. zu entfleischen. Ingleichen vergesse man niemals, jeden einzelnen Finger oder Zehe an der Spitze mit einem kleinen Einschnitt zu versehen und ferner den ausgezogenen Schwanz an der Spitze zu durchstechen, sowie einen kleinen Schnitt oder Nadelstiche an die Ohrspitzen zu machen. Diese Vorsicht ist üherall da gut, wo Verdoppelungen der Haut sind, in welchen sich leicht das freigewordene Wasser der Haut ansammelt und Faulstellen reranlassen kann, wodurch natürlich die Haare ausgehen. Alles Lebrige geschieht in derselhen Weise wie bei der Behandlung grosser Sïugethiere.

Trïml sind ihres Gefieders wegen bedentend schwieriger abzubalgen als Säugethiere, und wenn Blut in die Federn gedrumgen, so ist solches ebenfalls viel mühsamer aus ihnen zu entfernen als aus den Haaren. I)as Blut geschossener Vögel vor dem Abhalgen auszuwaschen, wie Viele thun, ist nicht zweckmässign, weil gerade durch das Abhalgen aus der Wunde, selbst wemn sie gut verstopft worden, häufig neues Blut dringt und Alles wieder gewaschen wrden muss. Deshalb ist es hier wie bei allen Thieren gut, das Waschen erst nach dem Abbalgen vorzunehmen, weil darlurch jedes Nachbluten unmöglich wird und man im Stande ist, die Haut auch von innen blutrein zu machen.

Eine der wichtigsten Procerduren an einem torlten Vogel ist aher das Verstopfen der speiserühre vor dem Lbbalgen. weil durch dieselhe nicht selten der Macrensaft sich in solcher Menge ergiesst, dass nach dem Abbalgen hopf und Hals oft yanz schmutzig davon werden. Lm solehes, zugleich aber turh die schnell eintretende Fäulniss der Epidermis dieser Theile zu verhindern, stopfe ich jeden Voget, sowie er in meine Hände kommt, durch den geoffneten Rachen trockenes 汭expüine ein. - Noch besser thut man, wenn man schom unf der. Tagd, wleich nach dem sichuss, den Vüguh den chlumb rerstopft, wodurch sich diestlhen ungleich länger 
frisch erhalten lassen. Es kann dies geschehen mit Löschpapier, Werg etc. und mit trockenem Sand oder Erde.

Vögeln mit kurzem und dickem Schnabel ziehe man vor dem Abbalgen einen Faden durch die Nasenlöcher, da dieser beim Lmkehren des Kopfes und später grosse Erleichterungen gewährt und sehr zur Schonung des Gefieders beiträgt.

Was nun die Zeit des Abbalgens betrifft, so bin ich stets dafür, es so zeitig als möglich vorzunehmen, weil jede gewonnene Zeit zugleich ein Vorsprung gegen die Fäulniss ist. Kann man es haben, so balge man auch die Vögel noch warm ab, was die Arbeit sehr beschleunigt; im anderen Falle suche man dies gleich nach beendigter Todtenstarre zu thun. Wenn man aber nicht Zeit hat, dieses abzuwarten, so kann man durch gewaltsames Biegen und Recken das betreffende Thier für die Präparation gefügig machen.

Vor zwei Lieblingsmanieren beim Aufschneiden der Vögel muss ich dringend warnen; es sind dies der ron den Franzosen eingeführte Schnitt am Bauche der Vögel und der in Süddeutschland beliebte Aufschnitt unter einem Flügel. Alle Land- und Sumpfrögel ohne Ausnahme schneide man längs dem Brustbeine auf, wo dieselben eine federlose Stelle (Rain) zeigen und die sich darüber kreuzenden Deckfedern seitwärts abgebogen werden. Ist der Schnitt erfolgt, so lösc man die Haut vom Körper mittels Finger und Messer los, was leicht geht. Hierbei ist aber sehr auf die Reinhaltung des Gefieder's zu achten, was Anfängern viele Mühe macht und bei essbaren Kadavern mittels Zwischenlagern von Papier, Blättern etc., sonst aber durch Aufstreuen von Sägemehl, Moos etc. und im Nothfall Sand $u$. dgl, geschieht. - Hat man die Haut von den Brustmuskeln abgelöst, so suche man den Hals sammt Luftröhre und Schlund etwas herauszuziehen, damit sie zusammen mit einer Scheere und bei grossen Vögeln mit einer Kneifzange abgetrennt werden können.

Hat man Gelegenheit, so hänge man den Vogel an einer Schnur mit daran befestigten Drahthaken so auf, dass dei Haken unter dem Gabelbein ins Muskelfleisch gestossen wird. - Solches Aufhängen der Vögel (und selbst der meisten Säugethiere) erleichtert die Arbeit sehr, indem man immer beide Hände frei hat, und nur bei kleinen Vögeln und kleinen 
Säugrethieren ist deren Halten mit der linken Hand fast vorzuziehen. Nachdem also der Hals durchschnitten und die Haut behutsam abwärts gezogen worden, sind die Flügel in Achselgelenk abzutrennen und wird die Haut, namentlich am Rücken, mit Vorsicht bis an die Schenkel abwärts gestreift, wonach die Beine im Kiniegelenk durchschnitten werden, worunter aber nicht das fälschlich so benannte Fersengelenk zu rerstehen ist. Ist dieses geschehen, so tommt die Bauchpartie an die Reihe, wobei man wieder recht Acht zu greben hat, dass man das Bauchfell nicht verletzt, und ist man bis zum After gekommen, so durchschneide man auf der Rückenseite oberhalb zweier runder Körper (den Bürzeldrüsen) die Schwanzwirbel und zuletzt den After, nachdem man den lï̈rler abgehakt und wangrecht hingelegt hat. Diese Vorsicht ist höchst nöthig, indem viele Vügel, namentlich Raub-, Sumpf- und Wasserrögel, ihre flüssigen Exkremente beim I)urchschneiden des Afters auslaufen lassen, was schwierig auszuwaschen ist. - Schneidet man die Schwanzwurzel zu tief ab, so fallen die Federn aus, weshalb man lieber etwas höher durchschneidet und das sitzengebliebene Fleisch mit einem stumpfen Messer von der Haut abschält. Natürlich haben alle die Operationen unter möglichster Fernhaltung des Gefieders und häufigerem Aufstreuen ron Säıremehl etc. auf die blosse Haut zu geschehen, was doppelt nothwendig, wenn der Vogel fett ist.

Hierauf werden Hals und Kopf abgebalgt, indem man Gurgel und Schlund nebst dem Hals fasst und die Haut gegen den Kopf rückwärts streift, bis dieser auch allmälig zum Vorschein kommt. Ist mañ an die Ohren gekommen, so sind die Ohrhäute, welche sich beutelartig in das Ohr insenken, mittels eines Pfriemens oder stumpfen Messers :eitlich zu unterstechen und durch Aufsetzen des Daumens terauszuheben. Diese Vorsicht ist deshalb nöthig, weil sonst las Ohrloch der Haut blossgelegt und durch dasselbe das 'räservativ hindurchdringen und das Gefieder verunreinigen vürde. Nach den Ohren kommen die Augen zum Vorschein, ro man die Nickhaut behutsam durchschneidet und den lugapfel vorsichtig heraushebt. - Bei den Eulenarten rathe ch den Augapfel fest sitzen zu lassen, mit einer Scheere lie Hornhaut abzuscheiden und durch dieses Loch das Auge 
zu entleeren. Man hat durch dieses Verfahren den grossen Vortheil, die sonst so schwierige Physiognomie des Eulenkopfes leichter und sicherer zu erzielen. - Die meisten Schwimmvögel, viele Sumpfrögel und Spechte müssen wegen zu dicken Kopfes, welcher durch den meist sehr engen Hals nicht hindurchgeht, entweder am Hinterkopf oder an der Gurgel aufgeschnitten und abgebalgt werden, wobei letzterer Aufschnitt meist, vorzuziehen ist.

Ist der Kopf bis über die Augen abgebalgt, so erweitert man den Zugang zur Schädelhöhle durch Vergrösserung des Hinterhauptloches nach dem Gaumen zu, um das Hirn herausnehmen zu kömmen. - Kommt die Haut in Flüssigkeit, so wird der Kiopf einfach zurückgestreift; wird sie aber zu Balg gemacht, so muss die Kopfhaut gut mit Arsenilithon vergiftet werden und sind die Augäpfel durch eingelegte Werg- oder Baumwollkugeln zu ersetzen, und thut man gut, auf die Wangen auch einige Fasern aufzulegen. Das Zurüclistreifen der Haut über den Kopf ist oft ein mühsames Geschäft und erfordert vor allen Dingen ruhige Behandlung durch langsames Vorrücken, wobei der Faden durch die Nasenlöcher ron wesentlicher Bedeutung und die Sache sehr erleichtern hilft. Ist der Kopf zurückgestreift, so ist das Ordnen des Kopfgefieders das erste Geschäft, was durch leichtes Rückwärts- und Vorwärtsbürsten der Federn, unter richtiger Beobachtung der Lage der Haut an ihre ursprüngliche Stelle, geschehen muss. Ich rathe an, alle Sorgfalt darauf zu verwenden.

Nach Beendigung dieses Geschäftes kommen die Flügel an die Reihe, welche man ganz einfach bis ans Handgelenk abstreift, worauf die grossen Schwungfedern grosser Vögel mit einem stumpfen Messer von den Armknochen abgestossen und die Muskeln abgeschnitten werden. Sind die Armknochen gereinigt, so wird für den Balg die Flügelhaut gut vergiftet und der Flügel zurückgestreift. Ausserdem muss zuletzt aber das Handgelenk der Flügel aller Vögel von Rabengrösse an äusserlich aufgeschnitten, entfleischt und vergiftet werden, was ferner noch an den Wurzeln der grossen Handschwingen, nach Aufheben der kleineren Deckfedern, nothwendig geschehen muss. Nach den Flügeln folgen die Beine, wo die Eigenthümlichkeit vorkommt, dass sie nur so weit abgebalgt 
werden können, als sie mit Federu bewachsen sind. Deshalh lassen sich die Beine der Steinadler und Eulen bis an die Fusswurzeln abstreifen und vergiften, während dies bei allen anderen Vögeln im Fersengelenk aufhört. Bei allen kleinen Vögeln hat man das Tarsenbein an der hinteren Seite in seiner ganzen Länge mit einem entsurechenden Draht zu durchstechen und nach Entfernung des Drahtes einen Tropfen arseniksaures Natron hineinzubringen. Diese kleine Vorsicht, die man guten Bülgen schuldig ist, belohnt sich roppelt und zwar durch Erhaltung der Schilder beim späteren Aufstellen und durch den Schutz gegen Insektenfrass. Bei grösseren Vügreln, wie kleinen Raubvögeh, Raben, Tauben, Wasserläufern etc. etc. genügt diese Vorsicht schon nicht mehr und man ist genöthigt, solchen Beinen, nach dem Durchstechen derselben mit Draht, einen Gegenstand einzuführen, der sie vor dem Zusammenschrumpfen bewahrt. Ein solcher besteht in einer entsprechend langen und starken Schwungr- oder Schwanzfeder eines defekten Vogels. Man schneidet die Spitze etwas ab, taucht solche vor dem Einschieben in das Gift ein und lässt sie an den Fusssohlen "twas herausragen, damit sie nach einigen Tagen herausgezogen werden kann. Holz dazu zu nelımen, ist gefährlich, weil es abbrechen kann, es müsste denn Rotang sein. Noch grössere Beine, wie solche der Geier, vieler Adler, Harlỵen, vieler Sumpfvögel, Trappen, Strausse u. a. müssen nothwendig aufgeschnitten und entfleischt werden, so weit. es irgend geht, und dürfen sogar die Zehen nicht vergessen werden. Alsdam vergifte man sie gut und streue ausserdem noch ein wenig Alaumpulver hinein. Schwimmhäute und Lappenfüsse sind gleichfalls zu vergiften.

Wenn so der ganze Vogel entfleischt ist, wird die innere Haut, falls sie kein Fett besitzt, mit Arsenilithon gut ausgestrichen, zusammengeklappt und einige Stunden order einen Tay lang an einem schattigen Ort ruhig liegen gelassen. Besitzt aber die Haut Fett, so muss dieses entfernt werden, wie bei den fetten Säugethierhäuten. Kommt eine Haut in Weingeist oder dlaun, so fällt natürlich alle Behandlung. mit Arsenik weg."

Sendungen lebender Thiere. Reisenden, welche in der Lage sind, sich lebende Thiere zu rerschaffen und die- 
selben heimzusenden, ist dringend anzuempfehlen, dass sie dies nicht unterlassen.

Die kleinen Vierfüsser bekommt man unschwer von Eingebornen, welche deren Aufenthaltsorte kennen und Thiere zu fangen wissen. Man braucht ihnen nur zu sagen, dass man die Thiere lebend haben wolle. Namentlich kann man durch sie leicht ganz junge Thiere solcher Arten (Säuger und Vögel) erhalten, deren Verstecke und Nester sie kennen. Die Jungen gewöhinen sich im Allgemeinen leicht an das Leben in der Gefangenschaft, im Käfig. Anfänglich erfordern sie viele Nühe und Sorgfalt; man darf sie nicht einschiffen, bevor man sie einige Wochen auf dem Lande gefangen gehalten, gefüttert und möglichst gezähmt hat. In dieser Hinsicht darf man sich die Mühe nicht reuen lassen. Ein Thier, welches beim Anblick der Personen, von denen es gepflegt wird, nicht erschrickt, befindet sich immer viel besser und erträgt die Strapazen eines Transportes zur See weit leichter als ein solches, das wild und scheu ist; auch gibt es fast kein Thier, das nicht durch gute Behandlung mehr oder minder zahm gemacht werden könnte.

Gefangene Thiere, welchen die gewohnte freie Bewegung fehlt, dürfen ja nicht zu reichlich gefüttert werden. Das erste Erforderniss und das beste Mittel, sie am Leben zu erhalten, besteht darin, dass man ihnen nur die nothwendige Nahrung gibt. Das zweite Erforderniss ist Reinlichkeit. Man wird auf dem betreffenden Schiffe sicherlich Jemanden finden, welcher die Pflege der Thiere gegen eine kleine Entschädigung oder, aus Interesse an der Sache, auch sonst übernimmt. Hiebei ist namentlich auch dafür zu sorgen, dass die Thiere nicht durch Passagiere gereizt werden. Ebenso ist zu empfehlen, dass man jedem Thiere eine besondere Abtheilung im Käfig gebe.

Die körner-, frucht- und fleischfressenden Vögel sind im Allgemeinen leicht zu ernähren und verursachen wenig Mühe an Bord des Schiffes; wir empfehlen sie desshalb der Aufmerksamkeit des Sammlers ganz besonders. Alljährlich gelangen deren durch den Handel vom Senegal aus Tausende nach Europa, und es wäre sehr interessant, solche ebenfalls zu bekommen von andern Theilen der afrikanischen Küste, sowie von ostindischen und australischen Inseln, China und 
Japan etc. Die verschiedenen Fasanen und andere Hühnerarten, Tauben und Papageien grehören zu den interessantesten Vögeln eines jeden zoologischen Gartens. Zumeist sind auch die Kommandanten staatlicher Schiffe gerne bereit zur Lebernahme ron derartigen Sendungen für die Unterrichtsministerien, und die Verwaltungen zoologrischer Gärten vergüten gerne die greringen Kosten, welche dabei entstehen.

Die nicht giftigen Reptilien wie Schildkröten, Krokodile, Eidechsen und die meisten Schlangren sind noch leichter zu transportiren als die erwähnten Vögel. 


\section{DAS VOLK.}

\section{BEVÖLKERUNGSSTATISTIK.}

Gesammtzahl. Der Reisende soll wenigstens approximativ die Gesammtzahl der Bewohner eines von ihm besuchten Landes angeben können.

In Ermanulun! cmetlirher. Folliszühlungen ist es allerdings nicht leicht, auch nur annähernd richtig zu bestimmen, wie viele Bewohner eine Gegend hat. Man muss das aber doch versuchen, und zwar nach zwei Methoden, wobei das Ergehniss der einen zur Kontrole oder Probe für die Richtigkeit des andern dienen und aus beiden Resultaten ein Mittelwerth erhalten werden kann, der jedenfalls der Wahrheit näher kommt als die Zahl, welche man blos nach der einen Art bekommen hätte.

Die erste Methode ist die Schätzung de visu, d. h. nach direkter Beobachtung.

Beim blossen An- und Ueberblick einer Gegend sieht man bald, in welchem Maasse dieselbe als öde oder als berölkert gelten kann. Der gänzliche Mangel an menschlichen Wohnungen einerseits, eine mehr oder minder grosse Zahl ron Häusern, Dörfern etc. anderer'seits; Art und Grad der Bodenliultur; die grössere oder geringere Lebhaftigkeit des Verkehrs in den Ortschaften, auf den Strassen und Märkten; eine mehr oder minder starke Frequenz ron Festen: diese und andere Faktoren sind ebensoviele Anhaltspunkte zu einer ersten approximativen Beurtheilung der Volkszahl eines Landestheiles. Indessen sind das allerdings blos Indizien, die kein absolut sicheres Urtheil ermöglichen; denn es gibt einerseits 
Bevölkerungen ron sehr häuslichem simm, die wenig in Zirkulation sind, und andererseits solche, die sich fast fortwährend in Bewegrung und Wanderung befinden, so dass wenn auch die Volkszahl in beiden Fällen ziemlich gleich wäre, doch der Eindruck, welchen der Reisende empfüngt, ein ganz verschiedener sein müisste.

Man muss also die sache grenauer untersuchen. Zu dem Ende wählt man eine Lokalität, welche die mittlere Berölkerungsdichtigkeit am besten zu repräs+ntiren scheint. zählt die Wohnungen auf einem gewissen Areal, z. B. einem Quadratkilometer, und hestimunt die Zahl der Bewohner einer solchen nach einem Mittelwerth, so gut als dies möglich ist. Die auf diese Weise für einen Quadratkilometer erhaltene seelenzahl multiplizirt man mit dem Flächeninhalt des Landes und bekommt so ungefähr die Gesammtzahl der Bevölkerung.

Hiebei darf nicht ühersehen werden, dass es Ortschaften gibt, die zu gewissen Zeiten des Jahres ron ihren Bewohnern verlassen sind, so z. B. wenn die Heerden auf entfernte Weiden getriehen werden müssen, in Zeiten des Fischfangs, der Jagd u. dgl.

Wenn die Berölkermug sehr ungleich über das Land rertheilt ist, so unterscheidet man hienach in demselben rerschiedene Gebiete und sucht die Volkszahl eines jeden derselben separat zu ermitteln.

Ian kann auch zunächst die Bewohnerzahl derjenigren Ortschaften schätzen, in welchen ein grosser Theil der Berölkerung konzentrirt ist (Bevölkerungszentren: Städte, Flecken, Dörfer; - Lagerplätze bei Wilden) und nachher ein Vittel nehmen für den Rest des Territoriums.

Die zweite Methode besteht im Einziehen ron Erliundignnyen, beziehungsweise ron Angaben, die nach allgemeinem Lrtheil als offenkundige Thatsachen (notorisch) gelten.

$\mathrm{Zu}$ dem Ende frast man Häupter der stämme und andere Eingeborne, von welchen zufolge ihrer stellung, Erfahrung, Sach- und Menschenkenntniss rorausgesetzt werden kann, dass sie am besten im Stande seien, zutreffende Angaben zu machen. Lm den Erhehungen möglichste Zurerlässigkeit zu geben, wendet man sich hinsichtlich einer jerlen derselben an verschiedene Personen, so dass man für eine Angrabe mehr als eine Quelle hat. 
Durch diese Erkundigungen lernt man freilich mitunter nicht direkt die Gesammtzahl der Bevölkerung kennen, sondern diejenige der Haushaltungen, Familien, Zclte, Stenerpflichtigen oder Wehrfähigen. Bei den Kirgisen z. B. wird nach "Zelten" gerechnet, bei den nordamerikanischen Indianern nach der Zahl der "Krieger" eines Stammes; die Kabylen geben die Bevölkerung eines Dorfes nach der Zahl seiner "Gewehre" an, d. h. sie zählen nur die Männer, welche fähig sind, die Waffen zu tragen. In allen diesen Fällen muss der Reisende ermitteln, welchen Werth eine solche Einheit hat. Er wird z. B. durch Vergleichung finden, dass durchschnittlich auf eine Haushaltung oder ein Zelt 5 Personen kommen, auf cine Familie 3, auf ein Gewehr 4 u. s. f. Der Ansatz für die Einheit wechselt natürlich je nach den Lokalitäten; die Haushaltungen und Familien sind namentlich verschieden nach der Zahl von Weibern und Kindern; auf ein Zelt kommt hier eine kleinere, dort eine grössere Durchschnittszahl; der Zifferwerth, den „ein Gewehr" repräsentirt, hängt unter Anderm davon ab, in welchem Alter die Angehörigen eines Stammes anfangen und aufhören, die Waffen $\mathrm{zu}$ tragen.

Wenn antliche Volliszählungen existiren, ist die Aufgabe leichter, oft aber auch delikater. Wir haben bereits (S. 163) von den Fehlern gesprochen, welche mitunter solchen Daten anhaften, und exinnern hier daran, um dem Reisenden zu empfehlen, dass er nicht alle diese Zahlen ohne Vorbehalt acceptire, sondern sich damit bekannt mache, wodurch diese Erhebungen veranlasst und wie sie bei der Bevölkerung aufgenommen wurden. Wenn man weiss, ob und welche Gründe einerseits zu hohe, andererseits zu niedrige Angaben - Uebertreibungen und Verheimlichungen - veranlassen konnten, so wird man auch darnach einigermassen den Werth der Zahlen bemessen können. Ausserdem fällt in Betracht, welche Mittel angewendet wurden und in welchem Grade den mit der Zählung beauftragten Personen Vertrauen zu schenken ist.

Im Allgemeinen kann man nur die Zählungsresultate der zivilisirtesten Staaten als unbedingt glaubwürdig betrachten; die anderen sind kaum mehr als Näherungswerthe und oft auf blosse Annahmen basirt. Immerhin wird man sich die bestehenden Daten zu verschaffen suchen, aber aus erster Hand, d. h. aus den amtlichen Aktenstücken, nicht aus 
Reproduktionen und Auszügen, welche fehlerhaft und unvollständig sein können.

Es ist rathsam, bei Angalien üher die gresammte Volkszahl wenigstens zwei Gruppen derselben zu unterscheiden: die sesshafte und die flottante Bevölkerung. Die sessuafte

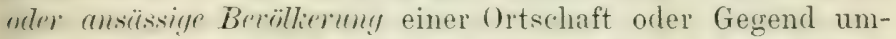
fasst die Personen, welche wohnhaft, d. h. für eine längere Zeit, auf eine gewisse Daner, niedergelassen sind: Grundhesitzer, Industrielle, Handwerker und andere Gewerbsleute, Beamte und Angestellte, Arbeiter, Gesellen, Lehrlinge, Dienstboten u. dgl. Die flottente Beriollermug besteht ans den Personen, welche sich nur zufällig und für liürzere Zeit in der Ortschaft oder Gegend aufhalten, wie Reisende, Touristen, Künstler u. a, m.

Es soll bemerkt werden, ob und wie man hiebei die IIannschaft von Truppentheilen und Schiffen, Post- und Eisenbahnangestellte, Züglinge ron Spezialschulen, die Insassen von Heilanstalten und Gefüngnissen etc. mitgerechnet hat, in welcher Zahl und zu welcher der zwei Gruppen.

Die Gesammtheit der Personen, welche sich an einem Or'te im Momente der Zühlung befinden, macht die orts-

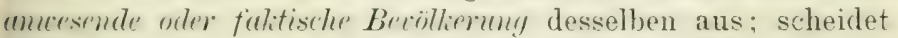
man hievon die nur zeitweilig oder vorübergehend Anwesenden (Durchreisende und Gäste) aus und rechnet man statt derselben die vorühergehenden Abwesenden hinzu, so erhält man die Woln-oder politische Becöllerun!. Es ist klar, dass die Personen, welche an einem Orte als, vorübergehend abwesend" notirt werden, anderorts in die Kategorie "vorübergehend Anwesende" (Durchreisende und Gäste) liommen, wenn die Volkszählung in einem grossen Gebiete gleichzeitig und nach den nämlichen Grundsätzen erfolgt.

Elemente der Bevölkerung. Es ist anzugeben, welches die Zusammensetzung der gesammten Volks- oder Einwohnerzahl nach den einzelnen Bestandtheilen ist. Solche Bestandtheile oder Elemente der Bevölkerung können nach mehreren Gesichtspunkten unterschieden und gebildet werden: man kann das Volk eintheilen nach Greschlerht uad Alter (männlich und weiblich, Kinder und Erwachsene: Knaben und Mädchen, Männer und Frauen), nach Russen und Syrachen, ferner was namentlich in Kolonien von Wichtigkeit ist - nach 
Einheimischen (Eingebornen) und Fremden mit Unterabtheilungen der Letzteren nach ihrer Nationalitiot; sodann nach Religimen und Konfessionen, in Gegenden mit Truppen auch nach Zivil und Militür.

Räumliche Gruppirung. Die Darstellung der Bevölkerungsverhältnisse eines Landes soll zeigen, wie die Bevölkerung über das Territorium rertheilt ist. Man gibt die Vertheilung nach natürlichen oder nach den politischadministrativen Abtheilungen des Landes an, d. h. einerseits nach physischen Abschnitten desselben: Zonen oder Regionen, andrerseits nach den politischen Bezirken, Prorinzen etc., wobei man in jeder dieser Abtheilungen wieder unterscheidet zwischen der strütischrn Beröllicrung, d. h. derjenigen der Bevölkerungszentren, und der Lamdberölkermu, d. h. derjenigen, welche nicht wie jene in einige grosse Ortschaften zusammengredrängt ist, sondern in gleichmässigerer Vertheilung über die Landschaft, mehr vereinzelt, die Gegend bewohnt.

Die räumliche Vertheilung nach Russen, Sprachen, Kronfrsimum wird am zweckmässigsten kartographisch dargestellt durch rerschiedene Signaturen und Farben, wie die nebenstehende Taf. XXII zeigt.

Dichtigkeit der Bevölkerung. Die Berijlkerm!stichtiglivit oder velatire Burillirmun ist das Verhältniss zwischen der Einwohnerzahl (absoluten Bevölkerung) eines Landes und seinem Areal. Man bezeichnet dasselhe in approximativer Weise durch Ausdrücke wie "schwach oder dünn bevöllert, mässig bevölkert, stark oder dicht bewohnt" u. 'dgl., oder aber ganz genau durch Angabe der auf eine Flächeneinheit (Quadratkilometer) entfallenden Einwohnerzahl.

Da die Bevölkerungsdichtigkeit zumeist in den verschiedenen Theilen eines Landes sehr ungleich ist, sind hierüber speziellere Nittheilungen zu machen. Man gibt also nicht nur die durchschnittliche Volksdichtigkeit des ganzen Landes an, sondern auch diejenige seiner einzelnen Abtheilungen, und fügt diesen Mittelzahlen unter Umständen noch Grenzwerthe (Minima und Maxima) bei.

Auch diese Verhältnisse werden am besten veranschaulicht durch kartographische Darstellungen, wobei ein höherer Grad der Bevölkerungsdichtigkeit durch einen dunkleren Farbenton bezeichnet wird. Als Beispiel für eine solche Darstellung 
Sprachenkarte der Solnveiz.

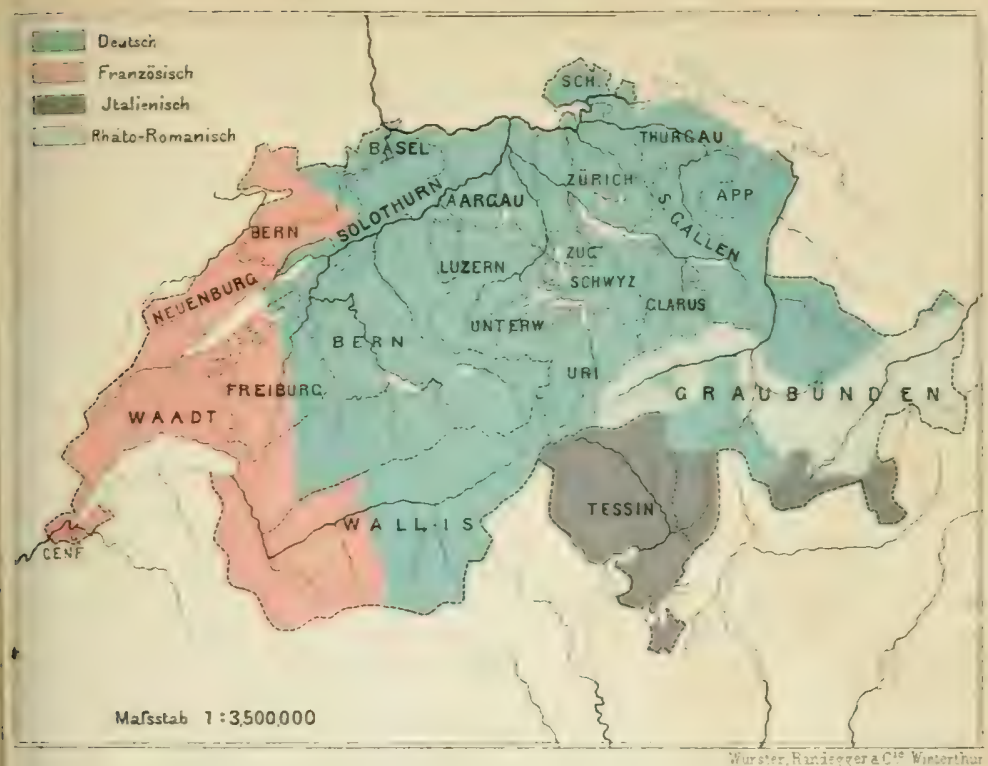

Religionskarte der Schweiz.

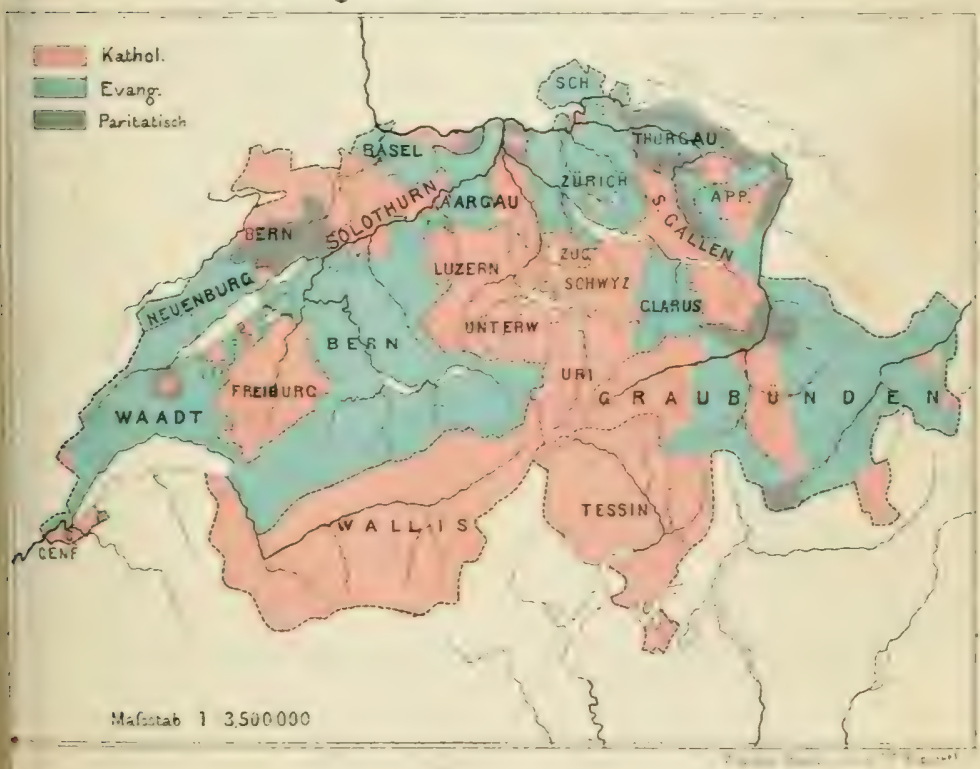



Taf. XXIII.

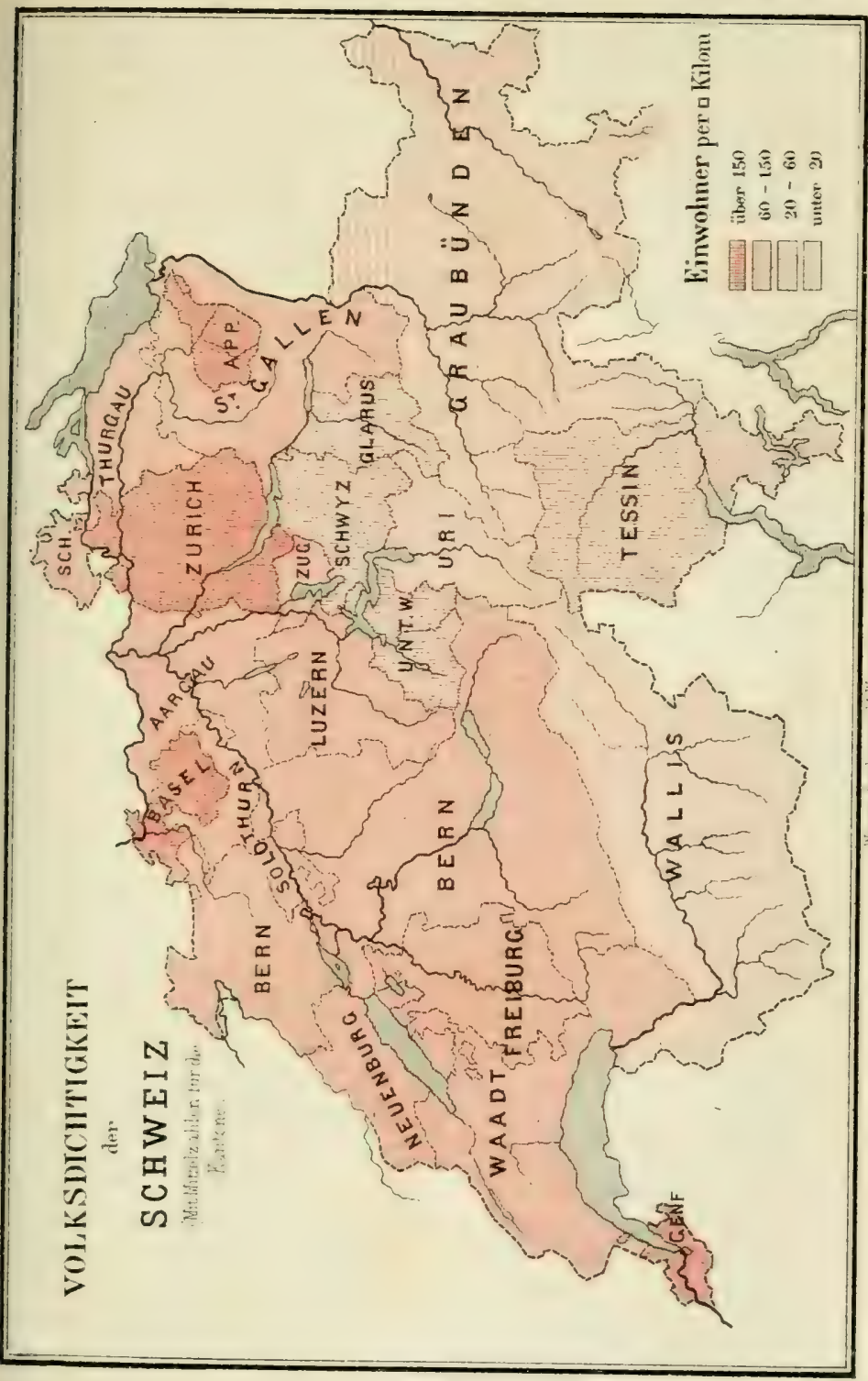



auf Grund der politischen Eintheilung eines Landes. nach der mittleren Volksdichtigkeit dieser verschiedenen Gebiete. geben wir die Taf: XXIII; für die andere Art der Darstellung, diejenige nach natürlichen Zonen oder Kegrionen. verweisen wir auf die Karten zu Belm und Wagner, die Berölkerung der Erde, II. (Ergänzungsheft Nr. 35 zu Petermann's geographischen Mittheilungen: Gotha 1874.)

Statistik der Stände und Berufsarten. Wenn man sich genügende Angahen rerschaffen kamn, so erstellt man auch eine Statistik:

der Kasten, wo die Gesellschaft noch in solche ron und gegen einander sich scharf abgrenzende Klassen getrennt ist;

der Stände, wo zwischen den Klassen der Gesellschaft zwar nicht die grellen Gegensätze und stahilen Grenzen wie hei den Kasten, aher doch noch deutlich ausuresurochene Unterschiede existiren, welche Xamen auch die einzelnen Ǩlassen tragen: Herren und Diener orler Sklaven: Lehensherren und Vasallen: Adel, Geistlichkeit, Büryerstand u. s. w.;

der Brmusurtrn oder Profosimem. wo Klassen der Gesellschaft kaum in anderel Weise unterschieden werden kömen als nach der Beschäftigumg der Einzelnen. Eine Statistik dieser Art ist leicht zu erstellen für wenig zivilisirte Länder, wo der griossere Theil des Volkes aus Jïgern und Fischem besteht; unschwer anch noch für Gebiete, deren Bevölkerung üherwiegend ron Hirten und drkersleuten gehildet wird: schwer aber für Länder mit srö̈serer Zivilisation und Arbeitstheilung, und zwar um so schwerer, je weiter diese liulturentwicklung gediehen ist, je zahlreicher mit der fortgeschrittenen Arbeitstheilung die Berufsurten (Tirnorlubtimen, Grurelor. Handel u. s. w.) garworden sind und jo maniefaltiger sich innerhall, derselben die Lnterschiede zwischen Krinund Grosslutrid, (bei Gewerben durch Hand- mond Maschinen-

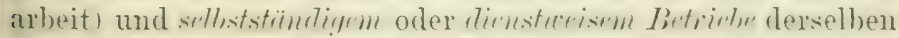
(auf eigene Rechnung orler im Lolne Anderer) grestalten.

Altersstatistik. Wenn nicht eingehende und gremaue amtliche Aufnahmen existiren, kann eine Gruprirung der Be-

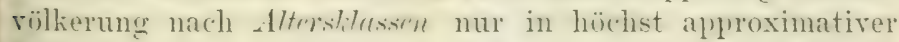
Teise vorgenommen werden, indem man etwa angiht, ol, die Zahl der Greise und ebenso diejenige der hinder relativ 
gross oder klein und welches etwa das Zahlenverhältniss der drei Abtheilungen ist, die man hienach unterscheidet.

Nur auf Grund sehr vollständigen und genauen Materials liann man soweit gehen, dass man eine grössere Zahl von Altersllassen, von 10 zu 10 oder von 5 zu 5 Jahren mit Unterabtheilung nach den Geschlechtern, aufstellt. Dass der Reisende von sich aus eine solche Aufnahme mache, daran ist gar nicht zu denken; denn bei den wilden und halbzivilisirten Völkerschaften können die Individuen ihr Alter nicht genau, sondern nur annähernd bezeichnen; höchstens von den jüngeren Kindern wissen sie die Zahl der Jahre anzugeben. Man kann aber das Alter auch nicht nach dem Aussehen der Leute abschätzen; denn die Männer altern oft ungewöhnlich rasch in kümmerlicher und schwerer Existenz, die Frauen vorzeitig in gewissen Klimaten bei frühem Heirathen, Entbehrungen und schlechter Behandlung.

Standes-oder Zivilstands-Statistik. Es sollte, wenm es auch nur in approximativer Weise möglich wäre, angegeben werden, in welchem Zahlenverhältniss (Prozentsatz) folgende Kategorien vertreten sind:

Verheirathete $\left\{\begin{array}{l}\text { Zusammenlebende. } \\ \text { Geschiedene oder Getrenntlebende. }\end{array}\right.$

Verwittuete (Wittwer und Wittwen).

\section{Lectige I Junggesellen.}

Zu dem Ende zieht man bei Stammeshäuptlingen, Dorfältesten etc. Erkundigungen ein, aus welchen man approximative Verhältnisszahlen berechnet.

Existiren amtliche Volkszählungen mit Angaben hierüber, so braucht man die letzteren nur auszuscheiden und zu rekapituliren.

Eheschliessungen, Geburten und Todesfälle. Wenn immer möglich, wird man wenigstens summarische Angaben über diese Zivilstandsfälle nach den drei Kategorien machen. Eine vollständigere statistische Darstellung hätte sich auf folgende Punkte zu beziehen:

Jährliche Zahl der Ehen:

Total - nach Altersklassen,

zwischen Einheimischen - zwischen Einheimischen und Fremden. 
Verhältniss der Ehen zu den Scheidungsfällen.

Jährliche Zahl der Geburten:

Total $\left.{ }^{1}\right)$ - männlich — weiblich,

Zahl der Zwillinge - Zahl der unehelichen Kinder. Verhältniss zwischen Ehen- und Geburtenzahl.

Verhältniss zwischen Einwohner- und Geburtenzahl (Procentsatz der Geburtsfälle).

Jährliche Zahl der Todesfälle:

Total ${ }^{1}$ ) - nach Jahreszeiten - nach dem Geschlecht - nach dem Alter.

Verhältniss zwischen Geburts- und Todesfällen.

Verhältniss zwischen Einwohnerzahl und Torlesfällen (Prozentsatz der letzteren: Sterblichkeit oder Mortalitätsziffer). Nittlere Lebensdauer.

Fälle hohen Alter's.

Todesursachen :

gewöhnliche (Alter, Krankheiten etc.),

ausserordentliche (Epidemien, Kriegr, Hungersnoth etc.).

Die erhaltenen Zahlen werden gewöhnlich in tabellarische Form gebracht, wobei die rerschiedenen Kolonnen Ueberschriften tragen, welche die Bedeutung derselben genügend hezeichnen müssen. Die Resultate können aber auch graphisch reranschaulicht werden, z. B. der Gang der Sterblichkeit nach den Jahreszeiten durch eine Kurve, wie dies für den Gang anderer Erscheinungen gezeigt worden ist ( $\mathrm{rgl}$. oben S. 411).

Bevölkerungsbewegung. Wenn Volkszählungen aus rerschiedenen Epochen rorhanden sind, so ist durch Vergleichung derselben zu ermitteln, ob eine Termmlwun! oder Vrmindcum, Zu- oder Abnahme der Berölkerung stattgefunden hat. Es ist dies sehr einfach, wem die Zïhlungen in gleichmässiger Weise rorgenommen worden sind. Dies wird aber selten der Fall sein, und dann hat man voreist zu untersuchen, wodurch sie von einander abweichen, welches die Differenzen sind in ihrer Anordnung, sowie namentlich in der Ausdehnung, welche zu verschiedenen Zeiten einem und demselben Titel oder Begriffe gegeben wurde. Die verschiedenen Arrangements sind auf Einen Plan zu reduziren,

1) Es ist anzugeben, ob die Todtgeburten mitinbegriffen sind und welche Ziffer sie bilden. 
und jede einzelne Kategorie, für welche bald weitere bald engere Grenzen angenommen waren, muss nun einen und denselben Begriffsumfang erhalten. Wenn z. B. eine ältere Zählung nur Ziffern en bloc für die Gesammtbevölkerung enthält, während spätere zwischen sesshafter und flottanter Bevölkerung unterscheiden, so sind zum Zwecke der Vergleichung vorerst die letzteren Zahlen wieder in Eine zusammenzufassen; wenn in die eine Zählung Truppen (Garnisonen, einquartirte Mannschaft etc.) aufgenommen sind, in die andere nicht, so hat man die bezüglichen Zahlen aus der ersten zu beseitigen, damit sie mit der zweiten dieselbe Grundlage erhalte.

Sind diese Vorarbeiten gemacht, so können nun die Vergleichungen vorgenommen und Schlüsse gezogen werden. Aus den Berechnungen wird sich ein Mittel (Durchschnitt) der Berölkerungs-Zu- oder Abnahme ergeben für den ganzen Zeitraum seit der ersten Volkszählung oder je für die Zeit zwischen zwei aufeinanderfolgenden Zählungen. Womöglich berechnet man die bezüglichen Werthe, positive und negative: Zuwachs und Abnahme für zehn- oder fünfjährige Perioden und drückt dieselben in Prozenten aus. Es zeigt sich hiebei, ob die Bewegung (Zu- oder Abnahme) mehr oder minder gleichoder ungleichmässig und wann sie am stärksten war.

Es ist von Werth, die Ursachen dieser Erscheinung kennen zu lernen, namentlich wenn dieselben ausnahmsweise sind. Der Bevölkerungszuwachs kann verursacht sein durch einen Ueberschuss der Geburten über die Todesfälle, eine mehr oder minder starke Einwanderung und bei wilden Stämmen durch Einkauf oder Raub von Sklaven. Die Abnahme kann herrühren von einem Ueberwiegen der Todesfälle über die Geburten, sei dasselbe normal oder - bei Hungersnoth, Seuchen, Krieg u. s. w. - ausnahmsweise, von Auswanderung (vereinzelter oder massenhafter) und von Menschenhandel (Sklavenjagden, Negerhandel). - Die Ein- und Auswanderung ist wohl zu unterscheiden von solchen Bewegungen, welche nur in Verschiebung eines Theiles der Bevölkerung innerhalb der Grenzen des Landes oder der Gegend bestehen: dem Zuströmen der ländlichen Bevölkerung nach den Städten oder dem zeitweisen Wandern eines Bevölkerungstheiles von gewissen Punkten nach bestimmten andern Stellen des Territoriums. Nur die eigentliche Ein- und Auswanderung - 
als Bewegungen, welche die Grenzen des Landes überschreiten - influiren auf das Total der Einwohnerzahl; jene andern Vorgänge aber, als blos interne Deplacirungen eines Theils des Volkes, modifiziren lediglich die räumliche Vertheilung der Bevölkerung in dem Territorium.

\section{RASSEN UND TYPEN.}

Die ethnischen Charaktere im Allgemeinen. Oft erscheinen die Eingebornen eines Landes auf den ersten Blick einander alle im höchsten Grade ähnlich; aber selten ist eine Bevölkerung durchaus homogen, und bei aufmerksamer Beobachtung wird man bald Differenzen und Nüancen wahrnehmen, welche die Unterscheidung von zwei oder mehr Gruppen veranlassen. Das Vorherrschen oder ausschliessliche Vorkommen einer solchen Gruppe in gewissen Theilen des Landes, einer andern Gruppe in bestimmten andern Gegenden führt zur Ermittlung der geographischen oder ethnographischen (d. h. rassenweisen) Vertheilung des Volkes in dem Territorium, welche wiederum zweckmässig kartographisch dargestellt wird.

Vor Allem aber handelt es sich nun darum, zu bestimmen, wodurch denn die Individuen, die wir beobachten, von andem Rassen und Typen abweichen. Wenn es nicht schwer ist, diese Unterschiede und Abstufungen wahrzunehmen, so ist es dagegen keineswegs leicht, anzugeben, worin sie bestehen, um so weniger, als Eigenthümlichkeiten, die vorab in die Augen fallen, wie die Verschiedenheiten der Hautfärbung, nicht auch die wesentlichsten Nerkmale sind.

Neben den zunächst hervortretenden Unterschieden der Hautfarbe, der Form des Kopfes (des Schädels und Gesichtes) und des ganzen Körpers (Wuchses), der Haare u. s. w., welche zwischen einem Europäer, einem Neger, dem Kalmüken, Javanesen und neuweltlichen Indianer bestehen, gilst es feinere Nüancen, welche zwar weniger hemerkbar als jene, aber doch in solchem Grade fühlbar werden, dass man weder zwei benachbarte Völker, noch die verschiedenen Bewolner derselben Gegend mit einander verwechselt. Hierauf beruht die Eintheilung des menschlichen Geschlechts in Rassen, Varietiiten und Typen, nach Werth und Bedeutung der Merkmale, welche zur Lnterscheidung dieser Gruppen dienen. 
Eintheilungen in Rassen sind schon mehrfach aufgestellt worden; leider existiren so viele Systeme als Autoren und bringt fast jedes Jahr eine neue Klassifikation. Die Wissenschaft hat hier noch lange nicht ihr letztes Wort gesprochen. Deshalb hat man nicht dahin zu streben, die Völkerschaften, welche man kennen lernt, in eine der bestehenden Eintheilungen unterzubringen, sondern sie nach allen Gesichtspunkten zu studiren und zu beschreiben, einerseits das Uebereinstimmende und Aehnliche, andrerseits das Unterscheidende aufzusuchen und hervorzuheben, ohne sich viel darum zu bekümmern, ob die Gruppen, welche man so erhält, den bisherigen Vorstellungen und Schablonen entsprechen oder nicht. Es gilt das nicht nur für das Studium der Völkerschaften ferner Länder, die noch nicht ethnographisch klassifizirt sind, sondern auch benachbarter Völker, die für ganz bekannt gehalten werden. Im einen wie im andern Falle soll der Reisende einzig darnach trachten, frei von vorgefassten Meinungen eine gute Charakteristik der Volksstämme zu geben, welche er besuchte.

Die Merkmale, wonach das menschliche Geschlecht in Rassen einzutheilen ist, können unterschieden werden in anatomische, physische, physiologische und physiognomische. Mitunter fügt man diesen Kategorien noch andere bei, wie pathologische, intellektuelle, moralische Eigenschaften u. s. w.

Die anatomischen Merkmale bestehen in der Bildung und den Dimensionen des Schädels, der Grösse des Gesichtswinkels, dem Vorspringen von Kinn und Backenknochen, der Insertionsweise der Zähne, dem Wuchse oder der Statur, den Dimensionen der verschiedenen Theile des Knochengerüstes u. s. w.

Als physische Merlimale bezeichnet man die Hautfarbe, Form, Stellung und Farbe der Augen und Haare, reichliche, dürftige oder fehlende Bartbildung etc.

Physiologische Merlimale sind diejenigen, welche sich darauf beziehen, wie die Organe funktioniren: auf Differenzen in Blutumlauf, Athmung, Verdauung etc., sowie in der allgemeinen organischen Entwicklung der Individuen.

Physiognomische Merkmale sind die Verschiedenheiten in Gesichtsausdruck, Mienenspiel, Gesten, Körperhaltung und Bewegungen.

Diese verschiedenen Charaktere haben sehr ungleichen Werth. Offenbar kommt den ersteren die grösste und wesent- 
lichste Bedeutung zu; gleichwohl sollen die übrigen nicht vernachlässigt werden.

Ich habe absichtlich die physiognomischen Nerkmale miterwähnt, während dieselben in den meisten Klassifikationen der Menschenrassen nicht genannt werden. Die Methode von II. Rochet ${ }^{1}$ ) scheint mir sehr verdienstlich, wenn ich auch nicht alle seine Folgerungen acceptire. In der That hat jede Rasse ihre eigenthümliche Physiognomie, desgleichen jeder Typus, den sie enthält, die seinige. Auch handelt es sich hier nicht um zufällige Dinge; denn wenn etwas sich verexbt, so sind es diese Familienähnlichkeiten.

Hinwieder habe ich oben die sprachlichen Merkmale unerwähnt gelassen, auf welche sich einige Klassifikationen gründen, und noch weniger habe ich die Religionsunterschiede u. dgl. berücksichtigen wollen; deun es sind das keine natürlichen, einer Rasse, einem Volke oder Individuum inhärirenden Charaktere. Die Sprache wird nicht ererbt, sondern erlernt. Aehnlich verhält es sich mit dem Religionshekenntniss $u$. dgl.; das sind Dinge, welche der Einzelne sich aneignet. Ein Kind europäischer Abstammung, das unter Wilden aufwächst, wird die Sprache dieser Wilden sprechen, ihren Glauben und ihre Gewohnheiten annehmen, wie ebenso ein Negrerkind, das ganz jung zu Weissen kommt, deren Sprache und Denkweise sich aneignet, so dass in beiden Fällen die Abstammung nur an den anatomischen, physischen, physiologischen und physiognomischen Merkmalen erkannt werden kann. Von den Völkern gilt dasselbe wie von den Individuen. Es fehlt ja nicht an Beispielen, dass ganze Völker eine andere Sprache und Religion, damit aber auch ganz andere Sitten angenommen haben. Auch braucht man nur die Bevölkerung eines Landes nach Sprache und Religion zu klassifiziren, um sofort zu sehen, dass man hiebei Abtheilungen erhält, welche mit den auf die körperlichen Merkmale gegriündeten selten übereinstimmen. Tölker, welche ihrer Abstammung nach sehr verschieden sind, haben oft dieselbe Religion und Sprache, und umgekehrt finden wir bei Angehörigen einer und derselben Rasse ganz verschiedene Sprachen und Religionssysteme. Es mag in ersterer Hinsicht nur daran

1) Bases de la classificution éthnographinue, par M. Rochet, Paris 1876. 
erinnert werden, dass in Asien und Afrika Volksstämme verschiedener Rassen die arabische Sprache und die muhamedanische Religion angenommen haben; ein Beispiel für den zweiten Fall aber bieten die verschiedenen Zweige der baskischen Rasse, wovon die Einen das Französische, Andere das Escuara und noch Andere das Spanische sprechen; ferner gewisse afrikanische Völkerschaften, von denen je ein Theil zum Christenthum, ein anderer zum Muhamedanismus sich bekennt, während ein dritter noch dem Fetischdienst anhängt.

Hiemit soll nicht behauptet werden, dass den Eigenthümlichkeiten in Sprache, Religion u. s. w. für den Zweck, welchen wir im Auge haben, gar keine Bedeutung zukomme; aber zwischen diesen und den früher genannten Eigenschaften besteht ein wesentlicher Unterschied. Die letzteren sind an. geboren; sie zu erwerben oder zu verlieren, ist nicht Sache von Willensakten, und wenn wirklich — was noch nicht sicher ist - an solchen Eigenschaften eine Rasse, welche dieselben sonst nicht besitzt, im Verlaufe der Zeit theilnimmt, so kann das jedenfalls nur geschehen in Folge von Mischungen (Kreuzungen) und erst nach vielen Generationen. Die Europäer erhalten durch langen Aufenthalt in Afrika nicht die körperlichen Eigenschaften - das krause Haar, die platte Nase uind die wulstigen Lippen - des Negers, und die nach den Unionsstaaten verpflanzten Neger sind dort nicht zu Weissen geworden. Nichts aber ist leichter, als dass ein solcher Europäer oder Neger eine andere Sprache und Religion annehme; er braucht dazu nicht einmal sein Land zu verlassen; dazu genügt der menschliche Wille, der eigene oder derjenige eines Andern (eines Eroberers z. B.). Im einen Fall handelt es sich eben um wesentliche oder inhärirende, im andern um zufällige Eigenschaften; die ersteren haben determinativen, die letzteren blos deskriptiven Werth.

Von den Eigenthümlichkeiten der ersteren Art darf keine vernachlässigt werden. In treffender Weise bemerkt hierüber ein kompetenter Gelehrter ${ }^{1}$ ): Weder die Form und Dimensionen des Schädels und der Glieder, noch die Farbe von Haut und Haaren können einzelı als sicheres Kennzeichen

1) Dr. Julius Jolly, Völkerkunde und Anthropologie ; "Im neuen Reich" 1874; S. $292 \mathrm{ff}$. 
zur Bestimmung der Menschenrassen dienen, ebenso wenig Form, Querschnitt, Fülle oder Mangel der Haare etc. Nur gestützt auf die Gestmmtheit aller dieser Merkmale, selbst der scheinbar unbedeutendsten, kann man zu einer guten Klassifikation gelangen.

Für den Reisenden handelt es sich, wie bemerkt, nicht sowohl darum, dass er klassifizire, sondern darum, dass er die Eigenthümlichkeiten der von ihm besuchten Völker und Vollsstämme, eine nach der andern, bestimme und notire. Hierüber haben wir noch einige Bemerkungen zu machen, wobei wir uns an die oben erwähnte Eintheilung und Reihenfolge der Kemneichen in anatomische, physische, physiologische und physiognomische halten.

Anatomische Merkmale. Die Messungen am lebenden Körper sind bereits (Vorbereitung, S. 115) besprochen worden. Für dieselben ist eine gute Ausuchl con Indiriduen zu treffen: als ungeeignet sind alle Diejenigen bei Seite zu lassen, welche abnorme und unförmliche Bildungen, künstliche Verunstaltungen $u$. dgl. aufweisen; die zu wählenden Individuen müssen den Typus der Rasse oder Varietät, welcher sie angehören, repräsentiren. Da aber dabei immer noch die individuellen Verschiedenheiten sich geltend machen, so sind die Messungen in möglichst grosser Zahl rorzunehmen, damit Durchschnittsresultate erzielt werden können, welche die wahren Mittelwerthe möglichst befreit von jenen Zufälligkeiten darstellen.

Die aus solchen Messungen sich ergebenden Zahlen sind erheblich verschieden, jenachdem sie von Männern, Frauen oder Kindern entnommen sind. Man hat daher die Messungen nach diesen drei Gruppen auseinander zu halten, für jede derselben eine Anzahl Individuen zu wählen und hiefür drei besondere Verzeichnisse anzufertigen.

Die tahellarische Einrichtung der Verzeichnisse soll auf Papier von grossem Format - schon vor den Messungen erstellt werden. Am linken Rande derselben bezeichnet man auf den einzelnen Horizontalzeilen kurz, aber doch genau, die Art der Messung; am Kopfe der folgenden vertikalen Kolonnen bringt man, als Leherschrift einer jeden derselben, die Bezeichnung des Namens, der Nationalität, des Geschlechtes und soweit möglich des Alters der betreffenden Person an. In der so überschriebenen Kolonne sind die einzelnen Messungs- 
resultate genau auf der Stelle einzutragen, auf welcher links die betreffende Messung benannt ist. Handelt es sich dabei um Individuen einer wenig bekannten Völkerschaft, so notire man auf dem Blatt oder dessen Rückseite den Namen, welchen dieser Stamm sich selbst gibt, womöglich mit Angabe seiner sprachlichen und sachlichen Bedeutung, resp. seines Ursprungs.

Wir haben schon früher bemerkt, dass der Reisende sich durch Vorübungen in den Stand setzen soll, solche Messungen rasch vorzunehmen. Aber auch wenn das geschehen ist, wird er noch mitunter zu kleinen Versprechen und kleinen Geschenken seine Zuflucht nehmen müssen, um die Abneigung zu überwinden, welche die Leute gegen die Vornahme dieser Messungen an ihnen haben und sie dahin zu bringen, dass sie solange als nöthig die erforderliche Stellung beibehalten. Mitunter wird es sich als schlechterdings unmöglich herausstellen, an einem Individuum alle wünschbaren Messungen vorzunehmen; man beginne daher mit den wesentlichsten: den drei Dimensionen des Kopfes ${ }^{1}$ ) und der Grösse (Wuchshöhe).

Wenn man in Folge von Kämpfen sich Schädel oder Skelette verschaffen kamn ron Individuen einer noch ziemlich ungenügend bekannten Rasse, so sende man sie einem anthropologischen Museum oder Fachgelehrten zu. Für den Transport verpackt man sie tale quale in ein Fässchen Weingeist oder man lässt sie von den Weichtheilen befreien und bringt sie nun in eine Holzkiste, welche im Uebrigen mit Gras und Moos ausgefüllt wird. Die wichtigsten Skelett-Theile nach dem Schädel sind die Beckenknochen, sodann Oberarmknochen (Humerus) und Schienbein (Tibia).

Können solche Sendungen, z. B. wegen Mangel an Transportgelegenheit, nicht gemacht werden, so misst man die verschiedenen Theile nach Massgabe des früher (S. 109) Gesagten und nimmt Photographien der Schädel auf (Ansichten von vorn, von der Seite und von oben).

Physische Merkmale. Als in die Augen fallende äusserliche Eigenschaften künnen die physischen Kennzeichen beschrieben werden. Immerhin hat die Beschreibung ihre

1) Hinsichtlieh der Dolichocephalie (S. 111) unterseheide man zwischen frontaler und occipitaler (durch grössere Entwicklung des vordern Kopftheils oder aber des Hinterhauptes veranlasste) Ausbildung derselben. 
Grenzen: eine Darstellung durch die Feder kann die verschiedenen Nüancen kaum genügend bezeichnen; vielmehr leidet eine solche immer an einer gewissen Unbestimmtheit und Willkür. Die beste Darstellung der physischen Kennzeichen sind Photographien der verschiedenen Individuen (Vorder- und Seitenansicht), auf welchen man einen Massstab für die Grössenverhältnisse, ferner Bemerkungen über die Farbe der Haut, Augen und Haare anbringt. Wenn der Beschreibung solche Photographien beigegeben sind, erlangt sie erst ihren vollen Werth; denn auch sie kann ihrerseits die bildliche Darstellung ergänzen, namentlich indem sie hervorhebt, was an den Bildern in Folge ihrer Kileinheit und aus andern Gründen sich nur schwer oder gar nicht wahrnehmen lässt.

Was den Wuchs oder die Körperform im Allgemeinen betrifft, so ist zu bemerken, ob die Individuen von liurzem, gedrungenem oder aher von hohem und schlankem Wuchse, korpulent oder mager seien, wohlgestaltet oder unschön, muskulüs oder schlaff u.s. w., vorausgesetzt, dass die einen oder andern dieser Eigenschaften nicht blos bei einzelnen Individuen auftreten, sondern bei ihrer grossen Mehrzahl, so dass sie typische Bedeutung haben.

Die Hautfarbe rührt bekanntlich ron einem Farbstoff (Pigment) in der Schleimschicht zwischen Epidermis und Lederhaut her; die Beschaffenheit dieses I'igments rerursacht die wesentlichen Farbenverschiedenheiten der Menschenrassen: dessen Menge sowie auch die Verschiedenheit der Epidermis (ob diese mehr oder minder zart und durchscheinend ist) bedingt den helleren oder lunkleren Ton der Farbe. Auch die Ungleichheiten im Blutgehalt der Lederhaut (grosse Blutfülle oder Blutarmut) bewirken gewisse Nüancen. Dagegen ist die Hautfärbung nicht in dem Maasse, wie nach einel weit rerbreiteten Meinung angenommen wird, rom Klima (beziehungsweise der geographischen Breite) abhängig, dass eine einfache Relation zwischen diesem Faktor und der dunkleren Hautfarbe behauptet werden könnte.

Yeugeborne, Kinder, Mämner, Frauen und Greise haben je ihre Besonderheiten in der Hautfürbung; ferner ist diese bei einem und demselben Individuum nach den Körpertheilen verschieden. Die immeren Handtläthen und die Fusssohlen 
sind im Allgemeinen von hellerem Ton als die übrigen Partien, und die der Sonne und Luft ausgesetzten unbekleideten Körpertheile sind dunkler als die bekleideten.

Diese Verschiedenheiten sind so gut als möglich darzustellen, sei es durch Vergleichungen mit Farben von Naturobjekten, die sich hiezu (als bekannt und konstant) eignen, und künstlichen Skalen, sei es dadurch, dass man zwei oder mehrere Farben mischt, bis man auf der Palette den richtigen Ton erhält und nun durch einen Pinselstrich diese Farbe in die Papiere (Albums oder Notizbücher) einträgt.

Wir sprechen später von dem Tätowiren und Bemalen verschiedener Körpertheile und erwähnen hier nur die natürlichen Fleclen, welche sich, wie die sogenannten Sommersprossen, bei manchen Individuen finden.

Zwischen dem Geruch der Haut (Ausdünstung derselben) und den Rassen scheint eine gewisse Beziehung zu bestehen. Man notire sich dieses Nerkmal, ohne dessen Werth zu überschätzen. Dieser Geruch tritt namentlich hervor nach starken Anstrengungen wie einem langen Marsche; er ist aber nicht zu verwechseln mit dem durch Unreinlichkeit entstehenden übeln Geruche.

Die Farbe der Augen, d. h. der Regenbogenhaut oder Iris (um die Pupille oder den Augenstern herum) ist bei den einzelnen Individuen ungleich. Eine bestimmte Augenfarbe ist nicht das ausschliessliche Erbtheil einer Rasse, kann aber bei einem Volke so vorherrschen, dass sie die Bedeutung eines ethnischen Merkmals erlangt. Es ist also $\mathrm{zu}$ untersuchen, welche Augenfarbe sich bei den meisten Angehörigen einer Völkerschaft vorfindet. Zu dem Ende notirt man sich diese Farbennüance für z. B. 100 zufällig herausgegriffene Personen und gibt nun durch einen Bruch (Prozentsatz) das Verhältniss an, in welchem eine jede der hiebei beobachteten Farben vertreten ist. Wenn eine dieser Zahlen alle andern weit übertrifft, so ist die betreffende Farbennüance als die vorherrschende anzusehen; man wird aber immerhin noch verifiziren, ob das mit weiter zu beobachtenden Thatsachen übereinstimmt oder ob so viele Ausnahmen vorkommen, dass die Aufstellung einer Regel unmöglich wird. 
Oft hält es schwer, die Augenfarbe genau zu bestimmen. Bei manchen Individuen hat die Iris mehrere verschiedene Farben, sowie Flecken und Streifen oder Strahlen von einer andern Nüance als Grundfarbe. In solchen Fällen muss man aus einiger Entfernung beobachten, damit man einen Gesammteindruck erhält und die Einzelnheiten keine störende Wirkung ausüben. Da ferner der von Augenbrauen und Wimpern geworfene Schatten auf die Beurtheilung der Augenfarbe influiren kann und diese zuweilen mit dem Befinden des Individuums wechselt - sodass Zorn und leidenschaftliche Erregtheit von Einfluss auf dieselbe sind - so ist auch diesen Verhältnissen bei der Wahl der Beobachtungszeit Rechnung zu tragen.

Die Farbe der Augen ist, wie diejenige der Haut, entweder durch die zutreffende Nummer einer Farbenskala oder durch einen Pinselstrich anzugeben. Es soll auch bemerkt werden, welches Aussehen "das Weisse des Auges" hat; dasselbe ist nämlich öfters nicht rein weiss, sondern gelblich oder von rothen Äderchen durchzogen.

Die Farbe der Haare steht nicht unbedingt in Beziehung zu derjenigen der Augen. Allerdings findet man sehr oft blaue Augen gepaart mit blonden Haaren und andererseits schwarze Augen mit dunkelfarbigen Haaren; es gibt aber auch zahlreiche Ausnahmen. Die Haarfarbe hängt ferner nicht schlechtweg von der geographischen Breite (beziehungsweise dem Klima) ab und ist ebensowenig in absoluter und ausschliesslicher Weise Erhtheil einer Rasse. Dieselbe ist daher in analoger Weise $z u$ ermitteln wie die Augenfarbe; d. h. man hat zu bestimmen, ob und in welchem Grade eine gewisse Nüance vorherrsche.

Diese ist auch ebenso zu notiren wie die Hautfarbe (pag. 554), unter Anwendung der nämlichen Skala.

Die Farbe der Haare ist nicht nur verschieden nach den Individuen und Geschlechtern, sondern auch bei einer und derselben Person nach dem Alter: selten bleibt einem Kinde die Färbung der Haare, welche es hatte, als es noch ganz jung war; in der Regel wird sie nach und nach dunkler, zuweilen aber auch heller; später, bei vorgerückterem Alter, werden die Haare (sogar, ja insbesondere die dunkelsten) grau oder weiss. 
Wichtiger noch als die Farbe ist die Beschaffenheit der Haare nach deren Bau oder Bildung. In dieser Hinsicht theilt man dieselben nach Beobachtung von freiem Auge ein in straffe oder ganz glatte, wellige, lockige, gekräuselte und wollige oder krause; andrerseits - auf Grund der Beobachtung durch das Auge oder das Gefühl - in feine und grobe, glänzende und matte, geschmeidige und harte oder rauhe. Nach der Form ihres Querschnittes, beobachtet mit dem Mikroskop, unterscheidet man die Haare in cylindrische mit kreisrundem Querschmitt und bandförmige mit länglichrundem Querschnitt. Es stellt sich heraus, dass diese Formen des Querschnitts der Haare - kreisrund, eirund, mehr oder minder länglich elliptisch — nach den Rassen verschieden sind. Man bezeichnet sie durch das Verhältniss zwischen dem kleinen und grossen Durchmesser eines Querschnitts: $\frac{d}{D}$, wobei man $D=100$ setzt, sodass $\frac{d}{100}$ den Grad der Abplattung des Querschnitts angibt. Diese Bestimmung ist nicht leicht; sie erfordert ein starkes Mikroskop, und der geringste Fehler bei Anfertigung des Schnittes - in der Haltung des Instrumentes oder des Haares - macht das Resultat falsch, indem ein schiefer Schnitt statt eines senkrechten erzeugt wird. Man thut daher gut, womöglich ron Haaren, die als vollkommen entwickelt gelten können (d. h. die Individuen angehören, welche das zweite Zahnen hinter sich haben und den Typus des Volksstammes repräsentiren), Muster zu nehmen, um diese einem Fachgelehrten zur Untersuchung vorzulegen ${ }^{1}$ ).

Leicht zu konstatiren ist die natürliche Lünge der Haare bei vollkommenem Wuchse derselben.

Man hat ferner die Stcllung der Haare zur Haut und zu einander - die Vertheilung derselben — zu beobachten. Im Allgemeinen bilden die Haare schiefe Winkel zur Haut; bei einigen Rassen stehen sie aber senkrecht zu derselben. Meist sind sie über den obern und hintern Theil des Kopfes gleichmässig vertheilt; in andern Fällen aber auch sehr ungleich, sodass sie in dichtem Wuchse aus gewissen Stellen hervorsprossen, welche durch kahle Zwischenräume von

1) Professor Ernst Häckel in Jena und Brunner-Bey in Paris gehören zu den Gelehrten, welche sich am meisten mit dieser Frage beschäftigt haben. 
einander getrennt sind (büschelfürmige Vertheilung der Haare ${ }^{1}$ ).

Alle diese Faktoren - Querschnittsbildung, Länge und Stellung der Haare - sind von Einfluss auf deren äusserliche Anordmung, die Hartracht; bald hangen sie in langen glatten Strähnen vom Haupte herunter, bald fransenartig; bald sind sie aufgerichtet oder stehen rom Kopfe nach allen Richtungen ab. Dabei ist selbstverständlich wohl zu unterscheiden, was natürlich und was lïnstlich ist; manche Völker rasiren sich das Haupt kahl und lassen nur einen Zopf wachsen; andere krïuseln künstlich ihre Haare, die sonst glatt (schlicht) wären $u$. dgl. m.

Im Ferneren ist zu achten auf die Fitle mind Ausdehmun! des Wuchses der Kopfhaare, sowie der übrigen Behaarung (Bartwuchs und Behaarung des Körpers). Die Haupt- oder Kopfhaare können reichlich oder spärlich vorhanden sein, ebenso die Haare des Bartes und diejenigen an verschiedenen andern Stellen des Körpers. Es scheinen in dieser Beziehung ziemlich ausgesprochene und bezeichnende Rassenunterschiede rorhanden zu sein. Die einen sind gänzlich bartlos; andere haben nur einige wenige Haare am Kinn; dritte sind durch rollen und starken Bartwuchs ausgezeichnet. Aehnliche Lnterschiede zeigen sich in der Behaarung verschiedener Stellen des Körpers; dieselben Theile sind bei den einen ganz kahl, bei andern dicht behaart; einige Rassen weisen an Brust, Rücken, Armen und Beinen ein starkes Haarkleid auf. Indem man sich solche Unterschiede merkt, darf man nie ausser Acht lassen, dass mainche Stämme die Gewohnheit haben, sich die Haare des Bartes und gewisser Stellen les Körpers auszureissen, sodass daselbst jede Spur von Haarwuchs beseitigt wird. Ferner ist nicht $\mathrm{zu}$ vergessen, dass reineswegs unbedingte Uebereinstimmung herrscht zwischen Fülle und Farbe der Kopfhaare einerseits und der übrigen

1) Auf diese Ungleichheiten des Haarwuchses gründet Professor Häckel die iruppirung seiner 12 Jenschenarten (mit 36 Rassen) in a) Wollhwarige oder L'intrichen Haare band-förmig platt), bestehend aus Büschelhaarigen mit ungleicher und liesharigen mit gleichmässiger Vertheilung der Wollhaare; b) Schlichthaarige der Lissotrichen (Haare eylindrisch), welche in Straffhaarige und Lockenharige erfallen. - Als büschelhatarige species" bezeichnet er die Papuas und Hottentten, als Vlieshaarige die Kaffern und Neger, als Struffhaurige die Australier, Maiyen, Mongolen, Arktiker und Amerikaner, als Lockenharige endlich die Dravidas, ubier und Mittelländer. Vgl. Dr. Ernst Hïckel, natürliche Schöpfungsgeschichte, $\therefore$ Aufl, Berlin 1874, S. 603 ff. 
Behaarung andrerseits, sodass man nicht einfach von den Eigenschaften der einen auf diejenigen der andern schliessen kann.

Die Ausdehnung des Kopfhaarwuchses (Haarbodens) ist von Einfluss auf das Aussehen der Stirn; wenn derselbe bis weit in die Schläfengegend und gegen die Augen hinab sich erstreckt, so erscheint die Stirn schmal und niedrig, im entgegengesetzten Fall aber breit und hoch. Auch ist die vordere Grenze des Kopfhaarwuchses verschieden gestaltet; bald zieht sie sich in fast gerader Linie von einer Schläfe zur andern, bald macht sie verschiedene Biegungen, sodass sie in ihrem Mitteltheil oder gegen die Enden hin nach oben und hinten zurücktritt. Die Ausdehnung des Haarwuchses wie diese rordere Grenze desselben variirt mit dem Alter, und die kahlen Stellen treten in nach Rassen und Individuen verschiedenen Formen auf: als zentrale Tonsur, mediane Kahlheit u. s. w. Die hintere Grenze des Kopfhaarwuchses ist nur von Bedeutung, wenn sie sehr tief in den Nacken hinabreicht oder gegentheils in ungewöhnlicher Höhe am Hinterhaupte zurückbleibt.

Wir gehen nun zu den andern äusseren Kennzeichen und deren Beschreibung über.

Die Form des Gesichtes kann rund, oval, länglich, quadratisch oder selbst breit-viereckig sein; das Oval ist nicht immer elliptisch, sondern wirklich eiförmig, wobei der breitere Theil nach unten oder oben gekehrt sein kann.

Es ist ferner zu unterscheiden zwischen gewölbter und flacher Form des Antlitzes: Bei jener treten die medianen Theile vor, die seitlichen zurück; bei diesen hingegen erscheinen die Backenknochen vorspringend wie die Nase.

In der Form des Profils tritt ein wichtiger Unterschied hervor; es ist derjenige zwischen Prognathismus und Orthognathismus (vgl. S. 112); bei dem prognathen Typus ist das Profil schief, indem Nase und Kiefern schnauzenartig vorspringen; der orthognathe Typus hingegen zeigt eine ziemlich senkrechte Profillinie: Stirne, Kiefer und Kinn liegen nahezu in einer Vertikalen.

Endlich machen sich Unterschiede im Aussehen des Gesichts darin geltend, dass entweder die Züge regelmässig, symmetrisch und alle Formen sanft gerundet oder aber die 
Züge unregelmässig, fratzenhaft-verzerrt und die Kontouren hart und eckig sind.

Was die einzelnen Theile des Antlitzes betrifft, so zeigt sich die Stim bald hoch, breit und weit, bald niedrig und schmal; senkrecht, schief oder gewölbt; mit mehr oder minder vortretenden Theilen (Stirnhöcker'n); einer Mittelfurche gegen die Nasenwurzel, oder mit Querfalten, welche sich gegren die Schläfen hinziehen.

Die Augubramenbogen treten oft weit vor oder sie sind wenig entwickelt. Die Augen erscheinen im ersteren Fall tiefliegend, andernfalls aber ziemlich in der Fläche des Gesichts oder gar über diese hinaus vortretend.

Die Augenbrauen selber sind gradlinig (wagrecht) oder gewölbt; bald stark ausgeprägt, bald unscheinbar; nit spärlichen oder dichten (buschigen) Haaren; oft soweit gegen die Nasenwurzel reichend, dass sie sich dort begegnen und vereinigen; bald daselbst durch eine Lücke von variabler Ausdehnung getrennt.

Die Aurfu zeigen ausser dem rorhin erwähnten Interschied der Lage (tief- und flachliegende Augen) namentlich folgende Formverschiedenheiten; die Oeffnung zwischen den Augenlidern ist bei den einen fast kreisförmig ("runde Augen"), bei den andern eine schmale und nach der äussern Seite (gegen die Schläfe) stark verengte Spalte ("mandelförmige Augen"); zwischen diesen Extremen gibt es eine Menge von Uebergängen. Sodann liegt oft der äussere Augenwinkel höher als der innere (schiefe Augen).

Die Wimpern geben durch Verschiedenheiten in Farbe and Länge dem Blicke einen besondern Ausdruck.

Die Baclienlinorhen sind mehr oder minder rorspringend; so das in starkem Grade der Fall ist, unterlasse man nicht, lies zu erwähnen.

Die Nase bietet wohl die meisten individuellen Formrerschiedenheiten dar; indessen zeigt sie auch bei jeder Zasse und Völkerschaft gewisse vorherrschende Formen, die nan zu unterscheiden und zu beschreiben trachten muss.

Im Profil betrachtet, erscheint sie grad, konkav (Stulp1ase), konvex, gleich dem Schnabel eines Raubvogels (Adleriase), ja selbst mit einem ellbogenartigen Winkel oder innie. 
Von vorn gesehen, zeigt sie bald eine ausgeprägte Kante (Firstform), bald einen gerundeten Rücken oder sie ist flach und platt, - im Allgemeinen um so flacher, je breiter, und um so mehr vorspringend, je schmäler sie ist.

Ihre Dimensionen können bestimmt werden mit dem Tasterzirkel (S. 111); als Höhe ist der Vertikalabstand zu messen zwischen dem untern Ende der Nase und ihrer Wurzel, als Breite die Distanz zwischen den von einander am weitesten entfernten Punkten der Nasenfügel. Den Grad des Vortretens der Nase bestimmt man durch eine Messung mittels eines kleinen Lineals oder Massstabs, den man am untern Ende der Nase (Basis-Insertion) aufsetzt und auf welchem man nun den direkten Ahstand zwischen dieser Stelle und dem rorspringendsten Punkte des Nasenendes nimmt (in Horizontalprojektion). Sowohl diese Grösse als die Breite der Nase drückt man in Prozenten ihrer. Höhe aus.

Die Tasentüher sind verschieden in Lage und Form ihres Lmrisses. Dieser ist im Allgemeinen horizontal; es kann aber auch sein rorderer (vom Gesicht am weitesten abstehender) Theil höher oder tiefer gelegen sein als die übrige Partie. Ebenso kann sich derselbe seitlich, an den Flügeln, in die Höhe ziehen, so dass die Nasenlöcher nach Aussen (im Profil gesehen) mehr als gewöhnlich offenstehend erscheinen. Die Form des Umrisses ist rund, oval, elliptisch oder lineal, je nachdem derselbe zwei gleiche Durchmesser oder aber zwei mehr oder minder verschiedene Axen hat. Ihre äussern Wandungen (Nasenflügel) können schmal oder breit (dick) sein. Auch die untere Partie der Nasenscheidewand ist ungleich gestaltet: schmal oder breit und bald von gleichmässiger, bald aber von nach dem Gesichte hin zunehmender Dicke; je nachdem erscheinen die Nasenlöcher mehr oder minder weit von einander abstehend und entweder parallel oder aber divergirend (von vorn nach dem Gesichte zu sich von einander weiter entfernend).

Der Itund ist klein und schmal oder gross und weit. Sein Aussehen hängt wesentlich von der Bildung der Lippen ab, welche ganz schmal und unscheinbar, oder voller, bis dick und wulstig sein können. Auch die Farbe der Lippen ist $\mathrm{zu}$ beachten. 
Die Zïlne sind verschieden in Stellung, Form und Farbe: senlirecht oder schief nach Aussen gestellt (S.112), regelmässig orler unregcelmässig, klein und dichtgedrängt oder yross, breit und ron einander abstehend, von gleicher oder ungleicher Länge (im letzteren Fall namentlich längere Eckzähne) mit weissem und undurchsichtigem oder bläulichem und durchscheinendem orler matt-wachsgelbem Schmelz (Email) - abgesehen von Färbungen in Folge verschiedener Gewohnlieiten wie des Betelkauens und des künstlichen Färbens der Zähne, wovon später die Rede sein wird.

Das Kimn ist bei den einzelnen Individuen rerschieden ausgebildet: rundlich oder eckig, flach oder spitzig-rortretend: mitunter durch ein Grübchen ausgezeichnet.

Die Ollen sind gross oder klein, breit oder schmal, dicht am Kopfe anliegrend orler von demselhen in rerschiedenem Grarle abstehend, namentlich in ihrem obern Theil, so dass sie sogar fast hängend erscheinen. Ihre Form ist im Allgemeinen eine ovale oder rundliche, bei grewissen Rassen aber mehr viereckig. Oft sind sie künstlich entstellt. Manchen Individuen fehlt das Ohrläppchen, und mitunter ist der Rand oder die Grenze ihrer Insertion nach oben und hinten nur undentlich ausgesprochen (verwischt). Wem sie ungewöhnlich hoch oder tief stehen, so rergleiche man diese Stellung (Insertion) mit der Höhe der Augen und Nasenflügel.

Der Hals ist kurz oder lang — was die charakteristische Haltung des Kopfes hedingt — und dick orler schmächtig.

Die Schultem können flach (wagrecht) sein oder nach Aussen abfallen. Im ersteren Fall sind sie breit und mehr oder minder stark.

I)ie Brust ist breit oder schmal, gewölbt oder flach und hohl. Die weiblichen Brüste sind mehr oder minder entwickelt, hald fest und halbkugrelförmigg, bald schlaff und hängend: bei einigen wilden Stïmmen erreichen sie ausserordentliche Dimensionen, namentlich in der Länge.

Die Arme sind dicker oder dünner, gleichmässig rund oder durch ausgebildete Nuskulatur ungleichmässiger. Nitunter zeigt sich eine erhebliche Differenz zwischen dem rechten und linken Arm einer und derselben P'erson, indem jener (weil mehr gebraucht) stärker ist. 
Die Hände sind breit (stark) oder schmal, kurz oder ]änglich; die Finger kurz, dick und stumpf oder lang, zart und nach rorn sich rerschmälernd; die Nägel oral oder viereckig (quadratisch), flach oder gewölbt. Auch das Handgelenk zeigt sich in Form und Dicke verschieden ausgebildet.

Die Taille, die Form des Kiörpers oberhalb der Hüften, ist schlank und leicht oder dick und plump, jenachdem der Rumpf in der Lendengegend entschieden verschmälert oder von ziemlich gleichem Umfang wie sonst erscheint, die Schultern vortreten.

Es ist anzugeben, ob die Hüften stark rorspringen oder mit dem höheren Rumpftheile gleichmässige Kontourlinien bilden.

Der Lnterleib oder Bauch zeigt sich manchmal sehr stark entwickelt; dies ist aber oft mehr eine Folge der Lebens-, resp. der Ernährungsweise als eine Rasseneigenthümlichkeit; wenigstens trifft man Fälle ausnahmsweiser Fettleibigkeit (Korpulenz) namentlich bei den wilden Völkerschaften, welche ausschliesslich Pflanzenkost geniessen oder nach langen Entbehrungen sehr viel Nahrung zu sich nehmen, sobald sie hiezu Gelegenheit haben.

Was die äusseren Genitalien anbetrifft, so machen sich Rassenverschiedenheiten namentlich bemerkbar in der Entwicklung des Penis und der kleinen Schamlippen.

Die Gesüsspartie erlangt zuweilen eine unter dem Namen Steatopygie bekannte ausseror dentliche Entwicklung in enormen, bei jeder Berregung zitternden Fettmassen, die als eine Art Appendix am Körper erscheinen.

Die Beine sind gerade oder krumm, stark oder schwach. Die Waden sind mehr oder minder stark ausgebildet, muskulös oder durch Fettbildung rundlich.

Der Fuss ist gross oder klein, lang und breit oder kurz und schmal. Das Fussgelenk zeigt mehrfache Verschiedenheiten in seiner Bildung; es ist grob (stark, massiv) oder fein, je nachdem das Bein an seinem untern Ende, um die Knöchel, einen grossen oder kleinen Umfang hat; auch ist die Verbindung zwischen Fuss und Bein ungleicb in Bezug auf die Lage der Verbindungs- oder Insertionsstelle: diese befindet sich entweder ganz nahe am Hinterende des Fusses, unmittelbar über dem Absatz, so dass dieser (beziehungsweise 
die Ferse) kaum nach aussen (hinten) vortritt, oder aber mehr in der Mitte des Fusses, so dass dieser nach allen Seiten über den untern Theil des Beines (die Knöchelpartie) hinausreicht.

Der Fuss ist flach oder platt, wenn dessen Sohle beim Auftreten den Boden mit ihrer ganzen Fläche berührt; gewölbt oder hohl, wenn diese Berührung nur an den Enden (rorn und hinten) stattfindet. Dieser Unterschied zeigt sich bei Betrachtung des Fusses ron der Seite her (im Profil), noch besser aber, wenn man das Individuum den Fuss auf eine Lage feinen Sandes oder Staubes setzen und etwas stark auftreten lässt: vom Plattfuss entsteht dabei ein vollständiger Abdruck (Umriss), während der gewölbte Fuss nur an seinen beiden Enden und höchstens noch am äussern Rande der Mittelpartie Spuren zurücklässt. Von der künstlichen Missbildung des Fusses sprechen wir später.

$\mathrm{Zu}$ beachten sind die Stellung und das Grössenverhältniss der Zehen: sie können von einander abstehen oder dicht zusammenschliessen und in der Grösse untereinander mehr oder minder verschieden sein. Man achte hiebei namentlich darauf, ob die ngrosse Zehe" am längsten ist oder aher die zweite, d. h. welche ron diesen beiden über die andere hinausreicht.

Das Geuicht des Körpers scheint keinen grossen Werth als Rassenmerkmal zu haben. Wenn man Wägungen rornimmt, so wähle man hiezu — abgesehen ron extremen Fällen, welche zu notiren sind - Individuen mittleren Schlages und unterlasse nicht, das Gewicht der Kleider und Schmuckgegenstände als Tara in Abrechnung zu bringen.

Physiologische Merkmale. Als physiologische Charaktere haben wir solche bezeichnet, welche sich auf die organischen Funktionen oder die Lebensprozesse beziehen. Dieselben sind nicht so leicht zu bestimmen, wie die bisher erwähnten; allein sie müssen ihrer Wichtigkeit wegen studirt werden.

Der Blutumlauf geht bei den verschiedenen Rassen mehr oder minder energisch vor sich. Das Mass hiefür geben die Herz- und Pulsschläge. Bei Zählung derselhen ist aher eine richtige Wahl in Bezug auf Individuen und Beobachtungszeit sehr wesentlich; denn Alter, Gesundheitszustand, momen- 
tanes Befinden - ob das Individuum z. B. eine starke körperliche Anstrengung oder eine reichliche Nahlzeit unmittelbar hinter sich habe - können erhebliche Unterschiede rerursachen. Bei diesen Beobachtungen namentlich muss man wie spielend operiren, damit nicht die zu untersuchende Person durch ein pedantisches Verfahren alterirt werde.

Tachdem man die Zahl der Pulsschläge in der Minute (Pulsfrequenz) bestimmt, misst man auch die Körpertemperatur, indem man die Kugel eines kleinen Taschenthermometers unter die Zunge des Individuums bringt (das hierauf den Mund zu schliessen hat) oder in die Armhöhle, wobei sodann der Arm dicht an den Körper anzuschliessen ist.

Ebenso sind Farbe und Konsistenz des Blutes zu bestimmen, welches man durch einen regelrechten Aderlass exhält; ferner ist anzugeben, ob die Flecken, welche dieses Blut auf weisser Leinwand erzeugt, dunkler oder blasser erscheinen als in unsern Gegenden und ob sie scharf begrenzt oder von einem schwachen serösen Rande umgeben sind.

Die Respriration wird charakterisirt durch die Zahl der Athemzüge (Einathmungen, Inspirationen) in der Minute, wobei darauf zu achten ist, ob sich erhebliche Unterschiede ergeben, jenachdem die Person steht, sitzt oder liegt. Endlich ist durch das Gehör auch auf den Rythmus des Athmens zu merken.

Die Terdanumy kann kaum anders beobachtet werden als in ihren gewöhnlichen bekannten Wirkungen, hinsichtlich deren allenfallsige Eigenthümlichkeiten zu notiren sind.

Die Körperstälic oder Musliclliraft hat eine gewisse Bedeutung. Ian hestimmt sie durch Anwendung eines unter dem Namen Dynamometer (Kraftmesser) wohlbekannten Instrumentes, indem man unterscheidet zwischen der Kraft des mit einer Hand bewirkten Druckes (force mamelle) und derjenigen des Zuges, welchen man mit beiden Händen in vertikaler Richtung ausübt (force rénalc). Passend ergänzt man diese Angaben durch solche über die Stärke des Zuges in horizontaler Richtung, welcher zuerst mit einer Hand, dann mit beiden zusammen ausgeübt wird an einem Seile, welches über eine Rolle läuft und an dessen anderm Ende ein Gewicht angebracht ist, das nun durch den Zug $\mathrm{um}$ einen grössern oder kleinern Betrag gehoben wird. 
Von Interesse sind auch Versuche zu dem Zwecke, die Muskelstärke der Arme und Beine mit einander zu vergleichen; denn hinsichtlich dieses Stärkeverhältnisses zwischen den untern und obern Gliedmassen scheinen namhafte Lnterschiede zu bestehen.

Die Sensibilitit lässt ausgesprochene Rassenverschiedenheiten erkennen, wenn auch sehr viel von Lebensweise, Erziehung, Gewöhnung und Charakter der Einzelnen abhäugt. Wie es sich auch in letzterer Hinsicht verhalte, so beobachte man, ob die Individuen, welche in Betracht kommen, Frost und Hitze, Hunger und Durst, körperliche Anstrengungen und Schmerzen ertragen können, ohne dass sie darunter allzusehr leiden.

Bemerkenswerthe Unterschiede zeigen sich in den Funktionen des Kehlkopfs und der Simnesorgane: in Klang und Höhe der stimme, Schärfe des Gesidets, Grehors und Grondts. Letzterer Sinn ist bei manchen Rassen sehr stark entwickelt, während dagegen der (reshumark oft sehr mangelhaft erscheint, indem die Fähigkeit fehlt, Dinge von einigermassen ähnlichem Geschmack durch diesen von einander zu unterscheiden. Das Grefill zeigt selten eine bemerkenswerthe Entwicklung als in Fällen, wo es durch häufigen Gebrauch besonders ausgebildet ist. In allen diesen Beziehungen notire man die an einer Anzahl von Personen gemachten Wahrnehmungen.

Zu erwähnen sind ferner die Eigenthümlichkeiten, welche die oryanische Entwicllum! in ihren verschiedenen Phasen zeigt. Die Dauer der S'humuprschuft scheint für alle Menschenrassen gleich zu sein; diejenige des stillens (Säugens) ist im Gegentheil sehr verschieden: bald währt sie nur einige Monate, bald dehnt sie sich auf mehrere (bis fünf) Jahre aus: aber das späte Entröhurn ist mehr eine individuelle Eigenthümlichkeit als eine solche der Rasse. Wichtiger sind das Zahmen und der Zahmurhel, d. h. die Altersperioden des erstmaligen Erscheinens der Zähne (Milchzähne) und ihres Ersatzes durch das definitive Gebiss; sodann die Pubertirt oder der Eintritt der Grordlerhtswifr, wonach die Rassen trotz der Wirkung verschiedener Einflüsse — in frühreifu und solche von langrsamer (später) Entwicklung eingetheilt werden können. MIan notire die Verschiedenheiten, welche 
in dieser Beziehung in einem und demselben Lande bestehen zwischen Knaben und Mädchen und - namentlich bei Letzteren - zwischen Angehörigen der wohlhabenden und solchen der armen Klassen, wie zwischen Stadt- und Landbevölkerung; denn die verschiedenen Einflüsse, von denen wir vorhin sprachen, sind nicht nur klimatische, sondern auch solche der Ernährung und Beschäftigung, der ganzen Lebensweise. $\mathrm{Zu}$ notiren ist auch, wann bei dem Knaben der Bartwuchs beginnt, bei den Mädchen die Menstruation eintritt und wie es sich mit der Fruchtbarkeit der Frauen (nach deren durchschnittlichen Kinderzahl) verhält; in welchem Alter bei jedem Geschlecht das Wachsthum vollendet ist, Verlust der Zïhne, Ausfall und Verfürbung der Haare, Erlöschen des Fortinflanzungscermögens und endlich allgemeine Abnahme der Kraifte (Altersschwäche) eintritt. Die letztere stellt sich bei gewissen Rassen erheblich früher ein als bei andern, namentlich bei den Frauen nach Massgabe ihrer frühen Reife und ihrer Lebensweise.

Dasselbe gilt denn auch von der Lebensdauer; es ist einerseits anzugeben, welches ihr durchschnittlicher Werth ist bei dem Volke, das man studirt; andrerseits sind die häufigeren Ausnahmen zu konstatiren, namentlich auch Beispiele von langem Leben, wenn diese einigermassen zahlreich und daher charakteristisch sind.

Physiognomische Merkmale. Als solche bezeichnet man den Gesichtsausdruck, die Mienen und Gesten, Körperhaltung und Bewegungen, welche einer Rasse oder einem Volksstamme eigenthümlich sind. Es gibt darunter Besonderheiten, welche dem Reisenden sofort auffallen, hinsichtlich deren es aber schwer hält, sich darüber in zutreffender Weise Rechenschaft $\mathrm{zu}$ geben und sie richtig zu beschreiben. Soll es dem Beobachter gelingen, die feinen oft kaum merklichen Nüancen zu unterscheiden, welche einer Rasse ein eigenthümliches Gepräge geben, so muss er die Physiognomie, das Muskelspiel des Gesichts, der Arme und Hände und die Haltung des Körpers in den verschiedensten Umständen und Lagen analysiren. Auch die physischen Charaktere, von denen wir eben gesprochen haben: der Teint, Farbe und Glanz der Augen, die Brauen, die Form der Nase u. s. w. sind von wesentlich bestimmendem Einfluss auf die Physiognomie; 
hier aber handelt es sich um den eigenthümlichen habituellen Ausclruck von Energie oder Wildheit bei den Einen, sanften und träumerischen Wesens bei Andern, welcher in Beziehung steht zu den wechselnden Gefühlen und Gemüthshewegungen.

Die Zustënde und Benegungen des Gemüthe's gelangen in sehr verschiedenem Grade zum Ausdruck. So verräth sich bei gewissen Rassen oder Individuen schon eine leise Regung des Innern durch Bewegungen der Nasenflügel, welche bei andern ein Zeichen tiefgehender Störung des gemüthlichen Gleichgewichtszustandes, einer heftigen leidenschaftlichen Erregung sind. Der Reisende wird nun darauf merken, wie bei einem Volke, das er beobachtet, Erstaunen und Ueberraschung, Lnwille, Verachtung, Spott, Freude und Kummer, Abneigung, Eckel, Scham, Furcht und Schrecken sich äussern; ob diese letzteren Gemüthsbewegungen mit Erröthen oder Erbleichen verbunden sind oder ob die Farbe und sonstige Beschaffenheit der Haut einen solchen Farbenwechsel und dessen Wahrnehmung verhindert.

Das Lachen, Bitten und tiefe Schmerzen sind oft von eigenthümlichen Bewegungen und Grimassen begleitet; bei starkem Schreck richten sich die Haare auf und treten besondere Bewegungen der Arme ein; grosser Zorn spricht, sich aus in wildem Blick, Ballen der Fäuste, Knirschen der Zähne und selbst Schäumen des Nundes.

$\mathrm{Zu}$ beobachten und $\mathrm{zu}$ notiren ist auch, welche Gesten angewendet werden bei Bejahung und Verneinung, zum Herbeirufen (Winken) vor Jemandem, bei Empfang, Begrüssung und Bewillkommnung von Freunden, Gästen und hochgestellten Personen. Die Gestitiulation im Allyemeinen ist bei den einzelnen Rassen sehr verschieden; die einen sind darin sehr mässig, andere verschwenderisch.

Die Aufmerksamkeit des Reisenden richte sich auch auf die genöhuliche Stellung oder Haltung des Körpers: ob diese eine aufrechte (stehende), sitzende, ganz oder halb liegende sei; auf die Art und Weise, wie die Individuen eines Volkes oder Stammes sich setzen, essen, schlafen, reiten, wie sie zu Pferde sitzen und wie absteigen; ferner auf den Ciang der Personen und die Gangart (Trab, Galopp, Pass) ihrer Reitthiere, sowie die Mittel oder Weisen, wodurch man 
bei diesen die Marschbewegung, ein schnelleres oder langsameres Tempo und endlich den Halt bewirkt.

Rassen und Mischlinge. Mit Hülfe der verschiedenen mehr oder minder hervortretenden Merkmale, von welchen die Rede war, wird man die Bevölkerung eines Landes nach ihren Rassenbestandtheilen klassifiziren können, so zwar, dass die hiebei aufgestellten wesentlichsten Abtheilungen als wohlunterschiedene Lokalrassen gelten dürfen, wenn ihnen auch nicht die Bedeutung reiner Menschenrassen im strengeren Sinne dieses Wortes zukommt.

Von diesen Rassen sind zu unterscheiden die durch deren Kreuzung entstandenen Bastarde oder MLischlinge. Dieselben haben auch meist eigenthümliche Benennungen. So heissen die durch Kreuzung zwischen Weissen und Negerinnen erzeugten Sprösslinge Tulatten, diejenigen ron Weissen und Indianerimen Mestizen ("rothe Mestizen"; analog: gelbe und braune Mestizen für die Kinder von Weissen und Frauen der gelben und braunen Rasse); das Kind von Indianer und Negerin heisst (hino, dasjenige ron Neger und Indianerin Sambo ${ }^{1}$.

Der Reisende hat zu beobachten, welche Merkmale die Mischlinge als solche charakterisiren, welche Eigenschaften sie rom Vater, welche andern aber von der Mutter haben. Diese beiden letzteren Gruppen ron Eigenschaften sind quali-

1) Vgl. z. B. Peschel, Völkerkunde, Leipzig 1874, S. 9; F, v. Hellwald, die Erde und ihre Völker S. 211 ff. ; Robert Hartmann, die Völker Afrikas, Leipzig 1879, S. 93 ; v. Klöden, Erdkunde, Berlin 1873. I. Bd., S. 1191. - Schon in diesen, noch mehr in den Namen für weitere Kreuzungen herrschen bedauerliche Yerschiedenheiten. Benennungen wie Sambo, Kreole, Castize, Quarteron, Quinteron werden auf die störendste Weise bald so, bald anders verwendet. Gegenüber der obigen Definition von Sumbo findet man diese Bezeichnung gebraucht für die Sprösslinge von Vegern und Mulatten. Die Einen verstehen unter Kreolen $\mathrm{\Lambda bkömmlinge} \mathrm{ron}$ EItern einer Rasse, geboren in einem andern als dem heimatlichen Frdtheil dieser Rasse (rsüdeuropäische Kreolen": in der neuen Welt geborne Kinder, deren Eltern beide spanische oder portugiesische Kolonisten; "Kreolneger" : in Amerika geborne Kinder eines Negerpaares), die Andern eine bestimmte Mischlmgsstufe: Kinder ron Weissen und Mestizen, für welche hinwieder die Benennung Castizen vorkommt. Eine Nomenklatur bezeichnet (nach Girtanner) als Terzcronen oder Jorissios die Kinder von Weissen und Mulatten, als Qwarteronen diejenigen von Weissen und Terzeronen, während eine andere (nach J. J, v. Tschudy, vgl. Klöden a. a. o.) schon für die aus der Vermischung von Weissen und Mulatten hervorgehenden Abkömmlinge die Benennung "Quarteronen" hat. Weiterhin werden freilich nach der einen und andern Terminologie die durch Vermischung von Weissen und Quarteronen (beziehungsweise eines Weissen mit einer (Quartera) erzeugten Sprösslinge als Quintcronen bezeichnet; aber es ist dies nun blos noch eine formale Uebereinstimmung der Definition, während sachlich derselbe Name Ungleiches (verschiedene Stufen in einem System) bedeutet. Bei solchen und ähnlichen Namen hat daher der Reisende zu bemerken, welchen Sinn er ihnen beilegt, beziehungsweise welche Bedeutung sie in dem Sprachgebrach des Landes haben, über welches er berichtet. 
tativ und guantitativ einander nicht inmer gleich. Der eine Mischling gleicht mehr seinem Vater, der andere seiner Mutter: er kann in ungleichem Grade physische Eigenschaften des Ersteren und intellelituelle oder moralische Eigenschaften der Letzteren ererht haben. Die Kreuzung kamn auch gewisse Fehler und Fähigkeiten entwickeln oder reduziren; es ist daher zu untersuchen, ob sie in ihren Produkten eine Veredlung oder im Gegentheil Degeneration zur Folge hahe.

Eine Frage, die noch weiterer Klärung bedarf, ist die nach dem Grade der Fruchtbarkeit ron Mischlingsehen, sowohl sleichartiger (ron Verbindungen zweier Mischlinge derselben Art und Stufe, z. B. Mulatte und Mulattin) als ungleichartiger (Verbindungen eines Mischlings mit einem Individuum , reiner Rasse", z. B. einer Inattin mit einem Weissen, oder zweier Mischlinge verschiedener $\Delta \mathrm{r}^{\prime}$ und stufe. z. B. von Mulatten mit Mestizen- oder mit Zamba- und China-Franen, ron Mulatten mit Terzeronen u. dgl.). Es ist zu konstatiren, ob diese Ehen häufig kinderlos bleiben oder im Gegentheil fruchtharer seien als solche ron Eltern unremischten, beziehungsweise weniger gemischten Blutes, und ob in ersterem Falle die Ursache der Lnfruchtharkeit nicht vielleicht in andern Faktoren als der Abstammung (in Fehlem der Lebensweise) zu suchen sei.

Zeigen sich bei den Mischlingen Fälle ron Atarismus, d. h. ron Rückkehr zu einem Ahnentypus, so unterlasse man nicht, dies vorzumerken.

Typen. Wenn man erwägt, wie häufig und lange Mischungen stattfanden zwischen Völliern, die nach Abstammung und ursprünglichen Wohnsitzen weit auseinanderstunden, aber durch Wanderzüge, Eroberungen und Zufälligkeiten verschierlener Art einander genähert und durcheinander gewürfelt wurden: so sieht man leicht ein, dass oft keinp wohlunterschiedenen Rassen zu treffen sind, indem die Bevölkerung ziemlich homogen erscheint und nur nach leichten, oft fast unmerlilichen Nüancen sich in Gruppen theilen lässt.

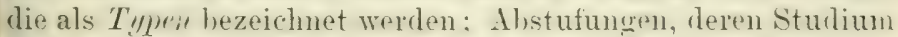
von nicht geringerem Interesse ist als dasjenige der Rassen. aher seine eigenthümlichen sohwierigheiten hat, imlen w zur Würdigung dieser feineren, ummessharen Enterschied einer weit ausgebildeten Beobachtungsgabe bedarf. 
Um den Unterschied zwischen Rasse und Typus recht zu erfassen, vergleiche man die Züge, unter welchen man sich gemeiniglich die sogenannte kaukasische oder mittelländische Rasse ausgestattet denkt, mit den Typen der geistrollen Darstellungen eines Karl Girardet und Benjamin Vautier. Die Schöpfungen der holländischen Malerschule weisen eine Fülle dergleichen Typen auf. In anderer Weise lernt man solche kennen aus literarischen Erzeugnissen wie die „Caractères" von La Bruyère. Da indessen nicht Jedermann ein Benjamin Vautier oder La Bruyère sein kann, haben wir zu untersuchen, ob es zur Bestimmung und Darstellung der Typen Mittel und Methoden gibt, welche einem Jeden zugänglich sind. Hierüber belehrt uns ein Schriftsteller ${ }^{1}$ ), den wir bereits zu erwähnen veranlasst waren, indem er ungefähr Folgendes sagt: Die beste Nethode zur Erkenntniss der Typen ist immer diejenige der Künstler und Naturforscher: sich jede Form und jeden Ausdruck von auffälligem Gepräge zu merken; sie zu verfolgen in ilnen Nüancen, Stufen und Mischungen, bei Individuen, in welchen sie uns neuerdings vor Augen treten; endlich durch Abstraktion aus zahlreichen derartigen Beobachtungen die charakteristischen Züge $\mathrm{zu}$ erfassen, vergleichend $\mathrm{zu}$ interpretiren und klassifiziren. „Der reine Typus, wie ihn die Feder des Schriftstellers, der Stift des Zeichners oder der Pinsel des Maler's uns vorführt, ist ein Idealgebilde, in welchem Charaktere rereinigt sind, die wir in Wirklichkeit nicht alle bei einem einzelnen Wesen beisammen und so ausgesprochen finden. Die Darstellung ist insofern übertrieben oder überladen; aber der Leser und Beschauer können sich darnach eine zutreffende Idee ron dem Typus machen, wie er ihnen konkret, um diesen oder jenen Zug ärmer, in zahlreichen Varietäten und Abstufungen entgegentritt." -

Man merke sich also jeden auffälligen $\mathrm{Zug}$ und beobachte, ob er der Mehrzahl der Bewohner gemeinsam ist (Nationaltypus) oder Merkmal gewisser Klassen und Stände (Kasten-, Standestypus etc.) oder blos die Eigenthümlichkeit einer bestimmten Berufsart, Gegend u. s. w. (Spezial- und Lokaltypen etc.). Man bemerke auch, ob und inwieweit ein der-

1) H. Taine, Notes sur 1'Angleterre, Paris 1872. 
artiger Zug bei der Gruppe, in welcher er sich findet, konstant sei, andernfalls, welche individuellen und lokalen Modifikationen er aufweist. Aus solchen Zügen bildet sich der Geist nach und nach von dem Einzelnen als Angehörigen und Repräsentanten einer gewissen Gruppe ein ideales Bild, welches zwar keinem bestimmten Individuum gleicht, aber ihnen allen - soweit sie Mitglieder einer solchen Gruppe sind - ähnlich ist.

Einen nationalen, Kasten- und Berufstypus richtig aufzufassen ist übrigens mitunter nicht besonders schwierig. Man trifft zuweilen Personen, die als wahre Inkarnationen solcher Typen gelten können, sodass man nur von der einen und andern ganz individuellen Eigenthümlichkeit zu abstrahiren hat, um nach einer solchen Person ein typisches Bild der Gruppe zu gewinnen, welche sie repräsentirt. Es ist das namentlich der Fall, wenn die Manier der Haar- und Barttracht (Schnurrbart, Kinn- und Backenbart), der Kopfund Körperhaltung durch Nachahmung wesentlich bestimmt wird. So z. B. gibt es in Italien einen Viktor Emanueloder Humbert-Typus mit langem Schnurrbart, in Deutschland unter den Offizieren und Beamten zwei Typen, welche den Kaiser Wilhelm und den Fürsten Bismarck imitiren; in Russland Generäle, welche, auf einige Distanz gesehen, eine gewisse Aehnlichkeit mit dem Czar zu haben scheinen. Analoge Verhältnisse wird man überall da beobachten, wo das Streben herrscht, Jemandem zu gleichen. Immerhin beruht der Typus namentlich auf Aehnlichkeiten, die, als Wirkungen gleicher Ursachen aus der Identität von Existenzrerhältnissen, der Lebensweise, Beschäftigungsart etc. hervorgehend, weder zufällig noch künstlich sind.

Fühlt man sich ausser Stande, Typen in der angegebenen Weise darzustellen, indem man die Züge zu einem Bild da und dort her nimmt, wo sie am besten ausgesprochen sind: so wähle man Individuen aus, welche den Typus, um den is sich handelt, am besten darstellen, photographire sie und rebe auf Grund dieser Porträts, die miteinander zu vergleichen sind, eine Darstellung des idealen Typus in Wort der Bild.

Geistige Eigenschaften und Mängel. Die geistige ind moralische Begabung ist, wie die Fehler, Mängel und 
Gebrechen, welche deren Kehrseite bilden, wesentlich individueller Art. Indessen bewirkt die Nachahmung, mehr oder minder bewusst oder unbewusst, auch hier in gewissen Kreisen eine übereinstimmende Entwicklung in bestimmten Richtungen. So werden manche Eigenschaften zum Gemeingut einer Station oder der Bewohner einer Gegend, ohne dass sie deshalb den Charakter eines Rassenmerkmals erlangen, d. h. als angeboren zu betrachten wären. So findet man bei Küstenbewohnern eine spezielle Befähigung für die Schifffahrt, wiewohl sie der Abstammung nach übereinstimmen mit den Bewohnern des Binnenlandes; in Städten und Ländern, wo Gesang und Musik gepflegt werden, hat fast Jedermann musikalisches Gehör, während dieses vielleicht in benachbarten Lokalitäten und angrenzenden Ländern selten orler wenig entwickelt ist. Die Eigenschaften und Mängel, welche eine Besonderheit kleinerer Gruppen oder Kreise bilden, sind in noch höherem Grade ein Resultat der Erziehnng und Beispiele oder, wenn man weiter zurückgehen will, der in einer gewissen Umgebung vorherrschenden Ideen. So beruht der Charakter des Genfer Volkes auf einem Fond, welchen Calvin nur modifiziren, aber nicht beseitigen konnte, und auf welchen sodann später die modernen Ideen ihren Einfluss ausgeübt haben.

Von den geistigen Fähigkeiten und Geschicklichkeiten sind die einen mehr allycmein, die andern lokal, noch andere ganz indirituell. Erstere finden sich bei der grossen Mehrzahl der Bewohner eines Landes und bilden einen Charakterzug des Volkes, in ihrer Gesammtheit den Nationalcharalter oder Tutionalycist desselben, „le génie de la nation." In diesem Sinne spricht man rom Handelsgeist und kolonisatorischen Geschick der Engländer, vom literarischen Talent der Franzosen, von der künstlerischen Begabung des Italiener's u. s. w. Was die Toliculen Eigenthümlichkeiten anbetrifft, so gibt es fast kein Land, wo man nicht den Bewohnern gewisser Gegenden oder Ortschaften ein ausgesprorhenes Geschick für bestimmte Arbeiten nachrühmt. Indiciducll ist \%. B. die Fähigkeit mancher Bewohner von Wüstengegenden and wenig liultivirten Ländern, sicher den Weg zu finden durch Steppen und Einöden, wo sich dem Ange kein Ialtpunkt bietet, oder durch Urwälder, wo, wie 
dem Fremden scheint, ein Baum dem andern grleicht. Aehnlich rerhält es sich mit der Befähigung, eine Spur zu erkennen und zu verfolgen: nach kleinen Anzeichen, die Andern entgehen, zu unterscheiden und zu errathen, welches Thier den Weg machte oder welchem stamme der Mensch angehörte, dessen Fuss auf dem Boden einen Abdruck hinterlassen hat $\mathrm{u}$. dgl. $\mathrm{m}$.

Die intellektuellen Eigenschaften stehen in Zusammenhang mit der Kultur oder Zivilisation eines Volkes unr Tolkstheiles. Oft betrachtet man die Langsamkeit der Auffassung, das Unvermögen zur Bildung abstrakter Ideen als cin Merkmal tiefstehender, unentwickelter Rassen; aber findet man diese Fehler - wenn man sie so nennen will — nicht auch heim Durchwandern unserer Landhezirke in abgelegenen Gegenden mit mangelhafter Volkshildung? Wem der Städter im Allgemeinen durch schnelle Auffassung und durch die Fähigkeit, einem Raisonnement zu folgen, sich vor dem einfachen Landmann auszeichnet, so beruht das auf der Uebung, die Ersterer hierin von Jugend auf erlangt hat. Es war dies für ihn durch die Verhältnisse geboten; aber Eltern, Kinder und Lehrer wissen auch, was Alles dazu grehörte, um dieses Resultat zu erlangen. Wenn üherall für denselben Zweck die gleiche Mühe aufgewendet würde, so dürften wohl die Differenzen, welche in dieser Hinsicht bestehen, ganz erheblich abnehmen.

Die moralischen Eigenschaften ihrerseits sind noch weniger denn die intellektuellen als etwas Angebornes zu betrachten. Dass die Rassen als solche geistig mehr oder minder begaht seien, kam man zugeben; aber die Annahme scheint unstatthaft, dass ein Individuum als guter oder schlechter Mensch geboren werde je nach der Lmgebung, in welcher er das Licht der Welt erblickt. Nur entwickeln sich die moralischen Eigenschaften und Fehler sehr frühzeitig, und es üht jene Lmgebung ihren guten orler schlechten Einfluss auf das Individuum von dessen frühester Jugend an. Die Vorstellungen, welche in seinen Kreisen über Gutes und Böses, über die Grenzen zwischen Erlaubtem und Inerlaubtem herrschen, die Macht des Beispiels und die Verschiedenheiten in der Selbstheherrschung müssen nothwendig sehr ungleiche Resultate herbeiführen. 
Welches auch die erste Ursache der Verschiedenheiten sei, welche hinsichtlich der geistigen Eigenschaften und Fehler die Einzelnen und ganze Gesellschaften aufweisen: sicher ist, dass diese Ungleichheiten vorhanden sind und der Reisende - dessen Aufgabe es ist, zu beschreiben - hat die Eiggenthümlichkeiten kennen zu lernen und zu konstatiren, welche er in dieser Beziehung bei den Völkerschaften, unter denen er lebte, beobachten konnte.

Diese Beobachtungen sind leicht zu machen, soweit es sich um mehr oder minder ausnahmsweise Entwicklung besonderer Fähigkeiten oder Geschicklichkeiten handelt; ebenso, wenn diese in grösserem oder geringerem Umfang fehlen und in gewissen Richtungen eine auffallende Ungeschicklichkeit vorhanden ist. Man wird das gelegentlich wahrnehmen oder bestimmte Proben anstellen, die dem einzelnen Fall angepasst sein müssen und sich danach leicht ergeben, wie sie auch unschwer auszuführen sein werden.

Die Stufe der Intelligenz wird beurtheilt nach der Art und Weise, wie die Individuen für Befriedigung ihrer Bedürfnisse sorgen; nach der grösseren oder geringeren Vollkommenheit der von ihnen verfertigten Geräthe, Werkzeuge und Instrumente; nach der Gewandtheit, die sie an den Tag legen, um aus einer Verlegenheit herauszukommen oder einen Fehltritt zu korrigiren; nach der Klugheit, die sich in ihren Fragen oder Antworten ausspricht u. s. f.

Was die intellektuellen Eigenschaften im engeren Sinne betrifft, wie Fassungskraft, Gedächtniss, Urtheilskraft, Abstraktions- und Generalisationsvermögen etc., muss man die Individuen auf die Probe stellen, um zu sehen, inwieweit diese Eigenschaften bei ihnen ausgebildet seien oder fehlen. Dabei darf nicht vergessen werden, dass einige dieser Gaben manchmal auf bestimmte Klassen von Thatsachen oder Ideen beschränkt sein können. So kann Jemand ein ausgezeichnetes Ortsgedächtniss haben, während ihm das Behalten von Namen und Zahlen schwer fällt, ja fast unmöglich wird.

Weniger leicht sind die Individuen $\mathrm{zu}$ beurtheilen hinsichtlich ihrer moralischen Eigenschaften, wozu auch Anstand und Würde, Muth, Energie, Ausdauer u. a. m. gehören. Oft fehlt es an Gelegenheiten, bei denen diese Eigenschaften sich geltend machen könnten; auch ist der Mensch in seinen 
Ilandlungen nicht immer konsequent. Angestellte Proben oder Versuche lassen nicht unbedingt sichere Schlüsse zu, denn die Individuen, welche man denselben unterwerfen will; können auf der Hut sein und sich bemühen, dem Fremden in vortheilhaftem Lichte zu erscheinen. Man hat sich daher so zu behelfen, dass man zu erfahren sucht, welche Eigenschaften und Tugenden von ihnen geschätzt, welche Fehler verachtet, welche Laster verabscheut werden.

In den Helden ihrer Sagen wird man die Eigenschaften rereinigt finden, welche nach ihrer Ansicht Vorzüge des Menschen sind, und ihren Feinden werden sie reichlich zur Last legen, was sie für Fehler und Laster halten. Aehnlich verhält es sich mit den Gestalten, welche ihre Dichter in Erzählungen und dramatischen Erzeugnissen auftreten lassen. Ebenso lassen die Urtheile, welche sie über Andere fällen, erkennen, welches die Ideale eines Volkes sind. Hört man Jemanden sich in Lob oder Tadel ergehen, so erkundige man sich nach dem Grunde des einen oder andern, und man suche zu erfahren, welches Benehmen für lobens- oder tadelnswerth gehalten wird. Oft tritt dabei in den angeführten Gründen eine überraschende Gehaltlosigkeit und Nichtigkeit zu Tage; oft auch ergibt sich, dass eine Handlung rühmlich betrachtet wird, die wir für schlecht oder strafbar halten. In solchen Fällen vergesse der Reisende nie, dass wir andere Völker, namentlich unzivilisirte, nicht mit dem Masse messen dürfen, an dessen Gebrauch wir gewohnt sind, und dass der Reisende die Aufgabe hat, Thatsachen zu konstatiren, nicht aber über die Einzelnen abzuurtheilen.

Pathologische Eigenthümlichkeiten. Die Aufmerksamkeit des Reisenden ist auch darauf zu richten, ob bei dem Volke, das er studirt, oder in bestimmten lireisen desselben gewisse Missbildungen, Affektionen und Krankheiten häufig seien, so der $K r(y) t^{\prime}$, totaler oder partieller Albinismas, Ophthalmic, Aussutz, Elephantiasis, Entzündungen und Fiebcrkankikeiten, Tyghus, Langenschuindsucht ctc., welches insbesondere die Kindertrantiheiten seien.

$\mathrm{Zu}$ konstatiren ist ferner, ob auffallende oder abnorme Verhältnisse vorkommen in Bezug auf die Zahl der Blïdsimingen (Idioten) und Crétins, der Irren, Evileptischen, Taub- 
stummen, Blindyebornen etc., sowie - was namentlich von Wichtigkeit ist - ob Kranliheiten, welche der bestimmten Tïllierschaft oder Grupre eigenthiumlich sind, vorkommen, und ob dieses Volk oder einzelne Kreise desselben allgemein verbreiteten Krankheiten mehr oder minder unterworfen ist, in grösserem oder geringerem Grade als bestimmte andere Völkerschaften und Gruppen derselben oder aber im selben Masse wie diese.

In wie ungleichem Grade Menschen verschiedener Abstammung ron einer und derselben Krankheit heimgesucht werden, kann man namentlich in Ländern beobachten, wo Eingeborne und Fremde neben- und untereinander wohnen. Eingeschleppte Krankheiten treten im Allgemeinen bei den Indiriduen, welche bis anhin davon frei waren, intensiver auf als bei den andern.

Wo eine cingeborne Rasse dem Aussterben entgegengeht, sind die Ursachen dieser Erscheinung zu ermitteln: ob sie in der Rasse selbst liegen oder in den verschiedenen Folgen, welche der Kontakt mit den Einwanderern für dieselbe hat.

\section{SPRACHEN UND DIALEKTE.}

Wenn wir die Sprache nicht als ein bestimmendes Rassenmerkmal betrachten, soll damit keineswegs gesagt werden, dass ihr aller und jeder ethnologische Werth abgehe. Es ist sicher, dass Sprachgemeinsamkeit ein Indicium gemeinsamer Abstammung sein kann; aber sie begründet erst eine Vermuthung und ist noch kein Beweis für einheitlichen Ursprung. Wenn die Bevölkerung ron ganz Frankreich, von Belgien und einigen Schweizerkantonen das Französische spricht, so darf aus diesem Umstande bekanntlich nicht der Schluss gezogen werden, dass diese Völkerschaften einheitlichen Ursprungs seien. In dem grossen Weltreiche der Römer herrschte die lateinische Sprache bei ganz verschiedenen Völkern, hinsichtlich deren Niemand versucht sein würde, an Gemeinsamkeit ihrer Abstammung zu denken.

In diesen beiden Fällen lassen wir uns durch die Gleichheit der Sprache nicht täuschen, weil wir aus der Geschichte wissen, dass und wie das Lateinische und Französische bei 
verschiedenen Völkerschaften, die vorher eine andere Sprache latten, eingeführt und herrschend wurde. Wo uns aber nicht die Geschichte als Führer und Lehrmeisterin zur Seite steht, könnten wir uns in solchen Fällen leicht irren.

Eroberer können ihre surache den unterworfenen Völliern aufgedrängt haben: ein Sprachgebiet umfasst dann Angehörige zweier oder mehr verschiedener Passen, und wenn man num blos nach der sprache urtheilen wollte. müsste man den Schluss ziehen, die Trherölkerung, die autochthone Passe, sei verschwunden. So haben die Nachkommen der alten Guanchen auf den kanarischen Inseln alle die spanische Surache angenommen und glaulte man deshall, dass gar lieine Abkömmlinge dersellen mehr existiren, his der Gelehrte sabil Berthelot nachwies - was dann neulirh Dr. Bernean bestätigte ${ }^{1}$ ) - dass sie im Gegentheil den Grundstock der Berölkerung jener ganzen Inselgruppe hilden. Es kömmen auch umgekehrt die Eroherer oder ilre Nachkommen sich mit der unterworfenen Bevïlierung verschmelzen und deren surache annehmen, wie es der Fall war mit den Normannen und Burgudern in Frankreich, den Vandalen in Sordafrika etc. Auch in diesem Falle enthält die Berölkerung des Landes Elemente, deren Existenz nicht durch die surache angezeigt und dargethan wird.

Die Ausbreitung und das Verschwinden einer spracht halten oft nicht gleichen schritt mit der Leberhandnahme odpr dem Zurückgehen und allmäligen Aussterben der Rasse mler Völkerschaft, welche der eigentliche Träger und Repräsentant jener Sprache war.

Von den Sprachen zweier benachbarter Gebiete wird immer die eine an Terrain gewinnen und die andere rerlieren. olme dass dahei das Volk. welches die letztere suricht, in Abnahme bergriffen wäre (der Passe. heziehungswaice Abstanmung nach hetrachtet). Das Franzïsische und spanische lringen immer weiter ror auf dem Gehiet der Escraraturache. welche sich noch bei Abkïmmlingen der alten Basken findet. In Nordafrika haben rirle Berbernstamme dis surache der Araher ingenommen und ihre eigene aufgegehen; wollte man ıun auf Grund dipser Surachverhälnisse alle jene Einge-

1) Vøl. auch Fr. v. Lüher, Kanarische Reisetage. Allgemeine Augsburger feitung 1575 und 1876 . 
bornen Nordafrikas für Araber halten, so wäre das ein starker Irrthum. Selten nur hat das Gebiet einer Sprache mit demjenigen einer Rasse ganz dieselben Grenzen.

Bei alledem sind gleichwohl die Fingerzeige bestens $\mathrm{zu}$ beachten, welche uns die Sprache gibt, und wer diese Aufschlüsse unterschätzen wollte, würde nicht gut thun. Wenn der Sprache nicht die Bedeutung eines bestimmenden Rassenmerkmals zukommt, so ist sie dagegen von der grössten Wichtigkeit hinsichtlich der Entwicklung, welche ein Volk genommen hat.

Um sich ein anderes Idiom anzueignen als dasjenige, welches man sich unbewusst von frühester Jugend an als Muttersprache erwarb, bedarf es immer einer gewissen nachhaltigen Geistesanstrengung. Es waren daher mächtige Beweggründe nöthig, um ein Volk dazu zu bringen, dass es eine andere Sprache als seine eigene annahm. Kein Volk gibt so leicht seine Sprache auf. Eine Aenderung der Religion kann sich sehr rasch vollziehen; auch manche alten Sitten und Gebräuche können in kurzer Frist durch andere ersetzt werden; aber ein Wechsel der Sprache erfordert immer viel Zeit zu seinem Vollzuge und setzt einen nachhaltig wirkenden Einfluss, einen langandauernden Kontakt voraus. Wenn die Sprachgemeinschaft von Völkern verschiedener Rasse uns nichts Sicheres lehrt in Hinsicht auf deren Verwandtschaft oder Abstammung, so verkündet sie uns doch, dass diese Völkerschaften lange Zeit dasselbe Schicksal hatten oder zu einander in engen Beziehungen standen.

Das Studium der Dialekte und die Entdeckung von Sprachinseln in einer dem Anscheine nach sprachlich-homogenen Bevölkerung sind überaus wichtig; sie können oft ein bedeutsames Licht werfen auf die Herkunft der jetzigen Bevölkerung oder eines wesentlichen Theiles derselben, auf die Frage nach den Elementen und dem Grundstock des Völkergemisches, das wir jetzt vor uns haben.

In dieser Beziehung hat der Reisende reichliche Gelegenheit $\mathrm{zu}$ werthrollen Studien nicht nur in fernen Ländern fremder Kontinente, sondern in den nächstliegenden und bestbekannten Gebieten des heimischen Erdtheils. So hat ein englischer Tourist - der durch seine Matterhornbesteigung und Grönlandreisen bekannte Eduard Whymper - 
dargethan, dass in einem Winkel Frankreichs, in der Gegend ron Gap, auf einem Raume ron wenigen Quadratkilometern verschiedene Dialekte existiren, welche - wie er sagt für die Bauern der Limgegend ebenso unverständlich sind wie für die Fremden.

Von grossem Werth sind diese Studien namentlich auch dann, wenn sie zur Entdeckung alter Dokumente führen, welche uns frühere Formen der Sprache oder des Dialektes kennen lehren.

In sprachlicher Hinsicht wird also der Reisende überall zu beobachten Gelegenheit haben, sei es um Sprachen, sei es um Dialekte zu studiren, die noch mehr oder minder unbekannt sind.

Einzusammelnde Materialien. Die linguistischen Materialien, welche der Reisende zu sammeln bemüht sein muss, sind von zweierlei Art.

Die einen betreffen den Wortschatz (das Vokabular) und die gelväuchlichen Redensarten (Phraseologie); sie sind praktisch wichtig hinsichtlich der kommerziellen und anderweitiger Verbindungen, welche später mit den besuchten Vülkern angeknüpft werden.

Die andern betreffen die Grammatik in ihren verschiedenen Richtungen: die Lautlehre (Phonologie), welche ron den Lautbestandtheilen der Wörter und deren Veränderungen handelt; die formenlehe (Morphologie), welche sich mit den Aenderungen der Form befasst, welche ein Wort eingeht, um verschiedene Beziehungen (Geschlecht, Zahl, Zeit etc.) zu bezeichnen; die Satzlehre (Syntax), deren Gegenstand die Art der Satzbildung ist. Sorgfältig gesammelte Angaben hierüher sind von grossem wissenschaftlichem Werth: sie tragen bei zum Fortschritt der Linguistik oder vergleichenden Sprachwissenschaft.

Vokabulare und Phraseologie. In erster Linie wird sich der Reisende nach etwa shom rorhandenen Volidularen erkundigen, welche von Missionären oder andern Reisenden erstellt und in Europa unbekannt geblieben oder doch nur wenig bekannt sein könnten. Ist das der Fall, so kann el sich entweder darauf beschränken, die Existenz dieser Arbeiten zu signalisiren und im Uebrigen deren Veröffentlichung abzuwarten, oder er kann mit Erlaubniss der Autoren mehr 
oder weniger umfassende Mittheilungen (Exzerpte) aus denselben geben.

Sind keine derartigen Sammlungen vorhanden, so hat sich der Reisende selbst an die Arbeit zu machen, um solche zu erstellen. Die Art des Sammolns solcher Angaben erfordert einige Bemerkungen.

Zunächst muss betont werden, dass dieselben, wie man zu sagen pflegt, aus erster Hand kommen oder an der Quelle geschöpft sein müssen; d. h. man muss sie aus dem Munde der Eingebornen selbst haben und nicht von Zwischenpersonen wie Dolmetschern, welche nicht im Lande geboren und aufgewachsen sind, dessen Sprache vielleicht nur unvollkormen kemmen, wenn sie auch als Kenner derselben erscheinen möchten, und welche entweder Wörter in falscher Aussprache mittheilen oder gar solche erfinden, um nur eine Antwort zu geben auf die Fragen nach den Ausdrücken, welche der Reisende in Erfahrung bringen möchte.

Es ist allerdings schwierig, Leute, deren Sprache man nicht kennt, direkt zu befragen; doch genügt es zu diesem Zweck für den Anfang, wenn man nur weiss, wie in der betreffenden Sprache die Frage lautet: "Wie heisst Das?" Man behilft sich dann mit dieser Frage und damit, dass man mit dem Finger auf die Gegenstände zeigt, deren Namen konstatirt werden sollen. Jene Phrase aber wird man bald kennen lernen, wenn man den Eingebornen Dinge vorzeigt, welche ihnen unbekannt sind, wie Uhren, Fernrohre, Taschenbücher u. dgl. Nachdem sie dieselben besichtigt haben, werden sie selbst die Frage stellen, deren Formel man zu erfahren wünscht; wenn der Reisende dieselbe von verschiedenen Personen wiederholt hört, wird er darüber bald ausser Zweifel sein und dieselbe gut im Gedächtniss behalten.

Mit Hülfe dieser einfachen Phrase wird man bald eine reiche Liste von Namen für sichtbare und greifbare Dinge erhalten, wenn man die Frage bei jeder Gelegenheit stellt, dabei nur einfache und wohlbekannte Gegenstände ausersieht und diese in unzweideatiger Weise bezeichnet.

Schwieriger ist es, Wörter zu sammeln, welche abstralite Begriffe und generelle Ideen ausdrücken. Wenn man indessen auf zwei ganz verschiedenartige Bäume zeigt und dabei beide Mal dieselbe Antwort erhält, so ist es doch 
wahrscheinlich, dass diese den generellen Begriff "Baum" bedeutet und nicht die spezifischen Bezeichnungen "Myrte oder "Palme" gibt. In analoger Weise wird man die Gattungswörter für "Vogel", "Fisch", „Säugethier" oder "Vierfüsser", "Thier", "Pflanze ${ }^{\text {" }}$ u. s. f. zu erfahren suchen. Mehrere grundverschiedene Dinge, die aber alle die nämliche Farbe haben, kömnen benutzt werden, um die Bezeichnung dieser Farbe kennen zu lernen, z. B. Schnee, Leintuch, Papier, um zu erfahren, was " weiss $^{\text {" }}$ heisst. Hiebei ist freilich zu berücksichtigen, dass nicht jede Surache besondere Ausdrücke für die verschiedenen Farben hat, deren Interscheidung uns geläufig ist, dass vielmehr in deren Bezeichnung - mit Ausnahme derjenigen für Weiss, Schwarz und Roth - sehr oft die grösste Unsicherheit und Konfusion herrscht. (Vgl. "Ausland" 1880, S. 246.)

Nach derselben Methode - mit Versuchen, die an Ort und Stelle nach Bedarf eingerichtet werden müssen und nicht vorher beschrieben werder können — wird man die Eigenschaftswörter (Adjectiva), grross", ,schön", „glänzend" u.s.w. kemen lernen, wemn man dahei zur Vergleichung Gegenstände wählt, die nach keiner andern Seite hin als nach dieser eine auffallende Aehnlichkeit haben.

Ln die Thätigkeitswörter (Verba) zu erhalten, muss man fragen, können: "was machst $d u$ ?" oder "was macht er?" und um sich die Formel hiefür zu verschaffen, muss man selhst Etwas thun oder durch Jemanden in dem Gefolge Etwas thun lassen, dessen Zwerk die Eingehornen nicht begreifen und das ihnen auffällt. Ihrer Verwunderung darüber werden sie fast ausnahmslos durch eben jene Frage Ausdruck geben, die man damn sofort selber anwendet in Bezug auf dieses oder jenes Individuum, das isst, trinkt, schläft, läuft u. s. w.

Es ist wohl kaum nöthig, diese Andeutungen noch zu vermehren. Jeder Reisende wird durch eigenes Nachdenken und wenn er: von der Sprache, die er studiren will, erst wenige Brocken kennt, selber auf hessere Methoden und einfachere Mittel kommen als diejenigen wälen, die man ilm zum Voraus angeben liönnte.

Jie gehräuchlichsten lierlensarten wiederholen sich sehr oft in Terhältnissen und mit einer Betonung, wodurch der 
Schlüssel zu deren Verständniss gegeben wird, sodass dem Reisenden nichts leichter sein wird, als ausser einem Vokabular auch ein Verzeichniss solcher Redensarten oder Dialoge anzufertigen, welches sozusagen die Kurantmünzen der Sprache enthält.

Bei diesen Arbeiten stösst man aber auf eine andere Schwierigkeit: diejenige einer sachgemässen Bezeichnung oder Transshription der Laute, welche mitunter von den uns gewohnten wesentlich verschieden sind. Wohl bestehen Systeme, die dazu bestimmt sind, eine richtige Transskription zu ermöglichen oder zu erleichtern, so das Universal-Alphabet von Lepsius (Berlin 1855), das "Standard-Alphabet" desselben Autors (London und Berlin 1863), die phonetische Methode von Professor Ernst Brücke ${ }^{1}$ ) u. s. w.; sie eignen sich aber nicht zum Gebrauche bei solchen Sammlungen ron Wörtern und Sätzen, welche nicht ausschliesslich für gelehrte Gesellschaften oder Sprachforscher von Fach, sondern mehr für andere Reisende und für Handelsleute bestimmt sind. Man ist also darauf angewiesen, die Aussprache so gut als möglich darzustellen mit Hülfe der Lautzeichen unserer allgemein bekannten europäischen Sprachen, sowie gewisser Kombinationen von solchen und besonderer Zeichen, deren Bedeutung in einem Schlüssel an der Spitze der Sammlung erklärt wird. Hat man vor der Abreise das Ohr in genauer Auffassung der Laute geübt, d. h. sich gewöhnt, die Modulationen zu unterscheiden, welche eine und dieselbe Sprache im Munde verschiedener Personen erleidet und hat man sich auch zu Hause mit dem Studium der Dialekte in der Umgegend beschäftigt: so wird sich dies in dem fremden Lande sehr förderlich erweisen. Solche Vorübungen werden dem Reisenden um so mehr zu Statten kommen und sind um so nothwendiger, als unter den fremden Völkern sein Sinn durch die Neuheit anderer Erscheinungen (wie der Physiognomien, Gesten etc.) in Anspruch genommen wird. Um sich übrigens zu vergewissern, dass die angewendete Transskription richtig ist, wird der Reisende sich wiederholt überzeugen, ob die Eingebornen die aufgeschriebenen Wörter verstehen, wenn er sie ihnen vorliest.

1) Ueber eine neue Methode der phonetischen Transskription, von Professor Ernst Brückc, Wien 1878. 
Eine Kontrole des aufgenommenen Vokabulars ist in allen Fällen nöthig, einerseits nach der eben bezeichneten Richtung in Bezug auf die Aussprache der Wörter - ob die Eingebornen diese verstehen, wenn man sie ihnen nach der angewendeten Lautbezeichnung vorspricht, - andererseits in Bezug auf deren Inhalt und Bedeutung, in welcher Hinsicht die gleichen Fragen nach dem Namen eines Gegenstandes etc. wiederholt und an verschiedene Individuen zu stellen sind, his man sich genügend überzeugt hat, dass die Antworten auf eine und dieselbe Frage identisch sind. Wenn der Reisende - getrieben ron dem Wunsche, rasch eine seinen Bedürfnissen entsprechende Sammlung zu bekommen - die ersten Befragungen über die Maassen ausdehnt, so riskirt er dabei, schliesslich unzuverlässige Angaben zu erhalten, indem die Eingebornen - ermüdet von der Anstrengung, welche ihnen das Aufmerken und Nachdenken verursachen, die nöthig sind, um die Fragen gut zu verstehen und richtig zu beantworten - statt des gewünschten Wortes irgend ein anderes, vielleicht einen scherzhaften oder groben Ausdruck, angeben.

Solche Sammlungen sind nicht gerade von wissenschaftlichem Werthe. Sie können gute Dienste leisten bei suäteren Verkehrsbeziehungen mit den besuchten Völkerschaften; es wäre aber nicht wohl gethan, wenn man in dem Material solcher Sammlungen Indizien einer Verwandtschaft mit diesem oder jenem Volk erblicken wollte. Nichts ist gewöhnlicher, nichts aber so trügerisch, als das Surhen nach Sprachähnlichliciten und Etymologien, wenn es nicht mit Kenntniss und kritischem Sinn geschieht. Ohne diese sichernden Eigenschaften kann man hiebei zu ganz baroken Resultaten kommen, etruskische Inschriften mit Hülfe eines irländischen Dialektes erklären, gegrenseitige Beziehungen herausfinden zwischen dem Japanischen und Italienischen, welche gewisse Wörter von ähnlichem Klang, wenn auch verschiedener Bedeutung (ja sogar ein wirklich beiden Sprachen gemeinsames, d. h. in Sim und Aussprache übereinstimmendes Wort "tanto") haben. Derartige zufällige Aehnlichkeiten haben schon oft Reisende zu Lommentaren und Hypothesen veranlasst, welche mehr ihrer Einbildungskraft als ihrer Wissenschaft Ehre machten, sodass man nicht genug davor gewarnt werden kann, nicht 
in diesen Fehler zu verfallen. Man vergesse nie, dass die Sprachverwandtschaft nicht in solchen Wortähnlichkeiten besteht, sondern in einer Analogie der Struktur, des Baues der Sprachen, ihres ganzen grammatischen Systems. Die türkische Sprache z. B. hat mehr persische und arabische als wirklich türkische Worte; nichtsdestoweniger ist sie weder mit dem Persischen noch mit dem Arabischen "verwandt".

Hinwieder geht zu weit, wer solchen Vokabularien jeden andern als ihren praktischen Werth bestreiten will. Fremden Sprachen entlelute Wörter haben auch ihre lehrreiche Seite; nur muss man sich dabei in den Grenzen des Wahrscheinlichen halten oder sich auf Thatsachen der Geschichte stützen können.

Solche Entlehnungen sind zunächst Indizien früher bestandener Verbindungen. Die arabischen Worte in der spanischen Sprache, namentlich deren südlichen Dialekten, würden uns - auch wenn wir es nicht sonst wüssten - sagen, dass zwischen Spaniern und Arabern ehemals viel engere Beziehungen herrschten als heutzutage. Wörter phönizischen Ursprungs bei den Stämmen der afrikanischen Nordküste verrathen die Existenz einstiger Kolonien, von denen jede andere Spur hat verschwinden können.

Sodann lehren uns die Entlehnungen aus fremden Sprachen oft die neue Ideenströmung kennen, welche durch jene Beziehungen verursacht wurde. Eigene Bezeichnungen hat jedes Volk nur für die Dinge, welche ihm bekannt sind und seine Aufmerksamkeit erregen; bietet sich ihm ein neuer Gegenstand dar, den Fremde bringen, so wird es für diesen sehr oft auch das fremde Wort annelimen und erhalten, allerdings mit mehr oder weniger starken Veränderungen seiner Aussprache. Ein Volk, welches rom Nomadenzustand zur sesshaften Lebensweise, d. h. von Jagd oder Viehzucht zum Ackerbau übergeht, muss für die Werkzeuge zur Bodenbearbeitung neue Ausdrücke schaffen oder solche entlehnen aus der Sprache derjenigen, welche diese Instrumente einführten. Eine neue, von Missionären gepredigte oder von Eroberern aufgedrungene Religion bringt gewöhnlich einen Schatz neuer Worte nit sich. Für alle die verschiedenen, hier in Betracht kommenden Richtungen liessen sich zahlreiche Beispiele anführen. Die französische Sprache hat kein Aequivalent für das deutsche 
Wort ,heimelig", die deutsche Sprache keinen für ,chic". Die Bergbewohmer haben eine Menge von den Städtern unbekannten Ausdrücken zur Bezeichnung verschiedener Bergand Thalformen. Die Sprachen nomadischer Stämme sind sehr reich an Wörtern, welche die verschiedenen Altersstufen, $\mathrm{Zu}$ stände und Varietäten des Viehes bezeichnen, sehr arm aber an Namen für die Farben und deren Nüancen. Der Araber hat zwanzig oder dreissig Benennungen für die spielarten der Dattel, das Französische noch mehr für die verschiedenen Gerichte, welche aus Kartoffeln bereitet werden kümnen. Wem wir bei einem andern Volk eine Idee orler ein Objekt entlehnen, so nehmen wir von ihm zumeist auch die Bezeichnung dafür an, z. B. Duo, Maximum, Spleen, Comfort, Villa, Grog, Thee, Tabak, Meeting, Siesta u. s. f. Seit Vauban sind die militärischen Ausdrücke der Franzosen in fast alle Sprachen übergegangen. In den Ländern des Islam sind die Bezeichnungen, welche Peligion und Kultus betreffen, Worte arabischen Ursprungs. Die Geschichte dieser verschiedenen Entlehnungen wäre die Geschichte der Zivilisation eines Volkes und des Antheils, welchen seine Nachbarn daran genommen haben.

Es ist also ron hohem Interesse, bei dem Studium eines noch ziemlich unbekannten Idioms die Worte fremel'n $Z$ \%smmuls aufzusuchen und nachzuforschen, ob das Idiom keine ihm eigenen und gleichbedeutenden Ausdriicke zu deren Wiedergabe hat, ob also die entlehnten Worte auch entlehnte Begriffe repräisentiren, die vordem bei dem betreffenden Vollip nicht existirten. Bei Yülkern, die ihren frühern Wohnsit\% rerlassen haben und ausgewandert sind, kömnen Begriffe und die zugehörigen Worte verloren gegangen sein, und es kamn das Volk, als die Idee oder der Gegenstand bei ihm von Neuem auftauchte, zu deren Bezeichnung sich eines fremden Iusdrucks bedient haben. Denken wir uns z. B. einen Stamm, ler ehemals an der Meeresküste lebte, damn aber sich tiof $n$ 's Imere eines Kontinentes begeben hat: sicherlich lionnte rr im Bimnenlande die Worte leicht vergessen, womit er vormal. Ieer und Wellen, Golfe, Vorgebirge u. s. w. bezeichnete. Wenn in anderes Volk stepuen und Wüsten verlisst, um sich am leere oder im Gehirge anzusiedeln, so werden die Vorstelungen und Ausdrücke für strpure, Wüste u. derl. aus seinem 
Gedächtniss und Wortschatz verschwinden; wenn es jene Objekte wieder kennen lernt, so wird es dafür neue Bezeichnungen verwenden.

Wie dem auch sei, so wird man womöglich erforschen, wam, wie, durch wen und unter welchen Verhültnissen die neuen Wörter eingeführt oder gebildet wurden.

Interessant sind auch die Wandlumgen der fremden Wörter in einer syrache. Wir brauchen im Deutschen für Speisewirthschaft das Fremdwort "Restauration"; im Französischen heisst sie aber nicht "restauration", sondern "restaurant". Aelınlich verhält es sich mit manchen andern Entlehnungen aus dem Französischen: die Deutschen brauchen sie in einem andern Sinne als demjenigen, welchen das Wort in der fremden Sprache hat und bedienen sich des fremden Wortes nicht, welches die Franzosen in letzterem Sinne verwenden. Solche Fälle sind beispielsweise:

"Galanterie" und quincaillerie, "Delikatessen" und comestibles, "Briefcouvert" und enveloppe.

Ein Substantiv ,Parterre“ für Erdgeschoss (rez-de-chaussée) kommt im Französischen gar nicht vor u. s. f.

Andrerseits kann auch innerhalb einer Sprachgemeinschaft bei den verschiedenen Genossen derselben ein Wort in ungleichem Sinne angewendet werden. In den süddeutschen Dialekten finden wir "laufen" und "springen" in der Bedeutung von gehen und hüpfen, für welch' letzteres Zeitwort ein Dialektausdruck gebraucht wird, der mit dem englischen Verb to , jump verwandt ist; "Luft" ist daselbst synonym mit Wind; Alpenbewohner verstehen unter "Alpen" nicht dieses Gebirge, sondern hochgelegene Weiden, und in Gegenden der Pyrenäen wird als "colline" ein von zwei Berggipfeln eingerahmtes enges Thal bezeichnet. Oft besteht die Verschiedenheit nur in ungleicher Ausdehnung des Begriffes, welcher durch ein Wort bezeichnet wird, in Erweiterung oder Einschränkung desselben. So versteht man in Süddeutschland unter "Tannen" sowohl Fichten ("Rothtannen“) als eigentliche Tannen ("Weisstannen") und hört man in den Dialekten daselbst den Ausdruck "reiten" ( rite") nicht hlos angewendet auf das Reiten (welches die Franzosen durch die Kombination "monter à cheval" ausdrücken müssen), 
sondern auch vom Fahren gebraucht; hinwieder wird die Bezeichnung "Kind" im Volke da und dort eingeschränkt auf die Kinder weiblichen Geschlechts ( und der Gemsjäger versteht unter "Thier" einfach die Gemse, welche in seinen Augen Repräsentant sämmtlicher Wildthiere, das "Thier" par excellence ist.

Endlich gibt es in jeder Sprache, namentlich bei rasch fortschreitenden Völkern, rrultete Ausdrürlir und übrobte Wörter, die erhalten bleiben, obwohl sie den Ideen oder dem jetzigen Zwecke der Objekte, welche sie bezeichnen, nicht mehr entsprechen. Solche Wörter werfen ein gewisses Licht auf alte Gebräuche, Glaubensmeinungen u. s. w. Dahin gehören die deutschen Wörter "Federmesser" und "Buchstaben", da man sich jener Messer kaum mehr zum Federnschneiden, wohl aber zum Bleistiftspitzen u. dgl. bedient, die Buchdrucklettern aber in der durch jenes Wort bezeichneten primitiven Form von Stäbchen nicht mehr existiren; ferner die deutschen und entsprechenden französischen Ausdrücke ,huldigen" (présenter ses hommages), „das Loos werfen" (jeter un sort), „bezaubern" (ensorceler) u。 dgl.

Grammatik. Der Reisende soll sich nicht auf das Sammeln von Wörtern und Redensarten beschränken, sondern wenn immer möglich seine Kenntnisse der Sprache vertiefen und den Bau und Mechanismus derselben kennen lernen. Dabei wird er seine Aufmerksamkeit zunächst der Phomologic zuwenden, d. h. den Lauten, welche zur Bildung der Wörter, zum Ausdruck der Gedanken verwendet werden.

In allen Sprachen sind Vokale und Konsonanten zu unterscheiden; aber Art, Zahl und Zeichen derselben sind bei den einzelnen Sprachen sehr verschieden. So haben das Eranzösische und Portugiesische Nasenlaute, welche wir bei len benachbarten Völkern nicht oder nur ausnahmsweise als Provinzialismen) treffen; das Französische, Spanische and Italienische mouillirte Laute, welche in der deutschen ind englischen Sprache nicht vorkommen; das Englische sesitzt seinen eigenthümlichen s-Laut (th), das Polnische eine verschiedenen l etc.; das deutsche und französische $r$ sind twas verschieden; die chinesische Sprache kennt das $r$ gar iicht, und die Chinesen können es nicht aussprechen; die taliener, noch mehr aber die Franzosen haben Mühe, bei 
Erlernung der deutschen Sprache sich das $h$ derselben anzugewöhnen, und sowohl ihnen als den Deutschen bereitet die Aussprache gewisser Kehllaute des Spanischen und Arabischen Schwierigkeiten. Die französische Sprache hat verschiedene $e$ und dafür auch verschiedene Schriftzeichen $(\dot{e}, \grave{e}, c)$; das Deutsche besitzt jene $e$-Laute ebenfalls, unterscheidet sie aber nicht durch verschiedene Buchstaben (abgesehen von der inkonsequenten mehr oder minder regellosen Verwendung des ii). Aehnlich verhält es sich mit dem Schwedischen und Englischen hinsichtlich des i der ersteren Sprache. Der Buchstabe $u$ bedeutet im Französischen nicht denselben Vokal wie im Deutschen; seinen französischen Laut bezeichnen

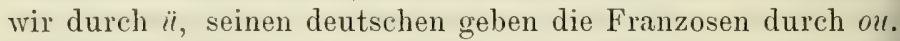
Das Schriftzeichen $s$ als Anlaut ist im Französischen und Deutschen nicht derselbe Konsonant: dort scharf, hier weich und jenem Laut entsprechend, welchen die Franzosen, Engländer und Andere durch z bezeichnen, während der deutsche und italienische Buchstabe $z$ wieder einen andern Laut ( $t s$ ) bedeutet $\mathrm{u} . \mathrm{s}$. f.

Es muss daher die erste Sorge des Reisenden sein, ein genaues Verzeichniss der in einer Sprache vorkommenden Laute, sowie der allenfalls vorhandenen Schriftzeichen aufzunehmen, so zwar, dass Werth und Bedeutung der einen und andern in unzweideutiger Weise zur Darstellung kommen. Dies erfordert oft Angaben darüber, wie der Laut durch die Sprachwerkzeuge gebildet wird, welches das zu seiner Erzeugung nöthige Spiel der Organe ist, ob z. B. die Zungenspitze an die Zähne gelegt werden muss oder an den Gaumen und wie etc.

Die Vokale können unterschieden werden als einfache und nasale, kurze und lange, betonte und unbetonte, mit offener und geschlossener Aussprache. Wichtiger als die Klassifikation an sich ist dabei die richtige Wiedergabe der Laute durch ein ausreichendes Zeichensystem. Diesen Zweck kann man erreichen, indem man zur Darstellung der Modifikationen eines Vokals Accent- und andere Zeichen anwendet: $c$ (stummes, d. h. kurzes und dumpfes e), $\dot{c}$ (helles e), $\dot{c}$ (ii), $\hat{\imath} ; a, \quad \grave{\imath}, \hat{\imath}, \quad \grave{\imath}$ etc.; oder indem man dem Zeichen einen dessen Aussprache erläuternden Zusatz beifügt, z. B. $e$ nasal, é wie das erste $e$ in "sehen", $\grave{e}$ wie das erste $e$ in "geben", 
$c$ wie das zweite $e$ in "sehen, geben". u. s. w., oder endlich durch Gebrauch besonderer Zeichen, deren Bedeutung ein für allemal erklärt und festgestellt wird.

Die Konsonanten können zunächst unterschieden werden in die Sonorlaute $(m, n, l, r)$ und die Gerïnschlante, welch' letztere die Spriranten ( $f, e, s, s c h, c h)$ und die Erplosiclante $\left.(b, l), d, t, \mid l, l_{i}\right)$ umfassen, wie folgende Uebersicht ${ }^{1}$ ) zeigt.

\begin{tabular}{|c|c|c|c|c|c|}
\hline & & labiale & dentale & palatale & gutturale \\
\hline \multirow{2}{*}{ 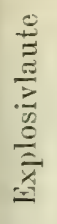 } & 总 & $\mathrm{p}$ & $t$ & $\begin{array}{l}\text { der k-Laut, wel- } \\
\text { chen die Slaven vor } \\
\text { ä, e, i bilden }\end{array}$ & $\mathrm{k}$ \\
\hline & $\stackrel{3}{\mathscr{3}}$ & b & d & $\begin{array}{c}\text { der entsprechende } \\
\text { weiche }\end{array}$ & $g$ \\
\hline \multirow[t]{2}{*}{$\stackrel{\Xi}{\stackrel{0}{\Xi}}$} & $\Xi$ & f & $\begin{array}{c}\text { th (engl.) } \\
\vartheta\left(\begin{array}{c}\text { (neu-gr.) } \\
\text { s }\end{array}\right.\end{array}$ & $\mid \begin{array}{c}\mathrm{v} \text { (unser sch, frz. } \\
\text { ch etc. deutsch ch } \\
\text { nach i }\end{array}$ & $\begin{array}{l}\text { ch der } \\
\text { Deutschen } \\
\text { nach a }\end{array}$ \\
\hline & $\stackrel{\mathscr{C}}{\mathscr{C}}$ & $\mathrm{v}$ & $\begin{array}{l}\text { th (engl.) } \\
\mathrm{z} \text { (franz.) }\end{array}$ & $\mid \begin{array}{c}\mathrm{V} \\
\mathrm{Z} \text { (russ. } \not \mathrm{HC}, \mathrm{fr} . \mathrm{j} \\
\text { etc.) }\end{array}$ & \\
\hline \multirow{3}{*}{ 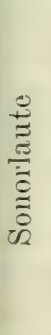 } & 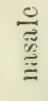 & $\mathrm{m}$ & $\mathrm{n}$ & & $\begin{array}{c}\text { n vor } \\
\text { Gutturalen }\end{array}$ \\
\hline & $\underset{\Xi}{\stackrel{D}{\Xi}}$ & & 1 & $\begin{array}{l}\text { ital, gl, span. } 11 \text {, } \\
\text { port. lh }\end{array}$ & $\begin{array}{c}\text { pol. } 1 \\
\text { russ. } \mathcal{A h}\end{array}$ \\
\hline & 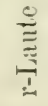 & & $r$ & & $\begin{array}{c}\mathrm{r} \\
\text { (das schnar- } \\
\text { rende) }\end{array}$ \\
\hline
\end{tabular}

Es gilt hichei dieselhe Bemerkung, welche hinsichtlich er Vokale gemacht wurde: dass es hauptsächlich auf treue tierlergahe der Laute ankommt, erfolge diese durch Buchaben und Kombinationen derselben, durch hesondere Zeichen

1) Ygl. die rollständige Konsonantentabelle bei Sievcrs Grundzüge der Photik, 2. Auflage. Leipzig 1881, S. 106 ; ferner Max Müller, Vorlesungen über die issenschaft der Sprache, II. Theil, Leipzig 1870, S. 167. 
oder durch eines der Transskriptionssysteme, wovon oben (S. 582) die Rede war.

Einige südafrikanische Sprachen haben ausser den eigentlichen Konsonanten gewisse Laute, die entstehen, wenn die Zungenspitze an Zähne oder Gaumenpartien angelegt und dann plötzlich zurückgezogen wird. Diese eigenthümlichen Schnalzlaute werden durch besondere Zeichen oder Buchstaben dargestellt $z$. B.

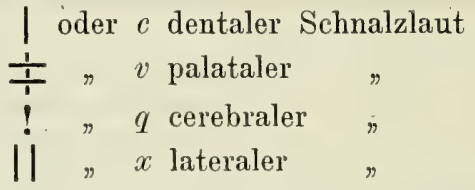

Um wohl zu unterscheiden, was an der Aussprache allgemein, also Norm, was hingegen blos individuell ist, muss man sich dieselben Worte von verschiedenen Personen vorsprechen lassen. Das Verzeichniss der Vokale und Konsonanten wird, je nach der Sprache, mehr oder minder reichhaltig ausfallen.

Mitunter kann ein Laut den andern ersetzen oder vertreten; d. h. von zwei verschiedenen Lauten wird ohne Unterschied der eine für den andern verwendet (Permutation). So z. B. hat die Kabylensprache für "Mann" die Wörter argaz und ergaz, für "Frau“ thamet't'uth und themet't'uth; in Dialekten der Tuaregs findet man für "Tag": ahel und achel, für "Bock": achular, ahular und afular. Die Eskimosprache (Innok) verwandelt $e \mathrm{zu} i$ im Plural von amè-rk, "Haut" (ami-t, Häute) und $g$ zu $r$ im Plural von kignt, „Zahn" (kirut-il, Zähne) etc. Einige solcher Aenderungen erklären sich aus Gründen des Wohllauts, der Euphonie. Es bewirken solche in gewissen Sprachen ganz regelmässige Aenderungen der Vokalisation, die dahin gehen, den einen Selbstlaut mit einem andern in Einklang zu bringen (Vokalharmonie, Homophonie ${ }^{1}$ ). So nimmt im Yakutischen die Endung, womit der Plural gebildet wird und welche aus den Konsonanten $l-r$ nebst einem inlautenden Vokal besteht, als solchen regelmässig den Selbstlaut des Wortes, welchem sie als Suffix angefügt wird: axa-lar, die Väter; oxo-lor, die Kinder, äs̈̈-lär, die Bären.

1) Vgl. Max Müller, Vorlesungen über die Wissenschaft der Sprache; deutsch von Dr. C. Böttger; Leipzig 1863, S. 250. 
In einigen Dravida-Dialekten hingegen wird der Vokal eines Wortes durch denjenigen seiner Endung bestimmt; so bildet man aus den Wörtern liatti (Messer) und mulu (Tiger) die Pluralformen kattulu und pululu, anstatt latti-lu, und $\left.y^{\prime} u l i-7 x^{1}\right)$. Dergleichen Eigenthümlichkeiten sind zu konstatiren und mit zahlreichen Beispielen zu belegen.

Tom Gesichtspunkt der Morpholorie aus, d. h. mit Rücksicht auf die Formen der Wörter und die Bildung derselben unterscheidet man drei Gruppen von Sprachen.

$1^{\circ}$ Einsilbige oder isolirende Sprachen.

Die Wörter dieser Sprachen, deren typischer Repräsentant das Chinesische ist, bestehen aus unveränderlichen, inflexibeln Wurzeln, die einfach aneinander gefügt werden. So bildet man aus tse (Kind) einerseits, nan (Mann, männlich) und niu (Weib, weiblich), die Ausdrücke nan tse (Sohn) und niu tse (Tochter); aus fiu (Vater) und $m$ (Mutter) ebenso: fu mu, Eltern (Vater und Mutter). Da die Zahl dieser Wurzeln verhältnissmässig gering ist und jede mehrere Bedeutungen hat, so präzisirt man deren Sinn entweder durch besondere Betonung oder durch Zusammenschweissen ron zweien derselben, welche in ihrer Bedeutung übereinstimmen. So kann tao bedeuten: Fahne, Weizen, bedecken, Weg u. s. w.; lu: Thau, Edelstein, schmieden, Weg etc.; aber tao lu kann nur die Bedeutung "Weg" haben, weil nur in ihr die beiden Ausdrücke übereinstimmen. - Eine solche Sprache hat weder Deklination noch Konjugation, und ob ein Wort Substantiv, Adjektiv oder Verb, Subjekt, Objekt etc. sei: das hängt lediglich ab von dessen Stellung im Satze und ron der Beifügung gewisser accessorischer Redetheile.

$2^{\circ}$ Agglutinirende oder polysynthetische Sprachen.

Bei diesen findet die Bildung der Wörter dadurch statt, dass einer invariablen Wurzel, welche ihren vollen eigenthümlichen Sinn und Werth heibehält, eine oder mehrere Wurzeln angefiigt werden, deren individuelle Bedentung abgeschwächt wird und welche nur noch dazu dienen, den Hauptausdruck in Bezug auf gewisse Verhältnisse (Zustand, Thätigkeit) näher zu bestimmen. Diese Beifügung heisst

1) Diese Rückwirkung ron Lauten auf einen vorangehenden Vokal erinnert sinigermassen an die Erscheinungen des Umlauts in der deutschen Sprache. 
Pritix, Suffix oder Infix, je nachdem sie vor dem Hauptausdruck, dessen Beziehungen durch sie angegeben werden sollen, oder an das Ende desselben zu stehen kommt oder aber in denselben aufgenommen wird. Die Präfixe und Suffixe zusammen, welche darin übereinstimmen, dass sie den Wurzeln. nur äusserlich angefügt werden, heissen Affixe. Die einen wie die andern dieser Zusätze (Affixe und Infixe) bilden mit der Wurzel je ein Ganzes, indem sie mit derselben zu Einem Gebilde verwachsen oder verschmelzen. Einige Beispiele hiefür wollen wir zunächst dem Japanischen entnehmen, dessen Wortbildung dem rorhin (sub. 1) betrachteten Falle noch ziemlich nalie steht, aber doch schon den charakteristischen Lnterschied erkennen lässt. Mit der Wurzel ncko einerseits, den Präfixen o und me andererseits werden gebildet: onclin Kater, meneko Katze; mit der Wurzel hito, den Suffixen de und no, sowie dem Infix tatsi: hito der Mensch, hitode mit dem Menschen; hitono des Menschen; hitotatsino der Menschen.

Einige agglutinirende Sprachen zeichnen sich aus durch die Verschmelzung oder Einverleibung mehrerer Vorstellungen in Ein Wort und den Polysynthetismus oder die Vereinigung einer grossen Zahl von Ideen in einem einzigen Ausdruck. Es ist dies der Fall bei den amerikanischen Sprachen (der Indianer und Eskimos); so heisst im Algonkin das Wort mindurcma: meine Schwester; in der Tscherokesensprache linturon: ich wasche mich, takumglictut ich wasche meine Kleider, und der grönländische Ausdruck aulisariartarasuarpol: bedeutet: er ist schnell fischen gegangen.

$3^{\circ}$ Flektirende Sprachen.

In diesen Sprachen findet die Wortbildung nicht nur durch ein Zusammenfügen (Agglutiniren, "Aneinanderleimen") rerschiedener Elemente, sondern auch dadurch statt, dass die Wurzel - die fast immer ihre selbständige Bedeutung verloren hat - noch ihren Lautbestand ändern und dass hiedurch verschiedenen Beziehungen Ausdruck gegeben werden lann: ich finde, ich fand, ich habe gefunden; wir lesen, wir lasen; ich kenne, ich kannte, ich habe gekannt; esse, du issest u. s. w. Aehnlich wird in der Kabylensprache ron $\mathrm{ct}^{\prime}$ " geben" gebildet: eflir ich gebe, theflicll du gibst, iflia ex gibt. 
Der Reisende hat also zu untersuchen, in welche dieser drei Klassen die Sprache gehört, womit er sich beschäftigt: welchem dieser drei verschiedenen morphologischen Systeme sie entspricht. Zu dem Ende muss er prïfen, welche Lautgruppen oder Silben in der betreffenden Sprache die Bedeutung von Wrum.rir haben, $d$. h. welche dieser Laute und einfachen (einsibigen) Lautlomplexe für sich allein einen simn geben, selbständige Bedeutung haben oder als Grundhestandtheil eines Wortgebildes übrig hleiben, nachdem die Affixe und Infixe eliminirt wurden, welche es enthielt, und nachdem man ferner auch die Lautveränderungen berücksichtigte, mit welcher dessen Flexion verbunden ist.

In den Sprachen, deren Wurzeln ihre Bedeutung erhalten hleibt, sind diese unschwer herauszufinden. Da in mon tse, miu tse, fu mu (s. S. 591) jede Silbe ihren selbständigen Sinn hat, so sind dies ebenso viele Wurzeln. In onelio, menclie, hito, hitode, hitome, hitodutsimen (s. S. 592) lassen sich leicht die Wurzeln nelon und hito erkemmen. Schwieriger ist aber das Aufsuchen der Wurzeln in den flektirenden sprachen: man muss dabei oft in mehrfachen Tersuchen zahlreiche Wörter zusammenstellen, die ein gemeinsames Element zu haben scheinen. Eine aufmerksame Vergleichung und besonnene hritik werden zur Entdeckung der Wurzeln oder Stämme führen, auch wenn diese keine selbständige Bedeutung mehr haben und durch die Affixe maskirt sind. so tritt uns in den französischen Würtern heurer, bumhenr, mulh"ur die gemeinsame Silhe ,heur" entgregen, welcher ihre selbständige Bedentung erhalten geblieben ist in der Wendung -heur et malheur" (Glïck und Tnglück): man muss aber auch einsehen, dass es fehlerhaft wäre, wenn man - nur ler Lautgleichheit wegen - die gleiche Wurzel in lureter stossen) und hrure (Stunde, Zeit) ammehmen wollte. Stellt nan die deutschen Wörter finden, ich fand. Fund, Findliny, Erfiudung zusammen, so lässt sich nicht verkennen, dass lenselben eine gemeinsame Idee zu Grunde liegt, als deren Cräger sich die Konsonanten und ein Inlaut der Silhen find ", fand", fund" darstellen, in welchen aber jene Idee icht scharf ausgedrückt, sondern nur vag angedeutet ercheint. Das Verfahren, welches einzuschlagen ist, besteht, lso darin: Es sind Wörter zusammenzustellen und zu ver- 
gleichen, welche in Form und Sinn eine gewisse Uebereinstimmung zeigen; sodann ist aus denselben ihr gemeinsames Element, ihr Grundbestandtheil, herauszuschälen durch Beseitigung aller Partikeln, Vor- und Nachsilben und unter Ausschluss von Lautveränderungen, die nachweislich jüngeren Datums sind und daher das Zurückgehen auf einen früheren Lautbestand nothwendig machen. In den semitischen Sprachen sind es die Konsonanten, welche die Wurzel ausmachen und auf deren Aehnlichkeit folglich Alles ankommt. So liegt den arabischen Wörtern qatala (er tödtete), qutila (er wurde getödtet), qafl (Mörder), qitl (Feind) die Konsonanten - Trias qtl mit dem Begriff "tödten" zu Grunde.

Wenn die Wurzeln, welche man erkannt hat, in der Sprache eine selbständige Bedeutung haben und bei der Wortbildung unverändert bleiben, indem sie hiebei nur aneinander gereiht werden, so ist die Sprache, um welche es sich handelt, als eine einsilbige zu betrachten; als eine agglutinirende aber, wenn die Wörter gebildet werden durch Verschmelzung einer invariabeln Wurzel mit Partikeln ohne eine klar ausgesprochene selbständige Bedeutung; als eine flektirende endlich, wenn die Wurzeln selbst variabel sind, denselben nur vage Ideen zu Grunde liegen und die Wörter gebildet werden einerseits aus diesen in ihren Bestandtheilen modifizirten Wurzeln, andererseits aus accessorischen Elementen, wie dies die Affixe und Infixe sind.

Dieses Aufsuchen der Wurzeln führt zur Erkenntniss einer Anzahl interessanter Thatsachen: es ergibt sich dabei, welche Rolle eine Wurzel bei der Wortbildung spielt; welches die trennbaren Partikeln sind; wie sie verwendet werden, als Präfixe, Suffixe und Infixe; wie sie die Idee modifiziren, welche in der Wurzel ausgedrückt ist; welche Tragweite die mit gewissen Aenderungen in Vokalen und Konsonanten verbundene Flexion oder Biegung der Wörter hat; wann eine Kontraktion oder Elision stattfindet, d. h. der Wegfall eines Lautes oder die Reduktion mehrerer Laute zu einem einzigen etc. etc. Das Auffinden der Wurzeln selbst ist von grossem Werth, indem sie den alten Fond an Ideen und Worten repräsentiren, welchen die Sprache besass, um die es sich handelt, oder das Volk, das dieselbe redet, und ein bedeutsames Licht werfen auf die Verwandtschaft von Idiomen, 
welche infolge der späteren selbständigen Entwicklung dieser letzteren nach verschiedenen Richtungen maskirt wurde, sodass sie an den Sprachen in ihrer jetzigen Form nur schwer und nicht ohne weiters zu erkennen ist.

Bei diesen Studien achte man auch darauf, ob die betreffende Sprache reich oder arm ist an onomutoportischen Wortbildungen oder Schallnachahmungen, d. h. an Wörtern, deren Klang die Vorstellung erwecken soll von der Sache, welche sie bezeichnen, wie Krach, Glucken u. dgl. Ebenso ist es von Interesse, die gebräuchlichen und oft sehr bezeichnenden Interjektionen kennen zu lernen.

Oft hängt die Bedeutung der Wörter von deren Betonum! oder Accent ab; man unterlasse nicht, zu ermitteln und anzugeben, welche Regeln in dieser Hinsicht herrschen.

Volle Berücksichtigung und Erwähnung verdient ferner der Umstand, ob eine Sprache reich an Vokalen oder Konsonanten ist. Es handelt sich dabei weniger um die Anzahl der Vokale oder Konsonanten, welche in dieser Sprache überhaupt vorkommen, als vielmehr um die Häufigkeit oder Seltenheit ihres Gebrauches in derselben. Eine Sprache kann eine verhältnissmässig geringe Zahl von Vokalen haben, diese aber bei Bildung der Wörter in reichem Maasse verwenden; eine andere kann ihre Wörter mit Konsonanten überladen und dadurch deren Aussprache erschweren, wenn sie auch keine grössere Anzahl von Mitlauten besitzt als jene.

In den oramatischen Kateyorien zeigen die Sprachen vielfache Verschiedenheiten. Manche haben keinen Artikel vor den Substantiven oder nicht die Unterscheidung des Geschlechts, an welche wir gewöhnt sind. So bedeutet das Kabylische ar'orum unterschiedslos ,das Brod", „ein Brod" oder "Brod". In der zentralafrikanischen Fulahsprache gibt es kein Maskulinum und Femininum, aber alle Wesen und Gegenstände werden in die zwei Klassen getheilt: $1^{\circ}$ Was zur Menschheit gehört; $2^{\circ}$ was nicht zu ihr gehört: Thiere und leblose Gegenstände. Uebrigens brauchen wir nicht soweit zu gehen, um ahnliche Verschiedenheiten zu finden; es bestehen ja schon grosse Differenzen in der Auffassung und Bezeichnung des grammatischen Geschlechtes zwischen dem Franzüsischen, Deutschen und Englischen. Die beiden letzteren unterscheiden mïmuliche, weibliche und sächliche Substantiven (Masculina, Feminina und 
Neutra); das Franzősische kennt die letztere Kategorie, das Neutrum, nicht. Die Geschlechtsunterscheidung für Sonne und Mond ist im Französischen wie im Englischen (und in fast allen anderen Sprachen) gerade das Gegentheil derjenigen, welche die deutsche Sprache hiefür hat: "Somne" ist in den anderen Sprachen männlich und "Mond" weiblich. Die Unterscheidung ron Fällen oder Kasus (Nominativ, Genitiv, Dativ, Accusativ etc.) hat für das Französische, Italienische u. s. w. kaum noch eine Bedeutung, ist dagegen von Wichtigkeit für diejenigen Sprachen, deren Substantive, Pronomen und Adjektive deklinirt werden, d. h. besondere Formen oder Endungen annehmen, jenachdem sie als grammatisches Subjelit oder Objelit angewendet werden oder die Idee des Besitzes, der Trennung u.s.f. ausdrücken. Die Zahl dieser „Fälle“ oder vielmehr derjenigen, welche an den Wörtern durch Aenderung in deren Form oder durch Endungen bezeichnet werden, ist bei den einzelnen Sprachen verschieden. Die einen beschränken sich auf die vicr Kasus: Nominatir, für das existirende oder handelnd auftretende Subjekt; Genitiv, welcher Art und Gattung bezeichmen und oft auch Ausdruck des Besitzverhältnisses sein muss; Datir, für das Geben oder Ertheilen oder Verleihen; Accusativ, zumeist als Bezeichnung des Gegenstandes, auf welchen die Thätigkeit übergeht oder an welchem sie ausgeübt wird. Andere haben ferner einen Vokativ als Fall des Anrufens, den Ablativ, welcher ein Trennen oder Entfernen ausdrückt; weiter einen Locativ, um ein Verhältniss des Ortes, der Bestimmung anzudeuten; Instrumentalis und Causativ zur Bezeichnung des Mittels, des Werkzeuges, der Ursache für eine Thätigkeit etc. etc. Als Pronomen der zweiten Person finden wir im Französischen und Englischen je nur zwei Wörter (tu, couss, thou, you, entsprechend dem deutschen du. and ith\%), bei deren Gebrauch es nicht darauf ankommt, ob man mit Männern oder Frauen spreche, sondern zunächst - abgesehen von den Anforderungen der Etiquette, welche hiebei im Deutschen und Italienischen wieder andere sind als im Französischen und Englischen - nur darauf, ob man sich an Eine Person oder deren mehrere wende. Die Kabylensprache aber hat hier in Einzahl und Mehrzahl je zwei verschiedene Formen, von denen die eine gegenüber männlichen, die andere gegen weibliche Personen anzuwenden 
ist: lietsch und liem im Singular, liumei und liunemthi im Plural. Die Eskimosprache (das Innok) hat für die dritte Person zwei Pronomen, um An- und Abwesenheit zu bezeichnen: omo, "er" als Anwesender: tabioma, „er" als $\mathrm{Ab}$ wesender. Ferner gibt es Sprachen, welche neben Einzahland Nehrzahlform noch einen Dual und selhst einen Trial haben zur Bezeichunug der Zwei- und Dreizahl im Sime der Verbindungen: Du und ich, er und ich, das Deine und Neine, das Seinige und Meinige: Du, er und ich; das Meine, Deine und Seine etc. Ehenso bestehen grosse Verschiedenheiten hinsichtlich der Zeit- und Modusformen des Verbums. Im Arabischen, überhaupt in den semitischen Sprachen, zeigt die Form des Verbums an, ob die Thätigkeit rollendet oder noch nicht abgeschlossen ist. Gewisse Idiome haben ein besonders accentuirtes Präsens in der Bedeutung: ich bin im Begriff das zu thun, ich bin damit gerade beschäftigt: ein Immediat-Perfelit: ich habe soeben das und das gethan: ein Immediat-Futurum für das unmittelbar hevorstehende: ich werde das sogleich thun etc. Der Conditionalis als spezielle Form für die bedingrende Rede kommt nicht in allen Sprachen ror, noch weniger der Conjunctiv; hinwieder besitzen die Eskimo neben unserem Imperativ eine besondere Form von verbietender Redeweise (Prohibitiv), die wir wiederzugeben hätten durch: ich will nicht, dass Du das thust.

Unsere passiven und reflexiven Zeitwörter sind in andern Sprachen nicht durch Analoga vertreten; hinwieder haben diese mitunter Spezialformen aufzuweisen zur Bezeichnung des gewöhnlichen Zustands u. dgl. Wenn wir von Jemandem sagen: "er trinkt", so kann das heissen : „er stillt den Durst" oder auch „er fröhnt der Trunksucht"; , er zeichnet" bedeutet bald: „er kamn zeichnen", bald "er ist mit Zeichnen beschäftigt", und auch : „das Zeichnen ist seine Beschüftigung, sein Beruf"; "er" arbeitet" will keineswegs immer ausdrüclien, dass der Betreffende gerade jetzt, wo man davon spricht, arbeite, sondern oft nur, dass er dies gewöhnlich thue: hinwieder sagt man offenbar nur in diesem letzteren Sinne (der Bezeichnung des gewöhnlichen Zustandes): „ich schlafe zut", „ich träume wenig " u. dgl. Für diesen Interschied lat also unsere Sprache keine besonderen Formen: in andern lber ist das der Fall. So sagen die Kabylen ilirez für: er 
arbeitet; d'a ikerrez für: er ist eben an der Arbeit; ikerrez für: er arbeitet gewöhnlich, er ist arbeitsam. Ebenso gibt es daselbst, wie auch in andern Sprachen, Verbalformen für den Gedanken, den wir durch "machen" oder "lassen", die Franzosen durch "faire" oder "rendre" ausdrücken: selinef, braten machen (von clinef, braten), sckchem eintreten lassen, "faire entrer" (clichem, eintreten); selhou, gut machen, "rendre bon", zu clhou, gut sein u. s. w. Der deutschen Sprache fehlt ein Analogon hiezu allerdings nicht ganz; aber dasselbe ist auf gewisse, nicht sehr zahlreiche Fälle beschränkt: trinken, tränken; stehen, stellen; liegen, legen; sitzen, setzen; härten = hart machen, schwärzen = schwarz machen u. a. m.

Diese Vergleichungen und Beispiele könnten leicht vermehrt werden; vielleicht sind sie aber schon $\mathrm{zu}$ zahlreich; ihr Zweck ist kein anderer als der, nach verschiedenen Seiten zu erinnern und darzuthun, dass die verschiedenen Sprachen nicht nach einem Modell zugeschnitten oder nach einer Form gegossen seien und man die Erscheinungen derselben nicht dem Schema und Rahmen der grammatischen Kategorien anpassen soll, welche uns von der Muttersprache her geläufig sind. Der Reisende muss vielmehr darnach trachten, ohne vorgefasste Meinung bei jeder Sprache oder Mundart die grammatischen Formen wohl zu erfassen und dieselben, wenn sie eigenthümlich sind, gut $\mathrm{zu}$ definiren, womit die Anführung zahlreicher Beispiele zu verbinden ist.

Die Syntax betrifft die Verbindung der Wörter zu Sätzen, die Stellung und Reihenfolge der ersteren in diesen, die Modifikationen, welche sie zufolge ihrer gegenseitigen Beziehungen erleiden $\mathrm{u}$. s. w.

In den einsilbigen Sprachen, wie dem Chinesischen, ist die Syntax Alles; denn hier hängt von der Stellung eines Wortes dessen Werth und Bedeutung als Substantiv oder Adjektiv, Subjekt oder Objekt ab. Demgemäss ist denn auch die Wortfolge etwas Unveränderliches. Diejenigen Sprachen hingegen, welche für die Kasus verschiedene Endungen und für das Verb eine formenreiche Konjugation haben, geniessen hinsichtlich der Wortfolge einer grossen Freiheit. Es kann hiebei die normale Aufeinanderfolge mannigfach geändert, ja gänzlich umgekehrt werden, ohne dass dabei Sinn und Verständniss des Satzes Schaden leiden; 
gegentheils erfolgen diese Umstellungen oder Inversionen im Interesse und zur Verschärfung des Sinnes, welchen man in dem Satz darstellen und hervorheben will. Zwischen diesen beiden Extremen finden sich Abstufungen in grosser Zahl. Wie verschieden die Reihenfolge der einzelnen Wörter schon in Zusammenstellungen der einfachsten Art ist, mögen zwei Beispiele zeigen. Im Baskischen sagt man nicht: an die Frau, sondern "Frau an die"; in der Kabylensprache nicht: mein Maulthier, sondern "Naulthier mir". Dabei erleidet oft fast jede Regel zahlreiche Ausnahmen, welche im Sprachgebrauche nicht minder fest begründet sind als jene.

Der Reisende hat die syntaktischen Eigenthümlichkeiten einer Sprache durch vielfache und mannigfaltige sätze darzustellen. Bei Anlage solcher Sammlungen wird man mit einfachen Sätzen beginnen, die nur aus Subjekt, Verb und einem Objekt bestehen; dann ist zu entwickelteren Satzbildungen überzugehen, in welchen Adjektive, Adrerbien u. s. w. als Attribute und verschiedenartige Bestimmungen (Adverbiale des Ortes, der Zeit u. s. w.) enthalten sind, sowie auch diverse Objekte rorkommen. Ein und derselbe Satz soll in verschiedenen Formen auftreten: bejahend und rerneinend, fragend und befehlend, in direkter und indirekter Rede, als bestimmte Aussage oder Behauptung, wie als blosse Annahme oder Vermuthung, Wunsch oder Bedingung etc.

Von grossem Interesse sind auch treue Aufzeichnungen (Transskriptionen) ron Fabeln und Erzählungen, Sagen und Liedern oder auch blos Sprichwörtern und sprichwörtlichen Redensarten, welche der Reisende zu hören bekommt, und denen er wörtliche Uebersetzungen beigibt.

Sprachverwandtschaft. Man hüte sich daror, in den Fehler zu verfallen, dass man zu schnell und ohne genügende positive Nachweise behauptet, eine Sprache, die man studirte, sei mit einer bestimmten andern "verwandt". Die Frage der Verwandtschaft zweier Sprachen ist sehr delikat und weit schwieriger zu beurtheilen, als man gewöhnlich meint.

Sprachen, welche zu einer und derselben morphologischen Klasse gehören, müssen keineswegs unbedingt mit einander verwandt sein. Die Einsilbigkeit, die Agglutination und die Flexion sind drei Zustände, welche ron Einer Sprache successive angenommen und passirt werden können, wenn sie 
nicht ihre Entwicklung abschliesst und stabil wird, bevor sie die höchste dieser Stufen erreicht hat. So finden wir denn in der nämlichen morphologischen Klasse Sprachen bei einander, zwischen welchen lieinerlei rerwandtschaftliche Beziehungen herrschen. $\mathrm{Zu}$ den einsilbigen Sprachen gehören das Chinesische, Annamitische, Siamesische, Tibetanische und, wie rersichert wird, gewisse Idiome der Eingebornen Mittelamerikas. Die Wurzeln dieser Sprachen sind so verschieden, dass dieselben nicht als verwandt betrachtet werden liömnen; auch machen es schon geographische Gründe nicht wahrscheinlich, dass die sämmtlichen Idiome dieser Klasse durch gemeinsame Abstammung (genetisch) mit einander rerbunden seien. Die agglutinirenden Sprachen sind die verbreitetsten der Erde und umfassen zahlreiche Familien. Hieher gehören die ural-altaischen, dravidischen und kaukasischen Sprachen, das Baskische, viele afrikanische Idiome, die australischen und malayisch-polynesischen Sprachen, das Japanische, Koreanische, die meisten Idiome derEingebornen Amerikas u.s.f. Zwischen ihmen besteht nur morphologische Uebereinstimmung; ein gemeinsamer Lrsprung derselben kann nicht angenommen werden; ebensogut könnte man sonst alle Erwachsenen als Geschwister betrachten, blos weil sie darin übereinstimmen, dass sie erwachsen sind. Die flektirenden Sprachen endlich umfassen die semitischen, hamitischen und indo-europäischen Idiome, d. h. die Hauptsprachen Vorderasiens, Nord- und Nordwestafrikas und fast ganz Europas. Eine entfernte Terwandtschaft aller Glieder dieser Sprachenklasse ist allerdings nicht unmöglich und nicht unwahrscheinlich; immerhin sind ihre Wurzeln so rerschieden, dass sie kaum alle miteinander in Beziehung gebracht werden können.

Das Kriterium der Verwandtschaft zweier Sprachen liegt also weder in der Aehnlichkeit gewisser Wörter, die zufällig sein kann, noch in deren Bildungsweise oder Morphologie, welche nur ein bestimmtes Entwicklungsstadium bezeichnet. Will man die Verwandtschaft, eine genetische Uebereinstimmung zwischen zwei Sprachen ergründen, so erfordert dies ein tiefes Eindringen in dieselben: das Auffinden und den Nachweis ron Aehnlichkeiten in ihrem grammatischen Bau und in ihren Grundbestandtheilen, den Wurzeln. Wenn die Individuen, welche eine und dieselbe Sprache reden, sich von einander 
trennen, so nehmen sie einen gemeinsamen Sprachschatz mit sich, der von nun an in verschiedener Weise behandelt wird. Dabei ist es nicht sehr wahrscheinlich, dass der Satzlaau bedeutende Veränderungen erleide, wiewohl es Beispiele fü̈: solche Fälle gibt. So enthält die Kabylensprache gewisse Wendungen, welche offenbar dem Arabischen entlehnt, beziehungsweise nachgebildet sind. Die Wörter unterliegren allmäligen Veränderungen in Aussprache und Endungen: es entstehen neue Wörter; aber der aus den Wurzehn der gehräuchlichsten Würter bestehende Grundstock des Sprachschatzes bleibt immerhin erkemnbar. Lnter diesen gebräuchlichsten Wörtern verstehe ich dabei diejenigen, welche ein Volk schon auf einer sehr frühen Stufe seiner geistigen Entwicklung, bei Beginn der Zivilisation, sozusagen beim Morgenroth derselben, besitzt: Wörter wie: Tater, Mutter, Sohn, Tochter, Bruder, Schwester, Kopf, Hand, Fuss, ich, du, mein, dein, Tag, Nacht, eins, zwei, drei. Das sind Ideen, die sehr früh, auf einer noch ungemein primitiven Stufe der Kultur, bestanden hahen müssen, und Wörter, die nicht leicht vercressen werden.

Hat man in den Wurzeln solcher Wörter, wie im siprachbau und in grammatischen Formen zweier Idiome Indizien einer Verwandtschaft derselben entdeckt, so kann man diese Lntersuchungen auf weitere Gruplen ron Wörtern ausdehnen, sn auf diejenigen, welche primitive Waffen und Geräthschaften, Hausthiere, Arbeiten u. dgl. bezeichnen. Solche Forschungen können nicht nur neue Nachweise für die Verwandtschaft zweier Sprachen liefern, sondern selbst Aufschlüsse üher die Stufe der Zivilisation, welche die Glieder einer Sprachgemeinschaft vor ihrer Trennung erreicht hatten.

Sprachgebiete. Der Reisende soll sich genau erkundigen, welche Ausdehnung das Gebiet einer Sprache hat, $d . h$. wie weit sie verbreitet ist. Die Eingebornen werden ihm sicherlich sagen liönnen, ob eine bestimmte Sprache derselben auch auf benachbarten Inseln herrscht, ob auf beiden Seiten eines Flusses oder Stromes, an beiden Abhängen eines Gebirges, in rerschiedenen Thälem das gleiche Idiom gesprochen wird, und welches die Grenzen desselhen sind. Womöglich sind diese Angaben durch eigene Beobachtungen zu verifiziren. 
Die Eingebornen, namentlich Greise, werden vielleicht auch sagen können, ob die Sprache früher über ein grösseres Gebiet rerbreitet war als jetzt oder ob sie im Gegentheil an Terrain gewonnen hat. Ist ihre Einführung verhältnissmässig meuen Datums, so wird sich vielleicht ermitteln lassen, wie, durch wen, um welche Zeit oder seit wie viel Menschenaltern sie eingeführt wurde, wobei selbstverständlich sachbezüglichen Angaben und Traditionen nicht mehr Werth beizulegen ist, als sie verdienen. Es kann sein, dass man auf diesfallsige Fragen die Antwort erhält: die Sprache sei immer dagewesen, es habe in dem Lande nie eine andere gegeben; oder: sie sei den Menschen ron übernatürlichen Wesen gebracht worden u. dgl., andrerseits können aber auch die Namen Derer, welche die Sprache einführten, und des Landes, woher sie liamen, im Gedächtniss des Volkes erhalten geblieben sein.

Koexistenz verschiedener Idiome. In jüngst eroberten Ländern und in Gegenden mit scharf getrennten Kasten und Klassen können auf demselben Gebiete zwei oder mehr Sprachen nebeneinander vorkommen: das Idiom der Eroberer und dasjenige der Besiegten oder die Sprache der höheren Kasten und diejenige der unteren Volksklassen. Es wird sogar behauptet, dass auf den Antillen, wo die Karaiben den männlichen Theil der Bevölkerung erschlugen, den wejblichen aber gefangen nahmen, nun die Sprachen nach den Geschlechtern verschieden sind, indem die Männer das eine, die Weiber das andere Idiom sprechen. Gewiss ist, dass überall, wo die Bevölkerung aus zwei nach Ursprung oder Abstammung verschiedenen Schichten zusammengesetzt ist, es eines langen Zeitraums bedarf, bis die Sprachen sich miteinander vermischen und ineinander verschmelzen oder die eine durch die andere besiegt und verdrängt wird. Wo verschiedene Volksklassen bestehen, welche zwar die Sprache gemeinsam haben, aher die gegenseitige Berührung möglichst vermeiden und einander fremd bleiben, da wird jene Sprache in den so getrennt lebenden Gruppen ein ungleiches Schicksal haben; ihre Entwicklung oder ihr Verfall wird in der einen Gruppe nicht denselben Gang nehmen wie in der andern, der eine Prozess nicht Schritt halten mit dem andern. Nur unter gleichen Verhältnissen kann die Sprache ihre Uniformität beibehalten. Der Reisende kann also in einem und demselben 
Lande zwei oder mehr Syrachen ron rerschiedenem Rang treffen, d. h. Sprachen, deren Träger gesellschaftlich nicht gleich, sondern in einem Verhältniss der Ueber- und Unterordnung stehen. Die eine dieser Sprachen - man könnte dieselbe als superponirte bezeichnen — wäre die feudule, aristoliratische, amtliche oder gouremementale, die andere die Tational-ader. Tollissurache; es kann aber auch unterschieden werden zwischen einer Kirchusprache, einer Schriftspuche und einer Profan- oder Vulyärsprache.

Bei genauem Zusehen findet man wohl fast überall in den einzelnen Kreisen der Gesellschaft - selbst durchgängig hoch zivilisirter Völker - Verschiedenheiten, wenn nicht der Sprache, so doch der Sprechweise: eine solche der Geistlichkeit, eine zweite der Literaten und anderer Leute ron allgemeiner Bildung, eine dritte als Sprache des Volkes. In den grossen Städten gibt es neben dem allgemein gebräuchlichen Idiom noch ein besonderes (Argnt) der Werkstätten und Arbeitsplätze aller Art, welches reich ist an eigenthümlichen, zum Theil da und dort entlehnten Ausdrücken; auf dem Lande neben der in den Schulen gelehrten Sprache oft ein Patois, das nur in den Familien und im Verkehr des Landvolkes unter sich angewendet wird. Die Handelsverbindungen geben Anlass zur Entstehung ron Mischsprachen, wie man solche als sabir in Afrika und als lingua franca in den Häfen der Levante kennt. Im politischen Verkehr endlich wird oft eine andere als die Landessprache oder diese mit eigrenthümlichen Formeln und Wendungen gebraucht, so dass es eine besondere diplomatische und Kanzlei-Sprache gibt.

Merkwürdig sind die Mittel, deren sich wilde oder halbzirilisirte Völkerschaften bedienen, um sich ihren Nachbarn verständlich zu machen. Die Indianer der Prärien haben eine Zeichen- und Geberdensprache, wobei mit den Pantomimen und Gesten eigentlümliche Rufe und lautes Geschrei verbunden werden, oder sie wenden Feuersignale an, deren Zahl und Grösse eine bestimmte Bedeutung zukommt. Die Lu-tseu-Nomaden im Westen Chinas bedienen sich im Verkehr mit den benachbarten Stämmen verschiedener Symbole. Sie übersenden z. B. in rothem Papier ein Stück Hühnerleber, drei Stücke Fett und eine Pfefferschote, um zu sagen: „Macht euch kriegsbereit." 
Dialekte. Die Verschiedenheit der Idiome einer Gegend nach deren einzelnen territorialen Abschnitten verdient die besondere Aufmerksamkeit des Reisenden. Es ist diese Verschiedenheit öfter sehr beträchtlich, in Neu-Guinea z. B. von einem Dorf zum andern so gross, dass die Einwohner solcher benachbarter Ortschaften Mühe haben, einander zu verstehen. Aehnlich verhält es sich im Allgemeinen überall da, wo die Stämme über ein weites Land zerstreut sind und in feindlichen Beziehungen zu einander stehen, ferner in Gebirgsländern, wo die Menschen, rom Verkehr mit der Aussenwelt abgeschlossen, in Weilern leben, die von einander durch unübersteigliche Schranken geschieden sind.

Die Dialekte in solch' abgelegenen und fast unzugänglichen Oertlichkeiten sind für die Studien, um welche es sich hier handelt, von grösstem Interesse; hier zumeist finden sich noch die Reste verschwindender Idiome, Spuren früherer Sprachen, deren Träger die Urbevöllierung des Landes war. Zwar kommen auch im Flachlande Sprachinseln vor, doch weit seltener als im Gebirge. Immerhin erkundige man sich in allen Fällen bei den Bewohnern eines Landes, ob sie sich nicht erinnern, in ihrer Jugend und auf ihren Wanderzügen irgend eine andere Sprache oder Mundart als die ihrige grehört zu haben, und bejahenden Falls, ob es in der Gegend noch Leute gebe, welche jenes Idiom sprechen oder sich dessen noch wohl erinnern, sodass sie über dasselbe Mittheilungen machen könnten.

Hat man einen Dialekt entdeckt, der besondere Aufmerksamkit $z u$ verdienen scheint, $d$. h. der nicht blos eine verdorbene Form der Landessprache ist, sondern sich durch originelles Gepräge auszeichnet, so wird man denselben in der Weise studiren, wie es oben von der Sprache im Allgemeinen dargelegt worden ist. Handelt es sich aber nur um Verschiedenheiten in der Aussprache und einige andere lokale Spracheigenthümlichkeiten (Provinzialismen), so beschränkt man sich darauf, diese zu konstatiren.

Es ist die geographische Verbreitung eines jeden Dialekts zu ermitteln und auf einer Karte anzugeben; ferner zu prüfen, ob benachbarte Dialekte zu einer Gruppe gehören, worin sie von einander abweichen und ob die Leute, welche diese verschiedenen Mundarten sprechen, einander verstehen 
oder nicht. Endlich ist - nach Massgabe des oben (S. 599) Ciesagten - zu untersuchen, zu welcher hekannten Sprache oder Sprachfamilie diejeniggen dieser Dialekte gehören, die von der herrschenden Landessprache gänzlich verschieden zu sein scheinen.

Schrift. Unter Schrift rersteht man die verschiedenen Arten bildlicher, für das Auge hestimmter Darstellungen der Sprachlaute und Gedanken, deren gemeinsamer Zweck ist, den Ideenaustausch mit abwesenden Personen zu ermöglichen, da die Mittheilung der Gedanken durch das gesprochene Wort auf die Anwesenden (Hörer) beschränlit ist.

Abgesehen von mnemonischen Vittehn, wie schnüre mit aneinander greihten Körnern von verschiedenen Farben (Colliers), Schnüre mit Knnotenreihen (Quiłos), Kerbhölzer' u. dgl. Dinge, welche an eine hestimmte Gedankenreihe erinnern sollen, gibt es folgende Schriftsysteme:

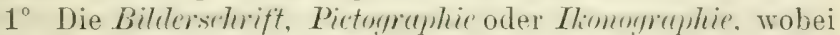
Bilder der verschiedenen Gegenstände angewendet werden: ein System, das bei den nordamerikanischen Indianern noch in Gebrauch ist. In ihrer ursprünglichen Form ist sie reine Bilder- oder Finurmschift, wobei die zu beschreibenden Szenen oder die Dinge, von welchen gesprochen werden will, so gut als möglich abgebildet werden, sodass eine Idee durch eine Reihe von Zeichnungen oder ein einziges ziemlich komplizirtes Gemälde dargestellt wird. Mehr oder minder idto"rraphisch ist sie, wenn ein Theil der Figuren nicht die abgebildeten Gegenstände selher, sondern eine mit diesen Objekten verbundene Vorstellung repräsentiren soll, sodass z. B. eine Thür und ein Ohr "hören" oder ein Auge und Wasser "Thränen" oder "weinen" bedeuten. Symbolisch endlich heisst sie, wenn die Bilder einen abggeleiteten, konrentionellen Sinn hahen, wonach beispielsweise "Wachsamkeit" durch einen Hahn, "Krieg" durch zwei gekreuzte Schwerter, "Gerechtigkeit" durch eine Waage dargestellt wird. Der Unterschied zwischen diesen drei Stufen der Ikonograthie ergibt sich vielleicht am besten aus folgendem Beispiel. Das Zeichen

würde bedeuten:

nach der ersten Art - Auge,

nach der zweiten Art - schen, nach der dritten Art - Vorschung. 
Es fehlt auch nicht an Uebergängen oder Zwischenstufen, wobei die Zeichnungen theils in der einen, theils in der andern Weise - als Bilder, Ideogramme und Symbole verwendet werden.

$2^{\circ}$ Die phonetische oder Lautschrift, welche durch konrentionelle Zeichen die Laute der Wörter darstellt, entweder die Silben oder die einzelnen Vokale und Konsonanten. Letztere Methode, die alphabetische oder Buchstabenschrift erfordert das geringste Material an Zeichen; etwa 30 solcher (Buchstaben oder Lettern, deren Gesammtheit das Alphabet der Sprache bildet) genügen, um mit Hülfe verschiedener Kombinationen derselben alle Wörter einer Sprache darzustellen; oft bedarf es hiezu deren noch weniger. Die Silbenschrift hingegen, erfordert ein grosses Material, da sie z. B. für $a b, a d, a t . ., b a, d a, t a . .$. ebensoviele verschiedene Zeichen haben muss. So ist berechnet worden, dass die chinesische Schrift nicht weniger als 43496 Zeichen umfasst, wovon allerdings ein grosser Theil selten oder gar nicht gebraucht wird. Auch hier gibt es eine Zwischenstufe; so hat die japanische Schrift besondere Zeichen für die einzelnen Vokale, aber auch solche für die Silben wie ka, ki, ko u. s. w.

$3^{\circ}$ Endlich gibt es yemischte Systeme, wobei Lautzeichen, Bilder, Ideogramme und Symbole gleichzeitig angewendet werden, wie dies in den altägyptischen Hieroglyphen der Fall war. Auch in der chinesischen Schrift kommen Fälle vor, wo den phonetischen Elementen ideographische Zeichen beigegeben werden; die letzteren, welche dann allerdings jeder Aehnlichkeit mit dem durch sie dargestellten Objekte bar sind, dienen dazu, den Sinn zu präzisiren, den im gegebenen Falle ein phonetisches Element haben soll, welchem an und für sich verschiedene Bedeutungen innewohnen. Sogar in der eigentlichen Lautschrift finden sich zuweilen noch Bilder von Objekten, die aber ihre ursprüngliche Bedeutung gänzlich verloren haben und nur Homophone sind, d. h. einen dem Namen des Objektes ähnlichen Laut darstellen, wie dies mit den Figuren unserer Bilderräthsel (Rebus) der Fall ist. Die Buchstaben sind auch zum Theil nichts anderes als vereinfachte schematisirte Bilder bestimmter Gegenstände; so das Zeichen a für den Anfangsvokal von ahu, dem alt-ägyptischen Worte für "Adler", welches Zeichen eine gewisse Aehn- 
lichkeit mit dem Bilde des Adlers hat, während M (Initial von mulach, Eule) dem Bilde einer Eule mit lalb ausgebreiteten Flügeln nicht unähnlich ist. Uebrigens sind die Lautzeichen und Alphabete nach den einzelnen Ländern und Sprachen sehr verschieden. Es müssen das nicht Buchstaben oder Lettern nach Art der unsrigen sein; sie können vielmehr, wie die alte Runen- und Keilschrift, blos in Kombinationen verschiedener Striche bestehen. Morse's telegraphisches Alphabet zeigt, dass man auch die heutigen Kultursprachen Europas, das Deutsche, Französische u. s. w. ehenso gut mit blossen Punkten und Strichen als mit unseren Buchstaben schreiben könnte.

Andererseits gibt es Surachen olune jode Schrift, die nur gesprochen und nicht geschrieben werden. Dies war z. B. der Fall mit der Eskimosprache bis zur Ankunft der Dänen in Grönland; die Eskimos kannten kein anderes Mittel des Gedankenausdruckes als das mündliche Verfahren: das Sprechen: selbst die Bilderschrift der nordamerikanischen Indianer war ihnen unbekannt; erst die Missionäre haben in Grönland eine Schrift eingeführt.

Syrachen olne eigene Schrift - wozu wir alle diejenigen rechnen, die wenigrstens heutzutage kein eigenes Schriftsystem mehr haben - gibt es viele. So wird z. B. das Malayische mit arabischen Buchstaben geschrieben; welches sein altes Alphabet war, ist unbekannt. Für die dravidischen Sprachen (das Tamul, Kanara, Telinga $u$. s. w.) verwendet man drei Alphabete, die ziemlich spät nach fremden Zeichen gebildet und dabei den dravidischen Lauten mehr order minder angepasst wurden. Das Annamitische hat einst dem Chinesischen eine Figuren- oder ideographische Schrift entlehnt, deren Zeichen aber seither merklich verändert. Ebenso scheint das tibetanische Alphabet aus dem nördlichen Indien zu stammen.

Man trifft also Sprochen mit entlehere Srhrift; in solchen Fällen wird die Aehnlichkeit der Lautzeichen Anhaltspunkte geben zur Beurtheilung der Herkunft des fremden Schriftsystems, wohei freilich wohl zu berücksichtigen ist, dass die Zeichen nicht den Lautwerth beibehalten mussten, welchen sie in der andern Sprache hatten, dass hierin vielmehr namhafte Aenderungen und Vertauschungen haben stattfinden können. 
Das Verhältniss der Schriftsysteme zweier Sprachen deren Aehnlichkeit oder Verschiedenheit — sagt uns, wie leicht einzusehen ist, nichts über das Verwandtschaftsverhältniss der Sprachen selber. Verschiedene Idiome können sich der gleichen Schrift bedienen; hinwieder kann eine Siache in einem Theil ihres Gebiets oder in einer Periode ihrer Geschichte mit andern Lautzeichen geschrieben werden als in andern Ländern und zu andern Zeiten. Das Malayische rerwendet, wie oben bemerkt wurde, arabische Buchstaben; aber andere Sprachen derselben Gruppe (das Javanische, Talaga, Makassar etc.) bedienen sich alter hindostanischer Zeichen. Das Japanische wurde ehemals mit einem koreanischen Alphabet geschrieben, später mit einer ideographischen Schrift, welche den Chinesen entlehnt und etwas modifizirt wurde; jetzt beabsichtigt man in Japan unser lateinisches Alphabet einzuführen. Dass die deutsche Sprache nicht immer die "deutsche Schrift" hatte und diese auch jetzt nicht ausschliesslich Anwendung findet, ist bekannt.

In Fällen, wo man es mit einem Schriftsystem neueren Datums zu thum hat, wird man zu ermitteln suchen, durch wen und unter welchen Umständen dasselbe eingeführt wurde; ob es einem andern Volke entlehnt wurde und ob vorher nichts Aehnliches existirte. So ist konstatirt, dass das jetzige armenische Alphabet aus dem Jahre 400 unserer Zeitrechnung stammt und von Sankt-Mesrop geschaffen wurde; dasjenige der Tscherokesen gar ist erst im Jahre 1830 erfunden worden. Den jüngsten Fall der Neu-Einführung eines Alphabets hätten wir in Japan vor uns, wenn es dort wirklich - wie angestrebt wird - dazu kommt, dass die jetzige Schrift durch die lateinische ersetzt wird.

Schriftproben, Schreibweise und Schreibmaterial. Trifft der Reisende eine noch ziemlich unbekannte Schrift an, so hat er dies zu erwähnen und Proben oder Muster derselben beizubringen. Handelt es sich um Figuren und Zeichen, die auf Felsen gemalt, in Baumstämme oder Steine eingeschnitten, auf Thontafeln eingegraben oder in ähnlicher Weise noch auf anderem Material angebracht sind, so stellt man sich Photographien oder Abdrïclie derselben her, wovon unten (bei Besprechung der Inschriften) noch die Rede sein wird. 
Der Reisende wird auch ganze Syllaburien oder Alyluabete sammeln und bei den einzelnen Zeichen angeben, welches ihr Sinn und Lautwerth ist.

Zu erwähnen sind allfällige Eïgrnthümlirhlieiten in der. Art de's Srhreibrus, von denen es abhängt, wir dir Sidwift yelesen werden muss. Bekamntlich wird in einigen Sprachen (Arabisch, Hebräisch u. a.) von rechts nach links geschrieben und nicht, wie wir es thun, ron links nach rechts. Bücher und Manuskripte in solchen Sprachen beginnen mit der Seite, welche nach unserm Gebrauch die letzte wäre. Auch gibt es Schriften oder wenigstens Inschriften (wie die alt-griechischen), deren Zeilen abwechselnd ron links nach rechts und umgekehrt gelesen werden müssen, indem auf eine von links nach rechts gehende Zeile eine solche folgt, die von rechts nach links geschrieben wurde, auf diese wieder eine ron links nach rechts u. s. f., - ein System, das als Furchenschrift (Bustrophedon) bezeichnet worden ist, weil dieser Gang des Schreibens und Lesens an denjenigen der gewöhnlichen Art des Pflügens erinnert. Das Chinesische und Japanische werden in Kolomnen, deren erste diejenige rechts ist, von oben nach unten geschrieben.

In den semitischen Sprachen, z. B. im Arabischen, schreibt man nur die Konsonanten; die Tokale werden nur durch sogenannte diakritische Zeichen (Punkte) angedentet. So wird das Wort Kital) (Buch) wesentlich nur durch die drei Konsonanten Krth geschrieben, zu denen dann als Andeutung der Vokale einige Punkte hinzukommen, ein Verfahren, womit die Vokalbezeichnung rerschiedener Stenographie-Systeme einigermassen analog ist. Ebenso gibt es Sprachen, worin die Worte ummittelhar, ohne Zwischenräume, aneinander gereiht werden und keine Interpunktion angebracht wird.

$\mathrm{Zu}$ beachten ist auch eine allfällige Korsistenz wrechirdener Srlurifsysteme, wie eine solche im alten degypten vorhanden war, wo drei Schriftarten (die hieroglyphische, hieratische und demotische) neben einander bestunden, und wie sie lieute noch in Japan rorkommt, wo neben der Liursirschrift (Hirakana) noch ein besonderes System (Katakana) angewentet wird. In solchen Fällen hat man die Lnterschiede dieser Systeme zu bezeichnen und auch anzugehen, welches Zweck und Gebrauch des einen und andern derselben ist. 
Manchmal handelt es sich nur um eine Formverschiedenheit der Buchstaben nach ihrem technischen Zwecke: ob sie als Druckschrift in Büchern, als Zierschrift zur kalligraphischen Ausfertigung werthvoller Manuskripte oder als Kursivschrift für die Geschäfte des Alltagslebens dienen sollen.

Man erkundige sich auch nach alten Dokumenten und Inschriften mit archaischen Schriftformen, d. h. mit Buchstaben, die - wenn sie auch nicht als uralt gelten können - doch ausser Gebrauch gekommen und als veraltet zu bezeichnen sind.

Es kann auch in dem Lande ein in Vergessenheit gekommenes Schriftsystem existirt haben, dessen Entdeckung von Interesse wäre. So besass die Berbersprache ein Alphabet (Tifinar), welches sich jetzt noch bei den Tuaregs findet, das aber bei den Stämmen in Marocco, Algier und Tunis gänzlich in Vergessenheit gerathen zu sein scheint; denn sie bedienen sich jetzt der arabischen Schrift, obwohl diese der Berbernsprache nur unvollkommen angepasst werden kann.

Ausser den Schriftproben wird der Reisende auch MIuster des gebräuchichen Schreibmatevials für seine Sammlungen zu erhalten suchen oder wenigstens die nöthigen Angaben hierüber beibringen. Man weiss ja, dass Feder und Papier nicht überall bekannt und das an ihrer Statt zur Verwendung kommende Material sehr verschieden ist. Es werden die Schriftzüge mit Pinsel oder Schilfrohr, die man in Farbe oder in den Saft gewisser Pflanzen taucht, auf Holz, Rinden, Gewebestoffen etc., mit einem Stift auf Muscheln, Schiefer oder Metall, selbst auf Gold und Elfenbein angebracht. Der arabische Taleb mit seinem Schilfrohr und sonstigem Schreibzeug, das er in seinem Burnus bei sich trägt; der japanische Schreiber mit seiner Rolle von Maulbeerpapier, chinesischer Tusche und dem Pinsel in einem Futteral, das neben Pfeife und Tabaksbeutel an seinem Gürtel hängt: das sind originelle Gestalten, die wohl verdienen, dass ihnen eine Beschreibung oder Zeichnung gewidmet wird.

Zahlensystem. Die Namen und Zeichen der ersten Zahlen (1, 2, 3 etc.) reichen in die ältesten Zeiten der Sprachgeschichte zurück; es hat daher das Zahlensystem noch grösseren Werth als das Alphabet. 
Noch gibt es Völkerschaften, welche nur für die Zahlen 1, 2 und 3 besondere Namen haben, alle weiteren aber insgemein mit einem Ausdruck bezeichnen, welcher unserem "viel" entspricht, wie denn auch wir sehr häufig für eine über 3 hinausgehende Anzahl das Wort "mehrere "gebrauchen.

Auf der Stufe dieses primitivsten Zahlensytems behilft sich der Mensch beim Rechnen mit dem Abzählen der Glieder eines Fingers. Andere Völkerschaften zählen an den Fingerspitzen einer Hand und gelangen so bis auf 5 , wofür oft der bezeichnende Name "Hand" vorkommt. Dieses Verfahren kann in verschiedener Weise weiter entwickelt werden. Durch Ausdehnung desselben auf beide Hände ergeben sich die Zahlen bis 10 , diejenigen bis 20 aber, indem es analog auch auf die Zehen der Füsse angewendet wird. Es können indess die Finger der Hand, mit welcher gezählt wird, selber ausser Berechnung bleiben, wodurch man auf 15 gelangt.

Ueber die bezeichneten Grenzen hinaus werden weitere Zahlen gebildet, indem man je 1, 2 etc. hinzufügt. So fahren die Grönländer, bei 5 angekommen, in der Weise weiter, dass sie sagen: fünf und eins von der andern Hand, fünf und zwei von der andern Hand etc. In mehreren Sprachen sind die Wörter für 6, 7 u. s. w. Ausdrücke, welche den Formeln $5+1,5+2$ etc. entsprechen, und bedeutet das Wort oder das Zeichen für 10 "die beiden Hände." Von diesem quxinüren oder Fünfersystem finden sich noch Spuren in den römischen Ziffern $\mathrm{I}, \mathrm{V}$ und $\mathrm{X}$, welche einen Finger, eine Hand mit ausgestreckten Fingern und die beiden Hände (die Gelenke aneinandergelegt, von da aus entgegengesetzt gerichtet) darstellen. In dem Dezimal-oder Zehnersystem ist die Grundzahl 10; die Wörter für die nächstfolgenden Zahlen bedeuten $10+1,10+2$ etc., diejenigen für 20,30 u. s. w. entsprechen den Ausdrücken 2.10,3.10 etc. (deutsch: zwei, drei, vier Zehner oder nzig"; zwanzig = zwei- oder zween-zig; dreissig = drei-zig; vier-zig; ein und vierzig, zwei und vierzig etc.; dreizehn, vierzehn u. s. w. statt "vierzig und eins", ,zehn und drei" etc.) Das quindecimale oder Fünfzehurrsystem ist seltener; es kam bei einem Stamm der alten Kelten vor, deren Bezeichnungen für $16,17 \mathrm{u}$. s. w. den Summen $15+1$, $15+2$ entsprachen, während ein anderer Stamm hiefür Ausdrücke nach den Formeln $10+6,10+7$ etc. hatte. Bei 
dem vigesimalen Zahlensystem kommen besondere Namen für die Zahlen bis 20 vor; diese selbst wird zuweilen mit dem Ausdruck "Mensch" (Repräsentant der 20 Finger und Zehen) bezeichnet; erst bei den weiteren Zahlen kehren die Worte für 1, 2, 3 u. s. f. wieder; diejenigen für $40,60,80 \mathrm{u}$. s. w. bedeuten 2.20, $3.20,4.20$ etc. Eine Spur dieses Systems findet sich in dem französischen Ausdruck "quatre-vingt" für 80.

Es können auch besondere Ausdriicke für 30, 40 , 50 ctc. rorkommen, wie die gebräuchlichen französischen soixantedix, quatre-vingt-dix für 70 und 90, welchen gegenüber die veralteten Wörter "septante", "huitante" und "nonante", weil systematischer, als Fortschritt zu betrachten sind.

Endlich finden sich Spezialbezeichnungen für 100, 1000 etc., seltener für die grossen Zahlen, die wir Million, Milliarde, Billion, Trillion u. s. w. nennen.

Was die Mittel zum Ausdruck der Zahlbegriffe anbelangt, so ist wohl zu unterscheiden zwischen den Zahluörtem einerseits und den Zahlzeichen oder Ziffern andererseits, also z. B. zwischen dem Worte "fünf" und der Ziffer 5 oder V. Es kann ein Volk Zahlwörter besitzen ohne entsprechende Zeichen für die schriftliche Darstellung und umgekehrt. Streng genommen könnten ja sämmtlichen Zahlen durch ein einziges Wort oder Zeichen, das nur wiederholt anzuwenden wär', ausgedrückt werden; ist doch z. B. 3 nichts anderes als "eins + eins + eins" $(1+1+1)$. So findet man in Sennhütten, Kellern, Fruchtspeichern etc. über die (ein- oder ausgegangenen) Quantitäten Nilch, Nost, Wein, Obst, Getreide u. s. f. Buch geführt durch Kreidestriche auf Brettern oder Einschnitte auf Holzstäben, wobei die Zahl der Striche und Kerben gleich ist derjenigen der verwendeten Einheitsmaasse. Anderwärts bringt man zum gleichen Zwecke (Bezeichnung der Quantitäten, resp. der Einheiten, die zu verrechnen sind) Knoten in einer Schnur an (Quipos) oder man legt Körner, Steinchen u. dgl. an einen hiefür bestimmten Ort. Ein besonderes Zeichen, ein längerer Strich oder Kerbeinschnitt, ein dickerer Knoten, ein Korn oder Steinchen von anderer Farbe als die übrigen repräsentiren dabei eine gewisse Anzahl, z. B. 10, wodurch das Verfahren einfacher und übersichtlicher wird. - Die kleinen Zahlen unter 10 werden wohl auch bezeichnet durch Ausstrecken der Finger, die Zehner aber durch die Hïnde, indem 
man diese so oft mal öfnet und schliesst oder heht und senkt oder (was bei den Komantschen der Fall ist) klatschend zusammenschlägt, als Zehner anzugeben sind.

Als muemonische Irittel werden Vorrichtungen nach Art der Rosenkränze u. dgl. verwendet, endlich auf höheren Stufen der Kultur die Ziffern. Dieser sind meist nur wenige; aber durch verschiedene Kombination derselben können sehr viele und grosse Zahlen dargestellt werden.

Alle die besprochenen Eigenthümlichkeiten des Zählens und Zahlensystems sind von grossem Interesse; der Reisende unterlasse nicht, dergleichen Beobachtungen zu machen und mitzutheilen. Womöglich wird er ein Verzrichniss der Zahlü̈rter und der Zahlzeichen des von ihm besuchten Volkes geben, sowie Beispiel" der Krmbinationen, womit bei einer geringen Anzahl von Ziffern die verschiedensten Zahlen ausgedrückt werden. Nicht bei allen Völkern werden, wie wir es thun, die Zehner ror die Einer, die Hunderter vor die Zehner gestellt u. s. f., einige geben die Anzahl der Zehner, Hunderter oder Tausender durch eine entsprechende Ziffer unter dem Zeichen für 10, 100 oder 1000 an. In den Sprachen, welche ron rechts nach links geschrieben werden, gehen wohl die höheren Zahlen den niedrigeren roraus; aber von unserem Gesichtspunkt aus betrachtet befinden sich jene hinter diesen (z. B. 83 statt 38 ). Zu erwähnen ist auch, wie die Brïche geschrieben werden.

Endlich wird man untersuchen, ob das Volk, mit dem man sich beschäftigt, eigye Zahluërter und Ziffern besitzt oder ob (eventuell woher) es diese cntlrhut hat. Dabei können die Zahlwörter einerseits. und die Ziffern andererseits verschiedenen Ursprungs sein. Unsere Ziffern heissen bekanntlich arabische, stammen aber aus Indien; wir haben sie von den Arabern als den Vermittlern zwischen Orient und Occident entlehnt; sie sind nun z. B. bei den Romanen (Franzosen, Italienern u. s. w.) ebenso wohl im Gebrauch als bei uns, während die Zahlwörter dieser Völker der lateinischen Sprache entstammen.

Hinsichtlich dieser historischen Beziehungen verweisen wir auf die ,Illustrirte Geschichte der Schrift" (Entwicklung der Schrift, der Sprache und der Zahlen) von Karl Faulmann (Wien 1880). 


\section{SITTEN UND GEBRÄUCHE.}

Das Studium der Sitten und Gebräuche eines Volkes ist ron grossem Werthe in Bezug auf die Erkenntniss seiner Vergangenheit, auf Ursprung und Geschichte desselben.

Eingelebte Gebräuche bleiben lange erhalten, und sie haben alle oder hatten einmal, so bizarr sie uns jetzt erscheinen mögen, Sinn und Berechtigung. Wenn man sie nicht mehr befriedigend zu erklären weiss, wenn die Einsicht und das lebendige Gefühl ihrer Bedeutung sich verloren hat, so ist dies nur ein Beweis hohen Alters derselben.

Die Persistenz der Sitten, Gebräuche und eingelebter Gewohnheiten zeigt sich z. B. in Indien, wo die Eingebornen ihren alten Gewohnheiten treu bleiben trotz täglicher Berührung mit den Engländern und langer Dauer der Herrschaft dieser letzteren. Es waren Gesetzesvorschriften, Machtmittel nothwendig, um die Wittwen von Nalabar zu hindern, dass sie auf den Gräbern ihrer Herren und Gatten sich selbst verbrennen, und ein gleich energisches Einschreiten wird nöthig werden, um den Fällen freiwilligen Opfertodes unter den Rädern des Wagens Jaggernaut ein Ende zu machen.

Die Gebräuche bleiben oft noch erhalten, nachdem der Ideenkreis, die Weltanschauung eines Volkes sich gänzlich geändert hat; bei einiger Aufmerksamkeit und Sachkenntniss können wir bei uns noch Bräuche entdecken, welche aus den Zeiten des Heidenthums herrühren. Ebenso finden wir bei andern Völkern Gewohnheiten und Uebungen aus alter Vorzeit, die noch von den Urbewohnern des Landes oder von dessen ersten Eroberern herstammen.

Es ist zu unterscheiden zwischen natïrlichen Gewolnheiten und blossen Nachahmungen von solchen.

Die ersteren sind eine Folge gegebener Verhältnisse, oft so sehr, dass sie sich aus diesen als etwas Nothwendiges und Unvermeidliches ergeben. Man trifft sie daher bei allen Völkern, welche sich auf derselben Kulturstufe befinden oder unter den nämlichen Lebensbedingungen stehen. Blutrache, Frauenraub etc. bezeichnen transitorische Zustände, Stadien, welche von fast allen menschlichen Gesellschaften durchgemacht werden mussten oder müssen; auch findet man die- 
selben auf den verschiedensten Stellen der bewohnten Erdoberfläche. Die Sitte, Wohnungen auf Pfählen im Wasser zu errichten, konnte an Flachküsten und sumpfigen oder Ueberschwemmungen ausgesetzten Ländern zur Nothwendigkeit werden; sie kann daher bei verschiedenen Völkern aufgekommen sein, die miteinander in keinen Beziehungen standen und kein Wissen von einander hatten. - Wesentlich verschieden hievon ist der Sachverhalt bei blos angenommenen, überkommenen oder nachgeahmten Bräuchen, wie Beschneidung, Männerkindbett, solchen Pfahlbauten, zu deren Errichtung kein Grund vorlag u. dgl. Solche Sitten, welchen es unter den Verhältnissen, in denen man sie findet, an imnerlicher $\mathrm{Be}$ rechtigung, an "raison d'être" fehlt, können in einem Lande eingeführt worden sein durch die ersten Ansiedler oder von Eingebornen in sklavischer, nicht einem wohl erkannten und mit Bewusstsein angestrebten Zwecke dienender Nachahmung dessen, was sie bei andern Völkern und Individuen sahen, mit welchen sie in Berührung kamen.

Diese zwei Kategorien von Sitten und Gebräuchen sind nach ihrer wissenschaftlichen Bedeutung sehr verschieden: die ersteren haben lediglich den Werth eines deskriptiven Elements, eines charakteristischen Bestandtheils der Beschreibung von Land und Volk; den letzteren aber kommt eine geschichtliche Bedeutung $\mathrm{zu}$, denn sie sind Indizien alter Beziehungen, wo nicht gemeinsamer Abstammung, der Blutsverwandtschaft zwischen den Völkern, welche in diesen Sitten übereinstimmen. Wenn verschiedene Stämme eines Volkes sich von einander trennten, brachten sie die Sitten ihrer Heimat mit in ihre neuen Wohnsitze und sie blieben ihnen treu aus Anhänglichkeit an dies Erbtheil ihrer Vorfahren oder durch die Macht der Gewohnheit, wenn auch die alten Bräuche in den Verhältnissen der neuen Heimat nicht begründet und insofern nicht weiter berechtigt waren. Andererseits werden durch den Kontakt mit fremden Völkern Neuerungen veranlasst. Friedliche Beziehungen haben einen Ideenaustausch und gegenseitige Entlehnungen in Brauch und Sitte zur Folge; bei feindlichen Verhältnissen aber zwingt der Eroberer dem Besiegten seine Sitten auf, und es bleiben Spuren eines solchen Zustandes in den Gewohnheiten eines Volkes oft länger erhalten als in seiner Erinnerung. Es ist das nicht in Wider- 
spruch mit dem, was oben von dem geringen Einfluss der englischen Herrschaft in Indien gesagt wurde: nicht alle Eroberer haben Religion, Sitten und Gebräuche der unterworfenen Völkerschaften so respektirt, wie dies in unsern Zeiten zu geschehen pflegt.

Der Reisende wird also nicht nur eine Beschreibnng der Sitten und Gebräuche des von ihm besuchten Volkes geben, sondern auch nach einer Erlikumug oder nach dem Ursprun! derselben suchen. Er wird finden, dass diese Bräuche zum Theil Folgen eines jetzigen oder früheren sozialen Zustandes, zum Theil durch eigenthümliche Naturverhältnisse bedingt sind, eine dritte Gruppe derselben aber fremdes Produkt ist, das entlehnt oder eingeführt wurde und dessen Herkanft num ermittelt werden soll.

Hiebei kann auf Mitwirkung der Eingebornen kaum gerechnet werden, ausgenommen, es handle sich um erst kürzlich in Aufnahme gekommene Sitten. Meistens wird man die Erklärungsgründe für die einen und die Quelle der andern Bräuche selbst ausfindig machen müssen. Die Zahl der Personen, die genaue Angaben hierüber liefern könnten, wird immer eine kleine sein, und auf Fragen nach dem Grunde oder Ursprung irgend einer auffallenden Erscheinung dieser Art wird man gewöhnlich die Antwort erhalten: "Das wissen wir nicht" oder "Das ist immer so gewesen." Wie Wenige gibt es ja rerhältnissmässig selbst bei uns, die derartige Fragen nach Gründen and Ursachen in befriedigender Weise zu beantworten vermögen!

Nach diesen Vorbemerkungen geben wir nachstehend eine Tebersicht verschiedenartiger Volksbräuche, welche in Betracht kommen können. Dabei handelt es sich indess weder um eine vollständige Liste, noch um eine ausführliche Darlegung derselben; vielmehr haben wir lediglich den Zweck im Auge, die Aufgabe des Reisenden zu erleichtern durch den Hinweis auf eine Anzahl bemerkenswerther Eigenthümlichkeiten, die beobachtet $z u$ werden verdienen, und welche sodann die Aufmerksamkeit auch auf andere Erscheinungen des Volkslebens lenken werden.

Begrüssungen. Wir entblössen das Haupt, die Chinesen aber bedecken sich, um zu grüssen. Bei Empfang von Gästen stehen wir auf, die Polynesier und Malayen aber 
setzen sich. Kehrt man Jemandem den Rücken, so betrachten wir das als eine arge Unhöflichkeit; auf einigen Inseln des grossen Ozeans aber gilt das als Respektsbezeugung; das Küssen der Hand oder des Kleides ist hei vielen Völkern ein Zeichen der Achtung, das zu geben nicht unterlassen werden darf. Einem Höhergestellten, den man anredet, die Hand zu reichen, würde bei uns als eine zu familiäre Lmgangsform betrachtet, während das in den Vereinigten Staaten üblich ist.

Nicht weniger verschieden sind die Höflichkeitsformehn bei der Anrede. Im Orient überschïttet man den Angesprochenen mit einer wahren Litanei ron Segenswünschen für ihn und seine Vorfahren; dann erkundigt man sich nach der Gesundheit seiner Familienmitglieder; dabei darf aber ja nicht auch von den Frauen gesprochen werden, was ein ganz unverzeihlicher Mangel an Takt wäre. Bei uns hingregen sind die Begrüssungsformeln kurz, und wenn man mit der Familie des Angesprochenen einigermassen bekannt ist, so wäre es unhöflich, wemn man sich nicht auch nach dessen Mutter, Frau oder Schwester erkundigen würde.

Wir wenden fast nur "Herr als Titel an, das Fürwort "Du" aber nur gegenüber Freunden; der Nuselmann verschwendet den Titel "Sidi" (gnädiger Herr, Seigneur), redet aber dabei Jedermann mit "Du" an. Uebrigens hat der Gebrauch dieses Fürworts (das ,Dutzen“) in vielen Ländern gar nicht den Charakter familiärer Tertraulichkeit oder eines Mangels an Respekt. Bei den Indianern, Eskimos etc. redet man sich nicht mit dem Namen, sondern mit dem Verwandtschaftstitel an; sind zwei Männer nicht rerwandt, so gebrauchen sie statt dessen die Anrede "Freund."

Wir grüssen nur unsere Bekannten: an vielen Orten auf dem Lande wird aher jeder Vorübergehende ohne Lnterschied gegrüsst und zwar oft unter Beifügung ron Grussformeln, welche etwas Rührendes haben.

In Tibet tauschen Personen gleichen Ranges, die sich zum ersten Mal sprechen, mit einander leichte Schärpen von weisser oder karmoisinrother Seide aus: ein Höhergestellter erhält die Schärpe beim Kommen, eine Person tieferen Ranges beim Gehen.

Wir verbeugen uns gregenüber Höhergestellten: in vielen Gegenden aber darf ein solcher erst damn angeredet werden, 
nachdem man sich vor ihm auf die Erde geworfen hat, oder man muss selbst während des Sprechens in dieser Lage bleiben und darf auch nicht $\mathrm{zu}$ ihm aufblicken.

Vor dem Eintritt in ein Haus oder in die Kirche nehmen wir den Hut rom Kopfe; der Japanese aber zieht die Schuhe $a b$, wenn er in ein Haus, der Muselmann, wenn er in eine Moschee eintreten will.

Freundschaftşbezeugungen. Die Art und Weise, freundschaftliche Gesinnungen auszudrücken, verdient bei noch wenig bekannten Völkern wohl studirt zu werden; man kann damit späteren Reisenden unliebsame Missgriffe ersparen und es ihnen möglich machen, sofort $\mathrm{zu}$ verstehen $\mathrm{zu}$ geben, dass sie in friedlicher Absicht kommen. Die Freundschaftsbezeugungen sehen feindlichen Demonstrationen oft zum Verwechseln ähnlich: oft sind es Schreie, Sprünge und Gesten, die keineswegs beruhigender Art scheinen, wenn man mit ihrer Bedeutung nicht vertraut ist. Bisweilen werden Freundschaftsversicherungen bekräftigt durch Zeremonien wie die Opferung eines Hundes bei den Papuas, den Austausch injizirten Blutes oder einen blossen Tausch der Namen bei verschiedenen andern Völkern.

Verträge und Eidschwüre. Es ist sehr wichtig, die Formen kennen zu lernen, welche bei Vertragsabschlüssen und Verabredungen allgemein angewendet $\mathrm{zu}$ werden pflegen, damit diese perfekt und gültig sein sollen; zu wissen, welche Zeremonien oder Formeln dazu gehören, dass die vertragschliessenden Parteien sich für unbedingt gebunden erachten.

Ebenso hat man sich $\mathrm{zu}$ erkundigen, ob es verschiedene Eides- oder Betheuerungsformeln gibt und welches die höchste derselben, beziehungsweise eine solche ist, wonach die Eingebornen den geleisteten Schwur nicht mehr zu brechen wagen.

Eine Uebereinkunft bedarf mitunter zu ihrer Verbindlichkeit der Gegenwart von Zeugen oder, was besonders bemerkt zu werden verdient, es wählen die Kontrahenten, z. B. zwei Volksstämme, einen stummen Zeugen, d. h. sie bedienen sich eines Gedenkzeichens (eines aufgehobenen Steines u. dgl.), das später als Nachweis für die Gültigkeit der getroffenen Vereinbarung angerufen wird. 
Gastfreundschaft. Bei manchen Völkern findet man eine weit gehende Gastfreundschaft. Die Bewohner Schottlands waren in dieser Hinsicht ehemals sprichwörtlich; heute noch sind es die Kabylen: obgleich arm, stellen sie dem Fremden reichlich und olıne daron Aufhebens zu machen, zur Verfügung, was er nöthig hat: wenn Jemand die Mittel nicht besitzt, um seinen Gast angemessen zu bewirthen, so trägt das ganze Dorf hiezu bei, und das dargebotene Mahl geht im Allgemeinen weit über das hinaus, welches der Wirth für sich selbst zu verwenden gewolnt ist. Einen ähnlichen gastfreundlichen Sinn trifft man bei anderen Gebirgstölkern und Yomaden: nur muss man sich mit dem begnügen, was bei ihnen zu finden ist.

Anaya. Die Gastfreundschaft schliesst meistens auch die Pflicht zum Schutze des aufrenommenen Fremden in sich. Jemandes Gast sein, unter seinem Dache geschlafen haben, ist im Allgemeinen gleichbedeutend mit , unter dessen Schutze stehen." Dieser Schutz reicht aber oft nicht über die Schwelle der Wohnung hinaus, und Mancher, der das Leben des an seinem Herde weilenden Gastes respektirt, trägt kein Bedenken, denselben zu tüdten, wenn Dieser das Haus rerlassen hat. Bei den Kabylen des Gebirges erstreckt sich der Schutz des Gastes weiter und der Wirth übt ihn wirksam aus, indem er, sein Bruder oder sein sohn den Gast bis zu den Grenzen des Stammes begleitet und ihn dem Nachbarstamme empfiehlt. Es ist aber zum Schutze nicht immer eine Begleitung nothwendig: rielmehr genügt es, wenn der Gast Träger eines Gegenstandes (Stockes etc.) ist, welchen die Bewohner der Gegend als Eigenthum Dessen kennen, der die Gastfreundschaft gewährt. Ein solcher Gegenstand ist ein Talisman, ein symbolischer Geleitbrief, welcher als gleichbedeutend mit der Anwesenheit seines Eigenthümers gilt; es ist sein Anaya. Wer den Träger dieses Zeichens angreift, beraubt oder sonst unangemessen behandelt, fügt dadurch dem Beschützer einen sichimpf zu und hat dessen Rache zu gewärtigen. Das Anaya findet noch in andern Fällen Anwendung. Ein Mensch begreht z. B. einen Mord, um seine Ehre zu rächen, und flüchtet sich zu einem andern Stamm. Das Anaya, das ihm gewährt wird, ist nun grleichbedeutend mit Verleihung des 
Asylrechts. Droht Jemandem von seinen Feinden unmittelbare Todesgefahr, so kann er gerettet werden durch die Dazwischenkunft eines Dritten, selbst einer Frau, wenn er das Anaya dieser Drittperson anruft und erhält. Die Ertheilung desselben kommt hiebei der Ausübung des Begnadigungsrechtes gleich. In andern Fällen ist das Anaya ein Aequivalent des "Tabu", von welchem wir sofort sprechen werden. Bei Zwistigkeiten und Unruhen im Innern wie bei Bürgerkriegen, wird ein Weg, Brunnen, Marktplatz etc. durch das demselben ertheilte Anaya zu einer neutralen, gewissermassen geheiligten Stätte, wo selbst die unversönlichsten Feinde ruhig zusammentreffen dürfen: denn wehe dem, welcher zuerst den Frieden und das Schutzrecht bräche, dessen Symbol das Anaya ist!

Tabu. Das "Tabu" der Südsee-Insulaner ist eine Art Heiligung einer Person oder Sache durch die Priester oder Häuptlinge. Ein Nensch, ein Nahrungsmittel, ein Fleck Erde können als "Tabu" erklärt werden, und alsdann wagt Niemand sie zu berühren. Fast überall ist der Herrscher "Tabu", d. h. geheiligt; man wagt nicht, ihn zu berühren, noch die Augen zu ihm zu erheben. Die Verletzung des Tabu hat die schwersten Strafen, fast immer den Tod zur Folge.

Blutrache. Die Sitte der Blutrache (Vendetta) findet sich noch in vielen Ländern und hat wahrscheinlich früher überall geherrscht. Sie besteht in einer Verpflichtung der Glieder einer Familie oder eines Stammes, den Tod eines der Thrigen an dem Mörder oder dessen Familie zu rächen, ohne dass die Gerichte angerufen werden. Wo sie nicht beschränkt ist, veranlasst sie begreiflicher Weise Repressalien, und der Ehre beider Familien oder Stämme ist nicht eher Genüge geleistet, als bis dieselben sich sozusagen gegenseitig ausgerottet haben. In manchen Fällen aber hat diese barbarische Gewohnheit bestimmte Grenzen, indem man sich gegen die Ausübung der Blutrache sichern kann durch Bezahlung einer Busse (Diû der Araber, Wergeld der alten Germanen).

Zweikampf. Nit der Blutrache ist der Zweikampf oder das Duell insofern analog, als auch er bezweckt, eine Beleidigung direkt zu rächen, ohne dass man sich an die Gerichte wendet. $\mathrm{Ob}$ diese Sitte gut und wirksam sei oder nicht, kommt hier nicht in Betracht; der Reisende hat einfach 
zu honstatiren, ob sie noch existire oder nicht, wo und in welcher Form dies der Fall sei, ob als Duell nach unsern Begriffen, als Einzelkampf mit beidseitig gleichen Chancen oder mit Entscheidung durch das Loos, sodass nur einer der Gegner sich der Gefahr aussetzt. - Hier ist auch das Bauchaufschlitzen (Horilivi) zu erwähnen, welches bekanntlich in Japran ein Jeder an sich zu rollziehen hat, wenn er beleidigt oder entehrt wurde.

Diebstahl und Raub. Auf Diebstahl und Raub ist nicht überall Strafe gesetzt wie in der zivilisirten Gesellschaft: sie gelten vielmehr in manchen Iändern als etwas Verdienstliches, falls sie kühn und mit Erfolg unternommen wurden. und den Personen, welche sie ausüben, fehlt es seltsamer Weise oft nicht an Gefühlen, die mit solchen Lebensgrewohnheiten unvereinhar scheinen. Ein kurdischer Brigant ficl eines Tages unversehens einen methodistischen Geistlichen an und forderte demselben seine Kleider ab. Der Geistliche fragte ihn lialthlütigr, ob er sich nicht schäme, einen alten Mann anzufallen, der sich nicht vertheidigen könne, worauf sich der Brigant ganz rerwirrt unter Entschuldigungen entfernte. Zwei Amerikanerinnen, welche nur in Begleit ihrer Diener in Armenien reisten, wurden am Yan-See ron Räubern überfallen. Zur Ablieferung ihres Geldes und Schmuckes aufgefordert, antworteten die Damen, dass Ehrenmänner alleinreisenden Frauen Schutz angedeihen lassen, und sie wussten diese Seite so gut zu berühren, dass die Cavaliers sie wohlbehalten an ihren Bestimmungsort brachten.

Razzias, Sklavenjagden. In manchen Ländern sind Razzias oder bewaffnete, zum Zweck der Plünderung veranstaltete Ueberfälle an der Tagesordnung. Dabei bricht man unversehens in einen Stamm oder ein Dorf ein, tödtet die Menschen, zündet die Wohnungen an und bemächtigt sich des Viehes wie aller Gegenstände, die von Werth scheinen. Am häufigsten sind diese Razzias in Zentralafrika, wo sie ron den Hüuptlingen veranstaltet werden, welche selber die Lieferanten der Sklavenhändler sind. Die Wegnahme des Viehs ist dabei Yebensache: der Hauptzweck ist zugestandenermassen die Sklavenjagd. Von den Gräueln, welche diese Rauhzüge zur Folge haben, kann man sich kaum eine Vorstellung machen. 
Entführung. Hiebei handelt es sich nicht um Massen von Menschen, sondern mehr um Einzelfälle, meist um Frauen und Kinder, welche gefangen genommen und bei dem Stamme, der sie wegführte, als Sklaven gehalten werden. Oft ist der Menschenraub die Handlung eines Einzelnen: jeder Mann, der eine Frau will, muss eine solche aus einem benachbarten Stamme durch List oder Gewalt entführen. Als mehr oder minder simulirter Franemrab bleibt diese Sitte ihrer Form nach oft noch lange erhalten, wenn sie im Wesen längst erloschen ist, so zwar, dass der Gatte sich lächerlich machen würde, wenn er seine Gefährtin nicht durch Entführung erhalten zu haben. schiene.

Epigamie. Die Epigamie im weitern Sinne ist das Recht, eine eheliche Verbindung einzugehen. Dieses Recht ist den verschiedenartigsten Beschränkungen unterworfen.

Zunächst können Altersgrenzen festgesetzt sein. Bei den alten Peruanern durften die Männer sich erst mit 24 Jahren verehelichen, die Frauen mit 18 Jahren. Auch bei den Abiponen am Paraguay ist die Ehe erst für Personen reiferen Alters gestattet. Sehr frühe Eheschliessung findet man hingegen bei den Eskimos, den Arabern etc., bei letzteren sogar solche im Alter von 9 oder 10 Jahren.

Nitunter besteht blos ein gewisses Alterswrrecht: an manchen Orten gestattet die Sitte nicht, dass eine jüngere Tochter vor ihren älteren Schwestern sich vereheliche.

Fernere Einschränkungen beziehen sich auf die Verwandtschaftsmade; sie sind theils in besondern Vorschriften ausgesprochen, zum Theil beruhen sie nur auf der bei einem Volke herrschenden Ansicht über Ehen zwischen einander nahestehenden Personen, wobei gewisse Verbindungen infolge der herrschenden ungünstigen Meinung selten oder gar nicht vorkommen. Es sind aber diese Schranken sehr ungleich gezogen. Bei den Veddahs auf der Insel Ceylon kann der Bruder seine jüngste Schwester heirathen; die Hindus aber verbieten die Ehe zwischen Verwandten bis zum sechsten Grad, die Chinesen diejenige zwischen Personen gleichen Namens, die Araber diejenige zwischen Personen, welche von derselben Frau gestillt wurden (Milchbruder und Milchschwester) u. s. f. 
Endlich unterliegt das Recht des Eheabschlusses Bedinynugen besonderer Art. Bei einigen Indianerstämmen am Amazonenstrom muss der künftige Gatte rorerst beweisen, dass er in der Handhabung des Bogens hinlänglich geäbt ist, um durch Jagd und Fischfang den Unterhatt seiner Familie zu sichern. In Europa fehlt es nicht an einem Analogon hiezu: dass der Heirathskandidat sich ausweisen muss über den Besitz der Mittel, die für unumgänglich nöthig gefunden werden zur Ernährung einer Familie, als eine Garantie gegen die Gefahr, dass die Kinder der Gemeinde zur Last fallen.

Was die Frauen anbetrifft, so sind bei Völkern, wo die Gesellschaft sich Rechte auf die Töchter des Landes vindizirt, diese zuweilen gehalten, sich hievon loszukaufen durch eine Periode des Hetärismus, der Prostitution. Meist ist indessen die Pflicht dieser Preisgebung nur gegenüber dem Repräsentanten der Gottheit oder dem Landesherrn zu erfüllen. Ein Ueberrest dieser im Alterthum sehr verbreiteten Sitte war das jus mime noctis, "le droit du seigneur", welches ehemals in Frankreich ${ }^{1}$ ) bestand.

Der Reisende wird sich nicht auf die Konstatirung dieser verschiedenen Ë̈genthümlichlieiten beschränken, sondern die Grïnde und Vorwïnde für tieselben zu erfahren suchen, d. h. er wird sich einerseits bemühen, eine natürliche und logische Erklärung derselben zu geben, andererseits mittheilen, was bei dem betreffenden Volke zur Rechtfertigung eines solchen Gebrauches angeführt wird. Ferner sind unverkennbare Wirkungen solcher Eigenthümlichlieiten zu erwähnen, z. B. wie sich frühe Heirathen und Ehen zwischen nahen Blutsverwandten äussern in Folgen für die Nachkommenschaft, deren Lebenskraft oder Verfall.

Exogamie. Die Vorschrift oder Sitte, dass die Männer eines Volksstammes ihre Frauen aus einem andern Stamme zu nehmen haben, wird als Exoytumic bezeichnet. Eine solche Vorschrift kann die Vermeidung von Ehen zwischen Blutsrerwandten bezwecken; die Sitte kann ihren Grund haben im Nangel an Frauen beim eigenen Stamme, so zwar, dass sie wenigstens ursprünglich hiedurch veranlasst wurde, wenn

1) Vgl. die zweifelnde Bemerkung von Bluntschli; Ed. Osenbrüggen, Studien zur deutschen und schweizerischen Rechtsgeschichte, Schathausen 1868, S. 88. 
auch später diese Ursache aufhörte. Oft ist diese Sitte ein Ueberrest des Brauches, die Frauen aus einem fremden Stamme zu entführen. Bei kriegerischen Völkern war es lange Zeit eine Ehrenpflicht des Mannes, seinen Muth durch Raub von Frauen bei einem benachbarten Stamme zu beweisen; diejenigen, welche nicht fremde Frauen besässen und sich dieselben durch solche Entführung verschafft hätten, wären nicht als berühmte Krieger betrachtet worden. Später trat an die Stelle des wirklichen Frauenraubes eine blosse Simulation desselben; sodann wurde auch auf diese verzichtet, aber es erhielt sich die Sitte, Frauen von auswärts zu nehmen. So ist es manchenorts, z. B. in der Herzegowina, zwingender Brauch, dass die Jünglinge ihre Lebensgefährtinnen in einem andern Stamme oder Clan suchen.

Endogamie. In direktem Gegensatz zur Exogamie steht die Vorschrift oder Sitte, dass die Männer ihre Frauen aus dem eigenen Volksstamme zu nehmen haben: die Endogamie. Die Beweggründe hiefür können verschiedener Art sein. In mächtigen und stolzen Volksstämmen, Kasten oder Klassen, welche sich für edleren Ursprungs als andere hielten, wollte man hiedurch die "Reinheit des Blutes" bewahren und "Missheirathen" vermeiden. Die Verletzung des Brauches durch Eingehung einer "mésalliance" zieht oft den Verlust der Standesrechte und förmliche Degradation, d. h. die Versetzung in eine niedrigere Kaste oder Klasse, nach sich. Schwache Stämme aber verboten ihren Angehörigen, sich fremde Frauen zu nehmen, um sich nicht durch Entführungen Repressalien der hievon betroffenen Nachbarstämme zuzuziehen. So erklärt sich die Koexistenz der beiden einander entgegengesetzten Bräuche in einem und demselben Lande: die mächtigeren Stämme erlaubten sich ihre Frauen aus den schwächeren wegzuholen; diese aber fanden es gerathen, ihre Angehörigen in der Wahl ihrer Lebensgefährtinnen auf die Frauen des eigenen Volkes zu beschränken, damit nicht der ganze Stamm durch die Handlungen eines Einzelnen in Gefahr komme.

Polygamie. Die Sitte der Vielweiberei (Polygamie oder Polygynie), welche einem Manne mehrere Frauen zu nehmen erlaubt, ist weniger verbreitet als man gewöhnlich annimmt, indem manchenorts, wo die Vielweiberei gestattet ist, dieses 
Recht nicht oder nur von Wenigen benutzt wird. Polygamie herrscht gewöhnlich bei den Völkerschaften, wo die Stellung des Weibes eine niedrige, nach unserer Auffassung geradezu pmpörende ist, indem das Weib schwere Arbeit verrichten muss wie ein Sklave oder Lastthier, während sein Herr und Meister der Jagd und dem Fischfang nachgeht oder an der some faullenzt; unter solchen Verhältnissen berleutet eben eine Mehrzahl von Frauen ebensoviele Dienerinnen, die beinahe gratis zu arbeiten haben.

In den Küstenländern Afrikas, wo die Väter ihre Kinder rerkaufen, läuft die Vielweiberei - schrecklich, aber wahr! - auf eine niedrige kommerzielle Spekulation hinaus.

Bei kriegerischen Stämmen, welche einen hohen Ruhm darin erblicken, dem Feinde Gefangene abzunehmen und die Frauen benachbarter Völkerschaften oder sogar diejenigen schwächerer Glieder des eigenen Stammes zu entführen, ist das Weib eine Trophäe; je mehr Frauen Jemand hat, um so grösser ist sein Ansehen. Ueberdies befindet sich das Weib auch hier in der Rolle einer Sklarin oder ist wenigstens von Nutzen für häusliche Arbeiten.

Wo hingegen die Frauen ein müssiggängerisches Leben führen, da ist die Polygamie mit grossen Kosten verbunden und daher nur den Reichen möglich. Auch gilt sie als ein Luxus, als ein Zeichen der Macht und des Reichthums. Thatsächlich ist also in solchen Fällen die Vielweiberei, obwohl gestattet, nicht allgemeiner Brauch; vielmehr haben die meisten Männer nur Eine Frau. Gewöhnlich ist auch 'vorgeschrieben, dass Jemand nicht mehr Weiber ehlichen dürfe, als er angemessen zu unterhalten vermag.

In Afrika ist die Polygamie sehr verbreitet; für einen Fürsten ist es gewissermassen obligatorisch, sich eine grosse Zahl Frauen zu halten; diese Anzahl nimmt aber von den obern nach den untern Stufen der gesellschaftlichen Pangordnung rasch ah. In Asien war die Vielweiberei fast bei allen Völkern gestattet; thatsächlich kommt sie aber daselbst fast nur bei den Reichen vor. Mit der Vielweiberei ist die Sitte nicht zu verwechseln, welche in China existirt, sich sogenannte "kleine Frauen" (tsiei) zu halten, eine Art Beischläferinnen, welche von der rechtmässigen Ehefrau abhängig sind. Die Polygamie findet sich ferner bei den 
Mormonen in den Vereinigten Staaten (Utah); aber ihre Frauen haben wesentlich die Rolle von Haushälterinnen und als solche in mancher Beziehung eine ähnliche Stellung wie die "Squaws" der Rothhäute.

Was die Wirkungen der Vielweiberei betrifft, so wird gesagt, dass diese Sitte namentlich Entzweiungen and Intriguen im Schoosse der Familie zur Folge hat oder vielmehr auf die Zerstörung des Familienbegriffes hinausläuft. Dies ist allerdings der Fall, wo die Frau ein müssiges Leben führt, ohne Arbeit und einen bestimmten nützlichen Zweck, und demnach vollauf Zeit hat, sich mit Eifersüchteleien und Intriguen abzugeben, womit sie in Ermanglung von Besserem die Leere ihres Daseins auszufüllen versucht sein wird. Anders aber verhält es sich, wo das Weib Sklavin oder Dienerin ist; hier wird eine neue. Frau von den hisherigen Weibern germ gesehen; bringt sie ihnen doch Erleichterung, Hülfe bei den Arbeiten, welche denselben insgesammt obliegen. Aufgabe des Reisenden wird es sein, die Wirkungen kennen zu lernen, welche die Polygamie im einen oder andern Lande hat; dies wird erleichtert durch den oben erwähnten Umstand, dass oft im selben Lande polygame und monogame Haushaltungen nebeneinander vorkommen, womit Anhaltspunkte zu Vergleichungen gegeben sind.

Polyandrie. Weit seltener als die Vielweiberei ist die Polyandrie, wonach ein Weib die Ehefrau mehrerer Männer sein kann. Man findet diese Sitte in Tibet, in Südafrika und hei den Todas der Nilgherris im südlichen Indien, wo sie unter Brüdern oder durch Assoziation praktizirt wird und ihren Grund in der Armut hat.

Nach den Berichten der Reisenden zu schliessen, äussern sich die Wirlungen der Polyandrie nicht, wie man glaubeu sollte, in häuslichen Zwistigkeiten dieser ehelichen Gemeinschaften.

Bei den Naïrs in Indien und einigen andern wilden Stämmen ist die Polyandrie ein Recht der Frau, welcher es freisteht, eine grössere Anzahl — bis auf zwölf -- Männer $\mathrm{zu}$ heirathen.

Monogamie. Im Gegensatze zu den beiden soeben besprochenen Fällen der mehrfachen Ehe steht die Monogamie oder Monogynie, wonach der Mann nur eine Frau haben soll 
und umgekehrt die Frau nur einen Mann. Diese Einerehe ist Sitte und Gesetz in unseren zivilisirten Gesellschaften, finclet sich übrigens, wie bemerkt, aus ökonomischen Gründen auch oft in Ländern, wo die Vielweiberei gestattet ist.

Ehelosigkeit. Die Ehelosigkeit kann kaum als eine Sitte betrachtet werden. Indessen ist zu beobachten, ol, sie häufig sei und sind deren L'rsachen zu ermitteln. In einigen Ländern ist sie durch die Gesetze oder die öffentliche Meinung verpönt und untersagt, anderwärts im Gegrentheil gewissen Klassen oder Berufsarten vorgeschrieben (Cülibat der Geistlichen etc.).

Kauf der Frauen. In vielen Gegrenden werden die Frauen den Eltern oder ihrem Stamme ahgekauft. Die Bedingungen werden oft verabredet, ohne dass man die hauptsächlich Interessirte zu Rathe zieht; sie wird hinweggeführt. wenn die Andern sich über den Handel geeinigt haben. Mitunter wird auf etwas mehr Form gehalten; aber die Sache selbst bleil,t sich gleich. Hat der Kauflustige, beziehungsweise der Bräutigam, nicht die nöthigen Mittel zur Beibringung der verlangten Geldsumme oder Naturalien (Stücke Vieh etc.), so leistet er hiefür Ersatz durch Arbeit, indem er für eine gewisse Zeit lang in der Familie der Braut dient, wie dies von Laban aus der Bibel bekannt ist. Es ist nur eine andere Einkleidung der Sache, wenn an die Stelle eines Kaufpreises Geschenke treten, deren Werth und Vertheilung vorher genau bestimmt wurde. Im einen wie im andern Falle kamn der Leistung, welche der Bewerber ühernimnt, eine verschiedene Bestimmung gegeben werden: entweder bleibt dieselbe in den Händen der Eltern, oder sie kommt der Braut als Eigenthum zu, oder es findet zwischen der Braut und ihren Eltern eine Theilung dieser Summe statt. Falls zur Gültigkeit des ganzen Uebereinkommens die Zustimmling der Braut gehört, ist dies zu bemerken.

I)urch den Kauf der Frau wird nicht überall das Recht erworhen, diese hinwegzuführen. Bei einigen Vülkern muss der Mann in der Familie oder dem Stamme seiner Frau lebell. Eine ähnliche Sitte soll noch bei den Basken rorkommen: die alteste Torhter verlässt das väterliche Haus nicht: ihr Mann nuuss bei ihr wohnen und selbst ihren Namen annehmen, damit Haus und Name erhalten bleiben. 
Der Kauf einer Frau sichert dem Mann oft nicht einmal das Eigenthumsrecht auf die Kinder dieser Ehe. Bei einigen afrikanischen Völkern muss der Mann seine eigenen Kinder bei deren Geburt erkaufen oder dafür zum Voraus eine bestimmte Summe entrichten, ansonst dieselben seinem Vater (ihrem Grossvater von väterlicher Seite) gehören. Auf einer der Sunda-Inseln (Timor) steht das Eigenthumsrecht auf die Kinder ihrem Grossvater mütterlicherseits zu, und der Ehemann hat von diesem (seinem Schwiegervater) den Verzicht auf jenes Recht zu erkaufen. An der Küste von Guinea gehören die Kinder ihrem Onkel von mütterlicher Seite, und dieser kann sie verkaufen, ob die Eltern wollen oder nicht.

Eine weniger verbreitete Form des Frauenkaufs, die bei den Malayen und einigen abyssinischen Völkerschaften vorzukommen scheint, ist der Tunsch: wer sich ein Weib verschaffen will, gibt dafür seine Schwester oder eine andere Frau, die er etwa aus einem benachbarten Stamme entführt hat.

Mitgift. In einigen Ländern ist es Brauch, dass die Jungfrau bei der Verheirathung von ihrer Familie eine Mitgift erhält, sei es in Baar, sei es in natura (Vieh, Land), sei es als Aussteuer in Kleidern und Mobiliar, welche entweder nur für den eigenen (persönlichen) Bedarf der Frau oder für den ganzen Haushalt der neuen Familie berechnet ist. In einigen Schweizerkantonen wird diese Aussteuer auf einem Wagen mit gewissem Pomp durch die Gassen des Dorfes zum Hause des künftigen Gatten geführt (Brautfuder, Brautfahrt ${ }^{1}$ ). Anderswo hat im Gegentheil der Bräutigam die Aussteuer oder wenigstens den Brautschmuck (corbeille de mariage) auf die Hochzeit zu liefern. Es bestehen hierin manigfach gestaltete Volkssitten, deren Erwähnung stets von Interesse ist.

Verlobung. Auch hinsichtlich der Verlobung oder des Eheversprechens herrschen sehr verschiedenartige Gebräuche. Es gibt Länder, wo die Kinder von früher Jugend an durch die Eltern für einander als künftige Ehepaare bestimmt

1) Bei der Abfahrt vom Hause oder aus dem Dorfe der Braut wird woh] clurch Kinder, welche sich in den Weg stellen, die Strasse gesperrt und ist durch kleine Geldspenden der Durchpass zu erwirken. Anderswo findet dies am Hoch. zeitsmorgen statt, wenn die Brautleute zur Trauung gehen - ein Nachklang zu den im vorigen Paragraphen besprochenen Sitten und Gebräuchen. 
werden; man rerloht sie oft, wenn sie noch in der Wiege liegen, ja man verpflichtet sich hiezu eventuell schon vor ihrer Geburt. Wo aber mit der Verlobung zugewartet wird, bis die Kinder herangewachsen sind, erfolgt sie häufig olne Befragung des Mädchens, ohne Berücksichtigung ihres Willens und oft auch ohne dass der Bräutigam vorher seine Braut sehen durfte: in noch andern Fällen hat auch der Bräutigam nichts Wesentliches zur Sache zu sagen: die Eltern der beiden Betheiligten arrangiren die Ehe, und diese haben zu gehorchen; wenn allenfalls noch nach ihrer Einwilligung gefragt wird, so ist dies blosse Formalität. Die eigene und freie, auf gegenseitige Sympathien und den Willen der beiden künftigen Gatten begründete Wahl ist, abgesehen ron unserer zivilisirten Gesellschaft, mehr Ausnahme als Regel.

Auch die Formen, welche bei der Anfrage um die Hand eines Mädchens beobachtet werden, sind ron Land zu Land verschieden. Bald wird diese Aufgabe einer Mittelsperson (Brautwerber) übertragen, bald hat der Heirathslustige selbst sich an die Eltern des auserwählten Mädchens zu wenden.

Das eigentliche Verlübniss, d. h. die Eingehung des Eherersprechens durch die beiden Betheiligten, ist oft ein feierlicher Akt, begleitet ron allegorischen Zeremonien.

Das Verlöbniss hat mitunter den Werth eines Rechtsgeschäftes, selbst wenn es nur ein mündliches Versprechen war. In den Vereinigten Staaten hat Derjenige, welcher einem Mädchen die Ehe verspricht, dasselbe beim Bruche dieser Verpflichtung mit einer Geldsumme zu entschädigen. In rerschiedenen Gegenden Deutschlands erht die Braut das Vermögen des Bräutigams ganz oder theilweise, wenn dieser vor der Trauung stirbt. In Lika (österreichische Militärgrenze) hat die Braut bei Bruch des Verlöbnisses den Bräutigam eine Summe zu entrichten rom doppelten Betrage der Auslagen, welche letzterer bei Anlass der Verlobung hatte: wenn aber der Bräutigam sein Eheversprechen nicht halten will, muss er das Dreifache jener Auslagen als Entschädigung zahlen.

Auch hinsichtlich der Daner des Verlobungsverhältnisses oder Brautstandes, d. h. der Zeit zwischen der Eingehung les Eherersprechens und der Trauung, bestehen rerschiedene 
Gebräuche. In manchen Ländern folgt die Eheschliessung sehr bald auf das Verlöbniss und würde man sich kaum zu der Sitte eines langdauernden Brautstandes verstehen, die hingegen anderwärts (z. B. in Deutschland) Regel ist und den Vortheil hat, dass die Verlobten sich in dieser Zeit besser liennen lernen, was dazu angethan sein kann, die Zahl unglücklicher, voreilig abgeschlossener Ehen zu reduziren.

Ganz rerschieden sind endlich die Sitten der einzelnen Vülker, was den Verkehr der Verlobten anbetrifft. In manchen Ländern sind Braut und Bräutigam in dieser Hinsicht ganz frei: sie können sich nach Ermessen besuchen, so oft sie es wollen, und sich dabei allein sprechen, wenn es ihnen beliebt; anderwärts dürfen diese Besuche nur in Gegenwart der Eltern stattfinden, und in Montenegro darf der Bräutigam nach der Verlobung nicht mehr im Hause seines Mädchens erscheinen bis zur Hochzeit. In einigen Theilen der Schweiz hingegen wie auch in Schottland ist es Sitte, dass die Landmädchen ihre Verlobten Samstag Abends heimlich empfangen (Kiltgang).

Hochzeit. Es gibt wohl nichts Manigfaltigeres als die Zeremonien bei der Hochzeit, die Verschiedenheiten in Bezug auf das Hochzeitsgefolge, die damit verbundenen Freudenbezeugungen $u . s$. w. Die Bräuche wechseln hier nicht nur ron Land zu Land, sondern oft von Ort zu Ort. Dem Reisenden wird es um so leichter werden, diese Sitten zu beohachten und zu beschreiben, als im Allgemeinen der Fremde bei Hochzeiten ein gern gesehener Gast ist.

Keuschhoit und eheliche Treue. Ueberall ist die Frau zur Treue gegen ihren Mann verpflichtet, und es ist ohne Zweifel irrig, wenn einige Reisende berichten, dass bei gewissen Völkerschaften die Männer den Gästen ihre Frauen zur Verfügung stellen. Auf Verifikation hin hat es sich hiebei jeweilen herausgestellt, dass'es Wittwen und nicht Ehefrauen waren, welche den Fremden in dieser Weise angeboten wurden. Auf einem ähnlichen Irrthum beruht wahrscheinlich die Angabe, dass bei einigen arabischen Stämmen am Weissen Nil die Frauen nur an bestimmten Tagen jeder Woche die Verpflichtung hạben, ihren Gatten "treu" zu sein, während ihnen an den übrigen Tagen der Umgang mit andern Männern gestattet sei. Es ist nicht wahrscheinlich, dass, wo immer 
ie Frau als ein Eigenthum betrachtet wird, der Mann einen solchen Eingriff in seine Rechte dulde. Hiefür sprechen die viplen und weitgehenden Beschränkungen, welche den Frauen in Bezug auf den Verkehr nit Mämern oder das Zusammentreffen mit solchen auferlegt sind. Bei vielen lölkern darf sich die Frau nicht ror Fremden zeigen; wenn sie auf der Strasse Jännem hegegnet, so muss sie denselhen den Rücken kehren oder die Augen niederschlagen und es kommt selbst ror, dass es ihr untersagt ist, an andere Mitglieder der eigenen Familie als an ihren Nann das Wort zu richten. In den Ländern mit Polygamie lebt die Frau gewöhnlich unter einem strengen System der Klausur; sie darf nur in Beyleitung einer Verwandten oder sklarin und wohlverschleiert ausgehen. Bei den Kabylen wird ein Jeder mit Busse bestraft, den man im Gesuräche mit einer Fran antrifft oder der sich zu dem Brumnen hegibt, wo die Frauen Wasser holen.

Diese Strenge und diese Vorsichtsmassregeln gegenüber den verheiratheten Franen kontrastiren seltsam mit der Gleichgïltigkeit, welche gewisse Vülker in Bezug auf die Vergangenheit der Frau, auf deren Verhalten als Dädchen, an den Tag legen. Manche sind allerdings atuch hierin sehr streng, andere aber erstaunlich nachsichtig. Die Mädchen der Ouled Naïls, eines arabischen Stammes in Algier, leben als Tänzerimen von Beruf in freiester Weise: sie geben käuflich ihre Reize preis, und bei der Rückkehr zu ihrem stamm werden sie gleichwohl zur Ehe begehrt; ihrer gesammelten Ersparnisse wegen sind sie sogar als Franen sehr gesucht, obgleich Jedermann weiss, wie diese Mitgift erworhen wurde. In Japan werden die Mädchen von den Vätern fïr eine gewisse Zeit gegen Lohn öffentlichen Freudenhäusern ïbergehen: Niemand tadelt das im Geringsten: im Gegentheil sind diese Mädchen nachher wegen der so erworbenen gesellschaftlichen Talente als Frauen gesucht.

Der Ehebruch hingegen wird bei den meisten Vülkem hestraft, manchmal in schrecklicher Weise, wie durch Steinigung und Lebendigbegraben $u$. dgl.

Schwangerschaft und Niederkunft. Der Reisende heachte auch die Gehräuche, welche bei verschiedenen Völkern hinsichtlich der Schwangerschaft und Enthindung üblich -ind. Die Veuigkeit, dass eine junge Frau sich Mutter fühlt, 
gibt in manchen Familien Anlass zu Freudenbezeugungen, und das Régime, unter welchem die Frau lebt, wird für diese etwas sanfter, wiewohl sie im Allgemeinen die Hausgeschäfte bis zum letzten Augenblick, wo ihr dies noch möglich ist, weiter besorgt. Sehr seltsam ist es, dass hie und da auch der Mann in dieser Zeit seine Lebensweise modifizirt, indem er z. B. den Genuss des Fleisches gewisser Thiere unterlässt, aus Furcht, es könnten die Fehler derselben sich auf das Kind vererben oder auf dasselbe von nachtheiligem Einfluss sein, oder indem er in den paar Tagen unmittelbar vor und nach der Entbindung sich jeder schwereren Arbeit enthält, als ob seine Person es wäre, die zu dieser Zeit der Ruhe bedürfte.

Männerkindbett. Dies führt uns zur Erwähnung der sonderbaren Sitte des Männerkindbettes oder der Courade, welche bei verschiedenen Völkern herrscht und darin besteht, dass der Mamn sich zu Bette legt und sich sogar stellt, als erlitte er die Geburtswehen, wenn für seine Frau die Zeit der Entbindung heranrückt. Für diesen bizarren Gebrauch sind verschiedene Erklärungen und Auslegungen versucht worden, ohne dass es bis jetzt gelang, den wahren Grund seiner Entstehung zu finden. Es ist daher den Reisenden zu empfehlen, dass sie sich hierüber möglichst gut informiren; vor Allem aber hat man sich davor zu hüten, diesen Brauch - wie dies in Bezug auf die Basken der Fall gewesen ist - Völkern zuzuschreiben, welche denselben nicht haben oder wenigstens seit sehr langer Zeit nicht mehr üben.

Abortus und Kindsmord. Bei einigen Völkern, deren Existenz eine prekäre und welchen daher ein Familienzuwachs sehr unerwünscht ist, sind Abtreibung der Leibesfrucht und Kindsmord im Schwange. Die Schwierigkeit, ein kleines Kind ohne Mutter zu ernähren, hat dazu geführt, dass wenn die Mutter an den Folgen der Niederkunft stirbt, das Neugeborne mit ihr begraben wird. In vielen Ländern wird bei der Geburt von Zwillingen einer derselben dem Tode ausgesetzt. Die barbarische Sitte, neugeborne Mädchen zu tödten, ist noch sehr verbreitet; die Mädchen werden vielerorts als eine Last für die Familie betrachtet, und in vielen Stämmen, welche sie nicht tödten, steht ihnen dafür das harte Loos bevor, dass man sie nur erzieht, um sie später zu verkaufen. 
Stillen und Entwöhnen. Landeshrauch und Sittr machen es der Mutter zur Pflicht, dass sie ihre Kinder stillt, oder geben es ihrem Ermessen anheim, ob sie dies thun wolle. In manchen Ländern würden die Leute nicht begreifen, dass man das Stillen einer Amme überlasse, wenn es der Mutter nicht geradezu unmöglich ist. In diesem letzteren Falle hat eine muhammedanische Frau auf ihre eigenen Kosten für eine Amme zu sorgen.

Charakteristisch ist mitunter die Art, wie das hind in den ersten Zeiten seines Lebens eingewickelt und ron der Mutter, wenn sie ihren Geschäften ausser dem Hause nachgeht, getragen wird. In ersterer Hinsicht kann man hi* und da Bräuche beobachten, deren Zweck ist, dem Schädel eine bestimmte Form zu geben oder die normale Entwicklung der Glieder zu hemmen. Was das Tragen der Kinder anhetrifft, so wechselt der Modus desselben zuweilen von Ort zu Ort; oft ist er durch den Umstand bedingt, dass die Mutter für ihre Arbeit den freien Gebrauch der Arme nöthig hat.

Wie oben (S. 565) schon bemerkt wurde, ist die Dauer des Stillens sehr verschieden. In manchen Ländern werden die Kinder sehr spät entwöhnt. Bei den P'apuas z. B. soll es nicht selten rorkommen, dass man Kinder von 4 Jahren auf die Yutter zulaufen sieht, um die Brust zu nehmen. Die lange Dauer des Stillens hat namentlich zwei Yrsachen: Völkerschaften, die keine milchliefernden Hausthiere besitzen, sind darauf angewiesen, die Säuglinge mit Muttermilch zu ernähren; ferner wirkt die Idee bestimmend ein, dass eine Frau nicht schwanger wird, solange sie stillt. Nun ist aber eine gewisse längere I)auer des Intervalls zwischen zwei Schwangerschaftsperioden nicht nur erwünscht, sondern hie und da sozusagen ein Gebot der herrschenden Volksanschauung. Auf den Fidschi-Inseln z. B. gilt es als Schande für eine Frau, wenn sie Kinder schneller als in Intervallen ron mindestens drei oder vier Jahren bekommt.

Taufe und Beschneidung. Es kann nicht in der Aufgabe dieses Werkes liegen, auf alle die Zeremonien einzutreten, welche ühlich sind für die Kinder, Jünglinge unr Jungfrauen bis zu deren Eintritt in das Alter, mit welchem die Erlaubniss zur Verehelichung beginnt, oder bis zu deren Aufnahme unter die Erwachsenen. Die Zeremonien sind in 
den einzelnen Ländern sehr verschieden. Bei den Angehörigen der christlichen Religion findet die Taufe mit einer gewissen Feierlichkeit statt, bei den Muselmannen das erste Haarschuciden, dann die Beschneidung, welch" letztere anderswo durch analoge Operationen (unter dem Namen wharepin, sallik, makele u. s. w.) ersetzt wird. Wir müssen uns darauf beschränken, zu bemerken, dass auch hier reichlicher Stoff zu Beobachtungen für den Reisenden vorhanden ist.

Festgeschenke. Zahlreich und manigfaltig sind die Festanlässe, bei denen es üblich ist, einander Glückwünsche und Geschenlie darzubringen. Es genüge hier an die Ostereier, das Fest st. Niklaus, den Christbaum, die Neujahrsgeschenke und Neujahrsgratulationen zu erinnern. Jedes Volk hat in dieser Hinsicht mehr oder minder eigenthümliche Bräuche und Lebungen, deren Lrsprung und Bedeutung erforscht zu werden verdienen.

Ehescheidung. Nachdem oben vielfach von der Ehe tie Rede war, müssen wir hier auch einige Worte über die Tremnung oder Auflösung derselben anbringen. Das Verfahren hei derselben ist in den einzelnen Ländern ganz ungleich; am häufigsten ist der Nangel jeglicher Formalität, die zu heobachten wäre, die Her'schaft der Willkür. Von „Scheidung" ist kaum zu reden bei den wilden Horden, wo der Nann sich ron seiner Frau trennt, sobald es ihm nicht mehr konvenirt, mit ihr zu leben; ebenso, wo der Mann über Leben und Tod seiner Frau zu verfügen hat. Wo die Frau nicht gefangen genommen, sondem gekauft wird, kommt die Verstossung derselben seltener vor: es wird nicht gerne auf das Eigenthum verzichtet, das bezahlt worden ist, wäre hiefür auch kein anderer Grund vorhanden als der, dass wenigstens ein Theil der ausgelegten Summe zurückverlangt wird. In den Ländern mit Vielweiberei ist die Aufösung einer Ehe mehr oder minder in's Belieben des Mannes gestellt; mitunter ist es zu einer gültigen Scheidung genügend, dass der Mann seiner Frau erklärt: "Ich verstosse Dich!" In Japan sendet der Mann seine Frau einfach, unter Anzeige an den Stammeshäuptling, zu ihren Eltern oder Verwandten zurück. Anderswo hingegen bedarf es zu einer Scheidung triftiger Gründe. Als ein genügender Grund wird fast überall die Unfruchtbarkeit betrachtet. In den meisten einigermassen 
zivilisirten Länder'n sind für die Scheidung, das Verfahren liebei und die Massnahmen zur Solge für die Frau und die Kinder aus der zu trennenden Ehe bestimmte Vorschriften aufgestellt.

Gebräuche in Bezug auf den Landbau. Die mit dem Landbau verbundenen Lebungen und Zeremonien sind mehr als blosse Merkwïrdiglieiten. Oft hahen sie ihre Wurzehn in einem alten Kultus, der Verehrung von Gottheiten des Feldes, der Flur. Der Reisende achte daher wohl auf diess Gebräuche namentlich in Gegrenden. wo pine neue Religrion den alten Volkschlauhen verdrängte. I)ie Volkshräuche, welche sich auf die Bodenkultur beziehen, erhalten sich an längsten ron allen alten sitten: denn die landhantribenden Välkerschaften sind im Mllgemeinen honservativ, dem Alten treu zugethan. Die gewohnte Wiederkehr derselben Arbeiten und Erscheinumgen im stetigen hreislauf der Jahre, eine antheilvolle Achtsamkeit auf die Entwicklung der hultivirten I'flanzen und Thiere, der viele Aufenthalt im Freien und Lugang mit der Yatur, die Liebe zu diesem einfach-friedlichen Leben bilden einen stillen Sim. der wenig zu Neuerungen geneigt ist. Da bricht man nicht so leicht wie anderswo mit den Bräuchen der Vorfahren: wie die Väter thaten, so thun auch die söhne, ohne sich viel um die Gründe und die Zweckmässigkeit einer hestehenden Lebung zu hümmern: so erhalten sich dergleichen Zeremonien oder allegorische HandIungen Jahrhunderte lang. oft ohne dass Jemand in dem Lande um deren Bedeutung weiss.

Kriegsgebräuche. Unter kriegerischen Vülkerschaften bleihen aus Verehrung gegen die tapfern Ahnen deren sitten ebenfalls lange erhalten, so zwar, dass diese erst hei einer tief greifenden Aenderung der Lehensweist aufgegeben werden. Hiehẹr gehören die ählich gewordenen Formen der Kriegserklärung an feindliche Stämme, die Kampfweise, die Vertheilung der Bente und der Gebrauch, welchen der siegrer von seinem Triumphe macht. In dieser Hinsicht bestehen norh barbarische Sitten, wie das Skalpiren der Feinde, das Erdrosseln und Lebendigrerbremen derselben: der Brauch, sie his an den Hals in die Erde zu vergraben, um sie dam den Qualen ron Durst und Hunger zu üherlassen: sich mit Theilen des feindlichen Kürpers als Trophäen zu hehängen u. dgl. 
Kannibalismus. Bei manchen wilden Stämmen ist es noch üblich, die besiegten Feinde zu verzehren. Dabei sind mit dem Genuss des Menschenfleisches Vorstellungen verbunden wie diejenige der Befriedigung von Rache oder wie der Wunsch, Eigenschaften des Verstorbenen zu erwerben. Ian erzählt, dass zur Zeit des Aufstandes der Taë-pings in China ein chinesischer Bedienter, von seinem Herrn gefragt, was er mit dem blutenden Menschenherz machen wolle, das er in den Händen trug, die Antwort gab : „Das ist das Herz eines Rebellen, und ich will es essen, um muthig zu werden."

Seltener wird die Menschenfresserei (Anthropophagie, Kannibalismus) unter andern Verhältnissen geübt. Sie kann als ein Ausfluss des Aberglaubens im Gefolge religiöser Zeremonien vorkommen oder als letztes Nittel zur Erhaltung des Lebens bei Hungersnoth; dass sie aber irgendwo die blosse Folge einer Vorliebe für Menschenfleisch sei, ist nicht wahrscheinlich.

Achtung vor dem Alter. Sehr ungleich denken die verschiedenen Völker über ihre Greise. Wilde Horden betrachten dieselben als unnütze Mäuler und setzen sie dem Tode aus. Anderswo wird dem Alter Achtung gezollt. Die "Aeltesten" haben den Vorsitz im Rathe und die Leitung der öffentlichen Angelegenheiten. „Jugend ist Stärke, aber Alter ist Weisheit," sagen die Serben. Zwischen diesen beiden Extremen gibt es Abstufungen in Menge; im Allgemeinen aber wird selbst bei Völkern, die man nicht $\mathrm{zu}$ den zivilisirten zählt, Mangel an Respelit vor dem Alter als ein Verstoss gegen die gute Sitte betrachtet. Die Südslaven reden die Greise nie mit du an und vermeiden in ihrer Gegenwart selbst Scherze und Spiele.

Achtung vor Geisteskranken etc. In vielen Ländern herrscht eine abergläubische Achtung vor Irren und Blödsinnigen. Man lässt ilhnen volle Freiheit und hütet sich wohl, dieselben mit Gewalt $z u$ entfernen, selbst wenn ihre Gegenwart lästig ist. Aehnlich verhält es sich mit den Albinos an der Westküste Afrikas; dieselben sind nach den Berichten von Reisenden an Höfen afrikanischer Fürsten unter dem Namen dondos Gegenstand einer gewissen Verehrung.

Behandlung von Kranken. $\mathrm{Zu}$ einer Menge bizarrer Gebräuche, in welchen der Aberglaube eine grosse Rolle spielt, 
greben die Krankheiten und das Verfalıren bei solchen Veranlassung.

Wenn bei den Tarim am Karakul-See in Asien eine Person von den Blattern befallen wird, so verlässt der Stamm dieselhe, um - nachdem er dem Kranken noch für etwas Nahrung gesorgt hat — sich anderorts anzusiedeln. Wenu der Kranke genest, so findet er sich wieder bei seiner Familie pin; wo nicht, so bekümmert sich Niemand darum, was aus ihm geworden sei.

Bekanntlich werden bei wilden Stämmen und halbzivilisirten Völkern die Krankheiten gewöhnlich übernatürlichen Ursachen zugeschrieben, bösen Geistern, die in dem Körper des Erkiankten eingrezogen sind. Die Aerzte oder ,Medizinmänner" sind daun Zauberer oder Hexenmeister, welche mit magischen Formeln, Beschwörungen und Zeremonien aller Art den Kranken angeblich heilen. Mitunter besteht die Behandlung darin, dass man einige kabbalistische Zeichen auf Papier bringt, das man dann abwäscht oder kocht, um nun dieses Wasser dem Kranken als Arznei zu reichen.

Bei Verletzungen presst der Medizinmann seine Lippen auf die Wunde und stellt sich, als habe er aus derselben einen fremden Körper herausgeschafft, welchen er vorher im Munde verborgen hatte. In Marocco wird das Brennen angewendet, ohne Zweifel ein wirksameres Mittel, zu dem aber auch bei Wunden aller Art ohne Unterschied Zuflucht genommen wird, sodass man die fahrenden Heilkünstler nie ohne ihr Eisen und Kohlenbecken sieht. Chirurgische Operationen werden daselhst mit schlechten Messern vorgenommen; wenn die Patienten dabei mit dem Leben davonkommen, so verdanken sie das ihrer robusten Natur.

Muru. Auf Neuseeland besteht unter dem Namen Muru die Sitte, dass, wenn einem Maori ein Unfall oder Unglück begegnet, dessen Verwandte, Nachbarn, Freunde und Bekannte truppweise zu ihm ziehen, nicht etwa um ihn zu trösten, wie man glauben sollte, sondern um sein Haus und seine Vorräthe zu plündern. Man bestraft ihn so für sein Lnsliick als einen durch Unklugheit herbeigeführten Fehler, und man fügt, wie berichtet wird, der Plünderung noch eine tüchtige Tracht Prügel bei, um den Lnglücklichen auf wirksame Art zur Erkenntniss der Weisheit zu bringen. 
Tod und Leichengebräuche. Die bei Todesfällen üblichen Gebräuche gehören zu den Sitten, welche am meisten Beachtung rerdienen; kein Volk gibt dieselben leicht freiwillig auf. Wenn sie nicht immer ein untrügliches Zeichen gemeinschaftlicher Abstammung derjenigen Völker sind, welche in diesen Sitten übereinstimmen, so kann doch eine sorgfältige Interpretation derselben auf alte Glaubensanschauungen einiges Licht werfen.

Die Leichenzermonien sind zu zahlreich und manigfaltig als dass sie hier beschrieben werden künnten; um aber darzuthun, dass oft auch die kleinsten Details dieser Art ron Bedeutung sind, genügt es, an die chinesische Sitte zu erinnern, rom Trauerhause bis zum Orte der Bestattung kleine Stücke vergoldeten und versilberten Papiers auf den Boden zn werfen, welcher Brauch den Zweck haben soll, dafür zu sorgen, dass der Verstorbene den Weg finde, wenn er seine Familie besuchen will.

Die Belilcidung und somstige Ausstattung des Todten verdient beachtet $z u$ werden, da sich hierin oft gewisse religiöse Ideen aussprechen, wie der Glaube an die Fortdauer des Lebens im Jenseits.

In einigen Ländern ist das Eimbalsamiren üblich, das bei den alten Egyptern und den Inkas von Peru im Brauche war und auch den Vissayas auf den Philippinen bekannt gewesen zu sein scheint, da man auch dort ausgetrocknete einbalsamirte Leichen (Mumien) gefunden hat.

Bestattung. In Bezug auf die Beisetzung der Todten werden verschiedene Systeme befolgt.

Bei der Aussetzun! lässt man die Leichen unbestattet den Raubvögeln und andern reissenden Thieren zur Beute, welche die Fleischtheile verzehren. Die Gebeine werden nachher zerstreut oder werden gesammelt und begraben. Dies war Brauch bei den alten Guebern und ist es noch bei den Parsen Indiens, welche ihre Todten aussetzen in schweren Steingehäusen, die "dakmas" oder "Thürme des Schweigens" heissen. In manchen Ländern werden nur die Leichen der Verbrecher ausgesetzt und deren Gebeine zerstreut, zur Strafe für ihre Missethaten.

Die Wusserbestattun! (Immersion) besteht darin, dass die Leichen in's Wasser gervorfen und der Strömung überlassen 
werden. Mitunter bringt man die Leiche in einen kahnartigen Sarg, welcher dann in's Wasser gelbracht und dem Getriebe der Wellen ausgesetzt wird.

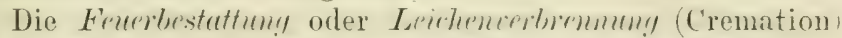
ist der Gehrauch, die Leichen auf Holzstössen orler Scheiterhaufen zu rerbrennen, wobei die Asche entweder gresammelt oder nach allen Winden zerstreut wird.

Bei der Bcerdigung wird die Leiche unmittelbar in ein Grab oder zunächst in einen Sarg gelegt, welchen man dam in das Grab, respr, eine natürliche oder künstliche Grube oder Höhle bringt (Begrähniss). Es kann aber auch die Leiche unmittelbar oder eingeschlossen in einen sarg nur auf die Oberflache des Erdhodens gelert und durch Steinplatten mit oder ohne darüber und dazwischen gehäufte Erde und steine greschützt werden. Die Sioux-Indianer hringen den Sareg auf vier hohen Pfählen an.

Manchmal trifft man bei einem Volk eine Koexistenz ver-

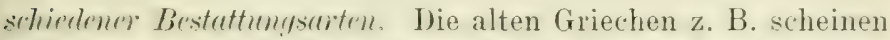
sowohl die Leichenverbremung als die Beerdigung angewandt zu haben $\left.{ }^{1}\right)$. Im alten Peru und Mexiko wurden die Könige und Stammeshäuptlinge (Kazikan) begraben: hinsichtlich der gemeinen Leute aber begnügte man sich damit, die ausgetrockneten Knochen in eínem Korbe an einen Baum aufzuhängen und zwar in augenfälliger Weise, damit der Torlte bei der Auferstehung seine Gebeine leicht finde.

Aufmerksamkeit verdient die Laye oder Stellun! der Leiche. Dieselbe wird horizontal auf den Rücken oder die Seite gelegt, und auch senkrecht in das Grab gestellt. In beiden Fïllen ist $\mathrm{zu}$ beachten, ob eine Regel eingehalten wird hinsichtlich der Seite (der Himmelsgegend), nach welcher hin der Kopt oder das Gesicht gerichtet werden. Auch eine kauernde Stellung der Leiche findet sich ror, wohei Kim und linie sich berühren. Es war das der Fall bei den Berbern Nordafrikas bis zur Einführung des Islam und bei den alten Pimas in Arizona (Vereinigte Staaten); heute noch findet man diese Sitte auf der Insel Wuap (Karolinen), wo nur die Kinder mit ausgestrecktem Körper, die Erwachsenen aber in zusammengekauerter Haltung beigesetzt werden.

1) Vgl. auch Anleitung zu wissenschaftlichen Beabachtungen in den Alpen. III. A bthlg. (Dr. J. Ranke, anthropologisch-vorgeschicht!. Beobachtungen) S. 120. 
Es ist ferner nicht ausser Acht zu lassen, welche Gegenstr̈nde in oder auf das Grab gelegt werden (Waffen, Schmuck, Creräthe und andere "Beigaben" in das Grab; Speisen etc.).

Die Verbrennung und Beerdigung sind oft mit Opfern verbunden. Bald schlachtet man Thiere, einen Stier oder Bock als Sühnopfer, ein Kameel, Pferd oder einen Hund für rie Bedürfnisse des Verstorbenen, damit er sich in das Land der Seelen begeben könne; bald aber auch werden Menschen geopfert, entweder zu dem Zwecke, dass der Todte auch ferner diejenigen um sich habe, welche demselben im Leben angehörten, oder auch blos zur Erhöhung der Bestattungsfeierlichkeiten. Bei einigen Negerstämmen werden, wenn ein Fürst stirbt, dessen Frauen und Sklaven auf seinem Grabe geopfert. Ebenso wurde es früher in Japan beim Tode des Mikado oder seiner Gattin mit deren nächsten Dienern gehalten; später begnügte man sich damit, die als Opfer bestimmten Menschen durch Thonfiguren zu ersetzen, welche in's Grab geworfen werden. In Indien hat die Sitte der Wittwenverbrennung (Selbstrerbremung der Frauen beim Tode ihres Gatten) erst vor Kurzem aufgehört. Beim Tode des Rajah Suchet Singh in Kaschmir wurden dessen 300 Wittwen verbrannt.

Wo der Brauch nicht herrscht, dem Todten in's Grab mitzugeben was ihm gehörte, fallen mit dem Erbe auch die Wittwen dem Sohne oder Bruder des Verstorbenen als Eigenthum zu.

Von Bedeutung ist auch die Wahl des Ortes der Bestattung. Wenn man die Leiche nicht in der Nähe beisetzt, sondern weithin transportirt, damit sie daselbst sich in gewissen Verhältnissen befinde, so ist die mit diesem Brauche verknüpfte Idee zu ermitteln. Die Visajas auf den Philippinen brachten die Särge auf hohe Felsen an der Meeresküste, damit ihnen Verehrung gezollt werde durch Diejenigen, welche sie von Weitem sehen. Einige Südsee-Insulaner tragen die Leichen auf hohe Berge; andere Völker bringen sie in Höhlen unter. Wahrscheinlich stehen diese Gebräuche in Zusammenhang mit der Vorstellung vom Lande der Seelen, ob dieses im Himmel oder unter der Erde oder in fernen Gegenden jenseits des Meeres angenommen wird; Zweck des Leichentransportes auf einen Berg, nach einer Höhle oder nach der Küste wäre 
dann immer der, den Verstorbenen seinem Bestimmungsorte näher zu bringen.

Selbst die Art der Anlaye und Schliessung des Grabes stelit in Konnex mit der Vorstellung rom künftigen Leben oder wenigstens mit der Idee einer Fortdauer des Empfindungsvermögens der Verstorbenen. Die Guarani begraben ihıre Todten nicht tief in den Boden, damit nicht zu viele Erde schwer auf ihnen laste. Die Indianer ron Peru graben ihre in den Kirchen beigesetzten Todten wieder aus, weil sie denken, dieselben fühlen sich wohler an der freien Luft. Anderwärts waltet das Streben, den Verstorbenen eine kühle und dauerhafte Wohnstatte zu bereiten; man bringt dieselben daher in eine Gruft oder Todtenkammer, und errichtet ïher den Gräbern Hügrel, Steinhaufen und riesige Denkmäler wis di* egyptischen Pyramiden.

Trauer und Todtenkult. Auf Neuguinea ist es Sitte, den Förper mit einem Gemisch von Kohle und Del schwarz zu hemalen, um zu zeigen, dass man um einen Verwandten trautert: während der Trauerzeit ist das Tragen lebhafter Farben rerboten. In Cochinchina trägt man zur Trauer Kleider, deren Saum nicht genäht ist und sich in Fransen auflöst. Anderswo wird die Trauer nicht nur durch eine besondere Farbe der Kileider und durch Enthaltung von lärmenden Vercnügungen an den Tag gelegrt, sondern auch durch absichtliche Verwahrlosung der Haartracht und der ganzen Toilette. Bei den Visayas musste nach dem Tode eines Helden die Menge während der ganzen Tranerzeit Schweigen heohachten. Die Chinesen hingegen äussern ihren Schmerz in lanten Trauerbezeugungen und halten einige Nonate lang im Trauerhause offene Tafel; sie glauben, dass der Verstorbene um so glücklicher sei, je mehr Geld verwendet wurde anf das Leichengefolge und die Festlichkeiten zu seinem Andenken.

In dieser Stelle wollen wir auch an den Kultus erimern, welcher den Todten oder den Manen der Vorfahren erwiesen wird. Er spricht sich aus in der auf den Unterhalt der Gräher rerwendeten Sorgfalt, ferner dadurch, dass zu bestimmten Zeiten Sprisen und Getränke auf die Gräber gehracht werden; in Japan durch Illuminationen, Feuerwerke und reichliche Trankopfer, in Afrika noch vielfach durch barbarische Menschenschlächtereien. 


\section{IDEENWELT, GLAUBE UND RELIGION.}

Um ein Volk recht kennen zu lernen, muss man sich mit seinem Denken möglichst vertraut machen. Seine Auffassung der Dinge, die Eigenschaften und Kräfte, welche es ihnen beilegt, sein Glaube und Aberglaube bestimmen seine Handlungen. Nur eine genaue Kenntniss der Anschauungen eines Volkes gibt uns die Mittel zum Verständniss seiner Entschliessungen, seines ganzen Verhaltens, und lässt uns den Geist seiner Institutionen erfassen.

Es ist der einzelne Mensch von seinem Nachbar vielleicht am meisten verschieden durch seine geistigen Anschauungen, und ron Volk zu Volk bestehen in dieser Beziehung ausgesprochene Unterschiede. Zwar sind die Gedanken individuell; aber bei genauerem Zusehen erkennt man, dass jedes Volk seine Besonderheiten der geistigen Auffassung, seinen eigenthümlichen Ideenkreis hat.

Glaubensvorstellungen fehlen keinem Volke. Der geistig tief stehende Mensch ist allem Aberglauben zugänglich und schafft sich dementsprechende Gestalten seiner Einbildungskraft. Ein Mangel allen Glaubens, ein absoluter Skepticismus kann nur bei zivilisirten Völkern vorkommen, und auch da ist er oft nur äusserer Schein, der von Manchem zux Schau getragen wird, um als starker Geist zu gelten, aber in Wahrheit dem inneren Menschen nicht entspricht und nicht Stand hält in Tagen der Prüfung. Der absolute Skepticismus wäre die Verneinung alles Denkens; man kann in Glaubenssachen die herrschenden Ansichten nicht theilen, und auf Das, was allgemein gelehrt wird, keinen Werth legen; aber man glaubt an das Gute; man glaubt, wenn nicht an einen persönlichen Gott und Schöpfer, doch an eine schöpferische und schaffend weiter gestaltende Kraft; man verwirft vielleicht die Idee, dass eine Vorsehung die Geschicke des Menschen leite, aber man muss zugeben, dass sie beherrscht werden durch unabänderliche Gesetze oder durch die Launen eines grossen Meisters, welchen man den Zufall nennt. Die Skepsis ist nicht der Geist der Massen; für diese sind Zweifel und Unglaube höchstens ein Uebergangsstadium zwischen einem Glauben, der als falsch aufgegeben wird, und demjenigen, der ihn $z u$ ersetzen bestimmt ist. 
Es ist allerdings nicht leicht, sich mit dem Denken und Fühlen der Völker vertraut zu machen. Wie Sir John Lubbock in seinem Werke über den Lrsprung der Zivilisation sehr gut bemerkt, weicht die ganze Geistesrichtung anderer Völker (und namentlich der Wilden) von der unseren so sehr ab, dass es oft ungemein schwer hält, ihrem Gedankengang zu folgen und die Motive ihres Handelns zu erfassen. Oft ist uns ihr Thun und Denken anverständlich: Gründe, welche sie ganz natürlich und einleuchtend finden, kommen uns absurd vor, und umgekehrt. Bei den gebildeteren Vülkern ergeben sich weitere Schwierigkeiten. Hier trifft man oft auf eine grewisse Zurückhaltung aus Furcht vor Spott, die bewirkt, dass die Gedanken nicht unbefangen ausgesprochen werden. Gerade die innersten Leberzeugungen treten am wenigsten zu Tage.

Um die Denk- und Sinnesweise, Glaube und Aberglaube der Einzehen kennen zu lernen, erscheint eine direkte Befragung kaum als geeignetes Mittel : hesser ist es, die Leute gesprächsweise zur Meinungsäusserung zu reranlassen. In freier Darlegung der (iedanken kommt am ehesten die wahre Leberzeugung, die ganze Denkweise zum Ausdruck.

So beachtenswerth die Cebereinstimmung wie die Verschiedenheit der Ideenwelt zweier Völkerschaften sind, so sehr hat man sich auch in dieser Hinsicht vor übereilten S'chlüssen zu hüten. Der gelehrte Max Müller ${ }^{1}$ ) warnt mit Recht vor verfrühten Verallgemeinerungen dieser Art. Ich kamn, sagt er, nicht zugeben, dass wenn zwei Mythologien in etwas Irrationellem oder Absurdem übereinstimmen, nun daraus folge, sie müssen gemeinsamen Lrsprungs sein oder während irgend einer l'eriode ihrer Geschichte miteinander in Kontakt gestanden haben. Auf den ersten Blick erscheinen solche Tehereinstimmungen allerdings auffallend. Aber wemn man der Reihe nach mehrere solcher Götterlehren kennen gelernt hat, machen diese Analogien weniger Eindruck und wird man rorsichtig gegen Zusammenstellungen, welche wesentlich auf solcher Grundlage ruhen.

Vorstellungen über Armuth und Reichthum. Dit Begriffe von arm und reich sind nach Ort und Zeit rer-

1) Vgl. dessen Vorrede zu Myths and Songs from the South-Pacific by Rer: W. Wyatt Gill. 
schieden. Die Eingebornen am Orinoko sagen: „Dieser Mensch ist so arm, dass er nicht einmal die Hälfte seines Körpers bemalen kann." In den Ländern zwischen Gambia und Niger gilt ein Mensch für reich, wenn er zum Mahle Salz geniesst (vgl. Peschel, Völkerkunde, S. 175 und 180). In den Städten rerbindet man mit den Worten "arm" und seich" andere Vorstellungen als auf dem Lande. Wenn man vor einem Jahrhundert sagte: "er besitzt eine Million," so glaubte man damit einen ganz ausserordentlichen Reichthum zu bezeichnen. Heute wird Derjenige, dessen Vermögen nur eine Nillion beträgt, nicht mehr als ein Nabob angestaunt.

Vorstellungen über Gegenstände und Beschäftigungen. Bei den Wilden begegnet man oft den seltsamsten Ideen über verschiedene Objekte und deren Benutzung. Bekannt ist, dass Solche eine Musikdose für die Tochter einer Orgel hielten und die Eingebornen von Taheiti eiserne Nägel aussäeten, in der Hoffnung, dieselben wachsen und sich vermehren zu sehen. Solche und ähnliche Irrungen z. B. dass eine Uhr oder ein Kompass für lebende Wesen gehalten werden -- scheinen uns noch mehr oder minder begreiflich; aber seltsam muss es uns vorkommen, wenn wir bizarre Ideen über ganz bekannte Gegenstände treffen. So ziehen nordamerikanische Indianer eine einzelne Angel, an welcher schon ein grosser Fisch gefangen wurde, einer grössern Zahl von noch ungebrauchten Angeln vor, und sie legen nie zwei Netze nebeneinander, aus Furcht, dieselben könnten auf einander eifersüchtig werden. Die Chinesen legen hohen Werth auf beschriebenes oder bedrucktes Papier; alte Bücher, Hefte und Zeitungen werden von ihnen nie zu Packmaterial $u$. dgl. verwendet, sondern verbrannt aus Achtung vor den Gedanken, deren Ausdruck die Zeichen auf dem Papier sind. Ein anderes Beispiel für den Glauben an die Kräfte beschriebenen Papiers ist jener Neger, welcher einen ihm übergebenen Brief unter einem Steine verbarg, damit der Brief nicht sehe, dass der Neger das Brot esse, mit dessen Spedition man ihn beauftragt hatte. Wenn der Reisende unter ganz unzivilisirten oder halbwilden Völkern in einem Buche liest, Notizen schreibt oder sich seiner Instrumente bedient, so macht dies oft auf die Zuschauer einen erstaunlichen Eindruck; leider flösst dies ihnen auch leicht solche Furcht ein, 
dass sie den weiteren Verkehr mit dem Fremden meiden oder sich seiner zu entledigen suchen.

Vorstellungen über fremde Länder und Völker. Tnrichtige und baroke Ideen über ferne Länder und deren Bewohner trifft man nicht blos bei Wilden; manche Europäer - und nicht blos solche, die nie über die Grenzen ihres Dorfes hinauskamen - hahen es in dieser Beziehung nicht viel weiter gehracht als irgend ein Südsee-Insulaner. Nach den Vorstellungen des Einen sind alle Länder einander ziemlich gleich; ein Anderer berölkert dieselben mit Wesen, welche in dem Maasse phantastischer werden, je grösser die Entfernung des Landes ist. Es ist von Interesse, die Ideen der Bewohner einer Gegend in diesen Punkten kennen zu lemen, nicht wegen deren grüsserer oder geringerer Fehlerhaftigkeit an und für sich, sondern weil sich hienach bemessen lässt, wie weit der geographische Horizont und die gewöhnlichen Verbindungen dieser Leute reichen. Die Länder, welche sie an besten kemmen, sind wahrscheinlich die Quellen eines Theils ihrer Bildung in Gewerben, Künsten und gesellschaftlichen Zuständen.

Kosmogonische Vorstellungen und Systeme. Sehr richtig ist die Kenntniss der bei einem Volke rorkommenden Ideen ïber Erschaffung der Welt und deren Geschichte, die Entstehung der Berge, Thäler und Gewässer, sowie namentlich auch der ersten Menschen. Dabei handelt es sich selbstverständlich wieder nicht darum, alles das zu korrigiren, was an diesen Vorstellungen nach unsern Ansichten falsch ist, sondern vielmehr darum, die Wege kennen zu lemen, welche der menschliche Geist wandelte bei Spekulationen über Dinge, deren Wesen zu ergründen seiner Intelligenz nicht vergönnt war.

Erklärung der Naturerscheinungen. Der Reisende macht oft die Erfahrung, dass Eingeborene auf Fragen über die Lrsachen alltäglicher Naturerscheinungen nicht zu antworten wissen; dass ihnen noch nie der Gedanke gekommen ist, nach eineï Erklärung für diese Vorgänge zu suchen. Dass die Sonne täglich in der Ostgegend des Horizontes aufgeht, auf der gegrenüberliegenden Seite untergeht, dass dann am Nachthimmel Mond und Sterne sichtbar werden und eine analoge Berregung machen : das ist ja ebenso selbst- 
verständlich, wie dass die Bäche und Ströme immer abwärts fliessen; nach Gründen zur Erklärung dieser Vorgänge zu suchen, kommt Vielen gar nicht in den Sinn. Anders verhält es sich mit selteneren und ungewöhnlichen Phänomenen, wie Finsternissen, Gewittern, Erdbeben, Vulkanausbrüchen. Diese sucht sich auch der Wilde zurechtzulegen, und er thut es in Erklärungen, die von Stamm zu Stamm verschieden lauten, in der Regel aber sich durch alles Andere eher auszeichnen als durch Scharfsinn und eine Tiefe des Gedankens, welche auf den Grund der Sache dringt. So halten die Bewohner der Futuna-Inseln (Horn-Inseln) dafür, die Erdbeben werden durch den Gott Mafuikefulu verursacht, wenn er sich auf seinem unterirdischen Lager umwendet. In Kamtschaka gelten die Blitze als Feuerbrände, welche die Bewohner der himmlischen Jurten auszuschleudern pflegen. Die Araukaner schreiben die Stürme Schlachten zu, welche die Geister ihrer verstorbenen Landsleute mit ihren Feinden zu kämpfen haben.

Solche Erklärungen sind aufzuzeichnen; gerade ihres bizarren und originellen Charakters wegen sind sie von Wertl, und oftmals liefern sie Indizien für Verwandtschaftsverhältnisse oder sonstige frühere Beziehungen jetzt getrennter Völkerschaften. Es bestehen nämlich bei einem Volke auf einer tiefen Stufe der Kultur keine Meinungsverschiedenheiten über die Ursachen einer Erscheinung. Ist einmal irgend welche Erklärung aufgestellt worden, so geht sie vom Vater auf den Sohn und vom Ahn zum Enkel über, ohne Zweifel und Widerspruch hervorzurufen, und wenn die Familien eines Stammes sich trennen, so nehmen sie die erworbene Auffassung mit sich als ein Erbstück ihrer bisherigen Gemeinschaft, das unter ihren Nachkommen von Geschlecht zu Geschlecht weiter überliefert wird. Sehr selten befassen sie sich damit, die bei einem benachbarten Stamme über den gleichen Punkt herrschende abweichende Ansicht zu diskutiren und in Würdigung zu ziehen; Jeder bleibt bei seiner Meinung und betrachtet die andere als absurd. Wer nicht ein Mann von grossem Einfluss ist, käme auch übel an, wenn er bei seinem Stamme über irgend Etwas eine andere als die bisher übliche Ansicht aufbringen, nene Lehren predigen und sich also anmassen wollte, klüger zu sein als die Andern und mehr zu wissen als die Vorfahren. 
Allseitig freie Forschung und Kritik sind ausschliessliche Attribute der fortgeschrittensten modernen Gesellschaften.

Gewisse Interpretationen ron Naturvorgängen zeigen eine Lebereinstimmung, welche keineswegs auf gemeinschaftlichen Ursprung oder frühere Beziehungen der Völker zu deuten ist. So werden die Gewitter fast überall bei den Naturvölkern als eine Manifestation des Zornes der Götter betrachtet; Leberschwemmungen und Dürre, Nisswachs, Hungersnoth und Seuchen als Züchtigungen u. s. f. Ideen dieser Art hahen ihren Grund in einer allen Menschenstämmen gemeinsamen Geistesrichtung.

Glaube an Geister und Götter. Der Glaube an unsichthare Wesen ist weit rerbreitet; er findet sich nicht blos bei wilden und halbwilden Völkern, sondern auch noch unter unsern Landleuten und selbst bei Städtern. Er wird begünstigt durch Enwissenheit, welche die wahren Lrsachen nicht liennt oder erkennen lässt, und eine geistige Apathie, welche denselhen nicht nachforscht, sondern sich mit der ersten besten Angabe begnügt, die darüber von irgend wem vorgebracht wird. Ein Stein rollt einen Abhang hinunter, ohne dass man wahrnimmt, wie er in Bewegung liam: ein Glas springt entzwei ohne wahrnehmbare äussere Veranlassung; aus einem Zimmer, in welchem Xiemand sich auflält, lïsst sich ein Krachen hören, während sonst Alles ruhigg ist; ein Fensterladen schliesst sich plötzlich, während kein Wind $\mathrm{zu}$ beobachten ist ... was liegt da näher als diese Vorkommnisse einem unsichtbaren Geist zuzuschreiben, der da umgeht. Der Wilde wendet diese Auffassung nur in einer crrösseren Zahl von Fällen an als die Geistergläubigen zivilisirter Völker. Wenn ihm auf einen Ruf in einsamer Gegrend das Echo antwortet, so ist dies die Stimme eines Geistes: es war ja sonst Niemand da, welcher den Ruf hätte erwidern kömen. Er beobachtet das Wehen des Windes: woher ries hommt, weiss er nicht: aber er sieht, dass er in Kileinen dasselbe bewirkt, wenn er in's Feuer bläst; nun liegt es nahe, im Winde den Hauch von Geistern zu sehen, welche da ihr Wesen treiben. Ist aber der Mensch darauf gekommen, rinen Schlauch als Blasehalg zu benutzen, so denkt er sich einen unsichtharen sichlauch als Quelle des Windes. Mitnuter werden die Winde sellost als (beister hetrachtet, welche 
eine unsichtbare Hand „entfesselt", wie wir noch sagen. Geister schleudern die Blitze und sprechen ihren Zorn aus im Rollen des Donner's. Nächtlicher Weile hört man im Walde seltsame Töne; selbstverständlich sind wiederum Geister die Urheber derselben. So wird das ganze All mit Geistern bevölkert, und bildet sich ein Glaube, von dem uns Reste erhalten sind in den Sagen ron der wilden Jagd, ron guten Bergmännchen und Zrergen, bösen Hexen und Kobolden, von Erscheinungen Verstorbener, ron. vielfachem Geister- und Gespensterspuk. Es bedarf dazu keines besonderen Hanges zum Wunderbaren: sonst würde man vielleicht diesen Glauben bei den Wilden nicht treffen; Lnwissenheit und Leichtgläubiglieit sind genïgende Quellen desselben. Ist einmal der Glaube an bestimmte Geister vorhanden, so steht nichts im Wege, die Zahl derselben in unbegrenzter Weise zu vermehren; sie haben, wiewohl Geister, ihre bestimmten Aufenthaltsorte in Luft und Wasser, auf Bergen, in Höhlen und Wäldern etc. Von diesen Wohnsitzen aus entfalten sie eine lebhafte Thätigkeit und mischen sich rielfach, fördernd oder hindernd, in die Angelegenheiten der Menschen; Glück und Unglück, auch Krankheiten aller Art sind oftmals ihr Werk. Es gibt gute und böse Geister; der menschliche Geist beschäftigt sich aber weit mehr mit den letzteren, aus Furcht ror denselben. Ein Stamm fürchtet auch die guten Geister des andern; wenn er mit letzterem in Zwiespalt geräth, so hat er es auch mit diesen Geistern zu thun.

Zu dem Glauben an Geister, Hexen u. dgl. gesellt sich derjenige an Zauberer, Magier, Hexenmeister, Teufelsbeschwörer u. dgl., d. h. an Menschen, welche über die Geister eine gewisse Macht ausüben, dieselben beschwören oder bannen, kommen lassen oder gehen heissen und Mittel gegen deren bösen Einfluss liefern können. Stellung und Ansehen dieser Zauberer beim Volk; die Leistungen (Exorzismen, Wunderetc.), wozu sie sich anheischig machen, um der leichtgläubigen Menge ihre übernatürliche Macht zu beweisen; die Zeremonien, welcher sie sich als Mittel hiezu bedienen, um die Sinne der Zuschauer und Hörer zu berücken: all" das ist ron Volk zu Volk und von Stamm zu Stamm verschieden; der Reisende achte darauf, wo immer sich ihm hiezu Gelegenheit bietet; denn es ist einerseits charakteristisch 
durch wie einfache Mittel oft sich die Menge bethören lässt: andrerseits von Interesse zu sehen, wie weit es die Zauberer in ihrer Kunst gebracht haben.

Von den Geistern zu den Göttern ist nur ein Schritt; die letzteren sind ursprünglich weiter nichts als mächtigere (ieister. Es hält oft schwer, zwischen den Geistern und Göttern eine Grenze zu ziehen, wie es ja auch nicht leicht ist, einen Unterschied zwischen Glaube und Aberglaube festzustellen und anzugeben, ob eine bestimmte Vorstellung in den Bereich des Aberglaubens oder in das Gebiet der Religion zu weisen sei.

Wie die Zauherer den Verkehr mit den Geistern besorgen, so gibt es auch Mittelspersonen für die Beziehungen zwischen dem Nenschen und seinen Gottheiten; diese Vermittler sind die Priester im weiteren Sinne des Wortes; sie offenbaren den Willen der Götter und in gewissem Grade werden ihnen auch Eigenschaften derselben beigelegt. Nur bei den vorgeschrittensten Völkern ist die Aufughe des Priesters beschränkt auf die bescheidenere, aber schöne Rolle, durch Lehre und Beispiel für das Gute zu wirken.

Glaube an die Seele. Allgemein ist der Glaube, dass der Mensch eine Serle habe, d. h. dass sein Körper der Sit\% eines von demselben mehr oder minder unabhängigen Wesens sei. Der Wilde glaubt, es bestehe der Schlaf darin, dass während desselben die Seele, dies andere Ich, als selbständiges Wesen den Körper verlassen und den Yorgängen beigewohnt habe, welche die Szenen seiner Träume bildeten. Anders weiss er sich nicht zu erklären, dass er so lebhaften Antheil an derartigen Ereignissen nahm, während sein Körper sich in Ruhe befand; eher als dass er in diese Auffassung Zweifel setzte, würde er glauben, er sei während des Schlafes auf wunderbare Weise in eine andere Gegend, auf den Schauplat\% der Szenen seiner Träume, getragen worden, wenn nicht unverdächtige Zeugen da wären, die ihm bestimmt erklären, dass er die ganze Zeit über seine Lagrerstelle nicht verlassen habe.

Bei mehreren Vülkern findet man die Vorstellung, dass die Seele sichtbar sei; sie ist der Schatten, welcher den liörper begleitet, auch das suirgellitld des Menschen, wit denn mitunter die Annahme vorkommt, dass der Mensch zwei 
Seelen habe: der dunkle Schatten ist die eine, das helle Spiegelbild die andere. Der Glaube an meluere Seelen im. IIenschen kommt, wie versichert wird, bei den Karaïben und nordamerikanischen Indianern vor, welche die Unbeständigkeit des Charakters, die Wandelbarkeit der Gesinnung auf diese Art erklären.

Die Krankheiten werden vielfach dem Umstande zugeschrieben, dass die Seele oder der Schatten nach Trennung vom Körper strebt, und die Vorsichtsmassregeln, welche alsdann den Genesenden empfohlen werden, gehen von der Anschauung aus, dass deren Schatten noch nicht fest genug an demselben hafte.

Auf analoge Weise werden Ohnmacht, Lethargie und Tod leicht erklärt: die Seele hat den Körper verlassen; der Tod ist nichts als ein langer Schlaf.

Die Seclen, Schatten oder Geister der T'odten weilen, nach allverbreiteten Vorstellungen, oft an den Stätten ihres früheren Aufenthalts; da durchirren sie die Gegend und besuchen zuweilen die Lebenden. Im Allgemeinen unsichtbar, können sie doch mitunter Form und Gestalt annehmen. Phantastische Schatten auf Friedhöfen in heller Mondnacht, Irrlichter, Nachtvögel und Fledermäuse haben daher fast überall Anlass gegeben zur Auffrischung und Befestigung des Glaubens an zurückkehrende und wandelnde oder umherschweifende Geister der Abgeschiedenen, Gespenster und Phantome (spectres, menants etc.). Schlangen und Skorpionen, welche Nachts unmerklich in die Hütten der Neger und anderer Wilden dringen, sind in deren Augen ebenfalls Verkörperungen der Geister, welche ihre früheren Bekannten, Verwandte, Freunde und Feinde besuchen.

In einigen Ländern werden den Seelen der Todten Rücksichten und Aufmerksamkeiten erwiesen, nach welchen anzunehmen ist, dass man diese Geister nicht für ganz ätherische Wesen hält. Es gibt Volksstämme, welche Wasser und Mundvorräthe auf die Gräber bringen, damit die Todten sich daran laben. In China stellen die Familienhäupter zu gewissen Zeiten ror ihren Häusern Tische auf mit Speisen, und es waltet der Glaube, dass die Schatten der Todten kommen, um an den gedeckten Tafeln Platz zu nehmen und sich zu erquicken. Selbst in Europa soll sich etwas Aehn- 
liches erhalten haben, indem es noch hie und da rorkomme, dass die Bewohner eines Hauses am dhend ror Allerheiligen sich frühzeitig zu Bette begeben, indem sie den Tisch gedeckt - vollständig zum Essen eingerichtet — lassen, damit die Verstorbenen daran Platz nehmen und geniessen, was für sie bestimmt ist.

Glaube an ein künftiges Leben. Der (ilaube an die seele oder Seelen in Menschen ist nicht identisch mit demjenigen an ein künftiges Lehen. Gewisse Välkerschaften stellen sich ror, dass die Geister noch einicge Zeit an den Orten umgehen, wo die Verstorbenen sich aufhielten, dass sie aher wie ein verghlimmender Docht allmälig erlöschen.

Der Glaube an ein anderes Leben, welches dem gewöhnlichen ziemlich ähnlich sei, spricht sich in der sorge aus, die sich verschiedene Völker geben, in der Nähe des Todten Gegenstände anzubringen, welche er zu seinen Lehzeiten benutzte und die er, wie sie glauben, noch weiter nöthig hat.

Bemerkt der Reisende Anzeichen eines Glaubens an die Fortdauer der seele nach dem Tode des Menschen, so erkundige er sich darüber, welche Torstellung über das Schicksal der Verstorbenen oder ihrer Seelen hiemit rerbunden ist. Irren die Geister der Abgeschiedenen in infinitum an den Stätten ihrer frühern Heimat umher? hewohnen sie Gehüsche, Höhlen, Berge: orler kommen sie an einen hesonderen Bestimmungsort, in eine entlegene Gegend, in den Himmel, in die Hölle? Welcher Zustand wartet ihrer dort als Belohnung oder Strafe: Geht die Seele in ein Thier, eine Pflanze oder in andere Individuen üher, d. h. glauben die

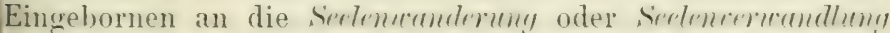
(Mrtrmpsisfluse), oder nehmen sie an, dass einst die seepe wieder von dem früheren Kürper Besitz nehmen werde, 1. h. dass eine Auferstehung stattfinde? Der Glaube an sine Seelenwanderung wird sich in der Yerehrung gewisser Thiere u. del. äussern, der Glaube an die Auferstehung in lem Bemühen, die zerstreuten Glieder und hörpertheile von Ferwandten und Freunden, die durch Feinde oder reissende Thiere getödtet wurden, zu sammeln und beisammen zu ralten. Dem gleichen Grundgerlanken entspricht auch der selsauch, die Leichname ron Verblechern zu zerstürdeln 
und die Theile nach allen rier Winden zu zerstreuen, damit ihre Auferstehung rerhindert werde.

Naturalismus. Als Naturalismus bezeichnet man auf religiösem Gebiete die Anbetung der Naturkräfte und Naturel'scheinungen, sowie ron Gegenständen der sichtbaren Aussenwelt, welchen der Mensch Intelligenz, Kraft und Willen zuschreibt, welche diesen Eigenschaften seiner selbst gleich oder überlegen sind. Bald besteht diese Religion nur in einer abergläubischen und unbestimmten Furcht, bald aber heruht sie auf gewissen Personifikationen, auf einer positiven Vergöttlichung. Gilt dieser Kultus Gestirnen (der Sonne, dem Monde oder Sternen), so wird er als Sabriismus bezeichnet. Oft bezieht er sich auf Naturkräfte, wie die Wärme, die Fruchtbarkeit der Erde, oder auf Naturerscheinungen wie Regen, Regenbogen u. s. w. Zuweilen findet sich auch die Verehrung ron Bergen (hohen Gipfeln, Vulkanen), Seen, Flüssen und Strömen, des Meeres, oder ron Quellen, Brumnen und Teichen: es gibt heilige Seen und Ströme, heilige Quellen und Brumen. Anderswo betet man das Feuer oder gewisse Pflanzen und Thiere an. Auch Gegenstände des menschlichen Gewerbfleisses, Werkzeuge u. dgl. können Objekte des Kultus sein.

Totemismus. Der Totemismus ist ein in Bezug auf seinen Gegenstand und seine Anhänger beschränkter Naturliultus: er gilt nur der Pflanzen- oder Thierart, woron ein Stamm oder eine Familie den Tamen hat, und wird auch nicht als Nationalkult rom ganzen Volke geübt, sondern nur von den Angehörigen desselben (Stamm oder Familie), welche jene I'flanzen- oder Thierart zum Emblem (Totem der Rothhäute) haben. Die Biber-Indianer z. B. verehren den Biber, nicht aber auch den Alligator und Schlangenarten, welche Gegenstand des Kultus (Totems) anderer Indianerstämme und einzelner Indianerfamilien sind. Derselbe Naturdienst findet sich bei den Australiern, wo das Totem den Namen Kobong hat.

Dieser Kultus entspringt ohne Zweifel aus der Achtung oder abergläubischer Furcht vor den Geistern der Vorfahren, welche Namen wie grosse Schlange, Prärienhund, Känguru, Opossum u. dgl. trugen: die gleichnamigen Wesen werden angebetet, weil man die Uebereinstimmung im Namen als 
eine Art Verwandtschaft betrachtet ("Namensvettern") oder" weil der Glaube herrscht, es seien die Seelen der Verstorbenen in diese Wesen übergegangen (Metempsychose). Wenn ein Thier, welches Gegrenstand dieses Kultus ist, von einem Anbeter desselben auf der Jagd durch Zufall getödtet wird, so entschuldigt sich der Wilde bei demselben für das Versehen, dem es zum opfer fiel, oder er sucht wenigstens sein Gewissen zu beschwichtigen unter Berufung auf die harte Nothwendigkeit, sich Nahrung zu verschaffen.

Fetischdienst. Dieser Kultus kann irgend einem materiellen Gegenstand gewidmet sein; aber dieses Objekt welches oft auch nur der Gott (Fetisch) eines Stammes, einer Familie oder eines Einzelnen ist - wird nicht in Beziehungen zu den Ahnen gedacht, und die Verehrung, welche ihm erwiesen wird, gilt ihm nur als Einzelngegenstand, schliesst aber nicht den Kultus anderer Exemplare gleicher Art in sich. Wenn also ein Thier, eine P'flanze, ein Stein als Fetisch angebetet wird, so ist das Individuum, Exemplar oder Stück Gegenstand des Kultus, nicht die Species. Wird ein Stein wegreworfen, welcher als Fetisch verehrt wurde, so gilt derselbe nachher auch in den Augen seines frïheren Anbeters nicht mehr als irgend ein andrer Stein. Vom Gützen- oder Bilderdienst unterscheidet sich der Fetischismus dadurch, dass der Fetischverehrer glaubt, seinen Gott zur Erfüllung seines Willens und seiner Wünsche zwingen zu können und denselben unter Lmständen bestraft, beseitigt oder zerstïrt, wenn er nicht leistet, was man ron ihm erwartet. Die Neger der Guineaküste schlagen ihre Fetische, wenn diese sich widerspenstig zeigen, d. h. die Wünsche ihrer Verehrer nicht erfüllen, und wenn die Neger etwas Unrechtes begehen wollen, so verbergen sie ihren Fetisch, damit er nicht Zeuge der büsen That sei. Es gibt auch Völkerschaften, welche bei grewissen Anlässen ihre Fetische verspeisen.

Götzen- oder Bilderdienst und Reliquienkultus. Als Götzendienst (Iflolatri', Abgötterei) bezeichnet man die Inbetung ron bildlich und plastisch dargestellten Göttern, in welche die Gläubigen Gebete richten, die ihrer Meinung ach durch die Gottheiten erfüllt werden können, ohne dass liese Erfüllung (wie der Fetischanbeter meint) zu erzwingen ist. 
So werden Statuen errichtet, vor denen man sich niederwirft, um von ihnen Beistand, Schutz und Hülfe zu erfiehen. Bald sind diese Bildnisse oder Idole selbst die Götter (Götzen), bald sind es nur Darstellungen derselben, ein Unterschied, welcher in der Theorie oft als wesentlich bezeichnet, ebenso oft aber von den Gläubigen in der Praxis selbst nicht gemacht und nicht beachtet wird.

Das Idol ist oft nur eine unförmliche Masse, ein aufrecht gestellter Stein oder eine ganz rohe und ungeschlachte Darstellung des Gottes (Nensch oder Thier), wovor die Gläubigen sich noch immer niederwerfen, nachdem sie längst gelernt haben, bessere Bilder anzufertigen.

Die Anbetung ron Thieren oder Darstellungen von solchen wird als Zonlatrie, diejenige von Schlangen speziell als OpthioTutrir bezeichnet; analog ist unter Phytolatrie die Verehrung ron heiligen Bäumen und andern Pflanzen $z u$ verstehen. Anthropulatrif heisst sowohl die Anbetung berühmter Menschen, Helden oder Heroen, als auch diejenige von Bildern, welche Gottheiten in Menschengestalt (anthropomorph) darstellen.

Anstatt einer Darstellung des Heros oder Gottes werden manchmal Gegenstände verehrt, die angeblich von denselben herrühren und die man als Reliquirn bezeichnet. Damit geht der eigentliche Bilderdienst in den Reliquienkultus über.

Schamanismus. Der Ausdruck Schamanismus oder Schamanenthum kommt her von der Benennung Sichmancu (Korruption des sanskritischen scramanas) für die Personen, welche bei den Volksstämmen im nördlichen Sibirien die Vermittler zwischen Menschen und Göttern spielen. Das Schamanenthum unterscheidet sich vom Fetisch- und Bilderdienst, indem es weder materielle Götter, noch Bildnisse von solchen kennt; seine Gütter werden als vom Menschen gänzlich verschieden, weit mächtigrer und nicht die Erde bewohnend gedacht. Mit diesen Gottheiten kann der gewöhnliche Mensch nicht direkt in Beziehung treten, vielmehr muss er sich hiefür an die Schamanen wenden. Der Schamane allein verkehrt unmittelbar mit seinen Göttern; unter konvulsivischen Anfällen beschwört er sie; in der Extase wird sein Geist zu ihnen versetzt und rernimmt er ihre Stimme. Diese Religionsform ist nicht auf Sibirien beschränkt; sie kommt auch bei den Eskimos vor, wo der Augcliol nichts 
anderes ist als der sibirische Schamane: ferner findet sie sich bei den Abiponen am Paraguay und auf einigen Inseln des Stillen Ozeans.

Spiritualismus. Als Spiritualismus kann jede Religion bezeichnet werden, deren Gottheit als ein Geist gedacht wird, d. h. als wesentlich rerschieden rom Menschen und den Dingen der Aussenwelt, und die man nicht anbetet in diesen Dingen, noch in symbolischen Bildnissen und Idolen. Als Differenz zwischen dem Spiritualismus und dem Schamanenthum ist der Lmstand zu bezeichnen, dass ersterer den Menschen mit seinem Gotte direkt in Verkehr treten lässt durch das Gebet, während letzteres hiefür eine Vermittlung durch einen andern Menschen (den Schamanen oder Angekok) als nothwendig annimmt.

Atheismus. Als Atheisten bezeichnen wir nicht Völker, welche die Existenz eines Gottes oder verschiedener Götter leugnen, denn, wie schon bemerlit, kommt wahrscheinlich eine solche Negation als Volksanschaumyg gar nicht ror: sondern wir verstehen unter Atheisten diejenigen (noch ziemlich zahlreichen) Vülkerschaften, welche sich mit der Frage, ob es einen Gott gebe, nicht beschäftigen, welche aus diesem Grunde keinen Gott kemnen oder hierüher nur vage Ideen haben und sich nicht damit befassen, dieselhen zu präzisiren. Diesen Zustand trifft man selten auf der untersten Stufe greistiger Entwicklung, denn für die Wilden, die Naturvölker mu excellener. ist die Welt voller Geister; die Gleichgültigheit gegen diese nichtmateriellen Dinge, der Mangel eines bestimmten Glaubens, den man als Atheismus bezeichnen kann, findet sich vielmehr in den Staclien des Lehergangs aus Barharei zu Bildung, eines eigenthümlichen Gemisches ron Halbharbarei und Halbzivilisation, gleich dem Dämmerschein, worin die Schatten der Nacht sich rerschmelzen mit dem Lichte des nahenden Tages.

Polytheismus. Unter Polytheismus versteht man den Glauben an eine Mehrzahl ron Güttern (die Vielgötterei). Diese Gottheiten haben oft ein ganzes Gefolge von Halbgïttern, Heroen und allerlei geistigen Wesen tieferen Ranges, deren Gesammtheit ein mehr oder minder komplizirtes mythologisches System bildet. Für die Zahl derselben gibt es kaum bestimmte Grenzen. Die alten Mexi- 
kaner hatten 2000 Götter, ohne die Dämonen, Geister und Seelen der Todten, welche nur Gegenstand des Lokalkultus waren. Die indische und japanische Mythologie sind noch reicher. Für diese manigfachen Gottheiten ist fast immer pine bestimmte Rangordnung oder Hierarchie vorhanden. Die einen sind nur Geister der Ahnen, denen kaum göttlicher Charakter beigelegt wird; die andern Heroen oder Halbgütter; dann folgen die Hauptgottheiten oder grossen Götter mit verschiedenen Attributen, und endlich kommt hisweilen noch ein oberster, höchster Gott vor, ein Gott aller Götter.

Dualismus. Eine Religion heisst dualistisch, wenn sie den Glauben lehrt, dass zwei entgegengesetzte Gottheiten die Welt regieren, ron welchen die eine der Urquell des Guten, die andere aber Quell alles Bösen ist, oder den Glauben an zwei rivalisirende Götter, wovon der eine Beschützer und Wohlthäter, der andere Feind und Verführer fes Menschen ist. Bei den alten Persern war Ormuzd das cute und Ahriman das böse Prinzip, Jener Gott des Lichtes, Jieser der Finsterniss. Die Rothhäute kennen Kitchi Manitu als den guten Geist und Matchi Manitu als seinen unversöhnlichen Gegner. Bei den Negern von Loango ist Zambi der höchste und gute, Zambi-Ambi der feindlich gresinnte Gott.

Monotheismus. Der Monotheismus ist der Glaube an rinen einzigen oder doch einen höchsten Gott, der weit erhaben ist über alle niederen Götter und Geister, der allein Himmel und Erde geschaffen hat, regiert und erhält. Die unteren Götter und Geister monotheistischer Religionen (Genien, Engel) haben keinen selbständigen Wirkungskreis; sie sind nur Vollstrecker der Gebote des höchsten Gottes, des Weltenmeisters, den die Völker verschieden benennen und sich auf verschiedene Art vorstellen, immer aber als den allmächtigen Beherrscher von Himmel und Erde.

Ursprung der Religion und Dogmen derselben. Falls der Reisende eine Religion kennen lerut, von der man noch wenig Genaues weiss, hat er sich nach deren Ursprung und Lehren zu erkundigen und hierüber zu berichten.

Für die Forschungen über Urspmun und Geschichte einer Religion kommen in Betracht: Nachrichten über den Stifter 
dieser Religion, seine Zeit und die Stätten seines Lebens und Wirkens; die Veranlassung zu seinem Auftreten als Apostel oder Reformator (Inspiration, "Offenbarungen" betreffend seine Sendung), sein Leben ror und nach diesem, rndlich die Mittel, welche zur Ausbreitung des neuen Glauhens angewendet wurden. Hieran schliessen sich auch allfällig mögliche Ermittlungen üher heilige schriften dieser Religion, ihre Entstehung, sowie die späteren Auslegungen und Erklärungen (Kommentare) derselben.

Die Kenntniss der Dogmen oder Glaubenslehren einer Feligion verschafft man sich aus den heiligen Büchern derselben oder, in Ermanglung solcher, von Priestern und andern Personen, welche in dem betreffenden Lande einen Iiuf als Gelehrte in religiösen Dingen besitzen. Die religiösen Schriften werden dem Reisenden selten verständlich sein; daher hat er sich dieselben erklären zu lassen oder sich womöglich eine Abschrift derselben zu verschaffen, um sie einem Fachgelehrten zu übermitteln.

Konfessionen und Sekten. Handelt es sich um Fieligionen, welche in Allgemeinen schon bekannt sind, so kann sich der Reisende darauf beschränken, kurz an die Hauptdaten und Grundzüge derselben zu erinnern; einlässlicher hat er hierüber nur zu berichten, hinsichtlich einzelner Punkte, die nicht oder nur ungenügend bekannt und beachtet wurden oder welche in neuer Auffassung darzustellen sind. Besondere Aufmerksamkeit ist den einzelnen Hauptrichtungen innerhalb einer Religion, den Komfessionen und Seliten zuzuwenden, d. h. Gruppen von Personen, welche sich zu einem Glauben bekennen, der in gewissen Punkten von den herrschenden religiösen Anschauungen und Gebräuchen abweicht. Es soll ermittelt werden, worin die Verschiedenheiten der Konfessionen und Sekten bestehen, wann diese Differenzen ihren Anfang nahmen und die konfessionelle Trennung (Glaubenssyultun!, Srhisma) oder Sektenbildung stattfand.

Tempel und kirchliche Anstalten. Unter Tempeln hat man nicht nur zum Gottesdienste bestimmte Gebäude (Kirchen, Ioscheen, Pagoden etc.) zu verstehen, sondern auch alle die Stätten (Höhen, Waldlichtungen, Uferplätze), welche dem Zwecke ler Gottesverehrung gewidmet sind. Das Betreten dieser 
Gebäude und Plätze ist häufig den Fremden verboten; der Reisende muss sich dann meist mit der Beschreibung begnügen, welche ihm Eingeborne davon geben. Wenn aber irgend ein günstiger Zufall ihm den Besuch jener Stätten ermöglicht, so unterlasse er nicht, eine genaue Beschreibung und wo immer möglich Ansichten derselben mitzutheilen.

Als Fivcleliche Anstalten bezeichnen wir alle Gebäude und Einrichtungen, welche zwar nicht für den Gottesdienst oder Kúltus im engern 'Sinne bestimmt sind, aber anderweitigen religiösen oder konfessionellen Zwecken dienen, wie Klöster, Priesterwohnungen, Fondationen unter kirchlicher Leitung und Verwaltung etc.

Geistlichkeit. In Ermanglung eines bessern Kollektivnamens bezeichnen wir hier als Gcistlichlieit oder Klerus die Gesammtheit der Personen, welche die (selbstgestellte oder von Andern ihnen übertragene) Aufgabe haben, sich in irgend einer speziellen Weise mit religiösen oder kirchlichen Angelegenheiten zu befassen. Wir zählen also hieher die Zauberer, Wahrsager, Opferpriester etc. unzivilisirter Völker, die Derwische und Marabuts, die Ulemas oder Doktoren des Gesetzes: Imans, Muftis etc.; die katholischen Pfarrer (curés), Bischöfe und Erzbischöfe, wie die Mitglieder der verschiedenen Orden: Mönche, Kapuziner etc.; die protestantischen Pfarrer (pasteurs), die Strassenprediger (street preachers) der Städte und Wanderprediger der Landschaften in den Vereinigten Staaten; endlich die Missionäre, welche die Religion den Ungläubigen in fernen Ländern, in den fremden Erdtheilen verkünden.

Der Reisende hat die Aufgabe, möglichst genau festzustellen, welche Rolle, Attribute und Prärogative die einzelnen Personen haben, denen es in dem besuchten Lande obliegt, sich in ihrer Stellung auf irgend eine besondere Art mit dem Gottesdienst und den religiösen oder kirchlichen Interessen zu befassen. Soll dieser Aufgabe in genügender Weise nachgekommen werden, so wird es für den Reisenden oft nöthig sein, seine persönlichen Ansichten und vorgefassten Meinungen über diese Dinge in den Hintergrund treten zu lassen, um unparteiisch und korrekt die Thatsachen zu konstatiren und $\mathrm{zu}$ würdigen. 
Kultus, Ritus, Zeremonien. Noch grössere Verschiedenheiten als im Glauben der Menschen finden wir in der Manifestation dieses Glaubens, in der Art, wie der Mensch mit seinen Güttern rerkehrt. Völker, welche derselben Religion angehören, können in ihrem Kultus oder kirchlichen Zeremoniell von einander ziemlich abweichen. Der katholische Kultus in Frankreich ist ein anderer als der in Spanien, Mexico oder gar in den Dörfern bekehrter Indianer.

Der Kultus besteht keineswegs überall in Huldigungen gegen die Götter. Es gibt Völker, welche ihren Grottheiten nicht Lob und Dank, sondern Vmrïrfe und Verünsrhumen zukommen lassen. Wenn uns dies ungeheuerlich erscheint, so ist es nichtsdestoweniger natürlich; denn jene Vülker kennen nur böse oder schwache Götter, welche es verdienen, dass man sie mit Vorwürfen und Injurien überhäuft für ihre Bosheit oder mangelhafte Pflichterfüllung. Anderswo besteht der Kultus namentlich in Opform, womit die Götter besänftigt und günstig gestimmt werden sollen.

Trunze spielen eine grosse Rolle bei den religiösen Zeremonien der Wilden, und dieselben sind häufig mit lärmenden Auffülrungen verbunden: Geschrei, Geheul und eine betäubende Musik sollen die Aufmerksamkeit der Götter erregen und denselben zur Ehre gereichen.

In Mexico und im ganzen spanischen Amerika wird der Gottesdienst an vielen Orten sehr oft mit Prozpssimen, Fruerwerk und Schüssen verbunden. Die Chinesen werfen Rralipten und verwenden massenhaft kleine P(ppierstïclie, die angezündet werden. Sehr verbreitet ist der Gebrauch von Lamprn, Kerzen und Faclieln zu Kultuszwecken; seltener derjenige von Blumen, welcher immerhin in verschiedenen Ländern Sitte ist. Gesan! und IIusil bilden selbst bei den meisten zivilisirten Völkern ein integrirendes Element des Gottesdienstes.

Womöglich wohne der Reisende den religiösen Zeremonien der von ihm besuchten Völker bei, nicht blos um eine genaue Beschreibung derselben liefern zu können, sondern auch, weil er hier Gelegenheit finden wird zur Erklärung von Einzelheiten, die ihm sonst entgangen wären und die aus Diskretion nicht zum Thema des Gesprächs gemacht werden können. In den religiösen Gebräuchen finden sich 
auch am ehesten Ueberreste aus ferner Vergangenheit, Symbole, für deren Herkunft aus altersgrauer Vorzeit der Umstand spricht, dass ihre Bedeutung mit dem jetzigen Glauben nicht mehr im Einklang steht.

Religiöse Werke. Eine Religion verlangt von ihren Bekennern meist nicht nur die Bethätigung ihres Glaubens durch Theilnahme am öffentlichen Gottesdienst und dessen Zeremonien, sondern auch religiöse Werke, wie Beten, Almosenspeuden, Truschungen etc. Hier kann man denn namentlich oft sehen, wie der Geist, welcher diese Werke vorschrieb, in Vergessenheit kam und an dessen Stelle der Buchstabenglaube trat. Palladius, der im vierten Jahrhundert nach Christus lebte, erzählt, dass ein gewisser Abt 300 Mal im Tag dasselbe Gebet hersagte und sich dies zu einem grossen Verdienst anrechnete. Eine derartig mechanisch-repetirende Gebetsverrichtung trifft man in manchen Ländern. Zu Benares in Indien hört man in allen Tonarten den Namen eines Gottes: „RamRam-Ram", was - wie ein geistreicher englischer Geistlicher bemerkt - die Gläubigen nicht hindert, diese Gebete zu zählen, als ob es ebenso viele Ruppien wären, die ihrem auf der himmlischen Bank deponirten Kapital beigefügt würden. In Tibet wird die Formel "Om mani padme hum" (Gott im Lotus! Amen!) unzählige Mal wiederholt. Sicher wird kein anderes Gebet täglich so oft Mal wie dieses gesprochen; denn kein Volk betet soviel wie die Tibetaner. Um diesem Bedürfniss zu genügen, nehmen sie ihre Zuflucht zu Gebetsmühlen, welche mit Hülfe einer Papierrolle und eines Uhrwerks die mystische Formel eine unbestimmte Anzahl Mal wiederholen. Anderswo besteht das Gebet darin, dass alle Anrufnamen eines Gottes nacheinander aufgezählt oder ausgesprochen werden. Nun besitzt Allah 99 solcher Namen, Wischnu 1000, Siva 1008; die Liste ist also mitunter sehr gross und es werden mechanische Hülfsmittel nöthig (Rosenkränze, tasbih der Muselmanen, japa-mala und smarani der Hindu), um sich zu vergewissern, dass man keinen jener Namen auslässt. Zudem hat es den Anschein, dass, wenigstens in Indien, angenommen wird, die Wirksamkeit des Gebetes stehe im Verhältniss zur Grösse der Perlen oder Körner und Steine dieser Rosenkränze; denn man sieht daselbst solche Kugeln von der Grösse eines Kinderkopfes, sodass deren Handhabung 
selber wieder mechanische Hülfsmittel erfordert. In Bezug auf die Almosen besteht meist ein starkes Missrerhältniss zwischen den religiösen Vorschriften und deren Beohachtung. Wer leht dem Gebote der Bibel nach, sein Gut mit den Armen zu theilen und sich so einen schatz im Himmel anzulegen: Was die Waschungen betrifft, welche der Koran rorschreibt, so werden dieselhen sehr häufig nur simulirt: tum dem Schein zu genügen, macht man einige Manipulationen, welche das Waschen vorstellen: in Wirklichkeit aber zeichnen sich die Anhänger Mohammeds nicht gerade durch Reinlichkeit des Gesichts und der Hände aus.

In rerschiedenen Gegenden sind Eufhaltsamlerit. Fastru.

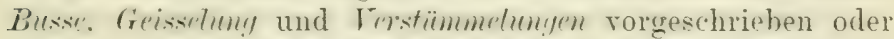
doch als verdienstliche Werke erklärt. Die Tonga-Insulaner sollen sich den kleinen Finger ahschmeiden, um ihn den Göttern zu opfern, und Indien hat die Sillstmefoutirmurn unter den Wagenrädern des (iottes von Jaggernaut (s. 614).

In manchen Länder'n endlich kommen Wullfulutrn oder Pilyry süyr vor als ein Mittel, den Himmel zu verdienen, Vergebung der Sünden oder den Ruf der Heiligheit zu erlangen.

Charakter der Religion. Unter dem Charakter einer Religion verstehen wir den Geist, welcher in deren Ansübung zu Tage tritt.

Es gibt Religionen, welche von unverträglicher und exklusiver Natur sind oder wenigstens in diesem simme gelehrt

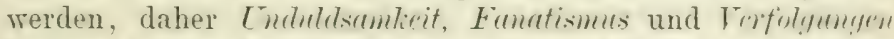
hervorrufen: andere sind propagandistisch, eifrig bemüht um Bekehrungen, (iewimung nener Anlänger (Pirstyten). Diese Charakterzüge hat eine Peligion oft nicht sowohl an und für sich, zufolge ihres innern und eigentlichen Wesens, als vielmehr zufolge des Verhaltens der einen und andern ihrer Bekenner und des Geistes, welcher dieselhen heseelt. Der Katholizismus z. B. hat in spanien die Inquisition und die Autodafés erzeugt, während er sich in Frankreich gegen andere Bekenntnisse toleranter zeigte und in der Schweiz viele Kirchen regelmässig jeden Sonntag der Reihe nach ron heiden Konfessionen (Katholiken und Protestanten) benutzt werden. Es ist selbst der muhammedanische Fanatismus kaum zu fürchten als in Zeiten. wo das Volk wegen besonderer Verhältnisse zum Hasse gegen die Lngliubigen aufgestachelt wird. Der pro- 
pagandistische Eifer endlich ist mehr eine individuelle Eigenschaft als eine solche der Religion.

Gewisse Religionen begünstigen den Formalismus durch die hohe Bedeutung, welche sie den äusserlichen Kultushandlungen beilegen; andere führen zum Fatalismus, indem sie lehren, dass der Mensch keinen Einfluss habe auf sein Geschick, das vorher bestimmt und unabänderlich sei.

So hat jede Religion ihr eigenthümliches Gepräge; meist ist aber wohl $\mathrm{zu}$ unterscheiden zwischen dem Geist und Charakter ihrer selbst, ihrer Formen und Lehren, auf der einen Seite und andererseits derjenigen Physiognomie, welche sie durch die Eigenschaften ihrer Bekenner und Ausleger erhält.

Aberglaube und abergläubische Gebräuche. Die Religion ist selbst in denjenigen ihrer Formen, welche als die höchsten gelten, noch mit Aberglauben verbunden.

Wir wollen hier nicht von den absurden Meinungen sprechen, welche im Mittelalter die Judenverfolgungen, Hexenprozesse u. dgl. verursachten; es genüge, zu bemerken, dass man heute noch bei uns, namentlich auf dem Lande, den Glauben trifft an Hexenkünste, an Verzauberung von Menschen und Vieh, an den bösen Blick, Gespenster u. dgl. Gewisse Personen werden für unheilbringend gehalten; der jettatore und die jettature in Italien (mit dem bösen Blick Behaftete) sind Analoga zu den Zauberern (jeteurs de charmes), wofür man den letzteren Ausdruck nicht mehr verwenden mag.

Noch an vielen Orten glaubt man mehr oder weniger, bewusst oder instinktiv, dass geuisse Wochentage von üblev Bedcutung seien, so der Freitag; dass gewisse Daten als Schiclisalstage verhängnissvoll seien, so der dreizehnte eines Monats. Morgens einem Leichenzuge zu begegnen, verdirbt Nanchem den ganzen Tag; zu dreizehn am Tische sitzen, stört das Mahl.

Man lässt läuten yegen. Blitzschlag, trägt eine Reliquie als Talisman gegen Unglück, beqräbt ein Thier unter dem Herde, um reich zu werden $\mathrm{u}$. dgl. $\mathrm{m}$.

Auf Geratherohl ein Buch zu off̈nen und die auf diese Art zufällig aufgeschlagenen Worte zu deuten, gilt als ein Mittel zur Erforschung der Zukunft, wie andererseits die Traumdeuterei, und in der That wird die Auslegung fast immer bestätigt, wenn sie nur - geschickt ist. Der Messmerismus 
(thierische Magnetismus) und die Srmmumbïlm hatten ihre Zeit, wie das Tischlilnyfen und Tischrïlirn und heute sehen wir grosse Gelehrte mit Merdien, Geistern (spirits) u. dgl. beschäftigt, überzeugt, dass es zwischen Himmel und Erde mehr Dinge - auch mehr Dimensionen - gibt, als unsere Philosophie sich bisher träumen liess.

Lourdes in Frankreich, Marpingen in Deutschland u. dgl. Stätten und Vorfälle mehr haben auf's Neue gezeiçt, wie sehr der Glaube an Wunder und Wundrersedefinumen noch verbreitet und festgewurzelt ist.

Kann man sich also wundern, bei Wilden und Halbbarbaren den Glauben an übrmutiislirhe Diure, an Zuubrer, Auguren, Orakel u. dgl. überall in Blüthe zu finden?

Ist die Religion der Völkerschaft, welche ein Reisender besucht, schon genügend bekannt und bietet sie ihm keinen Stoff zu Studien dar, so wende er seine Aufmerksamkeit dem Aberglauheu, dessen Formen und Bräuchen zu: auf diesem Felde findet er sicherlich noch reiche Ernte, sei er Schnitter oder Aehrenleser. Gewisse Formen des Aberglaubens sind namentlich deshalb von grosser Wichtigkeit, weil ihnen ein sehr hohes Alter zukommt. Wenn es z. B. richtig ist, dass bei den Bauern der Bretagne jetzt noch der Brauch herrscht, die Steine ron Carnac mit Oel zu salben und mit. Blumen zu schmücken, so muss angenommen werden, dass, was heute Aberglaube ist, ehemals Religion und Kultus war.

\section{KLEIDUNG UND SCHMIUCK.}

Die Sitte des Kleidertragens entspringt einerseits dem Bedürfnisse nach Schutz des Körpers gregen die Lnbilden der Witterung, andererseits einem gewissen Anstands- oder Schicklichkeitsgefühle. In den heissen Ländern kann wesentlich nur schamhaftigkeit oder Freude an Schmuck dazu reranlassen, den Körper in grösserem oder kleinerem Maasse zu bekleiden, und ron diesen beiden Bewegrründen scheint der letztere - die Lust am Schmuck - der rorherrschende zu sein; dafür spricht wenigstens der Lmstand, dass bei Völkerschaften, welche den Körper ganz zu tätowiren pflegen, die Frauen sich für gut bekleidet halten, wemn sie mit Tätowirungen bedeckt sind. 
Die Begriffe über das, was hinsichtlich der Bekleidung die Schicklichkeit gebietet, sind sehr verschieden. Bei einigen Völkern gehen nur die Männer einigermassen bekleidet, und bei vielen andern sieht man die Kinder beiderlei Geschlechts his zu einem gewissen Alter ganz nackt. Auch darüber, welche Theile des Körpers zu bekleiden seien, welche andere aber unverhüllt bleiben dürfen, weichen die Ansichten bei rerschiedenen Tölkern sehr ron einander ab. Bei den Hottentotten muss die Frau den Nacken verhüllen; in China darf sie den Fuss nicht sehen lassen: im ganzen Orient hat eine Frau, welche im Bade überrascht wird, nur ihr Gesicht zu bedecken, um die Decenz zu wahren.

Mit der Sittlichkeit eines Volkes hat dies nichts zu thun. Es cribt Vülkerschaften, welche sehr sittlich denken und leben, aber es gar nicht für nüthig finden, ihre Nacktheit zu verhergen; andere hüllen den ganzen Körper in Kleider, sind aber keineswegs besonder's tugendhaft.

Der Reisende wird diese rerschiedenen Eigenthümlichkeiten konstatiren, ohne daraus rorschnelle Schlüsse zu ziehen. Sodann hat er das Kostüm zu beschreiben und womöglich durch Zeichnung oder photographische Aufnahmen darzustellen; im letzteren Falle kann die Beschreibung sehr kurz grehalten werden: es sind lediglich die einzelnen Stücke anzugeben, woraus die Kleidung besteht, ferner die Stoffe, Faxben und Namen derselben. Die bildlichen Darstellungen sollen die Personen in einer natürlichen Haltung zeigen (Tuf: IXIV): man hüte sich davor, dass es den Anschein hat, als wäre denselben für die Aufnahme eine besonder Stellung angewiesen worden.

Volkstracht. Dem Reisenten muss daran liegren, aus den importirten Moden und den Liebhahereien der Einzelnen hinsichtlich ihrer Toilette herauszufinden, was der Volkstracht angehört. Selten findet man diese in Städten; hier ist sie zumeist entweder fast gänzlich verschwunden oder — wie bei den Ammen, Kindermädchen und Kellnerinnen der Schweizerstädte - durch ein Phantasiekostüm ersetzt. Oft werden städtische Moden selbst in den kleinsten Dörfern nachgeahmt, und findet man die Nationaltracht kaum noch bei alten Leuten und in abgelegenen Gegenden. Oft aber auch wird das Kostüm, welches die Landleute in den Tagen ihrer 
Taf. XXIV.

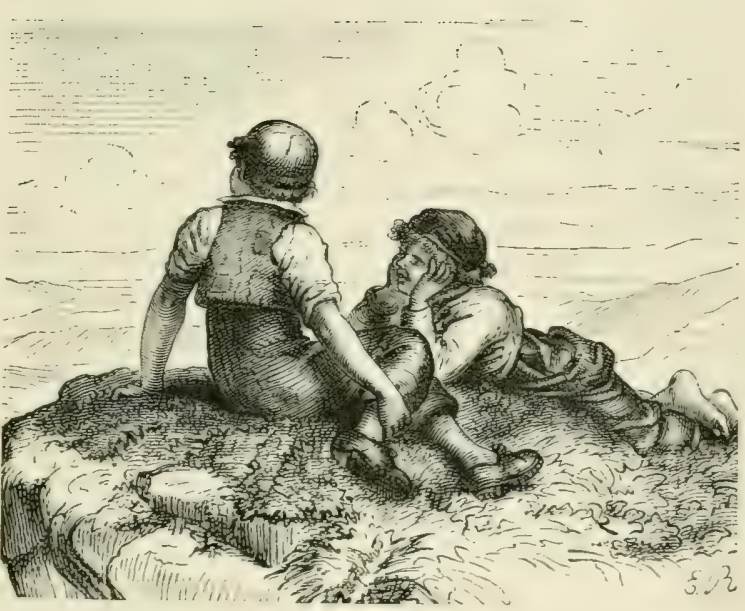

Appenzeller firtenknaben. 

Jugend trugen, von denselben wie eine Reliquie aufbewahrt, und zuweilen sind sie anf die Bitte von Gästen hin bereit, sich vor denselhen in dieser Tracht aus ihren jungen Jahren $\mathrm{zu}$ zeigen.

Die aussereuropäischen Völker legen mehr Werth auf di. Beibehaltung des traditionellen Kostüms, was nicht weniy dazu beiträgt, Szenen des Vollislebens eine charakteristischp Lokalfärbung zu geben.

Die Tracht ist mitunter hüchst einfitch. Bei einigen wilden Stämmen beschränkt sie sich auf eine Art Schürze oder kurzen Rock (jupon) aus Blattern, Gras, Schilf oder Federn. Anderswo besteht sie aus Thierhäuten, Schaffellen, Stüchen weicher Rinde und Geweben. Einige Völker haben eine sehr komplizirte und reiche Tracht.

Wie oben schon bemerkt wurde, hat der Reisende anzugeben, welches die Bestandtheile des Lostüms, die verschiedenen einzelnen Kleidungsstücke, deren Stoffe, Farhen und Namen seien. Dabei ist namentlich auch zu erwähnen. ob die Leute barhäuptig und barfuss gehen oder nicht. Die sitte, keine Kopfbederkung orler keine Fusshekleidung zu tragen, liontrastirt manchmal seltsam mit dem sonstigen Reichthum des Kostüms. In Japan würde man es als etwas Extravagantes betrachten, wenn eine Frau Strümpfe tragen wollte.

Die Art des Kopfputzes und rer Kopfbedeckung - der Mützen, Hauben, Frauen- und Herrenhüte, mit hohen und niedrigen Formen, breiten und schmalen Rändern, weichen oder harten, hellen oder dunkeln Stoffen, der Turbane, Pelzmützen ptc. - sowie diejenige der Fusshekleidung - Sandalen, Expadrillen, Mocassins, Schuhe und Stiefel aus Leder. Pelz etc. - ist als charakteristisch ebenfalls zu beschreiben.

Besondere Trachten. Manchmal tragen die einzelnen Kasten, Klassen, Stände oder Berufsarten hesondere Trächten. Der Reisende wird sowohl konstatiren, oh und inwieweit dies der Fall sei, als auch die Gründe solcher sitten zu ermitteln suchen. Dieselben sind oftmals nicht blos zufälliger Natur. In gewissen Ländern gibt es strenge Gesetze, di* rorschreiben, welche Stoffe, Farbe tind Form die einzelnen Personen je nach ihrem Range anwenden clürfen. In Cochinchina z. B. ist dem Volke durch die Luxusgesetze das Tragen 
ron Seide verboten. Im Königreich Annam hat nur der Herrscher das Recht, sich mit Stoffen von lebhafter gelber Farbe zu bekleiden; das Roth ist für die Mandarinen von hohem Rang bestimmt, das Blau für untergeordnetere Beamte.

Von diesen hierarchischen Unterschieden abgesehen, bestehen in dex Tracht Differenzen nach Geschlecht und Alter; wo dies nicht der Fall sein sollte, wäre das als eine Ausnahme zu betrachten, welche notirt $\mathrm{zu}$ werden verdiente.

Die Tracht wechselt auch nach den Jahreszeiten: es gibt Sommer- und Winterkleider, wie besondere Anzüge für Frül:ling und Herbst.

Oft kamn namentlich unterschieden werden zwischen der Werktags- und der Sonntags- oder Festkleidung, Haus- und Gesellschaftskleid, Morgen- und Abend-Anzügen.

Endlich sind die Spezialkostüme für besondere seltenere Anlässe zu erwähnen: Galakleider für Hochzeiten und Taufen, die Tranerkleidung, die Hoftracht und bei wilden Völkern das Kriegskostüm.

Von allen diesen verschiedenen Trachten sind kurze, aber ausreichende Beschreibungen zu geben. Es ist zu bemerken, ob sich eine ausgesprochene Vorliebe für gewisse Stoffe und Farben zeigt und ob etwa einige der letzteren eine besondere Bedeutung haben. Weiss und Rosa gelten bei uns als Farben ron freudiger Bedeutung; in China hingegen ist das Weiss Trauerfarbe. In einigen Schweizerkantonen haben die Bänder, welche Frauen und Mädchen sich in die Haare flechten, bestimmte Farbenverschiedenheiten, woran zu erkennen ist, ob die betreffende Person ledig oder verheirathet sei und ob sie der Aristokratie des Dorfes angehöre oder nicht.

Accessorische Bestandtheile der Toilette. Als solche bezeichnen wir die Gegenstände, welche nicht gerade zum Kostüm gehören, aber eine mehr oder minder übliche Beigabe und Ergänzung zu demselben bilden.

Fast alle wilden Völker lieben es, sich mit Hals- und Armbändem, sowie mit Rinyen an den Fingern, Armen, Beinen und selbst um den Körper zu schmücken. Dabei kommt es ihnen nicht gerade auf den Stoff an: Kupfer, Messing, Eisen, Elfenbein, Leder, Steine, Muscheln, Glas, Körner, Knochen, Zähne - alles ist ihnen recht. 
Mitunter tragen sie Diademe aus Federn, riesige Stecknade7n in den Haaren und unverhältnissmässig grosse Ohrrehrüre. Die alten Japanesen trugen eine Kette von Matagamas oder verschieden geformten Kleinodien an der Seite; ihre Frauen hatten ähnlich zusammengesetzte Halsbänder. Die Australier an der Botanybai hatten eine Art Rinylirenen (hausse-col) aus grossen Muscheln, die rom Halse bis auf die Brust hinunter reichten. Endlich beobachtet man bei verschiedenen Völkerschaften den Gebrauch einzelner Tüur'hen, Amulete oder Rusmuliunze', welche am Halse oder an der Seite getragen werden.

Als Komplemente der Kleidung sind zu erwähnen: die Handschule, welche in kalten Gegenden aus Pelz bestehen:

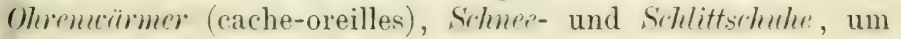
Schnee- und Eisflächen zu passiren.

Anderswo gelten als unvermeidlich Storli, Somnemsthim und Färhrr (diese auch für Männer, z. B. in Japan für gewisse als Yakumins bezeichnete Militärpersonen).

Treschentürler werden nicht überall für nothwendig erachtet; sie fehlen bei ganzen Völkern oder doch Ständen von solchen. In Japan verwendet man an Stelle unserer Taschentücher quadratische Stücke vegetabilischen Papiers, welche in einer Kleiderfalte getragen und nach dem Gehrauche weggeworfen werden.

Für die Horden, welche sozusagen zu l'ferde leben, wie lie Nomaden Innerasiens, die Gauchos in Südamerika etc., owie für andere Völker, wo der Mensch ron seinem Reithiere fast unzertrennlich ist, wie Araber, Tuaregs, Mexiianer u. A., sind auch Suttel und Rertzru!! als Accessorien les Kostüms zu betrachten.

Abzeichen. Es ist zu bemerken, was an dem Anzuge and dessen Accessorien zur Bezeichnung der Funktionen-oder les Ranges einer Person dient, also den Werth ron Alyseiden der Insignien hat.

Bei den wilden Stämmen ist oft eine Feder auf dem Kopf ie einzige Auszeichnung, welche der Häuptling trägt. Auf er Insel Wuap (Karolinen) erkennt man die Häuptlinge daran, ass sie sich mit gewissen .Musrhelu und yrsthuittrurn. Strinen chmücken, welche Andern zu tragen nicht erlaubt ist. 
Wo Siprzialliostïme oder besondere Farben zur Bezeichnung des Ranges und der amtlichen Funktion dienen, sind jene Kostüme und Farben selber als Abzeichen zu betrachten.

In der Regel hat aber nur ein bestimmtes Kleidungsstück oder Accessorium die Bedeutung eines Abzeichens. Bei gewissen Insulanern ist es eine Art Königsmantel, in Marocco der Sommenschim, in Indien der von einem Sklaven getragene Fricher, in Frankreich die Schürpe des Präfekten oder Maires, im Künigreich Annam ein Elfenbeintrifclchen, welches die Mandarinen auf ihrem Kleide tragen und auf welchem Rang und Funktion derselhen durch eine Inschrift bezeichnet sind.

Waffen. In Ländern, deren Kultur noch nicht sehr entwickelt ist, wo die Berölkerung vom Rauben und Plündern - oder doch noch ausschliesslich ron Jagd und Fischfang lebt, sind Waffen unentbehrliche Begleiter des Menschen, Bestandtheile seiner gewöhnlichen Ausrüstung. Diesen Charakter verlieren sie erst in Staaten, wo eine öffentliche Sicherheit besteht, deren Störung ein seltenes und ausnahmsweises Ereigniss ist. Dabei ist zu bemerken, dass auf einer primitiven Stufe der Kultur die Waffe dem Menschen nicht nur als solche, sondern auch als Werkzeug dient. Der Wilde erlegt Thiere und tödtet seinen Feind mit derselben Axt, womit er seine Hütte baut und sein Boot zimmert.

Da der Mensch zunächst für Nahrung und Sicherheit, für Schutz gegen wilde Thiere und Seinesgleichen zu sorgen liat, muss er auf Verrollkommnung seiner Waffen bedacht sein; Art und Beschaffenheit derselben, wie der Jagd- und Fischereigeräthe, sind demn auch Indizien für den Grad geistiger Entwicklung bei wilden und halbwilden Völkerschaften.

Auf den untersten Stufen der Kultur sind die Waffen sehr einfach; sie bestehen z. B. in einer Art Keulen aus knorrigen Baumästen, die später mit Spitzen versehen werden; in einer Art Speer oder Siriess, P'ike oder Lanze aus einem langen Stock, an dessen Ende ein starker Dorn, ein spitzes Horn oder Geweihstück und andere Waffen der Thierwelt angebracht sind. Auf diese primitissten Mittel zu Angriff und Abwehr folgen Aexte aus flachen scharfkantigen Steinen, die je durch irgend ein Band an einen hölzernen Stiel befestigt oder in ein Loch am Ende eines starken Baumastes 
eingetrieben sind. Das Bedürfniss, Wild oder Feinde aus der Ferne zu erlegen, führt auf die Erfindung der Wrutsplesse, Assugairn u. dgl., deren Enden im Feuer gehärtet oder mit spitzen Knochenstücken und scharfen Splitteru harter Steine versehen sind. Es gibt Wurfwaffen, die so pingerichtet sind, dass sie an den Ausgangspunkt der Wurfbewegung zurückfliegen, wie der Bumeran! des Australiers. In Waldgegenden werden Blaspoler, Pfeil und Boyen angewendet, wobei öfters das Vergiften der Pfeilspitzen durch Eintauchen derselben in gewisse Pflanzensäfte rorkommt. In weiten Ebenen bedient man sich des Lasso, eines Lederriemens, an dessen Ende eine Schlinge oder Bleikugeln (Bulus) angebracht sind. In Berggegenden kommt als gefährliche Waffe die Schleuder zur Anwendung.

Die Kenntniss der Metalle und ihrer Bearbeitung bewirkt. eine grosse Revolution im Gehiete des Waffenwesens. An die Stelle von Holz, Knochen und Stein treten für die Hiehund Stosswaffen, wenigstens für deren Schneiden und Spitzen, Bronce, Eisen und endlich Stahl, dessen Verwendung für die Fabrikation der Dulche, Schuerter, Sübel, Yuturgens ete. die Entwicklung dieses Zweiges der Waffentechnik abschliesst, während dieselbe andrerseits in den Fencrutiton auf den verschiedenen Stufen ihrer Ausbildung eine Fülle von zum Theil kunstvollen Formen hervorbringt.

Neben den Waffen im engern Sinne sind die Mittel zur Abwehr gegen dieselben, zum Schutze des Körpers gegen deren Wirkungen, ins Auge zu fassen: die Schilde aus Holz, Schildkrot, Alligatorhaut, Leder oder Metall; die Helme aus Fellen mit dem natürlichen Schmuck derselben (Mähne, Schweif, Hörner etc.) oder aus verschiedenen andern Stoffen; die Panzer aus Rinden, Kork, thierischen Häuten und Fellen, Leder und endlich Metalle.

Die Fischereigerithe zeigen eine ähnliche Stufenfolge von Formen wie die Waffen: Sprer, Wurtspirss und Pfeile dienen für Fischfang und Jagd, wie als Kriegswaffen, bis sie auf einer höhern Entwicklungsstufe durch besondere Instrumente, Harpune, Angel und Netze, ersetzt werden.

Im Jagdwesen spielen die Fallen eine grosse Rolle.

Alles das erfordert Beachtung und volle Aufmerksamkeit ron Seite des Reisenden. Derselbe hat Beschribungen oder 
Abbildungen (Photographien) dieser Gegenstände zu geben und womöglich IIusterexemplare von solchen zurückzubringen. In seinem Tagebuch wird er Notizen machen über die Art der Anfertignn! (Fabrikation) und des Gebranches dieser Objekte; in letzterer Hinsicht sind Beispiele mitzutheilen, die erkennen lassen, welche Geschicklichkeit die Bewohner in der Handhabung dieser Instrumente an den Tag legen.

Was speziell ceryiftete Waffen betrifft, so erkundige sich der Reisende nach der Substanz, womit die Vergiftung rorgenommen wird, nach Herkunft, Zubereitung und Wirkung derselben.

Bemalung. Alle wilden Völlier, die einen grossen Theil ihres Körpers unbekleidet lassen, pflegen sich zu bemalen, und zwar meist mit grellen Farben. Die Bewohner der Andamanen-Inseln begnügen sich indessen mit einem Lehmanstrich; die Eingebornen ron Neuguinea schwärzen, wie schon S. 641 bemerkt, den Körper mit einem Gemisch ron Kohle und Oel, wenn sie den Tod eines Verwandten oder Freundes betrauern; im Uebrigen aber bemalen sie sich ebenfalls mit lebhaften Farben.

Bei vielen Stämmen dienen rothe und gelbe Okererde und ähnliche Stoffe zur Bereitung der Farben, womit die Wilden sich Gesicht oder Körper mit ebenso grosser Sorgfalt einreiben, als nur ron gewissen Schönen des hochzivilisirten Europa auf das Schminken verwendet wird. Nicht selten kann man die Krieger der Rothhäute mit dem grössten Ernste diese delikate Operation vornehmen sehen. Jedes Tolk und jeder Stamm hat seine besondere Art der Bemalung mit einzelnen Linien, Flecken und Punkiten oder mit ganzen Zeichumuen und Figuren aller Art. Die Angehörigen einzelner Völkerschaften begnügen sich mit zwei- oder mehrfarbigen Linien auf Stirne oder Wangen; andere bedecken das ganze Gesicht oder den ganzen Körper mit mehr oder weniger symmetrischen Zeichnungen; zuweilen wird auch eine Hälfte des Körpers (nach Form oder Farbe der Zeichnung) anders bemalt als die zweite Hälfte.

Dergleichen Seltsamkeiten sollen bevbachtet, erwähnt und genügend dargestellt werden. Am besten sind selbstrerständlich farbige Abbildungen, welche dem Original entsprechen; sodann Photographien mit textueller Angabe der 
vorkommenden Farben. Ausserdem hat der Reisende mitzutheilen, wie die Operation bewerkstelligt und auf welche Zeitpunkte oder Anlässe sie erneuert wird: ob sie von Zeremonien begleitet ist oder nicht; ob Vorschriften bestehen über die Zeichnung (das Dessin), die Farbe, die Zahl der Striche oder Punkte etc., oder ob all das dem Belieben der Einzelnen überlassen wird; ob der ganze Körper bemalt wird oder nur einige Theile, und welche: ob einige dieser Malereien eine besondere Bedeutung haben, indem sie etwa den Rang oder die Kriegsthaten ihres Trägers anzeigen: endlich welche Unterschiede in der Bemalung rorhanden sind nach Stand, Geschlecht und Alter. Erwünscht sind auch Bemerkungen über die verwendeten Farbstoffe oder I'igmente und die Ingredienzien für deren Zubereitung.

Die Bemalung des Gesichtes kommt nicht nur bei Wilden, sondern in geringerem Grade auch bei Kulturvölkern vor, z. B. Bemalum! des yourcm Gresichts mit schwarzer Farbe bei den jungen Tibetanerinnen, das Frïbren der Auprubrumen bei den Orientalimnen, das Fürben der Lipren mit Karmin bei den jungen Japanesinnen, welche damit das Weiss ihrer Zähne hervorheben wollen. In Japan entfernen die Damen iiberdiess die Haare der Augenhrauen und bringen als Ersatz dafür zwei grosse Flerlien oder Flliegrn an, je drei bis vier Fingerbreiten über dem Auge.

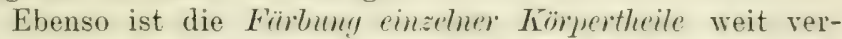
breitet. Die Orientalinnen färben sich mit Hennablättern die Fingernägel in Safrangelb oder Orange. In der Provinz Bagdad und bei den Frauen der Fellatahs im äquatorialen Afrika wird diese Färbung auf die Finger und Zehen ausgedehnt. Der Glanz der Augen sucht man oft zu erhöhen durch Färbung der Lider mit Schwefelantimon. Die FidschiInsulaner färben die Haare schwarz, weiss, flachscelb oder grellroth, mitunter sograr für dieselhe Person auf zwei rerschiedene Arten. Auch wird berichtet, dass die Frauen der Fellatahs ihre Zähne abwechselnd blau, gelh und purpurn fürben, indem sie nur ein Paar oder auch nur einen derselben des Kontrastes wegen in seiner natürlichen Farbe belassen. Die Zähme der Malayen sind häufig geschwärzt durch das Betelkauen; in Japan ist es Sitte, dass die verheiratheten Frauen ihre Zähne schwarz färben. 
Tätowirung. Das Tätowiren geht weiter als die Bemalung und das Färben: gewisse Zeichnungen werden nicht nur aufgetragen, sondern in die Haut eingestochen und sodann durch Einreiben von Farbstoffen hervorgehoben und unzerstörbar gemacht.

Die Sitte des Tätowirens ist weit verbreitet, aber auch sehr verschieden sowohl nach der Art als nach dem Umfang der Zeichnungen. Manche Individuen bringen nur ein Zeichen, ein Emblem auf dem Vorderarm an; andere tätowiren die ganze Körperoberfläche, sogar die Fusssohlen. Zwischen diesen Extremen gibt es zahllose Abstufungen.

Die Bedeutung des Tätowirens liegt nicht einzig in der Tendenz, den Körper zu schmücken; manchmal verbinden sich damit religiöse Ideen, mystische Vorstellungen verschiedener Art.

Ueber die Beobachtungen, welche der Reisende hinsichtlich des Tätowirens zu machen hat, kann auf dasjenige verwiesen werden, was oben über die Bemalung gesagt wurde.

Narben, Ringe u. dgl. an gewissen Körpertheilen. Gesicht und Körper werden auf ihre Kosten oft noch in anderer als der bisher erwähnten Art geschmückt, resp. verunstaltet.

Gewisse Völkerschaften bringen auf Stirne, Schläfen, Wangen, Brust, Armen oder Schenkel Einschnitte und infolge dessen Narben an, welche einige Aehnlichkeit mit dem Tätowiren haben, indem man auch hiebei Farben oder andere Stoffe einreibt, während die Wunde noch frisch ist, um sie auf diese Art sichtbar zu erhalten.

Diese Narben sind bisweilen Erkennungszeichen des Stammes, welchem deren Träger angehören; mitunter auch Gedenkzeichen von Heldenthaten. Bei den Frauen von Dekhan (Vorderindien) sind es lediglich Verzierungen; sie stellen Blumen mit deren lebhaften Farben dar.

Weit verbreitet ist die Durchlöherung der Knorpeln oder des Fleisches von Nase, Ohren und Lippen zu dem Zweck, in diesen Löchern Gegenstände anzubringen, welche als Schmuck dienen sollen.

Die Australier an der Botany-Bai pflegten sich einen Knochen von Fingerdicke und 50 Centimeter Länge durch 
die Nase zu stecken. Die westlichen Stämme der Eskimos (jenseits des Mackenzie) bringen in jeder Wange ein Loch an, welches sie nach und nach vergrössern und in welchem sie als Schmuck einen Stein tragen nach Art eines grossen Ianschettenknopfes. Die Eingebornen des südlichen Theiles der Insel Formosa durchbohren sich die Ohren, um darin entweder mit Schnitzereien versehene Holzstücke oder polirte Muscheln von lebhaften Farben anzubringen. Die WuapInsulaner (Karolinen) durchbohren sich Nase und Ohren an zwei Stellen, oben und unten; in der Nasenscheidewand tragen sie wohlriechende Blumen und sonstige aromatische Pflanzentheile, in den Ohren grosse Ringe ron Schildkrot. I)ie Sitte, die Unterlippe zu durchlöchern und darin ein Stück Holz zu tragen, besteht in Südamerika (bei den Botokuden) wie in Zentralafrika. Man macht hiehei schon in der Kindheit eine kleine Oeffnung in die Lippe und erweitert dann diese Oeffnung nach und nach bis zur gewünschten Grösse.

Die Nyambanas in Zentralafrika erzeugen künstlich eine

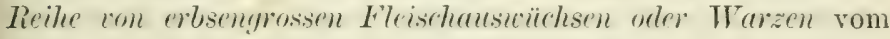
obern Theil der Stirne bis zur Nasenspitze.

Künstliche Missbildungen. Bei vielen Völkern herrscht die Sitte, dem Schïdt kïnstlich eine andere als seine natürliche Form zu geben; man presst den Schädel des Kindes in einer Weise, dass er die Form annimmt, welche bei jenen Völker'n als Typus der Schönheit gilt. Dieses Ideal gestaltet sich nach den einzelnen Völkerschaften sehr verschieden. Bald wird der Schädel zuckerhutförmig verlängert oder nach hinten gedrängt, bald wird er im Gegentheil abgeplattet oder in seiner Mittellinie nach unten gepresst, sodass rechts und links Höcker entstehen.

Sehr verbreitet ist die Vertüngermu! des Ohrüpushens, die mitunter so weit geht, dass die künstlich vergrösserten Lappen bis zu den Schultern reichen. Seltener ist das Flachdrürlien der Vuase, das meines Wissens nur bei den Wuap-Insulanern vorkommt, welche eine vorspringende Nase als eine Verunstaltung des Gesichtes betrachten und daher die Operation des Abplattens derselben an den ganz jungen Kindern monatelang vornehmen, bis der Zweck erreicht ist.

Deformationen der Zühm kommen in vielen Gegenden ror und in verschiedener Weise. Bei einigen Stämmen der 
Inseln Jara und Sumatra werden die Zähne bis zum Zahnfleisch abgefeilt. Anderorts bricht man sie ab oder formt sie auf verschiedene Art zu. Die Australier und Papuas reissen den Halberwachsenen die Schneide- oder Vorderzähne aus: bei den Dinkas am obern Nil werden nur die untern Schneidezähne, bei den Batokas am Zambesi im Gegentheil die obern entfernt. Gewisse Dayaken von Borneo sollen die Zähne durchbohren und in denselben kleine Metallstäbchen mit kugeligen Enden anbringen.

Die Finfernäycl werden bei einigen Stämmen scharf und spitz zugeschnitten. Die Siamesen, Ammamiten und Chinesen lassen dieselben wachsen und pflegen deren Entwicklung sorgfältig; die langen Nägel gelten bei ihnen als Schönheit und ein Zeichen rornehmen Wesens; man lässt daher die Nägel Dimensionen erreichen, wovon wir keine Idee haben und wonach die Hände aussehen, als trügen sie Ranken oder Pfropfenzieher.

Bekannt ist, dass die Chinesen der rornehmen Klassen die Frïsse künstlich verunstalten, indem sie einem Vorurtheil zu Liebe mit einer Sorgfalt, die buchstäblich als eine peinliche bezeichnet werden muss, deren Entwicklung hemmen und eine unbegreiflich raffinirte Verkrüppelung derselben betreiben.

Haar- und Barttracht. Eines der hauptsächlichsten Nittel für Schmuck und Putz des Nenschen besteht in der Haurtracht, und man findet demn auch bei einigen SüdseeInsulanem und Völkern des innern Afrikas die extravagantesten Formen dieses Kopfputzes, die jeder Beschreibung spotten und nur durch Zeichnung oder Photographie so dargestellt werden können, dass man eine richtige Vorstellung derselben erhält. Man braucht übrigens nicht weit zu gehen, um namentlich bei den Bäuerinnen verschiedene merkwürdige Moden zu treffen, wonach die Haare in Flechten und Locken getragen werden, zu denen Bänder und Maschen und andere Beigaben hinzukommen, derart, dass sich zuweilen auf dem Haupte ein ganzes Gerüst aufbaut. Es liegt aber ein bemerkenswerther Unterschied zwischen Natur- und Kulturvölkern darin, dass bei letzteren in der Regel nur die Frauen besondere Sorgfalt auf die Tracht des natürlichen Kopfschmuckes verwenden, während dies bei ersteren mit beiden Geschlechtern der Fall ist. 
Im Gegensatz zu dem Bestreben, ein mehr oder minder seltsames und umfangreiches Haargebäude zu errichten, steht die Sitte einiger Tölkerschaften, die Haare lim:z geschnitten oder das Hurut lichl resint zu tragen. Die Muselmanen und Chinesen, welche sich die Kopfhaare abrasiren, lassen dabei eine Partie als zentialen Zorpf stehen: ebenso behalten die Rothhäute einen Haurbusch bei. In Japan tragen die Kinder den Kopf rasirt, dabei aher cinige Zïpfir ron verschiedener Länge und Anordnung: die einen frei hängend, die andern zu einem Chimnon vereinigt. Die Kaffern lassen eine HuruJivone stehen, gewisse Insulaner an der Torresstrasse einen Querstreifen in Form einer Bürste.

Es ist nicht uninteressant, auch zu erfahren, welche IIittrl rerwendet werden einerseits zum Einreiben der Haare (Fette, Pommade, Cosmétiques), andererseits um sie in der gewünschten Anordnung zu erhalten: namentlich, was für Stoffe (Wolle, Haare, Werg etc.) zu roluminöser Gestaltung der Haartracht dienen müssen.

Der Reisende wird sich auch danach erkundigen, ob die Haartrachten, welche er bei fremden Völkern trifft, namentlich die exzentrischen derselben, überlieferte Sitte oder Gegrenstand der Iamme des Einzelnen oder der Mode sind, und im letzteren Fall, von wem der Impuls ausgeht, wer hierin den Ton angibt. Es kann die Art der Haartracht durch Befehl vorgeschrieben sein.

Aehnliches gilt in Bezug auf den Bartsrhmuck, das Tragen ron Voll-, Backen-, Kinn- und Schnurrbart einerseits, die Bartlosigkeit durch Rasiren etc. andererseits. In manchen Ländern lässt man den Barthaaren ihren natürlichen Wuchs in rollem Maasse; anderswo reisst man mit peinlicher Sorgfalt jedes Härchen aus oder rasirt das Gesicht kahl oder man lässt an gewissen bestimmten Punkten Haarbüschel stehen, deren Anordnung und Zuschnitt von Sitte, Laune oder Mode abhängt.

\section{NAHRUNG.}

Nahrungsmittel. Die Art der Nahrung ist kaum weniger charakteristisch als die der Kleidung. Einige Völkerschaften leben von wildwachsenden Wurzeln und Früchten, andere blos rom Ertrage der Jagd und des Fischfangs, dritte ron Milch 
und Fleisch ihrer Heerden oder von Getreide und Gartengewächsen; aber ausschlicsstich vegetabilische und ausschliesslich animale Kost ist doch selten; meist herrscht die eine vor und wird sie durch die andere ergänzt. Bei wilden und halbzivilisirten Völkern beobachtet man hierin allerdings keine grosse Abwechslung, sondern im Allgemeinen Einförmigkeit in Kost und Küche. So z. B. bildet Reis den Hauptbestandtheil jeder Mahlzeit in einem grossen Theil von Asien, Maniokmehl in Mittelamerika, die Banane in Tropenländern; Milchprodukte spielen dieselbe Rolle bei den Nomaden Innerasiens, Büffelfleisch und Mais bei den Indianern Nordamerika's. Eine weitgehende Verschiedenheit der Gerichte findet man fast ausschliesslich bei Kulturvölkern. Während ein Eskimo, um sich gütlich zu thun, einige Kilogramm Fett verschlingt und ein Wilder ein ganzes Schaf verzehrt, stellt der Chinese bei seinen Mahlzeiten eine grosse Menge verschiedener Gerichte in sehr kleinen Portionen auf.

Die Ernährungsweise hängt viel davon ab, welches Nahrungsmittel am leichtesten beschafft werden könne: es ist das mehr eine Frage der Mittel, des Geldes, als des Geschmackes. Sicherlich würden z. B. die armen Irländer lieber Fleisch als nur Kartoffeln geniessen, wenn nicht das Fleisch für sie ein unerreichbarer Luxusartikel wäre. Wenn in unsern Städten kaum Jemand zu finden ist, der sich nicht einige Abwechslung in den Speisen gönnen kann, so verdanken wir das den Verkehrserleichterungen und ausgedehnten Handelsbeziehungen, welche in jedem grösseren Orte Produkte aller Art konzentriren. In einiger Entfernung von den Städten wird die Nahrung schon einförmiger, weil die Beschaffung der selteneren Lebensmittel nicht mehr so leicht ist. Je unzivilisirter ein Land, desto mehr ist die Auswahl der Nahrungsmittel auf die Produkte der nächsten Umgebung beschränkt, und hierunter werden die Meisten auswählen, was für sie mit dem geringsten Aufwand an Mühe und Kosten verbunden ist. Der Reisende hat nun seine Aufmerksamkeit namentlich auf Ausnahmen von dieser Regel zu richten, d. h. zu beachten, ob sich ein Streben nach $A b$ vechslung in der Kost geltend macht, wenn auch diese Aufwand an Zeit, Mühe und Geld erfordert, oder ob es im Gegentheil verbotene Speisen gibt, deren Genuss man sich untersagt, 
obschon man sie zur Hand hat. In letzterer Hinsicht ist bekannt, dass Israeliten und Muhammedaner kein Schweinefleisch geniessen. Eine Völkerschaft im Thale von Kaschmir, die Dardi oder Chin, verabscheuen in gleicher Weise (als unrein) das Kuhfleisch, die Kuhmilch und die Butter von solcher, auch Geflügel. Ebenso ist bei den Hindus der Genuss von Kuhfleisch verpönt, aber aus einem andern Grunde, nämlich wegen der Verehrung, welche sie für dieses Thier haben.

Die Abneigneng gegen gewisse Fleischspeisen kann auch herrühren von der Furcht, sich mit Fleisch und Blut eines Thieres dessen Fehler anzueignen. Wohl aus diesem Grunde geniessen die Männer der Dayaken auf Borneo kein Damhirschfleisch: sie wollen nicht furchtsam werden; - den Frauen und Kindern ist dieses Gericht gestattet.

Der Widerwille gegen den Gemus gewisser Dinge, der Eliel vor solchen, hat nach Ländern und Völkern sehr verschiedene Grenzen; der Reisende achte darauf, was der Geschmack und der Magen eines Eingebornen vertragen kann. Ein Grönländer stillt seinen Hunger mit einem Stück rohen Specks von einem gestrandeten Wallfisch und geniesst Fette, die uns widerstehen würden. In Australien und Afrika leben Völker, welche - ohne Zweifel in Ermanglung von Besserem Kröten und Schlangen, auch Fledermäuse, Würmer und Raupen verspeisen. Auch in Amerika hat man beobachtet, dass Eingeborne Insekten und deren Larven verzehren.

Die Anthopophargie oder Menschenfresserei, die noch einigenorts vorkommt, kann wohl als Folge eines Fehltritts betrachtet werden. In Ermanglung anderer Nahrung, um sich vor dem Hungertod zu retten, tödtete und verspeiste der Mensch Seinesgleichen. War das unter solchen Umständen einmal geschehen, so wurde es später auch geübt gegen Feinde, Kriegsgefangene und selbst Stammesangehörige. Gewöhnlich aber ist diese abscheuliche Unsitte mit gewissen abergläubischen Vorstellungen verbunden (S.636). Als Ausnahme können Fälle des Genusses von Menschenfleisch in verzweifelten Situationen vorkommen, wie zur Zeit der grossen Hungersnoth in China, in den Jahren 1877 und 1878. (Vgl. auch O. Peschel, Völkerkunde, S. 166 ff.)

Eine grosse Verschiedenheit herrscht auch hinsichtlich der als Delikatessen besonders beliebten Gerichte. Die Völkerschaften 
Hinterindiens und des indischen Archipels scheinen eine eigenthümliche Vorliebe für faule Fische zu haben. Die Chinesen betrachten nicht nur ihre Schwalbennester, sondern auch gemästete Ratten als Leckerbissen. Ueber solche Besonderheiten in der Geschmacksrichtung eines Volkes kann sich der Reisende leicht informiren: er braucht nur die Märkte der Eingebornen und Lebensmittelverkäufer zu besuchen.

Gewisse Speisen sind bei einigen wilden Stämmen desswegen ungewöhnlich beliebt, weil man ihnen besondere Kräfte zuschreibt. Die Dakotah-Indianer glauben, dass der Genuss von Hundeleber klug mache; nach Ansicht der Javanesen wird man muthig, wenn man das Fleisch vom Tigerherz geniesst ${ }^{\mathbf{1}}$ ).

Endlich hat jedes Volk sein Nationalyevicht: der Italiener seine Polenta und Maccaroni, der Nordafrikaner sein Kuskussu etc.

Zubereitung der Speisen. Das Kochen der Speisen ist ziemlich allgemeiner Brauch; indessen gibt es Stämme, welche dieselben roh - einfach an der Sonne oder im Rauche getrocknet - geniessen. Die Tataren machen, wie behauptet wird, das Fleisch dadurch mürbe, dass sie es beim Reiten unter. den Sattel legen.

Die Art des Kochens ist verschieden. Zuweilen wird ein ganzes Thier am Spiesse gebraten, oder es wird, mit Blättern umhüllt, in ein als Backofen dienendes Loch gebracht, das man in die Erde gegraben und mit Brennstoffen versehen hat, die angezündet werden, bevor man das Thier in diese Grube bringt; oder es wird auch mit heissen Steinen umgeben, die man so lange durch neue ersetzt, bis das Fleisch gar geworden ist. Meist aber wird das Thier ausgeweidet und in Stücke zertheilt, die auf einen Rost oder in verschiedene Kochgefässe gebracht werden. Die Flüssigkeiten lässt man gewöhnlich in Gefässen über Feuer sieden; es gibt aber auch Fälle, wo das Sieden bewirkt wird durch in die Flüssigkeit gelegte heisse Steine. Nach dieser Sitte ist ein Indianerstamm im Norden der Prairien mit dem Namen der Steinkocher (Assinniboin) bezeichnet worden. In Irland

1) In der Ostschweiz kann man oft (halb scherz-, halb erusthaft) sagen bören, dass man durch Genuss der zähen Flechsen oder Selınen ( Schihohr $^{4}$ ) von Rindern singen lerne! 
wurden noch um's Jahr 1600 glühende Steine zum Erwärmen ron Milch benuzt, und Linné berichtet, dass sich im fimnischen ()stbotlande das Kochen mit Steinen als Rest einer grauen Vorzeit noch bis 1732 erhalten habe ${ }^{1}$ ).

Das Würzen der Speisen bietet noch mehr Verschiedenheiten dar als ihre sonstige Zubereitung. Die Papuas, Malayen und Hottentotten gebrauchen dazu nicht einmal Salz ${ }^{2}$ ); andere Völker verwenden neben dem Salz eine Menge von Gewürzen, um die Schmackhaftigkeit der Speisen zu erhöhen. Essig und Senf sind vielerorts unbekannt; Oel vertritt die Stelle unserer Butter, und bisweilen werden Honig und Zucker gebraucht, wo wir Salz und Pfeffer verwenden.

Das Feuer und dessen Unterhaltung. Wo das Kochen der Speisen gebräuchlich ist, zeigen sich Verschiedenheiten in der Art, wie das Feuer angelegt und unterhalten wird. Gewisse wilde Stämme verschaffen sich Feuer, indem sie zwei trockene Holzstücke krüftig an einander reiben, was in der Art geschehen kann, dass ein Stück fest angebracht und mit einer Höhlung oder einer Rinne versehen und nun in dieser das zugespitzte Ende eines harthölzemen Stabes schnell und unter kräftigem Druck hin- und herbewegt wird; man rersetzt auch wohl den Stab in drehende Bewegung, sei es direkt durch Drehen desselben zwischen den Händen, sei es mit Hülfe irgend einer mechanischen Vorrichtung wie einer liurbel. Oder man schlägt aus harten Steinen (Quarz, Feuerstein) Funken heraus, die leicht bremnbare Stoffe (dürre Blätter, Feuerschwamm) entzünden. Zum gleichen Zwecke hann man Gläser anwenden, welche die Sonnenstrahlen in einem Punkte konzentriren. Endlich bedient man sich verschiedener chemischer Feuerzeuge, Phosphorstreichhölzchen etc. Da die Beschaffung von Feuer, die uns so leicht gemacht ist, den Naturvölkern oft schwer fällt, treffen sie allerlei Vorkehrungen zum Interlult dr's Fruers, damit ihnen solches nicht ausgehe, was für sie von grosser Wichtigkeit ist. Beim Wechseln des Lagerplatzes werden wohlverwahrte Bränder mitgenommen.

Das Bremmaterial ist in den einzelnen Erdstrichen sehr verschieden. Meist werden Holz, Torf und Kohlen angewendet,

1) Vgl. Peschel, Völkerkunde 1874, S. 172.

2) Vgl. Peschel, a, a, O, S, 175 und oben S. 6\$4. 
aber in den Polargegenden müssen oft Wallfischseiten diesen Dienst leisten, in Steppen und Wüsten aber thierische Exkiemente. Wo verschiedene Arten von Brennmaterial vorhanden sind und sich Vorliebe für das eine oder Abncignmg gegen das andere zeigt, sind die Gründe dieses Verhaltens $\mathrm{zu}$ ermitteln. So sind gewisse Holzarten beliebt, weil ihre Verbrennungsprodukte dem Fleisch einen angenehmen Geschmack verschaffen; wo reichlich $\mathrm{Holz}$ vorhanden ist, pflegt man dieses dem Torfe und Mineralkohlen vorzuziehen. Die schon erwähnten Dardi oder Chin, welche die Kuh als ein unreines Thier betrachten, verschmähen es, getrockneten Kuhmist zu brennen, wie ihre Nachbarvölker thun, bei welchen der Kuhmist das wichtigste Brennmaterial ist.

Küchengeräthe. Das Koch- und sonstige Küchengeschirr ist mitunter, namentlich bei Naturvölkern, origineller Art. Als Gefässe dienen bald Muscheln, Schildkrötenschalen, Strausseneier, Fruchtschalen oder Kalebassen; bald ausgehöhlte und mit einem thönernen Rand rersehene Steine, mit Lehm überstrichene Weidenkörbe, sowie mehr oder minder grobe Töpferwaaren. Diese letzteren verdienen besondere Aufmerksamkeit wegen der Analogie mit den irdenen Geschirren der Höhlenund Pfahlbaubewohner Europa's aus der sogenannten vorgeschichtlichen Zeit. Es ist namentlich zu beachten, ob sie blos von Hand oder mit Hülfe der Töpferscheibe erstellt, blos an der Sonne getrocknet oder dem Ofenfeuer ausgesetzt (gebrannt) werden; ob die Masse derselben fein oder grob, rein (d. h. frei ron fremden Elementen) oder mit Steinchen, kleinzerschnittenem Stroh oder den holzigen Abfällen von Hanf und Flachs („Ageln") vermischt ist etc.; ob die Gefässe ganz schmucklos sind oder aber Verzierungen haben, wie Eindrücke von Muscheln, von Fingernägeln, Schnüren oder von einer Art Grabstichel; ob diese Verzierungen nur linear (wellenförmig, spiralig etc.) angeordnet sind oder in Zeichnung und Relief Menschen- und Thierfiguren darstellen sollen, endlich ob diese Töpferwaaren ihre natürliche Farbe haben oder aber bemalt, gefirnisst und glasirt sind.

Die Utensilien zur Aufbeuahung der Vorräthe sind sehr manigfaltig. Als solche dienen Gefässe aus Rinde, Blasen, Kalebassen und selbst Schädel; Holzgeschirre, Weidenund Binsenkörbe, Krüge, Amphoren, Schläuche etc. Wo 
reichlich $\mathrm{Holz}$ vorhanden ist, findet man kleinere und grössere Tröge, Kisten, Fässer, Kufen etc. in jeder Form.

Mahlzeiten. Der Reisende wird darauf achten, ob bei dem Volke, das er besucht, wie bei uns regelmïssige Mulllzeiten gebräuchlich sind, $d$. h. ob man übungsgemäss zu bestimmten Zeitpunkten speist oder aber, ob hierin keine Regel herrscht, vielmehr Jeder zu beliehiger Zeit isst, wenn er hiezu Lust und Gelegenheit hat.

Sind regelmässige tägliche Mahlzeiten im Gebrauch, so variiren dieselben nach Anzahl und l'rthrilumy, wie nach Bedentun! und Komprosition derselben. Mitunter gibt es nur Eine tägliche Mahlzeit, die auf die Mittacrszeit oder auf den Abend fällt. Bei den wilden Stämmen, deren Nahrung rom Erfolge der Jagd oder des Fischfangs abhängt und nicht durch grössere Vorräthe für eine längere Zeit gesichert ist, werhseln Tage des Leberflusses mit solchen des Mangels, und es ist merkwürdig genug zu beobachten wie diese Naturmenschen sich im einen und andern Falle benehmen.

Es verdient bemerkt zu werden, mit welchem Minimum an Sahrung die Angehörigen verschiedener Völkerschaften sich für gewöhnlich genügen lassen, und wie gross' Quantitriten sie aber andererseits verzehren können. Der Araber begnügt sich täglich mit einigen Datteh, der Kabyle mit seinem Brodkuchen, während der Eskimo in derselben Zeit einige Kilogramm Fleisch verschlingt und der Siamese seinen Magen mit einer erstaunlich grossen Masse ron Reis beladet.

Der Reisende hat ferner mitzutheilen, wir des Lissen yenommen wird, wie man dasselbe servirt, welche Formalitäten und Zeremonien dabei vorkommen. Oft nimmt man das Mahl stehend und nicht immer zu Hause, sondern wo man sich grerade befindet. In anderen Fällen werden wenigstens die Hauptmahlzeiten nicht ausserhalb der Wohnung genommen oder doch nur dann, wenn die Familie mit Feldarbeiten in ziemlich grosser Entfernung rom Hause beschäftigt ist. Wieder anderwärts speist man im Freien in der Nïhe des Hauses oder an einer Stelle, die für diesen Zweck mehr oder minder gut eingerichtet ist.

Die Körperhaltung während des Essens ist sehr verschieden; es gribt Völker, bei denen es gebräuchlich ist, hiebei auf die Fersen niederzukauern oder mit gekreuzten 
Beinen auf dem Boden zu sitzen; bei andern legt man sich auf die Seite nieder, den Kopf auf den einen Arm („auf den Ellbogen" ) stützend; bei uns endlich und bei den Völkern, welche unsere Sitten angenommen haben, setzt man sich um einen Tisch, dessen Platte sich in einiger Höhe über dem Boden befindet. Tischtuch, Servietten, Löffel und Gabeln sind in vielen Ländern unbekannt; statt letzterer beiden bedient man sich kleiner Stäbchen oder der Finger; einige wilde Stämme gebrauchen indess auch Muscheln als Löffel. Die Speisen werden bald alle miteinander aufgetragen, bald successive, in bestimmter Reihenfolge der einzelnen Gerichte, entweder je in besondern Gefässen (Schüsseln, Platten, Tellern etc.) oder in einem einzigen, aus dem Jeder der Reihe nach seinen Theil nimmt. Bei vielen Völkern speist zuerst das Familienhaupt; dann kommen die Frauen und Kinder an die Reihe, zuletzt die Diener und Slilaven. Zuweilen werden die Frauen vom Tisch ausgeschlossen, wenn Fremde da sind; auch liommt es vor, dass auch der Familienchef bei Ánwesenheit von Gästen sich nicht zu Tische setzt und die Speisen nicht berührt, bis die Gäste ihr Mahl beendigt haben, an welchem er nur auf deren dringende Einladung theilnimmt. In manchen Ländern gehört es zum guten Ton, sich sehr reichlich zu bedienen und sodanm durch ein gewisses Geräusch im Schlunde, das bei uns für höchst unpassend gelten würde, zu bezeugen, dass man in vollem Maasse gesättigt sei, worauf der Wirth sich dankend verneigt. - Mancherorts werden vor und nach dem Essen Gebete oder sakramentale Formeln gesprochen; diese achtungswerthe Sitte herrscht namentlich noch in Amerika, England und bei den wohlhabenden Schweizerbauern; auch jeder gute JIuselman pflegt vor und nach dem Essen zu beten.

Getränke und Erregungsmittel. Abgesehen rom Wasser, welches eigentlich genügen würde, den Durst zu stillen, findet man fast überall gewisse rurkerrschende Getrïule: Hilch bei den Hirtenvölkern, Oel bei den Eskimos; Most (von Aepfeln und Birnen), Bier und Thee in nördlichen Gegenden, Wein und Kaffee in südlicheren Ländern. In vielen Gegenden bereitet man geyoluene Getrinlie aus Nilch, gewissen Pflanzensäften, Wurzeln oder Körnern wie 
Reis, Mais, Gerste etc. Die Mongolen haben ihren Kumys (gegohrne Milch), die Südamerikaner ihre aus Manioc hergestellte Chicha, die Mexikaner ihre Pulque aus dem Safte der Agave; die Chinesen bereiten Wein aus Reis und die Polynesier ihre Kava durch Gährung einer bestimmten Pflanze. Eine Menge verschiedenartiger Getränke stehen in den amerikanischen Cafés oder Bar's dem Konsumenten zu Gebote: Brandy, Whisky, Gin, Sherry, Rhum und mehrfache Mischungen, bekannt unter den Namen Grog, Julep, Cocktail, Sangrie, Cobler, Punch etc. etc.

Der Reisende wird erwähnen, welches das gewöhnliche oder Vutimalyrtriank eines von ihm besuchten Volkes ist, woraus und wie es bereitet wird; ob es blos zur Lüschung des Durstes oder als Erregungsmittel dienen soll und in diesem Falle mässig oder in excessiver Weise genossen wird. Wenn Enthaltsomlirit iom grewiswen Gretrankien zu beobachten ist, so erkundige man sich nach den Gründen derselben, welche religiöse sein können - wie bei den Mohammedanern in Betreff des Weines - oder moralische, wie bei denjenigen, welche aus freien Stücken auf den Genuss starker geistiger Getränke verzichten.

Auch ist zu bemerken, ob das Volk im Allgemeinen sich durch Mässigkeit auszeichnet oder aber dem Trunke fröhnt, in welchen Klassen das der Fall ist und welches die Folgen dieser Exzesse sind.

$\mathrm{Zu}$ den stimulirenden, exzitirenden oder Erremumgsmittem sind auch die Betc-Blütter zu rechnen, welche die Malayen kauen; ferner diejenigen der crocu. welche ron den südamerikanischen Indianern in gleicher Weise gebraucht werden: sodann die verschiedenen Sorten Tuluk, welchen man in allen Erdtheilen verwendet findet; endlich Opium und Has hisch. Die Art ihres Gebrauches und Missbrauches, sowie dessen Wirkungen verdienen zum Gegenstand einiger Mittheilungen gemacht zu werden.

Preise der Lebensmittel. Es ist sehr zu wünschen, dass der Reisende Angaben beibringe über die l'reise der hauptsächlichsten Nahrungsmittel in einem Lande; denn darnach lassen sich in komparativer Weise die Existenzberlingungen der verschiedenen Länder beurtheilen. Lm diese Vergleichungen zu erleichtern, rerwandle man die im 
Lande üblichen Angaben (Quantitäten und Preise) in metrische. Wenn nur Tauschhandel betrieben wird, so ist mitzutheilen, welches Quantum (Maass oder Gewicht) der einen Waare für ein bestimmtes Quantum der andern gegeben werden muss.

\section{WOHNUNGEN.}

Das Bedürfniss nach Obdach ist, wie das nach Speise und Trank, Menschen und Thieren gemeinsam; es gibt kein Tolk, welches dieses Bedürfniss nicht empfände; aber in dessen Befriedigung zeigen sich grosse Verschiedenheiten.

Haupttypen. Der Mensch, welcher ausschliesslich rom Ertrage der Jagd lebt, begnügt sich mit einem natürlichen Obcluch, wie es ihm überhängende Felsen und Höhlen, sowie dichte Baumkronen und Wälder gewähren. Bewohnt er weite Ebenen, so legt. er sich unter freiem Himmel auf den Boden, indem er sich mit einer Thierhaut umhüllt oder mit Sand bedeckt, um sich gegen die nächtliche Kälte zu schützen. Der Fischer seinerseits sucht einen Zufluchtsort am Lfer; in Ermanglung eines solchen stürzt er seinen Kahn um und legt sich unter denselben. Gewisse umherschweifende Horden kennen kein anderes Schutzmittel als Tafeln von Baumrinde, woraus sie eine Schirmwand gegen die jeweilige Wetterseite errichten oder aber eine Art Dach, unter welches sie kriechen. Statt Rindenstücken werden auch grosse Blätter verwendet, die flach auf in den Boden gerammte Pfähle gelegt werden. Das sind aber nur temporäre und passagere Zufuchtsstätten, mit denen sich der Mensch nur auf den untersten Stufen und auch nur in der Jahreszeit begnügt, wo die Sorge um Nahrung ihn zwingt, von Ort zu Ort zu schweifen.

Ein solches Obdach kann den Menschen nicht mehr befriedigen, sobald er sich einigermassen über den thierischen Zustand erhebt. Sowie er nicht mehr vereinzelt, sondern familienweise lebt, einige Vorräthe, Jagd- und Fischereigeräthe besitzt, so bedarf er nothwendig eines besseren $\mathrm{Ob}$ daches, eines Ortes, wo er Alles aufbewahren kann, was er auf seinen Ausflügen nicht mit sich nimmt. Die Raubthiere nachahmend, sucht er zunächst die Höhlen auf oder gräbt er sich selbst solche. Wohnungen dieser Art sind noch 
sehr häufig; die Menschen, welche solche zu benutzen pflegen, werden als Höhlenbewohner oder (nach dem griechischen "Troglos", Loch, und dem alten Namen einer afrikanischen Völkerschaft), Troglodyten" bezeichnet.

Lnterirdische Wrommugrn zu bauen ist noch üblich in Nordchina, wo Millionen Menschen in Höhlen leben, welche in den Löss gegraben wurden, der in den tief eingeschnittenen Flussthälern ungeheure senkrechte Wände bildet. Ferner scheint dieser Brauch geherrscht zu hahen bei den , cliffbuilders" oder. Ureinwohnern ron Colorado und Ost-Ltah in Nordamerika, wie aus den zahlreichen (zum Theil natürlichen, zum Theil aber künstlichen) Höhlen zu schliessen ist, welche man in den Steilwänden der Thalschlünde (cañons) daselhst findet. Yölkerschaften in Gegenden, die ein kontinentales Klima nit exzessiven Temperaturextremen haben, legen sich unterirdische Wohnungen an, um sich darin wie dies in unsern Kellern der Fall ist - eine gleichmässigere, von der Luft im Freien nicht zu sehr beeinflusste Temperatur zu verschaffen.

Nomaden, die häufig ihre Aufenthaltsorte wechseln müssen, sind genöthigt, sich transportable Wohnungen anzulegen. Gemeiniglich sind dies Zelte. Das Zelt ist rorab die Wohnung der Hirtenvölker, welche ein Obdach mit sich führen müssen, weil sie zu öfterem Wechsel ihrer Wohnsitze genöthigt sind, um neue Weideplätze zu gewinnen, und weil sie zumeist in weiten Ebenen leben, die keine Höhlen und nur selten gutes Naterial zum Bau von Hütten darbieten. Die Zelte variiren nach Form, Stoff und innerer Einrichtung; bald sind sie kreisrund, bald länglich; als Stoff dienen Rinden, Thierhäute, Leder, Filz und Gewebe ${ }^{1}$ ). Die Einrichtung ist im Allgemeinen höchst einfach; zumeist findet sich eine Art Vorhang oder deren mehrere, um das Innere in zwrei oder mehr Gemächer einzutheilen. Für den Transport wird das Zelt entweder auf einem Wagen angebracht, wie die Kibitka der Kosaken, bald auf einem Lastthier, wie bei den Kalmüken.

In den Gegenden, wo sich keine natürlichen Zufluchtsstätten finden, bauen die sesshaften Bewohner und Halb-

1) Rindenzelt der Ostjaken, Lederzelt der Lappen, Yurten der Tartaren, Wigwams der Rothhäute etc. Vgl. Peschel, Völkerkunde, Leipzig 1874, S. 185. 
nomaden Hïttcn, wie solche mit den Materialien, welche gerade zur Hand sind, erstellt werden liönnen. Die Hütte in ihrer einfarchsten Form unterscheidet sich rom Zelt wesentlich nur durch etwas grössere Stabilität. Sie kann blos aus verschlungenen Zweigen gebildet sein, wie die Gurbi der Araber und Kabylen, und wenn das Klima es erlaubt, bleibt sie an den Seiten offen, besteht also nur aus einem ron Stangen (z. B. Bambus) getragenen Dache, wie die Ajupa der Tropenbewohner. Bei den fest angesiedelten Völkern werden solidere Hütten hergerichtet, sei es, dass man dieselben aus einem Flecht- oder Etterwerk mit Lehm erstellt, sei es, dass man für den untern Theil gestampfte Erde (Pisé), ungebrannte und nur an der Sonne getrocknete Ziegrelsteine (Adoben, Luftziegel), unregelmässige oder roh zubehauene Steine ohne Mörtel (Trockenmauern) oder mit Mörtel verwendet oder aber (wie bei den Block- und Sennhütten) Balken, deren Enden durch Pfähle, Kerben etc. anund ineinander befestigt sind; für das Dach werden verschiedene Materialien verwendet, wie sie sich in den einzelnen Gegenden als zu solchem Zweck geeignet darbieten: Blätter, Schilf und Stroh, Schindehn, Bretter, Schiefer etc.; zur Befestigung derselben dienen Ligamente aus Pflanzenfasern, Nägel und Pflöcke, Stangen und flache Steine. Zuweilen werden aher die Hütten ganz aus demjenigen Material erstellt, welches gerade am Berguemsten zur Hand ist, so die Tonliütten Mittelafrika's, die aus Nilschlamm errichteten Wohnungen der egyptischen Fellahs, diejenigen der irländischen Bauern, die aus Erdschollen, und diejenigen der schottischen Hochländer, welche aus Steinen ohne Mörtel erstellt sind, die Rindenhütten gewisser Indianer, die Schneehütten der Eskimos. Als Grundriss der Hütten findet man sowohl den Kreis, als auch Quadrat und längliches Rechteck. - Wenn die einfachsten dieser verschiedenen Formen (huttes der Franzosen) den Zelten nahe stehen, so unterscheiden sich die höheren Formen (cabanes) hievon durch Oeffnungen für Luft und Licht (Fenster), wie durch grössern Umfang und Eintheilung des Innern in verschiedene Räumlichkeiten (Verschläge, Zellen) durch feste Scheidewände. Die Rindenhütten der Indianer im Osten der heutigen Union sind je für etliche Familien eingerichtet, und anderwärts wohnen oft ganze 
Horden in einem einzigen, gewissermassen klosterähnlichen (aus aneinandergereihten Zellen hestehenden) Bau dieser Art. (Vgl. Peschel, a. a. O., S. 186.)

In der Regel sind die Hütten unmittelbar vom Boden aus auferbaut; zuweilen aber haben sie aufeinandergeschichtete Steine zur Enterlage (wie manche Semnhütten der Alpen und des Himalaya), sodass die eigentlichen Hütten in etwas erhöhter Lage üher dem Boden angehracht sind, oder sie ruhen auf Ifählen, was in feuchten und sumpfigen Gegenden der Fall ist. In Veuguinea findet man solche P'fahlhauten nicht nur an der Kü̈ste. wo diese Konstruktion durch die Bodenbeschaffenheit reranlasst ist, sondern auch im Innern. auf trockenem, festem Baugrunde (vgl. $\$$. 615) Hütten auf Bäumen (Rhizophoren etc.) scheinen ziemlich selten zu sein. aber solche auf Flössen sind in ('hina häufig, weil dasellsst für die dichte Bevöllerung Mangel an Boden und vorah an Bauplätzen herrscht. In .: fermen Westen "Amerika's entlich findet man Hütten oder Blockhäuser, die auf Rollen orler Rädern transportirt werden kümnen und nach Massgabe des Vordringens der Kultur dislozirt werden. Hat ein Volk sich bleibend angesiedelt: ist ihm dieses sesshafte Leben an refinitiv gewählten oder ererhten festen Wohnsitzen als Sitte in Fleisch und Blut ühergegangen: ist es geistig verwachsen mit dem Fleck Erde, den es bewohnt als das Land seiner Wahl oder das Erbe seiner Täter, und gelangt es hiehei zu einem gewissen Wohlstand: so treten Hürss an die Stellen der Hütten. Diese beiden Arten ron Wohnungen können in der Form des Grundrisses und im Material übereinstimmen; ihr wesentlichster Lnterschied besteht aber darin, dass beim Haus Stockwerke rorhanden sind, d. h. zwei oder mehr Stufen von Gemächern übereinander sich befinden. Selbstrerständlich nehmen wir daron Lmgang, an dieser Stelle die verschiedenen Formen zu besprechen, in welchen sich uns das Haus darbietet ron seiner einfachsten Gestalt bis zu den grossen Wohnungen unserer Städte, die kasernengleich eine Mehrzahl von Familien beherbergen.

Koexistenz der Typen. Die verschiedenen Wohnungstypen, welche wir soeben besprochen hahen, schliessen einander nicht unbedingt aus, vielmehr kann man solche in derselben Gegend, sogar am gleichen Orte, nebeneinander 
treffen. So hat Egypten moderne Paläste und daneben die elenden Hütten der Fellahs. Von Paris bis Sologne kann man die rerschiedenartigsten Wohnungen sehen, ron den elegantesten Gebäuden bis zur Hütte und Höhle. London hat Paläste, Häuser und Hütten, sodann seine Diebsnester und Kirypten, welche allem schlechten Gesindel als Stelldichein und Versteck dienen. Bei den Naturvölkern sind die Wohnungen freilich gleichförmiger; immerhin werden sich fast immer Verschiedenheiten zwischen den Wohnungen der Häuptlinge einerseits und denjenigen der übrigen Stammesangehörigen andererseits finden, wie bei uns ein fühlbarer Interschied zwischen dem Herrenhaus und der Pächterwohnung hesteht. Eine gewisse Bauart ist zuweilen ein Vorrecht des Herrschers. Im Königreich Annam z. B. hat nur der Monarch das Recht, eigentliche (zwei Stockwerke enthaltende) Häuser zu bauen und nur für das Gebälk der königlichen Gebäude darf Eichenholz verwendet werden.

Die Koexistenz zweier Typen kann ihren Grund auch in einem ron den Jahreszeiten abhängigen und durch sie bedingten Wohnungswechsel haben. Gewisse Völkerschaften begnügen sich im Sommer mit Laubhütten und ziehen sich auf den Winter in Höhlen zurück. Die Lappen bringen die günstige Jahreszeit in Hütten oder Zelten zu, welche sich auf Pfählen befinden; bei grosser Kälte benutzen sie aber unterirdische Wohnungen.

Endlich können Liebhabereien, Gewohnheit und Mode dazu reranlassen, zwischen Wohnungen rerschiedener Art zu wechseln. So haben in Algier die Häuptlinge der Eingebornen oft noch ein Zelt oder ein Gurbi neben dem Hause, welches die französische Regierung ihnen bauen liess, wie mancher reiche Engländer, der einen Palast besitzt, noch ein einfaches Haus oder eine Hütte erstellen lässt, um darin einige Monate zuzubringen.

Beschreibung. Der Reisende hat die hauptsächlichsten Wohmunstypen der von ihm besuchten Gegend zu erwähnen und darzustellen. Die Bauart oder Architektur derselben ergibt sich aus einer Zeichnung oder Photographie; hinsichtlich der verwendeten Baumaterialien sind die nöthigen Angaben im Texte zu machen. Die äussere Verzierung wird wenigstens zum Theil aus der Zeichnung ersichtlich sein; 
soweit dies nicht oder nur ungenügend stattfindet, sollen darüber einige Worte in die Beschreibung aufgenommen werden, z. B. über einen Farbanstrich in Rosa, Hellgrün oder zartem Blau; über Spiralornamente, Wellenlinien und Thierfiguren an den äusseren Wand- und Mauerfächen, sowie über daselbst angebrachte Trophäen (Thierfelle, Geweihe, Feindesschädel etc.). Die immer Eintheilum! ist durch einen Grundriss und nöthigenfalls durch Längs- und Querschnitte darzustellen. Dabei soll die Bestimmung einer jeden Räumlichkeit angegreben werden, wenn deren mehrere sind; beizufügen ist ferner, ob die blosse (gestampfte) Erde als Boden dient, oder ob dieselbe mit Backsteinen belegt ist oder endlich ein besonderer mehr oder minder weit über der Erde angemachter Fussboden rorkommt, und wie dieser beschaffen ist. Details, wie die Lage des Herdes, Stellung der Thüren und Fenster und die Art des Verschlusses und Stoffes derselben, namentlich bei letzteren (Gitter, Läden, auf Rahmen gespannte Gewebe, geöltes Papier, Fischmembranen, Blätter oder Tafeln von durchsichtigem Glimmer, Glas etc.) sind theils in Zeichnungen, theils durch Beschreibung darzustellen.

Besondere Aufmerksamkeit rerdient die ILiblimun; es soll von derselben ein Bild gegeben werden durch eine Gesammtansicht des Innern der Wohnung; daneben sollen gewisse Möbel und Accessorien von originellem Charakter noch separat abgebildet oder beschrieben werden. Auch sind Mittheilungen zu machen über die Art der Heizun! (Kohlenbecken, brasero, in Südamerika; monumentale Oefen im nördlichen Europa etc.) und der Brfourhtun! (gefangene Leuchtkäfer bei den Negern in Brasilien, Kerzen, Lampen mit Dochten etc.).

Der Vollständigkeit wegren sollen in der Beschreibung auch Angaben gemacht werden über die Zumünge zu. Wrshum!! und die nächste $L^{*} m g$ dum derselben: ob diese ein Hof oder Garten ist, ob Zäune und Mauern angebracht sind, die zum Schutz gegen Feinde und Raubthiere dienen sollen etc.

Endlich dürfen die Nelrugebüude nicht unerwähnt bleiben, welche mehr oder minder wesentlich zur Wohnung gehören, wenn sie auch von derselben getrennt sind.

Besondere Wohnungen. In der Regel wird eine Wohnung von einer Person und den sämmtlichen Gliedern ihrer 
Familie (in engerem oder weiterem Sinne dieses Wortes) benutzt; es gibt dann also so viele besondere Wohnungen, als ein Volk oder Stamm Familien zählt. Diese Regel hat aber zahlreiche Ausnahmen. Diener und Sklaven wohnen nicht immer mit ihren Herren zusammen unter einem Dache, und in den Ländern mit Polygamie hat mitunter jede Frau ihre eigene Wohnung.

Gemeinsame Wohnungen. Im Gegensatz zu den vorhin erwähnten Ausnahmen kommt es auch vor, dass mehrere Familien zusammen eine und dieselbe Wohnung benutzen. Dies findet oft statt in Höhlen; ferner ist in vielen Gegenden z. B. in Neuguinea, auf Borneo, sowie bei den Ostjaken eine Hütte, die einer ungeheuren Scheune gleicht, von einer grossen Zahl Personen bewohnt. Die Minatarees und Mandanen in Nordamerika haben polygonale Bauten, welche mehrere Haushaltungen beherbergen, und in den langen Hütten der Indianer am Columbiafluss halten sich jeweilen hunderte von Personen zusammen auf.

Bienenstockartige Wohnungen. In einer dritten Art von Wohnungen befinden sich ebenfalls sehr viele Leute unter einem Dache, aber in mehr oder weniger getrennten Gruppen und Haushaltungen auf mehrere Stockwerke vertheilt. So gibt es in Neumexiko Riesenbauten aus 5 bis 6 terrassenförmig angeordneten Stockwerken, die zusammen 300 bis 400 Personen beherbergen. In Nordchina sind ähnliche, aus 4 bis 5 Etagen bestehende Wohnungen in den Löss gegraben. Die grossen Häuser in unsern Städten sind unter dem Gesichtspunkt, der hier in Betracht kommt, den eben besprochenen Wohnungen nicht so ganz unähnlich; nur ist dabei jede Gruppe von Gemächern, welche einer besonderen Haushaltung angehört, von den andern besser abgegrenzt.

Zerstreute Wohnhäuser. In dünn bevölkerten Gegenden und namentlich bei wilden Stämmen findet man die Wohnhäuser, Hütten und Zelte vereinzelt über das Land zerstreut. Der Grund hiefür kann darin liegen, dass mehrere Familien in einer Gegend schwerer ihren Unterhalt fänden, wenn sie unmittelbar nebeneinander wohnen würden; oder dass die Bevölkerung aus Grossgrundbesitzern besteht, von denen jeder auf seinem arrondirten Gute (Hof) leben will. In jedem Fall verdient die Thatsache notirt und erklärt zu werden. 
Gebäudegruppen oder Agglomerationen. Meist sind eine Anzahl von Zelten, Hütten oder Häusern zu kleineren oder grösseren Komplexen - Duars oder Zeltkreisen, Weilern, Dörfern, Flecken und Städten - gruppirt. Diese Agglomerationen enthalten gewöhnlich verschiedene Wohnungstypen; wie um das Herrenschloss sich am Fusse des Burghügels die Bauernhäuser lagern, so um des Häuptlings Wohnung die Hütten und Zelte der Angehörigen seines Stammes. Aber auch das Gegentheil kommt vor: dass solche Gruppen oder Komplexe aus Wohnungen eines und desselben Typus bestehen, sei es dass diese Uehereinstimmung auf Gleichheit der Beschäftigung und des Vermögens beruht, sei es dass Sklaven, Leibeigene und Lehensleute als Wohnsitze besondere Lokalitäten angewiesen erhalten, deren elende Hütten einen scharfen Kontrast bilden zu den von der wohlhabenden Klasse bewohnten Ortschaften. Wenn auch Agrlomerationen jener Art blos aus Hütten bestehen, werden sie doch öfter durch eine starke Umzäunung gegen einen Handstreich gesichert. $\mathrm{Zu}$ gleichem Zwecke werden die bedeutenderen Häuserkomplexe mit Mauern und Wällen umgreben und so in geschlossene Städte verwandelt.

Lage der Ortschaften. Der Reisende achte auf die Eigenthümlichkeiten der yergraplischen Lage von Dörfern und Städten, und die Vortheile, welche aus derselben für eine Ortschaft entspringen; er wird dabei oft die Grïnde ermitteln können, welche bei der Wahl eines Platzes zur Anlage eines Häuserkomplexes, wie für die Entwicklung desselben bestimmend einwirkten.

Dass die Dörfer und Städte sich bald auf Anhöhen, bald in Elbenen befinden, ist nicht blosser Zufall. Wenn in einer Gegend die ersten Gebäudegruppen an bestimmten Punkten angelegt wurden, zum Theil an solchen, wo wir jetzt noch die namhaftesten Agglomerationen finden, und nicht an andern Stellen, wo solche nie vorkamen, so gab es dafür Gründe; diese Gründe können im Laufe der Zeit dahingefallen sein; aher sie waren massgebend bei Auswahl der Punkte für die ersten Niederlassungen, und die Erforschung derselben kann ein helles Licht auf eine ferne Vergangenheit werfen.

Wenn wir Dörfer und Städte auf schwer zugänglichen Höhen finden, so erblicken wir hierin einen Beweis dafür, 
dass zur Zeit ihrer Anlage sich ein Mangel an Sicherheit geltend machte, dass auf Schutz gegen Feinde Bedacht zu nehmen war. So ist es bei den Kabylendörfern, die wie Adlerhorste auf steilen Felsen angelegt sind; ferner mit Dörfern in Südafrika wie Humbi, Kalamba u. A., die uns der berühmte Reisende Cameron beschrieben hat; so verhielt es sich ferner mit den ältesten Städten in Spanien, Italien, Griechenland und Kleinasien, wie mit alten Städten und Schlössern unserer Gegenden.

Wahrscheinlich aus ähnlichen Gründen legen gewisse wilde Stämme ihre Dörfer mitten in grossen Wäldern an, wo dieselben den Blicken der Feinde rerborgen bleiben.

In Ländern, wo heutzutage diese Gefahren als verschwunden grelten, bestehen die Ortschaften, welche in der besprochenen Weise angelegt wurden, num in der Regel aus zwei sehr ungleichen Theilen: dem alten auf der Höhe, der mehr und mehr verlassen wird, und dem neuen am Fusse des Hügels oder Felsens, wohin sich der Verkehr und das Leben der Ortschaft konzentrirt.

In Gegenden, wo vollständige Sicherheit herrscht, werden die Stellen für Niederlassungen nach andern Gesichtspunkten ausgewählt. Ackerbauer werden in fruchtbarem Lande oder loch in nächster Nähe desselben ihren Wohnsitz nehmen, Fischer am Meeresstrande oder an Flüssen und Strömen. Sodann ist namentlich eine für den Verkehr und Handel grïnstige Lage von grosser Wichtigkeit; unter ihrem Einfluss können aus Gruppen von Hütten bedeutende Städte sich entwickeln.

Zu den Ursachen, welche die Wahl und den Entwicklungsgang einer Niederlassung bestimmen, gehört auch die Nähe von Stätten, die für heilig gehalten werden. Es kann dieser Umstand ein geographisches oder ein historisches Motiv sein.

Hinsichtlich all' dieser Beziehungen verweisen wir auf das anregende Werk von $J$. G. Kohl: „Die geographische Lage der Hauptstädte Europa's" (Leipzig 1874).

Ansichten und Pläne. Das Bild einer jeden Stadt und eines jeden Dorfes hat etwas Eigenthümliches an sich; dieses Charakteristische ist zum Ausdruck zu bringen in einer Ansicht, die man von einem Punkte aus aufnimmt, wo man die Ortschaft deutlich sieht und ihr doch nicht zu 
nahe ist. Wie wir schon (S. 219) bemerkten, sollen diese Ansichten vorzugsweise von der Seite aufgenommen werden, von welcher her man sich gewöhnlich der Ortschaft nähert, was nicht ausschliesst, dass man Ansichten beifügt von Standpunkten aus, wo die Stadt oder das Dorf sich vortheilhafter darstellen.

Die Dörfer haben in ihrem Plan, d. h. in der Anordnung oder Vertheilung der Gebäude, wenig Formenreichthum; man wird daher bei diesem Gegenstande nur verweilen, wemn es sich wirklich um eine charakteristische Eigenthümlichkeit handelt. Gewöhnlich sind die Wohnungen ziemlich regelmässig zu beiden Seiten einer langen Strasse angeordnet oder aber unregelmässig zerstreut um einen Platz, auf dem sich ein öffentliches Gebäude (Kirche, Noschee etc.) befindet. Gewisse Dörfer zeichnen sich aus durch ein Gebäude, das geräumiger ist als die andern und als Versammlungslokal, Rathhaus und Herberge für Gäste dient, so das Pangah bei den Dayaks auf Borneo, die Marna auf Neu-Guinea und den pacifischen Inseln, das Bai-Bai auf den Karolinen und die Djemâa der Kabylendörfer.

Die Anordnung der Gassen und Quartiere in den Städten ist im Allgemeinen sehr verschieden und manigfaltig. Fast nur die Städte der Vereinigten Staaten und des spanischen Amerika's sind nach dem gleichen einförmigen Plan gebant, wonach sie in der Vogelperspektive einem ungeheuren Schachbrett gleichen; so in Chicago, St.-Louis etc., ferner die peruanische und die chilenische Hauptstadt, Lima und Santiago, mit ihren rechtwinkligen Häuserinseln oder Quadras. In Europa und den übrigen Erdtheilen ausser Amerika trifft man diesen monotonen Charakter selten und nur in verhältnissmässig neuen Städten oder Quartieren. Die alten Städte aber, namentlich die orientalischen, haben oft ein wahres Labyrinth von Strassen, Plätzen und engen Gassen. Hierüber wird eine Planzeichnung mehr sagen als eine lange $\mathrm{Be}-$ schreibung.

Baustyl. Gewisse Städte erhalten durch Styl und Naterial ihrer Häuser ein eigenthümliches Gepräge. Eine arabische Stadt mit ihren terrassenförmigen Dächern, fensterlosen YIauern und engen Gässchen, die durch vorspringende Stockwerke oben fast geschlossen sind, ist grundverschieden 
von einer europäischen Stadt; Paris, dessen Häuser aus Bruch- und Sandsteinen erstellt sind, hat einen wesentlich andern Charakter als das aus Ziegelsteinen erbaute London. Der Baustyl ist bald massiv und schwer, bald leicht und gefällig; hier athmen mit Erkern, Spitzbogenfenstern und monumentalen Thüren versehene Bauten den Geist des Mittelalters; dort verrathen schmucklose Gebäude mit monotonen Linien den allzu nüchternen Charakter unserer Zeit.

Solche Eindrücke lassen sich freilich leichter empfinden als wiedergeben; das beste Mittel, sie Andern mitzutheilen, sind charakteristische Ansichten aus dem Innern der verschiedenen Städte.

Physiognomie der Stadtquartiere. In der Regel hat jedes grössere Quartier séine eigenthümliche Physiognomie, namentlich wo eine hochgelegene Altstadt und ein neuerer Stadtheil in tieferer Lage vorhanden oder wo einzelne Quartiere vorherrschend oder ausschliesslich von gewissen Kasten und Ständen bewohnt sind. Eine solche Vertheilung der Einwohnerschaft ist manchmal vorgeschrieben; in den orientalischen Städten z. B. sind den Israeliten besondere Quartiere angewiesen, ebenso den Franken oder Europäern etc. In andern Fällen findet eine derartige Gruppirung der Angehörigen einer Volksklasse in spontaner Weise statt als Folge der Ideen- und Interessengemeinschaft oder einer Gleichheit der Lebensweise und Beschäftigung; so wird oft ein Quartier von den Rentiers bevorzugt, ein anderes von den Kaufleuten, während in einem dritten die Arbeiter wohnen, und es gibt ganze Quartiere, die ron einander nach der Profession ihrer Bewohner unterschieden werden können. Dieselben Differenzen machen sich in noch schärfer ausgesprochener Weise geltend zwischen den eigentlichen Städten einerseits und den Vorstädten anderseits.

Diese Physiognomie der verschiedenen Quartiere einer Stadt oder desselben Quartiers zu verschiedenen Tageszeiten ist für den aufmerksamen Reisenden von grossem Interesse und bietet ihm reiche Gelegenheit zur Beobachtung der verschiedenen Volkstypen.

Strassenbeleuchtung, Wasserversorgung und Reinigung der städte. Der Reisende achte auf die Art der Beleuchtung, der Wasserversorgung und der Reinigung einer 
von ihm besuchten Stadt oder sonstigen grösseren Ortschaft. Es gibt Länder, wo jede Strassenbeleuchtung fehlt, so dass die Dörfer und Städte ron Sonnenuntergang an in Finsterniss gehüllt sind, wenn nicht Mond und Sterne oder starkes Dämmerlicht die Gegend erhellen; Länder ferner, wo das Trinkwasser in Zisternen angesammelt oder ron weither geholt wird; wo Staub und Schmutz in den Strassen angehäuft sind und die Beseitigung des Aases, sowie anderen Enraths den Hunden, Schweinen, Geiern und Insekten überlassen wird, welche die von den Menschen vernachlässigte Gesundheitspolizei ausïben. In andern Ländern wird den öffentlichen Bedürfnissen und Interessen nach diesen rerschiedenen Richtungen in mehr oder minder vollkommener Weise Rechnung getragen, oft mit einer Umsicht und Opferwilligkeit, welche dem Volke und dessen Behörden zur hohen Ehre gereichen.

\section{LEBENSWEISE.}

Leber die Lebensweise eines Volkes im Grossen und Ganzen werden mitunter ron Reisenden keine Angaben gemacht als die, ob dieselbe eine nomadisirende oder sesshafte sei. Zwischen diesen beiden Extremen des Lebens als Wandervolk oder mit festem Wohnsitz gibt es aber einen Mittelzustand, der reyc-

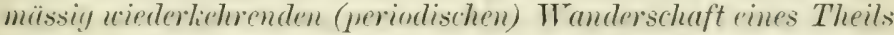
eler Becöllierung, welchen Zustand man z. B. bei den Piemontesen und Tessinern findet, die in der günstigeren Jahreszeit Arbeit in der Fremde suchen, den Winter aber in der Heimat zubringen, wie auch bei den Kabylen, welche zur Zeit der Ernte, um hiebei Dienste zu leisten, von ihren Bergen nach den Ebenen ziehen. In andern Gegenden, wie in der Auvergne, Maurienne und im Bündnerlande (namentlich Engadin) lommt eine längere einmalige (temporäre) Landesabuesenheit cirler Benculuer ror, welche zum Betrieb verschiedener Gewerbe (als Diensthoten, zur Schaustellung ron Murmelthieren: "montreurs de marmottes", als Kaminfeger, Maurer und Gypser, als Zuckerbäcker und Wirthe etc.) nach den grossen Städten des Auslands gehen, um später mit ihren Ersparnissen in ihr Vaterland zurückzukehren und den Abend ihres Lebens in der Heimat zuzubringen, die sie nie aus dem Sinn 
verloren. - Unter den Nomaden sind auch verschiedene Kategorien zu unterscheiden. Es gibt umherimende oder umherschueifende Völker, welche in beständiger Wanderung begriffen sind, wie die Zigeuner; andere, die uahren Nomaden, verlassen eine Gegend erst, wenn dieselbe - als Jagd-, Fischerei- oder Weidegebiet - erschöpft ist, und sie bleiben zudem bei ihren Zügen in den Grenzen ihres bestimmten Territoriums; dritte führen als Halbnomaden nur zu gewissen Jahreszeiten ein Wanderleben, z. B. um der Büffeljagd oder dem Fange von Wanderfischen obzuliegen zur Zeit der Züge dieser Thiere, oder um im Frühling ihr Vieh in die Alpen zu treiben und daselbst als Sennen oder Hirten den Sommer zuzubringen, während sie für den Rest des Jahres zum Familienherde zurückkehren.

Es genügt nicht, diese Lebensweise einfach nach den erwähnten Kategorien zu bezeichnen; es sind auch die Ursachen derselben, die treibenden Kräfte der vorkommenden Bewegungen zu nennen. Sodann soll man sich auch nicht mit diesen Kategorien begnügen, dabei nicht stehen bleiben. Ebensc, ja in noch höherem Maasse charakteristisch sind die feineren Nüancen, welche zu Tage treten im "farniente" der Südländer, im beschaulichen Dasein der Orientalen, im regetativen schläfrigen Wesen der Chinesen, im thätigen und ernsten Leben der Engländer, in der Lebhaftigkeit und Leichtigkeit des Franzosen, der fieberischen Hast, dem Geldmăchen ("money-making") der Amerikaner. Es ist eine wichtige Aufgabe des Reisenden, das Volk, unter dem er sich aufhält, nach allen diesen Gesichtspunkten kennen zu lernen und davon ein Gemälde zu entwerfen, das wahrheitsgetreu und sprechend genug ist, um uns einen Einblick in dieses Leben zu verschaffen.

Häusliches Leben. Welch' ein Unterschied zwischen der Existenz des Wilden in seiner Ajupa, des Negers in seiner Hütte, des Indianers in seinem Wigwam, dem Leben des Patriarchen in seinem Zelte, der Deutschen und Engländer in ihrem "Heim" und "home" und dem Hôtelleben amerikanischer Familien! Die Zeit ist wohl verwendet, die der Reisende in solcher Umgebung zubringt, um das häusliche Leben eines Volkes mit all' seinen kleinen, aber charakteristischen täglichen Vorkommnissen kennen zu lernen! 
Wo bei einem Tolke verschiedene Kasten oder Klassen bestehen, muss man trachten, eine jede derselben einzeln und besonders kennen zu lernen. Wenn man rom Leben im Palaste als Gegensatz zu demjenigen in den Hütten spricht, so ist nicht zu übersehen, dass auch erhebliche Unterschiede rorhanden sind zwischen dem Leben des einfachen Stadtbürgers und demjenigen der Bauern. Gleichheit oder Verschiedenheit der Beschäftigung spricht sich im ganzen Dasein der Einzelnen aus; jene gibt Berufsugenossen ein mehr oder minder übereinstimmendes, diese Leuten von verschiedenem Handwerk je ein eigenartiges Gepräge. So liefern - $u m$ beispielsweise nur einige in der Schweiz rorkommende Berufsarten zu erwähnen - Köhler, Flösser, Mähder, Hirten und Gemsjäger Stoff zu ebensovielen rerschiedenen Gemälden aus dem Volksleben.

Geselliges Leben. In Bezugr auf geselliges Leben, Feste, Spiele und Vergnügungen sind ron Land zu Land grosse Verschiedenheiten zu beohachten. Der Japanese hat seine Theehäuser, der Engländer seinen Klub, der Franzose seine Bälle und Konzerte. Als nationale Brlustigumen, Festr und Spicle findet man hier Hahnenkämpfe und Stiergefechte, anderswo Pferderenmen, Wettkämpfe der Boxer und Ruderwettfahrten; in der Schweiz Ring- und Schwingkämpfe, eidgenössische und kantonale Schützen-, Turn- und Gesangfeste etc. Der Chinese liebt seine fliegenden Drachen und Feuerwerke, der Araber Kampfspiele (Fantasias): ein anderes Tolk hat mehr Freude an Gesang und Musik: ein jedes amïsirt sich auf seine Weise.

Politisches Leben. Im politischen Leben zeigen sich die denkbar grössten Lnterschiede: in despotisch regierten Lündern ist dasselbe meist null: anderswo spielt es eine sehr wichtige Rolle. Sonntägliche, ror der Kirchthüre zusammentretende Versammlungen der Gemeinde-Einwohner zur Besprerhung ihrer genossenschaftlichen Interessen, Wahl ihrer Beamten, Dekretirung ron Steuern etc.; unter freiem Himmel tagende "Landsgemeinden", Zusammenkünfte der Surhems, die gravititisch diskutiren, während das Calumet herumgeht: tumultuarische Meetings der Irländer, die regelmässig mit allgemeinem Streit endigen: spanische und mexikanische P'ronunciamentos: das sind wahrlich Szenen, die ein Volk 
charakterisiren in der Art, wie es seine Rechte und Pflichten versteht und übt.

Geistiges Leben. In Hinsicht auf das geistige Leben macht sich nicht gerade eine solche Vielgestaltigkeit bemerkbar, wie in andern Beziehungen, und man könnte wohl die Völker von diesem Gesichtspunkt aus lediglich in zwei grosse Gruppen bringen : einerseits solche, welche ihre Geisteskräfte pflegen und entwickeln; andererseits solche, die das nicht thun. Aber bei näherem Zusehen nimmt man auch hier mehrfache Abstufungen wahr. In gewissen Ländern genügt es den Leuten, wenn sie einigermassen lesen und schreiben können; anderswo wird durchgängig auf sorgfältige Erziehung gehalten; alle Klassen geniessen eines guten Unterrichts, und ein reicher Schatz von Wissen findet sich nicht nur bei Gelehrten von Beruf, sondern selbst bei Handwerkern und Krämern. Zum Beispiel erzählt ein Reisender, dass er das Chamounithal besuchte in Gesellschaft eines Touristen, mit welchem er zufällig zusammengetroffen und hinsichtlich dessen er nach den geführten Gesprächen im Zweifel war, ob derselbe Theologe, Jurist oder Geologe, während sich schliesslich herausstellte, dass sein Begleiter, der sich in den verschiedenen Wissensgebieten so bewandert erwiesen hatte, ein einfacher Genfer Uhrenarbeiter sei.

\section{ORGANISATION}

\section{der Familie - der Gesellschaft - des Staates.}

Familie, Gesellschaft und Staat, wie wir dieselben verstehen, sind nicht überall vorhanden. In dieser Hinsicht bestehen zwischen einzelnen Ländern und Völkern fundamentale Verschiedenheiten.

Familie. Die Familie in ihrer eigentlichen und wahren Bedeutung ist begründet auf ein dauerndes Ehebündniss und das Zusammenleben der Verehelichten. Sie kann also nicht existiren bei den wilden Horden mit Weibergemeinschaft und auch nicht bei den Völkern, welche nur temporäre Ehen kennen, die rom einen oder andern Theil nach Belieben aufgelöst werden und die höchstens bis zur Geburt oder bis 
zum Entwöhnen eines Kindes als gültig und verbindlich betrachtet werden. $\mathrm{Zu}$ diesen vorübergehenden Verbindungen kann man das Krmliubinat zählen, d. h. eine illegale, heimliche oder offenkundige Geschlechtsgemeinschaft mit oder ohne Zusammenwohnen der Betheiligten. Das Konkubinat der alten Römer und die monyanatische Ekhe (Trauung zur linken Hand") der modernen Gesellschaft können - bei ihrem weniger ephemeren Charakter - zur Gründung einer Familie führen.

Wie die Dauerhaftigkeit eines Ehebundes, so erscheint auch das Zusammenleben seiner Glieder als unerlässlich zur Bildung einer wahren Familie. Wenigstens kann man diesen Yamen nicht wohl auf solche Verbindungen anwenden, wo - wie dies bei einigen wilden Vülkerschaften rorkommt dir Guttru nach wir cor yrtwm laben, jeder Theil bei seinem Stamm, wobei die Kinder dem Stamme der Mutter angehören.

Die wahre Grundlage der Familie ist also die Ehe, als auf die Dauer eingegangene und mit Zusammenleben verbundene Vereinigung ron Repräsentanten der beiden Geschlechter.

Wir sind freilich gewöhnt, als drittes Erforderniss die Legalität der Verbindung, eine gewisse Sanktion derselben, rorauszusetzen. Allein dieser legale Charakter kann dem ehelichen Bunde abgehen, ohne dass desswegen die Gründung einer Familie verhindert wird. Ist die Frau in dauernder Weise Genossin („Lebensgefährtin“) des Mannes, lebt sie mit ihm unter demselben Dache und werden daselbst die aus der Verbindung entspringenden Kinder erzogen : so ist die Fumilie konstituirt, in welcher Weise auch der Mann in den Besitz seiner Frau gekommen sei.

Frauenraub, Brautkauf, gegenseitige Einwilligung, Beobachtung gewisser Formalitäten - diese Lmstände geben der Ehe nach unsern Begriffen einen rerschiedenen (in dẹn einen Fällen unmoralischen, andernfalls geweihten oder greheiligten) Charahter; aher sie fallen ausser Betracht, wem es sich um die Folgen der Ehe, die Begründung eines Familienstandes handelt.

Für die Familie als solche ist es auch anerheblich, ob die Ehen nach Vorschrift und Sitte stattfinden zwischen Verwandten und Stammescenossen (Endorfumir S. 624) oder zwischen 
Fremden und Angehörigen verschiedener Stämme (Exogamie, S. 623). Hinsichtlich des Verhältnisses zwischen den Repräsentanten der beiden Geschlechter finden sich drei Kombinationen: die Ehe zwischen Einem Manne und Einer Frau Monogamie (S. 626); die Ehe eines Mannes mit vielen Frauen: Polygamie oder besser Polygynie (S. 624); die Ehe mehrerer Männer mit einer einzigen (ihnen gemeinsamen) Frau : Polyandrie (S. 626).

Da wir oben (S. 628 und 634) schon über die Schliessung und Scheidung der Ehe gesprochen haben, so betrachten wir hier lediglich die Familie als solche, d. h. nach ihren Verhältnissen, deren Begründung. und während der Dauer ihres Bestandes.

Die Familie hat gewisse typische Formen aufzuweisen, ron denen wir die hauptsächlichsten erwähnen. Trifft der Reisende eine Form derselben, die nicht zu einem dieser Typen gehört, so wird er dieselbe signalisiren und beschreiben. Die Terminologie, deren wir uns hier bedienen, mag etwas ungebräuchlich, vielleicht sogar prätentiös erscheinen. Wir stellen sie auch nur auf in Ermanglung von etwas Besserem und überlassen es dem Ermessen Derer, welchen eine sachbezügliche Terminologie erwünscht sein müsste, ob sie die nachfolgende anzuwenden für gut finden oder nicht.

$1^{\circ}$ Die ungetheilte Famitie (famille indivise) ist eine Gruppe von meist blutsverwandten Personen, worin die Frauen und Kinder nicht einem bestimmten Gatten oder Vater speziell, sondern mehr oder weniger allen zusammen angehören. Von der wilden Horde unterscheidet sie sich dadurch, dass sie eine engere, beschränkte Gemeinschaft darstellt, dass die Vermischung nicht illimitirt ist, sondern ihre bestimmten Grenzen hat. Wenn diese Gemeinschaft ihrem Verbande fremde Elemente beitreten lässt, so assimilirt sie sich dieselben. Die Familie als Ganzes nimmt neue Individuen in ihren Schoos auf, heirathet Frauen und adoptirt Kinder, wie dies noch auf der Insel Ceylon stattfindet ${ }^{1}$ ).

$2^{\circ}$ Wenn ein Verband von der Art des eben Besprochenen sich in zwei oder drei Gruppen theilt und die Vermischung nur innerhalb dieser Unterabtheilungen stattfindet, so haben wir die semmentarische Familie; in derselben besitzt das

1) Les Origincs de la famille, par M. Giraud-Teulon, Genève et Paris, 1874, pag. 60. 
Familienhaupt seine eigenen Frauen; die Brüder haben die ihrigen gemeinsam und die Schwestern gehören kollektir denselben Gatten an : die Kinder sind nicht mehr Eigenthum des Gesammtrerbandes, sondern einer einzelnen Gruppe desselben. Diese Form der Familie findet sich z. B. in Hindostan bei den Todas.

$3^{\circ}$ Die Indicidual-Familir unterscheidet sich ron den beiden vorgenannten Formen dadurch, dass es sich hier nicht mehr um Kollektirbeziehungen, sondern um persünliche Sonderrerbände handelt: jedes Individuum besitzt für sich allein eine oder mehrere Frauen (beziehungsweise einen Mann oder - in der Polyandrie - deren mehrere). Diese Form allein gestattet leicht eine Trennung der Familie (im weitern Sinn des Wortes) in mehrere gresünderte Haushaltungen.

In Bezug auf den Limfun! des Verbandes, welchen man als Familie bezeichnet, ist rorab zu unterscheiden zwischen Einzelnfamilien und Kollektirfamilien.

Als brsmuler oder Einzchfumilie (famille distincte) kann man diejenige hezeichnen, welche aus einem Vater mit einer oder mehreren Gattinnen und deren Kindern besteht. Dabei ist in der Regel nur Eine Generation von Kindern vorhanden; wenn diese letztern sich verheirathen, so verlassen sie ihre Eltern und gründen eine neue besondere Familie.

Die Kollclitifamilic hingegen besteht aus einer Anzahl ehelicher Verbände mit mehr oder minder scharfen oder verwischten Grenzen und den hieraus entsprossenden Kindern. Hieher gehören die ungetheilten und die segmentarischen Familien, welche wir oben (sub 1 und 2) besprochen haben; ferner die patriarchalischen Familien, in welchen das Haupt einer solchen (der Patriarch) mit seinen Kindern, nächsten Verwandten und den rerschiedenen Generationen, die um ihn aufgewachsen sind, zusammenlebt, eine Familienform, die sich da findet, wo die sich verheirathenden Söhme und Töchter hei ihren Eltern bleiben und keinen eigenen Hausstand gründen. Hieher kann man ferner auch die durch Assoziation gebildete Familie rechnen, welche aus rerschiedenen Personen (mit Blutsrerwandtschaft oder nicht) besteht, die sich freiwillig unter einem erwählten Chef zu einer häuslichen Gemeinschaft verbinden.

Mitunter werden in den Begriff der Familie auch die Diener und Sklaven einbezogen. 
Andrerseits denkt man sich unter Familie im weiteren Sinne des Wortes ausser den Personen, welche Einen Haushalt führen, auch die Gesammtheit Derer, die von der einen oder andern jener ersteren Personen abstammen oder sonst mit ihr gemeinsamen Ursprungs sind und mit diesen Anverwandten in Beziehung bleiben.

Verwandtschaft. In der ungetheilten Familie mit Frauengemeinschaft und einer fast unbegrenzten Vermischung der Geschlechter wendet der Einzelne die Namen Vater und Mutter gegenüber allen bejahrteren Personen an; die Namen Bruder und Schwester gegenüber allen Denen, welche ungefähr gleich alt sind wie er; die Namen Sohn und Tochter endlich auf alle Personen jüngeren Alters. In der segmentarischen $\mathrm{Fa}$ milie sind diese Bezeichuungen kaum weniger willkürlich, aber auf enger begrenzte Gruppen beschränkt. Nur in der Individualfamilie gestalten sich die Abstammungsverhältnisse und damit auch die Benennungen derselben in präziser Weise.

Bei den Völkern mit Polyandrie, wo mehrere Brüder oder auch Genossen ohne Blutsverwandtschaft gemeinsam eine Frau haben, werden die Kinder als solche des ältesten der Brüder, resp. des Chefs der Gemeinschaft, betrachtet oder aber in beliebiger Weise den Einzelnen zugetheilt, z. B. das Erstgeborne dem Aeltesten der Genossen, das folgende dem Zweitältesten u. s. w. Herodot (IV, 180) und Aristoteles (Pol. II, 4, 13) erzählen auch, dass bei gewissen Völkerschaften Lybiens die Kinder zu bestimmten Zeiten denjenigen Stammesgenossen zugesprochen wurden, mit welchen sie die meiste Aehnlichkeit hatten.

Viele Völker anerkennen nur eine Verwandtschaft von mütterlicher Seite. Auf den untern Stufen der Familienbildung, von denen wir gesprochen haben, setzt man einzig die Abstammungsverhältnisse von mütterlicher Seite nicht in Zweifel. Die Frau, welche ein Kind unter dem Herzen trug, ist sicherlich dessen Mutter; welcher Mann des Stammes aber der Vater sei, ist eine keineswegs mit Sicherheit zu beantwortende Frage. Für die Genealogie ist dann lediglich die Deszendenz von mütterlicher Seite (in weiblicher oder uteriner Linie) massgebend. Der Titel Onkel (von mütterlicher Seite) bezeichnet in diesem Falle einen wichtigeren Verwandtschaftsgrad als der Titel Vater. 
Andere Völker nehmen nur eine V'erwandtschaft in männlicher Linie an; d. h. ihre Genealogie berücksichtigt ausschliesslich die Deszendenz von väterlicher Seite, von den Männern, während dabei von den Frauen ganz abgesehen wird.

Es kann auch vorkommen, dass (wie das ehemals hinsichtlich der Erstgebornen bei den Basken der Fall gewesen sein soll) für die Söhne die Abstammung rom Vater, für die Töchter aber diejenige von der Mutter als massgebend gilt.

Wo die Frau bei der Verehelichung in den Stamm übergeht, welchem ihr Mann angehört, ist es nicht selten, dass sie nach der herrschenden Anschauung nun der Verwandtschaft zu dem Stamm, aus welchem sie hervorging, verlustig wird. Die aus einer solchen (exogamen) Ehe entspringenden Kinder gehören dann ausschliesslich dem Stamme des Vaters an, d. h. es wird nur eine Verwandtschaft mit diesem Stamme angenommen, der selber nur aus Deszendenten eines gemeinsamen Ahnherrn in männlicher Linie besteht. - Das Lmgekehrte findet statt, wenn der Mann bei der Verheirathung mit einer Angehörigen eines andern Stammes in diesen übergehen und seine frühere Stammesangehörigkeit aufgeben muss. Die Kinder haben dann nur Verwandte in weiblicher Linie.

Die eheliche Verbindung zweier Personen, die verschiedenen Volksstämmen angehören, zieht indess nicht immer den Verlust aller Verwandtschaft mit dem Stamme, welchem Jemand entsprossen ist, nach sich; alsdann bestehen für die Kinder, wiewohl sie einem Stamme enger angehören (dem des Vaters oder dem der Mutter, je nach dem Falle), Bande der Verwandtschaft mit dem andern Stamm, mit Grosseltern, Onkeln und Tanten in demselben.

In unsern zivilisirten Gesellschaften ist die Verwandtschaft ebenfalls eine zweiseitige, d. h. sie gilt sowohl für die Familie des Vaters als für diejenige der Mutter.

Der Reisende unterlasse nicht, die Verwandtschaftsysteme, welche er beobachten kann, wohl zu definiren, deren verschiedene Stufen zu bezeichnen und die Ausdrücke dafür zu sammeln.

Ein Punkt, der ehenfalls Aufmerksamkeit rerdient, ist der Verwandtschaftsgrad, welchen man Kindern beilegt, die zwar den gleichen Vater, aber verschiedene Mütter, oder dieselbe Mutter, aber verschiedene Väter haben. 
Neben der natürlichen gibt es eine fiktive Veruandtschaft.

So kommt in einigen Stämmen der sogenannte Brudereid vor, welcher zwischen zwei Personen eine Verbindung herstellt, die als gleichbedeutend mit einer gemeinsamen $\mathrm{Ab}$ stammung gilt. Die gegenseitige Infusion von Blut aus einer leichten Wunde schafft ebenfalls eine konventionelle Verwandtschaft zwischen Personen verschiedener Familien oder Stämme, eine Verwandtschaft, die als eine enge angesehen wird. Auf den Umstand, dass zwei oder mehr Individuen von derselben Amme genährt wurden, basirt die Anschauung verschiedener Völker eine unauflösliche Verwandtschaft, und diese Anschauung spricht sich noch aus in unsern, ohne Zweifel früher bedeutsameren Worten „Milchbruder “ und "Milchgeschwister."

Die Adoption, durch welche ebenfalls eine fiktive oder besser rein zivile Verwandtschaft geschaffen wird, bietet oft bemerkenswerthe Eigenthümlichkeiten dar. So können, wie versichert wird, bei den Irokesen und Huronen einzig die Frauen Kinder adoptiren. Bei andern Stämmen, welchen daran liegt, die Zahl ihrer Krieger zu vermehren, werden nicht blos Kinder und junge Leute, sondern Männer reifen Alter's - in der Regel Flüchtlinge oder Ueberläufer - adoptirt. Ferner ist es da und dort üblich, Kinder von Sklavinnen $\mathrm{zu}$ adoptiren oder vielmehr zu legitimiren. - In welchem Umfange immer die Adoption vorkommt, so informire sich der Reisende über die Zeremonien, mit denen sie verbunden ist, und über die Rechte, welche durch sie erworben werden. Bald wird dieselbe perfekt durch eine blosse Erklärung, bald muss diese Erklärung durch einen feierlichen Eid oder durch Bespritzen mit Blut bekräftigt werden. In Abyssinien wird dabei das Säugen nachgeahmt, indem der Adoptivvater dem zu adoptirenden Kinde eine Fingerspitze in den Mund hält. Was die mit der Adoption verbundenen Rechte anbelangt, so wird in gewissen Gegenden der Adoptivsohn einziger Erbe, mit Ausschluss der wahren und legitimen Söhne.

Familien- und Vornamen. Als äussere Zeichen der gemeinsamen Abstammung und also der Verwandtschaft von Abkömmlingen desselben Ahnen werden Familiennamen, Wappen und Totems angewendet. 
Wir haben uns hier nicht über den Lrsprung der Familiennamen im Allgemeinen auszusprechen. Der Reisende wird aber in jedem Einzelfall festzustellen suchen, ob bei dem von ihm hesuchten Volke die Erinnerung an die Zeit, in welcher diese Namen eingeführt wurden, noch vorhanden und lebendig sei. Für Japan z. B. ist geschichtlich erwiesen, dass die Namen piner jeden Familie gegen das Jahr $80 \mathrm{v}$. ('hr. festgestellt wurden. Bei vielen nordamerilianischen Indianerstämmen und bei den Eingebornen Australiens ist jener Vorgang viel jüngeren Datums.

In manchen Gegenden wird die Abstammung im Yamen einfach dadurch bezeichnet, dass man dem Namen des Sohnes denjenigen des Vaters beifügt ; "Achmed ben Jussef" z. B. bedeutet: Achmed Soln Josephs. Will man die Abstanmung weiter zurückverfolgen, so wird noch der Name des Grossvaters (von väterlicher Seite) hinzugefügt u. s. w. Beispielsweise heisst es dann: Amu ben Aïsa ben Malek etc. (Amu, Sohn des Aïsa, des Sohnes Maleks etc.), und für Frauen: Fatma ben't Ali ben Kaleb etc. (Fatma, die Tochter des Ali, des Sohnes Kalebs etc.).

Mitunter werden die Namen, statt von dem des Vaters (patronymisch), von demjenigen der Mutter (matronymisch) grebildet, sodass statt, $\mathrm{N}$., Sohn des $\mathrm{N}^{*}$ gesagt wird: $\mathrm{N}$., Solnn der $\mathrm{N}$. Auch findet sich eine Mischung dieser beiden Systeme vor, wobei die Kinder der Häuptlinge und Vornehmen nach den Vätern, diejenigen der Armen und der untern Klassen nach den Müttern benannt werden.

Gar sonderbar muss uns der Gebrauch erscheinen, den Tamen der Eltern nach denjenigen der Kinder zu gestalten. Diese bizarre Sitte findet sich in Australien und Amerika. Wird einem australischen Ehepaar ein Sohn geboren und erhält dieser den Namen Kadli, so heisst nun der Tater Kadlitpinna (Vater des Kadli) und die Mutter Kadlingangki (Mutter des Kadli); ein Indianer, welcher den Namen Queech-et hat und einen Sohn bekommt, den er Sah-neu nennt, verliert nun seinen Namen Que-ech-et und heisst fortan Sahneu-tee (Vater des Sah-neu).

Die patronymische Familienbezeichnung ist oft nach dem Samen eines berühmten Vorfahren oder Clanhäuptlings gebildet. Bei den alten Griechen z. B. wurden die Nachkommen des Atreus als Atriden henannt. Die schottischen Namen 
Mac-Donald, Mac-Gregor (Sohn des Donald, Sohn des Gregor') bezeichnen Angehörige von Clans, deren Häuptlinge (lairds) Donald und Gregor hiessen.

Den Prozess der Bildung ron Familiennamen, die nicht patronymische sind, kam man oft noch vor sich gehen sehen in der Anwendung gewisser Epitheta, Bei-oder Uebermamen, die eine einzelne Person bezeichnen, nach und nach aber auf deren ganze Familie, auf deren sämmtliche Nachkommen übertragen werden.

In gewissen Ländern trifft man den Brauch, dass der Ehemann seinen Namen aufgibt und denjenigen der Frau annimmt. Es soll das früher auch bei den Basken vorgelommen sein, wenn eine Tochter das elterliche Haus erbte; in diesem Falle sei ihr Familiennamen auf den Gatten und die Kinder übergegangen.

Die Tanf- oder Tormamen, welche in zivilisirten Ländern gebräuchlich sind, bezeichnen oft in charakteristischer Weise die zur Zeit dieser Namengebung (Taufe) herrschende Ideenrichtung. In Frankreich z. B. findet man von der Revolution her vielfach noch die Vornamen Regulus, Cajus, Brutus u. dgl.

Ein wunderlicher, meines Wissen nur in China existirender Gebrauch ist der, statt des Vornamens eine Nummer anzuwenden.

Es gibt Gegenden, wo eine und dieselbe Person neben dem unveränderlichen Familiennamen successive verschiedene Namen trägt. So erhält bei einigen Indianerstämmen der Mensch zunächst einen Namen für die Dauer seiner Kinderzeit (Nilchname, milli-nc(me), sodann einen andern für seine reiferen Jahre und endlich einen dritten für sein Greisenalter; daneben aber trägt er während seines ganzen Lebens stets denselben Familiennamen und zwar denjenigen seines Stammes.

Autorität in der Familie. Bei den meisten wilden Stämmen hat der Vater oder Familienchef eine unumschränkte Autorität, selbst das Recht, über Tod und Leben seiner Frauen und Kinder zu verfügen. Einen analogen Zustand findet man, wenn auch wesentlich gemildert, in der patriarchalischen Familie. Der Patriarch hat zwar nicht über Tod und Leben der Seinigen zu verfügen, aber er kann sie verstossen; jedenfalls haben sich alle andern Glieder der Familie, auch alle 
Erwachsenen, seinem Willen zu fügen, -- es wäre denn, dass es sich um eine freiwillige Vereinigung handelte, deren erwählter Chef nur "primus inter pares" ist und die Verpflichtung hat, seine Genossen zu Rathe zu ziehen. Bei den alten Römern war der pater-familias als Repräsentant der Götter, der Stadt und des Gesetzes unumschränkter Herr am häuslichen Herde.

Nach alter russischer Sitte ist der Familienvater Herr im Hause gleich, wie der Czar Herrscher über das Reich. Bei den russischen Bauern hört die väterliche Gewalt über die Kinder nicht auf, wenn auch diese herangewachsen und in's reife Alter eingetreten sind; der erwachsene und rerheirathete Soln bleibt unter der väterlichen Gewalt, bis er selbst erwachsene Kinder hat oder seinerseits Chef seines Hauses geworden ist.

Die Allmacht des Vaters wird in verschiedenen Ländern durch den Einfluss der Familie oder durch Satzungen gemildert. Es gibt Völkerschaften, wo Nutter und Kinder nicht in unbeschränkter Weise als Eigenthum des fatten und Vaters gelten, vielmehr die Oheime von mütterlicher Seite deren geborne Protektoren gregen die Macht des Vaters sind. Die Gewalt des Oheims von mütterlicher Seite geht mitunter so weit, dass derselbe das Recht hat, die Kinder (seiner Schwester) zu verkaufen. Wieder anderorts gilt der Schwiegervater (Vater der Frau) mehr als der Gatte oder Familienvater. - Da, wo die Autorität über die Familie dem Vater zusteht, ist sie oft durch Sitte oder Gesetz beschränkt. Bei den Komantschen z. B. dürfen die Eltern ihre Söhne nur züchtigen mit Zustimmung des Stammes. In Kalifornien sind die Kinder nach erlangter Reife nur den Häuptlingen gegenüber zum Gehorsam verpflichtet, und bei den Beduinen steht der Sohn nur solange unter der Autorität des Vaters, als er mit diesem im grleichen Zelte leht; die väterliche Gewalt über ihn hört auf, wenn er ein eigenes Zelt hat.

Es kommt auch der Brauch vor, dass der Frau die Autorität über die Familie (Mann und Kinder) zusteht. wobei der Mann wenig mehr als der Sklave seiner Frau und gewissermassen Eigenthum ihrer Familie ist.

Stellung des Weibes. Bekanntlich ist die Stellung der Frau in den einzelnen Ländern sehr rerschieden. Bald 
wird die Frau als Sklavin oder Lastthier behandelt und zu den schwersten Arbeiten gezwungen; bald gilt sie als Luxusobjekt, führt ein müssiges Leben in einem gewissen Comfort und unter eifersüchtiger Bewachung; bald ist sie die rerdiente und geachtete Hausmutter, die in allen wichtigen Angelegenheiten zu Rathe gezogen wird - und zwischen diesen Extremen finden sich zahlreiche Abstufungen. Der Reisende suche sich daher über die Stellung des Weibes bei cinem von ihm besuchten Volke genau zu informiren.

Leider am häufigsten ist das Weib eine oft brutal behandelte Sklavin oder unterwürfige Dienerin. Um so bemerkenswerther ist es, dass einige unzivilisirte Völker doch die Frau rücksichtsvoll behandeln, sie dem Manne gleichstellen, ja ihr noch mehr Rechte zuerkennen.

$\mathrm{Zu}$ erwähnen ist auch, welches die Rechtsstellung der Frau im Falle ron Verstossung und Scheidung sei, sowie im Falle des Wittwenthums.

Stellung der Kinder. Bei wilden Stämmen ist das Verhältniss zwischen Vater und Kind ziemlich gleich wie das zwischen einem Thiere und seinen Jungen. Der Vater hat gegen das Kind keine moralische Verpflichtung; er kann es verlassen, fortjagen oder tödten, ganz nach seiner augenblicklichen Laune. Die Beziehungen zwischen Vater und Kind beruhen nicht wie bei uns auf gegenseitiger Liebe, sondern nur auf egoistischen Motiven, brutaler Gewalt, physischer Ueberlegenheit. Daher sind demu auch die Fälle so häufig und weitverbreitet, dass hinder ausgesetzt, misshandelt, verkauft oder geopfert werden. Fast nur in unserer zivilisirten Gesellschaft werden die Kinder mit Liebe behandelt, und wenn sie herangewachsen sind, fast den Eltern gleichgestellt. Im Allgemeinen bleiben die Kinder sehr lange von ihren Eltern abbängig; in den Vereinigten Staaten jedoch erlangen Söhne und Töchter schon frühzeitig die Selbständigkeit.

Der Reisende unterlasse nicht, sich darüber zu erkundigen, ob die Kinder einer und derselben Familie je nach dem gegerseitigen Altersverhältniss ungleiche Rechte besitzen. In manchen Ländern haben die Erstgebornen, anderswo im Gegentheil die Jüngsten gewisse Privilegien (Majorat und Minorat). 
Ferner ist zu bemerken, wie sich das Verhältniss gestaltet, wenn zwischen Vater und Mutter eine Standes- (Kasten- oder Klassen-) Verschiedenheit besteht. Wem z. B. der eine Elterntheil frei, der andere Sklave oder leibeigen ist, welchem folgt nun das Kind in seiner bürgerlichen Stellung? dem Vater oder der Mutter: oder bilden die Kinder aus solchen Mischehen eine besondere Kaste oder Klasse?

Gesellschaft. Wie die Familie auf der Ehe beruht, so die Gesellschaft anf der Familie.

Auf der untersten sozialen Stufe, im Zustande fast thierischer Rohheit, bilden die Menschen nur Gruppen von Individuen, welchen die Familie unhekannt ist: Agglomerate ron I'ersonen beiderlei Geschlechts, welche in einem solchen Zustand ron Vermischung leben, dass unser Gefühl sich daroh empö̀t. Die Frauen und Kinder grehören Allen und Niemandem. Diese Agglomerationen, welche denen der heerdenweise lebenden Thiere gleichen, verdienen den Namen "Gesellschaften" nicht: es sind wilde Horden.

Als eigentliche Gesellschaften kömnen auch sufullige orler "ramum Irminimum nicht angesehen werden, selbst wemn sie aus Individuen bestehen, welche mit einander durch das Band der Ehe verbunden sind. Truppen ron Auswanderern, exilirte oder deportirte Familien, Internate oder lionvikte, Militärkolonien etc. sind keine wahren bürgerlichen Gesellschaften, solange sie wenigstens nicht die Organisation der gewöhnlichen Gesellschaft haben.

Die eigentlichen Grofllsthuften bestehen aus einer freiwilligen mehr oder minder zahlreichen Vereinigung von Familien und Individuen mit gemeinsamen Interessen, gegenseitigen Rechten und Pflichten, sowie einer gewissen Organisation, die auf Lebereinkommen und Satzungen beruht.

Die primitiven Gesellschaften bestehen in der Regel aus einer kleinen Anzahl ron Individuen, welchen weite-Riume zur Verfügung stehen. Die Fenerländer z. B. treffen in Gruppen von 15-20 zusammen und die Australier schweifen in Truppen von 20-50 Köpfen umher. Aehnlich rerhält es sich und muss es sich nothwendig verhalten mit allen noch in den Anfüngen der Zivilisation befindlichen Völkerschaften. Bei denjenigen, welche sich ausschliesslich ron Jagd und Fischfang ernähren, müssen die Indiriduen einzeln oder in kleinen Gruppen leben; 
würde sich deren eine grössere Zahl auf einer Stelle konzentriren, so müsste Nangel und Hungersnoth eintreten. Ebenso sind bei Hirtenvölkern die Familien genöthigt, sich über ein weites Areal in grossen Abständen von einander zu zerstreuen; sonst hätten sie nicht hinlängliche Weideplätze für ihre Heerden. Nur die Völker mit Ackerbau, Gewerben und Handel können in zahlreichen Gesellschaften dicht zusammen wohnen.

Familie und Gesellschaft sind ursprünglich identisch. Die ursprüngliche Gesellschaft war nur eine mehr oder minder zahlreiche Familie, deren verschiedene Glieder unter einem Oberhaupte zusammenlebten. Diese primordialen Gesellschaften vergrössern sich auf drei Arten: $1^{\circ}$ durch Zunahme der Nachkommenschaft des gemeinsamen Ahnherrn; $2^{\circ}$ durch Aufnahme fremder Individuen (Flüchtlinge, Ueberläufer etc.) in den Gesellschaftsverband; $3^{\circ}$ durch Vereinigung mehrerer vorher getrennter Gruppen.

Es sind vier Hanpttypen gesellschaftsbildender Elemente zu unterscheiden:

$1^{\circ}$ Die Tribus, in welcher die Einzelnen in der Regel blutsverwandt sind und das Eigenthum gemeinsam ist. Es ist das ursprünglich nichts anderes als die kollektive (ungetheilte oder segmentarische) Familie. Der Häuptling (Krieger, Patriarch, Domacin etc.) sorgt für alle Interessen und Niemand besitzt Etwas als sein Eigen. Allmälig aber entwickelt sich der Eigenthumsbegriff; neben dem Zelte des Vaters erhebt sich das des Sohnes, und bald besteht die Tribus aus mehreren Familien, die je ihre besonderen Interessen haben, aber unter einem Oberhaupte beieinander leben. - Die Tribus oder der Stamm heisst homogen, wenn er blos Abkömmlinge eines und desselben Ahnherren enthält, heterogen aber in jedem andern Falle. - Die Tribus erlangt zuweilen einen bedeutenden Umfang. Ein Kabylenstamm z. B. umfasst mehrere Dörfer mit gegenseitigen Rechten und Pflichten; er besteht aus verschiedenen Familien (liharouba), wovon jede ihr eigenes Dorf oder in einem Flecken ihr besonderes Quartier bewohnt und ihrerseits je in mehrere Haushaltungen zerfällt — eine Organisation, die mehr politisch als sozial ist.

$2^{\circ}$ Der Clan unterscheidet sich rom vorigen Typus weniger durch das Vorwiegen fremder Elemente als durch Verschieden- 
heit der Lebensweise und Beschäftigung der Stammesgenossen. Diese letzteren können gemeinsamen Ursprungs und gleichen Namens oder nur verbunden sein durch Interessen und alte Traditionen ${ }^{1}$ ); was den (lan charakterisirt, ist eine gewisse Individualität in den Privatangelegenheiten seiner Nitglieder, in deren Eigenthumsverwaltung, verbunden mit der Subordination unter ein Oberhaupt in Allem, was die gemeinsamen Interessen und speziell die Bedürfnisse der Vertheidigung betrifft. Das Oberhaupt des Clans wird oft durch Wahl bestimmt.

$3^{\circ}$ Die Fendulyesellsehaft (groupe féodal) wird von Guizot²) folgendermassen charakterisirt. Die Bevölkerung, welche den Lehnsherr ungibt, ist demselben vollkommen fremd; sie trägt nicht seinen Namen; zwischen ihr und ihm bestehen weder verwandtschaftliche, noch historische, noch auch nur moralische Beziehungen. Der Lehnsherr hat nicht die Lebensweise und nicht die Beschäftigung der Leute um ihn; er ist Krieger oder Müssiggänger, während seine Leute Arbeiter sind. Seine Familie ist nicht zahlreich, besteht lediglich aus Frau und Kindern und lebt getrennt ron der übrigen Bevölkerung des Schlosses oder der Piesidenz. Die Bauern und Leibeigenen gehören ihr nicht an; ihr Ursprung ist verschieden, der Unterschied in der Stellung sehr gross.

$4^{\circ}$ Die Gemeinde besteht aus mehr oder minder heterogrenen Elementen, aus verschiedenen Familien, je mit eigener Hanshaltung und gesöndertem Eigenthum, welche unter sich nur verbunden sind durch nachbarliche Beziehungen und gewisse gemeinschaftliche Interessen. Diese letzteren und die mit Rückisicht auf dieselben erforderlich scheinenden Massnahmen werden in Versammlungen der Gemeindemitglieder oder ihrer Repräsentanten besprochen, und wenn die Gemeinde sich ein Oberhaupt gibt, so ist das kein Krieger, noch ein Patriarch oder sonstiger Herr, vielmehr einzig ein Ferwaltungsbeamter.

Von srzialer Oryanisation kann nur die Rede sein, wenn innerhalb einer Gruppe (Tribus, Clan etc.) eine Theilung der Follen und der Arbeit zwischen den verschiedenen Mitgliedern stattfindet, sodass die Einen für Beschaffung, die Andern für

1) Vgl. HerbertSpencer, staatliche Einrichtungen; Kosmos 1881, pag. 294 (Note).

2) Guizot, Histoire de lu Cirilisution en burope, Paris 1859, pag. 105 und 106. 
Zubereitung der Lebensmittel zu sorgen, Dritte über die öffentliche Sicherheit zu wachen haben u. s. w. Nur in diesem Falle gleicht die soziale Gruppe einem organischem Körper, dessen Theile die verschiedenen Funktionen besorgen, indem sie einander gegenseitig ergänzen. Nur in diesem Fall haben wir ein organisirtes Gebilde vor uns, andernfalls blos ein Aggregat ron Individuen.

Ueberall, wo Spuren einer solchen Organisation vorhanden sind, suche der Reisende deren Grundlage und Mechanismus kennen zu lernen.

Solange die sozialen Gruppen isolirt und ohne gegenseitige Beziehungen leben, heisst die Gesammtheit derselben eine Völlerschaft; ein Voll oder eine Nation heisst sie aber, wenn die verschiedenen Gruppen miteinander verbunden sind und unter gemeinsamen Gesetzen leben.

Kasten und Klassen. Die sozialen Gruppen bestehen ursprünglich, wie schon bemerkt, fast nur aus Individuen mit ziemlich denselben Beschäftigungen, worunter die gemeinsame Noth eine gewisse Gleichheit bewirkt. Aber Glieder der Gesellschaft, welche sich durch physische Kraft, Gewandtheit und Intelligenz auszeichnen, erlangen bald grössern Einfluss als die andern oder verschaffen sich durch List und Gewalt eine besondere Stellung, sodass zwischen ihnen und der Masse ihrer Genossen ein Unterschied eintritt, der noch fühlbarer wird, wenn in Folge von Feindseligkeiten eine Gruppe sich vergrössert durch Gefangene, die sie zu ihren Sklaven macht, oder die zwei Gruppen der Sieger und Besiegten sich in eine Gruppe verschmelzen. Eine Ungleichheit der Stellung zwischen den einzelnen Gliedern der Gesellschaft entsteht auch schon durch die sich manigfaltiger gestaltenden Beschäftigungen, durch eine Theilung der Arbeit, infolge deren in dem Stamme Krieger, Priester, Ackerbauer, Hirten, Handwerker etc. als Klassen zu unterscheiden sind. Wie die Bevölkerung sich vermehrt und diese Klassen zahlreicher werden, theilen sich dieselben ihrerseits wieder, die Hirten 7. B. in Pferdehirten, Küher, Schafhirten etc., die Handwerker in Schmiede, Schreiner, Weber u. s. w. Diese Abtheilungen haben, neben den allgemeinen Interessen der Gesammtheit, in ihrem Rayon je gewisse übereinstimmende Ideen und Ansichten, Spezialinteressen und engere Be- 
ziehungen, welche einen Corpsgeist erzeugen, wobei die einen sich besser dünken als die andern, auf diese herabsehen und sich von ihnen fernhalten, sodass hiedurch dif sonst vorhandene Ungleichheit noch vermehrt und $\mathrm{zu}$ schärferem Ausdruck gebracht wird.

Diese Abtheilungen des Volkes werden als Kasten bezeichnet, wenn sie gegeneinander durch Tradition, Sitte oder Satzung scharf abgegrenzt sind, sodass diese Schranken weder. durch Heirathen, noch durch persönliche Verdienste oder anderswie leicht überschritten werden lönnen. Immumprs (Zünfte, Korporationen) heissen sie, wenn sie je die Personen ron gleicher Berufsart umfassen und diesen gegenseitigp Pflichten auferlegen; blos als Klusis'n werden sie bezeichnet, wenn die Grenzen nicht scharf gezogen und leicht zu überschreiten sind.

Der Reisende hat wohl zu beachten, welche Verhältnisse in dieser Beziehung das von ihm besuchte Land aufweist. Fast immer wird er eine gewisse soziale Hierarchie finden mit den Kategorien von Regierenden und Regierten. Dir ersteren bestehen aus den politischen, militärischen und kirchlichen Führern: Häuptlingen, Kriegern und Priestern. Die letzteren werden in der Regel nach ihrer Beschäftigung klassifizirt. Andere Unterschiede beruhen auf dem Besit\% (Reichthum), auf der Geburt oder Abstammung (dem ,Blut"), zuweilen auch, doch seltener, auf Geschlecht und Alter. Oefter kommen nur zwei Klassen vor: Adelige und Bürgerliche, Patrizier und Plebejer, Iterren und Bauern, Freie unt Leibeigene, Reiche und Arme etc.; mitunter aber gilht es vielfache Haupt- und Interabtheilungen. In einigen Ländern unterscheidet man hohen und niedern Adel. Zwischen Freien und Leibeigenen kann eine Mittelstufe vorkommen; dahin gehörten die ehemaligen „colliberts" in einigen Theilen Frankreichs, welche entweder die volle Freiheit erlangen oder zur Strafe für irgend einen Fehler - wieder in Knechtschaft fallen komnten. Unter den Sklaven sind auch verschiedent. Kategorien zu unterscheiden: zu Sklaven gemachte Kriegsgefangene; Leute, die wegen Schulden Leibeigene geworden, die ihre Verpflichtungen nicht anders als durch solche Dienstbarkeit abtragen kïnnen und oft derselben Rasse und demselben Volke angehören wie ihre Herren; Kulis oder als Ar- 
beiter engagirte Sklaven, welche ihre Freiheit erst wieder erlangen, nachdem sie die Kosten des Transportes und ersten Unterhaltes abverdient haben; ferner die gewöhnlichen, durch den Handel gelieferten und auf den Märkten gekauften Sklaven. Der Vollständigkeit wegen sind noch die freiwilligen und die freigewordenen Sklaven zu erwähnen.

Der Reisende achte darauf, ob in dem von ihm besuchten Lande für unrein gehaltene Kasten vorkommen, wie die Parias Indiens, oder rerachtete Rassen, wie die Cagots in Frankreich; welchen Ursprung sie haben und welches die Gründe der vorhandenen Geringschätzung seien.

Welche Volksklassen, Kategorien und Fraktionen bestehen mögen : wesentlich ist immer, dass die verschiedenen Gmupen scharf bestimmt und auscinander gehalten, sovie dass die Grïnde oder Vorwände fiir die Unterscheidum derselben erforscht uerden. Oft sind die untern Kasten und Klassen die Nachkommen einer Urbevölkerung, die höheren Kasten und Klassen aber Abkömmlinge und Rassenangehörige von Eroberern. Beruhen jedoch die Kategorien nicht auf Rassenverschiedenheiten, so ist $\mathrm{zu}$ prüfen, welche andern Ursachen Grund oder Anlass derselben sein können. Ferner soll näher ermittelt werden, welches die Stellung der rerschiedenen Kasten und Klassen ist, welche Vorvechte den einen derselben zukommen, welche Hindernisse für den Uebergang von einer Kategorie zur andern bestehen, in welchen Fällen eine Versetzung in eine höhere oder niedrigere Klasse eintritt.

Für Länder, wo noch Sklaverei und Leibeigenschaft herrscht, sind ebenfalls genaue Mittheilungen zu machen über die Stellung der Sllaven und Leibeigenen, über deren Behandlung und die Mittel, wodurch dieselben ihre Freilassung erwirken können.

Ueber die Stclluny der Eingebornen sind besondere Angaben beizubringen hinsichtlich solcher Länder, wo die Europäer dauernd Fuss gefasst haben.

Politische Organisation. Die primitivsten Gesellschaften haben keine Spur von politischer Organisation. Sie sind nur Aggregate von Individuen (Männern, Frauen und Kindern) ohne feste Ordnung, allein beherrscht durch das Recht des Stärkern. Indessen kommen sehr selten Gesellschaften vor ohne ein Oberhaupt, das sie sich gegeben haben 
oder das ihnen aufgenöthigt wurde. Dieser Chef ist bald der gemeinsame Ahnherr, der Patriarch ${ }^{1}$ ); bald ein Krieger, welcher als der würdigste erklärt wurde; bald irgend ein Ehrgeiziger, welcher sich durch List oder Gewalt den Besitz der Macht verschaffte. Es ist bemerkt worden, dass die patriarchalische Regierung mehr den Nomadenstämmen eigen sei, während Fischer und Jäger meist unter erwählten Häuptlingen stehen, deren Macht mit Ausnahme von Kriegszeiten eine sehr beschränkte ist, und dass die absolute oder despotische Regierungsform namentlich bei solchen sesshaften Völkern vorkomme, die zumeist aus Ackerbauern bestehen.

In dem Maasse, als die Gesellschaften fortschreiten und sich entwickeln, bildet sich in den Regierungsorganen eine Arbeitstheilung aus. Die Regierung, welche sich anfänglich auf Alles erstreckte, wird in eine militärische und bürgerliche getheilt; die religiösen Angelegenheiten werden einem besondern Stande anvertraut, Fragen der Gewerbe und des Handels den Korporationen, Innungen etc. oder gar den Einzelnen überlassen.

Benachbarte soziale Gruppen (Tribus, Clans u. s. w.) vereinigen sich zu einer politischen Gemeinschaft; sie bilden einen Staat, ein Volk, eine Nation. Dabei kann das einigende Band, das politische System sehr verschiedenartig sein; indessen gibt es gewisse Hauptformen, die häufig vorkommen.

Das Ganze bildet einen Bund (Staatenbund) oder eine Komföderation, wenn die Gruppen unter Beibehaltung ihrer Autonomie (ihrer eigenen Regierung und Souveränetät) sich nur zu Zwecken gemeinsamer Vertheidigung und der Wahrung gewisser Kollektivinteressen verbunden haben. Dabei wird über Krieg und Frieden, wie über die sonstigen gemeinsamen Angelegenheiten verhandelt in den Räthen, worin die verbündeten Gruppen oder Staaten repräsentirt sind. Die Vollziehung der Beschlüsse, die militärische und staatliche Oberleitung werden einem Einzelnen oder einem Kollegium anvertraut (General, Präsident, Bundesrath etc.), dessen Befugnisse aber begrenzt und temporäre sind, wobei es von den Gruppen (Staaten), welche den Inhaber der vollziehenden Gewalt er-

1) Auf den zentralen Karolinen (Mortlockinseln) gilt die älteste Frau des Stammes als dessen soziales Haupt; das politische Haupt ist der älteste Mann der ältesten Familie. Vgl. F. v. Hellwald, Naturgeschichte des Menschen; Stuttgart 1881, S. 149. 
nannt haben, abhängt, ob sie demselben die ihm verliehene Macht weiter anvertrauen oder aber abnehmen wollen.

Wenn die einzelnen Gruppen oder Staaten auf Kosten ihrer Souveränetät die Bande unter sich vermehren und stärken, die Zentralgewalt kräftigen und sich durch diese allein politisch nach Aussen vertreten lassen, so bilden sie in ihrer Gesammtheit einen Bundesstaat.

Im femdalen oder Lehensstrut ist das Land im Besitze von Herren, welche als Yasallen von einem Oberherrn abhängig sind, und ron demselhen das Grundeigenthum zu Lehen erhalten haben. Diese Lehensträger können Glieder einer mächtigen Familie oder Tribus sein oder Abkömmlinge ron Waffengefährten eines Eroberers, unter welche das Land vertheilt wurde, oder Clanchefs, welche einen der Ihrigen zu ihrem Oberhaupt gemacht haben. Sie können ihrerseits von ihmen belehnte Vasallen unter sich haben: die grossen Vasallen werden dann gegenüber dem Oberherrn als Suzeräne hezeichnet. Lehnsherr und Lehenträger (Vasall) stehen zu cinander in ganz bestimmten Verhältnissen in Bezug auf regenseitige Rechte und Pflichten, namentlich betreffend die Lieferung von Truppen: thatsächlich ist aher in der Regel die Macht der grossen Vasallen eine ziemlich unbegrenzte: es sind dieselben mitunter reicher und mächtiger als das höchste Staatsoberhaupt.

Der thenlivatische stant vereinigt die weltliche und geistliche Macht in denselben Personen, sei es, dass der Herrscher als Gott oder unmittelbarer Stellvertreter Gottes gelte, wie der Dalai-Lama in Tibet: sei es, dass die Regierung in den Händen der Priesterschaft liege, wie im alten Egypten oder bei den heutigen Mormonen.

Homarhisch (Momarhic, Alleinherrschaft) heisst der Staat, wenn die weltliche Macht einem Einzelnen als Regenten zusteht, der sie entweder direkt ausübt oder sie in gewissem Lmfang an Grosswürdenträger (Statthalter ron Provinzen, Satrapen etc.) delegirt, welchen er sie nach Belieben wieder entziehen kann. Die Monarchie heisst absolut oder umumschrïulit. wenn der Wille des Herrschers in Allem massgebend, wenn er das oberste Gebot ist, von welchem das Schicksal der Unterthanen gänzlich abhängt; sie heisst lomstitutionell oder beschiölit, wem dem Willen des Monarchen Grenzen 
gezogen sind durch eine Verfassung (Konstitution, Charte), d. h. durch eine Akte, welche die Rechte und Pflichten des IIerrschers und des Volkes festsetzt, oder durch die Mitwirkung gewisser Räthe (Parlamente, Kammern, Cortes etc.). Je nach dem die monarchische Gewalt beim Tode eines Herrschers zufolge rorhandener Bestimmungen an ein andres Glied derselben Familie (einen Leibeserhen) oder aber durch die Wahl auf einen Nachfolger übergeht, haben wir es mit einer kib-oder aber mit einer Wahl-MIonarchic zu thun. In der Republik oder dem Freistaat ruht die Macht in den Händen der Bürger. Die republikanische Staatsform lieisst aristolivatisch, wenn das Gemeinwesen durch einige bevorrechtete Familien oder eine privilegirte Kaste regiert wird; sligarhisch, wemn eine kleine Anzahl von Personen alle Macht an sich gerissen haben: drmoliratisch, wenn die Mehrheit oder gar die Gesammtheit aller Bürger (das Volli) an staatlichen Angelegenheiten sich betheiligen können. Rrim odrr. alssolute Demolivatie heisst die Republik, wenn deren Bürger in allgemeinen Versammlungen die hohen Beamten wählen, vorgeschlagene Gesetze annehmen oder verwerfen und selbst solche vorschlagen, sowie auch über Krieg und Frieden ent-

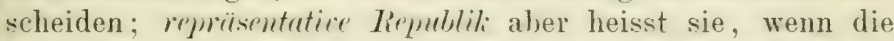
Bürger Vertreter (Repräsentanten) ernemnen, welche in ihrem Namen jene Rechte (Wahl der hohen Beamten, Erlass von Gesetzen etc.) ausüben. Als födrratire lirmblik bezeichnet man den republikanischen Bundesstaat.

Der Reisende darf nicht erwarten, dass jede Staatsform, welche er vorfindet, genau in eine dieser bekannten Kategorien gebracht werden könne. Er wird daher, anstatt sich an eine starre Klassifikation zu halten, vielmehr darauf Bedacht nehmen, die Vertheilun!y der Grorchlen genau kennen $z u$ lernen, zu erfahren, wie dieselben regulirt und begrenzt sind, in welchem Umfang und in welcher Weise die Bürger oder gewisse Klassen sich an der Entscheidung von Fragen des Gemeinwesens betheiligen künnen. Es sollen Irrthümer vermieden werden von der Art desjenigen, in welchem man sich lange Zeit hinsichtlich Japans befand, von welchem Staate man auf Aussagen der Missionäre und der älteren Reisenden hin glaubte, er habe zwei Herrscher, einen weltlichen (Taikun) und einen geistlichen (Mikado) - ein Irrthum, 
der so eingelebt war, dass die Mächte von 1854 bis 1858 immer mit dem Taikun verhandelten und erst später entdeckten, dass dieser angebliche zweite Kaiser nur der erste Vasall sei und in Wirklichkeit den Titel Shogun, d. h. Obergeneral, führe.

Es genügt indessen nicht, zu lionstatiren, wer Inhaber der staatlichen Gewalt ist; der Reisende muss auch zu erfahren trachten, welche Einflïsse (häusliche, innere, äussere) die Handlungen und Schlussnahmen der Regierung bestimmen. Er muss ferner eine Charakteristik des Regierungsystems oder Régime's geben können, d. h. eine Charakteristik der Art und Weise, wie die Macht ausgeübt wird und welche Wirkungen dies hat.

Das absolute Herrscherthum spiegelt sich wieder in der Hierarchie: Die Rangstufen oder Grade sind scharf bestimmt und, wie sehr triftig bemerkt wurde, ist ziemlich jeder Machtantheilhaber ein Sklave nach oben, ein Despot nach unten.

Anderswo ist Alles im Staate Kriegszwecken (der Vertheidigung oder Eroberung) dienstbar gemacht; die Privatinteressen werden denjenigen der Gesammtheit geopfert; es herrscht eine strenge Disziplin: eine starke Macht verlangt unbedingten Gehorsam.

Gewisse Regierungen haben die Manie, sich in die kleinsten Dinge des täglichen Lebens einzumischen. In Japan z. B. schrieb die Regierung vor den letzten Revolutionen vor, zu welcher Stunde ein Jeder, vom einfachen Krämer bis zum Statthalter einer Provinz, aufzustehen, zu speisen, zu spazieren, Besuche zu empfangen und schlafen zu gehen habe. Der Diktator Francia in Paraguay verschmähte es nicht, die Haushälterinnen zu überwachen und denselben, wenn sie sich nachlässig zeigten, Stockschläge ertheilen zu lassen.

Im Gegensatz hiezu respektiren andere Regierungen die Freiheit des Einzelnen in weitgehender Weise und erlassen nur Bestimmungen gegen den Missbrauch dieser Freiheit. Dabei gewöhnt sich dann der Bürger, in vielen Dingen sich selber: zu behelfen, die anderwärts in den Bereich staatlicher Thätigkeit gezogen werden.

Das System der Nachfolgerschaft (Succession) in der öffentlichen Geuralt ist wohl zu beachten. Wie bereits bemerkt, kann der Nachfolger ein Leibeserbe des früheren Inhabers 
der öffentlichen Gewalt sein, d. h. der gleichen Familie angehören wie dieser, oder er kam durch Wahl bestimmt werden. Weniger bekannt ist, dass es Gegenden gibt, wo im ersteren Falle auf den Vater nicht der Sohn folgt, sondern bald ein Schwiegersohn, bald ein Bruder des Verstorbenen, der älteste Sohn seiner Schwester oder auch derjenige, welcher die hinterlassene Wittwe heirathet. Die Erbfolge kann auf die männliche Linie beschränkt sein oder sich auf beide Linien erstrecken. Es gibt sogar Länder, wo die öffentliche Gewalt nur Frauen übertragen wird.

Der Reisende hat ferner die Beziehungen eines Stauts: nach Aussen ins Auge zu fassen, d. h. einerseits die Beziehungen des Staates zu seinen Kolonien, Vasallenländern, tributären, mediatisirten oder unter sein Protektorat gestellten Staaten, andrerseits diejenigen zu den übrigen soureränen Mächten.

Endlich hat sich der Reisende bekannt zu machen mit den Hülfsquellen cines Staate's. den Einkünften von Domänen, Grundrenten, Steuern und Abgahen der rerschiedenen Arten (mittelbaren und ummittelbaren, von Vermögen und Einkommen etc.), wie mit dessen Verthridimnusmitteln oder Whrhaft: Land- und Seemacht auf Friedens- und Kriegsfuss, Festungen etc.

\section{RECHT UND EIGEN'IHUI.}

Man würde sich sehr täuschen, wem man sich vorstellte. dass bei den wilden odẹ hallwwilden Völkern Jeder nach Belieben handeln und über die Frucht seiner Arbeit verfügen kömne. Nirgends mehr als gerade bei diesen Völkerschaften ist die persönliche Freiheit durch Satzungen aller Art eingeschränkt und gehemmt, Satzungen, welche-gleichwohl pünktlich befolgt werden müssen, wenn sie auch nicht greschrieben sind. Nirgends so wie hier muss der Bürger über seine geringfügigsten Handlungen Rechenschaft geben: nirgends anderswo steht er so sehr unter der Tyrannei von Meinungen und Sitten. Gleichheit der Rechte trifft man nirgends weniger als unter den Menschen im wilden oder Naturzustande. 
Recht. Unter Recht verstehen wir die Gesammtheit der (geschriebenen oder ungeschriebenen) Satzungen, welche die Stellung der Glieder des Gemeinwesens zu einander, die yegenseitigen Beziehungen derselben regeln $\left.{ }^{1}\right)$. Es ist G('crohnheitsrecht, wenn es blos auf Brauch und Herkommen (Lebung) beruht, Gesetź oder liodifizirtes Recht, wenn es niedergeschrieben und öffentlich bekannt gemacht wurde.

Bekanntermassen haben viele Völker keine geschriebenen Gesetze; es bestehen aber alte Satzungen, die durch Ueberlieferung (Tradition) von einer Generation auf die andere kommen; die Stammesältesten oder gewisse Klassen sind die Aufbewahrer und Ausleger dieser Bestimmungen. Solche Gewohnheitsrechte sind in der Regel sehr alt, und ihr Ursprung ist dunkel; sie haben sich allmälig entwickelt; mitunter aber wird berichtet, dass sie zu einer bestimmten, in den Annalen des Landes genannten Zeit ron einem Einzelnen, fix und fertig, als Gesetz aufgestellt worden seien ${ }^{2}$ ). Zuweilen auch stammen sie aus den heiligen Schriften des Volkes und sind nur eine Anwendung ihrer Dogmen auf die Vorkommnisse des Alltagslebens.

Auch das geschriebene Recht hat gewöhnlich seinen Ursprung in der Sitte, indem es einfach alte Bräuche und Uebungen sanktionirt.

Als offentliches Recht bezeichnet man die Gesammtheit der Bestimmungen über die öffentliche Gewalt, die Bezieliungen der Einzelnen (Privaten) zum Staat und der Staaten unter einander. Es umfasst: das politische Recht oder das ïffentliche Recht im engern Simne, welches die Organisation der Gewalten feststellt und die Verfassung zur Grundlage hat, wenn eine solche besteht; das internationale Recht oder Völlicrecht, welches auf Staatsverträgen oder Herkommen und Praxis beruht; das Strafrecht (Kriminalrecht), welches die Verbrechen und Vergehen gegen die soziale Ordnung definirt, die Strafen für dieselben festsetzt und das Verfahren hestimmt, welches zur Ahndung jener Rechtsverletzungen einzuschlagen ist; endlich das Ferwaltungsrecht (administra-

1) Vgl. von Holtzendorff, Encyclopädie der Rechtswissenschaft, I. Theil, Leipzig 1870, S. 11 u. ff. (Entwicklung der Rechts- und Staatsidee).

2) Vgl. Herbert Spencer, a. a. O. (Kosmos 1881) S. 296, Note. 
tive Recht), welches die Beziehungen des Staates und seiner verschiedenen Behörden zu dem Einzelnen (Privaten) regelt.

Als Pricatrerht bezeichnet man die Gesammtheit der Bestimmungen über die Beziehungen der Einzelnen (Privaten) unter sich ${ }^{1}$ ). Es umfasst das Zivilierht und das Handelswht; letzteres regulirt die besonderen Rechtsverhältnisse der Handeltreibenden, ersteres in allgemeiner Weise die Rechtsverhältnisse der Privaten überhaupt in Bezug auf ihre persönliche Stellung zu einander wie auf Eigenthumsfragen (Personen- und Familienrecht, Erbrecht etc.).

Wo Sammlungen geschriebener Gesetze bestehen, ist es dem Reisenden leicht, sich über das im Lande geltende Recht nach den verschiedenen Seiten des Gegenstandes zu orientiren; im andern Fall muss er namentlich darauf halten, seine Erkundigungen nur aus den besten Quellen zı schöpfen; in erster Linie trachte er darnach, zu erfahren, welche Sicherheit die Einzelnen für ihre Person und ihr Eigenthum geniessen, wie sie gegen Gewaltthätigkeiten, Erpressungen, Beleidigungen $u$. dgl. geschützt werden.

Nicht überall besteht ein öffentliches Recht im eigentlichen Simne des Wortes, sondern vielerorts kann der Herrscher nach Belieben über Leben und Eigenthum seiner Lnterthanen verfügen. Wenn auch Rechtssatzungen bestehen, so ist manchmal Niemand im Stande, denselben Nachachtung zu verschaffen, falls ein Mächtiger sie verletzt und mit Füssen tritt. Anderswo dagegen ist die Heilighaltung der persönlichen und politischen Rechte das erste und höchste Gebot, und wehe Dem, der dieselben antasten wollte!

Was das Straf- und Zivilrecht anhetrifft, so gibt es Gegrenden, wo dasselbe in einem einzigen Grundsatze besteht, jenem Prinzip der Vergeltung (Talion ${ }^{2}$ ), welches die Bibel in den Worten ausdrückt: Aug um Auge, Zahn um Zahn; wer Menschenblut vergiesst, dessen Blut soll wieder vergossen werden. Alle Jägerstämme leben diesem Grundsatz nach und wenden ihn mit unerbittlicher Strenge an. Andere Völkerschaften lassen eine pekuniäre Vergütung des begangenen Unrechts zu, blosse Geldbussen sogar für schwere Verbrechen.

1) Vgl, von Holtzendorff, a. a. O. S. $44 \mathrm{u}$. ff.

2) Vgl. Osenbrüggen, rechtsgeschichtliche Studien, Schafthausen 1868, S. 150 ff. 
Strafen. Die Strafen, welche in den einzelnen Ländern vorkommen, sind nach Art und Anwendung sehr verschieden. Vielerorts findet sich die "Lynchjustiz", wonach der Ergriffene ohne Weiteres gehängt oder sonstwie umgebracht wird, und sind schreckliche Steinigungen im Gebrauch. Anderswo sind zwar die Strafen weniger hart; aber Schuld oder Unschuld werden nicht beurtheilt nach Thatsachen, welche zu dem Vergehen in Beziehung stehen, nach den nähern Umständen des Verbrechens, sondern nach gewissen dem Angeklagten auferlegten Proben (Ordalien, "Gottesurtheile" des Mittelalters). Der Angeklagte muss z. B. einen Gifttrank nehmen oder wird einer Tortur unterworfen; wenn er dabei umkommt, so war er eben schuldig; im andern Fall wird er für unschuldig erklärt. In Travancore (Indien) muss der Angeklagte durch einen Fluss schwimmen, der von Krokodilen wimmelt; erreicht er wohlbehalten das jenseitige Ufer, so wird er freigesprochen. In Zivilstreitigkeiten wird oft beiden Parteien eine Probe auferlegt oder sie müssen eine Art Zweikampf bestehen; wer sich am besten aus der Sache zieht, erhält Recht. In andern Fällen wird wenigstens der Schein einer Urtheilssprechung gewahrt, wenn auch das Verfahren ein höchst summarisches ist. Kläger und Angeklagte erscheinen vor dem Herrscher oder vor dem Richter; sie setzen ihre Gründe auseinander; es werden einige Zeugen vernommen; hierauf wird das Urtheil gefällt und sofort vollzogen.

Die Strafen sind bald entehrende: Pranger, Knute, Bastonnade etc.; oft verbunden mit Entzug der Freiheit für einen kleineren oder grösseren Zeitraum: Bagno, Deportation, Gefängniss, Bergwerksarbeit etc.; bald sind sie vorwiegend materieller Natur: Verbannung, Busse, Konfiskation des Vermögens u. s. w. Eine bei den Kabylen übliche seltsame Strafe besteht darin, dass man die Ziegel der Wohnung des Schuldigen zerbricht. Uebrigens kann in zwei Ländern der nämlichen Strafe ein ganz verschiedener Charakter beigelegt werden. Die Bastonnade z. B., gegen welche sich unser Gefühl empört, ist eine Art täglichen Brodes und führt weiter keine besondern Folgen mit sich in gewissen Gegenden, wo sie allgemein angewendet wird "vom Herrscher, der sie gibt, ohne sie zu empfangen, bis zum Hund, der sie empfängt, ohne sie zu geben." 
Zwischen den Gesetzen und der Art ihres Vollzuges ist wohl zu unterscheiden. Die Gesetze können ausgezeichnet sein; wenn aber die Justiz bestechlich ist, wenn die Richter durch soziale oder politische Verhältnisse beeinflusst, voreingenommen und rerblendet sind: so hilft das gute Gesetz wenig; die Parteien können sammt demselben fast so übel daran sein, wie wenn gar kein Gesetz bestünde. Ein und dasselbe Gesetz kann mehr oder minder streng gehandhabt werden. Eine missbräuchliche Annahme mildernder Lmstände benimmt den Strafgesetzen oft einen so grossen Theil ihres Werthes, dass sie fast wirkungslos werden.

Eigenthum. Die Annahme, dass die Bewohner gewisser Gegenden kein Eigenthum kennen, ist irrig. Es gibt keinen Stamm, der nicht seine Weide- und Jagdgründe mit ihren Quellen und ihrem Wild für sein ausschliessliches Eigenthum hält. Die Wüste selbst hat ihre Herren, welche den Reisenden, der sie betritt, trefflich zu brandschatzen wissen. Dem Grundsatze nach besteht überall Eigenthum; Verschiedenheit waltet nur in den Bestimmungen darüber, in den Gesetzen, welche die Eigenthumsverhältnisse reguliren.

In dieser Hinsicht sind drei Hauptsysteme zu unterscheiden: $1^{\circ}$ der Krmmunismus, nach welchem die Güter unvertheilt der Gesammtheit angehören: $2^{n}$ der Sepuratismus, wobei die Güter unter verschiedene soziale Gruppen vertheilt, aber gemeinschaftliches Eigenthum der sämmtlichen Glieder einer solchen Gruppe sind; $3^{\circ}$ der Inclividualismus, wo die Einzelnen als solche Eigenthum besitzen können (privates oder individuelles Eigenthum).

Kommunismus herrscht, wo der Stamm eine ungetheilte oder patriarchalische Familie bildet. Hier gehört Alles und Jedes der Gesammtheit; wer diese verlässt, hat kein Recht, etwas mit sich zu nehmen.

Der Separatismus findet sich mehr bei den segmentarischen und bei solchen patriarchalischen Familien, welche auf dem Wege der Assoziation gebildet wurden. Jede Gruppe besitzt gewisse Güter für sich; aber der Grund und Boden gehört Allen gemeinsam an. Ebenso können bei den Jägervölkern die einzelnen Gruppen als solche separates Eigenthum besitzen, und die Waffen sind sogar privates oder individuelles Eigenthum; die Erde aber, d. h. das Jagdrevier, 
gehürt dem ganzen Stamme in seiner Gesammtheit. Unvertheilt ist das Grundeigenthum im Allgemeinen auch in den monarchischen Gesellschaften, deren Chefs für göttlichen Lrsprungs gehalten werden oder despotisch, mit unumschränkter Macht, herrschen. Dieser Stand der Dinge hat sich in muhammedanischen Reichen erhalten: das Land gehört dem Sultan; die Einzelnen besitzen es nur als Nutzniesser, so lange es dem Sultan beliebt.

Privateigenthum im vollen Sinne des Wortes findet sich fast nur bei den aus Ackerbauern, Handwerkern und Industriellen bestehenden Gesellschaften mit festem, bleibendem Wohnsitz. Dasselbe bezeichnet aber keineswegs eine bestimmte Stufe der Zivilisation; denn man findet es einerseits hei den rorgeschrittensten Vülkern, andrerseits bei den unkultivirtesten Stämmen. So besitzt bei den Eingebornen Australiens jedes männliche Individuum ausser seinen Waffen und Geräthen ein Stück Land, dessen Grenzen ihm genau lekannt sind. Der Vater ordnet, wenn seine Sühne noch in zartem Alter stehen, bereits an, wie sein Eigenthum unter dieselben rertheilt werden soll, und nach seinem Tode übernehmen die Söhne sein Erbe nach Massgabe jener Bestimmungen.

Teben diesen drei Haupttypen bestehen noch ycmischte S.ysteme, namentlich in Bezug auf den Grundbesitz. In Feuseeland z. B. gibt es dreierlei Grundeigenthümer: Stamm, Familie und Individuum. In manchen patriarchalischen Gosellschaften gehört zwar das Land im Ganzen dem Stamme an; aber daneben besitzen die Einzelnen kleine Grundstüclie zu eigen, die sie in ihren Mussestunden bebauen und deren Ertrag sie allein einheimsen. Auch da, wo oft der Privathesitz die herrschende Regel bildet, sind oft noch beträchtliche Partien des Bodens Kollektiveigenthum öffentlicher Gemeinwesen; es sind dies die Allmenden, Gemeinde- oder Genossenschaftsgüter ${ }^{1}$ ).

Sehr häufig findet man Ländereien reservirt zum Zwecke der Vorsorge für allgemeine Bedürfnissc. Im Orient werden die Kosten für den Unterhalt der Moscheen aus dem Ertrage solcher Grundstücke bestritten, in den Vereinigten

1) Fgl. z. B. Aug. v. Miaskowski, die schweizerische Allmend in ihrer geschichtlichen Entwickelung vom 13. Jahrhundert bis zur Gegenwart. Leipzig 1879. 
Staaten die Kosten für Schulen: anderswo sind dieselben für die Armen der Gemeinde reservirt oder beim Wachsen der Berölkerung zur Tertheilung an die neuen Familien bestimmt. Auch der Stat als solcher hat Landbesitz (Domänen), um aus dem Ertrag einen Theil seiner Ausgaben zu decken.

Das Eigenthum an Grund und Boden kann, obwohl zu Recht bestehend und anerkannt, ein blos temporäres sein, sodass die Ländereien nach Ablauf einer gewissen Frist oder nach Bedarf unter die Glieder der Gemeinschaft neu vertheilt werden. In solchen Fällen ist zu konstatiren, welches der Modus dieser Vertheilung ist und ob für dieselbe bestimmte Perioden festgesetzt sind.

Mit dem Eigenthum an Land ist nicht immer auch das Recht verbunden, dasselhe $z$ veräussern: wenigstens ist dieses Recht oft grewissen Einschränkungen unterworfen. Es kann z. B. rorgeschrieben sein, dass das Land nur an ein Mitglied des Stammes, nicht aber an einen Frenden verkauft werden dürfe. Dieser Punkt ist von wesentlicher Bedentung für Kolonisten, welche sich in einem solchen Lande ansiedeln wollen.

Die für Handänderungen des Grundbesitzes bestehenden Hemmnisse kommen manchenorts einem Verbote des Terkaufes gleich. Selbst in Ländern, wo das Grundeicrenthum rein privat und erhlich ist, kam der Besitzer darüber selten ganz frei verfügen. Es gibt Gegenden, wo es zwingende Sitte ist, dass die Landgüter nicht vertheilt und reräussert werden: sie gehen rom Vater auf den ältesten Sohn üher, und auch dieser hat nur die lebenslängliche Nutzniessung, muss aber das Gut wieder intakt seinen Nachkommen hinterlassen. So ist es noch in einigen Gegenden der Schweiz Brauch, dass die Güter einer Familie in einer Hand bleiben: beim Tode des Vaters hat das Kind, welches das Heimwesen übernimmt, die andern Erben zu entschädigen (auszulüsen).

An den Grundbesitz knüpfen sich oft gewisse Verpflichtungen. In den Feudalstaaten werden Ländereien zu Lehen gegeben als Belohnung oder Remuneration für geleistete Dienste; damit ist aber die Pflicht verbunden, dem Lehnsherr im Kriegsfalle ein bestimmtes Mannschaftskontingent zu stellen. In vielen Fällen haftet auf dem Grundbesitz Frohndienstpflicht. 
Alle diese Punkte - Rechte und Pflichten des Grundeigenthümers; Vorschriften über die Handänderung; Art der Besitznahme, Formalitäten hiebei, sichernde Rechtstitel etc. hat der Reisende wohl zu beachten. Es ist ferner zu konstatiren, ob mit dem Grundbesitz auch das Eigenthumsrecht auf allfällige Funde und Schätze in dem Boden verlounden oder ob dies (das Recht auf Mineralien, Quellen etc.) dem Gemeinwesen rorbehalten sei. Hierüber sind oft ganz genaue Bestimmungen vorhanden.

Wenn der Grundeigenthümer (Staat, Stamm, Private) den Boden nicht selbst bebaut, ist zu konstatiren, unter welchen Bedingungen er an Arbeiter (Fellahs, Leibeigene, Pächter, Meier etc.) überlassen wird, wie viel den Letzteren vom Ertrage ihrer Arbeit zukommt und welche Garantien dieselben hiefür haben.

Erbrecht. Die hinsichtlich des Nachlasses der Verstorbenen herrschende Praxis ist von Land zu Land verschieden. Hie und da geht beim Tode des Familienvaters dessen ganze Verlassenschaft auf den ältesten Sohn über; bei den Tataren soll im Gegentheil der Jüngste einziger Erbe sein; meist aber wird die Erbschaft unter die verschiedenen Familienglieder mehr oder minder gleichmässig oder ungleichmässig vertheilt.

Die Erbfolge ist nicht überall diejenige in direkter Linie. Bei manchen Völkern ist der Neffe auf Kosten des Sohnes erbberechtigt (Neffenerbrecht); anderswo erbt der Bruder die sämmtlichen Güter des Verstorbenen, auch dessen Frauen, oder er ist wenigstens verpflichtet, die hinterlassene Wittwe $\mathrm{zu}$ heirathen. Auch der Fall kommt vor, dass nicht die Verwandten erben, sondern die Personen, welche bei der Arbeit mitwirkten, deren Resultat das angesammelte Vermögen ist; ferner dass Adoptivsöhne oder von Sklavinnen geborne Kinder auf Kosten der legitimen Nachkommen erben. Die Frauen und Töchter haben in gewissen Ländern kein Erbrecht; in andern hingegen sind gerade sie allein erbberechtigt, mit Ausschluss der männlichen Verwandten.

Nach unsern Vorstellungen kann Jemand erst nach seinem Tode beerbt werden. Auf den Tonga- und Fidschi-Inseln besteht aber die Sitte, dass der Neffe sich das Eigenthum des Onkels (von mütterlicher Seite) schon zu Lebzeiten des letzteren ganz oder theilweise aneignen kann. 


\section{VERSCHIEDENE EINRICHTUNGEN.}

Neben den Institutionen von prinzipaler Bedeutung, welche wir oben - in dem Abschnitt über Familie, Gesellschaft und Staat - ins Auge fassten, finden sich in grosser Zahl rerschiedene Einrichtungen, auf welche wir hier nur in aller Kürze aufmerksam machen, wohl wissend dass der Gegenstand an dieser Stelle noch weniger als die bisher besprochenen Materien erschöpfend behandelt werden kann.

Die wichtigste Differenz, welche zwischen den einzelnen Völkern hinsichtlich dieser Institutionen vorhanden ist, besteht darin, dass in den einen Ländern es der Staat ist, der sich mit alledem zu befassen hat, während anderswo die Hauptrolle der privaten Initiative zukommt.

Staatsverwaltung. Bei Völkerschaften, deren Häuptlinge alle Macht in ihrer Person vereinigen und oft ohne Drittpersonen regieren, sind Stellen für öffentliche Dienstleistungen unbekannt; dagegen erlangen solche bei etwas zahlreichen Gesellschaften und namentlich bei zivilisirten Völkern eine grosse Bedeutung; sie bilden da in ihrer Gesammtheit zumeist einen sehr komplizirten Mechanismus, dessen Zusammensetzung und Wirkungsweise der Reisende klar zu legen hat. Man unterscheidet z. B. den Sicherheits- und Polizeidienst, Strassen- und Postdienst, Finanzdienst etc. etc.

Um mit ein paar Worten nur des ersteren zu gedenken: wie gewaltig verschieden sind nicht die Verhältnisse zwischen einer arabischen Stadt, wo eine im Schatten zerfallender Mauern halb eingeschlafene Schildwache mit Schlappschuhen den Schutz der öffentlichen Sicherheit vorstellt - einem Dorfe oder Flecken, wo der Feldhüter, der Nachtwächter, sowie allenfalls einige Runden diesen Dienst rersehen und endlich einer Grossstadt, wie Paris oder London, mit wohl organisirter Polizei, Policemen, Konstablern, Detektives und Agenten aller Art, welche für die öffentliche Sicherheit vielfach in einer Weise sorgen, die sich der Wahrnehmung Nichteingeweihter entzieht.

Gerichte. Hieher gehören die verschiedenen Institutionen für die Zivil- und Strafrechtspflege, die Gerichte im 
engeren Sinn mit ihren verschiedenen Instanzen, Fachgerichte (z. B. Handelsgerichte), Schwurgerichte oder Jury's etc.

Bildungsanstalten. Es gehören in diese Kategorie rorerst alle Erziehungs- und Unterrichtsanstaiten oder Schulen. von den Kleinkinderschulen bis zu den Universitäten. Dabei ist jeweilen $\mathrm{zu}$ bemerken, ob es öffentliche (staatliche) oder private (sei es ron Einzelnen, sei es von Gesellschaften und Korporationen unterhaltene) Einrichtungen und ob sie im letztern Fall unter' staatlicher Aufsicht oder aber ganz freie Schulen sind.

Die Anstalten unterscheiden sich in solche für allgemeine und solche für berufiche oder Fachbildung; nach der Unterrichtsstufe ferner in niedere, mittlere und höhere Schulen; nach besondern Verhältnissen in Bezug auf die Unterrichtszeit spricht man von Nachts- und Sonntags-, Alltags-, Halbjahrs- (Sommer- oder Winter-) Schulen. Der Schulbesuch ist allgemein oder nicht; ersteres kann die Folge bestehender Vorschriften (eines Obligatoriums, der ,allgemeinen Schulpflicht") orler blos der öffentlichen Meinung sein, sodass immerhin noch zwischen obligatorischem und fakultativem Schulbesuch zu unterscheiden ist. Es könmen ferner die Zöglinge einer Schule Wohnung und Nahrung im Anstaltsgebäude (Konvikt, Internat) oder ausserhalb desselben haben (interne und externe Schüler).

Hienach gibt es in den einzelnen Ländern eine Menge verschiedener Schulen und Bezeichnungen für deren Arten und Stufen: Volks- und Bürgerschulen, Elementar- oder Primar-, Ergänzungs- und Fortbildungsschulen; Sekundar-, Real- und Lateinschulen (Realgymnasien, humanistische oder Literargymnasien, "colligges", "lycées" etc.), technische Mittelschulen; Akademien, Universitäten und polytechnische Hochschulen; - weibliche Arbeitsschulen, Handwerker-, Landwirthschafts-, Thierarznei-, Handels- und Industrieschulen, Lehrerseminarien etc.; militärische Institute (Kadettenschulen etc.), See- oder Narigationsschulen; niedere und höhere Spezialschulen für bildende Künste, Gesang und Musik („Akademien“, „Konservatorien" etc.); - Blindenund Taubstummenanstalten $u$. a. $m$.

An die verschiedenen freieren Formen der Schulen und ihrer Kurse reihen sich an: die öffentlichen Vorträge und 
Tonlesungen, "Wandervorträge", "Fortbildungskurse", „cours publiques" $u$. dgl.

$\mathrm{Zu}$ den Bildungsanstalten rechnen wir ferner öffentliche Bibliothelen und Sammlangen, Mnseen, botenische und zoologische Gürten etc.

Krippen, Findel- und Waisenhäuser. Die Krippen haben wie Kindergärten und Kleinkinderschulen den Zweck, Kindern von Fabrikarbeitern und Leuten rerwandter Berufsarten für die Zeit, wo die Eltern ausser dem Hause beschäftigt sind, die nöthige Obsorge angedeihen zu lassen.

Die Findr- and Wrais'uhüus'r übernehmen Pflege, Erziehung und Berufsbildung von Kinder'n, deren Eltern unbekannt geblieben oder die elternlos geworden sind, beziehungsweise Vater oder Mutter verloren haben.

Armenhäuser und Asyle; Herbergen und Hospize. Unter diese Kategorie gehören verschiedene Wohlthätigkeitsund Rettungsanstalten: einerseits die ron ihren Insassen in der Regel für längere Zeit beanspruchten Armenhäuser. Invaliden-, Kranken- und Greisenasyle, andrerseits die für Hülfe von mehr vorübergehender Art bestimmten Herbergen und Hospize: Nachtruartiere für Ohdachlose, Herhergen für zeitweise arbeitslose Dienstboten (Mägdeherbergen), Handwerker und Emigranten: Anstalten für gefallene Mädchen, Hospize für Reisende etc.

Spitäler. Wir rechnen hieher die Gebäl-, Krankenund Irrenanstalten. In manchen Ländern haben die Spitäler keinen andern Zweck oder leisten sie kaum einen bessern Jienst, als die mit ansteckenden und ekelerregenden Krankheiten Behafteten (Aussätzige etc.) ron ihren Nitmenschen abzusondern ( Siechenhäuser ${ }^{“}$ des Mittelalters). Anderswo geniessen in diesen Anstalten die Kranken eine rortreffliche Behandlung und Pflege, welche man denselloen im Schoosse ihrer Familien unmöglich in dieser Weise angedeihen lassen könnte. Oft auch werden sie gratis behandelt und rerpflegt.

Besserungs- und Strafanstalten. Es gehören hieher gewisse, mit Landwirthschaft und Gewerbebetrieb verbundene Schulen für verwahrloste Kinder, Rettungsanstalten für jugendliche Verbrecher, Institute zur Besserung von Trunksüchtigen, Zwangsarbeitsanstalten für Liederliche und Vagabunden; sodann die Gefängnisse, Arbeits- und Zuchthäuser zur Be- 
strafung mehr oder minder schwerer Vergehen und Verbrechen. Zu letzterem Zweck wenden manche Staaten die Deportation oder die Versetzung in Strafkolonien und Bergwerke an.

Finanzinstitute. Als solche kommen namentlich in Betracht: die Baulien aller Art (Notenbanken, Diskontobanken etc.) des Staates und der Privaten; die Börsen für den Handel mit Wechseln und Effekten (Obligationen und Aktien von Eisenbahnen, industriellen Unternehmungen, Bankgeschäften etc.); die clcaring houses für die Scontration, d. h. die Ausgleichung gegenseitiger Schulden unter mehr als zwei Personen mittels Delegationen und Kompensationen.

Handelsinstitute. Hieher rechnen wir im Anschluss als Seitenstücke zu den eben genannten Anstalten: Die Leiłtoder Lombardbanken, welche Darlehen auf Börseneffekten und Waaren geben, letzteren Falls in Verbindung mit Lagerhäusern auf Lagerscheine zur Abtretung des Eigenthums an Waaren und Lagerpfandscheine (warrants) zur Verpfändung von solchen; die Waarenbörsen, wo sich die Käufer und Verkäufer einer und derselben bestimmten Waare einfinden, um ihre Geschäfte abzuschliessen — Institute (Getreidebörsen, Baumwollbörsen etc.), die sich von den Märkten und Messen dadurch unterscheiden, dass die Waaren gar nicht oder höchstens in Mustern mitgebracht werden. Hier ist auch der in verschiedenen Ländern mit der speziellen Sorge für die Interessen des Handels betrauten Handelskammern zu gedenken.

Versicherungsanstalten u. dgl. Unter dieser Rubrik sind ausser den Rentenanstalten und Lebensversicherungsgesellschaften, Feuer-, Transport- und Unfallversicherung etc., die verschiedenen gegenseitigen Hülfsgesellschaften, Kranken-, Alters- und Sterbekassen zu erwähnen; ferner die Sparkassen und Depositenbanken (caisses de dépôts et de sureté, safe deposits).

Vereinswesen. Bereits ist der gegenseitigen Hülfsgesellschaften und ähnlicher Verbindungen gedacht. Daran anschliessend, nennen wir von den verschiedenen Vereinen aller Art beispielsweise die folgenden: Konsumvereine zur Beschaffung billiger Lebensmittel für ihre Mitglieder, Wohlthätigkeitsgesellschaften wie solche für freiwillige Armen- 
unterstützung, Volksküchen oder Sparsuppenanstalten, Vorsorge gegen den Missbrauch geistiger Getränke, Verschaffung von Arbeit; Schutzaufsichtsvereine für entlassene Sträflinge; Thierschutzvereine etc.

Innungen und Bruderschaften. Die Immunen sind (obligatorische oder freiwillige) Verbände von Berufsgenossen, wie die Zïnfte in Deutschland, die alten guilds und corps de métiers in England und Frankreich, die artells in Russland etc. Oft sind aber diese Vereinigungen nur noch dem Namen und nicht mehr ihrem Wesen nach erhalten, indem sie lediglich aus den Nachkommen ihrer Begründer und früheren Mitglieder bestehen, sodass die jetzigen Theilnehmer den verschiedensten Berufsarten und Gesellschaftsklassen angehören.

Die Bruderschaften beruhen weniger auf materiellen, als auf moralischen Beziehungen und Verpflichtungen; das einigende Band ist wesentlich ein gemeinsamer Grundgedanke; so bei den religiösen Orden, dem Bunde der Freimaurer mit seinen "Logen" und verschiedenen gcheimen Gesellschaften. Die letzteren sind z. B. in China zahlreich; "weisser Lotus", "weisse Wolke", "Dolch" sind die Namen einiger derselben. Die Kuans oder Brüder in Narocco, Algier und Tunis gehören verschiedenen Orden an, deren Affiliirte in ganz Nordafrika verbreitet sind.

\section{GEWERBE.}

Als Gewerbfleiss oder Industrie im weitern Sinne des Wortes bezeichnet man jede Art nutzbringender Thätigkeit des Menschen, ob sie in Herrorbringung materieller Erzeugnisse oder in Dienstleistungen bestehe. So sprechen wir von dem Gewerbe (der Industrie) des Wilden, der täglich seiner Familie Fische und Wildpret liefert, sich eine Hütte, einen Kahn, Bogen und Pfeile anfertigt; von den Gewerben oder Industrien der Viehzüchter, Ackerbauer, Weber, Schneider und Schuster; der Verfertiger von Geräthschaften aller Art, auch wenn diese ganz primitiv sind; der Goldwäscher, Diamantengräber, wie Derer, welche Erze gewinnen und 
daraus die Metalle herstellen; nicht minder von dem Gewerbe oder der Industrie der Fuhrleute, der Pferde-, Eselund Droschkenvermiether, der Fremdenführer, Dienstboten, Wasserträger etc. etc. Die Thätigkeit der Individuen aller dieser verschiedenen Gruppen hat das gemeinsame Ziel der Befriedigung eigener Bedürfnisse; dieselbe ist in den einen Fällen eine direkte, indem der Mensch sich das benöthigte - unmittelbar selber verschafft oder erzeugt; in den andern Fällen ist sie eine indirekte, indem durch Dienstleistungen Lohn erworben wird, welcher als Mittel zur Befriedigung der Bedürfnisse dienen muss.

Als Industrie eines Landes in diesem umfassenden Sinne ist also die Gesammtheit der Beschäftigungen zu verstehen, durch welche die Bewohner desselben direkt oder indirekt für ihren Lebensunterhalt, ihr Fortkommen, für die Befriedigung ihrer Bedürfnisse sorgen.

Indessen wird das Wort Industrie oder Gewerbe meist in engerm Sinne gebraucht. Arbeiten, die Jemand selten vornimmt, wie die Erstellung einer Hütte oder eines Kahnes für den eigenen Gebrauch, werden in der Regel nicht als ein Gewerbe desselben bezeichnet. Oft schränkt man den Begriff noch mehr ein und schliesst von demselben alle die Thätigkeiten aus, deren direktes Ziel der Unterhalt des Individuums und seiner Familie ist, sodass er nur auf diejenigen Beschäftigungen angewendet wird, welche in Erzeugung ron Produkten für den Handel (Tausch und Verkauf) und in bezahlten Dienstleistungen bestehen. Bei dieser Auffassung werden Thätigkeiten wie das Weben und die Anfertigung von Kleidern für den eigenen Bedarf, Kultur und Zubereitung von Gemüsen etc. für den täglichen Gebrauch in der eigenen Familie u. dgl. mehr, als Hausarbeiten (häusliche Beschäftigungen) angesehen, nicht aber als eigentliche Gewerbe bezeichnet oder dies doch nur insofern, als sie eine den Hausbedarf übersteigende Quantität von Produkten liefern und dieser Ueberschuss einen Gegenstand des Handels bildet.

Im einen wie im andern Falle wird es nöthig, die vielen Gewerbe nach ihren rerschiedenen Arten zu betrachten.

Sammelgewerbe. Als solche bezeichnet man alle Thätigkeiten, die wesentlich in der Gewinnung (im Einsammeln) von blossen, ohne Zuthun des Menschen erzeugten Natur- 
produkten bestehen. Das Sammeln von wildwachsenden Beeren, Harzen, Balsam, Gummi, von Arzneipftanzen und deren Theilen (Rinden, Blüthen etc.), von essharen Schwämmen (Trüffelı, Morcheln u. s. w.), Schnecken und Muscheln (Austernfang oder "Austernfischerei"), von Perlmuscheln, Schwämmen und Korallen ("Korallenfischerei“), ron Blutegeln, Fluss- und Seekrebsen (Hummernfang ete.), wie die eigentliche Fischerei (auf Sardellen, Häringe, Thunfische, Kabeljau, Wale u. s. w.) all Das gehört in die Kategorie dor Sammelgewerbe. Desgleichen ist die Jagd hieher zu rechnen, sofern sie die unmittelhare Nutzniessung des erbeuteten (lebenden oder todten) Wildes, beziehungsweise gewisser Theile desselben, zum Zwecke hat; also die Jagd auf wilde Pferde und andere Thiere, die man lebend erhalten und verwenden will; die Jagd auf Hasen, Wildenten, Schnerfen, Krammetsvögel u. dgl. Thiere mehr, bei denen es sich lediglich um das Fleisch handelt; die Jaggd auf Eidergänse und Strausse zur Gewinnung ihrer Federn, auf Robben und Walrosse wegen Fett und Fell derselben, auf Elephanten zur Erlangung des Elfenheins, aufPelzthiere wie Füchse, Fischottern, Biber, Zobel u. s.w. Als Sammelgewerbe hat man ferner zu betrachten die Ausbeutung der Wälder zur Gewinumg vou Bau- und Nutzholz aller Art (Marquetterie-, Farbhölzer etc.); ebenso den Berghau, die Gewinnung von Bruchsteinen, Marmor, Schiefer, Steinsalz, Eis, Salpeter, Gyps, Phosphaten, Guano, Erdöl, Naphta, Torf, Kohlen, gediegenen Netallen (Gold), Edelsteinen (Diamanten) u. s. w.

Urproduktion. Darunter verstehen wir solche Gewerbe, welche Naturerzeugnisse gewinnen, an deren Entstehung oder Ausbildung der Mensch einen gewissen Antheil hat und die nicht ohne sein Zuthun und seinen Willen bereits in der Natur vorhanden (präexistent) waren. Die Arbeit des Menschen besteht hiex nicht mehr einfach in der Besitznahme vòn Gegenständen, welche Natur und Zufall in seine Hand geben; vielmehr sind die Objekte (Thiere und Pflanzen), um welche es sich hier handelt, selbst in gewissem Grade Resultat seiner Bemühungen, Frucht seines Fleisses. So verhält es sich mit den Gewerben der Viehzucht und Landwirthschaft.

Jene - die Gewerbe der Vieh- oder Thierzüchter rereinigen an einem gegebenen Orte Thiere einer bestimmten 
Art zur Gewinnung gewisser Produkte: der Wolle von Schafen, der Milch von Ziegen und Kühen, des Fleisches von Ochsen, der Eier von Hühnern, des Honigs ron Bienen etc. Danach sondern sich diese Gewerbe in verschiedene Spezialitäten: Viehzucht im engern Sinne (Rindvieh-, Pferde-, Schaf-, Schweinezucht etc.), Geflügelzucht, Bienenzucht, künstliche Fischzucht u. s. w.

Diese - der Landbau, die Boden- oder Pflanzenkultur bestehen darin, dass der Mensch Samen, Knollen und Stecklinge in die Erde bringt, woraus sich nun durch die Kräfte der Natur und seine fördernde Arbeit (Bodenbearbeitung, Düngen, Jäten, Giessen etc.) Nutzpflanzen entwickeln, die Nahrung liefern für Mensch und Vieh (Getreide mit mehlreichen Körnern, Kinollengewächse und andere Gemüse- oder Küchenkräuter, Futterpflanzen etc.) oder aber Stoffe zu Geweben (Faser- oder Gespinnstpflanzen: Hanf, Flachs u. dgl.), Oele u. s.f. Die einzelnen hiehergehörenden Spezialgewerbe werden bald nach den Pflanzen, welche Gegenstand der Kultur sind, beziehungsweise nach Produkten derselben, bald nach der Art des hiefür zu verwendenden Landes benannt: Getreide- und Futterbau, Obst- und Weinbau, Acker- und Gartenbau, Forstwirthschaft, Blumenzucht, Spargelzucht etc.

Ton den Sammelgewerben unterscheiden sich die verschiedenen Zweige der Urproduktion immer dadurch, dass bei ersteren der Mensch die Naturerzeugnisse da nehmen muss, wo er sie durch Aufsuchen oder zufällig gefunden hat und ganz so, wie eben die Natur sie giebt, während er bei letzteren diesen Objekten gewisse Standorte anweist, wie sie ihm geeignet scheinen, und er dieselben für seine Zwecke zu vervollkommnen sucht, was ihm in den meisten Fällen und oft in grossartiger Weise gelingt, sodass die Pflanze oder das Thier, welches unter seiner Pflege und Wartung sich entwickelte, von der wilden Stammform sehr erheblich verschieden sein kann. Für die Sammelgewerbe ist die Natur eine Quelle, aus welcher der Mensch schöpft; für die Urproduktionen aber ist dieselbe ein Hülfsmitte], Werkzeug oder Arbeiter. Daher ist in den beiden Fällen der Effekt wie qualitativ so auch quantitativ verschieden: der Mensch, welcher ein Sammelgewerbe betreibt, kann die Quantität des Naturproduktes, das er zu seinem Gebrauche 
in Besitz nimmt, nur vermindern; der Landwirth und Thierzüchter hingegen trachtet auf Vermehrung dieser seiner Schätze, und es wird auch das Streben nach Vermehrung, wie dasjenige nach Vervollkommnung der in Rede stehenden Produkte zumeist von Erfolg gekrönt.

Handwerk und Fabrikation. In diese Kategorie kann man alle Gewerbe einreihen, welche die Naturprodukte rerändern, kombiniren und umwandeln, sodass hiedurch denselben bestimmte gew ünchte Eigenschaften verliehen oder aus denselben neue Objekte gebildet werden. Die meisten Naturerzeugnisse, welche uns ron den Sammelgewerben und der Lrproduktion geliefert werden, sind nicht unmittelbar zur Befriedigung der menschlichen Bedürfnisse geeignet; mit wenigen Ausnahmen - wie roh geniessbaren Früchten, Austern u. dgl. - müssen sie, um den genannten Zweck zu erfüllen, eigens hergerichtet oder zubereitet werden: man muss die Getreidekörner zu Mehl verarbeiten und hieraus das Brod backen, die Wolle spinnen und das Garn verweben etc. Die Veränderung, welcher hiebei die Naturprodukte unterworfen werden, kann entweder blos deren Aeusseres, die Form, oder aber auch die stoffliche Beschaffenheit des Körpers betreffen, mit andern Worten wesentlich blos mechanischer oder aber chemischer Art sein; im ersteren Falle ist wieder zu unterscheiden zwischen den einfacheren Formänderungen, welche das Objekt lediglich in eine zweckmässigere, respektive beliebtere Gestalt bringen sollen, und der weitergehenden kombinirenden Bearbeitung, deren Resultat neue Objekte sind, worin die rormaligen als integrirende Bestandtheile erscheinen. So erhalten wir drei Kategorien dieser form- und stoffverändernden Gewerbsthätigkeiten. Die erste derselben - cinfuche Formünderung finden wir z. B. vertreten beim Schleifen (Façonniren) der Diamanten und mancher Halbedelsteine, beim Graviren und Ziseliren, im Färben und Bedrucken von Geweben etc.; in manchen Fällen hat sie es mit der (mechanischen) Zerlegung eines Ganzen in seine Theile, einer Zerkleinerung des Rohmaterials $\mathrm{zu}$ thun, so beim IIahlen des Getreides, beim Gewerbe des Metzgers, beim Bretterschneiden in der Sägemühle, beim Zuschneiden von Kleidern u. s. f. Eine Umgestaltung der zweiten Art - Kombination der 
Theile eines Stoffes oder verschiedener Materialien zu einem neuen Objekte, worin die konstituirenden Bestandtheile mehr oder minder leicht zu erkennen sind - findet statt bei den Flechtarbeiten (Korbmacherei, Strohhutfabrikation u. dgl.), heim Spinnen und Weben, in verschiedenen Baugewerben, der Fabrikation vieler Geräthe und Werkzeuge, Maschinen, Uhren u. s. w. Gewerbsthätigkeiten der dritten Art - mit Truandlung der zu bearbeitenden Stoffe in neue Produkte, welche dem angewendeten Naterial durchaus nicht mehr gleichen - haben wir in der Milchwirthschaft (Käserei), in der Bereitung ron Most und Wein aus Obst und Trauben, der Brauerei, der Branntweinbrennerei und Essigfabrikation, der Farbenindustrie, Metallurgie etc.

Lnter den Erzeugnissen der Fabrikation werden Fabrikate und Halbfabrikate unterschieden, jenachdem dieselben das definitive Endprodulit der ganzen Reihe von Umwandlungen sind, welche die rerschiedenen Stadien der Bearbeitung eines Objektes (Rohstoffes) in sich schliesst, oder aber noch weiterer Bearbeitung unterliegen. Bei der grossen Zahl von Gliedern, welche die Kette der Umformungen eines Objelites haben kann, und da jeder Fabrikationszweig seine Erzeugnisse als sein Fabrikat, das Material dazu aber in derjenigen Form, in welcher es zur Verarbeitung an ihn gelangt - als Rohstoff bezeichnet, haben die drei Ausdrücke mehr nur relative Bedeutung als einen fest bestimmten Sinn. Z. B. wird in den Spinnereien aus roher Wolle, roher Baumwolle etc. Garn angefertigt; dieses wird durch eine andere Industrie zu Geweben rerarbeitet und ist also "Halbfabrikat" ; ähnlich verhält es sich aber auch mit den Geweben, insofern dieselben wieder als Stoff dienen, woraus erst eine dritte Industrie (der Schneider, Näherinnen etc.) das Endprodukt der Reihe (Konfektionsartikel) herstellt. Andrerseits sind die Garne das „Fabrikat“ des Spinners und Rohstoff für den Weber etc.

Eine speziellere Klassifikation der einzelnen Zweige des Handwerks- und Fabrikbetriebs kann vorgenommen werden nach Analogien und Verschiedenheiten in dem zu bearbeitenden Material, den Erzeugnissen und deren Bestimmung, sowie in dem von jenen beiden Faktoren bestimmten Charakter der Arbeit; ob die zu verarbeitenden Stoffe mineralische 
pflanzliche oder thierische Rohmaterialien oder selbst schon Fabrikate seien; ob die Erzeugnisse physischen oder geistigen Bedürfnissen dienen, als Nahrungs- und Genussmittel, für Wohnung, Kleidung, Heizung, Beleuchtung, Schmuck, für Zwecke der Mittheilung und des Austausches ron Gedanken, der Kunst, der Vervielfältigrung etc. - Die Art des Betriebes (Handwerk, Kloingewerbe, Hausindustrie einerseits; Fabrikbetrieb, Grossindustrie andrerseits), die Provenienz ihres Materials und die $A b s a t z g e b i e t e$ (wonach zwischen bodenständigen und Exportindustrien unterschieden werden kann), die Lohnverhältnisse etc. sind Gesichtspunkte, die ebenfalls berücksichtigt werden müssen und die wir theilweise unten noch zur Sprache bringen.

Handel. Als Handel bezeichnen wir die Gewerbsarten, wobei der Mensch Objekte ron Denjenigen, welche sie gesammelt, kultivirt, fahrizirt, eingetauscht oder angekauft haben, erwirbt, um sie sodam an Konsumenten oder andere Käufer abzusetzen, ohne dass hiebei irgrendwelche erhebliche Veränderungen dieser Objekte vorgenommen werden müssen. Zum Unterschied ron den bisher betrachteten Gewerben hat es der Handel nicht mit Erzeugung von Gütern, sondern mit deren Austausch oder Lmsatz durch Uebertragung des Eigenthumsrechts zu thun. Hiebei findet entweder ein Krauf und Verkauf von Waaren gegen Geld statt oder ein Tuusch ron Waaren gegen Waaren (Tauschhandel). In Nordamerika tauschen die Trapper gegen Glaswaaren, Gewebe, Spirituosen und Waffen von den Indianern Bären-, Biber- und Büffelfelle ein, welche sie dann in den Forts und Comptoirs verkaufen, wo man sich mit dem Pelzhandel beschäftigt. Die Händler in Afrika tauschen gegen Freifrachtartikel Goldstaub, Elfenbein, Ebenholz und andere Kostbarkeiten ein, welche sie nachher in den Faktoreien der Küste verkaufen. Auf dem Mississippi und den übrigen schiffbaren Flüssen Nordamerikas erscheinen zahlreiche Fahrzeuge, um von den Farmern gegen Bedarfsartikel derselben landwirthschaftliche Produkte einzutauschen und diese alsdann auf die Märkte der grossen Städte zu bringen. In Holland, Frankreich, der Schweiz durchziehen Händler das Land, um Vieh und andere Produkte für den Konsum der grossen Ortschaften zu kaufen. Die Hausirer hingegen rersehen sich in den 
Städten mit Artikeln, welche sie auf dem Lande absetzen. Der Krämer nimmt seine Artikel bei einem Engros-Geschäfte, um sie sodann in kleinen Quantitäten (en détail) wieder zu verkaufen; das Engros-Geschäft (der Grossist) seinerseits bezieht die Taaren ron den Produzenten und gibt sie an kleinere Häuser (Detaillisten) ab. Sofern dieser Güteraustausch sich imnerhalb der Grenzen des betreffenden Landes rollzieht, ist er Binmenhandel, andernfalls Aussenhandel; der letztere umfasst den Export (Ausfuhr von Produkten und Fabrikaten des eigenen Landes) und den Import (Einfuhr der Waaren aus fremden Ländern). Hiebei ist ron Wichtigkeit, auf welchem Wege der Waarentransport vor sich grehe, ob zu Wasser oder über Land, mit Eisenbahnen, Wagen, Karavanen etc. Wenn der Aussenhandel seine Absatz- oder Bezugsorte in fremden liontinenten hat, mit welchen er zu Schiff rerkehrt, heisst er äbersecischer Handel; dahin gehört der direkte Bezug von Kolonialwaren. Falls ein Volk seine Produkte und Fabrikate auf eigenen Schiffen ausführt und fremde ebenso einführt, sagt man, es treibe Alitirhandel; lässt es aber die Handelsobjekte durch andere schifffahrttreibende Völker aus- und einführen, so wird dies als Pussichundel bezeichnet. - Objekt des Handels können die verschiedensten Waaren oder Güter sein: Land, Häuser, Lebensmittel, Fabrikate, Edelmetalle, Werthpapiere, Bücher, Kunstgegenstände etc., und danach unterscheidet man Güterund Häuserhandel, Waarenhandel, Geld- und Effektenhandel, Buch- und Kunsthandel etc. Unterscheidungen wie Eigenhandel und Auftrags- oder Kommissionshandel, Einzelhandel und Gesellschaftshandel beziehen sich auf die Art, wie die handeltreibenden Personen sich an dem Geschäfte betheiligen.

Miethgewerbe. Sie bestehen darin, dass derjenige, welcher eine solche Industrie betreibt, gewisse Objekte erwirbt, die er zur Benutzung gegen Entgelt Andern überlässt. Es wird hier also lediglich das Nutzungsrecht und nicht (wie beim Handel) das Eigenthumsrecht abgetreten, was Denjenigen, welche diese Einrichtungen benutzen, den Vortheil gewährt, dass sie die grössere einmalige Ausgabe für kaufsweise Aneignung der bezüglichen Objekte, sowie den oftmals erforderlichen Aufwand an Mühe und Kosten für Unterhalt und Besorgung derselben vermeiden können. 
Je nach der Besonderheit des Falles wird eine solche Benutzung als Niethe im engeren Sinn oder als Pacht und Leihverhältniss bezeichnet, wobei für manche Fälle ziemlich unterschiedslos der eine wie der andere Ausdruck zur Anwendung liommt. In allen Städten findet man Unternehmer, welche das Vermiethen von Reitthieren als Geschäft betreiben (Pferdehalter etc.); Andere rermiethen Fahrzeuge, Wagen und Schiffe. In Leihbibliotheken und Lesezimmern stellt man deren Benutzern Bücher, Zeitungen und Zeitschriften zur Verfügung; anderswo geschieht dasselbe mit Zeichnungsmustern, Musikalien etc. Man rermiethet möhlirte und unmöblirte Zimmer oder ganze Häuser, Werkstätten, Magazine, verpachtet Landgüter, Gärten, Weinberge u. s. w. In manchen Städten sind Mübel aller Art, selbst Kleider und Toilettengegenstände, miethweise zu haben. Auf dem Lande werden von einzehnen Unternehmern oder Vereinen landwirthschaftliche Maschinen an Kleinbauern und Pächter vermiethet. $\mathrm{Zu}$ diesen Gewerben gehört auch dasjenige des Geldverleihens. Die Entschädigung, welche in diesem Falle an den Darleiher zu zahlen ist, wird Zins genannt; in analoger Weise bedient man sich der Ausdrücke Nieth- und Pachtzins.

Hülfsgewerbe. Als solche bezeichnen wir die gewerbsmässigen Verrichtungen von Personen, welche sich gewisse Kenntnisse und Fertigkeiten erworben, sich Fähigkeiten und Mittel angeeignet haben, womit sie nun Dienste leisten, welche Andern Zeit oder Mühe ersparen. Der an den Strassenecken ron Paris stationirte Aurergnat verdient sein Brod durch Besorgung ron Aufträgen, als Packet- und Wasserträger etc.; hiezu hat er sich befähigen müssen, indem er einerseits eine genaue Kenntniss des betreffenden Stadtquartiers erwarb, andrerseits seine physischen Kräfte entwickelte. Der Holzhacker, blos ausgerüstet mit Säge und Bockgestell, verrichtet eine Arbeit, die wir wohl selbst auch besorgen könnten, die wir uns aber durch Anstellung und Bezahlung eines Andern ersparen wollen. Der Fälle, welche in diese Kategorie zu rechnen sind, gibt es eine Menge; wir nennen weiter die Gewerbe der Kaminfeger, Gassenkehrer, Stiefelputzer, Packer, der Wäscherinnen und Glätterinnen, der Barbiere und Coiffeure. Auch die Geschäftsund Vermittlungsbureaux aller Art, von den Dienstboten- 
und Annoncen- bis zu den Heiratsbureaux, haben denselben Zweck: Andern gegen Entgelt gewisse Schritte, Bemühungen und Zeitverlust zu ersparen; ebenso verhält es sich mit Wallfahrten, die für Andere in deren Auftrag nach Einsiedeln, Mekka u. s. w. gemacht werden. Die Transportgewerbe der Maulthier- und Kameeltreiber, der Droschken- und Omnibusbesitzer, der Kahnführer, der Posten wie der grossen Schiffsund Eisenbahngesellschaften gehören ebenfalls hieher, insofern es sich bei denselben nicht blos um Benutzung von Gegenständen, sondern auch um persönliche Dienstleistungen handelt.

Sanitätsgewerbe. Das Gewerbe des Arztes besteht darin, dass er seine Kenntnisse, Fertigkeiten und gewisse Mittel dazu verwendet, uns von körperlichen Uebeln $\mathrm{zu}$ befreien oder doch dieselben zu lindern, wofür wir ihn honoriren. Unter die Mittel zu diesem Zwecke sind auch die verschiedenen ärztlichen Etablissements zu rechnen, worin Kranke und Schwache im Interesse ihres Wohlbefindens und der Wiederherstellung ihrer gestörten Gesundheit, beziehungsweise eines normalen Zustandes, eine besondere Pflege und Behandlung finden. Hiefür reicht die Thätigkeit des Arztes nicht aus; er hat Wärter oder Krankenpfleger beizuziehen, und wenn das Etablissement einen grossen Umfang annimmt, wird für dasselbe ein zahlreiches Verwaltungspersonal (für Korrespondenz und Buchhaltung, Besorgung der Küche, Zimmer, Gartenanlagen etc.) nothwendig. Die Verschiedenheiten der ärztlichen Gewerbe und Anstalten ergeben sich aus der Spezialität der zu behandelnden Gebrechen und des Verfahrens zu ihrer Beseitigung oder Linderung; jenachdem spricht man von Wundärzten, Augenärzten, Zahnärzten etc., von gymnastischen Heilanstalten, Wasserheilanstalten u. s. w.

Vergnügungsgewerbe. Die Gewerbetreibenden dieser Kategorie wenden gewisse Kenntnisse, Fähigkeiten und Mittel an, um Andern Vergnügen oder Ergötzungen und sich selbst damit Einnahmen zu verschaffen.

Es gehören hieher die Taschenspieler, Seiltänzer, Bänkelsänger, wandernden Musikanten etc., wie die vielen Budenbesitzer, welche an Messen, Märkten und Festanlässen auf öffentlichen Plätzen irgend welche Merkwürdigkeiten zur 
Schau stellen (Riesen und Zwerge, Panoramen, "Museen", Menagerien u. s. w.); ferner Besitzer oder Unternehmer von cafés-chantants und mancher Bäder, welche ihre Besucher mehr durch Spiel und andere Vergnügen als zur Erquickung oder Heilung anziehen. Enthält diese Gruppe nicht wenige Spezialitäten von Gewerben, welche einfach darauf ausgehen, dem Publikum mit allerlei Mitteln Geld abzunehmen, so fehlt es auch nicht an solchen, die ihre Aufgabe in grösserem Sinne auffassen, die eine ernsthafte Unterhaltung mit Belehrung oder einem moralischen Zweck zu verbinden, dem Hörer oder Zuschauer einen geistigen Genuss von nachhaltiger Wirkung zu verschaffen streben und dadurch einen erzieherischen Einfluss ausüben. Dies ist der Fall bei guten Schaustücken verschiedener Art, Theatern, Konzerten etc.

Erziehungsgewerbe. Sie bestehen in der Verwendung von Kenntnissen, Fertigkeiten und materiellen Mitteln zur Belehrung, geistigen und kürperlichen Ausbildung Anderer durch berufsweise Unterrichtertheilung und Anleitung. Bietet schon das Lehrpersonal an den verschiedenen Lnterrichtsanstalten, wie diese selbst (rgl. S. 728) eine grosse Manigfaltigkeit dar, so wird letztere noch rermehrt durch die verschiedenen Spezialitäten des Lehrberufes, welche an jenen Anstalten nur ausnahmsweise oder gar nicht rertreten sind, wie Tanz-, Schwimm-, Fecht- und Reitlehrer. Eine Menge von Personen beiderlei Geschlechts finden ihren Lebensunterhalt in Ertheilung ron Privatunterricht auf den verschiedensten Gebieten des Wissens und Könnens (Sprachen, Mathematik, Gesang und Musik, Kalligraphie, Zeichnen und Malen etc.); als Hauslehrer, Hofmeister, Erzieher, Gouvernanten und wie die Bezeichnungen alle heissen; als pädagogische, technische und administrative Leiter von Erziehungsinstituten und Pensionaten, wie als Lehrer und Gehülfen an solchen in den verschiedensten Stellungen.

Résumé. Wir sehen, dass die Gewerbe ihrem wesentlichen Charakter nach uns entweder materielle Dinge Produkte - oder immaterielle Dinge - Dienste - zur Verfügung stellen.

Die Produkte werden direkt oder indirekt aus der Natur bezogen: direlit durch blosses Sammeln von schon Vorhandenem (Sammelgewerbe) oder durch Kultur und Aufzucht 
an bestimmten Orten und in gewissen Quantitäten (Urproduktion); indirelit, d. h. aus zweiter Hand, rom Sammler oder Urproduzenten, zu dem Zwecke, sie umzuändern und in dieser neuen Form zu verkaufen (Fabrikation) oder dieselben ohne eine solche Aenderung an die Konsumenten abzusetzen (Handel).

Die Dienste beziehen sich einerseits auf die Oekonomie, anderseits auf das körperliche und geistige Wohl; auf die Orlimomic, indem sie uns die Ausgaben für selbsteigene Beschatfung gewisser Produkte vermeiden lassen (Miethgewerbe) oder aber Mühen und Zeitverluste ersparen (Hülfsgewerbe); auf das Wrolbefinden, indem sie Krankheiten und Gebrechen heilen oder lindern (Sanitätsgewerbe), durch Vergnügungen zerstreuen, erheitern und anregen (Vergnügungsgewerbe), durch Ausbildung körperlicher und geistiger Fähigkeiten fördern und Kenntnisse und Fertiglieiten rerschaffen (Erziehungsgewerbe).

Dieser Klassifikation der Gewerbe nach den beiden vorstehend unterschiedenen Gruppen sind in Bezug auf die zweite derselben einige Bemerkungen beizufügen. Wir haben schon angedeutet, dass die Miethgewerbe sich dem Handel anschliessen, insofern auch sie uns Gegenstände verschaffen, nur nicht als Eigenthum, sondern zur zeitweisen Benutzung; unter diesem Gesichtspunkt werden sie dem auch in die Kategorie der Handelsgewerbe eingereiht (Alicthhandel). Alsdann pflegt man ron ihmen und den verschiedenen Gewerben, welche wir oben als in Dienstleistungen bestehend charakterisirt haben, einige auszuscheiden, wobei es sich nicht nur um Ueberlassung von Gegenständen als Nutzobjekt oder Konsumartikel, sondern auch um Dienstleistungen handelt, wie dies der Fall ist einerseits beim Personen- und Waarentransport (Verkehrsyererbe), andrerseits bei derjenigen Industrie, welche es vornehmlich mit Beherbergung und Erquickung zu thun hat (Wirthsycuerbe, Industrie der Gasthöfe, Pensionen, Restaurants, "Fremdenindustrie"). Danach bleiben für weitere Abtheilungen der zweiten Gruppe (Heilungs-, Vergnügungs-, Erziehungs- und Hülfsgewerbe) nur noch solche Industrien, wobei unzweifelhaft die Leistung von Diensten, beziehungsweise das persönliche Element derselben, die Hauptsache ist. 
In sehr vielen Fällen beschäftigt sich das einzelne Individuum nur mit Einer bestimmten Gewerbsthätigkeit und ist diese seine Berufsart blos ein kleiner Zweig eines grossen Gewerbes, herrscht also eine weitgehende dibeitstheilum, wie dies z. B. bei Spezialärzten, Fachlehrern, vielen Lhrenarbeitern etc. der Fall ist; sehr oft aber auch betreibt ein und dasselbe Individum mehr als eine Gewerbsart (z. B. Landwirthschaft and einen Handwerks- oder Fabrikationszweig), wovon jedoch eine zu dominiren pflegt, sodass für Zwecke der Berufsstatistik (vgl. S. 543) zwischen Hauptand Nebengewerbe der Einzelnen zu unterscheiden ist.

Räumliche Vertheilung. Selten findet sich eine und dieselbe Industrie gleichmässig äber eine Gegend ron namhafter Ausdehnung verbreitet; vielmehr ist die Vertretung und Gruppirung der einzelnen Gewerlye oft ron Ort zu Ort. rerschieden. Den besten Ueberblick dieser Verhältnisse gibt man durch eine lictorf) (uphische Durstellung mittels kourentioneller Zeichen und Farben ${ }^{1}$ ); immerhin ist dieses Bild zu ergänzen durch eine chlitirende and beschreibende Durstellun!f im Texte des Reisewerkes. In diesem sind unter Anderm die Faktoren zu besprechen, welche bewirkten, dass eine bestimmte Industrie ausschliesslich oder vorherrschend an gewissen Orten sich entwickelt hat oder hier doch früher als an andern, dass manche Länder oder Gegenden in Bezugr auf einzelne Gewerbszweige sich einer Art Monopol erfreuen. In der That ist die räumliche Gruppirung der Gewerbe nicht immer blos eine leicht erklärliche Folge ron Naturverhältnissen, sodass sie sich aus bekannten Grössen errechnen und konstruiren liesse, wie die Unbekannte einer Gleichung. Wohl müssen, wo ein Produkt gewonnen werden soll, die Bedingungen dazu vorhanden sein; Betrieb ron Viehzucht setzt die Existenz, von Weiden, Wiesen, Matten voraus, Ackerbau das Vorhandensein urbaren Landes. Nur wo diese Grundbedingungen erfüllt sind, werden jene Gewerbe der Urproduktion sich entwickeln. Dagegen kann man nicht auch behaupten, dass die letzteren überall rorkommen, wo die Bedingungen dazu gregeben, wo sie durch die Verhältnisse ermöglicht wären. Die Handwerks- und Fabrikgewerbe

1) Vgl. Dr. H. Wartmann, Atlas über die Entwicklung von Industrie und Handel der Schweiz, Winterthur 1879. 
sind weniger an die Scholle gebunden, vom Boden und dessen Schätzen abhängig; doch bevorzugen sie im Allgemeinen, aus naheliegenden Gründen, solche Lokalitäten, wo das Rohmaterial gewonnen wird, welches sie verarbeiten, oder die wenigstens in der Nähe derartiger Fundstätten liegen. Aber diese Regel erleidet zahlreiche Ausnahmen. Die Hochöfen, wo aus den Erzen die Metalle bereitet werden, findet man wohl in der Nachbarschaft der Ninen, die Sägemühlen in waldreichen Gegenden und deren Nähe; aber die Baumwolle wird nicht in den Gegenden versponnen und verwoben, wo sie wächst; sie koinmt in verarbeitetem Zustande erst nach langem Transporte zurück in ihr Ursprungsland. Die Uhrenmacherei hat ihre Hauptsitze in Genf, Neuenburg und den Jurathälern, hätte sich aber eben so gut ganz anderswo entwickeln kömnen. Aehnlich verhält es sich mit der Art ron Monopol, welches Lyon, Zürich und Basel in der Seidenindustrie (Lyon in Luxusartikeln, Zürich in kuranten Stoffen, Basel in Bändern) haben, wie mit denjenigen von St. Gallen für Stickereien, ron Marseille für Seifen, von Elbeuf für Tücher, von Sheffield für Rasirmesser u. s. w.

Gewerbliche Charakterbilder. Der Reisende hat sich mit den Hauptgewerben des ron ihm besuchten Landes bekannt zu machen, d. h. mit denjenigen, welche je von einem starken Bruchtheil des Volkes betrieben werden und wesentliche Eirmahmsquellen des Landes sind. Sowohl von ihrer Bedeutung als von der Art ihres Betriebes ist ein churateristisches Bild zu entuerfen. Jedes Gewerbe verleiht einer Gegend - selbstverständlich in um so höherem Grade, je mehr es darin vorherrscht - gewisse Eigenthümlichkeiten, besonders charakteristische Züge. Ein Jägerdorf hat eine andere Physiognomie als ein Fischerdorf oder eine Niederlassung von Bergleuten; eine Gegend, deren Bewohner blos Viehzucht treiben, bietet ein ganz anderes Bild dar als eine solche, wo Ackerbau, Handwerk und Fabrikation eine Rolle spielen. Diese Seite der Sache verdient mehr Berücksichtigung als ihr oft zu Theil wird. Man kann auf genaue statistische Angabe (über die Zahl der Arbeiter, die Höhe der Produktion, die Arbeitslöhne etc.) halten und sich dabei nicht minder angelegen sein lassen, von einer Beschäftigung, von der Art eines Gewerbebetriebs, die man zu beobachten 
Gelegenheit hatte, eine lebendige Darstellung zu geben. Welche Fülle charakteristischer Bilder bietet sich uns dar in Scenerien und Beschäftigungen wie indianischen Büffeljagden, dem Häringsfang der Holländer, in den Marmorbrüchen von Carrara, dem Bergwerksbetrieb auf Elba, der Viehzucht Australiens oder der südamerikanischen Pampas, der Theekultur in China, dem Reisbau Indiens und der lombardischen Ebene, der Käserei in den Alpen, der Uhrenfabrikation in Genf und Besançon, der Hüttenwerke in Creuzot, dem grossartigen Fabrikwesen ron Birmingham, Sheffield und andern Hauptplätzen der Industrie. Ein und dasselbe Gewerbe kann uns unter manigfachen Formen entgegentreten. Die Bodenkultur z. B. ist in den einzelnen Ländern und Erdtheilen überaus verschieden. Der Tatare düngt die Erde durch Abbremnen der Vegetation, welche sich auf ihr entwickelt hat; dann säet er den Buchweizen aus; hat er seine Ernte eingeheimst, so begibt er sich weiter, um für die nächste Aussaat ein andres Stück Erde zu benutzen als jenes, das er nun achtzehn bis zwanzig Jahre in Ruhe lässt. In Nordafrika findet man dicht neben einander den Araber, der sich zumeist darauf beschränkt, mit einem als Pflug dienenden krummen Ast den Boden etwas aufzureissen, und den Kabylen, welcher keine Mühe scheut, um sein Feld gründlich $\mathrm{zu}$ bearbeiten und auf nackten Felsen Kulturen anzulegen, indem er die nöthige Erde auf seinem Rücken herbeischafft. Wie verschieden wurden und werden noch - nach Zeiten und Ländern das Spinnen und Weben betrieben! In China sind es Hausindustrien, womit die Bauernfamilien sich an den langen Winterabenden beschäftigen und deren Produkte sie im folgenden Sommer in die nächste Stadt auf den Markt bringen. Ganz ähnlich verhielt es sich einst — noch in der ersten Hälfte unseres Jahrhunderts - mit dem Betrieb dieser beiden Gewerbe in der östlichen Schweiz. Wie anders ist es nun hier! Naschinenbetrieb in Fabriken hat die Hand- und Hausarbeit ersetzt und verdrängt. Dieselbe Sachlage finden wir vielerorts im westlichen Europa, rorab in England.

Influirende Verhältnisse. Verschiedene Faktoren bedingen die Entwicklung der Gewerbe in einem Lande; die persönlichen Eigenschaften ihrer Tertreter dürfen dabei in erste 
Linie gestellt rerden. Es hängt ja das Gelingen einer jeden Unternehmung gutentheils ron der Befähigung des Lnternehmers ab; so ist es auch für die Gewerbe von grösster Bedeutung, dass an ihrer Spitze Männer stehen von grosser intellelitueller und moralischer Tüchtigkeit, Männer von unternehmendem Geist und praktischem Simn, die Kenntnisse und Arbeitslust, Energie und Lmsicht zugleich besitzen. Ein zweiter mesentlicher Faktor ist die Tüchtigkeit der Arbeiter, durch welche die Leistungen in hohem Grade beeinflusst werden. Gute Arbeiter, sant $H$. Taine ${ }^{1}$ ), sind diejenigen, welche Bedürfnisse haben und diesen durch andauernde Arbeit zu genügren trachten, welche weder die Anstrengung noch die Einfürmigheit einer Arbeit scheuen, weil sie die letztere an und für sich lieben und die moralische Energie besitzen, womit der Mensch Mühen und Strapazen ertragen kann; Eigenschaften, die ror Vergnügungssucht, überspannten Ideen und einem launenhaft wechselnden Sinn bewahren. In dem Wettiampf der Gewerhe verschiedener Länder spielen die Eigenschaften ihrer Arbeiter eine bedeutende Rolle; das Land, welches über Heissige, mässige und intelligente, mit guter Schulbildung ausgerüstete Arbeiter verfügen kann, ist hiedurch gegenüber Konkurenten, welche in dieser Hinsicht weniger günstig situirt sind, in grossem Tortheil. Einen dritten wichtigen Faktor bilden die Geldrerhältnisse. Wenn viele Kapitalien disponibel und dieselben leicht erhältlich sind, wird das Gedeihen der Industrie befördert; umgekehrt sind ihrer Entwicklung enge Grenzen gezogen, wo das Kapital spärlich rorhanden und dieses nur zu drückenden Bedingungen, gegen ühermässigen Zins, erhältlich ist.

Ausser diesen drei Faktoren wirken aber noch gar manche Verhältnisse auf die Stellung der Gewerbe in einem Lande ein. Zu diesen L'mständen gehört vorab das Ansehen, dessen sich in der öffentlichen Meinung die Handarbeit zu erfreuen hat, der Grad ron Achtung, welcher ihr gezollt wird. In Ländern, wo diese Arbeit als erniedrigend gilt und blos von Sklaven, Leibeigenen oder untern Kasten und Klassen verrichtet wird, kann die gewerbliche Entwicklung keine hohe Stufe erreichen; rollends fehlt es an jedem frischen Impuls

1) H. Taine, Notes sur l'Angleterre, Paris 1872, pag. 82. 
für sie, wo einzig das Waffenhandwerk als ein edler Beruf angesehen wird, wo Jagd und hriegr als das Höchste, Plünderung und selbst Raub als erlaubt oder gar als ruhmroll gelten, während die Beschäftigung mit ehrlicher Arbeit für eine Beeinträchtigung der Würde des Menschen gehalten wird.

Von nicht geringem Eintluss sind ferner die Besonderheiten in den Eigenthumsverhältnissen. Wo diese so gestaltet sind, dass sie Anlass veben zu Zweifeln darüber, ob man die Frucht langer Arbeit werde ernten können oder nicht, da muss der unternehmende sinn erlahmen, welcher nöthig ist, um den Boden zu erschliessen und ihm nachhaltig Schätze abzugewimnen: die granze Thätigkeit des Y'roduzenten wird alsdann nur darauf berechnet sein, möglichst rasch Erträge zu bekommen: aber eine Bearbeitung und Verbesserung des Bodens von der erst nach längrerer Zeit eine vortheilhafte Wirkung zu erwarten stünde, wird unter solchen Umständen selten sein. Die Lrprodulition kann ferner beeinträchtigt werden sowoll durch eine übermässige Zerstückelung (Parzellirung) des Grundeigentliums als durch das andere Extrem: wenn das Land sich ansschliesslich oder überwiegend in den Händen einiger weniger Grossgrundbesitzer befindet.

Von nachtheiliger Wirkung auf die Inclustrie erweist sich oft der Bestand örtlicher oder allgemeiner Gewerbesteutern; der Mangel jedweden Schutzes des Produzenten gegen die fremde Konkurrenz; oft aber auch ein Lebermaass solchen Schutzes, wobei der Produzent jener Impulse verlustig geht, die nur der Kampf ums Dasein gebiert.

Ton den Hindernissen, welche die Beschaffenheit der Verkehrswege und Transportmittel, sowie der Mangel an Absatz. (Märkten) mit sich bringt, haben wir oben (Abschnitt "der Boden", S. 377) schon gesprochen. Es bleibt uns noch ührig, des grossen Einfusses zu gedenken, welchen die politischen Zustände eines Landes, Freiheit und Rechtssicherheit auf dessen gewerbliche Entwicklung haben. „Die Kultur des Bodens steht im Verhältniss zur Freiheit seiner Bewohner", sagt Montesquieu. In der That wird man unter einem despotischen Regiment, unter einer drückenden Herrschaft keinen blühenden Landbau finden. Wenn Afrika nicht mehr der "Kornspeicher Roms" ist, so trägt daran das 
Regierungssystem einen grossen Theil der Schuld. Aehnlich wie mit der Bodenkultur verhält es sich aber mit andern Gewerben. Ihre Entwicklung in einem Lande wird mitbestimmt durch die Freiheit und Rechtssicherheit, durch die geordneten Zustände, deren seine Bewohner sich erfreuen; an ihrer Industrie erkennt man nicht allein ihren Thätigkeitssinn, sondern auch, ob derselbe in Freiheit schalten kann oder durch allerlei Schranken und Fesseln mehr oder minder gehemmt ist.

Werkzeuge und Methoden. Die Instrumente und Arbeitsmethoden oder Arten des Verfahrens, welche in den Gewerben eines Landes zur Anwendung kommen, sollen dem Leser in Wort und Bild vorgeführt werden. Eine solche Darstellung ist von mehrfachem Interesse. Sie hat zunächst ihre pittoreske, ethnographische Seite. Beispiele, welche dies darthun, sind überaus zahlreich. Wir erinnern nur an einige derselben. Die Erntegeräthe Sense und Sichel sind bei uns in ihrer Form seit Jahrhunderten gleich geblieben und haben nur im Material Verbesserungen erfahren; die Formen aber, in welchen sie bei den einzelnen Völkern auftreten, sind sehr verschieden, sodass eine Zusammenstellung der Sicheln und Sensenblätter ein interessantes ethnographisches Objekt ist. Für den Fischfang wird in China der Kormoran verwendet, in Südamerika der Wurfspiess, in Nordschottland ein Dreizack etc. Wenn in den Haciendas von Columbien die Reiskultur einfach dadurch betrieben wird, dass man einige Handvoll Saatkörner in die Löcher wirft, welche durch die Hufe des Viehes entstanden, und diese Körner in die Erde treten lässt: so ist dies einfache Verfahren des Getreidebaus nicht minder charakteristisch als jene verschiedenen Methoden des Fischfangs. Die Kenntniss der Werkzeuge und gewisser Manipulationen von Naturvölkern ist ferner das beste und mitunter das einzige Mittel zur richtigen Auffassung urgeschichtlicher Funde in unsern Gegenden. Die Sache hat aber auch ihre praiktische Seite. Unter Umständen wird man die Frage prüfen, ob ein von einem fremden Volke mit eigenen Instrumenten in seiner gewohnten Weise betriebenes Gewerbe nicht bessern Erfolg bringe, wenn man jene Werkzeuge und Methoden durch die unsrigen ersetzt. 
Lohnverhältnisse. Mittheilungen über die Arbeitslöne und die sachbezüglichen Verhältnisse in cinem Lande sind immer von grossem Interesse. Genaue Angaben hierüber können in Betreff von Ländern, die Reiseziele von Auswanderern sind, den letzteren als Führer dienen, wenn sie Arbeit suchen; ebenso werden dergleichen Zahlen Lnternehmern und Kapitalisten, welche in solchen Ländern industrielle Etablissemente errichten wollen, gute Dienste leisten. In allen Fällen erhält man dadurch Aufschluss über die Lage der arbeitenden Klassen in dem besuchten Lande; nur darf man sich dabei nicht auf eine blosse Angabe des Lohnes beschränken, sondern muss die Lehensverhältnisse der Arbeiter mit in Betracht ziehen; denn ron diesen Lmständen hängt es $a b$, ob der Lohı für den Arbeiter eine grosse oder kleine Summe darstellt. In China z. B. rerdient ein gewöhnlicher Arbeiter im Jahre 60 bis 90 Franken brutto; daraus muss er seinen Lebensunterhalt bestreiten. Bei uns wäre das schlechthin unmöglich; der chinesische Arbeiter kann aber so wohlfeil leben und ist so genügsam, dass er mit jener geringen Summe alle seine Auslagen deckt und sich noch Etwas erübrigt. In manchen Gegenden sind die Arbeiterfamilien trotz niedriger Löhne doch verhältnissmässig gut situirt, weil auch Frauen und Kinder verdienen können und nicht der Mann allein für die Kosten des Haushalts aufzukommen hat. Anderswo wird dasselbe erreicht durch Verbindung ron Fabrikarbeit mit etwas Landwirthschaft, welche einen namhaften Theil der Lebensmittel für den Bedarf der Arbeiterfamilie liefert.

\section{HANDEL.}

Bei der Uebersicht über die rerschiedenen Erwerbszweige war bereits (S. 737) auch rom Handel die Rede. Seine grosse und vielfache Bedeutung erfordert aber, dass wir auf denselben etwas einlässlicher zu sprechen kommen und das dort Gesagte nach mehreren Richtungen ergänzen, wesshalb wir dem Gegenstand ein besonderes Kapitel widmen. Immerhin können wir nur in Kürze auf die verschiedenen Gesichtspunkte, welche hiebei wesentlich in Betracht kommen, 
aufmerksam machen. Auf Erörterungen über die besondere Wichtigkeit des Handels glauben wir hier verzichten zu können. Jedermann weiss, welche grosse Rolle er spielt in Bezug auf die menschliche Wohlfahrt im Allgemeinen, wie hinsichtlich der Beziehungen zwischen den einzelnen Ländern und Tölkern und mit Rücksicht auf Reiseunternehmungen insbesondere.

In den primitirsten menschlichen Gesellschaften besteht kein Handel; die Individuen beschäftigen sich da kaum mit etwas Anderem als damit, sich direkt die Dinge zu verschaffen, welche zur Befriedigung ihrer Bedürfnisse nöthig sind. Jagd, Fischfang, Viehhaltung und Anbau von Pflanzen haben da nur den Zweck, für den Hausbedarf zu sorgen; ebenso verhält es sich auf dieser sozialen Stufe mit dem Spimnen, Weben, Färben, mit der Anfertigung von Geräthen und mit andern Gewerben.

Von Handel kann erst die Rede sein, wenn die Individuen in ihrem Gewerbe mehr produziren als sie für sich selbst und ihre Familie bedürfen, um diesen Ueberschuss gegen andere Objekte nder gegen Dienstleistungen auszutauschen; so, wenn der Jäger mehr Wild, als für ihn und die Seinigen zur Ernährung nöthig wäre, tödtet, um mit einem Theil daron Korn oder Salz einzutauschen oder aber Arbeit ron Menschen, die ihm eine Hütte bauen, Fallen und Netze verfertigen helfen; wenn er Thiere erlegt, nicht blos, um aus ihrem Fleische zu leben, sondern um für ihre Haut Waffen, eine Flinte, Pulver, Glasschmuck, Branntwein etc. zu bekommen, d. h. Dinge, die er sich nur verschaffen kann, wenn er dafür andere in Tausch gibt.

Wenn aber in einer Gegend, bei einem Volksstamme, Handel gar nicht oder nur in embryonärem Zustande vorkommt, so folgt daraus keineswegs dass sich derselbe hier nicht entwickeln könne. Wenn die Individuen nur so viel erzeugen, als sie für sich und ihre Familien unumgänglich brauchen, so hat dies seinen Grund mitunter lediglich darin, dass sie mit einem Ueberschuss nichts anzufangen, denselben nicht zu verwenden wussten. Man offerire ihnen, einen Vorrath an Erzeugnissen umzutauschen gegen Artikel, welche ihnen konveniren, und sie werden sich bald mit einer regelmässigen Produktion solcher Vorräthe befassen. Јa man 
braucht ihnen nur Dinge vorzuweisen, die nach ihrem Geschmack sind und sie werden bald selbst Tauschangebote machen.

Der Reisende hat in Betreff ron Gegenden, welche dem Handel noch nicht erschlossen sind, die Aufgabe, zu konstatiren, welche Produlite mit Vortheil ron dort bezogen und welche Artikel dafür an Zahlungsstatt dorthin geliefert werden könnten. Es handelt sich dabei selbstrerständlich nicht um eigentliche Ein- und Verkäufe; denn Geld hat in solchen Gegenden oft nicht mehr. Werth als eine glänzende Medaille aus einem ganz gewöhnlichen Metall, und man zieht ihm auffallende Stoffe, Glasschmuck, Nä̈rel, Angeln, Waffen, Pulver etc. bei Weitem ror. Bei Beurtheilung der Frage, welche Artikel den Eingehornen als Tauschobjekte angehoten werden können, dürfen wir uns nicht durch unsre eigenen Ideen rom Werthe dieser Gegenstände leiten lassen, sondern nur durch die Erfahrungen, welche wir hierin mit den Eingebornen machen; Artikel, von denen man noch nicht weiss, ob und in welchem Maasse die Eingebornen ihnen Werth beilegen, muss man denselben ror Allem einmal vorzeigen, ehe man irgend welchen Schluss auf ihr Lrtheil darüber zieht.

Tausch. Derselbe wird überall da angewendet, wo nicht Geld oder andere Dinge, die gleich demselben als allgemeiner Werthmesser dienen (wie Kaurimuscheln, Steinsalzstiicke etc.), in Gebrauch sind und besteht eben darin, dass die eine Waare direkt (ohme Vermittlung durch Geld) gegen eine andere Waare gegeben wird (Naturalwirthschaft). In solchen Fällen hat der Reisende zu konstatiren, mit welchen Artikeln namentlich Tausch getrielen wird, welcher Ausdehnung derselbe fähig ist und welche Gegrenstände die Eingebornen namentlich gegen ihre Produkte einzutauschen suchen.

Eigentlicher Handel. Darunter verstehen wir den Einkauf und Verkauf von Waaren gegen Geld. Letzteres das übrigens, wie wir sehen werden, sehr verschiedener Art ist - spielt für diese Art des Produktenumsatzes die Rolle eines Mittels, indem es für jede Art ron Waare genommen oder gegeben und der Werth jeder Waare in Geld ausgedrückt wird. Wer sich einen Gegenstand verschaffen will, braucht bei diesem System (der Geldwirthschaft) nicht für eine andere Waare zu sorgen, welche dem Geschmacke des 
Verkäufers jenes Gegenstands zusagen müsste, um den letztern hiemit einzuhandeln; an die Stelle dieser Waare tritt ein Quantum Geld. Ebenso braucht sich der Verkäufer hiebei nicht darum zu bekümmern, ob seine Abnehmer Produkte besitzen, welche den Gegenwerth für seine Waare bilden und seinen Wünschen entsprechen würden: den Gegenwerth erhält er in Geld. Auf diese Weise erlangt der Handel eine Regelmässigkeit, welche er vor dem Tausch voraus hat.

Wir haben schon erwähnt, dass der eigentliche Handel nach Ausdehnung und Richtung desselben weiter unterschieden werde und fügen hierïber noch einige Bemerkungen bei.

Binnenhandel. Den im Innern des Landes vor sich gehenden Umsatz von Waaren — wobei die Produkte also nicht über die Grenze gehen, sondern in dem Lande konsumirt werden, das sie erzeugte — bezeichnet man als innern oder Binnenhandel. Das Studium desselben ist von statistischem Interesse, aber nur von mässiger Bedeutung in Hinsicht auf Handelsverbindungen, die mit der betreffenden Gegend angeknüpft werden könnten. Indessen soll es doch nicht vernachlässigt werden; denn eine genaue Kenntniss dieser Branche in einem Lande - insbesondere der Artikel, welche daselbst den Gegenstand von Angebot und Nachfrage bilden - liann unsere Geschäftsleute dazu führen, dort Einkäufe zu machen und sich so - nicht selten mit gutem Erfolg für sich und ihre Abnehmer — eines Theils des früher internen Handels zu bemächtigen, oder auch versuchsweise und als Muster Waaren dorthin zu liefern, welche geeignet wären, mit daselbst begehrten Artikeln eigener Produktion $\mathrm{zu}$ konkurriren und sie $\mathrm{zu}$ ersetzen.

Aussenhandel. Derselbe besteht in dem über die Grenze gehenden Waarenverkehr zwischen In- und Ausland, umfasst also die Ein- und Ausfuhr oder den Import- und Exporthandel. Gegenstand des ersteren sind Produkte des Auslands, welche an inländische Konsumenten abgesetzt werden; Gegenstand des letzteren inländische Erzeugnisse, welche als Konsumartikel ins Ausland gehen.

Möglichst vollständige Verzeichnisse dieser Ein- und Ausfuhrartikel mit Angabe ihrer Herkunft und Bestimmung, sowie der in den Handel gebrachten Quantitäten sind von grossem Werth. Wenn amtliche Daten dieser Art vorhanden 
sind, so braucht man sie nur zu reproduziren und vielleicht mit einigen Erläuterungen zu begleiten; sind aber keine solchen Dokumente vorhanden, so muss man bei kundigen Personen - Zollbeamten und Geschäftsleuten - möglichst zuverlässige Aufschlüsse über den Import und Export zu erhalten suchen.

Sofern der Aussen- oder auswärtige Handel die Waaren zu Schiffe übers Meer bezieht oder versendet, wird er als Serhandel bezeichnet. Die Bedeutung, welche derselbe in einem bestimmten maritimen Lande erlangt, wird mitunter bemessen nach Zahl und Kapazität (Tonnengehalt) der Handelsschiffe, welche während eines gewissen Zeitraums (eines Jahres z. B.) in dessen Häfen ein- und ausfahren. Man liefert zu diesem Zwecke tabellarische Lebersichten des Schiffverkehrs oder der Schifffahrtsbewegung mit Angaben über die Zahl der Schiffe, Tomengehalt, Nationalität oder Flagge, Provenienz und Bestimmungsort derselben.

Transit. Man nennt Transit oder Durchfuhr eines Landes - nur uneigentlich als Transit- oder Durchfuhrhandel desselben bezeichnet — den Verkehr in Waaren, welche rom Auslande äber die Grenze hereinkommen, aber nicht im Lande konsumirt werden, sondern wieder über die Grenze ins Ausland gehen. Es hält oft schwer, diese transitirenden Waaren für statistische Zwecke rom Import und Export scharf zu trennen; die Ein-, Aus- und Durchfuhrtabellen unterscheiden, trotz ihres Titels, in den Ziffern keineswegs immer zwischen diesen drei Kategorien. Es soll aber dieser Unterschied so viel als möglich beachtet und hervorgehoben werden; die Kaufleute finden hierin oft nützliche Fingrerzeige, was die Vermeidung unnützer und kostspieliger Zwischenhändler, die Anbahnung direkten Verkehrs mit Produzenten und Konsumenten solcher Artikel betrifft.

Handels-Régime. Selten ist der Handel, insbesondere der auswärtige, ganz frei. Alle Einrichtungen nun, wodurch in einem Lande diese Freiheit beschränkt wird, bezeichnen wir in ihrer Gesammtheit als das Handelsregime des betreffenden Landes.

Hieher gehören vorah die Handelsverbote oder Prolibition'm. In einigen Gegenden ist jeder Handel mit dem Auslande absolut rerboten; meist aber beschränken sich die 
Verbote auf gewisse Artikel (partielle Prohibition, z. B. Verbot der Einfuhr ron Waffen, der Ausfuhr von Getreide etc.); auf eine gewisse Zeit als Ausnahmemassregel, deren Aufhebung von bestimmten Verhältnissen abhängig gemacht wird (temporäre Prohibition); auf Artikel von einer gewissen Provenienz oder Bestimmung, wobei der Handel mit denselben Waarengattungen erlaubt ist, sofern diese aus andern Ländern kommen oder nach andern bestimmt sind als denjenigen, welche das Verbot betrifft (bedingte Prohibition); endlich auf gewisse Plätze der Grenze oder Küste, während die Ein- und Ausfuhr an den übrigen Punkten gestattet ist (lokale Prohibition). Eine jede solche Massregel kann bestimmten Handelszweigen sehr gefährlich werden, nicht am wenigsten die temporären Prohibitionen, namentlich, wenn es ins Belieben des Herrschers gelegt ist, von einem Tag auf den andern die Ein- oder Ausfuhr irgend eines Artikels zu verbieten.

Weiter haben wir hier der Monopole zu gedenken. In gewissen despotisch regierten Staaten wird das Recht, mit den Fremden Handel zu treiben, vom Souverän für sich allein in Anspruch genommen. So kauft und verkauft er zu Preisen, wie es ihm beliebt ("Monopolpreisen"), ohne dass die Unterthanen wagen dürfen, sich darüber zu beklagen. Oft wird die Ausbeutung dieses Alleinhandels Günstlingen und Grosswürdenträgern überlassen, oft um eine bestimmte (jährliche oder einmalige) Gegenleistung an Einzelne oder Gesellschaften vergeben. Mitunter besteht zwar kein rechtlich anerkanntes, wohl aber ein faktisches Monopol, indem gewisse Kasten, Klassen oder Korporationen sich eines bestimmten Geschäftszweiges bemächtigen, und alle davon fern zu halten wissen, die sich ihrem Einfluss zu entziehen versuchen. Selbstverständlich ist das Monopol nicht immer ein absolutes und unbegrenztes, sondern auf spezielle Artikel und den Handel mit gewissen Gegenden beschränkt. Als Beispiel solcher Privilegien erwähnen wir die den verschiedenen ostindischen Kompagnien verliehenen Monopole des auswärtigen Handels ${ }^{1}$ ).

1) Mit dem Monopol oder Recht des Alleinhandels, welches die Staatsgewalt dem Fiskus vorbehält oder Privaten verleiht, um aus denselben Einnahmen zu erzielen, sind die Regalien oder Hoheitsrechte nicht zu verwechseln, welche der Stat sich im Interesse der öffentlichen Ordnung vindizirt. Dieser Unterschied ( $z$ wischen fiskalischen Interessen und solchen der öffentlichen Ordnung) tritt $z$. B. hervor in der Gegenüberstellung von Tabaksmonopol und Münzregal. 
Eine sehr gebräuchliche Einrichtung ist das Institut der Ziille, wonach Ein- und Ausfuhr gestattet sind gegen Entrichtung gewisser Abgaben. Letztere, die eben als Zölle bezeichnet werden, sind meist durch feste Tarife regulirt (Zolltarife), bald nach dem Quantum der Waare (Stückzahl; Gewicht, letzteres mit Einschluss der Verpackung oder ohne dieselbe: Stückzölle; Gewichtszölle, - Brutto- und Tettozölle), bald nach dem Werth der Artikel (Werthzölle, Zölle ad ralorem), oft auch nach anderweitigen Gesichtspunkten, wie Art und Volum der Waare, Herkunft und Bestimmung derselben. Ihrer Höhe und Bestimmung nach erscheinen die Zülle bald nur als Kontrolgebühr (droit de statistique) oder Finanzmassnahmen, indirelite Steuern, welche einen Theil der für staatliche Zwecke erforderlichen Gelder liefern sollen (Finanzzölle), bald als Mittel zur. Begünstigung der einheimischen Gewerbe durch Erschwerung oder faktischen Ausschluss fremder Konkurrenz (Schutz\%ölle, Prohihitivzölle), bald als zollpolitische Repressalien gegen einzelne Länder (Kampfzülle). In einigen Ländern werden Zülle, die bei der Einfuhr ron Waaren erhoben wurden, zurückerstattet, wenn dieselben Waaren binnen einer gewissen Zeit wieder ausgeführt werden oder es sind solche transitirende Güter gänzlich zollfrei. Dergleichen Rückzahlungen kommen unter den Bezeichnungen Rürkälle, draudurlis, Ausfuhrurimien ete. auch zur Anwendung für Produkte, die als Rohstoffe eingeführt und in veränderter Form (, veredelt") ausgeführt werden.

Ausser an der Landesgrenze werden die Waaren oft noch mit Abgahen belastet bei der Einfuhr in eine Stadt (Octrri) oder beim Transport über gewisse Strassen und Brücken (Wey- und Brïrlingwder oder Strassen- und Brückenzölle). Im Gegensatz zu den Grenzzöllen werden diese internen $\mathrm{Ab}$ gaben wohl auch als Binnenzölle bezeichnet.

Verkehrsmittel. Im Hinblick auf Handelsverbindungen, die mit einer noch ziemlich unbekannten Gegend angreknüpft werden könnten, hat der Reisende mitzutheilen, auf welche Weise daselbst der Verkehr zu bewerkstelligen ist, insbesondere der Transport ron Waaren an bestimmte Orte im Innern des Landes oder an solche Küistenplätze, welche niclit in direktem Schiffsverkehr mit Europa stehen. 
In den fremden Kontinenten vermisst man oft bitter die bequemen Verkehrsmittel, an die wir gewöhnt sind, vor Allem gute Strassen. Da muss der Händler seine Waaren bald auf Wagen, die von Ochsen gezogen werden, bald auf Lasthieren, bald mit Hülfe von Trägern durch wüste und schwer zugängliche Gegenden transportiren; oft muss er sich Andern beigesellen und auf die Abreise einer Karawane warten, um die Märkte im Innern des Landes zu besuchen; oft mit von Eingebornen bemannten Fahrzeugen einen Fluss hinaufschiffen und die Waaren partieen- und etappenweise absetzen in dem Maasse als ihm Tauschartikel offerirt werden.

Der Reisende hat die namhaften Handelsplätze der Küste und des Innern anzugeben und mitzutheilen, worin deren Bedeutung liegt, welches ihre Spezialität ist; er hat ferner genaue Daten zu liefern über Messen und Mürlte, Tag und Stunde, wann Käufer und Verkäufer sich zusammenzufinden pflegen; ebenso über allenfallsige Comptoirs und Falitoreien des Landes, deren Geschäftszweige und Jahresumsatz.

Hinsichtlich der Strassen, welche zu den wichtigsten Städten und Marktplätzen führen, sind Angaben zu machen über deren Länge, die täglichen Etappen, geeignete Haltstellen (Karavanserais etc.), sowie über die Sicherheit der Wege, beziehungsweise über Vorsichtsmassregeln, die man zu treffen hat, um sich gegen einen allfälligen Handstreich zu schützen.

Ebenso sind die Wasserstrassen zu beschreiben. Dabei ist namentlich $\mathrm{zu}$ bemerken, ob die Flüsse und Ströme immer oder nur in einzelnen Jahreszeiten schiffbar sind und worin letzteres seinen Grund hat: in periodischen Hochwassern mit allzustarker Strömung, in zeitweise zu niedrigem Wasserstande oder in Eis; ferner ob die Schiffbarkeit eines solchen Gewässers an einzelnen Stellen unterbrochen ist durch Sandbänke, Stromschnellen und Wasserfälle und ob diese Hindernisse umgangen, die Fahrzeuge an jenen Stellen zu Lande bis nach der nächsten schiffbaren Flussstrecke befördert werden können. Die Beschiffung eines Gewässers kann auch gefährdet werden durch den Fremden feindselige Uferanwohner; in diesem Falle hat man den Verhältnissen entsprechende Vorsichtsmassregeln, unter Umständen eine ziemlich starke Entfaltung bewaffneter Macht zu treffen. 
Für Transporte zur See länggs der Küste, zwischen dem Kontinent und einer Insel oder zwischen den verschiedenen Theilen eines Archipels muss man sich häufig der Eingebornen bedienen, deren Fahrzeuge ihres geringen Tiefgangs wegen allein geeignet sind, gewisse seichte Stellen oder Untiefen zu passiren und die Landung auf flachen Küsten $z u$ bewerkstelligen. Es ist daher anzugeben, ob Küstenfahrer vorhanden sind, welche die verschiedenen Hafenplätze und Inseln besuchen oder, andernfalls, wie und unter welchen Bedingungen man nach diesen Punkten gelangen kann. Es ist hiebei ferner zu bemerken, dass gewisse Jahreszeiten vorzuziehen, andere zu vermeiden sind mit Rücksicht auf herrschende Winde und der Schiffahrt drohende Gefahren.

Die Handelsplätze sind zu besprechen in Bezug auf Einrichtungen für den Personen- und Waarenverkehr (Gasthöfe, Lagerhäuser, Bazars etc.), - auf die Sicherheit, welche man geniesst, oder auf Gefahren, die zu befürchten sind, und auf den Schutz, welchen man in letzterem Falle anrufen kann, - auf die spezifischen Elemente ihrer Besucher und die lokalen Handelsgebräuche.

Es darf auch nicht unerwähnt gelassen werden, welche lokalen Publikationsmittel dem Kaufmann zu Gebote stehen. In manchen Gegenden versehen öffentliche Ausrufer diesen Dienst, anderswo Maueranschläge oder Plakate auf Tafeln, welche in den Strassen herumgetragen werden; ferner Zirkulare, die man in den Häusern und an die Passanten austheilt; endlich Anzeigen in den Lokalblättern.

Geld. Unser Geld dient infolge einer gewissen Höhe und Konstanz seines Werthes, leichter Transportabilität, Aufbewahrungsfähigkeit und weitgehender Theilbarkeit als allgemeines Werthmaass, Umlaufs-, Tausch- und Zahlungsmittel. Diese verschiedenen Dienste und Zwecke des Geldes werden in manchen Ländern mehr oder minder vollständig oder unvollständig, vollkommen oder unvollkommen durch gewisse Waaren erfüllt, so durch Felle, Salzstücke in Form von Wetzsteinen, Bretter, geschnittene Steine von bestimmter Form, Kakaobohnen, Kauris und verschiedene andere Muscheln; Barren oder Stangen Silbers, wovon man ein Stück abschneidet, dessen Werth demjenigen des anzukaufenden Objekts entspricht; an einer Schnur gereihte Metall- 
stücke, ron denen man bei einem Kaufe eine gewisse Anzahl ablöst und hergibt; Goldstaub etc.

Gewöhnlich versteht man unter Geld Stücke von Gold, Silber und andern Metallen, die ein Bild oder ein Gepräge tragen, welches ihren Werth und zugleich ihre Herkunft bezeichnet; es sind das die Mïnzen. Dieselben weichen in den einzelnen Ländern vielfach von einander ab in Stoff (Gold- und Silbermünzen, Bronce-, Kupfermünzen etc. Goldwährung, Silberwährung etc.), Gewicht oder Schrot und Feingehalt oder Korn (Münzfuss), Form und Grösse. Der Reisende gebe ein genaues und vollständiges Verzeichniss der Münzen eines ron ihm besuchten Landes; sind dieselben noch wenig bekannt, so legre er sich eine Sammlung derselben an oder wenigstens eine Sammlung getreuer photographischer Nachbildungen der Münzen unter Angabe des Werthes einer jeden (in Franken und Rappen, Mark und Pfennig).

Mitunter dienen auch dann, wenn schon Münzen eingeführt sind, gewisse Waaren noch immer als Werthmesser. So schätzen die Osseten im Kaukasus nach „Kühen" ab (ein Artikel ist 2, 3, 4 Kühe, 1/10, 1/100 Kuh "werth), die Wogulen in Sibirien nach "Eichhörnchen"; in Afrika spricht. man von "halben Sklaven" etc. In solchen Fällen hat der Reisende $\mathrm{zu}$ konstatiren, welches der in Münzeinheiten ausgedrickte Geldrerth des Artikels ist, der als Norm gilt.

Es können in einer Gegend - entweder neben einheimischem Gelde oder ausschliesslich - fremde Münzen kursiren. Dies ist in der Lerante und einem grossen Theil Afrikas mit den Maria-Theresia-Thalern der Fall; aus denselben werden oft durch blosse Theilung in zwei oder vier Stücke kleinere Münzen hergestellt. Der spanische Piaster kursirt in den Vereinigten Staaten und manchen afrikanischen Ländern, so in Bornu, Wadaï, Darfur, Kordofan, Abyssinien und (unter dem Namen "Bu-Medfa" und "AbuAmud") Marocco. In Algerien sind die französischen Münzen gebräuchlich; dabei werden von den Kabylen die Goldstücke vorgezogen, während die Araber nur silberne Fünffrankenstücke wollen. In Zanzibar geschehen die Zahlungen in Maria-Theresia-Thalern oder amerikanischen Dollars. In allen diesen Ländern sind die Geldstücke um so beliebter, je matter 
und schmieriger sie aussehen; ein glänzendes Stück wird mit Misstrauen betrachtet. Nicht selten findet man uralte Münzen im Verkehr; so zirkulirten 1863 in Malaga neben dem spanischen Gelde noch maurische, römische und sogar phönizische Münzen.

Als symbolisches Geld findet man verschiedene Werthzeichen, meist auf den Inhainer lautende Papiere (wie Münzscheine, eigentliches Papiergeld, Bons, Schatzscheine, Banknoten), die entweder zu mehr oder minder hohem Preise ("Kurs") direkt an Zahlungsstatt gegeben werden können und deren Annahme öfter rorgeschrieben ist (Zwangskurs) oder die wenigstens an gewissen Kassen gegen reales Geld (Kurantmünze) ausgewechselt werden. Der Reisende gebe an, was für Papiere dieser Art sich in Lmlauf befinden, ob sie vicl oder wenig Vertrauen (Kredit) geniessen, welches die Differenz zwischen dem Nenn- und Kurswerth derselben ist etc.

Maasse und Gewichte. Noch manigfaltiger als die Systeme der Werthmaasse (Münzsysteme) sind diẹenigen der Mengenmaasse (eigentliche Maasse, im Sinne der Geometrie, und Gewichte). Vielerorts werden die Quantitäten in höchst ungenauer Weise nach Stücken, Körben, Säcken, Lasten u. dgl. angegeben. In manchen Ländern findet man gewisse übereinstimmende Namen für Maasse und Gewichte verbreitet; aber in einem solchen Gebiete bezeichnet oft ein und derselbe Ausdruck nicht durchwegs und überall das nämliche Quantum; vielmehr machen sich hierin provinzielle und lokale Verschiedenheiten geltend. In andern Fällen trifft man ein wohlfixirtes Maass- und Gewichtssystem, worin jede einzelne Benennung unzweideutig eine gut bestimmte Quantität bezeichnet.

Wie es sich auch hiemit in dem Lande rerhalte, das man besucht: stets gebe man möglichst genau an, welches die Aequivalente der Gewichts- und Maass-Einheiten nach unserm metrischen System (in Gramm, Liter oder Meter) seien.

Es ist festzustellen, welche Waaren nach dem Gewichte, welche hingegen nach geometrischen Maassen rerkauft werden; im ersteren Falle kommt in Betracht, ob die Verpackung (Emballage) im Gewichte bei der Preisherechnung inbegriffen ist (Bruttogewicht) oder hiefür ein Abzug gemacht und nur 
das eigentliche Waarenquantum (Nettogewicht) in Anschlag gebracht, eventuell wie viel Abzug (Tara) berechnet wird.

Handelsbräuche. Jedes Land und fast jeder einzelne Handelsplatz hat seine besondern kaufmännischen Gebräuche oder Usanzen. Zu den lokalen Bräuchen (Platzusanzen) gehören die an den einzelnen Orten verschiedenen Preisnormen, Kreditfristen und Verkaufsbedingungen. Es werden z. B. die Geschäfte gegen Baarzahlung (per comptant) oder auf Zeit abgeschlossen, mit oder ohne Sconto: mit Rabatt in dieser oder jener Form: durch Drauf- oder Dreingabe (13 für 12, 110 oder 105 für 100; d. h. es wird stillschweigend angenommen, man liefere 13, 105 oder 110 Einheiten, wenn man ron 12 oder 100 sprach), durch einen Abzug für den Verlust, welchen der Kleinhändler erleidet, wenn er Flüssigkeiten in geringen Quantitäten verkaufen, verschiedene Waaren in kleinen Partieen auswägen muss etc.

Spesen. Der Waarenhandel ist mit einer Menge von Unkosten ausser denen für Fracht und Zoll verbunden; dazu gehören die Gebühren, welche unter dem Namen "Kaplaken" an Schiffseigenthümer oder Kapitäne zu entrichten sind, Gebühren für das Messen und Wägen, Laden und Entladen (Löschen), Lagergebühren, Kommissionsgebühren, Provision und Courtage etc.

Conti finti. Der Kaufmann bildet sich ein Urtheil über den Kostenpreis einer Waare und den Gewinn, welchen er mit derselben muthmasslich machen könnte, an der Hand eines Conto finto, d. h. einer detaillirten Rechnung über ein bestimmtes Quantum (z. B. 1000 Kilogramm, 20 Ballen oder 40 Säcke von bestimmtem Gewicht) der Waare und alle Kosten, womit eine solche Sendung oder Lieferung verbunden wäre, wenn sie effektuirt würde. Diese "fingirten Rechnungen" sind also einfach Ein- und Verkaufsrechnungen über supponirte Bezüge oder Lieferungen; als solche müssen sie der Reihe nach alle die Ausgaben enthalten, welche vom Ankauf eines Waarenquantums bis zu dessen Verkauf und Bezahlung entstehen: den Betrag der Note des Waareneigenthümers, Kosten für Verpackung und Verschiffung, Fracht und Zoll, Kommissionsgebühren etc. Zahlreiche Muster derartiger Berechnungen ("Proforma-Fakturen" und "Proforma-Verkaufsrechnungen") findet man z. B. in den fachmännischen Be- 
richten über die österreichisch-ungarische Expedition nach Siam, China und Japan ${ }^{1}$ ).

Mustersammlungen. Der Reisende welcher Gegenden besucht, die noch ziemlich unbekannt sind, unterlasse nicht, Sammlungen anzulegen von Produkten, die zur Einführung in den Handel geeignet sein dürften, sowie von Gewebestoffen und andern Artikeln, für welche die Eingebornen eine ausgesprochene Vorliebe zeigen. Dergleichen Sammlungen nebst Notizen über Bezugsquellen und Absatzorte, Kaufsund Verkaufspreise, beliebte Formen und Farben etc. sind für den Handel von grossem Nutzen.

\section{LITERATUR.}

Als Literatur eines Volkes bezeichnet man im Allgemeinen die Gesammtheit seiner in Wort oder Schrift zum Ausdruck gebrachten Geisteserzeugnisse. In der Literatur eines Landes offenbaren sich die geistigen Eigenthümlichkeiten seiner Bewohner. Das Studium der Landesliteratur ist daher ein wichtiges Mittel zur Kenntniss des Volkes. Dabei handelt es sich für den Reisenden weniger um die grossen oder Hauptliteraturen, als um die einem kleineren Gebiet eigenen Erzeugnisse, für welche die Ausdrücke lokale und unedirte Literatur gestattet sein mögen.

Unter der Bezeichnung grosse Literaturn verstehen wir hier jene Erzeugnisse von Kultursprachen wie der französischen, englischen, italienischen etc., die mehr oder weniger einem jeden Gebildeten bekannt sind und über welche man sich in gewissem Grade leicht aus Fachschriften unterrichten kann. Wir setzen voraus, der Reisende habe solche für den speziellen Fall in Betracht kommende Darstellungen (Literaturgeschichten) zu Rathe gezogen und die hauptsächlichsten Werke, welche sie behandeln, in ihrem Originaltext gelesen, sodass er sich mit den wichtigsten Autoren der betreffenden Literatursprache in einer Weise bekannt machte, welche ihn zu einem Urtheil über dieselben befähigt. Er wird aber gut thun, wenn seine Zeit es erlaubt, diese Werke in dem Lande

1) Dr.K.v.Scherzer, fachmännische Berichte über die österreichisch-ungarische Expedition nach Siam, China und Japan (1868-1871). Stuttgart 1872. 
ihrer Entstehung nochmals zu lesen; Manches kann hiebei in neuem Lichte erscheinen, Manches so erst recht vollem Verständniss sich erschliessen. Der Gewinn an Allseitigkeit und Reife des Urtheils, den er hiebei macht, wird ihm zu Statten kommen bei einer Umschau unter den Erzeugnissen neuerer Schriftsteller, die sich noch nicht eines anerkannten und bereits gesicherten Rufes erfreuen, der Tagesliteratur, deren Werth nicht schon ron einer massgebenden Kritik abgewogen und festgestellt wurde.

Regionale Literatur. Die literarischen Erzeugnisse eines Landes, welchem in der üblichen Literaturgeschichte, die ihren Gegenstand nach den grossen Sprachgebieten zu bemessen und sich auf dieser breiten Grundlage aufzubauen ptlegt, keine besondere Stellung zuerkannt wird, bezeichnen wir als regimale Literatur, insofern sie durch eine gewisse Eigenart etwas für sich Bestehendes bilden. Dies gilt z. B. ron der belgischen Literatur, welche gewöhnlich einfach der französischen beigerechnet, beziehungsweise zugleich mit dieser besprochen und nicht getrennt behandelt wird. Aehnlich verhält es sich mit der Schweiz: die Literatur dieses Landes wird gemeinhin der deutschen, französischen oder italienischen zugetheilt, je nach dem die Schweizer, um deren Werke es sich handelt, der Sprache nach als deutsche, französische oder italienische Autoren zu betrachten sind. In diesen und andern Fällen wird eine aufmerksame Vergleichung erkennen lassen, dass eine solche Literatur ihr eigenthümliches Gepräge hat, welches - eine Folge besonderer landwirthschaftlicher und ethnischer Faktoren, der politischen und kirchlichen, sprachlichen und sozialen Verhältnisse, der Geschichte des Volkes und seiner ganzen Geistesrichtung - derselben ihren einheitlichen Charakter gibt und sie ron den Schöpfungen anderer Völkerschaften trotz Sprach- und Stammverwandtschaft unterscheidet ${ }^{1}$ ).

Der Reisende wird ferner auf die Presse eines von ihm besuchten Landes nach den wesentlichsten Gesichtspunkten (politische Tendenz, Ernst und Würde der Sprache oder Masslosigkeit des Tones etc.), sowie der Beredtsamlicit in ihren verschiedenen Gattungen (der forensischen, parlamen-

1) Vgl, z. B. Dr. H. Semmig, Die französische Schweiz und Savoyen, ihre Geschichte, Literatur, Kunst und Landschaft. Zürich 1881. 
tarischen, Kanzelredner etc.) kennen $z u$ lernen und $z u$ charakterisiren suchen.

Zur Ergänzung des Bildes, welches die literarische Produktion eines Landes gibt, ist auch der literarische Konsum desselben zu berücksichtigen. Hiebei kann die importirte Liteatur von wesentlicher Bedentung sein: sie wird naturgemäss in den Vordergrund treten, wenn das Land an eigenen literarischen Erzengnissen arm ist. In jedem Falle ist die Art der entlehnten Literatur, welche in einer Gegend vorherrscht, und sind die gesammten Verhältnisse ihrer literarischen Konsumtion ron charakteristischem Werthe.

Lokale Literatur. Ohne dass diese Kategorie von der vorigen scharf zu trennen wäre, kann man von ihr sagen, dass in derselben noch mehr als bei jener die eigenartigen Verhältnisse eines engumschriebenen Gebietes hervortreten, sodass sie nicht nur eine sekundäre Rolle spielen, sondern zum Hauptfaktor und wesentlichsten Element des Ganzen werden. Im Einklang mit dieser spezifischen Eigenthümlichkeit derartiger Produkte wird für dieselbe oft die Volksmundart der bestimmten Oertlichkeit verwendet, deren Boden das Substrat, deren Menschen mit ihren Besonderheiten den Kern der Darstellung bilden. Solche mundartliche Erzeugnisse sind meist nur in engen Kreisen bekannt, nicht selten aber weiterer Verbreitung werth, sodass dem Reisenden empfohlen werden kann, sein Augenmerk auch hierauf zu richten.

Unedirte Literatur. Als unedirte Literatur bezeichnen wir diejenige, deren Erzeugnisse nicht gedruckt oder nicht einmal niedergeschrieben und daher im Allgemeinen unbekannt sind. In vielen Gegenden existiren Denkschriften, Gedichte u. s. w. nur als Manuskript, ferner zahlreiche Sagen, Märchen, Erzählungen, Volkslieder, Sprüchwörter etc., die sich bisher nur durch mündliche Ueberlieferung erhalten haben. Es kann ein Volk auch olne Schriftsprache eine eigene und selbst eine reiche Literatur besitzen.

Gerade dieser unedirten Literatur hat der Reisende seine Aufmerlisamkeit zu schenken, um uns mit ihr bekannt zu machen. Man wird ron ihm keine vollständige Sammlung erwarten; wohl aber darf man verlangen, dass er einige charakteristische Produkte dieser Art mittheile. Er unter- 
lasse nicht, sich zu erkundigen nach MIanuskripten, die von Interesse sein, nach epischen Gedichten, die eine historische Grundlage haben könnten, nach volksthümlichen Sagen, Märchen und Erzïhlungen, deren Verfasser oft unbekannt ist und die zumeist das Werk mehrerer Dichter sind, welche nacheinander oder zu gleicher Zeit, aber von einander unabhängig, denselben Stoff bearbeiteten. Er sammle ferner Tollsticder, Balladen, Sprïchuörter etc.

Die Erzeugnisse der einen und andern Art, ob episch, lyrisch oder didaktisch, könmen ron grossem Werth sein. Die Sagen und Erzählungen haben sehr oft, wenn sie auch noch so phantastisch ausgeschmïckt sind, einen reellen geschichtlichen Kern; Mythen und Märchen, die uns vielleicht kindisch erscheinen, sind mitunter von grauem Alter und liömen Anhaltspunkte geben zur Würdigung früherer Verhältnisse, eines primitiven Zustandes der Gesellschaft. Die Sprüchwörter ihrerseits enthalten einen reichen Schatz von Volksweisheit, der die Frucht langer Erfahrungen und einer oft höchst originellen Auffassung der Dinge ist.

Man darf allerdings nicht meinen, dass es eine leichte Sache sei, zu sammeln, was am meisten des Sammelns werth ist. Die Lösung einer solchen Aufgabe erfordert ein besonderes Talent, eine gewisse Kunst. Direkte Fragestellung ist nicht immer das beste Mittel zu diesem Zweck, und eine Hauptschwierigkeit liegt darin, die wichtigsten Personen zu finden, an welche man sich mit Erfolg wenden kann. Man findet nicht alle Tage einen wahren Erzähler, sagt Julien Vinson ${ }^{1}$ ) mit Recht. Fast jede Familie und fast jeder Freundeskreis enthält indess ein Mitglied, das sich in dieser Richtung ror den andern auszeichnet; nicht immer wird das älteste Glied der Gesellschaft ihr bester Erzähler sein. Es handelt sich also darum, zu entdecken, wer in einem kleineren oder grösseren Kreise der treue Hüter dieser alten Schätze ist, ein ungelehrter Historiker, naiver Foet oder Künstler, der sich des Werthes seiner Gaben kaum bewusst ist. Hat man zur guten Stunde ihn gefunden, so nehme man in Thun und Lassen darauf Bedacht, ihn nicht zu stören, sondern soviel möglich im Flusse der Erzählung zu erhalten. Dazu.

1) Mythologie basque (Revue de Linguistique, Paris, oct. 1875, pag. 112-128). 
ist nöthig, dass man der Sache ein wirkliches und warmes, unverkennbares Interesse entgegenbringe, ihr jenen Glauben schenke, welchen der Dichter für die poetische Wahrheit seiner Schöpfungen in Anspruch nimmt; dass man sich aber ja nicht in den Ruf eines Gelehrten und zweifelnden Kritikers bringe, vor dem der MInd des Erzählers sich schliessen würde.

Bei der Aufzeichnung des Gehörten muss der Sammler sehr genau zu Werke gehen und vor sich selbst auf der Hut sein; er halte streng darauf, so viel als möglich die eigenen Worte - ipsissima rerba - des Erzählers zu geben. Wenn ihn auch vielleicht Dies oder Jenes in Idee oder Wortlaut choquirt, so darf er diese Einzelheiten gleichwohl nicht ändern oder unterdrücken; denn es könnte dies kaum anders als auf Kosten des originellen Charakters der Erzählung geschehen; man riskirt, dass ein erster Schritt auf diesem Wege weiter führt und man schliesslich dem Leser eine Reproduktion rorlegt, welche dem Original kaum mehr gleicht.

\section{KUNST UND WISSENSCHAFT.}

Hinsichtlich dieses Gegenstandes gelten in analoger Anwendung die allgemeinen Bemerkungen, welche in Betreff der Literatur gemacht wurden: es handelt sich wesentlich um die cinheimische Kunst, in dem Sinne, wie wir von regionaler oder Landesliteratur gesprochen haben, und um die Tokiale Pflege der Wissenschaft. Jene eigenartige Kunst einer Gegend kann sich aber in Erzeugnissen äussern, die wir nach unsern Begriffen nicht schön oder erhaben finden; die Pflege der Wissenschaften ihrerseits kann eine sehr einseitige und lückenhafte sein, sodass mehr über Mangelndes zu berichten wäre, als über Das, was vertreten und vorhanden ist.

Zeichnen und Malerei. In manchen Gegenden findet man von Eingebornen herrührende Zeichnungen auf Felswänden, Baumrinden, Schiefertafeln u. dgl. Materialien. Der Reisende hat solche als Proben einheimischer Kunst zu reproduziren, mögen sie auch noch so unförmlich sein. Behufs getrener Wiedergabe wird er sich der Photographie bedienen. Handelt es sich um farbige oder bemalte Zeich- 
nungen, so hat man auf den photographischen Nachbildungen möglichst genau die entsprechenden Farben anzubringen.

Bei kïnstlerisch etwas weiter vorgeschrittenen Völkern findet man mitunter originelle Leistungen, welche Talent and gute Naturauffassung verrathen, oft aber auch eine traditionelle Routine in stereotypen Formen, gewissermassen nach einer und derselben Schablone.

Von Interesse sind Angaben über die Fortpflanzung der Kunst, wenn wir uns so ausdrücken dürfen, d. h. Angaben betreffend die Uebertragung derselben, die Ueberlieferung ihrer Bräuche, Regeln und Lehren von einer Generation zur andern, sowie Nittheilungen über das Kunstschüleroder Lehrlingswesen und die Stellung der Künstler. Es gibt Länder, wo es Regel ist, dass die künstlerische Berufsthätigkeit rom Vater auf den Sohn übergeht, dieser die Ausïbung derselben als eine Art Erbe übernimmt; es gibt andere, wo der Schüler oder Lehrling für eine Anzahl Jahre sozusagen der Sklave seines Meisters sein muss, und wiederum Länder, wo der Males kaum besser behandelt wird als bei uns irgend ein Arbeiter: es wird demselben eine Aufgabe in der Weise übertragen, dass er während der Dauer seiner Arbeit Kost, Logis und einen bestimmten Taglohn erhält; wurde doch seiner Zeit der junge Murillo zu Sevilla in ähnlicher Weise honorirt, was ihn nicht hinderte, unsterblichen Ruhm zu erlangen!

Endlich sind noch Angaben beizufügen über die vorherrschende Art der Malerei (ob Fresco-, Oel-, Pastell- oder Aquarellmalerei) und die gebräuchlichen Materialien (Seide, Elfenbein, Pergament etc.).

Skulptur. Den besten Begriff von der Entwicklungsstufe, welche diese Kunst in einer Gegend erreicht hat, geben Photographien einiger der namhaftesten ihrer dortigen (einheimischen, inländischen) Erzeugnisse. Diese Produkte können blos eine Art roher Basreliefs sein, wie manche in Felsen gehauene allegorische Darstellungen, ferner hässliche Bildnisse von Göttern, grob aus einem Steinblock herausgemeisselt oder in einen Baumstamm geschnitzt, sowie unförmliche Statuetten aus Thon, Knochen, Elfenbein oder Metall; es kann aber auch die inländische (einheimische) Kunst zu grösserer Vollendung gediehen sein, sodass ihre 
Produkte sorgfältiges Studium der Form und wahren Schönheitssinn verrathen.

Architektur. Der Reisende hat soweit möglich durch Zeichnung und Photographie ron Wohnungen und öffentlichen Gebäuden die Baukunst eines Landes (die hürgerliche wie die monumentale) zur Anschauung zu bringen. Dabei hat er uicht sowohl die Objekte, welche nach seinem Geschmacke die schönsten sind, als rielmehr das am meisten Charakteristische, das Typische, aufzusuchen und auszuwählen. Bauten in ausnahmsweisem Styl, durch Eleganz ron allem Uebrigen unterschieden, sind oft nur Denkmäler fremder Kunst, etwa Monumente früherer Eroberer, oder Nachahmungen ron Vorbildern, die sich bei irgend einem andern Volke finden. Die wahre einheimische (regionale) Architektur ist diejenigge, deren Charakter uns in dem Lande überall entgegentritt, in den bescheidensten Wohnungen wie in den grossartigsten Bauten.

Musik. Was in einem Lande unter Musik rerstanden und produzirt wird, scheint uns oft jede andere Qualifikation eher als die einer Kunstleistung zu rerdienen: der Gedanke an Das, was wir Katzemuusik nennen, mag dabei mitunter am nächsten liegen. Fast immer wird der Reisende viel Zeit und Aufmerksamkeit rerwenden müssen, um den bestimmenden Charakter der Musik eines Landes, sowio die Unterschiede zwischen profaner, kirchlicher und Militäroder Kriegsmusik desselben zu erfassen.

Es soll erwähnt werden, ob die Tokal- oder die Instrumental-ıIusik rorzugsweise gepflegt werde; ob die eine oder andere ziemlich allgemein rerbreitet oder als eine Art Gewerbe auf hestimmte Klassen und Personen beschränlit sei; sodann, welche soziale Stellung Sängern und Musikern zukomme.

Die üblichen Musikinstrumente sollen beschriehen werden, wenn sie nicht schon genügend bekannt sind.

Wissenschaften. Verschiedene, der Wahrheit mehr oder minder nahe kommende Ansichten und Begriffe, mehr oder minder irrige Yorstellungen und zum Theil abergläubische Meinungen eines Tolkes werden bei Besprechung der Ideenwelt desselben (S. 6t2) ihre Stelle gefunden haben. 
Es können aber einzelne Zweige der Wissenschaft zu verhältnissmässig hoher Entwicklung gediehen sein bei Völkern, die wir im Lebrigen als Barbaren betrachten. Wir finden schiffahrttreibende Völker alter Zeit und Nomaden einer frühen Epoche der Kulturentwicklung im Besitz sehr namhafter astronomischer Kenntnisse, sehen aber allerdings oft auch diese Disziplin in Astrologie ausarten. Die Botanik kann auf Kenntniss einiger Arzneigewächse beschränkt sein, und oft verbindet sich mit diesem Wissen noch allerlei Aberglaube. Wir wollen diese paar beispielsweisen Bemerkungen nicht durch ähnliche über andere Disziplinen vermehren, sondern nur noch darauf hinweisen, dass der Reisende bei Besprechung dieses Gegenstandes namentlich auch die Faktoren zu würdigen hat, welche hemmend oder fördernd auf die Entwicklung der Wissenschaften bei einem Volke, beziehungsweise auf einzelne derselben, einwirkten. Ursachen der ersteren Art werden sich ihm häufig genug bemerkbar machen. Zu den allgemeinsten derselben gehören ungenügende Tollisbildung und übermässige Inanspruchnahme der Kräfte für den harten Kampf ums Dasein. Bei günstiger situirten Völkern und Klassen fehlt es nicht an Hindernissen anderer Art; bei der Abneigung Vieler gegen jegliche Neuerung, bei der weitverbreiteten Tendenz zum Autoritätsglauben erstarrt zu Zeiten auch in der Wissenschaft eine Lehre zum Dogma, ein weitreichender Zirkel ihrer Vertreter zu einer Art orthodoxer Hierarchie, wogegen die freie Forschung oft lange anzukämpfen hat, bis dem Fortschritt wieder Bahn gebrochen wird.

\section{URSPRUNG UND GESCHICHTE.}

Der Reisende hat nicht eine vollständige und einlässliche Geschichte des Landes oder Volkes zu schreiben, das er besucht; aber er muss sie kennen, an deren wesentlichste Begebenheiten erinnern, die wichtigsten Phasen, welche Land und Volk in ihrer Entwicklung durchgemacht haben, den Lesern vorführen und wohl auch auf Grund der bei seinem Aufenthalt gemachten Wahrnehmungen Irrthümer berichtigen, welche mitunter in Aufnahme gebracht werden von Autoren, 
denen eine genügende eigene Kenntniss der Menschen und Verhältnisse abgeht, wenn sie auch sonst anerkennenswerthe Verdienste erworben haben.

Ein vorgängiges Studium der Geschichte des Landes und Volkes, die ein Reisender zu besuchen gedenkt, wird demselben zur reichen Quelle des Genusses, sowie er die Stätten betritt, welche Schauplatz der Ereignisse waren, woron er sich Kenntniss verschaffte, und mit den Menschen verkehrt, die selbst oder deren Vorfahren hiebei eine Rolle spielten. Das Interesse an Land und Leuten wird durch solche vorbereitende Studien in hohem Grade gesteigert und wesentlich rertieft; ein Land $\mathrm{zu}$ bereisen ohne Kenntniss seiner Geschichte, heisst auf einen grossen Theil des Werthes verzichten, welchen die Reise andernfalls haben kann.

Nicht alle Länder sind so reich an geschichtlichen Erinnerungen, wie etwa Egypten und Hellas; aber wenige gibt es, welche nie die Bühne wichtiger Begebenheiten gewesen wären oder deren dunkle Vergangenheit nicht Anlass gäbe zu Fragen von höchstem Interesse. Es ist z. B. die Geschichte von Nordamerika erst neueren Datums; aber schon bietet sie in den Anfängen der Kolonisation, dem Freiheitskampf unter Washington und Franklin, der fortschreitenden Staatenbildung, dem Sezessionskrieg ete. weltgeschichtliche Momente dar; andrerseits drängen uns Reste einer merkwürdigen alten Zivilisation, die daselbst nicht selten sind, eine Reihe ron Fragen auf: woher kamen die Völker, welche die Tumuli und die symbolischen Monumente im Norden errichteten? was ist aus jenen geworden, welche in Colorado und Mexiko Ruinen von Städten und Tempeln hinterlassen haben? $\mathrm{Ob}$ der Reisende auf klassischem Boden wandle, ob er ein jungfräuliches Land erforsche: immer wird es ihm zu Statten kommen, wenn er sich über das Gebiet seines Aiffenthalts und Studiums zum Voraus so gut als immer möglich auch in historischer Beziehung unterrichtet hat.

Bei dieser, der Ausführung einer projektirten Reise vorangehenden Beschäftigung mit der Geschichte der Länder und Völker, die man besuchen will, soll man sich nicht auf klassische Werke älteren und neueren Datums beschränken, sondern auch periodische Fachschriften zu Rathe ziehen, um sich vertraut $\mathrm{zu}$ machen mit Untersuchungen auf den 
Gebieten der Ethnographie, Archäologie und Linguistik. Es hat z. B. die Geschichte der alten Egypter, Assyrer und Babylonier eine völlige Umgestaltung erlitten, seitdem man die alten Denkmäler und Inschriften jener Länder erforschte, statt sich blos auf die Zeugnisse griechischer und römischer Schriftsteller zu stützen.

Die Geschichte eines Landes oder Volkes hat in der Regel mehrere Perioden oder Epochen, in welchen sie aus nächtlichem Dunkel frühester Vergangenheit ins Zwielicht der Dämmerung und endlich in volle Tageshelle tritt: Der zeitgenössischen und historischen Epoche positiver Geschichte geht eine zum Theil sagenhafte und mythische, nur dürftig aufgeklärte, zum Theil in tiefes Dunkel gehüllte Periode voraus, welche die voryeschichtliche odter mü̈historische Zeit genannt wird. Diese Periode, über welche die historischen Lehrbücher kurz hinwegzugehen pflegen, umfasst die langen Jahrtausende, welche verflossen, bevor es eine geschriebene Geschichte gab - ungemessene Zeitabschnitte, in welche uralte Völkerwanderungen und Städtegründungen fallen, wie die ersten Anfänge noch heute bestehender Einrichtungen. Ueberall, selbst in den kultivirtesten Ländern, findet der Kundige noch Spuren dieser grauen Vorzeit, wo der aus einem thierähnlichen Zustande sich herausarbeitende Mensch die ersten Schritte that auf der Bahn der Zivilisation. Nur selten, ausnahmsweise und unvollständig sind diese Zustände erwähnt bei Geschichtsschreibern von Nationen, welche Zeitgenossen solcher Völker, aber bereits weiter vorgeschritten waren. Aufgabe des Forschungsreisenden ist es, die Spuren der vorgeschichtlichen Zustände in dem Lande selbst, worin diese herrschten, nachzuweisen und zu sammeln, um damit Beiträge zu liefern zur Erkenntniss jener für die Geschichte des menschlichen Geschlechtes so bedeutsamen Periode.

Die ersten Bewohner einer jeden Gegend wurden — selbst wenn diese ein Schöpfungscentrum gewesen wäre — in zahlreiche Wanderungen mithineingezogen, wurden verdrängt und vertrieben durch Andere, an deren Stelle später wieder neue Elemente traten; öfter entstand hiebei ein Gemisch der verschiedenen Völkerschaften, die successive auf dem gleichen Boden sich einfanden. Eine und dieselbe Gegend wurde derart im Laufe der Zeit von Menschenstämmen ver- 
schiedenster Herkunft in Besitz genommen und sah zu öfteren Malen den Typus ihrer Einwohnerschaft wechseln, gleichwie in einem Meeresbecken im Verlaufe der Ablagerung einer Reihe von Sedimentschichten die Thierbevölkerung wiederholt sich wesentlich änderte. Und wie wir uns von Wechselfällen der letzteren Art, von geologischen Aenderungen, ein Bild machen nach den Spuren, welche sie in Gesteinen hinterlassen: so haben wir die Aufgabe, die prähistorischen Vorgänge, die Schichtenfolge der Bevölkerungen zu ermitteln nach den Indizien, welche geblieben sind von Invasionen, Deplazirungen und Mischungen verschiedener Volksstämme, die successiv den gleichen Schauplatz betraten und auf demselben kürzere oder längere Zeit eine Rolle spielten.

Als Crbecöllierma oder Creinuoher (Autochthone, Aborigines) eines Landes müsste man im strengen Sinne des Wortes die ersten Menschen bezeichnen, welche in dem Lande selber ihren Ursprung gehabt hätten und nicht als Einwanderer von Aussen in dasselbe gekommen wären. Da aber, wenn man nicht zahlreiche Schöpfungszentren annehmen will, vorausgesetzt werden muss, dass die meisten Gegenden ihre Bewohner von Aussen - durch Wanderungen - erhalten haben, so legt man jenem Ausdruck (Urvolk, Autochthone) nur eine relative Bedeutung bei, indem man darunter die frühesten Bewohner eines Landes versteht, von welchen man Kunde hat, die Ersten, welche unseres Wissens von einer Gegend Besitz nahmen, im Gegensatz zu späteren Einwanderern.

Ein tiefes Dunkel liegt über Ursprung, Herliunft oder Abstammung der autochthonen Bevölkerung einer Gegend, wenn man auch diesem Ausdruck nur den erwähnten relativen Sinn und Begriff beilegt: die altesten Wandemengen, durch welche in ein Land diejenigen Menschen kamen, die wir als dessen Ureinwohner betrachten dürfen, verlieren sich meist in unergründlicher Nacht vorgeschichtlicher Zeiten; bei allen Wanderungen, die wir kennen, von den ältesten bis zu den neuesten, von fernen prähistorischen Perioden bis auf unsere Tage, wurden die invahirten Gegenden schon von andern Völkerschaften besetzt gefunden; die alten Arier stiessen zur Zeit ihrer Invasion in Indien auf dravidische Stämme, welche sie zurückdrängten, und nichts berechtigt uns zu dem Glauben, dass die ersten Arier, 
welche nach Europa kamen, diesen Erdtheil unbewohnt fanden. Wo immer sodann in geschichtlicher Zeit europäische Entdecker in entlegene, bisher unbekannte Gegenden den Fuss setzten: stets fanden sie das Land schon bewohnt von Völkerschaften, deren Herkunft selbst wieder unbekannt ist; so in Amerika, in Australien und anderwärts. Eine Ausnahme hievon bilden gewisse Atolle der Südsee und vulkanische Inseln, deren Entstehung neueren Datums ist. Was die jetzt unbewohnbaren Gegenden um die Pole betrifft, so darf angenommen werden, dass sie nie von Menschen besiedelt waren, obwohl die vielen Reste einer reichen vorweltlichen Flora, welche an manchen Punkten des hochnordischen Gebietes aufgefunden wurden, unwiderleglich darthun, dass in früheren geologischen Perioden auch diese jetzt vereisten Gegenden sich eines günstigen Klimas erfreuten, wobei sie zum Wohnsitz für Menschen wohl geeignet gewesen wären ${ }^{1}$ ). Im Uebrigen ist nicht gesagt, dass Gegenden, welche in neverer Zeit unbewohnt waren oder dies noch sind, sich immer in diesem Zustande befunden haben. Wenn die Besiedlung einer öden Gegend, eines entlegenen Thales, unseres Wissens erst in historischer Zeit erfolgte, so ist das noch kein genügender Grund, um a priori anzunehmen, dass eine solche Landoder Thalschaft früher nie bewohnt gewesen sei. In den Ebenen von Colorado und den Wüsten Innerasiens geben uns einzig Ruinen ehemaliger Städte Kunde von verschwundenen Völkerschaften, und sorgfältige Nachforschungen können auch anderwärts in Gegenden, die jetzt verödet liegen, Spuren früherer Bewohner derselben zu Tage fördern. In solchen Fällen muss man annehmen, dass jene Bevölkerungen ausgewandert seien, es wäre denn, dass eine grossartige Katastrophe ihnen den Untergang gebracht hätte, wobei aber wohl auch die Werke zerstört worden und spurlos verschwunden wären, welche von ihrer Existenz Kunde zu geben hätten.

Die Erinnerung an spätere Wanderungen hat sich noch erhalten in Traditionen, in denen oft Wahres und Falsches wunderbar vermengt ist, das Thatsächliche durch sagenhafte Zuthaten überwuchert wird, sodass sie mit Bezug auf den

1) Vgl. E. Kollbrunner, Prof. Dr, Oswald Heer's Studien über die Urwelt des hohen Nordens. St. Gallen 1881. 
wirklichen historischen Sachverhalt zumeist nur dann von erheblichem Werth sind, wenn untèr den Stämmen, in deren Nitte diese Ueberlieferungen kursiren, noch Greise leben, die noch Augenzeugen der Ereignisse, um welche es sich handelt, gekannt und die Berichte darüber unmittelbar von solchen Personen erhalten haben.

Auch die Ereignisse, welche Gegenstand der eigentlichen Geschichte bilden, in die historische Zeit fallen, sind aus verschiedenen Gründen oft vielfach entstellt worden. Die Geschichtsschreiber, welche als älteste Gewährsmänner für Vorgänge einer bestimmten Zeit gelten müssen, sind eben oft Angehörige einer gewissen Kaste oder Klasse und als solche mehr oder minder Partei, mehr oder minder befangen und voreingenommen oder geradezu im Dienste bestimmter Personen und Interessen, sodass sie bewusst oder unbewusst in ihrer Darstellung den Thatsachen mehr oder weniger Zwang anthun. Die Schmeichelei vergrössert die Verdienste eines Herrschers oder Feldherrn und stellt alles im günstigsten Lichte dar; sie weiss selbst von Siegen zu erzählen, wo in Wahrheit Misserfolge und Niederlagen vorlagen. Oft auch war der Autor einer Zensur unterworfen und durfte nicht schreiben, wie er wollte; und was die Berichte über fremde Völker anbetrifft, so fehlte nicht selten Alles, was nöthig gewesen wäre, um sie verlässlich zu machen: genügende Beziehungen oder Verbindungen von Volk zu Volk, Verständniss der Sprache und Denkweise einer fremden Völkerschaft etc. Wissen wir doch, dass im griechischen Alterthum "fremd" und "barbarisch" ziemlich dasselbe bezeichneten. Was die Geschichtsschreiber jener Zeit uns zu berichten wissen, hetrifft ein verhältnissmässig engumschriebenes Areal: Nordeuropa, das nördliche, mittlere und östliche Asien, wie Innerafrika sind dabei nicht vertreten. Durch das ganze Mittelalter hindurch stand es in dieser Richtung nicht viel besser: erst mit den grossen Entdeckungen an der Schwelle der Neuzeit bricht die Periode einer umfassenderen Kenntniss der Völker des ganzen Erdenrunds an. Dasjenige nun, worüber Tradition und Geschichte uns nicht oder haum in verlässlicher Weise berichten, ist womöglich zu erforschen nach einer Methode gleich derjenigen, womit der Geologe die Geschichte der Erde lionstruirt. Im Nachstehenden werden wir 
auf diesen Gegenstand näher eintreten; vorher mag noch daran erinnert werden, dass in unserer Zeit die grössten Leistungen auf dem Gebiet der Geschichte des Alterthums reisenden Forschern zu danken sind; es genügt, in dieser Hinsicht einige Namen zu nennen wie Champollion, MarietteBey, Brugsch, Lepsius, Layard, George Smith und Schliemann.

Erkundigungen und Indizien. Anhaltspunkte dafür, wo prähistorische Ueberreste in einem Lande $\mathrm{zu}$ finden sein dürften, wird man zunächst in den Publikationen dortiger archäologischer Gesellschaften finden, wenn solche vorhanden sind; sodann in Mittheilungen von Personen, welche das Land durchstreift und dabei auf Vorkommnisse dieser Art geachtet haben: auf Ruinen, Ueberreste einer früheren Industrie, Sagen ron einem verschwundenen Volk etc. Von solchen Personen lasse man sich die Punkte angeben, wo sie dergleichen Wahrnehmungen machten, und die Namen von Männern, welche darüber weitere Aufschlüsse geben können.

Es sind ferner die alten Autoren, Karten und Itinerarien $z u$ berathen mit Bezug auf die Lage früherer Städte und Denkmäler, wie dies z. B. in Betreff von Ithaka und Troya, Dodona und Delphi durch Schliemann und Andere geschehen ist.

Die archäologische Erforschung von Ländern, welche keine geschriebene Geschichte haben und deren alte Städte unter einer Decke von Schutt oder Vegetation verborgen liegen, ist sehr schwierig, da man sich hiebei fast blos durch Hypothesen und den Zufall muss leiten lassen.

Oft findet man werthvolle Angaben über ein Volk bei den Geschichtsschreibern und in Denkmälern anderer Völker, so bei Herodot und Strabo, in den Annalen und Hieroglyphen Egyptens über die alten Lybier und verschiedene Völker Asiens und Afrikas, bei Tacitus über die alten Germanen, bei Cäsar über die Gallier, in Schriften der Seefahrer des Mittelalters über die Azteken und Incas, in Reiseberichten von Weltumseglern der Neuzeit über die Südsee-Insulaner. Dergleichen Materialien sollen zu Rathe gezogen, aber nur mit Vorsicht und nach sorgfältiger kritischer Prüfung benutzt werden. 
Befindet man sich einmal in dem zu erforschenden Lande, so frage man bei Einwohnern desselben nach, ob ihnen darin Höhlen, Ruinen oder irgend welche Alterthümer bekannt seien. An solche Orte und Objekte knüpfen sich fast immer alte Sagen; von manchen heisst es im Volke, dass daselbst Geister umgehen; so waren in den ersten Zeiten nach Einführung des Christenthums namentlich die Orte, wo die Heiden noch ihren Göttern opferten, Gegenstand derartiger Erzählungen. Alte Monumente, deren Lisprung und Bestimmung das Volk nicht zu erklären weiss, werden gewöhnlich ron der Sage einem Riesengeschlechte zugreschrieben. Mitunter sind schon die Namen solcher Stätten bezeichnend, z. B. Wall, Burg, Castrum (Gaster), Heidenmaner, Baal, Bel, Melkart, Nimrud (Birs Nimrud), Cheiton, Derils etc. etc., ferner Feengrotte, Teufelshammer u. dgl.

Erdarbeiten zur Fundamentirung von Häusern und Brücken, zur Anlage ron Strassen, Eisenbahnen, Kanälen, zur Ausbeutung ron Steinbrüchen, Kiesgruben und namentlich auch von Torfmooren fürdern oft merkwürdige Funde zu Tage. Es ist sehr zu empfehlen, dass man solchen Arbeiten beiwohne oder sich doch bei den Arbeitern erkundige, ob und welche Funde etwa gemacht worden seien.

Häufig rühren die zur Erstellung neuerer Gebäude verwendeten Steine von alten Bauten und Ruinen her, welche ron der Berölkerung einer Gegend als eine Art Steinbruch benutzt werden. Wenn die aufmerksame Besichtigung ron Wohnhäusern und anderen Bauten der Landeseinwohner Grund gibt zur Annahme, dass ein solcher Fall rorliege, so erkundige man sich, woher das Material derartiger neuerer Gebäude stamme und suche sodann den Ort auf, welcher als Bezugsstelle angegeben wird.

Wenn der Reisende nicht in der Lage sein sollte, sich selbst mit eingehenden derartigen Lntersuchungen zu beschäftigen, so erkundige er sich wenigstens darnach, was Andere auf diesem Felde geleistet haben; er besichtige die öffentlichen und privaten Sammlungen ron Alterthümern, sei aber auf der Hut vor Händlern, welche oft allerlei irgendwo aufgefundene Dinge und Falsifikate als Alterthümer von berühmten Fundstellen zum Verkaufe anbieten. 
Will aber der Reisende auf archäologische Entdeckungen ausgehen, so ziehe er Einheimische zu Rathe, die ebenfalls dergleichen Forschungen obliegen; in Ermanglung solcher befrage er Hirten, Jäger und andere Personen, welche öfter abgelegene Lokalitäten besuchen; denn letztere bieten im Allgemeinen die besten Chancen für dergleichen Funde; so hat man unlängst in Nordafrika zahlreiche Dolmen entdeckt, 500 bei Tebessa, je ca. 2000 bei Mozela und Aïn bu Merzug, gegen 3000 bei Roknia.

Auch während der Reisende zu irgend eirem andern Zweck - z. B. in der Absicht, topographische und geologische Aufnahmen zu machen - das Land durchreist, achte er auf Alles, was dafür spricht, dass die Gegend in ferner Torzeit eine Wohnstätte des Menschen und Schauplatz seiner Thätigkeit war.

Zur Erleichterung dieser Aufgabe werfen wir in Nachstehendem einen Blick auf Objekte, welche für die prähistorischen Untersuchungen, die uns hier beschäftigen, von Wichtigkeit sind; dabei soll in Kürze, soweit möglich, auch die Rede sein ron den Lokalitäten, an welchen man die zu besprechenden Gegenstände findet, von den Merkmalen derselben und ron den Indizien, wonach die wahrscheinlichen Resultate genauerer Nachforschungen dieser Art zu beurtheilen sind.

Wenn es dem Reisenden unmöglich ist, diese Gegenstände genau zu untersuchen, so bestimme er wenigstens deren Fundort in genügender Weise, um entweder später zu demselben zurückzukehren oder Andern weitere Nachforschungen zu erleichtern. Wo immer möglich, nehme er aber eine genaue Untersuchung vor, gebe eine detaillirte, mit Ansichten und Plänen versehene Beschreibung, nehme Ausgrabungen vor und theile deren Resultat mit. In letzterem Fall müssen die einzelnen Objekte genau abgebildet und beschrieben werden, damit Andere die Richtigkeit der Schlüsse, die man daraus zieht, prüfen oder eine bessere Erklärung geben können.

Höhlen mit Spuren des Menschen. Seit den ältesten Zeiten scheinen die Höhlen als Wohn-, Zufluchts- und Begräbnissstätten benutzt und aufgesucht worden zu sein. Oft sind dieselben schwer zu entdecken, sei es dass ihr Eingang durch Buschwerk verdeckt, durch Erdschlipfe und 
Trümmerfälle verschüttet ist oder dass dieselben sich in den Felsen steiler Küsten befinden, wo sie nur vom Neere aus sichtbar sind.

Für prähistorische Forschungen sind bei Weitem nicht alle Höhlen von Interesse. Die einen wurden nie von Menschen benutzt; andere befinden sich in Verlaältnissen, welche allfälligen Spuren und Resten früherer Bewohner zum Voraus jeden Werth benehmen. Es ist also in dieser Beziehung zwischen verschiedenen Kategorien von Höhlen wohl zu unterscheiden.

Höhlen, welche Mündungen ron Mineralquellen sinł oder kürzlich noch waren, oder solche mit Gasausströmungen sind, weil für Menschen und Thiere unbewohnbar, ohne Ueberreste dieser Organismen.

Höhlen, in welche sich Gewässer stürzen oder welche erst unlängst rom Wasser frei wurden, konnten ehenfalls nicht bewohnt werden oder enthalten doch nur Reste neuerer Zeit.

Höhlen, die entstanden sind durch fliessendes Wasser, lassen keine sichern Schlüsse zu auf das Alter allfälliger organischer Reste, welche sie enthalten, da diese ron dem Wasser, welches sie mitbrachte, in buntem Durcheinander abgelagert werden konnten.

Solche Höhlen endlich, deren Boden auf irgend eine Weise in seiner Integrität gestört, durchwühlt und umgelagert worden ist - ron höhlengrabenden Thieren, ron Menschen etc. - eignen sich wiederum nicht für die Forschungen, ron welchen wir sprechen: denn auch in diesem Falle können aus den Funden keine zuverlässigen Folgerungen gezogen werden.

Höhlen in Form langer und enger Günge mit dunkelm Ende dienten zumeist nur wilden Thieren, kaum aber eimmal Menschen als Zufluchtsort.

Als Wohnungen von MIenschen (Troglodyten) benutzte Hïhl'n sind im Allgemeinen leicht zugänglich, heim Eingang hoch und breit, fast üherall ziemlich hell und nicht zu feucht. Dabei scheinen diejenigen hevorzugrt worken zu sein, welche einen Ausblick in das Land, sowie zugleich Schutz ror Ueberfällen gewährten, und in kalten Gegenden solche auf der Sonnenseite des Berg- oder Hügelzuges. 
Die als Begräbnissplätze benutzten Höhlen haben gewöhnlich enge und niedere Räume, die als Grabkammern dienen, vor welchen ein überhängender Fels einen geschützten Raum (eine Balm) bildet; da und dort findet man in denselben aber auch ein weites Gemach, welches als Lokal zur Begehung der Todtenfeierlichkeiten diente. Der Eingang solcher Höhlen war öfter oder ist noch durch eine schwere Steinplatte verschlossen.

Die Stationen der Höhlenberohner (Troglodyten) bestehen aus einer oder einigen Höhlen, die als Wohnung benutzt wurden, und einer, die als Grabstätte diente; sodann finden sich in der Nähe der Wohnstellen meist noch Vertiefungen und AushöhTungen, deren Zweck nicht bekannt ist. Entdeckt man eines dieser drei Vorkommnisse, so darf vermuthet werden, dass in der Nähe auch die beiden andern zu finden seien. Mitunter aber besteht eine solche Station blos aus einer Balm, d. h. einem durch ein Felsdach geschützten Raum.

Wenn die eben genannten Verhältnisse zutreffen und das Vorhandensein der Spuren oder Reste von Menschen wahrscheinlich machen, so ist damit noch nicht gesagt, dass nun ein Fund von wirklichem archäologischem Werth vorliege; damit letzteres der Fall sei, müssen die fraglichen Ueberreste auch ein genügend hohes Alter haben. Das Alter ciner Höhle im prähistorischen Sinne des Wortes bezieht sich aber auf die Zeit, da dieselbe bewohnbar wurde, nicht auf die Periode ihrer Entstehung. Höhlen, welche sich an Steilküsten durch brandende Wellen bildeten, wurden erst bewohnbar, wenn sie einmal davor gesichert waren, ganz unter Wasser gesetzt zu werden, wenn also die Gewässer einigermaassen zurück-, die Höhlen in dieser Weise aus deren Bereich heraustraten. Sie können dann Fischern als Zufluchtsstätte dienen, eignen sich aber nicht zu dauerndem Aufenthalt, wenn sie nicht einen besondern Ausgang nach der Landseite haben. Diese Küstenhöhlen konnten also erst bewohnt werden, wenn eine Hebung des Bodens sie dem Bereiche der Meereswellen entrückt hatte oder zwischen ihnen und dem Neere durch Erdschlipfe und Trümmerfälle von den steilen Felsen ein Damm gebildet worden war. Die Höhlen einer und derselben Küste sind um so älter, in je höherem Niveau sich dieselben befinden, da die höchstgele- 
genen zuerst vom Wasser frei wurden. Wenn im Binnenlande alte Küsten rorkommen, so enthält die innerste, rom Meere entfernteste derselben auch die ältesten Höhlen.

Das Alter von Höhlen, welche durch Bodendislokationen, Einstürze, Verwerfungen etc, in Kommunikation mit der Aussenwelt gelangt sind, kann nicht nach ihrer Lage, sondern - als identisch mit der Chronologie jener Vorgänge - nur nach den einlässlich zu untersuchenden Gesammtverhältnissen der dislozirten Schichten (namentlich nach den stratigraphischen Momenten) beurtheilt werden.

Höhlen, die erschlossen wurden durch die Reibung, welche ein Gletscher auf die Felsen seines Bettes ausübte, konnten erst bewohnbar werden, wenn der Gletscher mindestens bis zum Niveau jener Höhlen abschmolz. Ihr Alter reicht vielleicht in die Zeit der ersten grossen Ausdehnung des Gletschers hinauf; während der interglacialen Periode können sie offen geblieben und nachher wieder (durch Eis) abgesperrt oder verschlossen worden sein, ohne dass letzterer Fall nothwendig eintreten musste. Je grösser ihre Höhe über dem Gletscher und ihre Entfernung ron demselben, d. h. ihr vertikaler und horizontaler Abstand von dessen jetzigen Grenzen, desto grösser ist auch die Wahrscheinlichkeit, dass sie aus der Zeit der bedeutendsten Ausdehnung des Gletschers zu datiren sind.

Höhlen, deren Eröffnung auf die erodirende Thätigkeit des Wassers zurückzuführen ist, wurden um so früher bewohnbar, je grösser ihr jetziger Abstand ron dem betreffenden Gewässer, beziehungsweise dem Bette eines solchen ist. Wenn aus irgend einem Grunde - wegen Abnahme der Wassermasse oder Tieferlegung des Bettes durch Erosion - der Spiegel des Wassers sank, so konnten vorhandene Höhlen nach Maassgabe dieses Sinkens trocken grelegt werden. Das Verhältniss bleibt dasselbe auch für den Fall, dass ein solches Gewässer gänzlich verschwunden und nur ein wasserloser Thal- oder Seeboden geblieben ist.

Ebenso evident ist, dass Höhlen, welche als unterirdische Theile fliessender Gewässer funktionirt haben, erst bewohnbar wurden, wenn nur noch ein kleiner Theil derselben rom Wasser eingenommen war; im Allgemeinen wurden sie sicherlich erst dann bewohnt, wenn das Gewässer versiegt war oder sich einen andern Weg gebahnt hatte. 
Eine Höhle kann seit Langem bewohnbar und doch erst in neuerer Zeit wirklich bewohnt worden sein; aber die Wahrscheinlichkeit, in ihr Spuren von Bewohnern derselben zu finden, ist doch um so grösser, je weiter ihre Bewohnbarkeit zurückreicht. Sehr alte Höhlen verdienen in der Regel erforscht zu werden, sofern wenigstens ihr Boden noch intakt oder normal (im Sinne der früheren sachbezüglichen Bemerkung) ist. Enthalten sie keine Reste von Menschen und der Thätigkeit von solchen, so können sich Knochen von Thieren finden, welche die Gegend bewohnten, ehe der Mensch in derselben auftrat, und auch diese Funde sind von hohem Interesse.

Dass eine Höhle als Schlupfwinkel von Thieren und nicht als Wohnung ron Menschen diente, erkennt man rasch und leicht. Den Thierknochen, welche auf dem Boden der Höhle umherliegen, fehlen in einem solchen Falle die Epiphysen, d. h. die Enden, welche mit der Hauptmasse des Knochens durch Knorpeln verbunden waren, während dieser letztere Theil (das Haupt- oder Mittelstück, Diaphyse der Röhrenknochen) oft ganz geblieben ist, aber an den Enden die Zahnspuren fleischfressender Thiere zeigt. Die Raubthiere pflegen rämlich nur die Epiphysen zu verzehren und jene Diaphysen liegen zu lassen, weil sie ihnen schwer oder gar nicht beizukommen vermögen. Ein Unterschied im Verhalten der grossen Fleischfresser gegenüber dem Menschen in Bezug auf erlegte Thiere besteht darin, dass jene die Beute, wenn sie dieselbe nicht an Ort und Stelle verzehren, als Ganzes in ihre Höhle schleppen, während dex Mensch ein Thier von bedeutender Grösse zerlegt und nur gewisse Theile (Kopf, Glieder etc.) mit sich nimmt. Die Höhlen der Raubthiere werden daher gegenüber denjenigen, welche von Menschen bewohnt wurden, verhältnissmässig mehr Rumpfknochen erlegter Thiere aufweisen. Auch finden sich daselbst mitunter die Skelette der Fleischfresser, welchen die Höhle zum Aufenthalt diente, in natürlicher Lage ihrer Theile. Kommen daneben zufällig angenagte Menschenknochen vor, so zeigt dies, dass der Mensch selbst die Beute jener Räuber wurde.

Eine solche Höhle kann successive oder gleichzeitig von verschiedenartigen Raubthieren benutzt worden sein. Ersteres ist der Fall, wenn die Skelette der verschiedenen Arten und 
ihrer Beutethiere sich in verschiedenen Niveaux - d. h. die Arten nach Schichten oder Lagen getrennt, nicht in einer Schicht beisammen - finden oder wenn zwar die verschiedenerlei Skelette in derselben Lage (Schicht) beisammen, die einen derselben aber beschädigt, zerbrochen und in Unordnung gebracht sind durch die späteren Höhlenbewohner, deren Skelette ailein die natürliche Lage ihrer Theile zeigen. Der zweite Fall (gleichzeitige Bewohnung einer Höhle durch zwei oder mehr Rauhthierarten) fand wahrscheinlich statt, wenn in einer und derselben Schicht Skelette der beiden oder mehrerer Arten intaht (d. h. in natürlicher Lage der einzelnen Theile) gefunden werden, ohne dass dieselben durch irgend einen zufälligen Lmstand (Verschüttung z. B.) vor Angriffen geschützt gewesen wären. Die gleichzeitige Benutzung einer Höhle durch Thierarten, welche sich auszuschliessen scheinen, erklärt sich oft durch die Beschaffenheit der Höhle, welche jeder Species einen besondern Zufluchtsort gewährte, sodass nur der Eingang gemeinschaftlich war. Dabei kann übrigens später das eine Raubthier durch die andere Art vertrieben worden sein, was öfter wieder an den Knochenresten der Thiere zu erkennen ist, welche die gewöhnliche Nahrung des einen oder andern Fleischfressers bildeten. Es ist nicht gesagt, dass hiebei etwa stets der schwächere Räuber durch den stärkeren vertrieben wurde, vielmehr fand mitunter — durch List des ersteren - das Gegentheil statt.

Ausgrabungen in solchen Höhlen, behufs Erforschung dieser alten Fauna, sind mit gleicher Sorgfalt zu betreiben wie dergleichen Arbeiten bei Höhlen, die ron Menschen benutzt wurden.

Kemzeichen der Anuesenheit des Mrnschen in den Höhlen sind folgende:

Spuren einer früheren Feuerstelle, rauchgeschwärzte Wände, verkohlte Knochen und verschiedene Küchenabfälle, Ueberreste ron Erzeugnissen einer primitiven Industrie: zurechtgeschlagene (behauene) Feuersteine, bearbeitete Knochen etc.;

Knochen, die offenbar absichtlich (zur Gewinnung des Markes aus Röhrenknochen) zerschlagen wurden, welche die 
Spuren solcher Schläge oder Kerben ron schneidenden Werkzeugen an sich tragen;

das Vorherrschen der Knochen gewisser Körpertheile, welches zeigt, dass unter den Theilen der erbeuteten Thiere eine Auswahl getroffen und nur bestimmte Partien benutzt wurden.

Die Feuerstellen oder Herde sind, weil die Menschen rom Rauche möglichst wenig belästigt werden wollten, gewöhnlich nahe beim. Eingang der Höhle; man erkennt sie am Torkommen ron Kohlen, Asche und Küchenabfällen; auch finden sich in deren Nähe oft grosse flache Steine, die als Sitze, als Fleischbänke zum Zerstücken der Thiere, Zerschlagen der Kinochen u. dgl. Zwecken mehr gedient haben.

Die Knochen, welche man in ron Menschen bewolmten Höhlen fand, gehören immer nur einzelnen bestimmten Theilen grosser Thiere an, auf welche der Mensch Jagd machte; dieser zerlegte die Beute an Ort und Stelle, brachte gewisse Fleischstücke und markhaltige Knochen (Kopf, Glieder etc.) nach seiner Höhle, liess aber den Rest liegen.

Die Knochen tragen Spuren von Schlag- oder SchneideInstrumenten. Wenn Knochen durch Steine oder Erdmassen, die auf sie fielen, zerdrückt wurden, so brachen sie nur der Quere nach entzwei. Dagegen können gewisse atmosphärische Einflüsse die Bildung von Knochenbruchstücken in Form langer Splitter bewirken, gleich denen, welche der Mensch durch Zerschlagen der Knochen erzeugt. Das Vorkommen solcher Splitter für sich allein ist also kein genügender Beweis für die Anwesenheit des Menschen, wenn nicht an den Knochen Spuren von Schlägen vorkommen. Gewöhnlich findet man auch die Werkzeuge, welche zum Zerschlagen der Knochen dienten und oft nur Kieselsteine waren.

Verkohlte Knochen oder Gegenstände menschlichen Gewerbfleises beweisen für sich allein schon die Anwesenheit des Menschen, lassen aber in Ermanglung anderer Indizien Zweifel darüber, ob die Höhle als Wohnung oder zur Bestattung diente.

Die für Bestattungen revrendeten Höhlen bestehen gewöhnlich aus zwei verschiedenen Räumlichkeiten, einer solchen für die Bestattungen und einer zweiten zur Begehung der 
hiemit verbundenen Feierlichkeiten; dem letzteren Zwecke dient mitunter ein durch den vorspringenden Fels geschützter Raum (Balm) vor der Höhle.

Der Zugang zu dem Todtengewülbe oder der Räumlichkeit für die eigentliche Bestattung (Beisetzung) ist in der Regel durch eine Felsplatte verschlossen; öfter auch trifft man in der Nähe des Eingangs einen den Dimensionen des letztern entsprechenden Stein auf oder in der Erde. Ferner kommen hier mitunter Ueberreste von Opfergaben vor. Die Todtenkammer selbst enthält menschliche Skelette, die mehr oder weniger intakt sind, sowie Gegenstände, welche den Verstorbenen gehörten, Objekte, denen der Sammler alle Aufmerksamkeit $\mathrm{zu}$ schenken hat.

In dem Raume für die Bestattungsfeierlichkeiten findet man Objekte, welche auf den Bestand einer Feuerstelle hinweisen, Kohle, Asche, Küchenabfälle; zufällig wohl auch Werkzeuge und andereGegenstände menschlichen Gewerbfleisses.

Dem Reisenden und Sammler muss dringend empfohlen werden, nichts wegzunehmen odev zu disloziven, bevor alle Maassnahmen zu einer wirklich wissenschaftlichen Erforschung der Fundstätte getroffen sind.

Behufs Vornahme einer solchen Erforschung ist ror Allem nahe beim Eingang der Höhle ein Schacht oder Graben zu erstellen, um sich darüber zu vergewissern, dass die Schichten, welche den Boden der Höhle bilden, intakt geblieben, nicht durch Wasser oder sonstwie umgelagert und mit einander vermengt worden sind. Dieser Schacht oder Graben ist bis auf den anstehenden (,gewachsenen ") Fels hinunter zu treiben. Sind die Schichten von einander deutlich unterschieden, getrennt durch dünne Lagen von Thon oder Schlamm, welche auf wiederholt stattgefundene Ueberschwemmungen hinweisen, oder durch stalagmitische Ueberzüge des Bodens und Trümmerlagen, die von der Decke des Gewölbes herrühren: so verspricht die Untersuchung lohnende Resultate, weil in solchen Fällen jede Schicht nur die wirklich ihr eigenthümlichen Reste enthält. Ereignisse, wie Ueberschwemmungen und das Herabfallen von Felspartien der Gewölbedecke, wodurch die Materialien zur scharfen Trennung der einzelnen Schichten geliefert wurden, mussten auch die Höhlenhewohner (Menschen und Thiere) zeitweise vertreiben, was hinwieder dazu beitrug, 
die rerschiedenen Zeitabschnitte der Geschichte des Lokals in den Rückständen desselben erkennen und hervortreten zu lassen.

Es ist ferner ein Plan der Höhle aufzunehmen (nach der S. 62 gegebenen Anleitung); ebenso sind Lüngen- und Querprofile derselben anzufertigen.

Weiter ist die Frage zu prüfen, wie die Materialien, welche die Bodenschichten der Höhle bilden, in diese gelangten und sich ablayerten. Es sind das Ablagerungen von Erde, Geröll, Sand u. dgl. Material, welches das durch Felsspalten eindringende Wasser in die Höhle brachte; ferner Kieselund Kalkbildungen, die sich absetzten aus dem von der Gewölbedecke herabtropfenden Sickerwasser oder aus Quellen, welche aus dem Boden der Höhle hervorsprudeln, sowie auch Alluvionen ron Flüssen, welche bei hohem Wasserstande den Boden der Höhle überschwemmten.

Endlich sind die Schichten des Höhetenbodens geologisch mit denjenigen des Terains ansserhalb der Höhle in Bezichung zu brimgen, um Herkunft und Alter der ersteren zu ermitteln.

Nach diesen Vorarbeiten kann man zur Vornahme der Austmabungen übergehen. Diese müssen mit grösster Sorgfalt betrieben werden, um die Gegenstände, auf die man trifft, weder zu beschädigen noch mit einander $\mathrm{zu}$ vermengen, sondern dieselben in der Lage zu erhalten, die sie wirklich hatten. Letztere Bedingung ist in vielen Fällen von grosser Wichtigkeit wegen der Folgerungen, die man aus der gegenseitigen Lage der Objekte zu einander ziehen kann.

Obwohl die unteren Schichten als die älteren das grösste Interesse darbieten, dürfen doch auch die ihnen aufgelagerten jüngeren nicht vernachlässigt werden; denn das vergleichende Studium der verschiedenen Lagen nach ihren Einschlüssen und sonstigen Verhältnissen liefert einen Maassstab zur Beurtheilung der Aenderungen, welche in der Thierwelt jener fernen Zeit vorgekommen sind, sowie der Fortschritte in Gewerben, Sitten und Lebensweise des prähistorischen Menschen.

Die Nachgrabungen müssen sich immer bis auf das anstehende Gestein erstrecken; man hat sich hiebei davor zu hüten, dass man Stalagmitschichten für gewachsenen Fels halte, wozu oft ihre Härte und Farbe verleiten könnten, 
während gerade unter ihnen die altesten Ablagerungen sich befinden. Diese festen Kalkdecken müssen also durchbrochen werden, es sei denn, dass eine genaue Prüfung schon der ersten mit der Picke davon abgeschlagenen Stücke zeige, dass man es wirklich mit anstehendem Fels zu thun hat.

Damit man nicht Gegenstände, welche primitive Werkzeuge und von Menschenhand bearbeitet sind, für blosse Fragmente und Splitter von Steinen ohne weitere Bedeutung halte, fügen wir hier einige Abbildungen bei, die solche Objekte der primitivsten menschlichen Kunstfertigkeit darstellen, indem wir uns auf die ungeschlachtesten derselben beschränken, d. h. auf solche, die am ehesten zur' erwähntenVerwechslung Anlass geben könnten. Ungeformte Feuersteinsplitter ( $\mathrm{Fi}$. .223) in der Nähe eines Blockes (Fig. 2:24) desselben Vaterials sind untrügliche Zeugen menschlicher Thätigkeit, wenn der Block Spuren von Schlägen zeigt, welche geführt wurden, um von demselben jene Splitter abzutrennen. Steine, welche als Hämmer benutzt wurden ( $F$ ig. 225) unterscheiden sich von gewöhnlichen Steinen durch Spuren langen Gebrauches und dadurch bewirkter Abnutzung. Pfeil- und Lanzenspitzen (Fig. 226, 227 und 228) sind an ihrer Form kenntlich, die letzteren (Lanzenspitzen) auch an ihren bedentenden Dimensionen.

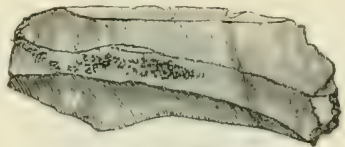

Fiig. 223.

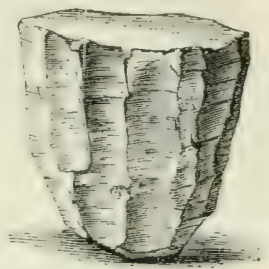

Fiy. 22t.

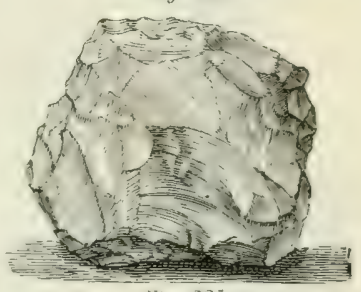

Fi, 2.2.

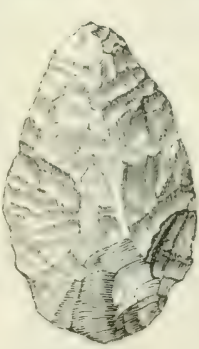

Fig. 2.2P.

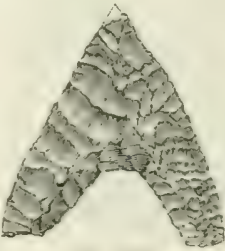

Fin. ?P?,

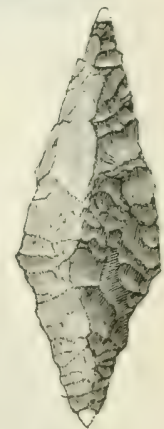

Fij. 2.27 . 

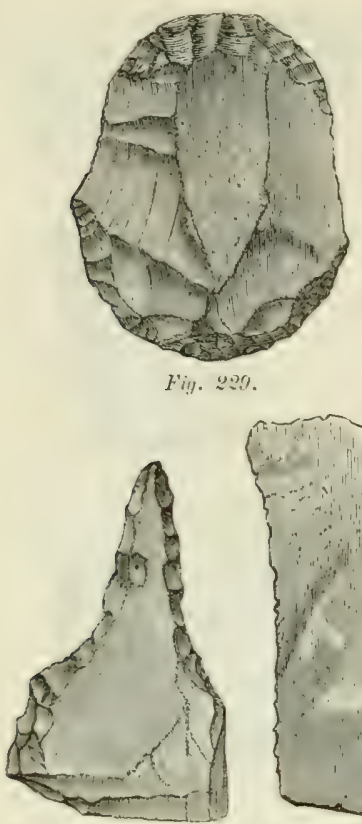

Fiy. $2: 30$.

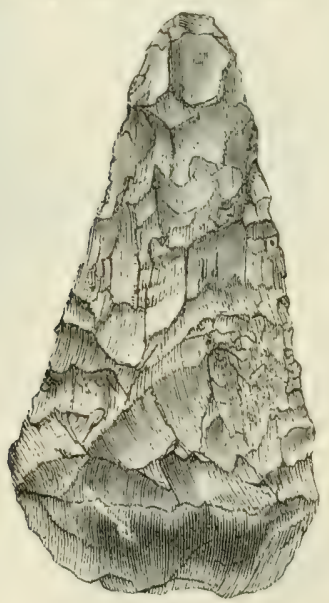

Fig. 2.32.
Steine zur Zubereitung der Thierhäute (Schabmesser, Fï. 229), solche zum Durchbohren der Häute, um diese dann mit Lianen oder Riemen zusammenzubinden (Fig. 230), Sägen (Fig. 231) und Beile oder Celte (Fig. 232 und 233) werden schon weniger mit beliebig geformten Steinfragmenten verwechselt; sie lassen, ob sie nun als Werkzeuge oder Waffen benutzt wurden, die an ihnen behufs Zuschärfung der Spitze oder Schneide vorgenommene Manipulation erkennen.

Die mit den Ausgrabungen betrauten Arbeiter sind sorgfältig zu beaufsichtigen, damit sie die Gegenstände nicht aufheben, bevor konstatirt ist, welche Lage dieselben hatten, und damit Beschädigungen zerbrechlicher Objekte vermieden werden. Die ausgegrabene Erde ist $\mathrm{zu}$ sieben, ansonst kleinere und schwer herauszufindende Gegenstände leicht unbeachtet bei Seite geschafft und verloren gehen könnten.

Im Verlaufe und nach Maassgabe des Fortschreitens der Arbeit mache man Notizen über die Beschaffenheit, Ausdehnung und Mächtigkeit der Schichten, sowie übe: die Lage der einzelnen gefundenen Gegenstände, was Alles auch durch Zeichnungen (Situationspläne und Profile) darzustellen ist, sodass hie- 
nach später zu jeder Zeit in unzweideutiger Weise konstatirt werden kann, welches die Verhältnisse der ausgebeuteten Schichten im Ganzen und Einzelnen, welcher Punkt die Fundstelle irgend eines Gegenstandes (Petrefakts oder Artefakts) und welches die Lage des letzteren war.

Wo immer möglich ziehe man zu den Ausgrabungen unparteiische Zeugen bei. Es ist das der beste Schutz gegen Zweifel, welche später gegen die Authentizität der Entdeckungen

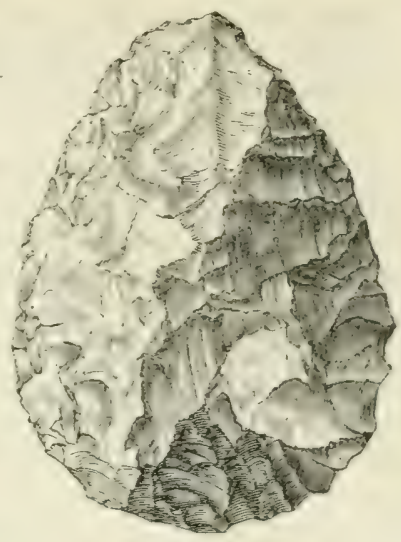

Fig. 233. erhoben werden kïmten. Der Forscher mag ein noch so glaubwürdiger Mann sein, so schützt ihn dies nicht ror dem Verdachte, dass seine P'hantasie mit im spiele sein könne: das Zeugniss eines unparteiischen Mannes, der einfach aufmerksam zugeschaut hat und nun herichtet, was er sellsst gesehen, ist in solchen Fällen mehr werth, als dasjenige des Gelehrten. Wenn einzelne Objekte Zeichnungen und Skulpturen enthalten, so nehme man hievon Photographien auf: keine andere Darstellung gewährt, selbst beim besten Willen des Zeichners, dieselhe Genauigkeit, lieine daher auch denselben Schutz gegen Anzweiflung ihrer Richtigkeit und Zuverlässigkeit.

Das relative Alter der Fundstïcke wird bestimmt:

$1^{\circ}$ nach der Stellung der Fundschicht im Profile des Höhlenbodens ;

$2^{\circ}$ nach den Beziehungen der Fundschicht zur Geologie der Lmgegend, ihrer Beschaffenheit, Bildungsweise und deren Ursachen.

$3^{\circ}$ nach den Thierresten, welche gewöhnlich (regehmässig, nicht zufällig) mit den betreffenden Objekten zusammen vorkommen. Für Thierarten, welche ganz ausgestorben sind, ist ein höheres Alter anzunehmen, als für solche, die zwar in der bestimmten Gegend nicht mehr, wohl aber anderwärts noch rorkommen, also nur aus der in 
Rede stehenden Gegend verschwunden sind; diese hinwieder müssen für älter gehalten werden als die Spezies, welche noch jetzt in dem Lande vorkommen.

$4^{\circ}$ nach dem Charakter der Kunstfertigkeit, von der sich Produkte finden, nach der mehr oder minder alterthümlichen und primitiven Form dieser Objekte.

Wenn sich in einer Schicht Reste verschiedener Art und Natur vorfinden, so dürfen dieselben nicht unter allen Umständen als gleichzeitig betrachtet werden. Gewisse Schichten bedurften zu ihrer Bildung einer langen Zeit, sodass sich in denselben Reste verschiedener Generationen ansammeln konnten, die man nun nebeneinander trifft. Dagegen ist. diese Gleichzeitigkeit oder Koexistenz offenbar vorhanden, wenn dieselbe Vergesellschaftung von Formen in zwei oder mehr deutlich unterscheidbaren Schichten eines Profils sich vorfindet.

Ein zeitliches Nacheinander ergibt sich aus dem Umstand, dass in untern Schichten gewisse Reste fehlen, welche sich in den obern einstellen; die Richtigkeit der Schlussfolgerung wird aber nur in dem Maasse gesichert, als sich dieselbe Aufeinanderfolge in mehreren verschiedenen Höhlen nachweisen lässt.

Was die als Begräbnissplätze dienenden Höhlen betrifft, so sind die Reste (Skelette und Artefakte) der Grabstelle mit denjenigen des Vorraumes für die Leichenfeierlichkeiten in dem Falle gleichzeitig, wenn die einen und andern auf der nämlichen Schicht abgelagert sind. Diese letztere kann in dem Vorraume (der Balm) oft ron neueren Ablagerungen bedeckt sein, welche im Innern der Höhle fehlen.

Die Schlïsse, welche sich aus den in Höhlen gesammelten Resten ergeben, sind höchst instruktiv. Wir können hier nur einen kurzen Ueberblick solcher Resultate geben, dessen Ergänzung im einzelnen Fall Sache des Forschers ist.

Aus den Menschenknochen erkennt man, wie die Rasse der Höhlenbewohner beschaffen war. Es ist in dieser Hinsicht auf den Abschnitt über anthropometrische Bestimmungen (S. 109 bis 115) zu verweisen.

Die Knochen gestatten bisweilen auch Schlïsse auf die Lebensweise und Gewohnheiten der urgeschichtlichen Menschen. So sind starke Muskeleindrücke an den Becken- und Schenkel- 
knochen als ein Merkmal grosser Kraft und Behendigkeit zu betrachten: horizontale Abnutzung der Zähne deutet auf die Gewohnheit hin, das zur Nahrung dienende Fleisch zu zerreiben statt zu kauen.

Wenn Menschenknochen mit Speiseresten gemengt sind und zudem Spuren von Schlägen, ron Verkohlung etc. zeigen, so spricht dies dafür, das die Höhlenbewohner Kannibalismus trieben. Immerhin darf eine solche Folgerung nicht vorschnell gezogen werden. Bei den Eskimos z. B. kommt es ror, dass Hunde und Füchse die Leichen ausgraben, zur Vermischung ihrer Reste mit Küchenabfällen Anlass geben, auch wohl dieselhen nach den Feuerstellen schleppen. Schlagspuren sodann können ron verschiedenen Lrsachen herrühren.

Die Thierknochen zeigen, welches die Fauna dieser urgeschichtlichen Zeiten und die Xahrung des prähistorischen Menschen war. Wenn Fischgräthe und Fischereigeräthe fehlen, so wird der Schluss gestattet sein, dass man es eher mit einem Jägerrolk als mit Fischern zu thun hat.

Jenarhdem Knochen ron Thieren, welche gezähnt werden künnen, ganz orler zerschlagen sind, kann angenommen werden, dass die Thiere grezähmt, d. h. als Hausthiere gehegt wurden oder nicht. Wenn an den Enden angenagte Knochen sich mit Hundeknochen zusammen finden, so ist hieraus auf das Vorkommen des Haushundes zu schliessen.

Aeltere Knochen, namentlich solche ron ungrewöhnlicher Grüsse (Mammuthknochen z. B.) künnen als Anzeichen ron Fetischdienst betrachtet werden. Der Altersunterschied zwischen diesen und den übrigen Knochenfunden ist nach dem $\mathrm{Er}_{\mathrm{r}}$ haltungszustand der einen und andern zu beurtheilen.

Das Vorkommen der Knochen ron Thieren, welche nicht zur Nahrung dienten, weist darauf hin, dass die Kürpertheile. ron welchen diese Knochen stammen, zur Gewinnung eines Nebenproduktes (z. B. des Posshaares) benutzt wurden.

Auf welche Art die Höhlenbewohner sich Feuer verschafften, ergibt sich mitunter auch aus Funden, z. B. aus dem Torkommen von Schwefelkiss- und Fenersteinknollen, aus welchen sie mit Kieseln Funken heratisschlugen.

Wozu die Sandsteinplatten dienten, welche man in der Nähe ron Feuerstellen findet iol als Sitze oder Fleischbänke), ist noch ungewiss. 
Das Fehlen ron Waffen, welche zur Erlegung der grossen Thiere geeignet waren, die als Nahrung verwendet wurden, spricht dafür, dass die urgeschichtlichen Menschen Gruben, Fallen u. dgl. Fangmittel anwendeten.

Art und Beschaffenheit der Werkzeuge sind Indizien für das relative Alter der Völkerschaft, den Grad ihrer Kunstfertigkeit, die Art ihrer Bekleidung etc.

Das Torkommen von durchbohrten Muscheln und Kinochen rerräth eine gewisse Liebe zu Schmuck; wenn sich Farbnittel rorfinden, so darf rermuthet werden, dass die Bewohner der Gegend sich zu bemalen oder zu tätowiren pflegten.

Scherhen von Töpferwaren sind ron grossem Interesse. Die Thongefässe können gröber oder feiner, gebramnt oder ungebramint, mit Ormamenten versehen oder ohne Verzierungen sein, und sowohl die Formen der Thonwaaren als diejenigen etwaiger Zeichnungen auf denselben erscheinen bald roh und unbeholfen, bald geschmackvoll und fein ausgeführt, sodass hiedurch die crewerbliche Kunstfertigkeit der Ureinwohner einer Gegend charakterisirt wird. Dieselbe ist im Weitern zu beurtheilen nach Zeichnungen an den Wänden der Höhle, auf Steinen, Knochen und Geweihstücken (Rennthiergeweih). Spuren solcher prïhistorischen Zeichnungen und Gravirungen sind namentlich dann werthroll und lehrreich, wenn sie den Charakter einer primitiven Schrift tragen.

Sehr wichtig ist die Kenntniss der Stoffe, woraus die Instrumente, Waffen, Schmuckgegenstände u. s. w. bestehen. Die Verwendung, beziehungsweise Verarbeitung der Metalle (Bronze, Eisen) hezeichnet eine höhere Kultur als der ausschliessliche Gebrauch von Stein, Holz und Knochen, sodass in der Darstellung solcher urgeschichtlichen Zustände durchwegs zwischen einer Stufe ohne und einer solchen mit Kenntniss der Metalle zu unterscheiden ist; erstere, für welche der Name Steinzeit in Uebung gelommen ist, wird passend als vormetallische Periode, letztere als Metallzeit bezeichnet. Bei den Steingräthen ist sowohl die Art des Gesteines als diejenige seiner Bearbeitung (ob diese durch Behauen oder durch Schleifen erfolgte) und bei den Metallwerkzeugen ebensowohl die Form (der Styl) als das Material zu beachten ${ }^{1}$ ).

1) Vgl. hierüber die Abhandlungen der Professoren Fischer und Ecker im Archiv für Anthropologie, Bd. VIII, IX und XII, Augsburger Ztg. 1876 (Beilage Nr. 68) und Westermanns Monatshefte 1830, sowie Dr. Ranke, Anleitung zu anthropologisch-vorgeschichtlichen Beobachtungen, S. $275 \mathrm{ff}$. 
Es drängen sich hiebei namentlich folgende Fragen auf: Findet sich die Gesteinsart in dem Lande selhst ror oder erst in einer weitentfernten Gegend, sodass in letzterem Fall die Stücke derselben eingeführt werden mussten und also auf uralte Handelsbeziehungen und Wanderungen hindeuten? Ist das Gestein so beschaffen, dass es offenbar gewisser Eigenthümlichkeiten wegen (Leichtigkeit der Hearheitung. Härte etc.) zu bestimmten Zwecken gewählt wurle: und ist dasselbe als Rohmaterial in die Höhlen grebracht, mit andern Worten hahen die Bewohner der letzteren die betreffenden Geräthe am Fundorte derselhen, in der Höhle selbst, angefertigrt? In letzterem Falle werden Splitter, als untauglich bei Seite geworfene Stücke, sowie Steinkerne orler Fieste grosser Blöcke vorkommen. Die Funde werden auch zeigen, ob mit dem Material sparsam umgegangen wurde oder nicht. woraus ein Schluss darauf gestattet ist, ob dasselbe schwer oder leicht zu heschaffen war; ebenso wird das reichliche oder seltene Vorkommen gewisser als Ziprrath verwendeter Steine. Muscheln und dergleichen mehr andenten, oh dieselben in dem Lande selbst zu finden waren oder nicht. Es ist ron hohem Interesse, die nïchstgelegenen Lrsprungsstellen. die wahrscheinlichen Bezugsyuellen aller dieser Materialien zu erkunden und auszumitteln, auf welche Art sie dahin gelangen komnten, wo man sie jetzt findet. Es ergeben sich hiebei Aufichlüsse und Nachweise hinsichtlich ältester Handelswege und Wanderungen.

Bei Höhlen mit Leichenfunden ist namentlich auf die Lage der slielette zu achten, auf die Bestattungsart, die angewandt worden sein muss, und Alles, was darauf Bezug hat (Tgl. S. 638). Aus dem Befund hierẗ̈pr kïmnen S.chlüsse auf gewisse Ideen und Gehräuche gragon werden. Man lionstatire, ob die frühere Bestattungsart mit derjenigen übereinstimmt, welche in der Gegend jet»t noch ïhlich ist, oder ob sie eine andere war: im letzteren Fall beschreibe man das Verfahren, welches ehedem angewendet worden zu sein scheint, so genau als möglich, d. h. soweit die Funde. dasselbe erkennen lassen.

Nachdem man die Beobachtungen gemacht, deren Vornahme an ort und stelle wünschenswerth orler nothwendig

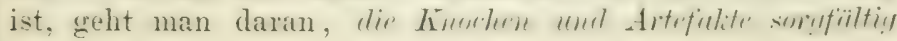


zu sammeln und anfzuheben, um die auf dem Lokale angestellten Beobachtungen später entweder selbst durch ein näheres Studium der einzelnen Fundstücke zu ergänzen oder diese Fachkundigen vorzulegen, kurz sie - auf die eine oder andere Art - wissenschaftlich $\mathrm{zu}$ verwerthen. Zu letzterem Zwecke ist namentlich auch eine systematische Klassifikation und Aufstellung der verschiedenen Funde nach sachgemässen Gruppen nothwendig. Es sind z. B. die einzelnen Theile desselben Skelettes zusammenzuleg'en und von Anderm getrennt zu halten; ebenso ist ein Steinwerkzeug mit dem Block, von welchem das Material stammt, und den dazu gehörenden Splittern in eine Gruppe zu bringen; ferner würden die in einem und demselben Grabe gefundenen Schmucksachen eine hesondere Gruppe bilden. Jede dieser Abtheilungen ist ron andern gleichen Alters, namentlich aber von solchen verschiedenen Alter's wohl zu trennen. Durch Aufschriften, Nummern und entsprechende Bemerkungen in einem Notizbuche ist dafür zu sorgen, dass später zu jeder Zeit konstatirt werden kann, unter welchen Verhältnissen irgend eines der Objekte aufgefunden worden ist.

Was die Terpactum! und Aufbecalerun! der Fundstäcke betrifft, verweisen wir auf das oben (S. 327 und 333) über die Behandlung ron Gesteins- und Petrefaktensammlungen Gesagte.

Alte Lagerplätze. Von den Lagern nomadisirender Stämme verschwand meist nach kurzer Zeit jede Spur. Es traten aber im Leben dieser Horden Momente ein, wo sie bei Aufsuchung neuer Jagd- und Weidegründe von Stellen, die ihnen zusagten, in dauerhafterer Weise als gewöhnlich Besitz ergriffen. Dabei war ihre erste Sorge die, gegen Gefahren, die ihnen drohen konnten, Schutzmassregeln zu treffen. Schwache Stämme suchten ihre Lager versteckt zu halten und schlugen sie daher in abgelegenen Waldlichtungen oder schwer zugänglichen Gebirgsthälern auf. Starke Stämme hingegen wählten sich als Lagerplatz eine dominirende Stellung aus, von wo man die Gegend überschauen und sich gegen einen Handstreich schützen konnte.

Zum Zwecke der Entdeckung solcher alten Lagerplätze ist es wichtig, zu ermitteln, welches die Richtung einer Wanderung war. In den meisten Fällen wurde bei letzterer 
von verschiedenen Wegen derjenige eingeschlagen, welcher der bequemste und zugleich am günstigsten für die Fristung der Existenz während der Dauer des Wanderzuges war; es wurden also Flachländer den gebirgigen vorgezogen, weite Thäler den engen, die Thalwege den Bergabhängen und Kämmen; in allen Fällen war die Nähe fliessenden Wasser's, das Trank und Speise gewährte, ron grosser Wichtigkeit. Einem auf der Wanderung befindlichen Stamme hätte es lästig fallen müssen, sich nur auf Wild angewiesen zu sehen; die Jäger hätten sich sehr oft ron den lebrigen tremnen müssen auf die Gefahr hin, in die Irre zu gehen und den Stamm nicht mehr einzuholen. Hievor blieb man bewahrt, wemn man einen Stromlauf rerfolgte. Es komnte der wandernde Stamm hiebei rasch rorrïcken: an einer Haltstelle angekommen, machte sich Alles ans Werk: die einen fischten, andere jagten, Frauen und Kinder suchten dürres Holz, schöpften Wasser, zündeten Feuer an und bereiteten die Speisen. Das Trinkwasser spielt an und für sich in derartigen Fällen eine so grosse Rolle, dass in den Ländern, wo man heute noch auf gleiche Weise - in Truppen oder Karawanen auf ungebahnten Wegen - reist, die Marschroute und die Eintheilung derselben in einzelne Strecken (nach Etappen) durch das Vorkommen oder Fehlen von Quellen, Brunnen und Bächen bedingt ist. Je zahlreicher eine wandernde Truppe, desto nothwendiger ist es für sie, darauf Bedacht zu nehmen, dass sie auf ihrem Narsche reichlich Wasser vorfinde; dies namentlich damn, wenn es sich um Nomaden handelt, die Heerden ron Vieh mit sich führen.

Bodengestalt und Bewässerung eines Landes werden also Anhaltspunkte bieten zur Erkenntniss der Richtungen für die Wanderzüge, der Betten und Bahnen für die Völkerströme grauer Vorzeit. Wenn eine solche Route èmittelt ist, so hat man nun weiter zu prifen, welche Punlite zu beiden Seiten der Linie als Lagerplatze besonders gerignet uareu. Dabei ist $\mathrm{zu}$ herücksichtigen, dass in jenen Zeiten die Flüsse und Ströme wasserreicher waren, daher Lager weniger nahe an denselben aufrgeschlagen wurden als dies heutzutage der Fall sein möchte und demnach Punkte ins Auge zu fassen sind, von denen ausser Zweifel stehen 
kann, dass sie schon damals nicht im Bereiche der Ueberfluthung lagen.

Es ist ferner nicht zu rergessen, dass viele Thäler seit den prähistorischen Zeiten vertieft worden sind und dass rormals das Wasser auf einem bedeutend höhern Niveau floss als jetzt. Man hat also nicht die Thalsohle oder den Thalweg ron heute, sondern die alten Flussterrassen auf beiden Seiten eines Gewässers als den Boden zu betrachten, auf welchem die Menschen der urgeschichtlichen Periode sich bewegten.

Die alten Lirhtunyen auf diesem Boden sind mitunter zu erkemen durch ihren geringen Gehalt an Dammerde und die Cnfruchtbarkeit, welche Folge dieses Umstandes ist. Es sind im Allgemeinen Terrains, die sich heute noch als unkultivirbar erweisen. Was die abyelegenen Thüler anbetrifft, so sind sie heute weit auffälliger als zu einer Zeit, da die Landschaft noch sehr stark bewaldet war; sie kömen aber Veränderungen (remaniements) erlitten haben, welche den Erfolg von Untersuchungen beeinträchtigen.

Einige Wahrscheinlichleit für Funde ist vorhanden, wenn in einer alten Lichtung Sinuen ion Graben, Evducillen und Trorlemmancen (aus Steinen ohne Mörtel) wahrnehmbar sind, und in einem abgelegenen Thale in der Höhe seiner ehemaligen Ausmündung ins Hauptthal Reste analoger Bauten sich zeigen, die zur Absperrung und Vertheidigung des Thaleingangs dienten.

Unter den dominirenden Punkten scheinen die Stämme der Naturvölker namentlich isolirte Häyel und Felsrorsprïnge (Promontorien) mit stcilen Wünden als Lagerplätze aufgesucht zu haben, die einen freien Blick auf die Umgegend gestatteten, von drei Seiten her nicht oder nur schwer zugänglich waren und blos auf einer Seite einen bequemeren, aber leicht zu vertheidigenden Zugang (Isthmus) hatten. Wo diese Bedingungen erfüllt sind, ist eine gewisse Wahrscheinlichkeit für Erfolg der Untersuchungen vorhanden, wenn man Reste von Trockenmauern bemerkt, die quer über den Istlımus oder längs der Steilwände hinführen, oder wemn der Zugang von Menschenhand verengt erscheint.

Indessen sollen die Nachforschungen nicht auf dergleichen ausgezeichnete Stellen beschränkt werden; denn in Ermanglung 
von Punkten, welche gewissermaassen natürliche Festungen vorstellen, wurden oft auf gewöhnlichen Hïgrln und Horkebruen Lager aufgeschlagen, die umgeben waren von Trockenmauern oder Erdwällen, sowie mit Gräben und mit in gewissen Abständen angelegten (ohne Zweifel leicht nit Astwerk zugedeckten) Fallgruhen. Diese Lager waren oft durch mehrfache I'mwallungen befestigt und ron grossem Lmfang.

Ausnahmsweise konnten auch an verschiedenen andern Orten Lager aufgeschlagen werden, so am . Werrsstrunde,

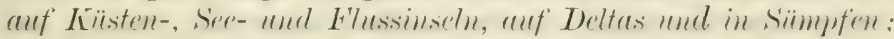
an solchen Stellen sind aher die Reste der alten Werke nur durch Zufall oder durch besonders sorgfältige Lntersuchungen aufzufinden.

Wenn von Punkten dieser verschiedenen Kategorien nach ihrer topographischen Eigenthümlichkeit und nach andem Indizien rorauszusetzen ist, dass sie alte Lagrerplätze waren, so erstelle man einen Plan derselben und ordne man Ausmabungrn an. Zur Vornalme der letzteren wird man sich eine Erlaubniss der kompetenten Behörde oder des Grundeigenthümers verschaffen müssen; in einer Gegend, wo keine solchen Formalitäten erforderlich sind, wird man hingegen mit den Anschauungen und Vorurtheilen des Volkes zu rechnen und sich abzufinden haben. Auch ist es auf alle Fälle angezeigt, sich durch einen Versuch üher die Chancen einer systematischen Ausgrabung zu orientiren und die Bewohner der Gegend für die Sache zu interessiren, sei es durch die Aussicht auf Arbeitsverdienst, sei es durch kleine wohlangewandte Geschenke.

Die Lokalität, auf welcher Nachgrabungen vorzumehmen sind, ist durch die Peste von Mauern und Gräben bezeichnet; es sind namentlich innerhalh dieser Grenzen Funde zu erwarten; immerhin sollen die Arbeiten nicht auf dieses Areal beschränkt, sondern über dasselbe hinaus fortgesetzt werden; denn hiebei kann man auf Waffen und andere Gegrenstände treffen, welche anstürmenden Feinden gehörten.

Was die Frage betrifft, wie tief man graben soll, so ist zu empfehlen, dass man hiebei womöglich bis auf den anstehenden (gewachsenen) Fels gehe; dis einzelnen Schichten, ron den obersten und jüngsten bis zu den untersten oder ältesten auf dem ursprïnglichen Boden, sind der Reihe nach 
sorgfältig zu studiren. Es kann sich treffen, dass eine solche Schicht absolut keine Fundstücke enthält und nur aus Schutt besteht, der nach dem Verlassen des Lagers entstand, dass aber die nächst tiefere Schicht reich ist an Funden, welche Zeugniss ablegen vom Leben und Treiben des Menschen an dieser Stätte. Selbstverständlich sind bei diesen Ausgrabungen die nämlichen Vorsichtsmassregeln zu treffen wie bei denjenigen in Höhlen (S. 784 bis 787).

Durch Erdeinschnitte und andere Aufschlüsse wird es nicht selten möglich, das geolorfische Terhältniss zwischen den Schichten, auf welchen die Ueberreste menschlicher Industrie ruhen, und denjenigen des umliegenden Terrains festzustellen. In solchen Fällen sind genaue Profite aufzunehmen und alle Lmstände zu notiren, welche zu einer approximativen Altersbestimmung dieser Lager dienen können.

Die Schlussfolummugn, welche aus den beobachteten Thatsachen yezoyen urrden liomen, sind zum Theil dieselben, von denen oben bei Besprechung der Höhlen die Rede war. Dazu tritt hier mitunter die Möglichkeit, Art und Form der Wohnungen zu ermitteln. Spuren von Pfählen in bestimmten Zwischenräumen machen es wahrscheinlich, dass Hütten vorhanden waren, die aus einem leichten Gebälk und einer Verkleidung aus Thierhäuten oder Astwerk bestanden. Wenn sie durch Fever zerstört wurden, trifft man oft noch Reste eines Lehmbestichs mit Abdrücken des Flechtwerks, welches damit überzogen war ${ }^{1}$ ). Solidere Pfähle und Reste morschen Holzes lassen darauf schliessen, dass die Gebäude aus Baumstämmen bestanden. Mauerreste werden zeigen, ob Backsteine, Feld- und Bruchsteine mit Mörtel oder Trockenmauern angewendet wurden, und die grössere oder geringere Nenge des Schuttes wird ein Urtheil darüber gestatten, ob das Mauerwerk einen wesentlichen oder nur unbedeutenden Theil der Baute ausmachte. Die Figur der Fläche zwischen den Pfahl- und Mauerspuren lässt erkennen, ob das Gebäude rundlich, quadratisch oder rechteckig war; selbst in Ermanglung solcher Reste kann oft noch nach andern Indizien (z. B. nach dem Areal, auf welchem Küchenabfälle vorkommen) ein Schluss auf die Form der Baute gezogen werden.

1) Wände oder Mauern aus einem derartigen Geflecht von Aesten mit Lehmbewurf (Etterwerk) trifft man in der Nordostschweiz hie und da bei alten, noch jetzt in Gebrauch stehenden Hütten und Häusern. 
Finden sich nur wenig oder keine ganzen Waffen und Werkzeuge vor, so ist anzunchmen, es sei das Lager freiwillig aufgegeben worden. Kommen die genamnten Objekte in grosser Zahl vor, so deutet dies darauf hin, dass ein schleuniger Abzug stattfand. Ob dieser durch eine Feuersbrunst oder eine Schlacht verursacht war, wird nach dem Vorkommen von Asche und Kohle oder menschlicher Geheine beurtheilt werden kömen. Bei genauer Untersuchung der Umfassungsmauern und Wälle wird man nicht selten noch Anzeichen einer stattgefundenen Belagerung entdecken: die Existenz von Breschen und Spuren einer Einschliessung oder Bezwingung des Platzes durch das Fener angezündeter Reiswellen, welche man um das Lager hertum aufläufte, wobei das Feuer die Erdwälle geschwärzt, die äusseren Mauersteine aber calcinirt und verglast hat.

Pfahlbauten u. dgl. $\left.{ }^{1}\right)$ Ein anderes Bausystem der nicht höhlenbewohnenden Naturvölker bestand und besteht zum Theil noch in der Anlage ron Bauten, die auf einem Roste von Pfählen ruhen. In dieser Weise wurden ganze Dörfer erstellt. Die einzelnen Hütten sind zuweilen von einauder ganz getrennt, isolirt und selbständig, meist aber in Gruppen zusammengestellt, so zwar, dass die Hütten einer Gruppe eine gemeinschaftliche Plattform haben, die auf Pfählen ruht. Wo Felsgrund vorhanden war, der es unmöglich machte, Pfähle in den Boden zu schlagen, befestigte man die letzteren, indem man sie mit Steinen umgab oder aus Steinen, Pfählen und Lehm eine künstliche Insel erstellte. Dieser Art sind die ténecières der Schweizerseen und die crannorges ("Sumpfburgen")

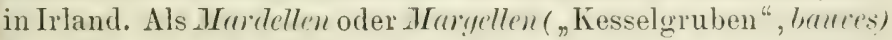
bezeichnet man Vertiefungen im Boden, die eigens zum Zwecke der Erstellung von Pfahlbauten angebracht zu sein scheinen. Die Teramaren endlich sind Bauten, wie die eben erwähnten; die aber nicht in Gewässern von erheblicher Tiefe, sondern in Torfmooren und seichten Lagunen angelegt waren.

Diese Bauart findet sich noch in verschiedenen Gegenden. Wo sie prähistorisch ist, d. h. in geschichtlicher Zeit nicht mehr angewendet wurde, hat die Entdeckung derselben ihre Schwierigkeiten; denn es sind daron oft nur einige Pfühle

1) Vgl. hierüber die Mittheilungen der antiquarischen Geselischaft in Zürich, Band IX, XII bis XV und XX, 1856 bis 1879 (Berichte von Dr. Ferd. Keller). 
geblieben, welche im Schilfe oder unter einer Allurialschicht (Kies, Schlamm etc.) rerborgen sind. Die der atmosphärischen Luft ausgesetzten Pfähle erlagen der Zersetzung; diejenigen, deren Köpfe fast bis zur Oberfläche des Wassers reichten, haben durch den Wellenschlag gelitten: gut erhalten sind meist nur die unteren, im Boden befindlichen Theile. Auch werden die Entdeckungen oft nur möglich bei Vornalme von Ausgrabungen oder doch sorgfältiger Untersuchungen des Bodens an Stellen in geeigneter Lage.

Man hat bemerkt, dass die Pfahlbauten sich im Allgemeinen an gut gewählten Orten befinden, z. B. in ruhigen Seebuchten mit flachem Lfer, wo der Verkehr mit dem festen Lande leicht hewerkstelligt werden konnte. In den Schweizerseen trifft man sie fast immer nahe bei den jetzigen Uferortschaften, sei es nun, dass die Lokalverhältnisse, welche für die crste Wahl ciner Stelle (bei Anlage der Pfahlhauten) massgebend gewesen waren, auch später (bei Anlage der Dörfer) den Ausschlag gahen, sei es dass die Pfahlbaubewohner bei zunehmender Zahl und infolge irgend welcher Umstïnde, die nun dem Festlande den Vorzug verschafften, ihre Hütten eben am nahen Ufer errichteten, wo sie alsdann durch die heutigen Dörfer ersetzt worden sind. Indess darf nicht vergessen werden, dass der Spiegel eines Sees hente eine wesentlich andere Lage haben kann als vormals. Bald ist das Niveau des Sees durch natürliche oder liünstliche Stauung erhöht worden und befinden sich nun die Pfahlbauten tief unter Wasser, bald ist durch Abfluss oder Verdunstung eine Senkung desselben eingetreten und liegen nun die Stationen in einem rom jetzigen See mehr oder minder weit entfernten Sumpfe. Uebrigens findet man die Pfahlbauten nicht nur an den Gestaden der heutigen Seen, sondern auch in Aestuarien, an Flussufern, überhaupt an den verschiedensten Stellen, die von Wasser bedeckt sind oder es früher waren, in sumpfigen oder trocken gelegten Niederungen, alten Torfmooren $\mathrm{u}$. s. w.

Man hat demnach die Ufer der Seen und Flïsse zu untersuchen, wo die Gewässer nicht tief sind, und den Boden, wo Spuren von Pfahlwerk oder künstliche Erhöhungen wahrnehmbar sind. Wenn Grund vorhanden ist zu der Annahme, dass die Lage des Wasserspiegels sich in erheblicher Weise 
geändert habe, so sind die muthmasslichen alten l'fer' zu untersuchen. Ferner erforsche man Torfmume und sumptiges Trmain. das sich von Weitem durch seine eigenthümliche Vegetation bemerklich macht, sowie auch mulden- und heckenfïmige Itemessirmendes Budens, welche früher von Wasser bedeckt sein lionnten.

Wen man spuren von einer I'fahlbanstation findet, so suche man in der Nähe, am jetzigen oder früheren Lfer, nach den Grabstätten, welche zu der Niederlassung gehörten.

Das Aufsuchen von Fundstïcken auf und in einem unter. Wrassm befindlirhen Bodrn hat eigenthümliche Schwierigkeiten. Wenn die Gegenstände auch ummittelbar auf dem Boden, in dem Schlamme desselben liegren, so sind dieselben derart mit einer Tuffkruste umgeben, dass es eines geübten Auges bedarf, um sie zu unterscheirlen. Die tieferen Schichten aber kamn man nur auf Gerathewohl mit der Dredsche oder anderen Werkzeugen durchsuchen, da nichts die Gegenwart der gesuchten Objekte verräth. Indessen hezeichnet es Prof. Desor ${ }^{1}$ ) als ein Indizium für die Wahrscheinlichkeit des Vorkommens der in Rede stehenden Objekte, wenn beim Graben in dem Schlamm zahlreiche Kohlenstücke zu Tage gefördert werden. In diesem Falle ist anzunehmen, dass die Station durch eine Fenershrunst zerstört wurde, welche die Bewohner zur Flucht zwang, ohne dass ihnen Zeit blieb, ihre Hausgeräthe, Werkzeuge, Waffen u. s. f. mitzunehmen. Zeigen sich keine Kohlen, so wird die Lntersuchung aller Wahrscheinlichkeit nach nur eine magere Ernte liefern.

Bevor man mit dem Herausschaffen des Materials am Grunde des Gewässers (Schlamm, Sand, Kies etc.) heginnt, müssen Pfähle eingeschlasgen werden, an welche das Schiff in zuverlässiger Weise zu befestigen ist; sonst würde man sich der Gefahr aussetzen, dass das Fahrzeug unter den Anstrengungen der Arbeiter, welche jenes Material heraufschaffen sollen, umschlüge.

Von den besonderen Instrumenten für diese Ausbeutung von unter Wasser befindlichen Pfahlbauten erwähnen wir diejenigen, welche in der Schweiz gebräuchlich sind und ron Prof. Desor ${ }^{2}$ ) empfohlen werden. Das eine (Fig. 2:3i) ist

1) Le Bel Age du Bronze lacustre en Suisse, par M. F. Desor, dessins par L. Farre. Paris et Neuchâtel, 1874, p, 2

2) E. Desor, die Pfahlbauten des Neuenburger Sees, Frankfurt a. M. 1866, p. VIII und IX. 


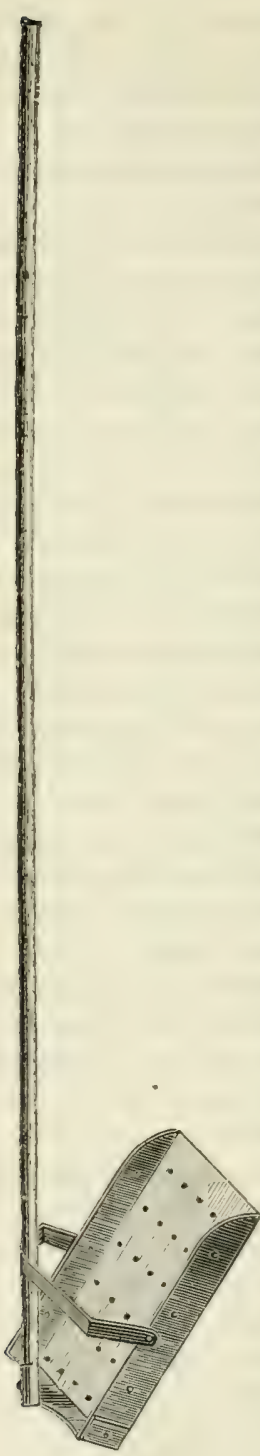

Fiy. $23 t$. ein Scharrinstrument für den Handgebrauch, das andere (Fig. 235) eine langgestielte Zange zum Ergreifen der kleinen Gegenstände, welche man unter Wasser sieht.

Die wichtigsten Schlussfolgerungen ans den beobachteten Thatsachen und gctundenen Objekten betreffen einerseits die geologischen Aenderungen, die seit der Zeit, aus welcher die Niederlassung stammt, vorgekommen sind, andrerseits die Bedeutung der Station und ihrer Bevölkerung in jener fernen Zeit, deren Kulturstufe und Geschichte.

Wir haben schon gesehen, dass das Niveau, in welchem diePfahlstïcke und dieSchicht mit Resten menschlicher Industrie(Fundschicht, Kulturschicht) vorkommen, zuweilen auf stattgefundene Aenderungen in den hydrologischen Verhältnissen der Gegend hinweist. Bei Anlage dieser Wohnungen muss sich der Boden unterWasser befunden haben; das letztere kann aber an einer solchen Stelle nicht sehr tief gewesen sein, da sonst sehr lange Pfähle nöthig gewesen wären. Wenn nun derselbe Boden heute entweder trocken gelegt oder aber tief unter Wasser ist, so beweist das eine wesentliche Aenderung

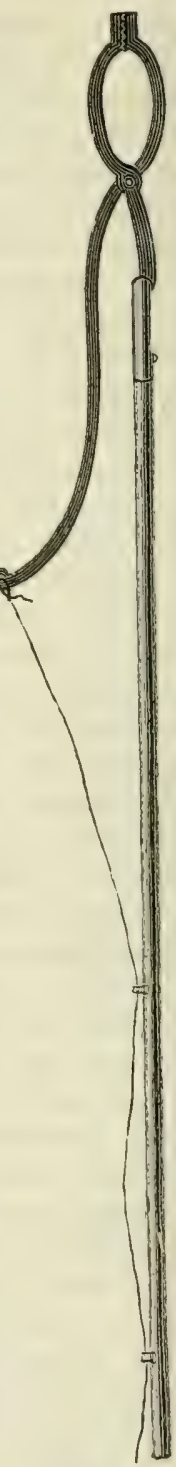

Fig. 235. 
der Verhältnisse; noch augenscheinlicher tritt eine solche hervor, wenn man z. B. in einem Torfmoor Reste von Kähnen (ausgehöhlte Baumstämme, Einbäume) findet oder durchbohrte Steine, die als Anker benützt worden sind.

Die Untersuchung des Holzes der Stämme, welche zu Pfählen verwendet wurden, gibt Aufschluss über die damalige Baumvegetation, welche eine namhaft andere gewesen sein kann als diejenige der heutigen Wälder in derselben Gegend.

Ebenso liefern die Thierknochen der Pfahlbauten Material zur Beurtheilung der Fauna jener Zeit.

Die Bedeutung einer Station bemisst sich zunächst nach ihrem Umfang, d. h. nach dem Areal, auf welchem sich Pfähle finden; ferner danach, ob die Station zum Wohnen oder blos zur Aufhewahrung von Vorräthen diente. Im ersten Fall muss zwischen ihrem Umfang und der Anzahl der Familien oder Haushaltungen in derselben eine gewisse Beziehung herrschen; im zweiten Fall aber sagt uns der Umfang nichts über die Bevölkerungszahl. Dass eine Station Wohnplatz gewesen sei, ist wahrscheinlich, wenn man zwischen dem Holzwerk Scherben von Thonwaaren, Küchenabfälle, Bruchstücke von Waffen, Schmucksachen u. dgl. findet. Wenn aber diese Gegenstände in grosser Zahl und fast intakt an einer Stelle beisammen gefunden werden, so ist anzunehmen, die Station sei als Magazin für Vorräthe benutzt worden.

Die Menschenknochen ergeben Anhaltspunkte zu Schlüssen über die Rasse, welcher ein Pfahlbauvolk angehörte; sie sind aber im Allgemeinen selten; ihr Vorkommen in den Stationen ist nur ein zufälliges, denn die Bewohner der Pfahlbauten hatten ihre Begräbnissplaitze auf dem festen Lande.

Aus Küchenabfällen oder Speiseresten lassen sich Schlüsse ziehen auf die Art der Nahrung und bis zu einem gewissen Grade auf die Lebensweise eines Pfahlbauvolkes. Finden sich in Menge Fischgräte und offene Muscheln, so haben wir es mit einer Fischerkolonie zu thun; Knochen wilder Thiere weisen auf Jagdbetrieb, Kornquetscher oder Mahlsteine, die zum Zerreiben von Getreidekörnern dienten, auf ein ackerbautreibendes Volk hin, dem die Kultur der Zerealien bekannt war. Mangel an Knochen von Hausthieren - ausgenommen von Hund, Katze und Ziege - beweist nicht, dass noch 
keine Viehzucht bestand; denn grosses Vieh, wenn solches vorhanden war, musste ohne Zweifel auf dem festen Lande untergebracht werden.

Wenn eine Station durch Feuersbrunst unterging, so hat man einige Chancen zur Ermittlung der für die Hütten angewendeten Bauart. Bestanden die Hütten nur aus Holz, Astwerk und Schilfrohr, so beseitigte das Feuer jede Spur derselben; waren sie aber mit einem Lehmbewurf versehen, so kann man noch calcinirte Stücke desselben finden, welche Abdrücke des übrigen Materials (ron Aesten und Schilfstengeln) enthalten und durch gewölbte oder flache Form zeigen, ob die Hütten rundlich oder viereckig waren.

Aus den Resten an Geräthen, Waffen, Schmucksachen u.s. w. kann auf den Grad der Kultur und den Wohlstand der Bewohner geschlossen werden.

Ein massenhaftes Yorkommen von Asche und verkohlter Stoffe beweist, dass die Station durch Feuer zerstört wurde. Jenachdem über der Kohlen- und Aschenschicht wieder Erzeugnisse des Gewerbfleisses sich finden oder nicht, ist zu schliessen, dass die Niederlassung nach dem Brande wieder bewohnt oder aber infolge der Katastrophe gänzlich aufgegeben wurde.

In jedem Falle wäre es höchst interessant, die Ausbeutungs-Arbeiten so betreiben zu können, dass die Funde nach den einzelnen Schichten eingeheimst und zusammengestellt werden könnten; denn es kann eine Niederlassung ron vielen Generationen benutzt worden sein, und eine solche nach den verschiedenen Fundschichten erstellte Sammlung gäbe ein Bild über den Fortschritt menschlicher Kunstfertigkeit und Zivilisation.

Die drei Hauptarten menschlicher Wohnungen, von denen im Vorstehenden die Rede war (Höhlen, Lager und Pfahlbauten) scheinen keiner besondern Rasse oder Periode eigenthümlich zu sein. Alle drei entsprechen einem natürlichen Bedürfniss des primitiven Menschen; sie hängen mehr mit dessen Lebensweise und den Hülfsmitteln des Landes als mit überlieferten Ideen zusammen. Das Vorkommen von Höhlen veranlasste den Menschen, in denselben Zuflucht zu suchen; in Ermanglung von solchen und bei einer höheren Stufe der Kultur schlug er sein Lager unter freiem Himmel 
auf; wo Seen vorhanden waren und sowohl zum Fischfang als zur Jagd sich Gelegenheit bot, erstellte der Mensch Wohnungen in der Nähe der Ufer, auf Pfählen im Wasser oder auf dem Lande. Wenn aber in der nämlichen Gegend alle drei Arten ron Wohnungen gefunden werden, so ist es wahrscheinlich, dass sie von verschiedenen Volksstämmen oder aus verschiedenen Perioden herstammen.

Kjökkenmöddinger. Die Existenz ron Lrbewohnern eines Landes wird uns nicht nur aus Resten ron Wohnungen derselben offenbar; neben diesen und in Ermanglung solcher gibt es noch andere Anzeichen dafür; so z. B. die Haufen von Muschelschalen und Speiseresten, welche die Archäologen mit dem dänischen Worte "Kï̈lifmmörldinup." bezeichnen. Solche Funde sind zuerst an den Küsten Dänemarks, seither aber auch in Asien, Australien und Amerika gemacht worden. In Brasilien heissen sie sombarpuis, in Patagonien paraderos. Sehr zahlreich sind sie an den Küsten von Oregon und KaIifornien; ebenso traf man sie am Golf von Mexico und auch im Mississippibecken.

Diese Haufen kommen in Form von Hügeln in rerschiedener Grösse am Neeresstrande, in Aestuarien und zuweilen auch an den Ufern grosser Ströme ror. Infolge ron Hebungen oder Senkungen des Bodens und anderer Ursachen können sie sich auch in einiger Entfernung von den jetzigen Ufern, auf dem Lande oder im Wasser, rorfinden. Oft sind sie ron Vegetation überzogen.

Es gibt auch Muschelhaufen, die zufällig rom Wasser gebildet sind und mit den "Kjökkenmöddinger" nicht verwechselt werden dürfen. Die charaliteristische Lïnmsirhaft der liünstlirhen. Wuschelanhüufungen liegt darin, dass letztere blos aus solchen Schalen bestehen, welche augenscheinlich greöffnet worden sind, um den Inhalt derselhen herauszunehmen. Die beiden Schalen einer Muschel sind ron einander getrennt und selten neben einander zu finden. Zudem enthalten die Haufen ein Gemisch von Arten, welche im Leben nicht zusammen (. gesellig" gleichen Verhältnissen rorzukommen pflegen, sodass offenhar ein künstlicher Transport derselben nüthis war, um diese Ansammlungen zu bilden. Endlich findet man in diesen Muschelhaufen verschiedene Spuren der Existenz des Menschen: 
Asche, Kohlen, Geräthe, Waffen, Schmucksachen, mitunter auch menschliche Skelette.

Zur Erlikirung des Vorkommens solcher Muschelhaufen nimmt man an, dass gewisse Volksstämme zu bestimmten Zeiten des Jahres sich an einem günstigen Punkte einfanden, um hier so riel Muscheln als möglich zu sammeln, dass sie die ganze Zeit über von diesen Muscheln lebten und diejenigen, relche nicht unmittelbar verzehrt wurden, öffneten, um den Inhalt zu trocknen und in dieser Form für später aufzubewahren. Indess muss bemerkt werden, dass im indischen Archipel, wo sich Pfahlbauten vorfinden, unter diesen Wohnungen mit der Zeit Haufen ron Muschelschalen entstehen, indem die Eingebornen letztere rorwegs ins Wasser werfen, sowie sie dieselben geöffnet und den Inhalt verspeist haben.

Ein Anschnitt wird es möglich machen zu konstatiren, ob diese Haufen in Beziehung stehen zu zeitweise benutzten Wohnungen; denn wenn sie periodisch für längere Zeit sich selbst überlassen waren, so lagerte sich darauf Flugsand ab, und sie bestehen alsdann aus einer Folge von Muschelschalenlagen, die von einander durch dünne Sandschichten getrennt sind. Die unter Pfahlhütten entstandenen Muschelansammlungen bilden mehr einzelne isolirte Haufen als eine zusammenhängend über einen grössern Raum sich erstreckende Masse.

Fanggruben und Verstecke. Mehr durch Zufall als auf positive Indizien hin entdeckt man zuweilen Gruben, welche zahlreiche Thierknochen enthalten, sowie unterirdische Verstecke mit verschiedenen Gegenständen und Vorräthen.

Jene Gruben können ron urgeschichtlichen Volksstämmen erstellt worden sein, welche von der Jagd lebten und diese in der Weise betrieben, wie es noch heute in Südafrika geschieht, wo ganze Heerden wilder Thiere (Girafen, Antilopen etc.) von allen Seiten eingeschlossen und dann auf grosse Gruben zu getrieben werden, in welche sie hineinstürzen.

Die Verstecke mit archäologisch interessantem Inhalt, welche man zuweilen unter Steinplatten und Blöcken findet, stammen ohne Zweifel aus Zeiten, wo frühere Bewohner einer Gegend durch eine feindliche Invasion zur Flucht veranlasst wurden und vor derselben in der Hoffnung auf einstige 
Rückkehr ihre Kostbarkeiten vergruben. Es können diese Verstecke aber auch eine ähnliche Bestimmung gehabt haben wie diejenigen der Indianer, Trapper und Händler des amerikanischen Westens, welche als temporäre Depots zur vorübergehenden Aufbewahrung ron Gegenständen dienen, die später vertauscht, verkauft oder sonstwie rerwerthet werden. In einem solchen Falle sind die Gegenstände sorgfältiger geordnet, als wemn sie vor einer eiligen Flucht vergrahen wurden.

An einigen Orten trifft man auch unterirdische Magazine nach Art der arabischen Silos, in welchen sich Vorräthe befinden oder befunden haben. Dergleichen Entdeckungen sind indess selten und gewöhnlich ist der Inhalt solcher Räumlichkeiten — welcher allein die Bestimmung dieser letzteren in genügrender Weise erkennen liesse - der Vernichtung durch Insekten oder chemische Zersetzung anheim gefallen.

Prähistorische Werkstätten $\left.{ }^{1}\right)$. Bei den Nachgrabungen in Höhlen und den übrigen Stätten vorgeschichtlicher Ansiedlungen, ron denen wir sprachen, entdeckt man in der Regel Spuren prähistorischen Gerrerbebetriebs, einer inländischen oder bodenständigen Industrie jener Zeiten. Wenn man z. B. Feuersteinblöcke trifft, die umgeben sind von ungeformten Splittern, misslungenen oder unvollendeten Pfeilspitzen u. dgl., so folgt diraus, dass diese Waffen und sonstigen Steingeräthe an Ort und Stelle rerfertigt wurden. Ebenso ist das Vorkommen ron Gussformen und von Produkten der Metallgiesserei, die schlecht gerathen oder an denen noch die Gussformmähte vorhanden sind, ein Beweis für die Existenz prähistorischer Metallverarbeitung in dem betreffenden Lande. Es finden sich aber nicht nur Leberbleibsel eines sozusagen als damalige Hausindustrie betriebenen Kleingewerbes der Vorzeit, sondern auch grosser Werkstätten, wahrer prähistorischer Fabriken, falls nämlich die Gegend das erforderliche Rohmaterial in genügender Quantität und rorzüglicher Qualität enthielt.

Aller Wahrscheinlichkeit nach waren diese Werkstätten in der Xähe derjenigen Oertlichkeiten erstellt, wo sich das jeweils nöthige Rohmaterial fand. In dieser Hinsicht rorah

1) Ygl. hierüber Dr. Ranke, a. a. O. (S. 790 oben) Kap. III. 
sind daher Nachforschungen zu veranstalten; alle Spuren alten Steinbruch- und Bergwerkbetriebs, Stollen, Schlackenhaufen, alle Reste primitiver Metallgewinnung und Verarbeitung, unvollendete oder ausgemusterte Exemplare und Theile von Waffen und Geräthe verschiedener Art sind wohl zu beachten. So hat man in England in einem Stollen, dessen Decke eingestürzt war, Knocheninstrumente gefunden, womit in den Kreidelagern nach Feuersteinknollen gegraben wurde. In diesem vielleicht seit 3000 Jahren verlassenen Stollen war in dem Staube, der alle Gegenstände bedeckte, noch ein Abdruck der Hand eines Arbeiters zu sehen!

Aus mancherlei Falitoren lassen sich Schlüsse ziehen auf die Bedeutung solcher rorhistorischer Werkstätten und ergibt sich, dass dieselben nicht nur für den lokalen Bedarf arheiteten, sondern namhaften auswärtigen Absatz hatten, also Handel trieben. Weitere Studien können dazu führen, dass in verschiedenen Gegenden gemachte Funde an Alterthümern sich als Produkte einer bestimmten Stätte vorgeschichtlicher Industrie erweisen und uns dadurch die Wege jenes uralten Handelsverkehrs bekannt werden.

Megalithische Monumente. Als megalithische Monumente oder einfach Meyalithe (rom griechischen $\mu \varepsilon y a s$, gross, und $\lambda \iota$ Fos, Stein) bezeichnet man urgeschichtliche Denkmäler aus rohen oder nur grob behauenen aufgerichteten oder doch auf eine schmale Stützfläche gestellten Steinblöcken, über welchen mitunter noch eine ebenfalls rohe Steinplatte angebracht ist. Man unterscheidet drei Gruppen derselhen: $1^{\circ}$ Blöcke; $2^{\circ}$ Pfeiler oder aufgerichtete Steine; $3^{\circ}$ Tische oder Dolmen.

Diese Monumente, welche zuerst aus dem nordwestlichen Europa (Carnac in der Bretagne, Stonehenge bei Salisbury in England etc.) bekannt geworden sind und die man lange als keltische und Druidensteine erklärt hat, finden sich fast in allen Erdtheilen; von wem sie herrühren, hat man bis jetzt nicht ermitteln kömnen. In öder, abgelegener, ehemals waldbedeckter Wildniss namentlich erheben sich diese in ihrer rauhen Grösse und Einfachheit imponirenden Denkmäler. Sie sind selten in Gegenden, wo Findlinge und andere Felsblöcke nur spärlich vorkommen, und aus dichtbevölkerten Ländlern mit weitgediehener Bodenkultur sind sie fast gänzlich 
verschwunden. In Belgien ist das letzte derselben ums Jahr 1828 zerstört worden, und die Pfeilersteine (Menhirs) von Carnac, deren im 16. Jahrhundert durch den Chorherr Moreau nicht weniger als 12000 bis 15000 gezählt wurden, sind nun auf wenige tausend reduzirt. Bei fortschreitender Kultur sind diese Denkmäler als Baumaterial, Feldmarken und Strassenrandsteine benutzt worden.

Im Allgemeinen sind die Megalithen schon ron Weitem als solche kemnbar: indessen soll man sie aufmerksam untersuchen, um sie mit ähnlich aussehenden Steinen und Blöcken, die kein Werk ron Menschenhand sind, nicht zu verwechseln.

Die schuebenden Steine, welche die Engländer $\log$ han oder logigan (Fig. 236) nennen, sind Felsblöcke, die auf eine ihrer Ecken gestellt und so im labilen Gleichgewicht befindlich sind, sodass sie dem Anscheine nach mit geringer Mühe ins Schwanken gebracht werden müssten. Sie können Naturspiele sein. Einige ruhen aber auf einem rundlichen Stein, der sich zur Hälfte in einer Höhlung des oszillirenden Blockes, zur andern Hälfte in dem die Unterlage bildendenFelsboden befindet, rnd es ist sehr wahrscheinlich, dass es sich hiebei um ein Werk des Menschen handelt.

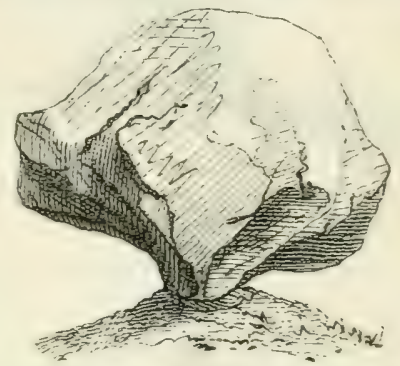

Fiv. $23 i j$.

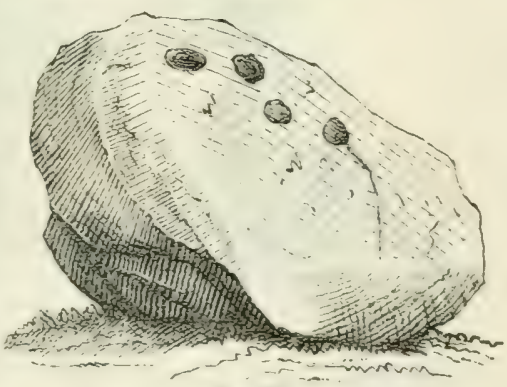

Fi. $23 \%$.

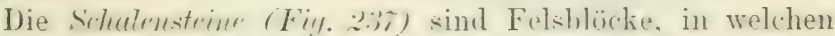
ohen schalen- oder tassenförmige Höhlungen und zuweilen Furchen oder Rimnen angebracht sind. Letzterer Lmstand hat Anlass gegeben zu der Vermuthung, es seien das Altäre gewesen. auf welchen man lebmet Wesen geopfert hätte, deren Blut in dis Höhlungen weffossen und durch 
die Rinnen abgelaufen wäre (daher die Benenmungen Opferund Altarsteine, sowie Druidensteine). Indessen ist seither konstatirt worden, dass viele dieser Schalen in einer Weise angebracht sind, die eine solche Annahme als unstatthaft erscheinen lässt.

Die Parasolsteine (Fig. 238) bestehen aus einem Fun-

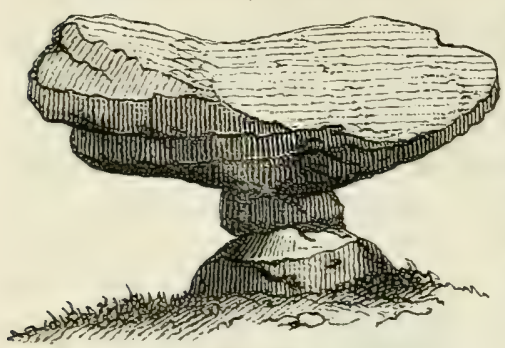

Fig. 239.

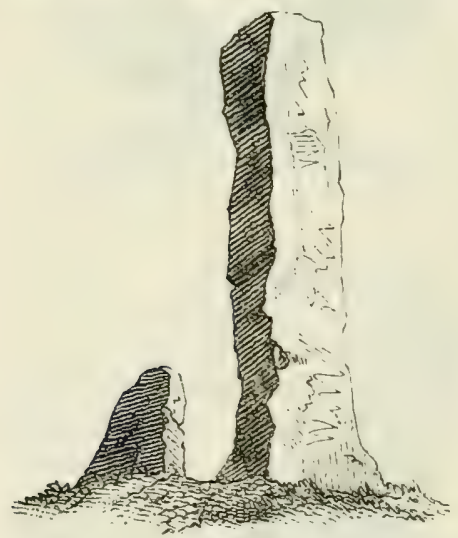

Fig. 239.

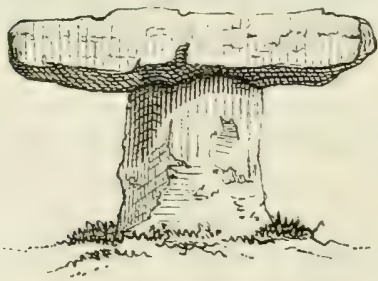

Fig. $2+0$. damentvon 4 oder 5 Steinen und einer grossen nach allen Seiten vortretenden Platte oder einem in analoger Weise angebrachten Block, sodass sie ron Weitem einem riesigen Hutpilz oder einem "Gletschertisch" gleichen.

Die einfachen Pfeiler oder Monolithe (Fig. 239) sind aufgestellte Steine von den verschiedensten Dimensionen. Als Peulvans oder aufgestellte Blöcke bezeichnet man die kleineren von 1 bis 2,5 m Höhe, als Menhirs die grösseren (man kennt solche bis zu $23 \mathrm{~m}$ Höhe).

Bilithe oder Doppelsteine (Fig. 240) heisst das durch Auflagerung eines Quersteins auf den Pfeiler gebildete $\mathrm{T}$-förmige Denkmal, Trilith oder dreifacher Stein (Fig. 241) ein solches, bei dem ein horizontaler Stein auf zwei Pfeilern ruht. Analog sind die Ausdrücke Quadritith, Pentalith etc. zu verstehen. Allgemein bezeichnet man als Polylithen dieverschiedenen 
Denkmäler, welche aus mehreren Pfeilern und einem auf denselben ruhenden (flachliegenden) Stein bestehen.

Steintische oder Dolmen (Fig.212) sind Monumente, bei denen eine Steinplatte auf rohen oder grob behauenen Blöcken ruht; diese kehren ihre rauhesten Flächen nach aussen : die glatteste Seite eines

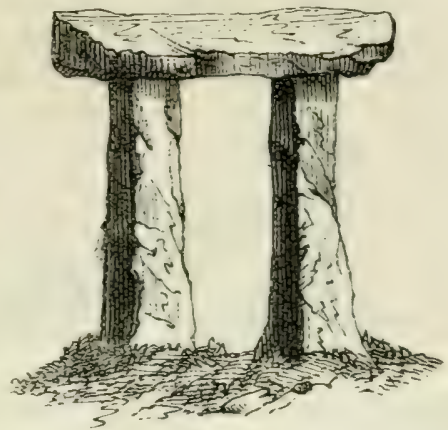

Fig. 241 . jeden ist nach dem Innern des Denkmals gerichtet. Das Monument ist bald frei auf offenem Felde angehracht (dolmen apparent), bald ron einem Erdwalle umgeben oder unter einem künstlichen Hügel verborgen (dolmen courert). Die Platte

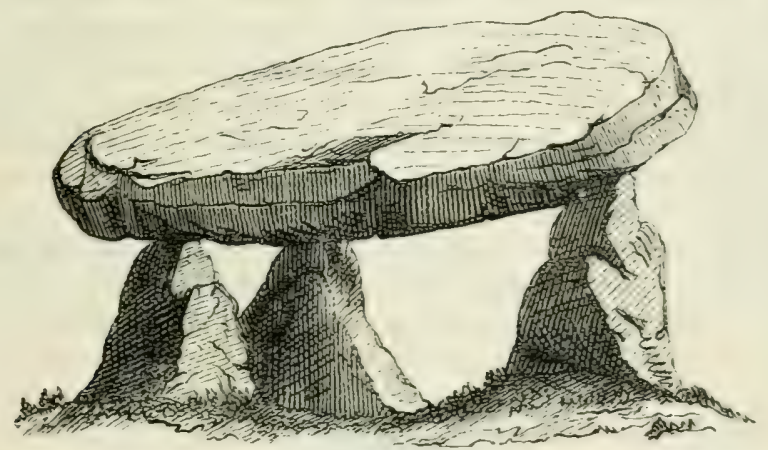

Fig. $2 \pm 2$.

kann ferner nur an ihren Enden auf Tragsteinen ruhen, nach Art einer gewöhnlichen Tischplatte (wohei sich das Monument ron einem Trilith etc. nur dadurch unterscheidet, dass die als Träger dienenden Steine plumper, der Querstein aber breiter ist) oder sie kann auf einer grossen Zahl im Kreise angebrachter Steine lagern: die letzteren lassen zwischen sich offene Räume (offene Dolmen) oder schliessen dicht zusammen (geschlossene Dolmen). 
Der Hall-Dolmen (Fig. 24.3) ist ein Denkmal, dessen Steinplatte nur an einem Ende auf einem Blocke, mit dem andern Ende aber auf dem Boden ruht.

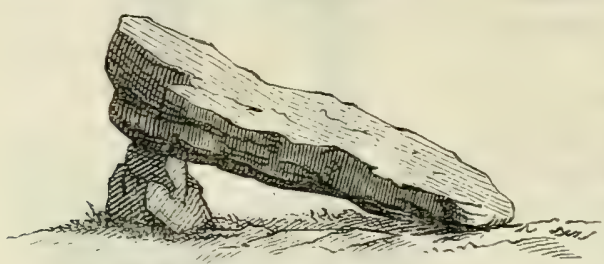

Fij. 243.

Diese verschiedenen Monumentformen sind nun auf manigfache Weise mit einanderkombinirt. Bald trifft man unförmliche Blöcke in scheinhar regelloser Gruppirung oder zu einem Kreise geordnet, in dessen Mitte sich zuweilen ein Pfeiler (peulran oder menhir) erhebt — ein Gebilile, das man in der Bretagne Curncillom nemnt. Bald sind die Pfeiler in zwei oder mehr gradlinige stciureiluen zusammengestellt und bilden eine Rirsmaller (avenue, allée de géants, jayantière), an deren Ende sich zuweilen ein Iolmen befindet, oder es sind die I'feiler und steine zu verschiedenen grad- und krummlinigen Figuren zusammengestellt: in Dreiecken, Rechtecken, Quadraten, in Kahnform, zu Halbkreisen, Ellipsen etc., und diese Steinsetzungen (crmmlerlis) liömmen ein-, zwei- oder mehrfach sein, umgeben auch wohl ein oder mehreve Nenhirs, Bilithen, Dolmen u. s. w. Mitunter sind dabei die Steine so nahe zusammengestellt, dass sie eine zusammenhängende Lmwallung oder Naner bilden. Eine dieser Kombinationen, Temedh genamnt (Fiy. 24), besteht in einer ein-oder mehrfachen

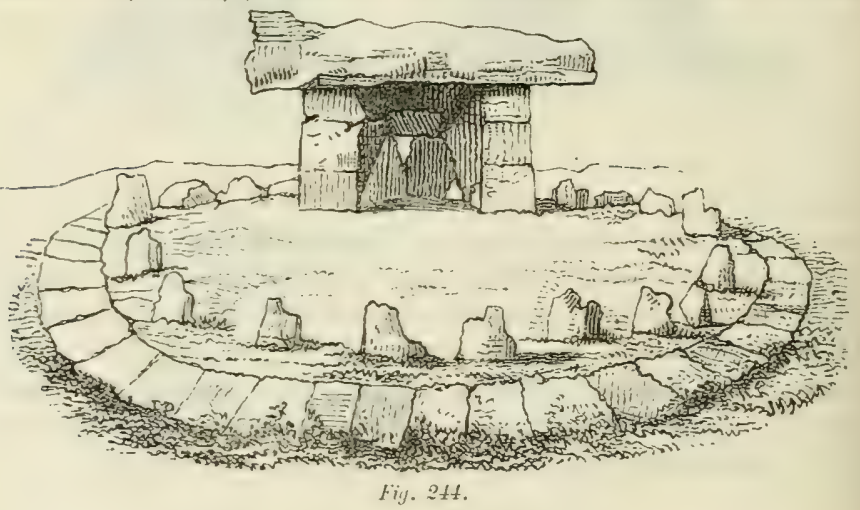


Steinpallisade mit einem in der Peripherie, statt im Centrum, angebrachten Dolmen.

Es ist sehr zu wünschen, dass an den Stätten solcher Denkmäler Tachyrabungen rorgenommen werden; denn sie allein können uns einigen Aufschluss über den Zweck dieser primitiven Bauwerke rerschaffen. Es ist aber schwer zu sagen, an welchen Punkten mit Ausgrabungen zu beginnen ist, wenn die Megalithen einen grossen Raum einnehmen. Im Allgemeinen sind die Umgebungen der Blöcke, die Stellen am Fusse einzeln stehender Pfeiler, die Zentren der Steinsetzungen und Dolmen als solche Punkte zu bezeichnen. Bei den Dolmen hat man vorher zu untersuchen, ob der Boden noch intakt sei. Bei Steinkreisen, in deren Nitte sich ein grösserer Block oder höherer Pfeiler befindet, sind die Ausgrabungen gegen die Peripherie hin vorzunehmen; denn dort sind die Gräber angebracht, über welche die durch den zentralen Block oder Pfeiler repräsentirte Gottheit wachen sollte.

Selbstverständlich soll ein Plan und eine Ausirlet (Zeichnung oder Photographie) des Denkmals oder der Monumentengrupue aufgenommen werden. Dabei ist hesonders auch auf die Orientirung $z u$ achten und diese in dem Plane durch einen nach Nord gerichteten Pfeil anzugeben. Ferner soll genau untersucht werden, ob sich Spuren von Schriftzeichen oder Buchstaben vorfinden; ist dies der Fall, so ist eine treue Abbildung oder ein Abchuch derselben anzufertigen.

Zur Erliturung dieser Denkmäler sind die verschiedensten Ansichten ausgesprochen worden. Die einen sehen in den Blöcken und Pfeilern Idole oder Göttersymbole, in den Dolmen Altäre und Tempel, in den Steinkreisen geweihte Einfassungen. Andere sind der Meinung, dass die Blöcke und Iffeiler Denkzeichen seien zur Erimnerung an wichtige Ereignisse (Schlachten z. B.) oder Zeugen für Vertragsabschlïsse und dass die Steinkreise Stäten bezeichnen, wo feierliche Versammlungen gehalten wurden. Eine dritte Ansicht geht dahin, die Megalithen seien Denkmäler für Verstorbene und zwar die Blöcke und P'feiler Grabsteine für Häuptlinge orler doch Jonumente zu deren Gedärhtniss, die Dolmen Todtenkammern und die steinkreise Friedhöfe. Der Forschungsreisende wird sich benühen, in jedem Einzelfall aus der Be- 
schaffenheit des Denkmals und aus den Ergebnissen der Ausgrabung zu ermitteln, welches wohl der Zweck dieser Bauwerke war, die nicht selten riesige Dimensionen aufweisen.

Gewisse Trilithen mögen nur die massiven Hauptthore (Pylone) von Bauten sein, deren weniger solide Mauern nicht

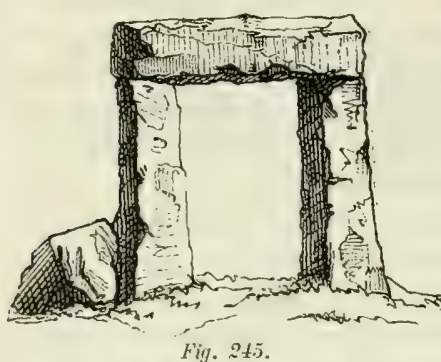

Fig. 245 .
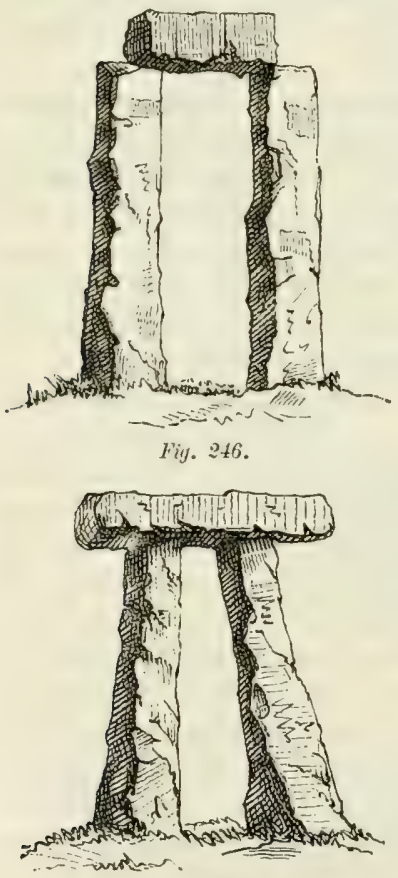

Fig. 247. erhalten blieben. Andere Trilithen können Theile einer Säulenreihe gewesen sein, die von einem Architrav gekrönt war. Aber es gibt auch Trilithe, welche augenscheinlich jederzeit für sich allein bestehende Denkmäler waren. Der Unterschied zwischen diesen dré Fällen spricht sich namentlich in den Verhältnissen des Quersteins (Architravs) auf den beiden Pfeilern aus. Im ersten Fall, bei Pylone-Trilithen (Fig. 245), deckt der Architrav die obern Pfeilerenden genau, ohne seitwärts über dieselben hinauszureichen; im zweiten Fall, bei den von einer Säulenreihe(Colonnade) oder Einfassung herrührenden Trilithen (Fig. 246), bedeckt der Querstein nur die Hälfte eines Pfeiler- oder Säulenkopfes; die andere Hälfte ist frei, weil sie als Stützfläche für den nächstfolgenden Architrav dienen musste; im dritten Fall, bei den als selbständige Monumente errichteten Trilithen (Fig. 24\%), ragt der Querstein mit seinen beidon Enden über die Pfeilerköpfe hinaus.

Ein bedeckter Dolmen kann durchathmosphärische Einflüsse frei gelegt worden sein. Hier- 
über muss die Beschaffenheit des umliegenden Terrains Aufschluss geben. Hinsichtlich der Deckplatte soll aufmerksam untersucht werden, ob sie nicht Spuren von Vertiefungen und Rinnen zeige, woraus geschlossen werden könnte, dass auf ihr blutige Opfer dargebracht worden seien. Gewisse Dolmen haben in einer der Steinplatten ein Loch; es scheinen das Gräber gewesen zu sein, wobei jene Oeffnung dazu diente, dem Verstorbenen die vermeintlich nöthigen Speisen zu verschaffen, oder aher nach dem Glauben der Erbauer dieser Monumente das Thor war, durch welches die Seele des Todten ihren Weg nach dem Jenseits nehmen musste.

Wenn sich auf den Steinen keinerlei Schriftzüge oder Buchstaben finden und jede Spur einer mit Hülfe metallener Werkzeuge vorgenommenen Bearbeitung fehlt, so berechtigt dieser negative Befund für sich allein noch nicht zu dem Schlusse, dass die Völkerschaften, von welchen jene Megalithen herrühren, weder ein Schriftsystem noch Kenntniss der Metalle besassen; denn die Nichtanwendung des einen und der andern bei diesen Denkmälern kann Folge gewisser Vorurtheile sein.

Es scheint, dass einige Volksstämme in Indien, Belutschistan und Kurdistan jetzt noch megalithische Denkmäler errichten und in Nordafrika unter den Eingebornen die Erinnerung noch lebendig ist an Zeiten, da bei ihnen dieser Brauch geübt wurde. In solchen Fällen ist es von Werth, bei den Stammesältesten Erkundigungen über diese Sitte einzuziehen. Indessen soll man sich nicht auf diese Informationen beschränken, sondern gleichwohl Nachgrabungen vornehmen. Findet man dabei Skelette intakt erhalten, so folgt daraus, dass die Megalithen der betreffenden Gegend Grabstätten bezeichnen. Aus dem Vorkommen zerstreuter menschlicher Gebeine lassen sich verschiedene Schlüsse ziehen: es kann sich um einen Opferplatz handeln oder um Gräber, die von Menschen, Thieren und Ueberschwemmungen beschädigt wurden. Der gänzliche Mangel an Skeletten und Knochen beweist nichts; es können die Leichname verbrannt worden oder infolge der besondern Bodenhesthaffenheit längst gänzlich verwest sein.

Was sachbezügliche Schlussfolgerungen anbetrifft, so ergeben sich solche aus der Stellung der Léichname (S. 791), 
wenn intakt gebliebene Skelette zum Vorschein kommen, sodann aus vergleichenden Untersuchungen der in verschiedenen Gräbern gefundenen Gegenstände. Wenn letztere (Gräber mit Inhalt) sich in mehreren Lagen übereinander befinden, so liefern die Funde einen Naassstab zur Beurtheilung der Fortschritte in der Zeit, da die Errichtung megalithischer Denkmäler Sitte war. Eine lange Dauer dieser Periode verräth sich oft schon in dem verschiedenen Aussehen der Denkmäler; in den Aenderungen, welche die Bauart derselben (namentlich der Dolmen) an einem und demselben Orte erlitt.

Megalithische Denkmäler von grossen Dimensionen müssen ron einer zahlreichen Berölkerung errichtet worden sein; denn bei der Einfachheit der mechanischen Hülfsmittel, welche dabei zu Gebote standen, bedurfte es gewiss vieler Hände, um die zuweilen riesigen Blöcke an den für sie bestimmten Platz zu bringen. Eine schwierig zu lösende Frage ist die: ob diese Arbeiten von unterworfenen Völkerschaften und Sklaren aufgeführt werden mussten, oder ob jeder Angehörige einer Gemeinschaft dazu beitrug, ähnlich wie anderswo beim Frohndienste.

Tumuli u. dgl. Unter der allgemeinen Bezeichnung T'umulus (Mehrzahl Tumuli) fassen wir hier die verschiedenen Arten von Hügelgräbern und künstlichen Erd- oder Steinhaufen zusammen. Dieselben werden nach den einzelnen Ländern und Besonderheiten ihrer Konstruktion verschieden benannt: Kuryane ("Tschudengräber") in Russland, Hounds in Nordamerika, C'aims oder Galgals in Grossbritannien etc.

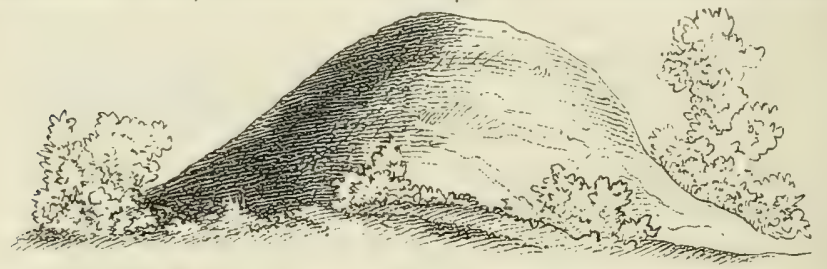

Fig. 24S. - Aeussere Ansicht eines Tumulus.

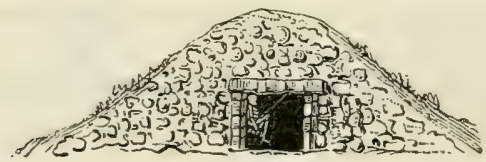

Fig. 249. - Durchschnitt eines Cairn. 


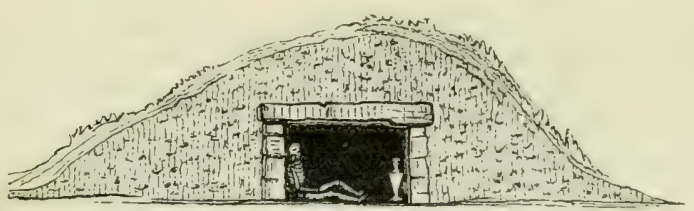

Fig. 250. - Durchschnitt eines Tumulus.

Die meisten dieser künstlichen Erd- und Steinhaufen sind Grabhügel; es gibt deren aber auch andere. So scheinen die Chirons oder ('hirats von Saintonge, Steinhaufen oder Blöcke in gewissen Abständen von einander, als eine Art Wegweiser die Richtung einer Verkehrslinie bezeichnet zu haben, wie ähnliche von Strecke zu Strecke sich erhebende Steinhaufen (Kellur) der heutigen Araber den Karavanen in der Wüste ihren Weg weisen. Viele Steinhaufen oder ungeformte Blöcke dienten zur Bezeichnung der Landes- und Grundeigenthumsgrenzen an Stelle unserer heutigen Marksteine. Andere Steinhaufen, wie die Ridjm der syrischen Beduinen, sind Gedenkzeichen, und manche Erdhügel in flachen Gegenden waren Hochwachten, von denen aus man einen heranziehenden Feind schon auf grosse Distanz wahrnehmen oder weithin Signale geben konnte.

Ob ein Tumulus Grabhügel gewesen sei oder nicht, kann nur durch Nachgrabungen ermittelt werden, wobei zudem ein negativer Befund nichts beweist, da es möglich ist, dass die Leichname unbedeckt und ungeschützt auf den blossen Boden gelegt worden und in Staub zerfallen, spurlos verschwunden sind. Meistens jedoch wurden zum Schutze der Leichen oder der Aschenkrüge (Urnen) Steinplatten angebracht, und bildeten diese eine Grabkiste oder Todtenkammer (rist oder colla) von sehr verschiedenen Dimensionen, manchmal bedeckte Dolmen oder einen geräumigen Saal, zu welchem ein unterirdischer Gang führte. Hier findet man dann Skelette in der Stellung oder Lage, welche dem Verstorbenen gegeben wurde, nebst den Waffen und Abzeichen, die er bei Lebzeiten getragen, und verschiedenen andern Gegenständen, die man ins Grab zu legen pflegte ("Beigaben“). Die Stelle der Waffen und anderer kostbarer Objekte vertreten manchmal kleine Modelle derselben, Nachbildungen von geringem Werthe, und statt der Skelette trifft man - je nach der Bestattungsart - oft 
die Asche der Verstorbenen oder unvollständig calcinirte Knochen in Gefässen von gröberer und feinerer Arbeit.

Die steinernen Grabkisten (cists oder kistvaens) befinden sich nicht immer in der Mitte des Hügels, oder wenigstens kommen ausser einer mittleren Kiste, die als erstes und ältestes Grab anzusehen ist, noch solche über und neben derselben vor, ein Umstand, der wahrscheinlich so zu erklären ist, dass für spätere Begräbnisse schon vorhandene Erdhügel benutzt wurden.

Die Grabhöhlen, Todtenkammern und Sääle nehmen in der Regel die Mittelpartie des künstlichen Hügels ein und befinden sich auf gleichem Niveau mit dem angrenzenden Boden oder etwas höher. Eine Ausnahme hievon machen die langgestreckten Hügel (lon!l barrous), in welchen ein unterirdischer Gang zu der am einen Ende des Hügels angebrachten Steinkammer führt. Bald ist diese Kammer oder Stube selbst der Bestattungsraum und findet man im Innern oder an den Wänden derselben die Skelette angebracht; bald ist das eigentliche Grab unter dem Boden und sind Nachgrabungen nöthig, um es aufzufinden. Nicht selten ist an der Aussenseite des Denkmals eine falsche Thüre angebracht, der wahre Eingang aber mit einer Steinplatte verschlossen oder durch Gebüsch maskirt. Ein besonderer Typus dieser Gebilde ist der, welcher aus einer Reihe verschiedener Höhlen besteht, die durch mächtige Steinhaufen von einander getrennt sind und woron jede ihren eigenen unterirdischen Zugang hat.

Zuweilen befindet sich auf dem Tumulus eine rohe Statuette (Kamenyja baby, Kumir oder Bolvani), die vielleicht eine Gottheit darstellt, manchmal auch ein Altar-Dolmen oder Cenotaph, und ist derselbe mit einer ein- oder mehrfachen Einfassung aus aufgestellten Steinen umgeben. Die Einfassung unmittelbar um den Hügel, welche zweifelsohne die aufgeschüttete Erde zurück- und zusammenhalten musste, nimmt zuweilen den Charakter einer Trocken- oder Mörtelmauer an.

Die Tumuli sind sehr verbreitet. Sie finden sich fast in allen Ländern. In manchen Gegenden, z. B. in Algier und dem Mississippi-Becken, haben sie bizarre Formen, die Schlangen, Menschen u. s. w. darstellen sollen und als symbolische MIonumente bezeichnet werden (Fig. 251). 


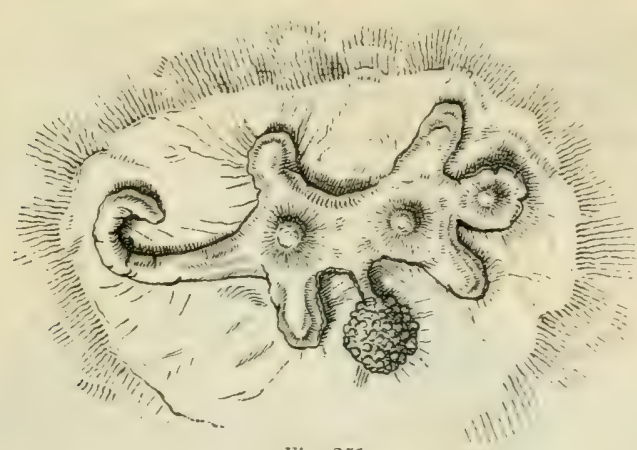

Fig. 251.

Wenn die künstlichen Hügel mit Sträuchern und Bäumen bewachsen sind, kann ihr Altry nach seinem Minimalbetrage aus der Anzahl Jahresringe jener Holzpflanzen bestimmt werden. Bekanntlich entspricht die Anzahl der konzentrischen Holzringe eines dikotyledonischen Baumes oder Strauches seinem Alter (nach Vegetationsperioden, beziehungsweise Jahren), wenn man nämlich die Ringe zählt auf einem am untern Ende des Stammes, nahe der Wurzel, geführten Querschnitt. Bei einem hohlen Stamm schätzt man die Zahl der Jahrringe, welche auf die Höhlung entfallen müssen, ab nach der Zahl der Ringe im noch vorhandenen Holz. Selbstverständlich ist das Verfahren nur ein approximatives und geben die erhaltenen Zahlen nur ein Altersminimum für das Denkmal; wie viel Jahre verflossen zwischen der Errichtung des Hügels und dem Zeitpunkt, da Samen von Holzpflanzen auf demselben zu keimen begannen, das können wir ja nicht bestimmen. Auch nimmt oft schon die Errichtung eines solchen Monumentes einen beträchtlichen Zeitraum in Anspruch; denn viele derselben sind nicht auf einmal erstellt worden, sondern ganz allmälig in der Weise, dass nach einer frommen Sitte jeder Vorübergehende einen Stein oder eine Handvoll Erde hinzufügte.

Was den Lrspmuy dieser Denkmäler anbetrifft, darf man sich nicht durch die sachbezüglichen Traditionen und Benennungen wie Hünengräber, Riesengräber, Druidensteine, keltische Monumente $\mathrm{u}$, dgl. leiten lassen. Vereinzelte Tumuli in einer Gegend, die keine Spur vorgeschichtlicher Wohn- 
oder Lagerstätten aufweist, können Nomadenstämmen zugeschrieben werden, welche für ihre Häuptlinge oder Patriarchen diese Bestattungsart anwendeten. Die Pfeilersteine, womit solche Grabhügel zuweilen geschmückt sind, waren ohne Zweifel Siegeszeichen. Die konzentrischen Steinsätze, welche den Hügel in einiger Entfernung rom Fusse desselben

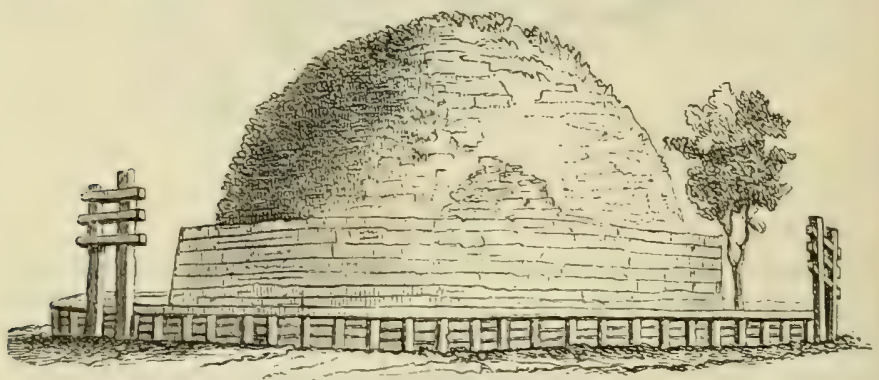

Fïg. 252.

umgeben, bezeichnen vielleicht die Grenzen, bis zu welchen das Volk und die Stammeshäuptlingre sich dem Grabe nähern durften, um den rerehrten Todten ihre Opfergaben darzubringen.

In die gleiche Kategrorie wie die Tumuli können die Topen oder Stupre (F"i!. 25:) gerechnet werden, buddhistische Grab- und Kultusdenkmäler, welche in Indien und Afghanistan und ron da bis ins südliche Sibirien verbreitet sind; namentlich gilt dies von den besondern Formen derselben, welche Darhobas genannt werden. Die Eingebornen haben hie-

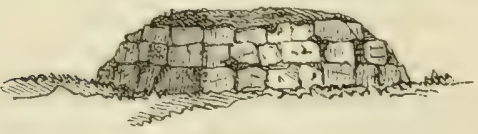

Fig. $253 a$.

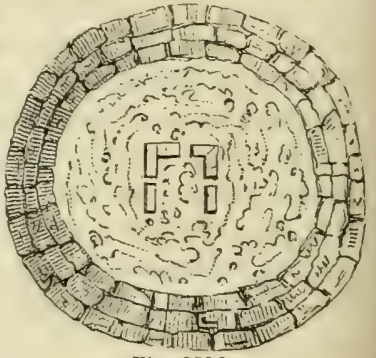

Fig. 2536 .

für die Bezeichnung Bihta, was "Haufe " oder „Hügel “ bedeutet.

Ferner sind die algierischen Bazinas und Medracen hieher zu zählen. Die ersteren (Fig. 2553) bestehen aus einer oder mehreren Einfassungen von stufenförmig angeordneten 
Steinen: in der Mitte befinden sich gewöhnlich drei grosse aufgestellte Steine, welche drei Seiten eines Rechtecks bilden, und der Innenraum ist mit Geschiehen und zerschlagenen Steinen gepflastert. Die zweiten (Fiy. 2if) sind Tumuli mit etwas flacher Böschung auf einem L'nterbau aus Mauerwerk.

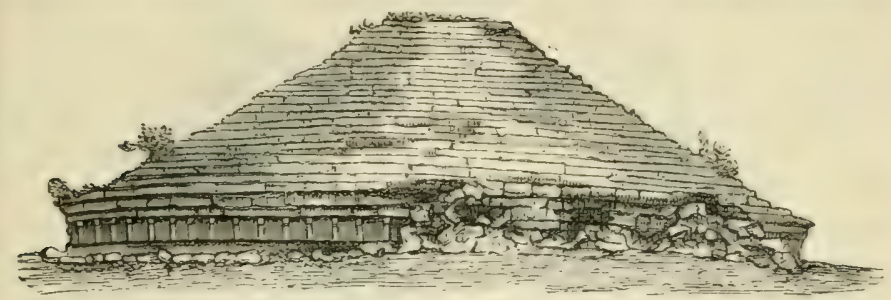

Fiij. 2.jt.

Die Noos (Fï. 255 $a, b, c)$ auf den Balearen sind lange kahnförmige Cairns ( nao" =Kahn, kleines Schiff); die berühmten Pyramiden Egyptens endlich können als in riesigen Dimensionen erstellte Cairns betrachtet werden.
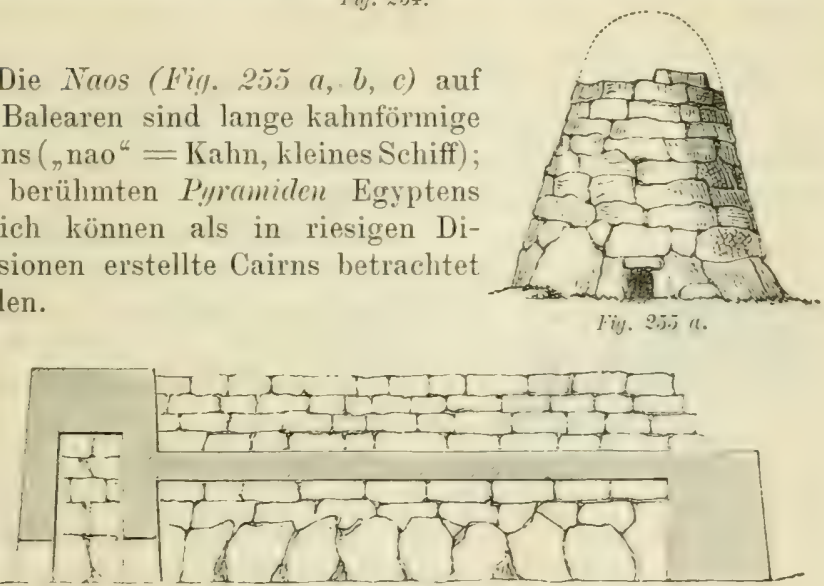

Fiv. 2.5 $b$.

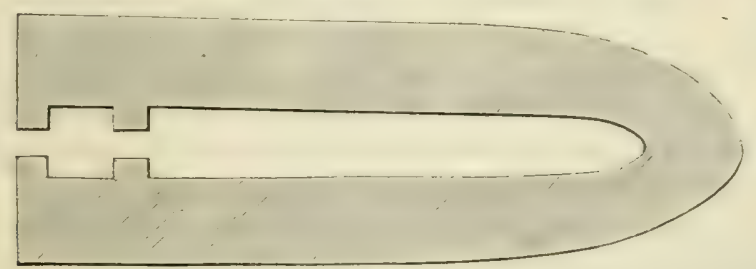

Fiv. 2.5.5 c. 
Verschiedene Grabformen. Ausser den charakteristischen Hügelgräbern, von welchen soeben die Rede war, kommen noch Todtengrüfte verschiedener Art vor, deren wichtigste wir in Nachstehendem kurz erwähnen.

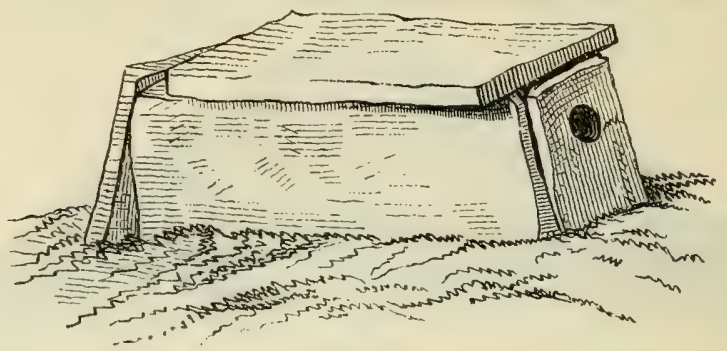

Fig. 2.56.

Als Strinliste, Cist oder Kistraen (Fig. 256) bezeichnet man einen auf ebener Erde errichteten Koffer oder Trog aus Steinplatten. Innerhalb der Kiste ist der Boden oft mit Geröllsteinen und Fliesen gepflastert.

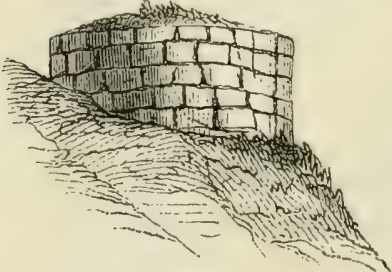

Fig. 257.

Die algierische Chucha ist ein kleiner, 2 bis 3 Meter hoher Thurm, welcher aus mehreren Steinlagen gebildet und oben meist durch eine grosse Steinplatte abgeschlossen ist.

Mausoleum wird eine monumentale und mit Skulpturen geschmückte Gruft aus behauenen Steinen genannt.

Als Grab bezeichnet man eine im Boden angebrachte Höhle (Grube), deren Formverhältnisse sehr verschieden sein können; es gibt längliche Gräber, in welchen die Skelette horizontal ausgestreckt liegen; ferner solche von kubischer Form, wobei den Leichen eine kauernde (hockende) Stellung gegeben wird; endlich vertikale Gräber mit aufrechter Stellung der beigesetzten Leichname.

Vertikale Gräber von cylindrischer Form, in welche man die Leichen hinunterlässt, werden Leichenschachte oder Brunnengräber genannt. In Felsen angebracht, gleichen sie Zisternen. 
Silo heisst ein solcher, oft mehrere Skelette enthaltender Schacht, der sich nach unten flaschenförmig erweitert.

trnen sind mehr oder minder grobe Thongefässe. Es gibt deren zwei wesentlich verschiedene Arten: die grossen Leichemurnen dienen zur Aufnahme eines Leichnams in sitzender oder aufrechter Stellung, die Asrhenmen nur zur Aufnahme theils der Asche, theils der mehr oder minder unvollkommen calcinirten Knochen eines Verstorbenen. Diese Urnen finden sich nicht immer in der Erde, sondern mitunter in Baum- und Felshöhlen.

Als Leichengrotte bezeichnet man eine natürliche oder künstliche Höhle, welche zur Bestattung verwendet worden ist. Oft enthält sie längs ihrer Wandungen eine Art Bänke, worauf die Todten liegen.

Das Hyprmüm ist eine ausschliesslich für die Glieder einer Familie oder für einige wenige privilegirte Familien bestimmte unterirdische Gruft.

Die Kataliomben sind unterirdische Gänge und Hohlräume (meist verlassene alte Steinbrüche), die als Nelropolen oder gemeinschaftliche Begräbnissstätten der Angehörigen eines grösseren Verbandes benutzt wurden.

Alte Zufluchtsorte und Befestigungen. Die drei Arten von Ansiedlungen, welche oben beschrieben wurden (Höhlen, Lager und Pfahlbauten) konnten nur für solche Völkerschaften genügen, die fast ausschliesslich von Jagd und Fischfang lebten. Wie aher diese Beschäftigungen durch andere ersetzt oder die Jäger- und Fischerstämme durch Hirten und Ackerbauer verdrängt wurden, konnten abgelegene Thäler und Waldlichtungen, steile Felsen und Pfahlbauten als Wolinplätze den neuen Bedürfnissen nicht mehr entsprechen, da sie theils von den Weiden und urbaren Ländereien zu entfernt, theils zur Unterbringung ron Viehheerden nicht geeignet waren. Statt der Rücksicht auf die Terraingestaltung wurde nun die Nachbarschaft der Weiden und bebauten Felder ausschlaggebend für die Anlage der Wohnungen. Diese waren ohne Zweifel häufig Hütten aus Astwerk und anderem wenig dauerhaftem und widerstandsfähigem Material, sodass sich davon keine Reste erhalten haben. Von andern Wohnstaitten hingegen sind Spuren geblieben. So findet man in verschiedenen Gegenden Anzeichen 
der einstigen Existenz von ganz oder halb unterirdischen Wohmungen. Hieher gehören z. B. die creuttes, crouttes oder boves im Departement de l'Aisne, eine Art Höhlen im weichen Fels, die mit einer Steinfaçade versehen sind; ferner die weems und vamha in Schottland und die pempits in England, Wohnungen, die ganz oder zum Theil unter der Erde angelegt waren. Vielleicht waren solche Bauten den Nachkommen der früheren Höhlenbewohner eigen, die eine gewisse Vorliebe für dunkle unterirdische Wohnräume bewahrt haben mögen; vielleicht auch machte das Klima und Rücksichten auf Sicherheit diese Bauart nothwendig.

Die Pfahlbaubewohner ihrerseits liessen sich bei ihrer späteren Uebersiedlung auf das feste Land ohne Zweifel meist in der Nähe der bisherigen Stationen nieder, welche nun blos noch zur Aufbewahrung von Vorräthen und als Zufluchtsorte verwendet wurden.

Es wäre interessant $z u$ wissen, welche Art Wohnungen diejenigen Völkerschaften erstellten, welche sich an leicht zugänglichen Orten, in freier Flur, ansiedelten. Bei dem herrschenden Mangel an Sicherheit mussten sie jedenfalls Reduits und Refugien anlegen.

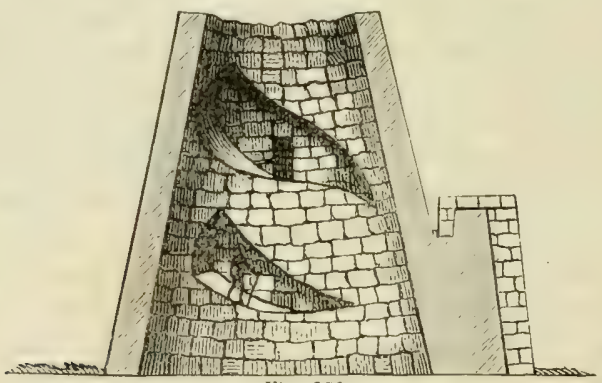

Fig. 25s.

Die Recluits waren bestimmt, Vorräthe aufzubewahren und dieselben vor Feinden zu verbergen, wie dies jetzt noch durch Fruchtgruben (Silos der Araber) geschieht.

Die Refurien waren geräumigere und solide Bauwerke, eine Art Citadellen, wohin die Bewohner einer Gegend sich selbst und ihre Fahrhabe flüchteten, zum Schutze für Leben und Eigenthum. Diesen Zweck hatten ohne Zweifel die murhays (Fig. 2.5 und i.5.9) auf der Insel Sardinien, die 


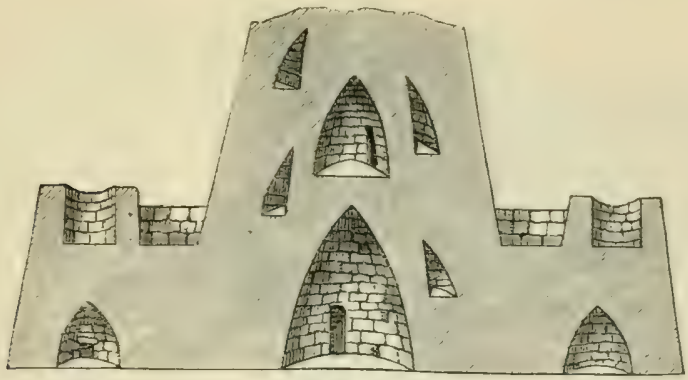

Fig. 259.

Pict's honeses in Grossbritamien, welche in ihrem Durchschnitt (Fiy. 260$)$ den nurhags gleichen, die tuluyots auf den bale-

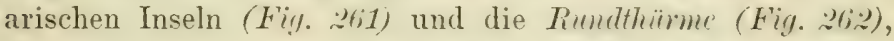
deren Ueberreste man fast in allen Ländern findet.

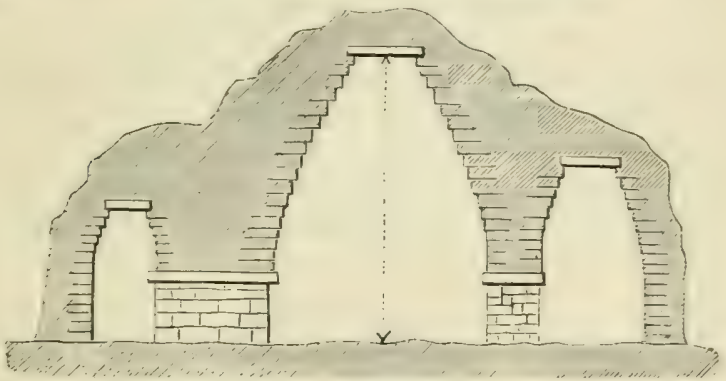

Fig. 260 ,

In seiner Weiterentwicklung wurde aus einem solchen Bau ein Font oder eine Feste mit Lmwallungen, Graben und Souterrains. Zur Vertheidigung wurden ferner Schanzen und grosse IIaum erstellt, wie diejenige von Bristol zum. Flusse

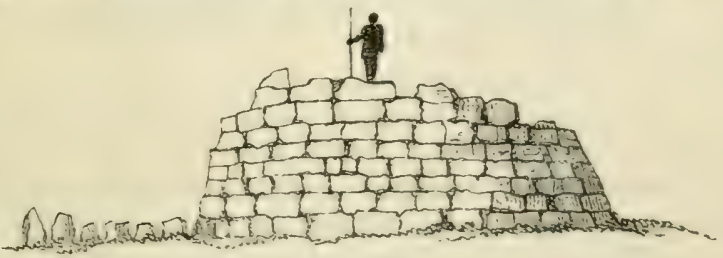

Fij. $2(j)$ 


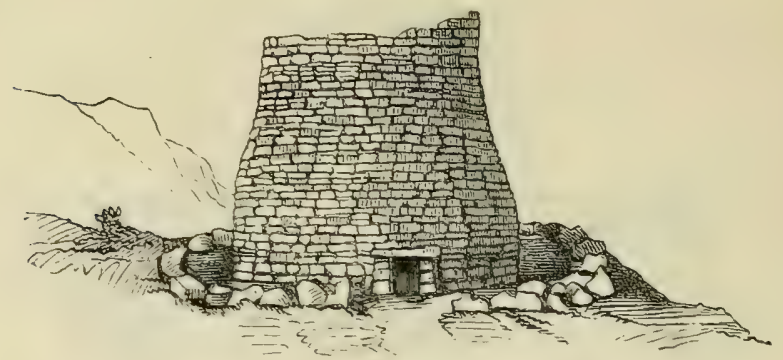

Fig. 262.

Dee zwischen England und Wales, die kaledonische Mauer zwischen England und Schottland, die Trajansmauer, die chinesische Mauer etc.

Diese alten Schanzen und Nanern kommen in der Regel am Rande fruchtbarer Ebenen ror. Eine sterile Gegend ohne Weiden und Kulturland und ohne Bewässerung reizte kein fremdes Volk zur Besitznahme und bedurfte daher keiner solchen Vertheidigungsmittel gegen Invasionen. Hatte aber ein Stamm ron einem ihm zusagenden Terrain Besitz genommen, so erstellte er bald Refugien und rerschanzte Lager; später, wenn er durch Vermehrung zu einem Volke geworden war, hatte er ein grösseres Territorium zu vertheidigen, und nun wurden die cinzelnen Forts bei Engpässen und auf dominirenden Höhen angelegt, wie ausgedehnte Verschanzungen und Mauern, welche ganze Länder abschliessen sullten.

Alte Städte. Die Existenz einstiger Städte und den Ort derselben erkennt man meist nur an Resten der früheren Mauern und Ruinenhaufen. Solche Ueberbleibsel findet man in der Regel auf Höhen, welche die Umgegend beherrschen, oder in Hochthälern, da eben in den fernen Zeiten, aus welchen diese Trümmer stammen, offene Städte in weiten Ebenen zu unsicher waren.

Die Aussenmauern bestehen gewöhnlich aus groben Steinblöcken, die mehr oder minder regelmässig auf einander gelegt sind und an ihrer Stelle entweder blos durch ihr Gewicht oder mit Hülfe dazwischen befindlicher kleinerer Steine, nicht aber durch Mörtel und Cement festgehalten werden. Man nennt solche Bauten (Fiy. 26i3) cylilopische 
Hauern und unterscheidet mehrere Typen derselben, nämlich $1^{\circ}$ solche aus grob vierkantig zubehauenen Blöcken von ungleicher Grösse, deren Fugen bald auf andere Fugen, bald auf Steinflächen treffen; $2^{\circ}$ solche aus unregelmässig vieleckigen Blöcken, die so gut als möglich zusammengefügt sind und eine

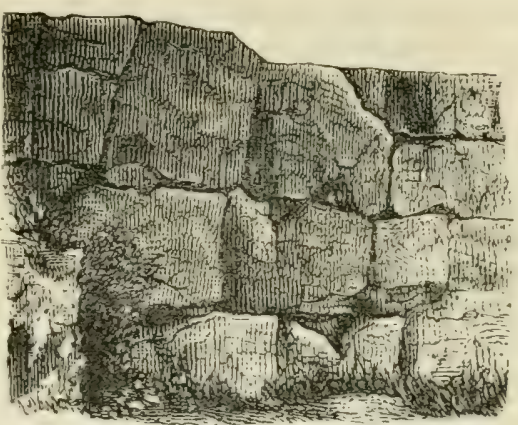

Fig. 263 . ebene Aussenfläche haben; $3^{\circ}$ solche ans viereckigren Blöcken in regelmässigen horizontalen Lagen, deren Fugen aber zum Theil schief statt vertikal sind. - In seinen dusgrabungen zu Mycener hat Schliemamn auch Hë̈rse' ron solch sogenannter cyklopischer Bauart entdeckt.

Die alten Thore sind meist mittels einer grossen Steinplatte erstellt worden, deren beide Enden auf der Mauer oder auf Pfeilern (Pfosten) ruhen. Wo der für das Thor bestimmte Raum zu hreit war, als dass man denselben oben mit einem einzigen Stein hätte abschliessen liömen, behalf

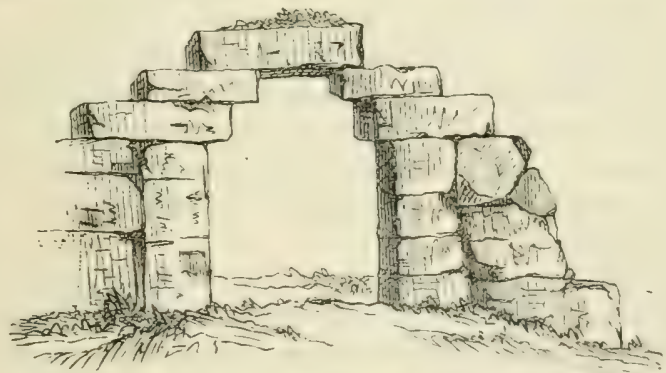

Fig. 2lit.

man sich mit der Vorsperrung (Fïr. s(ii), whei die oberen Lagen der Mauersteine, aus welchen das I'ortal besteht, der Reihe nach mehr und mehr rorragen, his sie einander so nahe kommen, dass die Oeffnung nun durch einen Stein 
abgeschlossen werden kann. Erst später wurden Thorbogen und Gewölbe erstellt, die einen wesentlichen Fortschritt der Baukunst bezeichnen.

In Gegenden, wo kein Baumaterial von der Dauerhaftigkeit des Steins zur Verfügung stand, trifft man selten noch aufrechte Mauerstücke, sondern meist nur Trümmerhaufen.

Ausqrabungen im Gebiet alter Städte müssen in grosse Tiefen gehen. Der Boden eines bewohnten Ortes wird beständig; wenn auch langsam erhöht; denn man führt immer wieder neues Baumaterial zu, während selten aller Abraum beseitigt wird; Material von abgebrochenen Häusern, Kohlenreste, Detritus und Unrath verschiedener Art bleiben theilweise auf dem Boden liegen, und neue Bauten werden auf diesem Terrain angelegt, welches etwas höher ist als das ursprüngliche. Um nun bei Nachgrabungen an solchen Stätten die Spuren frühester Kultur zu entdecken, muss man bis auf den natürlichen Boden hinunter graben, den die älteste Ansiedlung benutzte. Man darf nicht bei den ersten, Reste menschlichen Gewerbfleisses einschliessenden Schichten aufhören und sich auch nicht entmuthigen lassen durch die Armuth oder Inhaltlosigkeit einer Schicht, unter welcher eine reichere und interessantere folgen kann. Erst wenn man auf den gewachsenen Boden trifft, ist man sicher, tief genug hinunter gegraben zu haben.

Die Zugänge der alten Städte sind mitunter durch Ruinen ion Wasserlcitungen (Aquädukte) bezeichnet, und bei den ehemaligen Hauptthoren, sowie auch auf dem offenen Lande findet man noch da und dort Theile der alten Strassen, welche die wichtigsten Ortschaften mit einander verbunden haben.

Tempel und Altäre. Die alten Tempel befanden sich nicht alle innerhalb der Stadtmauern, sondern häufig ausserhalb derselben und zuweilen an abgelegenen einsamen and unwirthschaftlichen Orten. So kann man nahe der Quelle eines Flusses Altäre finden, welche in vorgeschichtlicher Zeit zu Ehren des Flussgottes errichtet wurden; in Waldlichtungen die Grenzen der geweihten Räume, in welchen man die Gottheiten der Wälder anbetete; auf Berggipfeln Tempel für den Sonnen- und Monddienst, auf Vorgebirgen 
Monumente, welche den Göttern des Meeres gewidmet waren. Nicht selten kommen Tempel und Altäre an Orten vor, die als besonders denkwürdig galten, sei es, dass man sie für den Sitz einer Gottheit oder Zeugen einer Offenbarung ihrer Macht hielt, sei es, dass sie Stätte eines Kampfes waren, dessen glücklicher Ausgang die Sieger vermochte, ihren Göttern ein Denkmal zu weihen. Endlich gibt es Gegenden, wo Tempel in den Fels gehauen sind, so die von Ghirsche und Ibsambul in Nubien, von Salsette in Indien; in solchen Fällen hat man die Felswände genau zu untersuchen, an deren Fuss die oft rerschütteten Eingänge dieser einstigen Tempel liegen.

Skulpturen und Inschriften. In Felsen grehauene Figuren und Schriftzeichen finden sich in den verschiedensten Gegrenden. Bald sind es Darstellungen von Menschen und Thieren, bald räthselhafte Zeichen. Meist ohne künstlerischen Werth, sind diese Skulpturen archäologisch von hoher Bedeutung. Wenn sie eine Episode aus dem Leben primitiver Völkerschaften darstellen, sind es kostbarere Annalen als alte Pergamente, da sie uns die Typen, Waffen, Ḱleidertrachten u. s. w. kennen lehren. Selbst die blosse Darstellung einer Jagdscene kann grossen Werth haben: es ist möglich, dass die abgebildeten Thiere längst nicht mehr Bewohner der Gegend sind oder überhaupt nicht mehr lebend vorkommen und erst die Bildnisse uns beweisen, dass in dem betreffenden Lande der Mensch Zeitgenosse jener Thiere war. Zeichen werden, auch wenn sie unverständlich sind, dennoch von Bedeutung durch Analogie mit andern, an verschiedenen und weitentfernten Orten entdeckten Zeichen; denn der Zufall allein erzeugt keine solchen Aehmlichkeiten.

Nicht alle Zeichen haben die Bedleutung einer Inschrift; einige dienen blos zur Andeutung von Eigenthumsverhältnissen; so haben nomadische Völkerschaften auf Steinen, Zisternen, Felswänden u. s. w. Zeichen, welche ausdrücken, dass das Recht auf die Weiden und Tränkpläize der betreffenden Gegend dem und dem bestimmenten Stamme zustehe.

Die eigentlichen Inschriften bestehen in der Regel aus einer Reihe von Figuren und Schriftzeichen in einer bestimmten Anordnung. Man kam sie nicht immer unmit- 
telbar entziffern; es ist schon desshalb nöthig, aber auch ohnehin höchst wünschenswerth, dass getreue Reproduktionen derselben angefertigt werden. Die besten Reproduktionen sind aber diejenigen durch die Photorrothlie und durch $A b$ drüclic. Zwar erlilärt S. Sharpe, das Zeichnen sei dem Photographiren rorzuziehen; aber derselbe Autor ${ }^{1}$ ) bemerkt später, dass es nicht möglich gewesen sei, die egyptischen Hieroglyphen in genügender Weise zu kopiren, so lange man sie nicht entziffern konnte; nun wird es aber der Reisende meistens mit Schriftzügen zu thun haben, welche ihm unverständlich sind und zu denen der Schlüssel erst noch gefunden werden muss; es wird also unerlässlich, sich der P'hotographie zu bedienen, wenn man eine Garantie für die Treue der Nachbildung haben will. Freilich ist die Photographie nicht in allen Fällen anwendbar. Wenn eine Inschrift sich im Schatten oder an einem dunkeln Ort befindet, kam man sie nur dam auf deutliche Weise photographisch reproduziren, wenn man sie mit Spiegeln oder mit elektricchem Licht beleuchten kann; ist sie auf einer Felswand angehracht, zu der man von unten her auf Leitern oder von oben her an Seilen gelangen muss, so kamn man den photographischen Apparat kaum benutzen. Das Verfalıren bei der Anfertigung von Abdrücken ist folgendes ${ }^{2}$ ). Man befreit zuerst die Inschrift von Allem, was sie verdeckt und verbirgt: von Erde, Staub, Moos, Gras etc. und reinigt sie mit einer starken Bürste oder einem grossen Waschschwamm. Der Stein soll hiebei feucht bleiben; andrerseits ist dafür zu sorgen (namentlich bei flacher Lage desselben), dass in den Vertiefungen kein Wasser liegen bleibt. Dann legt man über die Inschrift befeuchtetes Papier von grossem Format, das man durch Druck mit der Hand oder der vorher benutzten Bürste so fest gegen den Stein presst, dass es in alle Vertiefungen eindringt und dieselben ausfüllt. $\mathrm{Zu}$ dem Ende legt man je nach Erforderniss eine kleinere oder grössere Anzahl Bogen aufeinander und bestreicht sie auf der obern (beziehungsweise äussern) Seite mit Leim oder Gummilösung, sodass sie nach dem Trocknen eine zusammen-

1) Vgl. Samuel Sharpe, the Sinaitic Inscriptions. Athenaeum 1876 p. 433 (23. September).

2) Vgl. Instiuctions générules uux voyageur's, Paris 1875, p. 266; sowie Voyage dans le Lazistun par Théophil Deyrolle (Tour du Monde 1876 p. 390). 
längende feste Masse bilden. Selbstverständlich hat man unter Emständen einen Gehülfen nöthig, z. B. um das Papier an vertikalen Flächen gut auszuspannen oder um bei Wind dessen Räuder festzuhalten. Diese Papiermasse darf nun nicht eher abgenommen werden, als bis sie grut trocken geworden ist, sodass sie die erlangte Form beibehält.

Der Reisende soll die Anfertigung solcher Reproduktionen der einen oder andern Art nicht etwa aus dem Grunde unterlassen, dass er schon andere Inschriften aufgenommen habe; denn wie zahlreich diese auch sein mögen, so hat doch jede ihren eigenartigen Werth, sei es weggen ihres Inhaltes, sei es wegen ihrer melır oder minder alterthümlichen Formen. Namentlich zu beachten sind aber die Bilinmem und Trilingucn, d. h. Inschriften, welche den nämlichen Text in zwei oder drei Sprachen geben, wie das der Fall ist in Ländern, wo Eroherer Inschriften nicht nur in ihrer eigrenen Sprache, sondern auch in derjenigen des unterworfenen Volkes anbrachten, damit sie dem letzteren rerständlich seien, ferner in Ländern, wo die Koexistenz mehrerer Passen oder Stämme die gleichzeitige Anwendung verschiedener Idiome nöthig macht. Dergleichen mehrsprachige Inschriften erleichtern die Entzifferung von solchen, deren Schriftzeichen noch unbekannt sind, durch Vergleichung der beiderlei Texte. Wenn z. B. in einem solchen Falle ein Text, den wir verstehen, gewisse Namen oder sonstige Wörter in mehrfacher Wiederholung enthält, so wird man prüfen, welches in dem andern, uns noch unrerständlichen Texte die Buchstabengruppen sind, die ebenfalls wiederholt rorkommen; auf diese Weise ergibt sich eine erste Uebereinstimmung zwischen beiden Texten; mit deren Hülfe wird man weitere einander entsprechende Partien derselben ermittehn und so endlich den Schlüssel zu der unbekannten Sprache finden. Dabei ist zu bedenken, dass nicht alle Sprachen in der gleichen Richtung geschrieben werden. Wir haben hierüber oben (S. 609) gesprochen und fügen hier bei, dass es auch Inschriften gibt (wie diejenigen von Safa südöstlich ron Damaskus), welche in wunderlicher Weise bald ron rechts nach links, bald ron links nach rechts geschrieben sind und am Ende einer Zeile bald höher oben, bald weiter unten sich fortsetzen, sowie solche, deren Zeilen umbiegen, sich schneiden und sich in einander ver- 
schlingen. Enthält die Inschrift hieroglyphische Figuren ron Menschen und Thieren, so ist die Richtung der Zeilen gewöhnlich diejenige, in welcher die Figuren sich vorwärts zu bewegen scheinen. Es muss weiter bemerlit werden, dass die alten Inschriften nicht immer korrekt geschrieben sind. Mancher Bildhauer, der ein Wort oder einen Buchstaben rergiss, unterliess eine Korrektur an der rechten Stelle, um dadurch nicht das Aussehen seiner Arbeit zu verschlechtern, und fügte dann das Vergessene an einer andern Stelle der Inschrift bei, unbekümmert darum, ob hiedurch Verwirrung in den Text komme oder nicht.

Münzen und Medaillen. Alte Münzen, Medaillen, Gemmen, öfentliche und private Siegel liefern nicht selten werthvolle Aufschlüsse über die Geschichte eines Landes. Wir sprechen hier nicht ron primitiven Münzen, wie solche die alten Egypter hatten und welche einfach in metallenen Ringen oder runden Metallstücken, in denen ein Loch angrebracht war, bestanden, sondern ron Münzen und Medaillen, die ein Zeichen oder ein Bild enthalten. Solche übermitteln uns oft den Namen einer Stadt oder eines Herrschers, der in der Geschichte nicht erhalten geblieben ist. Die Medaillen insbesondere haben häufig die Bestimmung, ein Ereigniss zu verewigen. Ferner dienen Münzen und Medaillen oft als Anhaltspunkte zur Ermittlung des Alters einer Schicht mit Ueberbleibseln menschlicher Industrie. Wemn man nämlich unter solchen Fundstücken beim Ausgraben auch Mïnzen oder Nedaillen trifft, welche mit jenen in unzweifelhaft natïrlicher Tergesellschaftung erscheinen d. h. nicht erst später durch Zufall oder Absicht an diese Stelle gekommen sind - so hat man damit eine äusserste Grenze für das Alter der Fundschicht: die letztere kann aus keiner früheren Epoche stammen als derjenigen, in welcher die betreffende Münze angefertigt wurde. Leider haben auch die frühesten Münzen nur ein mässig hohes Alter, inden sie kaum weiter als bis zum Jahre 600 r. Chr. zurückreichen. Zudem tragen sie selten eine Jahreszahl, sodass man zuerst nach andern Faktoren ausmitteln muss, in welcher Zeit sie geschlagen wurden. Das Alter derjenigen, welche keine bekannten Namen, Bilder und Zeichen enthalten, muss nach den eingravirten, mehr oder minder 
alterthümlichen Buchstaben, ferner nach der Legirung und ihrem Feingehalt, sowie nach dem ganzen Charakter der Arbeit beurtheilt werden. Münzen mit dem Namen oder Bildniss eines bekannten Fürsten sind sicherlich zu Lebzeiten desselben angefertigt worden: ihr Alter liam also ziemlich genau ermittelt werden, da sein Maximum und Minimum durch Anfang und Ende der Recrentschaftsperiode des betreffenden Herrschers bestimmt sind. Das Münzzeichen einer Stadt unterrichtet uns weniger genau über das Alter der Münze, es sei denn, dass letztere an Orten gefunden werde, wohin sie kaum ror deren historisch bekannten Eroberung gelangen konnte.

Der Reisende, welcher nicht Numismatiker ron Fach ist, wird selten aus einer Münze, Medaille, Gemme oder einem Siegel alles das herauslesen kömnen, was Jemand, der in solchen Dingen gründlich zu Hause, daraus abzuleiten im Stande ist. Lm so mehr soll er sich's angelegen sein lassen, eine Summlumy solcher Objekte mit genauer Bezeichnung der Fundorte anzulegen und nach seiner Pückkehr ron der Reise diese Sammlung Fachmännern vorzulegen. Wird es ihm nicht möglich, diese Gegenstände selbst zu erwerhen, so unterlasse er wenigstens nicht, sich Aldrïler derselben in Wachs oder noch besser Alyüsse in Gyps oder greschmolzenem Schwefel zu verschaffen. Mit Hülfe solcher thgüsse kann später eine galvanoplastische Nachbildung des hetreffenden Objektes erstellt werden. Ein bekanntes Mittel, um rasch und leicht bildliche Darstellungen einer Münze zu erhalten, besteht darin, dass man ein Stück dünnes Papier auf dieselbe legt und dieses mit dem stumpfen Ende eines Bleistifts oder mit irgend einem ziemlich harten Körper so lange reibt, his das Geprärse der Münze auf dem Papier (in Schwarz oder bossirt) möglichst deutlich hervortritt.

Sagen. Sagenhafte Ueberlieferungen künnen, wenn kritisch rerwerthet, von wesentlicher Bedentung sein. Soweit sie sich auf den Ursprung eines Volkes beziehen, sind sie meist dunkel und unverständlich; in andern aber lebt die Erinnerung an Begebenheiten aus längrst rerflossenen Zeiten im Volke fort ron Geschlecht zu Geschlecht. So war im Jahre 1869 bei den Bewohnern der Jupiter-Ammon-Oase 
(Siwah) die Erinnerung daran, dass einst Alexander der Grosse in diese Gegend gekommen, noch nicht erloschen!

Der Reisende wird gegenüber dergleichen Traditionen kritische Umsicht walten lassen; andrerseits haben wir uns davor zu hüten, solche Sagen aus dem Grunde, weil ihr Inhalt uns auf den ersten Blick unwahrscheinlich vorkommt, ohne nähere Prüfung von der Hand zu weisen und sie als vermeintlich werthlos nicht weiter zu beachten. Die Volkserinnerung hat oft einen Namen getreu erhalten, während um denselben allmälig die Sage ihre Fäden spann und ihn zum Mittelpunkte eines Netzes fabelhafter Begebenheiten machte. Ein solches Beispiel erwälınt F. Lenormand ${ }^{1}$ ); es betrifft die Sage vom Ring des Gyges. Lediglich auf einige unter sich nicht harmonirende und zum Theil märchenhafte Erzählungen der Griechen (Herodot, Plato) über Gyges angewiesen, durfte man wohl annehmen, es sei dieser nicht mehr als eine mythische Person. Nun aber fand man auf einem assyrischen Denkmal des Assurbanipal den Namen Gugu, König von Ludi (Gyges, König von Lydien) als den eines Zeitgenossen des ninivitischen Herrschers erwähnt; damit ist Gyges als eine geschichtliche Persönlichkeit nachgrewiesen. Ebenso bergen die Sagen von Melkart, dem Herkules der Phönizier, von Ulysses etc., sowie die Tellsage ohne Zweifel je einen geschichtlichen Kern wirklicher Begebenheiten: bei jenen handelt es sich um Erlebnisse der ersten Seefahrer, bei dieser um die That eines Helden, der sein Vaterland von einem verhassten Joch befreite. Der Einwand, dass ähnliche Erzählungen sich auch bei andern Völkern finden, vermag diesen Sagen nicht jeden Werth zu benehmen; gab es doch sicherlich noch anderwärts als nur im Mittelmeergebiet Schiffer, deren Erlebnisse ganz ähnliche waren wie diejenigen von Melkart und Ulysses, und noch anderswo als in der Schweiz Männer, die handelten wie Wilhelm Tell. Bei dieser Auffassung setzt man sich ohne Zweifel weniger der Gefahr schwerer Täuschungen aus, als wenn man in jenen Analogien Beweise eines gemeinsamen Ursprungs verschiedener Völker sehen will, d. h. wenn man (ohne anderweitige Beweise für die Richtigkeit einer solchen Hypothese) annimmt, die Völker mit solch ähnlichen Ueberlieferungen

1) Vgl. Les Antiquités de la Troade, Gazette des Beaux-Arts, Paris 1876, p. 440. 
seien Zweige derselben Familie und haben nach ihrer Trennung in jenen Sagen die Erinnerung bewahrt an bestimmte einmalige Begebenheiten, die sich bei ilınen in der Zeit vor ihrer Trennung zugetragen hätten. Letzteres kann der Fall sein, wenn eine solche Uebereinstimmung in den Einzelheiten herrscht, dass hiedurch die Annahme einer parallelen Entwicklung ausgeschlossen ist, und namentlich wenn die Völker, um die es sich handelt, unter sich stamm- oder sprachverwandt sind. Wenn man aber eine Analogie der Sagen bei den alten Iren und Griechen ${ }^{1}$ ) oder gar bei Ungarn, Arabern und Aschantis ${ }^{2}$ ) trifft, kann man doch hierin nicht mehr ein Zweigsystem der selben, vormals einheitlichen Mythe erblicken; vielmehr ist man in solchen Fällen zu der Annahme genöthigt, dass diese einander so ähnlichen Sagen in verschiedenen Gegenden, bei mehr als einem Volke, sich spontan gebildet und entwickelt haben oder dass die eine Völkerschaft sie von der andern entlehnte und sich aneignete, zuerst als Bericht über Ereignisse, die sich anderwärts zugetragen haben, nach und nach aber - durch eine Art geistiger Assimilation — als Erzählung von Begebenheiten, deren Schauplatz das eigene Land gewesen sein soll.

Verschiedene Dokumente. Eine andere Quelle ron Aufschlüssen sind alte Gedishte, Chromilen und IIemeriven, sowie die Werle ron Geographen, Geschichtscheibern, Rednern u. s. w.

In den alten Gedichten tönt oft gleich fernem Wiederhall ein Nachklang fort von noch älteren Sagen und gewahrt ein kundiges Auge Reflexe entschwundener Glauhensanschauungen. Chroniken sind von grösstem Werth, soweit ihr Verfasser zeitgenössische Begebenheiten darstellt. Memoiren machen uns nicht blos mit Leben und Thaten der Personen bekannt, welche ihre Erinnerungen aufzeichnen, sondern auch mit den Sitten ihrer Zeit und mit manchen Einzelnheiten aus dem Leben historischer Persönlichkeiten. Die Geographen und Geschichtschreiber älterer Zeit geben oft bis ins Kleinste gehende Mittheilungen über Sitten und Gebräuche der Völker, welche Gegenstand ihrer Darstellungen

1) Vgl. Hisquisse de la Mythologie irlandaise par H. D'Arbois de Jubainville (Revue Archéologique, Paris 1878, pag. 384).

2) Vgl. Märchentheorie (Ausland 1877, pag. 113-115). 
sind. Aus Reden endlich, die uns erhalten geblieben sind, gewinnen wir je nach dem (politischen oder forensischen) Zweck und Charakter derselben ein Bild der öffentlichen Zustände and des Priratlebens gewisser Mitbürger der Redner. Was speziell die Geographen und Historiker betrifft, wird man nicht blos die Werke der jeweiligen Landesliteratur zu Rathe zichen, sondern auch solche auswärtiger Schriftsteller über das Land und Volk, womit man sich beschäftigt.

Ein livitisches Studium dieser verschiedenen Dokumente kann wichtige neue Beiträge zur Geschichte eines Volkes liefern, in bisher dunkel oder unbekannt gebliebenen Partien derselben Licht bringen und Irrthümer berichtigen, welche in Lnkenntniss dieser Quellen ihren Grund haben. Aber allerdings bedarf es hiezu, wie wiederholt bemerkt wurde, einer umsichtigen besomenen Kritik bei Benutzung dieser verschiedenen Materialien. Um die Aufschlüsse, welche uns ein Autor an die Inand gibt, nach dem Grade ihrer Verliisshichkeit angremessen zu würdigen, muss man ihn selbst recht kemmen gelernt haben; kennen in Bezug auf Charakter, Bildung, Wahrheitsliebe und Inparteilichkeit; wissen, wer und was er war, aus welchen Quellen er schöpfte, in welcher Gesellschaft er lebte und wirkte, welche Ideen zu seiner Zeit diese Umgebung und weitere Kreise bewegten und welche Gesinnungen er hegrte in Bezug auf die Völker, von denen er uns berichtet ete. Von alten Autoren sind oft verschiedene Ausgaben rorhanden, und es ist nicht gleichgültig, welche derselben man wähle. Im Allgemeinen ist zu warnen ror Berichten aus zweiter Hand und zu empfehlen, dass man auf die Quellen zurückgehe. Mit blosser Gelehrsamkeit, welche Berichte sammelt und zusammenstellt ist es nicht gethan; zu ihr müssen sich - wie Edmond Scherrer bemerkt ${ }^{1}$ ) - Scharfsinn und Methode gesellen, welche Gehalt und Tragweite der Zeugnisse zu beurtheilen und dieselben, söndernd und ordnend, in lichtvoller Darstellung trefflich zu verwerthen wissen.

Die Urkunden, von denen wir sprachen, sind nicht immer leicht $z u$ erlangen; oft müssen sie eigentlich entdeckt werden. Es sind mitunter Mamuskripte, welche in alten Kloster- und

1) Vgl. Ed. Scherrer, Mélanges d'histoire. Paris 1877, p. 216. 
Familienarchiven liegen, ohne dass noch Jemand um dieselben weiss, oder soltene Editionen in öffentlichen und Privatbibliotheken, mit denen es sich ähnlich verhalten kann. Zur Auffindung solcher verschollenen Dokumente bedarf es vielfacher Erkundigungen und oft mühsamer Nachforschungen.

Wenn man ein solches Dokument aufgefunden und als Geschichtsquelle von Belang schätzen gelernt hat, wird man es zu erwerben suchen; ist dessen Ankauf nicht möglich, so trachte man danach, einen Auszu(y aus demselben oder eine Abschift wenigstens seiner interessantesten Partien anzufertigen.

Es gibt Manuskripte, deren altersblasse Schrift kaum noch gelesen werden kann. Für solche Fälle empliehlt Baron von Bibra ${ }^{1}$ ) die Anwendung des nachstehend beschriebenen Verfahrens. Man bestreicht die stark verblassten, unlesbar gewordenen Stellen mit einem Pinsel, den man in eine frisch präparirte Lösung ron Ammoniakhydrosulphat taucht. Nach wenigen Sekunden tritt dis Schrift deutlich hervor. Nur spült man das Papier oder Pergament mit reinem Wasser $a b$ und lässt es trocknen zwischen Fliesspapier, das man so oft erneuert als nothwendig ist. Hierauf fertigt man die Kopie an. Es muss dies indess bald geschehen oder aber das Verfahren wiederholt werden; denn die Schrift verblasst schon nach einigen Wochen wieder. Ein anderes Mittel besteht in der Anwendung einer schwachen Tanninlösung, wobei das Verfahren im Lebrigen dasselbe ist wie das eben erwähnte, nur dass man hier das Trocknen des Papier's auch bewirken kann, indem man dasselbe einer Wärme von 60 bis $75^{\circ} \mathrm{C}$. aussetzt. Pergament wird immer am besten nach dem oben genannten Verfahren getrocknet. Beide Methoden der Auffrischung verblasster Schrift sind nur dann von Erfolg, wenn Galläpfeltinte zum Schreiben henutzt worden ist; auf Tusche wirkt weder das Ammoniakhydrosulphat noch das Tannin.

Das minutiöse Kopiren von Manuskripten und seltenen Drucken ist in vielen Fällen zu zeitrauhend; ein bequemeres Mittel der Reproduktion ist die Photographie. Ein berühmtes Beispiel hiefür lieferte Sevastianoff, welchem es gelang, ein photorraphisches Facsimile zu erstellen von einer 112 Blätter

1) Vgl. Journal für praktische Chemie, Leipzig 1878, p. 83. 
umfassenden Handschrift der Geographie des Ptolemäus, welche in dem Kloster auf dem Berge Athos aufbewahrt wurde. Dieses Verfahren hat den wesentlichen Vortheil, dass längst erloschene Schriftzüge des Originals in der Reproduktion wieder sichtbar werden, sodass eine solche Kopie oft leichter lesbar ist als das Original und Stellen, welche das Auge in letzterem nicht zu entziffern rermag, im Facsimile (namentlich mit Hülfe einer Loupe) deutlich gelesen werden können. Die Reproduktion eines Manuskripts auf photographischem Wege ist übrigens einer Auffrischung desselben durch Tannin auch desshalb rorzuziehen, weil letzteres die Manuskripte beschädigt, sodass es nicht immer angewendet werden darf.

\section{ALLGEVEINE BETRACHTUNGEN.}

Mit Recht ist gesagt worden, dass keine Seite der geographischen Wissenschaft grüsseren Reiz gewährt als das Studium der Beziehungen zwischen dem Menschen und der ihn umgebenden Yatur ${ }^{1}$ ). Man kann hinzufügen, dass dieses Studium eben so lehrreich als anziehend ist, indem der sinnende Geist in Kausalbeziehung stehende Thatsachen eher zu erfassen vermag als solche ohne wahrnehmbaren ursächlichen Zusammenhang. Lnstreitig besteht ein gewisser Zusammenhang zwischen der Bodengestalt eines Landes und seinem Klima, zwischen dem Klima einerseits, der Pflanzen- und Thierwelt andrerseits, sowie zwischen diesen letzteren unter sich. Die Existenz mancher Thierarten ist durch das Vorkommen gewisser Pflanzen bedingt. Infolge physischer und geistiger Eigenschaften ist nun freilich der Mensch ron allen Geschöpfen am wenigsten von seiner Umgebung abhängig oder an dieselbe gebunden; in allen Klimaten und ron den verschiedensten Nahrungsmitteln lebend, scheint er rermöge seiner höheren Begabung den Einflüssen der Aussenwelt nur in geringem Grade unterworfen $\mathrm{zu}$ sein. Indess haben zu allen Zeiten, von Hippokrates bis auf unsere Tage, Männer ron grossem Ruf solchen äusseren Verhältnissen eine hochbedeutsame

1) Fgl. Revue critique d'histoire et de littérature, Paris 1874 p. 217. 
Rolle in der Entwicklung des menschlichen Geistes zuerkannt. Es genügt, zum Beweise hiefür die Namen Montesquieu, Bossuet, Buckle und Pitter zu nennen und daran zu erinnern, dass selbst der Versuch gemacht wurde, die Geschichte irgend eines Yolkes, den Gang der Zivilisation in irgend einer Gegend aus den Verhältnissen des betreffenden Landes zu erklären. Ton andern Autoren sind diese Theorien, wonach die Geschicke der Einzelnen und ganzer Völker wesentlich durch geographische und meteorologische Faktoren bestimmt wären, scharf kritisirt worden. Sie bestreiten, dass Land und Volk zu einander in dem Verhältnisse von L'rsache und Wirkung stehen, und für diese Auffassung fehlt es nicht an gewichtigen Gründen.

Wenn der Mensch so sehr ron seiner Imgebung heeinflusst würde, so könnten die aufeinanderfolgenden Generationen der Bewohner eines Landes ron einander nicht erheblich verschieden sein, und ihre Geschichte müsste aus einer Reihe annäherud gleicher Evolutionen bestehen. Nun sehen wir aber im Gegentheil, dass mitunter ein Volk ohne Wechsel seines Wohnsitzes sich von Grund aus ändert, und dass die geschichtlichen Ereignisse auf einem und demselben Schauplatz sozusagen nie sich wiederholen. Es haben die Völker wie die Einzelnen ihre Perioden der Kindheit, der jugendlichen Entwicklung, der Reife und des Verfalls. Wir sehen Nationen, die ehemals in der Weltgeschichte eine glänzende Rolle gespielt, im Niedergang begriffen, während die geographischen Verhältnisse ihres Wohngebietes dieselben geblieben sind. Andrerseits kann bemerkt werden, dass die Angehörigen irgend eines Menschenstammes bei einem Wechsel ihres Wohnsitzes, der sie in neue und erheblich anders gestaltete Verhältnisse bringt, wesentliche Aenderungen erleiden müssten, wenn zwischen Land und Yolk so mächtige Kausalbeziehungen herrschten, wie eine gewisse Schule darthun will. Wenn man aber die Engländer Australiens, Kanadas oder Indiens und diejenigen in Grosshritannien vergleicht, so findet man, dass sie ron einander nicht merklich verschieden sind: in den britischen Besitzungen wie im Mutterlande treffen wir denselben Typus, dieselbe Sprache und dieselben Sitten, wiewohl seit der Gründung jener Kolonien geraume Zeit verflossen ist. Es ist damit nicht gesagt, dass der 
Menschı von den Verhältnissen seiner Umgebung gar nicht beeinflusst werde, dass er hievon ganz unabhängig sei. Wer jede Existenz solcher Beziehungen leugnen wollte, müsste verzichten auf das Verständniss von Erscheinungen, die ebenso unzweifelhaft konstatirt und ebenso bemerkenswerth sind wie die vorhin berührten Thatsachen; zu diesen Erscheinungen gehören die oft grossen Differenzen zwischen den Bewohnern flacher Landschaften einerseits, Gebirgsvölkern andrerseits, dem Menschen der Tropen und demjenigen gemässigter Klimate, ferner die überraschenden Analogien in Geschichte und Zivilisation von Völkern, die einander ganz fremd sind, aber in nahezu gleichen Verhältnissen leben.

Aus dem Gesagten ergibt sich, dass die besprochene Frage noch nicht abgeklärt ist. Zur Lösung derselben kann der Reisende mitwirken durch Beibringung neuer Beweise und Argumente für die eine oder andere der abweichenden Meinungen, die sich den Rang streitig machen. Die verschiedenen Gesichtspunkte, welche hiebei namentlich in Betracht kommen, wollen wir in Nachstehendem kurz besprechen; wir beginnen dabei mit dem Land als der Bühne, auf welcher die historischen Begebenheiten sich abspielen, alsdann werden wir unsere Aufmerksamkeit den Bewohnern des Landes als den in diesem grossen Drama der Geschichte auftretenden Personen zuwenden.

Die jetzige Konfiguration einer Gegend ist Resultat der manigfaltigen geologischen Vorgänge, deren Schauplatz sie seit alter Zeit bis auf unsere Tage war. Ihrerseits aber ist die Bodenkonfiguration von Einfluss auf das Klima einer Gegend. Dieses hängt, wie jedermann weiss, ebenso sehr von der Meereshöhe und Exposition des Bodens als von der geographischen Breite ab; ferner gestaltet es sich verschieden, jenachdem grosse Wasserflächen (Seen, Meere und Ozeane) in der Nähe sind oder nicht: im ersteren Fall sind die Temperaturverhältnisse weit gleichmässiger als im letzteren, der sich durch starke Extreme von Frost und Hitze charakterisirt. Ebenen, Hügel und Gebirge sind von sehr ungleichem Einfluss auf Stärke und Richtung des Windes. In weiten Ebenen wehen ungestüme Winde oft wochenlang 
in stets derselben Richtung. Wüsten, über welchen die Luft sich erwärmt und in die Höhe steigt, wirken als Aspirationscentra, nach welchen von allen Seiten her kältere Luft in der Tiefe hinströmt. Hügel vermögen Winde von ihrem Wege abzulenken und die Gewalt derselben abzuschwächen. Gebirge wirken durch Richtung, Form und Umfang in bestimmender Weise auf herrschende Winde und auf die Quantität der atmosphärischen Niederschläge ein. Indem die feuchten Winde an den Gebirgen in die Höhe zu steigen gezwungen sind, wird deren Wasserdampf kondensirt und bilden sich reichliche Niederschläge ron Regen oder Schnee. Langgestreckte Gebirgszüge, deren Richtung diejenige herrschender Luftströmungen kreuzt, bilden wahre Wetterscheiden, sodass die klimatischen Verhältnisse der beiden Seiten von einander sehr verschieden sind: die Gegend auf der einen Seite ist geschützt vor kalten Winden, von der andern werden durch das Gebirge die warmen Luftströmungen abgehalten; die eine empfängt viele Niederschläge, die andere deren nur wenige; die eine ist Wetterseite, die andere liegt im Wind- und Regenschatten. Bei einem Hochgebirge unterscheiden sich in solchen Verhältnissen die beiden $\mathrm{Ab}$ dachungen auch durch ungleiche Lage der Schneelinie. Ferner ist das Klima verschieden, jenachdem das Gebirge reich ist an Schluchten, in welche die Sonnenstrahlen kaum auf kurze Zeit Zutritt haben, oder dasselbe bedeutende Hochebenen und geräumige Thäler enthält, von deren Boden aus die Luft über ihnen erwärmt wird.

Nicht geringe Ungleichheiten des Klimas werden auch zwei Länder zeigen, die beide am Meere liegen, deren Küstenbildung und Bewässerung aber wesentlich verschieden ist, indem das eine durch Reichthum an Buchten und tief einschneidenden Fjorden wie an Seen und Flüssen sich auszeichnet, während das andere einförmige Gestade und nur spärliche, zeitweise trocken liegende Wasseradern hat.

Wie die Bodengestaltung von Einfluss ist auf das Klima, so das letztere auf die Vegetation. Wohl bedürfen die Pflanzen zu ihrem Gedeihen auch eines ihnen zusagenden Bodens, aber in der geographischen Vertheilung der Gewächse spielt das Klima die erste Rolle. Uebereinstimmung oder wesentliche Verschiedenheit in klimatischen Faktoren 
bestimmt die grossen Florengebiete; erst innerhalb derselben kommt die Beschaffenheit des Bodens als des Substrates für verschiedene Pflanzengesellschaften zur Geltung. Im Weitern ist zu berücksichtigen, dass die Zusammensetzung der Flora eines Landes nicht einzig auf den jetzigen Verhältnissen desselben beruht, sondern auch durch seine geologische Geschichte bedingt ist, daher zwei Gegenden mit annähernd demselbẹn Klima in ihrer Vegetation nicht identisch sein müssen.

Die Thiere sind zufolge ihrer Beweglichkeit weniger als die Pflanzen auf bestimmte Gegenden angewiesen, aber doch mehr oder minder von Ḱlima und Flora abhängig. Affen und Papageien sind charakteristisch für die Tropenländer, Rennthier und Seehunde für die Polargegenden. Eine Thierspezies kann nicht in jedem beliebigen Klima leben; aber einzelne Individuen derselben finden sich oft weit ausserhalb des normalen Wolngebietes der Art. So dringt der indische Königstiger oft bis in die Steppen Innerasiens vor und - weit seltener zwar - der Löwe aus der Sahara bis zu den afrikanischen Küsten des Nittelmeers. Es kann sogar die Fauna einer Gegend beim Wechsel der Jahreszeiten Aenderungen ihres Bestandes aufweisen, welche das Bild derselben wesentlich anders gestalten: Repräsentanten warmer Klimate können dabei durch solche kalter Länder ersetzt werden, und umgekehrt. Aber gerade dieser Umstand beweist, dass die Thiere ein bestimmtes Klima, das ihnen am besten zusagt, aufsuchen und dass hierin eine Lebensbedingung derselben liegt. Hinwieder gibt es unverkennbare Beziehungen zwischen der Fauna eines Gebietes und seiner Vegetation. Bei fortschreitender Entwaldung einer Gegend verschwinden die grossen Raubthiere; Büffel und Antilopen sind auf weite Grasflächen angewiesen, Rennthierheerden auf Moose und Flechten. Die Frage nach Herkunft oder Ursprung der Thierwelt eines Landes führt übrigens, wie die gleiche Frage hinsichtlich der Elemente seiner Flora, auf frühere Perioden der Geschichte des organischen Lebens zurück.

Den erwähnten Beziehungen zwischen Konfiguration, Klima, Vegetation und Fauna eines Landes stehen solche in umgekehrter Richtung zur Seite: zwischen den verschie- 
denen geographischen Objekten findet eine gewisse Wechselwirkung statt. Es ist $\mathrm{z}$. B. das Abhängigkeitsverhältniss zwischen Pflanzen- und Thierwelt kein so einseitiges, dass nur die letztere von der ersteren beeinflusst würde und nicht auch das Umgekehrte einträte. Es ist z. B. in Folge der Einführung von Schafheerden in Australien daselbst die Vegetation grosser Gebietstheile von Grund aus geändert worden. Durch jene Schafe wurden, in deren Wolle steckend, Samen einer Distelart eingeschleppt, welche nun rasch überhand genommen und auf weiten Flächen die frühere Flora verdrängt hat.

Die Vegetation ihrerseits wirkt in erheblicher Weise auf das Klima ein. Unbewachsener Boden, Sand und nackter Fels erlangen, der Sonnenstrahlung ausgesetzt, rasch eine bedeutende Wärme, die sich auch den Luftschichten über ihnen mittheilt, wogegen die Luft über bewachsenem Boden (Rasen, Gebüsch etc.) frischer bleibt und grosse Wälder, ähnlich wie Wasserflächen, eine moderirende Wirkung auf das Klima ausüben.

Endlich sind die klimatischen Verhältnisse nicht ohne Einfluss auf die Gestaltung des Terrains. Häufiger Wechsel von Frost und Hitze, Gefrieren und Aufthauen befördert die Verwitterung auch der härtesten Felsen in hohem Grade. Die Meteorwasser erodiren das Gestein und führen enorme Mengen desselben gelöst oder suspendirt zu Thal. Winde bilden stellenweise grosse Sandanhäufungen (Dünen etc.) und begünstigen die mechanische Erosion der Brandung an Steilküsten. Die horizontale und vertikale Gliederung des Bodens ist daher zu nicht geringem Theil eine Funktion klimatischer Faktoren.

Der Mensch nun steht unter dem Einfluss aller dieser manigfachen Verhältnisse. Die Kontiguration des Bodens hat unstreitig in manchen Fällen bestimmend eingewirkt auf des Menschen Lebensweise und Beschäftigung, auf die Entwicklung gewisser Fähigkeiten, Ideen und Einrichtungen desselben, mit andern Worten auf seine Geschichte.

Dem Naturmenschen stehen nur wenige Mittel zu Gebote für die Befriedigung seiner Bedürfnisse. Will er nicht blos von Wurzeln und Beeren wildwachsender Pflanzen leben, 
so muss er Jagd oder Fischfang, Viehzucht oder Ackerbau treiben; das sind die wenigen Beschäftigungen, unter welchen er zu wählen hat. Auf diese Wahl nun kann die Beschaffenheit seines Wohngebietes einen ganz wesentlichen Einfluss üben; es muss das aber nicht unter allen Umständen der Fall sein. Bewohner unfruchtbarer Inseln sind zum Fischfang genöthigt; aber im Allgemeinen werden Lebensweise und Beschäftigung des Menschen nicht einzig und ausschliesslich durch die Natur des Landes bestimmt.

Die grossen Ebenen machen ihre Bewohner nicht nothwendig zu Hirten; denn sie sind nicht nur zu Weiden geeignet, sondern können ebensowohl als Jagdgründe oder als Kulturland benutzt werden. Im Gedanken an Zentralasien scheint uns zwar der Begriff Steppe innig verbunden mit demjenigen nomadisirender Hirtenvölker; gleichwohl müssen wir uns sagen, dass diese beiden Dinge nicht nothwendig zusammengehören. Die Steppen Südafrikas und Australiens z. B. sind nur von Jägerhorden bevölkert. Die weiten Ebenen Mesopotamiens waren ehedem sorgfältig bebaut; diejenigen Vorderindiens sind es noch jetzt; die Prärien Nordamerikas, vormals Jagdgebiet der Rothhäute, werden mehr und mehr für den Ackerbau der Yankees in Besitz genommen. Die Bewohner der Ebenen müssen auch nicht nothwendig Nomaden sein oder werden. $\mathrm{Ob}$ die Lebensweise eine sesshafte oder nomadisirende sei, hängt nur insofern rom Boden ab, als dieser die Beschäftigung seiner Bewohner bedingt. Der Fischer muss sich an die Orte begeben, an welchen sich zu verschiedenen Zeiten des Jahres die Fische einfinden. Der Jäger muss neue Reviere aufsuchen, wenn in den alten das Wild selten wird. Der Hirte hat von Zeit zu Zeit mit seinen Heerden die Weidegründe zu wechseln. Nicht aus blosser Lust am Wandern, sondern nur aus Noth schweift der Mensch unstet von Ort zu Ort; was ihn zum Nomaden macht, ist also nicht die Bodenform der Ebene als solche, sondern der Mangel an Nahrung, der bei gewissen Beschäftigungsarten durch Verweilen an einem Orte eintritt und ihn zwingt, eine andere Stelle der nährenden Erde aufzusuchen. In diesem Sinne allerdings üben die Naturverhältnisse des Landes auf Beschäftigung und Lebensweise seiner Bewohner einen gewissen Einfluss; dieser 
ist aber mehr negativer als positiver Art, indem ron den wenigen Beschäftigungen, auf welche der Naturmensch als solcher sich in seiner Berufswahl beschränkt sieht, einzelne ausgeschlossen und dadurch die Annahme einer der andern nothwendig gemacht wird. Jagd und Fischfang sind nicht überall ergiebig; der Betrieb von Viehzucht erfordert die Existenz von Weiden; der Ackerbau lohnt sich nur, wenn fruchtbarer Boden vorhanden ist. Auf einer Insel von geringem Umfang, in einem Archipel und ebenso in einem von vielen Strömen oder grossen Bergketten durchzogenen Lande wird kein Nomadenleben bestehen. Es entwickelt sich überhaupt der Geist des Menschen oft nur desshalb in einer bestimmten Richtung von vielen, weil Schranken da sind, welche ihn daran hindern, irgend eine andere Bahn einzuschlagen, in welcher er sich sonst eben so wohl ergehen könnte, oder welche doch einer andern Entwicklung hemmend entgegentreten. Hätten z. B. die Phönizier, als sie sich an den östlichen Gestaden des Mittelmeers festsetzten, hier fruchtbare Ländereien oder weniger mächtige Nachbarn rorgefunden, so wären vielleicht aus ihnen statt berühmter Seefahrer bescheidene Ackerbauer geworden oder LänderEroberer statt Beherrscher des Meeres.

Reichgegliederte Küsten, hat man gesagt, machen ihre Bewohner zu tüchtigen Seeleuten. Gewiss ist unverkennbar, dass solche Küsten, deren Gewässer man in einzelnen Strecken von Kap zu Kap befahren kann und wo rorliegende Inseln in dem Festlandbewohner den Wunsch rege machen, nach denselben zu gelangen., dadurch frühe auf den Gedanken und den Versuch führen, das Meer zu befahren. Aber das gliederlos kompakte Arabien befand sich nicht in solchen Verhältnissen, und doch spielten die Araber ehemals im indischen Ozean dieselbe Rolle wie die Phönizier im mittelländischen Meere.

Es ist ferner behauptet worden, dass die grossen Wasseradern als leicht benutzbare Verkehrswege die Länder ihres Gebietes frühzeitig der Zivilisation erschliessen. Aber es ist das nicht der Fall gewesen in den beiden amerikanischen Kontinenten, die doch Flusssysteme besitzen, welche in der alten Welt nicht Ihresgleichen haben, und ebenso verhält 
es sich mit dem südlichen Afrika, dessen mächtigen Gewässern gegenüber unsere europäischen Ströme als unbedeutende Bäche erscheinen. Die alte Kultur Amerikas und Afrikas, im Reiche der Inkas und der Azteken wie im alten Egrpten, erstand nicht in den Gebieten jener grossartigen Gewässersysteme.

Aus einer Reihe geschichtlicher Thatsachen hat sich die Ansicht gebildet, dass Gebirgsländer die Wiege republikanischer Institutionen und Heimstätten der Volksfreiheit seien, während die einförmigen Flächen weitgedehnter Ebenen den stolzen Aufschwung des Geistes hemmen und die Bildung despotisch regierter Reiche hegünstigen. Es ist richtig, dass den Gehirgsvöliern in der Regel starkes Vertrauen auf die pigene hraft, lebhaftes Selbstbewusstsein und glühende Freiheitsliebe eigen sind: aber dieselben Eigenschaften tinden wir in kaum geringerem Grade hei den Beduinen der Wüste, und was den Kausalnexus zwischen Landesnatur und Staatseinrichtungen betrifft, so finden wir Völker- oder Stammesbümhisse, welche an die Eidgenossenschaft im Herzen des Alpengehirges erinnern, auch in der Wüste, eine absolute Theokratie im Hochlande ron Tibet wie im alten Egypten, in Amerika Repuhliken neben einem Kaiserreich, nicht selten auch in einem und demselhen Lande einen Wechsel der Regierungsform, von der Republik zur Monarchie, wie in Griechenland und Rom, oder umgekehrt von der Monarchie zur Republik wie in Frankreich.

Der Einfluss des Klimas auf den Menschen tritt mehr herror als derjenige der Bodenkonfiguration. Die KlimaVerschiedenheiten, sagt Montesquieu, bewirken eine Verschiedenheit der Bedürfnisse, woraus die Lnterschiede in der Lebensweise entspringen. Der Mensch milder "paradisischer" Himmelsstriche braucht sicli weder gegen brennende Sommerhitze noch gegen eine strenge Winterlälte zu schützen; ein Bedürfniss nach Kleidung, nach heizharen Wohnräumen und zur Ansammlung von Vorräthen für eine Jahreszeit, die keine Früchte bringt, fühlt er kaum oder gar nicht; er braucht nur die Hand auszustrecken um sich Nahrung zu verschaffen, während in andern Gegenden diese einzige Sorge fast die ganze Kraft des Menschen absorbirt. Offenbar sind das bedeutungsrolle Lngleichheiten. Eine höhere Geistes- 
kultur, das freie Spiel der schaffenden Phantasie, kann sich nur entwickeln, wenn die Sorge um die materielle Existenz nicht alles Sinnen und Denken in Anspruch nimmt. Aber wie ein Cehermass dieser Sorge, so hemmt auch ein gänzlicher Mangel derselben die geistige Vervollkommnung des Menschen, und es sind keineswegs die als Schoosshinder einer überreichen Natur begünstigten Völker, welche auf der langen Bahn der Kulturentwicklung unseres Geschlechtes die grössten Fortschritte gemacht haben. Die Eingehornen von Brasilien und Südafrika, wo ein äusserst fruchtbarer Boden in einem glücklichen Klima ohne Zuthun des Nenschen eine Fülle von Produkten liefert, sind nicht höher zivilisirt als die Eskimos und Feuerländer. Ein Zustand der Barbarei ist also nicht einem bestimmten Klima oder einer gewissen geographischen Breite eigen. Mamnigfaltigheit der Bedürfnisse wirkt stimulirend. Ausdauernde Arbeit gewinnt auch einem kargen Borden Ernte ab; der Lmstand, dass man nicht auf regelmässige und genügende Erträge zählen kann, veranlasst zur Vorsorge für die Zukunft; diese Eigenschaften aber sind ebensoviel oder mehr werth als blosse Vortheile des Ḱlimas. So zeirt sich denn der grösste Fortschritt da, wo der Mensch die Lngunst der Verhältnisse siegreich überwindet, und nicht da, wo die Verhältnisse von Natur am vortheilhaftesten zu sein scheineu. Zur Frklärung dieser Thatsache wird gewühnlich gesagt, das Kilima beeinflusse den physischen, intellektuellen und moralischen Zustand des Menschen; starke Hitze wirke entnervend, lähmend auf Körper und Geist; aber man findet in der heissen Zone leidenschaftlich-energische Naturen, und die Ruinen ron Indien, Java, Kambodscha und ZentralAmerika beweisen, dass die Tropenhitze kein absolutes Hinderniss der Kultur ist. Als ein solches erweist sich dagegen ein übermässig kaltes Ḱlima; demn da ist der Erdboden zur Unfruchtharkeit verurtheilt, wird der Geist abgestumpft, kann sich kein geselliges und politisches Leben entwickeln. Welch ein Kontrast zwischen dem Polarmenschen, den erstarrender Frost in eine niedrige, rauch- und dunsterfüllte Hütte bannt, deren engen Faum seine Familie mit den Hausthieren gemeinsam bewohnt - und dem Leben in Griechenland und Rom mit ihren olympischen Spielen und Volksversammlungen! 
Armuth oder Reichthum des Bodens sind oft von entscheidender Bedeutung. Grössere oder geringere Fruchtbarkeit desselben vermag die Art der Beschäftigung des Menschen zu bestimmen, und die Bodenschätze können eine feste Grundlage der Landeswohlfahrt werden, wo der Mensch sie weise $z u$ benutzen versteht. Aber die fruchtbarsten Länder sind nicht immer auch die bestkultivirten; Gold und Silber haben so wenig dem spanischen Reiche Heil gebracht als der armseligen Urberölkerung von Kalifornien oder Australien, und nicht ohne den britischen Unternehmungsgeist haben Eisen und Kohle Englands industrielle Grösse begründet.

Flora und Fauna - die, wie wir sahen, in enger Beziehung zum Kilima stehen - üben auch einen namhaften Einfluss auf den Menschen aus. $O b$ ein Land an Dürre leide oder sich einer üppigen Vegetation erfreue, ob es mächtige Hochwälder oder weite Gras- und Krautfluren besitze, muss bestimmend auf die Lebensweise seiner Bewohner einwirken. Die Verschiedenheit der Kulturgewächse bedingt auch Terschiedenheiten der Beschäftigung zu deren Produktion und gewerblicher Verwendung. Reichthum an Wild ermöglicht dem Menschen eine Existenz ohne Bodenkultur: auch liängt es von der Fauna ab, ob der Mensch einzelne Repräsentanten derselben zu bekämpfen hat oder solche durch Zähmung seinen Zwecken dienstbar und zu seinen Hausgenossen machen kann. Umgekehrt übt aber auch der Mensch Einfluss auf die Pflanzen- und Thierwelt eines Landes durch Ausroden von Wäldern, Entwässerung von Seen und Sümpfen, durch die ganze Bodenkultur einerseits, andrerseits durch Ausrottung schädlicher und Einführung nützlicher Thiere.

Alles in Allem genommen, erscheint uns die Einwirkung der Naturverhältnisse auf den Menschen nicht so gross und massgebend, dass sie allein genügen würde, um die vielen und bedeutenden Differenzen zwischen den verschiedenen Gruppen des menschlichen Geschlechtes zu erklären oder die Geschicke der Bewohner eines Landes vorherzubestimmen. Mehr als andere Organismen kann der Mensch gegen diese Einflüsse reagiren und sich denselben entziehen; es ist das um so mehr der Fall, je weiter er in der Kultur fort- 
schreitet. Hindernisse, die zu überwinden sind, kömnen Anlass werden zur Entwicklung seiner Fähigkeiten; umgekehrt bewirkt die Gunst der äussern Umstände oft Stillstand und Verfall. Wesentlich in sich selbst und nicht in den günstigen Verhältnissen ihres Wohngebiets haben diejenigen Völker, welche jemals in der Weltgeschichte eine hervorragende Stellung erlangten, den Grund ihrer Grösse gefunden, und Entartung trat ein, wenn keine Aufgaben mehr zu lösen waren, an deren Bewältigung die Kraft sich gestählt hätte. Die Natur bietet dem Menschen gewisse Mittel dar: von ihm aber hängt deren Verwerthung ab. Diese erfordert einen hestimmten Kraftaufwand, dessen nicht alle Menschen fähig sind. Hierin liegt ein erster Lnterschied zwischen den Völkern: die einen scheuen eine gewisse Mühe und Anstrengung, die sie weiter bringen kömnte, und verharren auf niederer Stufe; die andern arbeiten an ihrer Vervollkommnung, indem sie an den Schwierigkeiten ihre Kraft versuchen und dieselben siegreich überwinden. Die Schicksale eines Volkes den Naturverhälnissen allein zuzuschreiben, ist durchaus ungerechtfertigt: wohl hat die Natur ihren Antheil daran, aber auch der Nensch den seinen. Ein Geschenk der Natur sind des Menschen Aulagen; aber ob er dieselben entwickelt oder schlummern lässt, ist sein Verdienst oder Fehler. Zu weit geht indessen die Behauptung, dass alle Menschen und Völker das Loos haben, welches sie rerdienen. Erfolg und Misserfolg werden oft durch äussere Verhältnisse bedingt, um nicht zu sagen: vom Zufall. Ganzen Vülkern wie Einzelnen gegenüber thürmen sich oft Berge von Schwierigkeiten auf, während Andern das Glück lächelt und die Wegre vor ihnen wie von selbst sich ebnen. Die bessere Kraft kann einer Verkettung ron Widerwärtigkeiten erliegen, die geringere einem Zusammentreffen günstiger Faktoren ihre Erfolge verdanken. Manch ein unterdrückter Stamm wäre eher als seine Besiegrer des Looses werth, dessen diese sich erfreuen. Ein hochzivilisirtes Volk konnte sicherlich nicht ohne tüchtige Begabung die Stufe erreichen, auf welche es grelangt ist; aber der Anstoss zu manchem seiner Fortschritte kann doch ein zufälliger gewesen sein. Viele Vülker wären unkultivirt geblieben, hätten nicht - ohne ihr eigenes $\mathrm{Zu}$ thun - vorgeschrittenere Nationen mit ihnen Verbindungen 
angeknüpft, oder hätte sich nicht unter ihnen ein Mann erhoben, welchen eine grosse Idee begeisterte. Nichts wirkt mächtiger auf ein ganzes Volk als ein zündender Gedanke, ein gewaltiges Vorbild, im Guten oder Bösen. Nationen sind in Verfall gerathen, weil sie die Fehler ihrer Nachbarn kopirten; Völker sind gross geworden, die andere zum Nuster nahmen und zu übertreffen suchten; gross vor Allem sind sie geworden, wenn sie ihre Kraft bethätigten im Dienste einer treibenden Idee. 


$$
\text { A N H A NG. }
$$





\section{TAFEL I.}

\section{Erste Meridiane.}

Es kann beliebig (konventionell) irgend ein Meridian als derjenige angenommen werden, ron welchem aus man die andern oder also die geographischen Längen zählt. Als solchen Anfangsmeridian betrachten die Engländer denjenigen durch die Sternwarte zu Greenwich, die Franzosen denjenigen durch das Observatorium zu Paris. Die Deutschen gehen bei der Zählung bald von einem dieser beiden Meridiane aus, bald ron demjenigen der Insel Feiro $\left(20^{\circ}\right.$ westl. ron Paris), die Russen ron Pulkowa, die Amerikaner von Cambridge in Massachusetts oder Washington, die Spanier ron San Fernando bei Cadix etc.

Behufs Redulition ierschiedener Lïngenangaben auf densellen Anfungsmeridian muss man die Längendifferenz zweier Hauptmeridiane zu den gegebenen Zahlen addiren oder von denselben subtrahiren.

Nach der neuesten Zusammenstellung von A. Auwers in Behms geographischem Jahrbuch pro 1880 (wonach die oben S. 92 mitgetheilten Zahlen etwelche Aenderungen erleiden ${ }^{1}$ ) bestehen folgende Längenunterschiede:

Greenwich liegt $2^{0} 20^{\prime} 15^{\prime \prime}$ westlich von Paris.

San Fernando. $8^{0} 32^{\prime} 34^{\prime \prime}$ \% " \%

Ferro . . $20^{0}-$ -

Cambridge M. . $73^{0} \cdot 28^{\prime}-$ \%

Washington . $79^{0} 23^{\prime} 16^{\prime \prime}$ n "

Berlin . . $11^{0} 3^{\prime} 29^{\prime \prime}$ östlich \% "

Pullioua . . $27^{0} 59^{\prime} 25^{\prime \prime}$ \% \% \%

1) Ueber die Genauigkeit der nunmehrigen Angaben vgl. a. a. O. S. 304. 
Man hat also die Längenangaben einer Karte, welcher der Meridian von Greenwich zu Grunde gelegt ist, folgendermaassen zu ändern, damit sie sich auf Paris beziehen: a) zu den westlichen Längen muss $2^{0} 20^{\prime} 15^{\prime \prime}$ addirt, b) von den östlichen muss dieselbe Zahl subtrahirt werden.

$$
\begin{aligned}
& \text { Beispiele: a) } 35^{\circ} 40^{\prime} 0^{\prime \prime} \text { westlich von Greenwich, } \\
& +\quad 2^{0} 20^{\prime} 15^{\prime \prime} \\
& 38^{0} 0^{\prime} 15^{\prime \prime} \text { westlich von Paris. } \\
& \text { b) } 72^{0} 15^{\prime} 20^{\prime \prime} \text { östlich von Greenwich, } \\
& \frac{-2^{0}}{69^{0} 55^{\prime} \quad 5^{\prime \prime}} \text { östlich von Paris. }
\end{aligned}
$$

Betrüge die östliche Länge eines Ortes $P$ weniger als die $2^{0} 20^{\prime} 15^{\prime \prime}$, so hätte man dieselbe von jener Differenz $\left(2^{0} 20^{\prime} 15^{\prime \prime}\right)$ zu subtrahiren und erhielte so die westliche Länge des Punktes $P$ von Paris:

$$
\begin{aligned}
& \text { c) } 1^{0} 15^{\prime} 10^{\prime \prime} \text { östlich von Greenwich, } \\
& 2^{0} 20^{\prime} 15^{\prime \prime} \\
& 1^{0} 5^{\prime} 5^{\prime \prime} \text { westlich von Paris. }
\end{aligned}
$$

Analog ist immer zu verfahren, wenn Längen auf Paris zu reduziren sind, die sich auf einen Anfangsmeridian westlicl von Paris beziehen. Liegt aber der gegebene Anfangsmeridian ̈̈stlich von demjenigen, welcher bei der Reduktion zu Grunde gelegt werden soll, so ist das Verfahren einfach umzukehren, z. B.

$70^{\circ} 20^{\prime} \quad 0^{\prime \prime}$ westlich von Pulkowa,

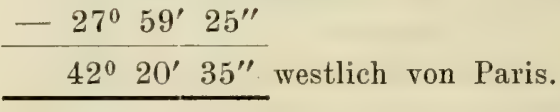

$10^{\circ} 16^{\prime} 12^{\prime \prime}$ östlich von Pulkowa, $+27^{0} 59^{\prime} 25^{\prime \prime}$

$38^{\circ} 15^{\prime} 37^{\prime \prime}$ östlich von Paris.

$12^{0} 10^{\prime} 5^{\prime \prime}$ westlich von Pulkowa, $27^{0} 59^{\prime} 25^{\prime \prime}$

$15^{0} 49^{\prime} 20^{\prime \prime}$ östlich von Paris. 


\section{TAFEL II.}

Länge der Meridian- und Parallellveisgrade.

(Abplattung der Erōe $=\frac{1}{299,15}$ angenommer.)

\begin{tabular}{|c|c|c|c|c|c|c|c|c|}
\hline$\frac{\dot{D}}{\stackrel{0}{0}}$ & $\begin{array}{l}\text { Meridian- } \\
\text { grad. }\end{array}$ & $\begin{array}{c}\text { Parallel- } \\
\text { grad. }\end{array}$ & 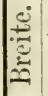 & $\begin{array}{c}\text { Meridian- } \\
\text { grad. }\end{array}$ & $\begin{array}{c}\text { Parallel- } \\
\text { grad. }\end{array}$ & 苟 & $\begin{array}{c}\text { Meridian- } \\
\text { grad. }\end{array}$ & $\begin{array}{c}\text { Parallel- } \\
\text { grad. }\end{array}$ \\
\hline & $\mathrm{m}$ & $\mathrm{m}$ & & $\mathrm{m}$ & $\mathrm{m}$ & & $\mathrm{m}$ & $\mathrm{m}$ \\
\hline 0 & 110563,7 & 111306,6 & 30 & $1108+1,0$ & 96474,8 & 60 & 111399,1 & 55793,1 \\
\hline 1 & 110564,0 & 111289,7 & 31 & 110858,0 & 95492,0 & 61 & 111415,8 & $5+100,8$ \\
\hline 2 & 110565,0 & 111239,2 & 32 & 110875,2 & 94481,9 & 62 & 111432,3 & 52391,8 \\
\hline 3 & 110566,7 & 111155,0 & 33 & 110892,8 & $934+2,0$ & 63 & 111448,3 & 50666,5 \\
\hline 4 & 110569,0 & 111037,2 & 34 & 110910,7 & 92373,7 & 64 & 111463,9 & 48925,6 \\
\hline 5 & 110572,0 & $110885, \mathrm{~s}$ & 35 & 110928,8 & 91277,1 & 65 & 111479,1 & 47169,7 \\
\hline 6 & 110575,8 & 110700,9 & 36 & 110947,2 & 90152,7 & 66 & 111493,9 & 45399,1 \\
\hline 7 & 110580,1 & 110482,4 & 37 & 110965,8 & 89000,8 & 67 & 111508,2 & 43614,4 \\
\hline 8 & 110585,1 & 110230,5 & 38 & 110984,6 & 87821,6 & 68 & 111522,1 & 41816,3 \\
\hline 9 & 110590,8 & 109945,2 & 39 & 111003,5 & 86616,1 & 69 & 111535,4 & 40005,3 \\
\hline 10 & 110597,0 & 109626,6 & 40 & 111021,6 & 85383,7 & 70 & 111548,3 & 38181.8 \\
\hline 11 & 110604,0 & 109274.9 & 41 & 111041,8 & $8 \pm 125,1$ & $|71|$ & 111561,3 & 36346,5 \\
\hline 12 & 110611,6 & 108890,0 & 42 & 111061,1 & 82840,8 & 72 & 111572,4 & 34499,9 \\
\hline 13 & 110619,7 & 108 & 43 & 111080,5 & 81531,1 & 73 & 111583,8 & 32642,7 \\
\hline 14 & 110628.5 & 1080 & 44 & 111100,0 & 80196,5 & 74 & 111594,4 & 30775,2 \\
\hline 15 & 110637,9 & 107538,0 & 15 & 111119,4 & 78837,3 & 75 & 111604,5 & $28898, \pm$ \\
\hline 16 & 110647,8 & 107022,0 & 46 & 111138.9 & 77453,9 & 76 & 111614,0 & 27012,5 \\
\hline 17 & 110658,4 & 106473,4 & 47 & 111158,4 & 76046,8 & 77 & 111622,9 & 25118,2 \\
\hline 18 & 110669,4 & 105892,6 & 48 & $11117 \pi, 8$ & $7+616,3$ & $78 \mid$ & 111631,3 & 23216,2 \\
\hline 19 & 110681,1 & 105279,9 & \pm 9 & 111197,2 & 73162,9 & $79 \mid$ & 111638,9 & 21306,9 \\
\hline 20 & 110693,3 & 104634,9 & 50 & 111216,4 & 71687,0 & $80 \mid$ & 111646,0 & 19391,1 \\
\hline 21 & 110706,0 & 103958,3 & 51 & 111235,6 & 70189,1 & 81 & 111652,6 & 17469,2 \\
\hline 22 & 110719,2 & 103250,1 & 52 & 111254,6 & 68669,6 & 82 & 111658,1 & 15541,8 \\
\hline 23 & 110732,9 & 102510,6 & 53 & 111273,4 & 67129,0 & $83 \mid$ & $11.1663,3$ & 13609,7 \\
\hline 24 & 110747,1 & 101 & 54 & 111292,1 & 65567,7 & 84 & 111667,6 & 11673,3 \\
\hline 25 & 110761,7 & 100 & 55 & $111:$ & $63:$ & 85 & 111671,4 & 9733,3 \\
\hline 26 & 110776,7 & 100105,9 & 56 & 111322,9 & 62385,1 & 86 & 111674,4 & 7790,3 \\
\hline 27 & 110792,2 & 90243,2 & 57 & 111347,0 & 60764,7 & 87 & 111676,7 & 5844,8 \\
\hline 28 & 110808,1 & 98350,2 & 58 & 111364,7 & 59125,6 & 88 & 111678,4 & 3897,5 \\
\hline \multirow[t]{2}{*}{29} & 110824,4 & 97427,4 & 59 & 111382,0 & 57468,1 & 89 & 111679,4 & 1949,1 \\
\hline & & & & & & 90 & 111679,9 & 0.0 \\
\hline
\end{tabular}




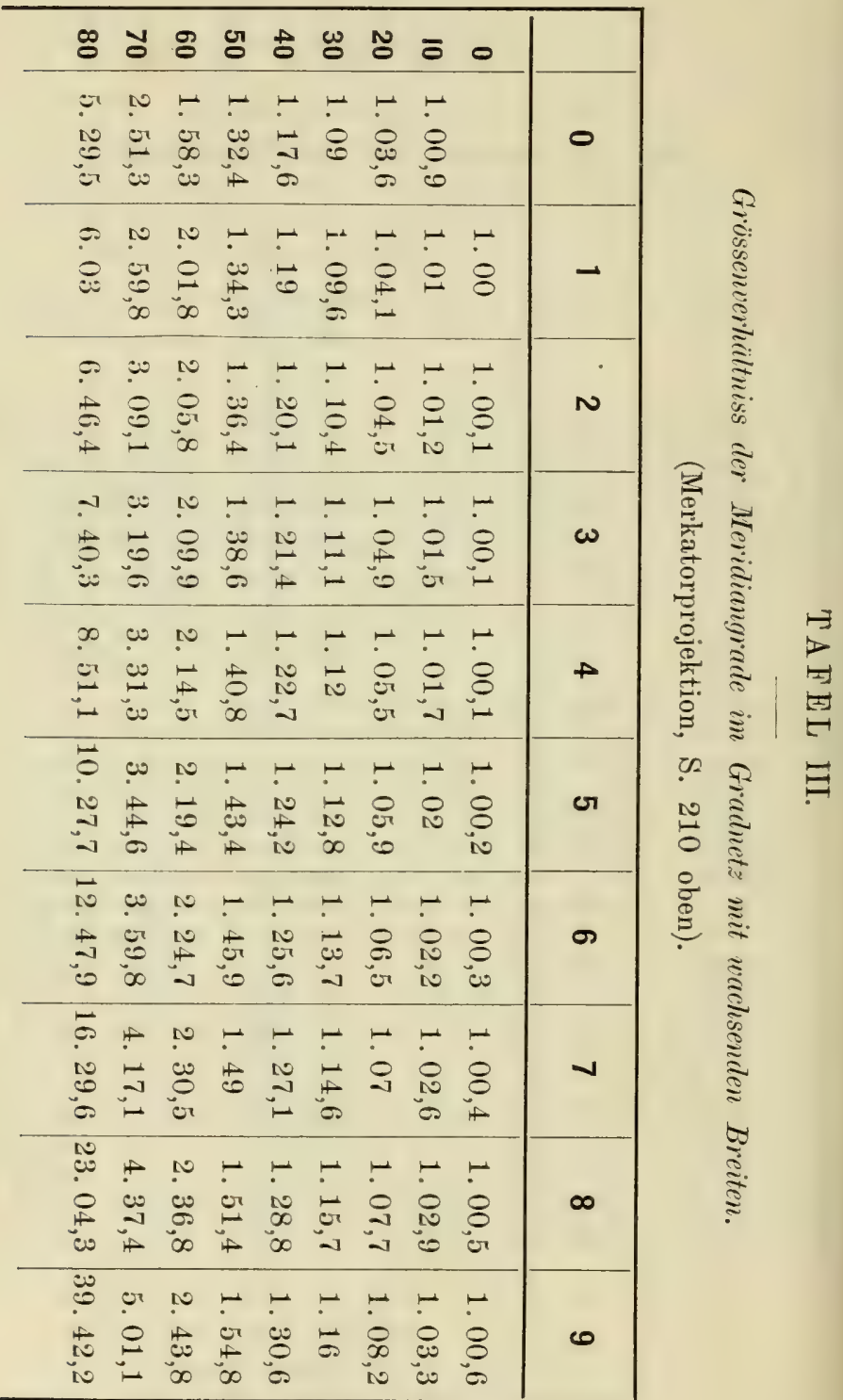


Die Zahlen der vertikalen Kolonne links geben die geographischen Breiten ron 10 zu 10 Grad, diejenigen am Kopfe der übrigen 10 Kolonnen die einzelnen Grade. Der Abstand des ersten Parallels (1) rom Aequator $\left(0^{\circ}\right)$ ist die Einheit $(1,00)$, welche den Zahlen der zehn Kolonnen zu Grunde liegt. Diesem Abstand muss derjenige zwischen den einzelnen Meridianen gleich sein. Wie gross man ihn annehmen will (ob z. B. gleich $1 \mathrm{~mm}$ ), hängt davon ab, welchen Inhalt und Lmfang die Karte haben soll. Wenn nun also dieser Abstand (zwischen Aequator und erstem Parallelkreis) als 1 bezeichnet wird, so muss derjenige zwischen dem ersten und zweiten Parallel gleich 1,001 sein, der Abstand rom rierten zum fünften Parallelkreis aber 1,002 , rom achten zum neunten 1,006 , von neunten zum zehnten $1,009 \mathrm{u}$. s. f. - Hat man den 30. Parallelkreis konstruirt und soll nun die Lage des 31 . in der Zeichnung bestimmt werden, so findet man hiefür auf der rorn mit 30 bezeichneten Zeile in der mit 1 überschriebenen Kolonne die Zahl 1,096. Diese gibt also an, wie gross der 31. Meridian- oder Breitegrad in der Karte erscheinen soll, wenn dem ersten der Werth 1 beigelegt wird. - Ist der 31. Parallelkreis gegeben und wollen wir nun den 33. auftragen, so benutzen wir die Summe der Zahlen für den 32. und 33. Breitegrad. Für jene finden wir (Zeile 30, Kolonne 2) 1,104

für diese (Zeile 30, Kolonne 3) 1,111

$$
\text { Summa } 2,215
$$

Dieser Werth $(\mathbf{2}, 215)$ muss nun der Distanz zwischen dem 31. und 32. Parallel gegeben werden.

Man ersieht aus der Tabelle, dass die Werthe für die hohen Breiten rasch zunehmen. Die Nerkatorprojektion lässt z. B. den 61. Breitegrad doppelt, den 72. dreimal, den 79. fünfmal, den 81. sechsmal so gross erscheinen als den ersten. 


\section{TAFEL IV a.}

\section{Zentrische Reduktion eines Winkels.}

Die zentrische Reduktion eines Winkels (vgl. oben S. 35) ist dann vorzunehmen, wenn die Aufstellung des Instrumentes nicht im Scheitel des zu messenden Winkels erfolgen kann, weun z. B. ein Thurm oder Baum den betreffenden Dreieckspunkt bildet.

$1^{\circ}$ Es sei der. Winkel $A B C$ (Fig. 265) zu bestimmen,

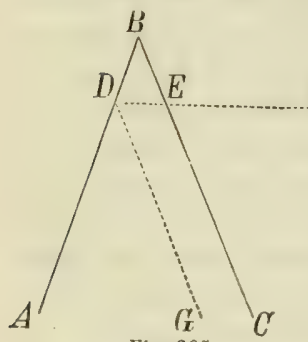

Fig. 265. in dessen Scheitel $B$ das Instrument nicht aufgestellt werden kann.

F Man placirt sich mit dem Instrument in einem möglichst nahe an $B$ gelegenen Punkt $D$ des Schenkels $B A$, visirt nach einem Punkte $F$, der so liegt, dass $D F$ den Schenkel $B C$ schneidet, lässt den Schnittpunkt $E$ durch einen Stab bezeichnen, misst den Winkel $A D F$ und hernach, indem man sich in $E$ aufstellt, auch den Winkel $C E F$. Nun ist der zu bestimmende Winkel $A B C^{\prime}$ gleich der Differenz (ter beiden yemessenen Winkel (AD $\left.F-C^{\prime} E F\right)$; wie nämlich die Figur zeigt, besteht folgende Gleichung: $A B C=A D G=A D F^{\prime}-G D F=A D F-C E F$.

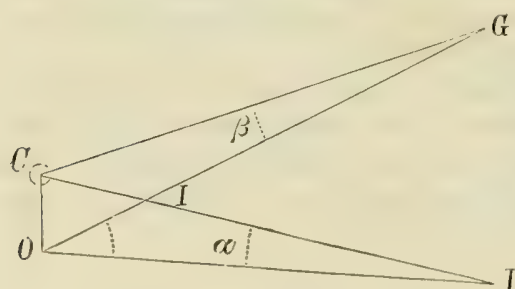

Fig. 266 .

$2^{\circ}$ Es sei der Winkel $D C G(F i g .266)$ zu bestimmen, in dessen Scheitelpunkt $C$ das Instrument nicht aufgestellt werden kann.

Man placirt sich mit Ddem Instrument in einem Punkte- $O$ nahe bei $C$, misst $O C$, visirt nach zwei Punkten $D$ und $G$ der Schenkel des zu bestimmenden Winkels, liest die Winkel $G O C$ und $D O C$ ab und bestimmt annähernd (durch Schätzung) die beiden Distanzen $C D$ und $C G$. 
Die Visirlinien $O D$ und $O G$ bilden mit den Schenkeln $C D$ und $C G$ die Winkel $\boldsymbol{a}$ und $\beta$. Es ist nun der zu bestimmende Winkel $D$ (' $G$ gleich dem gemessenen Winkel $G O D$ plus der Differenz jener beiden Winkel $\boldsymbol{c}$ und $\beta$, also

$$
D C G=D O G+\alpha-\beta \text {. }
$$

Die Hülfswinkel $\alpha$ und $\beta$ aber liömen leicht berechnet werden. Es rerhalten sich nämlich nach einem bekannten trigonometrischen Satze zwei Seiten eines Dreiecks zu einander wie die Sinus (rgl. oben S. 133) der gregenüberliegenden Winkel; man hat also folgende Proportionen:

$$
\begin{aligned}
& (1):(O)=\sin I O C: \sin ( \\
& C G: C O=\sin C O G: \sin \beta
\end{aligned}
$$

und demnach zur Bestimmung von \& und $\rho$ die Gleichungen

$$
\begin{aligned}
& \sin \alpha=\sin D O C \cdot \frac{C U}{C I)} \\
& \sin \beta=\sin C O G \cdot \frac{C O}{C G}
\end{aligned}
$$

\section{TAFEL IV b.}

\section{Berechumg der Koordinaten von Dreiecksmunliten.}

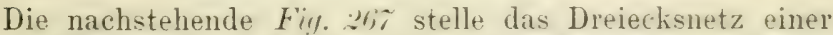
von $A M$ als Basis ausgehenden Triangulation vor. Man ziehe in der Zeichnung durch einen Dreieckspunkt $E$ den Meridian (vgl, oben S. 73) $Y Y$ als Ordinatenaxe und dazu die Normale XI als Abszissenaxe (rgl. oben S. 56 ).

Nun hat der Punkt $M$ die Koordinaten $M I=E 2$ (Abszisse) und $I I \sim=E 1$ (Ordinate). Dieselhen können bestimmt werden aus der Dreiecksseite $I I E$ und dein Winkel M E $Y$, welchen dieselbe mit dem Meridian bildet. Dieser Winkel (das Azimuth ron II) sei $35^{0} 25^{\prime}$ so ist

$$
\Pi\left[1=I L \cdot \sin 35^{0} 25^{\prime}\right.
$$

und $M I 2=I I E \cdot \cos 35^{\circ} 25^{\prime}($ rgl.oben S.133).

Die Koordinaten des Punktes $A$ ergehen sich in analoger Weise aus dem rechtwinkligen Ireieck $1: 3.4$, von welchem man wieder die Hypothenuse $(A \mathrm{E})$ und den einen 


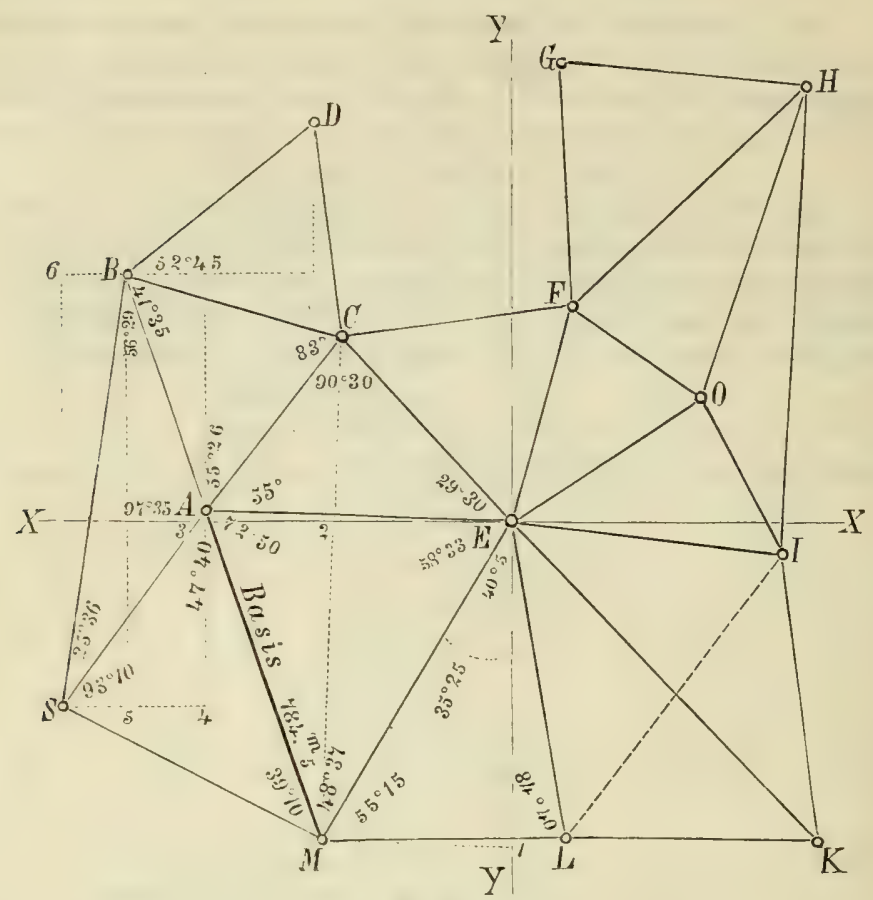

Fig. 267.

ihr anliegenden Winkel ( $A E X$ ) kennt. Der letztere ist nämlich gleich $A E Y-90^{\circ} ; A E Y$ aber (das Azimuth ron $A)$ ist die Summe des Azimuthes $M E Y$ und des Dreieckswinkels $A E M$, also

$$
\begin{aligned}
A E X & =M E Y+A E M-90^{\circ} \\
& =35^{\circ} 25^{\prime}+58^{\circ} 33^{\prime}-90^{\circ} .
\end{aligned}
$$

Hinsichtlich des Punktes $S$ finden wir Winkel $S A 4=S A M-4 A M$

$$
\begin{array}{r}
4 A M=A M 2 \\
A M 2=A M E-2 M E \\
\text { also } S A 4=S A M-(A M E-M E Y)
\end{array}
$$

$$
\begin{aligned}
& =47^{\circ} 40^{\prime}-\left(48^{0} 37^{\prime}-35^{0} 25^{\prime}\right) \\
& =47^{\circ} 40^{\prime}-13^{0} 12^{\prime}=34^{0} 28^{\prime}
\end{aligned}
$$


Man kennt also von diesem rechtwinkligen Dreieck wieder die Hypothenuse nebst einem anliegenden Winkel und kann somit die Katheten $S t$ und $A f$ berechnen. Die Abszisse von $S, \mathrm{~d}$. h. der senkrechte Abstand dieses Punktes rom Meridian $Y Y$, ist aber gleich $S \dot{t}+E, \cdot$, , und seine Ordinate ist $A 4-A 3$.

Bei Punkt $B$ fällen wir von $B$ aus eine Senkrechte $B$; auf $S 4$ und erhalten so ein rechtwinkliges Dreieck mit der bekannten Hypothenuse $B S$; der Winkel $B S 5$ ist gleich $B S A+A S \dot{y}$. Aus diesen Elementen lassen sich $B ;$ und $S 5$ bestimmen. Nun ist aber die Ahszisse des Punktes $B$ gleich derjenigen von $S$ mimus $S 5$, die Ordinate von $B$ gleich $B 5$ mimus der Ordinate von $S$.

In ähnlicher Weise wird die Lage jedes der übrigen Punkte durch seine Koordinaten bestimmt. Beim Notiren dieser Zahlen ist jeweils eine Bezeichnung dafür anzubringen, in welchem Quadranten des Koordinatensystems (Nordwest, Nordost, Südwest oder Südost) der betreffende Punkt liegt.

\section{TAFEL IV c.}

\section{Trigonometrische Höhenmessung.}

$1^{\circ}$ Es sei $O(F i g .268)$ eine Station, von welcher aus der Meeresspiegel in II sichtbar ist. Es soll die absolute Höhe derselben, $O N=x$, bestimmt werden.

Man misst den Zenithwinkel $M O Z$ sowohl bei Hochwasser als beim darauf folgenden Niedrigwasser des Meeres und nimmt aus den Messungen das arithmetische Mittel $z$. Für die gesuchte Höhe gilt nun die Formel

$x=1 / 2(m+1)^{2} R \cdot \tan ^{2}(z-90)$.

Hier bedeutet $R$ den Erdradius $C M=$ $C N=6366200$ Meter (Logarithmus dieser Zahl $=6,8038803$ ). Die Grösse

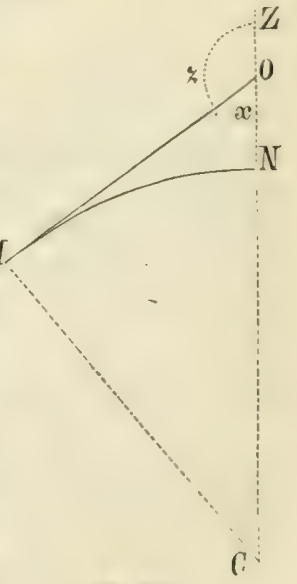

Fiy. 26 s. 
$m$ ist der Refraktionskoeffizient. Derselbe wird entweder durch andere gleichzeitige Beobachtungen direkt bestimmt oder $=0,08 \pm 0,02$ angesetzt $(+0,02$ bei kaltem, - 0,02 bei warmem Wetter). Nimmt man für $m$ den Werth 0,08 , so lautet die Formel

$$
x=0,5832 R \cdot \operatorname{tg}^{2}(z-90) .
$$

Setzt man aber für $m$ den Werth 0,06 ein, so ist $(m+1)^{2}=1,06^{2}=1,1236$, somit $1 / 2(m+1)^{2}=0,5618$.

Es sei nun z. B. der Zenithwinkel $z$ für den Mittelwasserstand des Meeres $92^{\circ}$, also $z-90=2^{\circ}$, so ist

$$
\begin{array}{r}
x=0,5618 \cdot R \cdot \operatorname{tg}^{2} 2^{0} \\
\log 0,5618=0,74958-1
\end{array}
$$$$
\log R=6,80388
$$$$
2 \log \operatorname{tg} 2^{0}=7.08617-10
$$$$
\log x=3,63963
$$

$x=4631,4$ Meter.

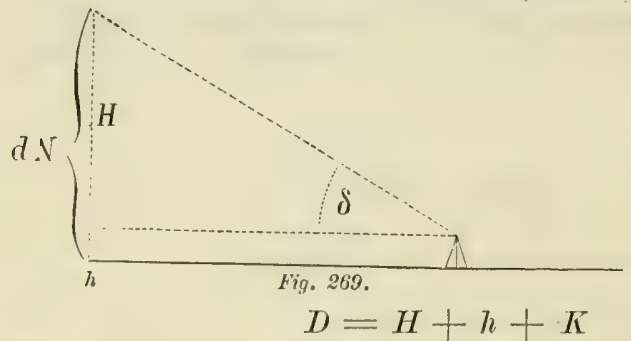

$2^{\circ}$ Der Höhenunterschied $D$ zweier Punkte mit dem Höhenwinkel $\delta$ und dem Horizontalabstand $K$ ist $\mathrm{zu}$ berechnen nach der Formel

worin $H$ die vertikale Kathete des rechtwinkligen Dreiecks, dessen Hypothenuse die schiefe Visirlinie zwischen beiden Punkten, und dessen andere Kathete die Horizontale in der Augenhöhe des Beobachters, $h$ die Instrumentenhöhe und $K$ die Korrektion für Strahlenbrechung und Erdkrümmung (Refraktionsfehler und Differenz zwischen wahrer.und scheinbarer Höhe, vgl. oben S. 47). Da $\frac{H}{\kappa}=\operatorname{tg} \delta$, ist $K \cdot \operatorname{tg} \delta$ als Werth für $H$ einzusetzen; $l$ aber ist gleich $\frac{0,42 . k^{2}}{R}$, wobei $R$ den Erdradius bedeutet. Die Formel lautet daher'

$$
D=K \cdot \operatorname{tg} \delta+h+\frac{0,42 \cdot K^{2}}{R} \text {. }
$$

Um für die Anwendung dieser Formel ein Beispiel zu geben, nehmen wir $R=2000$ Meter

$$
\begin{aligned}
& \delta=15^{0} 12^{\prime} \\
& h=1,4 \text { Meter. }
\end{aligned}
$$




$$
\begin{array}{rlr}
\log K & =3,30103 \\
\log \operatorname{tg} \delta & =9,43408-10 \\
\text { Num. } 2,73511 & \\
\log 0,42 & =0,62378-1 & \\
2 \log K=6,22584 & \\
-6,22584 & & \\
-\log K=-6,80388 \\
\text { Num. } 0,57804-1 & =0,264 \\
h & =1,400 \\
D & =545,051
\end{array}
$$

$3^{\circ}$ Es soll die Höhendifferenz $z$ zweier Punkte $A$ und $B$ (Fig. :\%(O) bestimmt werden aus den beiden (möglichst gleichzeitig gemessenen) Zenithdistanzen $\alpha$ und $\beta$. - Ist $s$ die Entfernung der beiden Punkte, a die approximative Höhe des einen derselben (A) und $r$ der Erdradius, so gilt die Formel

$$
z=\left(1+\frac{a}{r}\right) s \cdot \operatorname{tg} \frac{\beta-\alpha}{2}
$$

Beispiel. Es sei:

$$
\begin{aligned}
& a=1850 \text { Meter, } \\
& s=27570,7 \text { Meter, } \\
& \beta=92^{\circ} 14^{\prime} 31^{\prime \prime} \\
& \alpha=87^{\circ} 58^{\prime} 27^{\prime \prime}
\end{aligned}
$$

also $\dot{\beta}-\alpha=4^{0} 16^{\prime} 4^{\prime \prime}$ $1 / 2(\beta-\alpha)=2^{0} 8^{\prime} 2^{\prime \prime}$

Zur Vornahme der Berechnung

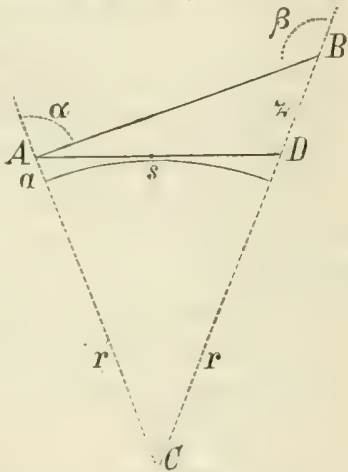

Fig. 270.

zerlegen wir die obige Formel durch Auflösung der Klammer in

$$
z=s \cdot \operatorname{tg} \frac{\beta-\alpha}{2}+{ }_{r} \cdot s \cdot \operatorname{tg} \frac{\beta-\alpha}{2}
$$

und berechnen nun die zwei Glieder wie folgt:

$$
\begin{aligned}
\log s & =4,44045 \\
\log \operatorname{tg} \frac{\beta-\alpha}{2}= & \frac{8,57128-10}{3,01173}=1027,4 \text { Neter. } \\
\text { 1) Num. } & =3,26717 \\
\log a=\frac{6,27890}{\log r}= & 6,80388 \\
\text { 2) Num. } 0,47502-1 & =\frac{0,3}{1027,7} \text { Neter. }
\end{aligned}
$$


$4^{\circ}$ Die Höhendifferenz der beiden Punkte kann aus einer einzigen Zenithdistanz berechnet werden unter Einführung eines Hülfswinkels

$$
\begin{aligned}
\mathscr{T} & =\frac{(0,5-n) 8 \cdot M}{r} . \\
\text { Hier ist } I L & =\frac{180^{\circ}}{\pi} \text { oder in Sekunden } \\
& =\frac{180 \cdot 60 \cdot 60^{\prime \prime}}{\pi}, \text { wonach }
\end{aligned}
$$

$\log \lambda=5,31443$.

Die Grösse " bezeichnet wieder den Refraktionskoeffizient $0,08 \pm 0,02(0,1$ bei kaltem Wetter, 0,06 bei warmem Wetter; Mittelwerth 0,08).

Die Formel lautet nun

$$
z=\left(1+\frac{a}{r}\right) s \cdot \operatorname{ctg}(\alpha-\varphi) \text {. }
$$

Für deren Berechnung, beziehungsweise Zerlegung, gilt das vorhin Gesagte; $r$ und s haben die gleiche Bedeutung wie in der vorangegangenen Formel.

Erstes Brispriel: Der Punkt $A$, von welchem aus operirt wird, sei tirf'r gelegen als $B$, dessen Höhe über $A$ bestimmt werden soll.

$$
\begin{aligned}
& a=2000^{\prime} \quad s=18427^{\prime} \text { (Schweizerfuss, } 10^{\prime}=3 \mathrm{~m} \text { ) } \\
& \alpha=88^{0} 17^{\prime} 4^{\prime \prime} n=0,06, \text { also } 0,5-n=0,44 .
\end{aligned}
$$

\section{Hiilfswinkel.}

$$
\varphi=\frac{0,44 \cdot s \cdot M}{,}
$$$$
\log 0,44=0,64345
$$$$
\log s=4,26545
$$$$
\log M=5,31443
$$$$
9,22333
$$$$
\log r=7,32679
$$$$
\log \varphi=1,89654
$$$$
\varphi=\begin{array}{r}
78,8^{\prime \prime} \\
=1^{\prime} 18,8^{\prime \prime}
\end{array}
$$$$
\alpha-\varphi=88^{\circ} 15^{\prime} 45^{\prime \prime}
$$

Hauptformel.

$$
z=s \cdot \operatorname{ctg}(\alpha-\varphi)+\frac{a}{r} \operatorname{ctg}(\alpha-\varphi)
$$


Wie man sieht, hat diese Methode den Vortheil, dass man gleichzeitig den von der Refraktion befreiten Zenithwinkel $(\boldsymbol{\alpha}-\boldsymbol{q})$ kennen lernt.

Zuceites Beispiel. Der Punkt A, ron welchem aus operirt wird, sei höher gelegen als $B$.

$$
\begin{array}{ll}
a=2558^{\prime} & s=18427^{\prime} \\
\alpha=91^{0} 45^{\prime} 34^{\prime \prime} & n=0,06 .
\end{array}
$$

Hülfswinkel.

\begin{tabular}{|c|c|c|c|}
\hline $\log 0,44$ & $=\overline{1} .64345$ & $\log s$ & $=4,26545$ \\
\hline $\log s$ & $=4,26545$ & $\log \operatorname{ctg}(\alpha-\varphi)$ & $=\overline{2} .48194$ \\
\hline $\log M I$ & $=5,31443$ & $\log$ von Glied 1 & $=2,74739$ \\
\hline $\log r$ & $=7,32679$ & $\log a$ & $=3,40790$ \\
\hline $\log \varphi$ & $=1,89654$ & $\log r$ & $=7,32679$ \\
\hline$\varphi$ & $=1^{\prime} 18,8^{\prime \prime}$ & $\log$ von Glied 2 & $=\overline{2} .82840$ \\
\hline$-\varphi$ & $=91^{0} 44^{\prime} 15^{\prime \prime}$ & 1. Glied & $=558,97^{\prime}$ \\
\hline & & 2. & $0,06^{\prime}$ \\
\hline
\end{tabular}

Hauptformel.

In Bezug auf die Cotangente des Winkels $a-\varphi$ mag, da $\boldsymbol{c}-\varphi>90^{\circ}$, bemerkt werden, dass sie ihrem absoluten Werthe nach gleich ist der Cotangente des Supplementarwinkels $180-(\alpha-\varphi)$ oder der Tangente von $\alpha-\varphi-90$, also der Cotangente von $88^{\circ} 15^{\prime} 45^{\prime \prime}$ oder der Tangente von $1^{0} 44^{\prime} 15^{\prime \prime}$. 


\section{TAFEL V.}

\section{Graphische Methode der barometrischen Höhenmessung.}

Von Prof. A. Weilenmann in Zürich.

Die beigegebenen Tabellen sind für den Gebrauch des Aneroidbarometer's berechnet. Die senkrechten Linien, beziehungsweise die Zahlen am Fusse, bezeichnen die Nitteltemperatur der Luftschicht zwischen den beiden Stationen, deren Höhenunterschied ermittelt werden soll (vgl. S. 50 oben); die wagrechten Linien, respektive die Zahlen links, geben die absolute Höhe in Metern, und die schiefen Linien mit den Ziffern rechts und oben geben den Luftdruck (Barometerstand) in Millimetern. Rechts findet man vier Rubriken für Korrektionen, wobei die Zahlen Meter bedeuten; die erste Rubrik, mit W überschrieben, gilt für den Winter, die zweite ( $F$ ) für den Frülling, die dritte (S) für den Sommer und die rierte $(H)$ für den Herbst. Diese Korrektionen gelten für das westliche Alpengebiet, sind aber auch für Beobachtungen in andern Gegenden brauchbar, wenn man nur die dem jeweiligen Klima entsprechende Rubrik nimmt, z. B. für Aequatorialgegenden immer die Kolonne Sommer (S). Diese Korrektionen müssen zu den gefundenen Höhen addirt werden. Ein Beispiel:

Untere Station. Barometer $723 \mathrm{~mm}$.

Lufttemperatur im Schatten $24^{\circ}$

Obere Station. Barometer $556 \mathrm{~mm}$. Sommer.

Luftemperatur im Schatten $10^{\circ}$

Summe der Temperaturen $34^{0}$

Nittel

$17^{0}$

Man sucht nun auf der ersten Tafel, welche rechts Barometerstände ron 680 bis $760 \mathrm{~mm}$ notirt hat, die senkrechte Linie auf, die der Temperatur $+17^{\circ}$ entspricht; man rerfolgt sie bis zur schiefen Linie, welche den (rechts angegebenen) Luftdruck oder Barometerstand von $723 \mathrm{~mm}$. bezeichnet, und merkt sich die Horizontale in der Nähe dieses Punktes. Die erwähnte Horizontale nach links ver- 
folgend, sieht man, dass sie eine Höhe ron $4: 20 \mathrm{~m}$ bedentet: allein jener Schnittpunkt der senkrechten und schiefen Linie liegt etwas über dieser Horizontalen und zwar nahezu um ${ }^{1} / s$ des Zwischenraums bis zur nächsten Horizontalen (von $430^{\circ}$ ): er entspricht also einer töhe von $423 \mathrm{~m}$. Piechts daneben findet man als Feuchitigkeitskorrelition für den Sommer $2 \mathrm{~m}$ angegeben. Die Höhe der untern Station betrïgt demnach 425 Neter.

Nun nimmt man auf der dritten Tafel (mit den Barometerstandsangaben $5 弓 0$ his $600 \mathrm{~mm}$ ) wierder die Senkrechte $17^{n}$ und verfolgt sie bis zur schiefen Linie ron $556 \mathrm{~mm}$. Die Horizontale durch diesen Punkt entspricht, wie man am Rande links sieht, einer Höhe von en6t Meter. Als. Feuchtigkeitskorrektion findet man rechts $11 \mathrm{~m}$, also ist die Höhe der obern Station $2665 \mathrm{~m}$ über Neer, und die Differenz der Höhen beträgt demnach

$$
2665-425=2240 \text { Neter. }
$$

Die ganze Rechnung beschränkt sich auf folgende Angaben :

Unterer Barometer $723 \mathrm{~mm}$. Temperatur $24^{\circ}$ ।

Oberer $\quad$ \%

$556 \mathrm{~mm}$.
$\Rightarrow \quad 10^{\circ}$ Sommer.

Mittel $17^{\circ}$

Höhe. Korreltion.

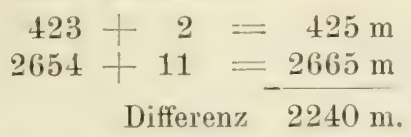

Wenn es sich um Zehntel ron Graden und Millimetern handelt, kann damit ebenso verfahren werden wie mit Ganzen.

Am günstigsten für die barometrische Ïöhenbestimmungr ist die Zeit von Mittags 12 his $3 \mathrm{Uhr}$ an einem schönen Sommertag, wenn eine entsprechende Beohachtung in der Ebene angewendet werden kann. Man braucht in diesem Falle nur die Luftemperatur aus der Ebene zu kennen; diejenige in der Höhe kann berechnet werien, indem man weiss, dass unter den angegehenen Verhältnissen die Temperatur in freier Luft um $1^{\prime \prime}$ auf je 101 Meter Höhe al,nimmt. Beispiel : 
1878, Juli 17, 1 Uhr Nachmittags.

Zürich, Barometer 727,2 mm, Temperatur 23,20

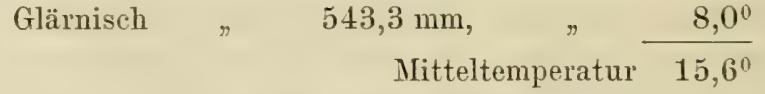

Höhe. Korrelition.

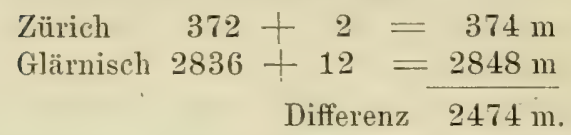

Temperaturabnahme in freier Luft $=2474: 101=24,5^{0}$ : also Luftemperatur senkrecht über Zürich in der Höhe des Glärnisch $=23,2-24,4=-1,2^{0}$; Mittel der beiden Temperaturen ron 23,2 und $-1,2=22^{\circ}: 2=11^{\circ}$. In den Tafeln findet man bei Verfolgung der Vertikalen $11^{\circ}$
Zürich
$(727,2 \mathrm{~mm})$
$367+$
$2=369 \mathrm{~m}$
Glärnisch
$(543,3 \mathrm{~mm})$
2792$$
+12=\frac{2804 \mathrm{~m}}{2435 \mathrm{~m} .}
$$

Nimmt man dazu die absolute Höhe der Station Zürich = $470 \mathrm{~m}$, so erhält man als Höhe für den Glärnisch

$$
2435+470=2905 \mathrm{~m},
$$

d. h. nur 8 Meter weniger als die wirkliche Höhe. - Die Beohachtung wurde mit einem Goldschmid-Weilenmann schen Aneroid gemacht.

Wenn man keine Hülfsstation hat, kann man die Höhe bis auf etwa $100 \mathrm{~m}$ genau bestimmen, indem man den Luftdruck im Niveau des Neeres $=760 \mathrm{~mm}$ annimmt.

Beispiel: Eine Station habe im Sommer $634 \mathrm{~mm}$ Luftdruck und $14^{\circ}$ Lufttemperatur.

Die senkrechte Kolonne für $14^{0}$ gibt uns

$$
1523 \mathrm{~m}+7 \mathrm{~m} \text { (Korrektion) }=1530 \mathrm{~m} \text {. }
$$

Im Sommer findet eine Temperaturabnahme ron $1^{0}$ durchschnittlich auf $135 \mathrm{~m}$ Erhebung statt.

$$
1530: 135=11,3^{0} \text {. }
$$

Die Temperatur im Niveau des Neeres ist hienach $14+11,3=25,3^{n}$, und das Mittel der beiden Lufttemperaturen (von $14^{0}+25,3^{\circ}$ ) beträgt also $19,6^{\circ}$. Auf der Vertilialen von $19,6^{\circ}$ aber findet man für $634 \mathrm{~mm}$ eine approximative Höhe von $1552 \mathrm{~m}$. - 
Die Tafel erweist sich für Reisezwecke auch darlurch nützlich, dass man mit ihrer Hülfe einen bestimmten Betrag der Höhenänderung innehalten kann. Nehmen wir z. B. an, das Aneroid zeige $656 \mathrm{~mm}$ Luftdruck bei einer Temperatur ron $15^{\circ}$ und man wolle sich um $120 \mathrm{~m}$ höher hinauf begehen. Welches wird der Stand des Aneroids sein, wenn wir diese Höhe erreicht haben und woran wir erkennen, dass wir sie erreichten? Um diese Frage zu beantworten, verfolght man die Vertikale $15^{n}$ his zur schiefen Linie von $656 \mathrm{~mm}$, welcher die Horizontale 1241 $\mathrm{m}$ entspricht : $120 \mathrm{~m}$ mehr sind $1361 \mathrm{~m}$. Dieser Horizontalen aber $(1361 \mathrm{~m}$ । entspricht bei $15^{0}$ ein Luftdruck von $646,7 \mathrm{~mm}$.

Endlich kann man sich der Tafel auch mit Vortheil bedienen, um zu ermitteln, welcher Luftdruck im Meeresniveau einem anderswo beobachteten Barometerstande entspricht. Zu diesem Zweck muss man wissen, welche mittler. Temperaturzu- oder Abnahme in freier Luft einer bestimmten Höhendifferenz $(100 \mathrm{~m})$ entspricht. Diese Temperaturänderung anf $100 \mathrm{~m}$ Höhe beträgt für Westeuropa durchschnittlich
$0,353^{0}$ im Winter
$0,671^{0}$ im Frühling
$0,740^{\circ}$ im Sommer
$0,419^{0}$ im Herbst.

Die Zahl $0,7 \pm 0$ ist auch für die Aequatorialgegenden zu gebrauchen, d. h. es ist anzunehmen, die Lufttemperatur steige daselbst durchschnittlich um diesen Betragn, wem man sich um $100 \mathrm{~m}$ abwïrts begibt, und falle um eben soviel für eine Erhebung von $100 \mathrm{~m}$.

Man habe nun z. B. im westlichen Europa bei $840 \mathrm{~m}$ Höhe über Neer und $9^{n}$ Grad Luftemperatur einen Barometerstand ron $681 \mathrm{~mm}$ beobachtet. Welches wird der grleichzeitige Luftdruck im Meeresniveau sein?

Die Temperaturzunahme bis zum Mper beträgt $0,419.8,4=$ $3,5^{0}$ : es ist also die wahrscheinliche Lufttemperatur an Meere $9+3,5=12,5^{0}$ und demnach das Mittel der beiden Temperaturen ${ }^{1 / 2}(9 \div 12,5)=10,8^{\circ}$. Wir verfolgen die Vertikale 10,8 his zur Schiefen $681 \mathrm{~mm}$ und finden die Horizontale $912 \mathrm{~m}$. Das ist aber (gegenübrel $840 \mathrm{~m}$ ) um $72 \mathrm{~m}$ zu viel. Wir gehen daher auf der Verti- 
kalen 10,8 bis zur Horizontalen $72 \mathrm{~m}$ und treffen so auf die schiefe Linie, welche einem Luftdruck von $753,5 \mathrm{~mm}$ entspricht. Das ist der gesuchte Barometerstand für das Meeresniveau ( $0 \mathrm{~m}$ absolute Höhe).

Hat man Barometerstände von mehr als $700 \mathrm{~mm}$, so kann die Tafel gleichwohl angewendet werden. Es geschieht dies in folgender Weise. Man denkt sich an der Stelle von 750 die Zahl 770 und für 740 die Angabe $780 \mathrm{~mm}$ und hetrachtet die zugehörigen Höhenzahlen als negative, also die entsprechenden Punkte als unterhalb des Meeresspiegels gelegen. Beispiele hiefür: $\begin{array}{crr}1^{\circ} \text { Entere Station. Barometer } 773 \mathrm{~mm} & \text { Temp. } 27^{\circ} \\ \text { Obere Station. } & 596 \mathrm{~mm} & 9^{\circ}\end{array}$ Sommer.

Nittel $18^{0}$

Höhe der unternstation -- $148 \mathrm{~m}$, Korr. -- $1 \mathrm{~m},-149 \mathrm{~m}$ " obern $\quad-2074 \mathrm{~m}, \quad$ \% $-10 \mathrm{~m}, 2084 \mathrm{~m}$

Niveaudifferenz $2233 \mathrm{~m}$.

2" Bei 840) Höhe hat man im Frühling $696 \mathrm{~mm}$ Luftdruck und $4,7^{\circ}$ Temperatur. Welches ist der entsprechende Luftdruck an Meeresniveau?

Temperaturzunahme bis zum Neere $0,671.8,4=5,7^{0}$. Luftemperatur am Neere also $4,7+5,7=10,4^{0}$. Mittel (von 4,7 und 10,4 ) $=7,5^{\circ}$. Auf der Vertikalen mit $7,5^{\circ}$ findet man für $696 \mathrm{~mm}$ die IIorizontale $722 \mathrm{~m}$, was (gegenüber $840 \mathrm{~m}$ ) $118 \mathrm{~m} \mathrm{zu}$ wenig ist. Diesen $118 \mathrm{~m}$ aber entspricht ein Barometerstand von $770,8 \mathrm{~mm}$ und das ist der gesuchte Luftdruck bei $0 \mathrm{~m}$ Höhe. 


\section{BAROMETRISCHE HÖHENMESSUNG.}

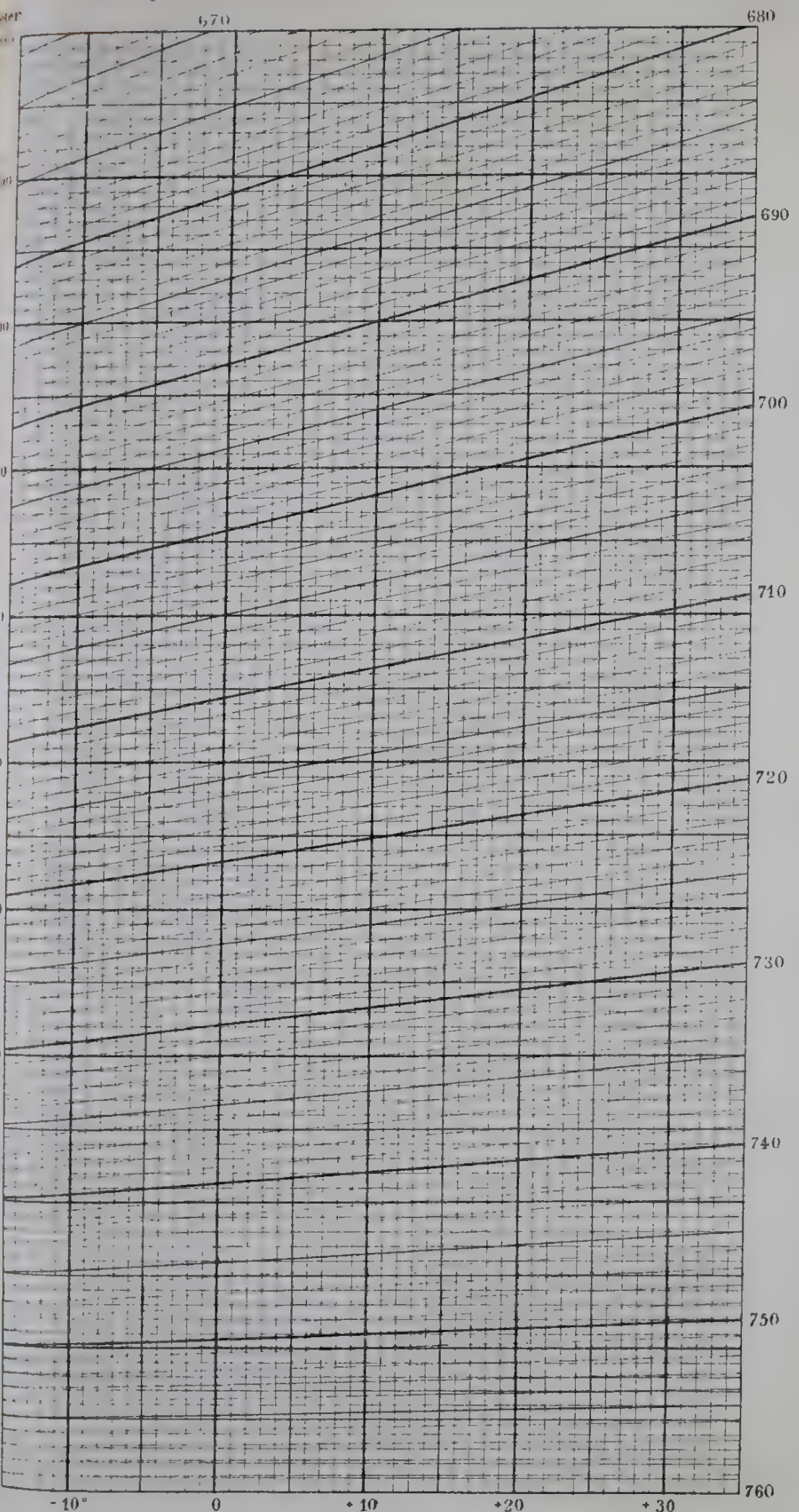

W. F. S. H.

EUCHTICKEITS- Meter

KORRECTION

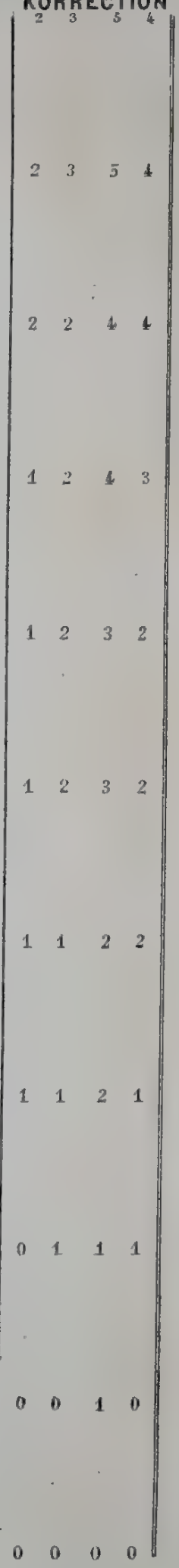

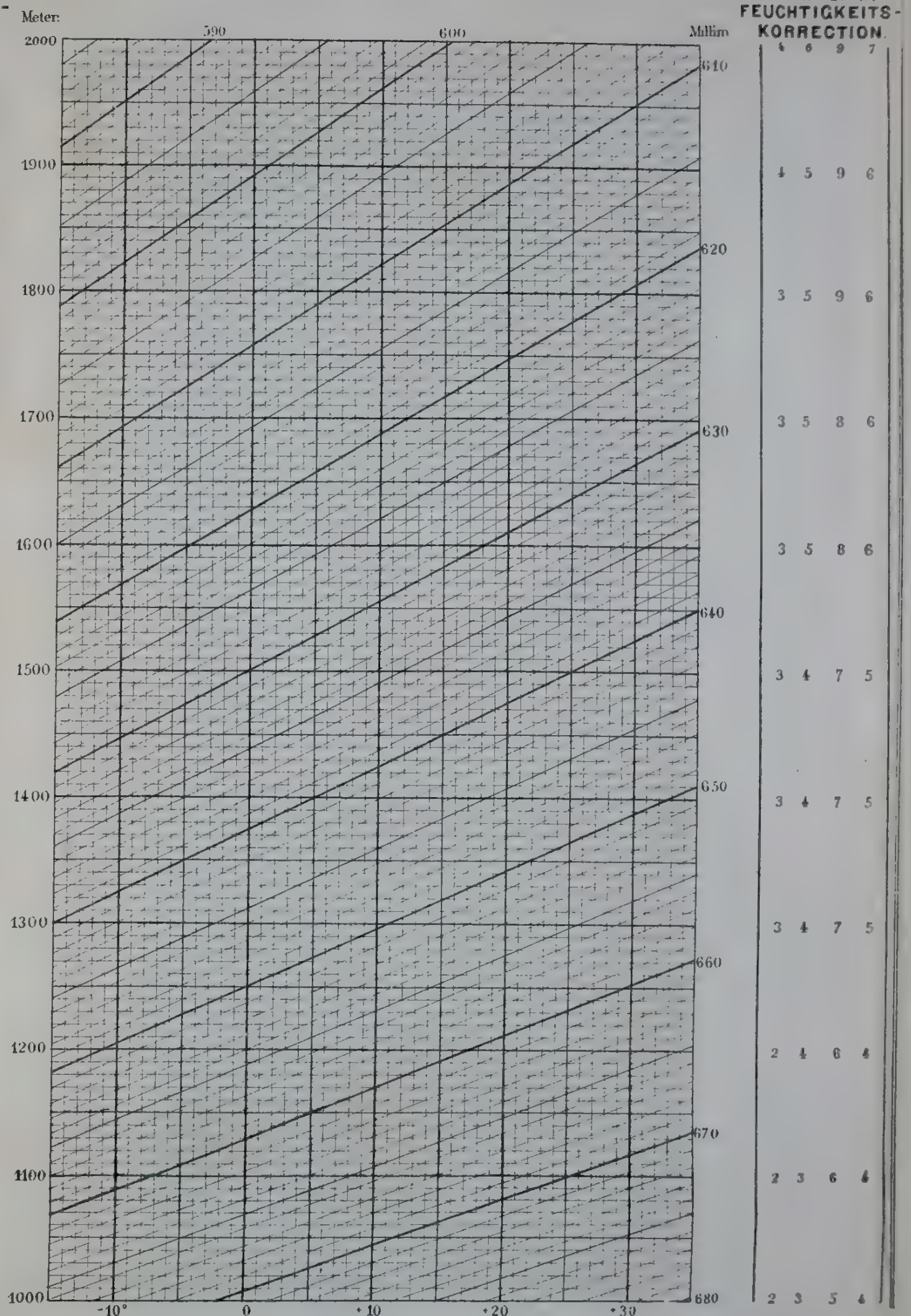


W. F. S. H.
FEUCHTIGKEITS-

1.:.in KORRECTION.

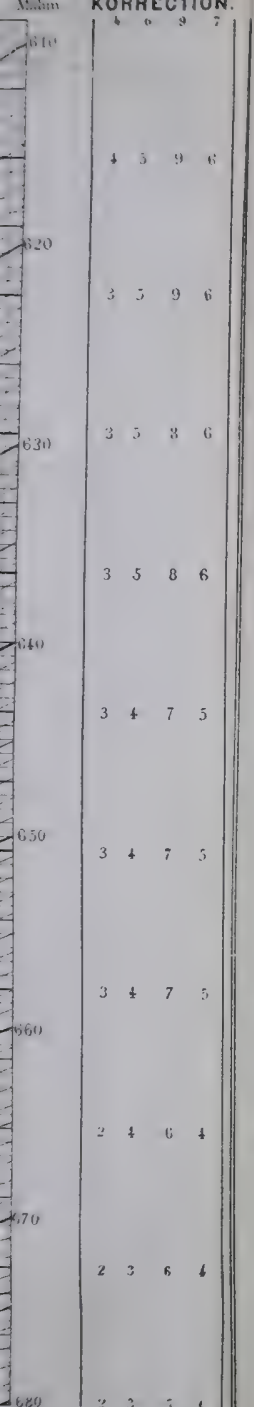

B.ARONETRISOHE, HOHENAESSING

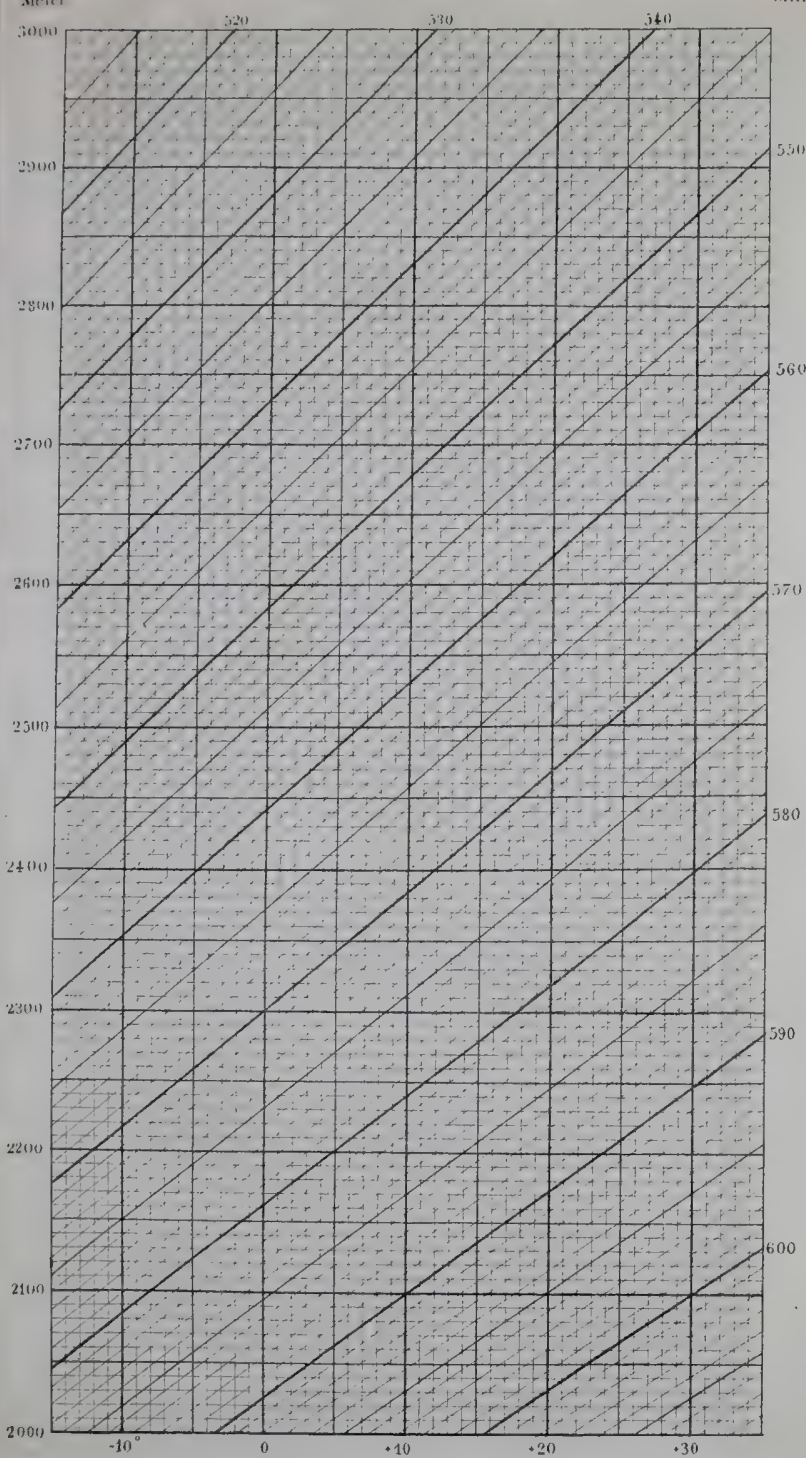

W. F. S. H.
FEUCHTIGKEITS $=$ Motor

KORRECTION.

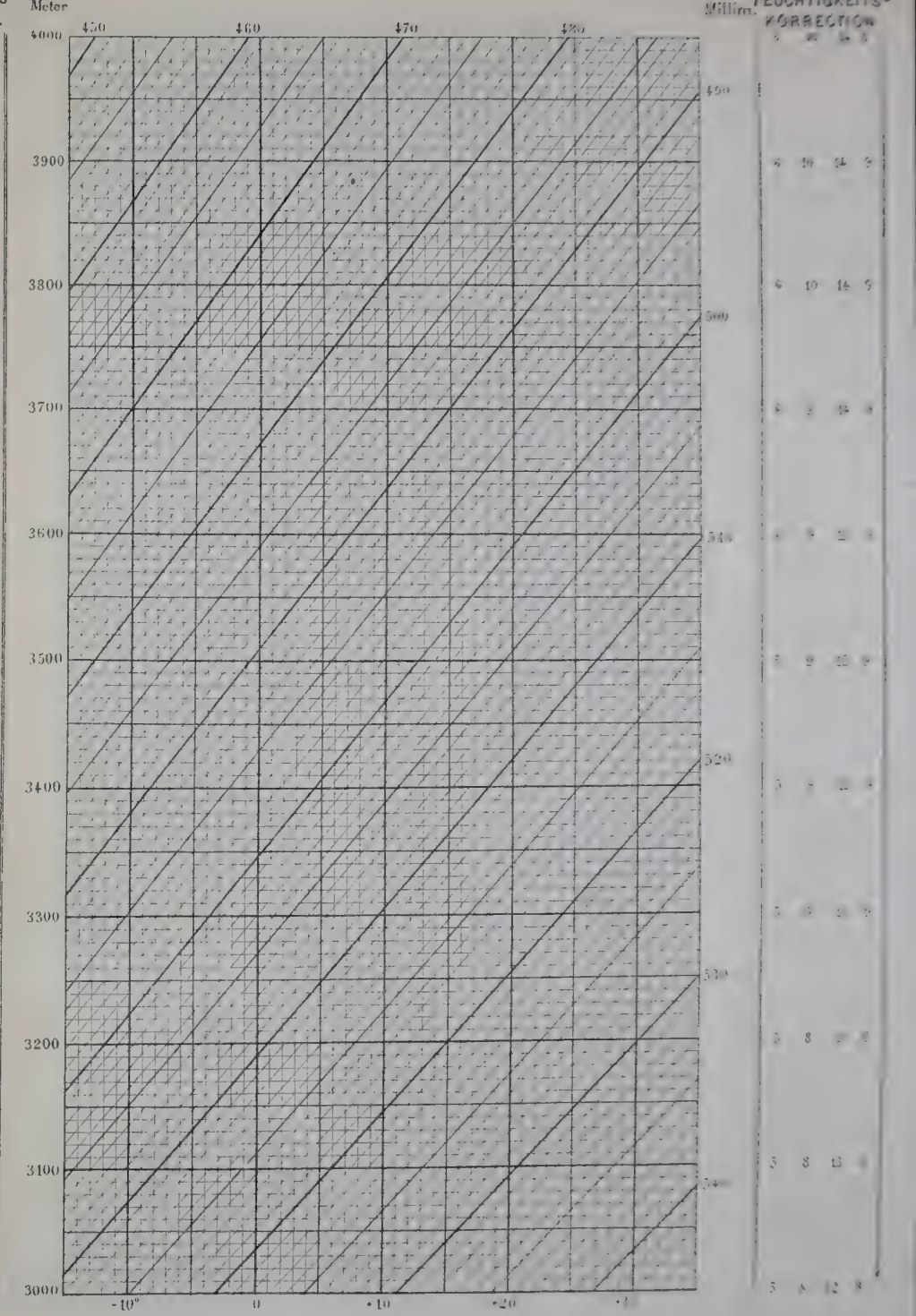




\section{TAFEL VI.}

Vergleichung der verschicdenen Thermometer-Shalen.

$0^{0}$ Celsius $=0^{0}$ Réaumür $=+32^{\circ} \mathrm{Fahrenheit.}$

$\begin{aligned} 100^{\circ} \%= & 80^{\circ} \% \text { REDUKTIONSTAFEL. }\end{aligned}$

\begin{tabular}{|c|c|c|c|c|c|c|c|c|c|c|}
\hline 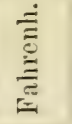 & & 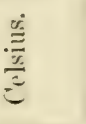 & $\underset{\Xi}{\stackrel{\Xi}{\Xi}}$ & 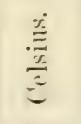 & 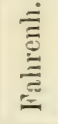 & 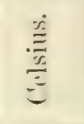 & 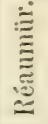 & 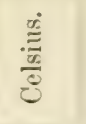 & 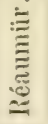 & 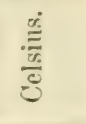 \\
\hline & & " & 1) & " & 0 & 0 & " & "1) & " & " \\
\hline 4 & - & 20,00 & 33 & $(0,56$ & 70 & 21,11 & 1 & 1,25 & 38 & 47.50 \\
\hline-3 & - & 19,44 & 34 & 1,11 & 71 & 21,67 & 2 & 2,50 & 39 & 48,75 \\
\hline-2 & - & 18,89 & 35 & 1.67 & 72 & 2.2 .22 & 3 & 3,75 & 40 & 50.00 \\
\hline & - & 18,33 & 36 & 2,22 & 73 & 22.78 & 4 & 5.010 & 41 & 51,25 \\
\hline 0 & - & $17.6 \mathrm{~s}$ & 37 & 2.75 & 74 & 23.33 & 5) & 6.25 & 42 & 52.50 \\
\hline 1 & - & $17,2: 2$ & 38 & $3.3: 3$ & 75 & 23.89 & 6 & 7.50 & 43 & 53.75 \\
\hline 2 & - & 16,67 & 39 & 3,89 & 76 & 24,44 & 7 & $\times, 75$ & $4 t$ & $5.5,00$ \\
\hline 3 & - & 16,11 & 40 & 4.44 & 77 & 25,00 & is & $10,(10)$ & 45 & $5(1,25$ \\
\hline 4 & - & 15.56 & +1 & 5,00 & 78 & 25.56 & 9 & 11.2 .7 & 46 & 57.50 \\
\hline 5 & - & 15,00 & 42 & 5.56 & 79 & 26,11 & 10 & 12.50 & 47 & 58.75 \\
\hline 6 & - & 14.44 & 43 & (6.11 & so & 215,67 & 11 & 13.7 .5 & 4s & (.) 11.110$)$ \\
\hline 7 & - & $13,5 !$ & 44 & $6,67 \%$ & 81 & 27.22 & 12 & $15,(1)$ & $4 !$ & 61,25 \\
\hline 8 & - & 13,33 & 45 & 7.2 .2 & 82 & 27.78 & 13 & 16.2 .5 & in & 62,50 \\
\hline 9 & - & 12,78 & 46 & 7.78 & 83 & $2-2 x .3: 3$ & 14 & 17.50 & 51 & $(i 3.75)$ \\
\hline 10 & - & 12,222 & 47 & 8,33 & St & 25.59 & 15 & 18.75 & 52. & 65,00 \\
\hline 11 & - & 11,67 & 48 & 8,59 & 85 & 29.44 & 16 & 20,00 & 53 & 66,25 \\
\hline 12 & - & 11,11 & 49 & 9,44 & $x 6 ;$ & 30,000 & 17 & 21,25 & 54 & 67,50 \\
\hline 13 & - & 10,56 & 50 & 10.00 & 87 & 30.56 & 18 & 22,50 & 55 & 68,75 \\
\hline 14 & - & 10,00 & 51 & 10,56 & 88 & 31,11 & 19 & 28.75 & 56 & 70,00 \\
\hline 15 & - & 9,44 & 52 & 11,11 & 89 & 31,67 & 20 & $25,(10)$ & 57 & 71.25 \\
\hline 16 & - & 8.89 & $5: 3$ & $11,6 \%$ & (10) & $3: 22$ & 21 & 265.25 & is & i2..io \\
\hline 17 & - & 8,33 & 54 & 12.22 & 91 & 32,78 & 22 & 27.50 & 59 & 73.7 .5 \\
\hline 18 & - & 7.78 & 55 & 12.78 & 92 & 33.33 & 23 & 28.75 & (6) & $7 \pi .0111$ \\
\hline 19 & - & 7.22 & 56 & 13.33 & 93 & 33,54 & 24 & 30.00 & 61 & 76,25 \\
\hline 20 & - & 6,67 & $\pi$ & 13,59 & 94 & 34.44 & 25 & 31,25 & fi2 & $77 ., 0)$ \\
\hline 21 & - & 6.11 & $5 s$ & 14,44 & 95 & 35,000 & 26 & $32,51)$ & 6.3 & $78.7)$ \\
\hline 22 & - & 5.56 & 59 & 15.00 & 96 & 35,56 & 27 & $33, \pi 5$ & 6.4 & $80,(1) 0$ \\
\hline 23 & - & 5,00 & 60 & $15,5 \overline{6}$ & 97 & 36,11 & 28 & 35,00 & 65 & 81,25 \\
\hline 24 & - & 4,44 & 61 & 16,11 & 98 & 36,67 & 29 & 36,25 & 66 & 82,50 \\
\hline 25 & - & 3,53 & 62 & 16,67 & 99 & 37.22 & 30 & 37,50 & 67 & -3.75 \\
\hline 26 & - & 3,33 & 63 & 17,22 & 100 & 37,78 & 31 & 38,75 & 68 & 85,00 \\
\hline 27 & - & 2,78 & 64 & 17,78 & 101 & 38,33 & 32 & 40,00 & 70 & 87,50 \\
\hline 28 & - & 2,22 & 65 & 18,33 & 102 & 38,89 & 33 & $\$ 1,25$ & 72 & 90,00 \\
\hline 29 & - & 1,67 & $66 i$ & 18.58 & 10.3 & $3: 1,44$ & 34 & 42,50 & 74 & $(y-\ldots)$ \\
\hline 30 & - & 1,11 & 67 & 19,44 & 104 & 40,00 & 35 & 43,75 & 76 & 95,00 \\
\hline 31 & - & 0,56 & 68 & 20,00 & 105 & 40,56 & 36 & 45,00 & 78 & 97,50 \\
\hline 32 & - & 0,00 & 69 & 20,56 & 106 & 41,11 & 37 & 46,25 & 80 & 100,00 \\
\hline
\end{tabular}




\section{TAFEL VII.}

\section{Paychrometrische Tabellen.}

Die folgenden Tabellen sind für einen Luftdruck von $760 \mathrm{~mm}$ berechnet; sie können aber ohne merklichen Fehler auch für Barometerstände bis auf $700 \mathrm{~mm}$ herunter gebraucht werden, und selbst bis zu $600 \mathrm{~mm}$ sind die Fehler, welche ihre Anwendung verursacht, nicht beträchtlich. Nehmen wir z. B. an, die Ablesung am befeuchteten Thermometer habe $10^{\prime \prime}$ ergeben und die Differenz zwischen beiden Thermometern sei $5^{0}$. Nun liefert die Tabelle für $760 \mathrm{~mm}$ Luftdruck folgende Zahlen:

Dunstdruck $6,2 \mathrm{~mm}$. Relative Feuchtigkeit $48 \%$. Thaupunkt $4,1^{0}$ (vgl. oben S. 418).

Bei denselben Angaben des Psychrometers, aber einem Luftdruck von $660 \mathrm{~mm}$ hat man :

I) unstdruck $6,5 \mathrm{~mm}$. Relative Feuchtigkeit $58 \%$. Thaupunkt $4,9^{0}$.

Die anzubringenden Korrektionen sind folgende:

$1^{\circ}$ Dic Dunstdruck-Korrelition ist für alle Temperaturen dieselbe, nämlich für je $100 \mathrm{~mm}$ Verminderung des Luftdrucks unter $700 \mathrm{~mm}$ und für je $1^{0}$ Temperaturdifferenz $=+0,06 \mathrm{~mm}$. So z. B. hat man bei $500 \mathrm{~mm}$ Luftdruck und $7^{0}$ Temperaturdifferenz die Angaben der Tabelle zu vermehren um

$$
0,06 \cdot 2,60 \cdot 7=1,1 \mathrm{~mm} .
$$

2" Die Korrelition fïr die relative Fenchtiglieit variirt mit der Temperatur. Für je $100 \mathrm{~mm}$ Verminderung des Luftdrucks unter $760 \mathrm{~mm}$ und $1^{0}$ Temperaturdifferenz des trockenen Thermometers hat man folgende Prozente zu addiren: 


\begin{tabular}{|c|c|c|c|c|c|}
\hline Grad & $\%$ & Grad & $\%$ & Grad & $\%$ \\
\hline-30 & 8,6 & -7 & 2,2 & 17 & 0,4 \\
\hline-29 & 8,4 & -6 & 2,0 & 18 & 0,4 \\
\hline-28 & 8,2 & -5 & 1,9 & 19 & 0,4 \\
\hline-27 & 8,0 & -4 & 1,8 & 20 & 0,3 \\
\hline-26 & 7,8 & -3 & 1,6 & 21 & 0,3 \\
\hline-25 & 7,6 & -2 & $1, \tilde{5}$ & 22 & 0,3 \\
\hline-24 & 7,4 & -1 & 1,4 & 23 & 0,3 \\
\hline-23 & 7,2 & 0 & 1,3 & 24 & 0,3 \\
\hline-22 & 7,0 & 1 & 1,2 & 25 & 0,3 \\
\hline-21 & 6,8 & 2 & 1,1 & 26 & 0,2 \\
\hline-20 & 6,6 & 3 & 1,1 & 27 & 0,2 \\
\hline-19 & 6,3 & \pm & 1,0 & 28 & 0,2 \\
\hline-18 & 5,9 & 5 & 0,9 & 29 & 0,2 \\
\hline-17 & 5,4 & 6 & 0,9 & 30 & 0,2 \\
\hline-16 & 5,0 & 7 & 0,8 & 31 & 0,2 \\
\hline-15 & 4,7 & 8 & 0,7 & 32 & 0,2 \\
\hline-14 & 4,3 & 9 & 0,7 & 33 & 0,2 \\
\hline-13 & 4,0 & 10 & 0,7 & 34 & 0,2 \\
\hline-12 & 3,6 & 11 & 0,6 & 35 & 0,1 \\
\hline-11 & 3,2 & 12 & 0,6 & 36 & 0,1 \\
\hline-10 & 2,9 & 13 & 0,5 & 37 & 0,1 \\
\hline 9 & 2,7 & 14 & 0,5 & 38 & 0,1 \\
\hline 8 & $2, \tilde{5}$ & 15 & $0, \overline{5}$ & 39 & 0,1 \\
\hline-8 & 2,4 & 16 & 0,4 & 40 & 0,1 \\
\hline
\end{tabular}

Es wird also die Korrektion bei $500 \mathrm{~mm}$ Luftdruck, $155^{0}$ Lufttemperatur und $7^{0}$ psychrometrischer Differenz (Ablesung am befeuchteten Thermometer $=8^{9}$ ) folgende sein:

$$
0,5 \cdot 2,6 \cdot 7=9 \% \text {. }
$$

Die Tabelle gibt . . . . $30 \%$

Korrektion $\frac{+9 \%}{9 \%}$

Relative Feuchtigkeit $39 \%$. 
Psychrometrische Tabellen.

\begin{tabular}{|c|c|c|c|c|c|c|c|c|c|}
\hline \multirow{3}{*}{ 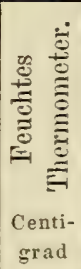 } & \multicolumn{9}{|c|}{ Differenz der beiden Thermometer. } \\
\hline & \multicolumn{3}{|c|}{00} & \multicolumn{3}{|c|}{10} & \multicolumn{3}{|c|}{20} \\
\hline & 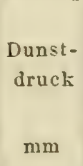 & 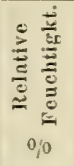 & 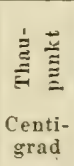 & $\begin{array}{l}\text { Dunst- } \\
\text { druck }\end{array}$ & 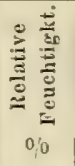 & 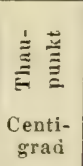 & $\begin{array}{l}\text { Dunst- } \\
\text { druck } \\
\text { mm }\end{array}$ & 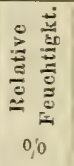 & $\begin{array}{c}\stackrel{\Xi}{\Xi} \\
\text { Centi- } \\
\text { grad }\end{array}$ \\
\hline 30 & 31.5 & 100 & 30.0 & 30.9 & 93 & 29.6 & 30.3 & 86 & 29.3 \\
\hline 29 & 29.8 & 100 & 29.0 & 29.2 & 92 & 28.6 & 28.5 & 85 & $2 \circlearrowleft .3$ \\
\hline 28 & 28.1 & 100 & 28.0 & 27.5 & 92 & 27.6 & 26.9 & 85 & 27.2 \\
\hline 27 & 26.5 & 100 & 27.0 & 25.9 & 92 & 26.6 & 25.3 & \$5๊ & 26.2 \\
\hline 26 & 25.0 & 100 & 26.0 & 24.4 & 92 & 25.6 & 23.7 & 85 & 25.1 \\
\hline 25 & 23.5 & 100 & 25.0 & 22.9 & 92 & 24.6 & 22.3 & 84 & 24.1 \\
\hline 24 & 22.2 & 100 & 24.0 & 21.6 & 92 & 23.5 & 21.0 & 84 & 28.0 \\
\hline 23 & 20.9 & 100 & 23.0 & 20.3 & 91 & 22.5 & 19.7 & 83 & 22.0 \\
\hline 22 & 19.7 & 100 & 22.0 & 19.0 & 91 & 21.5 & 18.4 & S3 & 20.9 \\
\hline 21 & 18.5 & 100 & 21.0 & 17.9 & 91 & 20.4 & 17.3 & 83 & 19.9 \\
\hline 20 & 17.4 & 100 & 20.0 & 16.8 & 91 & 19.4 & 16.2 & 82 & 18.8 \\
\hline 19 & 16.4 & 100 & 19.0 & 15.7 & 91 & $1 s .4$ & 15.1 & 82 & 17.8 \\
\hline 18 & 15.4 & 100 & 18.0 & 14.5 & 90 & 17.4 & 14.1 & 81 & 16.7 \\
\hline 17 & 14.4 & 100 & 17.0 & 13.5 & 90 & 16.3 & 13.2 & 81 & 15.6 \\
\hline 16 & $13 . \overline{5}$ & 100 & 16.0 & 12.9 & 90 & 15.3 & 12.3 & so & $14 . \overline{5}$ \\
\hline 15 & 12.7 & 100 & 15.0 & 12.1 & 59 & $1+.2$ & $11 . \overline{5}$ & 80 & 13.4 \\
\hline 14 & 11.9 & 100 & 14.0 & 11.3 & $\mathrm{~S} 9$ & 13.2 & 10.7 & 79 & 12.3 \\
\hline 13 & 11.2 & 100 & 13.0 & 10.6 & 89 & 12.1 & 10.0 & 78 & 11.2 \\
\hline 12 & 10.5 & 100 & 12.0 & 9.9 & so & 11.1 & 9.3 & 78 & 10.1 \\
\hline 11 & 9.5 & 100 & 11.0 & 9.2 & 88 & 10.0 & 8.6 & 77 & 9.0 \\
\hline 10 & 9.2 & 100 & 10.0 & 8.6 & 87 & 9.0 & 8.0 & 76 & 7.9 \\
\hline 9 & 8.6 & 100 & 9.0 & 8.0 & 86 & 7.9 & 7.4 & 75 & 6.8 \\
\hline 8 & 8.0 & 100 & 8.0 & 7.4 & 86 & 6.9 & 6.8 & 74 & 5.6 \\
\hline 7 & 7.5 & 100 & 7.0 & 6.9 & 86 & 5.8 & 6.3 & 73 & 4.5 \\
\hline 6 & 7.0 & 100 & 6.0 & 6.4 & 85 & 4.7 & 5.8 & 72 & 3.3 \\
\hline 5 & $6 . \overline{5}$ & 100 & 5. 0 & 5.9 & 85 & 3.6 & 5.3 & 71 & 2.1 \\
\hline 4 & 6.1 & 100 & 4.0 & 5.5 & $8 t$ & 2.5 & 4.9 & 70 & 0.9 \\
\hline 3 & 5.7 & 100 & 3.0 & 5.1 & 83 & 1.5 & 4.5 & 69 & -0.3 \\
\hline 2 & 5.3 & 100 & 2.0 & 4.7 & 83 & 0.3 & 4.1 & 67 & -1.5 \\
\hline 1 & 4.9 & 100 & 1.0 & 4.4 & 82 & -0.7 & 3.5 & 66 & $-2 . \overline{6}$ \\
\hline 0 & 4.6 & 100 & 0.0 & 4.0 & 81 & -1.8 & 3.4 & 64 & -3.9 \\
\hline
\end{tabular}


Psychrometrische Tabellen.

\begin{tabular}{|c|c|c|c|c|c|c|c|c|c|}
\hline \multirow{3}{*}{ 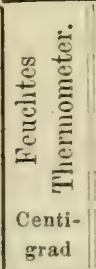 } & \multicolumn{9}{|c|}{ Differenz der beiden Thermometer. } \\
\hline & \multicolumn{3}{|c|}{$0^{\circ}$} & \multicolumn{3}{|c|}{10} & \multicolumn{3}{|c|}{20} \\
\hline & $\begin{array}{c}\text { Dunst- } \\
\text { druck } \\
\text { mm }\end{array} \mid$ & 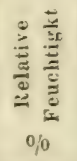 & 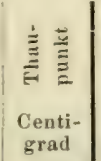 & \begin{tabular}{|l} 
Dunst- \\
druck \\
$\mathrm{mm}$
\end{tabular} & 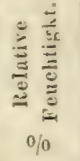 & $\begin{array}{c}\text { Centi- } \\
\text { grad }\end{array}$ & \begin{tabular}{|} 
Dunst- \\
druek \\
$\mathrm{mm}$
\end{tabular} & 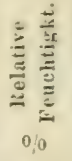 & 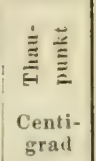 \\
\hline-0 & 4.6 & 100 & -0.0 & 4.1 & 82 & -1.7 & 3.5 & 67 & -3.5 \\
\hline-1 & 4.3 & 100 & -1.0 & 3.7 & 81 & -2.8 & 3.2 & 65 & -4.6 \\
\hline-2 & 4.0 & 100 & -2.0 & 3.4 & 80 & -3.8 & 2.9 & 63 & -5.9 \\
\hline-3 & 3.7 & 100 & -3.0 & 3.1 & 79 & -5.0 & 2.6 & 61 & -7.3 \\
\hline-4 & 3.4 . & 100 & -4.0 & 2.9 & 78 & -6.1 & 2.3 & 59 & -8.6 \\
\hline-5 & 3.1 & 100 & -5.0 & 2.6 & 77 & -7.3 & 2.1 & 57 & -9.9 \\
\hline-61 & 2.9 & 100 & -6.0 & 2.4 & 76 & $-8.4 \mid$ & 1.9 & 55 & -11.4 \\
\hline-7 & 2.7 & 100 & -7.0 & 2.2 & 74 & -9.6 & 1.6 & 52 & -13.0 \\
\hline-8 & 2.5 & 100 & -8.0 & 1.9 & 73 & -10.9 & $1 . t$ & 49 & $-14 . \overline{7}$ \\
\hline$-9 !$ & 2.3 & 100 & -9 & 1.7 & 71 & -12.2 & 1.2 & 46 & -16.5 \\
\hline-10 & 2.1 & 100 & $-100 \mid$ & 1.6 & 69 & -13.6 & 1.0 & 42 & -18.5 \\
\hline-11 & 1.9 & 100 & $-11.0 \mid$ & 1.4 & 67 & -14.9 & 0.9 & 39 & -20.4 \\
\hline-12 & 1.8 & 100 & $-12.0 \mid$ & 1.3 & 65 & -16.2 & 0.7 & 35 & -22.6 \\
\hline-13 & 1.6 & 100 & $-13.0 \mid$ & 1.1 & 63 & -17.7 & 0.6 & 31 & -24.8 \\
\hline-14 & 1.5 & 100 & $-14.0 \mid$ & 1.0 & 61 & -19.0 & 0.5 & 27 & -27.5 \\
\hline-15 & 1.4 & 100 & $\mid-15 .(1 \mid$ & 0.9 & 58 & -20.6 & $0 . t$ & 22 & -30.3 \\
\hline-16 & 1.3 & 100 & $|-16.0|$ & 0.8 & 55 & $|-22.1|$ & 0.3 & 16 & -33.9 \\
\hline-17 & 1.2 & 100 & -17.0 & 0.7 & 52 & -23.7 & 0.2 & 11 & \\
\hline-18 & 1.1 & 100 & -18.0 & 0.6 & 48 & -25.4 & 0.1 & 4 & \\
\hline-19 & 1.0 & 100 & -19.0 & 0.5 & 45 & -27.3 & & & \\
\hline-20 & 0.9 & 100 & -20.0 & 0.4 & 40 & -29.2 & & & \\
\hline-21 & 0.8 & 100 & $|-21.0|$ & 0.3 & 36 & $-31.2 \mid$ & & & \\
\hline-22 & 0.8 & 100 & -22.0 & 0.3 & 31 & -33.5 & & - & \\
\hline-23 & 0.7 & 100 & -23.0 & 0.2 & 25 & & & & \\
\hline-24 & 0.6 & 100 & $\mid-24.0$ & 0.1 & 19 & & & & \\
\hline-25 & 0.6 & 100 & $|-25.0|$ & 0.1 & 12 & & & & \\
\hline-26 & 0.5 & 100 & $|-26.0|$ & & & & & & \\
\hline-27 & 0.5 & 100 & -27.0 & & & & & & \\
\hline-28 & $0 . \bar{j}$ & 100 & -28.0 & & & & & & \\
\hline-29 & 0.4 & 100 & -29.0 & & & & & & \\
\hline-30 & 0.4 & 100 & $|-30.0|$ & & & & & & \\
\hline
\end{tabular}


Psychrometrische Tabellen.

\begin{tabular}{|c|c|c|c|c|c|c|c|c|c|}
\hline \multirow{3}{*}{ 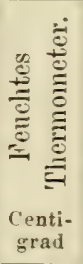 } & \multicolumn{9}{|c|}{ Differenz der beiden 'Thermometer. } \\
\hline & \multicolumn{3}{|c|}{$3^{0}$} & \multicolumn{3}{|c|}{40} & \multicolumn{3}{|c|}{$5^{0}$} \\
\hline & $\begin{array}{l}\text { Dunst- } \\
\text { druck }\end{array}$ & 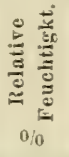 & 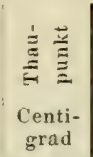 & $\begin{array}{c}\text { Dunst- } \\
\text { druck } \\
\text { mm }\end{array}$ & 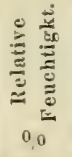 & 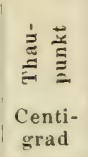 & $\begin{array}{l}\text { Dunst= } \\
\text { druck } \\
\mathrm{mm}\end{array}$ & 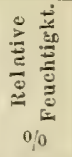 & $\begin{array}{l}\stackrel{\Xi}{\Xi} \\
\text { Centi- } \\
\text { grad }\end{array}$ \\
\hline 30 & $29 . \tilde{\gamma}$ & $7 !$ & 28.9 & & & & & & \\
\hline$\because 9$ & 27.9 & 7:1 & $=7.9$ & 27.3 & 73 & 27.5 & & & \\
\hline $2 x$ & 26.2 & 79 & 26.8 & 27.6 & 72 & 26.1 & 25.0 & 137 & 260 \\
\hline 27 & 24.6 & 78 & 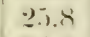 & 2411 & 72 & 25.3 & $\because 3 . \pm$ & 606 & 24.9 \\
\hline $21 ;$ & 23.1 & is & $\because 47$ & 22.5 & 71 & 24.2 & 21.9 & (i) & $2: 3.8$ \\
\hline 35 & 21.7 & 78 & 23.6 & 21.1 & $\pi 1$ & 23.1 & 20.5 & 65 & 22.7 \\
\hline 24 & $2(1,3)$ & it & 2.3 .6 & 19.7 & $71)$ & 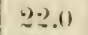 & 19.1 & 64 & (2) \\
\hline $2: 3$ & $1 ! .1)$ & 76 & 21.5 & 18.4 & 699 & $\because() . !$ & 17.8 & 63 & 201.4 \\
\hline$\because 2$ & 17.4 & 76 & 21.4 & 17.2 & (i) & 19.8 & 16.6 & $1 ; 3$ & 14.2 \\
\hline 21 & 16.7 & 15 & 19.3 & 160 & lis & 18.7 & 15.4 & $1 ; 2$ & 18.1 \\
\hline$\approx 11$ & 15.6 & $7 t$ & 18.2 & 14.9 & $6 i \pi$ & $17.1 ;$ & 14.3 & $\$ 1$ & 16.9 \\
\hline $1 !)$ & $14 . \overline{5}$ & 74 & 17.1 & $1: 39$ & liti & 16.5 & 13.: & 60 & 15.7 \\
\hline in & 13.5 & 73 & 16.11 & 12.9 & (iti) & 15.2 & $1 \geq .3$ & $5 !$ & 14.5 \\
\hline $1 \%$ & 12.6 & 7. & 14.9 & 12.0 & (ii.) & $1+.1$ & 11.4 & วิ8 & $1: 3.3$ \\
\hline $16 i$ & 11.7 & 72 & 13.7 & 11.1 & lit & 12.9 & 11).5 & $5 \pi$ & 12.1 \\
\hline 15 & $1(1.9)$ & 71 & 12.6 & 10.3 & (i:3) & 11.7 & 9.7 & 55 & 10.8 \\
\hline 14 & 10.1 & (1) & 11.4 & $\$ .5$ & $6: 2$ & 11.5 & 8.9 & 54 & 9.5 \\
\hline $1: 3$ & 9.3 & $6 ! !$ & $11) .3$ & 87 & li1 & 9.8 & 8.1 & 53 & 8.2 \\
\hline $1 \div$ & $\therefore .6$ & 68 & 9.1 & 8.11 & $5 !$ & 8.0 & 7.4 & 52 & (i.9) \\
\hline 11 & 8.11 & 67 & 7.9 & $\tau t$ & 5র & 6.8 & (i. 8 & 50 & 5.5 \\
\hline 111 & T.t & (ifi & 6.7 & 6.6 & $5 \pi$ & 5.5 & 6.2 & 48 & 4.1 \\
\hline 9 & 6.8 & 6.5 & 5.5 & (i.:) & $5 \overline{11}$ & 4.1 & 5.6 & 47 & 2.7 \\
\hline 8 & 6.2 & (i;) & 4.2 & $5.6 j$ & $5+1$ & $\because 8$ & 5.0 & 45 & 1.2 \\
\hline$\tau$ & 5.7 & $(; 2)$ & (3).1) & 5.1 & $5: 3$ & 1.5 & 4.5 & 43 & $-(1.3$ \\
\hline ij & 5.2 & (i) & $1 . \overline{7}$ & $4.6^{\circ}$ & 50 & 0.0 & 4.0 & $\$ 1$ & -1.9 \\
\hline 5 & 4.7 & 59 & 0.4 & 4.1 & th & -1.4 & 3.5 & 39 & $-2 . t$ \\
\hline$t$ & 4.33 & 57 & -11.9 & 37 & $41 ;$ & -2.8 & :3. 1 & 36 & - 5.1 \\
\hline 3 & 3.9 & $5 i$ & -2.2 & 3.3 & 41 & -4.3 & 2.7 & 34 & -6.8 \\
\hline$\because$ & 3.5 & 54 & -3.5 & 2.9 & 42 & -5.9 & 2.3 & 31 & -8.7 \\
\hline 1 & 3.21 & 52 & -4.9 & $2.6 i$ & 39 & -7.5 & 2.0 & 28 & -10.7 \\
\hline 0 & 2.8 & 50 & -13.3 & 2.2 & 36 & -9.2 & 1.6 & 25 & -13.0 \\
\hline
\end{tabular}


Psychometrische Tabellen.

\begin{tabular}{|c|c|c|c|c|c|c|c|c|c|}
\hline \multirow{3}{*}{$\begin{array}{c}\text { Centi- } \\
\text { grad }\end{array}$} & \multicolumn{9}{|c|}{ Differenz der beiden Thermometer. } \\
\hline & \multicolumn{3}{|c|}{$3^{0}$} & \multicolumn{3}{|c|}{10} & \multicolumn{3}{|c|}{$5^{0}$} \\
\hline & $\begin{array}{l}\text { Dunst- } \\
\text { druck }\end{array}$ & 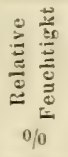 & 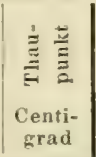 & $\begin{array}{c}\text { Dunst- } \\
\text { druek } \\
\mathrm{mm}\end{array}$ & 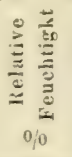 & 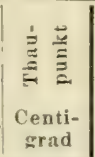 & $\begin{array}{l}\text { D) unst- } \\
\text { druck } \\
\text { mm }\end{array}$ & 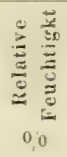 & 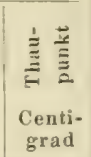 \\
\hline - 0 & 3.1 & ถั:3 & -5.5 & 5 & 4) & -7.5 & 2.0 & $: 3$ & -10.5 \\
\hline-1 & 2.7 & 51 & {$[-6.9]$} & 2.2 & 38 & $1-9.5$ & 1.6 & $2 \pi$ & -129 \\
\hline-2 & $\because .4$ & 48 & -8.4 & 1.9 & 35 & -11.4 & 1.3 & 23 & -15.5 \\
\hline-3 & 2.1 & 45 & -9.9 & 16 & 32 & -13.5 & 1.0 & 19 & -18.4 \\
\hline-4 & 1.8 & 43 & -11.6 & 1.3 & 28 & -15.8 & 0.8 & $1 \tilde{5}$ & -21.7 \\
\hline-5 & 1.6 & 40 & -13.5 & 1.0 & 24 & -18.5 & & & \\
\hline - li. & 1.3 & 36 & -15.5 & 0.8 & 20 & $\mid-1.4$ & & & \\
\hline-7 & 1.1 & 32 & $|-17.7|$ & 0.13 & 16 & -5.0 & & & \\
\hline-8 & 0.9 & 3. & $-2(1.2)$ & 1). 4 & 11 & -29.8 & & & \\
\hline-9 & 0.7 & 24 & -23.1 & 0.2 & 6 & & & & \\
\hline-10 & 0.5 & 20 & -26.4 & & & & & & \\
\hline-11 & 0.4 & 15 & -30.3 & & & & & & \\
\hline-12 & 0.2 & 10) & -37.0 & & & & & & \\
\hline-13 & 0.1 & $t$ & & & & & & & \\
\hline
\end{tabular}


Psychrometrische Tabellen.

\begin{tabular}{|c|c|c|c|c|c|c|c|c|c|}
\hline \multirow{3}{*}{ 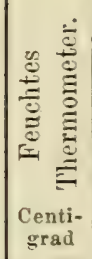 } & \multicolumn{9}{|c|}{ Differenz der beiden Thermometer. } \\
\hline & \multicolumn{3}{|c|}{$6^{0}$} & \multicolumn{3}{|c|}{$\pi^{0}$} & \multicolumn{3}{|c|}{$8^{0}$} \\
\hline & $\begin{array}{c}\text { Dunst- } \\
\text { druck } \\
\text { mm }\end{array}$ & 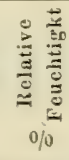 & 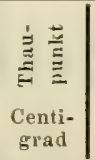 & $\begin{array}{c}\text { Dunst- } \\
\text { druck } \\
\text { mm }\end{array}$ & 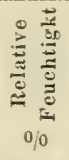 & $\left|\begin{array}{c}0 \\
\text { Centi- } \\
\text { grad }\end{array}\right|$ & $\begin{array}{l}\text { Dunst- } \\
\text { druck } \\
\mathrm{mm}\end{array}$ & 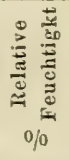 & $\begin{array}{c}\text { Centi- } \\
\text { grad }\end{array}$ \\
\hline 27 & 22.8 & 61 & 24.4 & & & & & & \\
\hline $\begin{array}{l}26 \\
25\end{array}$ & $\begin{array}{l}21.3 \\
19.5\end{array}$ & $\begin{array}{l}60 \\
59\end{array}$ & $\begin{array}{l}23.3 \\
2.3 .1\end{array}$ & $\begin{array}{l}20.6 \\
19.2\end{array}$ & $\begin{array}{l}55 \\
54\end{array}$ & $\begin{array}{l}22.8 \\
21.6\end{array}$ & 18.6 & 50 & 21.1 \\
\hline 24 & 18.5 & 59 & 21.0 & 17.9 & 53 & 20.4 & 17.2 & 49 & 19.9 \\
\hline 23 & 17 & 58 & 19.8 & & 53 & 19.2 & 16 & 48 & 18.6 \\
\hline 22 & 16.0 & 57 & 18.6 & 15 & 52 & 18.0 & 14 & 47 & 17.3 \\
\hline 21 & 14.8 & 56 & 17.5 & 14.2 & 51 & 16.7 & 13.6 & 46 & 16.0 \\
\hline 20 & 13.7 & อ๊ & 16.2 & 13.1 & 49 & 15.5 & 12.5 & 44 & 14.7 \\
\hline 19 & 12.7 & 54 & 14.9 & 12.1 & 48 & 14.2 & 11 & 43 & 13.4 \\
\hline 18 & 11.7 & 53 & 13.7 & 11 & 47 & 12.9 & 10. & 42 & 12.0 \\
\hline 17 & 10.8 & 52 & 12.5 & 10 & 46 & 11.5 & 9. & 40 & 10.6 \\
\hline 16 & 9 & 50 & 11.1 & 9 & 44 & 10.2 & 8. & 39 & 9.2 \\
\hline 15 & 9.1 & 49 & 9.8 & 8.4 & 43 & 8.8 & 7. & 37 & 7.7 \\
\hline 14 & 8. & 47 & 8.4 & $\tau$. & 41 & 7.3 & 7. & 36 & 6.1 \\
\hline 13 & & 4 & 7.1 & & 40 & 5.8 & 6 & $3 t$ & 45 \\
\hline 12 & 6 & $t$ & 5.6 & 6 & 3 & 4.3 & 5 & 32 & 2.8 \\
\hline 11 & 6.2 & 43 & 4.1 & 5.8 & 36 & 2.7 & 5. & 30 & 1.0 \\
\hline 10 & 6.5 & 41 & 2.6 & 4.9 & 34 & 1.0 & 4.3 & 28 & -0.8 \\
\hline 9 & 5. & 39 & 1.1 & 4 & 32 & -0.7 & 3. & 26 & -2.7 \\
\hline 8 & 4 & 37 & -0.6 & 3 & 30 & -2.5 & 3. & 24 & -4.7 \\
\hline 7 & 3. & 35 & $|-2.2|$ & 3 & 28 & -4.4 & 2.7 & 21 & -6.9 \\
\hline 6 & 3. & 33 & -4.0 & 2. & 25 & -6.4 & 2.2 & 18 & -9.3 \\
\hline 5 & 2.9 & 30 & -5.8 & 2.3 & 22 & -8.6 & 1.7 & 16 & -12.2 \\
\hline 4 & 2.5 & 28 & $-7.7 \mid$ & 1.9 & 19 & $\mid-11.0$ & 1.3 & 13 & -15.7 \\
\hline 3 & 2 & 25 & -9.8 & 1. & 16 & -139 & 0. & 9 & - 20.0 \\
\hline 2 & 1. & 22 & -12.3 & 1. & 13 & -17.5 & 0.5 & 6 & -26 \\
\hline 1 & 1. & 18 & $|-15.1|$ & 0. & 10 & -21.8 & 0.2 & 2 & \\
\hline 0 & 1.0 & 15 & -18.5 & 0.4 & 6 & -28.0 & & & \\
\hline-0 & $1 . t$ & 20 & $\mid-15.1$ & 0.9 & 12 & & & & \\
\hline-1 & 1. & 17 & -17.5 & & & & & & \\
\hline-2 & 0.8 & 13 & -21. & & & & & & \\
\hline
\end{tabular}


Psychrometrische Tabellen.

\begin{tabular}{|c|c|c|c|c|c|c|c|c|c|}
\hline \multirow{3}{*}{ 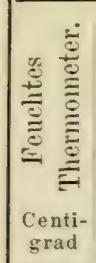 } & \multicolumn{9}{|c|}{ Differenz der beiden Thermometer. } \\
\hline & \multicolumn{3}{|c|}{$9^{\prime \prime}$} & \multicolumn{3}{|c|}{$10^{3}$} & \multicolumn{3}{|c|}{$11^{0}$} \\
\hline & $\begin{array}{l}\text { Dunst- } \\
\text { druck } \\
\text { mm }\end{array}$ & 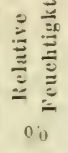 & 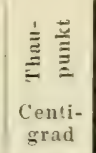 & $\begin{array}{l}\text { Dunst- } \\
\text { druek } \\
\text { mm }\end{array}$ & 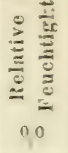 & $\begin{array}{c}\text { Centi- } \\
\text { grad } \\
\text { crien }\end{array}$ & $\begin{array}{l}\text { Dunst- } \\
\text { druck } \\
\text { mm }\end{array}$ & 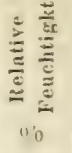 & 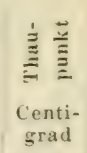 \\
\hline 24 & $16.1 ;$ & 44 & $1 !: ; 3$ & & & & & & \\
\hline $2: 3$ & 15.3 & $4: 3$ & $1-.11$ & 14.7 & $: 3 !$ & $17 . ;$ & & & \\
\hline 22 & 14.1 & $4:$ & $16 . \tau$ & $1: 3.5$ & $3 x$ & 16.11 & 12.9 & :it & $15 .:$ \\
\hline$\because 1$ & 13.0 & 41 & $1 . \overline{.3}$ & $12 .+4$ & 37 & $1+6 i$ & 11 ; & :3:3 & $13 \pi$ \\
\hline $2 !$ & 11.9 & $4(1$ & $1: 3.9$ & $11 . ;$ & if & 13.1 & $11.1 i$ & $: \because 2$ & 12.3 \\
\hline 19 & 10.8 & $8 !$ & $1 \because .5$ & 10.2 & 34 & $11 . i ;$ & 9.6 & $: 31$ & 10.7 \\
\hline 18 & 9.9 & 37 & 11.1 & 9.2 & :3:3 & 111.1 & $8.6 i$ & 29 & $! 1.1$ \\
\hline 17 & 8.9 & 36 & $\because .6$ & 8.3 & $: 1$ & 5.5 & $\tau . \tau$ & 27 & T.4 \\
\hline 16 & $\therefore .1$ & 34 & $\therefore 1$ & $7 . t$ & 30 & li.4) & 6.5 & $\therefore 6$ & $5.1 i$ \\
\hline 15 & $\tau .2$ & :3:3 & 6.5 & 6.6 & 28 & $\overline{5} .2$ & (i.1) & $\therefore 4$ & $\because 3.8$ \\
\hline 14 & 6.4 & 31 & 4.5 & 5.8 & $26 ;$ & 3.4 & 5.2 & 29 & 1.8 \\
\hline 13 & $5 . \tilde{~}$ & $\because 9$ & 3.11 & 5.1 & 25 & 1.4 & 4.5 & 211 & -11.3 \\
\hline 12 & 5.11 & $\geqslant T$ & 1.2 & 4.4 & $2-3$ & $-11.1 i$ & 3.5 & 15 & -2.5 \\
\hline 11 & 4.4 & 95 & -0.7 & 3.7 & $\approx 11$ & $-2 . \tau$ & 3.1 & 16 & -5.11 \\
\hline 10) & 3.7 & 93 & -2.8 & 3.1 & 18 & $-5.1)$ & 2.5 & 14 & -7.7 \\
\hline 9 & $3 . ?$ & 20 & -4.9 & $2 . \overline{3}$ & $16 j$ & - - & 1.9 & 11 & -10.9 \\
\hline 8 & 2.6 & 18 & -7.3 & 2.11 & 13 & -111.5 & $1 . t$ & 4 & -14.9 \\
\hline 7 & 2.1 & 15 & $-10.1)$ & 1.5 & 11) & -14.2 & 1).9 & 6) & --20.4 \\
\hline if & 1.6 & $1: 3$ & -13.2 & 1.1) & 7 & -18.4 & 11.4 & ;) & -24.2 \\
\hline$\tilde{5}$ & 1.1 & $11)$ & -17.4 & 0.5 & $t$ & -26.0 & & & \\
\hline
\end{tabular}




\section{T'AFEL VIII.}

\section{MIÜNZEN.}

\section{a) Gold- mud Silbermünzen der wichtigsten Lünder.}

In nachstehendem Verzeichniss geben wir den Werth der Rechnungsmünze, bezichungsweise der Münzeinheit, eines jeden der genannten Länder sowohl iu Franken als in deutschen Reichsmark. Unter a) sind die Goldmünzen, unter b) dieSilbermünzen aufgeführt. Die denNennwerth in Klammern oder narh Gleichheitszeichen beigesetzten Zablen geben in Franken den Metallwerth der einzelnen Stücke nach deren Feingehalt an.

Belgien. Rechnungsmünze: der Frane von 100 Centimes $=0,81$ Mark.

a) Cioldstücke vom 20 und 10 Franes in Werthe von 20 und $10 \mathrm{Fr}$.

b) Silbermünzen ron 5 Franes (5 Fr.), 2 Franes (Fr. 1.86), 1 Franc (Fr. 0.93) und 50 Centimes (Fr. 0. 46).

Brasilien. Rechuungsmïnze : ler Wilreis $=$ Fr. 2,४316 = 2,2936 Mark;

a) 20000Reïs $=$ Fr. 56.63; 10000 Reïs $=$ Fr. 28.32; 5000 Reïs =Fr. 14.16;

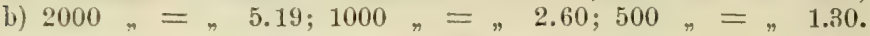

Britisch-Indien. Rechnungsmünze: lie Ruppie $=$ Fr. $2,3757=1,9243 \mathrm{Mk}$.

a) 15 Ruppien 1 Mohur $)=$ Fr.36.83; 10 Ruppien( $2 / 3$ Iohur $)=$ Fr.24.55; $5 \quad,(1 / 3$ Mohur $)=, 12.28$.

b) 1 Ruppie = Fr. 2.38; $1 / 2$ Puppie = Fr. 1. 19;1/4 Ruppie = Fr.0.59; $1 / 8,=\pi 0.30$.

Chili. Rechnungsmünze: der Peso von 100 Centavos $=\mathrm{Fr} .5=4,05$. Ilk.

a) 10 Pesos $(1$ Condor $)=$ H'r. 47. 28; 5 Pesos (1 Doblon $)=$ Fr. 23.64; $2 \quad(1$ Escudo $)=, 9.45 ; 1$ Peso $=$ Fr. 4. 73.

b) 1 Peso $=$ Fr. 5. - ; 50 Centaros $=$ Fr. 2. 50; 20 Centaros Fr. 1. -; 1 Decimo $=$ Fr. 0. 50;1/2 Decimo $=$ Fr. 0. 25 .

Columbien (Vereinigrte Staten ron Columbien). Iechnungsmünze: der Peso d'oro $=$ Fr. 5. $-=4,05$ Mark.

a) $20 \operatorname{Pesos}(1$ Doppel-Condor) $=$ Fr. 100. - ;
$10 \% \quad(1$ Condor)
$=$ = $50 .-$.

b) 1 Peso $=$ Fr. 5. - ; 2 Decimos $=$ Fr. 0. 93;

1 Decimo $=, 0.46 ; 1 / 2$ Decimo $=, 0.23$.

Dänemark. Rechnungsmünze: lie Krone voll 100 Oere $=$ Fr. 1,388s $=1,125$ Mark.

a) 20 Kronen $=F r \cdot 27.78 ; \quad 10$ Kronen $=$ Fr. 13. 89.

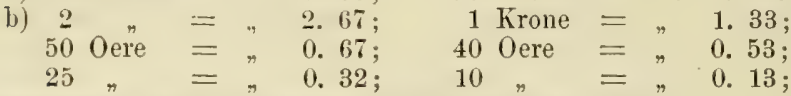

Deutschland. Rechnungsmünze: Die Reichsinark v. 100 Pfg. == Fr. 1,2345.

a) 20 Mark (1 Doppelkrone) = Fr. 24.69;

$10 \leadsto$ (1 Krone) $=$ 12. 35;

$5 \quad=$ Fr. 6. 17.

b) 5 Mark $=$ Fr. 5. 56; 2 Mark $=$ Fr. 2. 22; 1 Mark $=$ Fr. 1. 11; $1 / 2,=\pi 0.56 ; 1 / 5, \quad(20$ Pfennig $)=$ Fr. 0. 22. 
Egypten. Rechungsmïnze: der Piastor rom 411 Paras $=$ Fr. $11.25033=$ 0,2184 Mark.

a) 100 Piaster $=$ Fr. 25. 73; 50 Piaster $=$ Fr. 12. 86 : $25, \quad=-6.43$.

b) 10 Piaster $=$ Fr. 2. 50; 5 Piaster $=$ Fr. 1. 25; $21 / 2 . \quad$ Fr. $0.63 ; \quad 1.0 .25$.

England. Rechnungssmünz: (l+r Livre Sterling ron 20 silsilling = Fr. $25.2213=20.4292$ Mark.

a) 1 Sovereign (Iirre Sterling) $=$ Fr. 25. 22; $1 / 2 \quad \rightarrow \quad(10$ Shillings $)=, 12.61$.

b) 1 Crown (5) shillines $=$ Fr..., 1; 1 2 Crown (21 shillines)=Fr.2.91: 1 Florin $(2,-)=-2.32 ; 1$ Shilling $(12$ Pence $)=-1.16$; 6 Pence $=$ Fr. 0. 58; + Pence $=$ Fr. 0.39; 3 Pence $=$ Fr. 0. 29; $2, \quad=, 0,19 ; 1$ Penny $=, 0.10$.

Frankreich. Jïnzeinheit ller Franc von 100 ('pntimes = 1.51 Mark.

a) Golistïche ron 100 Franes. 50 Frances, 201 Franes, 10 Francs uni 5 Francs (rollwerthig);

b) Silberinünzen von 5 Francs (Fr. 5), 2 Francs (Fr. 1.86), 1 Franc

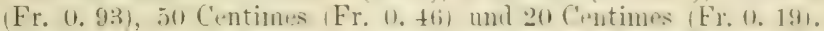

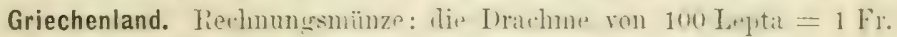
$=0,81$ Mark.

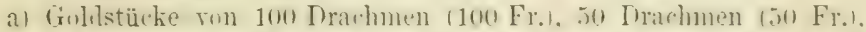

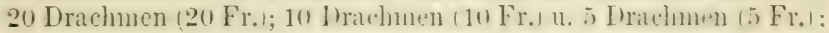

b) Silhermünzen ron 5 Drachnen ì Fr.ı. 2 Inrarhnen (Fr. 1. sli. 1 Drachme (Fr. 0. 93), 50 Lepta (Fr. 0.46) u. 20 Lepta (F. 0. 19), ganz entsprechend den französischen Münzsorten.

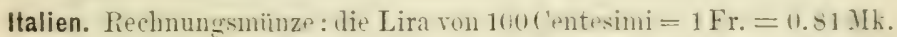

a) Goldstücke ron 100 Lire (100 Fr.), 50 Lire (50 Fr.), 20 Lire (20 Fr.), 10 Lire (10 Fr.) und 5 Lire (5 Fr.);

b) Silbermünzen von 5 Lire (5 Fr.), 2 Lire (Fr. 1. 86), 1 Lira (Fr. 0. 93), 50 Centesimi (Fr. 0. 46) u. 20 Centesimi (Fr. 0. 19), ganz wie in Frankreich.

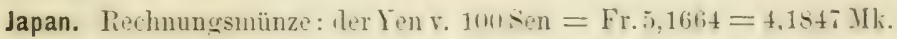

a) 20 Yen $=$ Fr. 103. 33; 10 Yen $=$ Fr. 51.67; 5 Yen $=$ Fr. 25. 83 ; $2 \%=\pi, 10.33 ; 1,=, 5.17$;

b) 1 Yen (Handelsmünze) $=$ Fr. 5. $39: 50$ Sen $=$ Fr. 2. 22; 20 Sen $=$ Fr. 0.89; 10 Sen $=$ Fr. 0.44; 5 Sen $=$ Fr. 0.22.

Mexiko. Rechnungsmünze: Acr Peso ron 1 (r) Centavos $=\mathrm{Fr}, 5,430 \mathrm{~s}=$ 4,3989 Mark.

a) 20 Pesos = Fr. 101. 99; 10 Pesos = Fr. 50. 99; $5, \quad=\% 25.49 ; \quad 21 / 2, \quad \%$ 12. 75 ; $1 \%=\%$ 5. 10 :

l) 1 Peso = Fr. 5.43; 50 Centares = Fr. 2. $11 ; 25$ centaros = Fr. 1.3\%; 10 Centaros $=$ Fr. 0. 54; 5 Centaros $=$ Fr. 0. 27. 
Niederlande. Rechnunssmünze: der hollänlische Gulden (Florin) ron 100 Cents $=$ Fr. 2. $10=1.70$ Mark.

a) 1)oppeldukaten $=$ Fr. 23.66; Dukaten Fr. 11. 83;

Doppel Wilhelmd'or $=$ Fr. 41.72; Wilhelmd'or $=$ Fr.20.86; $1 / 2$ Wilhelud'or $=$ Fr. 10. $43 ; 10$ Gulden $=$ Fr. 20. 83 ;

b) Rixdaler $(21 / 2$ Gulden $)=$ Fr. 5. 25; 1 Gulden $=$ Fr. 2. 10; $1 / 2$ Gulden $=$ Fr. 1.05; 25 Cents $=$ Fr. 0. 51; 10 Cents = Fr. 0. 20; 5े Cents $=$ Fr:0.10.

In den Kolonien (Holläntisch Indien) :

1/. Gulden $=$ Fr.0.51;1/10 Gulden $=$ Fr.0.20;1/20 Gulden $=$ Fr.0.10.

Norwegen. Rechmungsmïnze: der Specieslaler (t Kronen) $=$ Fr. 5,5555 $= \pm, 50$ Mark.

a) 5 Speciesdaler (20 Kronen) $=$ Fr. 27. 78; $21,2 \quad(10, \quad)=, 13.89$;

1) 2 Kronen $=$ Fr.2. 6 i: 1 Krone i 30 slilliners od. 100 Oere $=$ Fr.1.33; 24 Slillings $=$ Fr. 1. 07; 15 Skillings od. 50 Oere $=$ Fr. 0.67; $12 \quad$ od. 40 Oere $=$ Fr. 0.53; 3 Skillings od.100ere $=$ Fr. 0. 13 . Vgl. Dänemark.

Oesterreich-Ungarn. Lierhnungsmünze: der tiuklen von 100 Kreuzer = Fr. $2,4691=2$ Mark.

a) 4 Dukaten $=$ Fr. $47.41 ; 1$ Dukaten $=$ Fr. 11. 85;

8 Gulden $(20 \mathrm{Fr})=.20 \mathrm{Fr} . ; 4$ Gulden $(10 \mathrm{Fr})=.10 \mathrm{Fr}$;

b) 2 Gulden $=$ Fr. 4.94; 1 Gulden $(100$ Kreuzer $)=$ Fr. 2. 47; $1 / 5,=, 0.62$;

20 Kreuzer (geprigt von. 1868 an) $=$ Fr. 0. 29 ;

$10, \quad, \quad, \quad, \quad, \quad, 15$;

In rit-Theresia-Thaler, sug. Levantiner, Handelsmünze = Fr. 5.20 ;

Persien. a) Thoman, 100 Schahis $=$ Fr. 11. 86;

$$
1 / 2,50, \pi=\pi \text { 5. } 93 \text {; }
$$

b) Sachib-Keran, 20 Schahis = Fr. 2.08; Banabat, 10 Schahis=Fr.1.04; Abassis, $\quad 4 n={ }_{n} 0.41$.

Peru. Rechnun@rsmünze: der Sol von 10 Ineros orler 100 Cents $=$ $5 \mathrm{Fr} .= \pm, 05$ Mark.

a) $20 \mathrm{Sols}=100 \mathrm{Fr} . ; 10 \mathrm{Sols}=50 \mathrm{Fr} . ; 5$ Sols $=25 \mathrm{Fr} . ;$

$2 n=10 \% ; 1 \% 5 \%$;

b) $1 \mathrm{siol}=5$ Fr.; $1 / 2,=$ Fr. 2. 50 ;

$1 / 5 \Rightarrow=1 \pi ; 1$ Dinero $=$ Fr. $0.50 ; 1 / 2$ Dinero $=$ Fr. 0. 25.

Philippinen (Spranien). Rechnungsmünze der Duro von 100 Céntavos $=$ Fr. $5,096=4,127$ Mark.

a) Doblon de oro, 4 Pesos $=$ Fr. 20. 39;

Escudo de oro, $2, n=, 10.20$;

Escudillodeoro, $1 "=n$ 5. 10 ;

b) 50 Centavos $=$ Fr. 2. 60; 20 Centavos $=$ Fr. 1. 04;

$10 \pi \quad=\quad 0.52$. 
Portugal. Rechnungsü̈nze: ier Milreïs $=$ Fr. .,.60 $=4,536$ Mark.

a) Krone (Corõa), 10 Milreïs = Fr: 56. - ;

1/2 Krone, 5 Milreîs $=$ Fr. 28. - ; $1 / 5$ Krone, 2 Milreïs $=$ Fr. 11. 20; $1 / 10.1 \%$. 1.60 ;

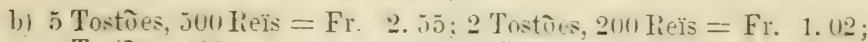
1 Tostão, $100,=0.51 ; 1 / 2$ Tostão, $50,=, 0.25$;

Rumänien. Rechnungsmünze: 1ẹ Lélı $\mathrm{r} .104 \mathrm{Bani}=1 \mathrm{Fr} .=11.81 \mathrm{Mk}$.

a) 20 Léi $=20$ Fr.; 10 Léi $=10$ Fr.; 5 Léi $=5$ Fr.;

b) 2 Léi $=$ Fr. 1.86; 1 Léu $=$ Fr. 0. 93;1/2 Léu $=$ Fr. 0. 46.

Russland. Rechnmosmünze: Aer Pubel ron 10 Kopelen $=4$ Er. $=$ 3,24 Mark.

a) $1 / 2$ Imperial, 5 Rubel $=$ Fr. 20.66; 3 Pubel $=$ Fr. 12. 40;

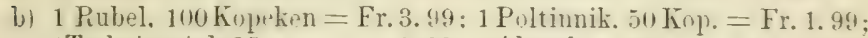
1Tschetrertak, $25 \%=, 0.99 ; 1$ Abassis, $20,=-0.45 ;$ 1Poln.Gulden, $15 \%=\% 0.34 ; 1$ Grivenik, $10 \%=0.23$; 1Pietak, $5, \quad=, 0.11$.

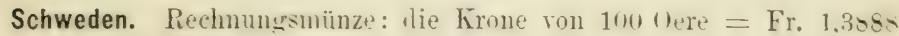
$=1,125$ Mark.

a) 20 Kroner $=$ Fr. 27. 78; 10 Kroner $=$ Fr. 13. 89;

b) $2,=, 2.67 ; 1 \mathrm{Krona}=, 1.33$; 50 Oere $=\pitchfork \quad 0.67 ; 25$ Oere $=m 0.32$; $10=0.13$.

Vgl. Dänemark und Norwegen.

Schweiz (Schweizerische Eirgenossenschaft). Rechnungsmünze: iler Franken von 100 Rappen $=1 \mathrm{Fr}$. $=0,81$ Mark.

Silbermïnzen: Fünffrankenstüık $=5$ Fr.; Zweifrankenst. $=$ Fr. 1. st; Frankenstück $=$ Fr. 0.93; Halbfranken $=$ Fr. 0. 46 .

Spanien. Pechnungsmünze, neue: die Ppseta $=1 \mathrm{Fr}$. = 1.81 . Mark; ältere: der Peso duro (Piaster) $=$ Fr. 5. $20=4,212$ Mark.

a) Doblon, 10 Escudos $=$ Fr. 26. $-;+$ Escudos $=$ Fr. 10. 40;

2 Escudos $=$ Fr. 5. 20;25 Pesetas = Fr. 25. -

b) Duro, $\quad=$ Fr. 5. 20; Escudo, 10 Realen $=$ Fr. 2.60;

5 Pesetas $=$ Fr. 5. - ; 2 Pesetas $=$ Fr. 1. 86;

1 Peseta $=, 0.93 ; 1 / 2$ Peseta $=$, 0.46 ;

Vol. für letztere Münzen Columbien und li* Länder iter lateinischen Münzunion (Belgien, Frankreich, Italien. friechenlant. Rumänien).

Türkei. Rechnungsmünze: der Piaster $==$ Fr. 11,2.2- $5=11.1>4.5$. Mh.

a) 500 Piaster $($ Beutel $)=$ Fr. 113. 92; 250 Piaster $=$ Fr. 56. 96; $100, \quad$ (Pfund) $=, 22.78 ; 50, \quad=n$ 11.39; $25 \quad="$ 5. 70 ;

b) 20 Piaster $=$ Fr. 4. 44; 10 Piaster $=$ Fr. 2. 22 ;

$5, \quad=-1.11 ; 2, \quad=, 0.44$;

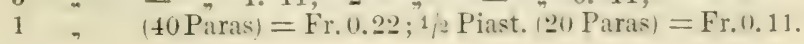


Tunis. Rechnungsmünze: der Piaster $=$ Fr. 0,6194 = 0,5017 Mark.

a) 100 Piaster $=$ Fr. 60. 45; 50 Piaster $=$ Fr. 30. 23;

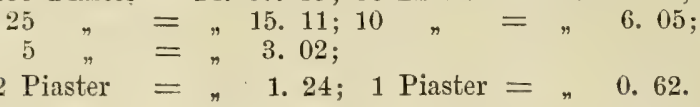

Uruguay. Rechnungsmünze: der Piaster od. Peso $=5 \mathrm{Fr} .=4,05 \mathrm{Mk}$. Silbermünzen: 1 Prso $=5$ Fr.; $1 / 2$ Peso, 50 Centesimos = Fr. 2. 50; 20 Centesimos $=$ Fr. $1 .-; 10$ Centesimos $=$ Fr. 0. 50 . Vgl. Chili lit. b.

Venezuela (Vereinigte Staaten von Venezuela). Rechnungsmünze: der Venezolano $=$ Fr. 5. $-=4,05$ Mark.

a) Bolivar (20 Venezolanos) $=$ Fr. 100; 10 Venezolanos = Fr. 50; 5 Venezolanos $=$ Fr. 25; 1 Venezolano $=$ Fr. 5;

b) 1 Venezolano $=$ Fr. 5. - ; $1 / 2$ Venezolano, 5 Decimos $=$ Fr. 2. 32; 2 Decimos $=$ Fr. 0.93; 1 Decimo $=0.46 ; 5$ Centavos $=$ Fr. 0.23. Vgl. die Bemerkung bei Spanien betreffend Columbien und die Staaten der lateinischen Münzunion.

Vereinigte Staaten von Nordamerika (Nordamerikanische Union). Rechnungsmünze: Der Dollar von 100 Cents $=$ Fr. 5,1825 $=$ 4,1978 Mark.

a) Doppeladler $(20$ Doll. $)=$ Fr. 103. 65; Adler (Eagle, 10 Doll. $)=, \quad 51.83$; Halbadler $\left(1 / 2\right.$ Eagle, $\left.5 D_{0}\right)=" \quad 25.91$; 3 Dollars $=$ Fr. $15.55 ; 1 / 4$ Eagle $(21 / 2$ Dollars $)=$ Fr. 12. 95; 1 Dollar $=$, 5. 18;

b) Tradedollar (Handelsmünze) $=$ Fr. 5, 44; $1 / 2$ Dollar (50 Cents) $=\pi 2.50$; $1 / 4 \%(25 n)=\# 1.25$; 20 Cents = Fr. 1. - ; Dime (10 Cents) Fr. 0. 50.

B. Alphabetisches Terzeichniss der gebränchlichsten Münzen. (Werth in Franken.)

Abassis, Silber, Persien, 4 Schahis, Fr. 0.41. - Abassis, Silber, Russland, 20 Kopeken, 0. 45.

Banu, Kupfer, Rumänien, 0. 01. - Beschlik, Silber, Türkei, 5 Piaster, 1. 11. - Budju, Silber, Algier, 1. 80.

Carolin, Gold, Schweden, 10.00 - Cent, Kupfer, Holland, 1/100 Gulden, 0. 02. - Cent, Kupfer, Union, 1/100 Dollar, 0. 05. - Centime, Kupfer, Frantireich, Belgien, Schweiz, 0. 01. - Centesimo, Kupfer, Itatien, 0. 01. - Christiand'or, Gold, Dänemark, 21.03. - Condor, 
Gold, Chili, 10 Pesos, 47. 28. - Condor, Gold, Columbien, 10 Pesos, 50. 00. - Coròa, Gold, Portugal, 10 Milreîs, 56. 02. - Crown. Silber, England, 5 Shillings, 5. 81.

Decimo, Silber, Chiti, 1/10 Peso, 0. 50. - Dime, Silber, Union, 10 cents. 0. 50. - Dinero, Silber, Peru, 0. 50. - Doblun, Goli, Chizi, 5 Pesos. 23. 24. - Doblon, Gold, Spanien, 10 Escudos, 26. - - Doblon de oro, Gold, Philimpinen, 4 Pesos, 20. 34. - Dollars, Gold, Guatemala, 5. 07. - Dollars, Gold, Union, 100 cents, 5. 18. - Dollars, Silber, Union (Trade-ilollar), 5. 44. - Drachme, Silber, Griechenland, 1. 00. - Ducat ad legem Imperii, Gold, Dänemark, Deutschland, Holland, Oesterreich, Schweden, 11.83. - Duro, Silber. Spanien, 2 Escudos, 5. 20. -

Eagle, Gold, Union, 10 Dollars, 51. 82. - Escudo, Fold, Chiti, 2 Pesos, 9. 46. - Escudo, Silber, Spanien, 10 Realen, 2. 60. Escudo de oro, Gold, Mexico und Philimpinen, 2 Pesos, 10. 20. Escudillo de oro, Golt, Mexico und Ihilippinen, 1 Peso, 5. 10. -

Florin, Silber, England, 2 Shillings, 2. 37. - Florin, Silber, Holland und Oesterreich, vgl. Gulien. - Franc, Silber, Frankreich, Belgien. Schueiz, 1. 00. - Franken, Silber, Schueiz, 1. - Friedrichsd' or. Gold, Dänemark, 20. 48. - Friedrichsd'or, Gold, Preussen, 20. 7s.

Gersch, Silber, Turkei, 1 Piaster, 0. 22. - Groschen (Silbergroschen) Silber, Norddeutschland, $1 / 30$ Thater, 0.125. - Guinee, Rechnungsmünze, England, 26.48. - Gulden, silber, Holluml, 100 cents, 2. 10. Gulden, Silber, Oesterreich, 160 Neukreuzer, 2. 47 (2 Mark). Gulden, Silber, Süddeutschland, 60 Kreuzer, 2. 12.

Halb-Imperial, Gold, Russland, 20. 66. - Jirmilik, Silber, Türliei. 20 Piaster, 4.44. - Jüslik (Medschidieh), Gold. Türlei, 100Piaster22. 80.

Kopeke (Kopeika), Kupfer, İussland, 1/100 Rubel, 0.04.-Kreuzer, Kupfer. Süddeutschland, ${ }_{1 / 60}$ Gulden, 0. 035. - Kreuzer (Nenkrenzer) Kupfor, Oesterreich, 1/100 Gulden, 0.025. - Krone, Rechnungsmünze. T)änemark, Schweden und Norwegen, 1. 39. - 10 Kronen, Gold, Dïnemark, Schweden und Norwegen, 13.89.

Lepton, Kupfer, Griechemland, $1 / 100$ Drachme, 0. 01. - Levantiner Thaler, vgl. Maria-Theresia-Thaler, S. 758. - Lira, Silber, Itrtien. 1. 00. - Lira (Medschidich), Gold, Türliei, 22. so. - Livre Sterling. Rechnungsmünze, England, 25. 22. - Léu, Silber, Rumänien, 1. 0u

Maria-Theresia-Thaler, Silber, Oesterreich, 5. 20. - Mark, Silber, Deutsches Reich, (1/3 Thaler) 1. 23. - 20 Mark, (iold, J)eutsche: Reich, 24.72. - Medschidieh (türkische Lira, Lirre turyue), Golk, 100 Piaster, 22. 80. - Milreïs, Silber, Brasilien, 1000 Reìs, 2. 50. Milreïs, Gold. Portugal, 1000 Reìs, 5. 60. - Mohur, Golil, IritischIndien, 36. 82.

Onça, Gold, Mexilio und Südamerika, 16 Pesos, 81. 37. - Onlik, Silber. Tïrkei, 10 Piaster, 2. 22.

Pagode, Gold, Britisch-Indien, 12. 24. - Para, Knpfer. Türliei, 1/4n Yiaster, 0.006. - Penny, Bronze, Enqland, 0. 11. - Peseta, Silli'r. Spanien, 1. - Peso duro (Peso iuerte, Piaster). Silher. Sifunien. 
2 Escudos, 5. 20. - Peso oder Piaster, Silber, Mexilio und Sïdamerilia, 8 Reales de Plata, 5. 40. - Peso oder Piaster, Silber, Südamerikn (Columbien, Uruguay, Chili), 5. - Pfennig, Kupfer, Deutschland, 0.01. - Pfund Sterling, vgl. Livre Sterling. - Pfund (Medschidieh), Gold, Türkei, 22.80. - Piaster, Silber, Egypten, 0.25.Piaster, Silber, Türliei, to Paras, 0. 22. - Piaster, Silber, Tunis, 0. 62. - Pistole, Gold, Mexiko, 4 Pesos, 20. 38.

Quadrupel, Gold, Amerika, 16 Pesos, 81. 37.

Rappen, Kupfer, Schuceiz, 0.01. - Real de plata, Silber, Amerika, 0. 68. - Real de vellon, Rechnungsmünze, Spanien, 0. 26. Reichsmark, rgl. Wark. - Rigsdaler, Silber, Dënemark, 2.81. Rixdaler, Silber, Holland, 21/2 Gulden, 5. 25. - Rixdaler species, Silber, Schweden, 5. 63. - Rubel, Silber, Russland, 100 Kopeken, 3. 99. - Ruppie, Silber, Britisch-Indien, 2. 33.

Silbergroschen, Sitber, Norddeutschland, 1/30 Thaler, 0. 12. - Shilling, Silber, Englamd, 1. 16. - Skilling, Kupfer, Dänemark, 0. 12. Skilling, Kupfer, Norwegen, 0. 05. - Sol, Silber, Peru, 5. 00. Sovereign, Gold, England, 20 Shillings, 25. 22. - Speciesdaler, Silber, Norwegen, 5. 54.

Tostào, Silber, Portugal, 100 Reïs, (1. 51. - Thaler (Vereinsthaler), Silber, Norddeutschland, 3. 70 (3 Mark). - Two-annas, Silber, Britisch-Indien, 0. 29.

Venezolano, Silber, Venezuela, 5. 00.

Wilhelmd'or, Gold, Holland, 20, 85.

Yen, Gold, Japan, 5. 16. - Yen, Silber, Japan, 5. 39. 


\title{
TAFEL IX.
}

\section{Einige Notizen iber Maasse und Gewichte.}

\author{
a) Metrisches System.
}

Die Grundlage desselben, als Einheit der Längenmaasse, bildet der Meter (Stab), definirt als der zehnmillionte Theil des Erdmeridianquadranten und hienach im letzten Decennium des vorigen Jahrhunderts $\mathrm{zu} 443,296$ Pariser Linien festgesetzt. Letzterer Werth ist noch heute der allgemein guiltige. Er beruht auf den Resultaten der französischen Gradmessung, die sich ron Dünkirchen bis Barcelona erstreckte und wonach der Erdmeridian-Quadrant zu 5130 ito Toisen berechnet wurde. Seitherige Messungen haben jedoch hiefür einen grösseren Werth geliefert und zwar 10000855,765 anstatt zehn Millionen Meter (nach Bessel).

Der Dezimeter $(\mathrm{dm})=0.1$. Ieter, der Centimeter $(\mathrm{cm}$, Neuzoll $)=0,01 \mathrm{~m}$, Millimeter $(\mathrm{mm})=0,001 \mathrm{~m}$.

Der Dekameter (1)m, Kette) $=10 \mathrm{~m}$, der Hektometer $(\mathrm{Hm})=100 \mathrm{~m}$,

Kilometer $(\mathrm{Km})=1000 \mathrm{~m}$, der Myriameter $(\mathrm{Im})=10000 \mathrm{~m}$.

Die Flächenmaasse sinl Quadrate der Längenmaasse: Quadratmeter $\left(\mathrm{m}^{2}\right)$ etc.; Einheit der Landmaasse ist die $\mathrm{Ar}$ (a), ein Quadrat von zehn Meter Seitenlänge oller ler Quadratdekameter $\left(\mathrm{Dm}^{2}\right)=$ $100 \mathrm{~m}^{2}$. Die Centiare (ea) ist gleich 1 Qumiratmeter, die Hektam 1 Quadrat-Hektometer $\left(\mathrm{Hm}^{2}=100 \mathrm{Dm}^{2}=10000 \mathrm{~m}^{2}\right.$, vgl. ohen Seite 72 u. 73). - Der Flücheninhalt ganzer Lünder wird durch Quadratkilometer $\left(\mathrm{K}^{2} \mathrm{~m}^{2}\right)$ und Quadratmyriameter $\left(. \mathrm{(I \textrm {m } ^ { 2 } )}\right.$ aussedrückt.

Die Körpermaasse sind Würfel der Längenmaasse: Kubikmeter $\left(\mathrm{m}^{3}\right)$ etc. Einheit der Hohlmaasse ist der Liter (1, Kanne), ein Würfel von 1 Dezimeter Kantenlänge oder der Kubikilezimeter $\left(\mathrm{dm}^{3}\right)=$ $0,001 \mathrm{~m}^{3}$. Der Deziliter ist $1 / 10$ Liter, der Centiliter $1 / 100 \mathrm{l}$, der Milliliter $1 / 1000 \mathrm{l}=1$ Kubikcentimeter $\left(\mathrm{cm}^{3}\right) ; 1$ J)ekaliter $(\mathrm{Dl})=10 \mathrm{l}$, 1 Hektoliter $(\mathrm{Hl}$, Fass $)=100$ Liter, 1 Kiloliter $(\mathrm{Kl})=1000 \mathrm{l}=$ 1 Kubikmeter. - Als Einheit für die übrigen Raummaasse - Festmaasse - erhielt der Kubikmeter die Bezeichnung Ster (s); 1 DeziSter $(\mathrm{ds})=1 / 10$ Ster, ein Centi-Ster $(\mathrm{cs})=1 / 100$ Ster, 1 Milli-Ster $(\mathrm{ms})=1 / 1000$ Ster $=1$ Liter; 1 Deka-Ster $($ Ds $)=10$ Ster. 1 HektoSter $=100$ Ster, 1 Kilo-Ster $=1000$ Ster $=1$ Kubihilehameter.

Einheit der Gewichte ist das Gramm (g) als Gewicht eines Kubilcentimeters (Milliliters) destillirten Wassers im Zustande seiner grössten Dichtigkeit (bei $+4^{0} \mathrm{C}$ oder $-3,20 \mathrm{R}$ ). Seine Unterabtheilungen sind das ] )ezigramm ( $\mathrm{lg}=0,1 \mathrm{~g}$ ), Centigramm ( $\mathrm{cor}=0.01 \mathrm{gr}$ und Milligramm $(\mathrm{mg}=0,001 \mathrm{~g}=$ Gewicht eines Kubikmillimeter: Wasser); seine Vielfachen sind his Dekagramm (Dg $=10 \mathrm{~g}$, Yeuloth). Hektogramm ( $\mathrm{Hg}=100 \mathrm{~g}$ ) und Kilogramm ( $\mathrm{Kg}=1000 \mathrm{~g}=$ Gewicht eines Liters oder Kubikidezimeters Wasser. Das Kilogrumm ist als Normalgewicht $z u$ betrachten. Zehn Kilogramm sini ein MIrriagramm $(\mathrm{Mg}), 100$ Kilogramm der metrische Centner (C), 1000 hilogramm die Tome ( $\mathrm{T}=$ (Gewicht eines Kubikmeters older Kiloliters W $\mathrm{W}$ asser). 
Die französischen Münzen (beziehungsweise diejenigen der lateinischen Münzunion) schliessen sich hieran in der Weise, dass der Franc als Einheit derselben 5 Gramm Münzsilber von $9 / 10$ Feinheit enthält. Es ist also das Gewicht von 100 Franes gleich 500 gr (ein Pfund), von 200 Francs ein Kilogranm.

B) Englisehe DLaasse und Gerichte.

I) Längenmaasse.

Inch, Zoll $(1 / 36$ Yard $)=2,5400 \mathrm{~cm} ; \quad 1 \mathrm{~cm}=0,3937 \mathrm{engl.} \mathrm{Zoll}$ Foot, Fuss $(1 / 3$ Yard $)=3,0479 \mathrm{dm} ; \quad 1 \mathrm{dm}=0,3281$ engl. Fuss

Yard, Elle $=0,9144 \mathrm{~m} ; \quad 1 \mathrm{~m}=1,0936$ Yards

Fathom, (2 Yards) $=1,8288 \mathrm{~m} ; \quad 1 \mathrm{~m}=0,5968$ Fathom

Pole od. Perch (Ruthe) $=5,0291 \mathrm{~m} ; \quad 1 \mathrm{~m}=0,1988$ Perch

IIile, $(1760$ Yards $)=1,6093 \mathrm{lim} ; 1 \mathrm{Km}=0,6214$ Mile.

\section{2) Flächenmaasse.}

Quadrat-Yard

$=0,8361 \mathrm{~m}^{2}$;

$1 \mathrm{~m}^{2}=1,1960$ Q-Yards

Rod (Quadrat-Ruthe) $=0,2529 \mathrm{a} ; \quad 1 \mathrm{a}=3,9541$ Rods

Rood $(1210$ Q.-Yards $)=10,1168 \mathrm{a} ; \quad 1 \mathrm{a}=0,0988$ Rood

Aere $(4840$ Q.-Yarls $)=0,4047 \mathrm{Ha} ; \quad 1 \mathrm{Ha}=2,4711$ Aeres.

\section{3) Hohlmaasse.}

Pint $(1 / \mathrm{s}$ Gallon $)=0,5679 \mathrm{l} ; \quad 1 \mathrm{l}=1,7608$ pints

Quart $(1 / 4$ Gallon $)=1,13591 ; \quad 1 \mathrm{Dl}=2,2100$ Gallon

Gallon $=4,5435 \mathrm{l} ; \quad 1 \mathrm{Hl}=22,0097$ Gallon

Peck (2 Gallons) $=9,08691 ; \quad 1 \mathrm{~m}^{3}=35,3166$ engl. Kubikfuss

$\operatorname{Bushel}(8, \quad)=36,3477 \mathrm{l}$;

Sack (3 Bushels) $=1,0904 \mathrm{HI}$;

Quarter $(8, \quad)=2,9078 \mathrm{Hl}$.

\section{4) Gewichte.}

1) Troy (Gold-, Silber-, Juwelen- und Medizinalgewicht).

1 Pound-troy à 12 ounces $(o z)=373,2419 \mathrm{gr}$.

1 Ounce-troy à 20 pennyweights $=31,1035 \mathrm{gr}$.

1 Pennyweight (dwt) à 24 grains $=1,5552 \mathrm{gr}$.

1 Grain (gr)

$=6,4799 \mathrm{cgr}$.

2) Avoirdupoids (Handelsgewicht).

1 Ton zu 20 Hundrerlweights $=1016,048 \mathrm{Kgr}$ (1,016 Milliers)

1 Hundredweight (Cwt) zu $12 \mathbb{G}=50,802 \mathrm{Kgr}$.

1 Pound avoirdupoids zu $16 \mathrm{oz}=453,592 \mathrm{gr}$.

1 Ounce avoirdupoids zu 16 drams $=28,349 \mathrm{gr}$.

1 Dran $=1,772 \mathrm{gr}$.

Umgekehrt ist

1 Gramm $=15,432$ Grains-troy $=0,6+3$ Penuyweight,

1 Kilogramm $=2,679$ के troy $=2,205$ \% avoirdupoids. 
C) Aeltere MLasse.

\section{I) Französische.}

1 Pariser Linie

$=2,256 \quad \mathrm{~mm}$

1 Pariser Zoll zu 12 Linien $=2,707 \mathrm{~cm}$

1 Pariser Fuss zu 12 Zoll $=0,32484 \mathrm{~m}$

1 Toise zu 6 Fuss $=1,94904 \mathrm{~m}$

1 Toise carré

$=3,79868 \mathrm{~m}^{2}$

Umgekehrt ist $1 \mathrm{~m}=2,1127$ Pariser Fuss (pieds de roi).

Dass $1 \mathrm{~m}=443,296$ Pariser Linien, wonach

$1 \mathrm{~mm}=0,443$ Pariser Linien,

wurde schon oben bemerkt.

\section{2) Deutsche.}

1 badischer (und schweizerischer) Zoll

1 rheinischer (preussischer) Zoll

$3 \mathrm{~cm}$

1 badischer (u. schweizer.) Fuss zu 10 Zoll

1 hessischer Fuss

1 nassauischer Werkschuh

$2,615 \mathrm{~cm}$

$0,3 \quad \mathrm{~m}$

$0,25 \quad \mathrm{~m}$

1 nassauischer Feldschuh

$0,3 \quad \mathrm{~m}$

$0,5 \mathrm{~m}$

1 rheinischer (preussischer) Fuss zu 12 Zolli1) 0,314 m

1 wiener (österreichischer) Fuss zu 12 Zoll 0,316 m

1 badisches (u. schweizer.) Klafter zu 6 Fuss 1,8 . m

1 hessisches Klafter zu 10 Fuss 2,5 m

1 badische (u. schweizer.) Ruthe zu 10 Fuss 3 m

1 nassauische Werkruthe $3 \mathrm{~m}$

1 nassauische Feldruthe

1 preussische Ruthe zu 12 Fuss

1 badische (u. schweizer.) Wegstunde $\quad 4,8 \quad \mathrm{Km}=0,48 \mathrm{MIm}$

1 deutsche (geographische) Neile $7,420+\mathrm{Km}=0,742 \mathrm{Mm}$

1 sächsische Postmeile

1 preussische Meile 2 )

$7,5 \quad$ Kin

$7,532 \mathrm{Km}$

1 deutsche (geographische) Quadratmeile 55,063 $\mathrm{Km}^{2}=0,55\left(16 \mathrm{MIm}^{2}\right.$

1) Ebenso gross ist der dïnische Fuss (fod), wovon 6 einen Faden (farn), 10 eine Ruthe (rode) bilden.

2) Ebenso gross ist die dïnische Meile (miil). 
I) Ilatsss', welche in yeoys. Karten häufig angenendet werden.

\section{1) Für horizontale Entfernungen.}

Myriameter

Deutsche geogr. Meile (1/15 Aequatorialgrad) . . . 7,420

Portugiesische Legoa (1/18 Grad, 3 milhas) . . . $\quad 6,173$

Lieue marine $(1 / 20$ Grad, 3 Seemeilen 1$)$. . . . 5,556

Lieue moyenne de France . . . . . . . 5,000

Englische League (lieue anglaise, 3 british miles) . . 4,82i

Schweizer Wegstunde (16000 schweizer Fuss) . . . 4,800

Alte französische Wegstunde (Lieue commune de France, $1 / 25^{\circ}$ ) $\quad 4,445$

Neue französische Wegstunde (Lieue nouvelle de France) - 4,000

Seemeile (S'ea mile, engl. geogr. Meile, mille marin, ${ }^{1} / 60 \mathrm{Grad}{ }^{1}$ ) $\quad \mathbf{I , 8 5}$

Englische Landmeile (statute mile, british mile, mille anglais) $\quad \mathbf{1 , 6 0 9}$

Russische Werst zu 500 Saschén oiter 1500 Arschin • 1.06 T

Kilometer . . . . . . . . 1,000

\section{2) Für Seetiefen.}

Russischer Faden, Saschén zu 3 Arschin . . . . 2,134

Deutscher . 6 preussische Fuss . . . . 1,883

Dänischer " Favn . . . . . . 1,883

Englischer, Fathom . . . . . 1,829

Schwedischer Faden, Famn . . . . . . 1,781

Holländischer " Vadem . . . . . . 1,699

Spanischer "Braza . . . . . 1,672

Portugiesischer " Brą̧a . . . . . . 1,650

Französischer , Brasse . . . . . . 1,624

1) Bei allen zivilisirten Seestaaten in Geltung. 


\section{ALPIIABETISCHES REAISTER.}

Abassis 882.

Abdachungen, Gefälle 5๊.

Veränderungenderselben 248 - 250 .

Abdrücke, natürliche (Fossile) 97.

- künstliche (von lebenden Pflanzen) $485-489$.

- künstliche ( ron Inschrif-

Aberglaube 662 . ten u. Münzen) $828,831$.

Abhäuten von Thieren 525-535.

Ablation 317.

Abkürzungen, topographische $1+1$.

- geologische 321. meteorolog. 421,429

- der Lufttemperatur mit der Höhe 414.865, 86\%.

Aborigines 771 .

Abortus 632 .

Absatz fuir Produkte 375-37\%, 402,750 .

Abschriften und Auszüge 835 .

Absolute Höhe 45, 49, 172, S59.

Absolutismus 716 .

Abstecken von Linien 27-29.

Abszissen 56, 451 .

Abweichung, astronomische 80 .

Abzeichen 667 . magnetische 26 .

Acre 886.

Ackerbau 734, 747 .

Ackererde $397,465$.

Adoption 704 .

Adressen von Lieferanten 156.

Aehnliche Dreiecke 32.

Aenderungen, ältere geologische $363-372$. der Flora $48 \pi$.
Aenterungen d. Fauna 509-510.

- d.Küsten 231-239.

- d. Nireauss.Nivea.

ఛ. Wasserläufen 293.

Aequivalente Projehtionen 211.

Aerolithen 449.

Aestuarien 234.

Affehte 567.

Affixe 592 .

Agglutinirende Sprachen

$$
\text { 591-592, 600. }
$$

Aktivhandel 738 .

Album 126, 152, 554 .

Alfa-Felder 485,486 .

Alkalität des Wassers $45 \mathrm{~S}-460$.

Alkohol(Konservirmittel) 500, 514 , $525,55 \%$

Allgemeine Betrachtungen

$=26-5+5$.

Allmenden 724 .

Almosen 661.

Alpenglühen $\$ 47$.

Alphabete 606, 609.

Altäre, vorhistorische 827 .

Altarsteine, vorhistorische sos.

Altazimuth 14 .

Alter, relatives, der Gesteine $335-36: 3$.

Alter, relatires, von prähistorischen Funden $787-785$.

- ron Höhlen 778-779.

- ron Holzptlanzen 81\%.

Altersstatistik 545,566 .

Anatomische Merkmale $5 \pm 8$,

อังิ1-55ะ.

Anaya 619.

Anemometer 434 .

Aneroid 17.

Anpassung 106, 105-109. 
Ansässige Bevölkerung 541 .

Ansichten(Zeichnungen) 215-220.

Anstalten, kirchliche 657 .

verschiedene $727-731$.

Anstehendes Gestein 95.

Anthelien 445 .

Anthropolatrie 654 .

Anthropometrie 109-118, 551.

Anthropophagie 636, 677 .

Antiklinale Schichten $309,310,322$.

Antiparallele Flüsse 456.

Antlitz 558.

Apotheke des Reisenden 155.

Apozenith 79.

Aquadukte, alte 826.

Aquarelle 123, 152.

Arbeiter, Eigenschaften $7 \pm 6$.

- Gerïthe u. Methoden 748 .

- Löhne 749 .

trchäismen 587. 610.

Archäologische Forschungen

Architektur 767 .

$$
77 t-830 \text {. }
$$

Ar 885 .

Argot 603 .

Arme s. Gliedmanssen.

Armenhüuser und Asyle 729.

Armuth, Begriffe $643-6+4$.

Arseniksaures Natron 528.

Artefakte, prähistorische 785,788 .

Aschenurnen 821.

Atheismus 655 .

Atmometer 20,422 .

Auferstehungsglaube 651 .

Auffrischung verblasster Schrift 835.

Aufuahme von Plänen 56-64.

- topographische 181-206.

- Hliegende 211-213.

- photographische 213.

- geologische 298-325.

- statistische 538-547.

Augen $110,113-114,554-555$.

Ausbalgen (der Säugethiere und

Vögel) 529-535.

Ausbrüche, vulkanische $270,271$.

Ausfuhr 163, 752, 755 .

Ausgrabungen $776,781,783$, $784-787,795,811,826$.

Ausgrabungen unter Wasser

$$
799-800 \text {. }
$$

Auskolkung 247.

Ausrüstung für Reisen 151-156.

Aussenhandel 738, 752.

Aussteuer 628.

Auswanderung 163, 546.

Autochthonen 791 .

Autorität in der Familie 706.

Azimuth 14, 79.

Azimuthe, korrespondirende 80.

Bälge (der Säugethiere und Vögel)

Bär (Sternbilder) 25, 74 .

$529-535$.

Balm 282, 778, 783, 788.

Banken 730 .

Barancos 268.

Barometer $17,52,430$.

Barometrisches Höhenmessen 49 . 431,864 .

Baumformen 484-485, 503-504. Basis u. Basismessung $36-42,186$. Bassin 452, 473 .

Bauten (Styl und Material) 688,

Bazinas 818.

$693,775$.

Becken (Anthropologie) 118, 552. - (Geologie) 243-245.

Begrüssung 616 .

Behaarung 557.

Beigaben ins Grab 640, 815.

Beinamen 706 .

Beine s. Gliedmaassen.

Bemalung des Körpers 670-671. Beobachtungen, Aufgabe des Reisenden $7-10$.

- Allgemeines 159-170.

- botanische 481-504, 817 .

- ethnographische 538-848.

- geologische 222-404.

- hydrologische 451-481.

- meteorologische 405-451.

- zoologische 505-537.

Beobachtungsgabe 3.

Bereditsamkeit 762 .

Berufsarten 543, 731-749.

Beschneidung 615, 633.

Bestimmen von Felsarten $94-97$.

- von Petrefaisten 97-99.

- von Pflanzen 101-106.

- von Thieren 106-109. 
Bevölkerungsstatistik 538-547.

Bewegung des Gletschereises 256. - des Wassers $463,474,478$. - der Luft $432-437$.

- der Bevölkerung 5 $45-547$.

Bezeichnungen, konventionelle, s. Zeichen und Ablürzungen.

Bilderdienst 653 .

Bilderschrift 605 .

Bildungsanstalten 728 .

Bilinguen 829.

Bilithen 80s.

Blöche, erratische 237, 248, 262. - hängende 250 .

Blut (Beschatfenheit und Zirku-

Blutrache $61 t, 620$. lation) 563,564 .

Blühen der Seen 475 .

Blüthen und Früchte, Sammlungen

Bodenamelioration 404 . $495-5112$.

Bodenanalyse 99-101.

Bodenarten 401, 402.

Bodentemperatur 412.

Botanik 101-106, 481-504.

Boussole 15, 16, 5̄, 212, 320 .

Brachycephale 112.

Brasse s. Faden.

Bräuche 614-643, 663, 760 .

Brautkauf 627 .

Breite, astronomische 86 .

- geographische 79-8t, $172,186,189$.

Brennmaterial $679-680$.

Cairns 814.

Camera 220.

Cassiopeja (Astronomie) $7 t$.

Castizen 568.

Centaros s. Münzen.

Cephalopoden 519-520.

Charaktere, ethuische $5+7-576$.

Chronometer 16, 84-87, 189.

Cirrus 424, 425, 433.

Cist $816,820$.

Clan 710.

Coelenteraten 520.

Conchylien 513.

Conti finti 760 .

Corona (Photometeor) 443.
Cosinus 133.

Coten 45, 195, 199, 200.

Couvade 632.

Crannoges 797.

Cromlechs 810.

Croquis, topogr. 177, 183, 206.

- geologische 295-299.

Crustaceen 520.

$[303-30 \%$.

Cumulus $424,425,433$.

Cyanometer 18.

Cyklonen 439 .

Cyklopenmauern 825.

Daghobas 818.

Dämmerung 446 .

Dammerde 397,465 .

Decimo s. Münzen.

Dekagramm etc. s. Maasse.

Deklination, astronomische 85.

Deltas 234, 235. magnetische 26.

Denkmäler s. Monumente.

Denudation 31\%.

Depressionen des Bodens 243 - 245.

Detailzeichnung, topogr. 139.

Dezigramm etc. s. Jaasse.

Dezimales 7ahlensystem 611.

Diả (Wergeld) 620.

Diagramme, meteorolog. 411,451 . hydrologische 468 .

Dialehte 578, 604.

Diaphysen 780 .

Dichtigkeit der Berölkerung 54:2.

Diebstahl 621.

Dikotyle Hölzer 504.

Dinero s. Münzen.

Diskordanz, geolog. 312, 322.

Distanzen, Schätzen und Mlessen $29-42$.

Dogmen 657 .

Dokumente 119, 162-164.

historische $833-836$.

Dolichocephalen 111, 552.

Dollar 882, 883.

Dolmen S09-814.

Dredsche 516-518.

Dreiech $36-39$.

Dreiecksnetz 190-194, 207.

Dreieckspunkte, Koordinaten 857.

Drosometer, 20, 425-426.

Druidensteine $808,817$. 
Dschaggernath-Kultus 614,661 .

Dualismus 656.

Duell 620.

Dukaten 883.

Dünen 230, 238, 243.

Dünste 423 .

Dunstdruck 418, $870--877$.

Durchschnitte s. Profile.

Durchsichtigkeit der Luft 416 .

Dynamometer 564 .

Ebenen, Ursprung und Bildung $239-243$.

- Wirkungen ders. $838,842$.

Ebbe 479.

Echinodermen 520.

Edelsteine 393.

Ehe 629 .

Thehindernisse 622 .

Eholiche Treue 630, 631.

Ehelosigheit 627 .

Ehescheidung 634 .

Eheschliessungen, Statistik 544. 545 .

Eide 618.

Eigenschaften des Reisenden $3-7$. - ethnographische 571-575.

Eigenthum 723.

Einbalsamirung 638 .

Einfluss geographischer Verhält-

Einfuhr 163, 752.

$$
\text { nisse } 826-848 \text {. }
$$

Eingeborne 542, 576, 714 .

Einrichtungen, verschied.727- 731 .

Einsilbige Sprachen 591, 600.

Eintheilung des Landes 175 .

Elektrizitait 437 .

Elektrometer 21, 437 .

Elterliche Gewalt 706.

Endogamie 624, 699 .

Entfermungen, Schätzen u. Messen

Entführung 622

Maasse 888.

$$
29-42 \text {. }
$$

Entlehnte Schrift 607.

$$
\text { - Würter 584, } 613 .
$$

Entomologische Sammlungen

513-524. Farben, konventionelle ('Topogra-

Entwöhnen 565, 633.
Epigamie 622.

Epiphysen 780.

Erbrecht 726.

Erdbeben 273-278.

Erdwärme 284-285.

Ausstrahlung 415.

Erkundigungen über das Land

$147-149$.

- im Allgemeinen 159-162.

- prähistorische $774-\mathbf{7 6 6}$.

- statistische 539.

Erosion 232, 233, 317, 779.

Erratische Blöcke 237, 248, 262.

Erstarrungsgesteine $347-356$.

Eruptionen, vulkanische 270, 271.

Eruptivgesteine 350-356.

Erzähler 764, 765 .

Erze $38 t-393$.

Errziehungsgewerbe $741-742$.

Escudo s. Münzen.

Ethnische Charaktere 547-576.

Etiketten für Sammlungen 327, $499,500-501,512$.

Etymologien 583.

Exogamie 623, 700 .

Exploitation 373-397, 732.

Export 752.

Exposition eines Ortes 399, 405. Extremthermometer 16-17,

$409-410$.

\section{Fabrikation 735-737.}

prühistorische 805 .

Facies, geologische $357,368,379$.

Facsimile, photographische 835.

Faden (Manss) 888.

Faktische Bevölkerung 541 .

Fakturen pro forma 760 .

Fallen und Streichen 319, 388.

Fallen u. Fanggruben $669,795,804$.

Fallhöhen 53.

Familie 540, 698-702.

Familiennamen 704-706.

Fanginstrumente 515-520, $521-522$.

Farbe der Haut 553, 567.

- des Himmels 416.

-. der Seen 475 . 
Farben, konventionelle (Geologie) 307,325 .

Fatalismus 662 .

Fata morgana 440.

Fathom 888.

Fauna, Vorbegriffe 10, 106-109. - Beschreibung 505-537.

- Prähistorische 789.

- Kausalbeziehungen 840,

Federbarometer 17 . $[841,846$

Federwolke 425 .

Felsarten s. Gesteine.

Feste 634, 697.

Fetischdienst 653, 789.

Fettpflanzen 490.

Feuchtigkeit der Luft 417-421. $870-879$

Feudalgesellschaft 711, 716.

Fever 679, 789.

Feuerbestattung 639 .

Feuersteingeräthe 781,785 .

Feuerkugeln 449.

Figurenschrift 605 .

Firn, 256, 257.

Fische 524-525, 526.

Fischerei 733.

Fischereigeräthe 515-519, 669,

Fischervölker 842.

Fixirmittel 221.

Fjorde 236-237.

Flachküsten $230,237-239$.

Flächeninhalt 64 .

Flächenmaasse $885,886,887$.

Flächenmessung $64-73$.

Fleischige Frïchte 494, 500 .

Flektirende Sprachen $592-600$.

Fliessende Gewässer, Geologie $289-294,388-391$. - - Morphologie 453-457.

- - Hydrologie 461-470.

- - Verkehrsmittel 471,843.

Flottante Bevölkerung 541.

Flussbetten, Entstehung 247.

Flussgebiete 452 . ehemalige 292.

Flusssysteme $453-456$.

Flussmündungen 477 .

Fluth 349.

Fluviometer 466 .

Flying surveys 27, 212.

Formalitäten $148,395,617$.
Formationen, geolog. 356-363.

Fossilien, Bestimmen 97-99.

- Sammeln 328-335.

Schlüsse 364-369.

Frau, Entführung 614, 622.

- Kauf und Tausch 627, 628.

- Mitcift 628.

- Stellung 707.

Frühjahrsfröste 399.

Frühlingspunkt 85.

Fuss s. Maasse.

- des Menschen 117, 562, 563.

Galgal 814.

Gandecken 264.

Gastfreundschaft 619.

Gebäude, Planaufnalıme 62-63.

Gebete 660.

Gebirge, Geologie 251-255.

Wirkungen 839,844 .

Gebräuche 614-643, 663 .

Geburten, Statistik 544.

Gedichte 764, 833 .

Gediegene Metalle 384, 385.

Gefälle, Schätzung und Messung: $54-56,456-457$.

Gegensonnen 445 .

Gehänge s. Abdachungen.

Geistiges Leben 698.

Geistlichkeit 658.

Geldverhältnisse $746,757$.

Genossenschaften $713,724,731$.

Gemeinde 711, 724 .

Geographische Karten 129.

Geologie, Vorbegriffe 94-98.

- Beobachtungen 223-373.

Gerichte 727, 762 .

Geruch 554, 565.

Geschenke 155, 634。

Geschichte 768-826.

Geschiebe 239, 465.

Geschwindigkeit, von Fussgängern

- des Lichtes 30.

- des Schalles 30.

- des Wassers 464-465.

- des Windes 435.

Geselliges Leben 697.

Gesellschaften 731 .

Gesellschaftliche Organisation $709-712$ 
Gesicht 558-560, 566-567.

Gesichtssinn 565 .

Gesteine, Bestimmen 94-97.

- Sammeln 326-328.

- relat. Alter 335-363.

Gewachsencr Fels 95.

Gewässer 451-481.

Gewalten, öffentliche 717 .

Gewerbe 543, 731-749.

Gewichte 759.

Gewitter 438-439.

Gewürze 679.

Geysir 272-2s8.

Gezeiten der Seen 474 .

Glatteis 427.

des Meeres $478-479$.

Glatube 642-663.

Gletscher 255-267, 779.

Gliederthiere 521-524.

Gliedmaassen 117-118, 561, $562-563$.

Glorie (Photometeor) 443.

Gnomon $7 \pi$.

Götzendienst 653 .

Goldsand 388-391.

Gottesurtheile 722 .

Grab, Anlage und Formen 641, Gradlïngen 853. [814-821.

Gradzähner 112, 561.

Grammatik 587-599.

Grenzen des Landes 174.

Grösse des Landes 174.

Grotten s. Höhlen.

Graupen $42 \pi$.

Gruben (Fallen) 804.

Grundlawinen 254.

Grundrisse (Pläne) 63-64.

Guano 393.

Haare 555-558, 566.

Haar- und Barttracht 674-675.

Härte des Wassers $458-460$.

Häusliches Leben 696-697, 732 .

Haffe $235,297$.

Hagel 428.

Halo 442.

Haltung des Körpers 567 .

Hamen 522.

Hammer, geologischer 306.

Handarbeit $375,396,746,749$.

Handel $737,742,749-761$.
Handschriften $834-836$.

Handwerk 735-737.

Handzeichnungen 121-126.

Hautbeschaffenheit 553-554.

Haus 687.

Hebungen u. Senkungen 223-231.

Heizung 689.

Herbarien 106, 495-502.

Herbergen 729.

Hetärismus 623,631 .

Hieroglyphen 606 .

Höfe (Pliotometeore) 442 .

Höhe, absolute und relative 42 , $45,46,172$.

- Schätzung und Messung $42-53,172,191,195-200$, $431,859-868$.

Höhentemperaturen 414, 865 .

Höhenwinkel 14, 79, 191.

- korrespondirende 80, 87.

Höhlen 282-28t, 684 .

- mit prähistorischen Resten $776-792,802$.

Höhlenbestattung 640, 778, 782 .

Holzarten 394, 502. [821.

Holzpflanzen, Alter 817.

Homophonie 590.

Horden 709.

Horizont, mathematischer 79 .

- geologischer 361.

Horizontabschluss 185, 186.

Humus 99-100, 397, 400.

Hügelgräber 814-819.

Hülfsgewerbe 739, 742 .

Hünengräber 817.

Hydrologie 451-481.

Hygrometer 19, 418 .

Hypogäum 821.

Hypsometrie 50-52.

Hypsometrische Karten 137.

- Tabellen 46.

Hypsothermometer 50.

Ideenwelt 642-663.

Ideogramme 605,606 .

Idiome 602-605.

Idolatrie 653.

Industrie $731-749$.

Infixe 592.

Informationen s. Erkundigungen.

Innungen 713,731 . 
Inschriften $827-830$.

Insekten $521-523$.

Insignien $667-668$.

Iusolation 415 .

Institutionen, diverse $72 \%-731$. Instrumente $13-21$.

Isobathen 200.

Isohypsen 132, 200-20t.

Isoklinale Schichten 309, 322.

Isolirende Sprachen 591, 600.

Isorachien 481 .

Itinerar 181, 212.

Jagd 512, 733.

Jagdgeräthe $668-670,748$.

Jalonnage 25.

Jargons 603.

Journal (Tagebuch) 168-170.

Journale (Presse) 662.

Jupiter, Trabantenfinsternisse 88.

Jus primæ noctis 623 .

Kalkgehalt des Bodens 99, 100, - des Wassers 462 . [401.

Kannibalismus $636,67 \%$.

Karten, Jaassstab 128-131.

- Lesen 21. 137.

- Zeichnen 126, 142.

- Kopiren 142-145.

- Verifiziren 177-181.

- Aufnahme 187.

- Entlehnung 213.

- Vereinigung 209.

- Projektionen210,853-855.

Kasten und Klassen 5 $\pm 3,712-714$.

Katakomben 821.

Kenntnisse, praktische 13-120.

Keuschheit 630, 631.

Kies (Gerölle) 99, 465.

Kiltgang 630 .

Kindbett 632 .

Kindermord 632.

Kirchliche Anstalten 657 .

Kisten für Transporte $491,500$.

Kjökkenmöddinger 803 .

Klassen der Gesellschaft 712-714.

Kleidung und Schmuck 663-675. des Reisenden 150.
Kilerus 658 .

Klima $405-451$.

- Kausalbezielsungen desselben 838-841.

Klimate, geologische 368-369.

Klinometer 55,320 .

Knochenfunde $780-782,789$.

Knollen (Pflanzen-) 490.

Kochen 678 .

Körper, Messungen 117, 118.

Körperform 118, 553, 562.

Körperhaltung 567, 66t-681.

Kohlenlager $378-384$.

Kolmatirung 232, 234.

Kommunismus 723.

Kompass 25-27.

Konfessionen $65 \%$.

KonfigurationilesLandes176-22.0. Kausalbeziehungen

$8.35-54 t$.

Konforme Projektionen 210.

Konkordanz geolog. 312.

Konnex geographischer Verhältnisse $826-845$.

Konservirmittel 500, 514, 520, 52 .

Konsonanten, Eintheilung 589.

Konventionelle Bezeichnungen s. Farben und Zeichen.

Konzessionen 396.

Koordinaten 56.

- sphärische 86.

- geographische 172 .

- voll Dreieckspunkten $85 \%$.

Korporationen $713,724,731$.

Korrespondirende Azimuthe 80.

Höhen $80,8 \%$.

Kostenpreis $376-378,761$.

Kraftmesser 564.

Kraniometrie 109-114.

Krankheiten 575-576.

- Behandlung derselben 637.

Krreolen 568 .

Kreuzscheibe $5 \pi$.

Kriegsgebräuche 635 .

Kritik 4, 834.

Kritze, glaciale 262, 264.

Krone (Photometeor) 443.

- (Münze) 883.

Kryptogamen 498 .

Krystallhöhlen 283.

Küchengeräthe 680 . 
Künftiges Leben (Glaube) 651 .

Künste $765-767$.

Künstliche Missbildungen 673.

Küsten, Geologie 231-239.

- Einfluss derselben 572,843.

Küstenflüsse 454 .

Kulmination 74,76 .

Kultus 659 .

Kurgane 814.

Kurs (Geld) 759 .

Kurven in Diagrammen 451 .

- in Karten 132, 200-20t.

Iänge, geographische $84-94,172$, $186,189$.

Iage, geographische 171,172 , 691,692 .

Lager (Guano-) 393.

- (Kohlen-) 378-354.

- Metall-) 385̃-393.

Lagerplätze, alte 792,802 .

Lagerstätte, geologische 98.

Lagerungsformen $309-312$.

Lagunen 297.

Iandbau, Gebräuche 635.

Landesbeschreibung 222.

Landesgrenzen 173.

Lautlehre 579, 587-591.

Lawinen 254.

Tuebensdauer 566.

Lebensweise $695-698,842$.

- der Thiere 108, 512.

Lehensstaat 716 .

Leibeigene 713,714 .

Leichenschachte 820 .

Leichenurnen 821.

Leichenverbrennung 639.

Leichenzeremonien 638 .

Leitfossilien 98, 361.

Lianen 502. 786.

Libelle (Instrument) 29, 42-43. (Kerbthier) 521.

Lichtungen 482, 794 .

Lirii 234.

Limbus des Thendolits 34,35 .

Limnische Kohlenlager 379 .

Linien abstecken 25.

Iissotrichen $55 \%$.

Iiteratur $761-765,774$.

Loghan 807.

Lothungen 54, 198-199.
Luftfeuchtigkeit $417-421$, $870-877$.

Luftspiegelung $439-440$.

Maasse und Gerrichte $759,885$. Maasse in geogr. Karten 888.

Maassstäbe (Reduktionen) $128-131,178-179$.

- (Böschungs-) 136.

Mächtigkeit (Geologie) 318.

Männerkindbett $615,632$.

Nagier und Medizinmänner s. Zauberer.

Magnetismus 21, 448 .

Magnetnadel 25-27, 438 .

Mahlzeiten 681-682.

Majorat 708 .

Manuskripte 764, 834-835.

Mardellen 797.

Marine Bildungen 364 .

Markt (Absatzorte) 375-377, 402.

Marschroute, Aufnahme 181-187.

- geologische $300-302$.

Massengesteine $308,329,347-355$.

Mauern, alte 823-824.

Mausoleum 820.

Maximumthermometer 410 .

Maximalgefälle 197.

Medaillen, alte 831.

Mediane 112 .

Medizinische Kenntnisse 6.

Medracen 819.

Meeres-Erosion 232-233.

Megalithen 806-814.

Mehrsprachige Inschriften 829 .

Meile s. Maasse.

Menhirs 808.

Meridian 73.

Meridiandurchgang 74,80 .

Meridiane, erste 851 .

Meridiangrade 853 .

Neridianhöhen $81,83$.

Neridianzeichen 78 .

Merkatorprojektion 210 .

Mesocephale 112.

Messband und Messkette $\mathbf{1 5}$.

Nesstisch 15 .

Messen und Märkte 756 .

Mestizen 568.

Metalle $384-393$.

Netallzeit 790 . 
Metamorphische Gesteine 355.

ILetempsychose 651 .

Meteorologie 405-451.

Methoden (Vorbereitung) 21-120.

Mineralien, Bestimnen 96.

Mineralquellen 289.

Minorat 70 s.

Minimumthermometer 409 .

Jischlinge 568 .

Missbildungen 575, 673 .

Mitgift 628 .

Mittagslinie 73, 186.

Mitteltemperaturen $411-412$.

Mofetten 272.

Mollusken 228, 329, 513-520.

Monarchie 717.

Mondbeobachtungen 89-91.

Mondhof 442.

Nonogamie 626, 700 .

Monokotyle Hölzer 485, 499, 503.

Monolithen 808.

Monopole 754 .

Monotheismus 656 .

Monumente, megalithische

- symbolische 816. $806-814$

- sog. keltische 817.

Moränen $247,263-267$.

Morphologie, grammatische 579, 5 $91-598$.

- hydrographische 473.

- orograph. etc. s. Geologie.

Mounds 814 .

Miüzen, alte 831.

— gebräuchliche 758,878 .

- Abdruicke 832.

Mulatten 568.

Muru 637.

Muscheln 513-515, 673, 682, $803-804$.

Musik 659, 767.

Muskelkraft 564,789 .

Muster s. Sammlungen.

Mythologie $643,65 \overline{5}-656$.

Nahrung $675-684$.

Namen, geographische $183-184$, 775.
Namen, Pflanzen- und 'Thier- 106, $499,502,504,510$.

Naos 819.

Narkotische Genussmittel 683.

Nase 114, 557-560, 567, 673.

Nation 712.

Naturalwirthschaft 751.

Naturalismus (Religion) 652.

Nebel 423.

Nebenmonde 443 .

Neffenerbrecht 726 .

Nehrungen 234.

Nekropolen 821.

Nemedlh 810.

Nephelie 423-42t.

Netze s, Fanginstrumente.

Niederkunft 631.

Nimbus (Wolke) 424, 425.

Nipptluth 481.

Niveau-denderungen 223-231, $466-471,474,778-779$.

Niveaudifferenz $45,53,191$, $195-200,860-868$.

Niveaulinien 132, 200-204.

Nivellement 42, 191, 195-200, $860-865$.

Nomaden 695-696, 842.

Nordlicht 448.

Notizen, laufende 167, 168.

- topograph. 184, 204, 205.

Nurhags 485.

Nutzpflanzen und nützliche Thiere $485,507-508$.

0asen 243.

Occultation 89 .

Odometer 34 .

Oefientliche Gewalten 717.

Ombrometer 20, 427 .

Opfer 640, 659-661.

Opfersteine 808.

Ordalien 722.

Orden, religiöse 731 .

Organisation d. Familie $698-709$.

- soziale 709-714.

- politische $714-719$.

Orientirung, topographische $22-27,142$.

- geologische 319-320.

Orkane 439 .

Orthocephate 112. 
Orthognathe 112.

Orthographie geographischer $\mathrm{Na}$ men 183-184.

Ortsanwesende Bevölkerung 541 .

Ortschaften $691-695$.

Osteometrie 114, 115.

Oszillationen der Erdrinde

Ozon 436-437.

$223-231$.

Ozonometer 21, 437 .

Palmen 483, 497-498, 499.

Panoramen 220-221.

Parallaxe 89, 90, 204.

Parallelkreise, Gradlängen 853.

Paranthelium 445.

Parasolsteine 808 .

Patois 603.

Pedometer 34 .

Pegel 466.

Peilungen 179, 191, 199, 212.

Pendel 94.

Peulvan 808.

Pfahlbauten 615, 797, 803.

Pfeilersteine 808, 810, 811.

Pflanzen, Abdrücke und Versteinerungen 329.

- Bestimmen 101-106.

- Sammeln 489-504.

Pflanzenwelt s. Flora.

Phonologie 579, 587-591.

Photographie und Zeichnen

- Naterial 152.

121-126.

Photometeore 439-449.

Phraseologie 581.

Physische Merkmale des Menschen $548,552,563$.

Physiognomische Merkmale des Menschen 548, 566-567.

Physiologische Merkmale des

Placers 391.

Menschen 548, 563-566.

Planaufnahme 55-64.

Planzeichnen 126-145.

Pläne, cotirte 199, 200.

Planimeter 175 .

Plateaux 250-251.

Plutonische Gesteine 308,
Pluviometer 20, 427.

Polarlichter 448.

Polarstern 25, 74-76.

Politische Organisation 714-719.

Politisches Leben 697.

Polizei 727.

Polyandrie 626, 700.

Polygamie 624-626, 700 .

Polygraph 125 .

Polysynthetische Sprachen 591, $592-600$.

Polylithen 808.

Polytheismus 655 .

Populationistik 538-547.

Position, geographische 171 .

Pothenotische Bestimmung von

Präfixe 592. Punkten 199.

Prähistorische Periode 770. - Forschungen 774-830.

Praktische Kenntnisse 13-120.

Prediger 658.

Presse 762.

Priester 649, 658.

Produkte $373-395$.

Professionen 543, 731-749.

Profile, topographische 132 ,

$214-215$.

- geologische $324-325$.

- hydrologische 465 .

Prognathismus 112.

Prohibitionen 753.

Projektionen, kartographische 210 , $853-855$.

Prostitution 623, 631.

Provinzen, geologische 357 .

Provinzialismen 604.

Pseudhelium 444.

Psychrometer 19, 419-421,

Publikationsmittel $75 \%$. $870-87$.

Pubertät 565-566.

Pulsfrequenz 564.

Pyramiden 819.

Quadratnetz 143.

Quarter 886.

Quarteron 568.

Quartiere (Stadt-) 694.

Quastenschlepper 518-519.

Quellen 285-289, 457-461, 826. 
Querströme 454, 455 .

Quinärsystem 611.

Quipos 605, 612.

Radiation 415, 419.

Radiaten 520 .

Rassen u. Typen, Charaktere imAllgemeinen 109-118, 547-576.

Rassen u. Typen, kartogr. Darstel-

Rastern 478 . lung ihrer Vertheilung 542.

Raub 621.

- der Franen 622.

Raubthier-Höhlen 780-781.

Razzias 621.

Recht $720-723$.

Rechtschreibung geographischer

Reduits 822 . Namen $319-320$.

Reduktionszirkel 144.

Refraktion 47.

Refugien 822.

Regalien 754 .

Regen 427, 429.

Regenbogen 441.

Regendichtigkeit 429 .

Regenmenge 427, 451 .

legenmesser 20, 427 .

Regenwahrscheinlichkeit 429 .

Regierungsform $714-719$.

Regionen 484.

Reichthum (Begriffe) 644. - (Boden-) 373.

Reif $399,426$.

Reinheit der Luft 416.

Reise-A usrüstung 149-156.

Reise-Journal 168-170.

Rekognoszirungen, topographische $176-177,187$.

- geologische 298-302.

Rektaszension 85 .

Reliefkarten 139.

Religion $642-663$.

Reliktenfauna 506.

Peliquien 654.

Remaniément 98, 262, 263.

Reptilien 525.

Republik 717.

Respektsbezeugungen 617 .

Respiration 564,
Restauration v. Manuskripten 835 .

Revüen, wissenschaftliche 13 .

Richtungsbeobachtungen 193.

Richtungswinkel 191.

Ridjm 815.

Riesengräber 817.

Riesentöpfe 264.

Ringsaufnahme 185, 186.

Ritus 659.

Roches moutonnées 263.

Röhrenknochen 780, 781.

Rollmass 15.

Ruhssen 474.

Rundthürme 823.

Sabäismus 652.

Säkulare Schwankungen 223-231.

Såugethiere, Abbalgen 529-531.

- Reste 328, 359, 780.

Sagen; 764, 775, 831-833.

Salsen 272.

Salz (Gewürz) 679.

- (Konservatif) 500, 501, 514 .

Salze des Borlens 100.

Samen, Aufbewahrung 493-495.

Sammelgewerbe 733,741 .

Sammlungen von Gesteinen

$$
326-328 .
$$

-.. von Petrefakten 328-335.

- von Pflanzen 489-504.

- von Thieren 512-537.

- anthropologische 552.

- literarische $763-764$.

-- merkantile 761 .

- numismatische 831.

- prähistorische 775 .

- sprachliche 579-557.

- Mitwirkur.g d. Eingebornen $164,165,764,776$.

Sand, 99, 100, 401, 465.

- goldführender 388-391.

Sandhügel 247.

Sandstürme 438.

Sanitätsgewerbe 740,742 .

Scenograph 124.

Schabmesser 786.

Schachteln (Insekten-) 523.

Schädelmessungen 109-114.

Schädelsammlungen 552 .

Schädelverunstaltungen 673 , 
Schädliche Pflanzen 486-487.

- Thiere 508-509.

Sehätzungen (statistische) 538.

Schalensteine 807.

Schallgeschwindigkeit 30 .

Schalthiere $228,513-520$.

Schamanismus 654 .

Schambaftigkeit 664 .

Schanzen, alte $823,824$.

Schlammvulkane 272.

Scharrinstrumente 516-518, 800 .

Schichtgesteine 308-323, 329,

Schichtwolken 425. $335-346$.

Schiefzähner 112, 561 .

Schiffbarkeit $471,756-75 \%$.

Schiffsverkehr eines Hafens 753.

Schleppnetz $516-518$.

Schlichthaarige 557.

Schliffe, glaciale 262, 264 .

Schnecken 513-516.

Schnee 428-429.

Schneelawinen 254.

Schneelinie 253.

Schotts 472 .

Schmuck (Toilette) 663-675.

Schraffen 134.

Schratten 246.

Schrift $605-610$.

- für Karten 140.

Schrittzähler 34.

Schulen 728.

Schuttkegel 249.

Schwangers chaft $565,631-632$.

Schwankungen, säkulare 223-231.

Schwebnetz 519 .

Sedimentgesteine $308-323,329$, $335-346$.

Seele (Glaube) 649-650.

Seelenwanderung 651.

Seen $294-297,472-477,506$.

Sehwinkel 204.

Seiches 474.

Seifen (Geologie) 391.

Seismograph 21, 275.

Seismometer 21.

Sekten 657.

Sekante, trigonometrische 133.

Sektionen einer Karte 185, 186, $208-210$

- des Schädelumfangs 113.
Selbstkostenpreis $376-378$.

Senkblei 31.

Senkungen 223-231.

Sense und Sichel 748 .

Sensibilität 565 .

Separatismus 723.

Sesshafte Bevölkerung 541.

Sextant 15,80 .

Sichel, Formen 748 .

Sicherheitsdienst 727 .

Siedetemperaturen 52.

Signale, 29, 63, 190.

Silbenschrift 606 .

Silo $805,821$.

Sinne 565 .

Sinus 133.

Sitten und Gebräuche 614-643.

Situationszeichnung, topogr. 131.

Skelette, menschl. 109-117, 552.

— ii Höhlen 780-781.

Skelettiren von Reptilien 526.

Sklaven $546,713,714$.

Sklavenjagden 546,621 .

Skeptizismus 642 .

Skulptur 766.

Skulpturen $827-830$.

Soffioni 272.

Sonnendienst 652 .

Sonnenhöhen 87.

Sonnenkreuz 445 .

Sonnenwärme 415 .

Sonnenzeiger 77.

Sonnenzeit 86.

Souterrains, Plønaufnahme $63-64,784$.

- Temperatur 412.

Soziale Organisation $714-719$.

Spalten (geolog.) 315.

Spesen 376,760 .

Spinnenthiere 524.

Spiritualismus 655 .

Spitäler 729.

Sprachen und Dialekte 549-550, $576-613$.

- kartogr. Darstellung 542.

Sprachkenntnisse 145-147.

Springfluth 481 .

Sprüchwörter 764 .

Staatsform 714-719.

Stadia 34.

Städte u. Stadtquartiere $693-695$. 
Städte, alte $824-826$.

Stände (Volksklassen) 543 .

Stagnirende Gewässer 471 .

Stalagmiten und Stalaktiten 283.

Standorte (von Pflanzen u. Thieren) $484,507$.

Statistik 119, 163, 538-547, 575.

Statur 117, 553.

Staublawinen 254.

Steatopygie 562.

Steilküsten 229, 233.

Steine, aufgestellte 808. — schwebende 807 .

Steinkocher 678.

Steinkohle 378, 384.

Steinreihen 810 .

Steinringe $810,811$.

Steintische 809.

Steingeräthe 668, 785, 786.

Steinzeit 790 .

Stellung der Familienglieder 707.

- der Gewerbe (influirende Faktoren) $745-747$.

- der Kasten 714.

- des Körpers 567, 664, 682. Steppen 242, 482, 842.

Sternberleckung 89 .

Sterndienst 652 .

Sternschnuppen 449.

Sternzeit 86.

Stillen 565, 633.

Stimme 565 .

Stockboussole 181, 212.

Stossseite 238, 265.

Straffharige 557 .

Strahlthiere 520 .

Strahlung 415,416 .

Strandbildungen 364 .

Strandhöhlen 229.

Strandlinien 229.

Strandseen 297.

Strassen 756 .

- alte 826 .

Stratigraphie $303-325$.

Stratus 424, 425, 433:

Streichen (Geologie) 319, 388.

Streifen, glaciale $262,264$.

Ströme 291, 452, 756 .

Strömungen $475,478-479$.

Stürme 434,438 .

Stunde (Wegmaass) 887, 888.
Stundenkreise 84.

Stundenwinkel 85.

Stupas 818.

Subaërische Bildungen 36t, 367.

Succession (Erbfolge) 718.

Suffix 592.

Synchronismus, geologischer 354 , $356-363$.

- archäologischer 788 .

Synklinale Schichten 309,310 .

Syntax 579, 598-599.

System, metrisches 885 .

- natürliches, d. Pflanzen 105.

- physiognomisches, d. Pflanzen $104-105$.

Systeme, kosmogonische 645 .

- der Numeration 611, 612.

Tabellen, meteorologische 450 .

Tabu 620.

'Tätowirung 663, 672.

Tagebuch 168-170.

Taille 118, 562.

Talayots 823 .

'Talion 721.

Tange 498.

Tangente, trigon. $47,48,133,457$.

Tangententafel 48 .

Tangentialbogen (Meteor) 443 .

Taschenkompass 16, 212.

Tasterzirkel 111.

'Tauschartikel 155, 751.

Taufe 633.

'T'aufnamen 704, 706.

Teiche 297, 472.

Teifun 439.

T'empel 657, 826 .

Temperatur $284-285,406-416$, 461,476 .

T'errainfalten 247.

Terrainmantel $6 t$.

Terrainzeichnung 132-139.

Terramare 797.

Terrassen 230, 241, 250, 251, 280.

Terzeron 568.

Teufelsmühlen 248 .

Thäler 247, 278-282.

Thalstufe 241, 280.

I'halweg 464 .

Thau 425, 426. 
Thaumesser 20, 425-426.

Thaupunkt 19, 417 .

Theodolit 13, 34, 46 .

Theokratie 716,844 .

Thermen 272, 288.

Thermometer $16-17,406-416$,

Thiere, Bestimmen 106-109. 869.

- Sammlungen 512-537.

- Versteinerungen 329.

Thierwelt s. Fauna.

Thon 99, 100, 401, 465 .

Tiefen, Schätzen und Messen 53, $54,198$.

- Mansse 888.

Tiefentemperaturen $284-285$.

Tiefseebildungen 364 .

Tischgeräthe' 682 .

'Tod 638.

Todesfälle, Statistik 544,545 .

Todtenkult 641 .

Todtenurnen 821.

Toilettenstücke $666-667$.

Topen 818.

Topographie 176-222.

Topographische Abkürzungen 141.

- Aufnahmen 181-213.

- Beschreibung 222.

- Karten und Pläne 127.

Topographisches Netz 190-194,

- Notizenbuch 204-205. 207.

Totem 652.

Traditionen $772,831-832$.

Trachten 664, 666 .

Training 5.

Transit 753.

Transporteur 37,38 .

Transportgewerbe 740,742 .

Transport lebender Pflanzen 490-493.

- - Thiere 535-537.

'Iransportverhältnisse $\quad \mathbf{7 5 5}-\mathbf{7 5 7}$, 740 .

Transskription, phonetische 582.

Transversalmaassstab 131.

Trauer 641.

Treue, eheliche 630, 631 .

Triangulation 40, 91, 190-194, $207,857$.
Tribus 710.

Trichter (Geologie) 246.

Trinkwasser $460,793$.

Trilinguen 829 .

Trilithen 808.

Trocknen der Pflanzen 496-497.

Troglodyten $684,777-778$.

Tromben 438 .

Tschudengräber 814 .

Tumuli $814-819$.

Tundren 482.

Typen $126,569-571$.

Udometer s. Pluviometer.

Uebergang (Basismessung) 188.

Ueberlieferungen $772,831-833$.

Ueberschwemmungen 470 .

Uebungen (Vorbereitung) 120, 121.

Ulotrichen 557.

Unebenheiten des Bodens

246-248.

Ungeschichtete Felsen 323,

Unkosten 396, 760. $347-355$.

Unterirdische Gewässer 779.

- Räume, Planaufnahme 63.

- $\quad$ - Temperatur 412.

Unterhalt des Feuers 679.

Unterrichtsanstalten 728 .

Urboden 783, 826.

Urgeschichte 768-826.

Urnen 821.

Urproduktion 543, 733, 742, 747.

Ursprüngliche Lagerung (Geo-

Usanzen 760 . logie) 309.

Väterliche Gewalt 707.

Vegetation s. Flora.

Vegetationsformationen 482 .

Vegetationsformen 103, 104, 483.

Veränderungen s. Aenderungen.

Verbotene-Speisen 677.

Verdunstung 421, 422.

Vereine 730,731 .

Vergeltungsrecht 721 .

Vergiftete Waffen $669,678$.

Vergnügungsgewerbe $\mathbf{7 4 1}, \mathbf{7 4 2}$.

Verifikationsbasis 190 . 
Verkehrsgewerbe $\mathbf{7 4 2}$.

Verkehrsmittel $\mathbf{7 5 5 - 7 5 7}$.

Verlandung 232, 234.

Verlobung 629.

Verpackung von Instrumenten 153.

- von Gesteinen 327, 328.

- von Petrefakten 333, 334.

- von Pflanzen etc. 500-504.

- zoologischer Sammlungen $512-537$.

- anthropologischer Objekte 552.

- prähistorischer Funde 792.

Versandung 232-234.

Verschneidungslinien 198.

Verschwinden von Sprachen 577.

Verstecke 805.

Versteinerungen s. Petrefakten.

Vertikalkreis 47, 79.

Verträge $148,618$.

Verwandtschaft $622,702-704$.

- der Sprachen 599-601.

Verwerfung (Geologie) 315.

Vielweiberei $624-626,700$.

Vigesimales Zahlensystem 612 .

Visirkompass 15.

Vögel, Abbalgen 531-535.

- fossile Reste 328.

Vogelschau 220.

Vokabularien 579-586.

Vokale 588.

Vokalharmonie 590.

Völkerschaft 712 .

Volksfeste 697.

Volksglaube 642-663.

Volkslieder 764 .

Volkssagen 764, 831-833.

Volkssitten 614-643.

Volkssprache 145, 603.

Volkszählungen 162, 163, 540 .

Vorgeschichte 770 .

Vorkenntnisse 7-13.

Vormetallische Periode 790.

Vornamen 704-706.

Vorstellungen (Begriffe) $643-645$.

Vulkane 267-272.

Vulkanische Gesteine 308, 347, $350-356$.

Wärmestrahlung 415, 416 . Waffen 123, 668-670.
Wagen (Astronomie) 25, 74.

Wald $394,482$.

Wallfahrten 661,740 .

Wanderungen 595, 696 .

- vorhistorische 771, 792.

Ward'sche Kisten 491.

Wasserbestattung 639 .

Wasserscheide 198, 452.

Wasserstandsmessungen 165, 466.

Wasserstrassen 756 .

Wasserwaage 45 .

Wechselwirkung der geographischen Objekte S26-848.

Wegekarten 181, 212.

Wegmaasse 888 .

Wegmesser 34.

Wehrfähige 540, 719.

Weibergemeinschaft 626,698 .

Weichthiere 513-520.

Wellenbewegung der Seen 474 .

Wergeld 620 .

Werke, religiöse 660 .

Werkstätten, prähistorische 805 .

Werkzeuge 748, 785-786.

Werst 888.

Wildbäche 249.

Wimpern 559.

Winde $432-436$.

Windrose 26.

Winkel 35, 191-194, 856.

Winkelspiegel 57.

Wirbelwinde 438 .

Wirthsgewerbe 742 .

Wissenschaften 767 .

Wohnbevölkerung 541 .

Wohnungen 684-695.

- unterirdische $685,822$.

Wollhaarige 557.

Wolken 423-425, 433.

Wisten 242, 243, 248, 483.

Wurzeln (Sprach-) 593-594.

Wurzelparasiten 501.

Yard 886.

Yen 879.

Zähne 112, 561, 565, 566, 673, 789. Zahlensystem, Zahlwörter u. Zahlzeichen $610-613$. 
Zauberer 637, 648, 658, 663 .

Zehen 563.

Zeichen, geologische 322.

- meteorologische 432, 450 .

- topographische 139.

Zeichnen und Photographie

$$
121-126 .
$$

- von Karten und Plänen

- Material 152. $126-145$.

- und Malerei 765.

Zeitmessung 94.

Zeitrechnung 86.

Zeitschriften, wissenschaftliche 13. Zeitungen 757, 762.

Zelt 685 .

\%enith 79.
Zenithdistanzen $14,79,859$. Zentrische Redultion 35, 856 . Zeremonien bei Begrüssuugen 617 . - bei Trauerfïllen 638 . - beim Kultus 659 .

Ziffern 612-613.

Zirkel 111, 144.

Zivilstand, Statistik 5 $44-545$.

Zölibat 627.

Zölle 755 .

Zonen (Pflanzen-) 484.

Zoologische Distrikte 507.

Zoophyten 520-521.

Zunahme der Bevölkerung 546. Zunamen 706.

Zweikampf 620, 722. 






\section{G Kaltbrunner, David \\ 150 Der Beobachter \\ K315}

PLEASE DO NOT REMOVE CARDS OR SLIPS FROM THIS POCKET

\section{UNIVERSITY OF TORONTO LIBRARY}




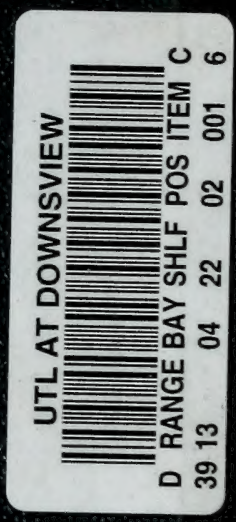

